\title{
WORLD TRADE
}

ORGANIZATION

\section{Q $01 / O E C D$}

AIDFORTRADE AT A GLANCE 2017

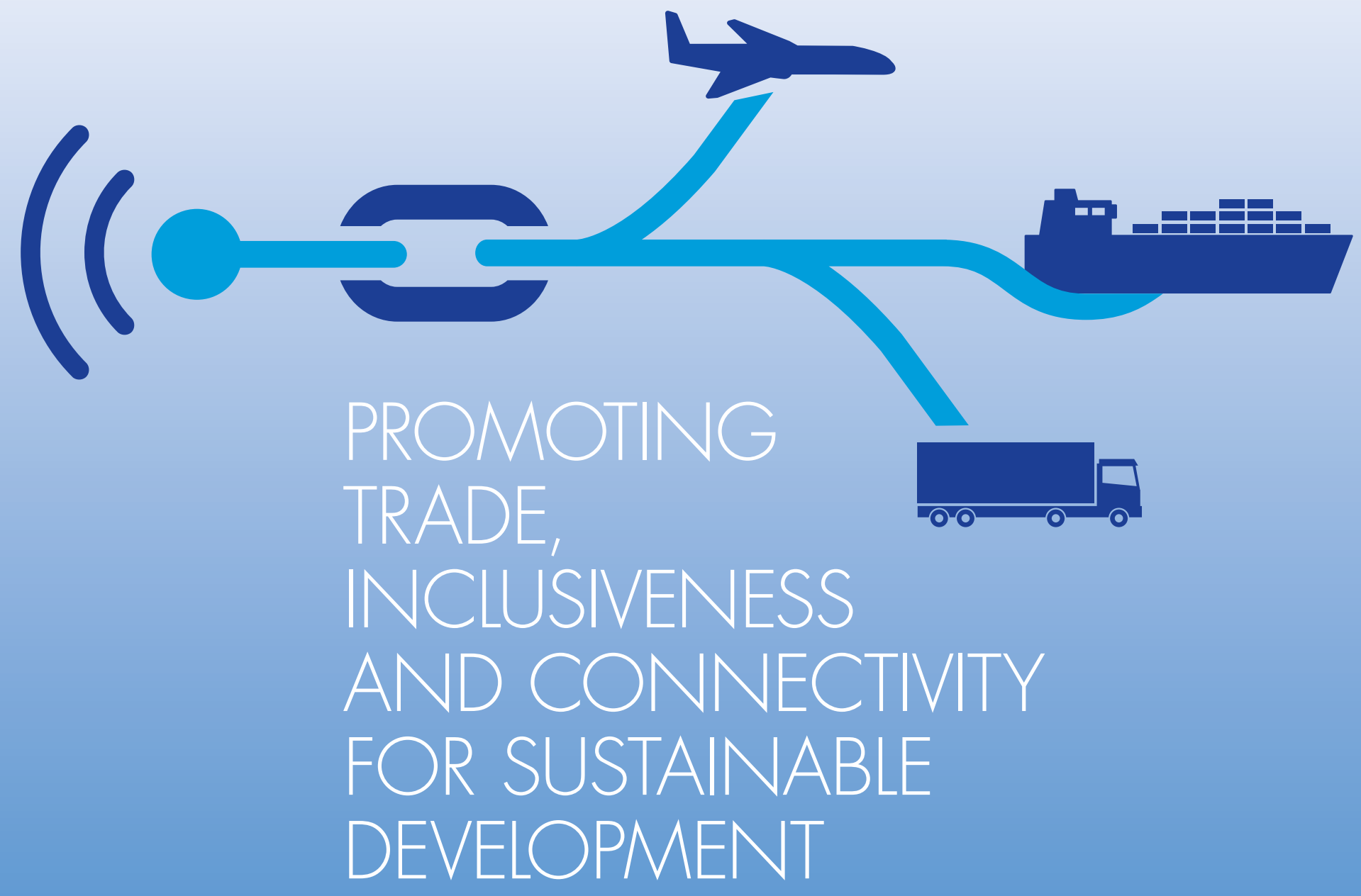


AIDFORTRADE

AT A GLANCE 2017

PROMOTING TRADE,

INCLUSIVENESS AND CONNECTIVITY FOR SUSTAINABLE DEVELOPMENT 
The opinions expressed and arguments employed herein do not necessarily reflect the official views of the OECD member countries or of the World Trade Organization or its members.

This document and any map included herein are without prejudice to the status of or sovereignty over any territory, to the delimitation of international frontiers and boundaries and to the name of any territory, city or area.

Please cite this publication as:

OECD/WTO (2017), Aid for Trade at a Glance 2017: Promoting Trade, Inclusiveness and Connectivity for Sustainable Development, WTO, Geneva/ OECD Publishing, Paris.

http://dx.doi.org/10.1787/aid_glance-2017-en

ISBN OECD: 978-92-64-27846-2 (print); 978-92-64-27847-9 (e-book/PDF format)

ISBN WTO: 978-92-870-4539-3 (print); 978-92-870-4554-6 (e-book/PDF format)

Biennial:

ISSN 2223-4403 (print)

ISSN 2223-4411 (online)

Corrigenda to OECD publications may be found on line at: www.oecd.org/publishing/corrigenda

(c) OECD, WTO 2017

You can copy, download or print OECD content for your own use, and you can include excerpts from OECD publications, databases and multimedia products in your own documents, presentations, blogs, websites and teaching materials, provided that suitable acknowledgment of OECD and WTO as source and copyright owner is given. All requests for public or commercial use and translation rights should be submitted to rights@oecd.org. Requests for permission to photocopy portions of this material for public or commercial use shall be addressed directly to the Copyright Clearance Center (CCC) at info@copyright.com or the Centre français d'exploitation du droit de copie (CFC) at contact@cfcopies.com. 


\section{FOREWORD}

The Aid for Trade initiative was launched in 2005 with the aim of addressing the supply side and trade-related infrastructure constraints that often hamper developing countries' participation in global trade. We are proud that more than USD 300 billion has been disbursed for aid-for-trade programmes and projects since the Aid for Trade Initiative was launched. We note that $27 \%$ of this total has gone to least-developed countries and recall the ongoing challenges they face.

The analysis collected for this report, from developing and least developed countries, regional economic communities and their development partners, underscores that aid for trade results in inclusive trade and development outcomes. The positive impacts reported from Trade Facilitation Agreement implementation actions are encouraging.

Promoting inclusive trade for sustainable development requires us to improve connectivity — both physical and digital. Without connectivity, trade does not take place, and we are all poorer. More and better aid for trade must be mobilized to address this challenge. The 2030 Agenda for Sustainable Development gives the Aid for Trade initiative even greater relevance.

High trade costs price many firms out of markets and reinforce economic isolation. This is also evident in the digital networks that intertwine with physical trade infrastructure and which are integral to trade. Some 3.9 billion people are still offline, with only 1 in 4 people in Africa using the internet and only 1 in 7 people in LDCs.

The digital divide is also a market access divide. Without an affordable connection, individuals and firms cannot access the market place of the world-wide web. And without the necessary skills and regulatory environment in place micro, small and medium sized enterprises cannot thrive.

This needs to change. We must bridge these gaps in connectivity. Failure to act may reinforce existing inequalities between developed and developing economies, and within countries between women and men, rural and urban, and large and small firms.

This joint OECD-WTO publication, with contributions from other organisations, looks at what is being done today and what more needs to done tomorrow to build the human, institutional and infrastructure capacities which will allow developing countries, and especially the least-developed, to benefit more from trade opportunities.
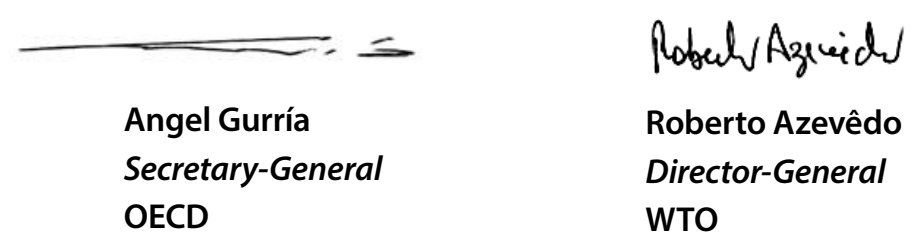



\section{ACKNOWLEDGEMENTS}

Aid for Trade at a Glance: Promoting Trade, Inclusiveness and Connectivity for Sustainable Development was prepared under the aegis of the OECD Development Assistance Committee and Trade Committee together with the WTO Committee on Trade and Development.

The OECD and WTO Secretariats would like to express their appreciation to all the governments, intergovernmental organisations, nongovernmental organisations and private firms that participated in the 2017 aid for trade monitoring and evaluation exercise.

The report has been prepared under the overall guidance of Frans Lammersen (OECD) and Michael Roberts (WTO). Managerial support was provided by Jorge Moreira da Silva, Ken Ash (OECD) and Shishir Priyadarshi (WTO).

Chapter 2 was written by Michael Roberts (WTO); Chapter 3 by Marie-Agnes Jouanjean (OECD) and Jan Hoffmann (UNCTAD); Chapter 4 by Martin Roy (WTO); Chapter 5 by Vanessa Gray and Cosmas Zavazava (ITU); Chapter 6 by Marcus Bartley Johns, Michael Ferrantino and Martin Molinuevo (WBG); Chapter 7 by Torbjörn Fredriksson and Diana Korka (UNCTAD); Chapter 8 by Jasmeer Virdee (ITC); Chapter 9 by Barbara Rippel and Daria Shatskova (EIF); Chapter 10 by Kati Suominen (Business for eTrade development); Chapter 11 by Raffaela Muoio (OECD); and Chapter 12 by Nazia Mohammed (WTO). The country profiles were prepared by Rainer Lanz (WTO).

In addition, the following persons are acknowledged: Sive Einarsson, Janos Ferencz, Javier Lopez-Gonzalez, Tomas Hos, Michael Laird, Evdokia Moïsé, Julia Nielson, Nadine Piefer, Anne-Lise Prigent, Cécile Sangare, Silvia Sorescu, (all OECD); Terfa Ashwe, Christophe Degain, Barbara Marcetich, Andreas Maurer, Théo Mbise, Roberta Piermartini, Roy Santana, Sainabou Taal, Lee Tuthill, Julia Zamora (all WTO); Maja Andjelkovic, Lillyana Daza-Jaller, Arsala Deane, Ankur Huria, Prasanna Lal Das, Daniel Saslavsky, (all WBG); Hanna Bucher Jose, Armando Cobian Alvarez, Christina Dienhart, Vanessa Erogbogbo, Loe Franssen, Marion Jansen, Michelle Ayu Chinta Kristy, Anna Claudia Zaleski Mori, Antonina Popova, Evelyn Seltier, Govind Venuprasad, Matthew Wilson, Quan Zhao, (all ITC); Youlia Lozanova (ITU), and Evgeniia Zhuravleva (EIF); statistical support was provided by Andrzej Suchodolski (OECD) and Ann Gordon (consultant).

The report was edited by Christine Graves and designed by Peggy Ford-Fyffe King. The team was assisted by Clare Lannigan and Susan Hodgson (OECD). 



\section{TABLE OF CONTENTS}

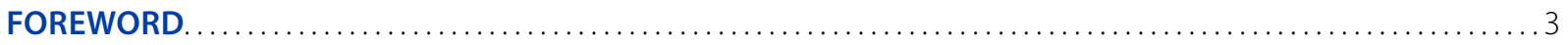

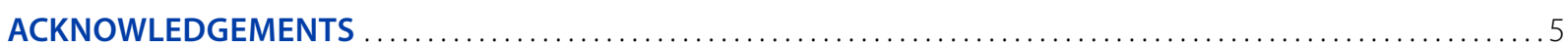

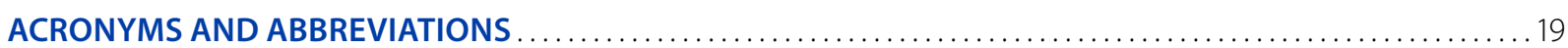

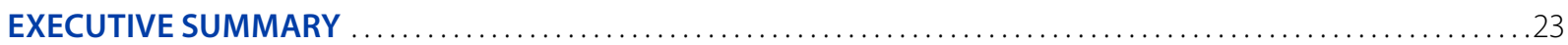

CHAPTER 1 OVERVIEW: PROMOTING TRADE, INCLUSIVENESS AND CONNECTIVITY

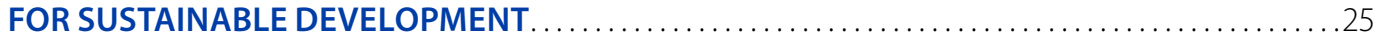

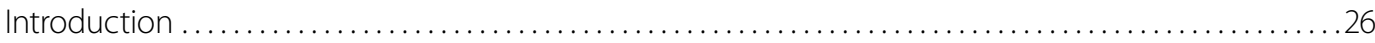

Who participated in the OECD-WTO aid-for-trade monitoring exercise? . . . . . . . . . . . . . . . . 27

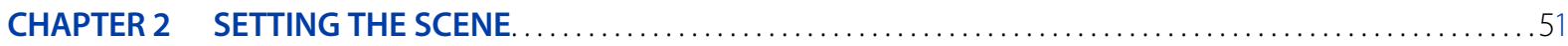

Contributed by World Trade Organisation

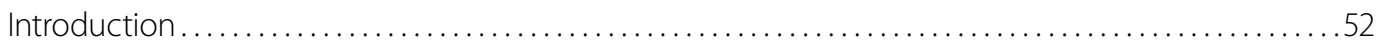

Digital connectivity adds a new dimension to the global economy $\ldots \ldots \ldots \ldots \ldots \ldots \ldots \ldots \ldots \ldots \ldots$

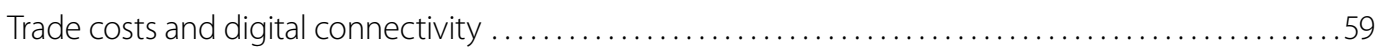

Tackling digital trade costs..................................................66

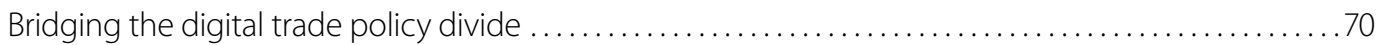

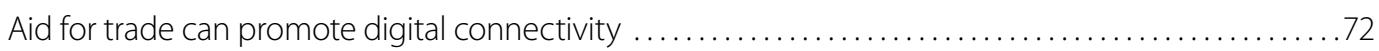

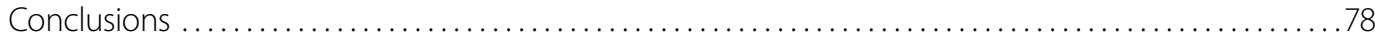

CHAPTER 3 DIGITAL CONNECTIVITY AND TRADE LOGISTICS -

GETTING GOODS SHIPPED, ACROSS THE BORDER AND DELIVERED $\ldots \ldots \ldots \ldots \ldots \ldots \ldots . \ldots 3$

Contributed by the Organisation for Economic Co-operation and Development

and the United Nations Conference on Trade and Development

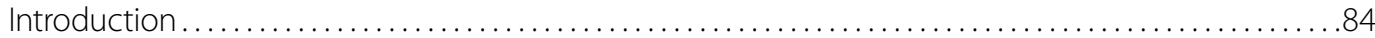

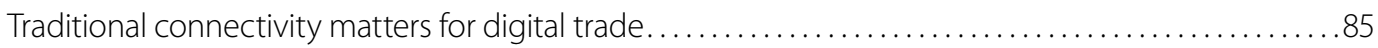

Implementing the Trade Facilitation Agreement for cross-border connectivity ................. 90

New opportunities and challenges arise from digitalisation and digital trade $\ldots \ldots \ldots \ldots \ldots \ldots . \ldots 9$

Information flows enable the trade logistics chain .................................... 101

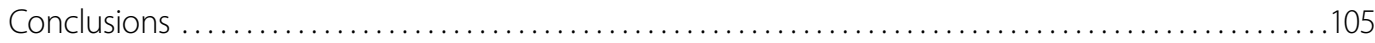


CHAPTER 4 SERVICES TRADE POLICIES AND THEIR CONTRIBUTION TO CONNECTIVITY

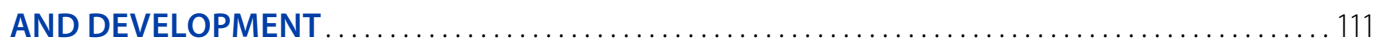

Contributed by the World Trade Organization

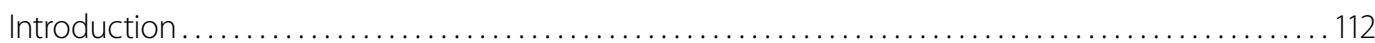

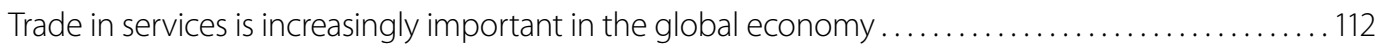

Services make a multifaceted contribution to promoting connectivity ....................... 116

Policies in services trade have an impact on connectivity.............................. 125

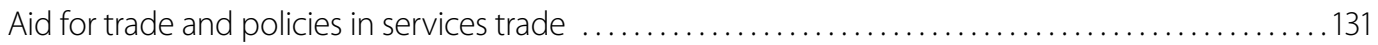

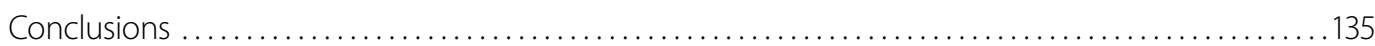

CHAPTER 5 SPANNING THE INTERNET DIVIDE TO DRIVE DEVELOPMENT $\ldots \ldots \ldots \ldots \ldots \ldots \ldots \ldots \ldots \ldots$

Contributed by the International Telecommunication Union

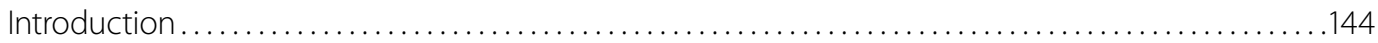

ICT infrastructure, connectivity and quality of service vary greatly . . . . . . . . . . . . . . . . . 148

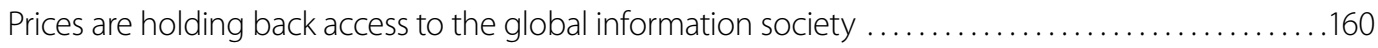

Socio-economic barriers keep many from joining the information society $\ldots \ldots \ldots \ldots \ldots \ldots \ldots . \ldots 169$

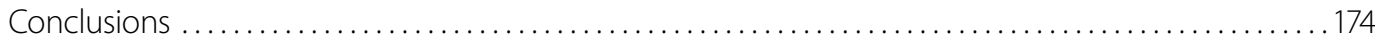

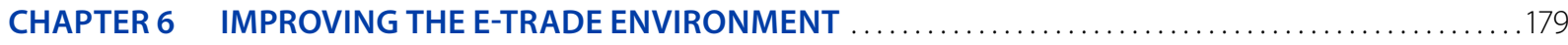

Contributed by the World Bank

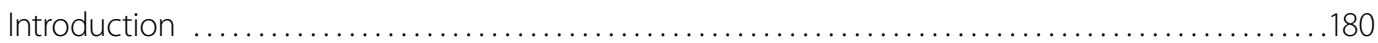

The e-trade environment should broadly support the digital economy $\ldots \ldots \ldots \ldots \ldots \ldots \ldots \ldots . \ldots 180$

E-trade is founded on infrastructure, a good business environment and human resources . . . . . . . 181

E-trade logistics and trade facilitation.......................................... 187

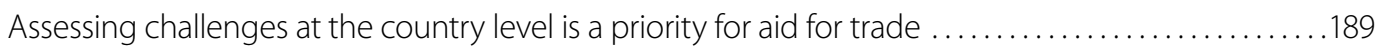

Conclusions ............................................................ 191

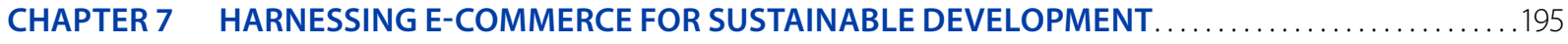

Contributed by the United Nations Conference on Trade and Development

Introduction

Assessing the readiness of countries to engage in e-commerce is a first step to better policy outcomes............................................................ 204

National policies and strategies can help to enable e-commerce .......................... 208

Informed decision and policy making is essential, as is stakeholder participation ................209

How can aid for trade support e-commerce readiness? ............................... 213

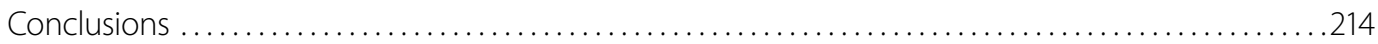


CHAPTER 8 CLOSING THE SMALL-BUSINESS AND GENDER GAP TO MAKE TRADE MORE INCLUSIVE ...219

Contributed by the International Trade Centre

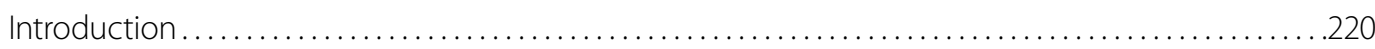

Connecting SMEs to international markets is a development priority ......................220

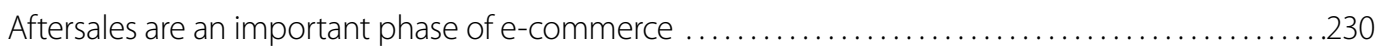

Online tools can help women-owned businesses connect to international markets ..............232

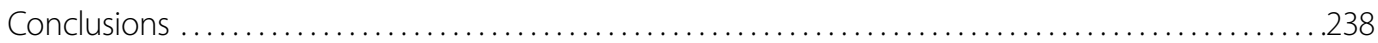

CHAPTER 9 PROMOTING TRADE INCLUSION IN THE LEAST DEVELOPED COUNTRIES

THROUGH CONNECTIVITY ................................................... 243

Contributed by the Enhanced Integrated Framework

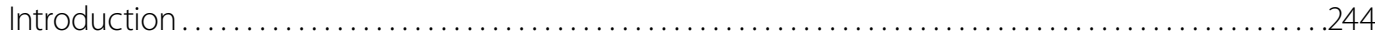

The least developed countries do not yet realise the full potential of Internet connectivity . . . . . .245

Regulatory measures can promote or hinder connectivity ............................. 249

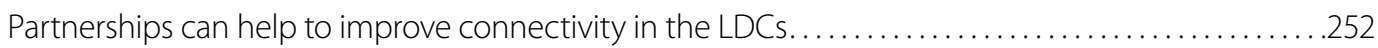

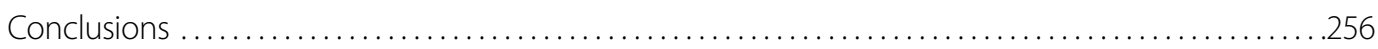

CHAPTER 10 PUBLIC-PRIVATE PRIORITIES FOR AID FOR TRADE IN THE DIGITAL ERA $\ldots \ldots \ldots \ldots \ldots \ldots 265$

Contributed by Business for eTrade Development

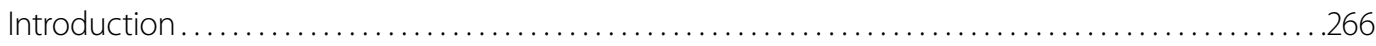

Views on the bottlenecks to digital trade in developing countries vary ......................267

How the private sector creates new e-commerce economies . . . . . . . . . . . . . . . . . . . . . . 275

Businesses can help policy makers find pathways for catalysing e-commerce .................... 281

Public-private partnerships can create a new development paradigm ........................ 284

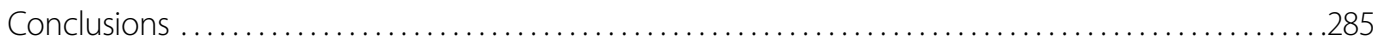

CHAPTER 11 FINANCING CONNECTIVITY: AID-FOR-TRADE PRIORITIES, POLICIES AND PROGRAMMES

Contributed by the Organisation for Economic Co-operation and Development

Introduction ............................................................ 290

Aid for trade is a crucial component of the development financing challenge................. 290

Aid-for-trade disbursements by sector, geographic region and income ...................... 296

Trade-related infrastructure is a development enabler .................................. 300

Donor support for ICT is critical for development. . . . . . . . . . . . . . . . . . . . . . . . . . . . . 306

Empirical findings demonstrate the effectiveness of aid for trade ........................... 310

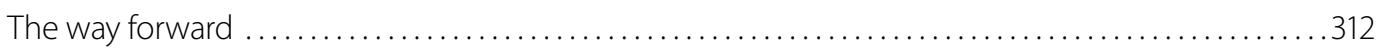

Conclusions ................................................................. 319

CHAPTER 12 AID FOR INCLUSIVE TRADE AND POVERTY REDUCTION $\ldots \ldots \ldots \ldots \ldots \ldots \ldots \ldots \ldots \ldots \ldots \ldots \ldots \ldots \ldots \ldots \ldots$

Contributed by the World Trade Organization

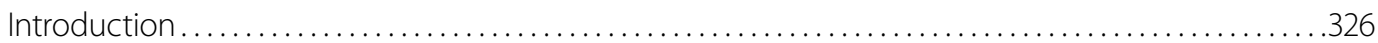

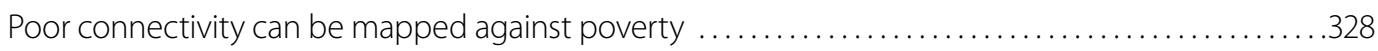

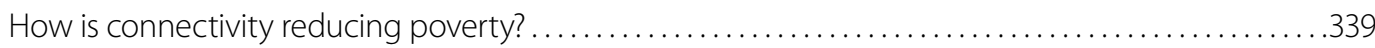

What have we learnt from the 2017 aid-for-trade programmes? ......................... 344

Conclusions ............................................................... 346 
COUNTRY PROFILES ............................ 353

Explanatory notes ............................. 355

Antigua and Barbuda ............................362

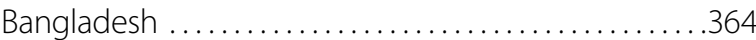

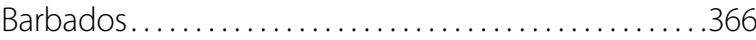

Belize.......................................368

Benin.......................................370

Botswana ...................................372

Burkina Faso................................. 374

Burundi ........................................... 376

Cameroon ....................................... 378

Central African Republic............................380

Chad ..........................................382

Colombia .......................................384

Comoros ....................................386

Congo ....................................... 388

Democratic Republic of the Congo .................390

Costa Rica.......................................392

Côte d'Ivoire.....................................394

Dominica ..................................... 396

Dominican Republic ..............................398

El Salvador ..................................400

Gabon ....................................402

Gambia ....................................404

Grenada........................................406

Guatemala ......................................408

Guinea ....................................... 410

Guinea-Bissau ..................................... 412

Honduras ................................... 414

Indonesia ...................................... 416

Lao People's Democratic Republic ................. 418

Lesotho

.420

Madagascar
Malawi ........................................424

Mali ........................................426

Mauritius ...................................4 428

Mexico ...................................430

Myanmar...................................4 432

Namibia...................................4434

Nepal ...................................436

Niger....................................438

Pakistan ........................................440

Papua New Guinea. ............................... 442

Paraguay .....................................444

Peru.......................................446

Philippines ...................................448

Rwanda ....................................450

Saint Kitts and Nevis...........................452

Saint Lucia. ........................................ 454

Saint Vincent and the Grenadines ..................456

Samoa ....................................458

Senegal ......................................460

Sierra Leone.....................................462

Sri Lanka ....................................464

Sudan......................................466

Suriname.................................468

Tanzania........................................... 470

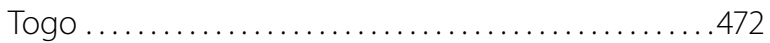

Tonga .....................................474

Uganda ..................................476

Uruguay...................................478

Viet Nam ....................................480

Yemen ......................................482

Zambia....................................484

Zimbabwe ..............................486 


\section{ANNEXES}

ANNEX A AID-FOR-TRADE KEY DATA

Table A.1. Aid for trade by category 493

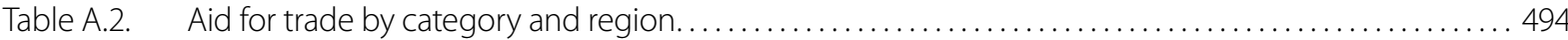

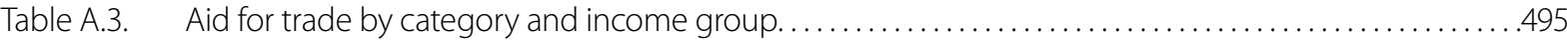

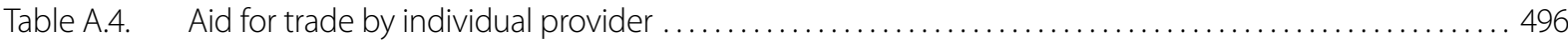

Table A.5a. Top 20 providers of aid for trade in 2015 , commitments................................497

Table A.5b. Top 20 providers of aid for trade in 2015, disbursements . . . . . . . . . . . . . . . . . . . . . . . . 497

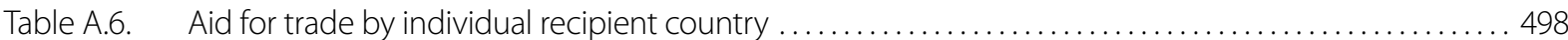

Table A.7a. Top 20 recipients of aid for trade in 2015, commitments . . . . . . . . . . . . . . . . . . . . . . . . . . 501

Table A.7b. Top 20 recipients of aid for trade in 2015, disbursements . . . . . . . . . . . . . . . . . . . . . . . . . . . . 501

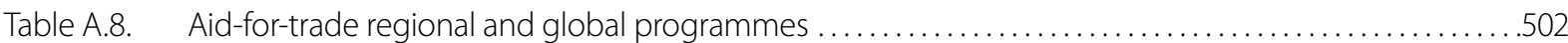

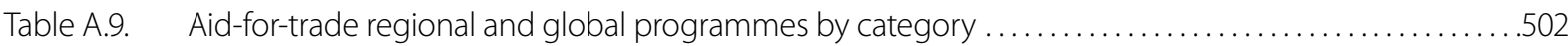

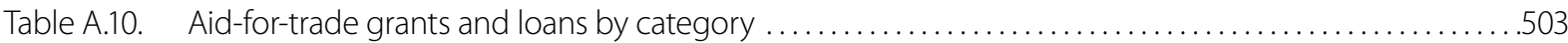

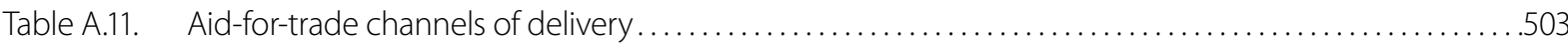

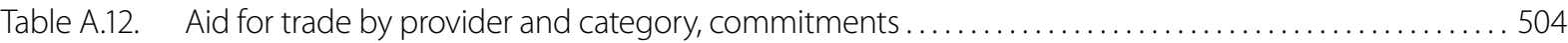

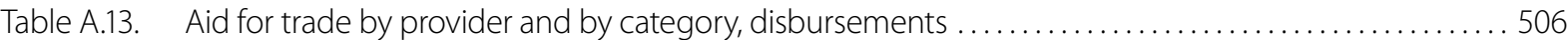

Table A.14. Aid for trade by provider and by region, commitments $\ldots \ldots \ldots \ldots \ldots \ldots \ldots \ldots \ldots \ldots \ldots \ldots \ldots$

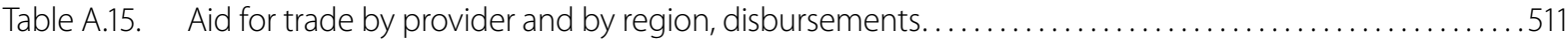

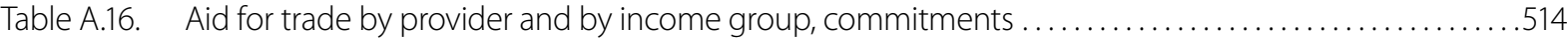

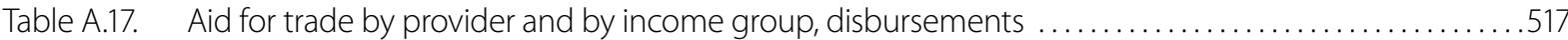

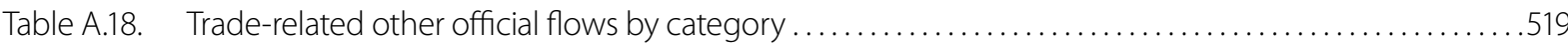

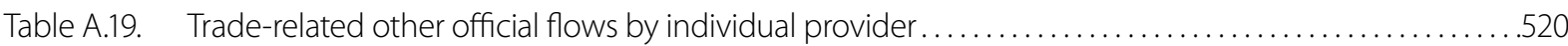

Table A.20. Trade-related other official flows by individual recipient country ...........................521

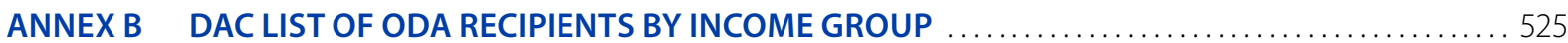

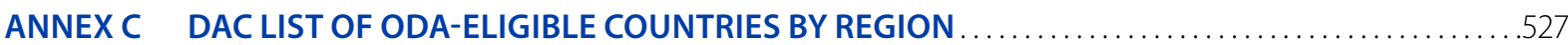

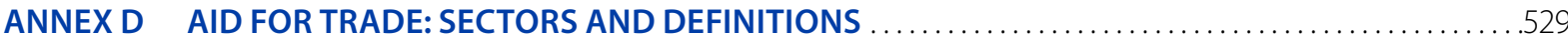

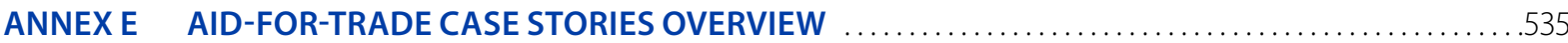




\section{TABLES, FIGURES AND BOXES}

\section{CHAPTER 1}

\section{Figures}

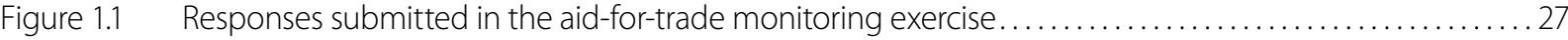

Figure 1.2. Program focus of case stories submitted in the context of the 2017 OECD -WTO aid-for-trade

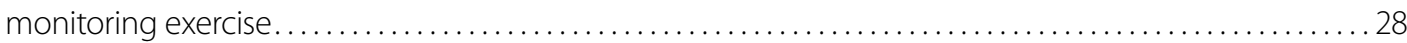

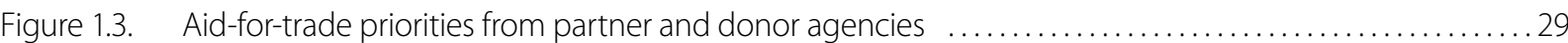

Figure 1.4. Freight and insurance costs as a percentage of the value of imports, ten-year moving

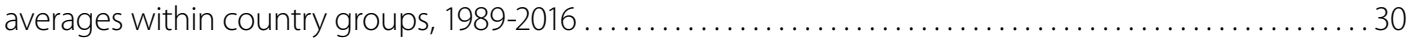

Figure 1.5. Automation tools in place, by type of tool and by country grouping $\ldots \ldots \ldots \ldots \ldots \ldots \ldots \ldots \ldots \ldots \ldots \ldots \ldots \ldots$

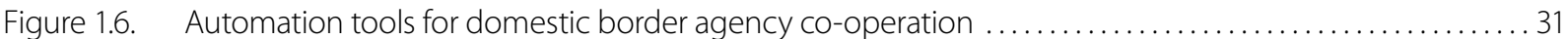

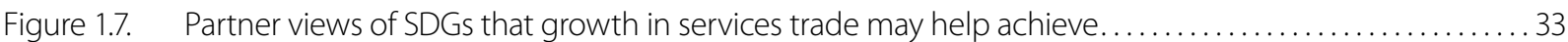

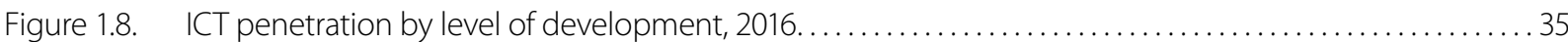

Figure 1.9. A stylised model of e-trade benefits at different levels of development ...................... 36

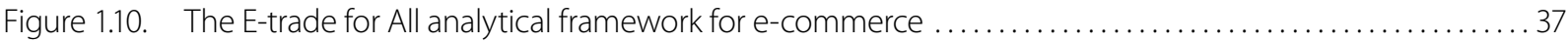

Figure 1.11. E-commerce readiness, by component indicators and geographic region ....................... 38

Figure 1.12 Relative proportions of small and large firms with a business website ......................... 39

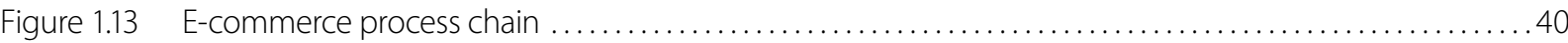

Figure 1.14. Beneficial outcomes from women and girls having online access . . . . . . . . . . . . . . . . . . . . . . 40

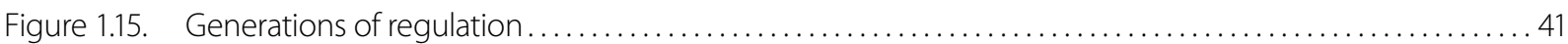

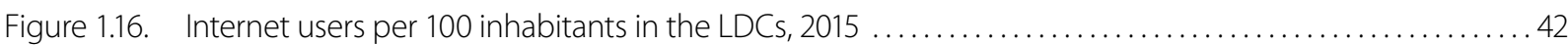

Figure 1.17. Merchants' perception of obstacles to cross-border e-commerce, by company size ............... 43

Figure 1.18. Aid-for-trade commitments and disbursements by category, $2002-15 \ldots \ldots \ldots \ldots \ldots \ldots \ldots \ldots . \ldots 4$

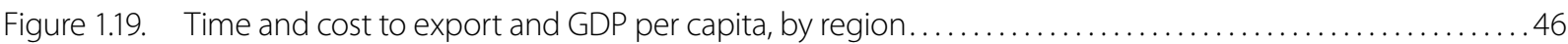

Figure 1.20. Poverty rates by region and percentage of Internet users . . . . . . . . . . . . . . . . . . . . . . . . . . . . 46

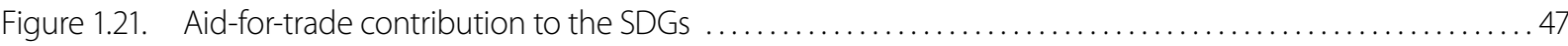

\section{Annex}

Annex 1.A1.

\section{CHAPTER 2}

\section{Tables}

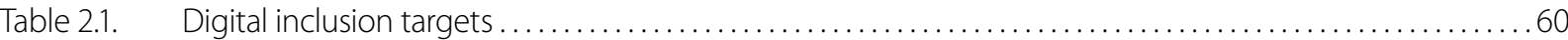

Figures

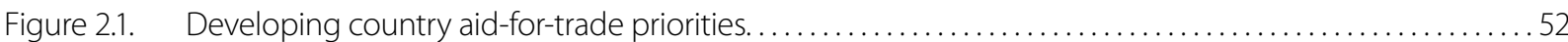

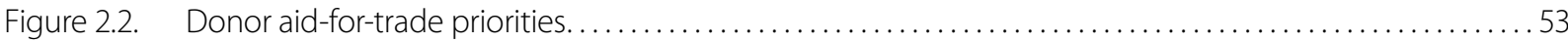

Figure 2.3. Top ten issues enterprises and consumers face in accessing and using Internet services, as cited by

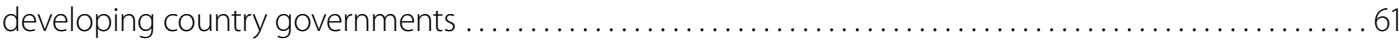

Figure 2.4. E-commerce access, transaction, payment and delivery pathways ......................... 61

Figure 2.5. Top ten export challenges faced by micro, small and medium enterprises in relation to cross-border e-commerce transactions......................................................... 62

Figure 2.6. Challenges the online purchase of goods presents to customs and other border authorities .........6 63

Figure 2.7. Frequency of ICT-related concerns raised in the WTO TBT Committee $\ldots \ldots \ldots \ldots \ldots \ldots \ldots \ldots \ldots \ldots 6$

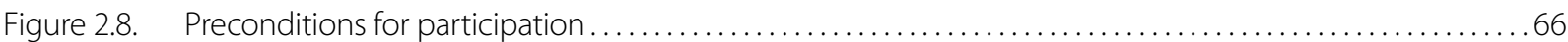

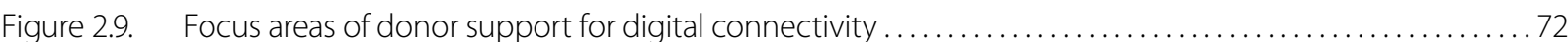

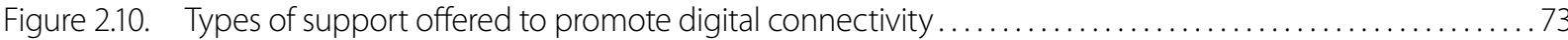




\section{Boxes}

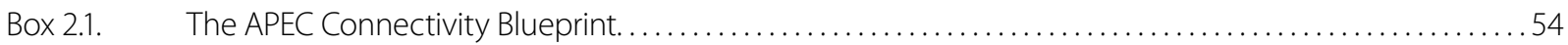

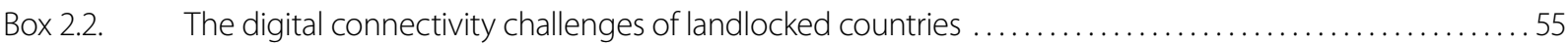

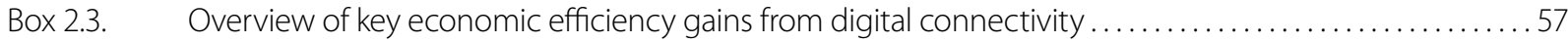

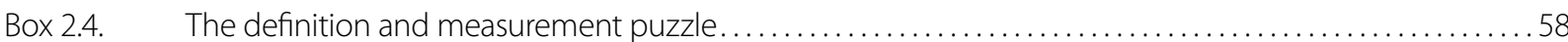

Box 2.5. Cross-border e-commerce problems reported by customs officials in Central Asia ..................64

Box 2.6. Selected national policy commitments made at the ITU Plenipotentiary Conference in 2014 . . . . .....67

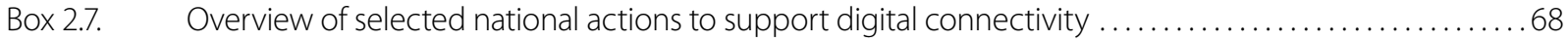

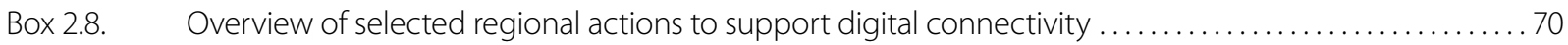

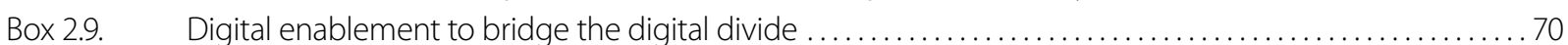

Box 2.10. Trade policy and the availability_and affordability_ of digital connections $\ldots \ldots \ldots \ldots \ldots \ldots \ldots . \ldots 71$

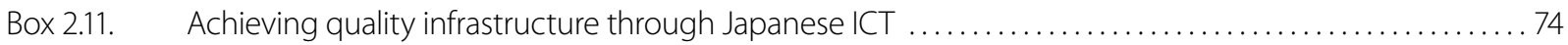

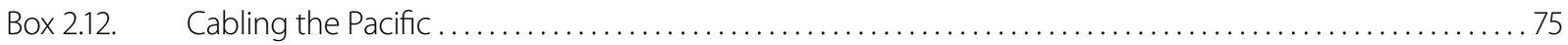

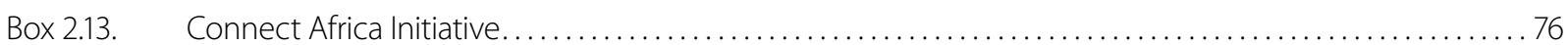

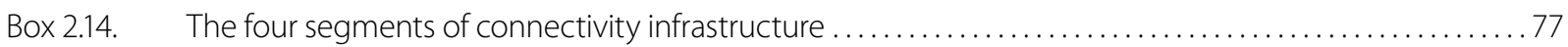

\section{CHAPTER 3}

\section{Figures}

Figure 3.1. Freight and insurance costs as a percentage of the value of imports, ten-year moving

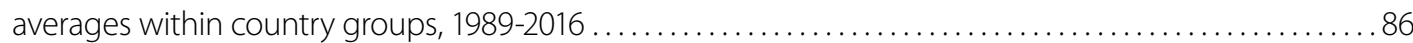

Figure 3.2. Average number of liner shipping companies per country, average vessel size (TEU) per country, and average size of the largest ship (TEU) per country, 2004-2016 ................... 88

Figure 3.3. Correlation between trade facilitation implementation, Human Development Index indicators and the Doing Business Index indicator for trading cross borders $\ldots \ldots \ldots \ldots \ldots \ldots \ldots \ldots \ldots \ldots \ldots$

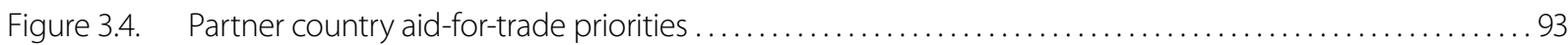

Figure 3.5. A sample snapshot of TFls in 2017, by income group . . . . . . . . . . . . . . . . . . . . . . . . . . 94

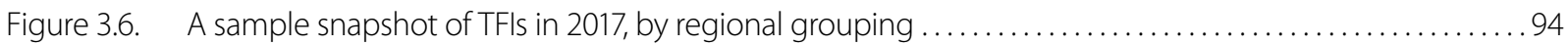

Figure 3.7. Automation tools in place, by type of tool and by country grouping ........................ 96

Figure 3.8. Automation tools for domestic border agency co-operation .............................97

\section{Boxes}

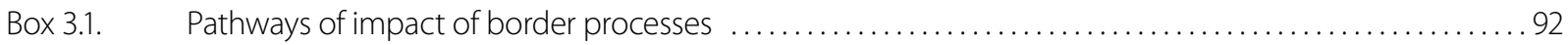

Box 3.2. Data exchange in agriculture and food chains ....................................... 103

Box 3.3. The potential of digitalisation for livestock and meat trading in Africa ....................... 104

\section{CHAPTER 4}

\section{Tables}

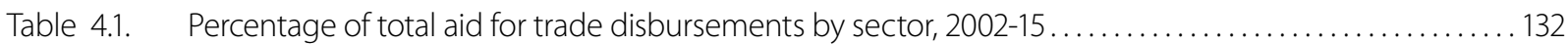

\section{Figures}

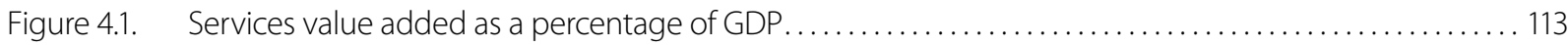

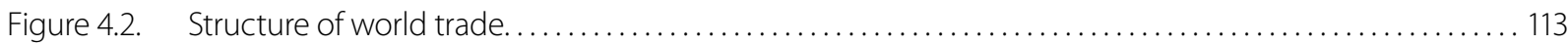

Figure 4.3. Partner country views on the relevance of trade in services for achieving the Sustainable

Development Goals......................................................... 115

Figure 4.4. The value of services in exports, as recognised in national development strategies $\ldots \ldots \ldots \ldots \ldots \ldots 118$

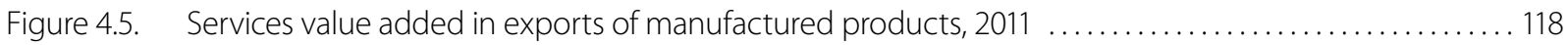

Figure 4.6. What are the main issues that enterprises and consumers in your countries face in accessing

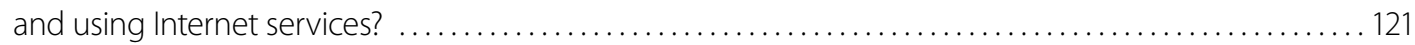

Figure 4.7. Exports of commercial services by main category and by sub-sector $\ldots \ldots \ldots \ldots \ldots \ldots \ldots \ldots \ldots$ 
Figure 4.8. Growth of global exports of commercial services by sub-sector, $1995-2014 \ldots \ldots \ldots \ldots \ldots \ldots \ldots \ldots 123$

Figure 4.9. STRI scores for developing and developed economies, by sector . . . . . . . . . . . . . . . . . . . . 126

Figure 4.10. Percentage of schedules with commitments for mode 1 and mode 3 in selected sectors ........... 127

Figure 4.11. STRI in relation to export and import times (averages 2014) .............................. 129

Figure 4.12. Official development assistance and private participation in infrastructure, by sector, 2004-15 ....... 133

\section{Boxes}

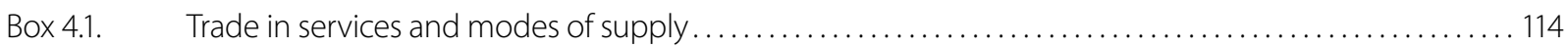

Box 4.2. Mobile payments in Rwanda and South Africa......................................... 120

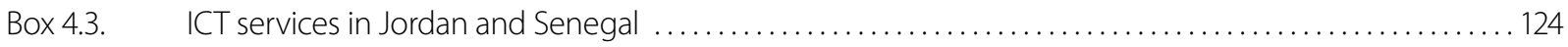

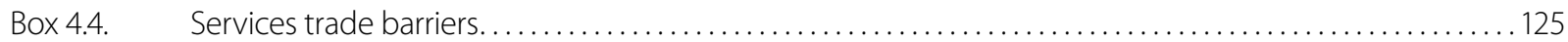

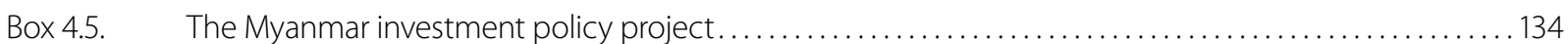

\section{CHAPTER 5}

\section{Tables}

Table 5.1. Countries with the highest fixed-broadband prices in 2015

\section{Figures}

Figure 5.1. Global changes in levels of ICT uptake, 2006-16 ....................................... 144

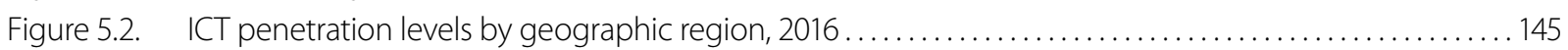

Figure 5.3. IDI values for the LDCs compared with all developing countries and global values ................ 146

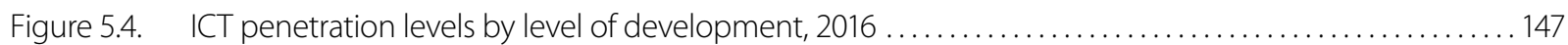

Figure 5.5. Number of countries that achieved the Broadband Commission target to make

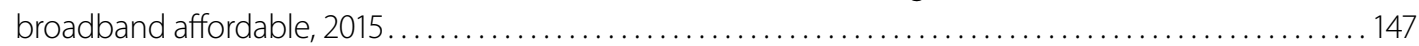

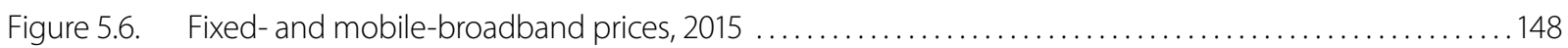

Figure 5.7. Global population covered by at least a $2 \mathrm{G}, 3 \mathrm{G}$, and LTE network ......................... 149

Figure 5.8. Mobile network coverage and evolving technologies in the LDCs ............................ 149

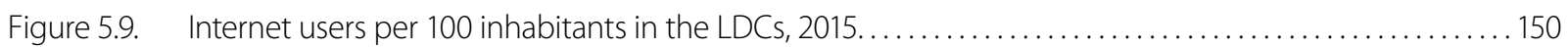

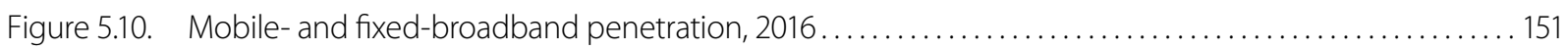

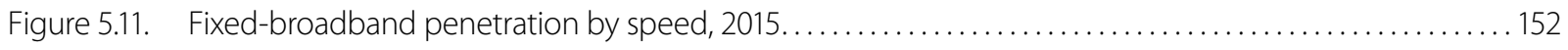

Figure 5.12. Fixed-broadband subscriptions by speed in selected countries, $2015 \ldots \ldots \ldots \ldots \ldots \ldots \ldots \ldots \ldots \ldots \ldots \ldots$

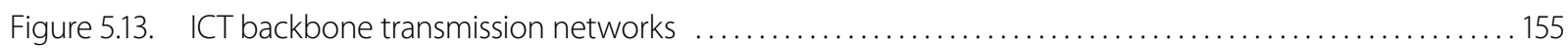

Figure 5.14. Route metres of fibre and microwave backbone per capita by region, 2016 ................... 155

Figure 5.15. Share of total international Internet bandwidth, by region . ............................ 156

Figure 5.16. International Internet bandwidth per inhabitant, by region, $2015 \ldots \ldots \ldots \ldots \ldots \ldots \ldots \ldots \ldots \ldots \ldots \ldots \ldots \ldots$

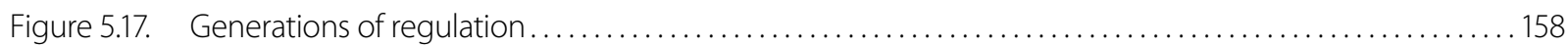

Figure 5.18. Winning formulas: regulatory recipes for successful ICT adoption . . . . . . . . . . . . . . . . . . 159

Figure 5.19. Fixed-broadband sub-basket, as a percentage of GNI per capita, in PPPUSD

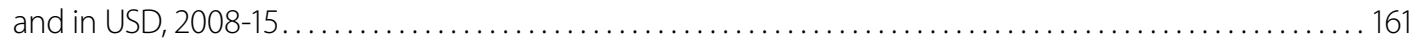

Figure 5.20. Most common entry-level fixed-broadband speeds, globally and by level of development. ......... 163

Figure 5.21. Availability of mobile-broadband services by type of service and level of development, 2012-15 .....166

Figure 5.22. Mobile-broadband prices as a percentage of GNI per capita, in PPPUSD, and in USD, 2013-15 . . . . . . 167

Figure 5.23. Use of the Internet on the move in selected economies, 2013 and $2014 \ldots \ldots \ldots \ldots \ldots \ldots \ldots$

Figure 5.24. Internet use by level of education in developed and developing countries, 2013-15 .............. 170

Figure 5.25. Proportion of individuals using the Internet, by gender, $2016 \ldots \ldots \ldots \ldots \ldots \ldots \ldots \ldots \ldots \ldots \ldots \ldots \ldots \ldots$

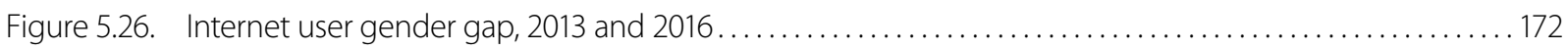

Figure 5.27. Demand- and supply-side measures to increase internet use $\ldots \ldots \ldots \ldots \ldots \ldots \ldots \ldots \ldots \ldots \ldots$ 


\section{Boxes}

Box 5.1. The least developed countries and the ICT Development Index .......................... 146

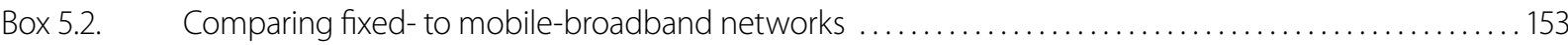

Box 5.3. Generations of ICT regulation . . . . . . . . . . . . . . . . . . . . . . . . . . . . . . . . . . . . . 157

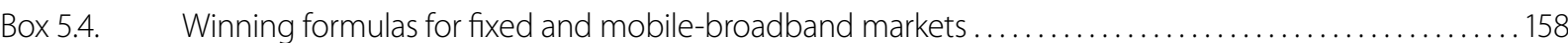

Box 5.5. The impact of taxation on broadband services deployment and adoption ....................... 159

\section{CHAPTER 6}

\section{Figures}

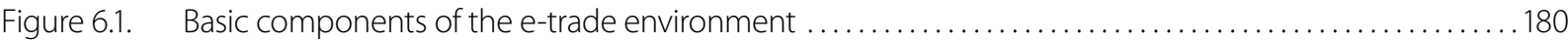

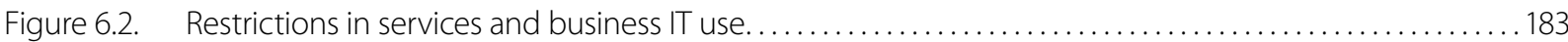

Figure 6.3. Proportion of individuals using the Internet, by education level . . . . . . . . . . . . . . . . . . . . . . 184

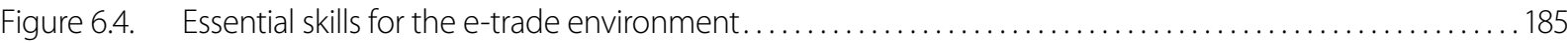

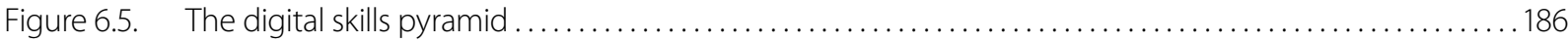

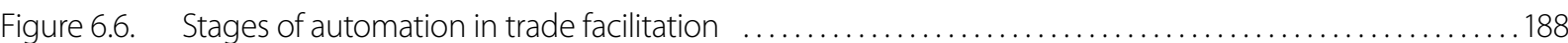

Figure 6.7. A stylised model of benefits of e-trade at different levels of economic development ............... 192

\section{Boxes}

Box 6.1. Improving the environment for e-payments

\section{CHAPTER 7}

\section{Tables}

\section{Figures}

Figure 7.1. B2C e-commerce sales worldwide, by region, 2013 and 2018.

Figure 7.2. Share of Internet users involved in online purchasing and social networking,

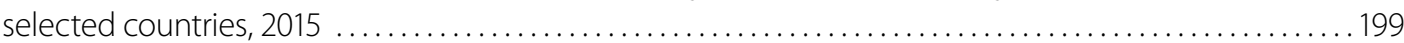

Figure 7.3. Share of enterprises receiving orders over the Internet in selected economies, by enterprise size ......205

Figure 7.4. Distribution of secure Internet servers by region and country type, $2013 \ldots \ldots \ldots \ldots \ldots \ldots \ldots . \ldots 206$

Figure 7.5. E-commerce readiness, by component indicators and geographical region . ..................207

Figure 7.6. The eTrade for All analytical framework for e-commerce .................................. 214

\section{Boxes}

Box 7.1. Partner country views on availability of e-commerce data . $\quad$.

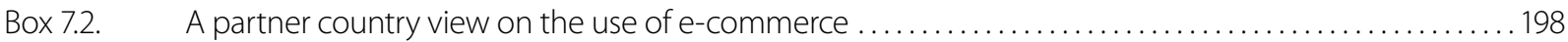

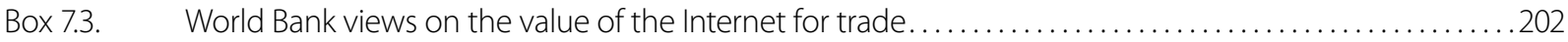

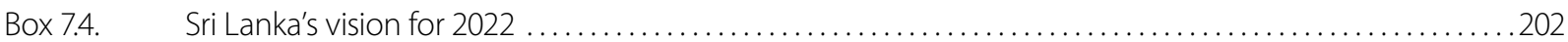

Box 7.5. Partner country views on the status of e-commerce in their countries .......................206

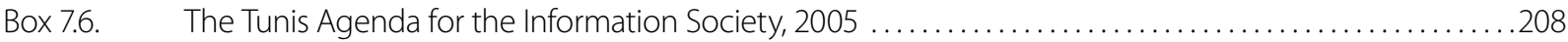

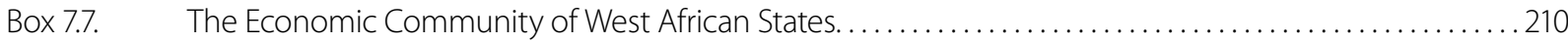

Box 7.8. The Asian Development Bank on challenges to e-commerce in Asia.......................... 212 


\section{CHAPTER 8}

\section{Tables}

Table 8.1. A checklist for policymakers to support small-business digitalisation.........................224

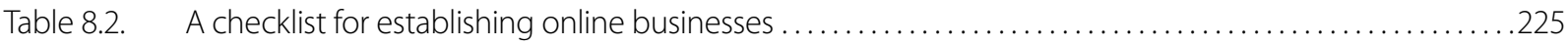

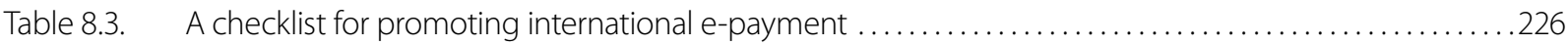

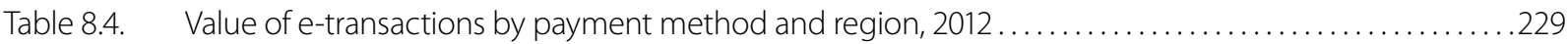

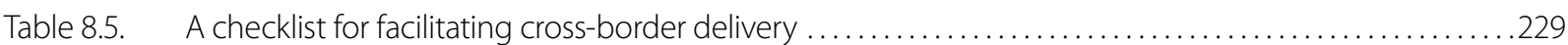

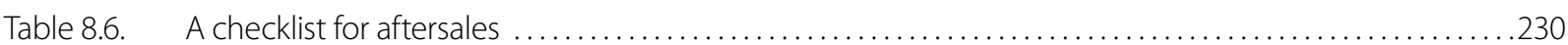

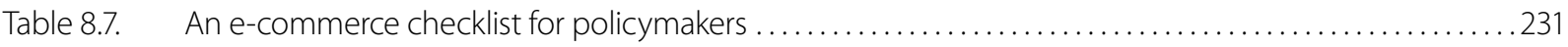

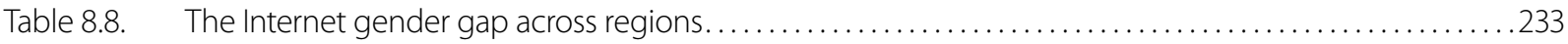

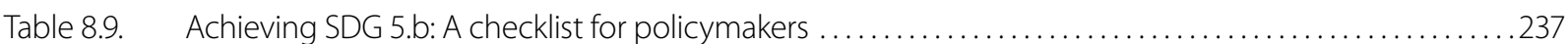

\section{Figures}

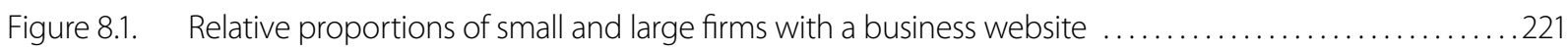

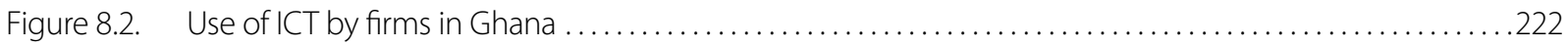

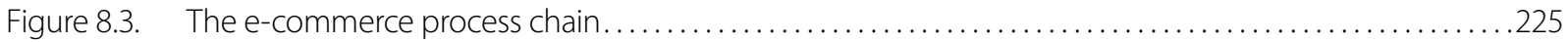

Figure 8.4. Advertising via social networks and traditional media by small and medium firms ................226

Figure 8.5. Many small firms in poor countries do not have bank accounts . . . . . . . . . . . . . . . . . . . . 228

Figure 8.6. Beneficial outcomes that can result from women and girls having online access.................2234

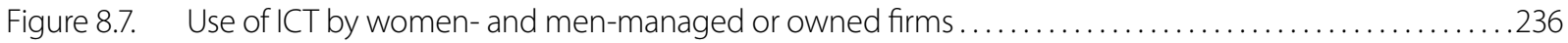

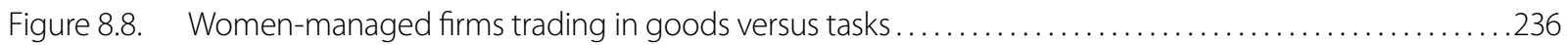

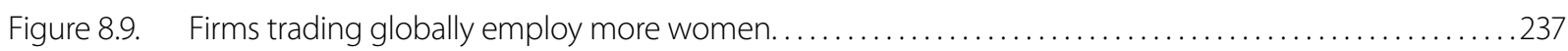

\section{Boxes}

Box 8.1. What can happen when SMEs leverage digital technologies?....

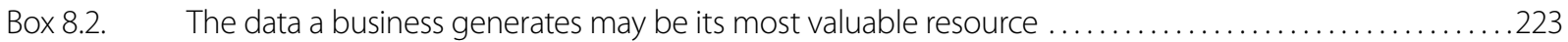

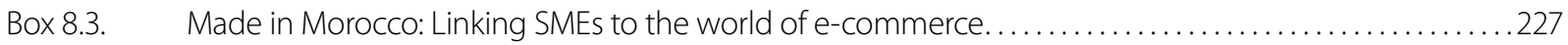

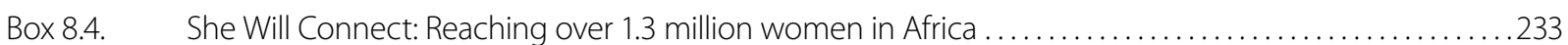

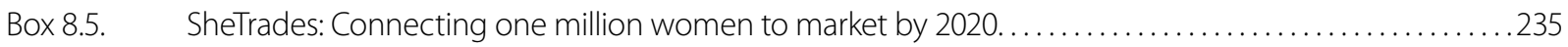

\section{CHAPTER 9}

\section{Figures}

Figure 9.1. Internet users and mobile cellular subscription per 100 people ..........................246

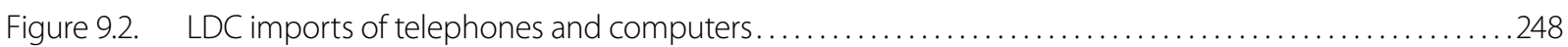

Figure 9.3. Level of competition in selected LDC telecommunications services, $2015 \ldots \ldots \ldots \ldots \ldots \ldots \ldots \ldots . .250$

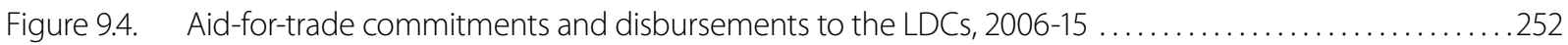

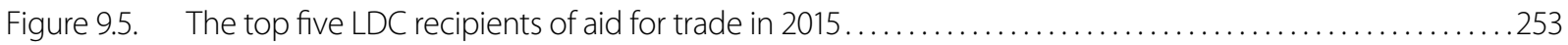

Figure 9.6. Aid-for-trade disbursements to the LDCs in 2015, USD million constant prices ......................253

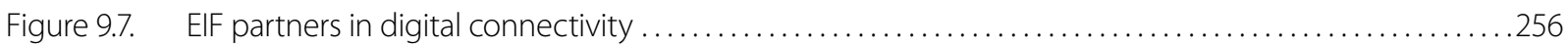

\section{Boxes}

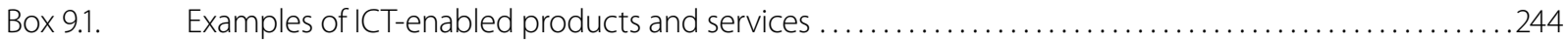

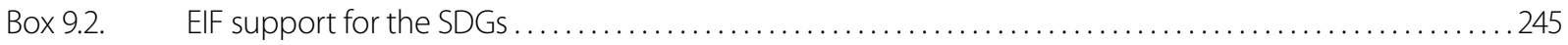

Box 9.3. Examples of $L D C$ regulatory reform in telecom services.................................... 249

Box 9.4. An example from Mauritania of the telecommunications regulatory framework .................... 251

Box 9.5. Burkina Faso's efforts towards regional harmonisation .................................... 254

\section{Annex}

Annex 9.A1. Examples of priorities related to digital connectivity and e-commerce identified

in the DTIS Action Matrices. 


\section{CHAPTER 10}

\section{Tables}

Table 10.1. S Small company rating of the top 15 Challenges in enabling environment for cross-border

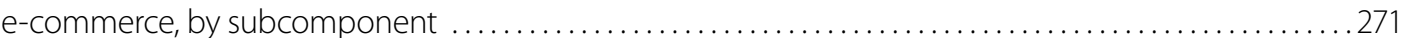

\section{Figures}

Figure 10.1. Percentage of companies that export, by company size and online activity..................268

Figure 10.2. N Number of markets companies sell into, by company's online sales activity...................268

Figure 10.3. Merchants' perception of obstacles to cross-border e-commerce, by company size $\ldots . \ldots . \ldots . . . .269$

Figure 10.4. Rating of the enabling environment for e-commerce and cross-border e-commerce,

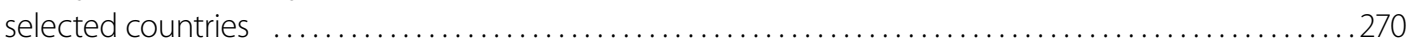

Figure 10.5. LAC Companies' answers to the question: "What would be the loss on your organization's productivity (measured as the value of sales per employee) if it did not have access to the

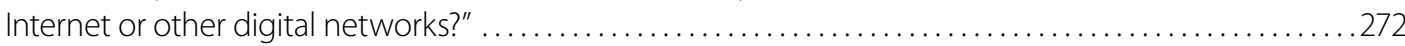

Figure 10.6. Percentage of online LAC companies with cross-border online sales or purchases in 2016,

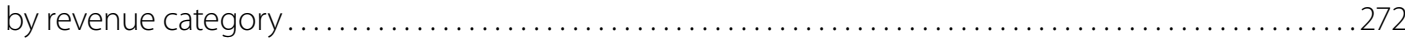

Figure 10.7. Challenges to cross-border online sales rated as "very significant" by LAC companies, by type

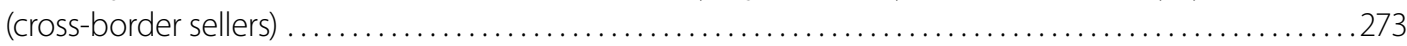

Figure 10.8. LAC companies perceived revenue growth at home and abroad if challenges were removed ........273

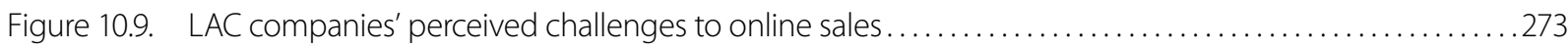

Figure 10.10. Revenue gains to companies if the top three barriers to e-commerce were removed, by market ..... . 274

Figure 10.11. Perceived priority barriers to starting to sell online, selected countries .....................274

\section{Boxes}

Box 10.1. Internet-based exporters in Latin America: Market access barriers and customs procedures .........272

Box 10.2. Private sector participation in initiatives to extend coverage . . . . . . . . . . . . . . . . . . . . . . . . 279

Box 10.3. The Framework Agreement on Facilitation of Cross-border Paperless Trade in Asia and the Pacific..... 282

\section{CHAPTER 11}

\section{Tables}

Table 11.1. Estimates of development co-operation flows of providers that do not report to the OECD DAC

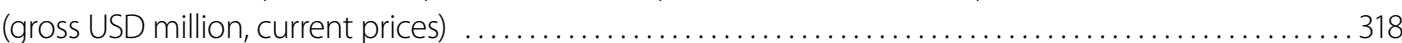

\section{Figures}

Figure 11.1. Financial flows provided to developing countries by DAC members and international financial institutions, USD billion, 2015 prices . . . . . . . . . . . . . . . . . . . . . . . . . . . . . . . . 291

Figure 11.2. Share of financial flows to developing countries by DAC and IFIs..........................292

Figure 11.3. Distribution of finance mobilised for development purposes from the private sector in 2012-15,

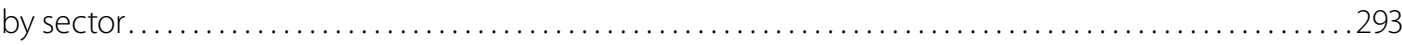

Figure 11.4. Distribution of finance mobilised for development purposes from the private sector in 2012-15,

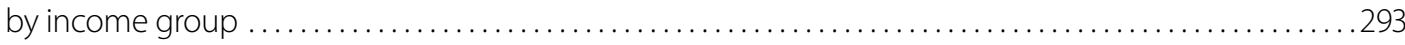

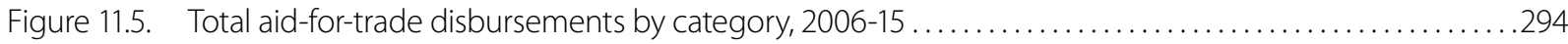

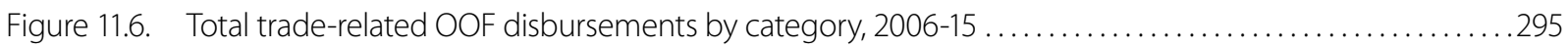

Figure 11.7. Share of total aid-for-trade disbursements by region and income group, $2006-15 \ldots \ldots \ldots \ldots \ldots . \ldots 297$

Figure 11.8. Share of total trade-related OOF disbursements by region and income group, $2006-15 \ldots \ldots \ldots \ldots . . \ldots 297$

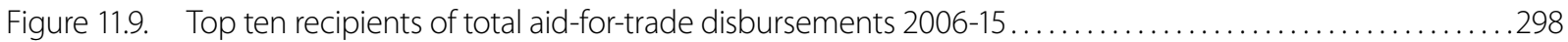

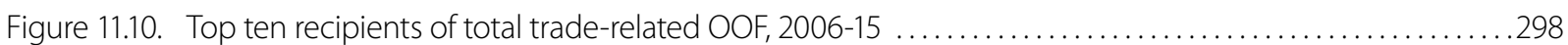

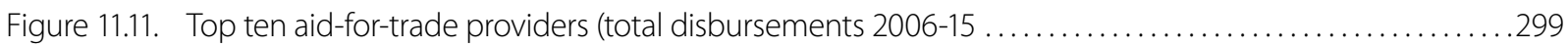

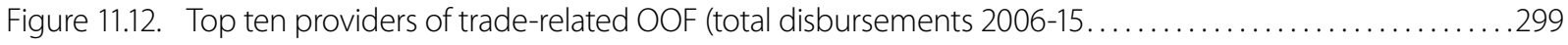




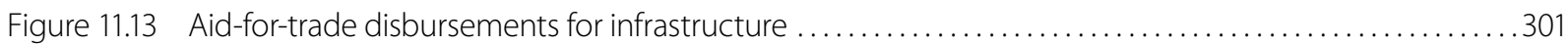

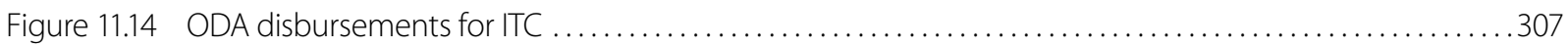

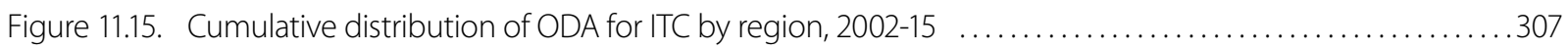

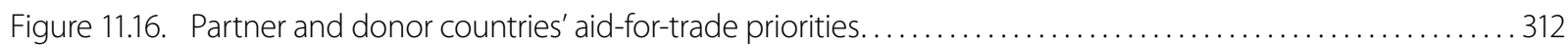

Figure 11.17 Drivers of change in the aid-for-trade strategies of partner countries since $2014{ }^{\prime} \ldots \ldots \ldots \ldots \ldots \ldots 313$

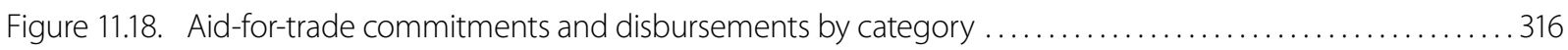

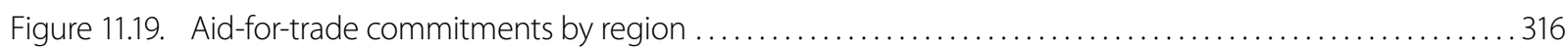

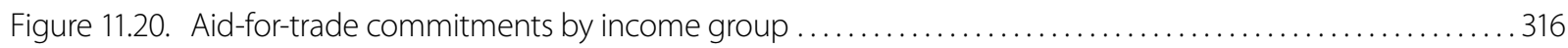

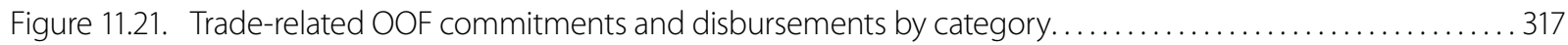

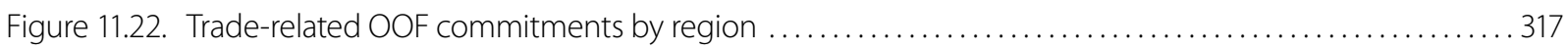

Figure 11.23. Trade-related OOF commitments by income group .................................. 317

\section{CHAPTER 12}

\section{Tables}

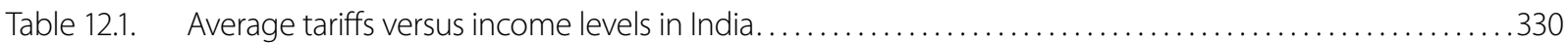

Table 12.2. Disaggregated import costs in Nepal (per twenty-foot equivalent unit). ........................334

Table 12.3. Who makes decisions on how a woman's cash earnings are used in Uganda? .......................338

\section{Figures}

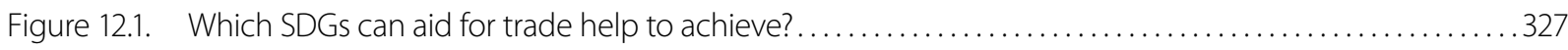

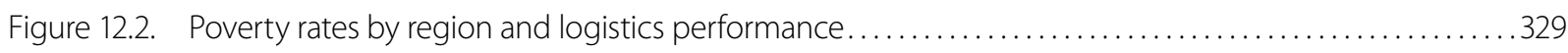

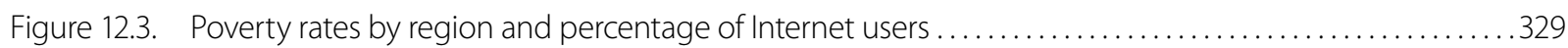

Figure 12.4. GDP per capita and Enabling Trade Index 2016 scores . . . . . . . . . . . . . . . . . . . . . . . . . . . 330

Figure 12.5. A basic analytical framework depicting the links between infrastructure andpoverty reduction ........332

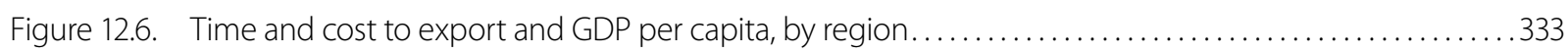

Figure 12.7. Fixed-and mobile-broadband prices in purchasing power parity $(2015) \ldots \ldots \ldots \ldots \ldots \ldots \ldots \ldots \ldots \ldots \ldots \ldots$

Figure 12.8. Top ten service sectors expected to contribute to women's economic empowerment ................342

\section{Boxes}

Box 12.1. The UK Department for International Development's approach to trade and poverty...............326

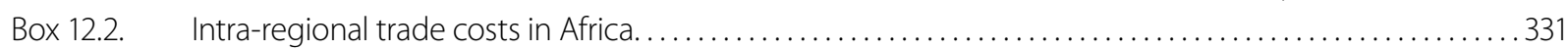

Box 12.3. Transmission channels through which the poor can benefit from tourism development..............335

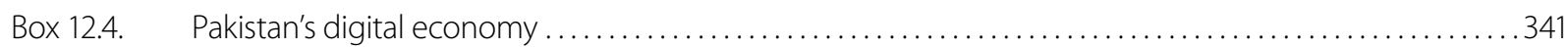

Box 12.5. Can growth in e-commerce make a contribution to women's economic empowerment? ............342

Box 12.6. How can aid for trade help implement the Sustainable Development Goals? . . . . . . . . . ..............345 


\section{ACRONYMS AND ABBREVIATIONS}

\begin{tabular}{|c|c|c|c|}
\hline $2 \mathrm{G}$ & $\begin{array}{l}\text { Second generation (of wireless mobile } \\
\text { telecommunications technology) }\end{array}$ & COMESA & $\begin{array}{l}\text { Common Market for Eastern } \\
\text { and Southern Africa }\end{array}$ \\
\hline \multirow[t]{2}{*}{$3 G$} & \multirow{2}{*}{$\begin{array}{l}\text { Third generation (of wireless mobile } \\
\text { telecommunications technology) }\end{array}$} & Congo DPR & Democratic Republic of the Congo \\
\hline & & CRS & Creditor Reporting System \\
\hline $4 \mathrm{G}$ & $\begin{array}{l}\text { Fourth generation (of wireless mobile } \\
\text { telecommunications technology) }\end{array}$ & DAC & Development Assistance Committee \\
\hline A4Al & $\begin{array}{l}\text { telecommunications technology) } \\
\text { Alliance for Affordable Internet }\end{array}$ & DFID & $\begin{array}{l}\text { UK Department for International } \\
\text { Development }\end{array}$ \\
\hline AAAA & Addis Ababa Action Agenda & DRC & Democratic Republic of Congo \\
\hline ADB & Asian Development Bank & DTIS & Diagnostic Trade Integration Study \\
\hline ADSL & Asymmetric digital subscriber line & \multirow[t]{2}{*}{ DTISU } & \multirow{2}{*}{$\begin{array}{l}\text { Diagnostic Trade Integration } \\
\text { Study Update }\end{array}$} \\
\hline AFD & French Development Agency & & \\
\hline AfDB & African Development Bank & EABN & East Africa Broadband Network \\
\hline AfT & Aid for trade & EASSy & Eastern Africa Submarine Cable System \\
\hline AlFT & EU-Africa Infrastructure Trust Fund & \multirow[t]{2}{*}{ EBRD } & \multirow{2}{*}{$\begin{array}{l}\text { European Bank for Reconstruction } \\
\text { and Development }\end{array}$} \\
\hline APPEC & Asia-Pacific Economic Cooperation & & \\
\hline \multirow[t]{2}{*}{ APTTA } & Afghanistan-Pakistan Transit-Trade & EC & European Commission \\
\hline & Agreement & \multirow[t]{2}{*}{ ECOWAS } & \multirow{2}{*}{$\begin{array}{l}\text { Economic Community } \\
\text { of West African States }\end{array}$} \\
\hline ASEAN & Association of Southeast Asian Nations & & \\
\hline ASYCUDA & Automated System for Customs Data & $\mathrm{EIB}$ & European Investment Bank \\
\hline $\mathrm{B} 2 \mathrm{~B}$ & Business-to-business & EIF & Enhanced Integrated Framework \\
\hline $\mathrm{B} 2 \mathrm{C}$ & Business-to-consumer & EU & European Union \\
\hline B2G & Business-to-government & \multirow[t]{2}{*}{ FA-PT } & \multirow{2}{*}{$\begin{array}{l}\text { Framework Agreement on Facilitation } \\
\text { of Cross-border Paperless Trade in Asia } \\
\text { and the Pacific }\end{array}$} \\
\hline BIGAN & $\begin{array}{l}\text { Burundi Internet General } \\
\text { Applications Network }\end{array}$ & & \\
\hline BOP & Balance-of-payments & FBA & Fulfillment by Amazon \\
\hline BPM & Business process management & \multirow{2}{*}{$\begin{array}{l}\text { FDI } \\
\text { FTA }\end{array}$} & Foreign direct investment \\
\hline $\mathrm{BPO}$ & Business process outsourcing & & Free Trade Agreement \\
\hline $\mathrm{C} 2 \mathrm{C}$ & Consumer-to-consumer & FYR Macedonia & $\begin{array}{l}\text { Former Yugolslav Republic } \\
\text { of Macedonia }\end{array}$ \\
\hline$C A B$ & Central African Backbone & GATS & General Agreement on Trade in Services \\
\hline CAR & Central African Republic & GATF & Global Alliance for Trade Facilitation \\
\hline CAREC & Central Asia Regional & $\mathrm{GB}$ & Gigabyte \\
\hline & Economic Cooperation & Gbit(s) & Gigabit per second \\
\hline CBI & Caribibean Community & GDI & German Development Institute \\
\hline & the Netherlands & GDP & Gross domestic product \\
\hline CBTA & Cross-Border Transport Agreement & GIF & Global Infrastructure Facility \\
\hline $\mathrm{CIS}$ & Commonwealth of Independent States & $\mathrm{GlZ}$ & $\begin{array}{l}\text { Gesellschaft für Internationale } \\
\text { Zusammenarbeit }\end{array}$ \\
\hline
\end{tabular}




\begin{tabular}{|c|c|c|c|}
\hline GNI & Gross national income & LDCs & Least developed countries \\
\hline GPI & Gender Parity Index & LICs & Low income countries \\
\hline GSMA & GSM Association & LIMCs & Lower middle income countries \\
\hline GSR & Global symposiums for regulators & LLDCs & Landlocked developing countries \\
\hline $\mathrm{G} 2 \mathrm{C}$ & Government-to-citizen & LPI & Logistics Performance Index \\
\hline JVC & Global value chain & LTE & Long-term evolution \\
\hline HICs & Higher income countries & Mbit/s & Megabit per second \\
\hline HTS & High-throughput satellites & $\mathrm{MICS}$ & Middle income countries \\
\hline IADB & Inter-American Development Bank & MOOCs & Massive open online courses \\
\hline \multirow[t]{2}{*}{$\mathrm{ICT}$} & \multirow{2}{*}{$\begin{array}{l}\text { Information and Communications } \\
\text { Technology }\end{array}$} & mPOS & Mobile point-of-sale \\
\hline & & MSMES & Micro, small and medium enterprises \\
\hline & International Development Association & \multirow[t]{2}{*}{ NCTTCA } & \multirow{2}{*}{$\begin{array}{l}\text { Northern Corridor Transit and Transport } \\
\text { Coordination Authority }\end{array}$} \\
\hline Dl & ICT Development Index & & \\
\hline IDS & Institute of Development Studies & \multirow[t]{2}{*}{ NEPAD } & \multirow{2}{*}{$\begin{array}{l}\text { New Partnership for Africa's } \\
\text { Development }\end{array}$} \\
\hline IFC & International Finance Corporation & & \\
\hline IMF & International Monetary Fund & $\mathrm{NGO}$ & Non-Governmental Organization \\
\hline \multirow[t]{2}{*}{ IMT } & \multirow{2}{*}{$\begin{array}{l}\text { international mobile } \\
\text { telecommunication system }\end{array}$} & NGSO & Non-geostationary satellite orbit \\
\hline & & OCTA & Association of the Overseas Countries \\
\hline loT & Internet of Things & & and Territories of the European Union \\
\hline IPCC & $\begin{array}{l}\text { Inter-Governmental Panel } \\
\text { on Climate Change }\end{array}$ & OECD & $\begin{array}{l}\text { Organisation for Economic } \\
\text { Co-operation and Development }\end{array}$ \\
\hline IPR & Intellectual property rights & OECS & Organisation of Eastern Caribbean States \\
\hline \multirow[t]{2}{*}{ ISCED } & \multirow{2}{*}{$\begin{array}{l}\text { International Standard Classification } \\
\text { of Education }\end{array}$} & OLICs & Other low income countries \\
\hline & & OOF & Other official flows \\
\hline IsDB & Islamic Development Bank & OPHDI & Oxford Poverty and Human \\
\hline IT & Information technology & & Development Initiative \\
\hline ITA & Information Technology Agreement & OSBP & One-stop border post \\
\hline ITC & International Trade Centre & PIAAC & Programme for International \\
\hline ITF & International Transport Forum & \multirow{2}{*}{ PIFS } & \multirow{2}{*}{ Pacific Islands Forum Secretariat } \\
\hline \multirow{2}{*}{ ITFC } & International Islamic Trade & & \\
\hline & Finance Corporation & & $\begin{array}{l}\text { Programme for International Student } \\
\text { Assessment }\end{array}$ \\
\hline & International Telecommunication Union & & Private participation in infrastructure \\
\hline IXP & Internet exchange points & PPIAF & \\
\hline JICA & $\begin{array}{l}\text { Japanese International } \\
\text { Cooperation Agency }\end{array}$ & & Advisory Facility \\
\hline $\mathrm{Kbit} / \mathrm{s}$ & Kilobit per second & PTD & $\begin{array}{l}\text { Post and Telecommunications } \\
\text { Department }\end{array}$ \\
\hline KFAED & $\begin{array}{l}\text { Kuwait Fund for Arab Economic } \\
\text { Development }\end{array}$ & PPP & Purchasing power parity \\
\hline \multirow{2}{*}{$\mathrm{KNCCl}$} & \multirow{2}{*}{$\begin{array}{l}\text { Kenya National Chamber of Commerce } \\
\text { and Industry }\end{array}$} & PPPS & Public-private partnerships \\
\hline & & PPPUSD & Purchasing power parity dollars \\
\hline & Latin America and the Caribbean & PMR & Product market regulation \\
\hline o PDR & Lao People's Democratic Republic & & Quality of service \\
\hline
\end{tabular}




\begin{tabular}{|c|c|c|c|}
\hline RECS & Regional economic communities & UPS & United Parcel Service \\
\hline \multirow[t]{2}{*}{ SADC } & Southern African Development & UPU & Universal Postal Union \\
\hline & Community & USAID & United States Agency \\
\hline \multirow[t]{2}{*}{ SATA } & South Africa Telecommunications & & for International Development \\
\hline & Association & USD & United States Dollar \\
\hline SDG & Sustainable Development Goal & VAT & Value Added Tax \\
\hline SIDS & Small island developing states & WAPP & West Africa Power Pool \\
\hline \multirow[t]{2}{*}{ SIECA } & Secretaría de Integración Económica & WB & World Bank \\
\hline & Centroamericana & WBG & World Bank Group \\
\hline SMEs & Small and medium enterprises & WCO & World Customs Organisation \\
\hline & Sanitary and phytosanitary & WEF & World Economic Forum \\
\hline SSL & Secure sockets layer & WiMAX & Worldwide interoperability for \\
\hline ST-EP & Sustainable tourism-eliminating poverty & & microwave access \\
\hline STRI & Services Trade Restrictiveness Index & WOUGNET & Women of Uganda Network \\
\hline TBT & Technical barriers to trade & WSIS & World Summit on the Information \\
\hline TFA & Trade Facilitation Agreement & & Society \\
\hline TFP & Total factor productivity & WTO & World Trade Organization \\
\hline TIP & Telecom Infra Project & WTR & World Trade Report \\
\hline TiVA & Trade in value added & & \\
\hline TMEA & TradeMark East Africa & & \\
\hline TRIPS & $\begin{array}{l}\text { Trade-Related Aspects of Intellectual } \\
\text { Property Rights }\end{array}$ & & \\
\hline UK & United Kingdom & & \\
\hline UMICs & Upper middle income countries & & \\
\hline UN & United Nations & & \\
\hline UNCITRAL & $\begin{array}{l}\text { United Nations Commission } \\
\text { on International Trade Law }\end{array}$ & & \\
\hline UNCTAD & $\begin{array}{l}\text { United Nations Conference on Trade } \\
\text { and Development }\end{array}$ & & \\
\hline UNDP & United Nations Development Programme & & \\
\hline UNECA & $\begin{array}{l}\text { United Nations Economic Commission } \\
\text { for Africa }\end{array}$ & & \\
\hline UNECE & $\begin{array}{l}\text { United Nations Economic Commission } \\
\text { for Europe }\end{array}$ & & \\
\hline UNESCAP & $\begin{array}{l}\text { United Nations Economic and Social } \\
\text { Commission for Asia and the Pacific }\end{array}$ & & \\
\hline UNESCO & $\begin{array}{l}\text { United Nations Educational, Scientific } \\
\text { and Cultural Organization }\end{array}$ & & \\
\hline UNESCO & $\begin{array}{l}\text { United Nations Educational, Scientific } \\
\text { and Cultural Organization }\end{array}$ & & \\
\hline UNIDO & $\begin{array}{l}\text { United Nations Industrial Development } \\
\text { Organization }\end{array}$ & & \\
\hline UNWTO & $\begin{array}{l}\text { United Nations World Tourism } \\
\text { Organization }\end{array}$ & & \\
\hline
\end{tabular}





\section{EXECUTIVE SUMMARY}

This is the sixth edition of the Aid for Trade at a Glance publication. Since 2007, successive editions of this flagship publication have shed light on the steps being taken by developing country governments and their development partners to leverage trade for development. The 2017 edition adds further weight to the already substantial body of evidence highlighting the effectiveness of aid for trade. It focuses on how and why trade connectivity is critical for inclusiveness, sustainable growth and poverty reduction. It is intended to inform both practice and policy regarding aid for trade's contribution to the 2030 Agenda for Sustainable Development.

Almost USD 300 billion has been disbursed for aid-for-trade support since the Aid for Trade Initiative was launched. Some 146 developing countries have received aid for trade, mainly in Asia (41.5\%) and Africa (38.7\%), with 27\% of the total going to LDCs. Regional and global programmes attracted almost $15 \%$ of total disbursements. More than threequarters of total disbursements have gone to four sectors: transport and storage (28.6\%), energy generation and supply (21.6\%), agriculture (18.3\%), and banking and financial services (11.1\%).

Physical connectivity enables the movement of goods and services to local, regional and global markets. Digital connectivity now intertwines with physical connectivity. Digital networks have rapidly become integral to global trade, and offer opportunities for growth as a market place. Accessible and affordable digital connections are indispensable for trade connectivity. Yet the Internet remains unavailable to 3.9 billion people globally, many of whom live in the least developed countries (LDCs).

The 2030 Agenda for Sustainable Development includes targets for universal and affordable access to the Internet. Mobile broadband networks are now available for more than 50\% of the population in LDCs, but digital devices and fixed network connections remain high in price, and limited in coverage. Affordability remains a key barrier to higher levels of ICT use.

The digital divide can also be viewed as a market access divide with the cost of digital connections as trade costs. Firms and consumers that are offline are locked out of the opportunities offered by the rapidly expanding market for goods and services purchased or supplied online. Lack of digital connectivity reinforces economic isolation.

Actions to boost connectivity are being undertaken by a broad range of countries at all levels of development. Measures should be taken to influence both the supply side (e.g. ICT infrastructure and network coverage availability) and the demand side (e.g. affordability and usage) of digital connectivity. National co-ordination mechanisms and strategies frequently miss perspectives and inputs from trade officials. In many countries where connectivity is lagging, more could also be done to improve the enabling trade environment for digital connectivity.

To bridge the digital divide additional finance must be mobilized to support the development of network infrastructure, dynamic ICT services markets, and adequate regulatory environments. Financing is essential to help develop affordable, reliable ICT infrastructure, and build up related services offerings, especially for under- or un-served populations. Bridging the digital divide also requires policies that increase ICT access and use. Aid for trade is supporting governments in these efforts, and demand is expected to grow. 
Border clearance delays and inadequate physical infrastructure also obstruct e-commerce. At the border, the digitalisation of customs and border agencies can support efficient customs services. Behind the border, the provision of efficient trade logistics still matters and is arguably even more important in an increasingly digital world. A priority for micro, small and medium sized enterprises (MSMEs) that emerges from the report is the need for action to streamline customs procedures for these firms. The coming into force of the WTO Trade Facilitation Agreement (TFA) will arguably address many of these concerns.

The TFA is a powerful tool to reduce trade costs. Trade facilitation tops the aid-for-trade priorities of both developing countries and their development partners, albeit in a broader conception that also includes physical connectivity, such as transport corridors, and digital connectivity too. There is also growing evidence of the positive impact of aid for trade in tackling border bottlenecks and contributing to inclusive trade outcomes.

The role of services trade in promoting connectivity is growing. Services provide the basic infrastructure to support trade in goods, facilitate supply chains, provide significant value added to manufacturing activities, and form the backbone infrastructure that enables e-commerce and the growing online supply of services. Services trade policies can enhance (or hinder) connectivity and thus access to the benefits of integration into the international trading system.

Governments together with other stakeholders have a central role in developing e-commerce strategies not only around ICT infrastructure, but also including trade logistics, e-commerce skills, legal frameworks, payment solutions and access to financing. Access to a digital connection is a necessary, but not a sufficient condition to engage in e-commerce. Actions by developing country governments to boost connectivity needs to be complemented by action in these areas if they are to make the most of e-trade opportunities for generating economic growth, job creation and poverty reduction.

Digital connectivity promises productivity gains across all areas of the economy, including traditional sectors like agriculture. Developing countries and the least developed can use e-trade as a productivity lever and device for trade connectivity. Digital connectivity helps connecting MSMEs and women-owned enterprises to customers and suppliers around the world. A significant connectivity gap exists between large and small firms, notably in low income countries and LDCs. The Internet may reinforce existing inequalities of access, such as those between women and men, rural and urban, and large firms and small firms. Policy makers should scale up access and training programmes to tackle this risk.

The publication sheds light on various examples of how the private sector is helping MSMEs, women, and rural populations to connect to the global economy. The private sector is vital to bridging the digital divide and more should be done to solicit their views on policy choices and public investment, and promote public-private collaboration for boosting connectivity. Moving ahead, both developing countries and their development partners expect a scaling up of digital connectivity and e-commerce programmes.

Findings show that the better the physical and digital connectivity, the more it contributes to market access, financial inclusion, women's economic empowerment and poverty reduction. These impacts get amplified when the public and private sector work together to build the institutional and physical capacity to help the poor connect and compete.

The experience of some LDCs demonstrates that investing in efforts to improve ICT brings benefits for trade and economic development. When LDC governments together with key stakeholders including the private sector, and international donors work together to focus development finance on trade inclusiveness for sustainable development inclusion, much can be achieved. 


\title{
CHAPTER 1
}

\section{OVERVIEW: PROMOTING TRADE, INCLUSIVENESS AND CONNECTIVITY FOR SUSTAINABLE DEVELOPMENT}

\begin{abstract}
This chapter provides an overview of the report which examines trade costs and their influence on sustainable development and poverty reduction. It analyses in particular the physical and digital connectivity required to plug into the global economy. It surveys the connectivity challenges faced by developing countries with a specific focus on the least developed, together with the action taken to tackle these constraints. It underscores that digital connectivity is not sufficient to engage in e-commerce-a range of other enabling factors must also be in place. It surveys the policies for supporting developing countries to engage in this form of trade. This overview provides a snapshot of what is happening in promoting trade inclusiveness and connectivity for sustainable development, the impact of that support and where improvements are needed.
\end{abstract}




\section{INTRODUCTION}

This is the sixth aid-for-trade monitoring report. The previous edition focussed on trade costs. It stressed that high trade costs make it hard for many firms in developing countries to fully exploit market access opportunities. Obsolete or illadapted infrastructure, cumbersome and time-consuming border procedures, limited access to trade finance and the costs of meeting an ever broader array of standards were shown to be pricing too many developing country firms out of international trade. This was found to be particularly true for small and medium sized enterprises in the least developed countries, and in sea- and landlocked countries. It is also true for trade in agricultural goods, - where perishability and trade measures push costs higher. In short, the report revealed that high trade costs can undermine the potential gains from trade.

Aid for Trade at a Glance 2017: Promoting Trade Inclusiveness and Connectivity for Sustainable Development continues the focus on trade costs. It puts a spotlight on connectivity, physical and digital. Both are critical for sustainable growth and poverty reduction. Physical and digital connectivity intertwine and are now inseparable to the conduct of trade. Physical connectivity enables the movement of people, goods and services and provides access to local, regional and global markets. Digital connectivity allows individuals and businesses to plug more directly into the global economy. At its most basic level, digital connectivity links individuals and businesses through digital networks. It facilitates the online purchase of goods and delivery of services.

Digitalisation and new technologies change how trade takes place, not why it takes place. Trade is still subject to comparative advantage, while informational asymmetries and trade barriers, both at the border and behind the border, continue to exist. However, new technologies are reducing the cost of supplying services across borders and connecting diverse actors along the value chain. They are helping to overcome many of the constraints that are associated with operating in international markets, leading to the adoption of new business models, the entry of new businesses and a shift in sources of comparative advantage.

Digitalisation has not only changed how trade is taking place, but also who is trading and what is being traded. A larger number of low-value transactions and small shipments are now crossing borders. Also, goods are increasingly bundled with services. Services represents a significant and growing share of exports of manufactured products, for both developed and developing countries. Global internet marketplaces, such as Alibaba, Amazon and eBay are helping consumers and micro, small and medium enterprises (MSMEs) to engage more directly in international trade. Some MSMEs are "born global". National and regional platforms, for example Jumia, leboncoin, MercadoLivre and Trini Trolley, grew by offering solutions to e-trade barriers such as payment and delivery bottlenecks. These online platforms help reduce informational asymmetries and search frictions, tackling the constraints posed by thin markets.

To better exploit the potential of e-trade, developing countries must pay greater attention to the trade policy dimension of digital connectivity and bridge the "digital trade policy divide". This implies integrating trade perspectives into digital connectivity strategies. Although digital connectivity is a necessary condition for e-commerce, it is not sufficient. A series of additional steps and policies need to be in place before the potential of e-commerce can be fully tapped.

In addition, some countries - the least developed in particular-require technical and financial assistance to build the human, institutional and infrastructure capacities needed to connect to and compete in international markets. Official development finance and trade-related assistance from South-South providers is already helping these countries to bridge the physical and digital divides. The private sector, meanwhile, is working to improve connectivity through commercial investments, public-private partnerships and through corporate social responsibility and corporate philanthropic foundations. 
This report puts a spotlight on what is happening in aid for trade and connectivity, what is not, and where improvements are needed. One conclusion that emerges is that aid for trade must act as a catalyst for removing both supply and demand side constraints to the diffusion of digital connectivity, with a particular focus on the least-connected.

\section{WHO PARTICIPATED IN THE OECD-WTO AID-FOR -TRADE MONITORING EXERCISE?}

In 2017, 63 developing countries, of which 25 were least developed countries (LDCs), submitted aid-for-trade selfassessment questionnaires in response to the OECD-WTO aid-for-trade monitoring and evaluation exercise. A total of 38 donors participated: 29 bilateral and 9 multilateral donors. Three providers of South-South trade-related support (i.e. Brazil, Chile and Indonesia) also submitted self-assessments. Lastly, 7 regional organisations (i.e. transport corridors and regional economic communities) participated in the 2017 exercise (Figure 1.1).

\section{Figure 1.1. Responses submitted in the aid-for-trade monitoring exercise}

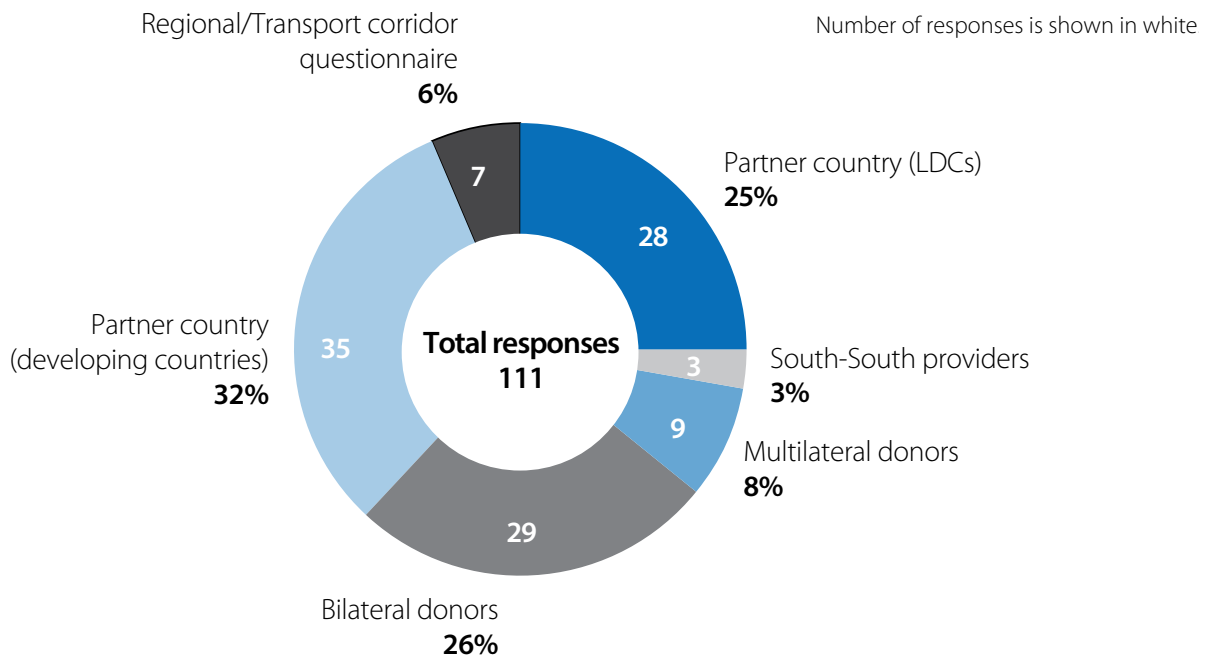

Source: OECD-WTO aid-for-trade monitoring exercise (2017a), www.oecd.org/aidfortrade/countryprofiles/

StatLink 刑Ist http://dx.doi.org//10.1787/888933525246

The monitoring exercise also invited the public and private sectors to submit case stories about aid-for-trade policies, programmes and projects. A total of 145 case stories were received before the cut-off date, including: 96 from the public sector, 25 from the private sector, and 24 from NGOs and academia.! The single largest category of case stories (34\%) focused on capacity building programmes in trade policy and regulations. Within that category, eight out of ten case stories focussed on trade facilitation. Experiences in building trade-related infrastructure were recounted in 30\% of the case stories, with two-thirds highlighting programmes aimed at improving information and communications technologies (ICT) in developing countries. Activities for building productive capacity were addressed in a total of 36 of the case stories, with 25 focussing on business services, 14 on agriculture, 9 on banking services, 5 on industry and manufacture and 1 case story on fisheries (Figure 1.2). 


\section{Figure 1.2. Program focus of case stories submitted in the context of the OECD-WTO aid-for-trade monitoring exercise}

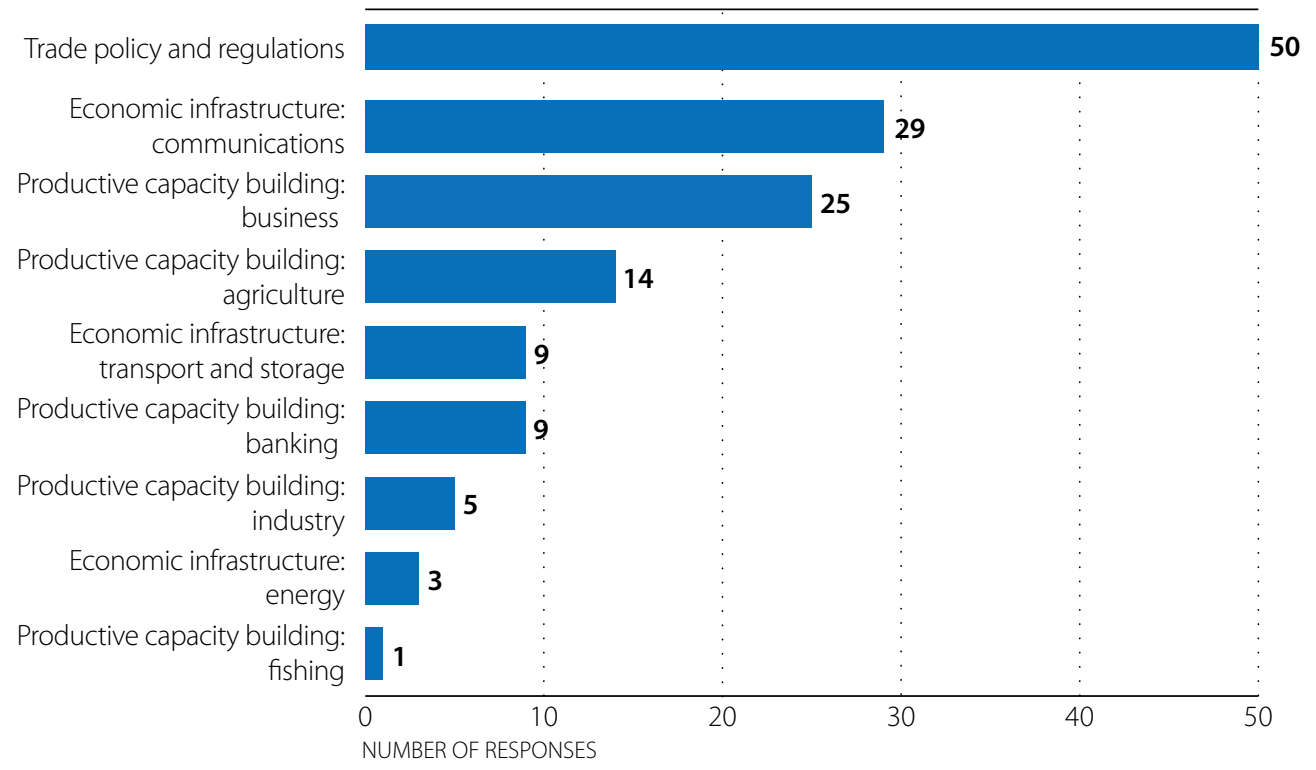

Source: OECD-WTO aid-for-trade monitoring exercise (2017b), http://www.oecd.org/aidfortrade/casestories/

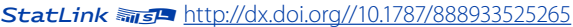

The following sections highlight the main findings of the monitoring exercise and other findings of the report.

\section{CHAPTER 2. SETTING THE SCENE World Trade Organization}

On 22 February 2017, the WTO Trade Facilitation Agreement (TFA) entered into legal force. The TFA adds a powerful instrument to the toolbox that can be drawn on by policymakers seeking to reduce trade costs. Trade facilitation emerges as the top aid-for-trade priority of both developing countries and their development partners who responded to the 2017 aid-for-trade monitoring exercise (Figure 1.3). The concept of trade facilitation is a broad one and includes transport facilitation and, increasingly, digital connectivity.

Digital networks offer an avenue for developing and least developed countries to connect to global trade. Digital connectivity intertwines with other modes of physical connectivity (air, maritime, road and rail) and underpins the global value chains that increasingly characterise international commerce. Digital networks also offer access to the rapidly expanding market of goods and services that is made available through the Internet. In the absence of affordable digital connections, there is no access to this new global market.

Access to digital connectivity requires the supply of hard infrastructure, but uptake also depends on a range of demandand supply-side factors, which in turn can be influenced by regulatory regimes. Services supplied and goods ordered online can be offered often at significantly lower cost than their offline equivalents. Many services are also digitally enabled, even if ultimately supplied physically or in person. Yet goods ordered online still need to be physically delivered. Often these goods face a series of obstacles that drive up their final costs and reduce the participation of developing country firms in supply chains. Logistics, customs and trade facilitation are examples of policy areas where analogue policies can help facilitate growth generated through digital connectivity.

The monitoring exercise points to action by a range of countries at different levels of income to harness digital connectivity for their development. Digital technologies are permeating a growing array of government functions and policy areas. The private sector and development partners are actively supporting many of these activities. 
Figure 1.3. Aid-for-trade priorities from partner and donor agencies

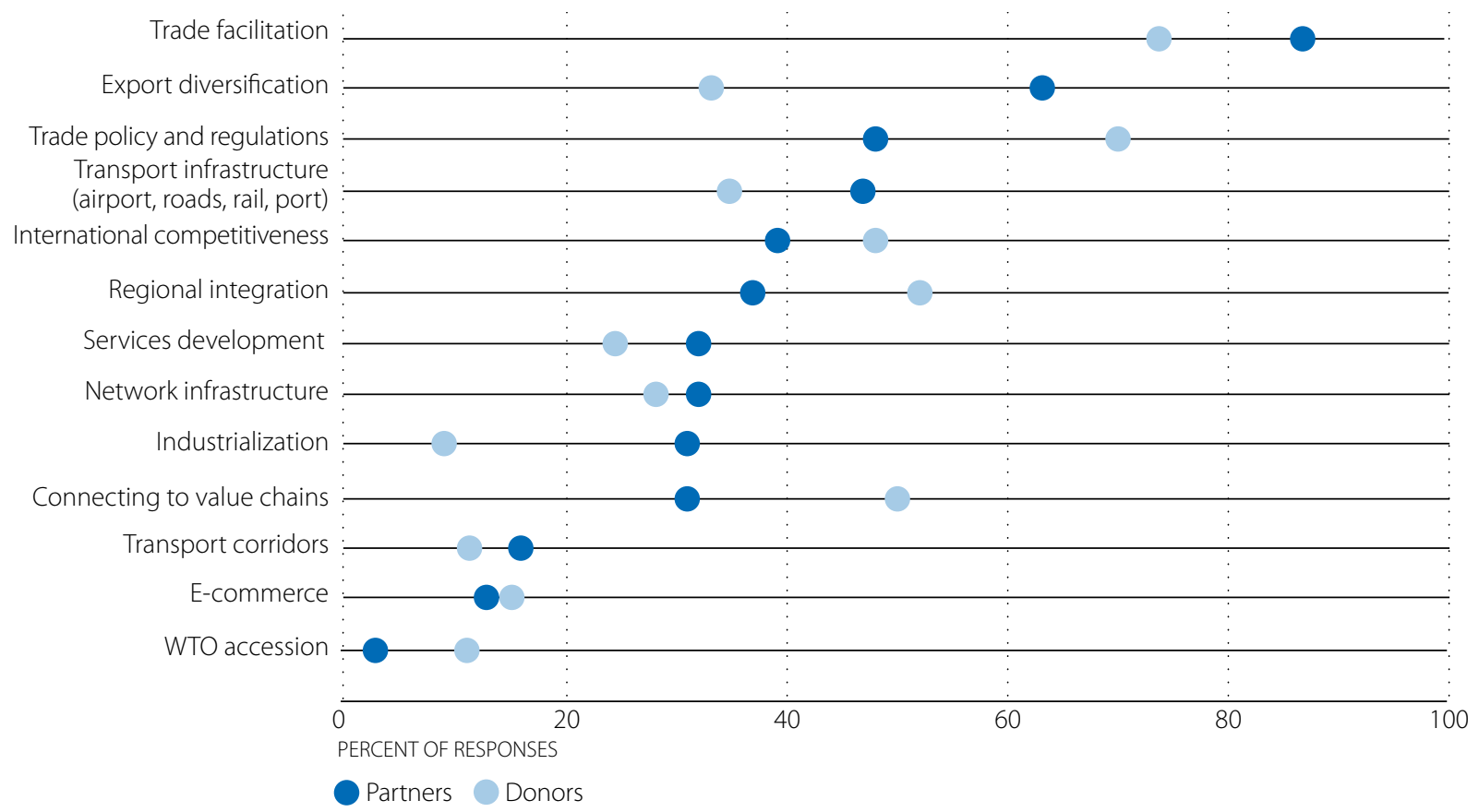

Source: OECD-WTO aid-for-trade monitoring exercise (2017a), www.oecd.org/aidfortrade/countryprofiles/.

StatLink ants http://dx.doi.org/10.1787/888933525284

Trade policy can have an important influence on digital trade connectivity costs, in terms of both the availability and the affordability of connections, and therefore on the ability of developing countries to use digital connectivity for their trade integration and economic development. The emergence of a possible "digital trade policy divide" is an issue of particular concern. The monitoring exercise suggests that trade ministries do not appear to be systematically engaged in ICT, digital or other e-government national co-ordination mechanisms. This same issue is also mirrored among development agencies where connectivity is not often considered from a trade perspective.

\section{CHAPTER 3. DIGITAL CONNECTIVITY AND TRADE LOGISTICS Organisation for Economic Co-operation and Development and United Nations Conference on Trade and Development}

Innovations in the digital economy reduce the costs of engaging in trade. This, in turn, can enable previously marginal buyers and sellers, or those in remote areas, to enter markets, thereby strengthening inclusive economic growth. However digital trade is not without challenges. First, transforming digital connectivity opportunities into digital trade for development requires tackling long-standing constraints to market integration as well, such as physical connectivity, and reduce the cost of physically moving goods across borders (customs efficiency) and behind the border (trade logistics services efficiency). While digitalisation can also help reduce those costs, it also creates new ways of trading requiring adaptation from both public and private actors.

Addressing traditional physical connectivity constraints is a necessity to unlock the opportunities created by digitalisation and digital trade. Traditional physical connectivity, such as hard infrastructure and the provision of efficient trade logistics (for example air, maritime road and rail transport services), still matter. Although it has reduced over time, physical connectivity still weighs heavily on trade costs (see figure 1.4). In fact, in the digital world physical connectivity may have become even more critical. However, digitalisation also provides an opportunity to reduce 
the cost of addressing physical connectivity bottlenecks and increasing market access. This creates positive spillovers for public and private actors. Digitalisation lowers the costs of moving goods by reducing co-ordination costs between different actors in global value chains (GVCs), and the costs of support services that are necessary to make trade happen, from transport to insurance.

\section{Figure 1.4. Freight and insurance costs as a percentage of the value of imports, ten-year moving averages within country groups, 1989-2016}

PERCENT OF VALUE OF IMPORTS

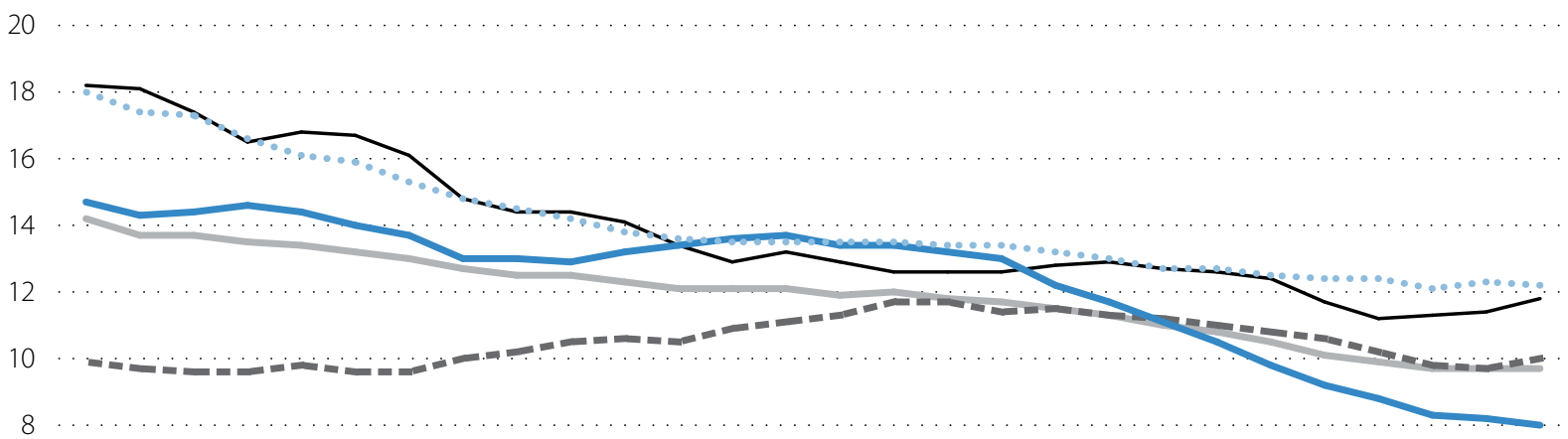

6

4

2

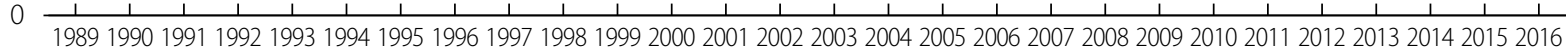

...... Developing economies: Africa

- Developing economies: Oceania
-ோ- Developing economies: Asia

Developing economies: America

Note: Averages within the country groups are un-weighted, i.e. each country's freight ratio is assigned the same weight when calculating the average. Data is for all modes of transport, representing the cost of international transport and insurance as a percentage of the CIF value (cost, insurance, freight) of the imported goods.

Source: UNCTAD.

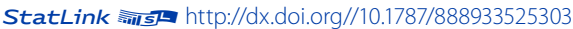

For trade facilitation, digitalisation also provides opportunities to reduce costs of implementation associated with co-ordination among authorities, and with private actors, and ways to manage the processing of increased trade flows. Measures such as customs automation, electronic documents and Single Windows are all easier to implement today than when trade facilitation negotiations started at WTO a decade ago. In addition, digitalisation of customs operations creates positive spill overs for both public and private actors. For instance, it increases transparency by decreasing risk management costs for customs authorities; increases the efficiency of customs operations and reliability for the private sector and finally decreases corruption opportunities.

The OECD Trade Facilitation Indicators (TFIs) measure progress in areas falling under the WTO TFA. The indicators highlight that, at its entry into force, implementation of the various substantive provisions of the TFA was well under way. While digitalisation and the flow of data across borders can support efficient customs services and the implementation of the TFA, digitalisation of clearance processes lags behind in many customs and other border administrations. A lack of ICT infrastructure is one reason for this. More progress is also needed to improve coordination between public authorities within and between countries (See figures 1.5 and 1.6). 
Figure 1.5. Automation tools in place, by type of tool and by country grouping

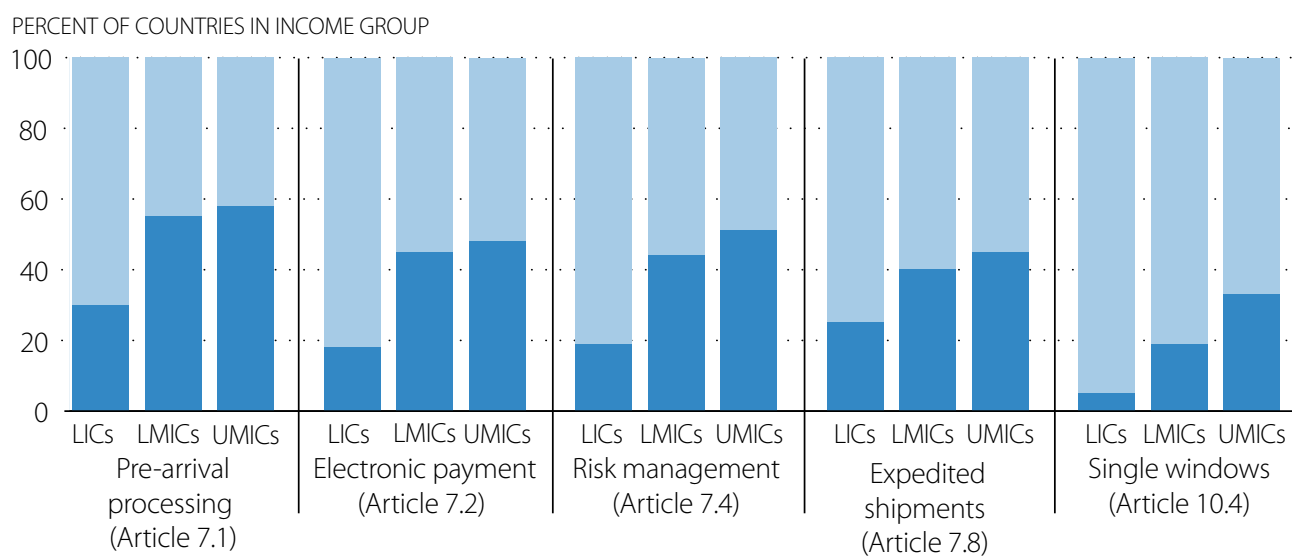

Already implemented Not implemented or in the process of implementation

Source: OECD (2017a), Trade Facilitation Indicators www.oecd.org/trade/facilitation/indicators.htm (accessed on 01 February 2017)

StatLink त्ञाI http://dx.doi.org/10.1787/888933525322

\section{Figure 1.6. Automation tools for domestic border agency co-operation}

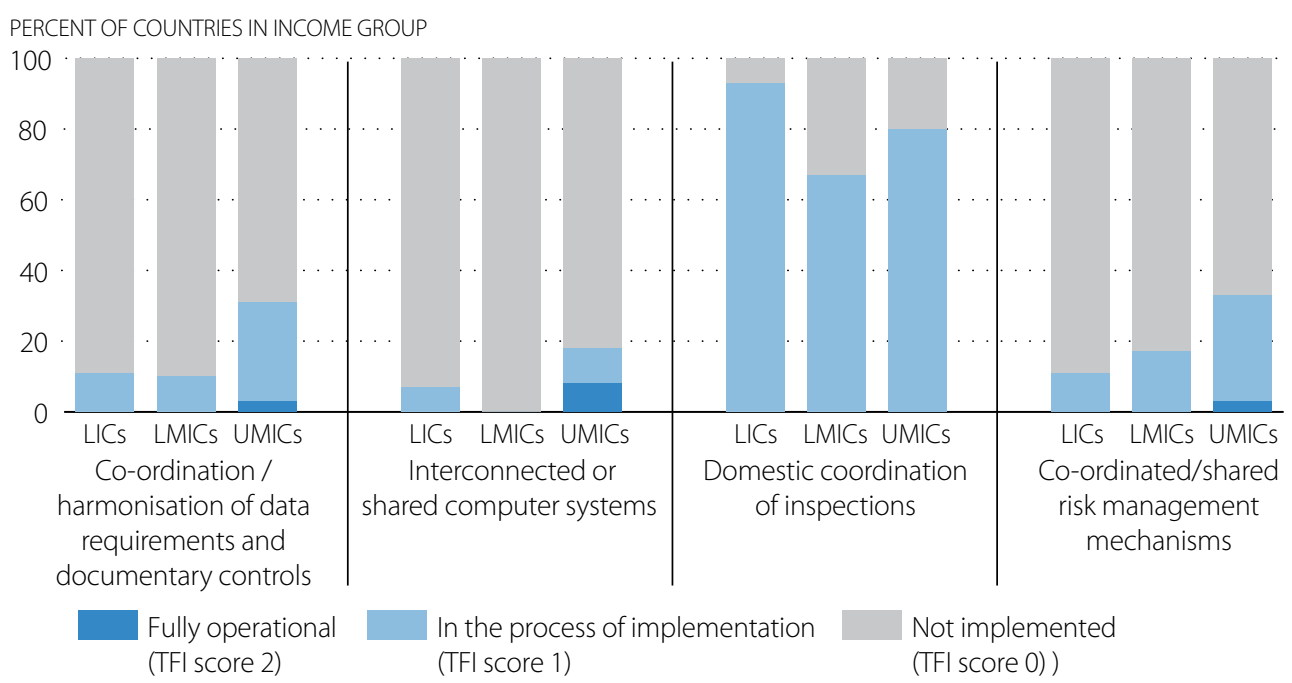

Source: OECD (2017a), Trade Facilitation Indicators www.oecd.org/trade/facilitation/indicators.htm

(accessed on 01 February 2017)

StatLink न्ना5ा http://dx.doi.org/10.1787/888933525341

Holistic approaches are required to deal with weak links or bottlenecks in terms of both physical and digital connectivity in the trade logistics chain, whether between logistics modes, between countries or between systems. For instance, good maritime connectivity requires not only efficient port infrastructure and competitive shipping lines, but also efficient hinterland services. Co-ordination at the regional scale has the potential to maximise returns to infrastructure investments. Also, digital connectivity requires systems that are capable of exchanging information seamlessly. This raises issues such as interoperability, and more broadly constraints preventing the continuity of information flows. Failure to consider these issues can substantially limit the gains from digitalisation.

Finally, digital trade changes the way goods are traded (increasing the volume of small value shipments traded, as well as the importance of parcel services as an export pathway and consolidation of containers) and who trades (i.e. micro, small and medium enterprises, or MSMEs). These "new" types of trade flows require customs and other border authorities to think about updating their systems to ensure an appropriate balance between control and facilitation for imports and exports. 


\section{CHAPTER 4. THE CONTRIBUTION OF SERVICE TRADE POLICIES TO CONNECTIVITY AND DEVELOPMENT World Trade Organization}

Services trade policies can play a fundamental role in addressing the difficulties faced by a number of developing countries in connecting to the international trading system, thereby reducing economic isolation. Indeed, wellfunctioning services markets are key to advancing both physical and digital connectivity. Services occupy a central place in both domestic economies and international economic relations. They generate more than two-thirds of world GDP and employ the greater proportion of workers in the large majority of countries. Services account for $49 \%$ of world trade, compared with 33\% for manufacturing and $18 \%$ for the primary sector when measured in value added terms. Services are also the predominant destination of foreign direct investment, representing approximately two thirds of world foreign direct investment (FDI) stock.

Services have a fundamental impact on achieving the 2030 Sustainable Development Goals given their weight in domestic economies, as well as their multi-faceted significance for trade. This is not only in relation to economic performance in general, but also to their role in specific areas such as energy, environment, health or education. This view is largely shared by developing country governments. As illustrated in Figure 1.7, respondents to the OECD/WTO aid-fortrade monitoring exercise considered that trade in services could make a significant contribution to the achievement of Sustainable Development Goals.

Services help connecting economies to the international trading system and the global trading system through four main channels. First, services provide the basic infrastructure on which trade in goods relies. A diversity range of services is necessary to bring final goods from their production site to consumers across borders. The more expensive or inadequate the underlying services, the harder it is to trade goods. Second, services are key enablers of global value chains (GVCs), which now play a preponderant role in connecting economies through trade. Services permit the coordination of GVCs, but also provide increasingly significant inputs to the production of goods. Thus efficient services are essential for industrialisation and trade. Third, services are key enablers of the digital supply of services and the functioning of e-commerce more generally. Telecommunication and IT services can have a transformational impact on economic development. They provide the basic infrastructure that allows for a range of services to be provided digitally and for goods to be offered and purchased online. Fourth, services supplied online enhance connectivity by providing developing countries with new export opportunities. Their share of world services trade has jumped and a number of developing countries have experienced the most rapid export growth in certain services segments.

Services policies play a fundamental role in connecting countries; when trade-facilitating, they promote connectivity, when trade restrictive, they tend to limit it. Services trade costs are much higher on average than for trade in goods. Barriers to trade in services contribute largely to such costs, which are relatively high and widespread. Sectors essential to physical connectivity (e.g., transport) and to digital connectivity (e.g., telecommunications) face trade restrictions in a number of countries.

Recent research has found that services trade policies can limit - or enhance - connectivity in different ways. Services sectors facing lower trade costs - themselves associated in part with lower services barriers - have been found to be more productive and to have higher productivity growth. Restrictive services policies limit physical connectivity. For example, policy restrictions in the road transport sector increase the price of trucking services and raise trade costs, especially for landlocked countries. 
Figure 1.7. Partner views of SDGs that growth in services trade may help achieve

Can services trade make a contribution to the achievement of the 2030 Sustainable Development Agenda?

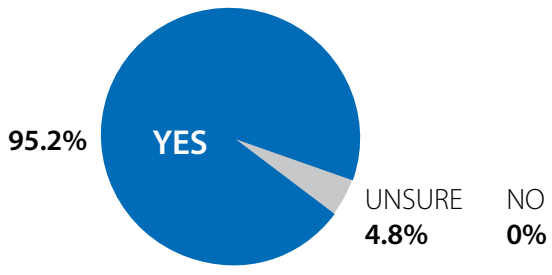

If, so which ones will be helped by growth in services?

In percent of partner country responses

\section{SUSTAINABLE GELPALST}

$63.3 \%$
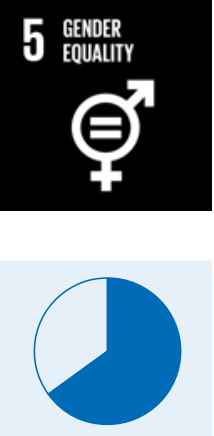

$65.0 \%$
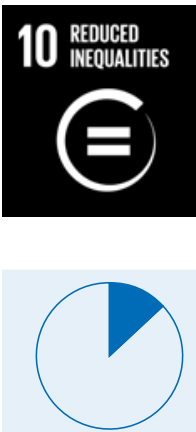

$13.3 \%$

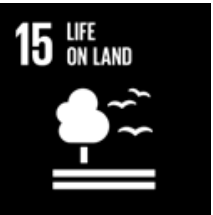

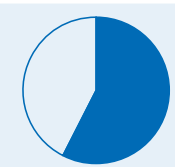

$63.3 \%$
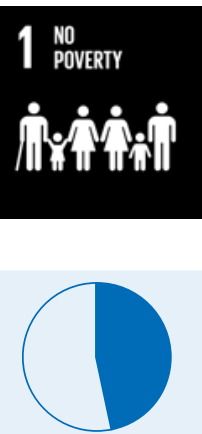

$46.7 \%$

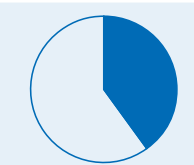

$40 \%$
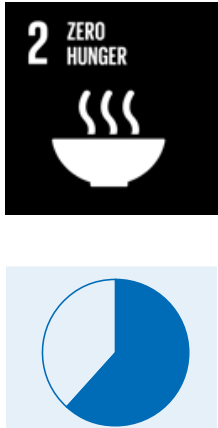

$61.7 \%$

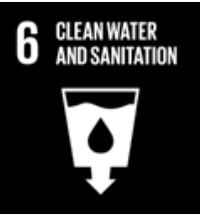

7 AFFORDABIEAND

11

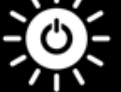

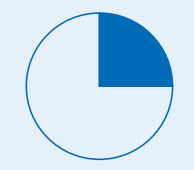

$25.0 \%$
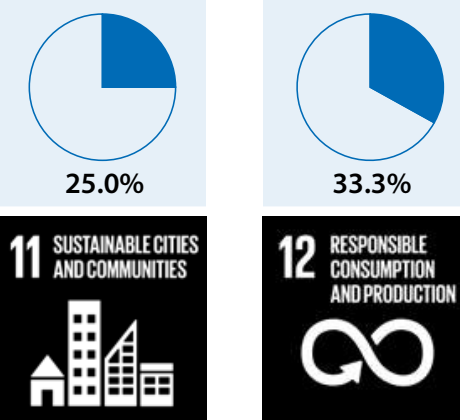

$33.3 \%$
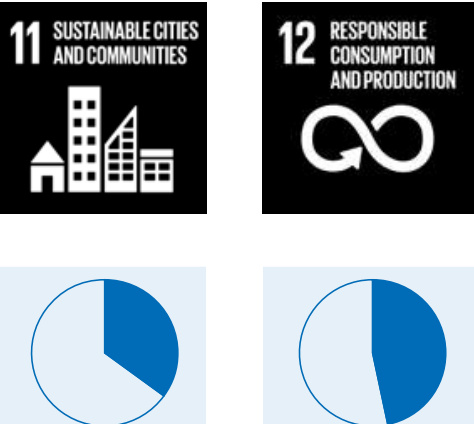

$35.0 \%$

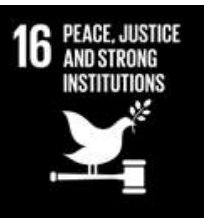

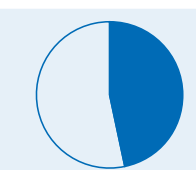

$46.7 \%$

17 PARTNERSHIPS FOR THEGOALS

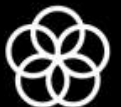

Source: OECD-WTO aid-for-trade monitoring exercise (2017a), www.oecd.org/aidfortrade/countryprofiles/.

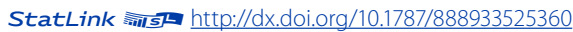


Services trade restrictions also negatively affect foreign investment, as well as the export of manufactured products. Further, countries that have introduced quality regulation - including allowing competition - have had greater success than others in developing their digital economy. Such regulatory settings are key to driving investment in information and communications technology (ICT) and uptake. Bridging the digital divide therefore hinges in significant part on such government policies.

Over the past 25 years, the regulation of the telecommunication sector has undergone fundamental transformations, as the large majority of countries has moved from monopolies to regulatory environments encouraging effective competition, with lower barriers to entry and often privatised state-owned incumbents. Competition in the telecommunications sector has reduced prices and increased penetration levels.

As reported by the UN Broadband Commission, a study of 165 countries between 2001 and 2012 showed that competitive markets had mobile broadband penetration levels that were 26.5\% higher than those countries without competitive markets. Many studies have also found that this change in policy approach has been associated with enhanced affordability, as well as higher quality and greater diversity of telecommunication services. Accordingly, adequate trade and investment policies in the telecommunication sector, supported by appropriate regulatory frameworks, figure as key building blocks to develop quality infrastructure and help reduce the digital divide, and consequently provide a platform to take advantage of digital opportunities.

\section{CHAPTER 5. SPANNING THE INTERNET DIVIDE TO DRIVE DEVELOPMENT International Telecommunication Union}

Rapid growth in ICT access and use as well as the evolution towards a global information society, promise new development opportunities for everyone. Internet uptake has been found to bring great benefits for people, governments, organisations and the private sector. It has opened up new communication channels, provided access to information and services, increased productivity, fostered innovation, and facilitated trade in goods and services. Information and communications connectivity and use are key building blocks of the digital economy, and indispensable drivers of e-commerce.

The importance of infrastructure and connectivity is recognised in the 2030 Agenda in Sustainable Development Goal 9 on industry, innovation and infrastructure. It issues a call to "significantly increase access to information and communications technology and strive to provide universal and affordable access to the Internet in least developed countries by 2020." Yet while the increasingly ubiquitous, open, fast and content-rich Internet has changed the way many people live, communicate and do business, major differences continue to exist in ICT access, use, and affordability, in particular in terms of broadband Internet access and use.

The benefits of the Internet are still unavailable to over half the world's population: 3.9 billion people globally remain offline (Figure 1.8). Many of these people live in the least developed countries (LDCs), where $15 \%$ of the population are using the Internet. Furthermore, in the vast majority of countries, there is a rural urban divide and the proportion of men using the Internet is higher than that of women; the gender gap is particularly pronounced in the LDCs. ICT infrastructure, connectivity and quality of service in the least developed countries are lagging behind the rest of the world.

Policy makers must make sure they address and overcome important infrastructure bottlenecks, in terms of both national backbones and international Internet connectivity. Similarly, fixed- and mobile-broadband prices remain high for the world's poorest countries, and unaffordable for low-income population groups. Moreover, developing countries, and in particular the LDCs, rely almost exclusively on mobile-broadband networks to deliver Internet access to end users, including many businesses. Although $3 \mathrm{G}$ and $4 \mathrm{G}$ (or higher) mobile-broadband networks have reached unprecedented levels of population coverage, their speed - or latency (the amount of time it takes for a data packet to traverse a network, which affects the quality of a connection - is inferior to that of fibre broadband networks, which continue to provide a more reliable and often cheaper option for data intensive applications. 
Figure 1.8. ICT penetration by level of development, 2016

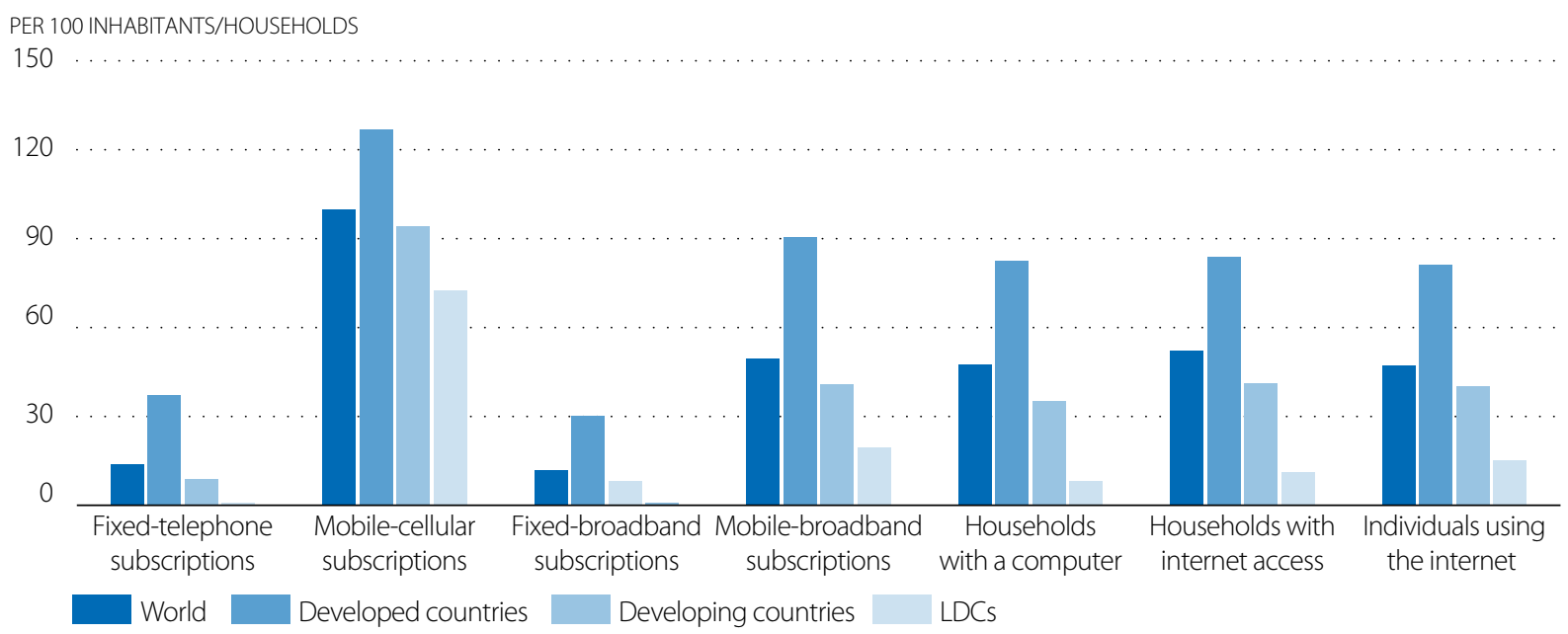

Note: ITU estimates.

Source: ITU (2016), Measuring the Information Society Report 2016.

StatLink 刑IS http://dx.doi.org/10.1787/888933525379

There are a number of important steps governments, and in particular the LDCs, can take to create an enabling regulatory environment that will help to stimulate investment and increase ICT access and use. Two-thirds of all LDCs are still in either the first or the second generation of regulation and need to urgently carry out basic reforms, including the promotion of privatisation, liberalisation, and intra-platform competition. Other important reforms for many LDCs include the removal of entry barriers to foreign ownership and investment. When private investment is not sufficient, it is possible to look into direct government investment; take advantage of public-private partnerships; use universal service funds and obligations to bring services to areas that provide limited business opportunities; and provide tax incentives for investments.

Yet while Internet infrastructure, access and quality of service remain important barriers to uptake, more people have access to Internet services than actually use them. To bring more people online, broader socio-economic factors and inequalities, outside the ICT ecosystem, need to be addressed. Education levels, in particular, are strong determinants of whether or not, and how, people use the Internet. Citizens need both digital and analogue skills to fully benefit from the opportunities of the information society. The availability of relevant local content is also critical to bring more people online.

\section{CHAPTER 6. IMPROVING THE E-TRADE ENVIRONMENT World Bank Group}

The strong growth of e-trade presents a number of opportunities for developing countries. First, lowering of trade costs through digital connectivity and e-commerce creates opportunities for new firms and entrepreneurs to participate in trade, as well as for entry into new markets. It also has the potential to help the extreme poor overcome some of the typical constraints faced in making the most of trade opportunities, although poverty still presents many challenges to involvement in e-trade. Traditional trade barriers also remain relevant.

The growing e-trade sector has the potential to act as a force for economic growth, expanding and diversifying exports and fostering inclusion by facilitating access by MSMEs to international markets. Importantly, these benefits are not reserved to global leaders in innovation and digital technologies; they are available to countries at all levels of economic development, as well as industries at different stages of development in one same economy. Figure 1.9 provides a stylised breakdown of what economies at different levels of development can gain from the various types of e-trade. 
The benefits from e-trade include increased competitiveness for countries at all levels of development, with productivity gains for all sectors of the economy. This includes traditional sectors such as agriculture, through online services that in their diversity range from market and weather information to tools for remote soil analysis and stock management.

Moreover, developing countries increasingly benefit from e-trade as a tool for creating niches for high-value goods, sold and delivered directly to consumers across the globe, such as Pakistani pashminas and Kenyan jewellery. LDCs are also engaging in this process. Finally, more advanced economies, as well as more e-trade savvy industries in developing countries, can offer high value-added business-to-business services that link into global value chains.

Figure 1.9. A stylised model of e-trade benefits at different levels of development

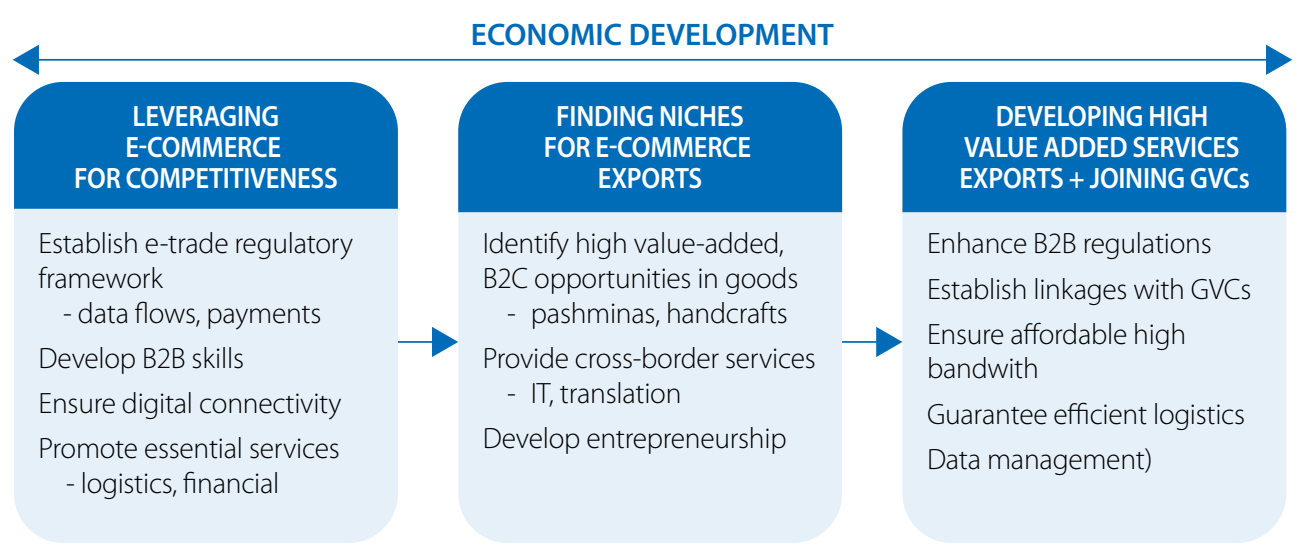

Source World Bank

High- and low-income countries alike, therefore, have good reasons to address the many challenges that e-trade presents. Important laws and regulations for e-trade, concerning areas such as privacy, consumer protection or intermediate liability, are still unclear and inconsistently applied even in high-income countries, bringing uncertainty to international digital markets. Countries at all development levels still encounter substantial trade costs, which disproportionally affect e-trade shipments. Access to digital connectivity, as well as solutions for digital payments, remain patchy and often inequitable, in particular in developing countries. Also, many developing countries and particularly LDCs have an important shortage of digital skills and, especially, of capacity for digital entrepreneurship.

Taking advantage of e-trade opportunities requires a solid understanding of the different types of e-trade, as well as better data on e-trade flows. It also requires thorough analysis of the drivers of e-trade competitiveness, including the key foundations for connectivity and the enabling conditions for participation in e-trade. There has been little systematic analysis of the drivers of e-trade competitiveness at the country level, underlining the need for the partners in the Aid for Trade Initiative to engage more actively in this area in the years ahead.

\section{CHAPTER 7. HARNESSING E-COMMERCE FOR SUSTAINABLE DEVELOPMENT United Nations Conference on Trade and Development}

While global trade growth has been stagnant for several years, e-commerce has been growing rapidly. According to estimates by the United Nations Conference on Trade and Development (UNCTAD), between 2013 and 2015 the value of online trade accelerated upwards, from USD 16 trillion to USD 25.3 trillion. The lack of comprehensive official statistics on e-commerce is a major challenge for mapping e-commerce uptake and measuring its impact on development. Available data and estimates show that in terms of value, business-to-business (B2B) e-commerce represents the lion's share of e-commerce (89\%), whereas business-to-consumer (B2C) appears to be expanding faster. Business-togovernment e-commerce is also on the rise and offers an entry point for many developing countries. 
Figure 1.10. The E-trade for All analytical framework for e-commerce

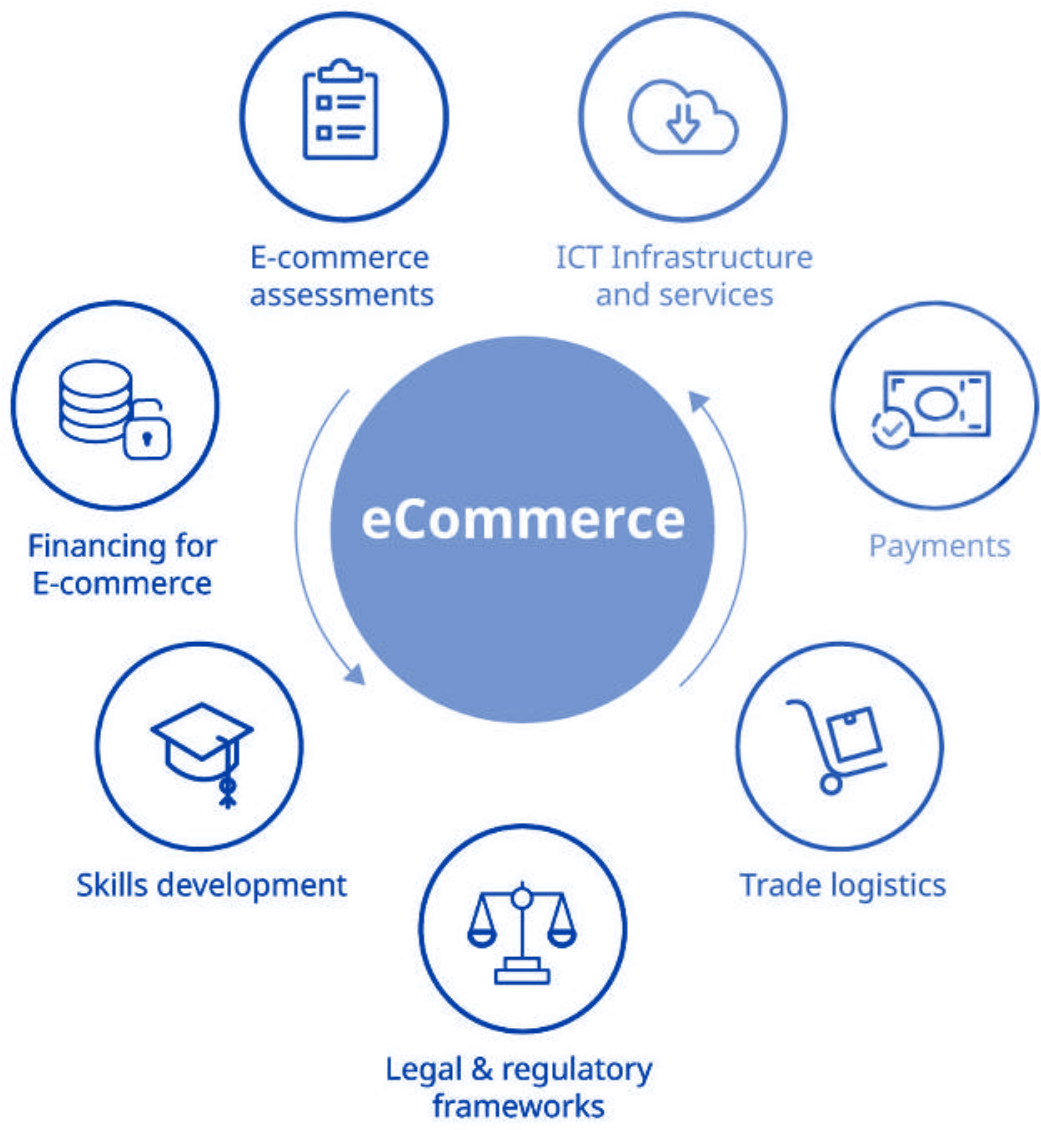

Source: UNCTAD

China and the United States had the largest B2C e-commerce markets in 2015, with USD 617 billion, and USD 612 billion, respectively. The United States, however, was the leader in B2B sales, at more than USD 6 trillion, well ahead of Japan (USD 2.4 trillion). In the ten major e-commerce economies for which data were compiled, e-commerce sales corresponded to more than a third of the aggregate GDP. While global e-commerce is still dominated by developed countries, the highest growth is observed in developing regions, especially in Asia. An estimated 1.6 billion people around the world are expected to make at least one online purchase in 2018; 75\% of them will be from developing and transition economies. Factors such as firm size and rural locations significantly affect the ability of enterprises to sell and buy online. The extent to which different countries, individuals and enterprises engage in e-commerce varies greatly, giving rise to a multi-faceted digital divide.

Digital connectivity is a necessary, but not sufficient, condition to engage in ecommerce. UNCTAD's e-Trade for All analytical framework for e-commerce features six key policy areas that need to be addressed in national e-commerce strategies: 1) ICT infrastructure, 2) payment solutions, 3) trade logistics, 4) e-commerce skills, 5) legal frameworks and 6) access to financing (Figure 1.10).

The UNCTAD B2C E-commerce Index (Figure 1.10.) groups indicators to help policy makers assess to what extent their economies are e-commerce ready and what areas are in greatest need of improvement. The Index comprises four readiness indicators: (i) Internet use penetration, (ii) secure servers per million inhabitants, (iii) credit card penetration, and (iv) postal reliability. The 2016 Index covers 137 economies, which represent 96\% of the world population and 99\% of global GDP. 
Figure 1.11. E-commerce readiness, by component indicators and geographic region

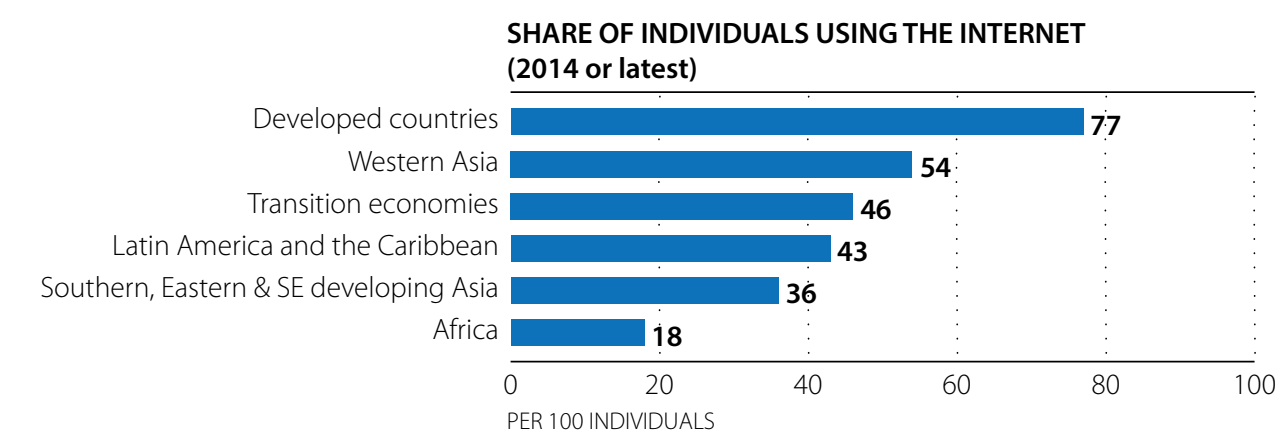

SHARE OF INDIVIDUALS AGE 15+ WITH CREDIT CARD (2014 or latest)

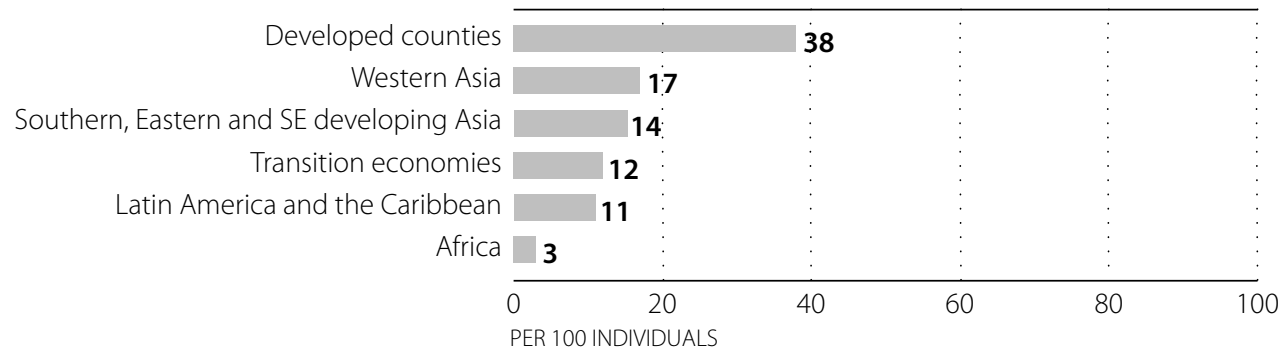

SECURE SERVERS PER MILLION PEOPLE (normalized, 2014)

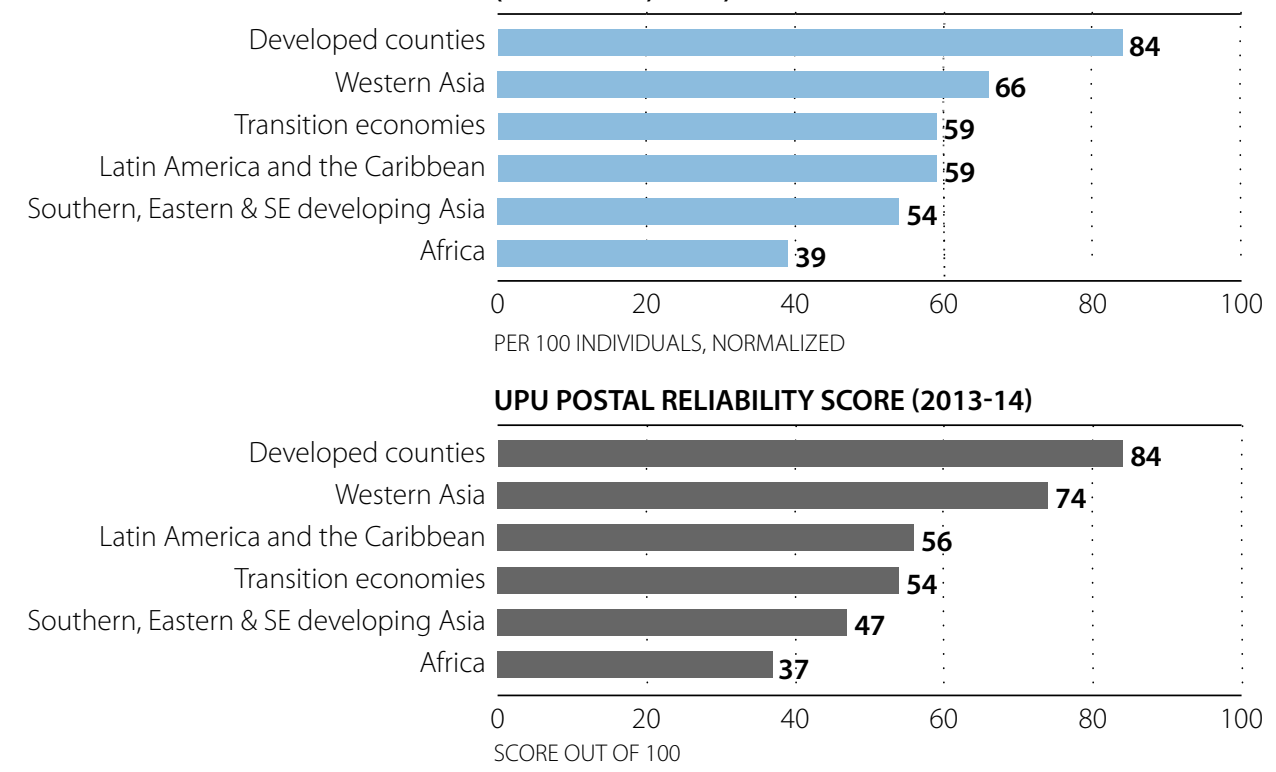

Note: Latest data available.

Source: Based on UNCTAD (2016), UNCTAD B2C E-commerce Index 2016. ITU, World Bank and UPU data. 
The Index shows that e-commerce readiness varies by region (Figure 1.11). Just over one-fifth of the population in Africa uses the Internet, compared to two-thirds in Western Asia. While Western Asia and transition economies fare well on most indicators, their credit card availability is average. Overall, Asia needs to boost Internet penetration, which currently stands at just over one-third of the population, as well as the number of secure servers. In Latin America and the Caribbean, the main barriers appear to be low credit-card penetration and relatively poor postal reliability. Africa ranks the lowest in all the indicators. Unless there is improvement in the underlying transaction and logistics processes, African online shopping is likely to remain confined to wealthier populations in urban areas. In all regions, there is a prominent divide when readiness is disaggregated by gender.

There is growing interest in examining the development dimension of e-commerce. E-commerce can be associated with reduced transaction costs, shorter customs clearance times, better supply chain management, the possibility of reaching new markets and new customers, enhanced productivity, increased inclusiveness, and greater consumer choice, just to name a few of the potential benefits. However, such advantages do not materialize automatically and e-commerce also poses a number of potential challenges to development. For example, uneven access to ICTs can lead to an inequitable distribution of the benefits of e-commerce. More research is needed to fully explain the development impact of e-commerce and to enable policy makers to make well informed decisions.

\section{CHAPTER 8. CLOSING SMALL-BUSINESS AND GENDER CONNECTIVITY GAPS International Trade Centre}

Digital connectivity is enabling firms of all types to connect to suppliers and customers around the world. However, firm-level data show that there is a significant connectivity gap between small and large firms. Compared to large firms, small firms are ten times less likely to have a business website and eight times less likely to use email. This is a problem, as poor digital and physical connectivity lowers the likelihood of firms engaging in international markets (Figure 1.12).

\section{Figure 1.12. Relative proportions of small and large firms with a business website}

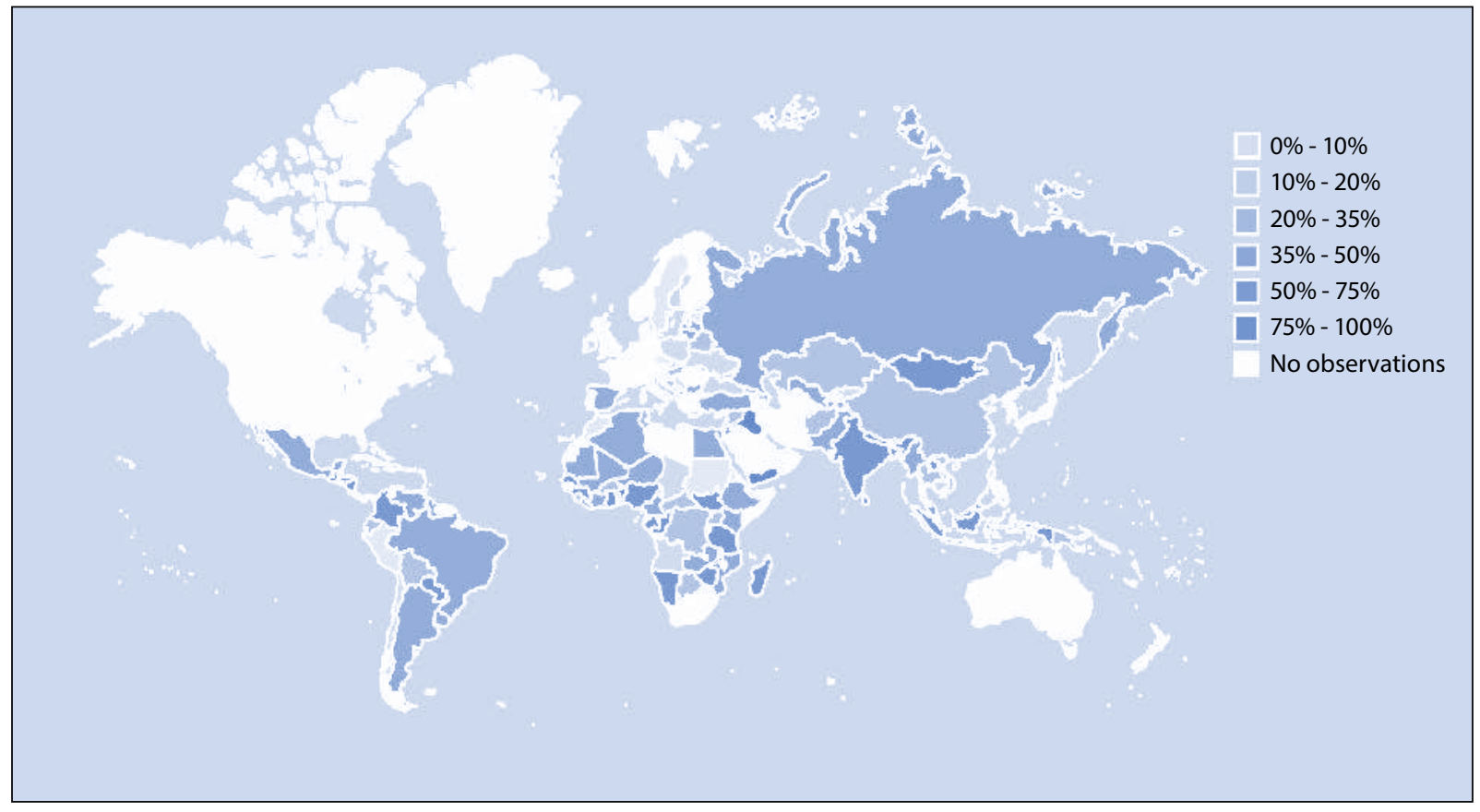

Note: Gaps are calculated on a percentage point basis. For example, if $40 \%$ of small firms have a business website compared to $60 \%$ of large firms, the gap is $20 \%$.

Source: ITC calculations based on World Bank (2016a) Enterprise Surveys data, www.enterprisesurveys.org (accessed 17 January 2017). 
MSMEs in the LDCs face the biggest barriers, as the connectivity gap for small firms in these countries, compared to large firms, is much larger than the gap observed in more developed countries. To support MSMEs in connecting to global markets, policy makers can promote e-literacy, encourage firms to digitalise their production processes and ensure that national ICT infrastructure meets the demands of consumers and firms alike.

E-commerce is transforming the global business landscape at an unprecedented speed. The e-commerce process chain is composed of four stages: establishing an online business, international e-payments, cross-border delivery and aftersales services. In order to enable this chain to function effectively, it is urgent that policy makers address issues such as the creation of national strategies for e-commerce growth, the establishment of regulations for the prevention of online fraud, and the facilitation of customs and other border procedures (Figure 1.13).

\section{Figure 1.13. E-commerce process chain}

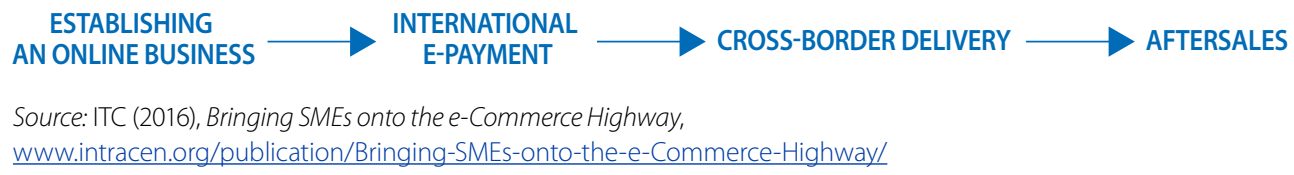

A growing body of firm level research associates exporting with higher firm level productivity, particularly among MSMEs. ITC field work suggests though that the exporter productivity premiums of women-owned firms are roughly half the size of comparable men-owned firms. Part of the reason for this may be due to lower use of connectivity technologies, which often help firms find new buyers and suppliers, by women. For example, women-managed firms are 12\% less likely to use email than men-managed firms. Discrimination at the border may also be a factor that contributes to reducing the benefits of trade. Digital tools like single windows eliminate the need for a large number of personal interactions, which can sometimes hinder women getting their goods across the border.

It is a known fact that women face greater barriers to trade. The obstacles range from having to pay larger bribes to gender-based violence. Digital solutions that remove the need for face-to-face interactions when trading, for example the "single window", can help reduce the negative incentives that women running a business face. Firm-level data also suggest that women-owned firms sometimes use technologies differently than those earned by men. Women-led companies in some East African countries are more likely to use mobile money as a means of paying employees and suppliers than men-led companies. This may be due to the advantages that mobile money offers women in terms of providing an independent and protected mechanism to save money (Figure 1.14).

Figure 1.14. Beneficial outcomes from women and girls having online access

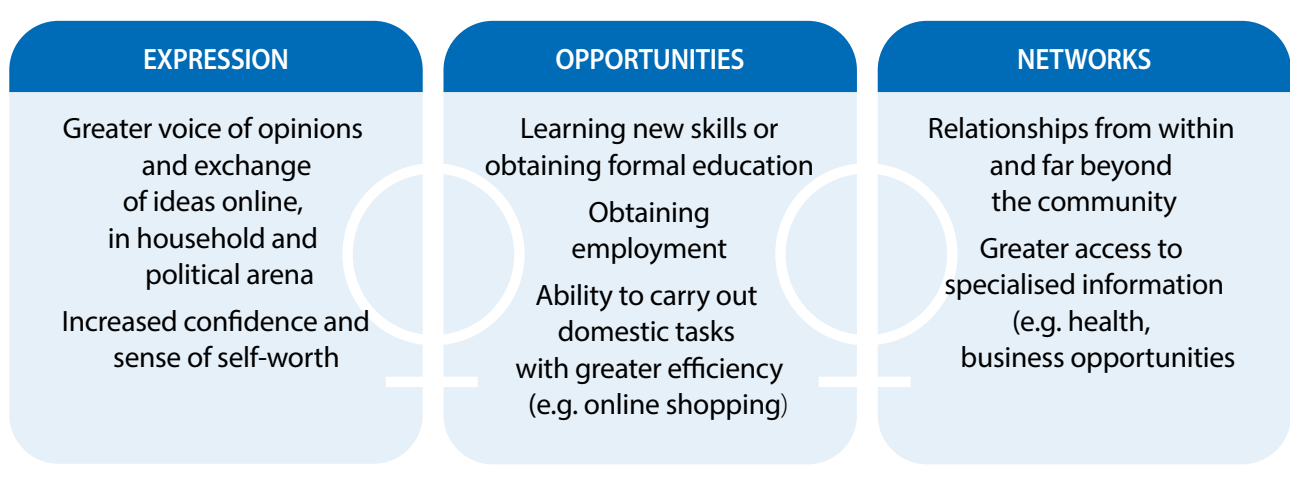

Source: Adapted from Intel (2012), Women and the web. 
The same data also show that firms trading internationally employ more women; if the company is women-led, an even higher share of employees is female. These findings boost the rationale behind trade-related technical assistance programmes that focus on helping women-owned enterprises enter international markets. To promote access by women to competitiveness-boosting digital technologies, policy makers should establish dedicated programmes to teach girls e-skills, increase online content promoting women's participation, and integrate the gender dimension into trade promotion initiatives and national ICT strategies.

\section{CHAPTER 9. PROMOTING TRADE INCLUSION IN THE LEAST DEVELOPED COUNTRIES Enhanced Integrated Framework}

Most people in the LDCs do not have access to affordable Internet connections (Figure 1.16). Improving connectivity and access to information could help make trade more inclusive and bring larger gains to the LDCs, in particular for the most isolated groups—namely women and people living in rural areas.

LDC digital connectivity is improving, and this progress is expected to continue. Even among those online though, the potential offered by digital connectivity is far from being fully exploited. High costs for setting up the physical infrastructure and the education required to fully exploit the Internet's potential are only two of the obstacles perpetuating the gap between LDCs and the rest of the world.

Expectations about ICT regulation have changed dramatically in the past decade. In a world in which more than half of the world's population is not using the Internet, ICT regulators must balance commercial incentives with wider social and economic goals, notably connecting the unconnected. As profound change seeps ICT markets, challenges are many - and the role of ICT regulation is ever more central. Regulation is needed that encourages the growth of networks, the provision of services and the diffusion of content, devices and applications in an affordable, competitive and safe way in particular among LDCs. Only one LDC - Uganda - has attained the ITU's fourth generation of regulation, joining the club of some of the most advanced countries in terms of ICT regulation

\section{Figure 1.15. Generations of regulation}

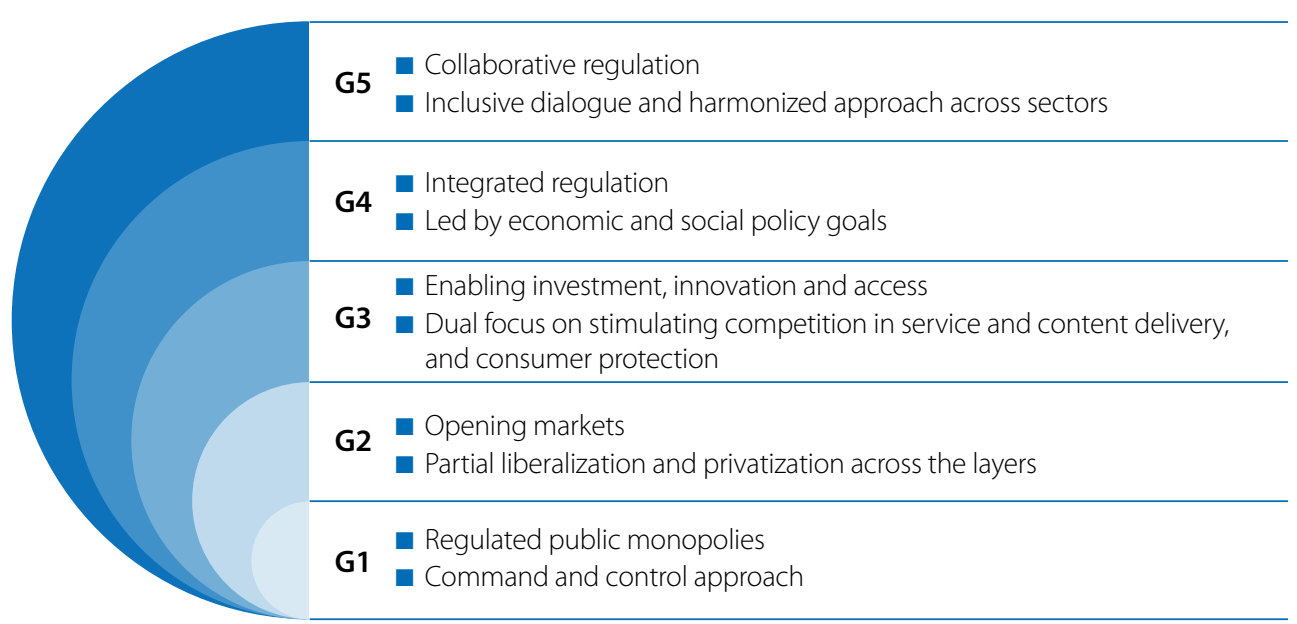

Source: ITU (2017), Global ICT Regulatory Outlook.

Research suggests that best-practice regulation does matter, and that both the design and the effective enforcement of regulatory frameworks are essential for broadband markets to thrive. Good regulation has an impact. Regulators need to ensure that market opportunities outweigh the challenges, while protecting consumers' interests. The LDCs need to come up with their own balanced mix of regulatory incentives and obligations to deliver on their regulatory goals and open the way to investment, innovation and market growth. 
LDC governments have a major role to play in accelerating the uptake of new technologies. They shape the enabling environment for businesses and can ensure that ICT policies and regulations benefit consumers by facilitating greater access at lower prices. The introduction of Internet-based government services is growing in the LDCs, which will help to provide services more efficiently to businesses and citizens.

\section{Figure 1.16. Internet users per 100 inhabitants in the LDCs, 2015}

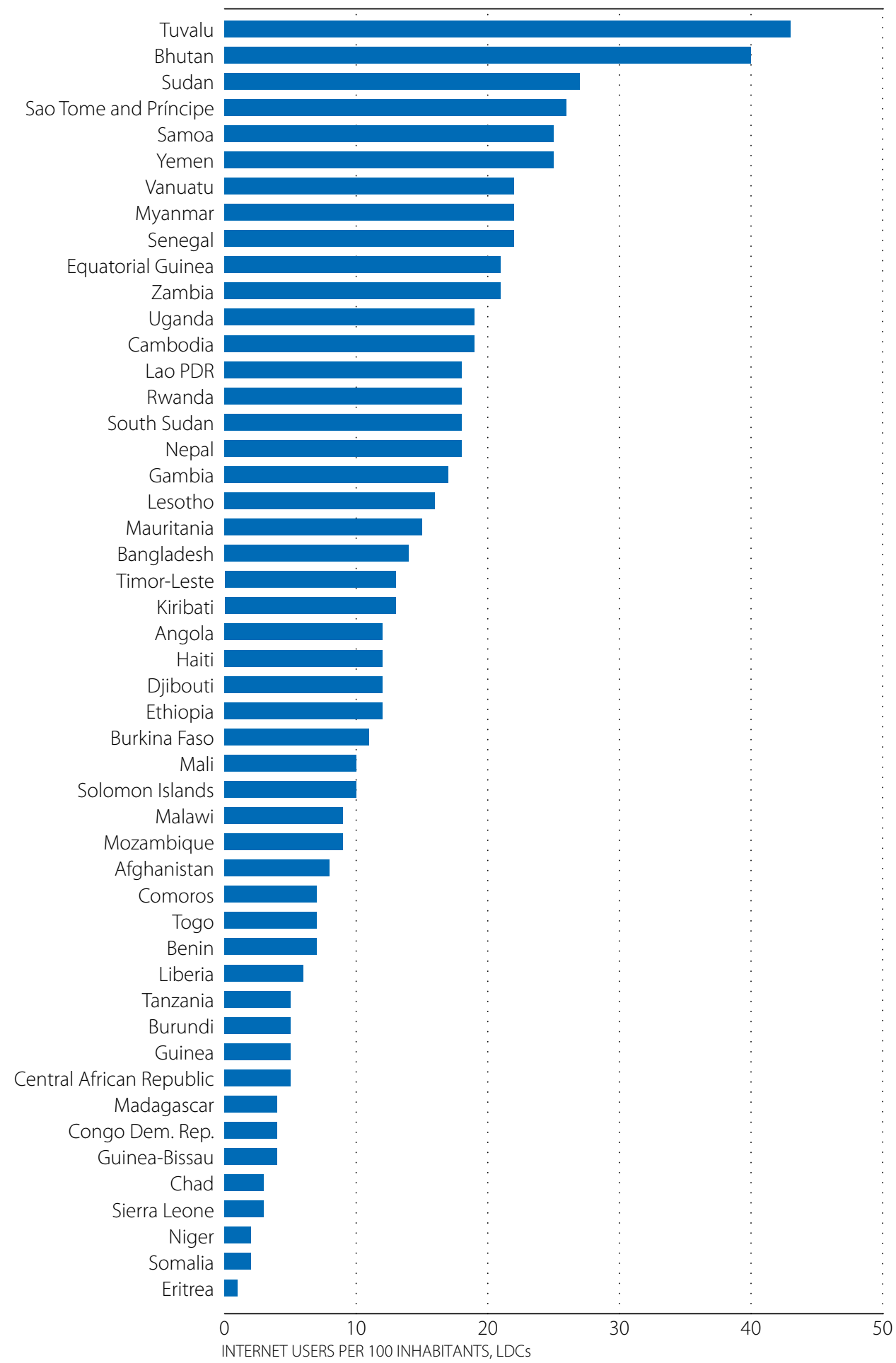

Source: ITU 


\section{CHAPTER 10. PRIVATE SECTOR AID-FOR-TRADE PRIORITIES IN THE DIGITAL ERA Business for eTrade Development}

Technology-powered trade is changing the patterns, players and possibilities of world trade. The private sector-from online merchants to e-commerce platforms, logistics companies, payment providers, IT companies and others-makes digital trade move. This means that the private sector is in the closest proximity to the opportunities, challenges, and e-commerce solutions to development issues. For this reason, private sector participation is critical to inform and guide policy making on e-commerce issues around the world. In partnership with the public sector, the private sector can develop new solutions to unlock e-commerce markets and promote cross-border e-commerce.

Company characteristics shape the perceptions of barriers to e-commerce. In every country, small companies tend to be considerably more affected by the various obstacles to e-commerce than large companies, with access to finance and e-commerce logistics posing particularly steep challenges for small businesses (Figure 1.17). Mid-size and large companies, meanwhile, wrestle most with logistics and digital and other regulations.

\section{Figure 1.17. Merchants' perception of obstacles to cross-border e-commerce, by company size}

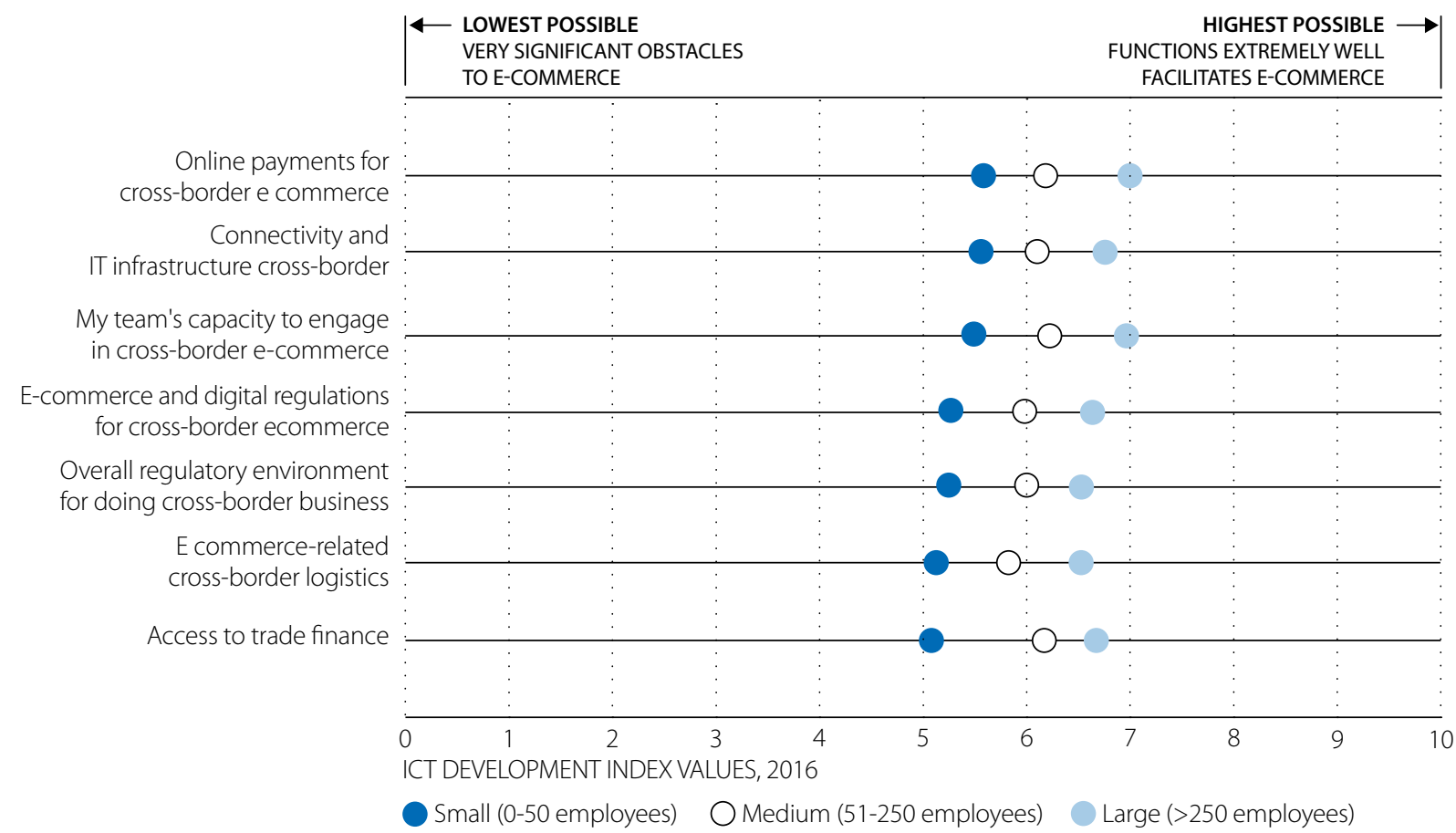

Source: Suominen (2017), E-commerce development survey and index.

StatLink 光is http://dx.doi.org/10.1787/888933525436

For trade policy makers, the challenges articulated by companies engaged in e-commerce require a rethink of the policy toolkit for trade, including trade rules, export promotion, trade facilitation, export credit, and trade infrastructure. In all these areas, trade policy makers intent on catalysing e-commerce need to work closely with ICT, finance ministries and regulators - as well as with the private sector-given that it is businesses that have the first-hand grasp of the challenges to e-commerce, as well as the corresponding solutions.

Some of the priorities to empower small businesses, in particular, to enter into e-commerce involve capacity building and new approaches including: simplified, paperless one-stop border clearance processes; better access to finance; improved regulatory environments; improved public-private policy dialogue on e-commerce policies; and funding for e-commerce development via social impact bonds. 


\section{CHAPTER 11. FINANCING CONNECTIVITY Organisation for Economic Co-operation and Development}

A total of USD 333.1 billion has been disbursed for financing aid-for-trade programmes and projects since the Aid for Trade Initiative was launched in 2006. To date, more than three-quarters of total aid-for-trade disbursements have financed projects in four sectors: transport and storage (28.8\%), energy generation and supply (21.8\%), agriculture (17.8\%), and banking and financial services (11.4\%). In addition, USD 245 billion in trade-related other official flows (OOF) 2 has been disbursed since 2006, of which $76 \%$ is from international financial institutions. Most of this non-concessional funding has been for projects in economic infrastructure (47.9\%) and for building productive capacity (51.3\%); it has been invested almost exclusively in middle income countries (94.6\%).

In 2015, aid-for-trade commitments reached USD 53.9 billion, an increase of USD 5.4 billion over 2014 and an additional USD 31.6 billion compared with the 2002-05 baseline average. Commitments for trade-related OOF increased by USD 5 billion to reach USD 60.1 billion, more than four times the 2002-05 baseline average. Commitments for economic infrastructure reached USD 31.8 billion, up 14.3\% compared to 2014.

OECD (2015) found that total infrastructure investments in developing countries amounted to roughly USD 1 trillion in 2013, of which more than half was financed by developing country governments and one-third by the private sector. Official development partners finance USD 55 billion of these infrastructure investments; bilateral donors financed around $46 \%$ and multilaterals $54 \%$ of this total amount.

\section{Figure 1.18. Aid-for-trade commitments and disbursements by category, 2002-15}

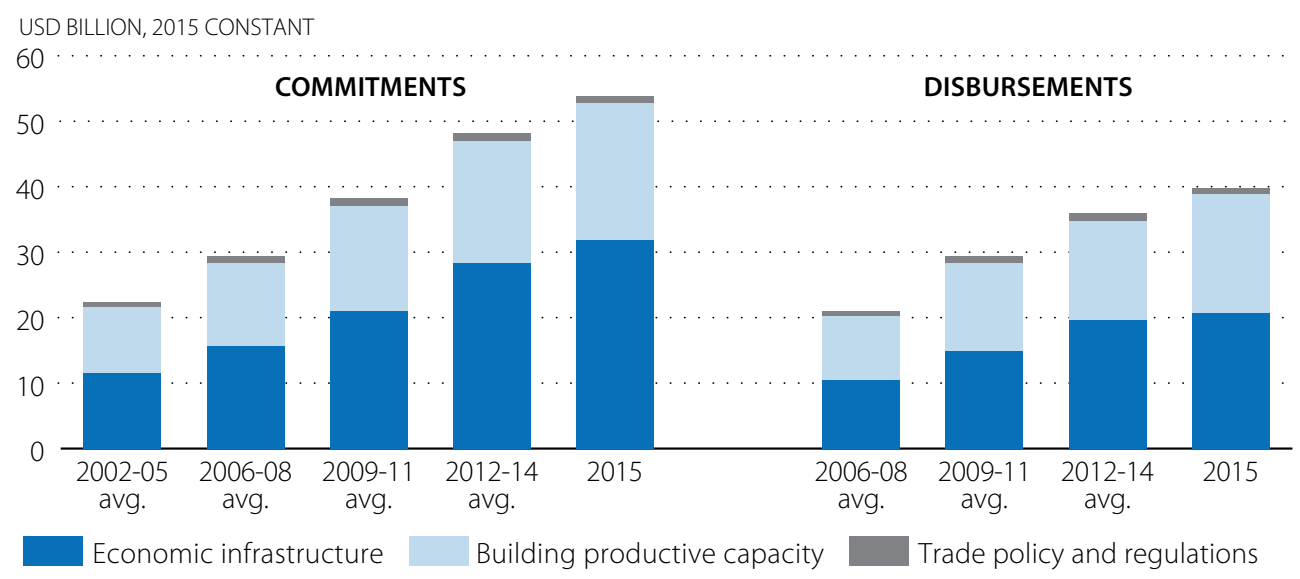

Source: OECD-DAC CRS: aid activity database (2017b), DOI: http://dx.doi.org/10.1787/data-00061-en, (accessed 07 April 2017).

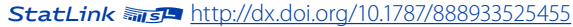

Many governments over the past two decades have sought to tap private sector investment and know-how through public-private partnerships (PPPs) to build and operate infrastructure - a trend that is increasingly evident. Examples are, for instance, the Programme for Infrastructure Development in Africa or the Master Plan for Connectivity 2025 of the Association of Southeast Asian Nations. Other approaches are based on transport corridors that are of particular relevance for landlocked countries. The most ambitious of these approaches is China's Belt and Road Initiative.

The case stories show that improving trade-related infrastructure helps to reduce transport costs, which in turn increases competitiveness and boosts trade flows. These impacts can lead to increased welfare and higher incomes and thereby reducing poverty. The case stories also underscore the role of the private sector in infrastructure delivery. Donors also have an important role to play in boosting private sector investment in infrastructure by lending technical support to governments seeking to attract funds, actively engaging their private sector arms in infrastructure projects, and providing effectively-designed risk-mitigation mechanisms. 
Aid commitments for projects in Information and Communications Technology (ICT), mostly in the form of technical assistance for regulatory reform, stood at USD 560 million in 2015. Information and communications technology hardware investments were largely financed by the private sector. The 2017 OECD-WTO monitoring exercise found that ICT is prioritised in the development strategy of two-thirds of the donors, followed by e-government and e-commerce (58\% and 50\% respectively). Nearly all partner countries (90\%) anticipate a need for future assistance in this area. Donors also report that this area is attracting growth in demand.

The African Development Bank promotes connectivity through the Connect Africa Initiative. Public institutions in developing countries are increasingly getting involved in ICT infrastructure development. For instance, the government of Pakistan has embraced the digital economy and now offers a wide range of services online. The case of Tonga offers a good example of the potential of ICT infrastructure to provide small islands and landlocked countries an opportunity to overcome the high transaction costs they face. ICT applications have been widely used to improve lives in rural agricultural communities, offering them better networking opportunities and facilitating access to advanced technologies. Furthermore, ICT enables farmers to enter new markets and gain access to digital services, such as credit or crop failure insurance, or to consult the latest weather reports. Large multinational companies have also been active in promoting access to e-commerce for small and medium enterprises. Several of these case stories illustrate the opportunities digital technologies offer to increase private sector engagement in development.

\section{CHAPTER 12. AID FOR INCLUSIVE TRADE AND POVERTY REDUCTION World Trade Organization}

A growing body of evidence highlights the effectiveness of aid for trade in generating positive trade outcomes. The focus on capturing trade outcomes (e.g. increases in exports or reductions in trade costs) is now being complemented by an increasing focus on tracing the impacts of aid for trade interventions on poverty reduction, in particular for women, on whom the burden of poverty falls heaviest. Poor connectivity is strongly associated with poverty. Regions with higher poverty rates score lower on the World Bank's Logistics Performance Index and the World Economic Forum's Enabling Trade Index. Doing Business indicators, as illustrated in Figure 1.19, demonstrate that the time and cost to clear customs are higher in regions with lower per capita incomes. A similar association is found between the lack of digital connectivity and poverty. As illustrated in Figure 1.20, Internet use is lower in regions with lower per capita incomes. Furthermore, for women and rural populations, limited digital and physical connectivity, together with sociocultural and other regulatory factors, intensify the burden of poverty.

Improved physical and digital connectivity are lowering trade costs and reducing poverty. Digital approaches to trade facilitation can reduce bottlenecks at borders, increase revenues, and facilitate the movement and participation of small traders and women in cross-border trade. Internet access reduces distance and information asymmetries, helping entrepreneurs earn income by selling online. Mobile money innovations promote financial inclusion by alleviating some of the constraints of traditional financial methods, particularly for women.

Both developing countries and donors consider that aid for trade can contribute to 2030 Agenda, in particular Sustainable Development Goal (SDG) 9 on industry, innovation and infrastructure; SDG 8 on decent work and economic growth; and SDG 1 no poverty (Figure 1.21). Furthermore both groups have expressed their interest in collaborating with various stakeholders, including with the private sector, to work towards the achievement of the 2030 Sustainable Development Goals. 
Figure 1.19. Time and cost to export and GDP per capita, by region

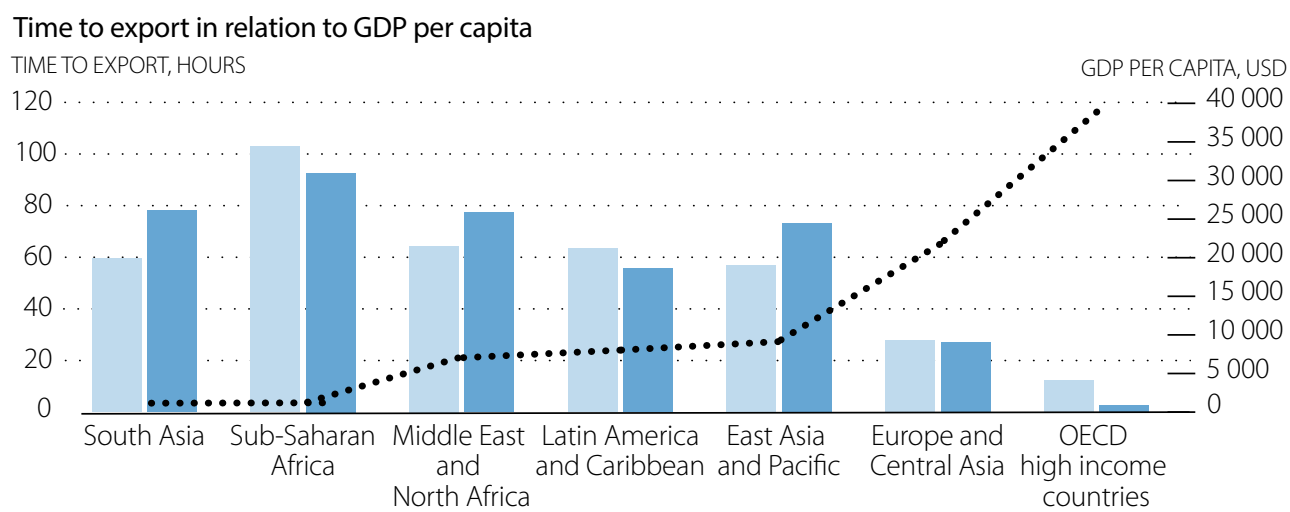

$\begin{array}{ll}\text { Time to export: } & \text { Time to export: } \\ \text { Border compliance } & \text { Documentary compliance }\end{array}$

Cost to export in relation to GDP per capita

COST TO EXPORT, USD

GDP PER CAPITA, USD

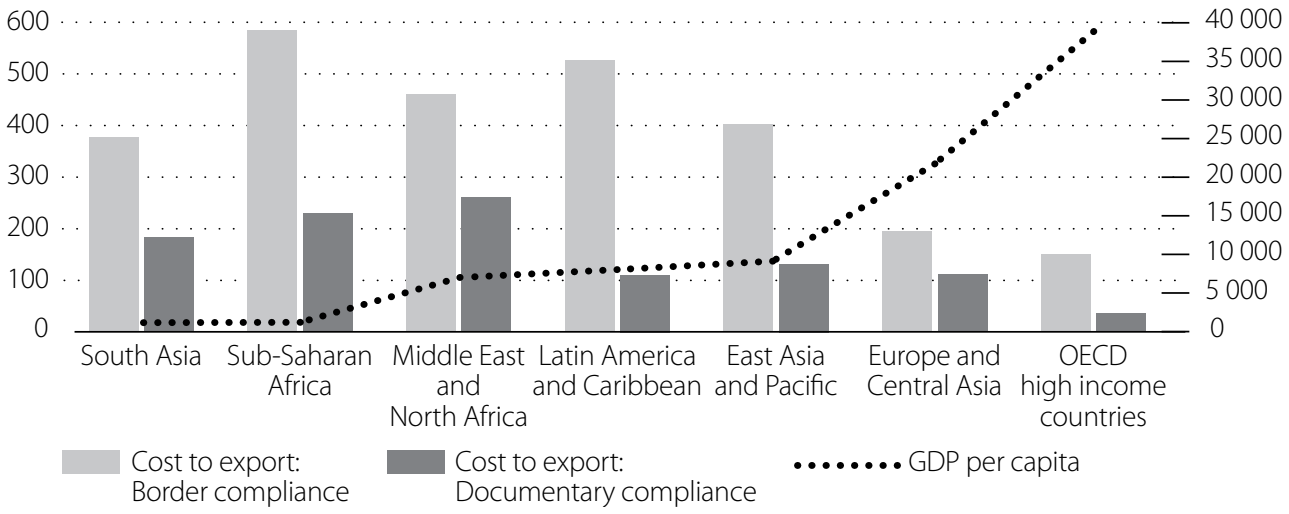

Source: World Bank (2016b) Doing Business, www.doingbusiness.org/data/exploretopics/trading-across-

borders and World Bank (2015) World Development Indicators, http://databank.worldbank.org/data/reports.

aspx? source $=$ world-development-indicators

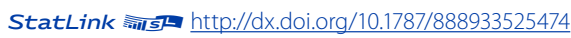

\section{Figure 1.20. Poverty rates by region and percentage of Internet users}

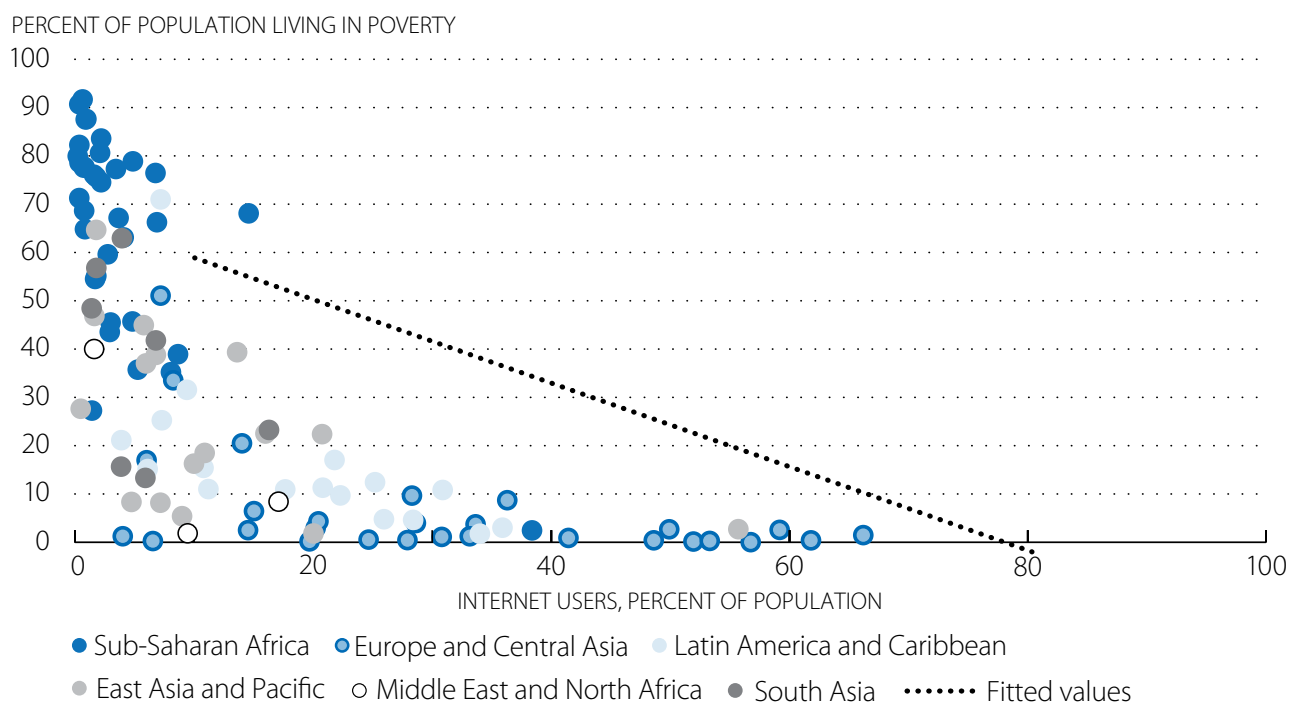

Source: World Bank, World Development Indicators (2008-2014 average); ITU, World Telecommunications/ICT Indicators, Internet Users (2007); World Bank Regional Classification 
Figure 1.21. Aid-for-trade contribution to the SDGs

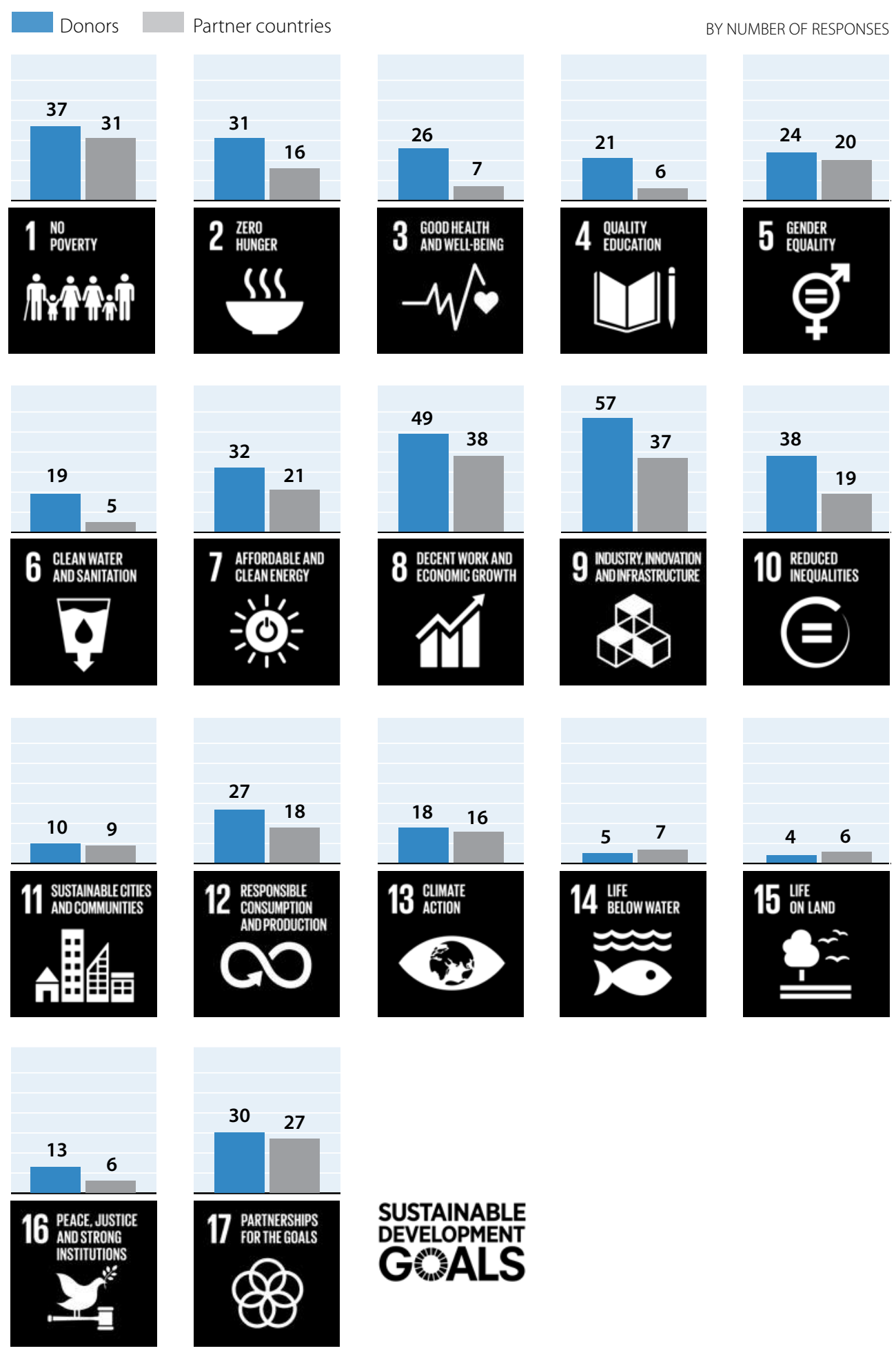

Source: OECD-WTO aid-for-trade monitoring exercise (2017a), http://www.oecd.org/aidfortrade/casestories/. 
ANNEX 1.A1.

Table 1.A1.1. Overview of responses to the OECD-WTO Aid-for-trade monitoring and evaluation exercise, 2017

\begin{tabular}{cccccc}
$\begin{array}{c}\text { Developing } \\
\text { countries }\end{array}$ & $\begin{array}{c}\text { Least developed } \\
\text { countries }\end{array}$ & Donors & $\begin{array}{c}\text { South-South } \\
\text { providers }\end{array}$ & $\begin{array}{c}\text { Regional economic } \\
\text { communities/ } \\
\text { transport corridors }\end{array}$ & Total \\
\hline 63 & 28 & 38 & 3 & 7 & 111 \\
\hline
\end{tabular}

\section{Table 1.A1.2. Partner country responses}

$$
\text { Region }
$$

Africa Benin, Botswana, Burkina Faso, Burundi, Cameroon, Central African Republic, Chad, Congo,

(31) Comoros, Côte d'Ivoire, Democratic Republic of the Congo, Gabon, The Gambia, Guinea,

Guinea-Bissau, Lesotho, Madagascar, Malawi, Mali, Mauritius, Namibia, Niger, Rwanda, Senegal,

Sierra Leone, Sudan, Tanzania, Togo, Uganda, Zambia, Zimbabwe

\section{Arab and Middle East Yemen}

(1)

\begin{tabular}{ll}
\hline $\begin{array}{l}\text { Asia and Pacific } \\
\text { (12) }\end{array}$ & $\begin{array}{l}\text { Bangladesh, Indonesia, Lao PDR, Myanmar, Nepal, Pakistan, Papua New Guinea, Philippines, } \\
\text { Samoa, Sri Lanka, Tonga, Viet Nam }\end{array}$ \\
\hline $\begin{array}{l}\text { Latin America and } \\
\text { the Caribbean (19) }\end{array}$ & $\begin{array}{l}\text { Antigua and Barbuda, Barbados, Belize, Colombia, Costa Rica, Dominica, Dominican Republic, } \\
\text { El Salvador, Grenada, Guatemala, Honduras, Mexico, Paraguay, Peru, Saint Lucia, Saint Kitts and } \\
\text { Nevis, Saint Vincent and the Grenadines, Suriname, Uruguay }\end{array}$ \\
\hline $\begin{array}{l}\text { Least developed } \\
\text { countries } \\
\text { (28) }\end{array}$ & $\begin{array}{l}\text { Bangladesh, Benin, Burkina Faso, Burundi, Central African Republic, Chad, Comoros, Democratic } \\
\text { Republic of the Congo, The Gambia, Guinea, Guinea-Bissau, Lao PDR, Lesotho, Madagascar, }\end{array}$ \\
& $\begin{array}{l}\text { Malawi, Mali, Myanmar, Nepal, Niger, Rwanda, Senegal, Sierra Leone, Sudan, Tanzania, Togo, } \\
\text { Uganda, Yemen, Zambia }\end{array}$ \\
\hline
\end{tabular}

\section{Table 1.A1.3. Donor agencies}

Bilateral

(29)

\section{Multilateral}

(9)

\section{Table 1.A1.3. Providers of South-South co-operation response}

Brazil, Chile, Indonesia

\section{Table 1.A1.4. Regional and transport corridor responses}

\begin{tabular}{ll} 
Africa (4) & COMESA, ECOWAS, TradeMark East Africa, Walvis Bay Corridor Group \\
\hline $\begin{array}{l}\text { Latin America and } \\
\text { the Caribbean (3) }\end{array}$ & CARICOM, OECS, SIECA \\
\hline
\end{tabular}




\section{REFERENCES}

Intel (2012), Women and the web, www.intel.com/content/www/us/en/technology-in-education/women-in-the-web. html (accessed on 21 February 2017).

ITC (2016), Bringing SMEs onto the e-Commerce Highway, International Trade Centre, Geneva http://www.intracen.org/ publication/Bringing-SMEs-onto-the-e-Commerce-Highway/ (accessed on 11 May 2017).

ITU (2016), Measuring the Information Society Report 2016, International Telecommunication Union, Geneva www.itu.int/en/TTU-D/Statistics/Pages/publications/mis2016.aspx

ITU (2017), Global ICT Regulatory Outlook, International Telecommunications Union, Geneva

OECD (2015), "Official Development Finance for Infrastructure Support by Multilateral and Bilateral Development Partners, Report To G20 Finance Ministers and Central Bank Governors", OECD Publishing, Paris.

OECD (2017a), Trade Facilitation Indicators, www.oecd.org/trade/facilitation/indicators.htm\#About-TFI (accessed on 01 February 2017)

OECD (2017b), "OECD-DAC Creditor Reporting System: aid activity”, OECD International Development Statistics (database). DOI: http://dx.doi.org/10.1787/data-00061-en, (accessed on 7 April 2017)

OECD-WTO (2017a), aid-for-trade monitoring exercise 2017 (questionnaires) www.oecd.org/aidfortrade/countryprofiles/ OECD-WTO (2017b), aid-for-trade monitoring exercise 2017 (case stories) http://www.oecd.org/aidfortrade/casestories/

Suominen, Kati (2017), "E-commerce development survey and index”, for United States Agency for International Development, http://pdf.usaid.gov/pdf docs/PA00MP8T.pdf.

UNCTAD (2016), UNCTAD B2C E-commerce Index 2016, UNCTAD Technical Notes on ICT for Development N7. TN/UNCTAD/ICT4D/07, United Nations, http://unctad.org/en/PublicationsLibrary/tn_unctad_ict4d07_en.pdf

World Bank (2015), World Development Indicators (database) http://databank.worldbank.org/data/reports. aspx? source $=$ world-development-indicators

World Bank (2016a), Enterprise Surveys (database) www.enterprisesurveys.org (accessed 17 January 2017)

World Bank (2016b), Doing Business (database) www.doingbusiness.org/data/exploretopics/trading-across-borders 


\section{NOTES}

1. After the 1 February deadline for the monitoring exercise, questionnaires were submitted by Albania, Guyana and the Asian Development Bank; 15 case stories (11 from public sector and 4 from private sector) were also received. These questionnaires and case stories have been uploaded to the joint OECD-WTO website, but are unfortunately not part of the analysis in this report.

2. Transactions known as OOF are those made by the official sector with countries on the DAC List of ODA Recipients, but which do not meet the conditions for ODA eligibility, either because they are not primarily aimed at development or because they have a grant element of less than $25 \%$. 


\title{
CHAPTER 2
}

\section{SETTING THE SCENE}

Contributed by the World Trade Organization

\begin{abstract}
This chapter surveys the responses submitted by developing countries, least developed countries, bilateral and multilateral donors, regional economic communities and south-south partners to the 2017 aid-for-trade monitoring and evaluation exercise. The 2017 exercise examines action to address physical connectivity constraints and reduce trade costs, in particular through national and regional actions to implement the WTO Trade Facilitation Agreement. It also extends consideration of trade costs into the area of digital connectivity, network infrastructure and service markets. A picture of concerted action--by governments, development partners and the private sector-- to promote trade, inclusiveness and connectivity for sustainable development emerges from this analysis.
\end{abstract}




\section{INTRODUCTION}

Entry into force of the World Trade Organization (WTO) Trade Facilitation Agreement (TFA) is a landmark, both for the WTO and for collective action to reduce trade costs. A key message that emerged from the 2015 edition of the Aid-forTrade at a Glance publication (OECD-WTO, 2015) was that high trade costs inhibit numerous developing countries from fully exploiting the market access opportunities created by the multilateral trading system. The TFA gives policymakers a powerful tool to reduce physical trade costs. The analysis in this 2017 edition of the publication extends consideration of trade costs into the area of e-commerce.

\section{Reducing physical trade costs}

The WTO's 2015 World Trade Report (WTR) estimates that developing countries have the most to gain from swift and full implementation of the TFA. Full implementation of the TFA could reduce trade costs by an average of $14.3 \%$, and by more than 16\%, for many African countries and LDCs (WTO, 2015).

Trade facilitation ranks high among developing countries' aid-for-trade priorities (Figure 2.1). Of the 63 developing country respondents to the 2017 aid-for-trade monitoring exercise, 54 (84\%) state that trade facilitation has risen to the top of the list of their aid-for-trade priorities. Among donor respondents, a similar story emerges: 27 out of 42 submissions (65\%) indicated that trade facilitation is a priority in their aid-for-trade programming (Figure 2.2).

Figure 2.1. Developing country aid-for-trade priorities

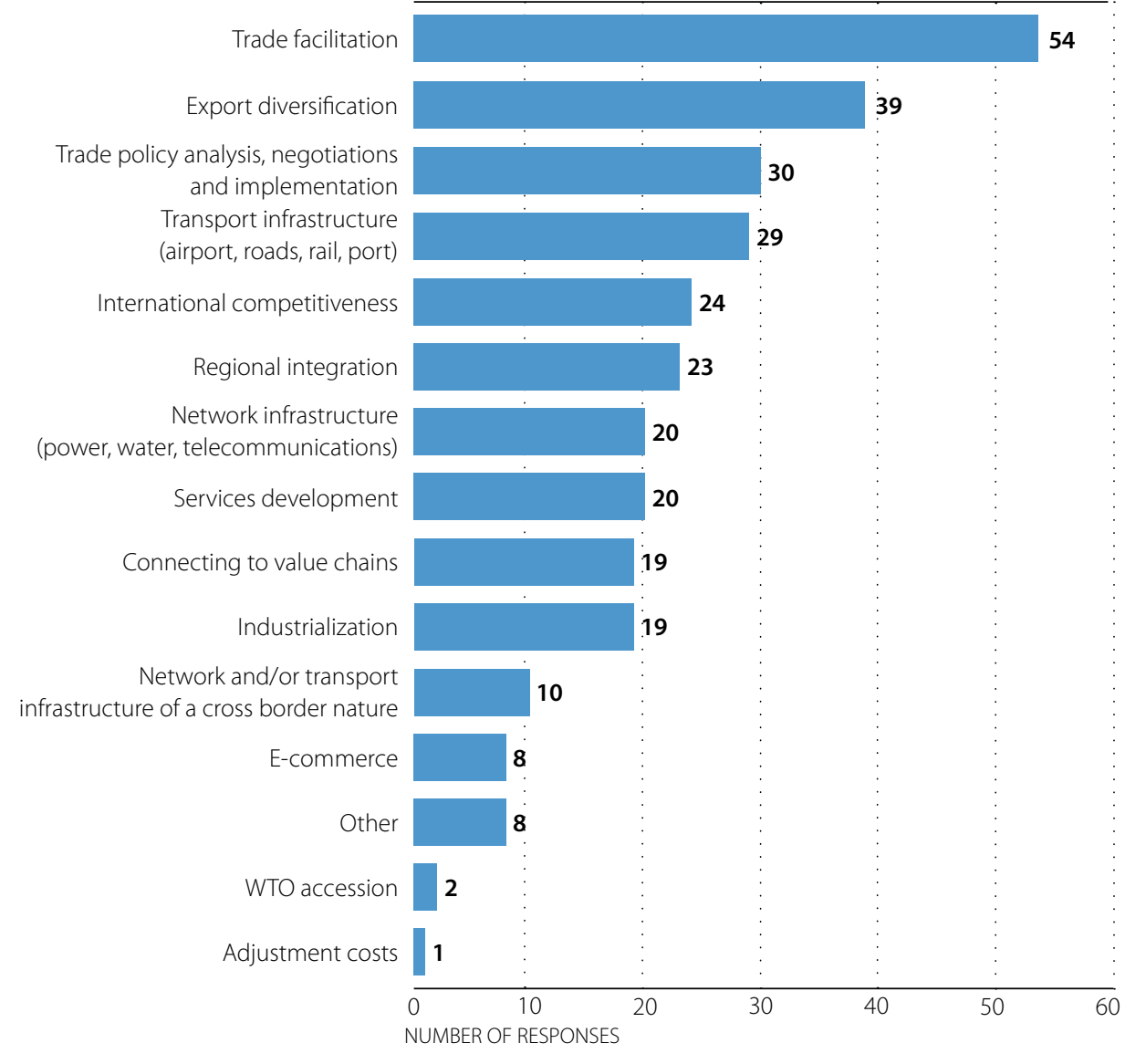

Source: OECD-WTO aid-for-trade monitoring exercise (2017), www.oecd.org/aidfortrade/countryprofiles/.

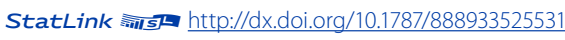


Figure 2.2. Donor aid-for-trade priorities

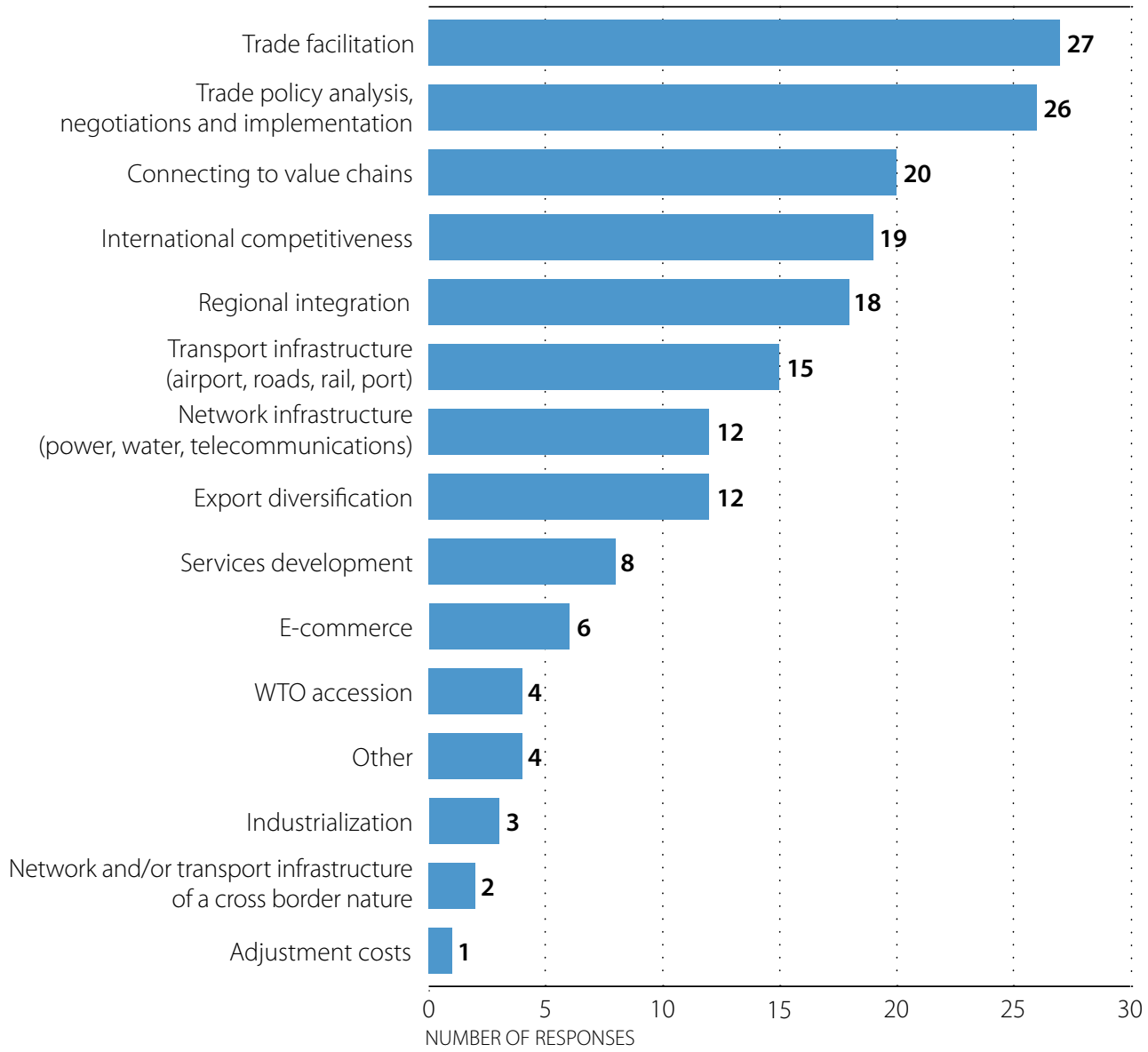

Source: OECD-WTO aid-for-trade monitoring exercise (2017), www.oecd.org/aidfortrade/countryprofiles/.

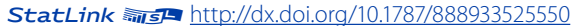

Furthermore, the partner country questionnaire responses suggest that trade facilitation is being integrated (i.e. mainstreamed) as a priority in national and regional development policy frameworks. Trade facilitation was noted as a priority in the national development strategies of $85 \%$ of the respondents -up from $45 \%$ in 2015 . Trade facilitation also was reflected as a priority in regional trade agreements by a growing number of respondents: 55\% compared to 32\% in 2015.

The 2017 aid-for-trade monitoring exercise further highlights that a majority of developing countries (46 out of the 64 replies from developing countries) have a broad conception of trade facilitation that extends also to transport facilitation. The responses to the 2017 aid-for-trade monitoring exercise outline a range of activities being undertaken by developing countries and LDCs, including with support from development partners, to improve trade connectivity by addressing trade facilitation issues. These efforts are being undertaken at the national, regional and multilateral level. It is also clear from the 2017 aid-for-trade monitoring exercise that digital connectivity exerts a growing influence on trade, as well as on efforts to reduce trade costs. The Asia-Pacific Economic Co-operation (APEC) Connectivity Blueprint is a case in point (Box 2.1). 


\section{Box 2.1. The APEC Connectivity Blueprint}

APEC leaders define connectivity under three distinct pillars: 1) physical connectivity that improves supply chain performance by connecting and integrating logistics, transport, energy and telecommunications infrastructure; 2) institutional connectivity that advances regulatory and procedural co-operation among economies; and 3) peopleto-people connectivity that enhances interaction, mobility and joint endeavours. The table below expands on these elements of connectivity agreed in the 2014 Asia-Pacific Economic Cooperation Leaders' Declaration.
Physical
Expand trade routes and corridors and strengthen regional quality transportation networks.
connectivity
Advance cross-border energy networks and interconnections.
Achieve universal and high-speed broadband access.
Develop and improve well-designed, sustainable, and resilient infrastructure by implementing, at the outset, a multi-year plan on infrastructure development and investment.

\section{Institutional connectivity}

\section{Advance logistics and transport facilitation.}

Enhance regulatory coherence and co-operation and strengthen the implementation of good regulatory practices.

Advance APEC's agenda on structural reform.

Modernize trade-related as well as customs and border agencies, including by progressing the development of Single Windows

Promote cross-border financial cooperation.

Expand the application of a safe and trusted ICT and e-commerce environment, especially in the area of electronic documents exchange including electronic means of authentication and improved security methods

People-to-people Advance work on cross-border education, science, technology and innovation, and services connectivity

Expand the facilitation of movement of tourists, business people, professionals and workers, women and youth

Source: APEC (2015)

\section{DIGITAL CONNECTIVITY ADDS A NEW DIMENSION TO THE GLOBAL ECONOMY}

Digital networks are leading trade into a new generation of connectivity. Global trade has evolved in numerous physical dimensions: road, maritime (including inland waterways), rail and air. Successive transport revolutions have extended the physical distances over which goods, services and ideas can be traded, expanding the volume and value of global commerce. Global value chains have emerged to organise sourcing, production and sale on the basis of complex webs of trade, with tasks separated into intermediate stages (OECD-WTO, 2012). The value chains that now characterise the global economy depend on the reach of integrated transport infrastructure networks to function. ${ }^{2}$ Global value chains also rely on digital connectivity, and count on digital networks to help co-ordinate production stages and to deliver an increasing range of tasks within value chains.

Digital networks interlink with transport systems, just as transport networks themselves intertwine, often in a physical sense. For example, as part of the pilot phase of the World Economic Forum's Internet for All program (WEF, 2016a), fibre optic cables will be laid alongside transport infrastructure on the Northern Transit and Transport Corridor connecting Kenya, Uganda, Rwanda, and South Sudan (WEF, 2016a). Transport networks have adopted and increasingly integrate digital technologies into their operations. Digital networks provide the communications backbone on which other 
Box 2.2. The digital connectivity challenges of landlocked countries

Geographical factors put landlocked developing countries (LLDCs) at a disadvantage in the development process, as they incur substantially higher transport and other trade transaction costs compared to coastal countries. The higher trading costs for the LLDCs emanate from factors associated with the physical infrastructure of the major transit routes for their traded goods, such as poor and inadequate roads, and the often long distances from sea ports. The costs associated with the soft infrastructure behind administrative border-crossing procedures, transit procedures, logistics and regulatory and legal systems for permitting passage of traded goods across borders also represent challenges.

The International Telecommunications Union (ITU) ICT Development Index (IDI) highlights similar problems in digital connectivity. When compared to transit in other developed countries, the LLDCs have lower scores on the aggregate IDI. The LLDCs also have the lowest IDI scores in the sub-index for access, which measures ICT infrastructure readiness--a basic requirement for using and benefiting from ICTs. The LLDCs have limited access to ICT infrastructure, including fixed and mobile telephony, Internet and broadband. One important reason for the lower LLDC IDI scores has to do with infrastructure gaps for broadband services and intraregional connectivity to undersea cables. A big challenge is the investment required for ICT infrastructure passing through neighbouring and coastal countries to access international networks that reduce commercial interest in investing in ICT infrastructure due to the high cost. There is also a need for more strategic approaches to infrastructure sharing; there are many instances of operators building parallel infrastructure on the same routes, thus making it more expensive for the end users who ultimately assume the cost of these investments through end user pricing

Source: ITU-UNOHRLLS (2013), "Enhancing ICT development and connectivity for the Landlocked Developing Countries".

transport systems function. For example, transport and logistics suppliers have been early adopters of tracking systems and intra-corporate communications mechanisms, to increase efficiency and reduce costs. An order placed at an online platform hosted in North America may initiate a delivery process that begins with the movement of cargo in Asia, destined for a final consumer residing in Europe and intermediated by logistical systems with global reach. Digital networks also rely on other backbone infrastructure networks, most notably electricity grids. Digital signals cannot be sent without electricity. Landlocked developing countries face challenges with physical as well as digital connectivity (Box 2.2).

Digital connectivity is not only about the backbone network for communications. Digital networks enable a growing array of services to be delivered directly across online platforms. Some services, such as remote health services or distance education, can now be performed using digital networks. For example, the growing area of e-health includes services such as health management information systems, tele-medicine, electronic medical records, clinical decision support and patient portals. In its 2015 report, the Broadband Commission argues that mobile phones offer the potential to revolutionise healthcare (ITU-UNESCO, 2015).

Payment systems are another example of how digital networks enable trade. Telenor submitted a case story explaining how in Pakistan the Easypasia mobile-phone banking service is being used in the Punjab and Sindh provinces to disburse educational stipends to some 750000 young girls, encouraging their educational participation and achievement (OECD-WTO aid-for-trade monitoring exercise 2017, Private sector case story 33). Digital payments have brought down the cost of disbursing the stipends--a cost that in the past sometimes exceeded the amount of the stipend itself. ${ }^{3}$

Payment systems were the issue most frequently covered by national digital or e-Commerce strategies among the developing countries that responded to the AfT M\&E exercise. ${ }^{4}$ Mauritius identified e-payment as a facilitator in its e-government Strategy 2013-2017. The African Development Bank described how mobile banking and mobile money services have already had a major impact on the economy of Kenya; they also are starting to make serious inroads in West Africa, where mobile phones are ubiquitous but bank accounts are scarce (OECD-WTO aid-for-trade monitoring exercise 2017, Public sector case story 15). USAID explained how a mobile money project run by the Reserve Bank of 
Malawi, the World Bank and the local banking sector had trained nearly 10000 people in digital and financial literacy, increasing the number of mobile money transactions in Malawi from 582000 per quarter in 2013 to more than 16 million in 2016. Mobile wallets have increased from 200000 in 2012 to more than 2.5 million today in Malawi (OECD-WTO aid-for-trade monitoring exercise 2017, Public sector case story 147).

The 2017 aid-for-trade monitoring exercise highlights how digital connectivity is infusing an ever broader range of government policy areas. Only 10 of the 63 developing country respondents to the aid-for-trade self-assessment questionnaire stated that their government did not provide e-government services. Some 50 governments responded that their administrations provided e-government forms and application downloads, while 36 respondents highlighted the use of electronic payments. Bangladesh highlighted its "a2i" (described as a public service innovation laboratory), whose primary goal is to ensure easy, affordable and reliable access to quality pubic services. It is also interesting to note the results reported in another case story regarding the social returns from moving government services online in Bangladesh. There, using cost-benefit research and analysis, the Copenhagen Consensus and BRAC (a nongovernmental organisation) reported returns of 663 takas for every taka invested in moving government procurement online (OECD-WTO aid-for-trade monitoring exercise 2017, Academia and NGOs case story 89).

The use of electronic methods for government procurement enhances transparency, compliance, and quality and improves the efficiency and effectiveness of public administration, which is a critical driver of economic development. In 2012, the government of Nepal, Asian Development Bank, United Kingdom and European Union partnered to fully digitise Nepal's public procurement system. In December 2015, the government of Nepal approved the rollout of a comprehensive national e-GP system (OECD-WTO aid-for-trade monitoring exercise 2017, Public sector case story 96).

Transport and ICT networks have facilitated the emergence of global value chains in merchandise goods. Digital networks are now encouraging similar fragmentation in services value chains. Approaches for outsourcing business process are being applied to generate digital input for local and international businesses. A case story from Digital Divide Data explains how these services can be generated in a socially responsible way. The company encourages its employees to complete their higher education while at the same time gaining work experience, thus propelling hundreds of families out of poverty. Since 2001, Digital Divide Data's program has increased lifetime earnings for youth in Cambodia, Kenya and Laos by a projected total of more than USD 300 million. The services Digital Divide Data offers include data analytics for the soccer industry, including such high profile clubs as Arsenal FC (OECD-WTO aid-for-trade monitoring exercise 2017, Private sector case story 152).

Services can now be fragmented across national borders, through collaborative processes, and delivered via digital platforms as never before (OECD-WTO, 2016).

The World Development Report 2016 discusses in detail the contribution of digital technologies: they help businesses to become more productive, people to find greater job opportunities, and governments deliver better services to all. By reducing information costs, digital technologies lower the costs of economic and social transactions for firms, individuals and the public sector (Box 2.3). They promote innovation and boost efficiency as existing activities and services become cheaper, quicker and more convenient. They also increase inclusion as people gain access to services that were previously out of reach (World Bank, 2016). The World Economic Forum goes further, suggesting that the world is entering a "fourth industrial revolution", as electronics and information technology produce a fusion of technologies that is blurring the lines among the physical, digital, and biological spheres (WEF, 2016b).

A large body of evidence has now been amassed that affordable and effective broadband connectivity is a vital enabler of economic growth, social inclusion and environmental protection. Broadband Commission (ITU-UNESCO, 2015). 
Box 2.3. Overview of key economic efficiency gains from digital connectivity

\section{UNCTAD and OECD (Chapter 3)}

Data flows and digitalisation of services, and in particular logistic services, can reduce the costs of physical delivery in remote areas. Across borders, they can support efficient customs services and the implementation of the WTO Trade Facilitation Agreement.

\section{WTO (Chapter 4)}

- Advances in telecommunications and related services have led to enhanced "tradability" of services, which has expanded export opportunities. Efficient telecommunications services have made it profitable to outsource, easier to manage and operate global value chains, and possible to develop e-government initiatives. As a result, telecom networks reduce trade costs for the exchange of both goods and services.

- Telecommunications and ICT services, combined with innovation, regulatory adaptation, and trade openness in the financial services sector, have made possible significant advances in payment solutions, particularly payments over the Internet and mobile services. This has contributed to greater financial inclusion.

\section{ITU (Chapter 5)}

High-speed, affordable broadband connectivity to the Internet holds widely recognised promise for social and economic development. Technological advances in areas such as the Internet of Things and artificial intelligence, combined with hyper-connectivity, are leading to an increasing variety of services and applications becoming available to serve economic, social, and entertainment needs.

\section{World Bank (Chapter 6)}

- The use of digital technology can facilitate participation in trade by improving access to information and reducing rent-seeking behaviour by middlemen or others.

- Use of e-commerce platforms or other technology can help disseminate best practices, for example in the provision of agricultural extension services, which can contribute to productivity increases.

- Digital technology can facilitate better access to market information and productivity-boosting inputs, help improve competition in transport and distribution services, and help farmers sell directly to consumers, especially higher value-added products.

\section{UNCTAD (Chapter 7)}

- The application of ICT can reduce transaction costs and enable the remote delivery of more goods and services.

- Access to ICT platforms and devices may enable a seller in a developing country to reach more potential customers in domestic as well as foreign markets, in a more targeted way, and often at lower cost than through traditional channels.

- Suppliers that rely more on e-commerce may be able to see reduced delivery costs, especially for electronicallyprovided content.

\section{Enhanced Integrated Framework (Chapter 9)}

- Mobile phones and their increased affordability have improved networking conditions for LDC traders, with benefits that include easy exchange of price and product information.

- Traders can finance trades without cash or access to bank accounts, via SMS and mobile phone banking, reducing transaction costs for producers, traders and consumers alike.

- The advantages resulting from information access also reach policy makers and regulators in the LDCs. Access to information is critical for planning and implementing trade-enabling policies.

\section{Business for eTrade Development (Chapter 10)}

The Internet enables developing country firm to trade more, and to optimise their trade - streamline logistics, gain foreign market intelligence, pay and transact quickly and securely, access financing and comply with trade rules. 
Discussion of the trade implications of digital connectivity has a long history at WTO (Box 2.4). In September 1998, the WTO General Council adopted a Work Programme on Electronic Commerce (WT/L/274). For the purposes of the work programme, "the term 'electronic commerce' is understood to mean the production, distribution, marketing, sale or delivery of goods and services by electronic means." Intentionally broad, the definition employed by the WTO reflects what has come to be known as the "digital economy". This definition aims to permit the inclusion of every possible aspect of trade influenced by ICTS, whether digitally supplied or digitally enabled, and every possibly relevant aspect of WTO agreements, whether related to goods, services or intellectual property. The terms e-commerce, e-trade, digital trade and online trade commonly refer to aspects of this broad phenomenon. At times, statistical work or research has sought to make finer distinctions for analytical purposes; in such cases, specific definitions need to be taken into account.

The digital economy now permeates countless aspects of the global economy, impacting sectors as varied as banking, retail, energy, transportation, education, publication, media and health. Information and communication technologies are transforming the ways social interactions and personal relationships are conducted, with fixed, mobile and broadcast networks converging, and devices and objects increasingly connected to form the Internet of Things (OECD, 2015).

\section{Box 2.4. The definition and measurement puzzle}

The Universal Postal Union (UPU), the United Nations Conference on Trade and Development (UNCTAD), the OECD and the WTO established a collaborative project to measure cross-border e-commerce transactions. A complementary line of work has been pursued by UNCTAD in its partnership work on Measuring ICT for Development. Under its G20 Presidency, Germany has tasked the UN Interagency Task Force on International Trade Statistics to develop proposals for efficient reporting systems.

The most common reply by developing country respondents to statistical questions on e-commerce (e.g. on the share of e-commerce in total trade, the percentage of goods exported and imported through this channel and the growth of e-commerce) was that there was no data or no capacity available to estimate these. Where estimates of growth were provided, they were not supported by source references. The conclusion that emerges from the responses to the 2017 aid-for-trade monitoring exercise is that many governments recognise the opportunities represented by digital connectivity, but face policy and planning difficulties resulting from a lack of data, notably in relation to digital trade and how it is permeating their economies.

\section{Comments on data to support digital trade policies}

Currently there is limited data on e-commerce transaction and there is also a capacity challenge in the analysis to capture the data on e-commerce. The Gambia

Currently this type of information has not been collected. Saint Vincent and the Grenadines

There has been no formal survey done on the e-commerce and the numbers related to it. Sri Lanka

Customs data does not separate between exports and imports done through traditional way and those completed by e-commerce. Yemen

Electronic commerce is at a very embryonic stage, however the government is aware of the importance of e-commerce and is looking to promote it. Burkina Faso

Source: OECD-WTO aid-for-trade monitoring exercise (2017), www.oecd.org/aidfortrade/countryprofiles/ 


\section{TRADE COSTS AND DIGITAL CONNECTIVITY}

Digital connectivity promises significant reductions in trade costs for digitally-enabled services, as compared to their analogue equivalents. The same is true for goods. In part this is due to the fact that digital delivery fees are not related to distance. The cost of transmitting a data file on a computer network is the same when the file is being transferred between two computers in the same office as it is between two computers at opposite ends of the globe. In contrast, physical delivery fees are not only related to size (i.e. the weight and dimensions of the goods being delivered), but to other physical characteristics as well (e.g. perishability, toxicity, mode of transport and distance).

Trade costs relating to the digital purchase of goods and services can be significantly lower than those accruing to physical delivery. In addition to transportation costs, a range of behind-the-border, at-the-border and beyond-theborder factors add further costs to the physical delivery of goods. For digitally-purchased goods that need to be delivered physically, there are also a series of offline trade costs that can be prohibitive for firms and consumers in developing countries, reducing their ability to break into e-commerce.

Many services can be transmitted at limited or close to zero cost over digital networks (OECD-WTO aid-for-trade monitoring exercise 2017, Private sector case story 47). Trade costs in this sense relate to the availability, affordability and capacity of the digital network connection. The United Nations (UN) 2030 Agenda for Sustainable Development (A/RES/70/1) Sustainable Development Goal (SDG) 9 includes targets for Internet access and networks--targets that complement other objectives agreed by the World Summit on the Information Society and Broadband Commission.

High-speed broadband Internet is transforming everything from health care, business and government services to education, disaster management and the social life of Tongans. Asian Development Bank (OECD-WTO aid-for-trade monitoring exercise 2017, Public sector case story 97)

The digital divide can also be considered a market access issue. Without an available, affordable digital connection, offline people and businesses have no access to the global market of goods, services and know-how available on the Internet. An available, affordable digital connection, therefore, can be considered the price of market access to digital trade. Table 2.1 gives an overview of the digital inclusion targets agreed in the context of the 2030 Agenda for Sustainable Development, the World Summit on the Information Society and the Broadband Commission.

This digital divide limits the production and dissemination of knowledge, exacerbates economic backwardness and dangerously intensifies the lack of understanding between peoples.

\section{Cuba, Ecuador, Nicaragua (WT/GC/W/635)}

More than half of the world's population is still offline. The majority of this offline population includes people who live in rural areas and are poor, female and illiterate. The main reasons for people not using the Internet include inequalities in income and education, the lack of infrastructure and relevant online content and services, as well as the high relative costs of access and usage (ITU, 2017).

A large percentage of the world's population remains offline. Closing this mobile coverage gap is not a technical challenge. It is primarily an economic challenge. GSM Association (OECD-WTO aid-for-trade monitoring exercise 2017, Private sector case story 47)

Historically efforts have focused on supply-side constraints; the shift to address demand-side barriers is just now taking place (OECD-WTO aid-for-trade monitoring exercise 2017, Public sector case story 39). Infrastructure for digital connectivity is a necessary pre-condition, but is not sufficient to ensure connectivity--other factors also need to be in place. Mobile financial services are a case in point. Such services require a cash-in, cash-out infrastructure, usually accomplished through a network of "agents" (e.g. retailers, merchants, post offices), who make it possible to turn cash into 
Table 2.1. Digital inclusion targets ${ }^{5}$

2030 Agenda for Sustainable Development

SDG 9(c)

\section{Broadband Commission for Sustainable Development}

Goal 2

Inclusiveness: Bridge the digital divide and provide broadband for all

\section{Target}

Significantly increase access to information and communications technology and strive to provide universal and affordable access to the Internet in least developed countries by 2020.

\section{Indicator}

Proportion of population covered by a mobile network.
Target 2.2.

A. In the developing world, $50 \%$ of individuals should be using the Internet by 2020.

B. In the least developed countries (LDCs), $20 \%$ of individuals should be using the Internet by 2020 .

\section{Target 2.3.}

A. The affordability gap between developed and developing countries should be reduced by $40 \%$ by 2020 .

B. Broadband services should cost no more than $5 \%$ of average monthly income in developing countries by 2020.

Sources: UNDESA (2016) Sustainable KnowledgePlatform, United Nations Department for Economic and Social Affairs https:// sustainabledevelopment.un.org/sdg9; Broadband Commission for Sustainable Development, www.broadbandcommission.org/publications/ Pages/default.aspx

electronic value (and vice versa). A host of supporting services, such as credit information and collateral registration, are also necessary. This ecosystem provides the opportunity to expand trade in many different services, such as deposittaking; lending; payment and money transmission; credit reference and analysis; financial intermediation and advice; insurance; and telecommunications and ICT-related services. Mobile payment services depend on the deployment of these ecosystems not only within national boundaries, but also across borders (WTO, 2016a). Domestic regulation is the building block that underpins these ecosystems.

The 2017 aid-for-trade monitoring exercise highlights that digital payment systems are increasingly present at the national level. Among the 63 developing country respondents to the 2017 aid-for-trade- monitoring and evaluation exercise, 25 indicated that consumers use mobile phones for domestic remittances and to transfer funds for payment at the national level. Of these, 22 respondents indicated that the necessary ecosystems exist for international payments to be made across borders.

\section{Mobile phone operators are able to transfer funds across borders upon satisfying regulatory} arrangements and conditions. Malawi

Source: OECD-WTO aid-for-trade monitoring exercise (2017), www.oecd.org/aidfortrade/countryprofiles/.

Other issues affecting the demand for digital connectivity are coming into sharper focus, including issues such as usable content, language, ICT skills and regulatory issues affecting the market where the service is consumed (e.g. regulations governing Internet access, domestic regulation of services, intellectual property rules and consumer protection laws).

The 2017 aid-for-trade monitoring exercise surveyed the views of developing country governments as to the issues enterprises and consumers face in accessing and using Internet services (Figure 2.3). Availability and affordability issues rank at the top, but are also supplemented by demand-side issues, such as those related to the perceived risk of online fraud, cybercrime, private data protection and the ability to use credit cards for payments--all factors that can serve to dampen demand. These issues also point to some of the potential downside risks to digital connectivity. 
Figure 2.3. Top ten issues enterprises and consumers face in accessing and using Internet services, as cited by developing country governments

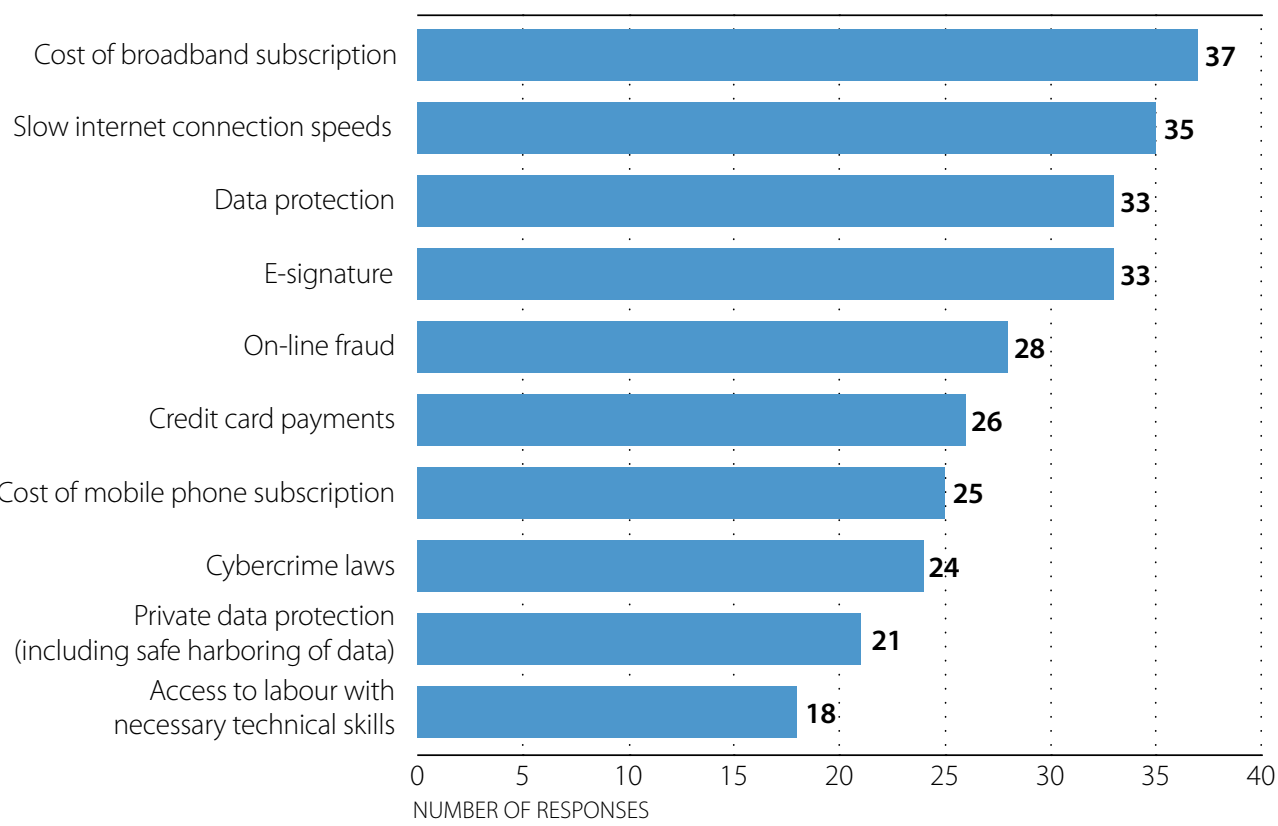

Note: Numbers refer to the number of governments citing the issues as a concern in the self-assessment questionnaire Source: OECD-WTO aid-for-trade monitoring exercise (2017), www.oecd.org/aidfortrade/countryprofiles/.

StatLink inisl http://dx.doi.org/10.1787/888933525569

\section{Comments on Internet connectivity issues}

The electronic signature law was recently approved but not yet implemented. El Salvador

No or slow connection. Guinea Bissau

High cost of Internet. Papua New Guinea

Access to information outside of major cities. Peru

Source: OECD-WTO aid-for-trade monitoring exercise (2017), www.oecd.org/aidfortrade/countryprofiles/.

Figure 2.4 below highlights the pathways for e-commerce transactions, distinguishing between four main forms of transaction and two main modes of delivery. A variety of issues influence the demand for transactions, payment and delivery. As is the case for mobile payments, many of these issues are strongly related to national regulatory environments.

Figure 2.4. E-commerce access, transaction, payment and delivery pathways
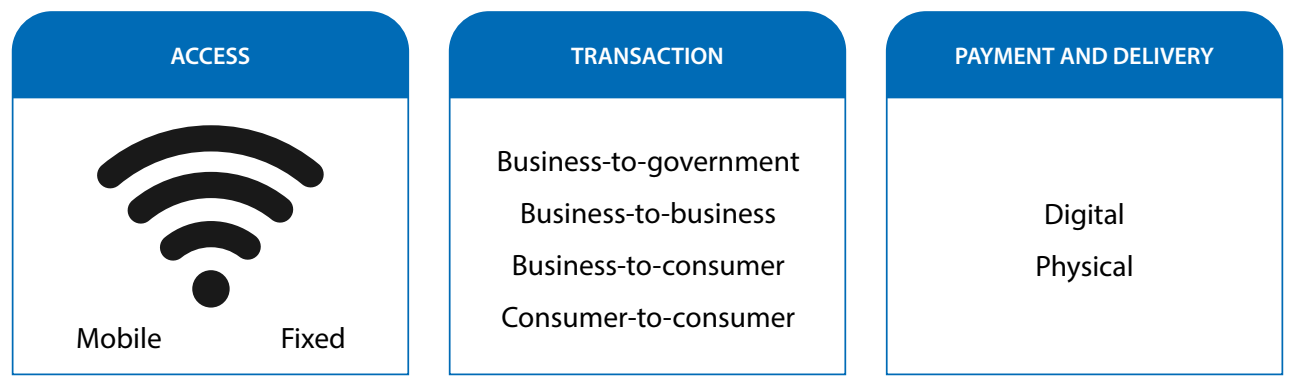
Digital delivery of services and the digital purchase of goods significantly reduce trade costs. In contrast, physical delivery costs emerge strongly as a factor limiting e-commerce participation for micro, small and medium enterprises (MSMEs; Figure 2.5). Offline costs are primarily related to shipping, with a particular emphasis on the high cost of small parcel shipments.

\section{Figure 2.5. Top ten export challenges faced by micro, small and medium enterprises in relation to cross-border e-commerce transactions}

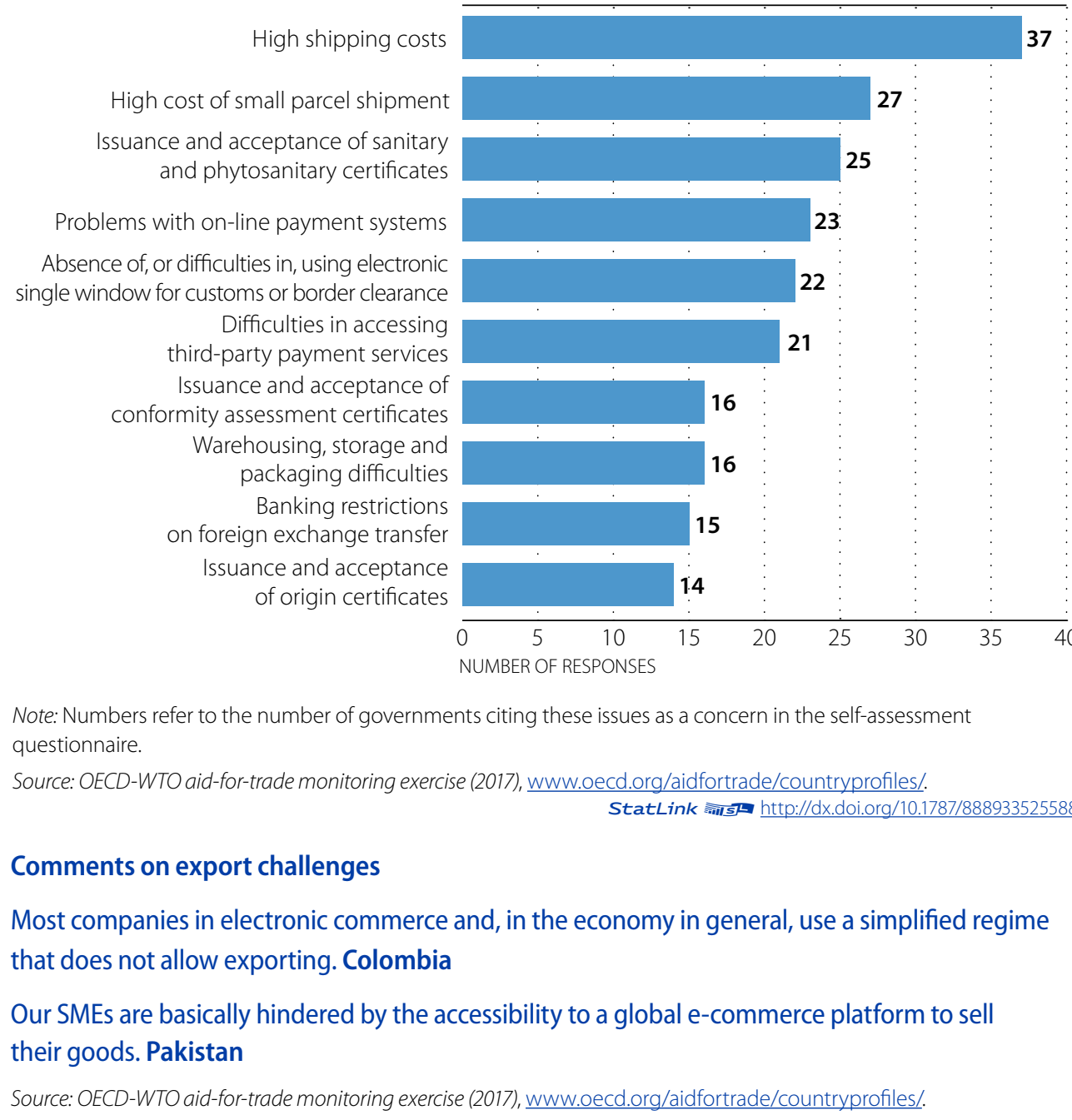

Issuance and acceptance of sanitary and phytosanitary (SPS) certificates ranks high among the problem areas cited by respondent governments. Electronic SPS certification promises to reduce transactions costs whilst improving compliance rates, reducing the opportunities for fraud that the current paper-based system offers, and thereby facilitating safe trade.

A case story submitted by the Standards and Trade Development Facility highlights how the introduction of electronic certificates has offered the opportunity to automate business processes related to SPS issuance and processing requirements, including request for certificates, scheduling of inspections (including through the automated use of risk assessment), payment of fees and integration into customs inspection processes. E-cert enables SPS authorities to store and access data that is important for determining records of compliance, which are the basis for the design of authorised operator schemes (OECD-WTO aid-for-trade monitoring exercise 2017, Public sector case story 84). A World Bank case story 
in Central America highlights how a regional ICT system is facilitating recognition of sanitary registrations. The project is expected to reduce the time, cost, and number of documents needed for sanitary registration by $25 \%$, generating estimated private sector savings of USD 17 million within three years of its completion. The system will also contribute to regional economic integration and accelerate growth (OECD-WTO aid-for-trade monitoring exercise 2017, Public sector case story 101).

When online orders of goods result in offline physical flows, a range of trade costs kick in, related to factors that stretch from distance-related transport costs to customs and other border agency compliance issues (Box 2.5). A dichotomy arises here. The digital networks on which trade operates depend on analogue regulatory systems (e.g. customs and other border clearance systems that require hard copies of official certification, versus digital documentation). One key conclusion of the 2016 World Development Report is that "To get the most out of the digital revolution, countries also need to work on the 'analogue' complements." (World Bank, 2016). These analogue complements were identified by the World Bank as including: "strengthening regulations that ensure competition among businesses, by adapting workers' skills to the demands of the new economy, and by ensuring that institutions are accountable" (World Bank, 2016). It emerges clearly from the 2017 aid-for-trade monitoring exercise that one of the analogue complements that needs addressing is the ability of customs and other border agencies to manage the physical clearance of e-commerce trade (Figure 2.6).

In 2010, Sierra Leone replaced its manual customs clearance system with the Automated System for Customs Data, leading to a substantial decline in average processing and clearance times. However, the day-to-day operation of the system remains frequently affected by the unreliability of Internet connectivity and electricity supply. (WTO, 2017)

\section{Figure 2.6. Challenges the online purchase of goods presents to customs and other border authorities}

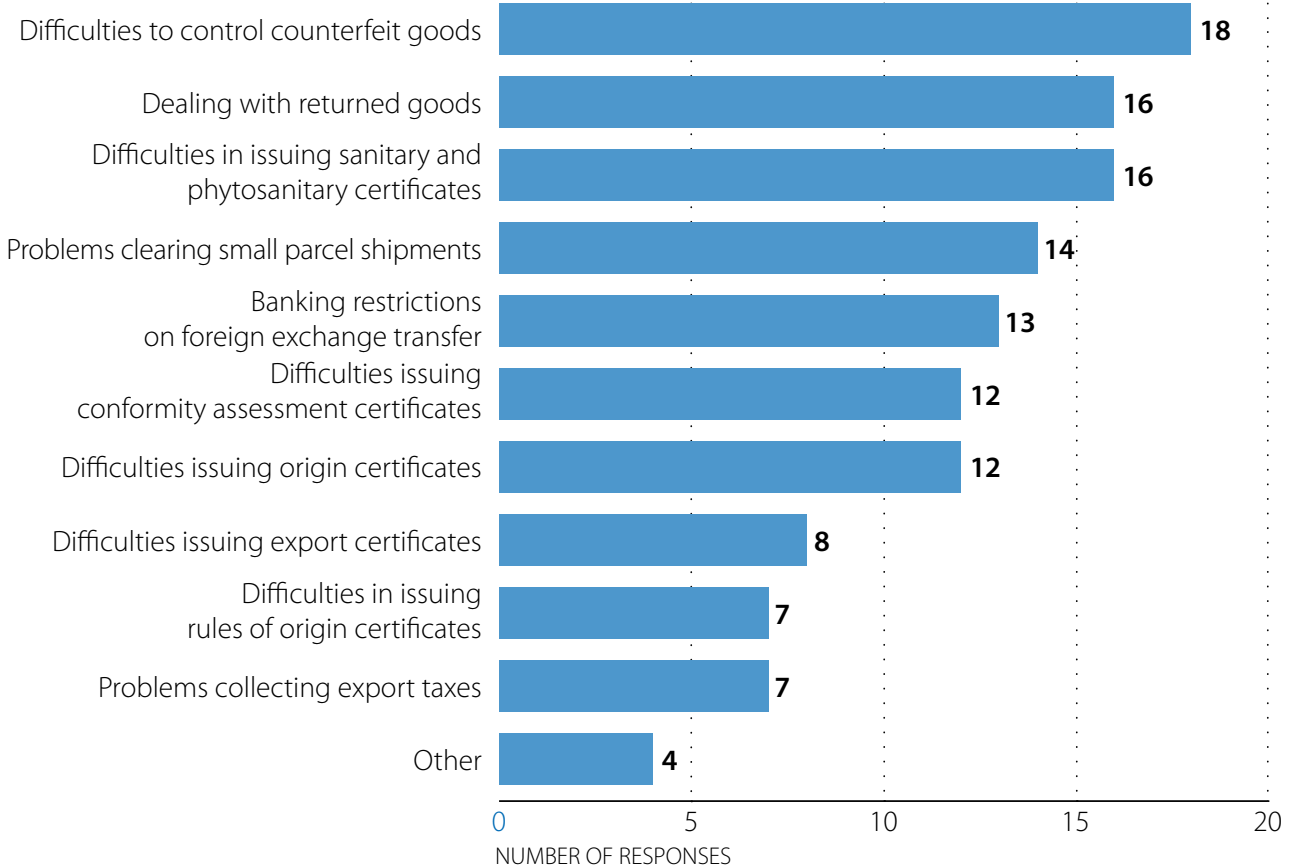

Note: Numbers refer to the number of governments citing the issues as a concern in the self-assessment questionnaire

Source: OECD-WTO aid-for-trade monitoring exercise (2017), www.oecd.org/aidfortrade/countryprofiles/. 


\section{Comments on customs issues}

With regards to the application of a customs de minimis threshold, this poses a challenge due to the under-invoicing of merchandise goods. The threshold established in Dominica is 150 Eastern Caribbean dollars. Dominica

Determining the actual value of the product is problematic. Zambia

Source: OECD-WTO aid-for-trade monitoring exercise (2017), www.oecd.org/aidfortrade/countryprofiles/.

At the 2015 Global Review of Aid for Trade, Maersk highlighted that the movement of a container of flowers sent from Kenya to Holland required more than 200 paper documents to be able to reach its destination. Maersk suggested that digital infrastructure built on the Internet-in a cloud in which all of this information could be accessed and sharedwould make it much simpler. Pursuing cloud-based ICT solutions to border clearance issues, however, supposes the free flow of data among parties in different legal jurisdictions, which in turn may require action in areas such as data ownership, data protection and restrictions on data use.

\section{Box 2.5. Cross-border e-commerce problems reported by customs officials in Central Asia}

\section{Coping with the volume of flows resulting from increases in the frequency of small parcel shipments.} Customs officials in Uzbekistan and other Central Asian states using paper-based customs systems have been overwhelmed by large inflows of small shipments. Single window facilities can address this problem. Azerbaijan has established a national single window; Kazakhstan, the Kyrgyz Republic, Tajikistan and Uzbekistan are developing theirs; and Afghanistan, Kazakhstan, and Turkmenistan are implementing UNCTAD's Automated System for Customs Data (ASYCUDA).

Uncertainty about how to estimate risks for small parcels. Increased import volumes also pose risk assessment problems: how new global rules on anti-terrorism and anti-money laundering should be applied to small parcel shipments is not always clear.

Confusion about how to assess duties. When assessing customs duties based on the method of parcel delivery rather than the nature of the traded good, traditional postal services benefit from preferences enshrined in decades-old international agreements, while those delivering by express service providers do not.

It is interesting to note that private sector engagement is helping to find solutions to e-commerce trade cost issues. The United Parcel Service (UPS) submitted a case story relating how it is working with USAID to empower MSMEs in the Association of Southeast Asian Nations (ASEAN) region. In 2013, UPS training for MSMEs focused on the technical knowhow they needed to navigate shipping and logistics hurdles and to use e-commerce to reach new markets. After early successes, UPS saw the potential of the program and expanded it to include collaboration with USAID, as well as the Untied States-ASEAN Business Council and several of its member companies. The resulting US-ASEAN Business Alliance for Competitive SMEs has trained more than 4600 businesses from all ASEAN countries.

A case story from Trini Trolley, an online shopping platform in the Caribbean that has been in operation since 2009, highlights how finding solutions to digital trade costs can unlock local commercial value (OECD-WTO aid-for-trade monitoring exercise 2017, Private sector case story 85). Prior to the existence of Trini Trolley, there was no online shopping facility in the Caribbean. Orders from international companies had long delivery times and high costs, and customers experienced difficulties with returns; some international firms even refused to ship to the Caribbean. (This case story is covered in more depth in Chapter 10.) 
Digital trade costs can also arise in regard to standards. Standards ensure, among other things, that products can "connect" or talk to each other. But when standards are incompatible, or when conformity procedures do not match, the cost of doing business rises, both domestically and across national borders. A growing number of trade concerns of this nature are being raised at the WTO Committee on Technical Barriers to Trade (TBT Committee). Measures to address them involve computers, servers and network components, mobile phones, mobile network standards and information security requirements, among others.

For example, in November 2016 concerns were raised about regulations to ensure ICT security, fourth-generation longterm evolution (4G/LTE) technologies in smartphones, and conformity assessment procedures for electronics and IT goods. ${ }^{6}$ Figure 2.7 highlights trade concerns that have been raised in the TBT Committee.

\section{Figure 2.7. Frequency of ICT-related concerns raised in the WTO TBT Committee}

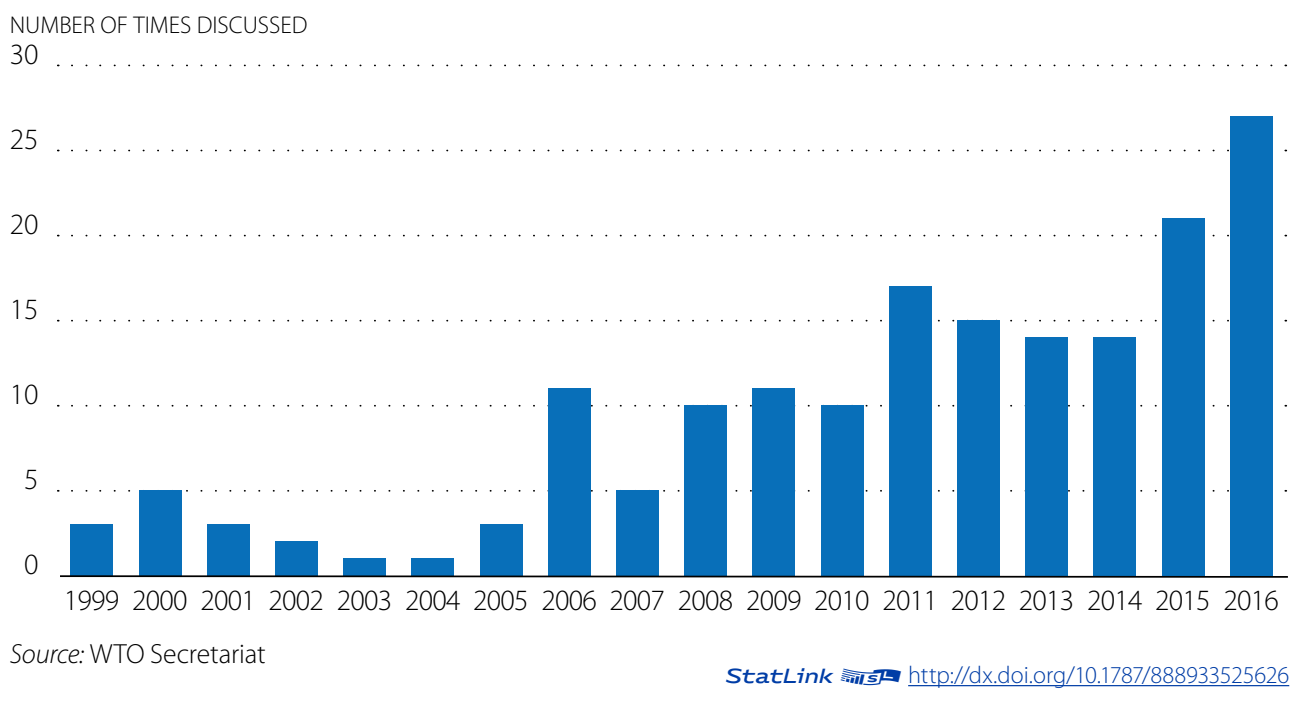

The International Telecommunication Union (ITU) Standardization Sector adopts recommendations (ITU T-Recs) on how telecommunication networks should operate. Over 4000 T-Recs are in force on fundamental components of today's ICTs. The United Nations Commission on Trade Law (UNCIRAL) has also developed a network of rules relating to e-commerce/ electronic contracts, covering the use and recognition of electronic signatures, the use of electronic communication in international contracts, and legislative text on the principles of non-discrimination, technology neutrality and functional equivalence in electronic commerce.

The intellectual property rights (IPR) system facilitates various ways of trading in physical goods and services using electronic means. The system enables the electronic flow of data and information necessary for e-commerce to function. In the digital world of the Internet, IPR conventions, such as trademarks to identify market products and services, copyrights covering the software running websites and apps, and agreements defining usage rights (i.e. licences), allow traded goods to move digitally; their significance has increased appreciably. IPRs already play a significant role in offline trade, channelling and framing commercial information and proprietorship.?

Under the territoriality principle, IP rights may differ considerably in their scope between different Members (and may even be absent altogether). ${ }^{8}$ This patchwork of distinct national international property rights regulations poses challenges for the protection and enforcement of IPRs on the Internet, a global medium that straddles different jurisdictions. The extent of intellectual property rights coverage and their enforcement among different members may vary significantly; enforcement action by a rights owner can in many cases involve costly multi-jurisdictional litigation and other procedures before numerous national authorities. As intellectual property has traditionally been regulated, administered and enforced on a territorial basis, the "borderless" nature of the Internet can raise trade costs in both registering and enforcing intellectual property rights in the context of global networks. 
Figure 2.8 provides a checklist of factors essential for connectivity and participation in digital trade networks. Addressing each of these issues implies costs. The figure offers a useful checklist of digital connectivity issues--both from a cost and an inclusion perspective.

Figure 2.8. Preconditions for participation

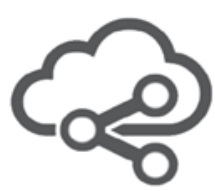

Connectivity

- Infrastructure

- Services

- Platforms

- Devices

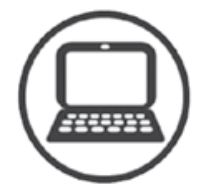

Digital literacy

- Basic education

- Language skills

- Digital know-how

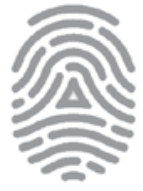

\section{Identity}

- Legal identity

- Branding

- Presence

- Positioning

\section{BANK} 프

\section{Financial inclusion}

- Universal financial access

- Online payments

- Access to venture capital

- Trade finance constraints

Source: Simon Lacey (Huawei) and Usman Ahmed (Paypal).

\section{TACKLING DIGITAL TRADE COSTS}

The ITU has been promoting connectivity since its inception, starting with efforts to support wireless telegraphy (ITU, 2016). More recently, the ITU has been at the forefront of efforts to bridge the digital divide ever since the term was coined in the 1990s. An important milestone here is the World Summit on the Information Society (WSIS). The 2003 Geneva phase of the WSIS resulted in a Declaration and Action Plan that, among other things, called for the development of national e-strategies. The 2005 Tunis Declaration followed up on this by focusing on financial mechanisms to bridge the digital divide and on Internet governance questions.

Taking into consideration the leading role of governments in partnership with other stakeholders in implementing the WSIS outcomes, including the Geneva Plan of Action, at the national level, we encourage those governments that have not yet done so to elaborate, as appropriate, comprehensive, forward-looking and sustainable national e-strategies, including ICT strategies and sectoral e-strategies as appropriate, as an integral part of national development plans and poverty reduction strategies, as soon as possible and before 2010 (WSIS, 2005).

A series of regional summits has complemented the WSIS process under the ITU's Connect the World program. The aims of these summits is to mobilise human, financial, and technical resources for the implementation of the WSIS connectivity targets. Five regional summits have been convened to date: the Connect Africa Summit (Rwanda, 2007), the Connect CIS Summit (Minsk, 2009), the Connect Arab Summit (Doha, 2012), the Connect Americas Summit (Panama, 2012), and the Connect Asia-Pacific Summit (Bangkok, 2013). A case story submitted by the African Development Bank (AfDB) highlights how a total of USD 55 billion has been pledged for the development of the infrastructure and services necessary to achieve the targets agreed at the Connect Africa Summit. It also describes the AfDB's activities in support of international fibre connectivity, national backbone initiatives, policy and regulation, and e-applications (OECD-WTO aid-for-trade monitoring exercise 2017, Public sector case story 16).

The establishment in 2010 of the Broadband Commission for Digital Development marked a further milestone in global connectivity efforts. ${ }^{9}$ A joint initiative of the ITU and the United Nations Educational, Scientific and Cultural Organization (UNESCO), the Broadband Commission unites government leaders, top industry executives, thought leaders, policy pioneers, international agencies and organisations concerned with development around five core targets: making 
broadband universal; making broadband affordable; connecting homes to broadband; getting people online; and achieving gender equality in access to broadband. A key target of this initiative was that by 2015 all countries would have a national broadband policy or strategy, or would include broadband in their universal access/service definition.

\section{Comments on progress in national e-strategies}

163 national e-strategies had been developed by 2011. (ITU, 2011)

151 national broadband plans had been developed by 2016. (ITU/UNESCO, 2016)

A third milestone in the ITU's efforts to promote connectivity is the ITU Connect 2020 Agenda for Global Telecommunication/ICT Development (ITU, 2014). The Agenda's four goals are:

1. to enable and foster access to and increased use of telecommunications/ICT (growth)

2. to bridge the digital divide and provide broadband for all (inclusiveness)

3. to manage the challenges resulting from telecommunications/ICT development (sustainability)

4. to lead, improve, and adapt to the changing telecommunications/ICT environment (innovation and partnership).

Affiliated targets include:

- 55\% of households worldwide should have access to the Internet by 2020

- $60 \%$ of individuals worldwide should be using the Internet by 2020 .

- Worldwide telecommunications/ICT should be 40\% more affordable by 2020.

- In the LDCs, 15\% of households should have access to the Internet by 2020.

A total of 107 national statements on policy commitments were given at the ITU Plenipotentiary Conference, held from 20 October to 7 November 2014, in Busan, Korea (Box 2.6).

\section{Box 2.6. Selected national policy commitments made at the ITU Plenipotentiary Conference in 2014}

The Cambodian ICT Master Plan 2020 and the National Master Plan of Science and Technology 2014-2020 were officially announced in August and in October respectively. Five priority projects have been identified in the Cambodian ICT Master Plan, such as e-government framework developed since 2004, cybersecurity, e-education, e-commerce and e-tourism. Cambodia

With regard to the goals and related targets to be achieved by 2020, in the upcoming five years Ethiopia aims to foster people's access to ICT. Mobile penetration will reach 100\% from the current $30 \%$. Similarly $50 \%$ of households' will have fast, broad and reliable Internet connectivity. Ethiopia

We are currently deploying optical fibre networks to connect all of the inland provinces, and we hope that over 1600 kilometres of optical fibre cable will be connected through co-operation between our government, the World Bank, and the European Investment Bank. Mauritania

We are designing regional optical fibre networks, which will link to the national network, and which will allow us to provide broadband in 21 regions, connecting many districts and several thousand localities reaching 4 million inhabitants, and we will build many more kilometres before 2027. Peru

Source: ITU (2014), "On the road to implement the Connect 2020 Agenda", www.itu.int/en/connect2020/Documents/pp14-connect2020commitments.pdf. 
The 2017 aid-for-trade monitoring exercise highlights how national e-strategies and broadband plans are being used to make digital connectivity available and affordable, and to create the necessary enabling environment for digital trade. The monitoring exercise responses did not highlight any relationship between income level and the deployment of such national plans. Of the 33 respondents that cited national e-commerce or digital-related strategies, 15 are LDCs and 16 are middle income countries. Box 2.7 highlights actions reported by the Democratic Republic of Congo, Côte d'Ivoire and Myanmar in the monitoring exercise.

\section{Box 2.7. Overview of selected national actions to support digital connectivity}

Democratic Republic of Congo (DRC): In 2002, the government adopted a framework law that sought to separate regulation, regulatory and operational functions so as to stimulate competitiveness in telecommunications and postal services. The framework law entrusted regulation to the Post and Telecommunication Regulatory Authority of Congo. In 2009, the DRC adopted a sectoral policy: the Development of the Telecommunications and ICT Sector Strategy in the DRC. This document was the reference framework for government action in the period 2010-2015. These laws are being revised pending the adoption of the new law on e-trade in the DRC. At this stage, e-commerce in the DRC is still at an embryonic stage.

Côte d'Ivoire: An e-commerce ecosystem is beginning to take shape in Côte d'Ivoire. National regulatory reforms have been adopted to drive and regulate electronic transactions, including laws to protect personal data, protect consumers, and fight cybercrime. The government has created a Ministry of Posts and Digital Economy, and has opened an academic institution that focuses on new technologies. E-commerce is gradually taking hold and online businesses are tapping into burgeoning consumer demand. Nevertheless, the growth of e-commerce is still limited by issues such as limited logistics and payment services, and high costs for electricity and broadband. The government recognises these challenges and has launched an ICT development initiative targeting infrastructure, accessibility of services, development of national expertise and implementation of a technological free-zone.

Myanmar: In 2012, Myanmar began reforming its telecommunications. In 2013, it enacted a new Telecommunications Act that provided for: the expansion of the telecommunications network and the sector's development; the establishment of types of licenses and basic rules on interconnection, competition and dispute resolution; the creation of an independent regulator (the Myanmar Telecommunications Commission); and the establishment of the overall government policy on private sector participation in the sector (OECD-WTO aid-for-trade monitoring exercise 2017, Public sector case story 113). Liberalisation facilitated the entry of two competing mobile operatorsOoredoo and Telenor-entered the market in 2014. This in turn led to a significant decrease in the cost of a SIM card: from USD 150 in 2013 to USD 1.50 in 2015. By the end of 2014, GSMA reported that there were 11.7 million mobile connections, with a year-on-year growth of 25\%, making Myanmar one of the fastest growing markets in the world (OECD-WTO aid-for-trade monitoring exercise 2017, Academia and NGOs case story 05).

Web content is also increasing in the Myanmar language thanks to efforts such as Bindez, a start-up that connects Myanmar people worldwide with information and content in their own language. This provides a solution to a challenge that has faced many countries coming online in the past few decades: how to make their countries' languages talk with computers (OECD-WTO aid-for-trade monitoring exercise 2017, Private sector case story 48).

Source: OECD-WTO aid-for-trade monitoring exercise (2017), www.oecd.org/aidfortrade/countryprofiles/.

In 2007, Sri Lanka's information technology (IT) and business process management (BPM) sectors agreed a ten-year plan to generate annual export revenues of USD 1 billion and employ more than 80000 people. These targets have been surpassed and IT is now Sri Lanka's fifth largest export earning sector. A new vision for 2022 has been developed with the following targets: growing revenue to USD 5 billion and creating 200000 jobs. Sri Lanka's goal is to move up the value chain, shifting from a focus on cost to one based on value. For this purpose, the IT sector has constructed its strategy around three targets: 1) building capacity by tripling the number of IT graduates by 2020 (there were only 6000 graduates in IT and related fields in 2015); 2) innovating by encouraging the creation of 1000 start-ups and promoting links between academia and the private sector; and 3) fostering regional development by taking the IT/BPM industry to the regions, promoting linkages with universities. 
The 2017 aid-for-trade monitoring exercise highlights action being taken by a variety of respondent countries to promote digital connectivity (Box 2.7). It makes it clear, however, that there is great disparity among respondents in terms of starting points and progress in implementing these strategies. Looking across its developing country members, the Asian Development Bank (ADB) notes that:

Some countries have the necessary policies and legislative framework already in place, but very slow implementation progress; others have formulated their policies but are still awaiting adoption; some have IT or ICT plans that are not implemented. (OECD-WTO aid-for-trade monitoring exercise 2017, Public sector case story 115)

An ADB case story suggests that within the Central Asian Regional Economic Corridor, countries are implementing facilitating legislation at different speeds, grouping the countries based on their progress. The countries in the first group—including Azerbaijan, the People's Republic of China (hereafter China), Kazakhstan, and Pakistan-have complete legal coverage of cybercrime; nearly all have data and privacy protection laws, with China including consumer protection as well. The countries in the second group have laws in two or fewer of the four major legislative areas. All countries have at least a draft law on electronic transactions. There is, however, no evidence that any country, aside from China, has implemented consumer protection legislation. In Turkmenistan and the Kyrgyz Republic, government officials report that consumer trust remains low, a factor that limits e-commerce growth. By contrast, in Azerbaijan e-commerce and public trust have grown since 2009 thanks to the passing of legislation on information safety and related issues. For Tajikistan, the WTO accession process has helped to promote the legal transparency that facilitates e-commerce (OECD-WTO aid-for-trade monitoring exercise 2017, Public sector case story 124).

\section{Action on e-commerce and digital-related strategies}

E-commerce sectoral cyber strategy adopted in 2013 by the Government. Burkina Faso

There is a Draft strategy for e-government which takes into consideration e-commerce. Dominica

Mali has adopted a national policy document and a strategic plan to develop ICTs in 2004.

In 2010, a sector-wide development policy for e-commerce was created. Mali

The draft National ICT Strategic Plan 2016-2020 also creates the conducive environment for e-commerce to flourish in Mauritius. Mauritius

Senegal strategy entitled "2025 Digital Senegal" is currently being drafted. Senegal

National ICT Strategy expired in 2015. We are currently in the process of developing a new strategy. Saint Vincent and the Grenadines

Source: OECD-WTO aid-for-trade monitoring exercise (2017), www.oecd.org/aidfortrade/countryprofiles/.

The 2017 aid-for-trade monitoring exercise also highlights various regional initiatives to promote digital connectivity (Box 2.8). Issues covered in Asian regional frameworks include plans to facilitate the establishment of mutual recognition of digital signatures, intellectual property protection, personal data and consumer protection, alternative dispute resolution for electronic transactions, ICT training and education, ICT rural community development, and infrastructure development for postal services within the region.10 Some regions have ICT or e-strategies integrated into other development objectives or plans, for example agriculture and rural development, public health, financial services, and environment and natural disaster management. 
Box 2.8. Overview of selected regional actions to support digital connectivity

In the Association of Southeast Asian Nations (ASEAN), an e-task force is charged with the development of a broad and comprehensive action plan for an ASEAN e-space, as well as the development of competencies to compete in the global information economy through the establishment of an information infrastructure. The task force will examine the physical, legal, logistical, social, and economic infrastructure needed.

The Asia-Pacific Economic Co-operation (APEC) recently launched a wide-ranging agenda that outlines programs designed to use advances in IT to boost productivity and stimulate growth, and to extend basic services to the community. The action agenda includes ways of promoting the right policy environment and build capacity to create a framework to strengthen markets, e-commerce, knowledge and skills development, and providing affordable and efficient access to communications and the Internet. APEC supports the development of distance learning and IT capacities as core competencies for teaching and learning, and for extending health and medical services. (OECD-WTO aid-for-trade monitoring exercise 2017, Public sector case story 124)

The Economic Community of West African States (ECOWAS) Vision 2020 seeks to harmonise telecommunication policies in order to benefit from the digital economy. Over 2013-2014 and with the support of UNCTAD, ECOWAS conducted two online training sessions and three regional workshops that trained 315 policy and law makers on the legal aspects of e-commerce. Areas identified for further legislative harmonisation included: electronic transactions, data protection, computer crime, consumer protection, online content and domain names (OECD-WTO aid-for-trade monitoring exercise 2017, Public sector case story 59).

\section{BRIDGING THE DIGITAL TRADE POLICY DIVIDE}

The 2017 aid-for-trade monitoring exercise highlights action by many developing countries and LDCs to promote digital connectivity. It also points to a possible "digital trade policy divide" (Box 2.9). Of the 63 respondents to the monitoring exercise, 33 stated that they did not have an e-commerce or other digital-related strategy. Comparison of these answers, however, with the statistics collected by the ITU on national e-strategies and broadband strategies suggests a different picture. All 63 partner country respondents have either an e-strategy or broadband strategy or both. Why the divergence in results? One explanatory factor may be terminology. Some respondents may not have considered their national ICT or broadband strategies to qualify as e-commerce or other digital-related strategies, as phrased in the questionnaire for the monitoring exercise. Others may have decided not to reference a national strategy that may have expired or was in the process of being updated.

Box 2.9. Digital enablement to bridge the digital divide

A paradox in the digital divide, as outlined by Huawei (2015), is that while it is narrowing, at the same time it is deepening. The worldwide development of digital networks, coupled with the increasing affordability of ICTs, has contributed to bringing more and more people within range of a phone signal ( $87 \%$ of the world population and 55\% for $3 \mathrm{G}$ networks). However, 1 billion people remain disconnected from any form of telecommunications; 3 billion lack access to broadband Internet; and in developing countries, only three out of ten people use the Internet, compared to eight out of ten in developed countries. The exponential increase in connections, sensors, devices, data, video and analytics is set to deliver advances in agriculture and health, and to reinforce economies, contribute to protecting the environment and improve transportation. Further sophistication in technology means that the analogue complements necessary for the digital economy to operate are now becoming more necessary than ever. Putting these analogue complements into place can be achieved by supporting users, implementing sound policies and lowering the costs of access. Huawei refers to these actions "digital enablement solutions". They argue that they need to run on market principles: built for scale and industrialisation, and valuing all income levels. The value generated would benefit all, not solely in financial terms, but in benefits across people and communities.

Source: Huawei (2015), "Connecting the Future, Digital Enablement, Bridging the Digital Gap to Connect People and Society" www. huawei.com/minisite/digital-enablement/download/Digital+Enablement ENGLISH+online.pdf 
However, another possible explanation for the inconsistency in the responses to the 2017 aid-for-trade monitoring exercise as compared to the ITU figures on national e-strategies and broadband plans may lie in the extent to which national co-ordination mechanisms do or do not exist. Twenty-one of the 63 respondents reported having national coordination mechanisms. The aid-for-trade monitoring results did not suggest the systematic participation of national ministries of trade in these mechanisms; rather, only 10 of the 21 respondents cited the presence of trade ministries in national co-ordination mechanisms."

The 2017 aid-for-trade monitoring exercise results also lead to the conclusion that the private sector is not systematically present in co-ordination mechanisms. Pakistan was a notable exception; the government's self-assessment reply noted the presence of the private sector in national digital co-ordination mechanisms and indicated that the e-commerce policy unit within the ministry of commerce consults with relevant agencies, as well as with representatives of leading private sector e-commerce enterprises. Likewise, Uganda noted that its ICT Sector Working Group included representation from both the private sector and government.

\section{Box 2.10. Trade policy and the availability—and affordability—of digital connections}

"Reduce the cost of mobile phones and ICT devices. Governments must work to reform tax and patent regimes so that ICT device costs can come down. They will also need to incentivize the private sector to develop high quality, low-cost smartphones"... "Getting everyone online requires balanced policies that address demand as well as supply; regulation as well as competition; fixed-line as well as mobile broadband; public access as well as individual subscriptions. Government ministers and others must spearhead efforts to convene all actors and develop a clear, coherent plan for sequencing reforms and stimulating the investments needed to enable reduced costs and wider access. Donors and aid agencies must come to the party with financial and practical support." Alliance for Affordable Internet (OECD-WTO aid-for-trade monitoring exercise 2017, Academia and NGOs case story 2).

"Substantial challenges still exist in the development of technology neutral and convergent licensing regimes, promotion of competition, establishment of fair interconnection rules and tariffs, management of resources such as radio frequency spectrum and numbers, design and execution of universal access strategies and the enforcement of standards. Policy and regulatory intervention that abolish exclusivity on market entry, reduce license fees and simplify licensing procedures as well as those promoting open, transparent and non-discriminatory access to the networks are the foundation for improved national and regional broadband networks. Besides, most member countries face challenges in new policy areas in particular those pertinent to electronic transaction and cyber security." African Development Bank (OECD-WTO aid-for-trade monitoring exercise 2017, Public sector case story 16)

Despite the vast opportunities presented by a digital economy, Asia has yet to overcome challenges to fully realise its potential to harness e-commerce for sustainable development. In addition to the absence of national legislation to support cross-border e-commerce, developing countries in Asia face barriers related to poor ICT infrastructure, trade facilitation and logistics, e-payments, and inadequate skills development. National strategies to understand the underpinnings of e-commerce are also lacking in many countries. Even as Asia's developing countries further strengthen their capacity for e-commerce, most of them face institutional issues, such as complicated border clearance procedures and red tape, and disharmonised customs requirements between states hinder intra-regional trade. Market related risks — such as fraud, costs of adaptation, and a risk of crowding out-also serve as barriers to entry. Asian Development Bank (OECD-WTO aid-for-trade monitoring exercise 2017, Public sector case story 124)

The cost of computers and telecommunications remain generally high, because of insufficient liberalisation and deregulation of markets, and years of chronic underinvestment. Asian Development Bank (OECD-WTO aid-for-trade monitoring exercise 2017, Public sector case story 116)

As regards affordability, 57\% of the world population currently cannot afford the Internet, because the costs of end-user devices, services, access and ancillary costs (including usage and device taxes) are still too high for many. Broadband Commission (OECD-WTO aid-for-trade monitoring exercise 2017, Public sector case story 41) 
Aid-for-trade support can help governments establish co-ordination mechanisms. El Salvador noted that support from USAID helped to ensure co-operation on e-commerce questions with a diverse range of stakeholders, including the Salvadoran Chamber of Tourism, the Innovation and Quality Directorate, the National Science and Technology Council and the Ministry of Tourism.

The importance of the trade dimension to digital connectivity questions was highlighted by a case story from Australia outlining co-operation with the World Intellectual Property Organization to create an enabling environment for increased domestic innovation, inward investment and technology transfer. Other case stories from the African Development Bank, the Asian Development Bank and the Alliance for Affordable Internet highlight the influence that trade ministries can play in ensuring available, affordable digital connections. Box 2.10 brings together some of the insights from these cases stories.

Australia offers an example of a donor that is supporting efforts to address the affordability and availability of digital connectivity through telecommunications reform. Australia's response to the self-assessment questionnaire highlights how in Indonesia, it has provided specialist advice to enable the country to award radio spectrum for $3 \mathrm{G}$ mobile telephony and Internet services in the most transparent and economic way possible. This resulted in an auction from which government secured over USD 700 million in revenue and one of the fastest roll-outs of 3G services in the world. Similarly, in Vanuatu Australia helped to introduce private sector competition and independent regulation, expanding mobile coverage from $20 \%$ of the population in 2007 to $85 \%$ in 2009. The prices of handsets dropped from USD 100 to USD 25 and monthly Internet access rates dropped from USD 200 to USD 60.

\section{AID FOR TRADE CAN PROMOTE DIGITAL CONNECTIVITY}

Of the 40 donor respondents to the 2017 aid-for-trade monitoring exercise, 25 noted that e-commerce or digital issues featured in their in-country dialogues with partner countries and regional partners. Figure 2.9 provides an overview of the relative importance of specific focus areas for donor support (ICT development, e-government, e-commerce, broadband, telecommunications and other). Figure 2.10 provides more detailed information on the type of support offered.

Research by the OECD suggests that aid-for-trade support (disbursements) to promote digital connectivity averages between USD 650 million and USD 700 million annually, with the largest share (34\%) financing telecommunication projects, followed by investment in information and telecommunication technology (21\%), policy and management (17\%) and finally research and development (10\%).

\section{Figure 2.9. Focus areas of donor support for digital connectivity}

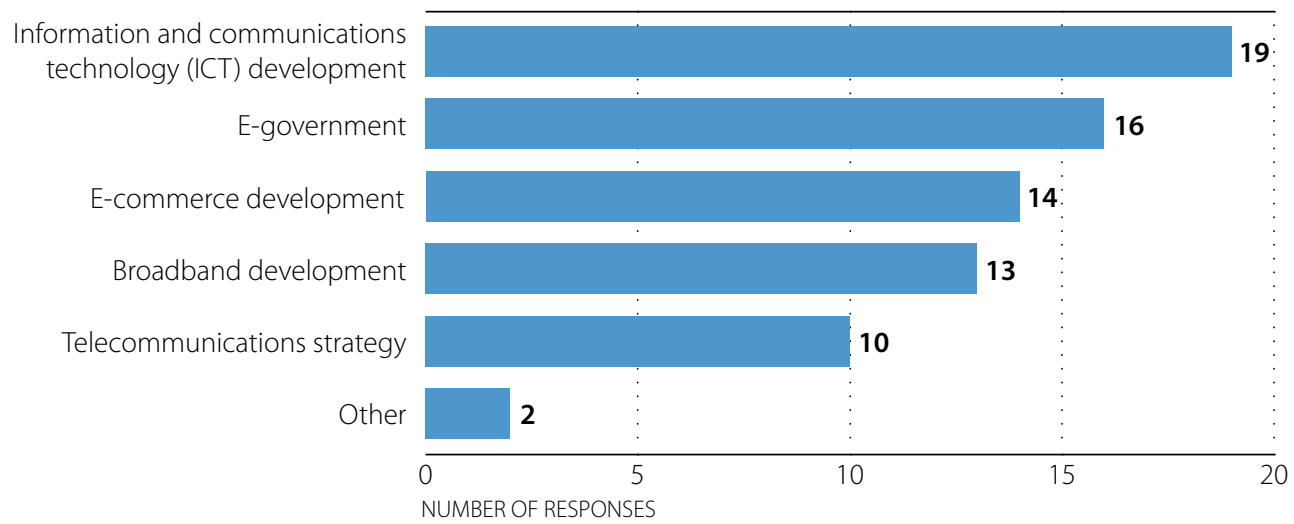

Note: Numbers indicate the total number of responses for each focus area.

Source: OECD-WTO aid-for-trade monitoring exercise (2017), www.oecd.org/aidfortrade/countryprofiles/. 
Figure 2.10. Types of support offered to promote digital connectivity

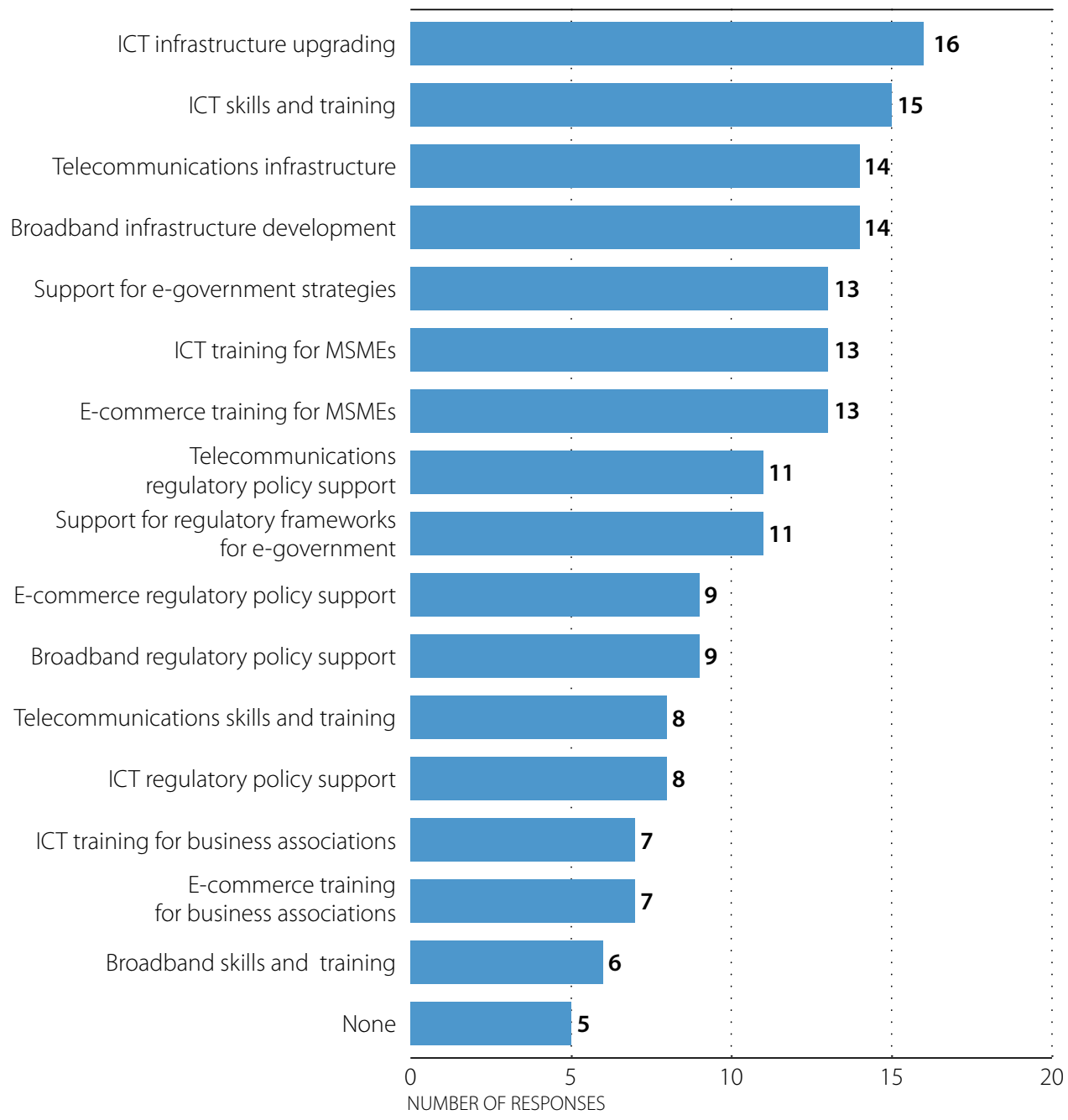

Note: Numbers indicate the total number of responses for each type of support.

Source: OECD-WTO aid-for-trade monitoring exercise (2017), www.oecd.org/aidfortrade/countryprofiles/.

StatLink न्ताIs http://dx.doi.org/10.1787/888933525664

The 2017 monitoring exercise suggests that demand for aid-for-trade support in this area is growing, and expected to rise further. Among the donor respondents, 11 highlighted significant growth in demand in this area over the past five years. Of the 40 donor respondents, 31 anticipated growth in future demand both from both partner countries and regional partners. This conclusion looks well-founded: 57 of the 63 developing and LDC governments responding to the 2017 aid-for-trade monitoring exercise anticipated a need for future assistance in order to meet their e-commerce strategic objectives.

Both the European Commission and Germany indicated that they are updating their strategies to address digital development. Germany noted that a more coherent strategy was being developed to pull together its initiatives in this area--initiatives that include support to the IT industry in Kosovo in a joint project with Norway (OECD-WTO aidfor-trade monitoring exercise 2017, Public sector case story 63). The European Commission noted that it had submitted a proposal for a new European Consensus on Development in November 2016 which included a Digital for Development statement. The European Bank for Reconstruction and Development (EBRD) has launched the Knowledge Economy Initiative, working with countries on innovation-related issues such as improving telecommunications regulation and developing ecosystems that allow venture capital and private equity firms to grow. The EBRD also provides funding to the private sector, including for projects related to the development or expansion of e-commerce. 
Other donors, most notably Japan and Korea, are already active in promoting digital connectivity and have wellestablished programmes in place. In addition to their own bilateral programmes, both Japan and Korea also contribute to multilateral programmes. Cases in point are the Korean e-Asia and Knowledge Partnership Fund and the Japan Fund for Information and Communication Technology administered by the Asian Development Bank. Box 2.11 outlines Japan's work on ICT infrastructure.

\section{Box 2.11. Achieving quality infrastructure through Japanese ICT}

Japan possesses one of the highest levels of Information and Communications Technology (ICT) in the world, as well as a proven development assistance track record in this field. For instance, Japan has contributed to ICT development in various regions as a leading international supplier of optical submarine cables. A Biometrics authentication system has also been adopted by over 70 countries, protecting people's safety and security. And Japan is supporting implementation of ICT for disaster management in many countries using its knowledge as a country affected by natural disasters. Japan is also making active strides in technology transfers aimed at making practical use of ICT. With the introduction of digital terrestrial broadcasting in Botswana, Japan is striving to develop businesses that make use of data broadcasting and transfer TV program creation technology. And through its communication satellite business located in Turkey, Japan has not only produced and delivered satellites but has also provided high-level technology education programs aimed at autonomous development. Japan's ICT support is also contributing to the optimisation and increased lifespan of existing public infrastructure. In the case of Vietnam's Can Tho Bridge construction, support has been given to introduce a system for real-time measurement of strain and oscillations. By detecting abnormalities quickly, serious damage and deformation can be prevented. As a part of Myanmar's postal service, Japan has worked to digitise money transfer services. Japan offers multifaceted support precisely because it possesses such comprehensive capacity for ICT development.

Source: OECD-WTO aid-for-trade monitoring exercise (2017), Public sector case story 75, www.oecd.org/aidfortrade/casestories/ casestories-2017/CS-75-Achieving-Quality-Infrastructure-through-the-ICT-of-Japan.pdf

Korea's own ICT-based growth is considered by some as a model to follow. In the 1990s, the Korean government pursued a series of long-term plans. The Korea Information Infrastructure plan launched in 1995 led to the completion of fibre optic networks across the country. The government also established several master plans: 1) the Informatization Promotion Act (1995), followed by the First Master Plan for Informatization Promotion (1996); 2) Cyber Korea 21 (1998), addressing the changing environment caused by the Asian financial crisis; 3) the e-Korea Vision 2006 (2002), updated by Broadband IT Korea Vision 2007 (2003); and 4) the UKorea Master Plan. All these measures led to the construction of advanced information infrastructure and growth in the ICT industry. Korea also engaged in a range of training programmes and de-regulation measures; for example, the government opened up the broadband Internet service market, removing regulation or controls over licensing and pricing. Having appropriate regulatory measures encouraged facility-based competition among service providers. Increased competition put downward pressure on tariffs, which, in turn, led to an increase in demand for Internet services (OECD-WTO aid-for-trade monitoring exercise 2017, Public sector case story 124).

Dialogue with regional partners is another important feature of e-commerce development, particularly in the areas of ICT and broadband development. Australia supports the ASEAN in improving regional connectivity, including the development of an ASEAN Master Plan for Connectivity, which covers physical connectivity such as international undersea telecommunications cables and domestic broadband coverage. Australia is also among the donors that support the World Bank in the Indo-Pacific region for the development of ICT infrastructure, such as international undersea cable connections, and lends policy and regulatory technical assistance to improve access to ICT infrastructure assets and services. 
Infrastructure is a big hurdle for many countries, especially those that are poor or with large rural or remote populations. Many developing markets require massive investment to move up to more advanced mobile technologies. (WEF-BCG, 2016)

The 2017 aid-for-trade monitoring exercise highlighted the multifaceted engagement of the private sector in e-commerce and ICT development more broadly. Case stories submitted by partner countries and donors indicate significant collaboration between the public and private sectors. Among donors, 54\% stated that they worked with the private sector to support growth in e-commerce in partner countries and regions.

In the past, financing of ICT infrastructure in most developing countries has been based on public investment. Lately, a significant influx of investment has taken place where private-sector participation has been encouraged, based on a sound regulatory framework, and where public policies aimed at bridging the digital divide have been implemented. (World Summit on the Information Society, 2005)

A prominent example of private sector participation in infrastructure projects to bridge the digital connectivity divide is in the area of submarine communication cables. These cables carry $90 \%$ of the world Internet data; the remaining $10 \%$ is transferred via satellite. As of 2016, some 350 submarine cables stretching over more than 1.2 million kilometres had been installed.

Three funding structures have emerged for this cable infrastructure: public-private partnerships; consortia of private sector operators; and privately owned cables. Box 2.12 highlights the important role that development finance has played in bringing submarine communication cables to regions that might not otherwise enjoy digital connectivity, in particular through cabling initiatives in the Pacific.

\section{Box 2.12. Cabling the Pacific}

Samoa: The ADB approved a USD 25 million grant for a submarine cable project to support a fibre-optic cable system linking Samoa to Fiji's international submarine cable network. Currently, Samoa is connected to the American Samoa-Hawaii cable system via the Samoa-American Samoa cable, which is operating at near capacity. The project will enable broader Internet access to meet Samoa's growing demand, providing fast and affordable access. The ADB grant financing was complemented by funding from the World Bank and Australia. The Samoa Submarine Cable Company provided USD 8.2 million in equity; the government of Samoa covers taxes and duties of USD 6.7 million. The total project cost was estimated at USD 57.4 million. The project aims to enhance low-cost broadband services to Samoa, strengthen the regulatory and legal environment for ICT, and facilitate e-health investment in Samoa. Part of the project will involve implementing an e-health patient information system to improve patient care.

Tonga: Under the Pacific Regional Connectivity Program, the Asian Development Bank, the government of Tonga, Tonga Cable and the World Bank Group joined forces to finance and support an 827-kilometer submarine fibre-optic cable system linking Tonga to Fiji via the Southern Cross Cable-the main trans-Pacific link between Australia and the United States. Tonga Cable is the owner and manager of the fibre-optic cable. The project team completed the job in four years, under budget and one day ahead of schedule. International connectivity costs have already fallen by more than 60 per cent.

Source: Asian Development Bank, OECD-WTO aid-for-trade monitoring exercise (2017), Public sector case story 8, www.oecd.org/ aidfortrade/casestories/casestories-2017/CS-08-Samoa-Submarine-Cable-Project.pdf and Public sector case story 97, www.oecd.org/ aidfortrade/casestories/casestories-2017/CS-97-AsDB-Tongas-High-Speed-Revolution.pdf 
Development finance is being used in a similarly catalytic fashion in Africa to promote connectivity. The Eastern Africa Submarine Cable System (EASSy) is a good example. EASSy runs from Mtunzini in South Africa to Port Sudan in Sudan, with landing points in nine countries and connecting to an additional ten landlocked countries. Inland connectivity is important as it means that landlocked countries no longer have to rely on satellite Internet access to carry voice and data services. EASSy is owned and operated by a group of African (92\%) and international (8\%) shareholdersall telecommunications operators and service providers. Box 2.13 highlights other regional projects being taken forward in the context of the Connect Africa Initiative. The issue of connectivity for landlocked countries was also highlighted by the Asian Development Bank in its submission to the 2017 monitoring exercise. It noted that landlocked countries must either use satellite access, which can be prohibitively expensive as well as being comparatively slow, or depend upon neighbouring countries for terrestrial access to submarine cable landing stations.

\section{Box 2.13. Connect Africa Initiative}

The Central African Backbone (CAB): The project implements a telecommunications network made up of onward terrestrial fibre connections linked to an undersea optical fibre cable system in the African Western Coast. A broadband backbone leverages the fibre optic infrastructure laid along the oil pipeline between Kribi, Cameroon and Doba, Chad.

The East Africa Broadband Network (EABN): The project implements an integrated East African Broadband ICT infrastructure network that provides cross-border connectivity between Burundi, Kenya, Rwanda, Tanzania and Uganda. It links up with global gateways through submarine fibre cable systems.

The South Africa Region Backbone (SATA Backhaul): The project is improving cross-border links that interconnect the South African Development Community (SADC) member states through optical fibre networks and. It links them to submarine cable systems, including the EASSy.

The Economic Community of West African States (ECOWAS) Power Pool-based Fibre Network: The project expands broadband access by leveraging the West Africa Power Pool's (WAPP) communications infrastructure network. It links the WAPP network to national and regional infrastructure to bridge connectivity gaps in the ECOWAS region.

Source: African Development Bank, OECD-WTO 2017 aid-for-trade monitoring exercise (2017), Public sector case story 16, www.oecd.org/ aidfortrade/casestories/casestories-2017/CS-16-AfDB-Connect-Africa-Initiative.pdf

The private sector is also directly engaged in providing digital connectivity solutions. Facebook submitted a case story on the Telecom Infra Project (TIP)--an engineering-focused initiative that is bringing together operators, infrastructure providers, system integrators, and other technology companies to collaborate on the development of new technologies and approaches to building and deploying telecom-network infrastructure. For Facebook, TIP is a new investment that ties into other connectivity efforts already underway through Internet.org (OECD-WTO 2017 aid-for-trade monitoring exercise 2017, Private sector case story 154). Other examples of private sector action include Google's Project Loon and Nokia's FastMile. Huawei identifies four segments to connectivity infrastructure as per Box 2.14.

In addition to infrastructure initiatives, the private sector is directly engaged in a wide variety of actions to promote digital connectivity--both as part of corporate social responsibility initiatives and as part of regular commercial operations. Several of these actions seek to promote local adoption and use, such as The Rural Taobao Initiative run by the Alibaba Group (OECD-WTO 2017 aid-for-trade monitoring exercise 2017, Private sector case story 23). Other initiatives seek to promote ICT awareness and skills, such as IBM's Digital-Nation Africa. Telenor submitted examples of projects designed to close the digital gender divide (OECD-WTO 2017 aid-for-trade monitoring exercise 2017, Private sector case story 45 and 46). Jumia Market explained how it has helped to economically empower tens of thousands of traders in Africa in the past three years through e-commerce, focusing on success stories of three local traders in Cameroon. 
A case story submitted by Amazon highlighted how a small rural business in Thailand (Lanna Clothes Design) was empowered to expand internationally through e-commerce (OECD-WTO 2017 aid-for-trade monitoring exercise 2017, Private sector case story 88). Facebook also highlighted how its Express Wi-Fi, launched in Nigeria in 2016, is providing affordable and fast Internet services that are reducing the costs of business for information technology entrepreneurs in the Alaba International Market in Lagos (OECD-WTO 2017 aid-for-trade monitoring exercise 2017, Private sector case story 153).

\section{Box 2.14. The four segments of connectivity infrastructure}

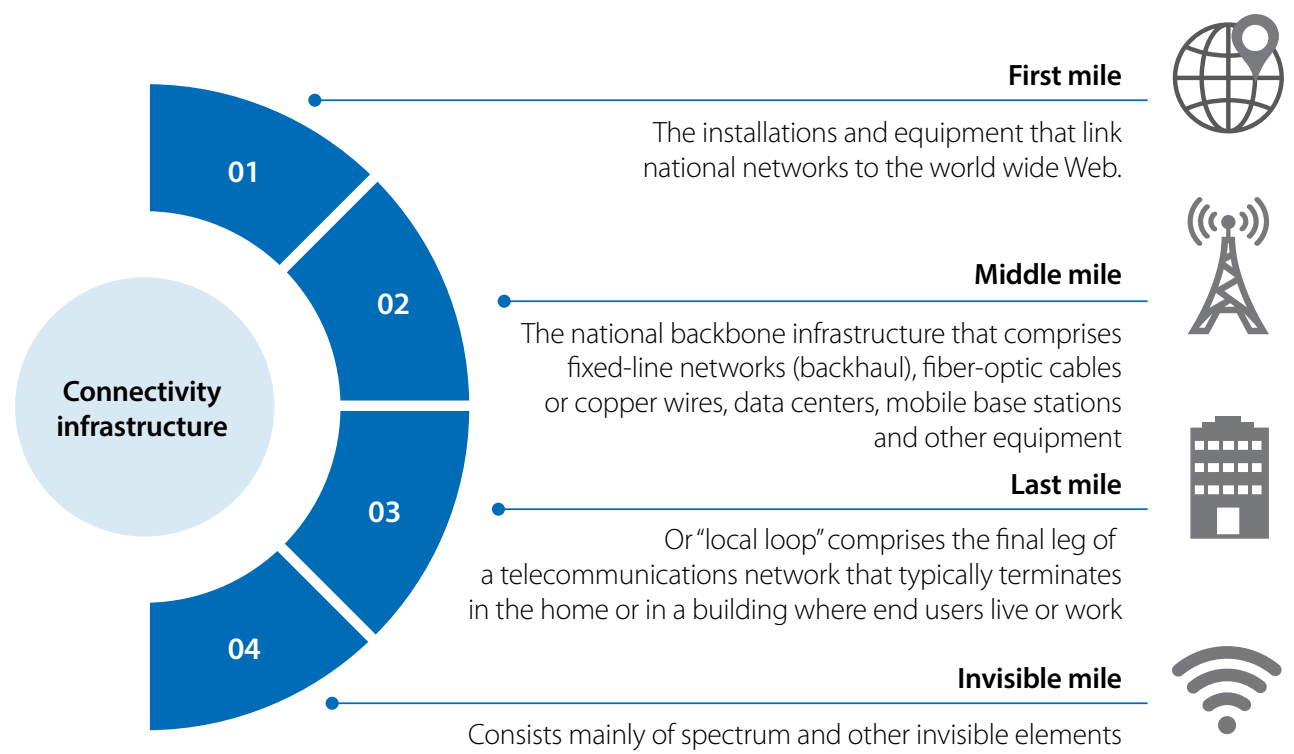

First mile: Regulatory regime governing the acquisition and operation of satellite dishes and the competitive conditions that apply to international gateways and landing stations will dictate the degree of interest that private sector actors will have in deploying and managing this critical infrastructure.

Middle mile: The balance struck by the independent regulator between ensuring competition and adequate financial returns on operating infrastructure is critical. Other policy instruments to increase infrastructure investment include subsidies, co-financing arrangements and reducing the cost of importing equipment and components (import tariffs and other trade costs). Governments can also mandate by law the laying of optical fibre at the same time as other infrastructure (e.g. pipelines and roads).

Last mile: Government intervention to promote inter-modal competition over the same infrastructure is an option, as are so-called "fibre-to-the-home" projects to replace antiquated copper wiring, notably for building developers to future-proof their projects.

Invisible mile: How spectrum is governed constitutes the primary lever here, notably ensuring that spectrum pricing makes its exploitation commercially viable, that spectrum access is provided on competitive terms and that essential fixed assets are shared among operators, while finally allowing those who purchase spectrum to resell it without too many restrictions or conditions.

Source: Huawei (2015) "Connecting the Future, Digital Enablement, Bridging the Digital Gap to Connect People and Society" www.huawei.com/minisite/digital-enablement/download/Digital+Enablement_ENGLISH+online.pdf 


\section{CONCLUSIONS}

This chapter has surveyed issues influencing digital connectivity, taking as its starting point the information submitted by developing countries and LDCs, bilateral and multilateral donors, regional organisations, South-South partners and the private sector in response to the OECD-WTO 2017 aid-for-trade monitoring exercise. A picture of concerted action to promote digital connectivity by governments, development partners and the private sector emerges from this information.

The 2017 aid-for-trade monitoring exercise highlights the critical role played by the ITU in efforts to promote digital connectivity. The Connect 2020 agenda (ITU, 2014) and the Broadband Commission have galvanised action from a broad cross-section of actors to bridge the digital divide. A message that also emerges is that efforts to close the digital divide are expanding their focus from supply-side issues (e.g. undersea optical fibre cabling) to examining the demand-side issues that affect digital connectivity (e.g. competition among telecom providers). Here the analysis suggests that ministries of trade, and of trade policy more generally, can play a role in ensuring not just that digital connectivity is available, but also that it is affordable. An enabling regulatory environment is indispensable to ensure that digital connectivity promotes economic opportunity.

There is another issue of concern that emerges from the analysis of the responses to the OECD-WTO 2017 monitoring exercise, which can be termed the "digital trade policy divide". Trade ministries do not appear to be systematically engaged in ICT, nor in digital or other e-government national co-ordination mechanisms. If left unaddressed, this lack of engagement may limit policy action on the demand side. 


\section{REFERENCES}

APEC (2015), APEC Connectivity Blueprint, APEC Policy Support Unit (APEC\#214-SE-01.30) http://publications.apec.org/ publication-detail.php?pub id=1603

Broadband Commission for Sustainable Development (n.d.), Broadband Commission for Sustainable Development, webpage, www.broadbandcommission.org/publications/Pages/default.aspx

Communication from Cuba, Ecuador and Nicaragua (14 July 2011), "Effective Participation of Developing Countries in Electronic Commerce as a Means to Combat Poverty", WT/GC/W/635.

Huawei (2015), "Connecting the Future, Digital Enablement, Bridging the Digital Gap to Connect People and Society" www.huawei.com/minisite/digital-enablement/download/Digital+Enablement ENGLISH+online.pdf

ITU (2011), National e-Strategies for Development: Global Status and Perspectives, International Telecommunications Union, Geneva www.itu.int/ITU-D/cyb/app/docs/National estrategies for development 2010.pdf

ITU (2014, "On the road to implement the Connect 2020 Agenda", International Telecommunications Union, Geneva, www.itu.int/en/connect2020/Documents/pp14-connect2020-commitments.pdf

ITU (2016), "Overview of ITU history", International Telecommunications Union, webpage, www.itu.int/en/history/ Pages/TUsHistory.aspx

ITU (2017), "Connecting the Unconnected; Working together to achieve Connect 2020 Agenda Targets", background paper to the special session of the Broadband Commission and the World Economic Forum at Davos Annual Meeting 2017 http://broadbandcommission.org/Documents/ITU_discussion-paper_Davos2017.pdf

ITU-UNESCO (2015), The State of Broadband 2015, www.broadbandcommission.org/Documents/reports/ bb-annualreport2015.pdf

ITU-UNESCO (2016), The State of Broadband 2016, http://broadbandcommission.org/Documents/reports/ bb-annualreport2016.pdf

ITU-UNOHRLLS (2013), "Enhancing ICT development and connectivity for the Landlocked Developing Countries", Kenya. http://unohrlls.org/custom-content/uploads/2014/04/ITU-OHRLLS-issues-note-and-outcome.pdf

OECD (2015), OECD Digital Economy Outlook 2015, OECD Publishing, Paris. DOl: http://dx.doi.org/10.1787/9789264232440-en

OECD-WTO (2012), Trade in Value-Added: Concepts, Methodologies and Challenges, Organisation for Economic Co-operation and Development, www.oecd.org/sti/ind/49894138.pdf

OECD-WTO (2016), Measuring Digital Trade: Towards a Conceptual Framework, Working paper for Working Party on International Trade in Goods and Trade in Services Statistics, Organization for Economic Co-operation and Development, Paris, www.oecd.org/officialdocuments/publicdisplaydocumentpdf/?cote=STD/CSSP/ WPTGS(2017)3\&docLanguage=En

OECD-WTO (2015), Aid for Trade at a Glance 2015: Reducing Trade Costs for Inclusive, Sustainable Growth, WTO, Geneva/OECD Publishing, Paris. DOI: http://dx.doi.org/10.1787/aid glance-2015-en

Shawn Tan (2015), "The effects of the Internet on Firm Export Behaviour" in World Development Report 2016 "Digital Dividends", World Bank, Washington DC http://www.worldbank.org/en/publication/wdr2016

UNCTAD (2015),"Review of Maritime Transport 2015", United Nations Conference for Trade and Development, UNCTAD/ RMT/2015, Geneva, http://unctad.org/en/pages/PublicationWebflyer.aspx?publicationid=1374 
UNDESA (2016), "Progress towards the Sustainable Development Goals", Report of the Secretary-General, E/2016/75, United Nations Department for Economic and Social Affairs, https://sustainabledevelopment.un.org/sdg9

USAID (2012), "Sara gets the message." Text Plant Profits for Malawi Farmers. www.usaid.gov/news-information/ frontlines/economic-growth/sara-gets-message-texts-plant-profits-malawi-farmers (accessed 28 February 2017).

WEF (2016a), "Internet for All: A Framework for Accelerating Internet Access and Adoption", World Economic Forum, Geneva, www3.weforum.org/docs/WEF Internet for All Framework Accelerating Internet Access Adoption report_2016.pdf

WEF (2016b), "The Fourth Industrial Revolution: what it means, how to respond", World Economic Forum, Geneva, https://www.weforum.org/agenda/2016/01/the-fourth-industrial-revolution-what-it-means-and-how-to-respond/

WEF-BCG (2016), "Internet for All: A Framework for Accelerating Internet Access and Adoption", World Economic Forum in collaboration with the Boston Consulting Group, https://www.weforum.org/reports/ internet-for-all-a-framework-for-accelerating-internet-access-and-adoption

World Bank (2016), "Digital Dividends" World Development Report, Washington DC, http://www.worldbank.org/en/ publication/wdr2016

World Summit on the Information Society (18 November 2005), Tunis Agenda for the Information Society, http://www.itu.int/net/wsis/docs2/tunis/off/6rev1.html

WTO (2015), "Speeding up trade: benefits and challenges of implementing the WTO Trade Facilitation Agreement", World Trade Report 2015, World Trade Organization, Geneva, www.wto.org/english/res e/publications e/wtr15 e.htm WTO (13 June 2016a), "Financial Inclusion and the GATS - Barriers to Financial Inclusion and Trade in Services " Note by the Secretariat, S/FIN/W/88/Add, World Trade Organization, Geneva.

WTO (2016b), Committee on Trade and Development, Thirty-Third Dedicated Session on Small Economies Note on the Meeting of 4 November 2016, Software and Services in Sri Lanka - Presentation by Sri Lanka (Association of Software and Services Companies), WT/COMTD/SE/M/33, https://www.wto.org/english/tratop e/ecom e/wkprog e.htm

WTO (2017), "Sierra Leone, Trade Policy Review, Report by the Secretariat", World Trade Organization, Geneva, WT/TPR/S/303/Rev.1, www.wto.org/english/tratop e/tpr e/tpr e.htm 


\section{NOTES}

1. In the 2015 monitoring and evaluation exercise, none of the questions contained in the donor, South-South and REC/TC questionnaires asked about the mainstreaming of trade facilitation in policy documents.

2. Of particular importance is maritime transport. Around $80 \%$ of global trade by volume, and over $70 \%$ of global trade by value, are carried by sea and are handled by ports worldwide (UNCTAD, 2015).

3. In its input to the aid-for-trade monitoring exercise, Pakistan stated that $11 \%$ of mobile users in Pakistan are using mobile phones for financial transactions.

4. Payment issues with business-to-business transactions and business-to-consumer transactions were cited by 23 developing country government respondents.

5. In addition, the World Summits on the Information Society (WSIS) held in Geneva in 2003 and Tunis in 2005 resulted in declarations that contain relevant objectives. The Geneva Declaration sets out a series of qualitative targets and goals on connectivity, as well as lines of action for government and other stakeholders (http://www. itu.int/net/wsis/docs/geneva/official/poa.html). The Tunis Declaration (http://www.itu.int/net/wsis/docs2/tunis/ off/6rev1.html) focuses on financing and Internet governance. Further to these global declarations, the WSIS process also convened a series of regional summits that resulted in regional targets on digital inclusion.

6. The TBT Committee serves as a WTO forum where members discuss concerns related to standards. The opportunity to raise these and other concerns in an open, multilateral forum offers WTO members an effective way of fostering dialogue and understanding, and of finding ways to use multilateral rules to resolve concerns, thereby helping to reduce potential trade conflicts. This type of cross-border co-operation also helps to identify capacity-related concerns.

7. By establishing compatible domestic IPR systems, the WTO Agreement on Trade-Related Aspects of Intellectual Property Rights (TRIPS Agreement) helps build the legal structure in which the use rights to IP-protected digital products can be traded in the form of IP licences, which in turn shape much of commercial trans-border information flows. The TRIPS Agreement itself provides no specific rules on how its obligations on protection and enforcement of territorial IPRs could best be implemented in a space that transcends national boundaries. However, over more than 20 years since its conclusion, members have developed approaches and solutions to tackle these questions in their national jurisdictions, which in some areas have settled into common practices and are sometimes now reflected in bilateral or regional agreements covering IPRs. The non-discrimination provisions in the TRIPS Agreement ensure that these national or regional solutions regarding IPR protection in the digital sphere are available to nationals from all WTO member countries.

8. Under the current TRIPS transition period regime, least-developed country members are exempt from applying the TRIPS Agreement--except for the non-discrimination principles--until 2021. Hence the LDCs do not need to implement the TRIPS IPR protection standards before that date, while their nationals can already enjoy the TRIPS standards for their intellectual property rights when other WTO members engage in online or offline commercial activity in their jurisdictions--a significant advantage in enabling creative and innovative firms in the LDCs to seek effective access to global markets through e-commerce platforms.

9. The Broadband Commission for Sustainable Development grew out of the Broadband Commission for Digital Development, established in 2010 jointly by the ITU and UNESCO. 
10. E-ASEAN Framework Agreement 2000; South African Development Cooperation (SADC) Declaration on Information and Telecommunications Technology 2001; SADC Regional Infrastructure Development Master Plan 2012; South Asian Sub-regional Economic Cooperation ICT Masterplan 2006; Pacific Regional ICT Strategic Action Plan (PRISAP) 2015-2020.

11. Ministries of trade were cited explicitly as being present in national co-ordination mechanisms in the selfassessment responses of Botswana, Burkina Faso, Congo, El-Salvador, Pakistan, the Philippines, Rwanda, Sri Lanka, Saint Lucia and Uruguay. 


\title{
CHAPTER 3
}

\section{DIGITAL CONNECTIVITY AND TRADE LOGISTICS - GETTING GOODS SHIPPED, ACROSS THE BORDER AND DELIVERED}

\author{
Contributed by the Organisation for Economic Co-operation and \\ Development and the United Nations Conference on Trade \\ and Development
}

\begin{abstract}
Innovations in the digital economy can reduce the costs of engaging in trade and facilitate the physical delivery of traded goods, making trade potentially more inclusive. This chapter examines the opportunities and challenges brought about by digital connectivity and digital trade along the trading chain. It highlights that digital trade for development requires addressing, in addition to digital connectivity, new and old constraints to market integration and physical connectivity. It underscores the importance of efficient trade logistics services and emphasises the need to co-ordinate investments within regions and across hard and soft infrastructure. It then examines progress in cross-border connectivity and gives an update on the implementation of the WTO Trade Facilitation Agreement. Finally, while many opportunities to reduce trade costs arise from digitalisation, the paper highlights that the ability to adapt to the requirements and characteristics of digital trade flows, can influence the ability to realise the full potential for development.
\end{abstract}




\section{INTRODUCTION}

Trade has long been a driving force of economic growth. New production systems, integration of global value chains and trends toward reliance on just-in-time delivery systems mean that more than ever, trade needs to be faster and more reliable. This calls for increasing the quantity and quality of information exchange.

Digital connectivity and data flows are supported by hard and soft infrastructure, ranging from cables and wires to data flow regulations, which enable trade transactions in two ways:

First, the digitalisation of many logistics services and regulatory border controls increases the efficiency and the ease of doing trade. Data flows facilitate information sharing among the various actors and bodies participating in the trade logistics chain, thereby reducing the co-ordination costs associated with moving goods from production to consumption.

Second, data flows reduce information asymmetry and lower co-ordination and transaction costs. They make it easier for businesses or consumers to connect with potential trade partner, strike a deal, and get information about regulations and standards as well as about consumer preferences. Increased flows of information have tremendously improved access to knowledge about trade opportunities, reducing the cost of entry into the market, in particular for SMEs. Moreover, goods and services can increasingly be purchased or delivered through digital platforms, opening-up whole new areas of opportunity, in particular for some services that were previously non-tradable.

This chapter discusses how digital connectivity and data flows support the physical delivery of traded goods and services. The opportunities created by digital trade, and in particular the digital delivery of goods and services, are increasing and the process of engaging in trade increasingly involves data flows. Yet trade in goods is still very much a physical process, in particular for items produced in developing countries. This means that while digitalisation provides the opportunity to connect with new trade partners, transforming those opportunities into trade still requires reducing the cost of physically moving goods across (customs efficiency) and behind (trade logistic services efficiency) borders.

Data flows and digitalisation of services, in particular logistics services and regulatory border controls, and innovations in the digital economy can reduce the costs of physical delivery, enabling previously remote areas or small producers and buyers to participate in trade. Across borders, they can support efficient customs services and the implementation of the WTO Trade Facilitation Agreement. Behind the border they can decrease the cost of moving goods by reducing the cost of co-ordination among the various support services needed to make trade happen, from transport to insurance.

However, while digital connectivity can provide new opportunities for developing countries to participate in international trade, traditional trade costs related to physical connectivity can still represent a significant barrier to the physical delivery of goods. In addition, digital trade-and in particular e-commerce (encompassing the physical delivery of goods digitally purchased) — changes how and what is traded (OECD, forthcoming). Customs authorities are faced with an increasing influx of small parcels and low value shipments, requiring different handling than large and bulk shipments. In addition to the additional workload, this increase in trade in small parcels can raise questions about the impact and relevance of de minimis thresholds. It can also challenge the capacity of customs authorities to monitor the compliance of traded goods with standards, including, for instance, safety norms for manufactured products, or sanitary and phytosanitary (SPS) measures for agriculture and food products, as well as intellectual property regulations.

The first section of this chapter discusses the importance of traditional physical connectivity to unlock the opportunities created by digitalisation and digital trade. It looks at connectivity behind the border, in particular the importance of efficient maritime and air connectivity, emphasising the importance of co-ordinating investments within regions 
and across hard and soft infrastructure for the reduction of trade costs. It then investigates progress on cross-border connectivity, giving an update on the implementation of the WTO Trade Facilitation Agreement and emphasising the challenges for developing countries. The second section focuses more specifically on new opportunities and challenges from digital connectivity and digital trade. It highlights the opportunities offered by data flows and digitalisation for more efficient cross-border operations and logistics chains. However, these opportunities can be challenged by digital connectivity constraints, as well as by lack of capacity on behalf customs authorities and logistics services to adapt to the new ways of doing trade.

\section{TRADITIONAL CONNECTIVITY MATTERS FOR DIGITAL TRADE}

While digitalisation has revolutionised trade in services by making it easier to supply services over a distanceincluding across borders - the physical delivery of goods and services still depends on physical connectivity, including transport networks, intermodal connections, and functioning markets for transport services. This aspect of connectivity entails important bottlenecks, especially in developing countries and the LDCs, with particular challenges for small island developing states (SIDS) and landlocked developing countries (LLDCs). Many LLDCs are in Africa; for them, trade flows and costs depend not only on the efficiency of their own customs and other border agencies, but also on those of neighbouring transit countries. Collier (2008) called this situation the "landlocked with bad neighbours trap". The physical movement of goods is often impaired by poor supply and quality of hard infrastructure which, in addition to difficult regulatory environments and inefficient logistics services, results in a lack of trust in the logistics chain. The following sections goes back to new data and evidence on trade costs, and focuses on both behind-the-border and across-the-border issues, highlighting that traditional connectivity challenges still matter, and might actually be increasingly important in a digital world.

\section{Getting goods shipped and delivered involves many behind-the-border issues}

Lead firms in digital trade (in particular digitally enabled purchasers of goods) are well aware of traditional connectivity constraints to their businesses. While digital trade reduces fixed transaction costs (e.g. the cost of searching for and screening trading partners), the negotiation and implementation of a contract, and its monitoring and execution, it might not reduce transport costs. Small businesses face difficulties organising and negotiating prices for their trade logistics. Weight to value still matters and it might be difficult for logistics service providers to supply transport services for small quantities to remote areas, simply because it is not profitable. Such constraints can be a barrier to the benefits of inclusion offered by digital trade. That said, innovations allowed by data flows can also reduce the cost of physical delivery to remote areas.

Global trade involves certain transport-related and other transaction costs that, while unavoidable, are in practice often higher than necessary due to unnecessarily bureaucratic trade procedures and documentation requirements. Trade facilitation has tremendously reduced trade costs at the border. However, trade costs relating to the efficiency of trade logistics services have gained in importance.

The following sections focuses on these behind-the-border issues, highlighting that 1) traditional connectivity challenges still matter, and might actually be increasingly important in a digital world; and 2) digitalisation and new ways of organising trade pose both challenges and opportunities for connectivity and market access. 


\section{Transport costs: paying for physical connectivity}

International transport costs are a key component of trade costs. Recent research in Asia and the Pacific suggests that tariffs account for less than $10 \%$ of bilateral trade costs, while other policy-related trade costs (i.e., of a non-tariff nature) account for $60-90 \%$ of bilateral trade costs. In other words, transport costs, maritime connectivity and procedures have a stronger bearing on trade costs than customs duties (ESCAP 2015). Policy makers and shippers have an interest in understanding the determinants of international transport costs. Being able to explain the differences in the prices traders pay for the international transport of merchandise can help identify possible areas for intervention. Extensive research has helped identify the main determinants of freight costs (ECLAC, 2002; Sourdin and Pomfret, 2012; Cullinane et al., 2012; Wilmsmeier, 2014).

\section{Figure 3.1. Freight and insurance costs as a percentage of the value of imports, ten-year moving averages within country groups, 1989-2016}

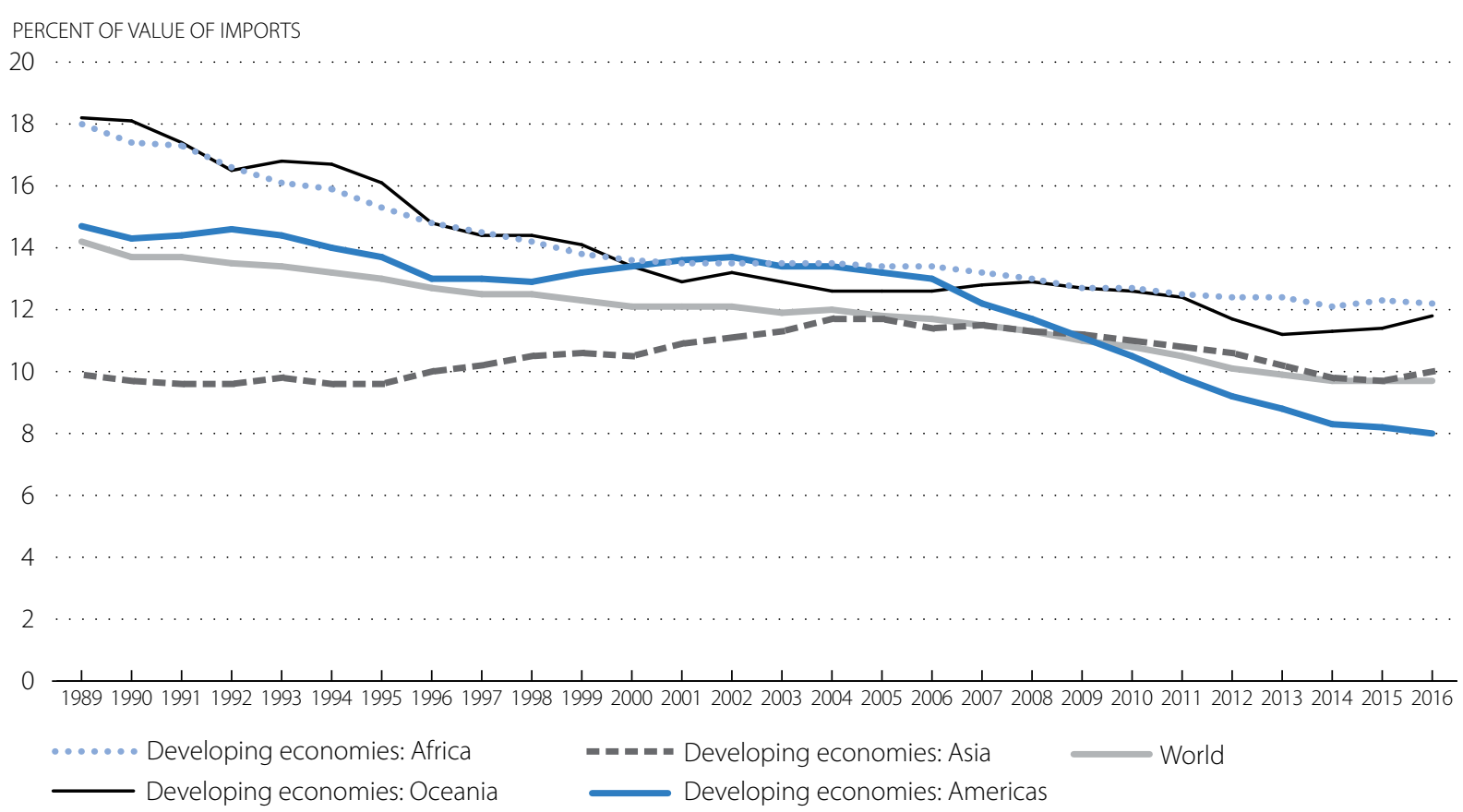

Note: Averages within the country groups are un-weighted, i.e. each country's freight ratio is assigned the same weight when calculating the average. Data is for all modes of transport, representing the cost of international transport and insurance as a percentage of the CIF value (cost, insurance, freight) of the imported goods.

Source: UNCTAD.

StatLink -iाIs http://dx.doi.org/10.1787/888933525683

Based on data on merchandise imports, UNCTAD has estimated expenditures for international transport and insurance (all modes) by country group (Figure 3.1). On average, these costs amounted to approximately $9.7 \%$ of the total value of imports during the decade 2007-16. Among the main regional groupings, African countries have the highest freight costs, averaging 12.2\% in 2016 compared to 8\% for developing countries in the Americas. In addition, many countries in Africa and Oceania report low scores in Doing Business or the Logistics Performance Index (although those figures are also influenced by the composition of imports) (World Bank, 2016; 2017). While transport costs are effectively higher in African and Oceania, they appear to be even more important in proportion to the value of imported goods in the countries in those regions; on average, these countries tend to import relatively lower-value types of manufactured goods than developed economies. In other words, the cars, clothes or tools imported into Africa are of lower value per unit, on average, than those imported into Europe or North America. Therefore, the cost of transport represents a higher share of the import value. 
Overall, analyses suggest that developing countries, especially in Africa and Oceania and including many SIDS and LLDCs, pay more for their transport connectivity than developed countries. The main reasons are to be found in these regions' trade imbalances, as well as their lower trade volumes and shipping connectivity. There is potential for policy makers to help remedy this situation through investment, as well as port and trade facilitation reforms, especially in the regions' seaports, transit systems and customs administrations.

Broadly speaking, connectivity relies on various dimensions that can be grouped into three categories: geography, infrastructure and cost-effectiveness (including marginal costs and weight-to-value issues). Many African and Oceanian developing countries are confronted with transport infrastructure bottlenecks. The largest ships that can be accommodated in most of ports in these two regions are far smaller than those that call at ports in other regions. This, along with the fact that private sector participation through concessions is less frequent in Africa and Oceania, contributes to higher transport costs. Also many developing economies, in particular in Africa and Oceania, are particularly negatively affected by their geographical position--far away from most major shipping routes. Because of the distance to large markets and the relatively small size of domestic markets, it is difficult for logistics services to cover their costs when supplying these economies.

The SIDS in Oceania, as well as several smaller Africa economies, have relatively small markets. Because of merchandise trade deficits, ships delivering cargo in Africa and Oceania are likely to arrive fully loaded, but to have spare capacity when returning to Europe, Japan or China. Freight rates for imports thus tend to be higher than freight rates for exports, as transporters make the exporters pay for the losses incurred on the return journey. Although comprehensive data is not available, and available data, as presented in Figure 3.1 only reflects imports, anecdotal evidence suggests that freight rates for exports are indeed lower than those for imports in most countries in Africa and Oceania. As a result, shippers may be confronted with oligopolistic markets, where low levels of competition can lead to higher prices. In this context, it would be a mistake to try to further restrict competition by, for example, introducing national or international cargo reservation regimes.

There is also a clear case for policy makers and port authorities to strengthen transnational co-operation in order to promote the development of efficient systems than can help to prevent regions or countries from becoming peripheral and uncompetitive. While not much can be done about a country's geographical position, there are some policy options that can reduce costs, for example by improving port infrastructure and increasing efficiency in the logistics chain, including through trade and transport facilitation; more efficient port operations; or measures to make a port more attractive as a port of call. This would entail more port investments, trade and transport service liberalisation, and economic reforms to strengthen industry output and trade relations.

Some solutions also exist to increase the efficiency of infrastructure investments, in particular at the regional level. Increasing a country's connectivity does not require making it a regional gateway with immediate connection to main shipping routes and large infrastructure. Isolation can be considerably reduced by relying on a hub-and-spoke model at the regional level — with adequately scaled infrastructure investments for both maritime and land connectivity —and drawing on relative regional locational comparative advantages. Such systems, nevertheless, require the development of regional or sub-regional hub ports; they also call for the upgrading of inter-island connectivity and corridors, ensuring efficient cargo handling and other logistics services to enable the reduction of freight costs from the gateway to the final destination. Another option to be considered is the promotion of infrastructure networks based on regional/subregional hub ports that can be serviced by larger vessels, corridors and networks of rural feeder roads, with appropriate inter-modal connectivity and efficient logistics services. In Africa, a number of countries have been able to benefit from their geographical position by offering trans-shipment services. Egypt, for example, benefits from the traffic passing through the Suez Canal; and Morocco and Mauritius have both established important hub ports. Many other African countries, however, are relatively far away from the major East-West shipping routes. 
While regional solutions are promising, they are not without issues. A range of vested interests and other politicaleconomy considerations, related to both hard and soft infrastructure, can make the implementation of regional models difficult. These considerations include the appropriation of benefits by a country benefiting from his neighbour's investment in hard infrastructure; ; the appropriation of benefits by intermediaries and the need to ensure competition in logistics services; and finally a range of issues relating more broadly to non-tariff measures (Jouanjean et al, 2016).

The following sections explore relative connectivity constraints for two modes of transport: maritime and air.

\section{Maritime connectivity accounts for the lion's share of international trade}

Containerisation has been one of the most significant innovations in trade logistics, with a greater impact on trade growth than trade liberalisation (Bernhofen et al., 2012). Yet some of the benefits of containerisation are lost if trade facilitation shortcomings, such as the breaking of seals or reloading of content, interrupts their movement.

Maritime trade is estimated to account for $80 \%$ of the volume and $70 \%$ of the value of international trade; on average, these shares are higher for developing countries (UNCTAD 2016b). Manufactured goods are mostly transported in standardised containers through a global network of regular liner shipping services. This enables small and large importers and exporters of finished and intermediate "containerisable" goods from relatively remote countries to trade with each other, even if their individual trade transactions would not economically justify chartering a ship. Thanks to regular container shipping services and transhipment operations in hub ports, today basically all coastal countries are connected to each other (Hoffmann 2012).

Countries or ports that manage to become transhipment centres benefit in two ways. First, they generate additional income for their own port service providers. Second, their domestic importers and exporters benefit from improved connectivity, i.e. from more frequent and less costly services from and to overseas markets and providers. It would, however, not be realistic for every country to become a transhipment hub; the deployment of carriers is volatile, and there is a risk of overinvestment and overcapacity if all countries try to concentrate cargo in their own ports. The efficiency of hub-and-spoke systems relies on negotiations and long-term strategies at the regional level, which often face political economy hurdles. More analysis is necessary to underscore the benefits "spoke" countries perceive from their neighbours' investments in infrastructure.

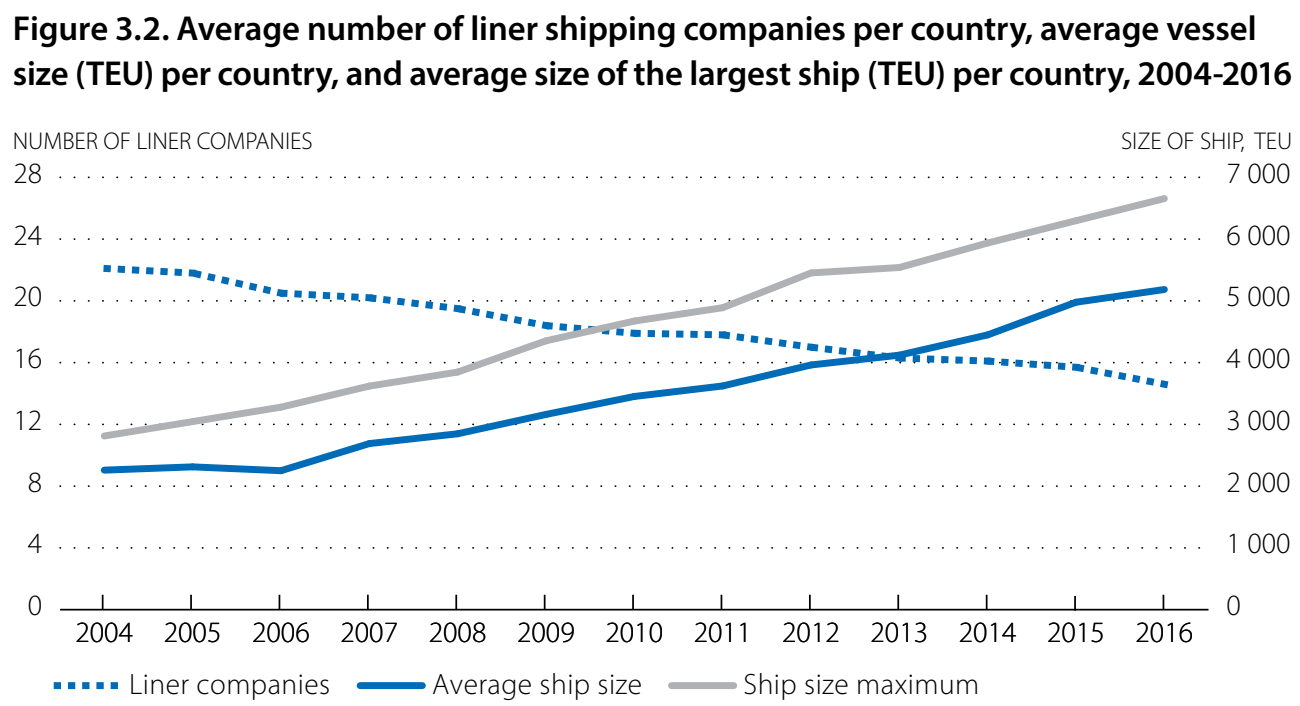

Note: TEU = twenty-foot equivalent units. Data represents averages per country of vessel deployment in 160 countries. Source: UNCTAD (2016b) Review of Maritime Transport 2016 
The Liner Shipping Connectivity Index (LSCI) indicates the overall position of a country within global container shipping networks (UNCTAD, 2016b). As of May 2016, the best connected countries in East Asia are China and the Republic of Korea; Singapore and Malaysia have the highest LSCI in South East Asia; Sri Lanka and India in South Asia; Morocco, Egypt and South Africa in Africa; and Panama and Colombia in Latin America and the Caribbean.1 All of these countries are hubs in their regions. While the average LSCI has increased continuously since the index was first generated in 2004, several countries do not appear to have improved their liner shipping connectivity over the past decade.

Overall, the LSCI underscores the positive impact of containerisation on maritime connectivity. At the same time, however, there appears to be a consolidation in the industry, with container ship sizes increasing while the number of companies providing services from and to the average country's seaports is going down. This decrease in competition is problematic for port authorities, shippers and intermodal transport providers; it poses particular challenges for smaller trading economies, which already experience low levels of competition. The number of carriers competing for the average country's cargo declined by 34\% over 12 years - from an average 21.1 companies in 2004 to 14.6 companies in 2016. While this last number of companies per country should suffice to guarantee a competitive market, the average hides a growing number of countries where there are only a few providers offering container services, leading to potentially oligopolistic markets. In 2004, 44 countries had five or fewer providers, compared to 56 in 2016 -an increase of $27 \%$. During the same period, the number of countries with only one provider doubled, from five countries in 2004 to ten countries in 2016. Finally, the industry is also suffering from massive overcapacity.

For countries willing to increase their maritime connectivity, evidence suggests that three main policy areas can help in improving their $\mathrm{LSCl}$, in particular if they want to position themselves as hubs in their regions:

The first is the size of the market served by the gateway port, the hinterland. Expanding the market for the port's services requires facilitating international trade and transit to ease access by neighbouring countries to the port. In West Africa, for example, the ports of Benin, Côte d'Ivoire, Ghana, Nigeria and Togo all compete for cargo from neighbouring landlocked countries. Inland transport is expensive, however, and cumbersome border-crossing procedures, combined with road blocks, make it difficult to expand the hinterland. Therefore, one way to improve the shipping connectivity of West African countries would be to improve their intermodal inland transport and trade connectivity. The application of collaborative tools, trade and transit facilitation measures, and the latest technologies can help. Positive examples include programmes by regional initiatives such as TradeMark East Africa, in the East African Community, and the Borderless Alliance in Western Africa. However, the existence of too many gateways in the same region reduces the size of the market served by each, lowering returns on investments.

The second area is the trade logistics market in the gateway country needs to be competitive. Ideally, shippers should be able to choose among various terminals, as well as trucking and shipping companies. Any restriction on transport services, such as cargo reservation regimes for trucking, or cabotage restrictions in shipping, leads to lower maritime connectivity.

Finally, the third area is efficient and modern seaports, with physical infrastructure capable of accommodating ever larger vessels, the necessary water depth and ship-to-shore container handling cranes. Modern port operations and customs also help to avoid delays and uncertainties, which in turn improves transport connectivity. 


\section{Air transport has an increasing role in global value chains}

Air transport connectivity differs from maritime connectivity in many ways. First, air transport is characterised by pointto-point transport services as compared to liner shipping, whereby a ship may call at a number of countries and ports along a route, with cargo being frequently transhipped. A second difference is the combination of cargo and passenger services, with an important share of air cargo being moved along with passengers. This is rarely the case for sea shipping, mostly because today passengers rarely use vessels for long distance journeys, or if they do it is in very different circumstances. Finally, distance has a far stronger bearing on air transport costs, with higher fuel per tonne-km ratio. As a result, air connectivity is more dependent on the distance to market, while for maritime connectivity the geographic position of the port as well as economies of scale, play a relatively larger role.

However, with the internationalisation of production and the increasing importance of just-in-time models, as well as the evolution of cargo generated by digital trade, air connectivity is increasingly important for countries' participation in global value chains, especially for the transport of high-value intermediate goods.

The air connectivity index (ACl) is a tool developed by the World Bank to measure a country's integration into the global air transport network. Shepherd (2016) finds that air connectivity is very positively associated with the total value of trade. As an indicative order of magnitude, a $1 \%$ increase in a country's ACl is associated with a $6.3 \%$ increase in total exports and imports. Moreover, air connectivity is very positively associated with global value chain participation. A one point increase in the $\mathrm{ACl}$ is associated with a $2.9 \%$ increase in global value chain participation. Overall, countries that perform particularly well on air connectivity tend to perform very well on global value chain connectivity metrics. Industry makes extensive use of air cargo linkages whenever possible and the sectors that appear to benefit vary considerably in terms of sophistication and capital intensity, from textiles and clothing to electrical goods and pharmaceuticals.

Once again, regulation matters for the optimisation of air connectivity, which requires a strong supporting framework (ICAO, 2017). This includes, among other things, market access (e.g. liberalisation), optimal air navigation services, aircraft, airport systems, facilitation and security, inter-modality and airline activities.

Whether in maritime or air transport, more investments are necessary for developing counties to increase their connectivity. Beyond investments in hard infrastructure, more needs to be done to support the efficiency of trade logistics services, and in particular to ensure that bottlenecks in this area do not act as weak links in the value chain. For example, maritime connectivity requires efficient hinterland services; spill-overs should be taken into account to maximise the benefits from infrastructure investments. Avoiding bottlenecks, in particular for land-locked countries, and maximising returns on investments also requires co-ordination among neighbouring countries, not only on hard infrastructure but also on the regulatory environment for trade logistics services. Digitalisation can reduce the cost of such co-ordination and support better linkages between transport modes and countries' logistics services.

\section{IMPLEMENTING THE TRADE FACILITATION AGREEMENT FOR CROSS-BORDER CONNECTIVITY}

Inefficient procedures at the border represent an important source of trade costs along the value chain, increasing poorly connected countries' remoteness from neighbouring and international markets. For example, it has been estimated that in Central and Eastern Africa, on average, crossing a border with maize, rice or sorghum has the same effect on relative prices as travelling 518 hours between towns in the same country (Brenton et al., 2013).

Developing countries are no longer simply providers of raw materials; they increasingly participate in global value chains, importing raw materials and intermediate goods to produce manufactured goods for export. This is evidenced by the fact that the share of developing countries in the total global volume of seaborne imports is estimated to have more than tripled since 1970 (UNCTAD, 2016b). Crossing one border is already burdensome; factors such as the internationalisation of production processes and geography (e.g. the constraints faced by landlocked countries, many of which are developing economies, in accessing gateways to regional and international markets) increase the number of times borders are crossed along production chains before the final goods reach consumers. 
Helping goods cross borders efficiently, in particular in a world of internationalised production processes, is broadly recognised by the trade community as a priority and is now firmly on the global trade agenda with the entry into force of the WTO Trade Facilitation Agreement (TFA) in February 2017. Trade facilitation measures have the potential to reduce the time, cost and uncertainty involved in importing and exporting. They improve the day-to-day operations and processes of international production networks and, in more exceptional cases, assist in things such as the rapid delivery of emergency relief goods (Roberts and Mohammed, 2017).

The objective of the TFA is to simplify and harmonise international trade procedures. The agreement contains provisions for expediting the movement, release and clearance of goods, including goods in transit. These provisions have the potential to benefit countries at all stages of development. It is estimated that a complete implementation of the trade facilitation measures arising from the WTO Agreement could reduce trade cost by $16.5 \%$ for low income countries, 17.4\% for lower middle income countries, 14.6\% for upper middle income countries, and 11.8\% for OECD countries, boosting global growth and leading to significant welfare gains (Moïsé and Sorescu, 2013). UNCTAD (2016a) demonstrates a close statistical association not only between diverse trade facilitation measures and trade competitiveness, but also between trade facilitation implementation and broader development indicators. Case stories collected by the OECD and WTO for the Aid for Trade Global Review 2017 also provide anecdotal evidence about how the trade facilitation measures promote quick gains in reducing trade costs.

The TFA covers a range of trade facilitation measures, grouped under 12 articles. Countries self-assess and declare their capability and readiness to implement each of these measures without assistance (category A notifications). A countryby-country analysis of the number of notifications on the date of the entry-into-force of the TFA shows a close correlation between the implementation levels of different articles of the Agreement and indicators of trade efficiency. While a statistical correlation does not in itself prove causality, the data suggest that implementing Article 7 on customs procedures and Article 10 on formalities has had a stronger bearing on a country's Doing Business Index indicator for trading across borders than, for example, Articles 5 on impartiality and 9 on inland customs transit Figure 3.3).

\section{Figure 3.3. Correlation between trade facilitation implementation, Human Development Index indicators and the Doing Business Index indicator for trading across borders}

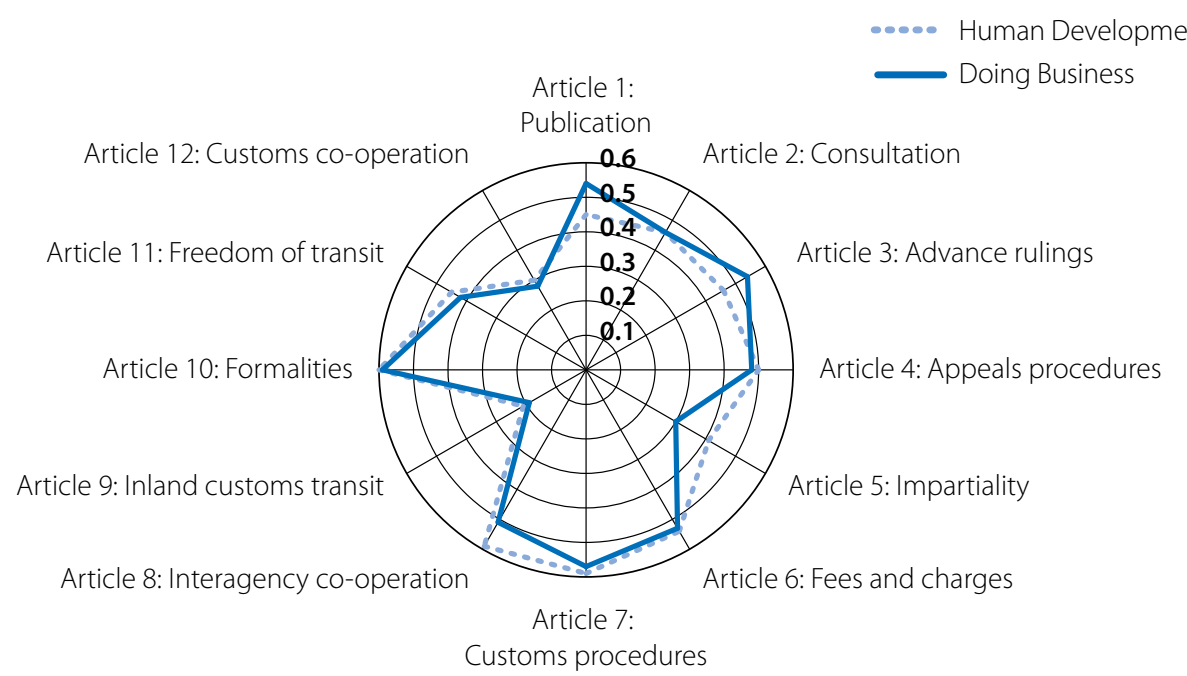

Notes: The values on the axes represent the partial correlation coefficient, which varies between -1 and +1 (in this figure all correlations are positive, and only values between 0 and +1 are shown). A value of +1 implies that the two variables move together at 100\%, while a correlation coefficient of 0 implies that the two variables are not correlated.

Source: Author's calculations, based on individual category A notifications (WTO, 2017), Doing Business Index indicators for trading across borders and the UNDP Human Development Index in 2014.

StatLink 青IS http://dx.doi.org/10.1787/888933525721 
The OECD developed trade facilitation indicators (TFIs) in 2012 as a tool for monitoring and benchmarking country performance. These TFIs are used to analyse the impact of cross-border procedures on various trade and global value chain metrics. The TFIs are not designed to assess the compliance of countries with specificTFA provisions, but only to measure effective trade facilitation endeavours, based on worldwide best practice in the areas covered by the WTO TFA. They offer a snapshot of the state of play on trade facilitation around the world and provide a baseline for monitoring future progress. As such, the TFIs can be used by governments as an instrument for targeting initiatives aimed at reducing trade costs across the border. They also highlight the main advances made by countries, as well as the challenges they need to address, on their paths to implementing measures in areas covered by the Agreement.

The use of the TFls has permitted the identification of various trade facilitation measures that are particularly important for developing country participation in global value chains. This is achieved by comparing specific sets of trade facilitation measures against the level and intensity of a country's integration into global value chains (Moïsé and Sorescu, 2015). The OECD found that a small increase (+0.1) in TFI performance ${ }^{2}$ is associated, on average, with an increase in imports of value added ranging between 1.5\% and 3.5\%; the increases in exports of value added range between 1\% and $3 \%$. More recently, the OECD explored the impact of border processes using a computable general equilibrium model (CGE; Box 3.1).

\section{Box 3.1. Pathways of impact of border processes}

Border procedures impact operations of the supply chain by reducing stock management (which is particularly important for perishable goods), speeding up adaptation to consumer preferences and increasing participation in time-sensitive global value chains. The OECD used its TFIs in a CGE model to better understand and identify the pathways of impact of border processes, and to improve understanding of their potential economy-wide effect.

The results of the modelling exercise underscored the extent to which trade facilitation matters both for exports and imports. On the supply side, reduced costs result from better stock management and the ability to rapidly adjust to consumer preferences. Consumers benefit directly from faster delivery of goods, but also indirectly from smooth intermediate trade flows, which ultimately speed up the delivery of the final goods. Full implementation of the WTO TFA is estimated to have the potential to increase trade flows by $0.6 \%$ and increase GDP by $0.04 \%$ to $0.41 \%$, depending on the country's level of development. A previous estimation of the impact of the WTO TFA on trade costs underscores that reductions in trade costs decrease as country's income levels decrease. The model is able to differentiate effects on trade in intermediates, used as inputs in the importing country, and trade in final goods. The modelling exercise suggests that middle income countries (MICs) are the ones experiencing the strongest growth. Trade in intermediates experiences the strongest growth. Low income countries (LICS) as well as lower middle income countries (LMICs) present a stronger increase in exports than in imports.

Source: OECD (2017a, forthcoming) Economy-wide impacts of trade facilitation: a metro model simulation

The predictability and speed of the movement of goods across borders is important in shaping companies' sourcing decisions. The measures that appear to have the largest influence on imports of value added are, by decreasing order of magnitude: the availability of advance rulings, the streamlining of border procedures and controls, the proportionality and transparency of import and export fees and charges, and the automation of the border process. For exports of value added, the most impactful measures are: the availability of trade-related information, opportunities for dialogue with the trade community, the proportionality and transparency of import and export fees and charges, the automation of the border process, and the streamlining of border procedures and controls.

Regional integration also crucially depends on the facilitation of cross-border transit and trade, and on co-operation between neighbouring countries. The WTO TFA can help regional connectivity without requiring a multitude of regional trade agreements, often called a spaghetti bowl. Benefitting from preferences provided by those regional 
trade agreements often requires the processing of additional paperwork linked to certificates of origin (UNCTAD 2016a). Intra-regional connectivity helps tackle geographical constraints by bringing together many small economies and landlocked countries; intra-regional trade usually grows faster than global trade, and international production networks are often organised by region. It is not just what a country does that matters for its connectivity, but also what its neighbours do. There is a strong positive association between improvements in infrastructure and trade facilitation in neighbouring countries, on the one hand, and greater value chain connectivity at home on the other (Shepherd, 2015).

Aid-for-trade facilitation continues to play a key role in ensuring that partner countries meet their commitments under the WTO TFA, and that they realise trade and development gains. The OECD-WTO 2017 aid-for-trade monitoring exercise confirms that efforts are already under way to implement trade facilitation measures in partner countries. Development partners have provided assistance for initiatives ranging from support for the establishment of national trade facilitation committees to providing hard and soft infrastructure between borders and along corridors. The case stories gathered as part of the monitoring exercise also underscore the importance of regional approaches to measures requiring co-operation among two or more countries, as well as the overall importance of trade facilitation for landlocked developing countries as a means of linking them to their regions, and to global markets. Overall, the aidfor-trade monitoring exercise underscores the priority given by countries to trade facilitation (Figure 3.4).

Figure 3.4. Partner country aid-for-trade priorities

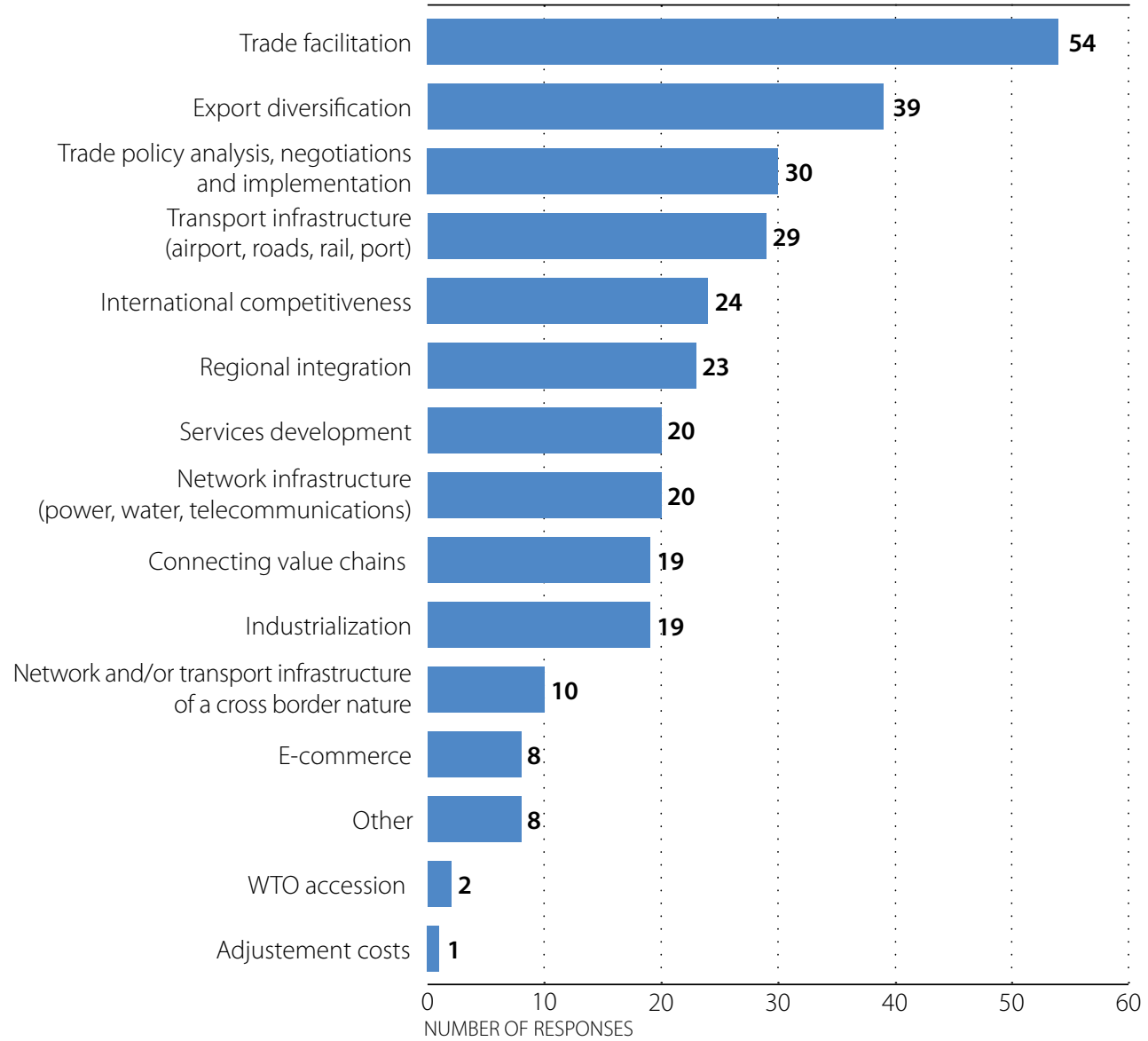

Source: OECD-WTO aid-for-trade monitoring exercise (2017), www.oecd.org/aidfortrade/countryprofiles/. 
The OECD TFIs demonstrate that when the WTO TFA entered into force, implementation of its various substantive provisions already was well under way among all income groups and across regions (Figures 3.5 and 3.6; OECD, 2017b). While there are some differences across countries and regions, as well as among different income groups, worldwide performance on a number of substantive provisions under the TFA is relatively even. Unsurprisingly, implementation of the best-endeavour provisions is more heterogeneous. Many of these provisions are linked to automation, and more generallydigitalisation and data flows, for internal and external border agency co-operation as well as information availability. For these, progress is closely associated with the income level of the country, emphasising the importance of tackling the digital divide for further trade facilitation.

\section{Figure 3.5. A sample snapshot of TFIs in 2017 , by income group}

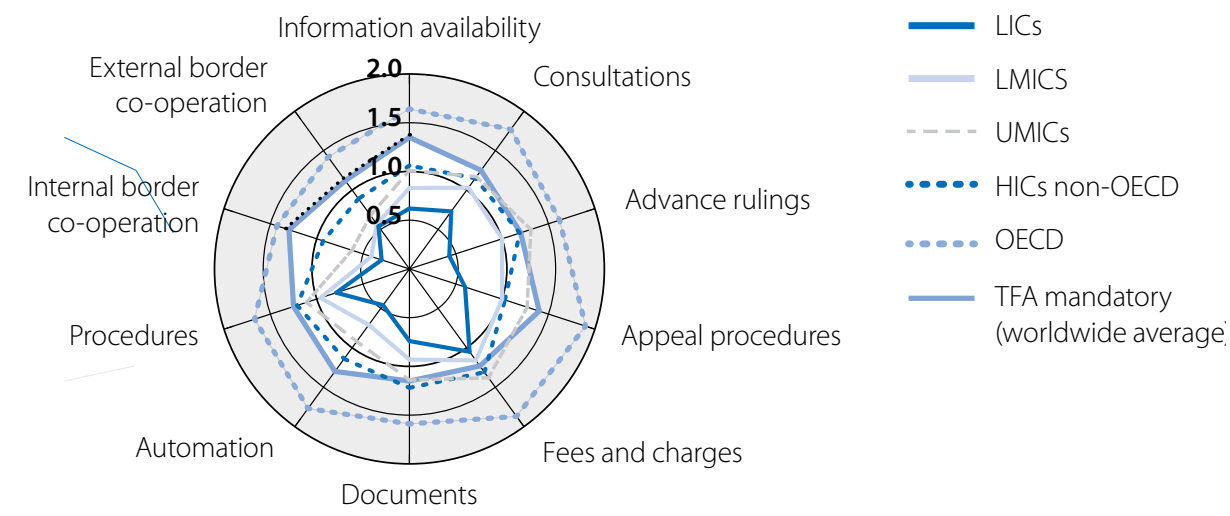

Note: The shaded area depicts measures that go beyond the mandatory provisions of the TFA. The dotted portion of the grey line highlights the fact that all TFA provisions for external border agency co-operation are "best endeavours". Source: OECD (2017c), Trade Facilitation Indicators, www.oecd.org/trade/facilitation/indicators.htm (accessed on 01 February 2017).

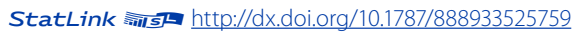

\section{Figure 3.6. A sample snapshot of TFls in 2017 , by regional grouping}

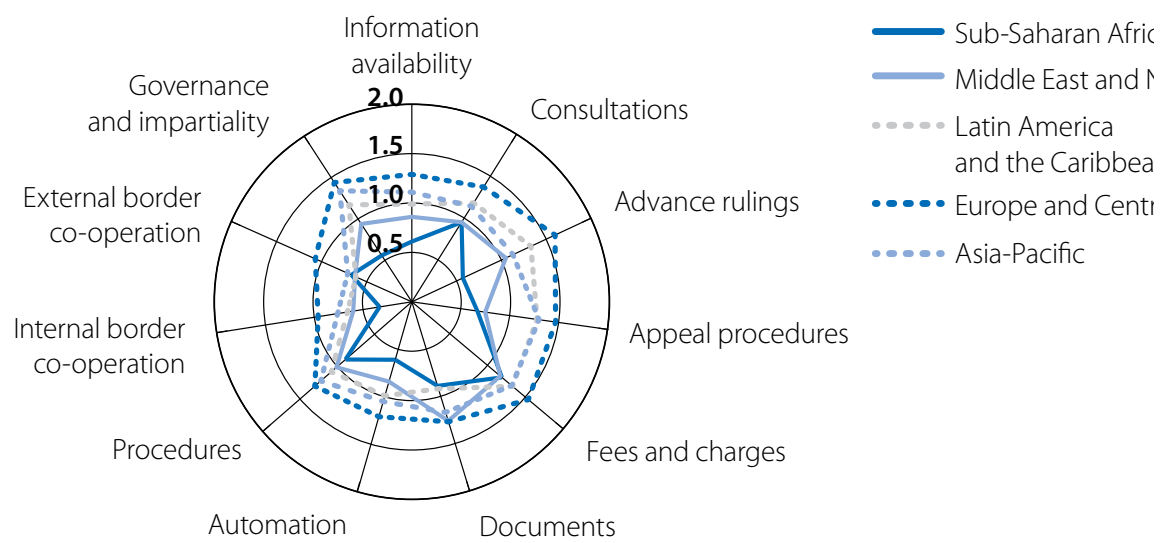

Note: The geographical groupings include OECD members.

Source: OECD (2017c), Trade Facilitation Indicators www.oecd.org/trade/facilitation/indicators.htm (accessed on 01 February 2017) 


\section{NEW OPPORTUNITIES AND CHALLENGES ARISE FROM DIGITALISATION AND DIGITAL TRADE}

Because of digital technologies and digitalisation of processes and information, data are being generated everywhere, and at an exponentially increasing rate, by all actors of the economy. For the movement of goods across borders, this includes government agencies, as well as private actors along the trading chain.

The following section explores new opportunities and challenges arise from digitalisation and digital trade. The two parts focus on the cross-border dimension. First, it looks at how trade facilitation benefits from the new tools made available by technological advances. Measures such as customs automation, electronic documents and single windowsplatforms that enable parties involved in trade and transport to fulfil all import-, export- and transit-related regulatory requirements through a single facility-make all of these steps easier to implement today than when trade facilitation negotiations started at WTO a decade ago. Second, it looks at the challenges created by digital trade for customs authorities. Finally, the third part underscores the benefits and challenges of digitalisation and data flows on trade logistics services.

\section{Data flows and digitalisation contribute to trade facilitation}

Digitalisation can support the reduction of trade costs at the border by increasing the efficiency of customs and transit logistics, thereby reducing costs and supporting the implementation of the WTO TFA. Co-ordination and exchange of data among public and private entities, for instance customs authorities and freight services, can facilitate the implementation of transit agreements, helping to generate returns on investments in technology. Traders investing in the latest technologies expect their counterparts in control agencies to use them. Digitalisation of customs management also helps to increase transparency and thereby reduce opportunities for corruption while limiting uncertainty (OECD-WTO aid-for-trade monitoring exercise 2017, Public sector case story 35).

Case stories from Ghana and Senegal also show how the establishment of electronic single windows has improved their World Bank Doing Business rankings and logistics performance. Senegal was ranked best reformer in Doing Business 2009 and is now among the top ten worldwide. In the framework of South-South partnerships, Senegal offers its expertise and technology transfer to other developing countries, including Kenya and Burkina Faso. The Ghana National Single Window (GNSW) programme enables e-payment of customs duties, reducing the time and costs of import procedures per consignment by 400 hours and USD 50, respectively; Ghana's ranking in the World Bank Trading Across Borders Report has also substantially increased, from 167th place in 2016 to 154th in 2017. Similar improvements were registered in the World Bank Logistics Performance Index, where Ghana rose from 100th place in 2014 to 88th in 2016, the largest improvement since the survey was launched in 2007 (OECD-WTO aid-for-trade monitoring exercise 2017, Public sector case stories 128,135$)$.

In Rwanda, a customs-centred electronic single window system was implemented at a cost of USD 3.3 million. Its highimpact results include a decrease in the time needed to clear goods, from 11 days in 2010 to 34 hours in 2014. The cost of clearance was reduced from 30000 RWF to 4000 RWF in just a one-year period (2013-14). Improved inter-agency co-operation through information sharing was facilitated by the use of UNCTAD's Automated System for Customs Data (ASYCUDA). This, in turn, streamlined work by reducing the need for multiple verifications of the same consignment (TMEA 2015).

The importance of data flows and digitalisation for border management is evidenced by its high position on the agenda of the World Custom Organisation (WCO), which declared "Data Analysis for Effective Border Management" its theme for 2017. The objective is to support initiatives aimed at leveraging the potential of data to help address the concerns and expectations of traders, transport and logistic operators, and governments, with a particular focus on investigating best practices in e-commerce. The WCO has underscored the need to improve the digitalisation of processes, the sharing of information among e-commerce stakeholders, and customs risk management and harmonisation in low-value shipment processes. 
Digitalisation of information paves the way for effective identification of risks. It also allows for management of the large volumes of data that are required by import regulations--for instance SPS regulations; these volumes are increasing with the increase in trade flows. Efficiency in the management of import regulations can be boosted, for example, through the adoption of electronic documents documents (see OECD-WTO aid-for-trade monitoring exercise 2017, Public sector case story 101). Registration of information online and e-certification can speed-up clearance at the border. Border agency co-operation and the creation of single windows to support efficient and transparent cross-border trade require the co-ordinated use of information. The digitalisation of information and inter-operability of documents and systems can help reinforce and lower the cost of border agency co-operation, including the implementation of single windows. This could involve, for example, sharing inspection and control results among agencies involved in the management of cross-border trade and supporting the delegation of control, or the co-ordinated and shared use of infrastructure and equipment at the domestic and cross-border level. While seamless data flows require co-operation among institutions, digitalisation of information and processes can also decrease costs associated with the implementation of inter-agency co-operation itself.

Numerous provisions of the WTO TFA are linked to automation and more generally to digitalisation: risk management, expedited shipments, pre-arrival processing, electronic payment systems and single windows (Figure 3.7). According to the 2017 TFls, risk management is implemented in an automated environment in 35\% of the countries in the sample-mainly UMICs; the rest of the countries (largely LMICs and LICS) either do not have such automated environment or are in the process of implementing them. Information on expedited shipments and associated release procedures shows that for $65 \%$ of the surveyed countries, certain types of goods may benefit from expedited release, depending on specific qualifying criteria (i.e. either goods entering through air cargo facilities or low-value goods).

\section{Figure 3.7. Automation tools in place, by type of tool and by country grouping}

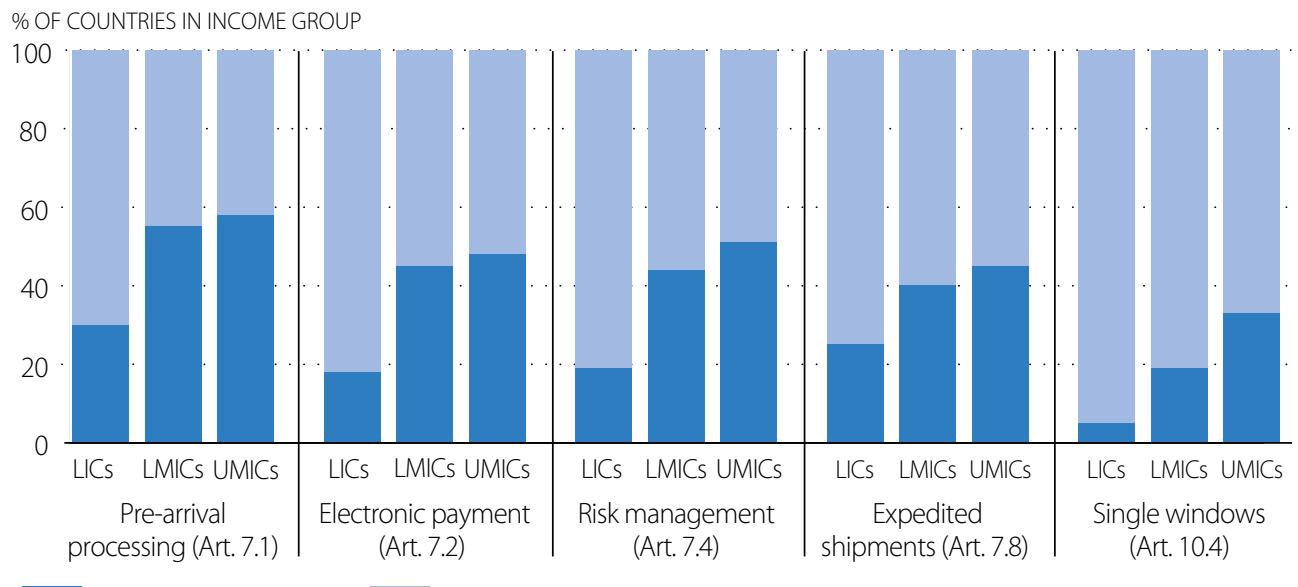

Already implemented Not implemented or in the process of implementation

Source: OECD (2017c), Trade Facilitation Indicators www.oecd.org/trade/facilitation/indicators.htm (accessed on 01 February 2017)

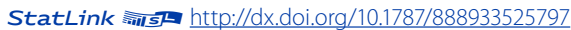

As regards features such as pre-arrival processing and its application in an automated environment, around half of the MICs seem to have systems for the electronic payment of duties, taxes, fees and charges, integrated with an automated declaration/cargo processing system, as well as digital certificates and signatures; implementation of these features remains much lower in the LICs. The most challenging area, as already highlighted by the 2012 and 2015 TFIs, is the set up and operation of single windows. Most information technology (IT) systems in the LMICs' and UMICs' are ready for electronic data interchange (EDI) EDI systems, which are essential for reducing the complexity of document submission. 
In most of the LICS, these systems are still in the process of implementation. Information on the progress achieved on IT and EDI systems, as well as on wide-ranging challenges in the area of border agency co-operation, suggest that the missing link in the development of single windows is the quality of co-operation and information exchange among the numerous government agencies, customs departments, and border control posts (OECD, 2017b).

Cross-border co-operation can be facilitated by the creation of infrastructure, including information and communication technology (ICT) infrastructure, to ensure efficient connectivity among country systems enable information flow, and allow systems to understand each other. Digitalisation of customs documents and information about shipments, however, is not without challenges. For example, the adoption of electronic documents involves the recognition of electronic signatures, standardisation of data exchanges and inter-operability across applications and systems, cybersecurity, and legal validity of electronic documents.

The OECD (2016) has identified key management areas of domestic border agency co-operation and critical for ensuring effective and sustainable cooperation: --communication and information exchange, standardised and efficient communication, and information exchange among the various agencies. A formal agreement among all participating agencies can clarify which information will be shared and with whom, and how the information will be exchanged and traced. An effective early warning system, be it through contact points in individual agencies or using IT solutions, can greatly enhance information exchange efficiency. The domestic co-ordination of inspections is increasingly well understood. On the other hand, co-ordinated or shared risk management mechanisms among agencies involved in the management of cross-border trade, as well as interconnected computer systems and the harmonisation of data requirements, are still work in progress for all LICs and UMICS (Figure 3.8). Finally, the 2017 TFIs show that in developing countries, the co-ordination or harmonisation of computer systems, co-operation in risk management, and the systematic sharing of control results among neighbouring countries at border crossings to improve risk analysis are still at a very early phase (OECD, 2017c).

\section{Figure 3.8. Automation tools for domestic border agency co-operation}

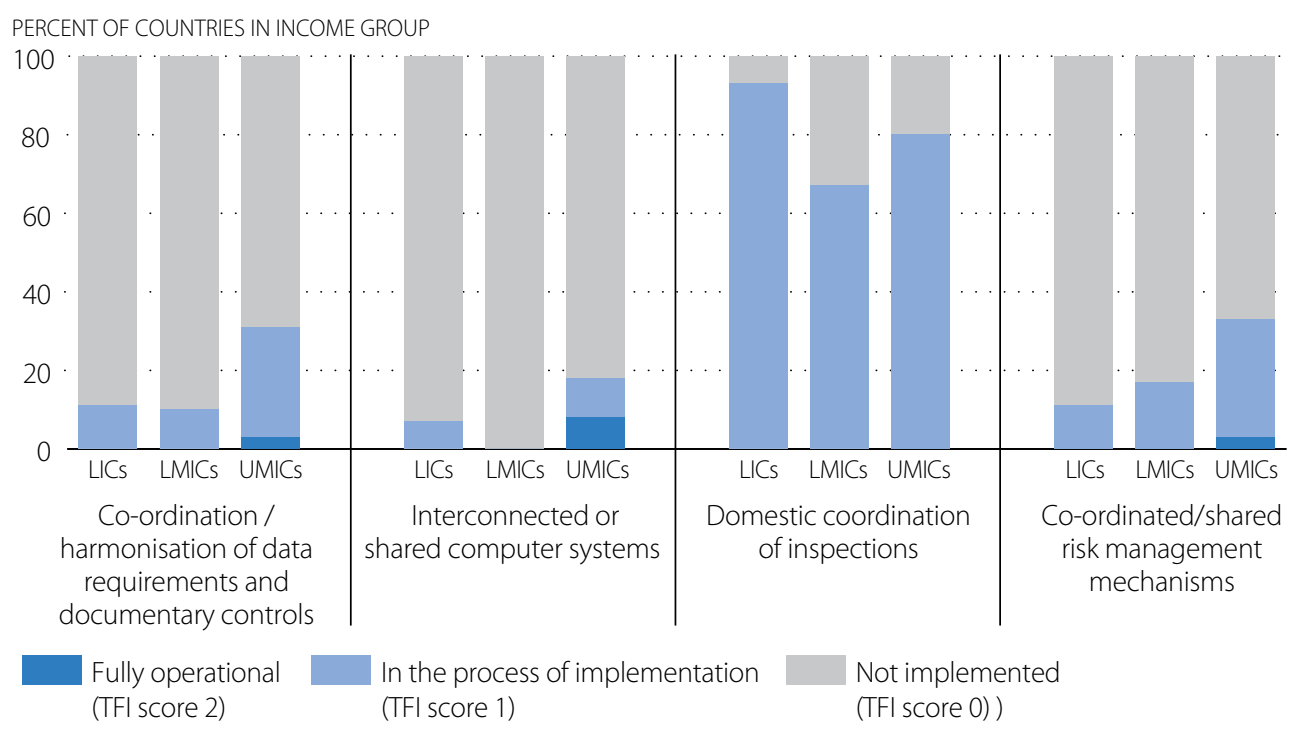

Source: OECD (2017c), Trade Facilitation Indicators www.oecd.org/trade/facilitation/indicators.htm (accessed on 01 February 2017). 
USAID (2012) highlighted the flow of information between customs authorities in the East African Community (EAC) as one of the most important constraints for border crossing through transit corridors. Electronic customs management systems, nationally owned and managed, were not able to communicate seamlessly with each other within the EAC. Moreover, information on goods crossing the border could not be shared with private sector clearing agents in charge of the documentation. As a consequence, information had to be filled out by the transporter at each border crossing, and therefore was only available on arrival; this resulted in errors and prevented agents from initiating administrative processes ahead of a shipment's arrival. More recently, various regional initiatives have been implemented using software solutions that are owned, operated, and maintained by the region's revenue authorities, enabling advance completion of customs declarations and saving hours of transit time at border crossings.

The inter-operability of electronic documentation systems is more easily ensured if, from the outset, the use of international standards is agreed. For instance, countries can adopt United Nations (UN) data and trade document standards and tools, such as those developed by the UN Centre for Trade Facilitation and Electronic Business (UN/CEFACT). These data standards are used extensively throughout the world, facilitating inter-operability and scalability at the national, regional and global levels. UN/CEFACT's EDI standard is the leading global data interchange standard. The exchange of data, for instance on risk profiles, reduces both the number of documents required and the physical control of goods crossing the border. ${ }^{3}$

Finally, transparency, digitalisation of information and automation, and the additional, predictability and simplification of trade procedures have proven efficient in reducing incentives and opportunities for corruption. Transparency allows market participants and stakeholders to better understand the conditions and constraints for entering and operating in a market. Predictability--enabled by the non-discretionary and consistent application of rules--guarantees efficiency and integrity in border agencies. The simplification and streamlining of border procedures diminishes the discretionary power of customs and other border officials, fostering integrity. Automation provides support in harmonising the interpretation and implementation of regulations across all border points (OECD, 2015b).

In Ghana, the GNSW reduces unnecessary human interface in trade transactions, allowing most processes to be undertaken automatically and thereby greatly increasing transparency and reducing the possibility of irregular interventions and payments. Automation of the application and issuance of certificates of origin by the Kenya National Chamber of Commerce and Industry has reduced the average time needed to obtain a certificate of origin from 84 to 12 hours. Also, since traders are no longer required to physically travel to obtain certificates, logistics costs have fallen from USD 75 to USD 17; the reduction in human interaction also has limited the occasions for illicit activities.

\section{New actors and the evolving nature of consignments present challenges for customs authorities and trade facilitation}

While data and information exchange can facilitate the implementation of the TFA, digital trade is also changing traditional trade patterns and potentially create new challenges. Digitalisation is changing some of the traditional determinants of trade. Conventionally, analysis testing the determinants of trade flows (using gravity equations) emphasises the importance of distance as well as historical links and common legal systems. While these are still significant determinants, they decrease in importance as variables explaining digital trade flows values (Austin and Olarreaga, 2012). In particular, the influence of distance decreases drastically with digital trade, while shipping costs and language have a greater impact on cross-border digital trade than on offline trade.

But also, digital trade is changing the "who" and the "how" of trade. The "who" of trade: Digital trade enables the entry of new actors into cross border transactions. Reductions in the costs of entry enable smaller businesses, and even consumers, to participate directly in international trade. While trade was previously a largely business-to-business (or government) operation, digital trade has enabled the direct involvement of consumers in cross-border transactions 
through business to consumer (B2C) and also consumer to consumer (C2C) transactions. Consumers, but also MSMEs, have limited knowledge and experience in regulations, however, and are not well versed in liability issues; they also can be confronted by traditional regulatory barriers at the border. An analysis by the World Economic Forum (WEF), in collaboration with the World Bank and Bain \& Company (WEF, 2013) and using data provided by eBay, highlighted that small businesses seemed to suffer disproportionately from both regulatory and logistical barriers to trade. Understanding and navigating the regulations, policies and procedures governing the export market, as well as the trade logistics chain, entails a high entry cost and upfront investment for small firms, independent of volumes traded. For this reason, merchants selling goods internationally on the eBay platform have a tendency to sell to buyers in countries whose regulations are easier to navigate than the average. This is why various platforms develop projects aimed at supporting MSMEs in navigating the regulatory regimes of importing countries as well as international trade logistics (see OECD-WTO aid-for-trade monitoring exercise 2017, Private sector case story 28).

The "how" of trade: The direct interaction between sellers and buyers on online platforms, bypassing the need for wholesalers that usually trade in bulk, reduces the size of internationally traded shipments. So while digital trade is not necessarily changing the nature of what is traded, it is changing the nature of shipments. The composition of trade flows in relative terms features fewer large or bulk shipments and higher numbers of low-value small shipments. ${ }^{4}$ Small parcels do not always follow the same pathway as large shipments. Moreover, logistics companies reduce costs by consolidating containers, mixing cargos of different types, originating from different sellers, in the same container, resulting in reduced accuracy in terms of the information about each cargo in the container (UNECE, 2011).

In addition, small parcels are more costly to trade. In its input to the OECD-WTO 2017 aid-for-trade monitoring exercise, Paraguay highlights that the high cost of small-parcel shipments, as well as warehousing, storage and packaging difficulties, among the challenges faced by micro, small and medium enterprises (MSMEs) engaging in cross-border e-commerce transactions. To counter this, some of the large digital platforms are providing services to MSMEs selling on their platforms, negotiating freight forwarding contracts on their behalf. Using their position as holders of key information - which allows them to reach scale and reduce logistics costs — online portals such as Amazon and Alibaba are themselves becoming players in the transport of cross-border trade (Transport Intelligence, 2017). Large market place platforms and actors of the express delivery industry are also providing training and various services, such as warehousing services or management of orders, to inform and simplify global operations of small and isolated actors (see OECD-WTO aid-for-trade monitoring exercise 2017, Private sector case stories 88, 98).

These changes in the nature of consignments, and the proliferation of small packages crossing the border via postal or express services, challenge the capacity of customs authorities to monitor the enforcement of standards and trade in counterfeit products using border risk-management strategies.

Customs agencies use informed compliance, risk management and audits to increase the efficiency of cross-border trade while still fulfilling their monitoring mission, and this despite increasing trade flows. ${ }^{5}$ These strategies exploit the increasing amount of data available to customs agencies using a range of new algorithm and data analysis tools ${ }^{6}$ (Jeacocke and Kouwenhoven, 2017). Data analytics has become increasingly important, enabling selective approaches to and techniques for cargo processing. These techniques allow customs agencies to concentrate their resources on checking consignments with the highest risk profiles, and therefore potentially representing a higher probability of noncompliance with domestic standards, or greater health or phytosanitary risks. They also allow compliant exporters to benefit from more efficient border procedures: unnecessary delays are eliminated and the costs of crossing the border are reduced. These selectivity systems not only promote increased efficiency by reducing the number of examinations required, but also increase the discovery of non-compliance and thereby increase trust in the quality of imported goods. Also, the targeting and simplification of procedures offer an opportunity to reduce the discretion of individual officers and limit opportunities for irregular payments. 
However, risk assessment can be difficult to implement for small shipments, which are often used by traffickers of counterfeit products to avoid detection and minimise the risk of seizure by customs authorities. It is also difficult to monitor whether goods comply with standards. For instance, the horticultural industry has expanded globally through the emergence of e-commerce; using an automated search algorithm to survey e-commerce trade on ten major online auction sites, such as eBay, shows that biosecurity is not effectively regulated in the online plant trade (Humair et al., 2015).

This is a particularly important topic for the International Plant Protection Convention (IPPC), which is concerned with the potential impact of e-commerce on the implementation of phytosanitary measures ${ }^{7}$ designed to minimise the risks of contamination with pests and plant diseases when importing plants and plant products into domestic markets (IPPC, 2012). Previously, regulations were primarily geared to managing bulk shipments or consignments of commodities moving through traditional transportation pathways (overland freight, air freight and ocean freight). With digitally enabled trade, plants and plant products are increasingly traded through other pathways, such as postal services, express delivery in small packages or mixed consignments. No traditional risk analysis can be implemented for such packages. They are not separately identifiable from any other parcels, and the plant or plant product traded is often not accurately described and therefore is by-passed by traditional national plant protection screenings. IPPC analysis of websites selling insects, or plants and plant products, highlights that very few provide information about the requirements for import in different countries, or whether or not these restrict shipment to specific locations.

An example of these challenges is provided by Yemen in its input into the OECD-WTO 2017 monitoring exercise (see Yemen contribution to OECD-WTO, 2017). In Yemen, application of regulations on exports depends on the size of the consignment. Digitally enabled trade in goods coming from Yemen usually involves small quantities transported via air shipment using express carriers, and the transactions are considered non-commercial. As a consequence, for the export of one kilo of honey or coffee by air from Yemen, all or most requirements are waived. ${ }^{8}$ Large shipments (more than 20 kilos) face requirements such as export certificates, SPS certificates and certificates of origin-which have become prohibitively expensive. All of this favours trade in small quantities.

Monitoring of small shipments, however, implies additional costs. Without adaptation in how checks are implemented, digitalisation could increase the burden on customs authorities, potentially challenging their capacity to fulfil their mission. The ongoing increase in the quantity of small parcels is also challenging the relevance of de minimis thresholds. In addition to the shifting cost-benefit of collecting duties and taxes, compared to the cost of tracking payment, small parcels can require increased handling, and therefore can represent an additional burden for already stretched customs authorities. De minimis thresholds vary considerably among countries and according to the Global Express Association, in April 2016 some countries did not have any de minimis provision at all (e.g. Bahrain, Costa Rica, El Salvador, Guatemala and Saint Lucia). This means that their customs inspect and collect duties, if applicable, on all arriving packages. In other countries, thresholds are as low as USD 0.33 (the Philippines) or as high as USD 1000 (Azerbaijan, but only for 50 kg noncommercial shipments; for all postal shipments below the threshold it is USD 200 per 20kg). In the European Union (EU), duties are not collected for products below a USD 170 threshold and in the US the threshold is USD 800 (Global express association, 2016).

Further work is needed to explore the role of de minimis provisions in the context of digital trade, and in particular how they shape the decisions of both firms and consumers. Preliminary analysis seems to highlight that increasing the de minimis threshold might not change consumer behaviour, as other parameters matter more to consumers - in particular the quality of the product and the reputation of the trading partner (Hintsa et al., 2014). Raising the de minimis threshold would allow customs administrations to reallocate resources to higher priorities, such as security or illicit trade risks, unless innovative customs processes were to allow for the application of risk management approaches to packages under the threshold. Increased digital connectivity therefore requires not only investment in new types of infrastructure; it also requires thinking about new systems, better adapted to new ways of trading. 


\section{INFORMATION FLOWS ENABLE THE TRADE LOGISTICS CHAIN}

Data flows and digitalisation are not only necessary for trade partners to purchase and order goods or services online; they also underpin co-ordination of international production networks as well as trade logistics. Information is a key resource for trade and global value chains, creating trust, reducing transaction costs and enabling better management of stocks and production processes. Time-related uncertainty, which requires traders to hold inventories or to build redundancies into supply chains, has a cost. Ansòn et al. (2017) find that time and uncertainty are particularly important for the movement of intermediate goods, in other words for international production networks as developed in global value chains. It is, therefore, important for developing countries wishing to bolster their economic development to address issues of time and uncertainty. Being able to access real-time information about the location of a shipment is crucial to the organisation of global value chains. Moreover, the availability of information about products traded, for instance through traceability, increases trust in the quality of the goods exchanged.

Co-ordination is increasing among buyers and sellers in international production networks. However, the physical movement of goods also implies co-ordination among a large range of actors with diverse responsibilities along the trade logistics value chain, requiring different levels of knowledge about the characteristics of the transported goods. The concept of trade logistics was traditionally organised around a division of responsibilities; and with no one actor in the chain, in particular the consignor, taking full responsibility for dispatching the goods, the financial interests of both buyer and seller were protected and the liability of the carrier minimised. Containerisation in the twentieth century revolutionised trade by dramatically reducing transport costs, but it also considerably increased the complexity of coordination. In search of efficiency and cost reduction, the trade logistics chain has increasingly outsourced activities and adopted strategies of consolidated cargos, as well as multi-modal transport chains. In addition, carriers are now transporting goods in sealed containers and rely on the shipper's declaration for the identification of goods.

The idea that electronic information and co-ordination is critical for international trade is not new. Electronic data interchange (EDI) was already starting to be implemented at the beginning of the 1990s (Cuyvers and Janssens, 1992) when it was presented as a key trade facilitation tool (Schware and Kimberley, 1995). EDI is an umbrella term for various methods of automatic electronic transfer of orders, order confirmation and bills. These supply-management tools are based on a co-operative inter-organisational information system, providing electronic exchange of information among trade partners along the entire supply chain, from the original supplier through multiple production and logistics operations to the final consumer. Information about business transactions, such as orders, invoices and feedback about products, is sent directly, computer-to-computer, on private Internet networks. These fully automated systems enable the management of the movement of raw materials, stock and finished goods, organising the flow of information from one end of the supply chain to the other. Various EDI systems exist and most of them are compatible. While EDI systems were rapidly identified as means of speeding up the important functions of international trade, such as securing customs approval for shipments, implementation initially lagged behind in developing countries; it is now increasing.

Despite the increasing amount of information available, however, there is still a general lack of transparency along the trade logistics chain, with large discrepancies in access to information about the movement of goods between the country of origin and the final destination (UNECE, 2011). In a trading world, in which knowledge about product origin has economic value for logistics management as well as for consumers, being able to pass on information together with the traded goods throughout the trading chain can create a competitive advantage. However, information is often passed from one agent to another and can be lost along the way. For example, in order to reduce costs, freight forwarders consolidate shipments to take advantage of all the space available in containers, often called "less than full containers", by mixing consignments from different origins. According to the United Nations Economic Commission for Europe (UNECE, 2011), in doing so, they often provide only summary data to the shippers; the more detailed information about the consignment is lost. More generally, data gaps, asymmetry of information about logistics services and their prices, as well as the use of paper documents make the evaluation of costs uncertain and complicate the evaluation 
of profit margins for firms. This is evidenced by the heterogeneous costs paid by firms at similar border crossings and gateways. Jouanjean et al. (2016) found that clearing costs in the same country could vary markedly at different border crossings, and also according to the type of exporter using the same crossing.

It is not only information about the nature of the transported cargo that matters. Real-time information about the location and status of the shipment is equally important for all actors along the trading chain, and in particular for transit systems and mandatory transit support services, such as insurance. Yet customs authorities and logistics services alike face numerous inter-operability issues that constrain the flow of such information among actors in the chain. Reliable information systems can considerably reduce the costs of transit, not only through expedited border crossing and better management of reporting regarding the movement of transit vehicles, but also by potentially reducing the risks of fraud and thereby reducing insurance costs.

While containerisation has reduced trade costs, it also has resulted in an increase in the loss of container goods due to theft, piracy, accidents and damage (Miler R.K., 2015). This is a problem not only for the seller and buyer, but also for customs authorities; in order to allow for a clear attribution of customs duties, customs authorities need to know whether cargo has left the country through which it is transiting. Importers expect reductions in transit risks to result in a decrease in additional costs and insurance premiums, thereby increasing the overall competitiveness of the trade logistics chain.

Various transit management systems allow customs officers to record the passage of cargo at borders (UNECE, 2013), providing revenue authorities with information on the last border crossed by a specific cargo as well as the current country location. Such integrated systems help eliminate off-loading of undeclared goods and the need for physical escort and monitoring of sensitive cargo, such as batteries, fuel and cigarettes. The OECD/WTO case story 79 mentions how Ugandan cargo owners would frequently lose their goods in transit unless they employed physical police escort at a cost of USD 250 per day. In Rwanda, physical escorts are estimated to increase transit time from one day to three to four days, resulting in an estimated increase in transport costs of about USD 400-500 (The New Times, 2017).

Countries in the Eastern African Community (EAC) have been using electronic cargo tracking systems for real-time tracking of shipments for several years (OECD-WTO aid-for-trade monitoring exercise 2017, Public sector case story 79). However, each country implemented its own tracking system and the resulting multiple stand-alone tracking systems and platforms along the corridors in the region made it necessary for trucks or containers to be equipped with systems for all countries crossed or served. Recently, the revenue authorities of Kenya, Rwanda, and Uganda joined in commissioning the Regional Electronic Cargo Tracking System (RECTS), which will consolidate the three countries' systems and enable them to jointly track cargo from port to destination (TMEA, 2017).

Stricter traceability requirements have not only increased the need to track the location of a cargo; they also make it necessary to maintain a data thread along the value chain. Data flows accompany the production and exchange of goods and services every step of the way. Re-creating information lost along the chain, such as the name and address of the producer or information about handling, is costly and time consuming, if not impossible. Complete data threads increase transparency in the value chain and can enable market access for particularly sensitive sectors, for instance agriculture and food chains and, in particular, livestock, dairy and meat trading.

Nonetheless, digitalisation is not only a way to increase transparency in the trade logistics chain. The reduction in transaction costs enabled by digitalisation can support the participation of smaller actors in the market. Many analyses have documented, for example the detrimental effect low competition and cartels have on logistics in Africa, in particular for trucks. However, low population density, vast geographical spread, and limited investment and productivity mean that reaching producers effectively is extremely costly. The supply of logistics services in low-production areas is characterised by high levels of risk and low returns, and trade logistics service providers might find it difficult to cover their marginal costs. The resulting limited supply of services to producers, and the high costs of reaching local markets, weigh 
heavily on profits and therefore on decision to participate—or not—in the market (Teravaninthorn and Raballand, 2008; Engel and Jouanjean, 2015; Jouanjean et al, 2016). The increased use of mobile phones across East Africa presents new opportunities to overcome these issues through the development of trading platforms that can help to better organise the logistics underpinning market access and reduce the associated price.

Digital technologies and related innovations can be a first step toward the integration of smallholders or pastoralists into modern value chains. The process of modernising agriculture and food value chains entails increasing organisation and co-ordination among stakeholders, as well as a degree of institutionalisation (Box 3.2). In particular, it requires the standardisation of the quality and safety--and often traceability--of products to allow for the reduction of transaction costs along the value chain, as well as to meet consumer demands. From the producer side, access to information, as well as enforcement mechanisms and infrastructure, are equally important to guarantee the quality and safety required in the modern food chain. From the buying side, traders need to have access to information about production processes and this information needs to follow the product all the way to consumers in case of traceability requirements.

\section{Box 3.2. Data exchange in agriculture and food chains}

There is a growing need for downstream actors in the agriculture and food chain to have better access to data, in particular with the increasing demand for traceability and transparency throughout the chain. Traceability and transparency, as well as the management of stocks of perishable goods, require increasingly large amounts of data. Sharing this data seamlessly and managing it in a cost effective way can only be achieved digitally. As a consequence, food processors are increasingly asking farmers to collect data to improve their planning and logistics, support tracing and tracking, and substantiate sustainability claims at the retail level.

At the same time, data flows accompany the production and exchange of goods and services every step of the way. A circular "digital thread" connects processes from design to end use, drawing on data from users and delivering instructions for the production process, which itself is increasingly digitally co-ordinated. Agriculture is no exception to digitalisation; it increasingly relies on the use of ICT-based services, for instance for prescriptive farming and predictive maintenance, and is therefore both using and producing data that can help to address challenges along the food chain. A manufacturer of milking robots, for example, monitors operational data from products sold to farmers and uses the data to give farmers advice.

Data-sharing is confronted by barriers, however, such as the lack of uniformly accepted standards and, in particular, interoperability issues. Such challenges are particularly acute in agriculture, a sector characterised by a large number of small players. A large dairy co-operative, for example, would have to be able to exchange data with 10000 farmers.

But the problem of inter-operability is even more complex when thinking about the multitude of actors that could use the data for various purposes, thereby increasing efficiency. For instance, the accountant of a co-operative requires access to its electronic invoices, but also data from the cows milked by the robot need to be accessible to the veterinarian and for the herd book. All these actors would need to have access to the system to be able to read and transfer data. One key issue would be whether the system is proprietorially developed, for example, by the global players in the food chain, or if it relies on open systems.

The important challenge of standardised and mainstream data exchange needs to be addressed in order to benefit from big data analytics, as well as other data-driven business opportunities.

Source: OECD (2015a), The role of new data sources in greening growth: The case of drones. 
The development of digital platforms to bring together pastoralists and traders in East Africa is a promising way of enabling isolated pastoralists to connect to the market and increase their livelihood opportunities, reaping the benefits of unexploited trade opportunities in the region (Box 3.3). These platforms reduce the high transaction costs generated by chains of middlemen in the process of livestock trading. Digitalisation can potentially transform the whole livestock and meat value chain by increasing the amount of information available throughout the chain, from livestock inputs and production to transport, processing, and distribution, enabling traceability.

Virtual marketplaces also allow pastoralist to register information about their cattle on digital platforms and to localise them using connected chips. Through such systems they are able to provide information on cattle prices, vaccines and various certifications to traders across the border. Using these platforms, pastoralists and buyers can not only be informed about current supply and demand; they can also settle trading agreements. This can spare them travelling-often long distances--with their cattle to the market, without the certainty that this will result in a transaction or knowledge of the conditions of the transaction. It allows pastoralists to make an informed choice about selling their cattle in advance, based on information about market prices and without having to incur transport costs to the market. It also allows traders to better organise and co-ordinate their activities. In addition, traders can get better and transferable health and safety information about the livestock, which they can then feed into traceability processes. Moreover, these platforms usually propose additional services, including payment solutions, such as mobile-money payments, escrow to facilitate payments, and cut-out-cash transactions. They also often assist in the arrangement of transportation following a purchase.

Overall, various exchange systems can facilitate trade by increasing co-ordination among public and private trade operators, thereby boosting the efficiency of trade logistics and, finally, of market access. However, these systems still face issues of inter-operability, as well as constraints to the free flow of data.

\section{Box 3.3. The potential of digitalisation for livestock and meat trading in Africa}

The example of livestock and meat trading in Africa demonstrates how digital transformation can address various types of market failures (Carabine et al. 2015, Engel and Jouanjean, 2014). Livestock trading (cattle, camels, sheep and goats) is an important source of livelihoods in the Horn of Africa and has great trade potential in the region thanks to increasing demand. While livestock exports are a key element of the livelihood systems of pastoral and agro-pastoral populations in the region, they have long been undervalued by national governments, despite estimates showing that livestock trade from regional pastoral production systems reached USD 1 billion in 2010 (Akilu et al. 2013, Catley et al. 2013). The true extent of the trade is also likely to be underestimated due to the high level of informality in the sector. In Kenya, for example, informal livestock economic activity may contribute as much as 150\% more to GDP than government estimates suggest (Behnke and Muthami, 2011). Furthermore, the value chains involved in these sectors involve a large number of people and are important sources of regional employment. Exports from the region, mostly to the Middle East through Djibouti, are organised around a regional cross-border trade network arranged through a series of clan-based corridors linking interior rangelands to the ports. USAID (2010) estimated that cross-border livestock trade supported--either directly or indirectly--about 17 million people in the region, covering a wide range of actors including livestock producers, traders, trekkers, fodder traders, brokers and intermediaries. However, because of the extensiveness of pastoralism in the region, coupled with the poor supply of infrastructure, pastoralists experience difficulties in accessing markets and information; when they do, the high access costs mean that they only obtain small margins in return. 


\section{CONCLUSIONS}

The linkages between digital and physical connectivity are twofold:

First digital connectivity provides new opportunities for providers of physical connectivity in the form of innovative technologies for customs management and cargo tracking, automation and the electronic transmission of information among customs authorities and transport providers.

Second, it means that the way physical connectivity is operated--shipping networks, cross border operations, intermodal connections--has to adapt to the new requirements of global trade and global value chains. These include justin-time deliveries and traders' demands for speed, reliability and transparency, as well as those brought about by digital trade and the changing way goods are delivered.

Digital trade for development requires, in addition to digital connectivity, addressing new and old constraints to market integration and physical connectivity. Digitalisation and data flows provide an opportunity to reduce the investments needed to address some traditional connectivity bottlenecks, both at the border and behind the border, and in particular to decrease transaction and co-ordination costs. They offer an opportunity to lower the costs of participating in trade, facilitating the inclusion of smaller and marginal buyers and sellers.

In terms of trade facilitation, digitalisation can decrease the transaction costs associated with co-ordination and create positive spill-overs for both public and private actors. The advantages include increased transparency, decreased risk management costs for customs authorities, improved efficiency of customs operations and greater reliability for the private sector, coupled with decreases in the opportunities for corruption, among others. However, digitalisation of processes is still lagging behind in many developing countries. The main reason for this is the lack of ICT infrastructure. Co-ordination in and among countries also remains a problem, even where such infrastructure exists. Therefore, a further push by the donor community for the creation of the ICT infrastructure that can unlock those spill-overs is welcome. Various case studies and experiences demonstrate the benefits of regional systems for smoothing transit processes. They provide real-life examples of the positive spill-overs resulting from increased data sharing.

However, while it presents opportunities, digital trade is also creating new challenges for customs authorities. New actors, and in particular the capacity of consumers to make cross-border purchases of goods sent in small parcels and using different trade pathways than traditional business-to business-trade, force policy makers and customs authorities to rethink traditional enforcement tools. In particular, digital trade questions existing risk management strategies based on traditional pathways of cross-border trade, as well as the relevance and the level of de minimis thresholds for customs duty.

There are other requirements and needs that must be addressed to improve physical connectivity in today's trading environment. Traditional connectivity constraints involve not only hard infrastructure, but also the provision of efficient trade logistics-in particular the transport services that move goods from production sites to where they are consumed. It is important to avoid weak links or bottlenecks in the trade logistics chain. For instance, good maritime connectivity requires more than efficient port infrastructure and competitive shipping lines. It also calls for reliable hinterland services, as well as competent customs and transit operations for land-locked countries. Such complementarities are particularly important to make the most of spill-overs and benefits from infrastructure investments. Maximising returns on investments requires co-ordination among neighbouring countries, both on hard infrastructure and on the regulatory environment for trade logistics services.

Digitalisation can reduce the cost of co-ordination, support better co-ordination among logistics modes and among countries' logistics services, and increase co-ordination among public and private trade operators. This in turn can increase the efficiency of trade logistics and therefore improve market access for smaller buyers and sellers, for whom the costs of participation in trade were previously too high. However, issues such inter-operability, as well as constraints to free flows of data, can limit the gains available from digitalisation. 


\section{REFERENCES}

Aklilu, Y., P. D. Little, H. Mahmoud, and J. McPeak (2013), "Market access and trade issues affecting the drylands in the Horn of Africa", brief prepared by a Technical Consortium hosted by CGIAR in partnership with the FAO Investment Centre.

Ansón, J., J.-F. Arvis, M. Boffa, M. Helble, and B. Shepherd (2017), Time, Uncertainty, and Trade Flows. ADBI Working Paper 673, Asian Development Bank Institute, Tokyo.

Austin, S. and M. Olarreaga (2012), Enabling Traders to Enter and Grow on the Global Stage, eBay Report, eBay EU Liaison Office, Brussels.

Behnke, R. and D. Muthami (2011), The contribution of livestock to the Kenyan economy, IGAD LPI Working Paper no 3-11, Intergovernmental Authority for Development Livestock Policy Initiative, Djibouti.

Bernhofen, D., Z. El-Sahli, and R. Kneller (2012), Estimating the effects of the container revolution on world trade, Lund University Publications.

Carabine, E. , C. Cabot Venton, T. Tanner, and A. Bahadur (2015), The contribution of ecosystem services to human resilience, a rapid review, ODI, London

Catley, A., J. Lind, and I. Scoones (2013), Development at the margins: pastoralism in the Horn of Africa. In Pastoralism and Development in Africa: dynamic change at the margins, Routledge, New York, USA.

Collier, P. (2008), "The Bottom Billion: Why the Poorest Countries are Failing and What Can Be Done About It", Oxford University Press 2008. ISBN 978-0195373387.

Cullinane, K., T. Notteboom, R. Sanchez, and G. Wilmsmeier (2012), "Costs, revenue, service attributes and competition in shipping", in: Maritime Economics \& Logistics (2012) 14, 265-273.

ECLAC (2002), "The cost of international transport, and integration and competitiveness in Latin America and the Caribbean", FAL Bulletin 191, Santiago de Chile, http://repositorio.cepal.org/handle/11362/36199?show=full (accessed on 20 June 2015).

Engel, J. and M-A. Jouanjean (2014), The history, impact and political economy of barriers to food trade in sub-Saharan Africa: an analytical review, ODI, London, UK.

Engel, J., M-A. Jouanjean and P. Omanga (2015), Infrastructure for the participation of smallholders in modern value chains: lessons from the development of warehouse certification and receipting systems for maize in Kenya, ODI, London, UK.

ESCAP (2015), Reducing Trade Costs in Asia and the Pacific: Implications from the ESCAP-World Bank Trade Cost Database, Bangkok, www.unescap.org/resources/reducing-trade-costs-implications-escap-world-bank-trade-costdatabase (accessed on 20 June 2015).

Global express association (2016), Overview of de minimis value regimes open to express shipments world wide, www.global-express.org/assets/files/Customs\%20Committee/de-minimis/GEA-overview-on-de-minimis_April-2016.pdf

Hintsa, J., S. Mohanty, V. Tsikolenko, B. Ivens, A. Leischnig, P. Kähäri, and O. Cadot (2014), The import VAT and duty de minimis in the European Union-Where should they be and what will be the impact? Final Report, Crossborder Research Association, Lausanne.

Hoffmann, Jan (2012), Corridors of the Sea: An investigation into liner shipping connectivity. In: Les corridors de transport, Sefacil, http://www.sefacil.com/?q=page/tome-1-les-corridors-de-transport 
Humair, F., L. Humair, F. Kuhn, and C. Kueffer (2015), E-commerce trade in invasive plants. Conservation Biology, 29(6), 1658-1665.

ICAO (2017), Connectivity, http://www.icao.int/sustainability/Pages/Connectivity.aspx (accessed 3 March 2017)

IPPC (2012), The Internet trade (e-Commerce) in Plants Potential Phytosanitary Risks, implementation review and support system, International Plant Protection Convention.

Jeacocke S., N. Kouwenhoven (2017), Cognitive Computing for Customs agencies: improving compliance and facilitation by enabling Customs officers to make better decisions.

Jouanjean, M. A., D.W. te Velde, N. Balchin, L. Calabrese, and A. Lemma (2016), Regional infrastructure for trade facilitation-impact on growth and poverty reduction. London: ODI, London, UK.

Cuyvers, L. and G.K. Janssens (1992), "Electronic Data Interchange in International Trade", Logistics Information Management, Vol. 5 Iss: 2, pp.36 - 42

Miler, R. K. (2015), Electronic Container Tracking System as a Cost-Effective Tool in Intermodal and Maritime Transport Management. Economic Alternatives, (1), 40-52.

Moïsé, E. and S. Sorescu (2013), "Trade Facilitation Indicators: The Potential Impact of Trade Facilitation on Developing Countries' Trade", OECD Trade Policy Papers, No. 144, OECD Publishing, Paris.

DOI: http://dx.doi.org/10.1787/5k4bw6kg6ws2-en

Moïsé, E. and S. Sorescu (2015), "Contribution of Trade Facilitation Measures to the Operation of Supply Chains", OECD Trade Policy Papers, No. 181, OECD Publishing, Paris. http://dx.doi.org/10.1787/5js0bs/h9m25-en

OECD (2015a), "The role of new data sources in greening growth - the case of drones" Green growth and sustainable development forum, 14 \& 15 December 2015 - OECD, Paris, Issue note, Session 3

OECD (2015b), Implementation of the WTO Trade Facilitation Agreement: The Potential Impact on Trade Costs.

OECD (2016), Single Window and Border Agency Cooperation -Expanding Selected OECD Trade Facilitation Indicators

OECD (2017a, forthcoming), Economy-wide impacts of trade facilitation: a metro model simulation,

OECD Publishing, Paris.

OECD (2017b), Trade Facilitation and the Global Economy, OECD Publishing, Paris.

OECD (2017c), Trade Facilitation Indicators, www.oecd.org/trade/facilitation/indicators.htm\#About-TFI (accessed on 01 February 2017)

OECD (forthcoming), Digital trade: developing a framework for analysis.

OECD-WTO (2017), Aid-for-trade monitoring exercise 2017 (questionnaires) www.oecd.org/aidfortrade/countryprofiles/

Roberts, M. and N. Mohammed (2017), Trade issues affecting disaster response, WTO Staff Working Paper, No. ERSD-2017-07,www.wto.org/english/res_e/reser_e/ersd201707_e.pdf

Schware, R. and P. Kimberley (1995), Information technology and national trade facilitation : making the most of global trade, World Bank technical paper no. 316, The World Bank, Washington, D.C.

Shepherd, B. (2016), "Value Chains and Connectivity in the Pacific", International Trade Working Paper 2016/23, Commonwealth Secretariat, London. 
Shepherd, B. (2015), Infrastructure, trade facilitation, and network connectivity in sub-Saharan Africa. Background paper for the DFID project Regional Infrastructure for Trade Facilitation, Overseas Development Institute, ODI, London, UK.. Sourdin, P. and R. Pomfret (2012), "Trade Facilitation: Defining, Measuring, Explaining and Reducing the Cost of International Trade". Edward Elgar Publishing, 2012. ISBN: 9780857937421.

Teravaninthorn, S. and G. Raballand (2008), "Transport Prices and Costs in Africa: A Review of the Main International Corridors", World Bank, Washington, D.C.

The New Times (25 March 2017), Regional electronic cargo tracking system unveiled, www.newtimes.co.rw/section/ article/2017-03-25/209515/

TMEA (2015), TradeMark East Africa Formative evaluation of RRA Project.

TMEA (27 March 2017), Regional Electronic Cargo Tracking System Unveiled, www.trademarkea.com/news/ regional-electronic-cargo-tracking-system-unveiled/

Transport Intelligence (2017), Global e-commerce Logistics 2017, London.

UNCTAD (2016a), Trade Facilitation and Development, UNCTAD/DTL/TLB/2016/1, United Nations Conference for Trade and Development, Geneva, http://unctad.org/en/PublicationsLibrary/dt|tlb2016d1 en.pdf.

UNCTAD (2016b), Review of Maritime Transport 2016, United Nations publication, New York and Geneva. http://unctad.org/en/Pages/Publications/Review-of-Maritime-Transport-(Series).aspx

UNECE (2011), The data pipeline, Discussion paper for the Global Trade Facilitation Conference 2011, Connecting International Trade: Single Windows and Supply Chains in the Next Decade.

UNECE (2013), Single Window Interoperability, 5th. Latin American and Caribbean Regional Meeting on International Trade Single Windows, Mexico City.

USAID COMPETE (2012), Revenue Authorities Digital Data Exchange (RADDEx 2.0), East Africa Trade Hub.

WCO (2014), Revenue and the WTO Agreement on Trade Facilitation, Research Paper No. 33.

Wilmsmeier, Gordon (2014), "International Maritime Transport Costs: Market Structures and Network Configurations". Ashgate. ISBN: 9781409427247.

World Bank (2016), Logistics Performance Index, database, http://lpi.worldbank.org/ (accessed on 10 May 2017)

World Bank (2017), Doing Business Rankings, database, www.doingbusiness.org/rankings, (accessed on 10 May 2017)

WEF (2013), "Enabling Trade - Valuing growth opportunities", World Economic Forum, Geneva.

WEF (2014), The Global Enabling Trade Report 2014, orld Economic Forum, Geneva.

WTO (2014), Agreement on Trade Facilitation. WT/L/931. 15 July.

WTO (2015a), World Trade Report 2015: Speeding Up Trade - Benefits and Challenges of Implementing the WTO Trade Facilitation Agreement, Geneva.

WTO (2015b), Trade facilitation agreement facility, tfafacility.org (accessed 1 December 2015) 


\section{NOTES}

1. For the LSCl of all coastal countries from 2004 to 2016, see http://stats.unctad.org/maritime.

2. TFI values range between 0 and 2 , where 2 denotes the best performance possible for a given indicator.

3. An example is the co-operation between Switzerland and the EU (OECD, 2016)

4. Low-value shipments does not refer to shipments with low value-to-weight ratio. They are, rather, shipments of small quantities, even small parcels, which often tend to have a higher value-to weight-ratio than bulk shipments.

5. For example, the US Customs and Border Protection (CBP) sends informed compliance letters to notify importers that an audit or enforcement action may follow.

6. For instance, cognitive computing for customs agencies.

7. Set and monitored by national plant protection organisations.

8. Note, however, that commercial flights to Yemen have ceased to operate regularly since March 2015 due to ongoing conflict. 



\title{
CHAPTER 4
}

\section{SERVICES TRADE POLICIES AND THEIR CONTRIBUTION TO CONNECTIVITY AND DEVELOPMENT}

\author{
Contributed by the World Trade Organization
}

\begin{abstract}
This chapter examines how trade in services contributes to connectivity. It discusses the role of policies in services trade, looking at how these promote integration into the international trading system. The chapter details the economic relevance of services for national economies, as well as in international trade and investment. It identifies key channels through which trade in services contributes to physical and digital connectivity, examining relevant service sectors. The chapter discusses policies that affect trade in services and reviews recent research that underscores the impact of such policies on sectoral performance, economic welfare and development. Finally, it highlights the positive contribution that aid for trade can make in support of services policies.
\end{abstract}




\section{INTRODUCTION}

Services are central to everyday life. Service suppliers support education and health, bring goods from producers to individuals and enterprises that consume them, transport people and merchandise, ensure the functioning of the financial system, help meet energy demands and achieve environmental policies, provide information and entertainment, offer services for tourists, and form the backbone of countries' digital infrastructure.

Services occupy a growing and central place in both domestic economies and international economic relations. They now account for the bulk of global foreign direct investment and world trade. Service sectors also play a multifaceted and significant role in connecting countries to the international trading system, and matter greatly to economic development and the achievement of the Sustainable Development Goals (SDGs).

Services notably affect connectivity by:

n providing basic infrastructure to support trade in goods

- facilitating supply chains and entering trade as value added embodied in goods

vroviding the backbone that enables e-commerce and online supply

- enhancing export diversification through cross-border electronic supply.

This chapter examines the contribution of services trade to connectivity. It discusses the role of policies in this sector-including foreign direct investment policies and international commitments -in promoting digital and other connectivity, in the context of aid for trade. The first section sets the scene by highlighting the economic relevance of services in national economies, as well as in international trade and investment. The chapter then identifies some key channels through which trade in services promotes connectivity, highlighting relevant service sectors. The following section underscores, in light of recent research, the role services trade policies play in promoting connectivity. It examines current levels of trade openness in services, discusses the role of international commitments, and reviews the impact of policies on sector performance, economic welfare and development. The final section looks at the possible contributions of aid for trade in supporting services policies that will promote connectivity. The chapter concludes that restrictive policies in services trade increase economic remoteness. An enabling policy environment, on the other hand, enhances connectivity and fosters economic growth and performance. Improving investment policies in services sectors, for example, can help attract the foreign direct investment (FDI) required to develop ICT infrastructure, helping bridge the digital divide and meet the SDGs. Aid for trade can make a significant contribution by providing support for quality services policies at both the sector-specific and cross-sector levels.

\section{TRADE IN SERVICES IS INCREASINGLY IMPORTANT IN THE GLOBAL ECONOMY}

Service sectors and trade in services occupy an important and growing place in both national economies and international trade. Services generate more than two-thirds of global gross domestic product (GDP), employ the highest proportion of workers in the large majority of countries, and generate most new jobs. The contribution of services to national economies has been increasing over time for countries at all levels of development. Figure 4.1 shows services value added to GDP for low income and middle income countries. Even for the lowest income countries, services industries are central and have consistently been gaining in importance over time. The share of services in GDP is even greater in high income countries, where it reaches over $70 \%$ on average. In short, for countries at all levels of development, services are now even more important than in the past.

The importance of services in world trade has long been considered much more limited than the sector's contribution to domestic economies. This perception is changing, however, as understanding of the role of services in global trade improves. The important role that trade in services plays in economic growth and development is increasingly evidenced by its contribution to export diversification, the role of services as inputs to the production of goods, and the importance of service sectors as a destination for foreign direct investment. 
Figure 4.1. Services value added as a percentage of GDP

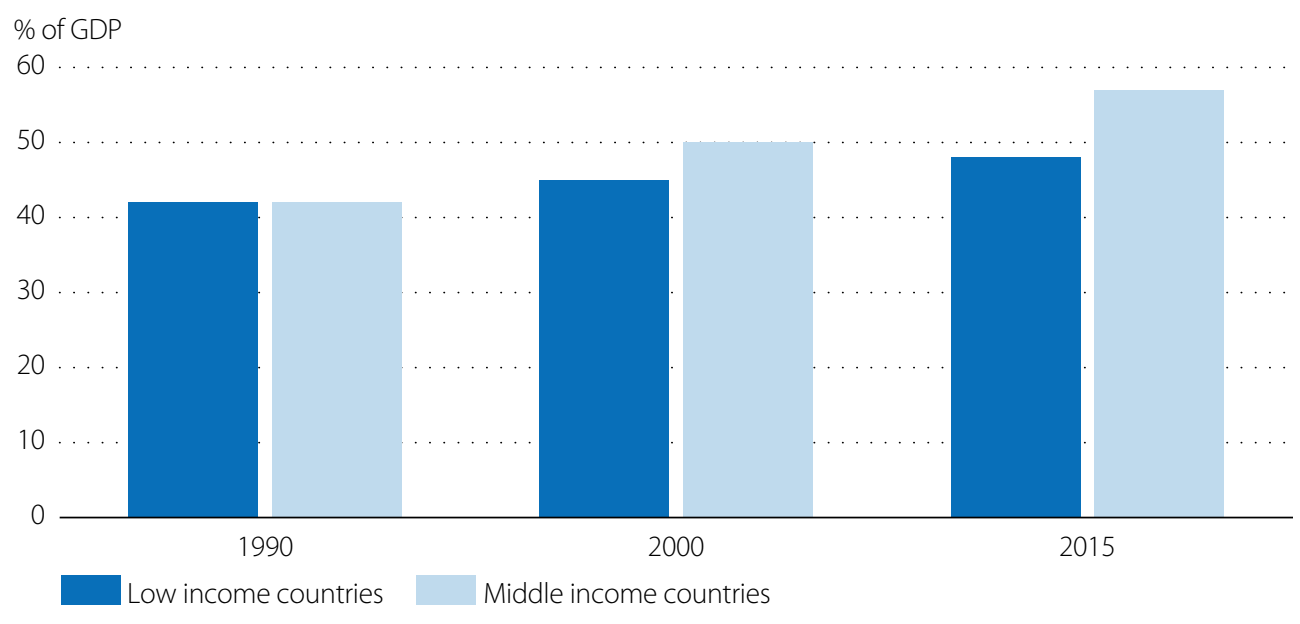

Source: World Bank Development Indicators, http://databank.worldbank.org/data/reports.aspx? source=worlddevelopment-indicators\&Type=TABLE\&preview=on (accessed 10 May 2017)

StatLink 部西 http://dx.doi.org/10.1787/888933525835

Advances in information and communications technology, exemplified by the global expansion of the Internet, are transforming the tradability of services. It is increasingly easy to export services across borders, either as a final product or as an intermediate product for the production of another service or a good. Trade in services has also been spurred by trade and investment liberalisation, which has allowed the fragmentation of production across borders. This is reflected in the growing relative importance of services. Measured on a balance-of-payments (BOP) basis, trade in services now accounts for 23\% of total trade in goods and services, compared to 18\% in 1995.

The magnitude of trade in services is more accurately reflected when taking into account services that are exported indirectly, namely services that are embodied in exports of goods. When trade is measured in terms of value added rather than gross (or BOP) terms, services account for $49 \%$ of world trade, compared to $18 \%$ for the primary sector and 33\% for manufacturing (Figure 4.2). Trade in value added (TiVA) statistics show how services drive manufacturing competitiveness and employment, and are key to the export of manufactured products. Even in countries where services account for a small proportion of total exports in gross terms, services often account for a significantly larger share of total exports in value added terms. For example, services currently account for 19\% of Argentina's total exports in BOP terms, but the proportion jumps to $43 \%$ in value added terms (WTO, 2011).

\section{Figure 4.2. Structure of world trade}
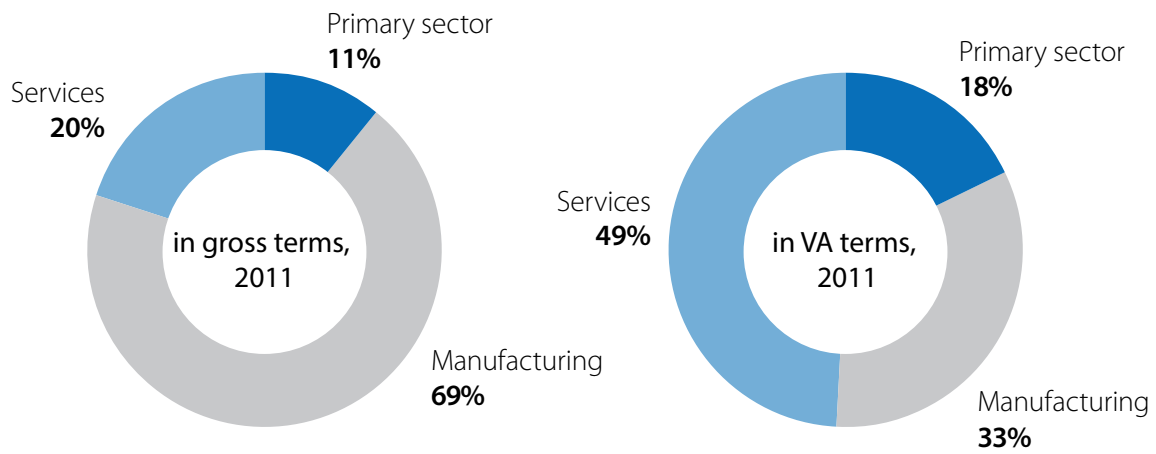

Source: OECD-WTO (2016), Trade in Value Added database,

https://stats.oecd.org/Index.aspx?DataSetCode=TIVA_2016_C1 (accessed on 01 May 2017).

StatLink 青IS http://dx.doi.org/10.1787/888933525854 
The importance of trade in services is further underscored when taking into account the principal means of supplying services, which is through a commercial presence abroad (GATS mode 3; Box 4.1). Indeed, BOP data focuses on transactions between residents and non-residents, and does not capture services that are supplied within the country through business establishments owned or controlled by foreigners. This category (mode 3) accounts for about 55\% of world trade in services, compared to 30\% for cross-border supply (mode 1), 10\% for consumption abroad (mode 2), and 5\% for movement of persons (mode 4; Maurer et al., 2016). And while mode 3, which involves FDI, is, overall, the main mode of supply for services trade, services are also the predominant destination of FDI. Services now account for almost two-thirds of global FDI stock (UNCTAD, 2016), as compared to 25\% in 1970 and less than 50\% in 1990.

\section{Box 4.1. Trade in services and modes of supply}

In an effort to cover the various means through which services are provided internationally, the General Agreement on Trade in Services (GATS) defines trade in services by reference to four modes of supply. These can be summarised as follows:

Mode 1 (cross-border supply), analogous to trade in goods, occurs when a service is delivered from the territory of one World Trade Organization (WTO) member to the territory of another member. Examples of mode 1 include international transport and supply of services over digital networks, where the service supplier is not present in the territory of the member where the service is consumed.

Mode 2 (consumption abroad) involves the supply of a service in the territory of one member to the service consumer of another member. An example of supply through this mode is tourism.

Mode 3 (commercial presence) is the supply of a service by a service supplier of one member through the establishment of a commercial presence (subsidiary, branch or other forms of business establishment) in the territory of another member. Mode 3 can be relevant for all sectors, e.g. the establishment and operation abroad of foreign insurance companies, hotels, supermarkets.

Mode 4 (movement of natural persons) concerns the supply of services through the temporary presence of a natural person of one member in the territory of another member. This mode of supply can involve the temporary movement of, for example, independent professionals (e.g. lawyers or accountants), or intra-corporate transferees whereby certain personnel are transferred from their parent company to a subsidiary in the territory of another member.

Given their weight in domestic economies, as well as their multi-faceted significance for trade, services have a fundamental impact on achieving the 2030 Sustainable Development Goals. This is not only in relation to economic performance in general, but also to their role in specific areas such as energy, water, environment, health or education. This view is largely shared by developing country governments. As illustrated in Figure 4.3, 95\% of respondents to the OECD-WTO 2017 aid-for-trade monitoring exercise considered that trade in services could make a contribution to the achievement of the Sustainable Development Goals (SDGs), in particular with respect to "quality education" (80\% of respondents), "industry, innovation and infrastructure" (78\%), "good health and well-being" (75\%), and "decent work and economic growth" (73\%). In addition, 92\% of developing country governments said that developing capacity in services and trade contributes to women's economic empowerment. 
Figure 4.3. Partner country views on the relevance of trade in services for achieving the Sustainable Development Goals

Can services trade make a contribution to the achievement of the 2030 Sustainable Development Agenda?

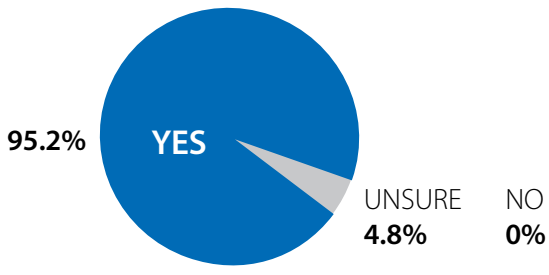

If, so which ones will be helped by growth in services?

In percent of partner country responses

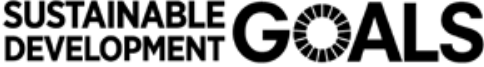

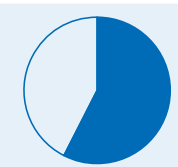

$63.3 \%$
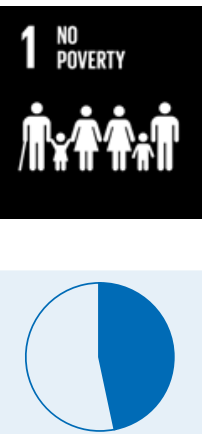

$46.7 \%$

$63.3 \%$
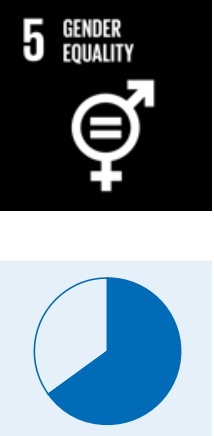

$65.0 \%$
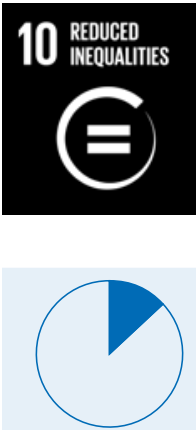

$13.3 \%$
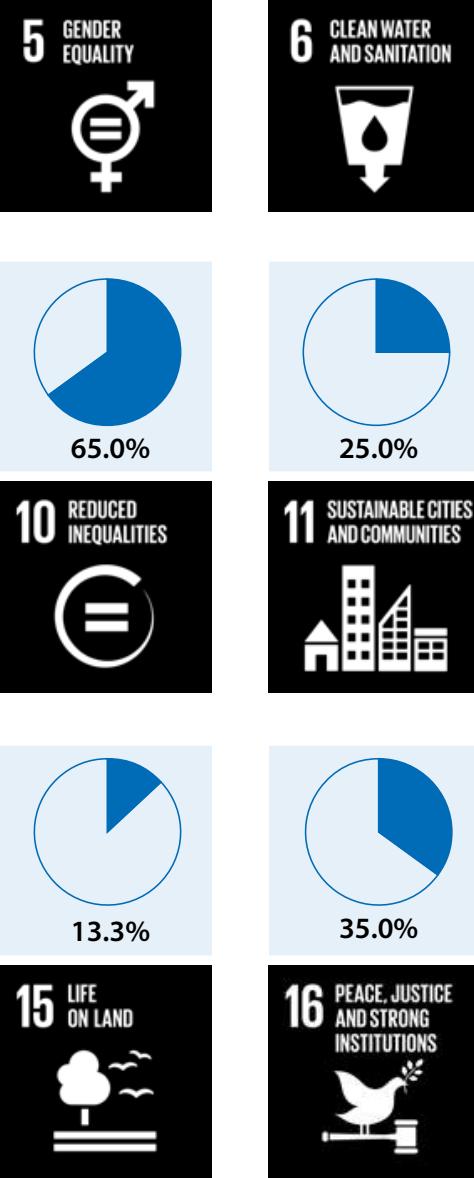

$25.0 \%$
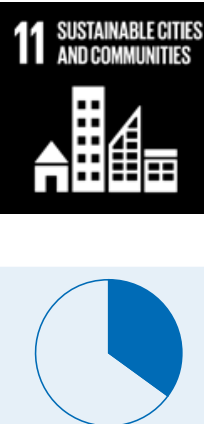

$35.0 \%$

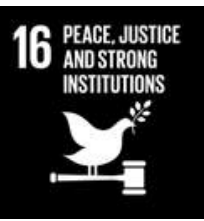

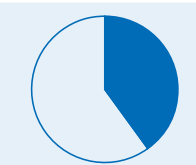

$40 \%$
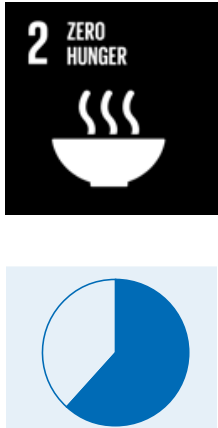

$61.7 \%$

7 AFFORDABIEAND 11 $0=$

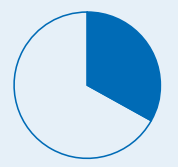

$33.3 \%$

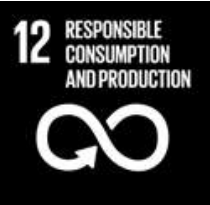

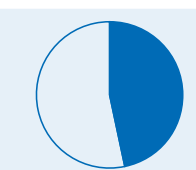

$46.7 \%$

17 PARTNERSHIPS FOR THEGOALS

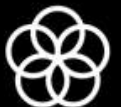




\section{SERVICES MAKE A MULTIFACETED CONTRIBUTION TO PROMOTING CONNECTIVITY}

A number of developing countries, in particular the LDCs, continue to face difficulties in connecting to the global economy through trade and see their opportunities to benefit from their potential reduced as a result. Promoting connectivity, including by reducing trade costs, has been identified as a priority in the context of aid for trade (WTO, 2016a). Services play a fundamental and growing role in promoting connectivity in the global economy.

This section highlights four important - and sometimes overlapping - channels through which services, in particular trade in services, exercise a determinant impact on connecting countries to the international trading system:

1. providing the basic infrastructure to support trade in goods

2. facilitating supply chains and being used as inputs into the production and export of goods

3. providing the backbone that enables e-commerce and the online supply of services

4. enhancing export diversification through cross-border electronic supply of services.

\section{Services provide essential infrastructure for trade in goods}

Services promote connectivity by providing the basic infrastructure on which trade in goods relies. To put it bluntly, without services, goods cannot be traded. The more expensive or inefficient the underlying services, the harder it is to trade goods.

A diversity of services is needed to bring final goods from their production site to consumers across borders. These include, most obviously, services such as maritime transport (e.g. freight, port services), road transport, air transport (e.g. freight, airports), logistics services (e.g. freight forwarders, customs brokers, storage, warehousing), express delivery services, and distribution services (wholesale and retail).

While hard infrastructure, such as roads or port facilities, has been a traditional focus of aid for trade, it is also crucial to consider the quality and cost of the services that make use of such infrastructure. The quality of government measures, especially the extent to which they facilitate competition, influences the efficiency of service markets. At the same time, this enabling environment, or soft infrastructure, is strongly influenced by measures that limit trade in services, such as foreign ownership restrictions or limits on cross-border supply (e.g. quotas or limits to cabotage in road transport). By restraining competition, these measures raise costs and limit the quality of the services provided which in turn limits connectivity and negatively affects trade. Respondents to the OECD-WTO 2017 aid-for-trade monitoring exercise clearly recognised these inter-relations: $90.5 \%$ of developing country governments said that their national development strategies linked trade-related infrastructure to the development of related service sectors (OECD-WTO, 2017).

An example from Rwanda illustrates the impact of an adequate services enabling. In Rwanda, reform of trucking arrangements to allow greater ease of market entry resulted in prices declining by more than $30 \%$ in nominal terms and was associated with an expansion of the domestic trucking fleet. This contrasts with the situation in other countries in the region, where restrictive entry regulations, quotas, and other measures have reduced competition, raising the costs of road transport services and thereby penalising farmers by making it difficult for them to get their produce to domestic and foreign markets (Teravaninthorn and Raballand, 2009). This example also suggests that the benefits of reduced border or customs barriers, for example through the Trade Facilitation Agreement (TFA), may not be fully realised if other obstacles to the flow of goods, further upstream, are not also tackled. Failure to introduce competition in transport services also may erode the benefits of investments in transport infrastructure (Cadot et al., 2014; Borchert et al., 2017). 
In the aid-for-trade monitoring questionnaire, developing country governments signalled that a number of service sectors would support the implementation of the TFA and help them to realise the associated economic benefits. These included road, air, maritime and rail transport, computer, financial, and distribution services (OECD-WTO, 2017).

The efficiency of service markets is also critical to the participation of small and medium enterprises (SME). Indeed, the cost of logistics has a larger incidence on such companies because of their lower volume, which means that these represent a larger proportion of their total costs (WTO, 2016c).' Responses to the OECD-WTO 2017 aid-for-trade monitoring exercise confirm that high costs of service markets can hinder exports for micro, small and medium enterprises involved in e-commerce. The two challenges most cited by developing country governments in this regard were "high shipping costs" and "high costs of small parcel shipments", ahead of other potential challenges such as sanitary and phytosanitary (SPS) issues, conformity assessments, or online fraud (OECD-WTO, 2017).

\section{Services facilitate supply chains and provide key inputs to goods exports}

Global value chains play a preponderant role in connecting countries through trade. Around half of world trade now takes place through global value chains. As for developing economies, 48\% of their exports, in value added terms, involve global value chains (OECD-WTO, 2016). ${ }^{2}$

Services, as well as trade in services, are key enablers of global production networks. The feasibility of international production networks, as well as their recent growth, has been made possible by, among other things, significant technological advances that have increased the ease of delivering services across borders. A wide range of services act as enablers of global value chains, for example, computer, research and development, advertising, telecommunications, financial and professional services.

In addition to permitting the co-ordination of international production networks, services also provide increasingly significant inputs into the production of goods. Accordingly, services are increasingly traded through trade in goods, and account for a growing share of the value added of many goods produced. Research suggests that the share contributed by services to value added in goods exports from low income countries grew from 16\% in 1992 to 22\% in 2012 (Balchin et al., 2016). Overall, value added from services accounts for about one-third of manufacturing exports of developed economies, and more than one-quarter (26\%) of those of developing economies (WTO, 2014). For some low income countries, for example Ethiopia and Myanmar, the value of services embodied in goods exports is greater than the value of the services they export directly (Balchin et al., 2016).

In value added terms, developing countries are important service exporters. Efficient services are essential to enable them to export goods and connect to international markets. The cost and quality of the underlying services affect the performance of the economy as a whole. Without adequate and affordable services, developing manufacturing is a formidable task. Inadequate enabling environments for trade in services, which create barriers to trade and to competition, limit the range, quality and affordability of services, holding back connectivity and competitiveness in the export of goods.

Developing country governments appear to value the role services, as intermediate inputs, can play in improving the performance of other sectors and boosting manufactured exports. As many as 79\% of respondents to the OECD-WTO 2017 aid-for-trade monitoring exercise said that their national development strategy links growth of services capacity and trade to growth in industrial capacity and manufactured exports; only $11 \%$ said that their development strategy does not make such a link (Figure 4.4.). The sectors identified as most important in this regard were transport, computer, research and development, financial, and professional services. 
Figure 4.4. The value of services in exports, as recognised in national development strategies

Question: Does your national development strategy (or other national economic policy documents) link growth in services capacity and trade to growth in industrial capacity and manufacturing exports?

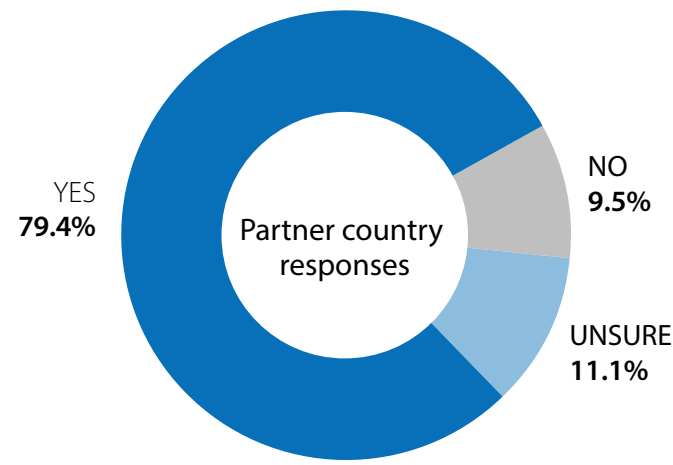

Source: OECD-WTO aid-for-trade monitoring exercise (2017), www.oecd.org/aidfortrade/countryprofiles/. StatLink 규표 http://dx.doi.org/10.1787/888933525892

Imported services also add value added to exported goods. Figure 4.5 shows that a significant share of the value added from services embedded in manufactured products is from foreign services: almost 20\% for Viet Nam, 24\% for Singapore, 20\% for Thailand and 18\% for China. ${ }^{3}$

\section{Figure 4.5. Services value added in exports of manufactured products, 2011}

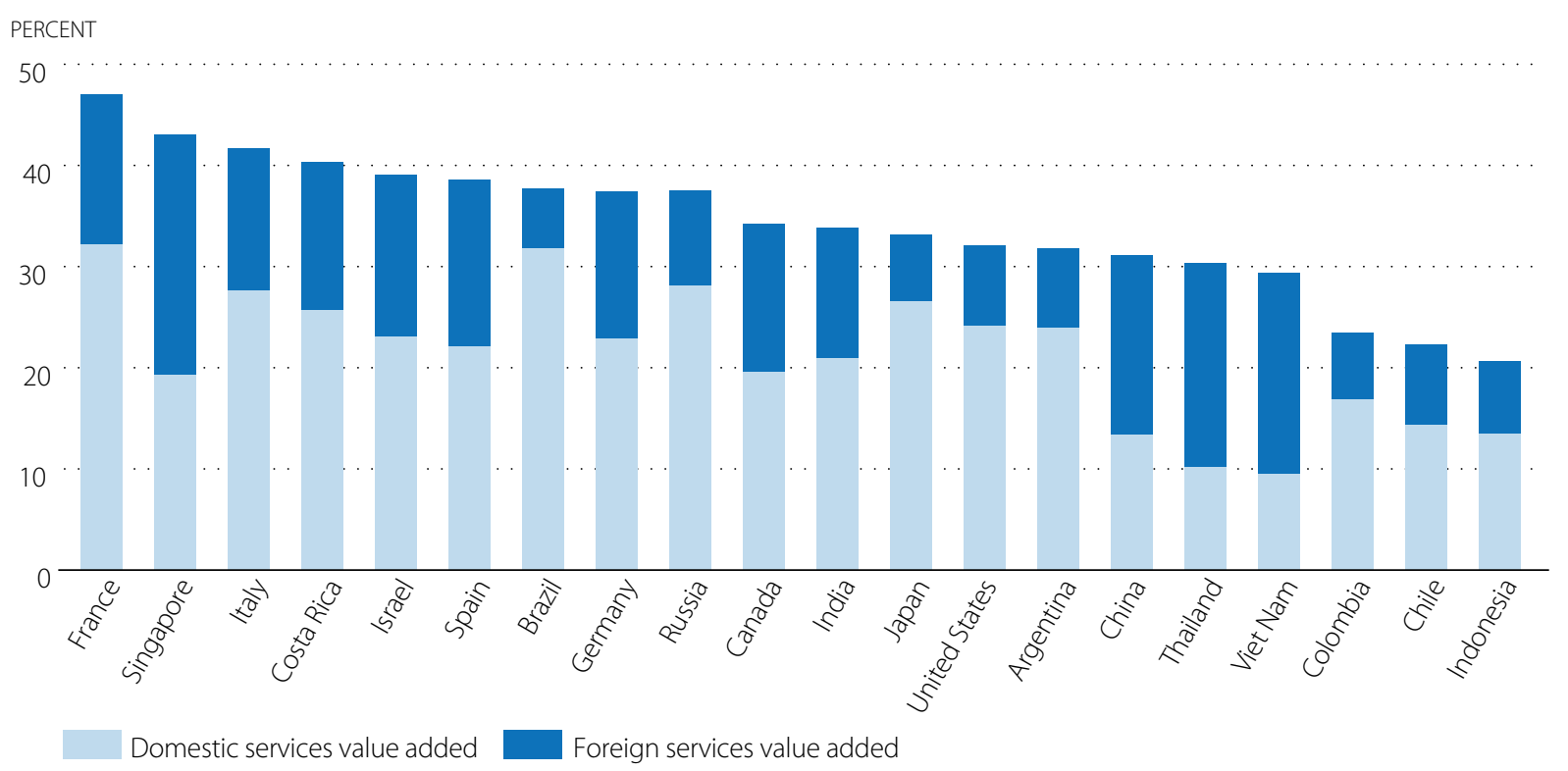




\section{Services provide the infrastructure that enables e-commerce and online supply}

Services in sectors such as telecommunications and computers, in particular, but also financial and distribution services, are key enablers of electronic supply of services and in e-commerce more generally.

Telecommunication services, including Internet, mobile telephony, and data transmission services, provide the basic infrastructure and transmission capacity that allow a range of services to be provided over digital networks, and also allow goods to be offered and purchased through these networks. ${ }^{4}$ Technological developments, such as growth in broadband networks -including mobile broadband - have improved the quality and capacity of these services and brought costs down, making it easier to connect producers, sellers and consumers across borders.

Infrastructure services such as telecommunications promote connectivity in four principal ways: First, advancements in telecommunications and related services enhance the tradability of services, in turn expanding export opportunities, especially for developing countries. These technologies reduce the need for establishing a commercial presence abroad or for travel by persons to supply services to foreign markets. Efficient telecommunication services have made it profitable for outsourcing to take place, for global value chains to be managed and operated, and for e-government initiatives to be developed. As a result, telecom networks reduce trade costs for the exchange of both goods and services (Fink et al., 2005; Tang, 2006).

Second, telecommunication services underpin data flows across borders, which have skyrocketed in recent years. Indeed, use of cross-border bandwidth grew by 45 times between 2005 and 2014, and is projected to grow by another 9 times in the coming five years (McKinsey Global Institute, 2016). Nowadays, broadband access to the Internet and other data networks offers the higher speeds that are required to exploit newer technologies, such as cloud computing, and to use or offer services that require the transfer of large quantities of data (WTO, 2016c). These data flows often relate to some aspect of the supply of goods and services (if not to the service itself), or to the coordination of activities between a foreign-invested enterprise and its parent abroad. Cross-border data flows, boosted by basic and value added telecom services, such as data processing and storage via cloud capacity, allow companies not only to sell their goods and services, but also to coordinate their logistics and the activities of their subsidiaries and partner offices across the globe. These flows may involve customer information for product development and support, human resources data, financial and merchant data, or product-specific technical data (Tuthill, 2016: 357).

Third, telecommunication services, and more specifically the Internet, constitute the backbone for key pillars of e-commerce such as online retail and wholesale trade (e.g., Amazon, AliBaba). Indeed, without increased capacity and speed, and the lower communication costs brought about by improvements in telecom and computer services, the sale of goods online as it stands today, including inventory management, would not be possible.

Fourth, information and communication technology (ICT) services, combined with innovation, regulatory adaptation, and trade openness in the financial services sector, have made possible significant advances in payment solutions, particularly payments using Internet and mobile services. This has contributed to greater financial inclusion by allowing unbanked segments of the population to access and make use of a range of financial services.

Various types of services and service suppliers, operating through diverse business models, are needed in order to bring financial services to low-income populations. Trade in services has an important role to play in this regard, as illustrated by the examples of South Africa and Rwanda in Box 4.2. Although policy-makers and regulators may not consider financial inclusion initiatives to be trade related, when foreign service suppliers are involved in any of the modes of supply, financial inclusion-related regulations also become trade policies (WTO, 2016b: 14).

In light of the above, ICT services, in particular broadband platforms, can have a transformational impact on economic development and serve as catalysts for attaining the SDGs. They can offer consumers improved and sometimes new access to a wide array of basic and other services. They can also enable companies to develop new products and find innovative ways of reaching their consumers, connecting with other companies and managing their internal operations (e.g. cloud computing and data storage) without having to invest in servers or other costly equipment and staff. 
Box 4.2. Mobile payments in Rwanda and South Africa

Developments in the mobile payment business demonstrate the potential for trade in services. In South Africa, for example, three very different types of service suppliers (MobiCash, a cashless financial platform; Boloro, a mobile payment network; and Big Save Group, one of the largest wholesalers operating in South African townships), launched a joint mobile payments ecosystem in 2016. The objective was to roll out MobiCash and Boloro services across Big Save's thousands of "scaza" shop members, accelerating their financial inclusion and extending financial interoperability to formerly unbanked businesses and communities. MobiCash uses multi-factor identity authentication mechanisms, such as fingerprints and voice biometric technology, to authorise transfer of funds. Boloro offers consumers the ability to securely pay for goods and services using any kind of mobile phone and any source of funds.

Both Mobicash and Boloro are foreign-owned. MobiCash, headquartered in Hong Kong, allows unbanked customers easy access to banking and payment services. It currently offers its mobile banking platform in 13 African countries: Botswana, Burundi, Cameroon, Democratic Republic of the Congo, Ghana, Kenya, Malawi, Rwanda, South Africa, Tanzania, Uganda, Zambia and Zimbabwe. Boloro South Africa is a subsidiary of Boloro Global Limited, which is headquartered in New York. Boloro also operates in South Asia, the Middle East and Africa, and will soon launch operations in Latin America, the Caribbean and East Asia.

In Rwanda, in May 2016, KCB Bank and GoSwiff, a global provider of payment acceptance solutions, launched a mobile point-of-sale (mPOS) service for Rwandan merchants. Their objective was to drive financial inclusion and digital payments in the country. The new mobile payment service, a first of its kind in Rwanda, will make it possible for businesses of any size to accept digital payments, including insurance premiums and public disbursements, with the simple use of a mobile application and an mPOS terminal.

Both KCB Bank and GoSwiff are foreign-owned. KCB Bank Group, established in Kenya in 1896, is East Africa's largest commercial bank. It has subsidiaries in Burundi, Rwanda, South Sudan, Tanzania and Uganda. Today KCB Bank Group has the largest branch network in the region, with over 250 branches, 962 ATMs and 11,000 agents offering banking services on a 24/7 basis. Incorporated in 2010, GoSwiff is headquartered in Singapore and currently has operations in 25 countries around the world.

Services trade policies can make an important contribution to online and mobile banking - and thereby to financial inclusion - in at least three ways:

1. by ensuring that a full range of institutional options and business models are available to a large range of suppliers

2. by encouraging adequate regulatory frameworks and facilitating competition and innovation in the financial services market, thereby supporting the introduction of new financial products and technologies, as well as new distribution channels

3. by supporting the development of financial infrastructure, for example by eliminating restrictions $t$ hat prevent nonbanks from accessing the national payment system, or by allowing the entry and operation of digital payment platforms.

Source: Adapted from WTO (2016b), "Financial Inclusion and the GATS—Barriers to Financial Inclusion and Trade in Services".

Indeed, the Internet is now one of the most important business platforms for companies, domestically and internationally. The Internet promotes efficiency because it makes transactions quicker, cheaper, and more convenient to carry out (World Bank, 2016a; OECD-WTO, 2015). McKinsey Global Institute found that selling through digital channels can lead to productivity gains of 6-15\% (WTO, 2016c).

The potential benefits of the ICT revolution are arguably greater for SMEs. Online markets offer the opportunity to better integrate their enterprises — and the developing countries where they operate_-into global trade by making it easier to connect to distant consumers. Online trade possibilities not only reduce costs; they give SMEs a global presence that was, in the past, only feasible for large multinational enterprises. 
As noted in the WTO's 2016 World Trade Report (2016c), to fully reap the benefits of online trade, ICT infrastructure must be in place, the quality of services offered must be adequate and prices must be affordable, especially for SMEs. Policies in services trade play an important role, in particular in terms of enabling —or not—foreign investment to expand the supply of services, and of allowing contestability to maintain competitive pressure on prices and quality of services.

The responses of developing country governments in the OECD-WTO 2017 aid-for-trade monitoring exercise confirm that the quality and cost of broadband networks are critical to online activities (Figure 4.6). Among the main obstacles faced, by both enterprises and consumers, in accessing and using Internet services, cost of broadband subscriptions and slow Internet connection speeds were the top issues cited ( $62 \%$ and $58 \%$ of respondents, respectively).

\section{Figure 4.6. What are the main issues that enterprises and consumers in your countries face in accessing and using Internet services?}

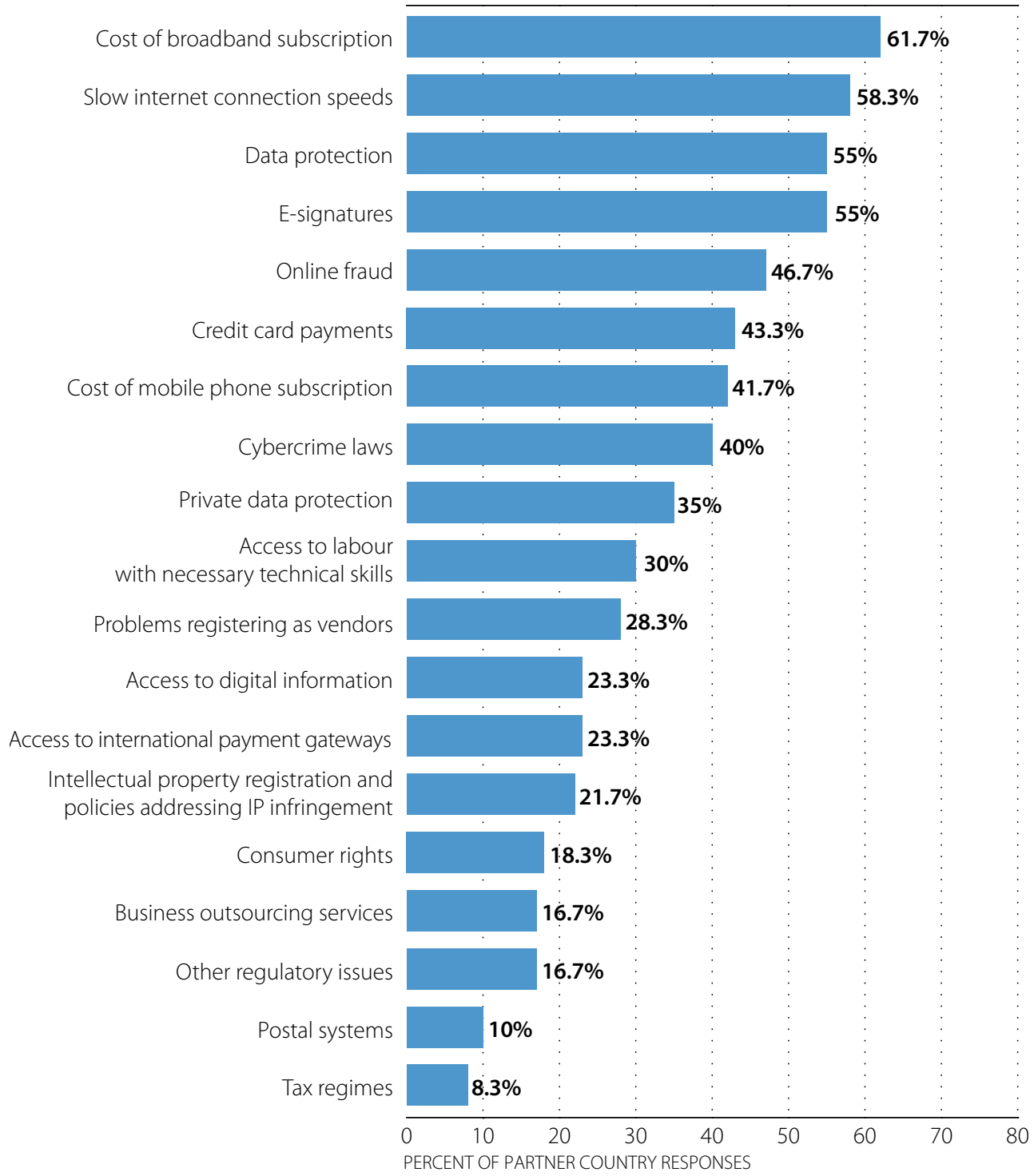




\section{Trade in services enhances export diversification through online supply}

A fourth channel through which services promote connectivity, and in particular digital connectivity, comprises services whose cross-border trade (mode 1) is enabled by advances in communications technology, making them easier to supply from a distance. Electronic supply of services also can occur within borders, including through foreign commercial presence. Services supplied online include intermediate services for the production of goods or other services (as noted above), but also final export products for direct consumption. Services provided online span almost all sectors: professional, business, audio-visual, education, distribution, financial or even health services.

As noted already, the strong growth of trade in services is largely a result of the Internet revolution. Studies have found that greater Internet penetration and usage are associated with higher levels of trade in services, both in terms of exports and imports (Choi, 2010; Freund and Weinhold, 2002).

Technological advances and increased tradability have led to significant change in the composition of trade in services, as shown in Figure 4.7. The relative importance of travel and tourism in BOP statistics has diminished considerably, while other commercial services now account for $56 \%$ of global trade in services and include some of the most dynamic components of world trade today.

Figure 4.7. Exports of commercial services by main category and by sub-sector

\section{By category (1995 and 2016)}
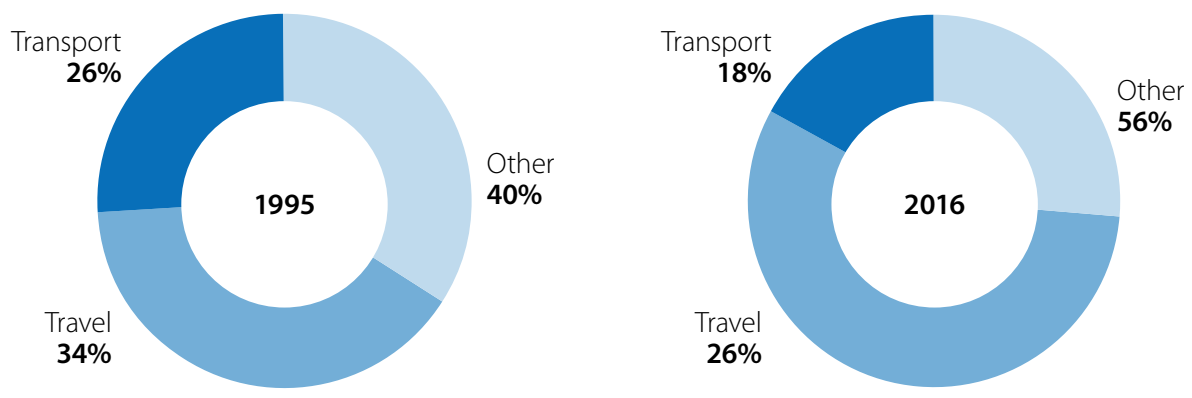

\section{By sub-sector, 2015}

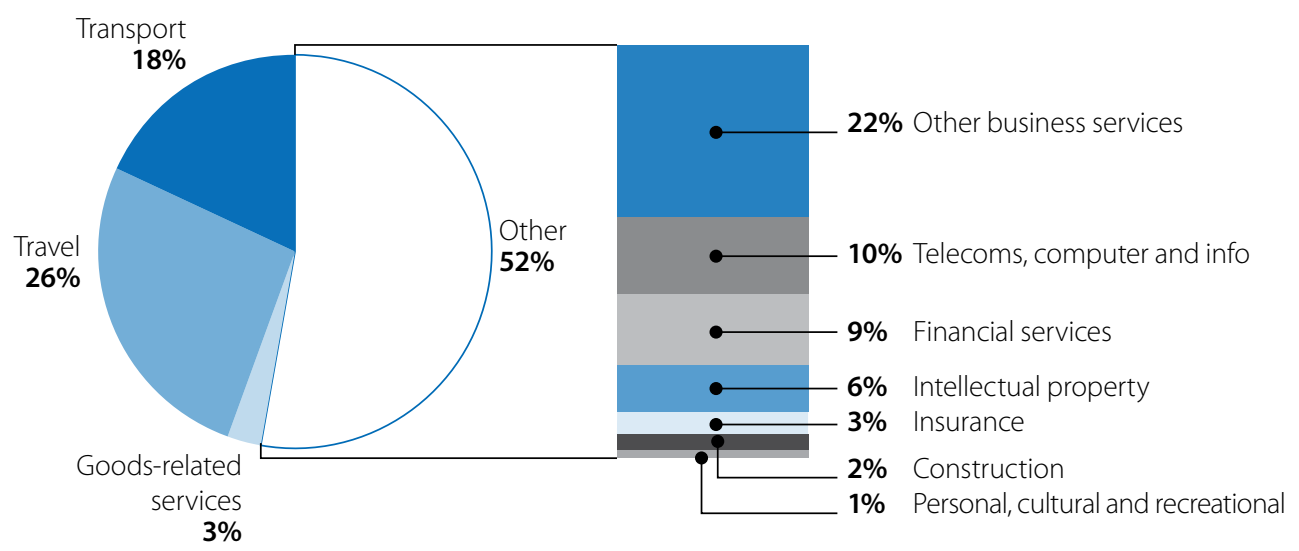

Source: Computed on the basis of WTO Statistics Database, http://stat.wto.org/StatisticalProgram/ WSDBStatProgramHome.aspx?Language $=\mathrm{E}$ 
Figure 4.8 shows that some service sectors falling under the "other commercial services" category are among those that have experienced the most vigorous growth in recent decades, with trade in computer services exhibiting an average annual growth of 18\% (in BOP terms) since 1995, financial services 11\%, and other business services 9.6\%. Not surprisingly, these are all services that can be supplied electronically and that have benefited significantly from the increased efficiency of digital networks. The cross-border supply of these services offers potential for new export opportunities and for export diversification.

Figure 4.8 Growth of global exports of commercial services by sub-sector, 1995-2014

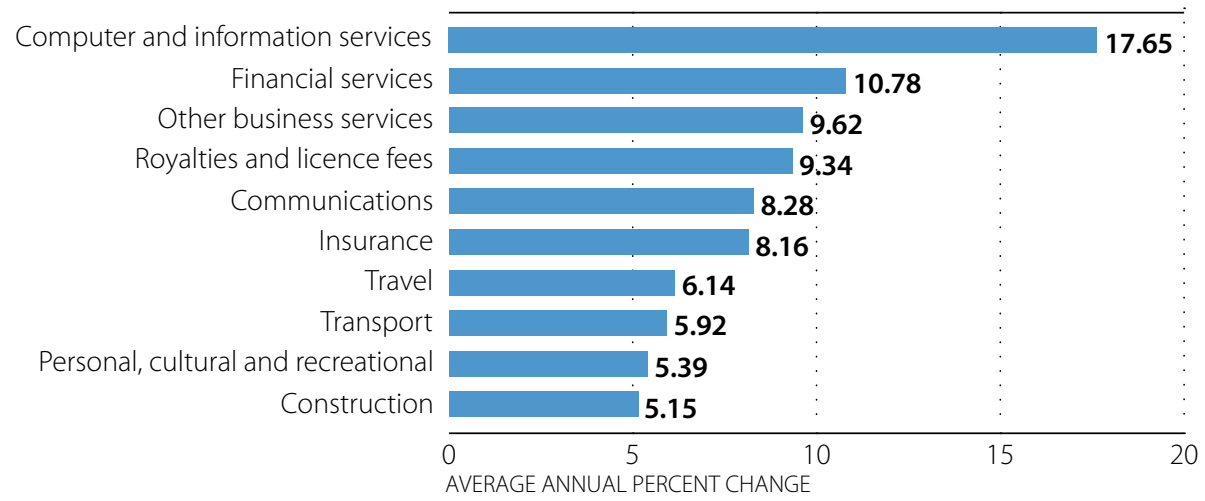

Source: Computed on the basis of WTO Statistics Database, http://stat.wto.org/StatisticalProgram/ WSDBStatProgramHome.aspx?Language $=$ E.

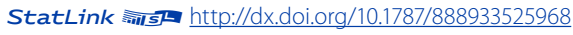

Developing countries are taking greater advantage of direct export opportunities offered by the digital revolution. Their share of global trade in services has risen from 29\% in 2005 to 38\% in 2015. In the OECD-WTO 2017 aid-for-trade monitoring exercise, a majority of developing country governments said that computer, financial, and tourism services were the fastest growing export sectors in their countries (OECD-WTO, 2017).

India offers a prominent example of a developing country that has built up export capacity in sectors such as computer services and business process outsourcing (BPO). With about $20 \%$ of the total global exports of computer services, India is, together with Ireland, the global leader in this field; it also accounts for $60 \%$ of the global market for offshoring of information technology (IT) services (OECD-WTO, 2015).

In a number of developing countries, services export opportunities related to offshoring and digitalisation have been facilitated by government policies and engagement with the private sector. The success of the Philippines in BPO was underpinned by the abolition of foreign ownership limitations, the creation of information technology parks, and the promotion of affordable access to liberalised telecommunications (Balchin et al., 2016). Cases in Jordan and Senegal (Box 4.3) illustrate how suppliers of a variety of ICT-enabled services, benefitting from reliable and competitively priced telecom infrastructure as well as promotion efforts by the government, have expanded across their respective regions. Increased possibilities to supply services cross-border through digital networks also provide better access to essential services, thereby helping to meet the SDGs focused on health, education and energy. They are also central to the efforts of tourism operators to expand their consumer base and service offerings (Dihel and Goswami, 2016). 
Box 4.3. ICT services in Jordan and Senegal

In Jordan, start-up companies have used ICT developments to expand their trade in services. Jordan has produced a number of local ICT service companies that have expanded trade with other countries in the Gulf through a combination of modes of supply. As trade has grown, some of the companies have moved segments of their operations to locations such as Dubai. For example, MarkaVIP, an online retailer, has grown far beyond its roots in Jordan. Its delivery network extends to six Gulf countries as well as Lebanon, and it plans to begin offering products in Egypt. MarkaVIP's head office is now in Dubai, where most of its customers are located. However, harnessing Jordan's reserves of educated people, MarkaVIP has kept most of its back office, as well as its call centre and finance employees, in Amman, supplying these services remotely. Other successful Jordanian-founded companies include Jamalon, an online bookseller that is expanding substantially in the Gulf. Arabia Weather, the region's largest online private weather company, was founded in Amman and has established itself in Dubai as it expands its presence in the region. Aramex, a logistics group, is another example of a company that started up in Amman, rapidly expanding to take advantage of the growing trade opportunities offered by the region's larger markets, while continuing to supply back office services from Jordan. Jordan has also carved out a niche in ICT innovation for cross-border online outsourcing, for example through the translation and cultural adaptation of English-language media and web content. Jordan's government has promoted the ICT sector as a source of jobs, considering its main resources to be its people. One of the means of support is Oasis500, a government-promoted business accelerator to help start-ups grow through mentorship and funding. Government support was also lent for the development of the Jordan Gaming Lab, a training facility for aspiring software designers that was set up in 2011. It has helped Jordan become one of the region's leading suppliers of original gaming content. Jordan has a telecoms infrastructure that surpasses most other countries in the region in terms of bandwidth, infrastructure, consistency, and price, constituting a clear asset for ICT companies and making online trade more feasible.

Senegal is another developing country that has recently experienced strong growth in services exports, driven in large part by the export of ICT services. Senegal's most important export services (on a BOP basis) are in the area of "other commercial services" (49.5\%), followed by travel (36.5\%) and transport (12.8\%). ICT services are the main component (51.6\%) of the "other commercial services" category. Policies targeting the domestic environment have played a key role in facilitating the success of service suppliers in ICT and BPO. Key steps include the liberalisation of the sale of computer terminals in 1997, the lowering of tariffs on computer imports, and a series of policies to create a more competitive and efficient telecommunication sector. These policy choices include privatisation of the incumbent telecom operator, pre-commitments on telecommunication services, adoption of the Reference Paper on Regulatory Principles in the extended GATS negotiations on telecommunications, and the establishment of an independent telecom regulator. All of this helped provide ICT and BPO service operators with access to relatively low-priced and robust infrastructure that has allowed them to expand. These efforts have been complemented by reforms in other areas, such as the inclusion of incentives in the investment code and the adaptation of the labour code to take into account the work schedules of call-centres.

Exports of Senegalese BPO and ICT services are mostly in mode 1, although some suppliers have also established a commercial presence abroad, mostly in other West African countries. Experts also travel regionally to work for subsidiaries and to provide consulting services directly (mode 4). For example, Call Me_created in 2002 as a subsidiary of Chaka Group, the Senegalese computer engineering firm - is 100\% owned by Senegalese interests. Call Me provides BPO services, including voice services and outsourced appointment-taking for visa applications. It also provides advisory services (quality management, team training, and performance in customer teams). Call Me has numerous customers in Senegal and abroad (France, Belgium, Switzerland). In Africa, Call Me has opened subsidiaries in Mali (2003), Côte d'Ivoire (2004), Guinea and Mauritania (2005), and Cameroon (2008). Currently, the domestic Senegalese market accounts for approximately 25\% of Call Me's turnover, while 60\% is generated from other African markets and 15\% from non-African foreign markets.

Sources: Jordan case adapted from John Reed (Financial Times, 22 December 2015), "Jordan seeks to reinvigorate its IT". Senegal case adapted from Doumbouya et al. (2015), "Business Process Outsourcing and Information Technology Services: A Case Study of Senegal”. 


\section{POLICIES IN SERVICES TRADE HAVE AN IMPACT ON CONNECTIVITY}

The previous section highlighted four channels through which trade in services can play a fundamental role in connecting countries to the trading system and the global economy. However, the policies governments apply in relation to services trade have an impact on connectivity, either enhancing or limiting it (Box 4.4). An enabling policy environmentpromoting competition, openness to trade and investment, and with adequate regulatory frameworks_can enhance connectivity, lower trade costs, and foster growth and economic performance.

This section focuses on the role of policies in services trade. It first presents the state of costs and of restrictions in services trade, before discussing the role of international commitments. It then reviews how policies in services trade affect diverse facets of connectivity and, more generally, impact economic performance.

Box 4.4. Services trade barriers

Barriers to trade in services are not barriers at the border. They are, rather, embedded in legal and regulatory frameworks and most typically involve government measures that discriminate between foreign and domestic services or suppliers (GATS Article XVII: National Treatment). Services trade barriers may also take the form of nondiscriminatory measures that, for example, limit or restrict the total number of service suppliers or operations; the value of transactions; or the type of legal entity through which a supplier may provide a service (GATS Article XVI: Market Access). Taken together, market access and national treatment measures largely determine the extent to which there is international contestability and competition in a country's service market.

Across modes of supply, services trade barriers may include, for example, monopolies, discretionary foreign investment screenings, foreign equity limits, caps on the number of licences, restrictions on the temporary movement of natural persons supplying services, and discriminatory subsidies or licensing requirements. Services trade policies also include measures closely related to the supply of services by foreign suppliers, whether across borders, through establishment, or by means of natural persons moving to supply services.

\section{Barriers to trade in services raise costs}

Economic isolation is not solely the result of geography and low levels of development. Policies in services trade can have a fundamental economic impact, engendering significant costs, and limiting connectivity and related economic benefits. Furthermore, because services constitute inputs to merchandise trade, they are an important determinant of trade costs for goods. Yet restrictions to investment and cross-border trade in services remain high and widespread.

The costs of cross-border trade in services are much higher on average than those of trade in goods. By one recent estimate, trade costs were $277 \%$ ad valorem for final services and 194\% for intermediate services (Miroudot and Shepherd, 2016: p. 73). ${ }^{6}$ Overall, services trade costs have only decreased slightly over the past 10-15 years, in contrast with trade costs for goods, which have come down significantly.

While such measures encompass all types of trade costs (e.g. distance, consumer preferences, regulatory divergence) and do not represent measures of protection, barriers to trade in services contribute significantly to estimated services trade costs. The OECD and the World Bank have developed services trade restrictiveness indices (STRI) that captureby country, mode of supply, and service sector-the extent to which government policies restrict services trade. These datasets show high overall levels of services barriers, although variations across sectors, regions and levels of development are important. ${ }^{8}$

Sectors such as professional and transport services, for example, tend to be more restricted than telecom, computer or distribution services. Figure 4.9 shows the levels of restrictiveness for a sample of sectors and highlights STRI scores for developing and developed economies. It reveals that developing economies have, on average, higher levels of restrictiveness in all sectors covered. The gap between developed and developing economies is particularly important in telecommunication and financial services, two backbone infrastructure service sectors. 
STRI scores also show the extent to which service sectors that are particularly important for connectivity are subject to varying levels of trade restrictions around the world. Sectors fundamental to the movement of goods within and across borders, such as transport services, face significant restrictions in a number of countries. Similarly, despite the role of telecommunication services as an enabler for the electronic supply of services and for e-commerce more generally, services trade in mode 3 is limited in a number of countries by restrictions on the establishment and operation of foreign suppliers.

\section{Figure 4.9. STRI scores for developing and developed economies, by sector}

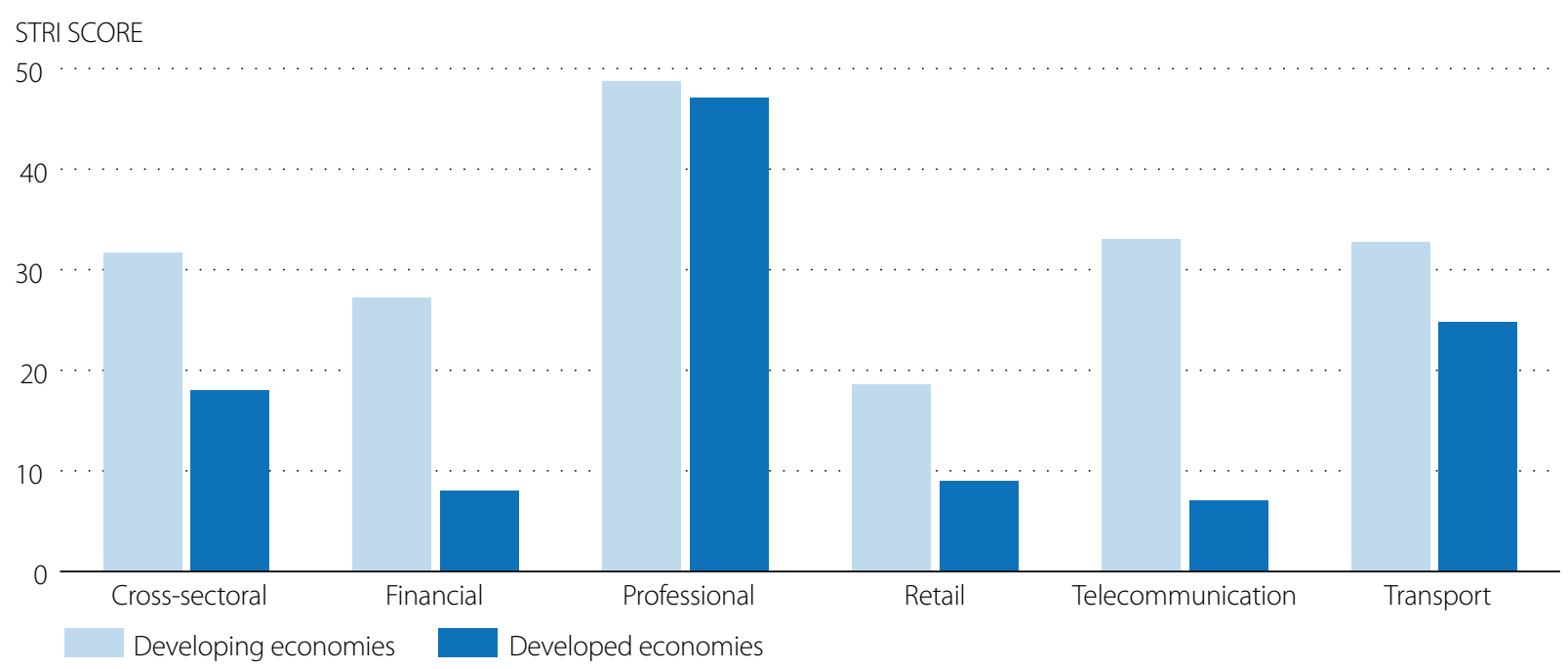

Source: Computed on the basis of the World Bank's Services Trade Restriction Database, http://iresearch.worldbank.org/servicetrade/home.htm, (accessed 01 May 2017).

StatLink 게패 http://dx.doi.org/10.1787/888933525987

While STRIs do not yet track the evolution of restrictiveness levels over time, evidence suggests that there have been slight reductions in these levels. Indeed, a recent study shows that over the past decade, most trade policy changes in the service sectors have been trade-facilitating rather than trade-restrictive, for both developing and developed countries, and that most of these policy changes concerned mode 3. However, the number of trade restrictive measures, and their relative importance, appears to have increased in the aftermath of the 2008-09 financial crisis (Roy, 2016).

\section{Uncertainty around lack of binding commitments may raise costs further}

The uncertainty associated with the fact that a significant range of policies in services trade are not bound to the WTO may result in certain additional costs. Research has shown that the predictability of market access conditions underpinned by the WTO system of disciplines has commercial value in itself (WTO, 2014). In the case of goods, trade policy uncertainty — measured as the gap between bound and applied tariffs (also known as tariff "water") —is a significant trade impediment (Osnago et al., 2015). ${ }^{9}$

In the case of trade in services, even when barriers are low, there is often no certainty that these may not rise in the future as a result of pressures for protection. The perceived benefits of increased bindings on services in regional trade agreements likely explains, in good part, the proliferation of such accords over the past 15 years. 
Figure 4.10. Percentage of schedules with commitments for mode 1 and mode 3 in selected sectors

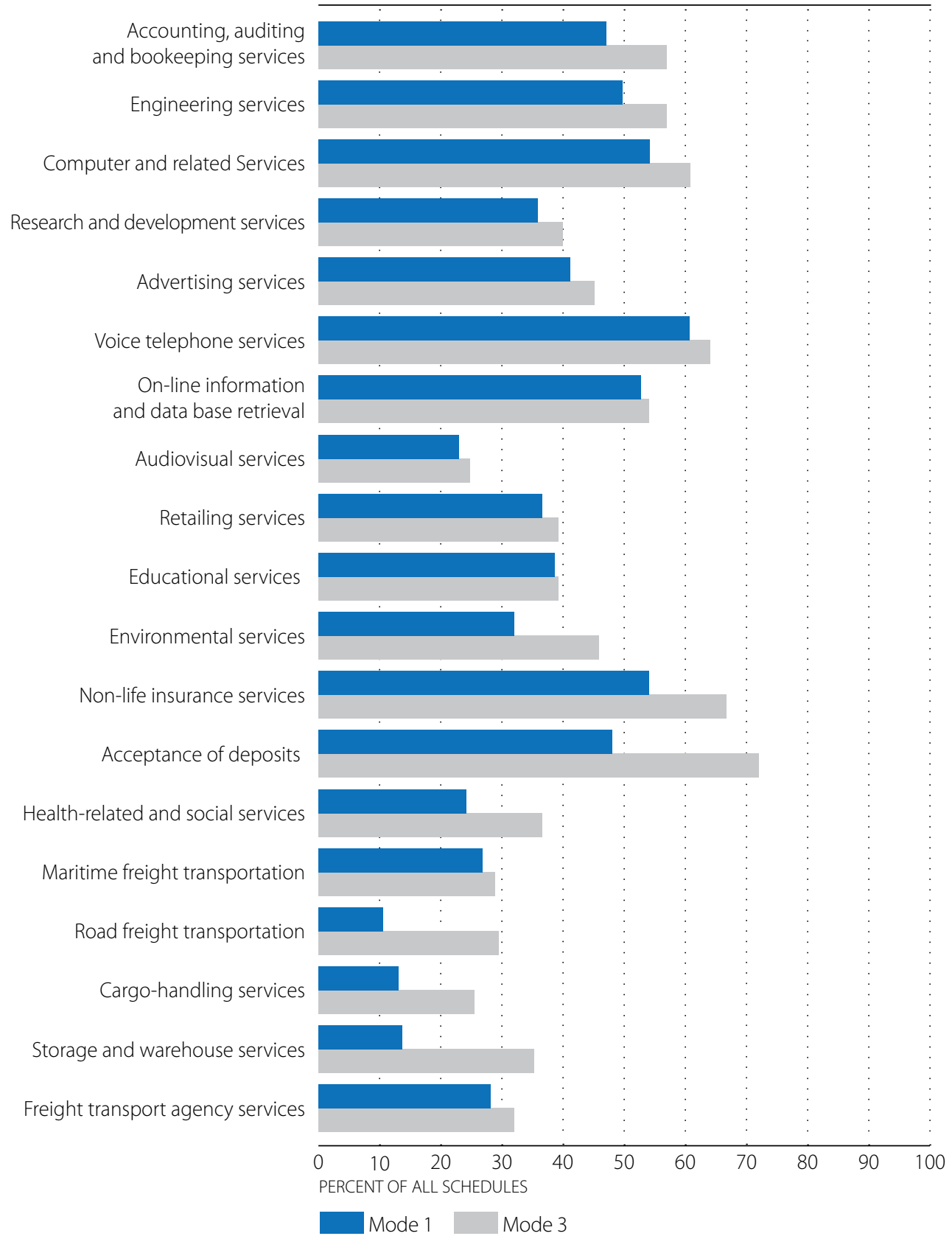

Note: The figure shows whether guarantees of a minimum level of market access and national treatment are provided for each sector and mode. It does not assess the level of openness guaranteed, how this level relates to the openness currently granted in practice, or whether it contains water.

Source: Computed on the basis of WTO Statistics Database, http://stat.wto.org/StatisticalProgram/ WSDBStatProgramHome.aspx? Language $=\mathrm{E}$

StatLink Aints http://dx.doi.org/10.1787/888933526006

WTO members have not so far managed to secure levels of binding obligation under the GATS agreement that are close to existing levels of openness (the equivalent of applied tariffs in the case of goods), although there are some exceptions (e.g. commitments of many acceding members). The majority of members have no specific commitments in the majority of service sectors. Further, where market access commitments are undertaken, these may contain water. 
Figure 4.10 shows the proportion of WTO members' schedules that have commitments for modes 1 and 3 in the service sectors that were highlighted above as being important for digital and other connectivity. For a number of services that underpin trade in goods, such as transport-related subsectors and retailing services, the proportion of schedules with commitments is rather low. In comparison, the proportion of schedules that contain commitments on cross-border supply and commercial presence for digital infrastructure services such as voice telephony, computer services, and database retrieval is higher, although more than two-thirds of the schedules provide no guarantees of treatment whatsoever in these areas. The Figure further highlights that fewer commitments are undertaken under mode 1 than mode 3, even for services where digital networks provide opportunities for cross-border electronic supply, such as accounting, engineering, research and development, advertising and audiovisual or educational services.

The regulatory principles in the Reference Paper on basic telecommunication services have been inscribed in the schedules of a number of members as "additional commitments"10 This Reference Paper aims to address the difficulty of effectively realising commitments on liberalisation in a sector that is characterised by dominant operators, even following the introduction of competition. The regulatory principles embodied in the Reference Paper concern anticompetitive cross-subsidisation, terms of interconnection, misuse of information, licensing criteria, transparency and other matters relevant to the prevention of abuse by dominant operators with respect to basic telecommunications. The proportion of members' schedules that include additional commitments in relation to the Reference Paper stands at 58\%. Of the 61 WTO members that have not inscribed the Reference Paper in their schedules, over half (31) are African governments.

The absence of commitments does not mean necessarily that supply by foreign suppliers through commercial presence or cross-border trade is prohibited, or that principles like those embodied in the Reference Paper are not applied. However, it signals that the openness or the regulatory practices that are in place are not secured by the WTO, and that they could be reversed at any time.

The limited sectoral scope of commitments under the GATS also means that other binding disciplines of the agreement that may have particular relevance for digital connectivity do not apply. For example, the guarantees of access provided by the GATS Annex on Basic Telecommunications apply only to the sectors where members have undertaken commitments. The Annex contains disciplines aimed at ensuring, among other things, that service suppliers have non-discriminatory and reasonable access to basic telecommunication networks for supplying their services, whether educational, professional or computer services. The obligations cover all forms of access and use necessary to supply such services, as well as the movement of information within and across borders. This last aspect is obviously of great relevance for preventing undue restrictions on movement of data.

\section{The openness of services trade policy has an impact on connectivity}

The growing availability of data on services regimes and trade flows has enabled research on the openness of services trade policies, which have been found to limit connectivity in various ways.

\section{Services trade policies affect productivity and performance}

Research has found that service sectors with lower trade costs - which are themselves associated in part with lower services barriers - tend to be more productive and to have higher growth in productivity than those with higher trade costs (Miroudot et al., 2012). Across developed countries, services policies, in particular restrictions to FDI in services, have been found to explain differences in total factor productivity (TFP), which in turn largely mirror differences in productivity growth, as well as aggregate growth (Van der Marel, 2012). 
Not surprisingly, there is also a negative correlation between entry barriers and regulatory restrictiveness in services, on the one hand, and investments in digital technologies and ICT on the other (World Bank, 2016a). This suggests that barriers to entry and competition in service sectors reduce the incentive of suppliers to invest in digital technologies (e.g. use of cloud facilities by transport companies, supply of online services by professional services firms, or use of the Internet by retailers).

Barriers to trade in services also may shield domestic suppliers from competition, leading to higher prices and reduced incentives to invest, innovate, or otherwise improve service quality. Indeed, services trade restrictions, measured by the STRI, are negatively associated with performance in a number of important service sectors, as measured by comparable indicators across a broad range of countries. For example, countries that are more trade restrictive in commercial banking have less-developed credit markets (Nordås and Rouzet, 2016).

\section{Restrictive policies in services trade limit physical connectivity}

With respect to transport and physical connectivity, higher levels of services trade restrictiveness in logistics, maritime and road transport are associated with greater delays in the domestic legs of transport (Nordås and Rouzet, 2016; Figure 4.11).

Focusing more specifically on the transport of containerised cargo on liner vessels, a study finds that government restrictions in the shipping sector, especially in relation to foreign investment, significantly increase maritime transport costs (Bertho et al., 2016). Because most global trade in merchandise takes place through this mode of transport, these restrictions considerably reduce seaborne trade flows."

As noted earlier, policy restrictions in the road transport sector increase the price of trucking services, and thereby increase trade costs, especially for landlocked countries. In Africa, for example, evidence suggests that the high price of transport is largely the result of government policies regulating the sector (Raballand and Macchi, 2009). Studies suggest that when government restrictions to competition are in place, investments in infrastructure produce lower returns in terms of reducing transport prices and trade costs.

Figure 4.11. STRI in relation to export and import times (averages 2014)

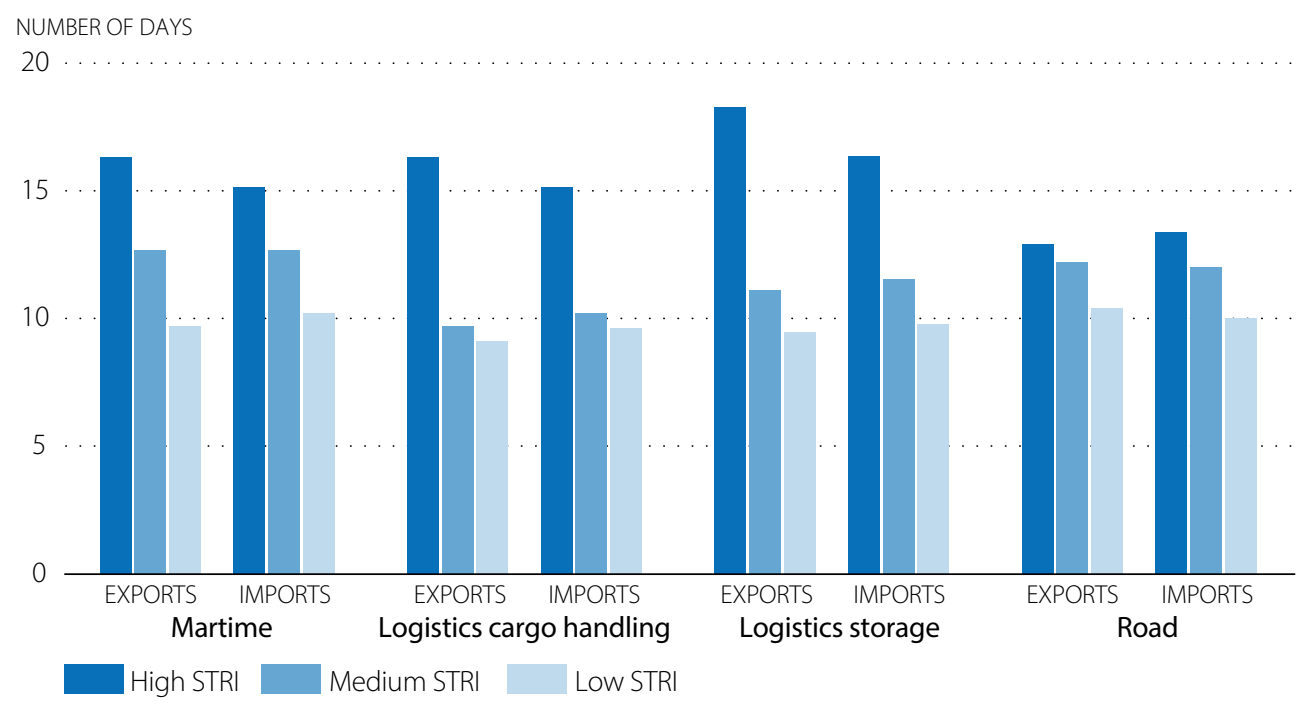

Source: Nordås and Rouzet (2016), "The Impact of Services Trade Restrictiveness on Trade Flows". 


\section{Services trade restrictions negatively affect foreign investment}

Recent research also evidences the negative impact of services trade restrictions on foreign investment inflows into service sectors. Countries with lower restrictiveness are significantly more likely to attract foreign investment in services than countries with more trade-restrictive regulatory frameworks (OECD, forthcoming (b)). Furthermore, restrictions not only limit new investments, but also are associated with lower sales for foreign affiliates already established in the host country. Aside from affecting foreign suppliers, regulatory restrictions also discourage small domestic firms and newer firms from competing in a market, with implications for innovation and job creation. This dissuading effect can limit investments in new technologies and network infrastructure, and restrain expansion in productive capacity, as well as curbing competition and availability of high-quality, low-costs services. This, in turn, has implications for connectivity because of its impact on the infrastructure services relied on for trade in goods, global value chains and digital services.

\section{Restrictions in services trade limit trade in goods}

Services trade policies also have implications in terms of connecting to the international trading system for goods. Achieving a reduction in trade costs for goods largely hinges on improving the performance of the services used by the goods-producing enterprises, reducing their costs and increasing their diversity and quality (Hoekman and Shepherd, 2017). A body of country-specific studies has firmly established that openness in services trade positively affects the productivity of manufacturing industries (Arnold et al., 2011; Arnold et al., 2015; Arnold et al., 2008; Duggan et al. 2013).

Recent research has also emphasised the role of FDI policies for the service sectors. Using data for over 100 developing countries, Hoekman and Shepherd (2017) find that openness in services trade is a significant determinant of performance in manufactured exports, with inward FDI being the main channel through which services policies negatively affect exports. This is consistent with earlier research suggesting that investment openness is an important determinant of countries' participation in global value chains-even more important than tariff barriers (OECD-WTO, 2015; Kowalski et al. 2015).12

\section{Restrictions limit cross-border trade in services}

Restrictiveness in services trade is found to raise costs for foreign exporters, thereby limiting cross-border trade in services -including services supplied over digital networks. ${ }^{13}$ Yet these restrictions are also found to limit the services exports of the country imposing the measures (Nordås and Rouzet, 2016). This may be because restrictions, by limiting competition, negatively affect the performance of domestic suppliers, reducing incentives to improve efficiency through innovation, adoption of new technologies and investment. This in turn affects the capacity of domestic suppliers to compete in international markets. Also, because services companies, like producers of manufactured goods, use inputs from other service sectors, raising the cost of imported inputs can make them less competitive and limit their export potential (Nordås and Rouzet, 2016). ${ }^{14}$

\section{Services policies for the telecommunication sector can help bridge the digital divide}

Policies in services trade also play a key role in the development of the backbone infrastructure that enables digital trade, with resulting impacts on the economy as a whole.

Over the past 25 years, regulation in the telecommunication sector has undergone fundamental transformations. A large majority of countries has moved from monopolies to regulatory environments that encourage effective competition, with reduced barriers to entry and often privatised state-owned incumbents (ITU, 2016b). Many studies have found that these changes have been associated with enhanced affordability, as well as higher quality and greater diversity of telecommunication services (Lestage et al., 2013). 
As noted in Chapter 5, countries that have introduced quality regulation-including, in particular, regulation allowing competition - have had greater success than other countries in stirring up market growth and developing their digital economy. Positive regulatory settings are necessary to drive ICT investment, use and uptake. Bridging the digital divide, therefore, hinges largely on government policies..$^{15}$ As reported by the UN Broadband Commission (2013), a study of 165 countries shows that between 2001 and 2012, mobile broadband penetration levels were 26.5\% higher in countries with competitive markets (UN, 2013; ITU, 2014).16

Open trade and investment policies in the telecommunication sector, supported by adequate regulatory frameworks, can thus be seen as key building blocks for the development of quality infrastructure to help reduce the digital divide and take advantage of digital opportunities. Policies affecting foreign commercial presence may prove to be a particularly determinant factor. Studies have shown that markets characterised by more intense competition have seen greater price decreases and improved services; others have linked telecommunications liberalisation to higher GDP growth rates (Mattoo et al. 2006; Eschenbach and Hoekman 2006), as well as higher productivity of firms in other sectors (Arnold et al., 2008; Balchin et al., 2016).

Finally, the quality of digital infrastructure, including telecom infrastructure, as well as the availability and use of ICT services are perceived by governments as key determinants of a country's participation in global value chains (OECD et al., 2014). In surveys of SMEs, unreliable and/or low-band Internet access was ranked as the leading perceived constraint to entering, establishing or moving up ICT value chains (WTO, 2016b).

\section{AID FOR TRADE AND POLICIES IN SERVICES TRADE}

Services are essential channels for connectivity. Yet services trade policies, depending on the direction they take, can either severely limit or greatly enhance the service sector's contribution to economic growth, development, and integration into the world trading system. Services trade barriers, together with inadequate regulatory frameworks that limit competition and investment, thereby raising costs_-including trade costs-are key impediments to connecting through services.

This suggests that aid for trade can play an important role in supporting the governments of developing countries in their efforts to enhance connectivity by adapting their policies to provide an enabling environment for service markets. This can promote the emergence of service providers, improve the quality and cost of services for other users, and encourage innovation and investment.

Table 4.1 shows that service sectors receive a significant part of aid-for-trade flows. Transport and storage account for a sizable share of total flows (28.54\% in 2015), as does energy (29.83\% in 2015). However, for these two categories a significant share of disbursements relate to hard infrastructure (physical installations such as roads or airports) rather than soft infrastructure (government policies and service markets). Indeed, classification of aid-for-trade data does not provide sufficiently disaggregated information to fully capture the extent to which development assistance currently contributes to the regulation of service markets or, even less, to services trade policy. Other services categories, such as communications, business and other services, or tourism, account for a relatively small—and diminishing —share of total flows. ${ }^{17}$ 
Table 4.1. Percentage of total aid for trade disbursements by sector, 2002-15

\begin{tabular}{lccccc} 
& $\mathbf{2 0 0 2 - 0 5}$ & $\mathbf{2 0 0 6 - 0 8}$ & $\mathbf{2 0 0 9 - 1 1}$ & $\mathbf{2 0 1 2 - 1 4}$ & $\mathbf{2 0 1 5}$ \\
\hline Transport and storage & $\mathbf{2 7 . 4 6}$ & $\mathbf{3 0 . 5 6}$ & 30.51 & $\mathbf{2 9 . 3 6}$ & $\mathbf{2 8 . 5 4}$ \\
\hline Communications & $\mathbf{2 . 5 6}$ & $\mathbf{1 . 5 8}$ & 1.58 & 1.66 & 1.05 \\
\hline Energy & 21.89 & 21.48 & 23.51 & 27.92 & 29.83 \\
\hline Banking and financial services & 7.24 & 8.05 & 8.08 & 10.15 & 10.15 \\
\hline Business and other services & 5.76 & 6.33 & 4.67 & 3.34 & 3.44 \\
\hline $\begin{array}{l}\text { Agriculture, forestry, fishing, mining, } \\
\text { manufacturing }\end{array}$ & 31.49 & 28.06 & 28.02 & 24.96 & 24.93 \\
\hline Trade policy and regulations & 3.19 & 3.28 & 3.19 & 2.38 & 1.90 \\
\hline Tourism & 0.42 & 0.66 & 0.44 & 0.23 & 0.16 \\
\hline
\end{tabular}

Source: OECD-DAC CRS: aid activity database (2017b), DOl: http://dx.doi.org/10.1787/data-00061-en, (accessed 07 April 2017).

In view of the important contribution of services trade policy to connectivity, there are two areas where aid for trade could make a difference:

1. helping to improve foreign investment policy for services

2. providing assistance in the design, assessment, and implementation of trade-related service sector reforms, and associated regulatory frameworks.

Foreign investment policy, while applicable to all economic sectors, is particularly relevant for services. This is true for two reasons: 1) most global FDI goes into service sectors; 2 ) the barriers to FDI in services are for the most part supply barriers through mode 3 (commercial presence). In some countries, FDI policy is still restrictive. Improving the policy environment for FDI in services can help attract the foreign and private investment needed to fill infrastructure gaps and investment shortfalls, contributing to achieving the SDGs in these countries. Indeed, UNCTAD has stressed that public finances alone will not suffice to meet SDG-implied demands for financing and has stressed that the contribution of the private sector is therefore indispensable for many developing countries (UNCTAD, 2014). FDI is especially important for the LDCs.

Indeed, funding for the development and upgrade of public infrastructure for sectors such as transport (ports, roads, railways, airports) and energy (electricity and natural gas transmission and distribution) will, to a good extent, come from the private sector. As shown in Figure 4.12, this is particularly true for the ICT sector, where private investment in public infrastructure, including land-based and submarine cables, dwarfs official development assistance: the former totalled USD 702 billion between 2004 and 2015, a hundred times more than official development assistance for communications (USD 6.8 billion) over the same period. ${ }^{18}$ Private participation in ICT infrastructure projects during this period largely took the form of greenfield investments (73\%).

These data clearly underscore the preponderant role of private investment-typically foreign investment-in developing digital infrastructure and, thereby, in helping bridge the digital divide. They also point to the importance of the enabling environment framed by government policy, a key determinant of FDI. 
Figure 4.12. Official development assistance and private participation in infrastructure, by sector, 2004-15

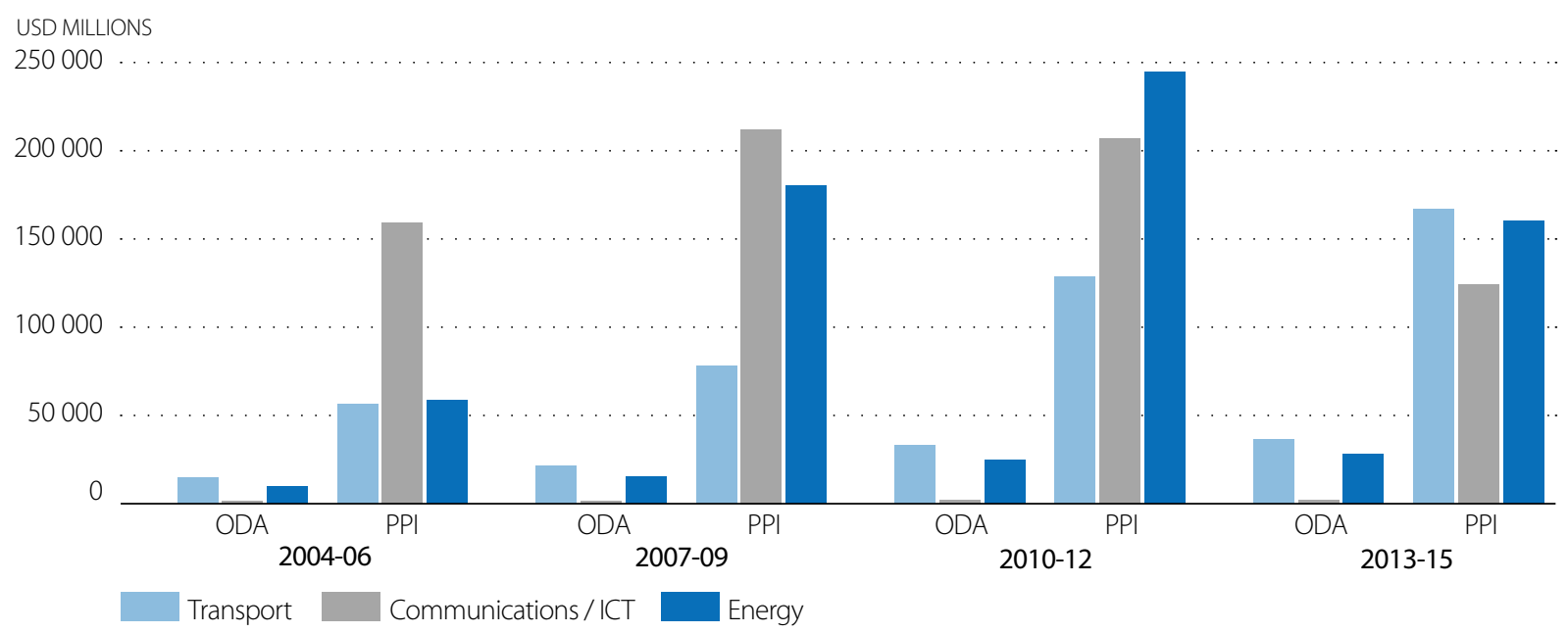

Note: PPI = private participation in infrastructure. The PPI data from the World Bank Private Participation in Infrastructure database records contractual arrangements for public infrastructure projects in low and middle income countries that have reached financial closure, in which private parties assume operating risks. Projects recorded in the database do not have to be entirely privately owned, financed or operated; some have public participation as well. Accordingly, the value of investment projects in the database is the total investment value, and not solely the amount invested by the private sector.

Source: Data on private participation in infrastructure from the World Bank PPI Database (2016b), https://ppi.worldbank.org/data, (accessed 01 May 2017); ODA statistics from the OECD-DAC CRS: aid activity database (2017b), DOl: http://dx.doi.org/10.1787/data-00061-en, (accessed 07 April 2017). StatLink 部穴 http://dx.doi.org/10.1787/888933526044

Despite the overall benefits, however, upgrading of FDI policies is not always easy to carry out, especially for smaller countries with stretched capacities. In developing country governments where there is an interest, assistance in this regard could, for example, help to:

assess the costs/benefits of the existing policies

assess the extent to which the existing policies depart from international best practice and how this impacts on attracting investments

- devise and set up less restrictive ways to achieve national policy objectives in relation to foreign investment

- simplify procedures and enhance transparency

- update foreign investment laws and regulations, and implement the new policies

assess, monitor and measure the effects of new policies in terms of attracting and retaining investment, as well as their effects on employment, the development of service sectors, and their contribution to connectivity.

Technical assistance of this kind_-involving officials, politicians, and other stakeholders_can also help to inform the decision-making process. A recent project in Myanmar provides an example of development assistance along those lines (Box 4.5). 
Box 4.5. The Myanmar investment policy project

Myanmar shares borders with China, India, Bangladesh, Thailand and Lao PDR — countries representing almost 40\% of the world's population and many of the world's fastest growing economies. Myanmar itself has substantial natural resources and vast stretches of underutilised land.

Although investors showed keen interest in opportunities in Myanmar, the economy was underperforming because of excessive and outmoded regulations. Despite a pro-market reform program, in 2014 FDI in Myanmar was declining. To boost the economy, attracting investment in a wide range of sectors with employment generation potential was essential. Yet growth and diversification were hampered by unclear, discretionary, and onerous entry and screening procedures that burdened would-be investors. The government requested assistance from the World Bank Group to address the inadequacies in the legal and regulatory environment that impeded investment. The goal was to assist Myanmar in attracting sustainable private sector investment by generating savings through streamlined administrative procedures.

In the fall of 2016, Myanmar's national legislature passed an investment reform law, culminating a three-year World Bank Group effort to accelerate economic reform and increase investment and trade. The new law is expected to streamline tax laws, regulatory processes, and investment approval requirements so as to generate substantial new foreign and domestic investment.

Source: OECD-WTO aid-for-trade monitoring exercise (2017), Public sector case story 100, http://www.oecd.org/aidfortrade/casestories/ public-sector-2017.htm

In the OECD-WTO 2017 aid-for-trade monitoring exercise, developing country governments underscored that improvements in the investment climate figured highly among their priorities. Indeed, $98 \%$ of the respondents indicated that their national development strategies included actions to improve the investment climate. For $93 \%$ of respondents, such actions included updates to their investment policies and regulations; 68\% indicated that over the past five years they had taken concrete steps to facilitate the entry and operations of foreign investors).

Another area where development assistance can make a difference is in improving services-specific policies. As with foreign investment regimes, this assistance might involve helping interested countries to achieve policies in favour of connectivity services, whether on a sectoral basis (e.g. telecommunication or financial services) or with regard to specific modes of supply (e.g. modes 1 and 4). This may, for example, involve introducing competition in previously monopolised segments of the telecommunication market, relaxing limits on the supply of certain professional services in modes 1 or 4, or allowing new financial services products and transactions to be undertaken between non-resident financial institutions and resident consumers. While decisions on whether or not to undertake reforms obviously rest with the government, when the intention is to look at enhancing connectivity and upgrading policies in services trade, this type of assistance can be quite valuable. Indeed, the adequate sequencing of reforms can be an important factor and, because they often take place on a sector-by-sector basis, technical considerations - and therefore expertise — can be paramount. As for cross-sectoral FDI policies, support can also help in assessing the cost of existing policies, scoping the impact of policy change (including on the pursuit of social or other government policy objectives), and updating relevant regulations and ensuring their effective implementation.

Assistance might also cover adapting and reinforcing regulatory regimes in service sectors subject to trade-related reforms. There is broad recognition that increasing international contestability in service markets often requires adapting domestic regulatory frameworks. For example, allowing new transactions in cross-border financial services may require new supervisory functions as well as adaptation of prudential measures. Introducing competition in telecommunication services typically involves modifications in domestic policies in areas such as cross-subsidisation and anti-competitive practices, interconnection, universal service obligations, or the set-up and functions of an independent regulator. 
Technical assistance to facilitate the improvement and adaptation of regulatory frameworks for countries that have undertaken or decide to undertake reforms also would help ensure that the benefits of liberalisation are not undercut by inadequate regulatory frameworks.

Beyond the adaptation of regulatory frameworks to accompany liberalisation, development assistance could also target regulatory deficiencies that limit trade in services. This might include ensuring that domestic regulations are not discriminatory or unnecessarily burdensome, that they are transparent, or that they do not restrict trade (e.g. licensing and qualification procedures and requirements for companies or natural persons), it can also include ensuring that regulations promote effective competition in the market (adequate competition policy frameworks), and that they enable and foster the development of e-commerce.

Finally, assistance of this sort may include help in establishing a legal framework governing electronic transactions, and in ensuring its effective implementation and enforcement. It could involve, more specifically, devising the necessary regulatory framework to support online payment solutions, or updating relevant regulatory frameworks in the light of best practice in areas such as electronic signatures and authentication, fraud protection for consumers, protection of personal information, cybersecurity, or measures to limit unsolicited commercial electronic messages.

\section{CONCLUSIONS}

Services play a pivotal role in connecting countries to the global economy, including by enhancing trade in goods. They are an important contributor to economic growth, employment, financial inclusion and more generally to the Sustainable Development Goals. However, if policies in services trade are not sufficiently facilitating, they can hinder both physical and digital connectivity, making the achievement of development objectives more difficult.

Aid for trade can help by providing support for developing country governments that want to improve connectivity by reforming their policy environment for service markets. This support may focus, for example, on reducing trade costs by facilitating competition and contestability in the service sectors, or by increasing the transparency of regulatory frameworks.

Enabling environments can serve as a catalyst for attracting additional investment in infrastructure. They can also help to improve the performance of the service sectors in developing countries, thereby increasing their capacity to meet a diversity of societal needs and to take advantage of opportunities to export goods and services. 


\section{REFERENCES}

Arnold, J., A. Mattoo, and G. Narciso, (2008), "Services inputs and firm productivity in Sub-Saharan Africa: Evidence from firm level data', Journal of African Economies 17 (4): 578-99.

Arnold, J., B. Javorcik, and A. Mattoo (2011), "Does services liberalization benefit manufacturing firms? Evidence from the Czech Republic", Journal of International Economics 85(1): 136-46.

Arnold, J., B. Javorcik, M. Lipscomb, and A. Mattoo (2015), "Services reform and manufacturing performance: Evidence from India", The Economic Journal 126: 1-39.

Balchin, N., B. Hoekman, H. Martin, M. Mendez-Parra, P. Papadavid, D. Primack, and D. Willem te Velde (2016), Trade in Services and Economic Transformation, Overseas Development Institute, London: UK.

Bertho, F., I. Borchert, and A. Mattoo (2016), "The Trade-Reducing Effects of Restrictions on Liner Shipping", Journal of Comparative Economics 44 (2), pp. 231-42.

Borchert, I., B. Gootiiz, A. G. Goswami, A. Mattoo (2017), "Services Trade Protection and Economic Isolation", World Economy 40:3, pp. 632-652.

Borchert, I., B. Gootiiz and A. Mattoo (2012), "Guide to the Services Trade Restrictions Database", World Bank Policy Research Working Paper (WPS6108).

Cadot, O., A. Fernandes, J. Gourdon, A. Mattoo and J. de Melo (2014), "Evaluating Aid for Trade: A Survey of Recent Studies", World Bank Policy Research Paper 6742, Washington DC.

Choi, C. (2010), "The Effect of the Internet on Service Trade", Economics Letters 109, pp. 102-104.

Dihel, N. and A. G. Goswami (2016), From Hair Stylists and Teachers to Accountants and Doctors: The Unexplored Potential of Trade in Services in Africa, World Bank Group, Washington DC.

Doumbouya, S.F., A. Ndiaye, and D. Primack (2015), "Business Process Outsourcing and Information Technology Services: A Case Study of Senegal", in S. Stephenson and C. Tumuhimbise (eds.), Services Exports for Growth and Development: Case Studies from Africa, African Union Commission, Addis Ababa.

Duggan, V., S. Rahardja, and G. Varela (2013), Service sector reform and manufacturing productivity: Evidence from Indonesia, Policy Research Working Paper 6349, World Bank, Washington, DC.

Eschenbach, F., \& Hoekman, B. (2006), Services policy reform and economic growth in transition economies. Review of World Economics, 142(4), 746-764.

Fink, C., A. Mattoo, I.C. Neagu (2005), "Assessing the Impact of Communication Costs on International Trade", Review of International Economics 67:2, pp. 428-445.

Freund, C. and D. Weinhold (2002), "The Internet and International Trade in Services", American Economic Review 92 (2), pp. 236-240.

Hoekman, B. and B. Shepherd (2017), "Services Productivity, Trade Policy and Manufacturing Exports", World Economy 40:3, pp. 499-516.

ITU (2014), "Trends in Telecommunication Reform - Fourth-generation regulation: Driving digital communications ahead", International Telecommunication Union, Geneva.

ITU (2016a), ICT Facts and Figures 2016, International Telecommunication Union, Geneva.

ITU (2016b), "Trends in Telecommunication Reform 2016: Regulatory Incentives to Achieve Digital Opportunities", International Telecommunication Union, Geneva. 
Jafari, Y. and D. G. Tarr (2017), "Estimates of Ad Valorem Equivalents of Barriers Against Foreign Suppliers of Services in Eleven Services Sectors and 103 Countries", World Economy 40:3, pp. 544-573.

Kowalski, P., J. Lopez Gonzalez, A. Ragoussis, and C. Ugarte (2015), "Participation of Developing Countries in Global Value Chains: Implications for Trade and Trade-Related Policies", OECD Trade Policy Papers, no. 179, OECD Publishing, Paris.

Lestage, R., D. Flacher, Y. Kim, J. Kim, and Y. Kim (2013), "Competition and investment in telecommunications: Does competition have the same impact on investment by private and state-owned firms", Information Economics and Policy 25, pp. 41-50.

Mattoo, A., Rathindran, R., and Subramanian, A. (2006), Measuring Services Trade Liberalization and its Impact on Economic Growth: An Illustration, Journal of Economic Integration, 21(1), 64-98.

Maurer, A., R. Lanz, and J. Magdeleine (2016), "Measuring Trade in Services in a World of Global Value Chains", in Sauvé and Roy (eds.), Research Handbook on Trade in Services, Edward Elgar Publishing, Cheltenham, UK, pp. 42-65.

McKinsey Global Institute (2016), "Digital Globalization: The New Era of Global Flows", March 2016, McKinsey \& Company.

Miroudot, S. and B. Shepherd (2015), "The Paradox of 'Preferences': Regional Trade Agreements and Trade Costs in Services", World Economy, 19 May. DOl: 10.1111/twec.12178

Miroudot, S. and B. Shepherd (2016), "Trade Costs and Global Value Chains in Services", in Sauvé and Roy (eds.), Research Handbook on Trade in Services, Edward Elgar Publishing, Cheltenham, UK, pp. 66-84.

Miroudot, S., J. Sauvage, and B. Shepherd (2012), "Trade Costs and Productivity in Services Sectors", Economics Letters 114(1), pp. 36-8.

Miroudot, S., J. Sauvage, and B. Shepherd (2013), "Measuring the Cost of International Trade in Services", World Trade Review 12(4), pp. 719-735.

Nordås, H. and D. Rouzet (2016), "The Impact of Services Trade Restrictiveness on Trade Flows", World Economy.

OECD (2017a), Services Trade Restrictiveness Index (database), http://www.oecd.org/tad/services-trade/services-traderestrictiveness-index.htm

OECD (2017b), "OECD-DAC Creditor Reporting System: aid activity", OECD International Development Statistics (database). DOl: http://dx.doi.org/10.1787/data-00061-en, (accessed on 7 April 2017)

OECD (forthcoming (a), "The Trade Effect of Services Trade Restrictions", OECD Trade Policy Papers, Paris.

OECD (forthcoming (b), "Trading Firms and Trading Costs in Services; Firm-Level Analysis", OECD Trade Policy Papers, Paris.

OECD, WTO, World Bank Group (2014), "Global Value Chains: Challenges, Opportunities, and Implications for Policy", Report prepared for submission to the G20 Trade Ministers Meeting, 19 July 2014, http://www.oecd.org/tad/gvc report_g20_july_2014.pdf

OECD-WTO (2015), Aid for Trade at a Glance 2015: Reducing Trade Costs for Inclusive, Sustainable Growth, WTO, Geneva/ OECD Publishing, Paris. DOl: http://dx.doi.org/10.1787/aid_glance-2015-en

OECD-WTO (2016), "Trade in value added (Edition 2016)", OECD-WTO: Statistics on Trade in Value Added (database). DOl: http://dx.doi.org/10.1787/2644abe4-en. 
OECD-WTO (2017), aid-for-trade monitoring exercise 2017 (questionnaires) www.oecd.org/aidfortrade/countryprofiles/ Osnago, A., R. Piermartini, and N. Rocha (2015), "Trade Policy Uncertainty as Barrier to Trade", WTO Staff Working Paper ERSD-2015-05.

Raballand, G. and P. Macchi (2009), "Transport Prices and Costs: The Need to Revisit Donors' Policies in Transport in Africa", Bureau for Research and Economic Analysis of Development (BREAD) Working Paper 190, Washington, DC. Reed, J. (22 December 2015), Jordan seeks to reinvigorate its IT, Financial Times, https://www.ft.com/ content/01d01d48-8a34-11e5-90de-f44762bf9896

Roy, M. (2016), "Charting the Evolving Landscape of Services Trade Policies: Recent Patterns of Protection and Liberalization", in Sauvé and Roy (eds.), Research Handbook on Trade in Services, Edward Elgar Publishing, Cheltenham, UK, pp. 25-41.

Tang, L. (2006), "Communication Costs and Trade of Differentiated Goods", Review of International Economics 14:1, pp. 54-68.

Teravaninthorn, S. and G. Raballand (2009), Transport Prices and Costs in Africa: A Review of the Main International Corridors, World Bank, Washington DC.

Tuthill, L. (2016), "Cross-border Data Flows: What Role for Trade Rules?", in Sauvé and Roy (eds.), Research Handbook on Trade in Services, Edward Elgar Publishing, Cheltenham, UK, pp. 357-382.

UN Broadband Commission (2013), "The State of Broadband 2013: Universalizing Broadband", Report by the ITU and UNESCO, Geneva.

UNCTAD (2014), "World Investment Report 2014. Investing in SDGs: An Action Plan", United Nations Conference on Trade and Development, Geneva.

UNCTAD (2016), "World Investment Report 2016. Investor Nationality: Policy Challenges", United Nations Conference on Trade and Development, Geneva.

Van der Marel, E. (2012), "Trade in Services and TFP: The Role of Regulation", World Economy.

World Bank (2016a), World Development Report 2016: Digital Dividends", https://openknowledge.worldbank.org/ handle/10986/23347, Washington DC.

World Bank (2016b), Private Participation in Infrastructure Database, https://ppi.worldbank.org/data, (accessed 01 May 2017)

World Bank (2017), World Development Indicators (database), http://databank.worldbank.org/data/reports. aspx?source=world-development-indicators\&Type=TABLE\&preview=on, (accessed 10 May 2017).

World Bank (n.d), Services Trade Restrictions Database, http://iresearch.worldbank.org/servicetrade/home.htm, (accessed 01 May 2017).

WTO (2011), "Trade in value-added and global value chains: statistical profiles", www.wto.org/english/res_e/statis_e/miwi_e/ countryprofiles_e.htm

WTO (2014), "World Trade Report 2014 - Trade and Development: Recent Trends and the Role of the WTO", World Trade Organization, Geneva. 
WTO (2016a), "Aid-for-trade Work Programme 2016-2017: Promoting Connectivity", Committee on Trade and Development; Aid for Trade, 16 February 2016, WT/COMTD/AFT/W/60.

WTO (2016b), "Financial Inclusion and the GATS - Barriers to Financial Inclusion and Trade in Services", Note by the Secretariat, Committee on Trade in Financial Services, S/FIN/W/88/Add.1.

WTO (2016c), "World Trade Report 2016 - Levelling the Trading Field for SMEs", World Trade Organization, Geneva.

WTO (n.d.) WTO Statistics database, http://stat.wto.org/StatisticalProgram/WSDBStatProgramHome.aspx?Language=E 


\section{NOTES}

1. In a survey of firms, transportation and shipping costs were cited by SMEs as a leading impediment to engaging in global trade in manufacturing. SMEs in the US ranked this as the second most important impediment, while other firms did not include this among their top 5 impediments.

2. Estimations on the basis of data for 2011.

3. This does not take into account services provided within the territory through a foreign suppliers' commercial presence (mode 3).

4. Telecommunications are broadly defined in the GATS Annex on Telecommunications as "the transmission and reception of signals by any electronic means".

5. The LDC share of world trade in services remains very low in BOP terms, accounting for $1 \%$ of exports and $2 \%$ of imports in 2015. However, for a number of LDCs, services account for a high proportion of their total exports due to the relative importance of tourism: travel accounts for $10 \%$ of their total exports of goods and services, and for 53\% of LDC total exports of commercial services (2015).

6. Miroudot and Shepherd estimated the trade costs for 2011 using the World Input-Output Database for 40 economies. See also Miroudot et al (2013) and Miroudot and Shepherd (2015). The approach used in these studies does not calculate trade costs relative to a benchmark country, but rather is based on the country's trade in services in relation to domestic consumption of services. Such estimates focus on cross-border trade and do not attempt to assess trade costs for mode 3 (commercial presence) or mode 4 (movement of natural persons).

7. In a recent study, Jafari and Tarr (2017) calculate ad valorem equivalents of services trade barriers on the basis of the World Bank's STRI. In another study, the OECD (forthcoming (a)) has done similar work on the basis of STRI.

8. See OECD (2017a) for OECD STRI and Borchert et al. (2012) for the World Bank's STRI.

9. This study, which covers 149 countries, shows that the elimination of tariff water increases the probability of exporting by $12 \%$; a $1 \%$ decrease in water increases export volumes by $1 \%$. The study also finds that, on average, trade policy uncertainty is equivalent to a level of tariffs between $1.7 \%$ and $8.7 \%$.

10. The Reference Paper has been inscribed in schedules of commitments as "additional commitments". Additional commitments allow members to undertake legally binding commitments with respect to government measures other than those relevant for "market access and national treatment".

11. Restrictions are found to increase shipping costs by $26 \%$ to $68 \%$ and to reduce trade flows by $48 \%$ to $77 \%$.

12. Hoekman and Shepherd (2017) find that a 10\% increase in services trade restrictiveness is associated with a $5 \%$ decrease in bilateral trade in manufactured products. In terms of sectors, trade/investment restrictions on transport services and retailing services have the largest impact on the export performance of merchandise goods.

13. Cross-border trade in services here refers to transactions between residents and non-residents, and essentially serves as a proxy for modes 1,2 and (in part) mode 4

14. The negative impact of high STRI scores on exports may be due, at least in part, to the fact that services trade barriers are not always discriminatory, but rather include behind-the-border measures that impose costs on domestic suppliers as well. 
15. As observed in Chapter 5, significant gaps persist between developing and developed economies with respect to Internet access and, even more so, broadband access. In developed economies in 2016, fixed and mobile broadband subscriptions covered, on average, $30.1 \%$ and $90.3 \%$ of the population, respectively; in developing economies, these penetration rates stood at $8.2 \%$ and $40.9 \%$ (ITU, 2016a). The cost of mobile broadband is also much higher in a number of developing countries.

16. Higher STRI scores in telecommunication services are associated with lower penetration rates for fixed, mobile and broadband Internet (Nordås and Rouzet, 2016). See also Borchert et al. (2017).

17. Total flows, in constant dollars, have more than doubled over the period reviewed.

18. ODA for communication/ICT does not typically involve infrastructure upgrade. 



\title{
CHAPTER 5
}

\section{SPANNING THE INTERNET DIVIDE TO DRIVE DEVELOPMENT}

\author{
Contributed by the International Telecommunication Union
}

\begin{abstract}
Information and Communication Technologies (ICTS) are key building blocks of the digital economy, to facilitate trade and drive e-commerce. Strong growth in ICT infrastructure, connectivity, access and use promise great development opportunities but the full potential of the Internet remains untapped, as over half the world's population remains offline. Unless policy-makers address infrastructure, affordability but also broader socio-economic challenges outside the ICT ecosystem, the Internet is liable to reinforce existing inequalities, instead of addressing them. This chapter analyses progress but also the gaps that exist in developing countries - and in particular the least developed countries -in terms of infrastructure, connectivity and quality of service, particularly for mobile and fixed-broadband Internet. It addresses some key connectivity bottlenecks and points to recommendations to overcome these. The chapter looks at fixed-and mobile- broadband prices, and the affordability of services in developed and developing regions. In addition to addressing supply-side barriers, it examines demand-side barriers outside the ICT ecosystem, including broader socio-economic inequalities, digital and analogue skills, and the availability of relevant local content.
\end{abstract}




\section{INTRODUCTION'}

An increasingly ubiquitous, open, fast and content-rich Internet has changed the way many people live, communicate and do business. Internet uptake has been found to bring great benefits for people, governments, organizations and the private sector. It has opened up new communication channels, provided access to information and services, increased productivity and fostered innovation, and it facilitates trade in goods and services. Information and communications connectivity and use are key building blocks of the digital economy, and indispensable drivers of e-commerce.

The importance of infrastructure and connectivity is recognized by Sustainable Development Goal (SDG) 9, on industry, innovation and infrastructure. It issues a call to "significantly increase access to information and communications technology and strive to provide universal and affordable access to the Internet in least developed countries by 2020" (SDG Target 9c, UN 2016). ${ }^{2}$

This chapter analyses the gaps that exist in developing countries-and in particular the least developed countries (LDCs) - in terms of infrastructure, connectivity and quality of service, particularly for mobile and fixed-broadband Internet. ${ }^{3}$ It addresses some key connectivity bottlenecks and points to recommendations to overcome these. The chapter looks at fixed- and mobile- broadband prices, and the affordability of services in developed and developing regions. In addition to addressing supply-side barriers, it examines demand-side barriers outside the ICT ecosystem, including broader socio-economic inequalities, digital and analogue skills, and the availability of relevant local content.

\section{Global trends show rapid growth-as well as gaps—in the use of information and communications technology}

The rapid growth in access to and use of information and communications technology (ICT) throughout the world is illustrated by Figure 5.1. The steep rise in mobile-cellular subscriptions worldwide, which began early in this century, is tailing off as the global penetration rate approaches 100 subscriptions per 100 inhabitants. At the same time, there has been a gradual decline in the penetration rate for fixed-telephone subscriptions, owing to the tendency for new users to prefer mobile over fixed lines.

\section{Figure 5.1. Global changes in levels of ICT uptake, 2006-16}

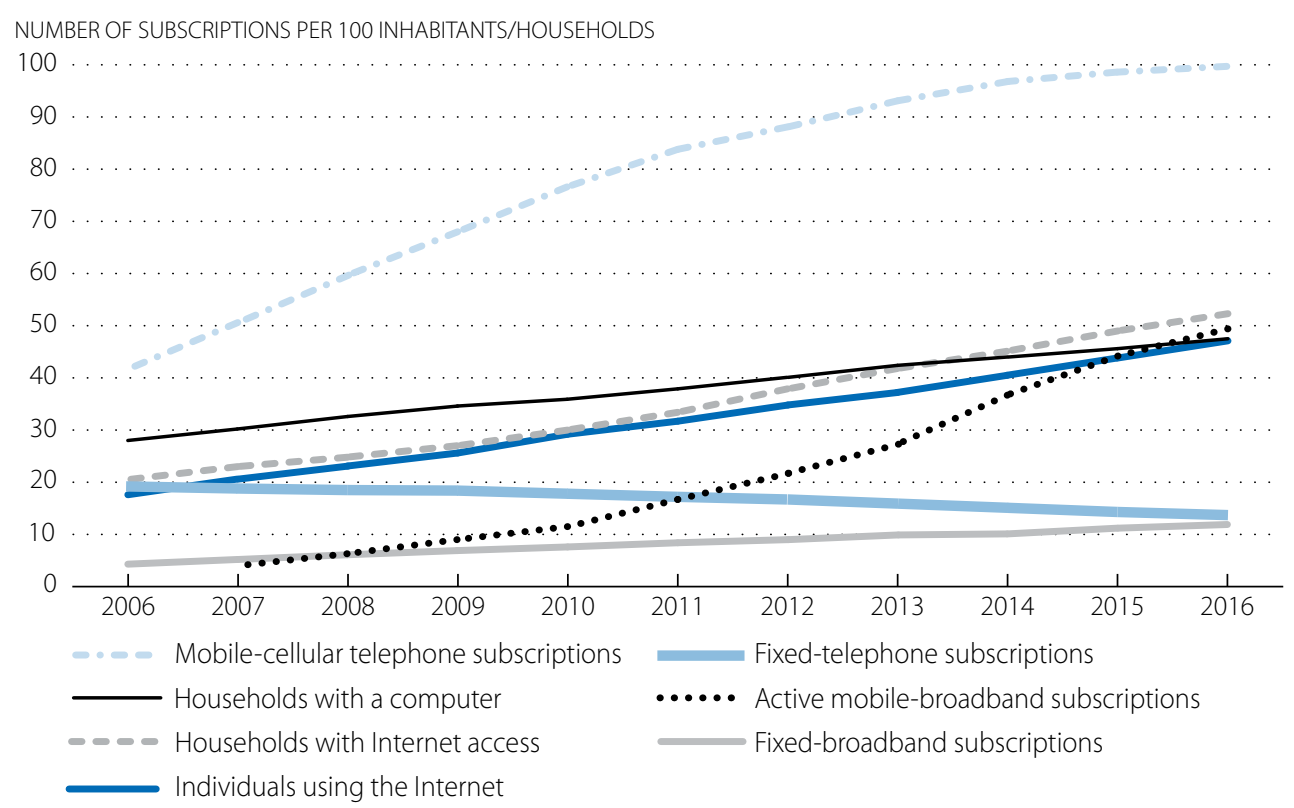

Note: The figures for 2016 are ITU estimates.

Source: ITU (2016b), Measuring the Information Society Report 2016.

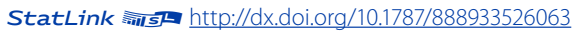




\section{The benefits of the Internet are still unavailable to over half the world's population}

Nonetheless, many people still do not—or do not fully_-benefit from the rapid expansion of the digital economy and the opportunities it offers. Global figures mask substantial differences in connectivity and access levels, which vary greatly between and within countries, especially in terms of high-speed broadband access and Internet use.

Globally, 3.9 billion people, constituting more than half the world's total population, are still offline. The majority of these people live in the world's most vulnerable countries. In many developing countries-in particular the LDCs, the landlocked developing countries (LLDCs) and small island developing states (SIDS) — development challenges also hamper the spread of ICTs. These challenges include limited and costly access to national and international connectivity in small and isolated communities, difficulties in the rollout of terrestrial communication infrastructure across large land areas, and lack or limited direct access to the sea.

Figure 5.2 compares the 2016 figures for key ICT penetration indicators in the International Telecommunication Union's (ITU) six geographic regions. Figure 5.4 compares the figures for developed countries, developing countries and least developed countries. These comparisons highlight that developing countries, and in particular the LDCs, lag behind developed countries in terms of fixed-broadband penetration, household access to ICTs and Internet uptake (Box 5.1). While mobile-cellular penetration has reached over $70 \%$ in the world's LDCs, mobile-broadband penetration stands at just below 20\%, compared to close to 50\% globally and 90\% in the world's developed countries.

\section{Figure 5.2. ICT penetration levels by geographic region, 2016}

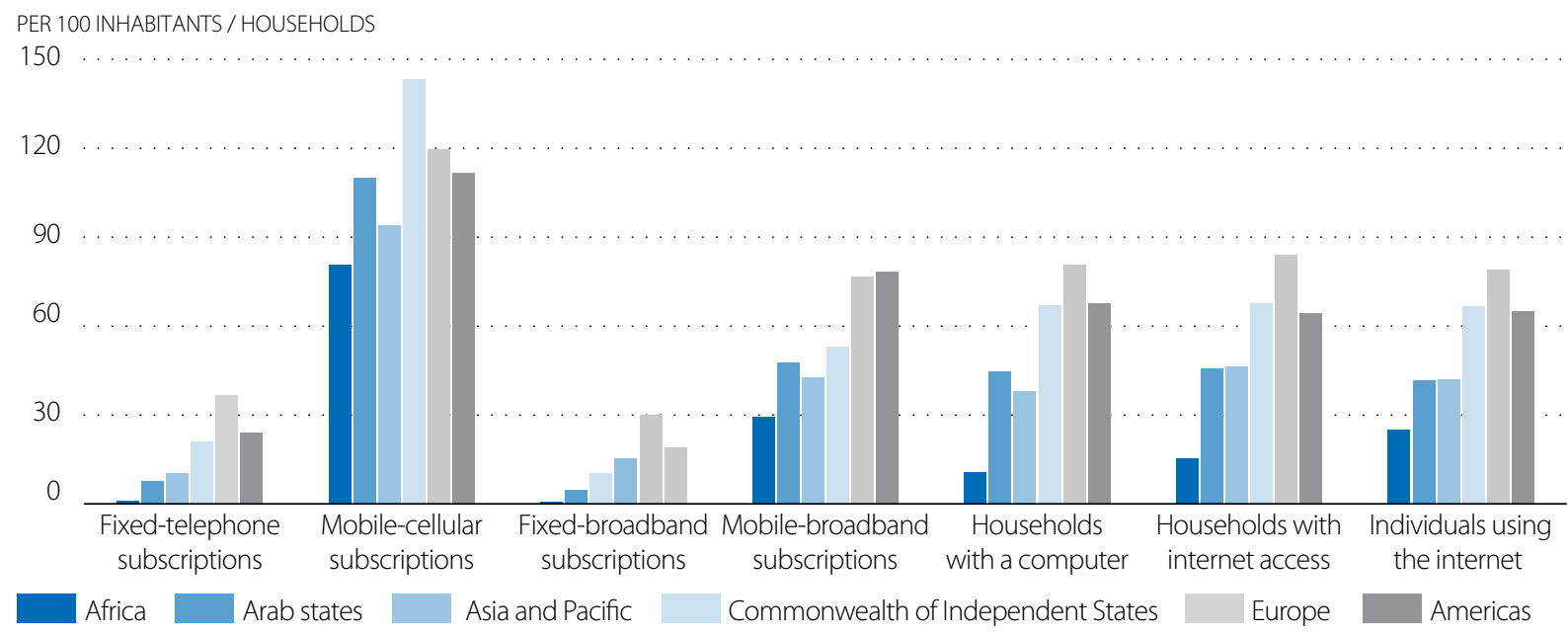

Note: ITU estimates.

Source: ITU (2016b), Measuring the Information Society Report 2016. 


\section{Box 5.1. The least developed countries and the ICT Development Index}

The 2016 ICT Development Index (IDI), published by the ITU, is a composite index that combines 11 indicators for ICT access, use and skills into one benchmarking measure to highlight progress for 175 economies. Comparison of the rankings suggests that LDCs are not catching up fast enough in terms of ICT development. All of the bottom 27-ranked countries are LDCs. The highest ranking LDC is Bhutan, in 117th place. This is of particular concern given the potential role of ICTs in facilitating sustainable development.

Figure 5.3 compares the IDI performance of LDCs with that of developed countries, developing countries and the global average in the period 2015-16. The overall performance of LDCs during this period follows the trend of the previous period (2010-15), remaining below that of the higher- and middle-income developing countries. The LDCs record an average improvement in their IDI value: 0.16 points between 2015 and 2016, as compared to 0.22 points for all developing countries (including the LDCs) and 0.24 points for developing countries other than LDCs.

Figure 5.3. IDI values for the LDCs compared with all developing countries and global values

2015

$\longleftarrow$ LOWEST POSSIBLE

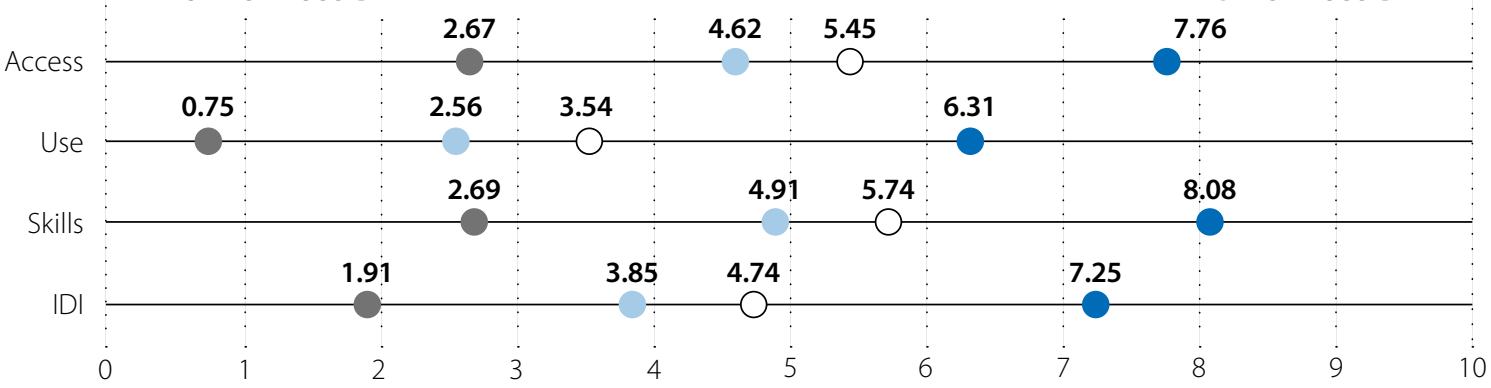

ICT DEVELOPMENT INDEX VALUES, 2015

2016

$\longleftarrow$ LOWEST POSSIBLE

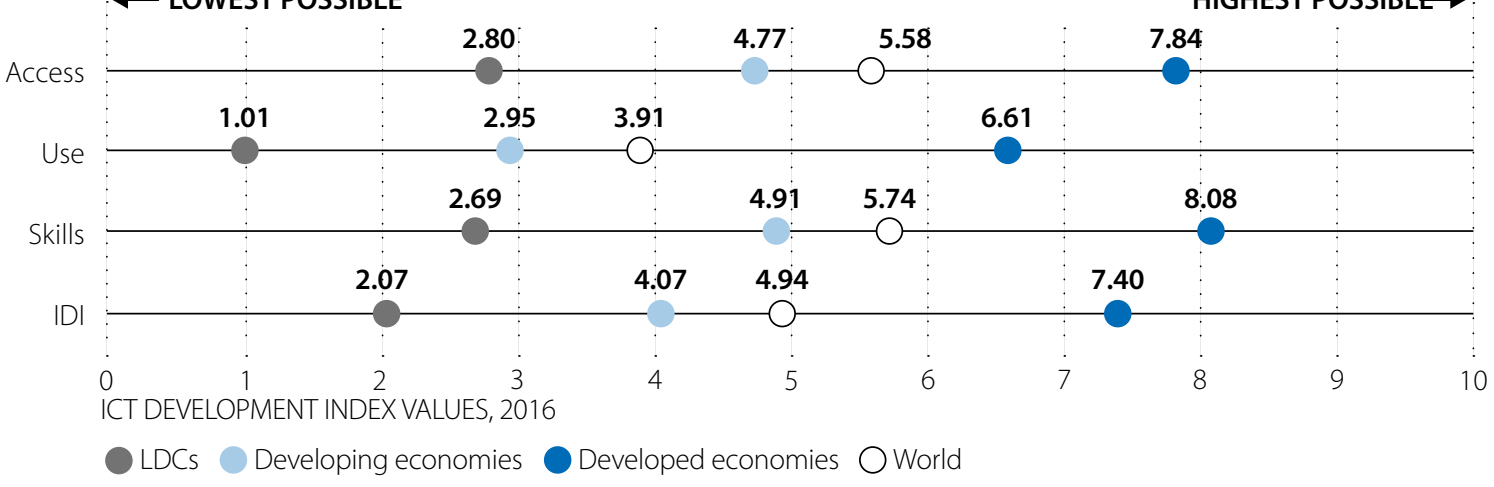

Source: ITU (2016b), Measuring the Information Society Report 2016. 
Figure 5.4. ICT penetration levels by level of development, 2016

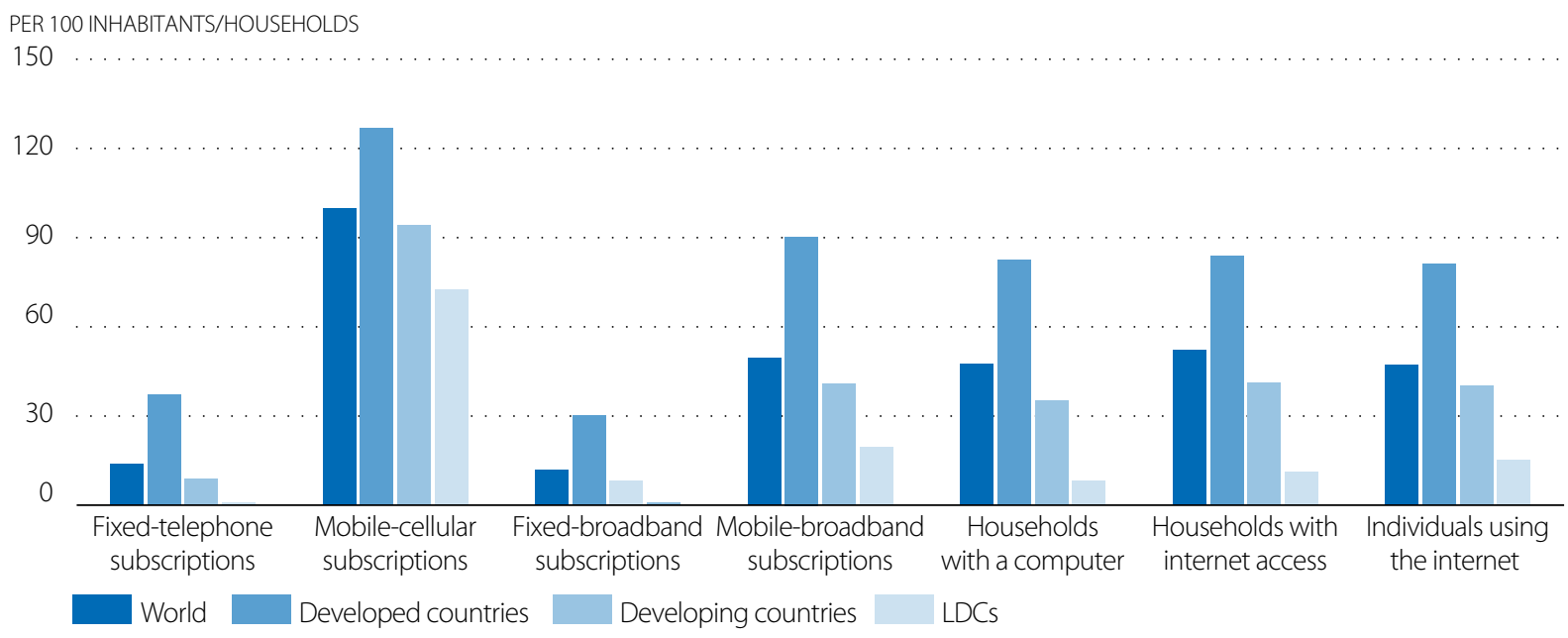

Note: ITU estimates.

Source: ITU (2016b), Measuring the Information Society Report 2016.

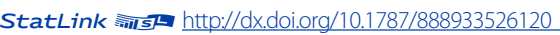

There is evidence that for many people in the developing countries, and especially the LDCs, ICTs remain unaffordable and thus out of reach. The relatively high cost of ICT services, in particular broadband services, compared to low income levels remains a major barrier to wider ICT access and use.

\section{Making broadband affordable is a development target}

In 2010, the Broadband Commission for Digital Development, an initiative led by ITU and UNESCO to increase awareness of the importance of broadband for achieving international development goals, identified four specific ICT targets: broadband strategies, affordability, connectivity and use. Target 2 is about making broadband affordable: "By 2015, entrylevel broadband services should be made affordable (less than $5 \%$ of average monthly income) in developing countries through adequate regulation and market forces" (Broadband Commission for Sustainable Development, 2015). By the end of 2015, this target had been achieved in all developed and 83 developing countries, but only in 5 LDCs (Figure 5.5).

\section{Figure 5.5. Number of countries that achieved the Broadband Commission target to make broadband affordable, 2015}

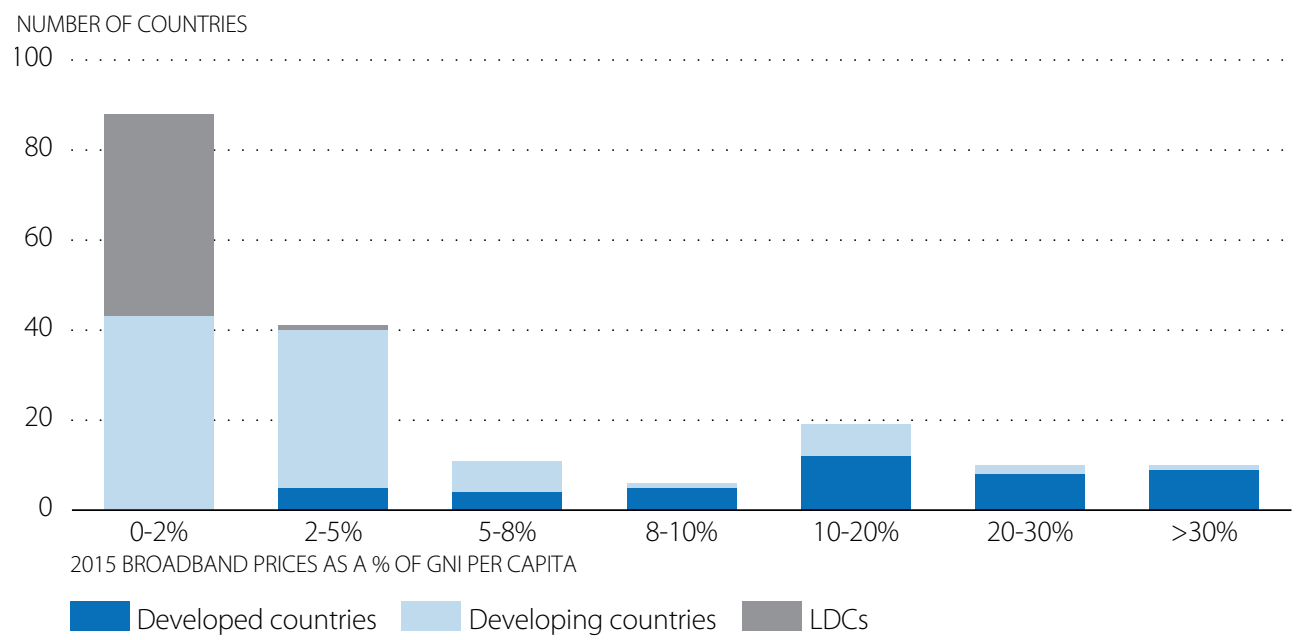


A comparison of fixed- and mobile-broadband prices for 185 economies worldwide highlights the fact that mobilebroadband services tend to be cheaper, with more countries achieving the affordability target in terms of mobilethan fixed-broadband prices. The available data also show that the global average price of a basic fixed-broadband plan (56.3 PPPUSD) is twice as high as the average price of a comparable mobile-broadband plan (26.7 PPPUSD). In the LDCs, the average monthly fixed-broadband price is more than three times higher than the average monthly mobilebroadband price (Figure 5.6).

\section{Figure 5.6. Fixed- and mobile-broadband prices, 2015}

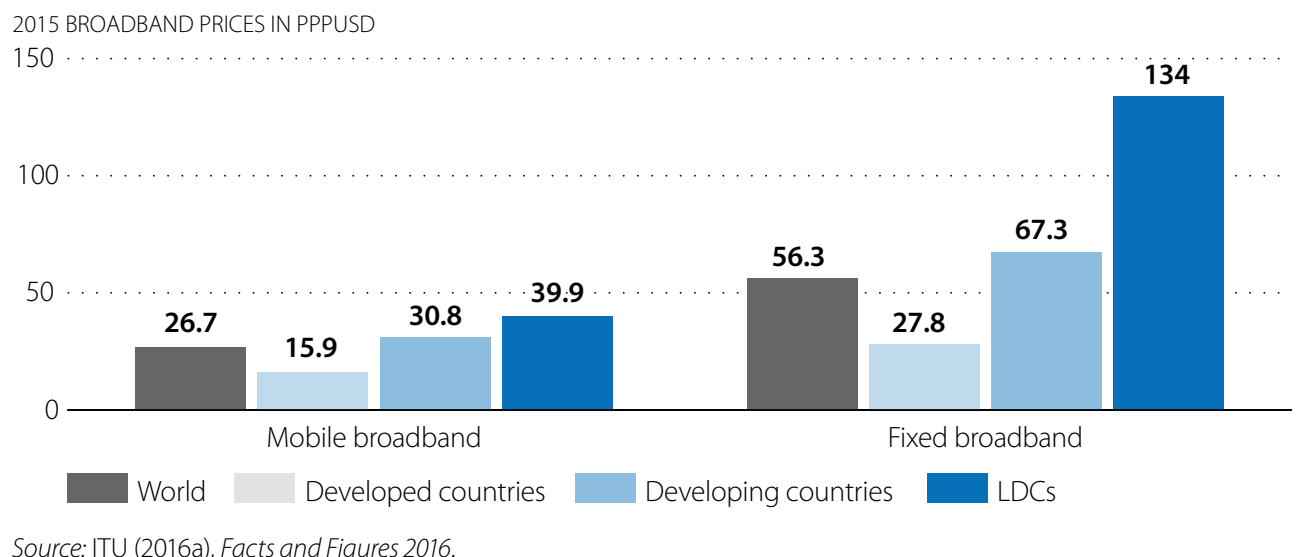

StatLink 게 St http://dx.doi.org/10.1787/888933526158

\section{ICT INFRASTRUCTURE, CONNECTIVITY AND QUALITY OF SERVICE VARY GREATLY}

High-speed affordable broadband connectivity to the Internet holds widely recognized promise for social and economic development. Technological advances in areas such as the Internet of Things and artificial intelligence, combined with hyper-connectivity, are leading to an increasing variety of services and applications that can serve economic, social, and entertainment needs. Advances in mobile networks have made connectivity, including to highspeed broadband communication networks, potentially ubiquitous.

\section{Local access networks highlight the importance of mobile broadband in addressing the digital divide}

Mobile-cellular services have spread much faster than anticipated, allowing people living in previously unconnected areas to join the global information society. As of 2016, second generation (2G) mobile telephony is quasi ubiquitous, with $95 \%$ of the world's population and $85 \%$ of people living in the LDCs covered by a mobile-cellular signal. Mobile-cellular penetration rates have reached $99.7 \%$ globally and $72.6 \%$ in the LDCs. It should be noted, however, that this does not signify that almost everyone owns or uses a mobile phone; available data suggest that mobile-cellular penetration usually far exceeds mobile-phone use or ownership. It does testify, nonetheless, to the growth in mobile services, and the potential they have to address the digital divide.

This is true especially as mobile-networks evolve and deliver not only basic voice services, but also data and high-speed access to the Internet. Third-generation (3G) mobile coverage, which delivers higher speed access to the Internet as well as ICT services and applications to drive smartphone use and uptake, stood at 72\% globally in 2016 (Figure 5.7). Yet in rural areas, only $29 \%$ of the population was covered, highlighting the limited access to mobile broadband that continues to characterise many rural and remote parts of the world. In the meantime, the next generation of mobile networks - LTE (long term evolution, also referred to as 4G) - is spreading rapidly, bringing even higher speeds and improving the mobile-broadband experience. By the end of 2016, ITU estimates that almost half the world's population lived within reach of an LTE network. 
Figure 5.7. Global population covered by at least a 2G, 3G, and LTE network

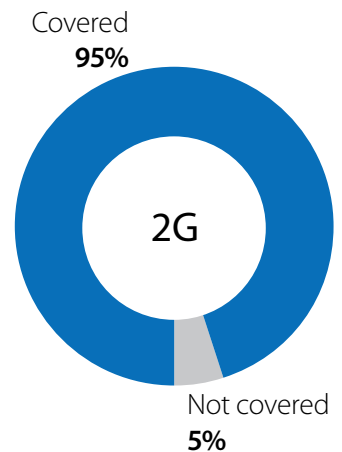

Population covered by $2 \mathrm{G}$ services, World, 2015

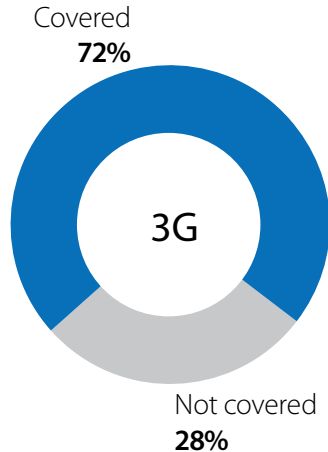

Population covered by $3 \mathrm{G}$ services, World, 2015

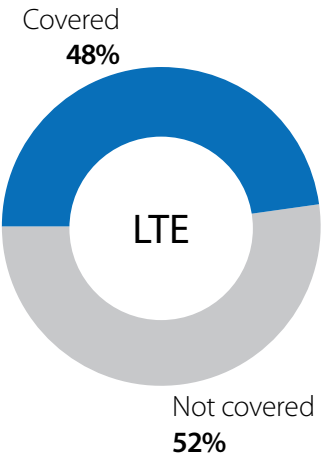

Population covered by LTE services, World, 2015

Note: These are population-weighted figures.

Source: Based on ITU (2015b), Facts and Figures 2015 and Facts and Figures 2016.

Mobile-broadband coverage has also spread rapidly in the LDCs. Almost all LDCs have launched 3G mobile-broadband services. Over 50\% of the population in the LDCs were covered by a mobile-broadband network. LTE services have been launched in about 15 LDCs and while coverage remains limited, these services are growing rapidly, in particular in urban areas (Figure 5.8).

\section{Figure 5.8. Mobile network coverage and evolving technologies in the LDCs}

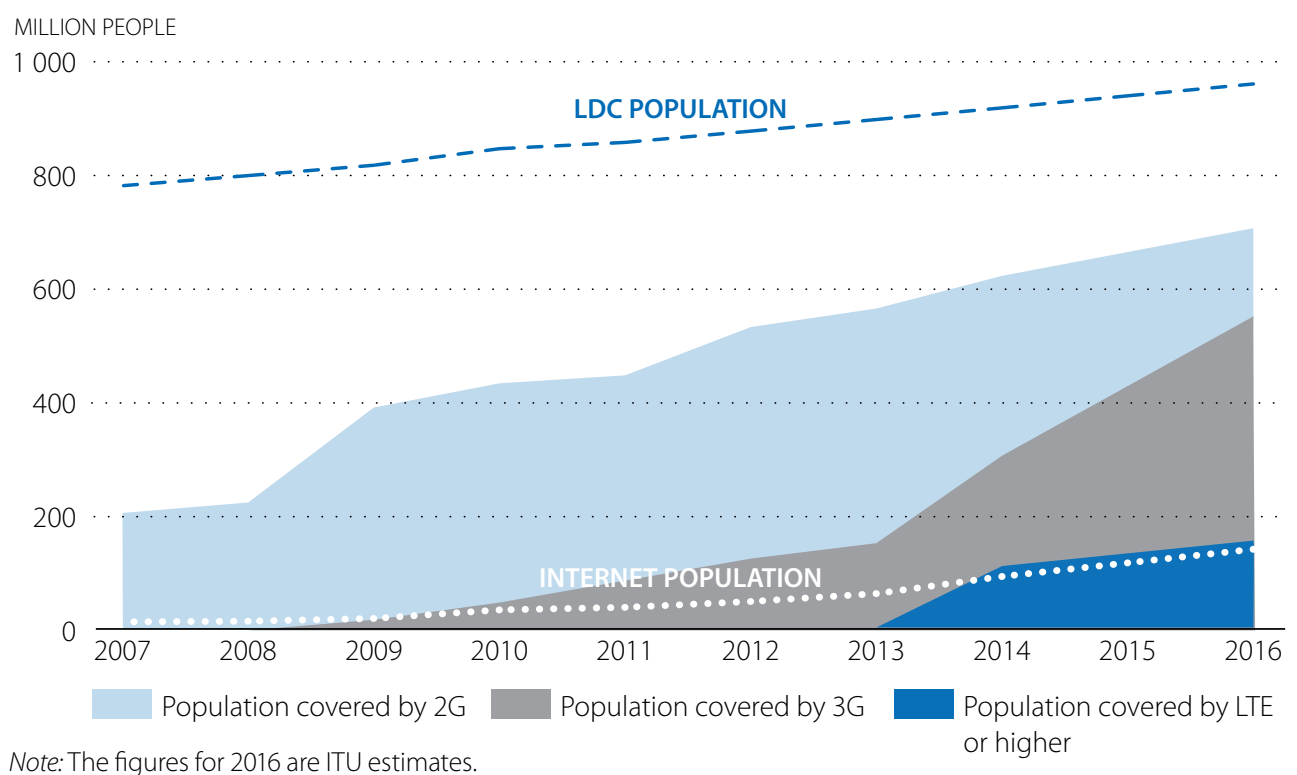

Source: ITU (2016a), Facts and Figures 2016.

StatLink त्ताIs http://dx.doi.org/10.1787/888933526196

Mobile population coverage is a very useful indicator of ICT development and access, as it is relatively easy to measure (by data provided from mobile operators). It is also convenient as it allows countries to set and track targets. Yet it is important to compare coverage to actual ICT use. As of 2016, for example, more than $50 \%$ of the population in the LDCs was covered in terms of mobile-broadband signal, and thus at least in theory had access to the Internet at high speed. Yet only $15 \%$ of the people in the LDCs were actually using the Internet. Penetration rates also vary considerably from country to country. For example, countries such as Tuvalu and Bhutan have around $40 \%$ Internet penetration rates, but rates in a number of the African LDCs are much lower-below 5\% (Figure 5.9). 
This paradox of connectivity versus use suggests that connectivity remains only one of the barriers to Internet use; it is important to take into account the affordability of services, but also socio-economic factors, as will be discussed later in this chapter.

Figure 5.9. Internet users per 100 inhabitants in the LDCs, 2015

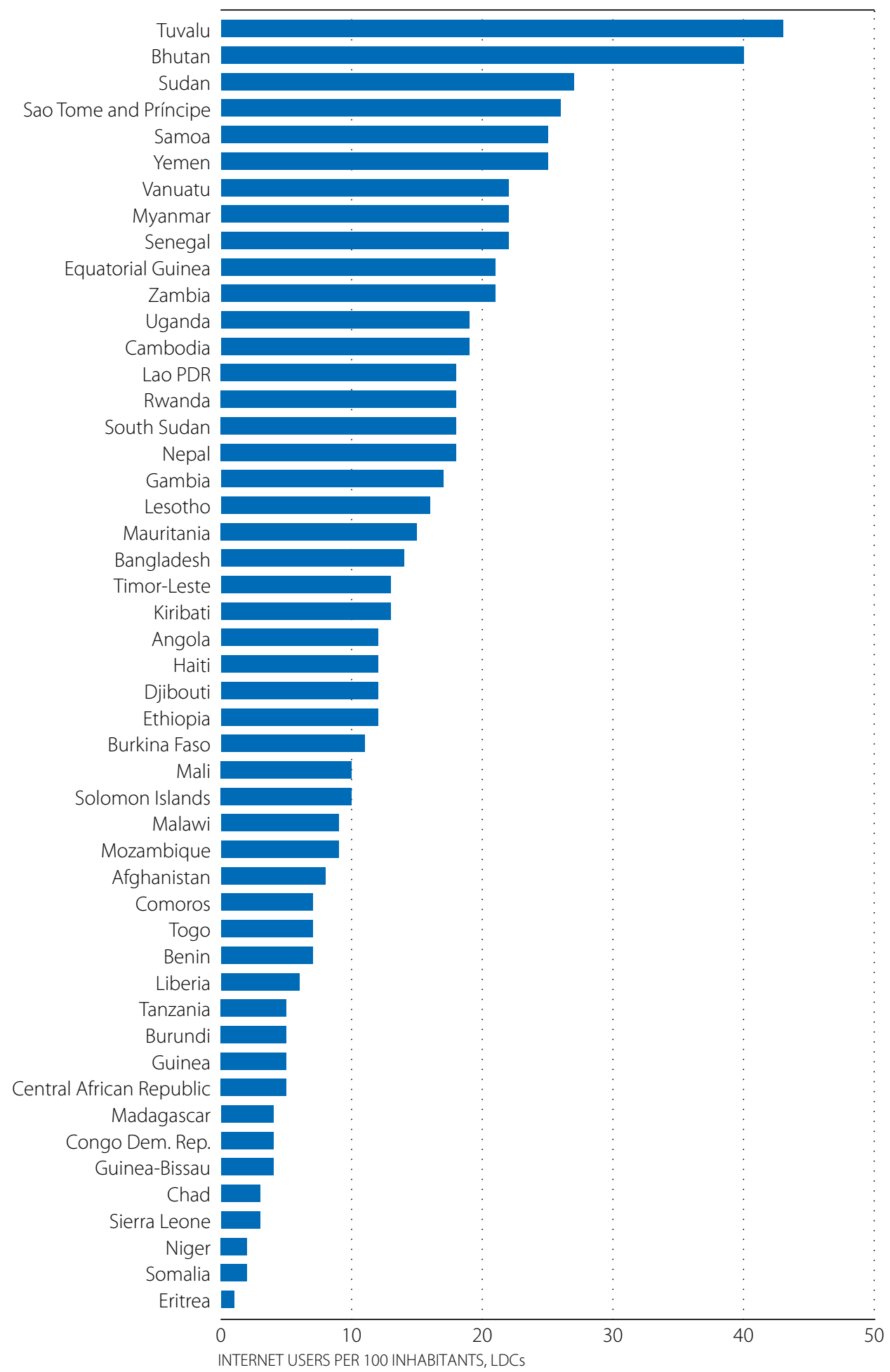

Source: ITU. 
Advances in mobile-broadband networks, including greater coverage and a growing number of services and applications, have driven mobile-broadband penetration rates. Indeed, mobile broadband remains one of the fastest growing market segments. ITU estimates that by 2016, penetration reached close to 50\% globally. Looking at specific country groups, mobile-broadband penetration is $90.3 \%$ in developed countries, $40.9 \%$ in developing countries and $19.4 \%$ in the LDCs. These figures highlight discrepancies, but they also show the that developing countries, and in particular the LDCs, have made progress in terms of mobile- compared to fixed-broadband penetration (Figure 5.10). Fixed-broadband penetration in local-access networks remains limited in nearly all developing regions and particularly in the LDCs; at the end of 2016 it had not reached $1 \%$, compared to close to $12 \%$ globally and over $30 \%$ in the developed countries.

Figure 5.10. Mobile- and fixed-broadband penetration, 2016

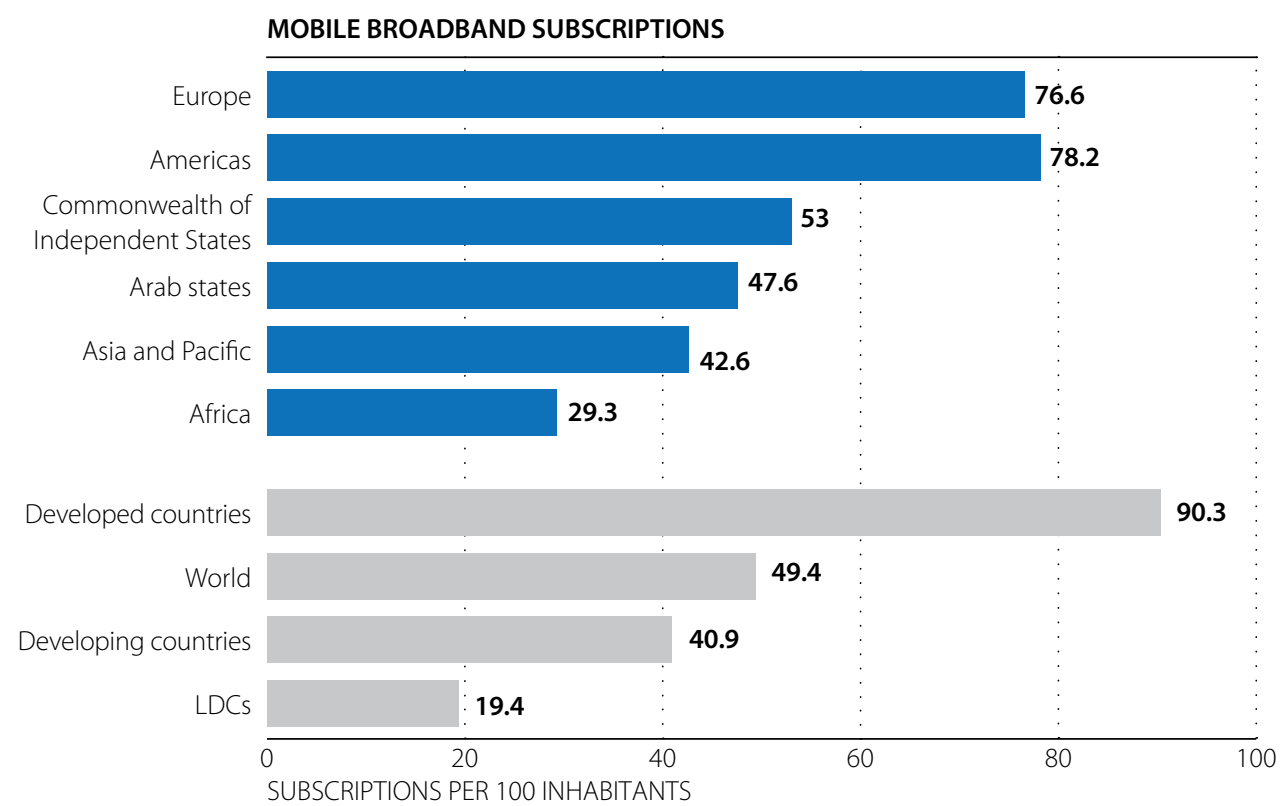

FIXED BROADBAND SUBSCRIPTIONS

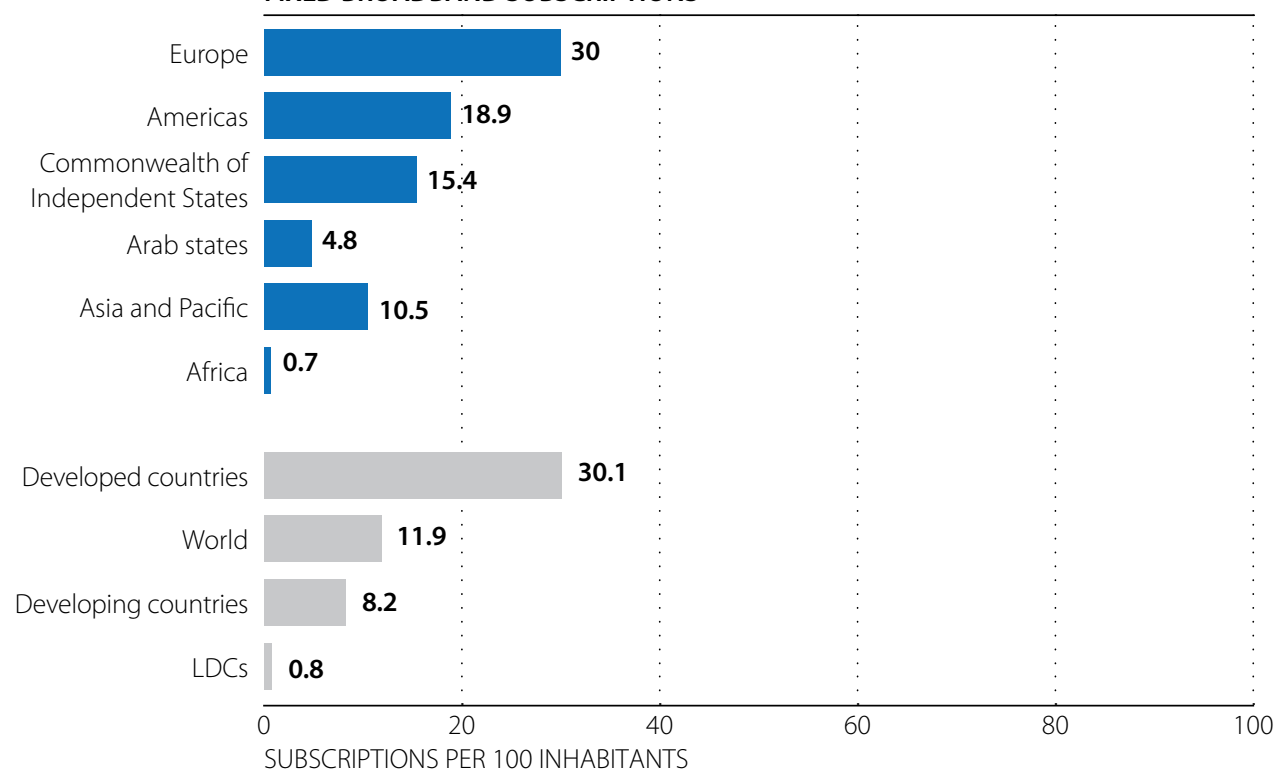

Note: ITU estimates

Source: ITU (2016a), Facts and Figures 2016. 
The marked divide between developed and developing economies in terms of fixed-broadband penetration is further compounded by the difference in speeds that subscriptions deliver. In early 2016, three out of four fixedbroadband subscriptions in the developed countries had advertised speeds of $10 \mathrm{mbit} / \mathrm{s}$ and above; two out of four in the developing countries reached these speeds. In the LDCs, overall fixed-broadband penetration remains very low: only $7 \%$ of fixed-broadband subscriptions are advertised at speeds above $10 \mathrm{mbit} / \mathrm{s}$ (Figure 5.11). This highlights the limits of fixed-broadband in connecting people and businesses in the LDCs.

Figure 5.11. Fixed-broadband penetration by speed, 2015

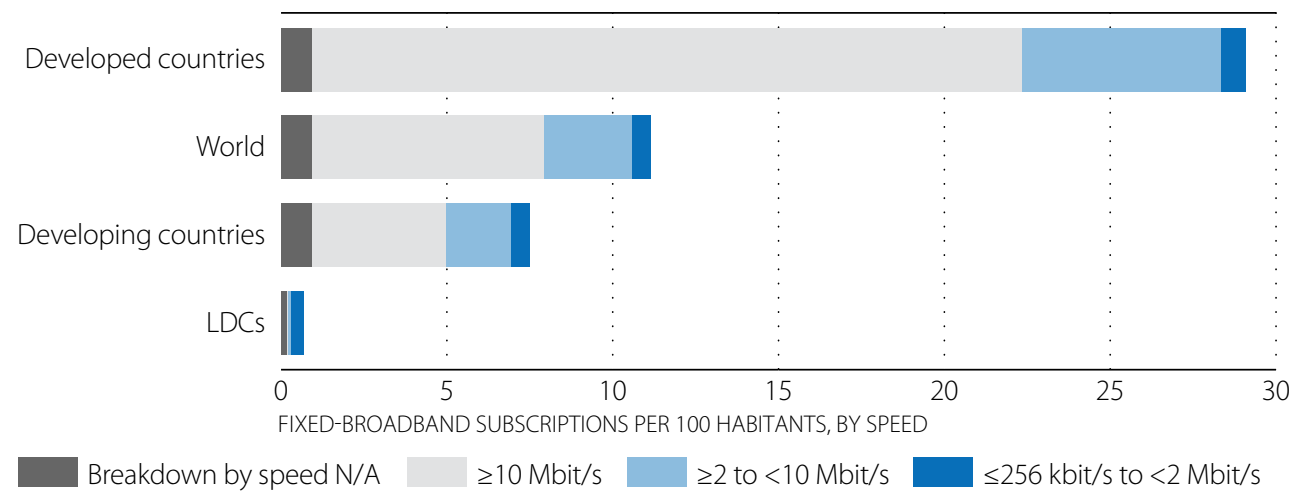

Source: ITU (2016a), Facts and Figures 2016.

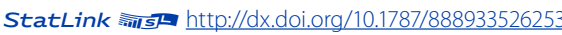

Country-level data, highlighted in Figure 5.12, further point to the major differences that exist in terms of the speed and quality of services that fixed-broadband subscriptions deliver in many developing countries. Although only limited country data are available for the LDCs, they suggest that fixed-broadband services remain negligible in low-income developing economies.

While the role of mobile-broadband is complementary to fixed-broadband in the more developed markets, it is increasingly predominant in many low-income developing economies, particularly the LDCs. This raises the question of whether mobile-broadband can replace fixed-broadband connectivity in terms of local access networks. This question is of particular interest to businesses, which often require relatively larger bandwidth, higher speed and greater quality of service to deliver online services (Box 5.2).

What is clear, however, is that fixed technologies will continue to play a vital role in providing backhaul networks to transfer data from both mobile and fixed networks. The increasing offload of mobile data traffic onto fixed networks highlights the growing integration of fixed and wireless networks: Cisco estimates that in 2015, 51\% of total global mobile data traffic was offloaded onto fixed networks through Wi-Fi or femtocell (Cisco, 2016). 


\section{Box 5.2. Comparing fixed-to mobile-broadband networks}

As highlighted in this chapter, developing countries, and in particular the LDCs, rely almost exclusively on mobilebroadband networks to deliver high-speed Internet access to end users, including many businesses. The question of how mobile-broadband networks compare to fixed-broadband networks is an important one, especially as mobilebroadband technologies evolve. Operators are already talking about the launch of IMT-2020 (5G), the next generation of mobile networks, which promises "lightning speed and ultra-reliable communications for broadband" (ITU, 2017a).

Today, 3 G and LTE (or higher) mobile-broadband networks have reached unprecedented levels of population coverage and promise theoretical speeds comparable to that of the copper and coaxial cables used by DSL and cable operators. Nonetheless, their speed - or latency (the amount of time it takes for a data packet to traverse a network, which affects the quality of a connection) - is inferior to that of fibre broadband networks. This means that fixed-broadband access networks continue to provide a more reliable and often cheaper option for streaming videos, gaming and downloading large files. Furthermore, mobile-broadband services often are linked to usage caps, while fixed-broadband offers are frequently "unlimited".

IMT-2020 networks will address some of these issues and; they promise to reduce latency. Nonetheless, because spectrum, which refers to the radio frequencies allocated to the mobile operators and others for communication over airwaves, is a limited resource — used not only by mobile operators but also, for example, for broadcasting and satellite services - the effective capacity that mobile networks can deliver is also limited. The number of users on the same mobile network will continue to impact speeds, as well as the quality of service. Operators are looking into ways of optimizing services, including by increasing the amount of spectrum and by using complementary network technologies to offload data.

These differences between fixed- and mobile-broadband networks highlight two issues that need to be taken into account, especially in developing countries, where many users only have access to mobile networks:

First, it is important for regulators to create the right regulatory environment and the incentives that will allow operators to launch the latest generation of high-speed mobile-broadband networks, including by making the necessary spectrum available. Almost all LDCs have launched 3G services, yet LTE services have been introduced in only about 15 LDCs.

Second, it is important to take advantage of technological advances and innovations that allow adaptation of and improvements in the existing networks. Small cells (low-powered cellular radio access nodes), for example, can increase capacity (and speed) in densely populated areas. Satellite networks can also be used to expand services to rural and remote areas.

At the same time, developing countries need to continue to invest in fixed-broadband infrastructure, both in terms of national backbone and of international connectivity. Mobile-broadband users can only benefit from high-speed services if the necessary backbone infrastructure is in place. By reducing the distance between end-users and the backbone infrastructure, mobile-broadband networks can be optimized. This will significantly increase the speed and the quality of mobile-broadband services, and allow the delivery of more data-intensive services and applications, including in rural and remote areas.

Finally, in areas where the speed and quality of Internet access remains limited, content providers must adapt services and applications, not only to the needs of end users, but also to the type of network. 
Figure 5.12. Fixed-broadband subscriptions by speed in selected countries, 2015

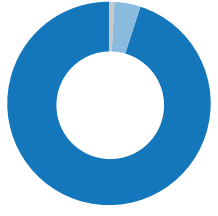

France

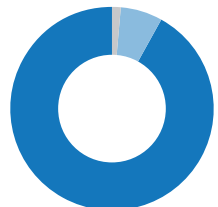

United States*

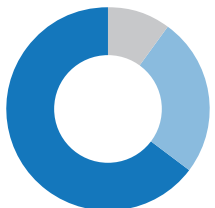

Russian Federation
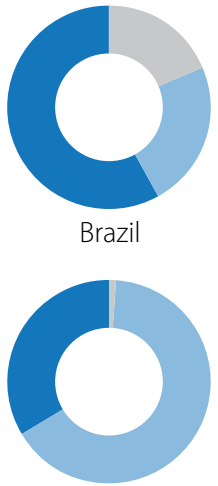

Armenia

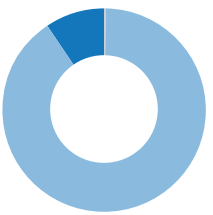

Morocco

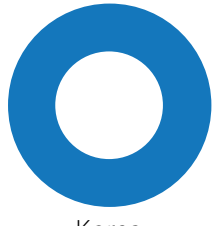

Korea

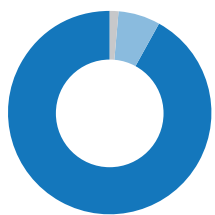

Japan

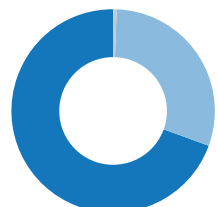

People's Republic of China
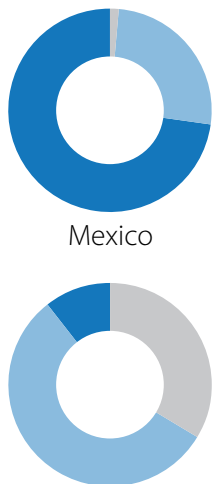

Malaysia

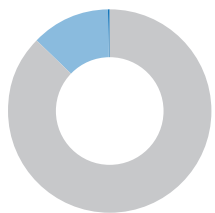

Namibia
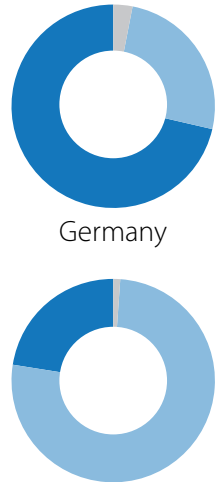

Italy

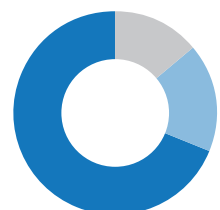

United Arab Emirates

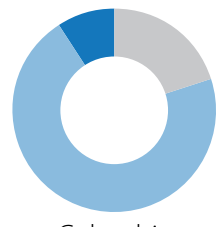

Columbia

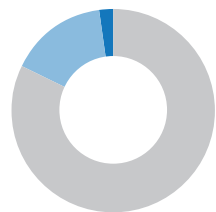

Venezuela

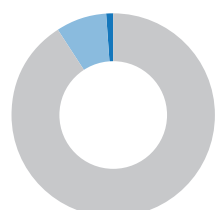

Zimbabwe
Circle size represents the fixed broadband penetration (\%)

40.3\% France

40.2\% Korea

37.2\% Germany

30.3\% United States

29.6\% Japan

$\mathbf{2 3 . 8} \%$ Italy

18.8\% Russian Federation

18.6\% People's Republic of China

12.8\% United Arab Emirates

12.2\% Brazil

11.6\% Mexico

11.2\% Colombia

9.6\% Armenia

8.8\% Malaysia

8.2\% Venezuela

3.3\% Morocco

1.7\% Namibia

1.1\% Zimbabwe

$\geq 256 \mathrm{kbit} / \mathrm{s}$ to $<2 \mathrm{Mbit} / \mathrm{s}$

$\geq 2 \mathrm{Mbit} / \mathrm{s}$ to $<10 \mathrm{Mbit} / \mathrm{s}$

$\geq 10 \mathrm{Mbit} / \mathrm{s}$

*2014 data.

Source: ITU (2016a), Facts and Figures 2016.

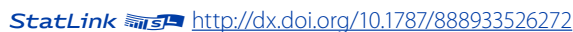

\section{National and international backbone infrastructure is critical to broadband access and use}

National backbone infrastructure and international Internet connectivity are critical building blocks to drive broadband demand, access, and use. Growth in broadband subscriptions is accompanied by continuous growth in national backbone capacities and international Internet bandwidth. Indeed, without growth in deployment of backbone infrastructure, service providers are unable to expand their markets to previously underserved regions, and to deliver high-speed and high quality services to customers. 
Data collected by ITU on the deployment of ICT transmission capacity shows that by the end of 2016, more than 10.1 billion km of fibre and microwave backbone transmission networks from 378 operators was available worldwide (Figure 5.13). While this data does not cover all operators or countries, it highlights the important expansion of and investments in international backbone infrastructure.

\section{Figure 5.13. ICT backbone transmission networks}

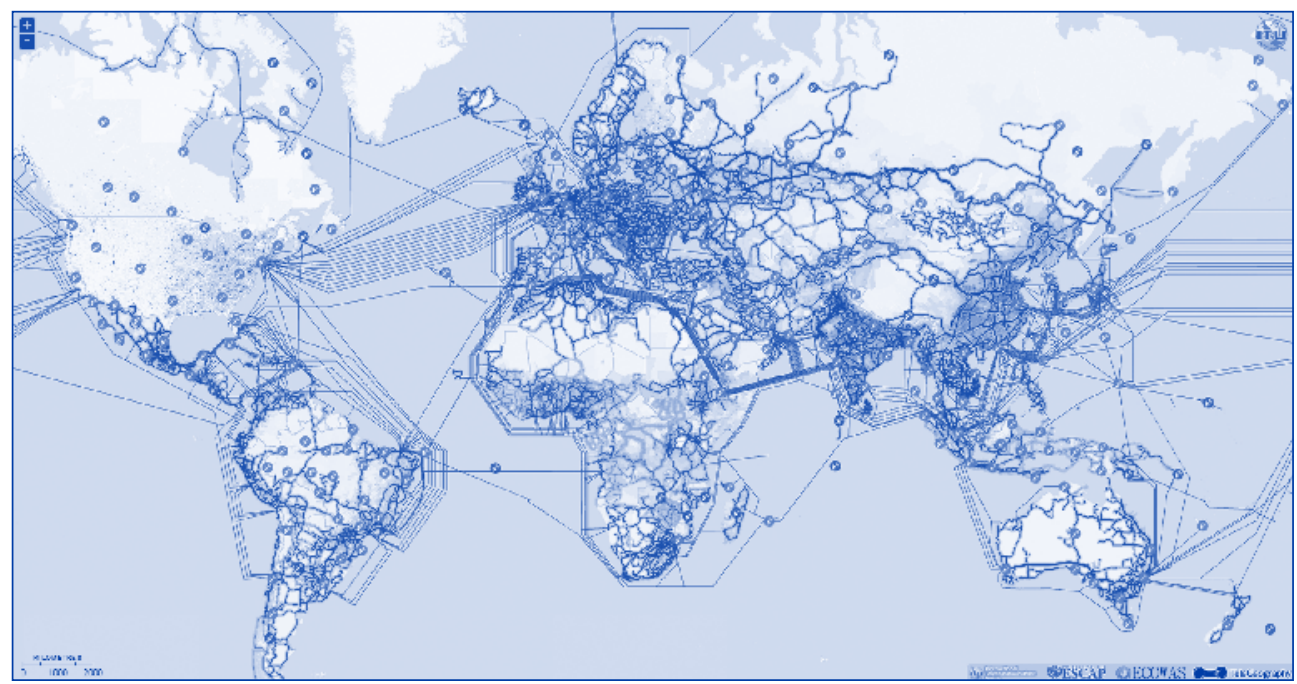

Note: This map includes fibre and microwave backbone transmission networks as reported by 378 operators worldwide. The map, which continues to be updated, does not cover all operators or countries.

Source: ITU Interactive Transmission Maps, http://itu.int/go/Maps (accessed 10 April 2017)

StatLink न्ता st http://dx.doi.org/10.1787/888933526291

At the same time, major differences exist among regions and countries. As highlighted in Figure 5.14, the route metres of fibre and microwave backbone networks per capita remain below one in the Arab States and Africa; they are highest in Europe. Tracking the population that lives within a range of up to 10,25 and 50km of an operational fibre transmission network also gives a measure of access. Populations living more than $50 \mathrm{~km}$ away from a network are considered to be out of reach. In 2016, about 20\% of Africa's population lived within a range of 10km; 36.3\% lived out of reach.

Figure 5.14. Route metres of fibre and microwave backbone per capita by region, 2016

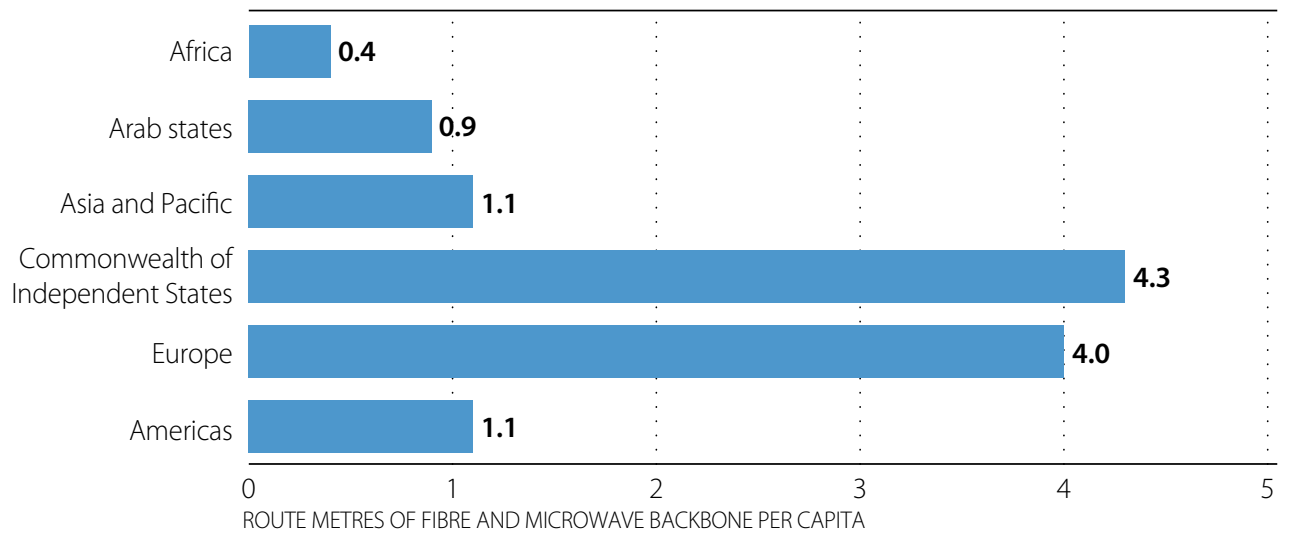

Source: ITU. 
The amount of international Internet bandwidth available in a country or region provides important insights into the quality and speed of networks and is another key indicator of the readiness of countries to become information societies. International Internet bandwidth is a key building block for delivering data-intensive applications and services through high-speed networks. While national fibre transmission networks are essential infrastructure for access to highspeed networks, information on bandwidth is also required to gauge the actual quality and speed available.

Over the past decade, total international Internet bandwidth has climbed sharply, from around $35000 \mathrm{gbit} / \mathrm{s}$ in 2008 to $100000 \mathrm{gbit} / \mathrm{s}$ in 2012 and $185000 \mathrm{gbit} / \mathrm{s}$ in 2015. This strong growth reflects the significant investment that has been made in backbone infrastructure-in particular in important submarine cable projects-in all parts of the world. The growth in international bandwidth has been strong in all regions. The developing country share of total international bandwidth increased from around 11\% in 2005 to almost 40\% in 2015. Europe leads by far, accounting for more than 40\% of total international Internet bandwidth in 2015; in the same year, Africa's share was less than 3\% (Figure 5.15).

\section{Figure 5.15. Share of total international Internet bandwidth, by region}

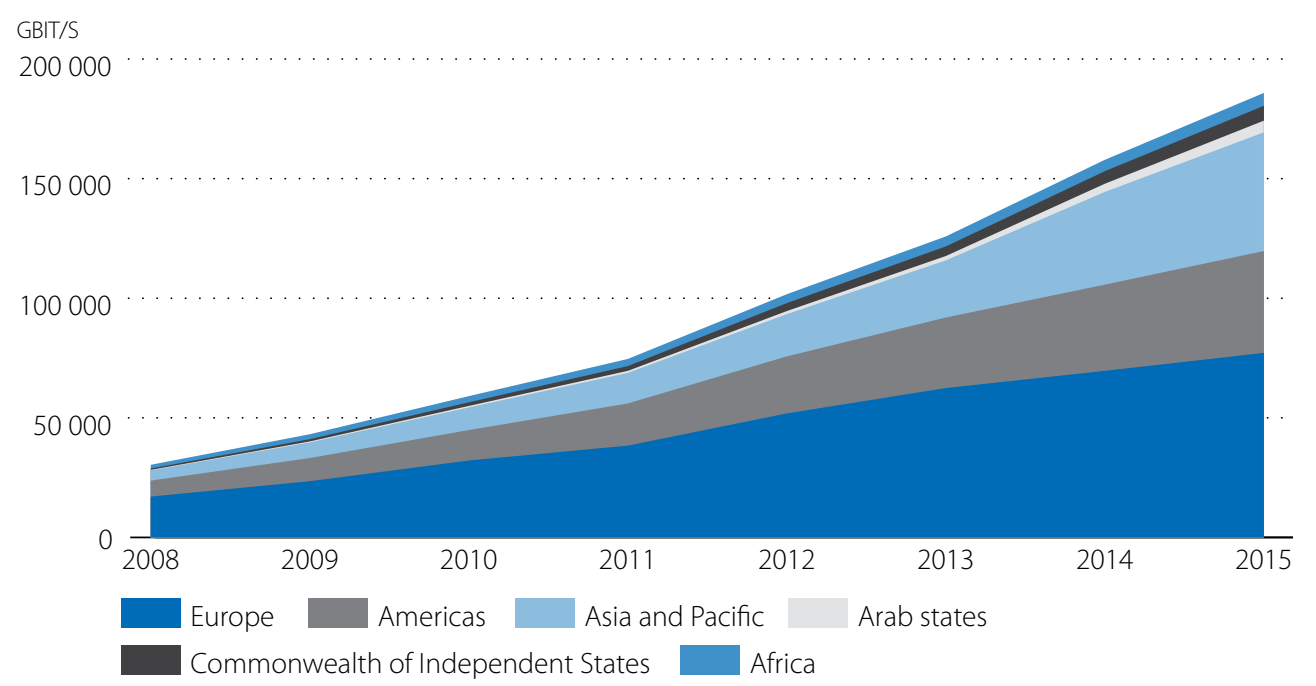

Note: 2016 data are ITU estimates.

Source: ITU (2016a), Facts and Figures 2016.

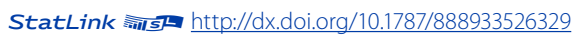

The impact of available international bandwidth on Internet use differs widely across regions and countries. Bandwidth per inhabitant has increased significantly over the past decade, yet there are huge differences between developed and developing regions: there is more than seven times as much international bandwidth per inhabitant $(93 \mathrm{kbit} / \mathrm{s}$ versus $13 \mathrm{kbit} / \mathrm{s}$ ) available in the former than in the latter (Figure 5.16). International Internet bandwidth per inhabitant remains particularly low in the LDCs, suggesting that the lack of international connectivity remains a major bottleneck in the Internet infrastructure of these countries.

Looking at regional differences, Europe stands out with around 160000 bit/s per inhabitant in 2013, compared to the global average of 52000 bit/s per inhabitant; it is followed by the Americas, with 54000 bit/s per inhabitant.

Europe's leadership in international Internet bandwidth is explained by the advanced level of broadband adoption and use in the region. Also, Europe's composition — made up of countries that are relatively small in geographic size and depend on international connections to reach the global Internet-is an important factor. The Internet backbone network in the European region is interlinked by several Internet exchange points (IXPs), physical locations that connect national networks, allowing Internet traffic to be exchanged and giving them access to the global Internet. IXPs are an important part of the Internet ecosystem and can help increase the quality of service and make it more affordable. 
Figure 5.16. International Internet bandwidth per inhabitant, by region, 2015

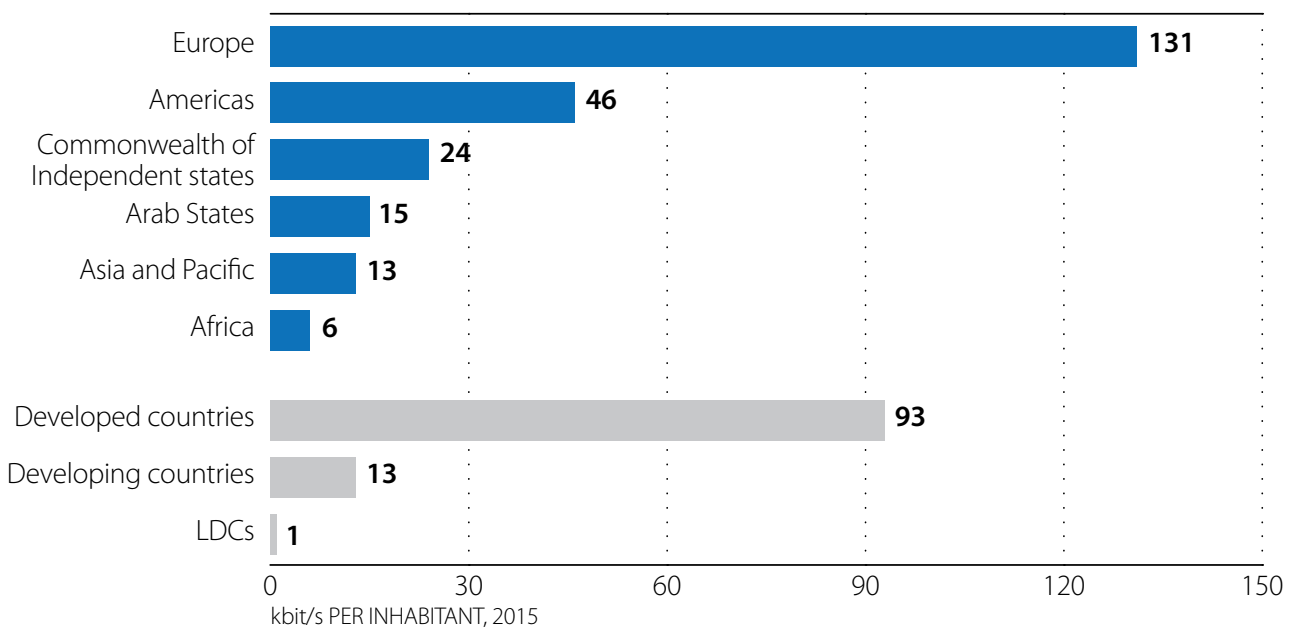

Source: ITU (2016a), Facts and Figures 2016.

Some of the world's largest IXPs are located in Europe and have an international reach, for instance the German Commercial Internet Exchange, the Amsterdam Internet Exchange and the London Internet Exchange. ${ }^{4}$ Many countries, however, do not have any IXPs, which limits the quality of their Internet services and adds to connectivity fees, thus increasing the price to consumers. Indeed, Figure 5.13 shows that only 16 of the 48 LDCs—one-third—had IXPs in 2016. This suggests that there is clear room for progress.

\section{Box 5.3. Generations of ICT regulation}

The ITU's Telecommunication Development Bureau annually collects self-reported data on the regulatory environment of 186 member countries. Data for 2007 through 2015 are coded giving each country and each year a score (between 0 and 100), which is associated with a generation of regulation. Five generations of regulation have been identified. This begins with the command-and-control approach of the first generation, eventually reaching the fifth generation characterised by harmonized collaboration across sectors (Figure 4.2).

The ICT Regulatory Tracker traces the transition of countries from generation one through to four (G1 to G4; Figure 5.17). The indicators correspond closely to the guiding principles outlined in the ITU Best Practice Guidelines of the Global Symposiums for Regulators (GSR), adopted annually by the global community of ICT regulators (ITU, 2016c). The Best Practice Guidelines are at the core of modern ICT regulation. They represent the collective wisdom of the current bodies in charge of ICT regulation.

Figure 5.17. Generations of regulation

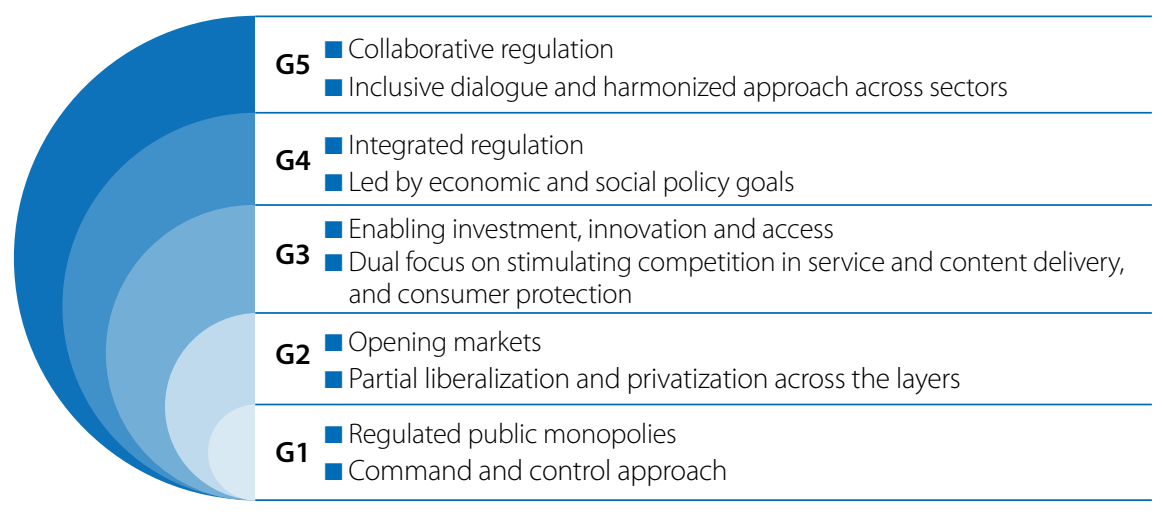

Source: ITU (2017b), Global ICT Regulatory Outlook. 


\section{Box 5.4. Winning formulas for fixed and mobile-broadband markets}

It is widely recognized that good regulation is key for the development of vibrant digital economies. Based on evidence produced using the ICT Regulatory Tracker, the choice of regulatory interventions appears to be equally important in promoting market growth.

There are many areas that require regulatory oversight and the focus on these might be significant differences in their focus across countries, analysis based on the ICT Regulatory Tracker demonstrates that a handful of key regulations can unlock the potential of an ICT market and turn it into a mass market in a short period of time.

ITU produced an evidence-based "recipe for success" comprising six policy and regulatory measures, which has helped 58 countries achieve $75 \%$ mobile-broadband penetration. Further, their markets have skyrocketed: penetration is $70 \%$ higher than the world average in 2015, and is significantly outpacing most other countries (Figure 5.18, left). Although there are multiple factors at work, for these countries regulation has made a significant difference.

With regards to fixed-broadband services, adopting a similar recipe for success—comprising five measures — 40 countries have achieved a considerably higher level of fixed-broadband service adoption (Figure 5.18, right). The average fixedbroadband penetration of countries deploying the five measures was 26\% in 2015, 15\% higher than the global average of $11 \%$. Although it is difficult to statistically establish direct causality, this nevertheless implies that regulation can facilitate market growth.

\section{Figure 5.18. Winning formulas: regulatory recipes for successful ICT adoption}

Active mobile-broadband subscriptions per 100 inhabitants

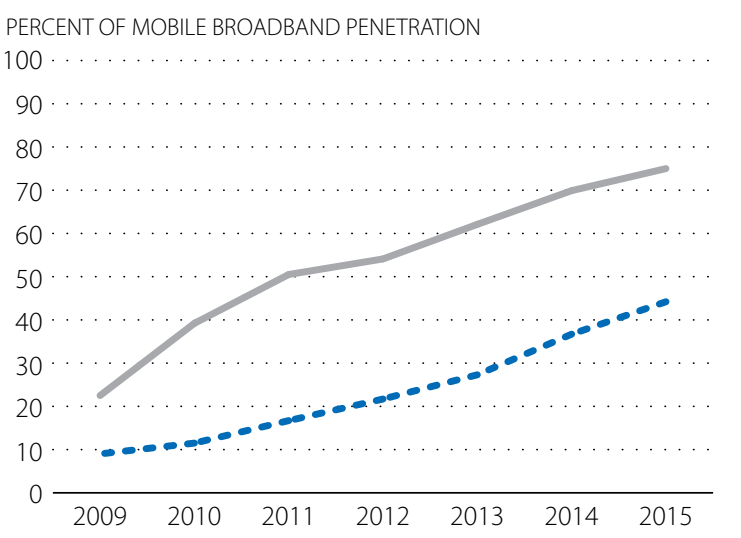

-.- World average Countries applying the winning formula of six measures

Winning formula for mobile broadband

1. Competition in mobile broadband

2. Competition in international gateways

3. Mobile number portability enabled (implemented, available to consumers)

4. Band migration allowed

5. Infrastructure sharing for mobile operators permitted, including Mobile Virtual Network Operators

6. National broadband plan adopted

Source: ITU (2017b), Global ICT Regulatory Outlook.

\section{Fixed broadband subscriptions per 100 inhabitants}

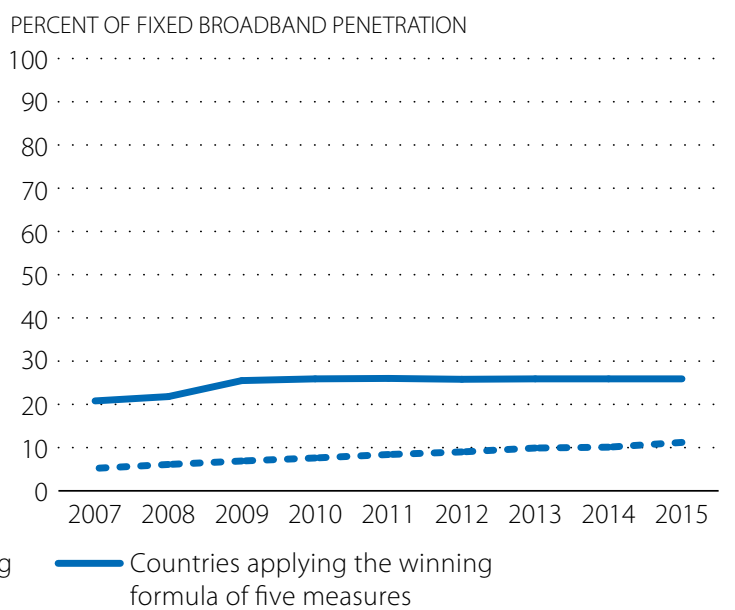

Winning formula for fixed broadband

1. Competition in DSL/cable supported

2. Fixed number portability enabled (implemented, available to consumers)

3. Infrastructure sharing/ co-location and site sharing for fixed mandated

4. Converged licensing framework in place

5. National broadband plan adopted 


\section{Winning formulas can address the broadband divide through improved regulation}

As the ICT market undergoes profound change, the role of ICT regulation becomes increasingly important for addressing the many challenges to connectivity. The biggest among these the creation of open markets where regulation encourages the growth of networks, the provision of services and the diffusion of content and applications in an affordable, competitive and safe way. This is especially important for the LDCs.

Expectations for ICT regulation have grown over the past decade. In a world in which more than half the world's population is not using the Internet, regulators have to reinvent the rules of the game to extend adoption and use of ICTS, align them with wider social and economic goals and set about to connect the unconnected. There are a number of important steps that governments, and in particular the LDCs, can take to address the broadband divide and to overcome infrastructure bottlenecks, in particular by creating an enabling regulatory environment.

Globally, more and more countries are working on fine-tuning their regulatory frameworks. They are moving towards the fourth and fifth generation of ICT regulation, which entails integrated and collaborative regulation to define the platforms and mechanisms for working with other sectors (see Box 5.3). On a very positive note, a third of LDCs have reached the third generation of ICT regulation, among them Burkina Faso, Malawi and Tanzania. One country—Uganda—has even attained the fourth generation, joining the club of some of the most advanced countries in terms of ICT regulation. However, two-thirds of all LDCs are still in either the first or the second generation of regulation and need to urgently carry out basic reforms, including for privatization, liberalization and intra-platform competition.

Among other important reforms many LDCs need to undertake is the removal of barriers to foreign ownership and investment. When private investment is not sufficient, solutions such as direct government investment and public-private partnerships can be explored. Universal service funds and obligations can also help to bring services to areas that provide limited business opportunities, providing tax incentives for investments. ITU, through its ICT Regulatory Tracker, helps countries identify the winning formulas and regulatory steps that can drive ICT investment, use and uptake (Box 5.4).

Within reasonable limitations, therefore, quantitative evidence suggests that best-practice regulation does matter. It also shows that for broadband markets to thrive, both the design and the effective enforcement of regulatory frameworks are essential. Good regulation has impact. Regulators need to ensure that market opportunities outweigh challenges, while protecting consumer interests.

Box 5.5. The impact of taxation on broadband services deployment and adoption

With regards to broadband services, which are a critical platform to deliver information and ensure economic growth, taxation tends to reduce the level of capital investment for the development of infrastructure, which is fundamental for the provision of services everywhere.

On the other hand, it is important to note that broadband penetration faces an affordability barrier in terms of service adoption, especially by consumers in developing countries, where the price of services is relatively higher. In general, it is considered that a broadband consumption tax increases the cost of ownership, thereby reducing the adoption of this services by the population. In reverse lower subscription prices generated by tax reduction, imply higher demand.

Considering the impact of digital technologies on the economy, by increasing the efficiency of production processes, facilitating the circulation of goods and creating new businesses, the taxation of digital goods and services should be approached with care, preventing any erosion of their spill-over contribution to GDP growth. It has been shown that excessive taxing of digital goods and services could limit adoption, restricting the positive contribution to GDP. Thus, the tax collected is outweighed by tax foregone on "lost" GDP. In this sense, in developing fiscal policies, Governments need to consider the tradeoffs between revenue generation and the potential negative impact of the development of the digital sector.

Source: ITU, GSR15 Discussion Paper Taxation in the digital economy, http://www.itu.int/en/ITU-D/Conferences/GSR/Pages/GSR2015/ GSR15-discussion-paper.aspx 
The LDCs can build on these winning formulas to come up with their own balanced mix of regulatory incentives and obligations, deliver on regulatory goals and open the way to investment, innovation and market growth. As LDC markets become more complex and their interplay with regulation more open, ICT regulators will need to stay pro-active, to demonstrate leadership, skill-up and reach out to new actors. While no single regulatory model is perfect, the guiding imperative is to integrate ICT regulation with other sectors in order to leverage on synergies and create efficiencies-thus speeding up the success in bridging the broadband divide.

Increasing numbers of ICT regulators around the world are teaming up with regulators from other sectors to address multi-sector issues. Such collaborative regulation brings all parties to the table to share sector-specific expertise as well as the responsibility for decision-making. Transparent and practical co-operation, coupled with communication across sectors and key players-including regulators, policy-makers and other stakeholders-are essential to ensure that regulation responds to market realities, stakeholder needs and consumer demand. Equipped with this collaborative, problem-solving attitude, regulators in the LDCs can better harness and maintain the growth of ICT markets while making progress towards broader development goals, such as the Sustainable Development Goals.

\section{PRICES ARE HOLDING BACK ACCESS TO THE GLOBAL INFORMATION SOCIETY}

The relatively high cost of ICT services remains one of the main barriers to ICT uptake, excluding many people from the global information society. Monitoring of prices for services, as well as the costs of end-user devices, is critical for developing policies that will make ICT services affordable to all.

\section{Fixed-broadband prices have dropped, but remain unaffordable in the poorest countries}

The price of fixed-broadband services globally has dropped substantially, making these much more affordable. The price of a basic fixed-broadband connection, as measured by the ITU fixed-broadband sub-basket, fell from around USD 80 in 2008, to USD 25 in 2015. Relative to average GNI per capita, this represents a drop from over $90 \%$ to 14\%. In developing countries, prices fell from around USD 200 to USD 26, impacting the global figures considerably.

Although the USD price of broadband services is approaching similar levels across developed and developing regions, these services nonetheless remain unaffordable for large parts of the population of the LDCs. In terms of PPP-adjusted prices, the PPPUSD cost is almost twice as high in the LDCs as it is in the developing countries as a whole. ${ }^{5}$

\section{Recent trends in fixed-broadband prices confirm that these services remain unaffordable in the LDCs}

Figure 5.19 reveals some interesting trends in broadband service prices. In 2014, for instance, average fixed-broadband prices became less affordable. Yet this price hike resulted mainly from increases in a small number of countries and stagnating or zero price drops in many others. ${ }^{6}$ In 2015, there was a renewed and significant drop in the price of fixedbroadband services. A price comparison in terms of USD and PPP-adjusted prices and as a percentage of GNI per capita highlights the following trends:

- Percentage of GNI per capita (Figure 5.19, top). At end 2015, fixed-broadband was more affordable than at end 2014, in both developed and developing regions. At 1.2\% of GNI per capita, these services were very affordable in developed countries, yet they were still relatively expensive in developing countries, where the monthly subscription to an entry-level service corresponded to close to $20 \%$ of GNI per capita. 
Figure 5.19. Fixed-broadband sub-basket, as a percentage of GNI per capita, in PPPUSD and in USD, 2008-15

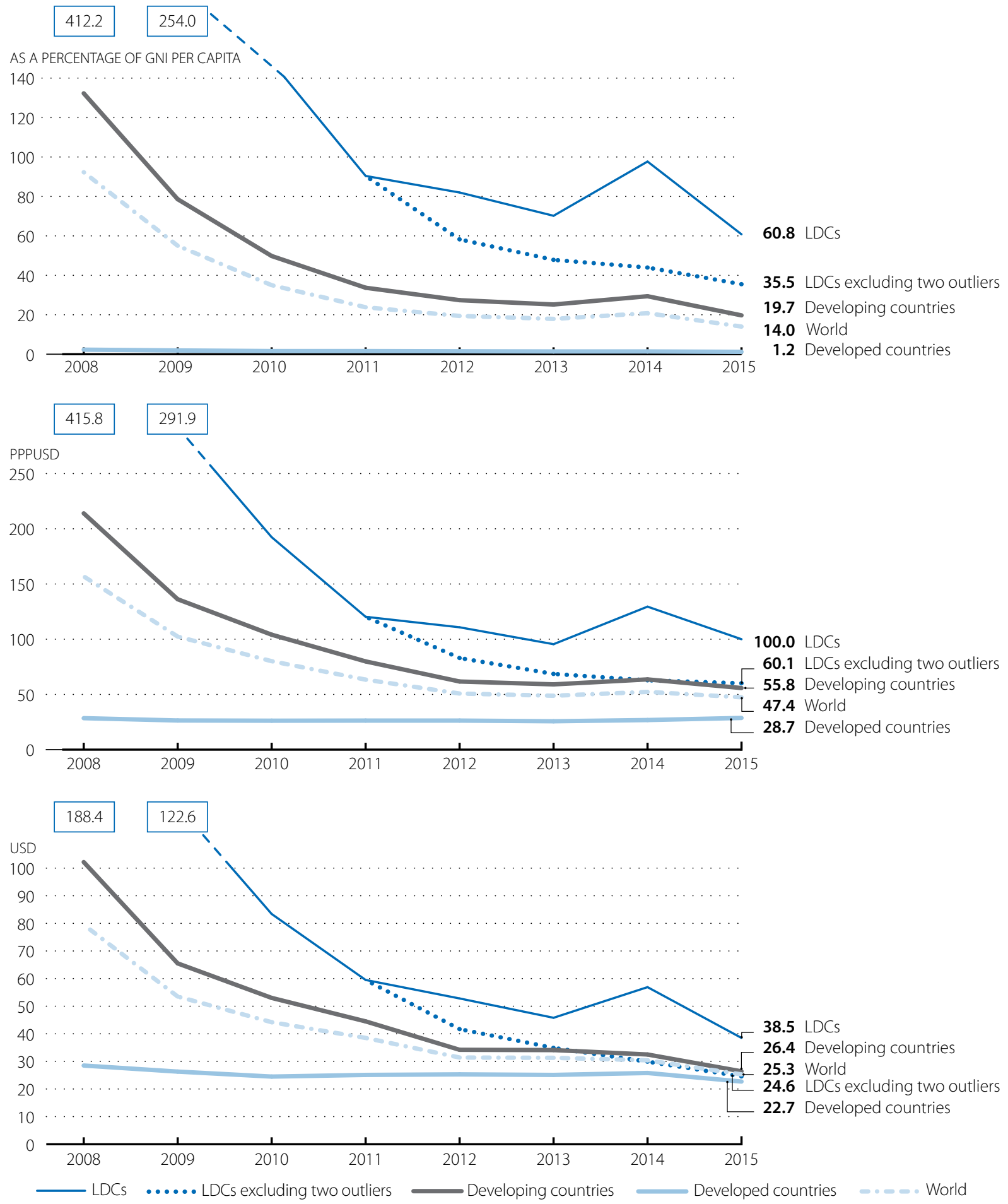

Note: Simple averages based on 144 economies for which data on fixed-broadband prices were available for the years 2008-15. The 2014 price hike in the LDCs is mainly the result of very substantial price increases in two countries (Uganda and Rwanda), which had a sizeable impact on the LDC average (especially because complete price data for the period 2008-2015 are only available for 25 LDCs). The dotted line shows the evolution of the average in the LDCs excluding these two countries.

Source: ITU (2016b), Measuring the Information Society Report 2016. 
Globally, the average price of an entry-level fixed-broadband subscription as a percentage of GNI per capita fell from close to $21 \%$ in 2014 to $14 \%$ in 2015. Prices dropped by one-third in the LDCs and other developing countries, while in developed countries they decreased at a lower rate. However, by end 2015 an entry-level fixed-broadband subscription still represented close to 61\% of GNI per capita in the LDCs, making it unaffordable for a large portion of the population.

- Purchasing power parity (Figure 5.19, middle). Although PPP-adjusted prices in the LDCs dropped from a high of PPPUSD 130 in 2014 to PPPUSD 100 in 2015, broadband services still remained on average more expensive than in 2013. The average for the LDCs was significantly influenced by very high prices in two countries, Rwanda and Uganda. When these two countries are excluded from the other LDCs included in the price comparison, the average for 2015 was PPPUSD 60; there was also a slight but sustained decrease between 2013 and 2015 (8\% and 4\%, respectively). At the global level, PPP-adjusted prices fell by about 10\% from 2014 to 2015, the same percentage decrease as in the developing countries as a whole.

- USD prices (Figure 5.19, bottom). Between 2014 and 2015, USD prices for fixed-broadband services decreased in developed and developing regions, and most strongly in the LDCs, thus reducing differences in the absolute USD price. By 2015, the average price of a fixed-broadband service stood at USD 23 and USD 26 in developed and developing regions, respectively, compared to USD 38 in the LDCs. Differences in USD terms compared to PPPUSD and GNI per capita prices are relatively small and would be even smaller in the case of the LDCs if the two outliers were not included in the average.

\section{Entry-level broadband services are becoming faster, but not everywhere}

So as to be able to make comparisons among countries, since 2008 ITU has collected data on entry-level fixed-broadband services, defined as an Internet connection of a minimum of $256 \mathrm{kbit} / \mathrm{s}$ with at least $1 \mathrm{~GB}$ of data included. While this benchmark has remained unchanged to date, a comparison of the speeds of entry-level fixed-broadband packages on offer today highlights the fact that minimum speeds have risen considerably over the past eight years. Providers offer higher speeds to meet the needs of Internet users, who access services and applications that require these speedsand also result in increased data traffic.

While in 2008 only about 30\% of all countries offered entry-level speeds above $1 \mathrm{mbit} / \mathrm{s}$, by 2015 close to $80 \%$ offered entry-level speeds of $1 \mathrm{mbit} / \mathrm{s}$ or above. Indeed, by 2015 not a single developed country offered a connection with speeds below $1 \mathrm{mbit} / \mathrm{s}$; the majority of plans advertised speeds of above $10 \mathrm{mbit} / \mathrm{s}$. This indicates that while the price of connections has decreased, speeds have, on average, increased—although not equally for all subscribers (Figure 5.20).

Yet speeds have not increased equally in all countries and regions of the world. Developing countries are only gradually upgrading broadband infrastructure to deliver higher speeds. In 2012, over 50\% of all countries were still offering services at speeds below $1 \mathrm{mbit} / \mathrm{s} ; 10$ mbit/s remained the exception for entry-level fixed-broadband packages. In 2015, more than $50 \%$ of countries continued to offer speeds of $2 \mathrm{mbit} / \mathrm{s}$ or less, and in the LDCs the large majority of entrylevel plans offered speeds below $1 \mathrm{mbit} / \mathrm{s}$. 
Figure 5.20. Most common entry-level fixed-broadband speeds, globally and by level of development

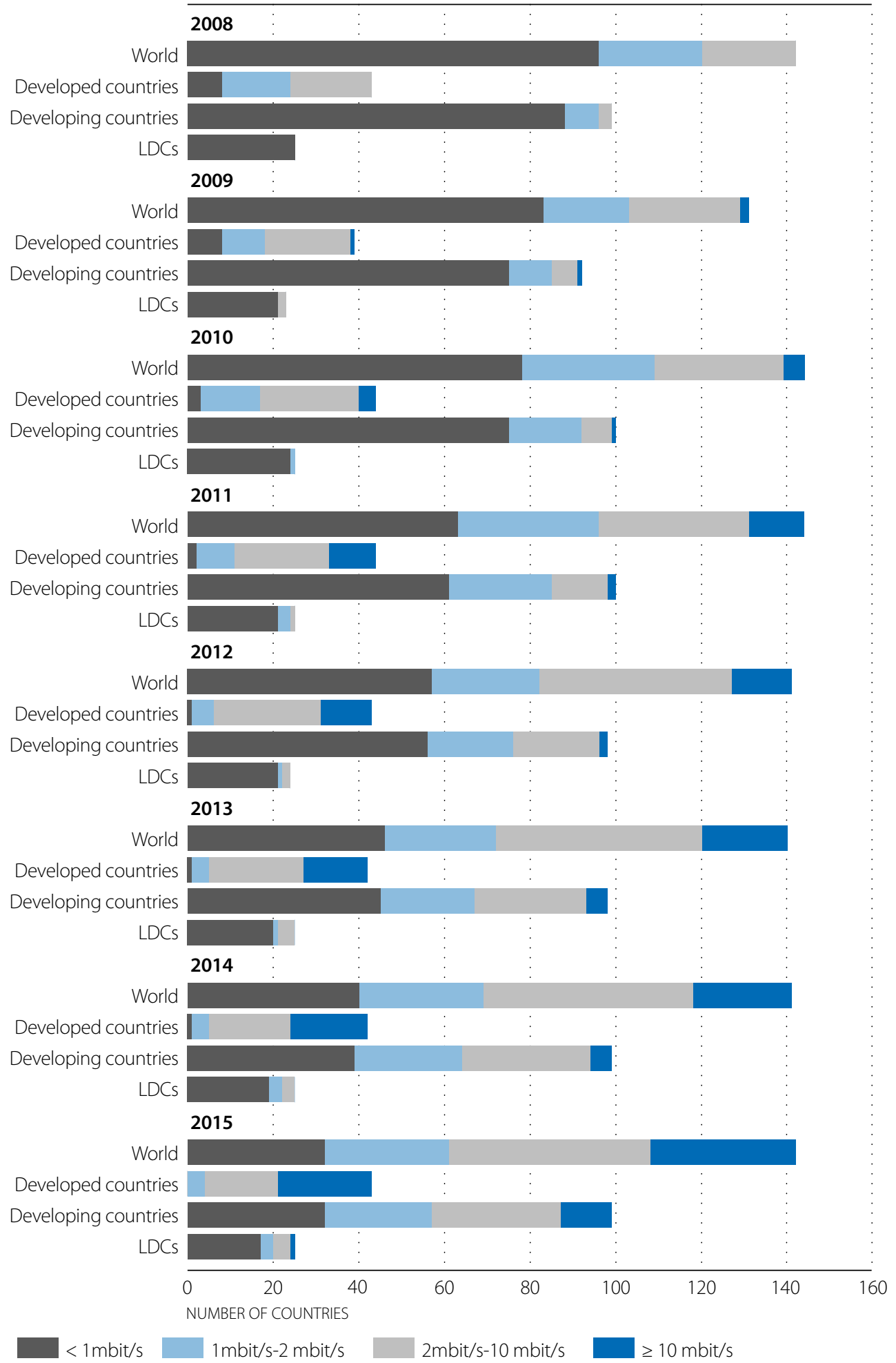

Note: Based on 144 economies for which 2008-15 data on fixed-broadband prices were available. Source: ITU (2016b), Measuring the Information Society Report 2016. 


\section{Some of the poorest countries continue to have the highest fixed-broadband prices}

The highest entry-level fixed-broadband prices are found in developing countries, and in particular in the LDCs. By the end of 2015, a fixed-broadband plan with a minimum of 1 GB of data per month cost more than USD 80 per month in ten developing countries (Table 5.1). Eight of those countries were LDCs, in which the total household consumption expenditure per capita ranged from USD 18 to USD 58 per month. This highlights how unaffordable fixed broadband is in these countries, especially considering international comparisons. The highest entry-level fixed-broadband prices in the developed world are recorded in Ireland, at USD 50 per month, which is significantly lower than in all the countries listed in Table 5.1, even though income in Ireland is much higher. Also, the entry-level plan in Ireland has a speed of 100 $\mathrm{mbit} / \mathrm{s}$, whereas in most LDCs the entry-level speed is $256 \mathrm{kbit} / \mathrm{s}^{8}{ }^{8}$

\section{Table 5.1. Countries with the highest fixed-broadband prices in 2015}

Economy$$
\text { prices }
$$

(USD/month)
Mobile-broadband (computer-based) prices (USD/month)
Total household

expenditure** (USD per capita/month)
Development status

\begin{tabular}{|c|c|c|c|c|}
\hline Chad & 501 & 17 & 58 & LDC \\
\hline Central African Republic & 489 & N/A & 32 & LDC \\
\hline Uganda & 300 & 11 & 41 & LDC \\
\hline Solomon Islands & 275 & 73 & $\ldots$ & LDC \\
\hline Kiribati & 188 & 56 & $\ldots$ & LDC \\
\hline Cuba & 180 & N/A & $308^{*}$ & non-LDC \\
\hline Equatorial Guinea & 101 & N/A & 272 & LDC \\
\hline Rwanda & 97 & 8 & 39 & LDC \\
\hline Burundi & 83 & N/A & 18 & LDC \\
\hline Republic of the Congo & 82 & 17 & 107 & non-LDC \\
\hline
\end{tabular}

Notes:

"N/A" = service is not available.

"..." = information is not available.

* $=2014$ data

** = Total Household expenditure calculated by dividing the indicator "household final consumption expenditure (current USD)" by the population of the country.

Source: ITU (2016b), Measuring the Information Society Report 2016. Data on household final consumption expenditure from the World Bank.

Entry-level fixed-broadband plans cost less than USD 15 per month, nonetheless, in a number of LDCs, including Bangladesh, Bhutan, Ethiopia, Cambodia, Mauritania, Malawi, Lesotho, South Sudan and Sudan. Yet fixed-broadband uptake is also very low in these countries, with the exception of Bangladesh and Bhutan. ${ }^{9}$

The much higher prices in other LDCs must have specific supply-side causes which, if addressed, could significantly contribute to making fixed broadband more affordable in these countries. For example, in LDCs with very high fixed-broadband prices, operators often market fixed-broadband services as a premium or business service. For instance, Foris Telecom in Uganda and Airtel in the Republic of the Congo advertise fixed Internet for business customers, whereas households are only offered mobile-broadband services. In some cases, even when not specifically stated, some typical business broadband-service features are added by default to entry-level fixed-broadband plans; for example, a minimum guaranteed speed (Orange WiMAX offer in the Central African Republic) or low contention ratios (CBINET ADSL offer in Burundi). ${ }^{10}$ Whereas normally operators would offer these extra features for a higher price, proposing basic plans to residential customers, in several LDCs they are added to basic fixed-broadband plans, making these unaffordable for residential customers. 
Another element that may explain the high prices in some countries is the technology used in the fixed-broadband network. ADSL services rely on traditional fixed-line (copper wire) network, but this infrastructure has limited reach in most LDCs. As a result, ADSL plans are offered only by the incumbent operator (i.e. the operator having access to the legacy fixed-line infrastructure) and at very high prices (ITU, 2013). Fixed wireless technologies, such as fixed WiMAX, are often a more affordable alternative for extending the reach of the fixed-broadband network in countries with limited basic fixed-line infrastructure and reduced or sparse demand. Significant investment is needed in the LDCs to extend the basic wired-line infrastructure. Making the appropriate technological choice in each situation could help streamline limited investment flows allocated to fixed services.

Other infrastructure elements may have an impact on the underlying costs of fixed-broadband provision in the LDCs. These include limited and expensive international connectivity and backhaul connections, as well as deficiencies in the power grid. Yet these factors are - to a large extent—common in the broadband infrastructure chain, and therefore also affect mobile-broadband prices. Nonetheless, an analysis of mobile-broadband prices in countries with very high fixed-broadband prices reveals that mobile-broadband is much cheaper. This suggests that the infrastructure elements common to fixed and mobile broadband are not the main determinant of very high fixed-broadband prices. Instead, the regulatory challenges facing the fixed-broadband market, and the resulting limited competition in some LDCs (ITU, 2013), may better explain some of the differences in fixed and mobile-broadband prices.

Another distinct element in the LDCs that may have an impact on fixed-broadband prices is the way in which prices are communicated. Price information is not always available on operators' websites, but rather is communicated by phone, by e-mail or through paper advertisements. This makes information on prices more difficult to obtain, even for telecommunication regulators, and bespoke prices and/or one-off offers may be common. For instance, MTN Rwanda does not advertise fixed-broadband prices on the website, but the small alternative operator Hai advertises fibre-optic packages starting at USD 97 per month for $10 \mathrm{mbit} / \mathrm{s}$. No one publishes prices for fixed-wireless broadband plans, although data from the Rwanda Utilities Regulatory Authority show that in 2014, most fixed-broadband subscriptions in the country relied on fixed-wireless technologies.

Fixed-broadband Internet access cannot always be replaced by mobile-broadband access, particularly for users requiring high capacity and high speed. Some of the most promising future ICT opportunities are linked to areas requiring high connectivity, such as big data analytics and the Internet of Things. Developing countries, and the LDCs in particular, are among those that could benefit the most from these ICT developments (ITU, 2015a; Cisco 2016). Therefore, policy-makers and regulators in these countries should not disregard the issue of very high fixed-broadband prices. Rather, they should address the concrete commercial and infrastructure-related problems mentioned above that make fixed broadband a premium service, unaffordable for residential customers and small/micro undertakings.

\section{Availability and affordability of mobile-broadband services is growing in many countries}

Mobile-broadband services are becoming more affordable and more available in more and more countries, including LDCs, where the availability of prepaid handset-based plans almost doubled in the period 2012-15, and tripled in the case of post-paid computer-based plans (Figure 5.21).

In addition to 3G, mobile-broadband networks based on LTE and other advanced technologies are now available in $70 \%$ of countries worldwide. However, the availability of LTE broadband networks varies across development levels. LTE technologies have been deployed only in $38 \%$ of the LDCs, as compared to $58 \%$ of developing countries as a whole and 91\% of developed countries (GSMA, 2015). This suggests that the speed and capacity experienced by mobile-broadband users may differ significantly across countries. 


\title{
Figure 5.21. Availability of mobile-broadband services by type of service and level of development, 2012-15
}

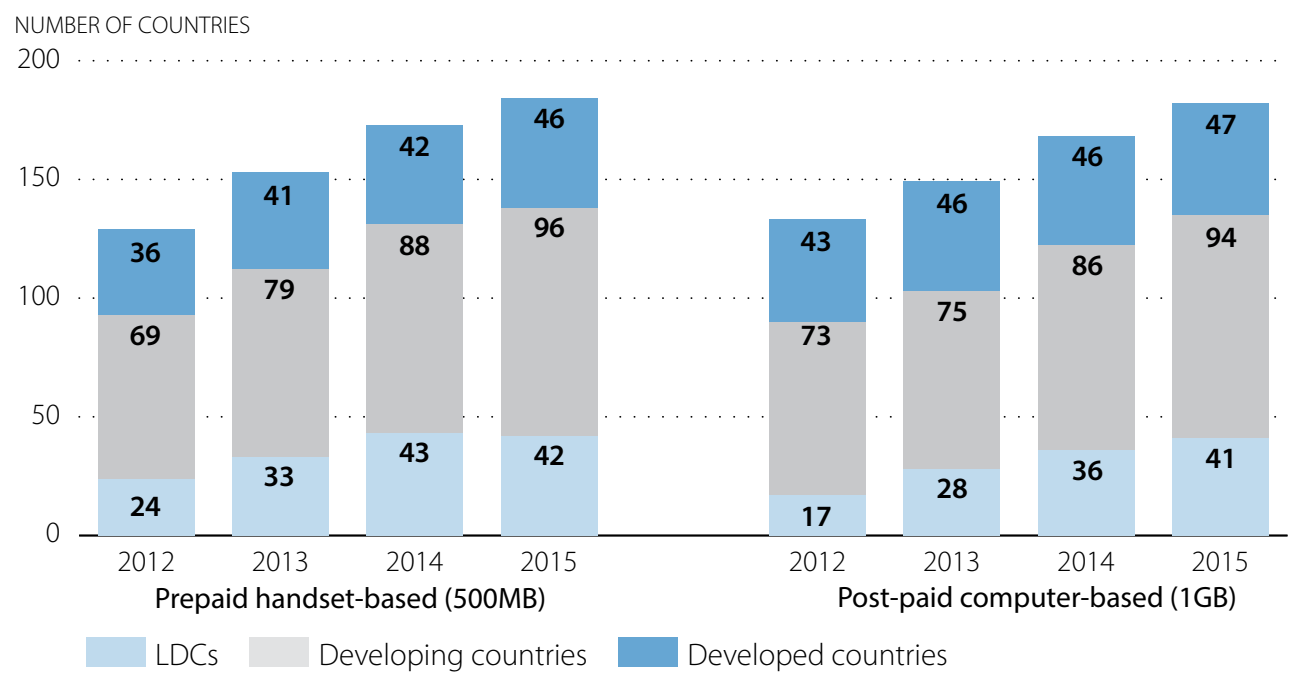

\begin{abstract}
Note: A mobile-broadband service is counted as being available if it was advertised on the website of the dominant operator or if prices were provided to ITU through the ICT Price Basket Questionnaire, which is sent out annually to all ITU member states/national statistical contacts. Data on mobile-broadband prices were collected from 2010-14. Since 2015, data on mobile-broadband prices have been collected by ITU from operators' websites.
\end{abstract}

Source: ITU (2016b), Measuring the Information Society Report 2016.

StatLink न्ता st http://dx.doi.org/10.1787/888933526424

\section{For the least developed countries, affordability of mobile broadband is still an issue}

A key factor for the growing uptake of mobile broadband, apart from the increasing availability of these services, has been the drop in prices. Globally, handset-based mobile-broadband prices, based on ITU price data, have fallen from an average of USD 23 in 2013 to USD 13 in 2015 (Figure 5.22)." In parallel, average prices for computer-based mobile-broadband services have decreased from USD 21 to USD 16. These reductions have been remarkable in the LDCs: handsetbased prices have more than halved, in both USD and PPP terms, over the period 2012-15, while there has been a 40\% reduction in computer-based prices.

The countries with the least affordable computer-based mobile broadband are mainly LDCs. Indeed, of the 19 countries in which computer-based mobile-broadband plans correspond to more than 20\% of GNI per capita, 17 are LDCs. Most of these countries have in common very low income levels and a limited proportion of households with a computer (a prerequisite for using a computer-based mobile-broadband plan).12 Even in some countries with higher income levels, such as Angola, Kiribati and Papua New Guinea, the high cost of computer-based mobile-broadband plans (more than USD 35 per month) makes them unaffordable for a majority of the population.

While in developing countries, handset-based mobile broadband is more affordable than computer-based mobile broadband (5.1\% compared to 7.6\%, on average, in 2015), prices still remain relatively high, especially for low-income populations (Figure 5.22). In nine LDCs, the cost of a handset-based mobile-broadband service corresponds to more than $20 \%$ of GNI per capita, thus making it unaffordable for most of the population. This is reflected in comparatively low mobile-broadband penetration in these countries.

On average, mobile broadband prices in the LDCs still represent 11\% of GNI per capita for handset-based services and $17 \%$ for computer-based plans. This means that these services, and particularly computer-based mobile broadband, are still unaffordable for large segments of the population in the LDCs. 
Figure 5.22. Mobile-broadband prices as a percentage of GNI per capita, in PPPUSD, and in USD, 2013-15

500 MB PREPAID HANDSET-BASED

AS A PERCENTAGE OF GNI PER CAPITA

35

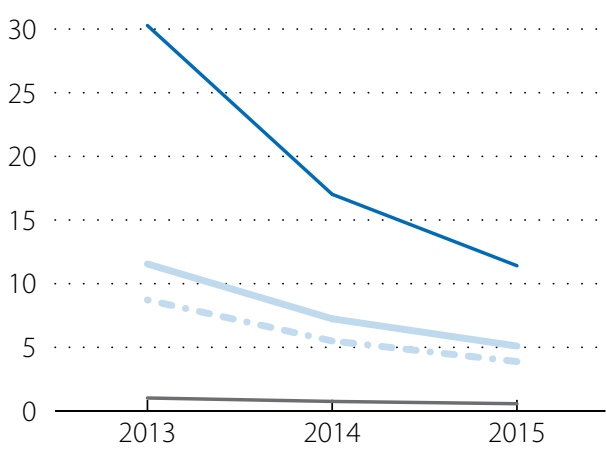

PPPUSD

60

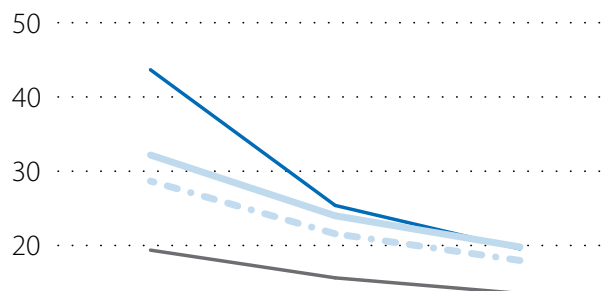

10

0

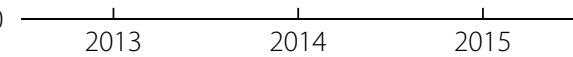

USD

30

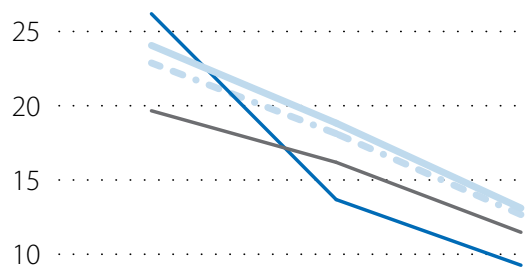

5

0

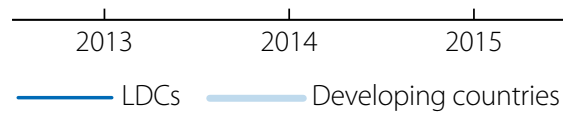

1 GB POST-PAID COMPUTER-BASED

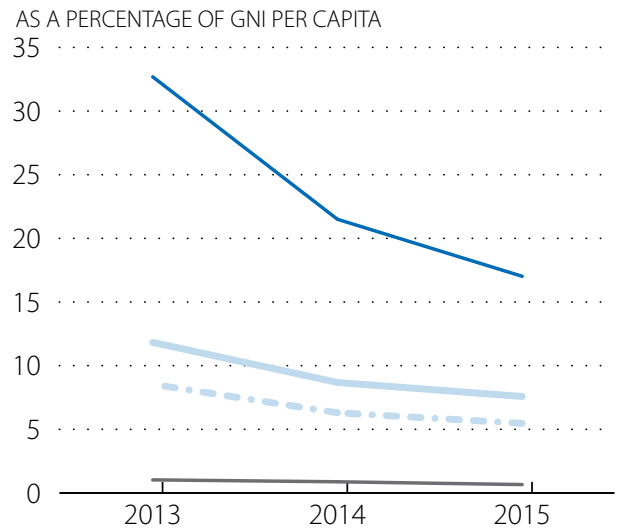

PPPUSD

60

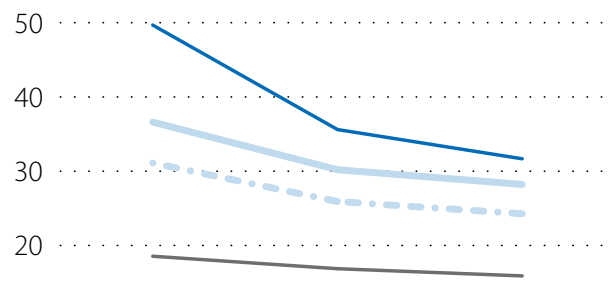

10

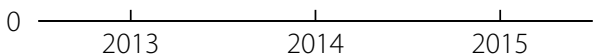

USD

30

25

20

15

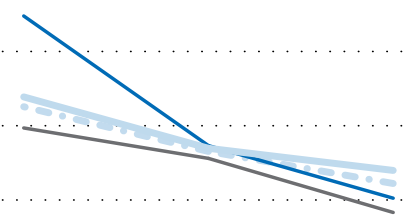

10

5

0

$\begin{array}{ccc}\frac{1}{2013} 2014 & \frac{1}{2015} \\ \text { Developed countries } & \ldots & \ldots\end{array}$

Note: Simple averages based on data on handset-based and computer-based mobile-broadband prices available for 153 and 147 economies, respectively.

Source: Adapted from ITU (2016b), Measuring the Information Society Report 2016.

StatLink न्ना15 http://dx.doi.org/10.1787/888933526443 
Figure 5.23. Use of the Internet on the move in selected economies, 2013 and 2014

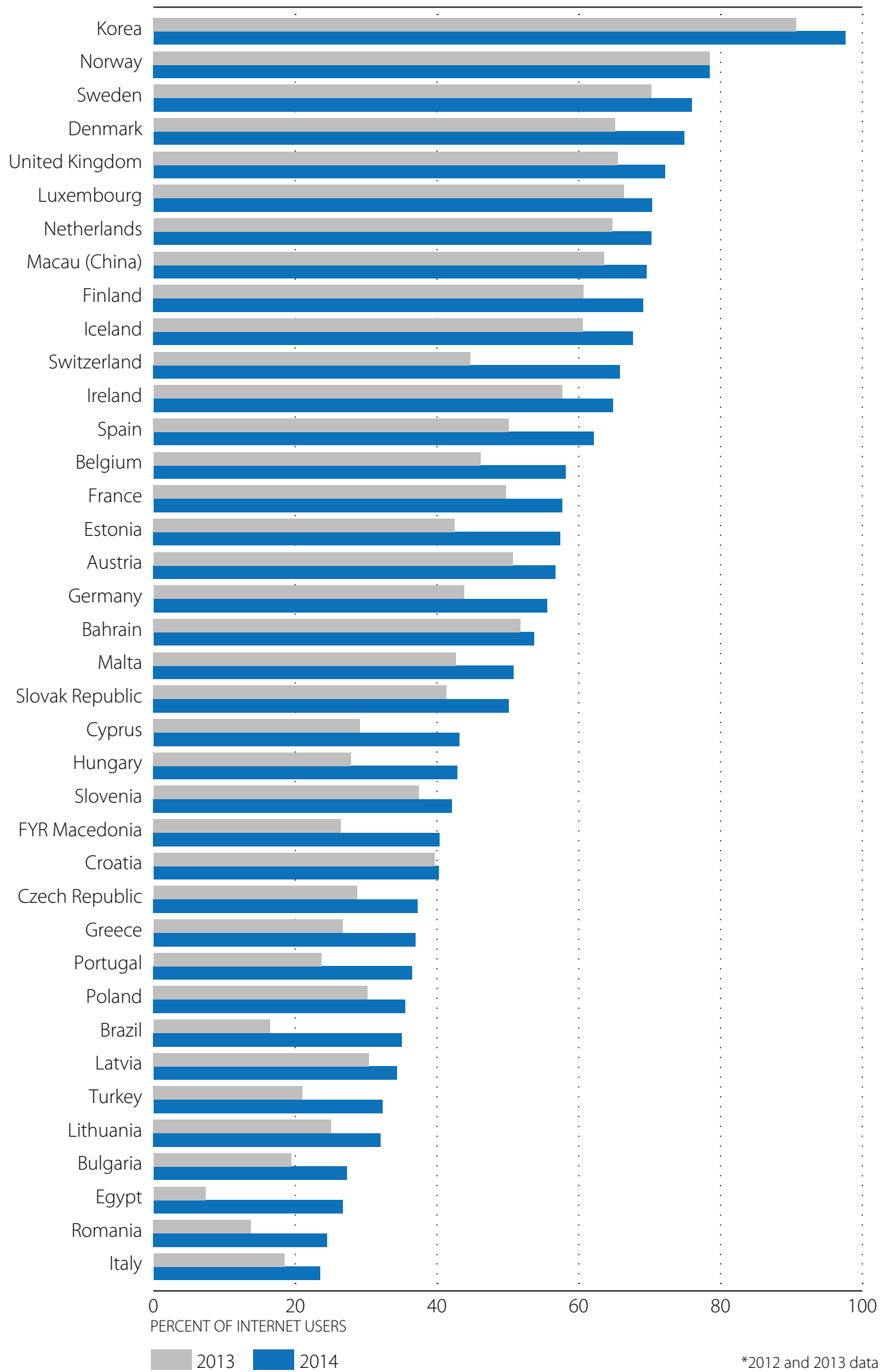

Note: "On the move" = Internet use via a mobile phone or other mobile access device, e.g. a laptop computer, tablet or other handheld device. For developing countries: Internet use through the above mentioned devices connected to a mobile phone network and at a location away from "home", "work", "place of education", "another person's home" and "community and commercial access facilities". For European countries: Internet use through the abovementioned devices "away from home and work".

Source: ITU (2014) and Eurostat for European countries. 


\section{More and more people are connecting on the move}

The increasing availability of mobile-broadband services, coupled with decreasing prices, is changing the way people access the Internet. Available data show that in a majority of developed countries, a growing number of Internet users are connecting to the Internet through mobile networks while on the move (Figure 5.23). ${ }^{13}$ The limited data available from developing countries suggest that increases in the accessibility and drops in prices of mobile broadband may be having a strong impact on how people go online in the developing world as well. For example, the percentage of users accessing the Internet on the move tripled in Egypt between 2013 and 2014; it doubled in Brazil over the same period. As Internet usage continues to grow in developing countries, and in view of the low fixed-broadband subscription figures in most of these countries, a significant proportion of new Internet users may go online exclusively through mobile networks. This highlights the importance of affordability of mobile-broadband services to expand Internet use in the developing world.

Prepaid services also have driven uptake. In particular, affordable prepaid handset-based plans have been a major driver of uptake for mobile voice and SMS services; they could have a similar effect in promoting handset-based mobilebroadband services. It is important to note, however, that in addition to the price of the mobile-broadband service itself, other factors — such as the cost of a smartphone - may be decisive factors influencing uptake (OECD, 2013a; GSMA, 2016).

\section{SOCIO-ECONOMIC BARRIERS KEEP MANY FROM JOINING THE INFORMATION SOCIETY}

While limited access and high costs are important barriers to ICT uptake, research on Internet user behaviour suggests that socio-economic factors outside the ICT ecosystem keep many people from joining the information society.

Available data show that the reasons households do not have Internet access at home differ across developed and developing countries. While the cost of services and equipment appears to be the key barrier in developed countries, people in developing countries face other challenges. The most often-cited response is that people "do not need the Internet". This suggests that non-users are either not aware of the information, services and applications available over the Internet, or that there is not sufficient content made available that is relevant for specific user groups. Lack of confidence, knowledge and skills is another important and often-cited barrier, pointing to the importance of raising levels of education to allow people to benefit from online opportunities.

\section{Education matters, but so do income, gender and age}

An analysis of Internet users and their activity points to a strong link between low levels of educational attainment and low Internet penetration rates (Figure 5.24). Indeed, ITU data show that education levels are one of the most important indicators of whether or not people are Internet users, in developing as well as developed countries. Internet use in most developed countries is almost universal among people with tertiary education, but a large proportion of citizens with lower educational attainment remain unconnected, despite having similar access to infrastructure and services.

Differences in educational levels also help explain other divides, such as income, gender and age. A number of studies suggest that the offline population remains disproportionately poor, rural, elderly, and female (Facebook, 2015; ITU, 2016b; McKinsey, 2014). 
Figure 5.24. Internet use by level of education in developed and developing countries, 2013-15

\section{DEVELOPED COUNTRIES}

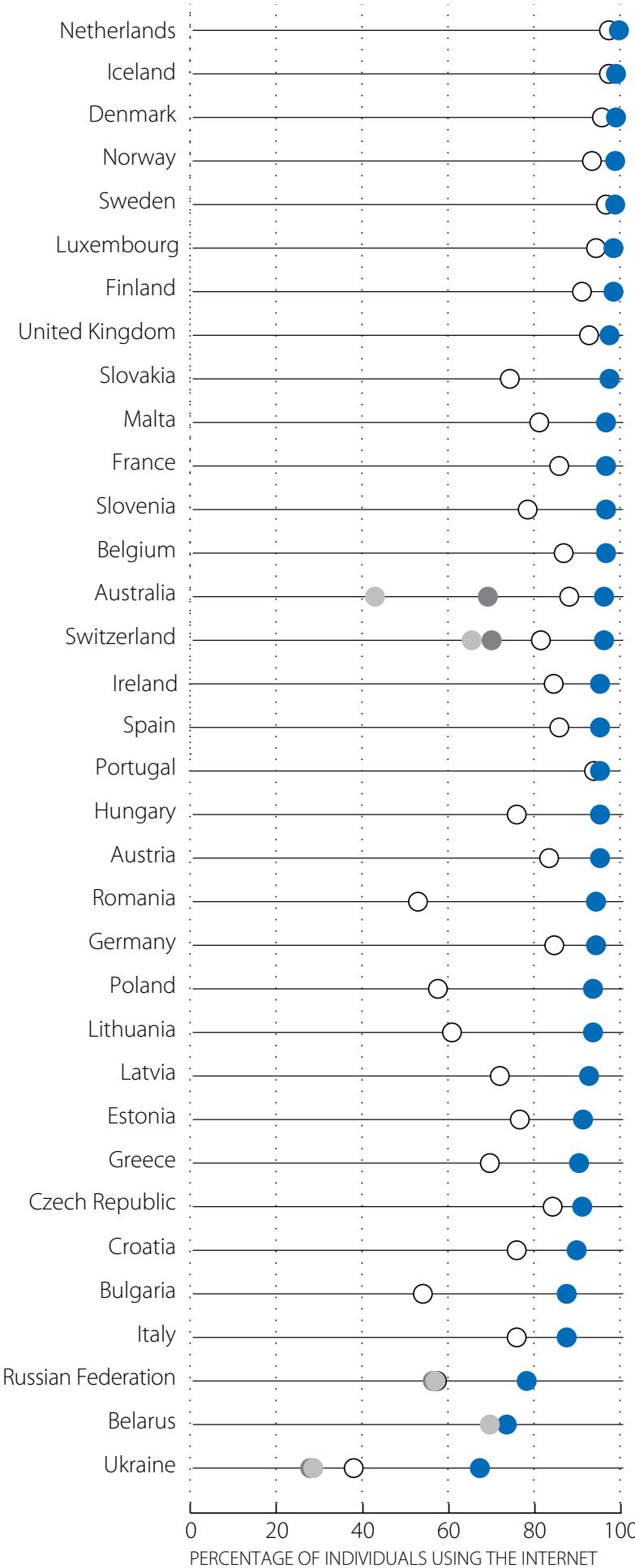

\section{DEVELOPING COUNTRIES}

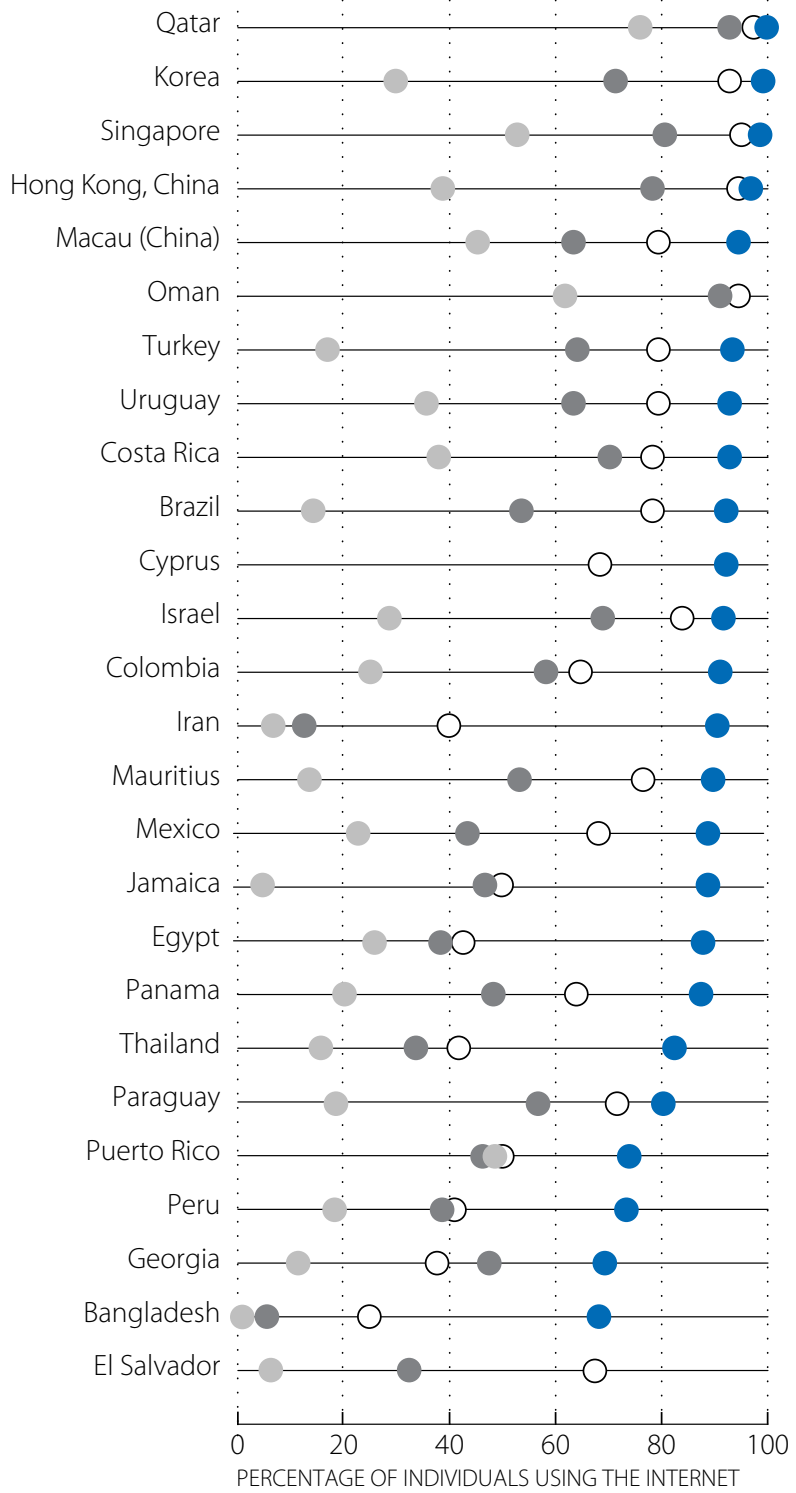

Notes: Latest data available. ISCED = International Standard Classification of Education

Source: ITU (2016b), Measuring the Information Society Report 2016.

StatLink न्ताIS http://dx.doi.org/10.1787/888933526481 


\section{The gender gap is particularly pronounced in the LDCs}

Data on Internet use broken down by gender, for example, indicates a very clear gender divide. In the vast majority of countries, the proportion of men using the Internet is higher than the proportion of women (Figure 5.25). Only in selected countries, in Europe and the Americas in particular, are there more women than men online, proportionally. Data also point to significant differences between developed and developing countries; the gender gap is particularly pronounced in the LDCs. These findings are reflected at the global level, where ITU reports a 2016 Internet-user gender gap of 12.2\% in 2016 (Figure 5.26).

Figure 5.25. Proportion of individuals using the Internet, by gender, 2016

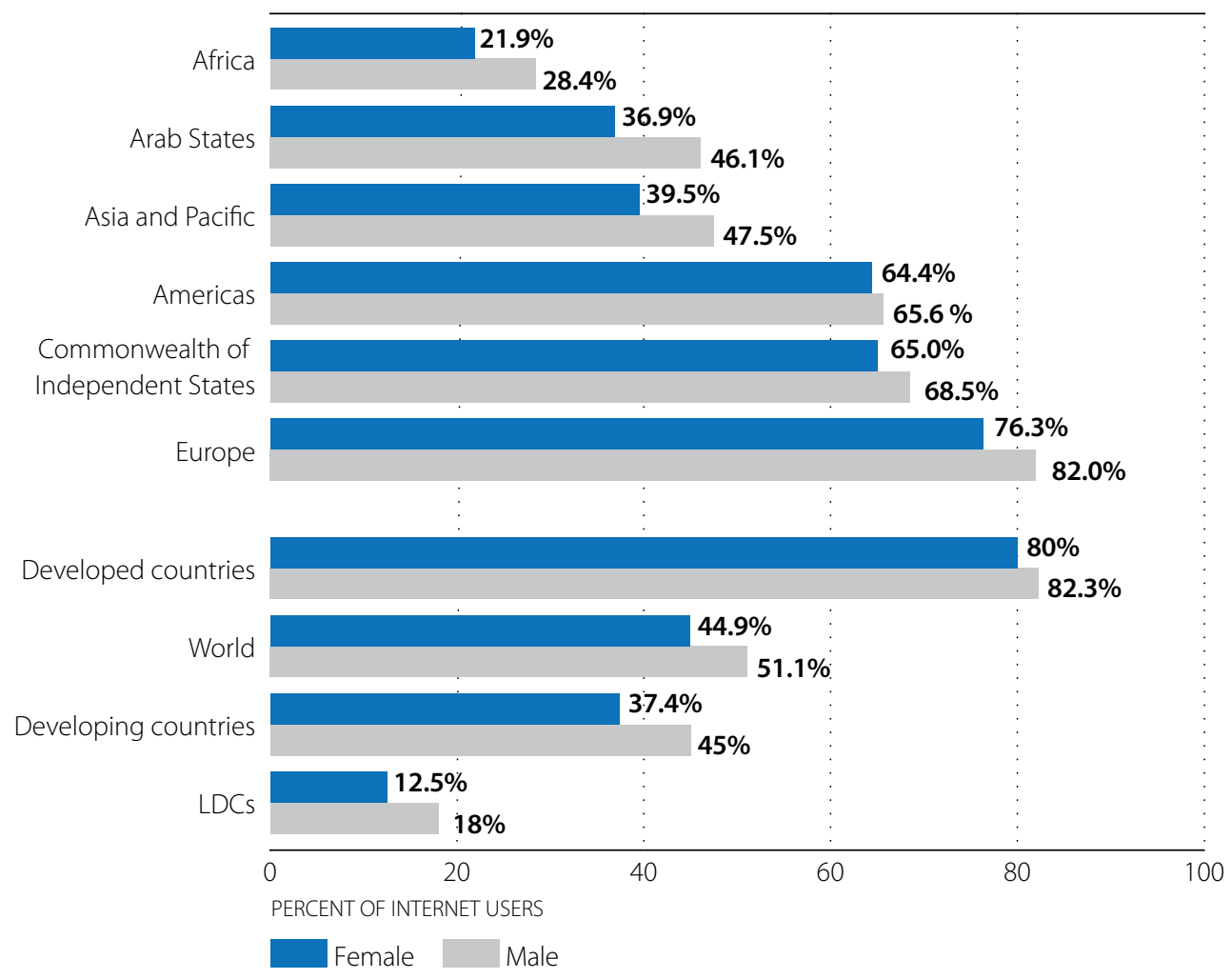

Note: Estimates

Source: ITU (2016a), Facts and Figures 2016.

Differences in levels of education and school enrolment, and in tertiary education levels, could be important factors explaining why more men than women use the Internet. Some of the countries in which more women than men are Internet users are also countries that do well on the gender parity index (GPI), which measures parity between girls and boys in terms of school enrolment ratios. Gender equality in these countries is also reflected by a high proportion of women in the labour force. 
Figure 5.26. Internet user gender gap, 2013 and 2016

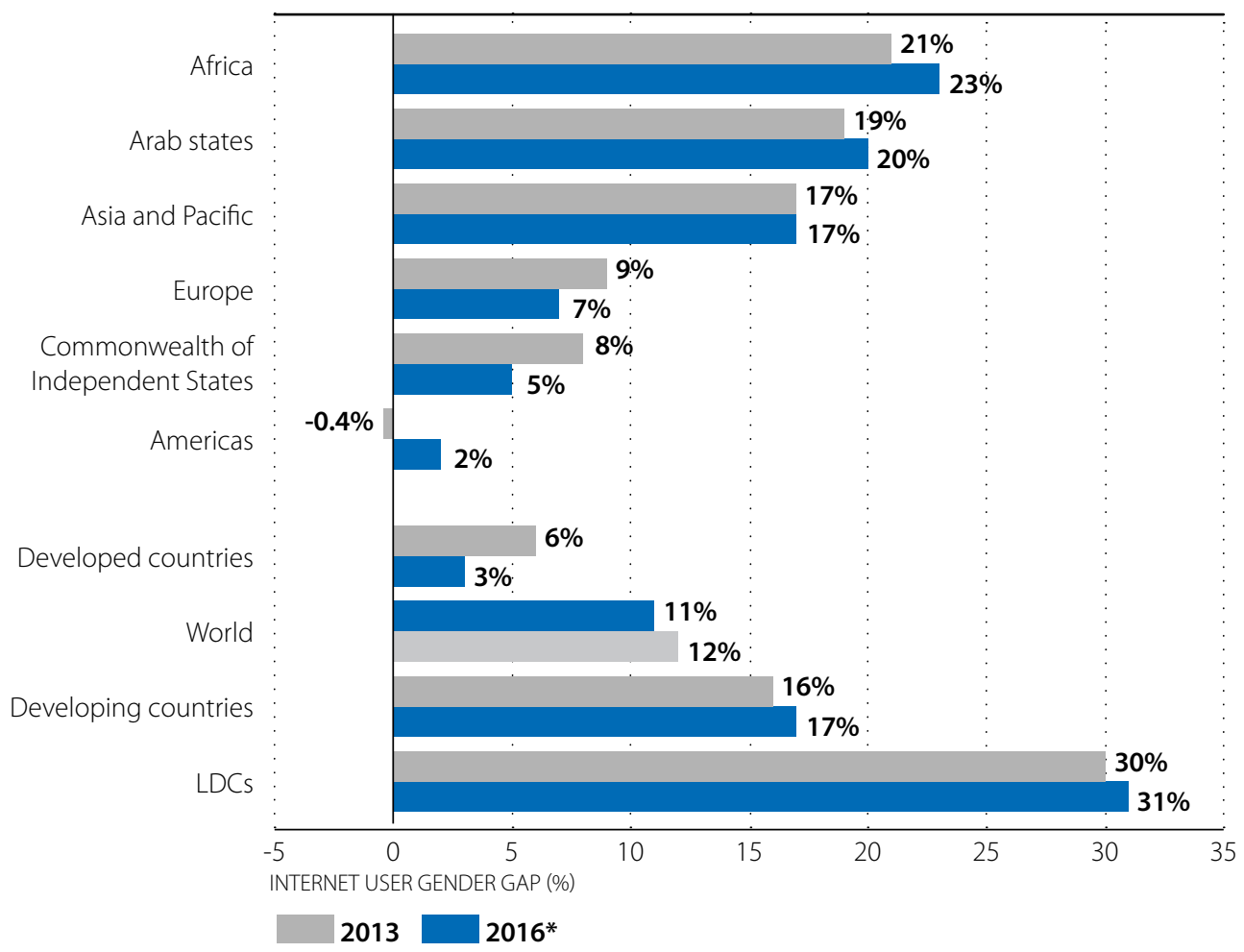

*Estimates.

Notes: The gender gap represents the difference between the Internet user penetration rates for males and females relative to the Internet user penetration rate for males, expressed as a percentage.

Source: ITU (2016a), Facts and Figures 2016.

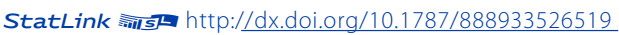

\section{Tapping into the full potential of the Internet means addressing socio-economic inequalities}

A recently published ITU discussion paper identifies similar barriers to greater ICT uptake and use. The paper states that "the key reasons for people not using the Internet are structural inequalities in income and education as well as the lack of infrastructure, relevant online content and services and high relative costs of access and usage." (ITU, 2017c). It provides an overview of possible measures that could help to increase the number of Internet users, both from the demand and the supply side. These include measures such as creating and developing local content-in local languages; addressing cultural and social acceptance; providing training; and making women a special focus group. On the supply side, suggested measures include developing large-scale cost-effective rural solutions to expand networks, and building fixed infrastructure to support the digital economy (Figure 5.27).

ITU research also finds that among the online population, important differences exist in terms of the types of online activity Internet users engage in. Education levels seem to influence the type of activity in which users engage, with implications for their potential gains. Many Internet users, in particular those with lower levels of education and income, make very limited use of the Internet and are not able to exploit its full potential. In developing countries, the Internet is still mainly used for communication and entertainment purposes. In developed countries, citizens use the Internet to a greater degree for reading newspapers, magazines, and books, interacting with government, and performing banking and e-commerce services. 
Figure 5.27. Demand- and supply-side measures to increase internet use

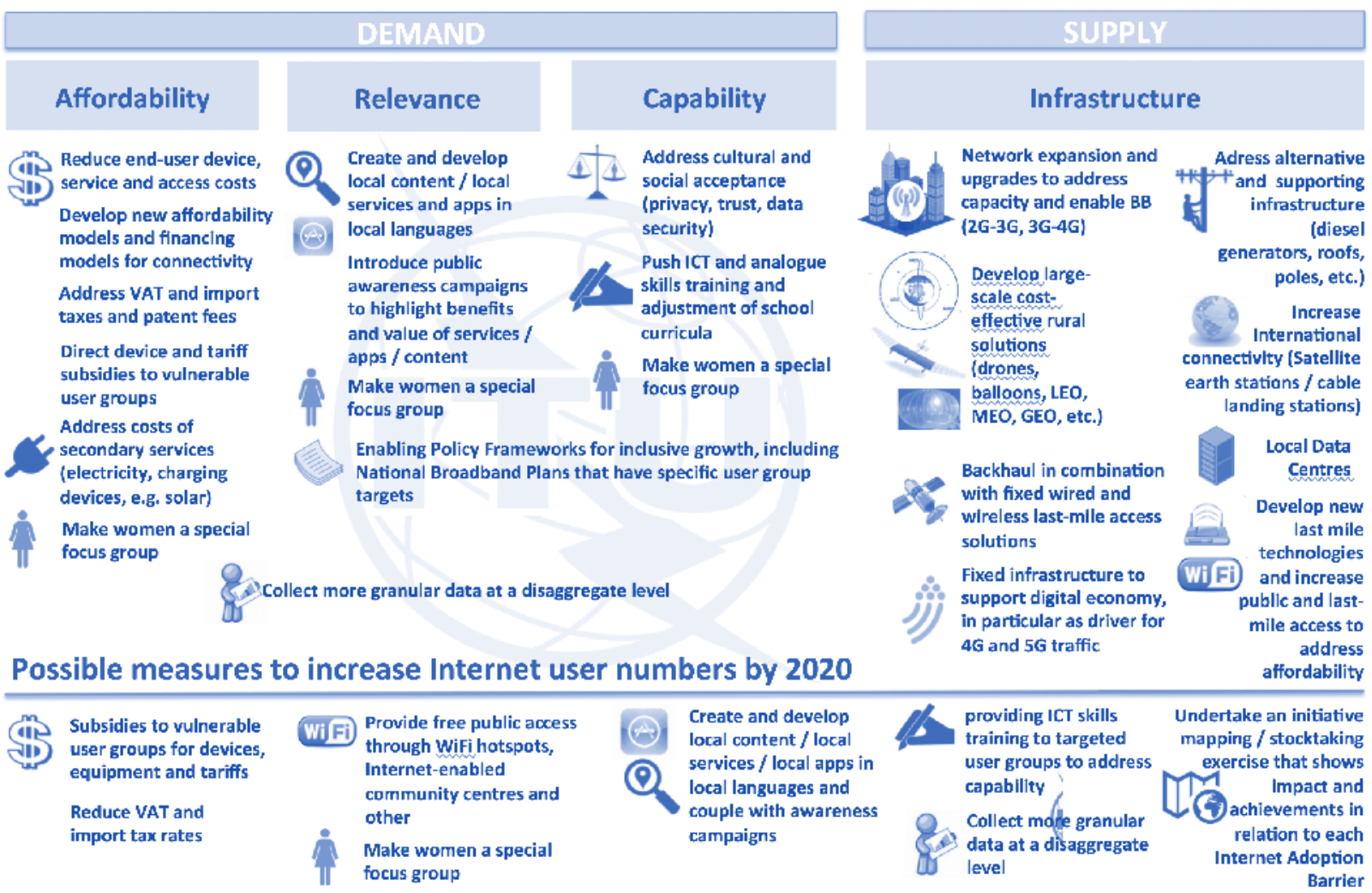

Source: ITU (2017c), Connecting the Unconnected Working together to Achieve Connect 2020 Agenda Targets.

Similar findings are observed among children and adolescents. An OECD study shows that wealthier students are more likely to use the Internet for educationally advantageous activities, such as gathering information and reading the news, while poorer students are more likely to use it for communication and playing games (OECD, 2016). The same study suggests that even in countries with almost universal Internet access, the lack of knowledge and familiarity with the use of the Internet to find information can hamper young people in their studies and job-finding prospects. The study shows that traditional education is critical to increasing the ability of students to use ICT tools for learning purposes. Reading content on the Internet requires the same skills as reading a book or newspaper. While it is important to integrate the Internet into education, results from the OECD Programme for International Student Assessment (PISA) show that the highest-performing students in digital reading were "not more exposed to the Internet at school than are students in other OECD countries" (OECD, 2015).14

These findings suggest that the Internet can reinforce existing inequalities, leaving the most vulnerable population groups even further behind. The mobile phone has rightly been hailed as a development enabler that provides crucial communication channels. Yet for large population groups, including the poor and less privileged, access to information and new services—and therefore to the full potential of the Internet—remains largely untapped.

To turn the Internet into a truly universal tool for development, policy-makers must tackle not only the supply-side challenges of the Internet, including infrastructure deficiencies and high prices, but also the demand-side barriers that exist outside the ICT ecosystem. This means addressing broader socio-economic inequalities. Above all, people need to acquire not only the necessary digital skills, but also analogue skills—such as basic literacy and numeracy —in order to exploit the full potential of the Internet. ICT policy-makers must act within the context of a larger Internet ecosystem if they are to empower people and make Internet content easily accessible to disadvantaged groups. ICT policies must be linked to investments in education in order to develop the necessary human skills and raise education levels to bring more people online and make them more effective as online users. 


\section{CONCLUSIONS}

This chapter has highlighted the rapid growth in ICT access and use, and the evolution towards the promise of a global information society that delivers new opportunities for development to everyone. Despite this progress, however, major differences continue to exist in ICT access, use, and affordability, in particular in terms of broadband Internet access and use.

ICT infrastructure, connectivity and quality of service in the least developed countries are lagging behind the rest of the world. Policy makers must make sure they address and overcome important infrastructure bottlenecks, in terms of both national backbones and international Internet connectivity. Similarly, fixed- and mobile-broadband prices remain high for the world's poorest countries, and unaffordable for low-income population groups.

This chapter identifies and number of important steps governments, and in particular the LDCs, can take to create an enabling regulatory environment that will help to stimulate investment and increase ICT access and use. Two-thirds of all LDCs are still in either the first or the second generation of regulation and need to urgently perform basic reforms, including to promote privatization, liberalization, and intra-platform competition. Other important reforms for many LDCs include the removal of entry barriers to foreign ownership and investment. When private investment is not sufficient, it is possible to look into direct government investment, take advantage of public-private partnerships, use universal service funds and obligations to bring services to areas that provide limited business opportunities, and provide tax incentives for investments.

Yet while Internet infrastructure, access and quality of service remain important barriers to uptake, more people have access to Internet services than actually use them. To bring more people online, broader socio-economic factors, not related to ICT, need to be addressed. Education levels, in particular, are strong determinants of whether or not, and how, people use the Internet. Citizens need both digital and analogue skills to fully benefit from the opportunities of the information society. 


\section{REFERENCES}

Broadband Commission for Sustainable Development (2015), "About Broadband Commission for Sustainable Development", webpage, www.broadbandcommission.org/about/Pages/default.aspx

Cisco (2016), "VNI Global Fixed and Mobile Internet Traffic Forecasts", webpage, www.cisco.com/c/en/us/solutions/ service-provider/visual-networking-index-vni/index.html

Facebook (2015), "State of Connectivity 2015: A Report on Global Internet Access", internet.org by Facebook, newsroom.fb.com/news/2016/02/state-of-connectivity-2015-a-report-on-global-Internet-access/.

GSMA (2015), "Data demand explained", GSMA - Spectrum4all, London, www.gsma.com/spectrum/wp-content/uploads/2015/06/GSMA-Data-Demand-Explained-June-2015.pdf GSMA (2016), "The Mobile Economy Africa 2016”, GSMA Intelligence, London, https://www.gsmaintelligence.com/research/?file=3bc21ea879a5b217b64d62fa24c55bdf\&download

ITU (2013), Measuring the Information Society Report 2013, International Telecommunication Union, Geneva, https://www.itu.int/en/ITU-D/Statistics/Documents/publications/mis2013/MIS2013 without Annex 4.pdf

ITU (2014), Manual for Measuring ICT Access and Use by Households and Individuals 2014, International Telecommunication Union, Geneva, www.itu.int/en/ITU-D/Statistics/Pages/publications/manual2014.aspx.

ITU (2015), GSR15 Discussion Paper Taxation in the digital economy, http://www.itu.int/en/ITU-D/Conferences/GSR/ Pages/GSR2015/GSR15-discussion-paper.aspx

ITU (2015a), Measuring the Information Society Report 2015, International Telecommunication Union, Geneva, www.itu.int/en/ITU-D/Statistics/Documents/publications/misr2015/MISR2015-w5.pdf

ITU (2015b), Facts and Figures 2015, International Telecommunication Union, Geneva, https://www.itu.int/en/ITU-D/Statistics/Documents/facts/ICTFactsFigures2015.pdf

ITU (2016a), Facts and Figures 2016, International Telecommunication Union, Geneva, https://www.itu.int/en/ITU-D/Statistics/Documents/facts/ICTFactsFigures2016.pdf.

ITU (2016b), Measuring the Information Society Report 2016, International Telecommunication Union, Geneva, www.itu.int/en/TU-D/Statistics/Pages/publications/mis2016.aspx

ITU (2016c), "Best Practice Guidelines”, webpage, www.itu.int/en/ITU-D/Regulatory-Market/Pages/bestpractices.aspx

ITU (2017a), "ITU agrees on key 5G performance requirements for IMT-2020", ITU Press Release, www.itu.int/en/mediacentre/Pages/2017-PR04.aspx

ITU (2017b), Global ICT Regulatory Outlook, International Telecommunications Union, Geneva

ITU (2017c), Connecting the Unconnected Working together to achieve Connect 2020 Agenda Targets, Background paper to the special session of the Broadband Commission and the World Economic Forum at Davos Annual Meeting 2017, broadbandcommission.org/Documents/ITU discussion-paper Davos2017.pdf

ITU (n.d.) "ITU Interactive Transmission Maps", webpage itu.int/go/Maps (accessed 10 April 2017)

Mc Kinsey (2014), Offline and falling behind: Barriers to Internet adoption, Mc Kinsey and Company, www.mckinsey. com/ /media/mckinsey/dotcom/client service/high\%20tech/pdfs/offline and falling behind full report.ashx

OECD (2013a), "Mobile Handset Acquisition Models”, OECD Digital Economy Papers, No. 224, OECD Publishing, Paris. DOI: $\underline{\text { dx.doi.org/10.1787/5k43n203mlbr-en }}$ 
OECD (2013b), "Reading Framework", in PISA 2012 Assessment and Analytical Framework: Mathematics, Reading, Science, Problem Solving and Financial Literacy, OECD Publishing, Paris. DOI: dx.doi.org/10.1787/9789264190511-4-en OECD (2015), Students, Computers and Learning: Making the Connection, OECD Publishing, Paris. DOl: $\mathrm{dx.doi.org/10.1787/9789264239555-en}$

OECD (2016), "Are there differences in how advantaged and disadvantaged students use the Internet?", PISA in Focus, No. 64, OECD Publishing, Paris. DOl: $\underline{d x . d o i . o r g / 10.1787 / 5 j l v 8 z q 6 h w 43-e n ~}$

UN (2016), "Transforming our World: The 2030 Agenda for Sustainable Development", A/RES/70/1, http://www.un.org/ga/search/view_doc.asp?symbol=A/RES/70/1\&Lang=E 


\section{NOTES}

1. This chapter is based on the data and analysis of the ITU Measuring the Information Society Report 2016, and on data from the ITU World Telecommunication/ICT Indicators database.

2. The indicator used to track SDG Target 9c is the "proportion of the population covered by a mobile network, by technology". This can be considered as a minimum indicator for ICT access since it provides people with the possibility to subscribe to and use mobile-cellular services. By including the breakdown "by technology", the indicator provides flexibility in terms of technological developments. As technologies evolve and as more and more countries deploy and commercialize more advanced mobile-broadband networks (4G, 5G etc.), the indicator will be able to reflect and capture these.

3. Among the $48 \mathrm{LDCs}$, nine are SIDS, and 17 are LLDCs.

4. For information on Internet Exchange Points, see: www.datacentermap.com/ixps.html, https://en.wikipedia. org/wiki/List of Internet exchange points by size and www.telegeography.com/telecom-resources/ internet-exchange-map/

5. To monitor fixed-broadband prices, ITU uses the "fixed-broadband sub-basket": the price of a monthly subscription to an entry-level fixed-broadband plan. It is calculated as a percentage of a country's average monthly GNI per capita, and also presented in USD and PPPUSD. For comparability reasons, the fixed-broadband sub-basket is based on a monthly data use of minimum 1 Gigabyte (GB). For plans that limit the monthly amount of data transferred by including data volume caps below $1 \mathrm{~GB}$, the cost for the additional bytes is added to the sub-basket. The minimum speed of a broadband connection is $256 \mathrm{kbit} / \mathrm{s}$.

6. It should be noted that in 2014, the price of fixed-broadband services fell in six LDCs, remained the same in more than half of all LDCs, increased slightly in two LDCs, and increased substantially in two LDCs (Uganda and Rwanda). The high prices in the latter two countries had a sizeable impact on the average, especially since complete price data for the period 2008-2015 are only available for 25 LDCs. In the remaining LDCs, fixedbroadband services were not available or not advertised during one or more years during that period. While in 2015 prices remained high in Uganda, they dropped substantially in Rwanda as well as in a number of other countries, including Zambia and Mali.

7. The only exception was oil-rich Equatorial Guinea, in which the household final consumption expenditure per capita was USD 272 per month in 2015. Household final consumption expenditure is an indicator produced in the context of national accounts and therefore does not reflect income and consumption inequalities. As a result, depending on the distribution of income/consumption within the population, the actual economic wealth of most households may be significantly lower than the average value derived from the national accounts. Data from household income and expenditure surveys provide better indicators to measure household economic wealth, but data availability is limited in developing countries. For more information, see, (ITU, 2014), pp. 140-146.

8. Measured in terms of household final consumption expenditure per capita, income levels are seven times higher in Ireland than in Equatorial Guinea, the LDC with the highest household final consumption expenditure per capita (among all those for which data is available).

9. Of the 44 LDCs with data available on fixed-broadband prices in 2015,37 had a fixed-broadband penetration rate below one subscription per 100 inhabitants. Bangladesh recorded 2.4 fixed-broadband subscriptions per 100 inhabitants, and Bhutan 3.6. 
10. In Burundi, CBINET offers contention ratios for ADSL services of 1:4. Contention ratios for common residential fixed-broadband plans are around 1:15 in most countries.

11. To monitor mobile-broadband prices, ITU collects data on (a) prepaid handset-based mobile-broadband plans with a data allowance of $500 \mathrm{MB}$ per month, and (b) post-paid computer-based mobile-broadband plans with a data allowance of $1 \mathrm{~GB}$ per month. The plan selected in each country for each service is not necessarily the one with the cap closest to $500 \mathrm{MB}$ or $1 \mathrm{~GB}$, but the one from the dominant operator that is cheapest, while including a minimum of $500 \mathrm{MB} / 1 \mathrm{~GB}$. The validity period considered for the plans is 30 days or four weeks.

12. ITU's definition of "computer" includes desktop computers, laptop (portable) computers and tablets (or similar handheld computers). Smartphones are not considered computers.

13. "On the move" is defined as the use of the Internet via a mobile cellular telephone or other mobile access devices, for example a laptop computer, tablet or other handheld device. For developing countries, it refers to Internet use through the above-mentioned devices connected to a mobile phone network when the location is away from "home", "work", "place of education", "another person's home" and "community and commercial access facilities". For European countries, it refers to Internet use through the above mentioned devices "away from home and work". For more information on the definitions of Internet use by location, see page 55 in Manual for Measuring ICT Access and Use by Households and Individuals 2014 available at: www.itu.int/en/ITU-D/ Statistics/Pages/publications/manual2014.aspx.

14. In the 2009 and 2012 PISA assessments, OECD assessed reading digital media separately from reading printed text (OECD, 2013b). 


\title{
CHAPTER 6
}

\section{IMPROVING THE E-TRADE ENVIRONMENT Contributed by the World Bank}

\begin{abstract}
For many governments, making the most of e-trade to generate opportunities for economic growth, job creation and poverty reduction is a priority. Upgrading e-trade competitiveness requires an understanding of the diverse elements of the e-trade environment, from the foundations of connectivity to the key enabling conditions, as a basis for policy reform and aid for trade. This chapter surveys the key reasons why e-trade matters for developing country participation in trade. It examines the key elements of the e-trade environment, including the foundations for connectivity. It looks at the enabling conditions for e-trade, with examples of World Bank projects. The chapter introduces a new approach being piloted by the World Bank for assessing the e-trade environment at the country level, in order to assist developing country governments in undertaking reform and identifying priority areas for assistance from the World Bank and other partners.
\end{abstract}




\section{INTRODUCTION}

For many governments, making the most of e-trade' to generate opportunities for economic growth, job creation and poverty reduction is a priority. The rise of e-trade results in new opportunities for participation in trade, but also presents new challenges to governments in upgrading their e-trade competitiveness. This requires an understanding of the diverse elements of the e-trade environment-from the foundations to connectivity to the key enabling conditionsas a basis for policy reform and aid for trade.

This chapter surveys the main reasons why e-trade matters for developing country participation in trade. The first section of the chapter provides detail on the central elements of the e-trade environment, including the foundations for connectivity and the enabling conditions for e-trade, with some examples of World Bank projects. The second section introduces a new approach being piloted by the World Bank for assessing the e-trade environment at the country level, in order to assist developing country governments in undertaking reform and identifying priority areas for assistance from the World Bank and other partners.

\section{THE E-TRADE ENVIRONMENT SHOULD BROADLY SUPPORT THE DIGITAL ECONOMY²}

A flourishing environment for e-trade requires, more broadly, a favourable environment for the digital economy, where businesses and consumers can leverage digital technologies for improved competitiveness and increased economic welfare. The foundations of the digital economy rest on a modern telecommunications infrastructure, a favourable environment for domestic and foreign investments, and an educated population that can engage in and contribute to the information society.

E-trade, as a component of the digital economy, also requires specific enabling conditions that build on those foundations. Businesses require digital skills and entrepreneurship to engage in e-trade, as well as a sound regulatory framework that addresses challenges such as digital documentation, signatures and data flows. They also depend on efficient trade facilitation and logistics suited to e-commerce deliveries. Finally, reaping the full benefits of e-trade requires the capacity to embrace data as a tool for growth, although this is not addressed in detail in this chapter. Figure 6.1 reflects these basic components of the e-trade environment.

Figure 6.1. Basic components of the e-trade environment

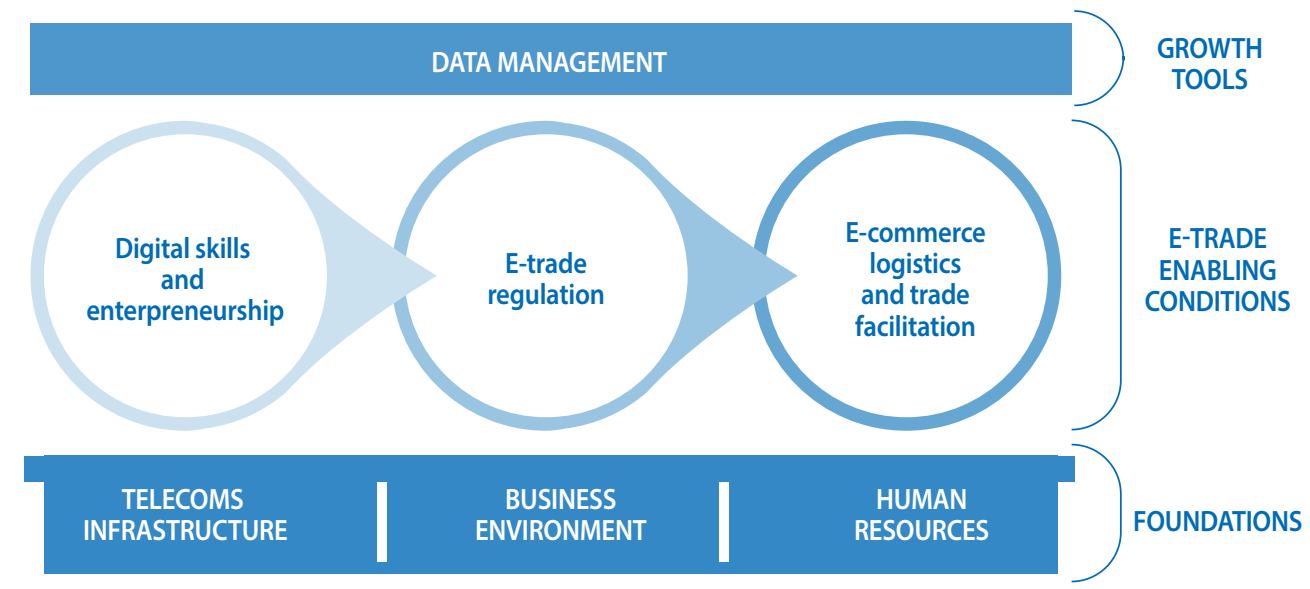

Source: World Bank 


\section{E-TRADE IS FOUNDED ON INFRASTRUCTURE, A GOOD BUSINESS ENVIRONMENT AND HUMAN RESOURCES}

The supportive foundations for e-trade comprise three main components: 1) a modern, reliable and affordable tele-communications infrastructure; 2) an open, transparent and predictable business environment; and 3) the availability of highly skilled human resources. These components are not foundations for e-trade only. They are requirements of a modern digital economy that can support not only growing international trade, but also other essential aspects of economic growth, such as increasing firm productivity and social inclusion, including by facilitating the delivery of public services. ${ }^{3}$

\section{Telecommunications infrastructure}

On a global scale, the first hurdle for the expansion of e-trade is the lack of access to digital connectivity. As noted by the World Development Report 2016, the lives of the majority of the world's people remain largely untouched by the digital revolution. Only around 15\% can afford access to broadband Internet. Mobile phones, reaching almost four-fifths of the world's people, provide the main form of Internet access in developing countries. But even so, nearly 2 billion people do not own a mobile phone, and nearly $60 \%$ of the world's population has no access to the Internet. Making the Internet universally accessible and affordable should be a global priority. The unfinished task of connecting everyone to the Internet—one of the targets of the Sustainable Development Goals (SDGs) — can be achieved through a judicious mix of market competition, public-private partnerships, and effective regulation of the Internet and telecommunications sectors (World Bank, 2016a).

International development assistance has proved a valuable tool for supporting the development of telecommunications infrastructure in developing countries. Aid for trade in support of digital connectivity averages between USD 650 million and USD 700 million annually. The largest share of this support (35\%) goes to financing telecommunication projects, followed by investments in information and telecommunications technology (24\%), policy and management (17\%), and finally research and development (10\%). The 2017 aid-for-trade monitoring and evaluation exercise suggests that demand for aid-for-trade support for connectivity is growing, and is expected to rise further. Among donors, 11 respondents highlighted significant growth in demand in this area over the past five years. Of the 41 donor respondents, 31 anticipated growth in future demand from both partner countries and regional partners. This expectation looks well-founded: 57 of the 63 developing and least developed country (LDC) governments responding to the aid-for-trade monitoring exercise anticipated a need for future assistance in order to meet their e-commerce strategic objectives. The exercise also highlighted the multifaceted engagement of the private sector in e-commerce, and in the development of information and communications technology (ICT) more broadly. Case stories submitted by partner countries and donors through the exercise indicated significant collaboration between the public and private sectors. Among the donors, 54\% stated that they work with the private sector to support growth in e-commerce in partner countries and regions.

Importantly, development assistance funds act as a key catalyst for private investment in connectivity, since large-scale infrastructure projects often require the involvement of both the public and private sectors, including investments in infrastructure as well as reforms in the regulatory environment. This is demonstrated by examples of projects involving the World Bank in Africa and the Pacific Islands:

- The World Bank supported a Regional Communications Infrastructure Program in Africa in a series of projects beginning in 2007. . Together with the International Finance Corporation (IFC), it developed the Eastern Africa Submarine Cable System (EASSy), illustrating how both public and private sector approaches are needed in ICT infrastructure development. Two projects underline this need. The first was a USD 424 million World Bank programme that supported improvements in the enabling environment and the regional integration of telecommunications terrestrial networks through financing 
of public-private partnerships and broadband capacity purchases. The second was a USD 240 million investment through IFC in the EASSy submarine cable, connecting the east coast of Africa (from South Africa to Sudan) to Asia and Europe. These projects contributed to a 90\% reduction in wholesale capacity prices in East Africa. In Kenya, this helped to increase the number of Internet users to 14 million in 2012, up from 2 million in 2007. Similar approaches are underway in other parts of Africa, bringing together the public and private sectors in infrastructure investment while also supporting the regulatory reform necessary for a competitive environment in ICT services.

- In Southeast Asia, the World Bank has been supporting the development of Myanmar's ICT sector by creating an enabling policy, regulatory and legal environment for a competitive telecommunications market. In early 2013, the World Bank, together with the Public-Private Infrastructure Advisory Facility (PPIAF), provided assistance to the Myanmar Post and Telecommunications Department in building a regulatory framework to enable the liberalisation of the telecommunications market. PPIAF also supported the PTD in developing a roadmap for the operational sector, and in designing and implementing a regulatory framework. Finally, PPIAF worked to increase the PTD's technical and administrative capacity to manage the reform process. This work was supported by International Development Assistance (IDA) financing, in the form of a credit for USD 31.5 million. The assistance from the World Bank and PPIAF led to the finalisation of the key regulations, providing a legal basis for implementation of sector liberalisation. With the regulatory framework and capacity-building initiatives in place, the PDT launched a competitive, transparent process for issuing licenses to the selected bidders. Telenor (Norway) and Ooredoo (Qatar) obtained their licenses in January 2014 and launched commercial services later that year, with a projected investment in infrastructure development of over USD 1 billion. This contributed to a drastic reduction in the cost of SIM cards — from USD 300 in 2012 to USD 1.50 in 2015-bringing mobile phone technology within reach of most of the population.

\section{Business environment}

A favourable business environment, based on transparent and pro-competitive policies, is necessary for e-trade and for the digital economy more broadly. Laws and regulations that ensure easy entry and exit of firms, and an open trade regime that exposes companies to foreign competition and investment, play fundamental roles in allowing businesses to access digital technologies and use them for greater competitiveness.

Barriers to market access and domestic or foreign competition reduce firms' incentives to invest in digital technologies or complementary skills and reorganisation (Figure 6.2). Without competitive pressure, private firms lack incentives to invest in costly or risky new technologies (World Bank, 2016a). To capture the full growth potential of digital globalisation, countries need to cultivate a healthy business environment that nurtures start-ups, allows inefficient firms to exit, ensures a level playing field, and establishes a solid legal framework for intellectual property and property rights. The existence of regulatory barriers to entry in the services sector-as captured by the OECD's Product Market Regulation — correlates negatively with firms' investments in digital technologies (Figure 6.3). This implies that lowering barriers to entry in services could facilitate greater investment by firms in technology. 


\section{Figure 6.2. Restrictions in services and business IT use}

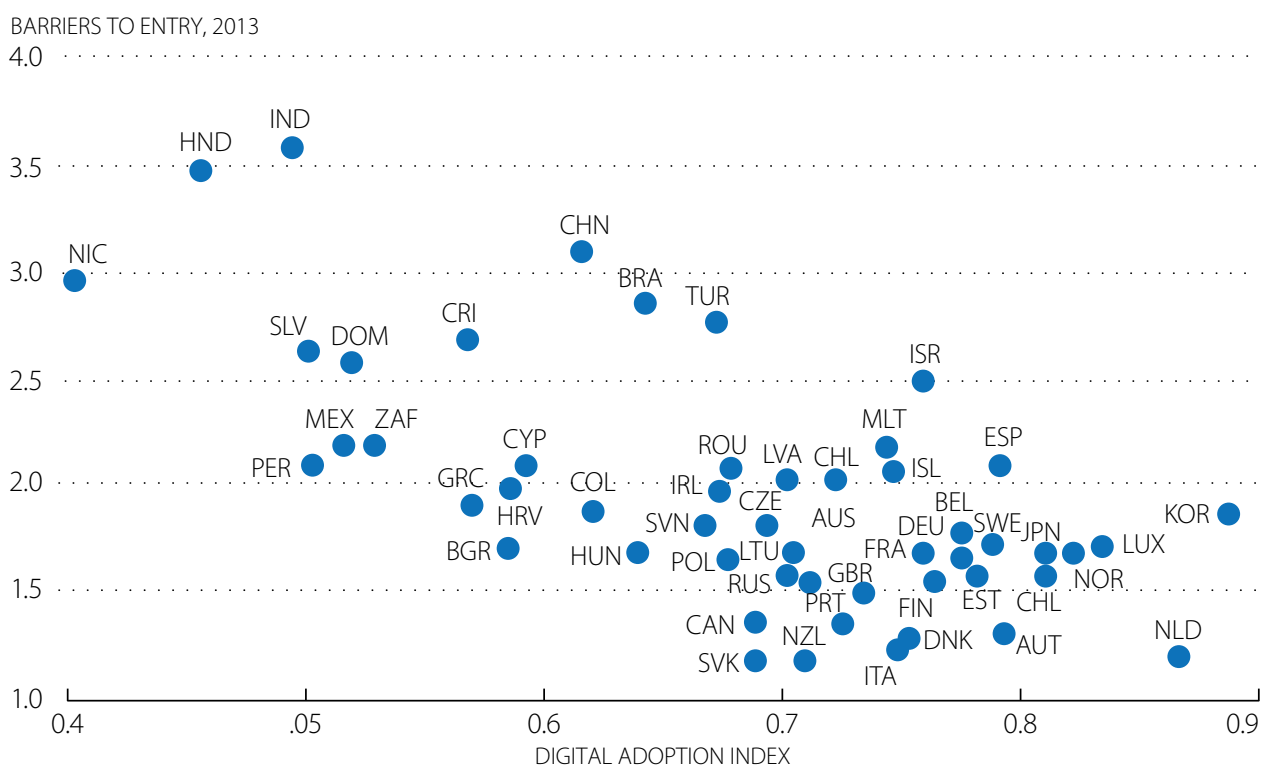

Note: The $y$-axis shows the barriers to entry for service sector, sub-index of the Product Market Regulation (PMR). The PMR index is available for 47 OECD and large developing countries, as well as for 8 smaller Latin American countries. The x-axis shows the Digital Adoption Index, as computed for the World Development Report 2016.

Source: OECD (2017), "Economy-wide regulation”, OECD Product Market Regulation Statistics (database). DOI: http://dx.doi.org/10.1787/data-00593-en; World Bank (2016b), "Digital Adoption Index", World Development Report 2016: Digital Dividends (database), www.worldbank.org/en/publication/wdr2016

\section{Human resources}

Education is central to any competitive, modern economy. Digital technologies facilitate access to remote markets and create opportunities even in local and traditional ones, but only for a skilled population that can engage with digital technologies and adapt them to meet their needs. In fact, education appears to be one of the most important indicators of whether or not people are Internet users. Internet use in most developed countries is almost universal among people with tertiary education, but a large proportion of citizens with lower educational attainment remain unconnected, despite similar access to infrastructure and services (Figure 6.3).

Yet the education systems of many countries, including middle-income countries, fall short in providing basic skills, such as literacy and numeracy, to all members of the population on a universal basis. For example, in countries like Albania, Indonesia, Jordan, Kazakhstan, Malaysia and Peru, more than half of the 15-year-olds are functionally illiterate (World Bank, 2016a).

Specific types of skills are also relevant for e-trade, including basic cognitive skills, social and behavioural skills; and technical skills. Basic cognitive skills associated with the "old economy", such as literacy and numeracy, knowledge-based problem solving, verbal ability and mental agility, remain indispensable in the information society. In addition, social and behavioural skills are needed to participate in modern labour markets, including creativity, teamwork, problem solving, and critical thinking in ever-changing environments. Figure 6.4 summarises the fundamental set of cognitive, social, and technical skills that provide the most relevant foundations for participation in e-trade. 
Figure 6.3. Proportion of individuals using the Internet, by education level

\section{DEVELOPED COUNTRIES}

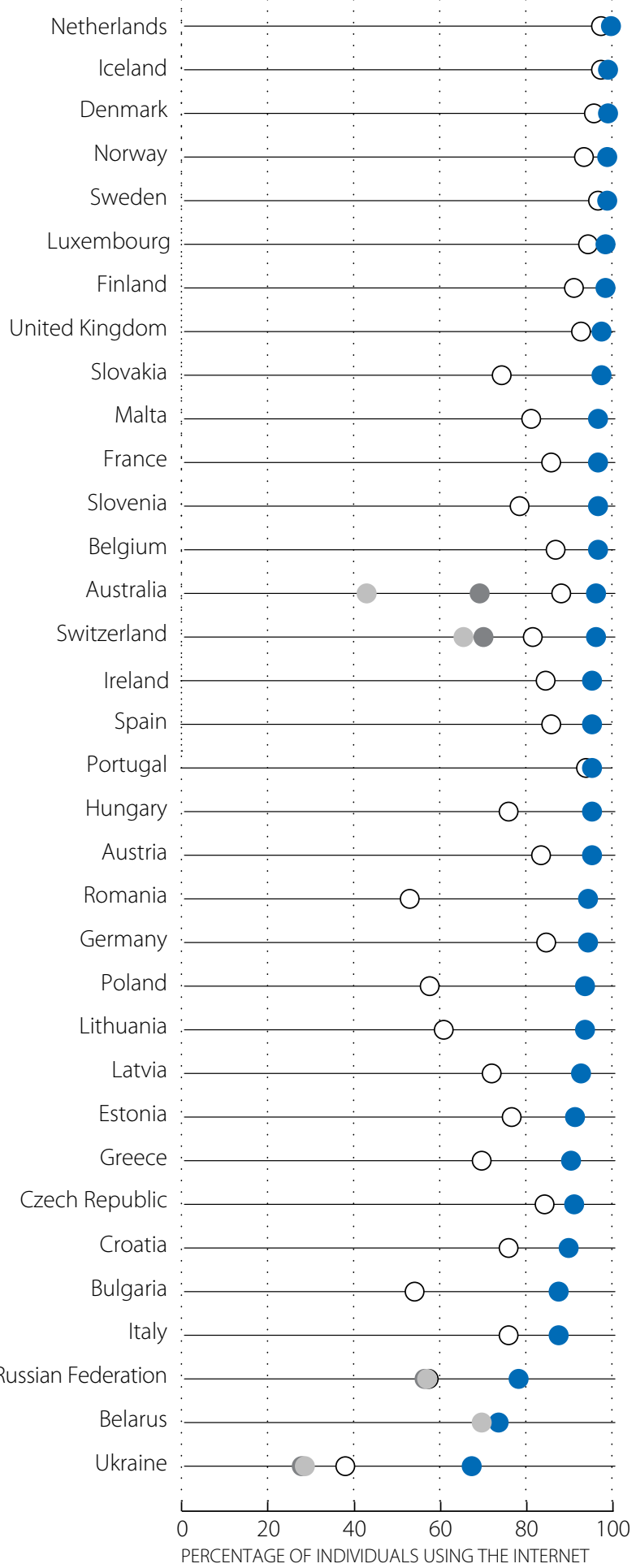

DEVELOPING COUNTRIES

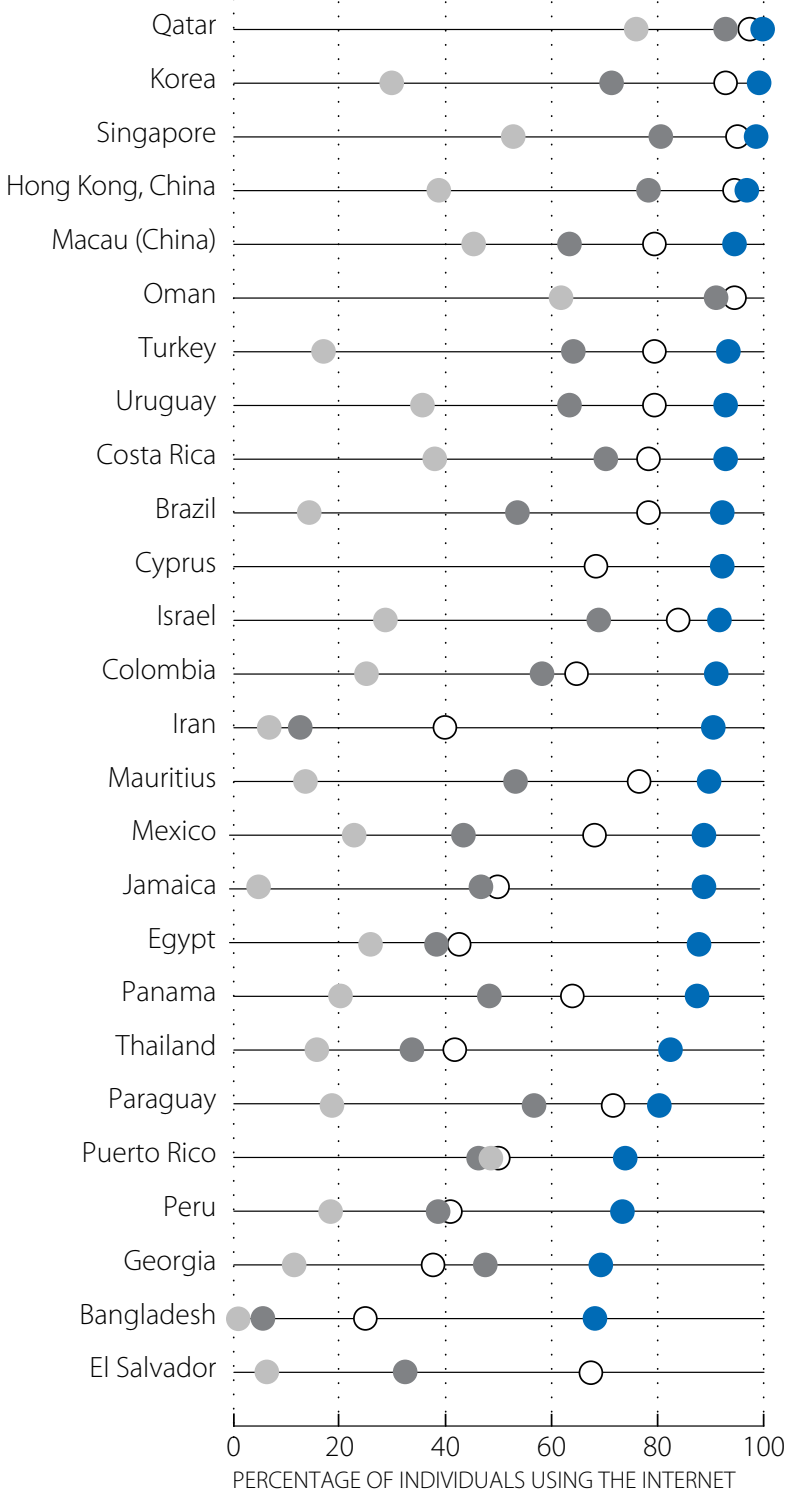

Source: ITU (2016), Measuring the Information Society Report 2016.

StatLink *iा Sम http://dx.doi.org/10.1787/888933526538 
Figure 6.4. Essential skills for the e-trade environment

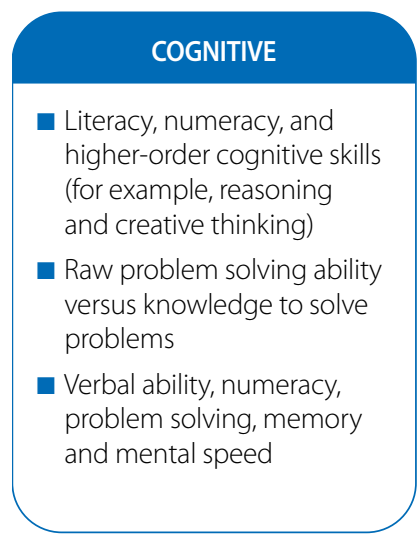

\section{SOCIAL AND BEHAVIORAL}

Socio-emotional skills and personality traits

- Openness to experience, conscientiousness, extroversion, agreeability, and emotional stability

- Self-regulation, grit, mind-set, decision making and interpersonal skills
TECHNICAL

Manual dexterity and the use of methods, materials, tools, and instruments

- Technical skills developed through post-secondary schooling or training, or acquired on the job

- Skills related to specific occupations (for example, engineer, economist, IT specialist)

Source: World Bank (2016a), World Development Report 2016: Digital Dividends, adapted from World Bank (2014), STEP skills measurement surveys: innovative tools for assessing skills.

\section{E-trade enabling conditions}

Building on the foundations of a modern digital economy, e-trade also requires a number of specific enabling conditions. The talent and entrepreneurship required to develop digital business are often missing, even where basic education and skills do exist. In addition, the legal and regulatory environment may support e-traders, but on the other hand it may introduce formal and informal barriers that inhibit the digital economy, for example by restricting means of electronic payment or introducing regulatory barriers to information flows. When e-commerce involves the movement of physical goods across borders, reliable transport and logistics services are critical to ensure that the traded goods make their way from the warehouse of the merchant to the hands of the customer abroad. Finally, reaping the full benefits of e-trade and the digital economy requires being able to understand and process vast amounts of data in order to improve efficiency and tailor responses to the relevant markets.

\section{Digital skills and entrepreneurship}

To benefit from e-trade, modern education programmes need to be expanded to include the development of skills and entrepreneurship for digital markets. In addition to basic literacy and numeracy, e-trade participants must be proficient in digital literacy and business development, adapting cognitive, social, and technical skills to the digital business environment. There are three main layers of digital skills (Figure 6.5), each spanning the spectrum from basic to advanced and including or combining different complementary skills. ${ }^{5}$

For the most effective participation in e-trade, all of these layers of digital skills are required. Basic user skills are essential for consumers to be able to go online and perform online/mobile transactions. Specialist skills are needed to build applications, web sites and platforms. Combinations of technical and other skills (communication, design, occupationspecific skills) are required for conceptualising and offering online products, services, and tasks. Finally, e-leadership, innovation and business skills are needed to come up with new business models related to and/or based on different types of digital trade; and to innovate in markets, products, delivery, processes and organisation. 
Figure 6.5. The digital skills pyramid

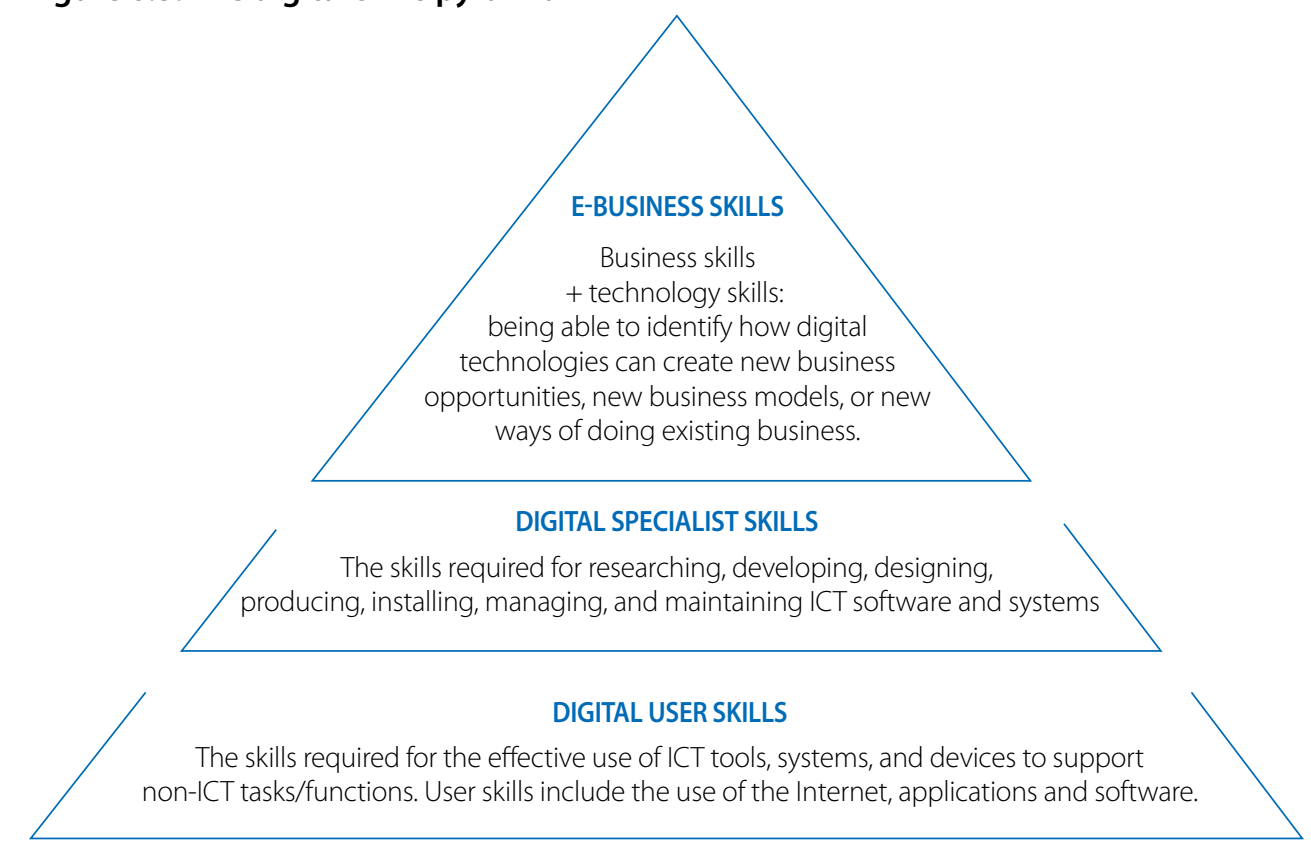

Notes: The bottom layer corresponds to users of digital/ICT tools; the next layer corresponds to producers of digital/ICT tools; the top layer corresponds to those who apply, create and invent innovative business models and applications of digital/ICT tools.

Source: Based on European Commission (2004), van Welsum and Lanvin (2012).

The importance of some of these roles and skills will change over time. For example, as connectivity of products and appliances continues to grow (the Internet of Things), data scientists will become far more central to the operations of many firms. Such roles will also require broader skills sets, combining analytic, software, and analytics architecture skills with business acumen and communications skills (evolving towards the next layer in the pyramid).

\section{Legal and regulatory framework}

The legal and regulatory environment can be an enabler or a barrier to e-trade. A weak or outdated regulatory framework can create direct barriers to e-trade, as well as hindering the development of the necessary enabling environment (for example, barriers to trade in services that are relevant for e-trade). Providing a supportive legal and regulatory environment involves a co-ordinated effort across fields in order to prevent restrictions and provide the key regulatory enabling conditions for e-traders.

An enabling regulatory framework also is essential in order to promote consumer trust in digital markets. Such regulations include:

- laws and regulations for electronic documents and e-signatures

regulations for electronic payments (Box 6.1)

- consumer protection measures, such as the restriction of spam, right of withdrawal (e.g. procedures for returning products acquired through e-commerce), and online dispute resolution

- cybersecurity

rules on intermediary liability, addressing the legal responsibility of digital platforms for the goods and services traded by their users

- privacy and data protection regulations, ensuring that reasonable safeguards exist for the use of personal information, including consent to use by third parties, and the "right to be forgotten". 
However, regulations can also introduce excessive burdens or unwarranted restrictions. In particular, regulatory restrictions on data flows can have a chilling effect on e-trade. For instance, a McKinsey report estimates that the free flow of data can enable increases in GDP growth between USD 250 billion and USD 450 billion annually - approximately equivalent to the GDP of Finland or Norway (McKinsey Global Institute, 2014). E-commerce platforms, cloud computing systems, and general online business transactions rely on the ability of consumers and traders to share information across borders. Regulations requiring the storage of information on local servers can have the effect of barring certain types of international transactions or inhibiting the use of certain digital technologies, thus obstructing e-trade. On the other hand, a government may be concerned about the privacy of its citizens when information is no longer under its regulatory purview. The challenge lies in achieving the balance between regulatory policies that enable and promote trust in the digital market, while avoiding unwarranted restrictions to international trade.

The use of international standards can help governments strike this balance. Domestic regulation on privacy and data protections, for instance, can be informed by international standards set out in the Asia-Pacific Economic Cooperation (APEC) Privacy Framework of 2005 and the OECD Guidelines on Protection of Privacy, as well as by lessons from the implementation of the European Union Data Protection Directive. Similarly, the OECD Consumer Protection Recommendation of 2016 reflects internationally recognised standards for online consumer protection. The United Nations Commission on International Trade Law (UNCITRAL), in turn, has developed model laws for electronic signatures and documents that seek to reduce regulatory divergence for e-traders.

\section{E-TRADE LOGISTICS AND TRADE FACILITATION}

While e-commerce facilitates international transactions, physical goods bought digitally still need to travel a certain distance and arrive at the consumer's location. E-commerce of goods is, in this sense, just another expression of international trade. E-commerce goods, just as other goods, need to be transported and cross physical borders; and as is the case for traditional trade in goods, e-commerce goods that cross borders are subject to customs and border management procedures.

\section{Box 6.1. Improving the environment for e-payments}

An enabling regulatory environment is essential for expanding access to online payments. A large body of World Bank data and research helps identify the key issues involved in reforming payment systems, including through large data projects such as the Global Findex Database and the Global Payments Systems Survey.

With World Bank assistance, Rwanda made rapid strides toward a modern payment system in support of a growing economy and a more inclusive financial system. In February 2011, an automated transfer system -infrastructure that combines the management of high-value and retail payment transactions — was implemented. The cost of sending money to Rwandaonce the highest-cost country for international remittances, worldwide-dropped by 7 percentage points, from 19\% in 2010 to 12\% in 2014, largely as a result of improvements in the infrastructure for the payment system. In Indonesia, the World Bank supported the nation's central bank in developing policies and shaping a regulatory environment conducive to expanding access to payment services (e.g. e-money, the use of agents and fund transfers) as part of the reform of its national payment system.

With government assistance programmes generally operating at large volumes, distributing public benefits electronically can expand the ways in which recipients can obtain social assistance at lower cost; at the same time, it also supports the development of online payments. As a result, financial access is increased and programme expenses for the government are reduced. In Mexico, World Bank support to the Bansefi development bank helped create an electronic distribution channel for Oportunidades, the country's signature conditional cash transfer programme, lowering transaction costs for more than six million low-income families.

Source: Adapted from World Bank (2017b), Project Examples on Payment Systems and Remittances, www.worldbank.org/en/topic/ paymentsystemsremittances (accessed 22 May 2017). 
However, because e-commerce often involves the shipping of small quantities of merchandise-often, indeed, one single product - in individual shipments, it faces additional challenges compared to traditional trade in goods, which is normally conducted in larger volumes per shipment. In developing countries, the costs of transportation and logistics are high because of poor transport infrastructure, the high costs of monopolistic service provision and other inefficiencies. Meeting these costs is especially onerous for small businesses shipping small parcels, which is the hallmark of businessto-consumer (B2C) e-commerce in goods. Given the limited size of individual shipments, small and medium enterprises (SMEs) have higher fixed costs per parcel (or "per unit") than large exporters shipping large volumes (Suominen, 2014).

The scale of growth in e-commerce is putting pressure on regulators to consider the relevant challenges. In Europe alone, 4 billion parcels were sent in 2014. As the number of shipments, exporters and consignees increases exponentially, policy makers will have to start considering the pressure exerted on distribution systems and the resulting impact on urban traffic congestion, emissions, reliability and costs, among many other things. This will require a coherent approach to urban logistics planning, combining "soft" measures (such as restrictions on vehicle weight, size, emissions; zoning; driving and load/unload times, etc.) and "hard" measures (creation of extra parking bays, public-private partnerships (PPPs) approaches to infrastructure development; logistics zones, etc.)

Lowering the border costs associated with e-commerce in goods requires more effective trade facilitation: in other words, the simplification, harmonisation, standardisation and modernisation of trade procedures. Trade facilitation seeks to reduce trade transaction costs at the interface between business and government and is a priority for many customsrelated activities (Grainger, 2007). Enabling automation and reducing the friction in cross-border trade are essential to lowering trade costs and connecting producers to markets and value chains. This can be especially relevant for e-commerce in goods, due to the importance of these costs for the typical SME or individual trader participating in e-trade.

Figure 6.6. Stages of automation in trade facilitation

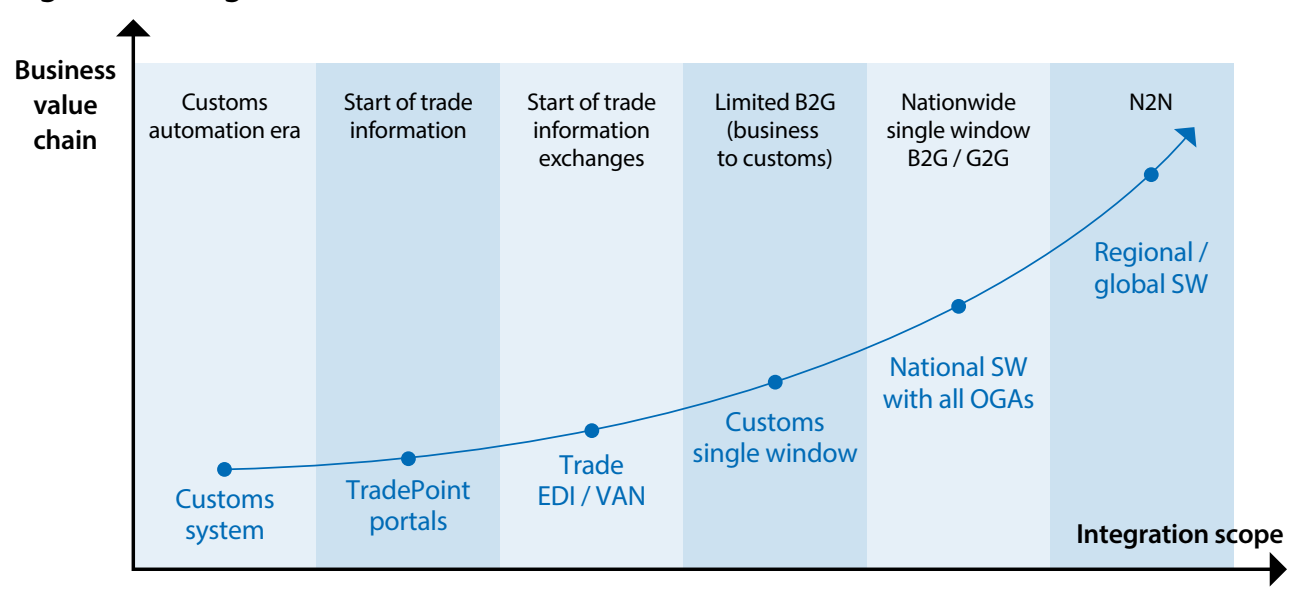

EDINAN = Electronic Data Interchange/Nalue Added Network; B2G = Business to Government; SW = Single Window; OGA = Other Government Agencies; N2N = Nation to Nation)

Source: Koh Tat Tsen (2011).

The automation of border management brings about specific legal and regulatory challenges in areas that govern the relationship between government and traders. Automation of trade facilitation and logistics in developing countries and the LDCs requires addressing numerous aspects of the border regime in order to lower costs (Figure 6.6). The first is the level of automation among the trade-related agencies that regulate cross-border trade. The second is the interconnectivity within agencies and their offices, among agencies, and with agencies of neighbouring countries, particularly where there are regional communities and customs unions. The third is network access and bandwidth, which relates to national telecommunications infrastructure, as borders, though vital, are often off the grid. ${ }^{4}$ 
The fourth is the importance of addressing legal issues (see discussion below) to ensure an effective trade facilitation system. Finally, the level of sophistication of the business community, and in particular the logistics providers, ${ }^{6}$ is critical in allowing them to take advantage of electronic developments. The challenges to and capacity for ICT access among SMEs, and in many cases women traders, deserve special attention.

The submission of trade data to governments by commercial entities, and the processing and storage of that data in automated trade transaction systems, entail a number of regulatory challenges. While some of these have to do with broader regulations on data and electronic transactions, as mentioned above, a number of additional regulationrelated concerns have to do, precisely, with to the automation of trade. These include: the legal implications involved in the submission of a single declaration to multiple government agencies; the ownership and control of data obtained by government authorities; the legal and regulatory provisions concerning rights of access to government information systems; and whether the reviews take into account best practices under the UNCITRAL Model Law on Electronic Commerce and the United Nations Convention on the Use of Electronic Communications in International Contracts, and are cognizant of international agreements like the recent WTO Trade Facilitation Agreement (TFA).

While some of these legal issues may need to be addressed at an economy-wide level, trade facilitation reform often brings them to light and places them in a specific context, acting as a catalyst for addressing the overall legal framework, particularly during the implementation of automation systems like electronic single windows and port community systems. For developing countries, setting up the enabling legal and regulatory frameworks also requires investing in new institutional mechanisms and systems which, for example, enable electronic record management and archiving, provide the legal certainty and basis for electronic messages; create and empower entities to emit electronic signatures; put in place systems for protection of data; or work with the banking sector to enable electronic receipts and notices of payments.

\section{ASSESSING CHALLENGES AT THE COUNTRY LEVEL IS A PRIORITY FOR AID FOR TRADE}

As in other areas of trade, governments need a clear overview of the key challenges they face and the priority areas for reform as a basis for co-ordinating across government, engaging with the private sector and other stakeholders, and seeking development assistance. There has been little systematic analysis of the drivers of e-trade competitiveness at the country level and doing more on this front needs to be a priority for the Aid for Trade Initiative in the years ahead.

To facilitate better policy making and more targeted aid for trade, the World Bank, the United Nations Conference on Trade and Development (UNCTAD) and other organisations collecting data relevant to e-trade-including the International Telecommunications Union (ITU), the United Nations Office on Drugs and Crime (UNODC), the Universal Postal Union (UPU) and the World Economic Forum (WEF) - have developed a new tool for assessing the e-trade environment at the country level. It is now available online on the World Bank's TCData360 and World Integrated Trade Solution portals (tcdata360.worldbank.org and wits.worldbank.org and respectively).

The new tool includes around thirty indicators grouped under the following pillars of the e-commerce environment:

- ICT infrastructure and services

- payment solutions

u trade logistics and trade facilitation

- e-commerce skills readiness

- legal and regulatory frameworks

access to finance

- e-commerce readiness assessment and strategy formulation 
These indicators can help to assess the key enabling conditions that underpin e-trade, including connectivity and skills, as well as the regulatory and policy frameworks that affect e-trade. They are available for a large number of countries, and they enable international comparisons.

Robust evidence-based policy making would involve bringing these indicators into contact with data on the extent to which different countries engage in e-commerce-for example, metrics on B2C e-commerce, and on the share of e-commerce sales in overall retail sales. At present, such data only exist for a few dozen countries, all but a few of which are high-income countries. Moreover, the information that does exist is widely scattered, and in some cases only available from private vendors. The development of systematic, internationally comparable and publicly available metrics of e-commerce itself is an emerging and important priority for the international statistical community.

The limited availability of data on the extent of e-commerce can be supplemented by public trade data, including services trade data at the lowest level possible to more accurately reflect e-trade transactions, and private data related to data flows.

Even in the absence of precise measures of e-commerce, the available indicators of the e-commerce enabling environment can play a useful role in fundamental analytical work. They can point to where more in-depth analytical work is needed, helping to identify the need for-and support the implementation of-key trade-related reforms for e-trade competitiveness. They can also identify critical reforms whose implementation can be driven by ministries of trade/ commerce, as a stepping stone or complement to the wider, more complex reforms that require efforts across government agencies (and are therefore likely to be more time-consuming). The tool also aims to highlight where reforms and programmes may be needed in "non-trade" areas, such as infrastructure or skills development.

An assessment of the available e-trade indicators can be used, together with several analytical toolkits that have been extensively applied by the World Bank, to analyse, at the national level, the trade environment and its challenges, providing a basis for policy reforms and programmes implemented by the World Bank and other partners.

These toolkits include:

- The Regulatory Assessment Toolkit (http://hdl.handle.net/10986/17255), which looks at regulations affecting services sector competitiveness; it has been implemented in seven countries, both at the sector-wide and sector-specific levels.

- The Trade Competitiveness Diagnostic Toolkit (http://hdl.handle.net/10986/2248), which sets out a modular approach to determining and improving trade competitiveness; it has been implemented in more than nine countries.

- The World Bank Group Trade Facilitation gap analysis approach, which has been implemented in more than 40 countries through the Trade Facilitation Support Program.

While policy assessments of e-commerce ideally will contain more in-depth analysis of key policy and regulatory issues affecting the e-trade environment, the ease of obtaining information on policies and regulations varies. For example, at-the-border policies applied to trade in goods related to e-trade will be relatively easy-including tariffs on imported IT equipment or the existence of a de minimis regime applying to imports of goods. Similarly, data some aspects of services, such as the commitments taken through the General Agreement on Trade in Services (GATS) or free trade agreements (FTAs) in sectors relevant to e-trade, are relatively easy to obtain, although information on applied regimes is more difficult. The most complicated situation is in the area of domestic regulatory policies affecting e-trade. As noted above, these assessments often require a more in-depth review of regulations in sensitive policy areas, such as consumer and privacy protection, as well as evaluations of how such regulations are applied in practice by the regulatory bodies as well as by the courts. 
Such reviews should be conducted through desk-based analysis as well as in-country data collection and validation. The resulting country-level detailed analysis would allow policy makers to assess their performance in e-trade and identify the main challenges to increased participation in global e-trade. This kind of analysis supports more coherent policy making by governments. Rather than focusing on specific elements of the e-trade environment in isolation, it enables countries to develop e-trade strategies that bring together the wide range of government agencies involved. Malaysia, for example, has developed a national e-commerce council, chaired by the Ministry of International Trade and Industry, which brings together 21 government agencies working on e-trade. The idea is to implement a national strategy aimed at doubling e-commerce growth from around 10\% in 2016 to 20\% in 2020. Of course, mechanisms like this need to be backed up by effective implementation of reforms in order to be effective, but having a strong co-ordination mechanism across government, and an evidence base on which to ground decisions, is an important starting point.

As well as assessing the e-trade environment more systematically in developing countries, it is important to develop a stronger understanding of the potential e-trade holds for countries at different levels of development. This is important in addressing any misconception that e-trade opportunities exist only for advanced economies.

\section{CONCLUSIONS}

The strong growth of e-trade presents a number of opportunities for developing countries. First, the lowering of trade costs through e-trade creates opportunities for new firms and entrepreneurs to participate in trade, as well as for entry into new markets. It also has the potential to help the extreme poor overcome some of the typical constraints faced in maximising trade opportunities, although poverty still presents many challenges to involvement in e-trade and traditional trade barriers remain relevant.

The growing e-trade sector has the potential to act as a force for economic growth, expanding and diversifying exports, and fostering inclusion by facilitating access by SMEs to international markets. Importantly, these benefits are not reserved to global leaders in innovation and digital technologies; rather, they are available to countries at all levels of economic development, as well as industries at different stages of development in one same economy. Figure 6.7 provides a stylised breakdown of what economies at different levels of development can gain from the different types of e-trade, as summarised below:

- First, e-trade can increase competitiveness for countries at all levels of development, providing productivity gains for all sectors of the economy. This includes traditional sectors, such as agriculture, through the use of specialised services traded online; these range from market and weather information to tools for remote soil analysis and stock management.

- Second, developing countries and even LDCs are increasingly benefitting from e-trade as a tool for creating niches for high-value goods, sold and delivered directly to consumers across the globe, such as Pakistani pashminas and Kenyan jewellery.

- Finally, more advanced economies, as well as more e-trade savvy industries in developing countries, can offer high-value-added business-to-business services that link into global value chains. 


\section{Figure 6.7. A stylised model of benefits of e-trade at different levels of economic development}

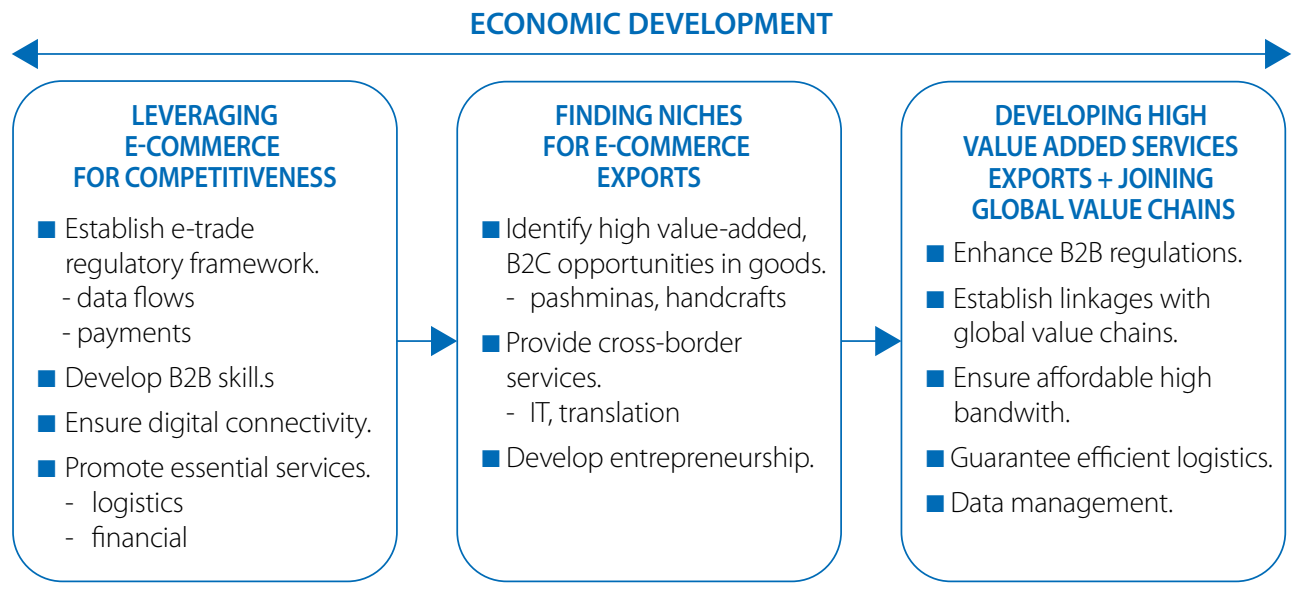

Source: World Bank

High- and low-income countries alike have good reasons to address the many challenges that e-trade brings with it. Important laws and regulations for e-trade, such as those on privacy, consumer protection or intermediate liability, are still unclear and inconsistently applied, even in high-income countries. This, in turn, brings uncertainty to international digital markets. Countries at all development levels still face substantial trade costs, which disproportionally affect e-trade shipments. Access to digital connectivity, as well as solutions for digital payments, remain patchy and often inequitable, in particular in developing countries. Also, many developing countries, and particularly the LDCs, face an important shortage of digital skills_especially of capacity for digital entrepreneurship.

Taking advantage of e-trade opportunities requires a solid understanding of the diverse types of e-trade and better data on e-trade flows. It also requires thorough analysis of the drivers of e-trade competitiveness, including the basic foundations for connectivity and the enabling conditions for participation in e-trade. There has been little systematic analysis of the drivers of e-trade competitiveness at the country level, underlining the need for more engagement in this area by the World Bank and other partners in the Aid for Trade Initiative over the coming years. 


\section{REFERENCES}

European Commission (2004), E-skills for Europe: Towards 2010 and Beyond in: The European E-Skills Forum Synthesis Report.

Grainger, A. (2007) "Customs and Trade Facilitation: From Concepts to Implementation", World Customs Journal, vol. 2, no. 1 .

Gramckow, H. P., and O. Ebeid (2016), Establishing small claims courts and the impact on service delivery in the justice system. Justice development note, no.9. World Bank Group, Washington, DC.

Hoppe, M. and R. Newfarmer (2014), Malawi Policy Note Series: Using Trade to Raise Incomes for the Next Generation, World Bank, Washington, DC.

ITU (2016), Measuring the Information Society Report 2016, International Telecommunication Union, Geneva, www.itu.int/en/ITU-D/Statistics/Pages/publications/mis2016.aspx.

Koh Tat Tsen, J. (2011), "10 years of Single Window Implementation: Lessons learned for the future", discussion paper for Global Trade Facilitation Conference 2011, Connecting International Trade, United Nations Economic Commission for Africa, www.unece.org/fileadmin/DAM/trade/Trade Facilitation Forum/BkgrdDocs/TenYearsSingleWindow.pdf

Kunaka, C. (2011), Logistics in Lagging Regions: Overcoming Local Barriers to Global Connectivity, World Bank, Washington, DC., http://documents.worldbank.org/curated/en/516741468178736065/pdf/897290NWPOP132085290B00PUBLIC001421. $\underline{\mathrm{pdf}}$

McKinsey Global Institute (2014), "Global flows in a digital age: How trade, finance, people, and data connect the world economy", McKinsey and Company, www.mckinsey.com/business-functions/strategy-and-corporate-finance/ our-insights/global-flows-in-a-digital-age.

OECD (2017), "Economy-wide regulation", OECD Product Market Regulation Statistics (database).

DOl: http://dx.doi.org/10.1787/data-00593-en

Suominen, K. (2014), "Aid for eTrade: Accelerating the Global eCommerce Revolution", CSIS Europe Program's working paper, http://csis.org/event/aid-e-trade-accelerating-global-e-commerce-revolution.

van Welsum, D. and B. Lanvin (2012), "e-Leadership Skills - Vision Report, Prepared for the European Commission, DG Enterprise and Industry, October 2012, http://eskills-vision.eu/fileadmin/eSkillsVision/documents/Vision\%20report.pdf.

World Bank (2014), STEP skills measurement surveys: innovative tools for assessing skills. Social protection and labor discussion paper; no. 1421, World Bank Group, Washington, D, http://documents.worldbank.org/curated/ en/516741468178736065/pdf/897290NWPOP132085290B00PUBLIC001421.pdf.

World Bank (2016a), World Development Report 2016: Digital Dividends, World Bank, Washington DC.

World Bank (2016b), "Digital Adoption Index", World Development Report 2016: Digital Dividends (database), www.worldbank.org/en/publication/wdr2016

World Bank (2017a), "E-trade for Development. Opportunities, Challenges, and Policy Considerations for Developing Countries", World Bank, Washington DC.

World Bank (2017b), Project Examples on Payment Systems and Remittances, http://www.worldbank.org/en/topic/ paymentsystemsremittances (accessed on 22 May 2017). 


\section{NOTES}

1. The term "e-trade" is used for trade in all forms of goods and services (both traditional and digital) traded internationally through electronic means. The authors use the term "e-trade" as an equivalent to "e-commerce".

2. This Section draws on World Bank (2017a).

3. For instance, in the justice sector (Gramckow and Ebeid, 2016)

4. The OECD Programme for International Assessment of Adult Competencies (PIAAC) database classifies computer use/skills in the following categories:

- straightforward computer use, which includes basic routines such as data entry or sending and receiving e-mails

- moderate computer use, which refers to word-processing, use of spreadsheets or database management

- complex computer use, which encompasses developing software or modifying computer games, programming or maintaining a computer network.

5. Utilities, particularly electricity, also are crucial enablers. Lack of power is often one of the major reasons for a border to go offline.

6. The professionalisation of logistics service providers and customs brokers is often a determinant. 


\title{
CHAPTER 7
}

\section{HARNESSING E-COMMERCE FOR SUSTAINABLE DEVELOPMENT}

\author{
Contributed by the United Nations Conference on Trade and Development
}

\begin{abstract}
As the digital economy expands and touches more business activities, it is important to consider how policies can help to harness e-commerce for sustainable development. This chapter examines the potential of developing countries to engage in and benefit from the expansion of e-commerce. It presents recent estimates of the value of global e-commerce, identifies related opportunities and challenges, gauges the e-commerce divide, and considers the extent to which countries are ready to engage in e-commerce. Finally, it identifies key policy areas to be addressed in national e-commerce strategies and highlights the need for more concerted policy efforts to support developing countries in this area. It discusses how to create synergies and greater scale in the overall efforts of the international community to enable more countries to engage in and benefit from e-commerce, and considers how aid for trade can support the strengthening of e-commerce readiness in developing countries.
\end{abstract}




\section{INTRODUCTION}

As a starting point for the analysis in the chapter, it is appropriate to consider recent trends in e-commerce, which highlight the most prominent opportunities and challenges associated with the shift from offline to online trade'.

\section{E-commerce is evolving rapidly, but data are scarce}

The global landscape of e-commerce is rapidly evolving, with increasing relevance for developing countries. However, the lack of statistics on e-commerce is a major challenge for mapping e-commerce uptake and measuring its impact. There are no comprehensive official data on the value of domestic and international e-commerce. Only some countries - mainly developed ones_currently compile data on e-commerce revenue. Very few report data on crossborder e-commerce. There is generally more information available on business-to-business (B2B) and business-toconsumer (B2C) transactions. This chapter also makes occasional reference to consumer-to-consumer (C2C) e-commerce and, to a lesser extent, business-to-government (B2G) transactions.

\section{Box 7.1. Partner country views on availability of e-commerce data}

"Currently there is limited data on e-commerce transaction and there is also a capacity challenge in the analysis to capture the data on e-commerce." Gambia

"Currently this type of information has not been collected." Saint Vincent and the Grenadines

"There has been no formal survey done on the e-commerce and the numbers related to it." Sri Lanka

"Customs data does not separate between exports and imports done through traditional way and those completed by e-commerce." Yemen

Source: OECD-WTO aid-for-trade monitoring exercise (2017), www.oecd.org/aidfortrade/countryprofiles/

Official statistics were compiled by the United Nations Conference on Trade and Development (UNCTAD) for B2C and B2B sales in the major e-commerce markets in 2015 (UNCTAD, 2017; Table 7.1). They show that global B2B and B2C e-commerce reached USD 25.3 trillion in 2015, a staggering USD 9 trillion above the 2013 value. B2C sales amounted to just over USD 2.9 trillion, slightly more than 11\% of the overall global estimate. B2B sales reached over USD 22 trillion, almost 8 times the B2C value. Yet while B2B represents the largest share of e-commerce, B2C appears to be expanding faster (UNCTAD, 2015).

China was the world's largest B2C e-commerce market in 2015, at USD 617 billion, followed closely by the United States at USD 612 billion. The United States, however, was the leader in B2B sales, at more than USD 6 trillion, well ahead of Japan (USD 2.4 trillion). In the ten economies for which data were compiled, e-commerce sales corresponded to more than a third of the aggregate GDP; in Japan and the Korea, they represented well over 50\%.

The available information suggests that the market for e-commerce expanded significantly over the past decade and that it continues to grow. Such observations are supported by estimates made by private consultancy firms. While global e-commerce is still dominated by developed countries, the highest growth is observed in developing regions, especially in Asia. 
Table 7.1. B2B and B2C e-commerce in ten major economies, 2015

\begin{tabular}{llccccc}
\multirow{2}{*}{ Country } & \multicolumn{2}{c}{ Total } & \multicolumn{2}{c}{ B2B market } & B2C market \\
& & USD billion & \% of GDP & USD billion & \% of all e-commerce & USD billion \\
\hline $\mathbf{1}$ & United States & 7055 & $39 \%$ & 6443 & $91 \%$ & 612 \\
\hline $\mathbf{2}$ & Japan & 2495 & $60 \%$ & 2382 & $96 \%$ & 114 \\
\hline $\mathbf{3}$ & China & 1991 & $18 \%$ & 1374 & $69 \%$ & 617 \\
\hline $\mathbf{4}$ & Korea (Rep.) & 1161 & $84 \%$ & 1113 & $96 \%$ & 48 \\
\hline $\mathbf{5}$ & Germany (2014) & 1037 & $27 \%$ & 944 & $91 \%$ & 93 \\
\hline $\mathbf{6}$ & United Kingdom & 845 & $30 \%$ & 645 & $76 \%$ & 200 \\
\hline $\mathbf{7}$ & France (2014) & 661 & $23 \%$ & 588 & $89 \%$ & 73 \\
\hline $\mathbf{8}$ & Canada (2014) & 470 & $\mathbf{2 6 \%}$ & 422 & $90 \%$ & 48 \\
\hline $\mathbf{9}$ & Spain & $\mathbf{2 4 2}$ & $\mathbf{2 0 \%}$ & 217 & $90 \%$ & 25 \\
\hline $\mathbf{1 0}$ & Australia & $\mathbf{2 1 6}$ & $\mathbf{1 6 \%}$ & 188 & $87 \%$ & 28 \\
\hline & Total for 10 above & $\mathbf{1 6} \mathbf{1 7 4}$ & $\mathbf{3 4 \%}$ & $\mathbf{1 4 3 1 7}$ & $\mathbf{8 9 \%}$ & $\mathbf{1 8 5 7}$ \\
\hline & Total for world & $\mathbf{2 5} \mathbf{2 9 3}$ & & $\mathbf{2 2 ~ 3 8 9}$ & & $\mathbf{2 9 0 4}$ \\
\hline
\end{tabular}

Notes: Figures in italics are estimates. Missing data were estimated based on average ratios. Converted to USD using annual average exchange rate.

Sources: UNCTAD (2017), Ministers to discuss opportunities and challenges of e-commerce with Jack Ma, eBay, Jumia, Huawei, Etsy, PayPal,

Vodafone and more

Projections of future growth vary considerably, depending on the methodology used. According to eMarketer, B2C e-commerce is forecast to double from USD 1.2 trillion in 2013 to USD 2.4 trillion in 2018 (Figure 7.1). The fastest growth is expected in Asia and the Pacific, where the market share is set to grow from 28\% in 2013 to $37 \%$ in 2018. The only other region that is forecast to increase its share of the global market is the Middle East and Africa: from 2.2\% to $2.5 \%$ over the same period. Conversely, the combined share of Western Europe and North America is expected to fall, from $61 \%$ to $53 \%$. These estimates resonate with predictions that the next billion online consumers will be from developing countries.?

Figure 7.1. B2C e-commerce sales worldwide, by region, 2013 and 2018

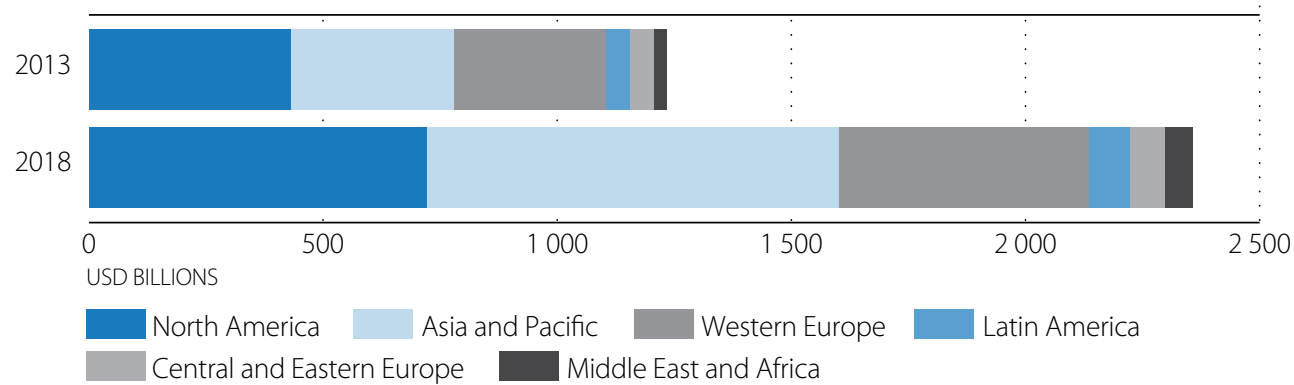

Notes: Estimates are based on the analysis of data from research firms and government agencies, historical trends, reported and estimated revenues from major online retailers, consumer online buying trends, and macro-level economic conditions. Data include products and services ordered, and leisure and unmanaged business travel sales booked, using the Internet via any device, regardless of the method of payment or fulfilment.

Source: UNCTAD (2015), Information Economy Report 2015: Unlocking the Potential of E-commerce for Developing Countries, based on eMarketer data, www.emarketer.com (accessed on 01 July 2014) 
This trend is visible also in terms of the number of people buying online. An estimated 1.1 billion people around the world made at least one online purchase in 2013, accounting for $41 \%$ of all Internet users (Table 7.2). With some 460 million online shoppers, Asia and Oceania accounted for the largest share (43\%), which is expected to grow further until 2018. Western Europe and North America follow, accounting for 17\% and 16\% respectively of global digital buyers. The highest growth between 2013 and 2018 is anticipated for the Middle East and Africa.

\section{Table 7.2. Estimated number of online buyers worldwide, by region, 2013 and 2018}

\begin{tabular}{lccc|ccc} 
& \multicolumn{2}{c}{ Total (million) } & Growth & \multicolumn{3}{c}{ Online buyers as a share of: } \\
& & & & & $\begin{array}{c}\text { World total } \\
\text { of online buyers }\end{array}$ & $\begin{array}{c}\text { Population } \\
\text { Internet } \\
\text { users }\end{array}$ \\
& $\mathbf{2 0 1 3}$ & $\mathbf{2 0 1 8}$ & $\mathbf{2 0 1 3 - 1 8}$ & $\mathbf{2 0 1 3}$ & $\mathbf{2 0 1 3}$ & $\mathbf{2 0 1 3}$ \\
\hline Asia and Oceania & $\mathbf{4 6 0 . 3}$ & 782.4 & $\mathbf{7 0} \%$ & $42.6 \%$ & $14.9 \%$ & $42.1 \%$ \\
\hline Western Europe & $\mathbf{1 8 2 . 3}$ & 210.2 & $15 \%$ & $16.9 \%$ & $49.0 \%$ & $64.0 \%$ \\
\hline North America & $\mathbf{1 7 2 . 3}$ & 203.8 & $18 \%$ & $16.0 \%$ & $59.7 \%$ & $72.0 \%$ \\
\hline Middle East and Africa & $\mathbf{9 3 . 6}$ & 170.6 & $82 \%$ & $8.7 \%$ & $7.1 \%$ & $31.3 \%$ \\
\hline Latin America & $\mathbf{8 4 . 7}$ & 139.3 & $64 \%$ & $7.8 \%$ & $18.6 \%$ & $28.2 \%$ \\
\hline Central and Eastern Europe & $\mathbf{8 6 . 4}$ & 117.4 & $36 \%$ & $8.0 \%$ & $24.1 \%$ & $41.6 \%$ \\
\hline World & $\mathbf{1 , 0 7 9 . 6}$ & $1,623.7$ & $50 \%$ & $100.0 \%$ & $15.2 \%$ & $41.3 \%$ \\
\hline
\end{tabular}

Source: UNCTAD (2016a), UNCTAD B2C E-commerce Index 2016, eMarketer data, www.emarketer.com (accessed on 01 July 2014).

In most developing and transition economies, people buying online constitute a small proportion of all Internet users. Unlike social networking, for which activity rates are relatively high among developing country Internet users, the share of these that engages in online shopping is generally lower than in developed countries (Figure 7.2). This may reflect limited purchasing power, but it also points to other mitigating factors, such as a lack of trust, limited shopping options (including content in local languages) and poor delivery services.

\section{Box 7.2. A partner country view on the use of e-commerce}

"Electronic commerce is at a very embryonic stage, however the government is aware of the importance of e-commerce and is looking to promote it." Burkina Faso

Source: OECD-WTO aid-for-trade monitoring exercise (2017), www.oecd.org/aidfortrade/countryprofiles/

Some developing countries feature prominently as online sellers of goods and services. In these countries, enterprises are increasingly exploiting the opportunities created by improved connectivity and the greater willingness among consumers to shop online. China, in particular, has seen the emergence of major players, such as the Alibaba Group and JD.com (formerly 360Buy.com), which now figure among the world's top e-commerce companies. As of 15 September 2014, Alibaba and Amazon ranked third and fourth, respectively, in market capitalization among the world's largest Internet companies (WSJ, 2014). 
Figure 7.2. Share of Internet users involved in online purchasing and social networking, selected countries, 2015

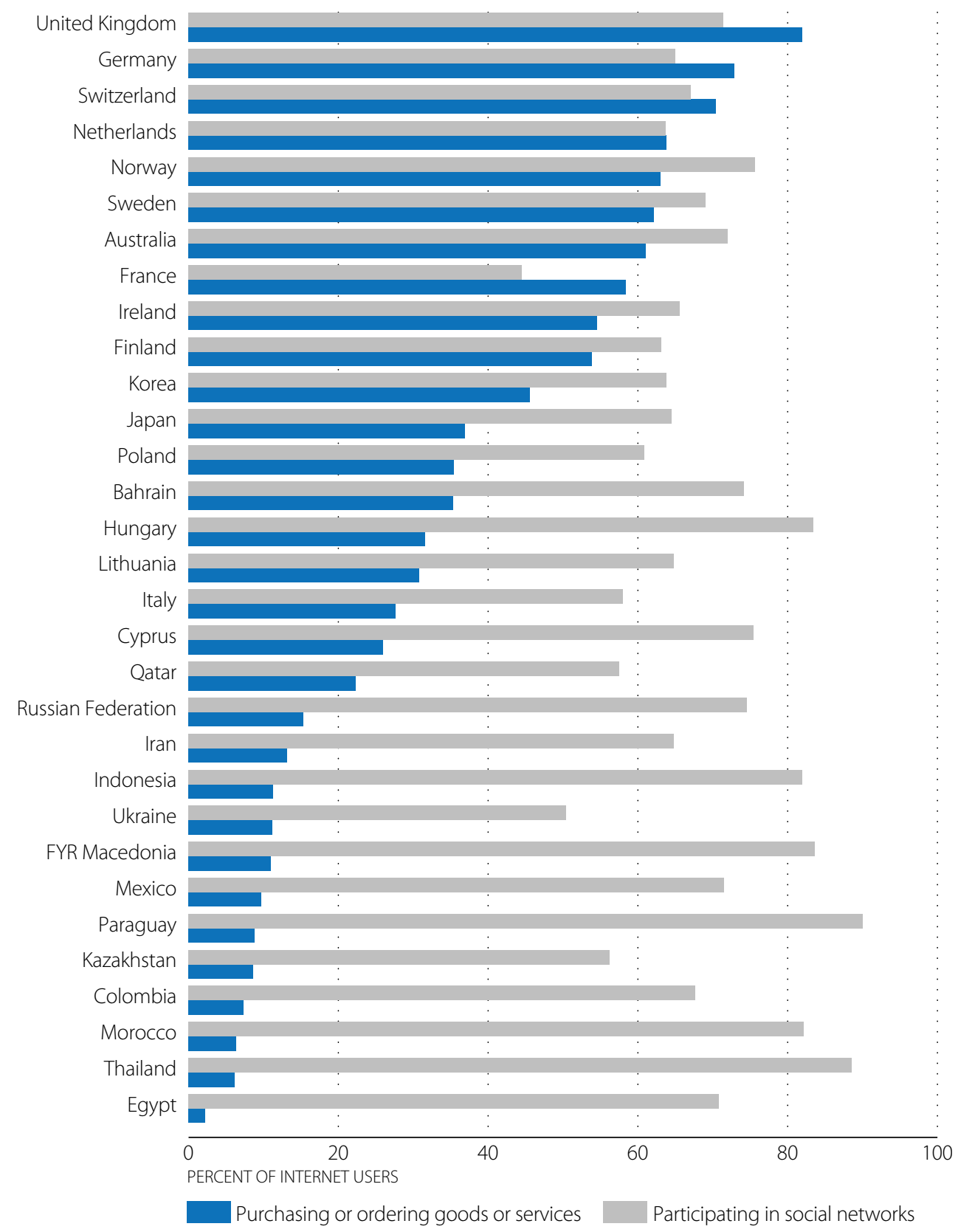

Source: ITU.

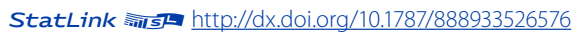

A relatively small number of companies accounts for a substantial share of the e-commerce market, with the level of concentration varying by country and region (Table 7.3). In the United States, the top ten leading web retailers accounted for about half (52\%) of total sales by the top 500 web merchants in 2013 (Internetretailer.com, 2014). In the more fragmented European market, the top ten accounted for $37 \%$ of sales by the top 500 web retailers in 2012 , and the top 100 for $80 \%$. The level of concentration is higher in Asia, where the combined sales of the top ten accounted for as much as $86 \%$ of web sales by the region's top 500 web retailers in 2012. By comparison, the share was about 51\% in Latin America in 2013. 
Table 7.3. Top ten Internet retail companies in the United States, Europe, Asia and Latin America, 2012-13

\begin{tabular}{|c|c|c|c|c|}
\hline & $\begin{array}{l}\text { United States } \\
2013\end{array}$ & $\begin{array}{c}\text { Europe } \\
2012\end{array}$ & $\begin{array}{l}\text { Asia } \\
2012\end{array}$ & $\begin{array}{l}\text { Latin America } \\
\qquad 2013\end{array}$ \\
\hline 1 & $\begin{array}{l}\text { Amazon.com } \\
\text { (United States) }\end{array}$ & $\begin{array}{l}\text { Amazon.com } \\
\text { (United States) }\end{array}$ & Alibaba Group (China) & B2W Digital (Brazil) \\
\hline 2 & Apple (United States) & Otto (Germany) & Rakuten (Japan) & Nova Pontocom (Brazil) \\
\hline 3 & Staples (United States) & Staples (United States) & 360Buy.com (China) & SACI Falabella (Chile) \\
\hline 4 & Wal-Mart (United States) & $\begin{array}{l}\text { Home Retail Group } \\
\text { (United Kingdom) }\end{array}$ & $\begin{array}{l}\text { Amazon.com } \\
\text { (United States) }\end{array}$ & $\begin{array}{l}\text { Wal-Mart Latin America } \\
\text { (United States) }\end{array}$ \\
\hline 5 & $\begin{array}{l}\text { Sears Holdings } \\
\text { (United States) }\end{array}$ & Tesco (United Kingdom) & $\begin{array}{l}\text { Suning Commerce } \\
\text { (China) }\end{array}$ & Netshoes (Brazil) \\
\hline 6 & $\begin{array}{l}\text { Liberty Interactive } \\
\text { (United States) }\end{array}$ & Apple (United States) & Jia.com (China) & $\begin{array}{l}\text { Máquina de Vendas } \\
\text { (Brazil) }\end{array}$ \\
\hline 7 & Netflix (United States) & CDiscount.com (France) & eBay (United States) & Dell (United States) \\
\hline 8 & Macy's (United States) & Tengelmann (Germany) & 51Buy.com (China) & $\begin{array}{l}\text { Amazon.com (United } \\
\text { States) }\end{array}$ \\
\hline 9 & $\begin{array}{l}\text { Office Depot } \\
\text { (United States) }\end{array}$ & $\begin{array}{l}\text { Shop Direct Group } \\
\text { (United Kingdom) }\end{array}$ & HappiGo (China) & Magazine Luiza (Brazil) \\
\hline 10 & Dell (United States) & $\begin{array}{l}\text { Sainsburys } \\
\text { (United Kingdom) }\end{array}$ & Vamcl (China) & Saraiva e Siciliano (Brazil) \\
\hline $\begin{array}{l}\text { Share of } \\
\text { top } 500 \text { sales }\end{array}$ & $52 \%$ & $37 \%$ & $86 \%$ & $51 \%$ \\
\hline
\end{tabular}

Sources: UNCTAD (2015), Information Economy Report 2015: Unlocking the Potential of E-commerce for Developing Countries; based on internetretailer.com data, www.digitalcommerce360.com/internet-retailer/

\section{Assessing cross-border e-commerce is challenging}

All of the estimates provided above include both domestic and cross-border e-commerce. A prominent policy challenge today is to determine the contribution of e-commerce to international trade; in other words, to assess the share of e-commerce that is cross-border. The lack of official statistics in this area makes it very difficult to provide an overall picture (UNCTAD, 2016b). ${ }^{3}$ Existing data and estimates suggest that the share of cross-border e-commerce may be higher in certain developing countries.

In many developed countries, the international dimension of e-commerce is still modest. For example, European e-commerce sales are predominantly domestic in nature. In 2015, whereas 20\% of the enterprises in the European Union's EU-28 sold online, on average only 8\% reported making e-sales to other EU countries (Eurostat, 2017). In Ireland, which ranks first among European Union countries in businesses making e-sales, with 30\%, only slightly more than half of them reported selling to customers in another EU country. In Canada, $80 \%$ of the value of online sales was attributable to customers in Canada, 15\% to customers in the United States and the remaining 5\% to customers in other countries (Statistics Canada, 2014).

While the number of enterprises selling cross-border online may be limited, those that do could be sourcing intermediate goods from enterprises in other countries, either online or offline. Thus, the object sold through a domestic B2C e-commerce transaction may be produced through global value chains, with inputs from firms in several other countries. This is the case, for example, for sports shoes sold on domestic retail websites. 
In developing countries, although official statistics on cross-border e-commerce are scarce, there are some data from private sources. Compared with the situation in developed countries, cross-border B2C or C2C transactions weigh more significantly in a number of developing countries. For example, in 2013 more than half of the e-commerce in both India and Singapore was cross-border. In Latin America, cross-border trade accounted for the bulk of online buying by consumers in Colombia, Paraguay and the Bolivarian Republic of Venezuela, partly resulting from underdeveloped domestic e-commerce (Payvision, 2014). According to eMarketer, in Argentina, 40\% of digital buyers made a cross-border transaction in 2015, compared to 45\% in Brazil and 60\% in Mexico (eMarketer, 2016).

Data from the Universal Postal Union (UPU) on the volume of international postal traffic offer important insights into recent trends in cross-border e-commerce of goods. Between 2011 and 2016, global deliveries of small packets, parcels and packages more than doubled, although admittedly not all of these were linked to e-commerce transactions. The UPU data confirm, however, the increasingly important role of developing countries in cross-border trade, especially in Asia and Oceania (Table 7.4). That region's share of postal deliveries sent abroad rose from 26\% to 43\% during the same period, while its share of received postal deliveries surged from $15 \%$ to $25 \%$. The data further show that developed countries and Asia and Oceania run significant trade surpluses in this area, whereas Latin America and the Caribbean as well as transition economies import considerably more than they export.

Table 7.4. International deliveries of small packets, parcels and packages, 2011 and 2016 (Regional flows as a percentage share of global flows)

2011

\begin{tabular}{|c|c|c|c|c|c|c|c|}
\hline Sent from $\nabla$ & Sent to & $\begin{array}{c}\text { Developed } \\
\text { countries }\end{array}$ & Africa & $\begin{array}{l}\text { Asia and } \\
\text { Oceania }\end{array}$ & $\begin{array}{c}\text { Latin America and } \\
\text { Caribbean }\end{array}$ & $\begin{array}{l}\text { Transition } \\
\text { economies }\end{array}$ & World \\
\hline $\begin{array}{l}\text { Developed } \\
\text { countries }\end{array}$ & & $46.3 \%$ & $2.4 \%$ & $12.1 \%$ & $7 \%$ & $2.8 \%$ & $70.6 \%$ \\
\hline Africa & & $0.7 \%$ & $0.2 \%$ & $0.1 \%$ & $0 \%$ & $0 \%$ & $1 \%$ \\
\hline Asia and Oceania & & $21.6 \%$ & $0.3 \%$ & $2.7 \%$ & $0.5 \%$ & $0.4 \%$ & $25.5 \%$ \\
\hline $\begin{array}{l}\text { Latin America } \\
\text { and the Caribbean }\end{array}$ & & $1.7 \%$ & $0 \%$ & $0.1 \%$ & $0.3 \%$ & $0 \%$ & $2.1 \%$ \\
\hline $\begin{array}{l}\text { Transition } \\
\text { economies }\end{array}$ & & $0.5 \%$ & $0 \%$ & $0 \%$ & $0 \%$ & $0.3 \%$ & $0.8 \%$ \\
\hline World & & $70.8 \%$ & $2.9 \%$ & $15 \%$ & $7.8 \%$ & $3.5 \%$ & $100 \%$ \\
\hline
\end{tabular}

2016

\begin{tabular}{|c|c|c|c|c|c|c|c|}
\hline Sent from $\nabla$ & Sent to & $\begin{array}{c}\text { Developed } \\
\text { countries }\end{array}$ & Africa & $\begin{array}{l}\text { Asia and } \\
\text { Oceania }\end{array}$ & $\begin{array}{c}\text { Latin America and } \\
\text { Caribbean }\end{array}$ & $\begin{array}{l}\text { Transition } \\
\text { economies }\end{array}$ & World \\
\hline $\begin{array}{l}\text { Developed } \\
\text { countries }\end{array}$ & & $26.3 \%$ & $0.9 \%$ & $20.8 \%$ & $2.7 \%$ & $2.4 \%$ & $53.1 \%$ \\
\hline Africa & & $0.7 \%$ & $0.2 \%$ & $0.2 \%$ & $0 \%$ & $0 \%$ & $1.1 \%$ \\
\hline Asia and Oceania & & $33.2 \%$ & $0.4 \%$ & $4.2 \%$ & $1.4 \%$ & $4.0 \%$ & $43.2 \%$ \\
\hline $\begin{array}{l}\text { Latin America and } \\
\text { the Caribbean }\end{array}$ & & $1.0 \%$ & $0 \%$ & $0.1 \%$ & $0.2 \%$ & $0 \%$ & $1.3 \%$ \\
\hline $\begin{array}{l}\text { Transition } \\
\text { economies }\end{array}$ & & $0.7 \%$ & $0 \%$ & $0.1 \%$ & $0 \%$ & $0.5 \%$ & $1.3 \%$ \\
\hline World & & $61.9 \%$ & $1.5 \%$ & $25.4 \%$ & $4.3 \%$ & $6.9 \%$ & $100 \%$ \\
\hline
\end{tabular}

Note: The table shows international deliveries

Source: Universal Postal Union. 


\section{Box 7.3. World Bank views on the value of the Internet for trade}

"The internet enables more products to be exported to more markets, often by newer and younger firms. A 10\% increase in internet use in the exporting country is found to increase the number of products traded between two countries by $0.4 \%$. A similar increase in internet use of a country pair increases the average bilateral trade value per product by 0.6\%". Source: Shawn Tan (2015), The effects of the Internet on Firm Export Behaviour, World Bank www.worldbank.org/en/publication/wdr2016

\section{E-commerce offers opportunities for development, but also challenges}

There is growing interest in the development dimension of e-commerce. The United Nations General Assembly has committed to harnessing the potential of information and communications technologies (ICTs) to advance the 2030 Agenda for Sustainable Development and achieve other internationally agreed development goals (UN, 2016). In doing so, they note that this could accelerate progress across all 17 Sustainable Development Goals (SDGs). The digitalization of trade is of direct relevance to several of these goals.

For example, digital trade can be leveraged to promote the empowerment of women as entrepreneurs and traders (SDG Target 5b). E-commerce and digital trade can support productive activities, decent job creation, entrepreneurship, creativity and innovation. They can encourage the formalization and growth of micro, small and medium enterprises (MSMEs) in developing countries, including through access to ICT-enabled financial services such as online and mobile payments (SDG Target 8.3). They can also promote the integration of MSMEs into value chains and markets (e.g. by leveraging virtual marketplaces) in support of SDG Target 9.3. Moreover, digital trade can help to significantly increase the exports of developing countries (SDG Target 17.11), in particular with a view to doubling the least developed countries' share of global exports by 2020.

Yet as the rapid uptake of ICTs and e-commerce is transformational, it creates both opportunities and challenges for developing countries, including the LDCs.

\section{Box 7.4. Sri Lanka's vision for 2022}

In 2007, Sri Lanka's ICT and business process management (BPM) sectors agreed a ten-year plan to generate annual export revenues of USD 1 billion and employ more than 80000 people. Today, these targets have been surpassed and ICT is now Sri Lanka's fifth-largest export-earning sector. A new vision for 2022 has been developed with the following targets: growing revenue to USD 5 billion and creating 200000 jobs. To make this happen, Sri Lanka's goal is to move up the value chain - shifting from a focus on cost to one based on value. The ICT sector has constructed its strategy for making this happen around three targets:

1. building capacity by tripling the number of ICT graduates by 2020 (there were only 6000 graduates in ICT and related fields in 2015)

2. promoting innovation by encouraging the creation of 1000 start-ups and fostering links between academia and the private sector

3. underpinning regional development by taking the ICT/BPM industry to the regions, again by promoting linkages with universities.

Source: OECD-WTO aid-for-trade monitoring exercise (2017), www.oecd.org/aidfortrade/countryprofiles/ 
In terms of opportunities, the application of ICTs can lower transaction costs and enable the remote delivery of more goods and services. For example, automating customs declarations has been shown to bring clearance times down and to reduce the period that goods stay in transit. Access to ICT platforms and devices may enable a seller in a developing country to reach more potential customers in domestic as well as foreign markets, in a more targeted way, and often at lower cost than through traditional channels. Meanwhile, suppliers that increase their reliance on e-commerce may be able to see reduced delivery costs, especially for electronically-provided content. This has an impact on global value chains, as more inputs can be digitally delivered, which in turn facilitates the management of fragmented production networks.

Greater ICT use can enhance the productivity of enterprises and more productive enterprises are generally more likely to export. The potential for such productivity gains, however, remains far from fully exploited in most developing countries. In addition, e-commerce offers opportunities for entrepreneurship, innovation and job creation. There are now thousands of e-commerce start-ups throughout developing countries, but many of them have yet to become profitable and reach a significant scale. ${ }^{4}$ Mobile payment has emerged as a regional East African means of extending payment solutions to the unbanked.

E-commerce can help enterprises, in particular small and medium ones, to overcome barriers to their expansion. Digitalization can allow small businesses to engage in peer-to-peer collaboration, and innovate using alternative funding mechanisms (such as crowdfunding). New cloud-based solutions can reduce the need for enterprises to invest in ICT equipment. E-commerce can furthermore facilitate the scale up of SMEs by providing vehicles to build verifiable online transaction records that may help attract new customers and business partners, as well as financing opportunities.

E-commerce has also been shown to support rural development. In China, for example, several villages have successfully sold local agricultural products online through the country's leading e-commerce sites (UNCTAD, 2015). Positive side effects have included upstream crop revitalization as well as the emergence of a supporting logistics ecosystem, and of processing and packaging industries.

Consumers stand to benefit from e-commerce in numerous ways, in both monetary and non-monetary terms. Internet browsing, e-mail inquiries and social networking allow them to compare prices and features of products more easily, thanks to reviews by other consumers. They can also make their purchases at times that are convenient to them, or from online discounters. Also, consumer choice is expanded when products from far afield can be discovered, ordered and delivered over long distances.

\section{E-commerce poses a number of potential challenges}

Nonetheless, uneven access to ICTs can lead to an inequitable distribution of the benefits from e-commerce, bypassing those with little education and/or literacy, as well as MSMEs in rural areas or with limited ability or rights to connect. One of the commitments taken by all participants in the World Summit on the Information Society (WSIS) was to ensure that the benefits of ICTs are available to all.

The specific challenges to maximizing the benefits of e-commerce include: unreliable and costly power supply, limited awareness and skills regarding how to implement and use e-commerce, insufficient or inconsistent laws and regulations, limited or deficient transport and logistics infrastructure, lack of online or alternative payment facilities, limited purchasing power, cultural preferences for face-to-face interaction, and reliance on cash. These and other challenges are further explored in the next section, which aims to provide an overview of the numerous metrics available for assessing e-commerce readiness and the extent to which countries can address a range of e-commerce-related challenges. 


\section{ASSESSING THE READINESS OF COUNTRIES TO ENGAGE IN E-COMMERCE IS A FIRST STEP TO BETTER POLICY OUTCOMES}

This section looks at various factors affecting a country's ability to engage in and benefit from e-commerce. It draws on the UNCTAD B2C E-Commerce Index and the Global Cyberlaw Tracker. The analysis points to divides across regions and countries and underlines the importance of taking action at both the national and international levels to facilitate more inclusive e-commerce. Recognizing that e-commerce remains a difficult area of measurement, not least due to the fast changing nature of the digital economy, the section also mentions some recent initiatives to define, identify and improve relevant and comparable statistics, in collaboration with international agencies and national statistics offices from around the world.

\section{Numerous factors affect e-commerce readiness}

The extent to which different countries engage in e-commerce varies, giving rise to a multi-faceted digital divide. Internet access for both buyers and sellers is essential for online shopping. Based on ITU data, it is estimated that just under half (47\%) of the people around the world could theoretically make online purchases from home, work, telecentres or other locations using mobile devices. In the LDCs, only one out of nine people are online, and fewer still use broadband. Beyond cross-country divides, there are also differences within countries, not least between small and largefirms, and between women and men (ITU,2015). These gaps re present barriers to the contribution of ICTs and e-commerce to inclusive development.

Lack of access to the Internet is a constraint not only for consumers, but also for resident enterprises. Data show that the proportion of enterprises that access the Internet is heavily influenced by their size and location, with larger urban firms usually enjoying much higher and qualitatively better levels of use than smaller rural ones. Enterprises need a web presence for accepting orders, even if these are outsourced to a third party. Thus, the number of e-commerce web sites is an indicator of capabilities for receiving online orders. According to one source, around 110000 e-commerce sites in the world generated non-negligible revenue in 2014 (Moore, 2014). However, these data are neither regularly updated nor disaggregated by country.

Indicators developed by the Partnership on Measuring ICT for Development can help assess the capacity of firms to engage in e-commerce. They capture, for example, the number of enterprises with a web presence, and those placing orders (buying) and receiving orders (selling) online. Data for these indicators are collected through enterprise surveys by most developed countries, but only by selected developing and transition economies. Indeed, such statistics remain scarce for developing countries and virtually non-existent for the LDCs. Moreover, few existing enterprise surveys in developing countries ask about the value of e-commerce, distinguish between B2B, B2C or B2G transactions or capture the domestic vs. cross-border distinction. It is often more common for enterprises to purchase inputs than to sell online, as selling online requires additional effort, investment and skills.

Enterprise size is generally a strong determinant of e-commerce uptake, regardless of the level of development (Figure 7.3). In Oman, for example, 36\% of small enterprises received orders over the Internet in 2011, compared to $68 \%$ of large enterprises. In Azerbaijan, only $2 \%$ of small enterprises received orders online in 2012, compared to $11 \%$ of large enterprises. Even in the European Union, a similar pattern prevails: in 2012, 40\% of large enterprises, 25\% of medium enterprises and 15\% of small enterprises sold online. Where data for micro-enterprises are available, the gap in e-commerce adoption is even wider. In Cameroon, 28\% of micro-enterprises received orders over the Internet, compared to $36 \%$ of small enterprises. 
Figure 7.3. Share of enterprises receiving orders over the Internet in selected economies, by enterprise size

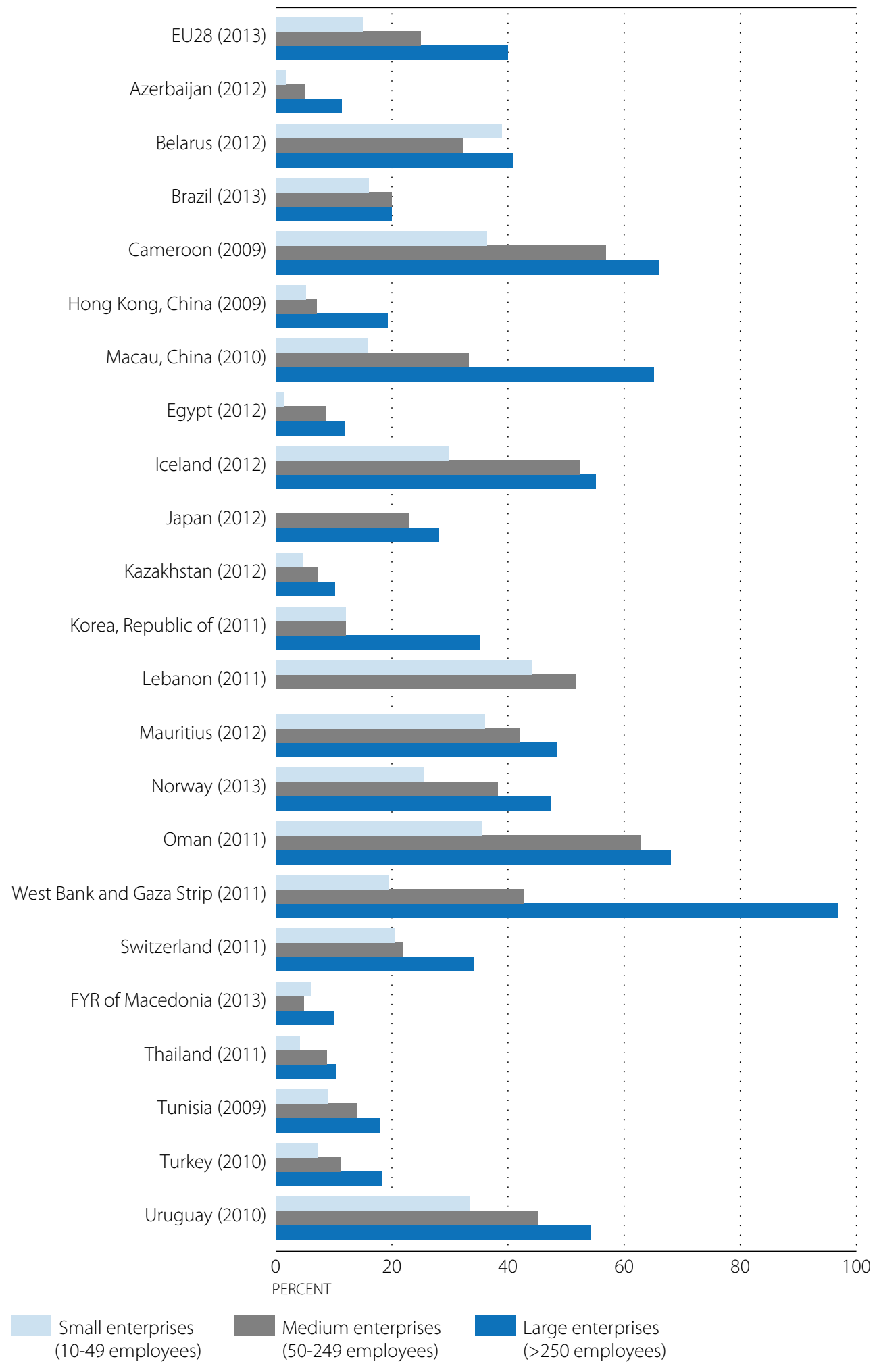

Note: Data is for the latest available year. Japan data is for enterprises with 50 employees or more.

Source: UNCTAD (2015) Information Economy Report 2015: Unlocking the Potential of E-commerce for Developing Countries.

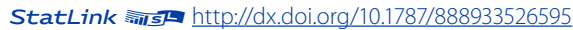


Box 7.5. Partner country views on the status of e-commerce in their countries

"Most companies in electronic commerce and, in the economy in general, use a simplified regime that does not allow exporting". Colombia

"Our SMEs are basically hindered by the accessibility to a global e-commerce platform to sell their goods". Pakistan Source: OECD-WTO aid-for-trade monitoring exercise (2017), www.oecd.org/aidfortrade/countryprofiles/.

Given that e-commerce sites require security software, one widely available proxy for the quality of e-commerce infrastructure is the number of secure servers using encryption technology for Internet transactions. There are considerable differences among countries in this respect. In 2013, there were over 800 secure data servers per million inhabitants in high-income economies, compared to only one server per million inhabitants in the LDCs (figure 7.4).

\section{Figure 7.4. Distribution of secure Internet servers by region and country type, 2013}

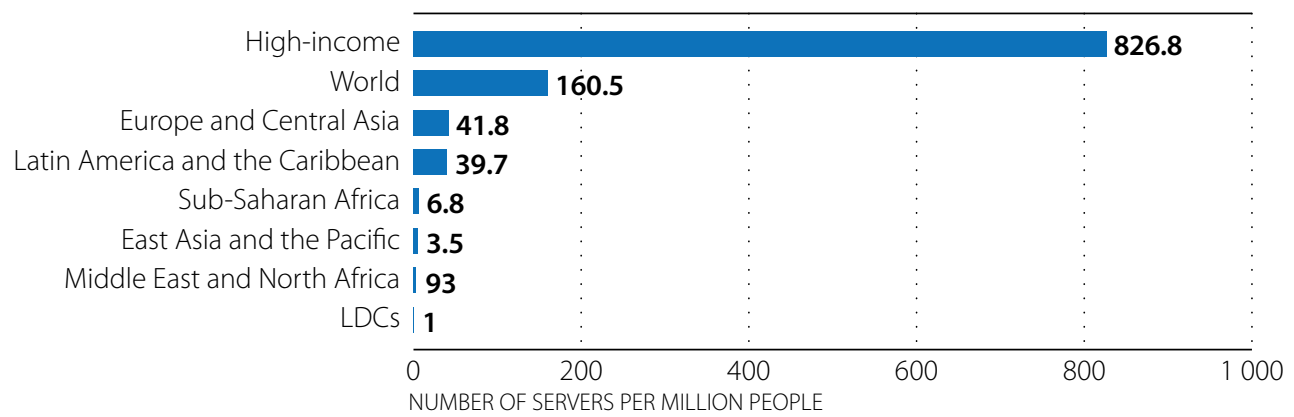

\footnotetext{
Notes: Regional data refer to developing economies only in each region. Secure servers are those using encryption technology in Internet transactions.

Source: UNCTAD (2016a) UNCTAD B2C E-commerce Index 2016, based on World Bank data, http://data.worldbank.org/ indicator/IT.NET.SECR.P6

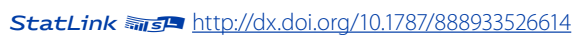

Products purchased over the Internet can be paid for online or offline. Credit cards are among the most convenient payment methods for e-commerce, capturing a large share of online transactions, and this is forecast to continue through 2019. Although other payment options are increasingly used, especially in developing countries, credit cards are very widely accepted on virtually any B2C web site. Therefore, not having a credit card constrains the ability of consumers to shop freely online. The World Bank's Global Findex survey provides estimates of credit card penetration among the population aged 15 years and older (World Bank, 2014).

Similarly, because a product ordered online must be delivered, data on delivery of physical goods is a key indicator. The UPU postal reliability score captures aspects such as the proportion of people who can have mail delivered at home and the quality of postal service.

An increasing number of countries are designing national policies and strategies to harness the full potential of e-commerce for economic development. The UNCTAD B2C E-commerce Index 2016 (UNCTAD 2016a) groups indicators to help policy makers assess to what extent their economies are e-commerce ready and what areas are in greatest need of improvement. The Index comprises four readiness indicators: 1) Internet use penetration, 2) secure servers per million inhabitants, 3) credit card penetration, and 4) postal reliability. The 2016 Index covers 137 economies, which represent $96 \%$ of the world population and $99 \%$ of global GDP. 
The UNCTAD indicator shows that e-commerce readiness varies by region (Figure 7.5). Just over one-fifth of the population in Africa uses the Internet, compared to two-thirds in Western Asia. While Western Asia and transition economies fare well on most indicators, credit card availability there is average. Overall, Asia needs to boost Internet penetration, which currently stands at just over one-third of the population, as well as the number of secure servers. In Latin America and the Caribbean, the main barriers appear to be low credit-card penetration and relatively poor postal reliability. Africa ranks the lowest in all the indicators. Unless there is improvement in the underlying transaction and logistics processes, African online shopping is likely to remain confined to wealthier populations in urban areas.

Figure 7.5. E-commerce readiness, by component indicators and geographical region

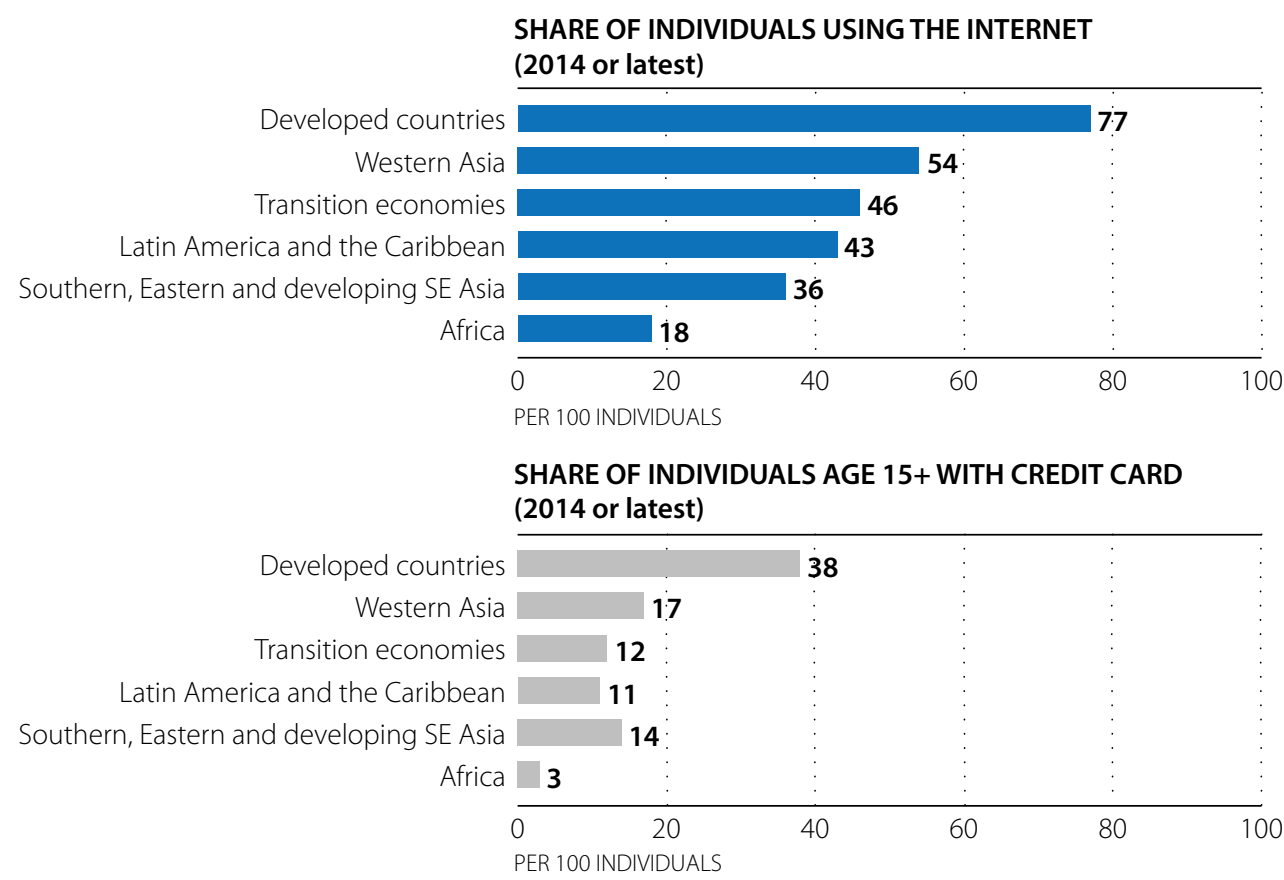

SECURE SERVERS PER MILLION PEOPLE

(normalized, 2014)

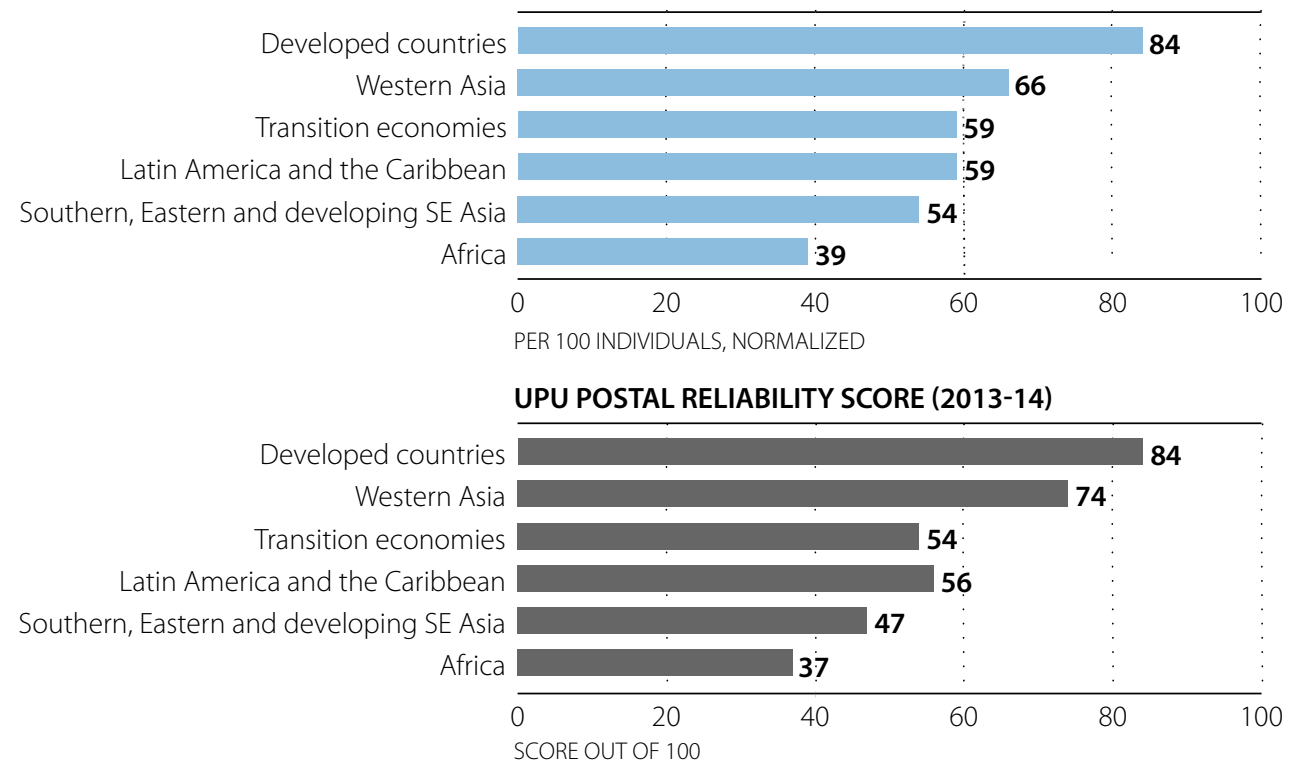

Note: Latest data available.

Source: Based on UNCTAD (2016a), UNCTAD B2C E-commerce Index 2016 ITU, World Bank and UPU data. 


\section{Weak legal and regulatory frameworks can result in low levels of trust in online transactions}

Barriers caused by legal and regulatory frameworks can be particularly damaging for MSMEs, which are usually less connected than larger firms, especially in developing countries. While data on legal and regulatory frameworks are not currently included in the UNCTAD Index, UNCTAD publishes information on four key qualitative indicators, which look at whether countries have a legal framework for 1) electronic transactions, 2) data protection/privacy online, 3) consumer protection when purchasing online and 4) cybercrime prevention. ${ }^{5}$

When considering legal frameworks, a key question for policy makers is to ascertain whether existing laws and regulations allow for a "level playing field" between e-commerce and regular trade. From a trade policy perspective, there may be barriers related to market access, technical standards, regulations and various border measures. Exports may also be hampered if enterprises in a country are unable to use certain online platforms and marketplaces for various reasons. For example for Amazon, eBay and PayPal the full range of services offered online are only available in a limited number of countries, sometime limiting existing options to buy-only. Moreover, producers in a country may be unable to compete internationally because they have insufficient resources to promote their brand names or to comply with technical and other standards. In many developing countries, difficulties with complying with regulations for international banking transactions represent additional barriers.

To help address some of these issues, and others, a number of initiatives have recently been launched to improve e-commerce-related statistics. One of them is the UNCTAD-UPU-WTO-OECD-World Customs Organization (WCO) initiative to improve measurement of cross-border e-commerce. Another is the recently-established WCO Working Group on E-commerce Measurement. Under the 2017 German Presidency, the G20 $0^{6}$ countries have also focused their efforts to better measure and understand e-commerce and its development dimension. More recently, eTrade for All, the multi-stakeholder initiative that aims to assist developing countries engage in and benefit from e-commerce, proposed a list of available, prominent e-commerce readiness indicators (World Bank, 2017). The eTrade for All indicators are available online and e-trade country profiles are provided on the eTrade for All online platform (etradeforall, 2017). To be able to offer a complete picture, more efforts are also needed to reinforce the capacity of developing countries to collect and compile relevant statistics.

\section{NATIONAL POLICIES AND STRATEGIES CAN HELP TO ENABLE E-COMMERCE}

This section discusses the role of governments and other stakeholders in e-commerce policy making. It identifies key policy areas to be addressed in national e-commerce strategies, including trade logistics, online payment solutions, online e-commerce and payment marketplaces, legal and regulatory frameworks, relevant skills, public e-procurement, and stakeholder participation in policy formulation and implementation. It examines how to tackle e-commerce divides, such as the ones identified in the previous sections, and how to make access to and use of e-commerce more inclusive.

\section{Box 7.6. The Tunis Agenda for the Information Society, 2005}

"Taking into consideration the leading role of governments in partnership with other stakeholders in implementing the WSIS outcomes, including the Geneva Plan of Action, at the national level, we encourage those governments that have not yet done so to elaborate, as appropriate, comprehensive, forward-looking and sustainable national e-strategies, including ICT strategies and sectoral e-strategies as appropriate, as an integral part of national development plans and poverty reduction strategies, as soon as possible and before 2010."

Note: 163 national e-strategies were developed by 2011.

Sources: ITU (2011), National e-Strategies for Development: Global Status and Perspectives; quoting the World Summit on the Information Society (2005), Tunis Agenda for the Information Society, www.itu.int/net/wsis/docs2/tunis/off/6rev1.html 


\section{INFORMED DECISION AND POLICY MAKING IS ESSENTIAL, AS IS STAKEHOLDER PARTICIPATION}

Governments have a crucial role to play in creating an environment that is conducive to maximizing sustainable development opportunities such as e-commerce. Informed decision-making is facilitated by a realistic assessment of where the country stands in terms of its national needs, strengths, weaknesses, opportunities and threats. As e-commerce opportunities expand and more business activities are affected, it is important to consider policies that can help harness e-commerce for sustainable development.

E-commerce policies should be coherent, and their objectives should be well integrated with the country's broader national development agenda, as e-commerce may support various other economic and social objectives, such as higher productivity, improved competitiveness, improved access to information, increased transparency of regulations, and more inclusive and equitable development.

While the role of governments is crucial in creating an enabling environment, engaging in effective dialogue with all relevant stakeholders is also essential. A national e-commerce strategy developed in collaboration with relevant stakeholders can play a useful role in helping to make e-commerce more inclusive and in maximizing its net benefits. Effective multi-sectoral and inter-ministerial co-operation is necessary for both strategy development and implementation. Examples of ministries that might be interested include those responsible for justice, finance, science, technology and innovations, ICT, international trade, rural development, employment, post and transportation, and education. Other stakeholders that should be involved include relevant government regulatory and promotional agencies, the trade facilitation committee, the postal service, national ICT associations, chambers of commerce, academia and consumer organizations, when they exist.

Assessing e-commerce readiness is a natural first step towards formulating an effective national e-commerce strategy and setting priorities. Tools such as the UNCTAD B2C E-Commerce Index, the UNCTAD E-commerce Policy Review and the Rapid eTrade Assessments of LDCs can help develop an understanding of national needs, strengths and weaknesses. Reports from other well-established policy review mechanisms, such as the WTO Trade Policy Reviews, the EIF Diagnostic Trade Integration Studies (DTIS) and the World Bank Poverty Reduction Strategy Papers, may also include helpful information with regards to e-commerce-related policies and challenges.

A comprehensive assessment needs to include a review of e-commerce trends. Any assessment should include a review of existing initiatives and a stocktaking of the resources and capabilities that could contribute to further e-commerce development. Identifying the main challenges and barriers to e-commerce in a comprehensive manner, and uncovering the dynamics underpinning them, help to ensure that the policy measures adopted are effective. Direct consultations with stakeholders can play a key role in this process, especially given the fast changing nature of ICT technologies.

Tracking progress is also essential. To this end, relevant performance indicators and realistic targets should be established at the outset. The monitoring exercise also may require new efforts to collect data.

\section{A review of selected relevant policy areas follows:}

Improving access to reliable and affordable ICT services is essential for e-commerce to thrive. Governments in developing countries are increasingly facilitating the deployment of networks, often through public-private partnerships, and/or with finance derived from government revenues or loans from international financial institutions. Some of the pre-requisites for e-commerce include affordable mobile communications, access to broadband Internet, interconnectivity between services and devices, as well as the skills and infrastructure necessary to secure and encrypt transactions. In addition, infrastructure improvements need to be accompanied by competent and effective regulation of telecommunications markets. Competitive and interoperable ICT markets, facilitated by independent regulators, help to deliver higher-quality, more reliable and affordable services. Inadequate power infrastructure, another common bottleneck to e-commerce adoption, also needs to be addressed. 
Strengthening logistics and transport infrastructure are imperative for both domestic and cross-border e-commerce facilitation. Poor logistics remain a barrier to e-commerce in many developing countries and investment in infrastructure if often much needed, especially outside the main urban centres. If people can order something online in one click, parcel delivery also needs to be reasonably quick and predictable. In this context, initiatives to strengthen the capacity of the postal sector can be relevant for facilitating e-commerce.

For cross-border e-commerce, additional infrastructure and regulatory issues may need to be addressed. Customsrelated procedures and formalities, reporting requirements and bottlenecks at ports can hamper e-commerce. Clear legislation on applicable tax rates and international refund policies are important. Often, the standardization, harmonization and simplification of customs and trade procedures go hand in hand with customs automation, which leads to significant gains in the time needed to clear goods through customs. UNCTAD's Automated System for Customs Data (ASYCUDA), which automates border procedures and serves to facilitate trade in more than 90 developing countries, has led to important reductions in the time needed for customs clearance. In Uganda, for example, use of the ASYCUDA allowed for a drop in the average time from payment to the release of goods from customs, from 8.8 days in January 2014 to 3.2 days in June 2014. Moreover, automating and modernizing customs procedures often improves revenue collection, as well as reducing the costs of trade?

Enhanced availability and use of electronic payment systems are important for facilitating e-commerce. Governments should seek to foster a regulatory environment that is conducive to online payments and the development of adequate payment solutions. This enables consumers and other buyers to feel confident and secure in making purchases online, and vendors to be assured of payment for delivery of their products and services.

Although many global e-commerce platforms are becoming increasingly accessible from locations around the world, there is ample scope for new platforms, tailored to local needs and opportunities, that are fully operational in developing countries. Developing e-commerce platforms can necessitate the involvement of both the public sector (including the postal system) and the private sector. Foreign direct investment (FDI) can provide funding, expertise and know-how that can help the e-commerce sector to expand. For example, foreign investors have contributed to the spread of new e-commerce platforms in sub-Saharan Africa. In some countries, however, there are concerns that opening up to global investors may crowd out local businesses. Both the pros and the cons of FDI in developing the e-commerce industry should be examined.

An adequate legal and regulatory framework is needed to enable e-commerce stakeholders to mitigate transaction risks, provide transparency and ensure a level-playing field. Despite progress over the past decade, considerable gaps in cyber-law coverage remain in many parts of the world. To facilitate cross-border e-commerce, it is important that each country's national legislation in the areas of e-transactions, consumer protection, data protection and privacy is compatible with that of its trade partners. Aligning such laws with international legal instruments also is desirable.

Box 7.7. The Economic Community of West African States

The Economic Community of West African States (ECOWAS) Vision 2020 seeks to harmonize ECOWAS members' telecommunication policies in order to benefit from the digital economy. In 2013-14, with the support of UNCTAD, ECOWAS conducted two online training sessions and three regional workshops. Through these efforts, 315 policymakers and lawmakers received training in the legal aspects of e-commerce. Areas identified for further legislative harmonization included: electronic transactions, data protection, computer crime, consumer protection, online content and domain names.

Source: OECD-WTO aid-for-trade monitoring exercise (2017), Public sector case story 59, http://www.oecd.org/aidfortrade/casestories/ casestories-2017/CS-59-Review-of-e-commerce-legislation-harmonization-in-ECOWAS.pdf 
Once relevant laws and regulations are in place, they need to be communicated transparently to producers and users of e-commerce services. They also need to be effectively enforced, and consumers as well as enterprises need to know how to seek redress if appropriate. National public information campaigns can constitute a key element of awarenessraising efforts, publicising the means that exist to legally protect online consumers. Moreover, as cyber legislation is still a relatively new territory for the legislature and judiciary in many developing countries, there is a need for further capacity-building in this area.

Government and the private sector should work together to foster e-literacy in the population at large and among consumers. This ranges from the revision of curricula at different stages in the education system, to in-work training and specialized professional skills development. Special programmes can provide consumers with the relevant knowledge and skills to acquire and use products purchased online, including raising awareness of their legal rights and obligations.

The lack of e-commerce skills, especially among small businesses, can hamper the capacity of the private sector to engage in e-commerce projects. Data scientists, web developers, and implementers of online payment features are in short supply and expensive to employ in developing economies (WEF, 2012). Micro and small enterprises need training in how to design e-commerce business strategies, evaluate different e-commerce tools and platforms, and create compelling advertisements, while paying attention to quality service and rapid delivery. In this context, it may be useful for governments at the national and local levels to involve intermediaries (such as chambers of commerce and business associations) in the provision of training. They are often in a privileged position to transmit information and knowledge about e-commerce to their members.

In the context of e-commerce skills development, governments should not leave behind women entrepreneurs. Small and micro women-owned businesses may gain from B2B, B2C and C2C transactions that use e-commerce platforms to reach domestic and foreign markets. It has been shown that women entrepreneurs, who are often restricted in their access to capital, can benefit from the ability of e-commerce to increase efficiencies and profitability with limited investment (UNCTAD, 2014). In Uganda, for example, the Women of Uganda Network (WOUGNET) is a nongovernmental organization that has undertaken various advocacy and training initiatives. Aimed at policy intermediaries such as government, chambers of commerce, business and trade associations, and professional education institutions, these efforts have helped to raise awareness regarding ICTs and women's entrepreneurship, including e-commerce (WOUGNET, 2017).

Governments can use e-procurement to incentivize resident enterprises to use the Internet. By making e-procurement a requirement for public tenders, they encourage small and medium enterprises to increase their use of the Internet as a business tool. An often cited example of good practice is ChileCompra (Chile), a public, electronic system for purchasing and hiring based on an Internet platform that caters to companies, public organizations and citizens (Chilecompra, n.d.). In Georgia, the government created an e-procurement platform in 2011; since then, all tendered government purchases are conducted through this centralized bidding platform, operated by the Competition and State Procurement Agency. It has helped to streamline procurement processes, increase competition, enhance transparency and reduce the scope for corruption (Luijken and Martini, 2014). ${ }^{8}$ Similarly, in Albania, the introduction of an e-procurement system in 2010 had positive results in the form of increased competition and considerable cost savings (Luijken and Martini, 2014).

Lack of awareness may hamper the transition from traditional ways of doing business, placing enterprises at a competitive disadvantage. There are various examples of pro-active efforts by governments to inform and alert consumers, businesses to the implications and opportunities of e-commerce. Some governments have raised the visibility of e-commerce through advertising on billboards, radio, TV and the Internet, encouraging consumers to buy online. 
With the expansion of e-commerce, new policy barriers to international trade are emerging. In the context of crossborder e-commerce, two policy issues have been very prominent on the international debate and action agenda: 1) new emerging barriers to trade, and 2) taxation.

National legal barriers that have been noted include stringent financial licensing agreements, and restrictions on the ability of foreign e-commerce companies to enter and engage in local e-commerce markets (Sweden, 2012). Some measures may aim at protecting local businesses from foreign competitors. For example, Chinese financial payment licensing agreements may have prevented eBay from offering Chinese consumers e-payment features equivalent to those provided through the national Alipay on the Taobao platform. This reportedly contributed to eBay's exit from the market in 2006 (New York Times, 2006). In India, foreign e-commerce companies are prohibited from selling. In addition, some governments and other cloud service customers have enacted data localization laws, reflecting concerns about national data being kept on servers in foreign jurisdictions (Kshetri, 2010; UNCTAD, 2013).

E-commerce also questions regarding the international tax concept that allocates jurisdictional tax claims over profits of multinational companies based on physical presence. It raises issues such as: where to tax non-resident e-commerce businesses, how to assess intra-group transactions, how to classify digital goods, how to identify tax payers, and where and how to collect consumption tax, as well as issues of enforcement. Even among developed countries, concerns have been expressed that e-commerce may exacerbate the risk of tax base erosion. ${ }^{9}$ Furthermore, the remote supply of digital products by suppliers with no direct or indirect physical presence in the consumer's jurisdiction presents challenges to value added tax (VAT) systems, as these may often result in no VAT_-or an inappropriately low amount thereof-being collected. This can create competitive pressures on domestic suppliers. The OECD Task Force for the Base Erosion and Profit Shifting Project found that the collection of VAT on B2C transactions was a pressing issue that needed to be addressed to create a level playing field among foreign and domestic suppliers (OECD, 2014). Whereas concerns related to tax implications from e-commerce are likely to be more pronounced in countries where the uptake of e-commerce is relatively high, finding ways to address these concerns is of relevance to all countries. More research is needed to fully understand the implications of existing tax regimes on e-commerce and to devise policy options. In all cases, balancing appropriate enforcement with facilitation of e-commerce should be a priority. Multi-stakeholder dialogue is an effective way to negotiate optimal solutions.

Further shifts from offline to online commerce are expected over the coming years. This will continue to change the ways in which consumers and enterprises interact. Some are better equipped to adapt to these transformations than others. From a policy perspective, it is important to create an environment that offers stakeholders in diverse locations and areas of society equal opportunities to take part in the process. In this context, international cooperation and effective dialogue among policy makers and other stakeholders will remain essential.

\section{Box 7.8. The Asian Development Bank on challenges to e-commerce in Asia}

"Despite the vast opportunities presented by a digital economy, Asia has yet to overcome challenges to fully realize its potential to harness e-commerce for sustainable development. In addition to the absence of national legislation to support cross-border e-commerce, developing countries in Asia face barriers related to poor ICT infrastructure, trade facilitation and logistics, e-payments, and inadequate skills development. National strategies to understand the underpinnings of e-commerce are also lacking in many countries. Even as Asia's developing countries further strengthen their capacity for e-commerce, most of them face institutional issues, such as complicated border clearance procedures and red tape, and disharmonized customs requirements between states hinder intra-regional trade. Market related risks—such as fraud, costs of adaptation, and a risk of crowding out—also serve as barriers to entry." Asian Development Bank

Source: OECD-WTO aid-for-trade monitoring exercise (2017), Public sector case story 124, http://www.oecd.org/aidfortrade/casestories/ casestories-2017/CS-124-Asian-Development-Bank-A-snapshot-of-e-commerce-in-Central-Asia.pdf 


\section{HOW CAN AID FOR TRADE SUPPORT E-COMMERCE READINESS?}

This final section considers how aid for trade can support the strengthening of e-commerce readiness in developing countries. In this context, it presents the multi-stakeholder initiative eTrade for All. It also discusses how to create synergies and greater scale in the overall efforts of the international community to enable more countries to engage in and benefit from e-commerce.

As noted in previous sections, there is a need for additional capacity-building and technical support to enable more countries to engage in and benefit from e-commerce. Assistance from the international community can help in several ways. Support may include the provision of training, policy advice, strategy formulation and other forms of assistance. At the country level, specific support from development partners may address areas such as e-commerce readiness assessments, financing of infrastructure investment, support for the development of legal and regulatory frameworks, and capacity building among diverse stakeholder groups.

To scale up the contribution of e-commerce to sustainable development, a concerted, holistic, cross-sectoral and multistakeholder approach is needed. Numerous development partners, foundations and private sector actors already offer successful models for facilitating greater connectivity, lowering costs and addressing regulatory issues. These models can help unlock the development potential of digital trade. However, these efforts generally target specific areas, such as broadband expansion, payment systems, logistics, trade facilitation, ICT skills development and regulatory improvements. They are seldom holistic or aimed at facilitating e-commerce or digital trade in general. A more concerted effort is therefore needed to ensure that the shift to online transactions does not leave any people, enterprise or country behind.

One way to capitalize on existing knowledge and maximize synergies with partners is to tap into the eTrade for All initiative. Launched in July 2016 at UNCTAD's 14th ministerial conference in Nairobi, this global initiative aims to improve effectiveness in channelling assistance to developing countries wishing to engage in and benefit from e-commerce and digital trade. ${ }^{10}$ The eTrade for All initiative pulls together public and private parties to improve the ability of developing countries to use e-commerce by raising awareness, enhancing synergies and scaling up existing and new efforts.

The eTrade for All initiative addresses seven policy areas that are of particular relevance to the development of e-commerce (Figure 7.6):

1. e-commerce assessments

2. ICT infrastructure

3. trade logistics

4. the legal and regulatory environment

5. e-payments

6. skills development

7. financing of e-commerce ventures.

The main tool of eTrade for All is a dynamic, online platform. This interactive, knowledge-sharing tool helps developing countries and donors navigate the supply of technical and financial support available to foster e-commerce and digital trade, learn about trends and best practices, and raise visibility for their various initiatives and resources. The online platform was officially launched in April 2017 and is organized around the seven policy areas described above. It also has a dedicated space where partners can upload, find and share relevant e-readiness indicators, as well as research on the seven main policy areas. Member states, donors, international organizations and the private sector can all participate in and contribute to this resource. It also helps them to find the latest information on e-commerce technical assistance in a given region or country and to identify the best partners and donors for putting together an e-commerce facilitation project. 
In 2017, the G20 made another significant contribution to the available knowledge base through the publication of a number of discussion papers on digital trade, including e-commerce related issues. These discussion papers present the views of international organizations and member states on the role of e-commerce in international trade and considering the development dimension.

\section{Figure 7.6. The eTrade for All analytical framework for e-commerce}

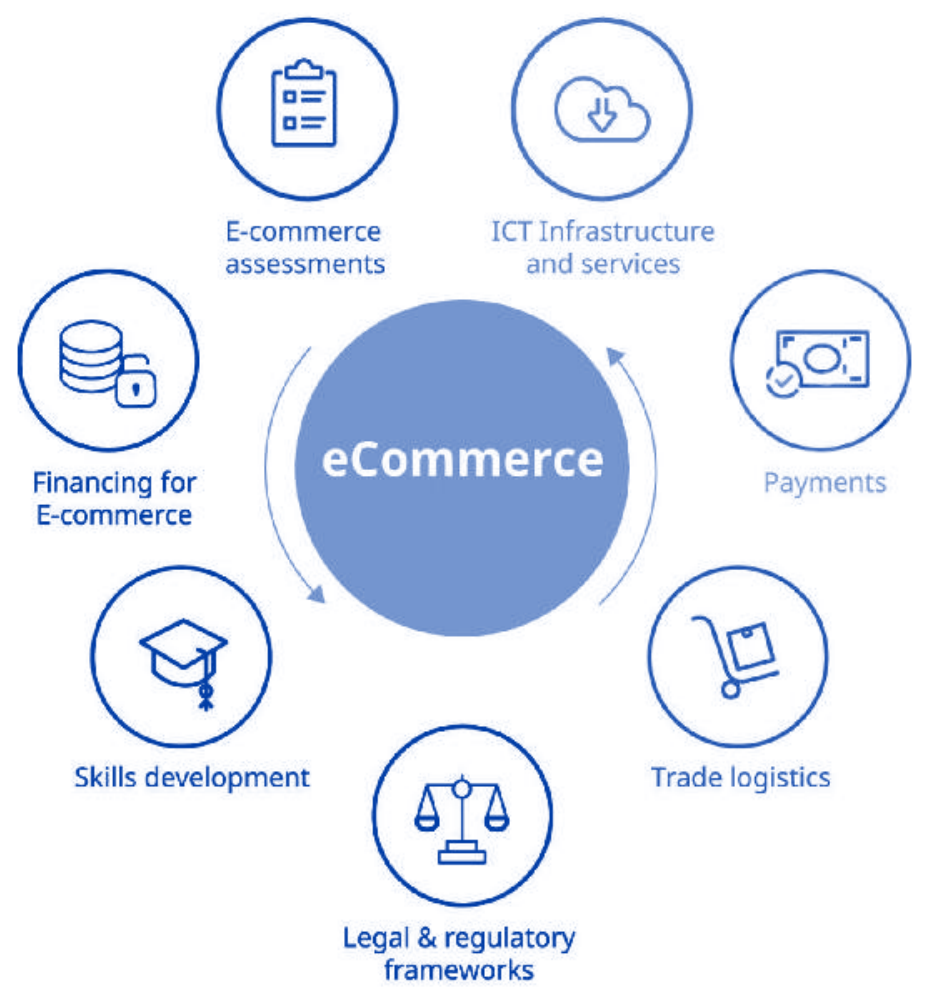

Source: UNCTAD (2016c), e-Trade for All, Policy areas, http://unctad.org/en/Pages/DTL/STI_and_ICTs/eTrade-forAll/eTrade-for-All-Policy.aspx (accessed 15 May 2017).

The Global Aid for Trade Review in July 2017 can contribute a great deal to raising awareness of the benefits and challenges of e-commerce for development from the perspective of the trade policy community. It can help shed light on the rules applicable to e-commerce, both from new and previously existing trade agreements. Increased knowledge and transparency in this area will benefit all stakeholders involved in e-commerce, allowing for safer, more predictable transactions.

\section{CONCLUSIONS}

Further research and dialogue are needed to better understand the implications of e-commerce for sustainable development and to recognize the needs of developing countries in their efforts to make the most of e-commerce opportunities. In this sense, there are a number of recognized international fora for multi-stakeholder dialogue, which offer a suitable neutral platform for exchanging information, establishing contacts and voicing concerns. These include the UNCTAD Intergovernmental Group of Experts on E-commerce and Digital Economy, the UNCTAD E-commerce Week, the UNCTAD E-Trade for All Initiative, the World Summit on the Information Society Forum, various OECD bodies and the WTO Global Aid for Trade Review.

To make the most of existing and upcoming initiatives, better data and monitoring are sorely needed. This will make possible more comprehensive assessments of the various aspects of e-commerce readiness and will help to understand better the impact of government strategies, policies, rules and regulations. 


\section{REFERENCES}

Chilecompra (n.d.), Chilecompra, webpage, www.chilecompra.cl/.

eMarketer (2016), See Cross-Border Ecommerce 2016: A Country-by-Country Look at Consumer Behavior and Trends, eMarketer, https://www.emarketer.com/Report/Cross-Border-Ecommerce-2016-Country-by-Country-Look-ConsumerBehavior-Trends/2001726

etradeforall (2017), E-trade for all initiative, webpage, https://etradeforall.org/.

Eurostat (2017), E-commerce statistics, database, http://ec.europa.eu/eurostat/statistics-explained/index. php/E-commerce statistics.

Internetretailer.com (21 April 2014), Top merchants gain ground in the new Top 500, www.digitalcommerce360. com/2014/04/21/top-merchants-gain-ground-new-top-500/

ITU (2011), National e-Strategies for Development: Global Status and Perspectives, International Telecommunications Union, Geneva, www.itu.int//TU-D/cyb/app/docs/National estrategies for development 2010.pdf.

ITU (2015), Facts and Figures 2015, International Telecommunication Union, Geneva, www.itu.int/en/ITU-D/Statistics/ Documents/facts/ICTFactsFigures2015.pdf.

Kshetri, N. (2010), Cloud computing in developing economies, IEEE Computer. 43(10):47-55.

Luijken, T. and M. Martini (2014), The role of technology in reducing corruption in public procurement, Anti Corruption Helpdesk, Transparency International.

Moore Robert J. (18 June 2014), "How Many Ecommerce Companies Are There?" The Data Point, http://blog.rjmetrics. com/2014/06/18/how-many-ecommerce-companies-are-there/.

New York Times (19 December 2006), "EBay is Expected to Close its Auction Site in China", nytimes.com, www.nytimes.com/2006/12/19/technology/19ebay.html?fta=y\& $r=0$.

OECD (2014), Addressing the Tax Challenges of the Digital Economy, OECD/G20 Base Erosion and Profit Shifting Project, OECD Publishing, http://dx.doi.org/10.1787/9789264218789-en.

OECD-WTO (2017), aid-for-trade monitoring exercise (2017) (questionnaires) www.oecd.org/aidfortrade/countryprofiles/

Payvision (2014), Key business drivers and opportunities in cross-border ecommerce 2014.

Shawn Tan (2015), "The effects of the Internet on Firm Export Behaviour", Background paper for the World Development Report 2016 "Digital Dividends", World Bank www.worldbank.org/en/publication/wdr2016.

Statistics Canada (11 June 2014), "Digital technology and Internet use, 2013", The Daily, www.statcan.gc.ca/dailyquotidien/140611/dq140611a-eng.htm.

Sweden (2012), E-Commerce - New Opportunities, New Barriers. A Survey of E-Commerce Barriers in Countries Outside the EU, National Board of Trade, Stockholm.

UN (2016), Outcome document of the high-level meeting of the General Assembly on the overall review of the implementation of the outcomes of the World Summit on the Information Society, Resolution adopted by the General Assembly on 16 December 2015, (GA/RES/70/125), http://unctad.org/en/PublicationsLibrary/ares70d125 en.pdf UNCTAD (2013), Information Economy Report 2013: The Cloud Economy and Developing Countries, United Nations, New York and Geneva. 
UNCTAD (2014), Empowering Women Entrepreneurs through Information and Communications Technologies, United Nations, New York and Geneva.

UNCTAD (2015), Information Economy Report 2015: Unlocking the Potential of E-commerce for Developing Countries, United Nations, New York and Geneva.

UNCTAD (2016a), UNCTAD B2C E-commerce Index 2016, UNCTAD Technical Notes on ICT for Development N%.

TN/UNCTAD/ICT4D/07, United Nations, http://unctad.org/en/PublicationsLibrary/tn_unctad_ict4d07_en.pdf

UNCTAD (2016b), In Search for Cross-border E-commerce Trade Data, UNCTAD Technical Notes on

ICT for Development N6, TN/UNCTAD/ICT4D/06, United Nations, http://unctad.org/en/PublicationsLibrary/

tn_unctad_ict4d06_en.pdf.

UNCTAD (2016c), e-Trade for All, Policy areas, http://unctad.org/en/Pages/DTL/STI_and_ICTs/eTrade-for-All/eTrade-for-

All-Policy.aspx.

UNCTAD (21 April 2017), Ministers to discuss opportunities and challenges of e-commerce with Jack Ma, eBay, Jumia, Huawei, Etsy, PayPal, Vodafone and more, UNCTAD News, http://unctad.org/en/pages/newsdetails.aspx?OriginalVersio $\underline{\text { nID=1466\&Sitemap_x0020_Taxonomy=UNCTAD\%20Home;\#2149 }}$

WEF (2012), Big data, big impact: new possibilities for international development, World Economic Forum, Geneva, www3.weforum.org/docs/WEF_TC_MFS_BigDataBiglmpact_Briefing_2012.pdf.

World Bank (2014), Global Findex, database, www.worldbank.org/en/programs/globalfindex.

World Bank (2017), World Integrated Trade Solutions, database, http://wits.worldbank.org/analyticaldata/e-trade/country/KEN.

World Summit on the Information Society (18 November 2005), Tunis Agenda for the Information Society,

www.itu.int/net/wsis/docs2/tunis/off/6rev1.html

WOUGNET (2017), Women of Uganda Network, http://wougnet.org/ (accessed on 17 May 2017)

WSJ (16 September 2014), "After Alibaba's IPO, 4 of the 10 most valuable web companies will be from Asia", Wall Street Journal, http://on.wsj.com/1qV8hDV 


\section{NOTES}

1. For the definition of e-commerce please refer to Chapter 2.

2. See for example: www.huffingtonpost.com/peter-diamandis/rising-billion-consumers b $7008160 . h t m l$ and www.computerworld.com/article/3084312/internet/the-next-billion-how-to-best-serve-the-internet-s-newusers.html.

3. OECD, UNCTAD, the Universal Postal Union (UPU) and WTO launched an initiative to improve the measurement of cross-border e-commerce in 2016. A first technical note takes stock of the very scarce available data and trends (UNCTAD, 2016b).

4. Across developing countries and LDCs, a range of e-commerce players have emerged in recent years offering new payment solutions (e.g. Alipay, JamboPay), e-commerce platforms (e.g. MercadoLibre, Zoom Tanzania, TriniTrolley, Kapruka) and innovative logistics (e.g. Giao Hang Nhanh and Grasshoppers).

5. For more information see: Summary of Adoption of E-commerce Legislation Worldwide http://unctad.org/en/ Pages/DTL/STI and ICTS/ICT4D-Legislation/eCom-Global-Legislation.aspX.

6. The G20 members are Argentina, Australia, Brazil, Canada, China, France, Germany, India, Indonesia, Italy, Japan, The Republic of Korea, Mexico, the Russian Federation, Saudi Arabia, South Africa, Turkey, the United Kingdom, the United States and the European Union.

7. For more information, see ASYCUDA - Automated SYstem for CUstoms Data, www.asycuda.org/.

8. See also Sunlightfoundation (16 January 2014), OpenGov Voices: How Georgia is handling procurement transparency, https://sunlightfoundation.com/2014/01/16/opengov-voices-how-georgia-is-handlingprocurement-transparency/ (accessed on 17 May 2017).

9. In the United Kingdom, for example, Amazon participated in a 2012 hearing organized by the Parliamentary Public Accounts Committee. Whereas Amazon had reported a turnover for its company in the United Kingdom of $£ 207$ million (USD 335 million) in 2011, it had shown a tax expense of only £1.8 million (USD 2.9 million). Moreover, the European-wide turnover of Amazon EU Sarl, which was reported as €9.1 billion (USD 11.6 billion), resulted in taxes of only $€ 8.2$ million (USD 10.4 million). Amazon also stated that for 2011, sales from the United Kingdom accounted for $25 \%$ of all international sales outside the United States, yet despite having over 15,000 staff and physical inventory in the United Kingdom, the company paid little corporate tax in that country. See minutes from the Committee, available at www.publications.parliament.uk/pa/cm201213/cmselect/ cmpubacc/716/71605.htm.

10. See https://etradeforall.org/. As of April 2017, eTrade for All comprised: the African Development Bank, Consumers International, Enhanced Integrated Framework, E-Residency (Estonia), International Association of Prosecutors, International Civil Aviation Organization, International Islamic Trade Finance Corporation (on behalf of the Islamic Development Bank Group), International Telecommunication Union, International Trade Centre, Internet Society, Organisation for Economic Co-operation and Development, United Nations (UN) Conference on Trade and Development, UN Economic Commission for Africa, UN Economic Commission for Europe, UN Economic Commission for Latin America and the Caribbean, UN Economic and Social Commission for Asia and the Pacific, UN Economic and Social Commission for Western Asia, UN Social Impact Fund, Universal Postal Union, World Bank Group, World Customs Organization and World Trade Organization. The initiative is also supported by a number of private sector entities through the Business for eTrade Development Council, which comprises the following entities: Alibaba Group, African Alliance for E-commerce, Bangladesh Association of Software and Information Services, BiziSol, Burundishop, DHL, eBay, Ecommerce Association of Bangladesh, EMOTA, Etsy, Fedex, GfK, Google, Grasshopper, Huawei, Impact Enterprises, International Council of Swedish Industry, Kapruka, King and Spalding, Latin American Ecommerce Association, Nextrade Group, Paypal, Ringier Africa, TCS Holdings, Tradekey, UPS, vTex, World Information Technology and Services Alliance and the World SME Forum. 



\title{
CHAPTER 8
}

\section{CLOSING THE SMALL-BUSINESS AND GENDER GAP TO MAKE TRADE MORE INCLUSIVE}

Contributed by the International Trade Centre

\begin{abstract}
Over the past three decades, the connections that bind the economic activities of countries have grown and deepened at a remarkable rate. This chapter looks at the role of digital connectivity in linking small and medium enterprises, and in particular women-owned or managed enterprises, with customers and suppliers around the world. Firm-level data show that there is a significant connectivity gap between small and large firms, as well as for women-owned or managed firms. This chapter uses a selection of firmlevel data to shed light on the causes and effects of these gaps, and to assess their ultimate impact on trade. Checklists to help policymakers identify policy solutions are also provided.
\end{abstract}




\section{INTRODUCTION}

Over the past three decades, the connections that bind the economic activities of countries together have grown and deepened at a remarkable rate. From 1980 to 2007, many of these ties took the form of increasing trade and financial flows, with trade growing roughly tenfold over the period (McKinsey \& Company, 2016). However, after the 2008 financial crisis these flows stagnated, returning to their pre-crisis peak only in 2014. In part, this is the result of relatively weaker global economic performance as the large amounts of debt amassed during the boom years slowed growth (Égert, 2012).

Another reason for stagnating flows is structural: after two decades of production out-sourcing to lower-cost countries, supply chains have begun to shorten as manufacturers in key developing economies, such as China, increasingly source parts from domestic factories rather than from abroad (Constantinescu et al., 2015). In contrast, since the early 1990s cross-border data flows have exploded at an exponential rate, barely registering the effects of the financial crisis. It is estimated that between 2005 and 2014, global data flows increased by a factor of 45; projections indicate that they will grow another nine times in the next five years (McKinsey \& Company, 2016).

What does the changing nature of cross-border connectivity mean for firms, and in particular small and medium enterprises (SMEs), and women-owned enterprises trying to break into international markets? On the one hand, it opens up new opportunities, makes it easier for new players to build an international reputation, reduces market research costs and expands outreach. On the other hand, it may increase existing gaps between SMEs and large firms, or between women-owned and men-owned enterprises if the former are not able to use increased cross-border connectivity to their advantage.

The International Trade Centre's (ITC) model of competitiveness among firms rests on three pillars: the capacity to compete, to connect and to change. In this chapter we take a detailed look at the "capacity to connect" pillar, which includes linkages to customers and businesses, and the role these linkages play in promoting competitiveness and exports. We assess the characteristics that determine whether SMEs and women-owned businesses manage to take advantage of new connectivity-related technologies, both at the firm level, in the business ecosystem, and at the national level. Using firm-level data, the chapter provides new evidence regarding the capacity of SMEs and womenowned businesses to reap the benefits of increased global cross-border connectivity.

\section{CONNECTING SMES TO INTERNATIONAL MARKETS IS A DEVELOPMENT PRIORITY}

SMEs make up the bulk of the economic tissue of an economy. They account for approximately 50\% of GDP and 60-70\% of total employment worldwide. Furthermore, in developing countries they tend to employ the poorer, more vulnerable segments of society such as young people and women (ITC, 2015a). Thus, investing in SMEs is a long-term and smart strategy, with sustainable returns that multiply across societies, regions, and countries.

SMEs often drive economic growth and social progress because of the segments of the population they employ and because their small size enables them to quickly adapt to changing market conditions and seize new market opportunities. At the same time, SMEs are vulnerable to economic forces largely out of their control, and may not have the resources to survive the ups and downs of the business cycle as well as their larger counterparts.

To survive and thrive in today's globalised economy, SMEs must focus on boosting their competitiveness, an area where they lag behind larger firms. Many SMEs neither import inputs nor export products. However, those SMEs which do engage in cross-border trade tend to be more productive and pay higher wages than those which do not (Baghdadi, 2005). Getting SMEs "export ready" can help them connect to global markets, boost wages and thereby foster inclusive growth. 


\section{There is a connectivity gap between SMEs and large companies}

Although the Internet has a levelling effect on many of the determinants of competitiveness, SMEs are still required to take active steps to leverage these benefits - and not all SMEs do. As a result, there is a gap between small and large firms on key connectivity indicators. Figure 8.1 uses World Bank Enterprise Surveys data to show the gap between small and large firms in terms of having a business website (expressed in percentage points). The data clearly show that small firms are substantially less likely to have a business website, a basic requirement for connecting to potential customers and suppliers in today's increasingly digital economy.

\section{Figure 8.1. Relative proportions of small and large firms with a business website}

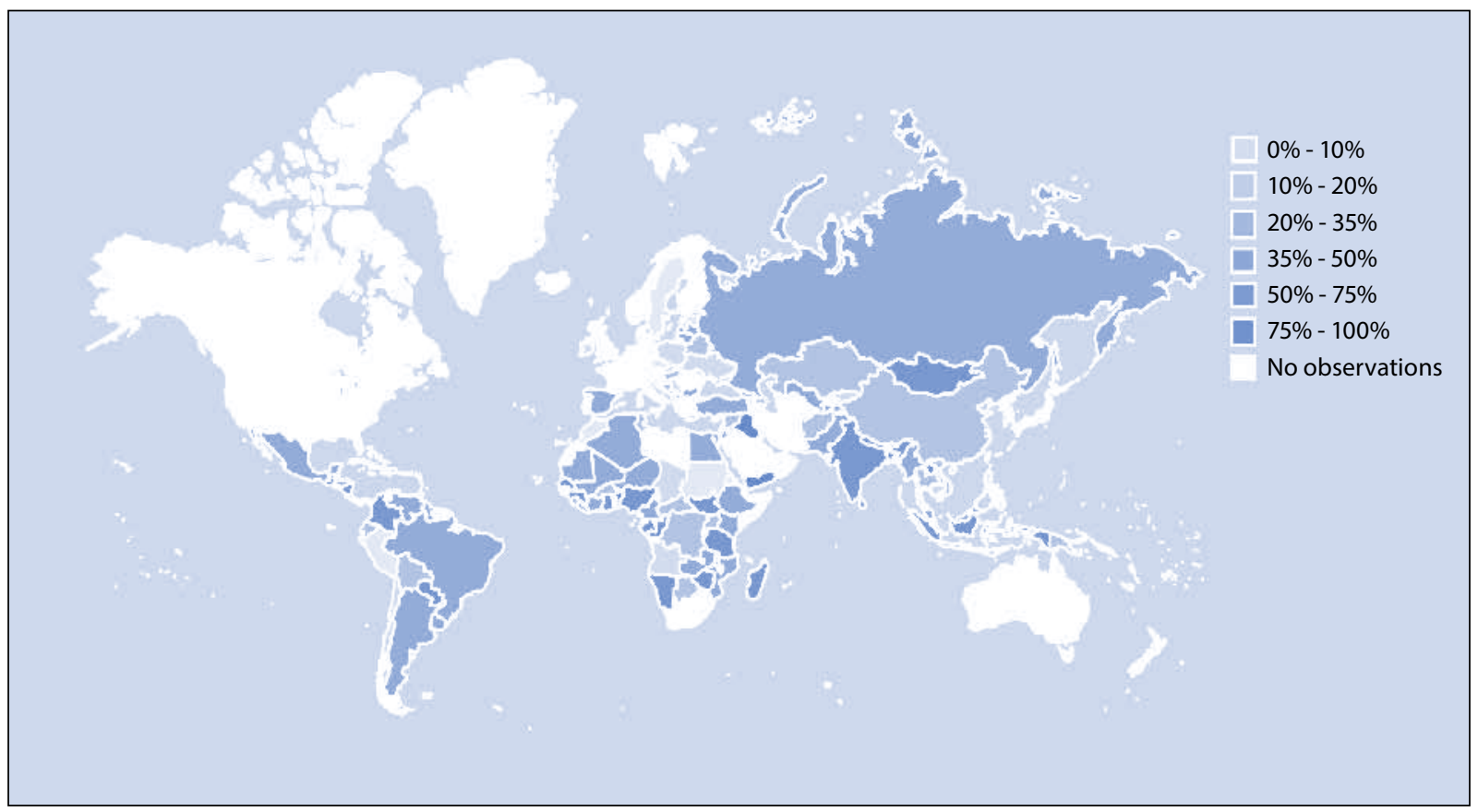

Note: Gaps are calculated on a percentage point basis. For example, if $40 \%$ of small firms have a business website compared to $60 \%$ of large firms, the gap is $20 \%$.

Source: ITC calculations based on World Bank (2016) Enterprise Surveys data, www.enterprisesurveys.org (accessed 17 January 2017).

Taking into account factors such as country, sector, firm age, and export status, large firms are ten times more likely than small firms to use email to communicate with buyers and suppliers, and eight times more likely to have a business website. Moreover, exporters are more than twice as likely to have a website as firms that do not export. While causality is difficult to prove either way (i.e. does having a website increase the chances that a firm that does not trade will become a trader, or is it simply that once firms begin to trade they establish a website?), the data do highlight the link between the probability of being an exporter and the simple fact of having a business website.

SMEs in the least developed countries (LDCs) perform particularly poorly when it comes to the capacity to connect. According to the ITC, small firms and medium-sized firms in the LDCs only score $22 \%$ and $54 \%$ of the e-connectivity score of large firms, respectively. This gap falls dramatically as the level of development rises, highlighting the challenge the LDCs face to catch up to the rest of the world (ITC, 2015a). 


\section{Connectivity gaps can persist even when ICT infrastructure is strengthened}

Ghana was one of the first African nations to establish widespread Internet infrastructure (Dholakia et al., 2004). This was possible thanks to the liberalisation of the telecommunications industry in the 1990s, and to the efforts of the Ghanaian government to build a knowledge-based economy. The National Information and Communication Technology for Accelerated Development policy, introduced in 2003, had the objective of engineering a socioeconomic development process led by information and communication technology (ICT) (Boateng et al, 2011).

\section{Figure 8.2. Use of ICT by firms in Ghana}

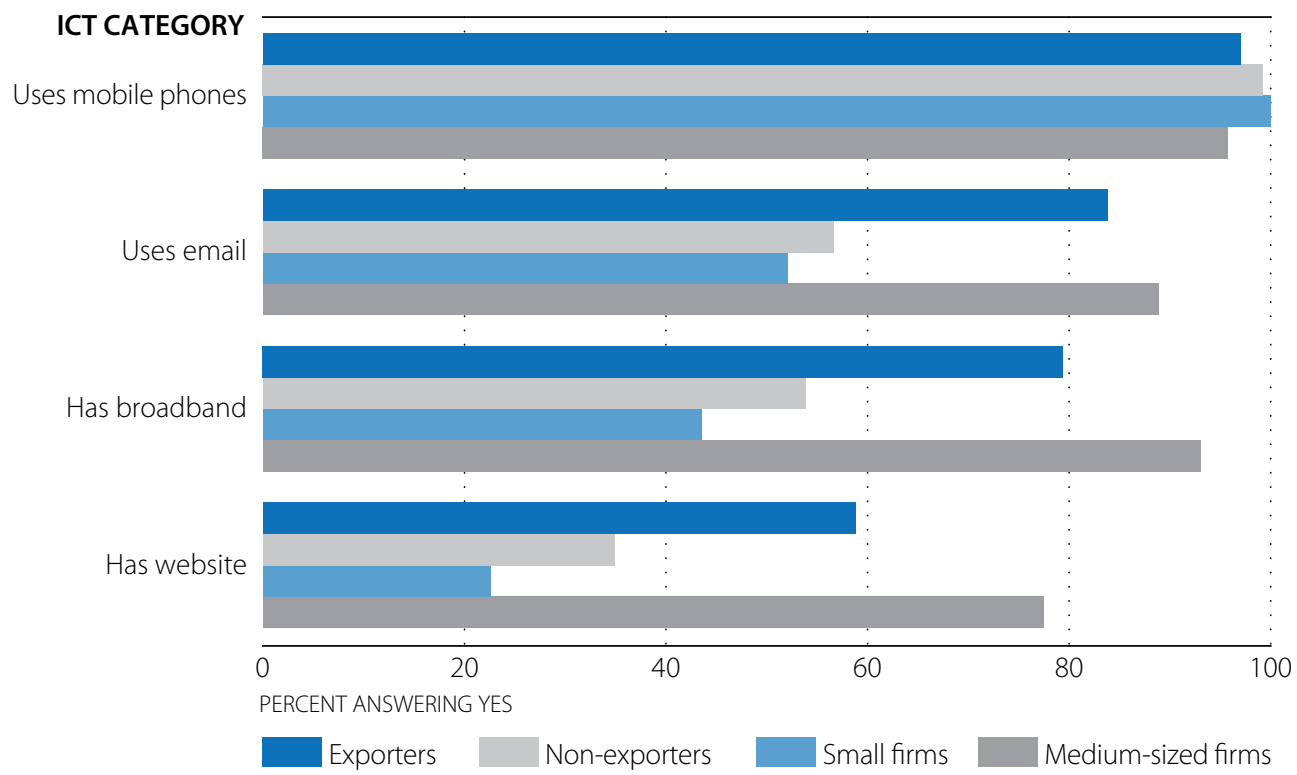

Source: SME Competitiveness in Ghana (2016), www.intracen.org/publication/SME-Competitiveness-in-Ghana.

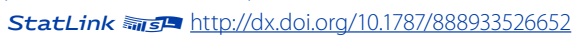

\section{Box 8.1. What can happen when SMEs leverage digital technologies?}

\section{Sara Maunda, groundnut farmer, Malawi}

In developing countries, the less well-off are often farmers growing one or two staple crops. Mobile Internet telephony can enable these farmers to bypass sometimes costly intermediaries, directly accessing weather forecasts, market pricing information and even features such as livestock tracking (USAID, 2012). When farmers have access to information about prices and stocks, the risks of under-selling, and of either over- or under-supplying their crops to a given market, are reduced. According to a World Trade Organization (WTO) study, the benefits farmers perceive from the use of mobile phones include access to agricultural information concerning stockpiles and prices, data visibility for value chain efficiency, and the ability to tap into new and existing markets (WTO, 2013).

Sara Maunda, a groundnut farmer in Malawi, reported that traders often offer prices per kilo of nuts far below market prices because the sellers are not aware of current market prices. Sara, however, is connected to a mobile platform called Esoko, which provides her with news about prices and stocks. As a result, she comes to the negotiation table with information that enables her to extract a much better price for her produce. Sara cites one example where she sold her produce for 24000 kwacha (USD 130) instead of 4500 kwacha (USD 27) thanks to the mobile website (USAID, 2012). 
Nevertheless, recent survey data reveal a persistent, large gap in connectivity between small and medium firms, amounting to a 34 percentage point difference across four indicators (Figure 8.2); the only indicator for which a gap does not exist is the use of mobile phones (ITC, 2016b). The same pattern is found between exporters and non-exporters. The indicator with the lowest average score for all firms was "having a website": only $43 \%$ of the firms in the sample had business websites. For SMEs, having a business website through which they can market, sell or simply provide up-to-date contact information can bring enormous advantages in terms of diversifying the client base.

Given the existence of this connectivity gap, what can smaller firms do to catch up to their larger counterparts? What is certain is that there is no one-size-fits-all solution for SMEs. Thanks to their small size, however, SMEs may be well placed to take advantage of changing business models that allow them to leapfrog the practices of larger, older firms, as long as the adoption costs of key new technologies are kept low. Box 8.1 and 8.2 offer two examples of SMEs using digital connectivity to boost their competitiveness.

\section{SMEs produce large amounts of valuable data}

Businesses, including SMEs, produce large amounts of valuable data that can be collected and analysed to generate insights on how to improve production methods or better anticipate the needs of customers (Box 8.2). SMEs with good ICT connections can benefit from advanced cloud-based analytical services which were previously only available to large firms with dedicated research teams. However, to benefit from these opportunities SMEs must integrate data collection into their business models. Teaching SMEs that the data they produce may be the key to their long term competitiveness is key.

\section{Box 8.2. The data a business generates may be its most valuable resource}

\section{Brodo Footwear, Indonesia}

Brodo Footwear is an Indonesian men's fashion company founded in 2010. In just four years, it has grown from a small company to one employing 100 people. It produces more than 4000 pairs of shoes per month and generates around USD 120000 in revenue per year.

In an interview, Yukka Harlanda, Brodo co-founder, explained, "The business evolved when we took it online, especially on social media" (Deloitte, 2015). Brodo increasingly uses Cloud tools and data analytics to focus on marketing and increase sales. These tools also help to gain a better understanding of inventory, customers and online traffic. Yukka continues, "The more we know about our customers, the more effective we can be in reaching them and satisfying their needs."

A recent McKinsey study, Online and upcoming: The Internet's impact on aspiring countries, focuses on a sample of emerging economies (Argentina, Hungary, Malaysia, Mexico, Morocco, Turkey, Viet Nam and Chinese Taipei). It reports that SMEs having access to broadband or mobile Internet and investing in digital technology experienced productivity gains of around 10\%; furthermore, their revenues increased by $6 \%$ and their costs fell by around 4\% (McKinsey \& Company, 2012). The gains experienced by SMEs spill over to the rest of the economy. Increases in Internet access are associated with greater market competitiveness, increased efficiency and benefits for consumers (McKinsey \& Company, 2012). 


\section{Policymakers can support small business digitalisation}

Policymakers have a specific role to play in supporting the digitalisation of SMEs. Below is a checklist of what they can do to help SMEs fully benefit from the opportunities of digitalisation in the coming decade (Table 8.1).

Table 8.1. A checklist for policymakers to support small-business digitalisation

\begin{tabular}{|c|c|}
\hline \multirow[t]{2}{*}{ 1. Promote the right skills } & $\checkmark$ Promote e-literacy in the population as a whole. \\
\hline & $\begin{array}{l}\checkmark \text { Ensure that a pool of highly educated programmers and analysts is available for firms } \\
\text { to help digitise their value chains and use the resulting data. }\end{array}$ \\
\hline \multirow[t]{2}{*}{$\begin{array}{l}\text { 2. Build awareness of the digital } \\
\text { value chain }\end{array}$} & $\begin{array}{l}\checkmark \text { Encourage firms to see internal processes as sources of data that can be digitised, } \\
\text { analysed, and used to update and develop new or existing processes. }\end{array}$ \\
\hline & $\checkmark$ Incentivise small firms to adopt digital solutions while small. \\
\hline \multicolumn{2}{|c|}{$\begin{aligned} \text { 3. Improve and update regulation } \checkmark & \text { Establish or update regulations relevant to online activities, such as online consumer } \\
& \text { protection and e-signatures. }\end{aligned}$} \\
\hline & $\checkmark$ Promote competition in ICT sectors to increase efficiency and lower costs. \\
\hline Build up digital infrastructure & $\begin{array}{l}\checkmark \text { Ensure good access to critical connectivity-related technologies such as the Internet, } \\
\text { mobile networks and location-tracking services. }\end{array}$ \\
\hline
\end{tabular}

Source: ITC (2016a), Bringing SMEs onto the e-Commerce Highway,

http://www.intracen.org/publication/Bringing-SMEs-onto-the-e-Commerce-Highway/

\section{E-commerce is fundamental for business competitiveness}

E-commerce is transforming the global business landscape at an unprecedented speed. The first e-commerce transaction on a commercial website was recorded only 21 years ago, in 1995; it involved the sale of a broken laser pointer on AuctionWeb, the predecessor of eBay, for USD 14.83 (Waxman, 2015). In 2013, global business-to-consumer (B2C) e-commerce sales were valued at USD 1.2 trillion (UNCTAD, 2015a); they are estimated to reach USD 1.92 trillion by the end of 2016 (Statista, n.d.). Billions of transactions are completed each day on the Internet and e-commerce is redefining business competitiveness, particularly for SMEs.

The cost of trading internationally has fallen and consumers increasingly look beyond national borders for the best online deals. Cross-border e-commerce involves goods and services delivered from a supplier in one country to a consumer in another country. According to a recent survey of 24 countries published in the Nielsen Global Connected Commerce Report (2016), more than half of the respondents (57\%) said they had purchased from an online retailer outside their country's border in the past six months. In the area of services trade, cross-border e-commerce also brings new opportunities for SMEs. Online software and app markets, such as App Store and Google Play, help deliver digital products from SME developers to billions of smart devices.

\section{Business-to-consumer e-commerce offers the greatest opportunities}

Cross-border e-commerce comes in different forms and shapes, involving many types of players, deals and procedures. Transactions may be between enterprises (business-to-business, B2B), between a business and a consumer (businessto-consumer, B2C), or between two individual consumers (consumer-to-consumer, C2C). B2B transactions account for the largest share of global cross-border e-commerce in value terms, exceeding USD 15 trillion in 2013. Cross-border B2C e-commerce has a much smaller global share, at USD 1.2 trillion in 2013. However, B2C trade is the fastest-growing section of international e-commerce and offers the greatest opportunities for SMEs, which represent the majority of the suppliers in cross-border B2C e-commerce. 
B2B and B2C cross-border e-commerce also differ in nature: $\mathrm{B} 2 \mathrm{~B}$, in most instances, is still made up of traditional international trade between import and export businesses that are connected by the Internet. Cross-border B2C e-commerce is potentially redefining international trade through its entirely new process chain, which links sellers directly with buyers.

\section{Competitiveness involves many steps along the e-commerce chain}

Cross-border e-commerce is conducted following a relatively standardised process chain, and many detailed elements along this chain need to be in place for SMEs to succeed (Figure 8.3).

\section{Figure 8.3. The e-commerce process chain}

$\begin{gathered}\text { ESTABLISHING } \\ \text { AN ONLINE BUSINESS }\end{gathered}$
$\begin{gathered}\text { INTERNATIONAL } \\ \text { E-PAYMENT }\end{gathered}$
http://www.intracen.org/publication/Bringing-SMEs-onto-the-e-Commerce-Highway/

\section{Establishing an online business requires a degree of online readiness}

Businesses do not need world-class programmers to build an online presence, but they do need to understand how web technologies work. Basic building blocks, such as setting up a website and using the communication tools provided by online platforms, are essential to get an online store up and running. Programming, graphic design and photo editing skills are useful for the development of a more sophisticated website, but these skills can also be outsourced to specialists. Table 8.2 outlines some of the most important factors that determine whether firms are ready to "go online".

\section{Table 8.2. A checklist for establishing online businesses}

\begin{tabular}{lll} 
Firm capabilities & $\checkmark$ Device to connect to Internet. & $\checkmark$ Secure online presence (e.g. SSL) \\
& $\checkmark$ Technical knowledge and skills & $\checkmark$ Language skills \\
& $\checkmark$ Business knowledge and skills & \\
\hline Business ecosystem & $\checkmark$ Affordable access to Internet & $\checkmark$ Access to a skilled labour market \\
& $\checkmark$ Access to registration as a vendor \\
& on online e-commerce platforms
\end{tabular}

Source: ITC (2016a), Bringing SMEs onto the e-Commerce Highway,

http://www.intracen.org/publication/Bringing-SMEs-onto-the-e-Commerce-Highway/

Online security, perhaps the most critical element of e-commerce, is defined as the protection of e-commerce assets from unauthorised access, use, alteration or destruction. Consumers need to know that when they conduct a transaction online, they will enjoy the same legal protection as they do with traditional businesses. It is therefore necessary for SMEs to apply a set of open, industry-led, technical standards that facilitate the interconnection and interoperability of businesses over networks (for instance, Secure Sockets Layer or SSL).

In general, to take a business online an SME may adopt one of four business models:

- Social media presence: Brick-and-mortar businesses that use social media platforms for real-time promotional purposes.

- Passive online presence: Brick-and-mortar businesses that design a website for passive promotional purposes rather than to engage in online commercial activity. 
- Active online presence: Bricks-and-clicks businesses that have both an offline and an online presence, enabling consumers to purchase goods or services online and offline.

- Pure-play online presence: Businesses that operate exclusively online, from giant e-commerce platforms (e.g. Amazon and eBay), search engines and Internet service providers, to SMEs that solely supply their services online, e.g. an app developer.

Each model has its advantages and shortfalls. For each SME, deciding which model works best depends on its knowledge of the market, as well as the resources available to invest in one or several of the four business models. Many SMEs in developing countries opt first for a social media presence, as the entry costs are low and the skills required to manage such an operation may be acquired through private use of these platforms. For instance, a recently conducted survey among female owned enterprises in Indonesia reveals that small firms are twice as likely to use social media networks to promote their products compared to more traditional forms of advertising (Figure 8.4).

\section{Figure 8.4. Advertising via social networks and traditional media by small and medium firms}

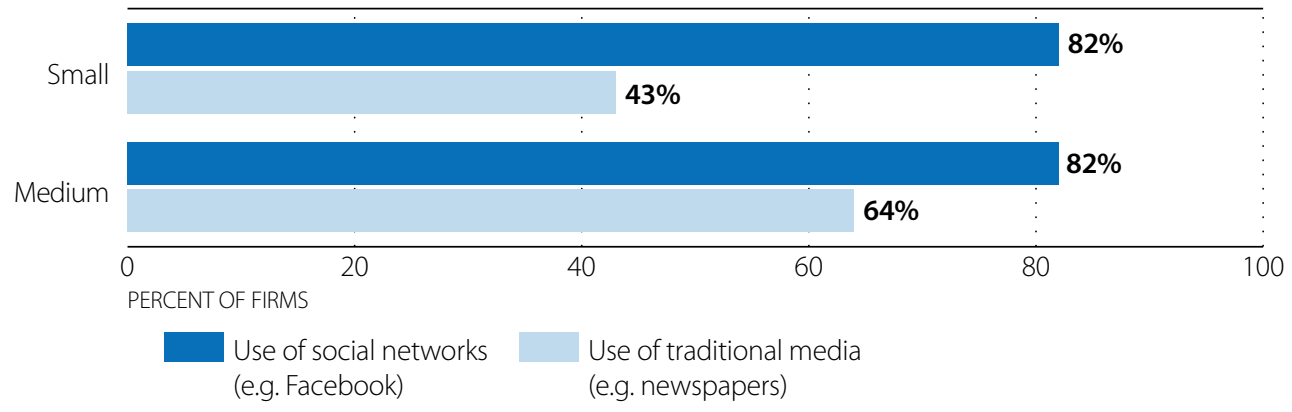

Source: SheTrades Initiative: Economic Empowerment of Women in the Indian Ocean Rim Association Countries http://www.intracen.org/itc/projects/women-and-trade/ (accessed 11 May 2017)

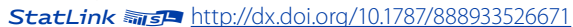

\section{International e-payment systems are vital to competitiveness}

E-payments are defined as payments that are initiated, processed and received electronically. Economic and behavioural changes are leading to a rise in non-cash payments, including those made online. Access to competitive payment solutions is vital for all forms of e-commerce; unlike bricks-and-mortar companies, online retailers often require payments to be made before a sale is completed, which underlines the trust consumers must have in e-payment systems. Table 8.3 outlines some of the most important factors for promoting the use of e-payment systems within firms.

\section{Table 8.3. A checklist for promoting international e-payment}

\begin{tabular}{ll} 
Firm capabilities & $\checkmark$ Bank account and online banking \\
& $\checkmark$ Sign-up for encryption solutions \\
& $\checkmark$ Knowledge of e-payment solutions \\
\hline Business ecosystem & $\checkmark$ Availability of third-party e-payment services provider \\
& $\checkmark$ Links between third-party e-payment services provider and local banks to \\
& enable local withdrawals
\end{tabular}

Source: ITC (2016a), Bringing SMEs onto the e-Commerce Highway,

http://www.intracen.org/publication/Bringing-SMEs-onto-the-e-Commerce-Highway/ 
Payment systems for online purchases can be classified mainly as account-based and electronic currency systems. Account-based payment systems allow payment through an existing personalised account, which can be executed using credit cards, debit cards, mediators such as PayPal, mobile/landline phones or online banking. Electronic currency systems include smart cards (mainly used to pay small amounts within organisations) and online cash systems (software-only electronic money instruments or prepaid cards).

E-payment offers considerable opportunities for SMEs to expand their customer base, launch new products and rationalise their business (Box 8.3). Adoption of e-payments is likely to increase the global reach of SMEs, improve their access to information exchange and management, and reduce their transaction costs, providing substantial benefits through improved efficiencies, and, ultimately, increased revenues.

\section{Box 8.3. Made in Morocco: Linking SMEs to the world of e-commerce}

The ITC has developed a comprehensive package of technical and advisory services, collectively referred to as "e-Solutions", to help firms better understand e-commerce and overcome barriers to selling goods and services over the Internet.

The full suite of services was put to the test in Morocco in 2015. In January of that year, a group of Moroccan SMEs that had been using e-commerce to sell products domestically formed a cooperative, called Made in Morocco. Their goal was to export their wares, ranging from olive oil and cosmetics to books and music. In May, the firms asked the ITC to help them boost their access to-and competitiveness in—foreign markets.

The ITC took a multi-pronged approach. On the payments side they helped to establish a formal commercial presence in Europe, the United States and the United Arab Emirates to enable the co-operative to handle import duties and domestic taxes. Thanks to these structures, the co-operative's members can process credit card payments and repatriate earnings in a cost-effective and transparent manner. The local presence also helps to counter customer unease with unfamiliar banks, reassuring them that they will benefit fully from local consumer protection laws, and makes it easy for unsatisfied customers to return purchases.

On the logistics side, the ITC brokered storage, distribution and transportation deals with international partners, including $\mathrm{DHL}$, to facilitate competitive shipping times and costs, improve knowhow about dealing with border procedures, and optimise transport routes. This made it possible for Made in Morocco firms to ship their goods to e-fulfilment warehouses where the products can be swiftly repackaged and dispatched when orders arrive.

Since the ITC initiated its collaboration with Made in Morocco, several members of the co-operative have begun to sell goods - such as couscous, spices, and home decoration items - in Europe. The co-operative is growing and now comprises over 400 SMEs. Made in Morocco has sharply increased export sales and has tripled its transformation rate (the share of website visitors who become customers).

Source: OECD-WTO aid-for-trade monitoring exercise (2017), Public sector case story 32, www.oecd.org/aidfortrade/casestories/ casestories-2017/CS-32-Made-in-Morocco-case-study-on-linking-SMEs-to-the-world-of-e-commerce.pdf

One barrier, however, is the lower likelihood of SMEs to have a bank account. Figure 8.5 shows that between medium and large firms, the differences in the fraction of firms that have a bank account are not huge. For small firms, however, there is a much stronger tendency to be unbanked. Mobile money offers a route for unbanked SMEs to gain access to the services that medium and large firms benefit from. 
Figure 8.5. Many small firms in poor countries do not have bank accounts

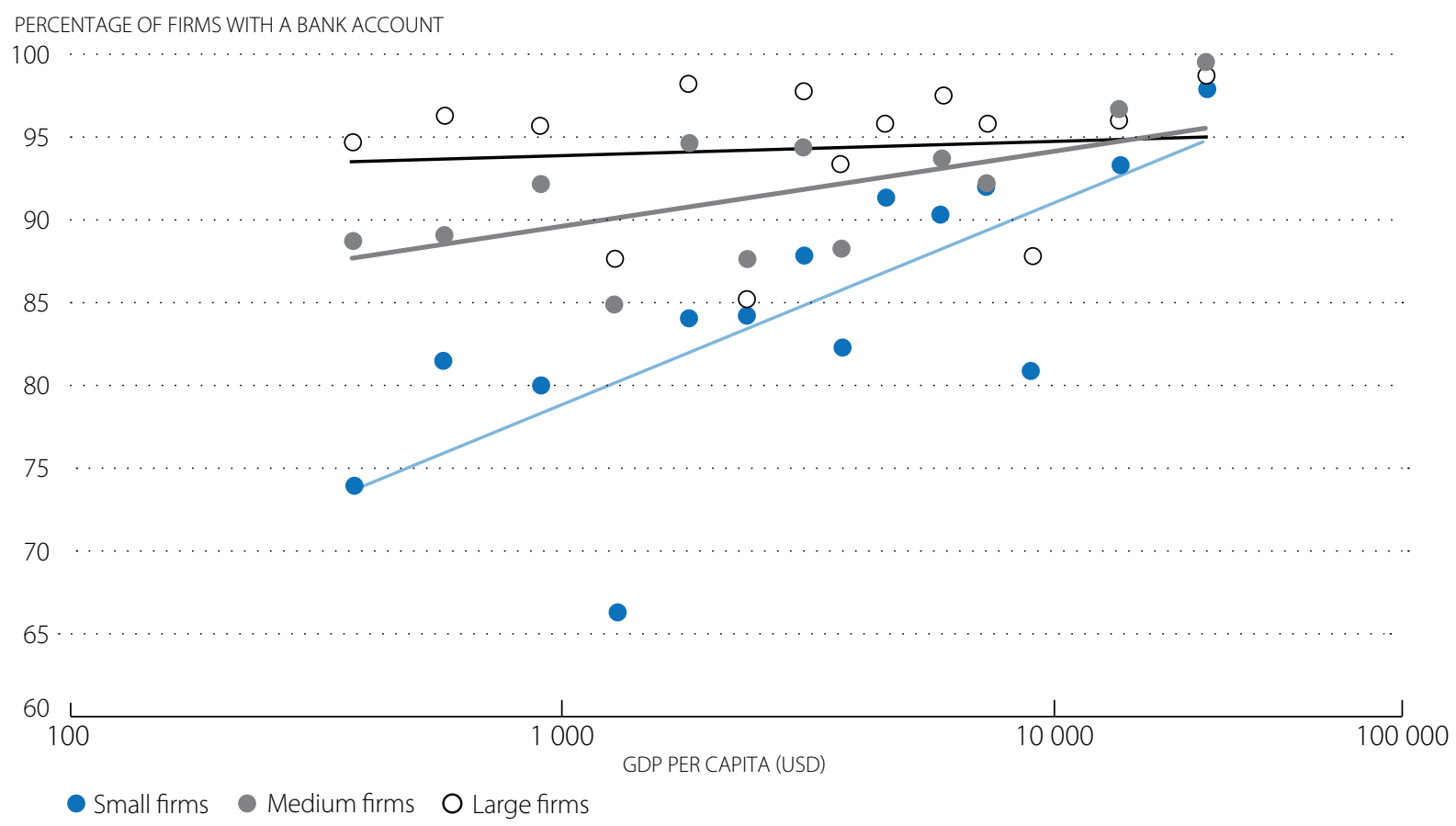

Note: Averages calculated using data from 140 countries.

Source: ITC calculations based on data from the World Bank (2016) Enterprise Surveys database, www.enterprisesurveys.ord (accessed 17 January 2017).

Credit cards account for the lion's share of retail e-commerce settlements. Still, usage patterns vary considerably, with most of the developed countries relying on accounts-based systems. Table 8.4 shows that credit cards are the dominant mode of e-payments in North America and Europe, with considerably more variation in the developing world. While mobile payments accounted for only $1 \%$ of the total value of e-payments in 2012, they are more important in several African countries "due to high degrees of financial exclusion, limited availability of fixed lines, cost of fixed lines and cost of the card infrastructure" (UNCTAD, 2015b). Nonetheless, in 2012 cash on delivery was the dominant mode of payment in Africa and the Middle East.

Despite the benefits associated with e-payments, a majority of SMEs have been slow in adopting the use of e-payment systems. In the poorer parts of Indian cities, for example, businesses perceive cash as a more convenient and safer mode of payment. In Ghana, problems with mobile money industries include connectivity, security, scalability, interoperability, accessibility, and agent training and representation (IMTFI, n.d.). In some cases, slow adoption is associated with implementation or regulatory constraints, or with the fact that e-payment providers focused initially on unsophisticated microfinance institutions as partners. Limited trust in online transactions is one of the reasons for SMEs' limited use of e-commerce.

A study of the adoption of e-payment solutions by hotels in the town of Kissi, Kenya concludes that the main factors influencing the adoption of e-payments are the entrepreneurs' background and the ease of use of electronic tools. According to the study, the adoption of e-payments by SMEs in the hotel sector is driven by the speed and convenience of e-payments, and the low cost of storage facilities. Speed and ease of use also are likely to improve the quality of service and save time, both of which would further encourage the use of e-payments (Stuart and Cohen, 2011; Mas and Ngweno, 2012). 
Table 8.4. Value of e-transactions by payment method and region, 2012

\begin{tabular}{lcccccc}
\hline Region & Credit card & E-wallet & Direct debit & Cash on delivery & Bank transfer & Other \\
\hline United States and Canada & $71 \%$ & $18 \%$ & $2 \%$ & $1 \%$ & $1 \%$ & $7 \%$ \\
\hline Europe & $59 \%$ & $13 \%$ & $5 \%$ & $5 \%$ & $8 \%$ & $11 \%$ \\
\hline Latin America & $47 \%$ & $10 \%$ & $4 \%$ & $8 \%$ & $13 \%$ & $18 \%$ \\
\hline Africa and Middle East & $34 \%$ & $5 \%$ & $0 \%$ & $48 \%$ & $3 \%$ & $10 \%$ \\
\hline Asia and Oceania & $37 \%$ & $23 \%$ & $1 \%$ & $11 \%$ & $14 \%$ & $14 \%$ \\
\hline World & $57 \%$ & $17 \%$ & $2 \%$ & $5 \%$ & $7 \%$ & $12 \%$ \\
\hline
\end{tabular}

Source: WorldPay (2014). Your global guide to alternative payments, Second edition, http://www.worldpay.com/global

\section{Cross-border delivery has diverse phases and forms}

The process by which goods are delivered to customers across borders can have a major impact on:

- the final price of the product or service (because of transport, delivery, custom duties and other costs)

- customer satisfaction (because of delivery time as well as product integrity)

- the reputation of cross-border e-commerce transactions (in terms of cost efficiency, time, and quality

of the product), which affects customers' willingness to consider buying online versus using

traditional methods.

Cross-border delivery (usually associated with the transport of goods by sea, road, rail or air) comprises a wide variety of distinctive but strongly interconnected phases, including payment of duties when a border is crossed, until final consignment of the product or service to the end user. Table 8.5 outlines some of the factors firms should consider when setting up their cross-border delivery networks.

\section{Table 8.5. A checklist for facilitating cross-border delivery}

\begin{tabular}{ll} 
Firm capabilities & $\checkmark$ Effective warehouse organisation \\
& $\checkmark$ Secure packaging for delivery of goods \\
& $\checkmark$ Capacity to handle surges in sales during peak periods \\
\hline Business ecosystem & $\checkmark$ Access to postal and express delivery services with tracking ability \\
& $\checkmark$ Access to warehouses and delivery services at destination
\end{tabular}

Source: ITC (2016a), Bringing SMEs onto the e-Commerce Highway,

http://www.intracen.org/publication/Bringing-SMEs-onto-the-e-Commerce-Highway/

\section{Delivering goods across borders}

To understand how the delivery of goods occurs, in practice, when an SME engages in cross-border e-commerce, it is necessary to first describe the type of goods that are most commonly sold via electronic means. Indeed, not all goods are suitable for e-commerce, and even less for cross-border e-commerce. Online tradable goods tend to share certain characteristics:

Size: The larger the good, the more costly and complicated the delivery. From a cost-efficiency perspective, businesses that sell small- or medium-sized goods are a better fit for e-commerce than companies that specialise in large goods. 
- Price: Goods that are traded online tend to be offered at more competitive prices than those sold in physical establishments, as there are no costs related to maintaining a physical presence. Although shipping costs can add significantly to the final price paid by consumers, they are often not borne by the supplier , and high shipping costs are the result of the consumers' location, in remote areas or in different countries.

- Specificity: The goods most commonly traded online and across borders are typical of, or specific to, a certain location, and are generally not available everywhere. For small manufacturers of traditional African handicrafts, for example, the Internet provides an opportunity to access both the African diaspora and foreign consumers more generally. This is the case of eShopAfrica (Ghana), SkinnylaMinx (South Africa) and Botswana Craft (Botswana), e-commerce firms specialised in selling African arts and crafts primarily to North American and European markets.

\section{Delivering services across borders}

There are differences between the supply of services and goods that have major implications for cross-border e-commerce. Services are non-storable and non-perishable, which means that supply and consumption generally occur simultaneously (for example, a hairdresser giving a haircut). It also means that no warehousing system is required for services supplied online, either domestically or cross-border. Furthermore, services are intangible and invisiblethey have no specific form that can be touched or seen (for example, a person cannot see or touch a data processing service provided by a computer). This is of great significance for electronic cross-border supply of services, as they are often not subject to border measures such as customs duties or procedures.

\section{AFTERSALES ARE AN IMPORTANT PHASE OF E-COMMERCE}

The aftersales phase of the e-commerce process includes all the activities that take place after buyers have made their payment online and sellers have delivered the product or service to their clients. The significance of this phase should not be underestimated, as it provides the basis for establishing a lasting relationship between SMEs and customers. Table 8.6 contains a list of factors that need to be addressed in order to provide aftersales services that satisfy customers.

\section{Table 8.6. A checklist for aftersales}

Firm capabilities $\checkmark$ Effective customer feedback mechanism and customer relations management

$\checkmark$ Return or cancellation policies

$\checkmark$ Provision of sufficient information to enable consumers to make informed choices, including information on available forms of redress

\section{Business ecosystem}

$\checkmark$ Availability of dispute settlement procedures

$\checkmark$ Mechanisms for recognising the validity of transaction-related records, including delivery records, chat records with salespersons, etc.

Source: ITC (2016a), Bringing SMEs onto the e-Commerce Highway,

http://www.intracen.org/publication/Bringing-SMEs-onto-the-e-Commerce-Highway/

Customers play a key role in aftersales, in two main phases:

- consumer evaluation of the product or service delivered to them, which can serve to inform subsequent customers as to the quality, functionality and cost of a purchase

- consumer assessment of, and potential recourse to, all available tools and instruments for redress in case the product or service does not meet their expectations. 
Once a product or service is delivered, the end user is faced with some questions: Does the product resemble the one presented on the supplier's website? Does it perform as indicated on the website? Was the product/service of good quality? Does it meet expectations as to its functionality? Were there additional costs on delivery (e.g. customs duties) that were not included in the information provided by the supplier about the final price of the online transaction?

SMEs engaging in e-commerce that want to be competitive internationally_and to be perceived by consumers as better, more reliable and trustworthy than others—-should:

- Give consumers clear, transparent and correct information about the goods or services supplied, their pricing, and all phases of the transaction, from payment to delivery.

- Ensure secure and reliable payments via the Internet.

- Deliver goods or services within a reasonable time frame.

- Provide adequate customer support.

\section{Policymakers can help by ensuring a conducive environment for e-commerce}

Making the transition to e-commerce can be demanding for SMEs. In some cases, small businesses lack the technical capabilities required; in other cases, the national environment holds them back. Many factors are critical to the efficient functioning of e-commerce, and most of these are beyond the control of SMEs.

Table 8.7. An e-commerce checklist for policymakers

\begin{tabular}{|c|c|}
\hline $\begin{array}{l}\text { 1. Establishing an } \\
\text { online business }\end{array}$ & $\begin{array}{l}\checkmark \text { Simple business registration process with the local authorities } \\
\checkmark \text { Policies and easy practices for intellectual property registration and infringement resolution } \\
\checkmark \text { Solid ICT and electricity infrastructure } \\
\checkmark \text { Regulations governing e-signatures and e-contracts } \\
\checkmark \text { National strategies for e-commerce growth }\end{array}$ \\
\hline $\begin{array}{l}\text { 2. International } \\
\text { e-payment }\end{array}$ & $\begin{array}{l}\checkmark \text { Functional financial market in line with international standards } \\
\checkmark \text { Foreign exchange system allowing easy convertibility of currency; regulations on the free } \\
\text { flow of currency } \\
\checkmark \text { Adoption of internationally recognised standards } \\
\checkmark \text { Regulations for preventing online fraud and combating cybercrime }\end{array}$ \\
\hline 3. Cross-border delivery & $\begin{array}{l}\checkmark \text { Transparent cross-border customs procedures and rules on the application of duties and taxes } \\
\text { for e-commerce } \\
\checkmark \text { Simple customs procedures and expedited customs clearance for small parcels } \\
\checkmark \text { De minimis threshold for import duty exemption to reduce the burden on SMEs and customs } \\
\text { authorities } \\
\checkmark \text { Mechanisms to ensure freedom and security of cross-border data flows } \\
\checkmark \text { Efficient physical and digital connectivity infrastructure } \\
\checkmark \text { Modernised national postal services to increase efficiency of delivery }\end{array}$ \\
\hline 4. Aftersales & $\begin{array}{l}\checkmark \text { Consumer rights policies and their enforcement } \\
\checkmark \text { Adequate infrastructure for implementing and monitoring consumer protection policies } \\
\checkmark \text { Appropriate policies for ensuring adherence by firms to national/international standards on } \\
\quad \text { consumer protection } \\
\checkmark \text { National initiatives for developing effective online dispute settlement schemes } \\
\checkmark \text { Elimination of duties on returned products }\end{array}$ \\
\hline
\end{tabular}

Source: ITC (2016a), Bringing SMEs onto the e-Commerce Highway,

http://www.intracen.org/publication/Bringing-SMEs-onto-the-e-Commerce-Highway/ 
The WTO Trade Facilitation Agreement, which entered into force in February 2017 after reaching the threshold of acceptance by two-thirds of WTO members, can support cross-border delivery. The agreement requests member countries that do not have a de minimis threshold to adopt one. However, due to the increased flow of low-value goods across borders, driven primarily by e-commerce sales, some countries have begun to lower their de minimis thresholds.

Yet, the establishment of de minimis thresholds is only one determinant of ease of cross-border delivery; at the same time, cross-border delivery is only one of the four components of the e-commerce process chain discussed here. Other policy factors across the e-commerce process chain that should be prioritised by national policy makers to encourage e-commerce growth are described in Table 8.7 (ITC, 2016a).

\section{ONLINE TOOLS CAN HELP WOMEN-OWNED BUSINESSES CONNECT TO INTERNATIONAL MARKETS}

There is a voluminous body of literature that supports the idea that empowering women in both economic and social contexts leads to stronger and more prosperous societies (Kabeer, 2012; Klasen, 2002; ITC, 2014; ITC 2015c). Moreover, a review of the evidence carried out by Kabeer (2012) concludes that although gender equality strongly promotes economic growth, the opposite is not necessarily true- that economic growth automatically promotes gender equality. Therefore, an agenda focusing explicitly on women's economic empowerment may be the best approach to tackle today's multiple and varied gender gaps.

One of the areas where the gender gap is greatest is in the ownership or management of enterprises. In terms of pure numbers, firms are much more likely to be owned or managed by men than women. In a survey of approximately 19000 firms across 99 developing countries, only 36\% were partially or wholly owned by women (Davies, 2015). This percentage drops to $15 \%$ amongst the subset of exporters. This is a problem, as women's participation in ownership or management is correlated with a number of key development outcomes, such as rises in GDP per capita (Amin, 2014).

Interestingly, there is little evidence for the widespread belief that women-owned or managed firms are less productive than their men-owned and managed counterparts. Once exporting is added to the picture, the results change somewhat. For women-owned firms, the exporter productivity premium (EPP)—the difference in productivity between exporters and non-exporters is roughly half the size of what it is for men-owned firms. This suggests that when women-owned firms face the same barriers to trade as men-owned firms, they find them more costly to overcome. Furthermore, the effect gets stronger as firm size increases, keeping the exporting firms owned or managed by women small (Davies, 2015).

At a first pass, it may not seem obvious why improved connectivity may have any effect on these factors; however, electronic systems that remove face-to-face interactions or mask the gender of the relevant parties can limit the opportunity for gender discrimination. For example, when trying to comply with standards and regulations - a process which often involves multiple face-to-face interactions-micro and small firms managed by women reported "discriminating behaviour of officials" as a greater problem compared to men-managed firms (ITC 2016c).

Connectivity also includes the extent to which enterprises connect with buyers and suppliers. The following section explores the ways in which women-owned or managed enterprises connect to regional and global markets.

\section{Is there a gender-based connectivity gap?}

To determine whether there is a gender-based connectivity gap at the firm level, the use of emails to communicate with buyers and suppliers by women-managed firms was compared to that of men-managed firms, using the World Bank's Enterprise Survey dataset (World Bank, 2016). The use of emails can be interpreted as a proxy for accessing the Internet. Taking into account factors such as country, sector, export status, firm size, year of survey and firm age, the analysis showed that women-managed firms are about 12\% less likely to use email than men managed firms. 
Why would women-managed firms be less likely to use the Internet? The reasons are surely varied, but according to Intel's publication Women and the Web (2012), almost 40\% of women surveyed cited lack of familiarity or comfort with technology as a reason. This is largely a reflection of the general disadvantages women often face at the early stages of education, receiving limited or no digital training. Surveys indicate that in developing countries, women are $8 \%$ less likely to have access to the Internet than men (Box 8.4). In Arab States, this percentage increases to 9\% (Table 8.8).

\section{Box 8.4. She Will Connect: Reaching over 1.3 million women in Africa}

Through the She Will Connect program, Intel is investing in closing gender gaps in technology access and accelerating career paths by empowering more girls and women to use technology, connecting them to economic and social opportunities, and inspiring them to become future innovators. The focus is on three areas:

1. Digital literacy skills: Intel is collaborating with NGOs across Kenya, Nigeria and South Africa to integrate digital literacy into their gender and development programmes targeting women and girls. Participants learn how to operate computers while gaining experience with the Internet, email, social media, online safety, and applications for word processing, spreadsheets and multimedia, among others. The objective is to give them the skills they need to succeed in a knowledge-based economy.

2. Peer networks and gender-relevant content: Research shows that the Internet can empower women by providing opportunities to connect with people outside of their communities, reinforcing digital literacy skills and increasing the continued use of ICTs. Content tailored for women and peer networks are being put in place to support this, in co-operation with gender-relevant partners such as World Pulse and UN Women.

3. Income-generation opportunities: Face-to-face training prepares women for broader opportunities. Partnerships with organisations that provide training in ICT as well as job placement, such as the African Centre for Women, enable women to access opportunities that can improve their income. She Will Connect is directly linking 10000 women with income generation opportunities and training programs to ensure lasting community-wide impact. Graduates from the program move on to online work opportunities that enable them to apply their newly acquired digital skills.

By the end of 2016, She Will Connect reached over 1.3 million women in Africa, approximately 200000 of them through face-to-face training.

Source: OECD-WTO aid-for-trade monitoring exercise (2017), Private sector case story 18, www.oecd.org/aidfortrade/casestories/casestories-2017/CS-18-Intel-She-Will-Connect.pdf

\section{Table 8.8. The Internet gender gap across regions}

Africa

Arab States
Asia and Pacific
Americas

Americas

\section{Commonwealth of Independent States}

\begin{tabular}{lcccccc}
\hline $\begin{array}{l}\text { Internet penetration } \\
\text { for men }\end{array}$ & $28 \%$ & $46 \%$ & $48 \%$ & $66 \%$ & $69 \%$ & $82 \%$ \\
\hline $\begin{array}{l}\text { Internet penetration } \\
\text { for women }\end{array}$ & $22 \%$ & $37 \%$ & $40 \%$ & $64 \%$ & $65 \%$ & $76 \%$ \\
\hline Gender gap & $6 \%$ & $9 \%$ & $8 \%$ & $2 \%$ & $4 \%$ & $6 \%$ \\
\hline
\end{tabular}

World gap

$6 \%$

Source: ITU (2016) ICT Facts and Figures 
Internet access gives women a voice, creates education opportunities, and facilitates strong networks (Figure 8.6). Indeed, studies indicate that countries with a higher proportion of women in primary, secondary and tertiary education also have higher numbers of top women managers (Amin and Islam, 2014). The advantages of education, in turn, determine what skills women bring to their businesses when they become managers, as well as their willingness to exploit international business opportunities.

Figure 8.6. Beneficial outcomes that can result from women and girls having online access
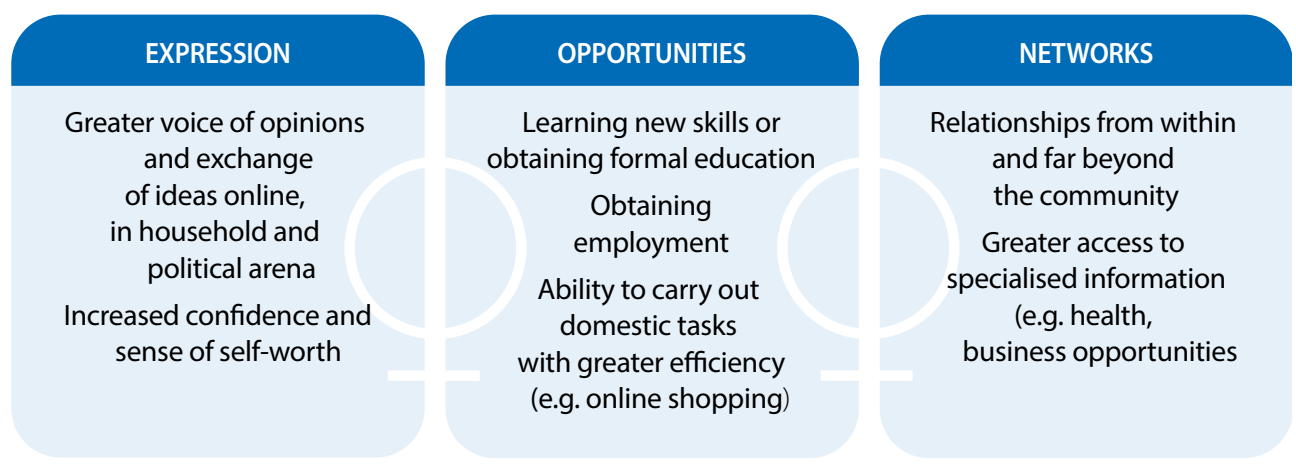

Source: Adapted from Intel (2012), Women and the Web.

\section{Digital solutions limiting face-to-face interactions can help}

To the extent that face-to-face interactions present a disadvantage for women-led companies, digital solutions that limit the opportunity for discrimination should benefit women-owned or managed firms. It is a known fact that women face greater barriers to trade at the border, for example. The obstacles range from having to pay larger bribes to genderbased violence (Brenton et al., 2011; Blackden et al., 2010; Morris and Saul, 2000; Ndiaye , 2010). In Liberia, 37\% of crossborder women traders were subjected to sexual-based violence and 15\% reported being forced to have sex (UNECA et al., 2010). Digital solutions that remove the need for face-to-face interactions when trading at the border or requesting an export licence at a government agency, for example, can help reduce the negative incentives that women running a business face.

The "single window", an electronic system designed as part of the 2013 WTO Trade Facilitation Agreement, enables traders to submit regulatory documents and certificates electronically, which reduces the need to visit multiple authorities for exporting a product (WTO, 2017). Systems like this may support women-owned enterprises wishing to enter international markets.

In the same vein, reducing the number of middle-men on the path to exporting a product may have greater benefits for women-owned or managed firms, as the number of face-to-face interactions is likely to be lower. There are a number of e-platforms dedicated to directly connecting women enterprises with international buyers. One such platform is the ITC's SheTrades app (Box 8.5). SheTrades allows thousands of women to connect in real time to buyers, enabling them to offer their products and services in a global market. When women-led businesses connect directly to buyers, they also retain a greater share of the profit they generate, thereby reducing the EPP gap. 
Box 8.5. SheTrades: Connecting one million women to market by 2020

The SheTrades initiative provides women entrepreneurs around the world with a unique network and platform to connect to markets. Through the SheTrades app, they are able to share information about their companies, increase visibility, expand networks, connect and internationalise. SheTrades, which aims to connect one million women entrepreneurs to market by 2020, also helps corporations include more women entrepreneurs in their supply chains.

Thanks to SheTrades, thousands of women businesses—located predominantly in Kenya, Mexico, Nigeria, India and Brazil—are now able to connect in real time, boosting their companies in the global market and in supply value chains. All registered companies' benefit from e-learning courses, mentoring sessions, webinars and guidebooks on topics such as negotiation skills, e-commerce and market analysis, among others. Opportunities to attend trade fairs and exhibitions within the SheTrades delegations are also offered through the platform.

Sara Yirga is owner and manager of Ya Coffee Roasters in Ethiopia, one of the companies registered on SheTrades. Her goal is to improve farming, roasting and quality standards, and to expand her market by meeting new business partners. SheTrades provides what Sara is looking for: a platform for networking with peers, but also a place where investors and buyers are ready to source products and services from women entrepreneurs. In Sara's words, "SheTrades is a tool that really helps many women achieve their dreams of connecting with other women on the other side of the world. I see it also as a platform to inspire and empower women from different walks of life, but having one thing in common, a business to run."

The SheTrades app is regularly updated, improved and upgraded with new functionalities. As of November 2016, it displays a tracking system that allows enterprises to go from commitments to implementation. Governments, individuals and research institutions, among others, can make specific, measurable pledges online.

Source: OECD-WTO aid-for-trade monitoring exercise (2017), Public sector case story 127,

www.oecd.org/aidfortrade/casestories/casestories-2017/CS-127-ITC-SheTrades-Connecting-one-million-women-to-market-by-2020\%20.pdf

\section{In what ways do women-owned enterprises use ICT tools?}

Supporting Indian Trade and Investment for Africa (SITA) is a UK Aid-funded project implemented by the ITC. Its aim is to boost the competitiveness and productivity of East African companies by enhancing and capitalising on Indian trade with investments in East Africa (ITC, 2015a). The early stages of project implementation included a firm-level survey of several hundred companies in Kenya, Tanzania, Uganda and Ethiopia working in the cotton, textile and apparel, pulses and sunflower oil sectors. The survey contains a number of ICT-related questions, which together with information on the gender of the manager or owner of the firm allow the analysis of how the use of ICT technologies by women-led firms in Africa compares to that of men-led firms.

Figure 8.7 shows five ways in which ICT is used by firms managed and owned by men as compared to women. Firms with elements of women's leadership or ownership are less likely to use ICT to communicate with employees and suppliers, which is in line with previous findings from the World Bank Enterprise Surveys (World Bank, 2016). However, the survey also finds that women-led or owned firms seem to be more likely to pay employees using electronic systems. This preference may be explained by data from the Global Findex Database, which indicate that $65 \%$ of men in developing countries have bank accounts, compared to $58 \%$ of women (World Bank, 2017). Mobile money offers a way for women to narrow that gap. It allows them to get paid quickly, saves them the time needed to travel to often distant bank branches, and_critically_offers them a way to save in a more secure, non-cash form (GSMA, 2014). 


\section{Figure 8.7. Use of ICT by women- and men-managed or owned firms}

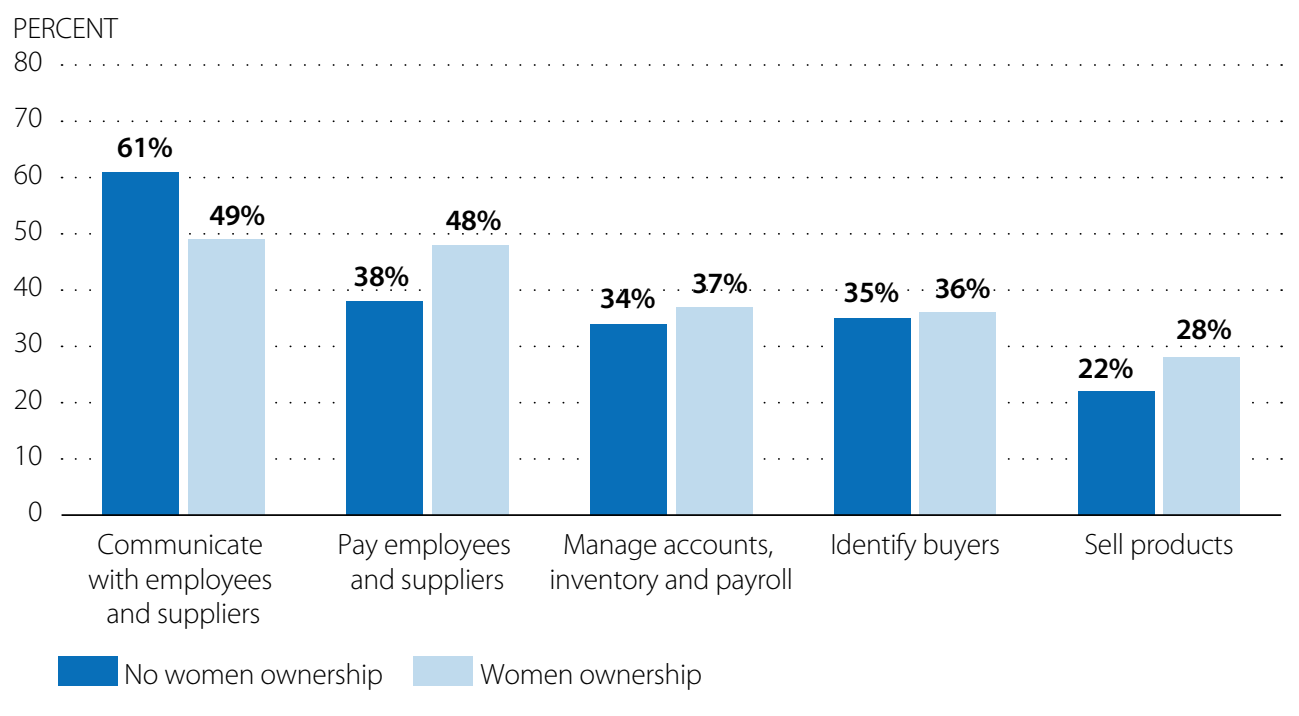

Source: Adapted from ITC (2015b), Supporting Indian Trade and Investment for Africa (SITA) data.

StatLink *iना SL http://dx.doi.org/10.1787/888933526709

\section{Do women exporters trade regionally or globally?}

The SheTrades app is a rich source of information on women-owned or operated firms. Creating a profile on the site involves filling in a variety of information on the company, from the product being produced to the destination of exports. Using profile information, it is possible to assess the types of business linkages women exporters make with the outside world, and specifically whether being part of a value chain makes any difference.

Figure 8.8 compares the share of firms exporting to their host region, to two regions (i.e. multi-regional) and to three or more regions (i.e. globally), split by whether they are inside or outside an international value chain. Here, being part of a value chain is defined as producing intermediates; being outside a value chain is seen as realising trade in final goods. The data indicate that half of the women-managed firms on the SheTrades platform who produce final goods for export, do so to countries within their own region. However, women-owned firms in a value chain are significantly more likely to sell beyond their host region, trading to two or more regions. This adds to evidence that suggests that being in a value chain helps firms to access markets.

Figure 8.8. Women-managed firms trading in goods versus tasks
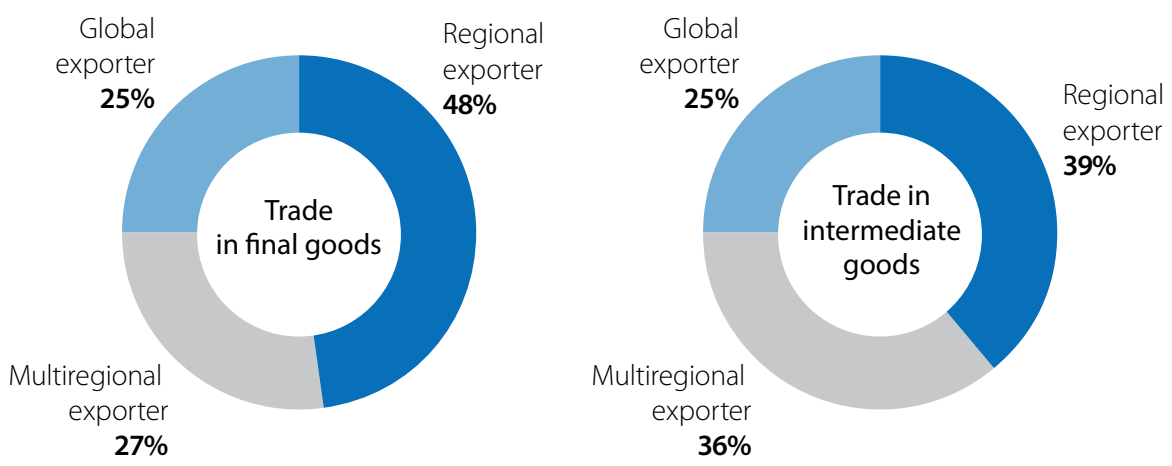

Source: ITC calculations based on SheTrades data, http://www.intracen.org/itc/women-and-trade/SheTrades/ (accessed 11 May 2017). 
Figure 8.9 illustrates a second interesting trend. It plots the percentage of women employees in a firm against where the firm trades: whether in its home region, in multiple regions, or globally. The results suggest that as firms expand their global reach, they employ proportionately more women, at least within the sample of firms surveyed by SITA. Furthermore, if the enterprise is women-led, the share of women employees is significantly higher, indicating that the involvement of women-led enterprises in international trade can boost women's participation in the labour force to a greater extent than the involvement of other types of companies.

Figure 8.9. Firms trading globally employ more women

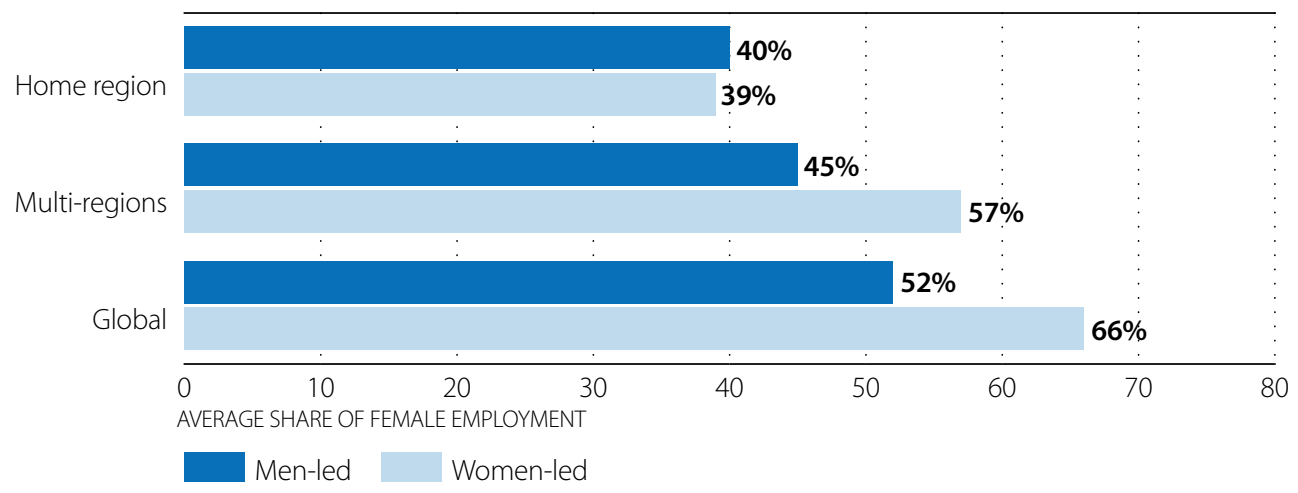

Source: Adapted from ITC (2015b), Supporting Indian Trade and Investment for Africa (SITA) data.

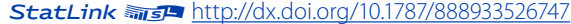

\section{A checklist for policymakers can help to meet the global goals}

Closing the gender-based connectivity gap will take considerable effort, especially by policymakers. A low supply of well educated, technically literate women limits the chances of women with the right skills making it to the top of any business. Those who manage to overcome these initial barriers and become managers also may face discrimination, which imposes costs on their business. These factors discourage women-led firms from entering international markets and reduce their opportunities for growth.

The Sustainable Development Goals (SDGs) provide a framework for countries to focus their efforts on promoting the connectivity of women-managed and owned firms. SDG 5.b states that countries should "enhance the use of enabling technology, in particular information and communications technology, to promote the empowerment of women." Establishing targets and ensuring that data collection processes capture the gender dimension are crucial steps to tackle the gender-based connectivity gap.

The following checklist of actions can help policymakers meet the objectives of SDG 5b. (Table 8.9).

\section{Table 8.9. Achieving SDG 5.b: A checklist for policymakers}

Business ecosystem $\quad \checkmark$ Establish dedicated programmes to teach girls e-skills.

$\checkmark$ Boost the affordability of the Internet so that more women with lower incomes have access.

$\checkmark$ Improve women's participation in producing online content.

$\checkmark$ Limit the opportunities for face-to-face discrimination by digitising processes.

National environment $\quad \checkmark \quad$ Integrate gender priorities into national ICT development strategies.

$\checkmark$ Integrate the gender dimension into trade promotion initiatives.

$\checkmark$ Ensure ICT statistics include gender disaggregation.

$\checkmark$ Mandate non-discrimination clauses to help women enter the labour force, thereby increasing the pool of potential women managers and owners. 


\section{CONCLUSIONS}

Over the past three decades, the connections that bind together the economic activities of countries have grown and deepened at a remarkable rate. In this general context, digital connectivity is helping to connect SMEs and womenowned or managed enterprises to customers and suppliers around the world.

Firm-level data show that there is a significant connectivity gap, however, between small and large firms. Small firms are found to be ten times less likely to have a business website and eight times less likely to use email, than large firms. This is a problem, as poor digital and physical connectivity lowers the likelihood of firms engaging in international markets. Firms that do not export are found to be two times less likely to have a website than firms that do. SMEs in the LDCs face the biggest barriers, as the connectivity gap for them, in comparison to larger firms, is significantly greater than in more developed countries. To support SMEs in connecting to global markets, policymakers can promote e-literacy, encourage firms to digitalise their production processes, and ensure national ICT infrastructure meets the demand of consumers and firms alike.

The exporter productivity premium is also roughly half the size for women-owned firms compared to men owned firms. Part of the reason for this may be their weaker use of connectivity technologies, which often help firms find new buyers and suppliers. For example, women-managed firms are 12\% less likely to use email than men-managed firms. Discrimination at the border may also be a factor reducing the benefits of trade for women. Digital tools, such as the single window, eliminate or reduce the need for personal interactions, which sometimes make it difficult for women to get their goods across the border.

Firm-level data also suggest that there are differences in the use of technologies between women- and men-owned firms. Women-led companies in selected East African countries are more likely to use mobile money as a means of paying employees and suppliers than men-led companies. This may be due to the advantages that mobile money offers women in terms of providing an independent and protected mechanism to save money.

To promote women's access to competitiveness-boosting digital technologies, there are numerous actions open to policymakers. These include establishing dedicated programmes to teach girls' e-skills, improving online content to promote women's participation, and integrating the gender dimension into trade promotion initiatives and national ICT strategies. 


\section{REFERENCES}

Amin, M. and Islam, A. (2014), Presence of Woman in Top Managerial Positions, in: World Bank Group Enterprise Note No. 29., Washington D.C.

Baghdadi, L. (2015), "Firms, Trade and Employment in Tunisia”, ITC working papers series, Working Paper No. 2015/07, International Trade Centre, Geneva. Switzerland.

Blackden, C. M., Manuel, C. and Simavi, S. (2010) Gender dimensions of investment climate reform: a guide for policy makers and practitioners, IFC E\&S. Washington, D.C.: World Bank Group. documents.worldbank.org/curated/ en/260721468321276647/Gender-dimensions-of-investment-climate-reform-a-guide-for-policy-makers-andpractitioners

Boateng, R, Heeks, R, Molla, A. and Hinson, R (2011) Advancing E-commerce beyond readiness in a developing country: Experiences of Ghanaian firms Journal of Electronic Commerce in Organizations, vol 9, no. 1, pp. 1-16.

Boateng, R., Molla, A., Heeks, R., and Hinson, R. (2011), Advancing E-commerce Beyond Readiness in a Developing Economy: Experiences of Ghanaian Firms, Journal of Electronic Commerce in Organizations, 9(1), 1-16.

Brenton, P., Bucekuderhwa, C. B., Hossein C., Nagaki S. and Ntagoma J.B. (2011) "Risky Business: Poor Women Cross-Border Traders in the Great Lakes Region of Africa." Africa Trade Policy Note 11, World Bank, Washington, DC.

Constantinescu, C., Mattoo, A., and Ruta, M. (2015), The Global Trade Slowdown: Cyclical or Structural?, IMF Working paper, No. 2015/06, International Monetary Fund, http://dx.doi.org/10.5089/9781498399135.001.

Davies, R. B. and Mazhikeyev, A. (2015), "The Glass Border: Gender and Exporting in Developing Countries", UCD Centre for Economic Research Working Paper Series, No. 2015/25, University College Dublin. School of Economics.

Deloitte (2015), SMEs powering Indonesia's success: The Connected Archipelago's Growth Engine, Deloitte Access Economics Pty Ltd.

Dholakia, N., Dholakia, R. R., and Kshetri, N. (2004). Global diffusion of the Internet, The Internet Encyclopedia. http://onlinelibrary.wiley.com/doi/10.1002/047148296X.tie072/abstract;jsessionid=FC7F7ED3A9BB2C2BAF6E3219C40F C8CD.f04t03 (accessed on 03 March 2017).

Égert, B. (2012), "Public Debt, Economic Growth and Nonlinear Effects: Myth or Reality?", OECD Economics Department Working Papers, No. 993, OECD Publishing, Paris. DOl: dx.doi.org/10.1787/5k918xk8d4zn-en

OECD (2012), "Public debt, economic growth and nonlinear effects: Myths or reality?", OECD Publishing

GSMA (2014), Mobile financial services for the unbanked, www.gsma.com/mobilefordevelopment/wp-content/ uploads/2015/03/SOTIR_2014.pdf (accessed on 27 February 2017).

Institute for Money, Technology \& Financial Inclusion (IMTFI) (2013), Trains at Different Stations: The Ghanaian-Kenyan Mobile Money Discourse, Institute for Money, Technology \& Financial Inclusion, http://blog.imtfi.uci.edu/2013/11/ trains-at-different-stations-ghanaian.html (accessed on 17 February 2017).

Intel (2012), Women and the Web, www.intel.com/content/www/us/en/technology-in-education/women-in-the-web. html (accessed on 21 February 2017).

ITC (2016a), Bringing SMEs onto the e-Commerce Highway, International Trade Centre, www.intracen.org/publication/ Bringing-SMEs-onto-the-e-Commerce-Highway/ (accessed on 11 May 2017).

ITC (2016b), SME Competitiveness in Ghana, www.intracen.org/publication/SME-Competitiveness-in-Ghana/ (accessed on 03 March 2017). 
ITC (2016c), SME Competiveness Outlook: Meeting the Standard for Trade, International Trade Centre, www.intracen.org/ publication/SME-Competitiveness-Outlook-Meeting-the-Standard-for-Trade/ (accessed on 11 May 2017).

ITC (2015a), SME Competiveness Outlook: connect, compete and change for inclusive growth, International Trade Centre, www.intracen.org/publication/SME-Competitiveness-Outlook-2015/ (accessed on 11 May 2017).

ITC (2015b), Supporting Indian Trade and Investment for Africa, International Trade Centre, http://www.intracen.org/ uploadedFiles/intracenorg/Content/Redesign/Projects/SITA/Newsletter/SITA Fact-sheet ENG WEB.pdf (accessed on 17 February 2017).

ITC (2015c), Unlocking Markets for Women and Trade, www.intracen.org/publication/Unlocking-markets-for-women-totrade/ (accessed on 11 May 2017).

ITC (2014), Empowering women through public procurement, www.intracen.org/publication/Empowering-WomenThrough-Public-Procurement/ (accessed on 11 May 2017).

ITU (2016), ICT Facts and Figures, http://www.itu.int/en/ITU-D/Statistics/Documents/facts/ICTFactsFigures2016.pdf (accessed on 30 May 2017)

Kabeer, N. (2012), "Women's economic empowerment and inclusive growth: labour markets and enterprise development", SIG working paper, No. 2012/01, School of Oriental and African Studies, UK.

Klasen, S. (2002), "Low Schooling for Girls, Slower Growth for All? Cross- Country Evidence on the Effect of Gender Inequality in Education on Economic Development", in World Bank Economic Review 16(3): 345-373, World Bank, Washington D.C.

Mas, I., and Ngweno, A. (2012), Why doesn't every Kenyan business have a mobile money account? http://papers.ssrn.com/sol3/papers.cfm?abstract id=2044550 (accessed 17 February 2017).

McKinsey and Company (2012), Online and Upcoming: The Internet's impact on aspiring countries, www.innovacion.cl/ wp-content/uploads/2012/05/Internet.pdf (accessed 27 February 2017).

McKinsey Global Institute, (2016), Digital Globalization: The New Era of Global Flows, www.mckinsey.com/mgi (accessed 17 February 2017).

Morris, G. A. and M. Saul (2000), "Women's business links: A preliminary assessment of women cross-border traders in West Africa." final report submitted to the West Africa regional programme', Development Alternatives, Inc. WIDTECH, August.

Ndiaye, T. (2010), "Women Informal Traders Transcending African Borders: Myths, Facts and Ways Forward", Export Roundtable on the Gender Dimension of Aid for Trade, 25 October, Geneva.

Nielsen (2016), Global connected commerce: is e-tail therapy the new retail therapy?, www.nielsen.com/content/dam/ nielsenglobal/jp/docs/report/2016/Nielsen-Global-Connected-Commerce-Report-January-2016 (accessed on 17 February 2017).

Simavi, S., Manuel, C. and Blackden, M. (2010), "Gender Dimensions of Investment Climate Reform. A Guide for Policy Makers and Practitioners", Washington DC: World Bank.

Statista (n.d.), "B2C e-commerce sales worldwide from 2012 to 2018”, webpage, www.statista.com/statistics/261245/ b2c-e-commerce-sales-worldwide/ (accessed 17 February 2017).

Stuart, G. and Cohen, M. (2011), Cash in, cash out Kenya: The role of M-Pesa in the lives of low-income people, http://www.microfinancegateway.org/library/cash-cash-out-kenya-role-m-pesa-lives-low-income-people (accessed 17 February 2017). 
UNCTAD (2015a), Information Economy Report 2015: Unlocking the potential of e-commerce for developing countries, United Nations Publications.

United National Economic Commission for Africa (UNECA), African Union (AU) and African Development Bank (AfDB) (2010)," Assessing Regional Integration in Africa IV", Enhancing Intra-African Trade. Addis Ababa: UNECA.

USAID (2012), Sara gets the message. Text Plant Profits for Malawi Farmers. www.usaid.gov/news-information/ frontlines/economic-growth/sara-gets-message-texts-plant-profits-malawi-farmers (accessed 28 February 2017).

Waxman, O. B. (2015), This is the first item ever sold on eBay, Time Inc., http://time.com/4018841/first-item-sold-listedebay/l (accessed 17 February 2017).

World Bank (2016), Enterprise Surveys (database) www.enterprisesurveys.org

World Bank (2017), Global Findex (database) www.worldbank.org/en/programs/globalfindex (accessed 11 May 2017)

WTO (2013), E-commerce in developing countries. Opportunities and challenges for small and medium sized enterprises, World Trade Organization.

WTO (2017), Trade Facilitation Agreement, www.wto.org/english/tratop e/tradfa e/tradfa e.htm (accessed 11 May 2017)

Worldpay (2014), Your global guide to alternative payments. Second edition, Worldplay, London offers.worldpayglobal. com/rs/worldpay/images/worldpay-alternative-payments-2nd-edition-report.pdf?mkt tok=3RkMMJWWfF9wsRonuq vPZKXonjHpfsX67u0vWqCXIMI\%2F0ER3fOvrPUfGj|4ATspq|\%2BSLDwEYGJlv6SgFOrXFMapv27gFXhc\%3D. 



\title{
CHAPTER 9
}

\section{PROMOTING TRADE INCLUSION \\ IN THE LEAST DEVELOPED COUNTRIES \\ THROUGH CONNECTIVITY}

\author{
Contributed by the Enhanced Integrated Framework
}

\begin{abstract}
The emergence of information and communications technology, especially mobile phones, has changed how people in the least developed countries (LDCS) do business and organise their lives. However, most people in these countries still lack access to affordable internet connections and the LDCs face profound challenges to connectivity. Introducing policies to improve the enabling environment for trade and investment can help. This chapter looks at the policy aspects of digital connectivity in the LDCs and reviews examples of recent reforms that have enabled e-commerce to play an increasingly important role. It emphasises, nevertheless, that there is no "one-size-fits-all" solution. Ultimately, users in the LDCs will guide markets and governments, demonstrating what they most urgently require in terms of digital connectivity. Led by LDC governments and with focused co-operation among key stakeholdersincluding the private sector and international donors - much can be achieved in the way of inclusion.
\end{abstract}




\section{INTRODUCTION}

For many people in industrial countries, reading the news, buying online and talking to friends over the Internet has become part of everyday life. Yet, in the least developed countries (LDCS), despite the proliferation of mobile phones, access to the Internet is still limited. The Internet's potential as an instrument for more inclusive trade, which can bring benefits for the poor, is yet to be fully explored.

This chapter examines why digital connectivity has been recognised as an important instrument for development. It looks at the LDC-related policy aspects of digital connectivity and reviews examples of recent reforms that have allowed greater integration of LDCs into the evolving trading environment, where e-commerce plays an increasingly important role. The chapter highlights existing initiatives that have shown some promising results, stressing, nevertheless, that there is no "one-size-fits-all" solution. Ultimately, users in the LDCs will guide markets and governments, demonstrating to them what they most urgently require in terms of digital connectivity.

The chapter focuses on SDG 9, Target 9.c: "Significantly increase access to information and communications technology and strive to provide universal and affordable access to the Internet in least developed countries by 2020". (SDG, 2015) The adoption of this target by the international community indicates a commitment to support digital transformation in the LDCs. It underlines that affordable access to information is crucial for enhancing trade and sustainable development.

The Internet increasingly allows access to information on a global scale, reducing information asymmetries and helping to create a virtuous circle for innovation across the globe. The Internet helps new services to emerge and improves already existing ones by making them more efficient. Internet enabled services are able to reach out to consumers, including connected consumers in rural areas, who otherwise would not be able to benefit from them. The main driver of increasing connectivity has been the decreasing costs of Internet access, mobile phone services and personal computers. In many LDCs, this quiet revolution has been led by mobile phones, which are allowing people, even in remote areas, to connect better with each other and with the rest of the world. Products and services enabled by information and communications technology (ICT) range from mobile payment systems to health services in remote regions where doctors are not always able to be present in times of emergency (Box 9.1).

\section{Box 9.1. Examples of ICT-enabled products and services}

Mobile phone banking is gaining more and more customers, especially in Eastern Africa and Southeast Asia. Wing Mobile in Cambodia and MTN Mobile Money in Uganda successfully offer people banking services.

Medical and health services are improved through Internet Cloud technology and digitalisation. Rwanda has adopted the use of drones to deliver blood donations to remote health centres.

Online education platforms are currently providing free education services across the world via massive open online courses (MOOCs), with unlimited participation and open access via the web. Already, universities in Tanzania and Zambia provide e-learning platforms. Uganda uses high speed Internet to facilitate e-learning and research in seven public universities.

Source: OECD-WTO aid-for-trade monitoring exercise (2017), www.oecd.org/aidfortrade/countryprofiles/ and Uganda (2015), www.ict.go.ug/initiative/infrastructure (accessed 15 February 2017).

While the digital economy is still emerging in many LDCs, some countries—such as Bangladesh, Nepal and Rwandahave already begun the transition. The most recent Enhanced Integrated Framework (EIF; Box 9.2) analytical study, conducted by the government of Nepal, prioritised incentives to attract investment in the information technology (IT) and ICT sectors, such as corporate income tax holidays until 2020; a 0\% excise tax on imported telecom and computer equipment; and 100\% ownership and dividend/capital repatriation for foreign investors. 


\section{Box 9.2. EIF support for the SDGs}

1 POVIRT mintini

$228 \% 0$

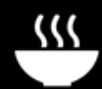

5

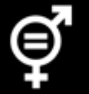

8 DECEBTWOAKANO

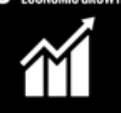

9 Moustr. movonor 사 4

17 PARTERRSHPS (8) 8
The Enhanced Integrated Framework (EIF) is a multi-donor programme designed to support LDCs in becoming more active players in the global trading system. Within its framework, LDCs, donors and international organisations work together to fully integrate the world's poorest countries into global trade in a way that contributes to poverty reduction and sustainable development.

EIF-supported projects contribute to several of the 17 SDGs:

- Some $95 \%$ of EIF projects focus on poverty reduction, and most of them aim at promoting the agricultural sector in the LDCs, helping to achieve SDG 1 (no poverty) and 2 (zero hunger).

- Close to $50 \%$ of EIF projects focus on gender (SDG 5). The EIF collects data on project beneficiaries at the disaggregated level to determine whether interventions are targeting both women and men. For example, the EIF currently implements a project in Rwanda to improve the livelihoods and earning potential of people engaged in cross border trade, $74 \%$ of whom are women.

- All EIF interventions support the LDCs in accessing new markets, providing opportunities for job creation and economic growth (SDG 8).

In addition, EIF projects in productive capacity building range from improvement in airport cargo handling to enhancement of the operations of sanitary and phytosanitary laboratories, processing centres and manufacturing facilities (SDG 9: industry, innovation and infrastructure).

Finally, SDG 17 (partnership) makes a call to "Significantly increase the exports of developing countries, in particular with a view to doubling the least developed countries' share of global exports by 2020."

These objectives are at the heart of the EIF.

\section{THE LEAST DEVELOPED COUNTRIES DO NOT YET REALISE THE FULL POTENTIAL OF INTERNET CONNECTIVITY}

Digital connectivity has great potential for inclusive growth and socio-economic development. Yet the ITU Facts and Figures Report reveals that many LDCs are still unable to implement broad-based connectivity (ITU, 2016a; Chapter 5). Some of the facts that characterise the LDCs include:

- Only about one out of eight people is online.

- Just 12.5 million women have access to the Internet, as opposed to 18 million men.

- Internet access is led by mobile telephone technology.

- Internet speed remains a huge challenge.

Not only are the absolute numbers of Internet users in the LDCs lower than in the rest of the world; the growth in Internet access in these countries also has been slower (Figure 9.1). While growth in the use of mobile phones has been strong in these countries, less than 20\% of the population have mobile broadband subscriptions (ITU, 2016c). Fixed-line Internet access in the LDCs remains below $1 \%$. Internet access in the LDCs will most likely continue to grow through mobile coverage, yet these countries risk falling even further behind on this important facilitator of international trade. 


\section{Figure 9.1. Internet users and mobile cellular subscription per 100 people}

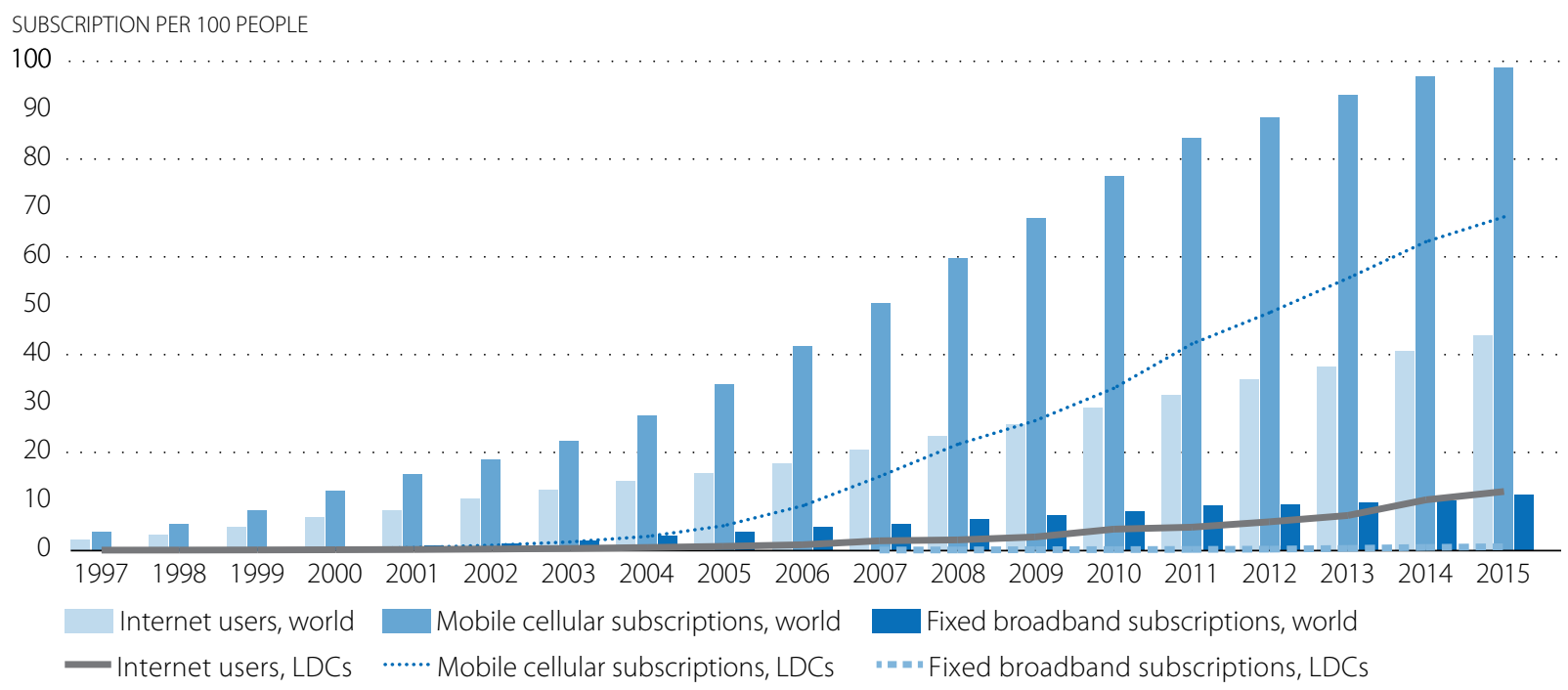

Source: Adapted from the World Bank, Internet users per 100 people, ITU, World Telecommunication/ICT Development Report and database.

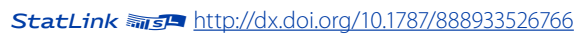

Among the possible explanations for the connectivity gap between the LDCs and the rest of the world, research shows that access to and costs of Internet infrastructure, as well as education levels, significantly influence Internet penetration.

\section{Country examples offer solutions for setting up physical Internet infrastructure}

Depending on a country's location-e.g. whether it is landlocked-and its ability to co-operate with neighbouring countries—e.g. through shared infrastructure projects - the costs for installing and/or accessing the necessary physical infrastructure for Internet connectivity can be either prohibitive or affordable, including for the LDCs. The World Bank (2016) has documented ways in which developing countries, particularly in Africa, have started to invest in shared infrastructure projects to reduce costs in network deployment, expand coverage, and close up the rural-urban digital divide by accelerating broadband uptake. This type of co-operation can help to reach the population living in rural areas.

\section{EIF analytical work in several countries' has provided examples of how countries address ICT infrastructure challenges:}

Sub-Saharan Africa: Niger, a landlocked country in West Africa, has access to undersea cable through Benin and Burkina Faso. Despite the presence of four mobile service providers, the only company that supplies fixed broadband Internet is the national telephone and telecommunications carrier, SONITEL (Société nigérienne des télécommunications). This situation has implications for competitiveness, and ultimately for the price of services. In contrast, thanks to competitive pricing arrangements prices in Rwanda and Uganda differ very little from what consumers pay in Tanzania, a neighbouring country with access to undersea cable. These countries use cross-border terrestrial connections (Schumann and Kende, 2013).

Asia: In Asia, the Digital Bangladesh Strategic Plan foresees speeding up the process of providing submarine cable connections to ensure the reliability of nationwide Internet connectivity and reduce the cost. Bhutan has invested in aerial fibre-optic cabling using the power-line infrastructure of the Bhutan Power Corporation; negotiations with Indian service providers to add more fibre-optic cable connections for greater reliability and quality are ongoing. 


\section{Improving education is important if countries want to gain from digital connectivity}

Pew Research Center (2015a) found that younger, better educated people with some knowledge of English are more likely to access the Internet. The governments of the LDCs invest around 3\% more on average than other developing countries in education; yet 19 million children in the LDCs still are not enrolled in primary education. Lack of basic education might lead children to miss out on opportunities that, as adults, could allow them to have better jobs and income (UN-OHRLLS, 2016). McKinsey (2013) estimates that African countries could increase productivity by USD 30-70 billion with the help of education and technology.

At the same time, improving basic education is an important prerequisite for increasing value-added production and engaging in the global economy. Basic digital literacy is becoming an essential prerequisite for competitiveness among countries. Countries that lack a workforce that is able to utilise IT instruments will find it increasingly difficult to keep up with the requirements for international trade.

Online education platforms play an important role in facilitating Internet penetration, assisting students and teachers in many LDCs. Better connectivity can, in turn, help LDCs increase education levels. A study by Schumann, R. and M. Kende (2013), found that large amounts of locally hosted content—such as educational and e-government services_-are correlated with lower average costs of Internet service, improved quality of the user experience and increased demand.

The global gender gap in Internet use, meanwhile, keeps growing. On average, it is much greater in Sub-Saharan Africa than in the rest of the world. Ensuring the participation of girls and women in basic digital skills training and online education is fundamental. Incorporating the gender dimension into national digital strategies can help in tackling the digital gender gap. Some developed countries have already done so; examples include the Digital Agenda for Spain, and Australia's Gender Equality and Women's Empowerment Strategy. Yet the gender dimension in ICT-related strategies is less evident in the LDCs, where the gap is more profound. According to the GSMA Connected Women Programme (2017), closing the 14\% gap in women's mobile access worldwide could create USD 170 billion in market opportunities for the mobile industry from 2015-2020, bringing growth and prosperity to many households.

\section{Connectivity depends on access to Internet-ready devices}

Trade policy plays a key role in determining the accessibility and price to consumers of ICT related equipment and services. Besides facing steep prices for Internet access (Chapter 5), the cost of purchasing an IT enabled device represents another major cost for the consumer. Poor countries rarely produce these products and therefore have to import ICT-related equipment and devices, and import tariffs can have an impact on accessibility for small businesses and low-income consumers. Tariff and trade analysis of data from World Integrated Trade Solutions (WITS) based on the WTO Integrated Data Base (IDB) show that average applied Most-Favoured-Nation (MFN) tariffs on telephones and computers are higher in the LDCs than in other developing countries.

While LDC imports have risen steadily in recent years (Figure 9.2), computers are still not common in households in these countries. High prices are partly responsible for this, but other reasons, such as unreliable electricity supplies, also discourage households from buying IT equipment. However, the LDCs have experienced a significant increase in imports of telephones, which rose from USD 526 million in 2012 to USD 2.6 billion in 2015; mobile phones represent over one-fourth of this total. While the number of people owning mobile phones in the LDCs is growing, smartphones that help enhance Internet access are not as common. A Pew Research Center survey (2016) indicates low levels of ownership in Ethiopia (4\%), Uganda (4\%), Burkina Faso (11\%), Tanzania (14\%) and Senegal (19\%). 


\section{Figure 9.2. LDC imports of telephones and computers}

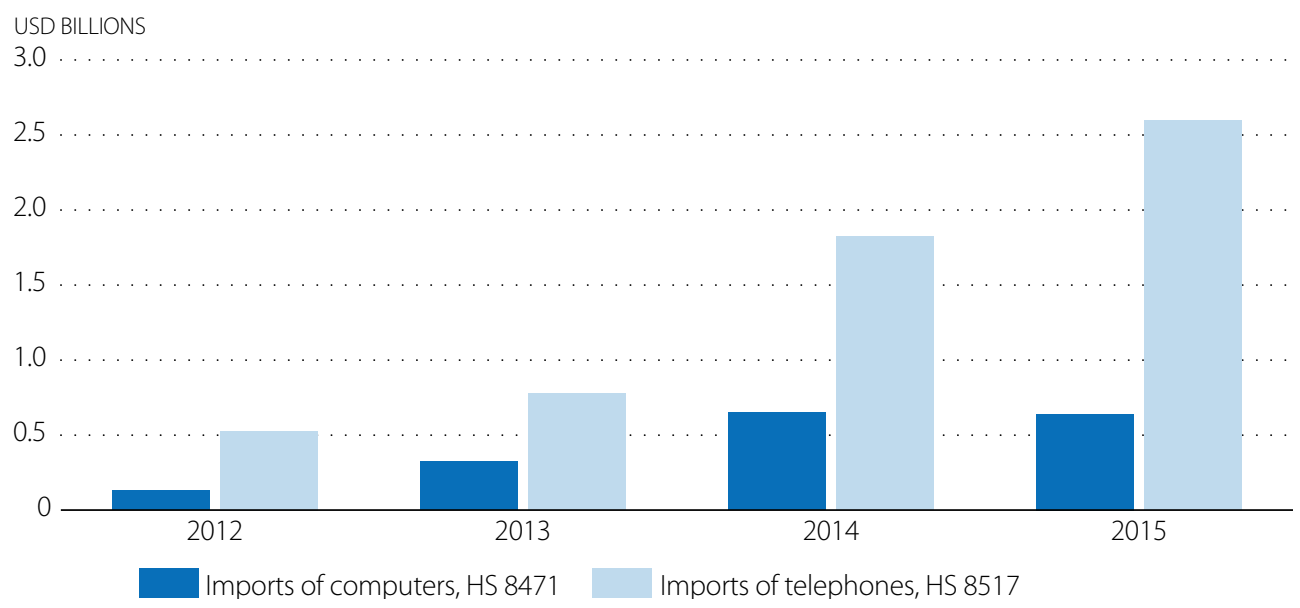

Note: The Harmonised System developed by the World Customs Organisation provides a uniform classification of goods with numerical codes (Bollyky, T.J. and P.C. Mavroidis, 2017) whereby 8517 refers to telephone sets, including telephones for cellular networks or for other wireless networks; and other apparatuses for the transmission or reception of voice, images or other data, including for communication via a wired or wireless network; 8471 refers to automatic data-processing machines and units thereof; and magnetic or optical readers, machines for transcribing data onto data media in coded form and machines for processing such data.).

Source: UN-COMTRADE accessed through World Integrated Trade Solutions (WITS), https://wits.worldbank.org/WITS/ WITS/Restricted/Login.aspx, (accessed on 24 February 2017).

StatLink नints http://dx.doi.org/10.1787/888933526785

In addition, many multinational companies are partnering with local producers to supply more affordable devices to the population. In Myanmar, Ooredoo - an international telecom company - is launching a subsidised 3G phone for less than USD 15. After the opening of the telecom sector in 2013, and with the presence of new service providers, the price of a SIM card was drastically reduced, from USD 150 in 2013 to just USD 1.5 in 2015 (Alliance for Affordable Internet, A4Al, 2015).

While the use of mobile phones is expanding, however, only one-quarter of people in sub-Saharan Africa have a computer at home; the lowest share is in Uganda, where only around 3\% of households have a computer (Pew Research Center, 2015b). Zambia envisages establishing a computer assembly plant through a public-private partnership to produce at least 250000 computers annually (Zambia, 2017).

A group of WTO Members at the WTO 10th Ministerial Conference (December 2015) agreed to expand the Information Technology Agreement (ITA), which was concluded in 1996, to completely eliminate tariffs on IT products covered in the Agreement. The purpose of the ITA expansion is to eliminate tariffs on 201 new-generation information and communications technology products, including telecommunication satellites (WTO, 2015a). This Agreement can potentially help LDC producers find access to new export markets. The LDCs could also explore ways of improving access to IT products in their own markets, thereby benefitting the consumers. While none of the LDCs are currently members of the ITA expansion agreement, as part of its WTO accession package Afghanistan committed to joining the Information Technology Agreement (ITA) of 1996 (WTO, 2015b). 


\section{REGULATORY MEASURES CAN PROMOTE OR HINDER CONNECTIVITY}

Access to digital ICT services is important for business and consumers in the LDCs. WTO member schedules of specific commitments under the General Agreement on Trade in Services (GATS) reflect the minimum level of treatment granted in accordance with the obligations of market access and national treatment. The telecommunications services sector is one of the most committed services sectors under the GATS (van Grasstek et al., 2016).

Fourteen LDCs have made commitments in the area of telecommunications services, namely Afghanistan, Bangladesh, Cambodia, Democratic Republic of the Congo, Djibouti, The Gambia, Lao PDR, Lesotho, Liberia, Nepal, Senegal, Uganda, Vanuatu and Yemen, thus ensuring greater transparency and predictability for their trading partners. Twenty-two LDCs have not taken any commitments in the telecommunications sector under the GATS.

The seven LDCs that have undergone the WTO accession process-Afghanistan, Cambodia, Lao PDR, Liberia, Nepal, Vanuatu and Yemen-have also incorporated into their schedules the obligations of the Reference Paper on Telecommunications, setting common guidelines that cover regulatory principles for basic telecommunication services, notably: interconnection; universal service obligations; independence of regulatory authorities; and fair and transparent allocation of scarce resources.

In an endeavour to take comprehensive stock of members' applied measures, the WTO and the World Bank (2017b) have been collecting relevant measures and classifying them in several categories: measures affecting access to markets; conditions affecting competition; and conditions on operations of foreign service suppliers (Box 9.3). The International Telecommunications Union (ITU) has also collected data on telecommunications services for the ICT Regulatory Tracker (Chapter 5), including information on regulatory authorities, regulatory regimes, and level of competition (ITU, 2017). According to the ICT Regulatory Tracker, by 2015 the majority of the EIF countries had established an independent regulatory authority for telecommunication or ICT; eight have yet to establish one.

Box 9.3. Examples of LDC regulatory reform in telecom services

\section{AFRICA}

In The Gambia, fixed-line services are provided by the government-owned Gambia Telecommunication Company. Since 2012, the government has introduced a new international gateway license to foster competition (Schumann and Kende, 2013).

In 2013, Sierra Leone granted six licenses to public Internet operators and started working on connecting the African coast with European cable (Africa Coast to Europe). The objective was to obtain affordable access to the international broadband network through the construction of a $17000 \mathrm{~km}$ submarine fibre optic cable from France to South Africa (WTO, 2017a). In 2015, Sierra Leone adopted the Telecommunications Amendment Act 2015, which terminated a monopoly over the international telecommunications gateway (WTO, 2014-15).

\section{ASIA AND THE PACIFIC}

Recent reforms in Myanmar, followed by the adoption of the Foreign Investment Law, allowed for 100\% foreign ownership of telecommunications services (WTO, 2014).

In Vanuatu, the monopoly of Telecom Vanuatu Limited was terminated in 2007, allowing the private sector to step in and provide telecom services. As part of the Telecommunications and Radio Communications Regulation Act No. 30 of 2009, a separate and independent regulatory body - the Telecommunications and Radio Communications Regulatorwas established. Reforms in the ICT sector, together with the installation of a major submarine fibre-optic cable in 2014, led to a significant decrease in Internet prices and helped connect the country to other regions in the Pacific (ITU, 2015).

Source: Adapted from WTO Trade Policy Reviews, WTO DG Monitoring Report, ITU, and Schumann and Kende (2013). 
To avoid anticompetitive practice, having a competition authority is also important. By 2015, 62\% of the EIF countries had established competition authorities. While mobile services in general tend to be relatively open, the ITU ICT Regulatory Tracker shows that fixed line telecom services remain under monopoly in several LDCs (Figure 9.3).

Figure 9.3. Level of competition in selected LDC telecommunications services, 2015

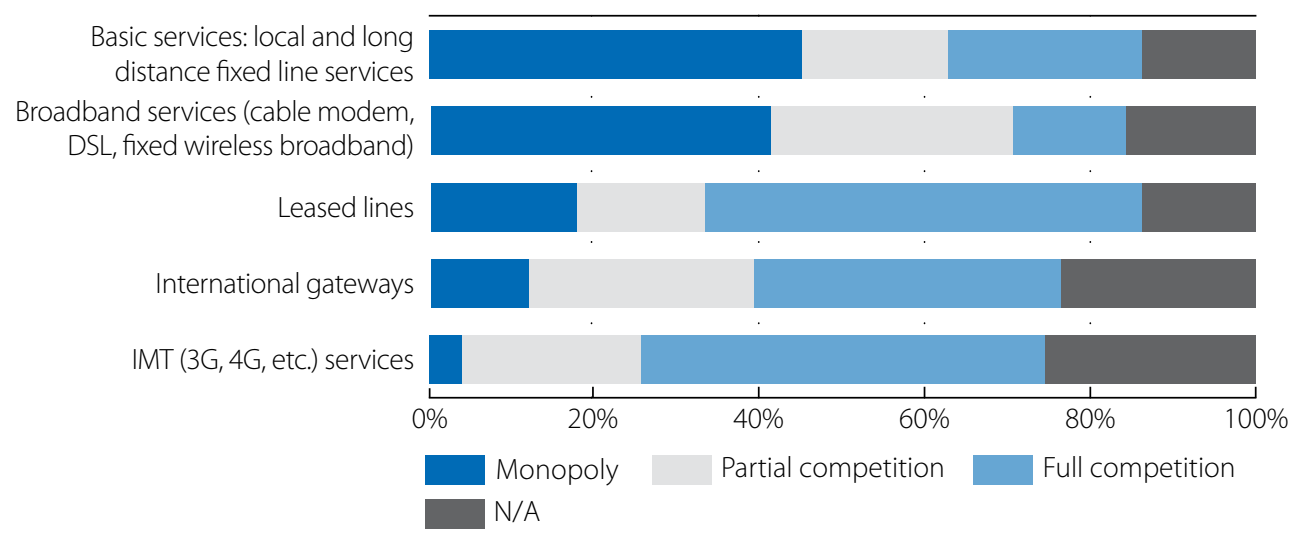

Source: ITU (2017) ICT Regulatory Tracker.

International gateways (earth stations) have an important impact on accessibility and affordability of Internet access. Often, fixed-services operators control the gateways and their prices reflect a de facto monopoly. Because global Internet services require international connectivity, a lack of competition in gateway services can have a direct impact on the cost of the internationally leased circuits used by Internet access providers.

\section{An overview of LDC telecommunications regimes reveals differences in approach}

Typically, entry into the telecommunications services market is contingent upon obtaining a license. Licenses are technologically neutral in Cambodia, Lesotho, Malawi, Mali, Mozambique, Rwanda, Tanzania and Uganda. However, Malawi, Nepal, Tanzania and Uganda have a separate international gateway license and fee.

In Burundi, Lesotho, Madagascar, Malawi, Mali, Mozambique, Nepal, Senegal, Tanzania and Uganda, new operators are permitted to own and operate international gateways. This is not the case for Rwanda and Zambia. While Bangladesh, Cambodia, Lesotho, Malawi, Mozambique, Nepal and Tanzania do not set nationality requirements for employees, in Madagascar, Mali, Rwanda, Senegal, Uganda and Zambia, these types of requirements are in place.

In 2014, Madagascar announced the opening up of the telecommunications market, allowing operators to introduce and provide services using new technologies, such as 4G, and encouraging competition (WTO, 2014-15). Similarly, since the adoption of 2010 legislation regulating telecommunications in Guinea Bissau, there are no restrictions on market access or national treatment for foreign suppliers (WTO, 2012).

This brief overview of the telecommunications sector in the LDCs shows that some countries have given great importance to competition in the telecommunications sector, while others have preferred to rely on incumbent service providers. The EIF Diagnostic Trade Integration Study (DTIS) provides a periodic update on country specific situations. These are evidence-based analytical studies that underpin the identification of the priorities that need to guide the trade agenda, as well as the aid-for-trade needs of the LDCs. They help LDCs determine their biggest constraints to trade integration and prioritize actions to address them, through trade-related support. The list of ICT-related priorities in the LDCs is annexed to this study (Annex 9.A1). 


\section{A good business environment is essential to digital expansion}

EIF analytical work highlights the need for LDC governments to put in place legal policy frameworks and supportive regulatory environments to generate greater investment in the ICT sector, allowing for an expansion of digital infrastructure. In order to further strengthen the ICT framework, over half of the LDC respondents to the OECD-WTO 2017 monitoring exercise reported that they had already adopted ICT-related strategies (Box 9.4). For example, Rwanda has an e-commerce cyber strategy in its SMART Master Plan 2015-2020 and the implementation of the national plan aims to provide fast Internet access with 4G long-term evolution deployment to 95\% by the end of 2017 (Rwanda, 2017).

Afghanistan's National Telecommunications Policy aims to establish a level playing field for fair, transparent and marketbased competition. Guinea recently passed a law on electronic transactions. ICT aspects are also reflected in GuineaBissau's National Development Strategy 2025; with EIF institutional capacity support, the country has embarked on electronic document management as well as financial software recycling. The local EIF project implementation unit in Guinea-Bissau, with the help of the United Nations Conference on Trade and Development (UNCTAD), has also implemented a system with pricing information on world markets. In Senegal, the 2025 Digital Senegal strategy is underway.

Almost 90\% of respondents to the OECD-WTO 2017 aid-for-trade monitoring exercise reported that ICT-related strategies are reflected in their national development plans. Business to business and business to consumer transactions, payment issues and access to online platforms are among the most frequent topics covered in ICT strategies with a trade-related component.

While having an ICT-related strategy is very important, it is crucial to implement it promptly. The Mozambique DTIS recommends developing a roadmap with clearly identified timeframes to achieve the objectives set forth in the 2013 Telecommunications Strategy.

\section{Box 9.4. An example from Mauritania of the telecommunications regulatory framework}

The regulatory framework in Mauritania has evolved considerably following telecom liberalisation in the 1990s. In 2013, the Government identified the development of high speed Internet as a new source of ICT growth, job creation and economic diversification. A regulatory authority was created and awarded three global licenses for mobile and fixed telephony and Internet:

1. Mauritel — the incumbent operator — is a subsidiary of the Maroc Telecom group, which owns 51\% of the capital (the rest is owned by the state).

2. Mattel—which entered the market in 2000 —is a subsidiary of Tunisie Telecom, which owns $100 \%$ of the capital.

3. Chinguitel — which entered the market in 2006-is a subsidiary of Expresso (100\% subsidiary of Sudatel), which owns $95.5 \%$ of the capital.

The liberalisation of the telecommunications sector has generated positive macroeconomic impacts on the economy, notably on GDP, employment and foreign investment. Today the telecommunication sector is one of the main contributors to economic growth, after the mining sector. Due to an increase in mobile services, the total size of the telecommunications sector has almost tripled, from USD 33.7 million in 2005 to USD 87.5 million in 2014. This sector is an important contributor to the state budget. Privatization and liberalisation reforms have generated additional income of almost USD 220 million from the three licensing fees, the sale of Mauritel's capital and the renewal of a $2 \mathrm{G}$ license for Mattel. The sector also regularly contributes to public finances through general and industry-specific taxes and customs obligations. For example, in 2011 the sector provided a total contribution of USD 83.2 million to public finances, accounting for 5.5\% of the state budget. Telecommunications also contribute to job creation, accounting for around 2\% of all jobs in 2012. Opening up the telecommunication sector to private participation has, furthermore, attracted private investment: from 2000 to 2010 , the three telecom operators invested USD 817 million, accounting for more than 15\% of total foreign direct investment in the country.

Source: Adapted from the DTIS Update of Mauritania (2016), http://www.enhancedif.org/en/files/dtis (accessed on 20 February 2017). 


\section{Digital government cuts costs and improves outcomes}

EIF analytical work in the LDCs indicates that the establishment of e-government systems has great potential to reduce time and costs, promote transparency and support constituencies in using the Internet. For example, over 20 e-government systems were developed in Uganda, ranging from the Electronic Single Window to eProcurement and eVisa (Uganda, 2015). E-government initiatives are also considered to serve as catalysts for increased national ICT use, as well as supporting the development of the ICT sector in general.

However, e-government solutions are still nascent in most LDCs. While the results of the OECD-WTO 2017 monitoring exercise show that some LDCs are already using digital government services-notably download of e-government forms and applications, online submission of forms and applications, and electronic payments-around 25\% of the respondents do not offer e-government services.

The provision of e-government services is closely linked to the availability of infrastructure. The DTIS of South Sudan confirms that once the country connected its ICT backbone to Indian Ocean submarine cables, the government was able to promote automation of government services—such as business and investor registration, customs management, tax filing, e-commerce and mobile banking -improving service delivery in the public and private sectors. Similarly, in Mauritania, the DTIS recommends establishing an e-government system for the greater expansion of the ICT sector, improving the efficiency of government services and providing incentives for citizens to go online. Finally, Bhutan has successfully implemented e-government deployment and use of telemedicine and is currently working on a government to citizen project.

\section{PARTNERSHIPS CAN HELP TO IMPROVE CONNECTIVITY IN THE LDCS}

Improving connectivity requires combined efforts of the international community, including LDC governments, donors, the private sector and development partners. According to the OECD Creditor Reporting System (CRS), in 2015 USD 10.5 billion of aid for trade was disbursed to the LDCs, an 11\% increase that followed the negative growth rate of the previous year. While the overall trend is encouraging, disbursements to the LDCs are just above one-quarter of total aid for trade.

The overall level of aid-for-trade commitments for the LDCs has fluctuated over recent years. Following a decline in 2014, it rebounded in 2015 with an annual growth of 33\%, bringing the total amount of LDC commitments to USD 17.2 billion. In 2015 the LDC share of aid for trade was, for the tenth consecutive year, the second highest (32\%) among the country categories, just four percentage points behind the lower middle income countries (Figure 9.4).

Figure 9.4. Aid-for-trade commitments and disbursements to the LDCs, 2006-15

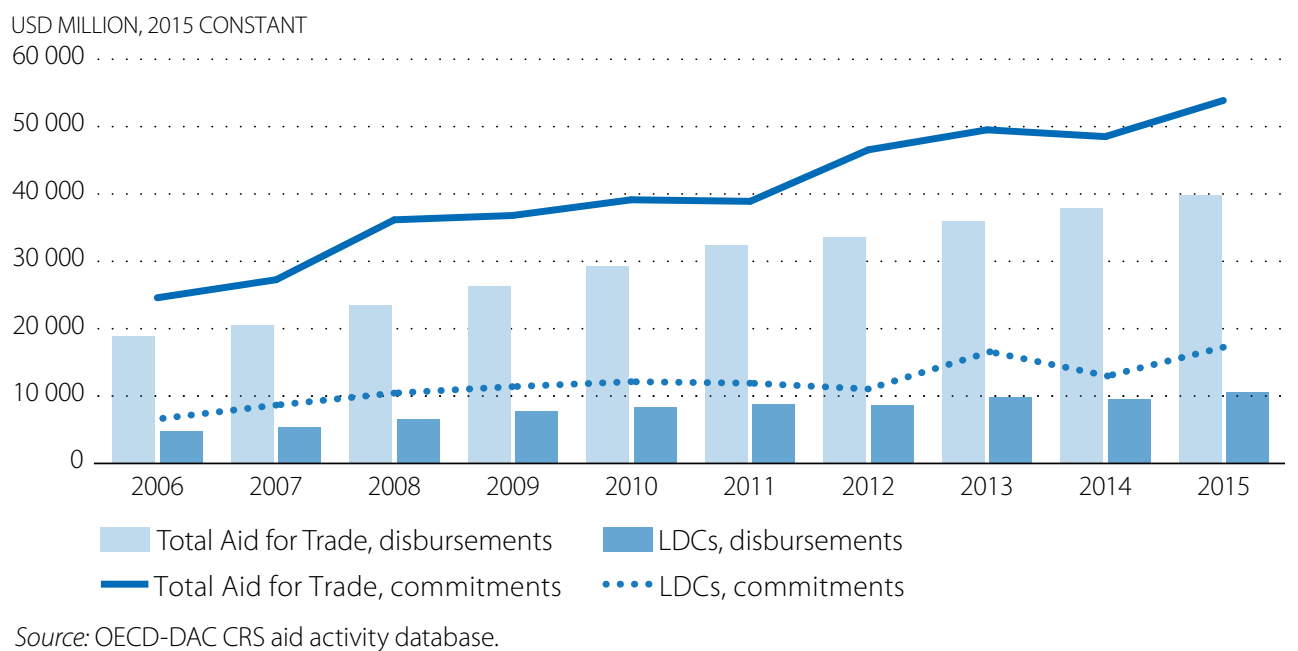

StatLink 光ISL http://dx.doi.org/10.1787/888933526823 
The allocation of aid for trade to individual countries within the LDC country grouping varies considerably. Afghanistan, Bangladesh, Ethiopia, Mozambique, and Tanzania, were the top five LDC recipients in 2015, accounting for 37\% of all aid-for-trade disbursements to the LDCs (Figure 9.5). On the other hand, there are a number of LDCs where aid-for-trade disbursements remain very limited. (Figure 9.6).

\section{Figure 9.5. The top five LDC recipients of aid for trade in 2015}

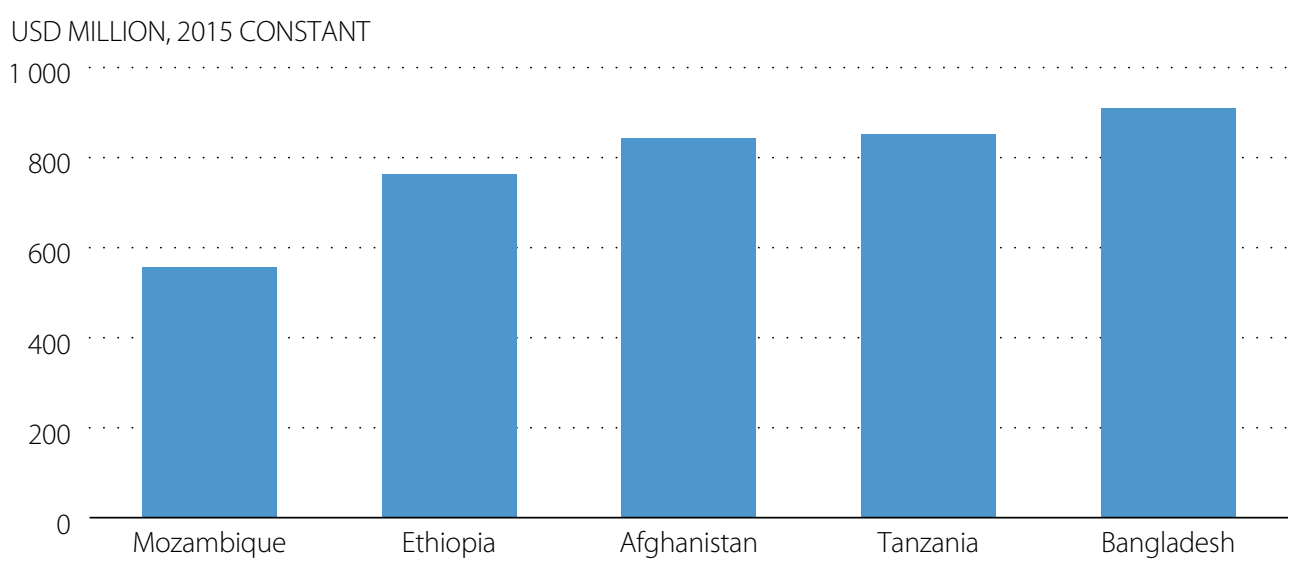

Source: OECD-DAC CRS aid activity database (accessed 1 May 2017).

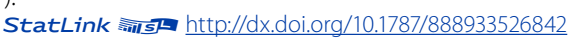

To ensure that all the LDCs get the support they need, the EIF follows a "leave-no-LDC-behind" approach to resource allocation. In 2017 the EIF initiated analytical work in Equatorial Guinea, the LDC that received the least aid-for-trade resources in 2015 according to the OECD CRS. In addition, the EIF is looking at re-launching its activities in the Central African Republic, which were previously put on hold. In total, the EIF has supported the implementation of 149 projects amounting to over USD 200 million.

Figure 9.6. Aid-for-trade disbursements to the LDCs in 2015, USD million constant prices

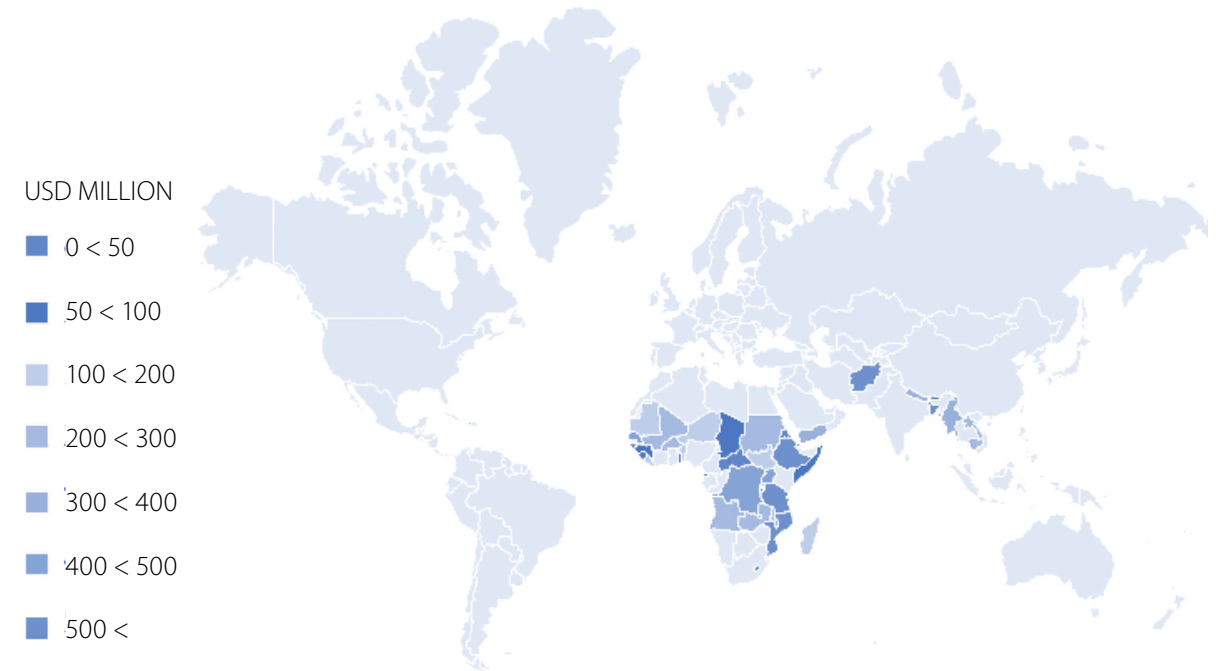


Since 2006, aid-for-trade disbursements from the donor community to the communications sector have increased almost two-fold; nevertheless they remain less than $2 \%$ of total aid-for-trade disbursements to the LDCs. To counter this trend and ensure the development of digital infrastructure, the catalytic role of the government in leveraging private sector engagement is paramount. The EIF, as the only aid-for-trade initiative exclusively dedicated to the LDCs — with a clear focus on helping countries to leverage additional resources-supports these efforts through analytical work, institutional structures on the ground and projects to build productive capacity.

\section{Analytical work and institutional support are essential}

Through the EIF, a number of countries have undertaken DTISs, which have provided inputs for subsequent country plans and strategies that have an impact on increasing connectivity, both in terms of digital and physical infrastructure. As for physical connectivity, much attention has been paid to trade facilitation reform, and the improvement of transportation systems at the national and regional levels.

While all DTISs highlight the importance of physical connectivity and infrastructure improvement for trade facilitation, the breadth and depth of the analysis of digital connectivity differs. This, in turn, reflects its relative importance for each LDC. Some DTISs include improvement in digital connectivity as one of the priorities of their Action Matrices; others make reference to digital connectivity as a cross-cutting issue; and several include a specific chapter on ICT. At the same time, while some LDCs focus on "hard" infrastructure improvements, others highlight the need to address the policies and regulations governing connectivity through the Internet.

In terms of digital connectivity, frequent topics include the need for greater competition in the telecommunications sector; ICT promotion through training and outreach; improved access to the Internet; and helping businesses to engage in e-commerce. Overall, 21 DTISs and DTIS Updates (DTISUs) have incorporated ICT-related priorities in their Action Matrices. New sharpened DTIS guidelines will include an analysis of e-commerce, helping up to 30 new DTISs/ DTISUs to integrate key aspects of the evolving trade environment (Box 9.5).

\section{Box 9.5. Burkina Faso's efforts towards regional harmonisation}

Following liberalisation and opening of its markets, telecom services are expanding in Burkina Faso. In 2006, the country sold most of the shares of the national telecommunications office, ONATEL, to a private investor (Morocco Telecom), conserving $20 \%$ of the shares in Burkina Faso. Shortly thereafter, the use of mobile services increased significantly, reaching 60 mobile phones per 100 people.

At the regional level, the West African Economic and Monetary Union, the European Union and the ITU have supported the harmonisation of regulations in the telecommunication sector and the establishment of an independent regulator. This includes the interconnection of networks and pricing, as well as co-operation among national regulatory bodies. International co-operation and the adoption of liberal policies in telecom have allowed Burkina Faso to establish one of the most solid enabling environments for foreign service providers, in regulatory terms, and to expand its mobile telecom market. The regulatory body responsible for e-communication (Autorité de régulation des communications électroniques) is considered one of the most efficient governmental agencies. Nevertheless, loopholes in the adoption and implementation of technical regulations could have an impact on investments in the sector.

In contrast with mobile services, fixed broadband telephony has not attracted competition and remains a monopoly in the country. Costs are high, the Internet has not expanded significantly and quality is yet to be improved. While mobile connection has helped to meet consumer demands for Internet, in Burkina Faso poor connectivity remains a burden for businesses, especially those using big data flows, such as financial services and IT.

Source: Adapted from the DTISU of Burkina Faso (2014), http://www.enhancedif.org/en/files/dtis accessed on 20 February 2017 
Through its institutional support for national structures, the EIF prepares the ground for greater inter-ministerial cooperation by setting up EIF National Steering Committees, which include government representatives at the highest level; it also organises private sector round tables and government donor dialogues. Over $90 \%$ of countries with ElF institutional support projects have regular government donor consultation mechanisms. These fora can be used to debate and evaluate trade-related ICT reforms and policies.

UNCTAD and other organisations, including the EIF, have formed an eTrade For All initiative that is helping developing countries to take advantage of emerging opportunities resulting from the global expansion of e-commerce. This initiative, with 21 members including the EIF, has highlighted seven key policy areas of particular relevance to e-commerce development, including assessing the readiness of the LDCs to engage in, and benefit from, e-commerce. Under eTrade For All, demand driven assessments have started to provide a rapid analysis of the current e commerce situation in Bhutan and Cambodia, for example, identifying opportunities, barriers and relevant policy measures. EIF offers support to countries in undertaking these assessments and in formulating concrete proposals to facilitate e-commerce, as well as helping LDCs identify areas in which they could benefit from assistance by eTrade for All partners.

\section{Partnership projects are enabling connectivity and addressing supply-side constraints}

This institutional and analytical work provides a solid groundwork for projects designed to develop productive capacity, helping the poorest communities integrate into world trade flows. Overall, the EIF has supported 38 such projects in $29 \mathrm{EIF}$ countries. The selection of projects involves consultations with the major in country stakeholders and is based on the potential of each project to contribute to export growth and poverty reduction. Priorities identified by in country stakeholders in the DTIS Action Matrices have been taken up by the EIF and translated into projects aimed at enabling connectivity, including:

- trade facilitation in The Gambia, Maldives, Rwanda and Uganda, amounting to USD 10.5 million

- implementation of information systems for tourism in the Solomon Islands

- establishment of online trade portals in Lao PDR, Lesotho and Malawi through concerted support from development partners

- improved competitiveness in Bhutan, the first ElF project with an e-commerce component.

The International Trade Centre (ITC) and UNCTAD—EIF partner agencies—are currently involved in projects to facilitate greater benefits from e-commerce in Rwanda.

In addition, EIF donors and development partners support the LDCs in improving their connectivity (Figure 9.7) For example, Australia has facilitated key reforms in telecommunications in Vanuatu, and mobile coverage in Kiribati and the Solomon Islands, focusing on ICT policy and regulatory reform to support competitive market structures, increase equitable access to services and enable private sector-led investments in ICT infrastructure and services. 
Figure 9.7. EIF partners in digital connectivity

Evidence-based analytical work

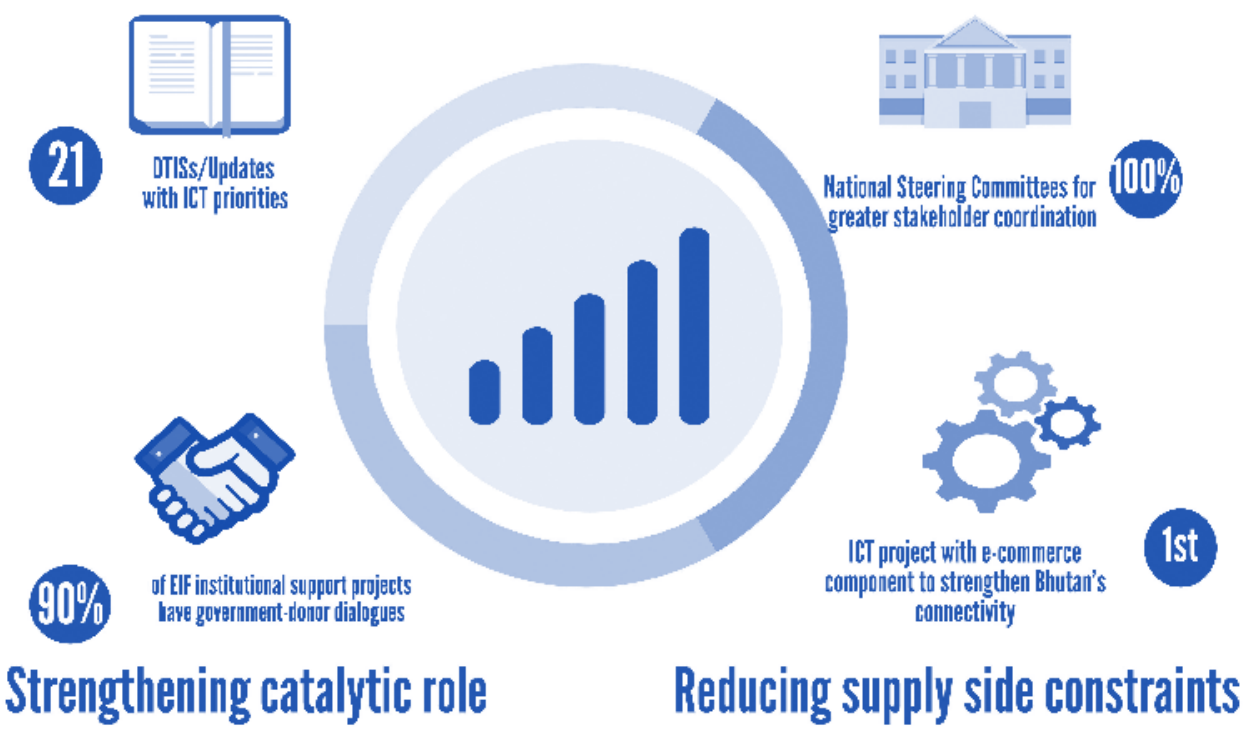

The EIF partnership will further explore synergies with ITU for providing inputs into DTIS/DTISU chapters on telecommunications, and for sharing resources and knowledge for projects to build productive capacity in ICT-related areas. Several EIF countries are already implementing ICT-related projects with support from the ITU (2016b); these include a rural connectivity project in Samoa and projects to enhance government services in Burkina Faso, Mauritania and Rwanda. With ITU support Afghanistan restored its telecommunication and broadcasting infrastructure. Kiribati, Samoa, Solomon Islands and Tuvalu have benefited from support for capacity building in the development of national ICT related policy and regulatory frameworks.

Because the development of Internet infrastructure remains quite costly, establishing closer co-operation among the private sector, donors, development partners and the government should be further explored.

\section{CONCLUSIONS}

Even though connectivity in the LDCs has increased over the past years and this trend is expected to continue, the full potential of digital connectivity is far from being exploited. The EIF partnership, together with other international partners, will continue to work to ensure that LDCs benefit from enhanced connectivity. LDC governments also have a major role to play in accelerating the uptake of new technologies. They shape the enabling environment and can ensure that ICT policies and regulations benefit consumers by allowing for greater access at lower prices. The use and expansion of affordable Internet should also reduce costs for nascent LDC businesses wishing to access global markets.

Up to date analysis of LDC priorities in digital trade, through a flexible and demand driven approach and using EIF diagnostics, will underpin the efforts of the international community to increase Internet connectivity and trade participation for the LDCs. It is crucial for donors, development partners and the private sector to remain engaged as the EIF assists countries in establishing the necessary institutional structure. The digital economy is here to stay, the earlier it is embraced, the more inclusive trade will become. 
Annex 9.A1. Examples of priorities related to digital connectivity and e-commerce identified in the DTIS Action Matrices (page 1 of 4 )

Afghanistan, 2012
Bangladesh, 2015

Reform licensing to enable greater competition. The recent issuance of new licenses that address earlier differences among GSM license terms, while authorising the introduction of broadband wireless services, can boost the level of competition. The Government could consider unifying licenses to make them technology and service neutral to encourage service providers to develop innovative services and leverage advanced technologies. The license award process should be transparent and competitive. Promoting measures to boost competition and coverage, such as number portability and domestic roaming, will be important for continued growth.

The Afghan Telecom Regulatory Agency (ATRA) should focus on implementing the Ministry's "open access" policy. This will ensure that the capacity will be available to competitive service providers on a non-discriminatory basis at transparent and cost-based tariffs. ATRA regulations will implement the policy and will ensure that access to the backbone remains non-discriminatory, transparent and costbased.

Install two additional international submarine cables to ensure minimal redundancy in case of failure of one of the three cables.

Benin, 2015 Improve infrastructure, including energy, water treatment, telecommunications and public services.

Remove monopolies in key telecom services and implement competition policy in telecommunications.

Bhutan, 2012

Continue to develop state-of-the-art broadband (fibre optic and other) infrastructure:

Complete the fibre optic network in Bhutan and connect the fibre network to all communities and their community centres.

Continue to secure several redundant fibre optic connections to the main Internet backbone with Indian telecommunications service providers.

- Continue to seek Quality of Service (QoS) guarantees for backbone data services from Bhutan as well as Indian service providers.

- Continue to track market developments in ICT infrastructure and related innovations.

- Immediate priority: ensure connectivity and QoS, essential for IT enabled services operations that require real time VolP connections.

Connect all communities to the internet to promote greater community participation and to enhance the capacity of all communities to become self-sufficient:
Complete building and connecting community centres in each of the group of villages called Gewogs.

Focus specifically on the 45 Gewogs for which funding is not available.

Undertake a study of demand for telecommunications services (or use results of universal access market studies if available).

Develop a community-access business plan based on a study of demand and on a resulting marketing plan.

Seek to integrate this with activities that promote using the Internet for marketing local skills and resources, and especially local businesses, such as local crafts and and community based tourism.

Create a legal and policy environment that enables e-commerce and ICT-enabled business:
Modernise and strengthen the ICT and media law and regulatory framework by redrafting the Media Act of 2006 
Annex 9.A1. Examples of priorities related to digital connectivity and e-commerce identified in the DTIS Action Matrices (page 2 of 4 )

$\begin{array}{ll}\text { Bhutan, } 2012 & \text { Nurture } \\ \text { sector: }\end{array}$
Develop the Bhutan Innovation and Technology Centre and the Thimphu TechPark Private Limited.

Establish collaboration linkages with the Education City.

\begin{tabular}{|c|c|c|}
\hline \multirow[t]{4}{*}{ Burkina Faso, 2014} & \multicolumn{2}{|l|}{ Improve licensing requirements. } \\
\hline & \multicolumn{2}{|l|}{ Revise universal access policies. } \\
\hline & \multicolumn{2}{|c|}{$\begin{array}{l}\text { Review competition rules affecting the telecommunications sector with a view to increasing } \\
\text { competition at all levels, including broadband access to the Internet. }\end{array}$} \\
\hline & \multicolumn{2}{|l|}{ Examine taxes that affect telecommunications services. } \\
\hline Chad, 2013 & $\begin{array}{l}\text { Accelerate the review and modernisation of } \\
\text { existing texts of the Support for Harmonisation of } \\
\text { ICT Policies in Sub Saharan Africa, in the context } \\
\text { of the Central African Economic and Monetary } \\
\text { Community (CEMAC), with ITU, CEMAC, World } \\
\text { Bank, etc.: }\end{array}$ & $\begin{array}{l}\text { Implement the universal access strategy and a } \\
\text { fund (if necessary) for basic telecommunications, } \\
\text { including high speed Internet access. } \\
\text { Review the } 2007 \text { ICT strategy. } \\
\text { Strengthen the capacity of the justice sector to } \\
\text { address ICT issues. } \\
\text { Strengthen cyber security in Chad. }\end{array}$ \\
\hline
\end{tabular}

Establish an operator to issue electronic certificates and prepare a secure register of these certificates.

Update the plan for the establishment of the N'Djamena fibre optic network and plan the connection points of the optical fibre.

Provide access to Internet for the Presidency and ministries, universities, neighbourhoods, schools and universities and hospitals.

Create public access to the Internet: Internet cafés and community access centres.

Encourage the participation of private investors in PPPs.

The ICT infrastructure management unit is responsible for privatising the International Telecommunication Company of Chad (SOTEL).

Audit and estimate the market value of SOTEL and its operations and market share.

Strengthen assets and consolidate operations in anticipation of privatisation.

Digitise the telephony network in N'Djamena to prepare for a supply of ADSL and cable.

Open to competition the market for fixed telecommunications infrastructure, which depends on the telephone network.

Open to competition the ICT market, and especially Internet infrastructure, including fibre optics.

Comoros, 2015 Improve the quality and reduce the cost of Internet access while increasing the capacity (promote competitiveness in telecommunications).

Djibouti, 2015

Pursue a policy to lower Internet prices for for individuals and businesses.

Operationalise an independent regulatory authority to regulate telecommunications activities 
Annex 9.A1. Examples of priorities related to digital connectivity and e-commerce identified in the

DTIS Action Matrices (page 3 of 4 )

Democratic Republic Modernise and harmonise the legal and regulatory framework for the ICT sector and

of the Congo, 2010 the "information society".

Approve a clear and unified national strategy for the introduction of high-speed infrastructure under the PPP framework and a regime of open access to networks.

Reorganise the Congolese Post and Telecommunications Office and National Satellite

Telecommunication Network with the adoption of a management contract and a PPP for the operation of the existing infrastructure.

Clarify and stabilise the appropriate and coherent fiscal regime, specifically for the ICT sector, consistent with international best practice. The Gambia, $2013 \quad \begin{aligned} & \text { Implement the West Africa telecommunication } \\ & \text { infrastructure }\end{aligned}$
Provide high-capacity and reliable bandwidth through the construction of a submarine cable landing station

Modernise and expand the national telecommunications backbone infrastructure

- Strengthen the legal and regulatory framework for the ICT sector (PURA Act 2001, IC Act 2009)

\begin{tabular}{|c|c|}
\hline \multirow[t]{13}{*}{ Haiti, 2013} & Increase learning opportunities in the ICT sector. \\
\hline & Modernise and strengthen the regulatory and legal framework of the ICT sector. \\
\hline & Conduct a study to prioritise the most necessary ICT services in rural areas. \\
\hline & Prepare a plan for the implementation of a single-window e-government strategy. \\
\hline & Promote e-commerce. \\
\hline & Develop an ICT ecosystem in line with government priorities. \\
\hline & Examine ICT infrastructure and the connectivity of industrial parks. \\
\hline & Review the investment code. \\
\hline & Create an ICT research centre. \\
\hline & Support the establishment of e-payment systems. \\
\hline & $\begin{array}{l}\text { Collaborate with development partners who develop mobile telephony to improve the efficiency } \\
\text { of agricultural value chains. }\end{array}$ \\
\hline & Prepare a digitisation strategy for cultural heritage. \\
\hline & Prepare a strategy on cyber security \\
\hline Lao PDR, 2006 & $\begin{array}{l}\text { Trade opportunities for the poor: engage in e-commerce and promote the traditional handicraft and } \\
\text { textile industry }\end{array}$ \\
\hline Mali, 2015 & $\begin{array}{l}\text { Pursue the modernisation of the telecommunications sector by providing public access to mobile } \\
\text { telephony and the Internet as widely as possible; and conduct cost benefit analysis. }\end{array}$ \\
\hline Mauritania, 2016 & Determine whether the award of a new mobile phone license could help reduce communications costs. \\
\hline Myanmar, 2016 & Provide training to enhance the institutional capabilities of the regulatory agency in telecom. \\
\hline
\end{tabular}


Annex 9.A1. Examples of priorities related to digital connectivity and e-commerce identified in the DTIS Action Matrices (page 4 of 4 )

Mozambique, $\mathbf{2 0 1 5}$ Prepare and assess service offers within the framework of liberalising trade in services: tourism, transport, energy, telecommunication, construction and financial services.
Use the national trade policy and strategy and other relevant development strategies/plans as a basis for formulating a negotiating strategy at the multilateral, regional (SADC, TFTA) and bilateral (EU-SADC EPA) levels.

Identify offensive interests where Mozambique may wish to have access to partners and draft possible service commitments in the context of the Free Trade Area of SADC, TFTA and EU-SADC EPA.

Monitor the implementation of the commitments undertaken
Rwanda, 2011
Promote competition for the provision of ICT services as entrepreneurial activities in order to use it as a tool for income generation.

Promote training schemes for the use of $\mathrm{ICT}$, particularly for youth and women and in rural areas, in order to increase the share of the population accessing the Internet.

Establish a master plan for telecommunications and set specific targets on regulatory reform, including the economic dimension of the sector.

The regulatory authority should redouble efforts to ensure expanded access for independent and international bandwidth.

The regulatory authority must broaden the spectrum of enterprises to be consulted on the adoption of the regulatory framework.

Draft and publish conditions for awarding new licenses.

Sudan, 2014

Support an information system to disseminate quality standards, with all standards published on the Internet.

Establish an electronic system for registration of tourists at the airport

Togo, 2010

Promote the communications systems (telephone and Internet) and the market information systems and assist with the emergence of e-exchanges for agricultural produce.

Vanuatu, 2007

Develop an e-business strategy and make it central to business development efforts. Ensure that technological upgrading remains central to efforts to develop the business environment. Improve the presence of the Vanuatu Investment Promotion Authority on the Internet. 


\section{REFERENCES}

A4AI (2015), The 2015-16 Affordability Report, Alliance for Affordable Internet, http://a4ai.org/affordability-report/ report/2015/

Bollyky T.J. and P.C. Mavroidis (2017), Trade, Social Preferences and Regulatory Cooperation The New WTOThink, in Journal of International Economic Law, 20 (1): 1-30, https://academic.oup.com/jiel/article/20/1/1/3056742/ Trade-Social-Preferences-and-Regulatory

GSMA (2017), Connected Women Programme, GSM Association www.gsma.com/mobilefordevelopment/ programmes/connected-women, (accessed 24 February 2017).

ITU (2015), ICTs in Sustainable Development Awards, www.itu.int/en/ict-sdg-award/2015/Pages/vanuatu.aspx, (accessed 17 February 2017).

ITU (2016a), Facts and Figures Report, International Telecommunications Union, Geneva, www.itu.int/en/ITU-D/ Statistics/Documents/facts/ICTFactsFigures2016.pdf.

ITU (2016b), LDC Project Highlights, International Telecommunications Union, Geneva, www.itu.int/en/ITU-D/LDCs/ Pages/Ldcs Projects.aspx.

ITU (2016c), Measuring Information Society Report, International Telecommunications Union, Geneva, https://www.itu. int/en/ITU-D/Statistics/Documents/publications/misr2016/MISR2016-w4.pdf.

ITU (2017), ITU ICT Regulatory Tracker, International Telecommunications Union, Geneva.

McKinsey (2013), Lions go digital: The Internet's transformative potential in Africa, www.mckinsey.com/industries/ high-tech/our-insights/lions-go-digital-the-internets-transformative-potential-in-africa.

Pew Research Center (2015a), Internet Seen as Positive Influence on Education but Negative on Morality in Emerging and Developing Nations, www.pewglobal.org/files/2015/03/Pew-Research-Center-Technology-Report-FINALMarch-19-20151.pdf.

Pew Research Center (2015b), Communications Technology in Emerging and Developing Nations, www.pewglobal.org/2015/03/19/1-communications-technology-in-emerging-and-developing-nations/.

Pew Research Center (2016), Smartphone Ownership and Internet Usage Continues to Climb in Emerging Economies http://www.pewglobal.org/2016/02/22/smartphone-ownership-and-internet-usage-continues-to-climb-in-emergingeconomies/.

Rwanda (2017), Rwanda Development Board, www.rdb.rw/departments/information-communication-technology/ clusters.html, (accessed 16 February 2017).

Schumann, R. and M. Kende (2013), Lifting barriers to Internet development in Africa: suggestions for improving connectivity, Analysys Mason.

Uganda (2015), Republic of Uganda, Ministry of ICT and National Guidance, www.ict.go.ug/initiative/infrastructure, (accessed 15 February 2017).

UN-OHRLLS (2016), Factsheet for Least-developed Countries, http://unohrlls.org/custom-content/uploads/2016/08/ Least-Developed-Countries-factsheet-2016 ENGLISH FINAL UPDATED-1.pdf.

van Grasstek, C. and M. Mashayekhi (2016), "The services trade agreements of developing countries", in Research Handbook on Trade in Services, eds. P. Sauvé and M. Roy, Edward Elgar Publishing. 
World Integrated Trade Solutions (WITS), https://wits.worldbank.org/WITS/WITS/Restricted/Login.aspx, accessed on 17 February 2017

World Bank (2016), Background Paper Digital Dividends for World Development Report 2016: The Economics and Policy Implications of Infrastructure Sharing and Mutualisation in Africa, World Bank, Washington DC. http://pubdocs.worldbank.org/en/533261452529900341/WDR16-BP-Infrastructure-Mutualisation-Garcia.pdf. WTO (Mid-October 2014 to mid-October 2015), Report to the TPRB from the Director-General on Trade Related Developments.

WTO (2017a), Trade Policy Review - Report by the Secretariat - Sierra Leone.

WTO (2015a), Briefing note: The Expansion of Trade in Information Technology Products (ITA Expansion), https:/www.wto.org/english/news e/news15 e/itabriefingnotes161215 e.pdf.

WTO (2015b), Report of the Working Party on the Accession of the Islamic Republic of Afghanistan, WT/ACC/AFG/36 WT/MIN(15)/6 para. 82.

WTO (2014), Trade Policy Review - Report by the Secretariat - Myanmar.

WTO (2012), Trade Policy Review - Report by the Secretariat - Côte d'Ivoire, Guinea-Bissau and Togo.

Zambia (2017), Zambian ICT Authority, www.zicta.zm. 


\section{NOTES}

1. EIF analytical work has been carried out in the following countries:

Afghanistan, Diagnostic Trade Integration Study, 2012.

Benin, Diagnostic Trade Integration Study Update, 2015.

Bangladesh, Diagnostic Trade Integration Study, 2015.

Bhutan, Diagnostic Trade Integration Study, 2012.

Burkina Faso, Diagnostic Trade Integration Study Update, 2014.

Burundi, Diagnostic Trade Integration Study Update, 2012.

Cambodia, Diagnostic Trade Integration Study Update, 2014.

Chad, Diagnostic Trade Integration Study Update, 2013.

Comoros, Diagnostic Trade Integration Study Update, 2015.

Djibouti, Diagnostic Trade Integration Study Update, 2015.

Democratic Republic of the Congo, Diagnostic Trade Integration Study, 2010.

Gambia, The, Diagnostic Trade Integration Study Update, 2013.

Haiti, Diagnostic Trade Integration Study, 2013.

Lao PDR, Diagnostic Trade Integration Study Update, 2006.

Lesotho, Diagnostic Trade Integration Study Update, 2012.

Madagascar, Diagnostic Trade Integration Study Update, 2015.

Malawi, Diagnostic Trade Integration Study Update, 2014.

Mali, Diagnostic Trade Integration Study Update, 2015.

Mauritania, Diagnostic Trade Integration Study Update, 2016.

Mozambique, Diagnostic Trade Integration Study Update, 2015.

Myanmar, Diagnostic Trade Integration Study Update, 2016.

Nepal, Nepal Trade Integration Study, 2016.

Niger, Diagnostic Trade Integration Study Update, 2015.

Rwanda, Diagnostic Trade Integration Study Update, 2011.

Senegal, Diagnostic Trade Integration Study Update, 2013.

Sierra Leone, Diagnostic Trade Integration Study Update, 2013.

South Sudan, Diagnostic Trade Integration Study, 2014.

Sudan, Diagnostic Trade Integration Study Update, 2014.

Timor-Leste, Diagnostic Trade Integration Study, 2011.

Togo, Diagnostic Trade Integration Study, 2010.

Uganda, Diagnostic Trade Integration Study Update, 2013.

Vanuatu, Diagnostic Trade Integration Study, 2007.

Zambia, Diagnostic Trade Integration Study Update, 2014. 



\title{
CHAPTER 10
}

\section{PUBLIC-PRIVATE PRIORITIES \\ FOR AID FOR TRADE IN THE DIGITAL ERA}

\author{
Contributed by Business for eTrade Development
}

\begin{abstract}
The enabling environment for digital trade is suboptimal in many developing countries, impeding the translation of new technologies into trade and growth. Yet there are huge gaps in the data available on private sector views, and on systematic public-private collaboration. This chapter discusses the findings from interviews with companies engaged in e-commerce to shed light on the challenges of the enabling environment for digital trade. It examines data that show that trade finance, logistics, and digital regulations are often suboptimal, making it difficult for developing country companies to engage in cross-border e-commerce. It provides highlights of various projects being championed by the private sector to cultivate e-commerce worldwide, including among women and rural entrepreneurs. The chapter proposes innovative solutions to these challenges and highlights ways of operationalising public-private partnerships in e-commerce development, as well as fresh ways of financing them, such as social impact bonds. It maps out policy pathways to overcome the challenges to e-commerce.
\end{abstract}




\section{INTRODUCTION}

A small number of "export superstars" - typically large multinational companies—currently shapes the trade patterns of practically all economies. Meanwhile, the majority of companies, particularly small businesses, have yet to engage in trade. Export participation rates for firms in East Asia and the Pacific are 10.4\%, in Latin America 12.4\%, and in subSaharan Africa 9.8\% (World Bank, 2017). Where these companies do export, they are normally "narrow" exporters, selling on average to only two to three markets. However, exporters derive a significant share of their sales from exports. For example, about $50 \%$ of sub-Saharan African exporters' revenues stem from exports. Yet the volume of this trade is still small, as is the number of exporters. Trade flows are driven by a limited number of firms: in most countries the top 5\% of exporters, the largest exporters, typically account for over $80 \%$ of exports (World Bank, 2016). Most new exporters, often at least 70\%, do not last more than a year as exporters.

However, these patterns are now radically changing. Using the Internet and e-commerce platforms, companies of all sizes are much more visible to prospective customers around the world and, research shows, much more poised to export and import, and to scale their sales, than ever before. For example, in a survey of developing country firms, Suominen (2017a) shows that while fewer than $20 \%$ of small offline sellers export, about $50 \%$ of small online sellers do so; and while offline exporters tend to export to only one market, over $60 \%$ of online sellers export to two or more markets. The Boston Consulting Group finds that small and medium enterprises that are heavy web users are almost $50 \%$ likelier to sell products and services outside of their countries than those that make less use of the web (Zwillenberg et al., 2014).

Similarly, eBay data shows that in Chile, all companies that sell on eBay also export, as opposed to only $18 \%$ of brickand-mortar companies; and they sell on average to 28 different markets, as opposed to the 2 to 3 markets the median exporter sells to (eBay Mainstreet, 2013). Unlike offline sellers, most online exporters also survive as exporters year after year-partly because, precisely, they are so diversified across markets.

In short, digitization is breaking the "iron law" of international trade - that exporting is possible only for a few.

Digitisation is not only impacting sales of goods across borders; it also is disrupting trade in services. By leveraging cloud-based tools, developing country businesses can efficiently build a regional footprint and local following, allowing them to service customers around the world. For example, the Indian software company Freshdesk has grown from two employees in 2010 to 800 today by helping 80000 companies worldwide, such as Cisco, Honda and 3M, to offer a better customer experience (Freshdesk, n.d.). "Born-digital" companies like Freshdesk are often also "born global", i.e. able to launch in several markets in quick sequence. Microwork platforms, such as Upwork and Freelancer, are expanding the opportunities for freelancers and small businesses in developing countries to sell their services or engage in "trade in tasks" with businesses in other countries.

These findings also mean that digitisation is opening up entirely new opportunities for developing countries to promote entrepreneurship, job-creation, productivity growth and trade across borders. It enables countries to grow both their intensive and extensive margins in trade - that is, to increase the number of exporting firms, the range of goods and services exchanged, the number of markets reached, and the volume and value of sales. It enables developing country companies and consumers to access a wider variety of goods and services at lower cost, streamline trade operations and logistics, and access new data to create operational efficiencies, develop deeper market insights, gain in competitiveness, and even productise data as a new revenue stream—all without having to build their own expensive information technology (IT) infrastructure (Suominen, 2017a; 2017b). As an example, by running its African and Middle East online booking operations on Amazon Web Services, the South African travel-booking website Travelstart has realized operational cost savings of $43 \%$ and reduced downtime by $25 \%$ (Amazon Web Services, n.d.). 
However, the gains from digitisation are not automatic. The enabling environment for digital trade is suboptimal in many developing countries, impeding the translation of new technologies into trade and growth. These issues have been discussed in previous chapters.

There are two obstacles standing in the way of solutions to these challenges:

\section{Lack of actionable, granular data on the enabling environment, which is critical to companies}

engaging in e-commerce. While the key components of the enabling environment for e-commerce are by and large understood, there is still relatively little data available - mostly only anecdotal evidence - regarding the obstacles companies face when engaging in e-commerce in any given country.

2. Lack of systematic collaboration between the public and private sectors. In many countries, public-private partnerships to fashion e-commerce policies and regulations, or to pool efforts to unlock specific challenges to e-commerce, are lacking.

The private sector is closest to the opportunities, challenges, and solutions to e-commerce development; as such private sector participation is critical for informing and guiding policymaking on e-commerce issues around the world. The private sector is also engaged in a stunning array of projects to bring women, rural populations, and small and medium enterprises (SMEs) into the stream of e-commerce. Yet there are huge gaps in the data available on private sector views and on systematic public-private collaboration. These gaps limit the ability of developing countries to fuel digital trade, to prioritize policy choices and investments in digitisation and e-commerce, or to build on the private sector's ongoing work to boost connectivity, fuel logistics and indeed, to create entirely new e-commerce markets. These knowledge gaps also complicate efforts to re-gear aid for trade to better support digital connectivity and trade.

The purpose of this chapter is to tackle these challenges by:

- discussing the findings of two new surveys and an index developed by the author, which examine the challenges of the enabling environment for digital trade by interviewing those closest to these challenges: companies engaged in e-commerce as merchants, e-commerce platforms, IT enterprises, and payment or logistics providers;

- providing highlights of various projects being championed by the private sector to cultivate e-commerce worldwide, including among women and rural entrepreneurs;

- mapping out, based on these findings, policy pathways to overcome priority challenges to e-commerce and fuel public-private partnerships in e-commerce development.

The chapter discusses the survey data, then turns to the examination of various projects. It offers recommendations for moving forward, including a new framework for public-private dialogue and partnerships for e-commerce development. Finally, the chapter offers conclusions.

\section{VIEWS ON THE BOTTLENECKS TO DIGITAL TRADE IN DEVELOPING COUNTRIES VARY}

Digitisation is reshaping the patterns, players, and possibilities of international trade. It is opening new trade opportunities for companies of all sizes and across all sectors. However, it is quite widely known that there are also numerous challenges that need to be overcome for digitisation to translate into trade and growth gains. These challenges include basic connectivity issues, especially in the LDCs; limited digital skills in many economies; and logistics and market access bottlenecks. They also include policy and regulatory issues, such as data privacy rules that limit access to customer data and its transfer; incomplete intellectual property frameworks; and legal liabilities for Internet intermediaries regarding content, such as user reviews on their portals. 
To date, however, there is very limited understanding of the policy priorities for unlocking the enabling environment in any one country. Two recent studies have been carried out by the author: one in 14 developing economies (Argentina, Brazil, Chile, Colombia, Mexico, Uruguay, Pakistan, Bangladesh, India, Philippines, Kenya, Nigeria, South Africa and Ghana) covering 3500 merchants and e-commerce ecosystem companies (e-commerce and payment platforms, shippers, banks, IT firms, etc.); and another covering some 300 Latin American firms. These studies aim to bridge the knowledge gaps, providing nuanced and actionable policy insights for governments to unlock their e-commerce economies.' The first study also creates a new E-commerce Development Index that enables the tracking of private sector views on e-commerce development in countries worldwide (Suominen, 2017a).The key findings from this study include:

In every size-category, companies with online sales are much likelier to export than companies that do not have online sales (Figure 10.1).

\section{Figure 10.1. Percentage of companies that export, by company size and online activity}

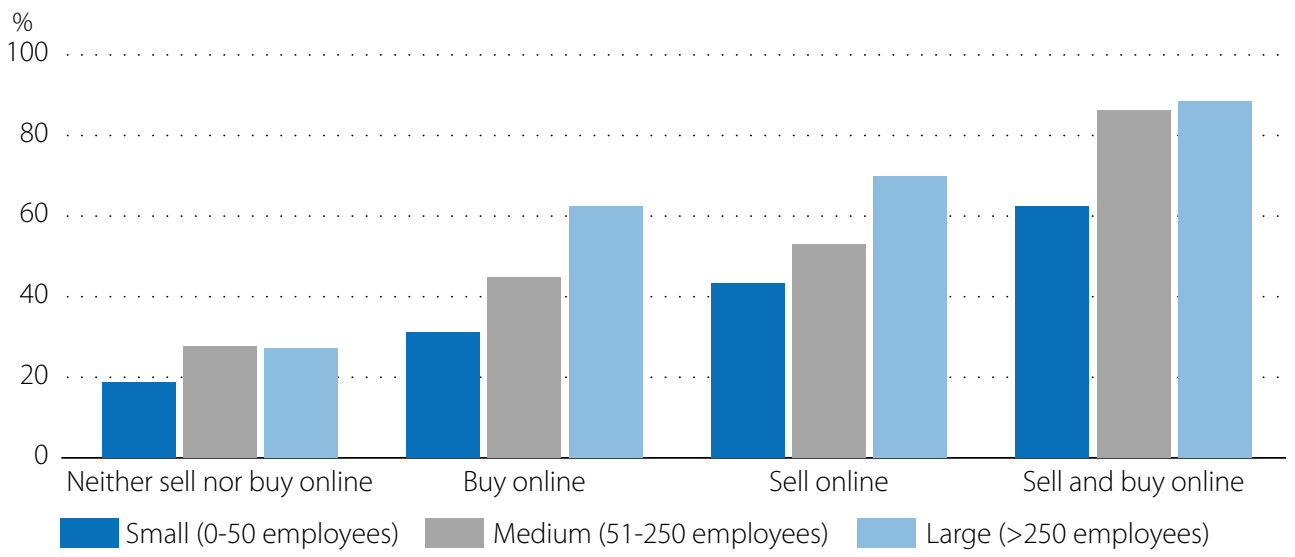

Source: Suominen (2017a), E-commerce development survey and index.

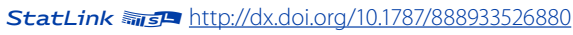

- Online sellers are more geographically diversified. Some $63 \%$ of online sellers export to two or more markets, while only one-a third of offline sellers do so; surveyed companies that neither buy nor sell online typically export to only one foreign market (Figure 10.2). Companies with online sales also derive a larger share of their revenues from exports than companies that do not buy or sell online. Similarly, companies that sell online are also likelier to be fast-growing (10\% or higher annual revenue growth), whereas companies that do not sell online tend to grow slowly (less than 10\% per annum).

Figure 10.2. Number of markets companies sell into, by company's online sales activity

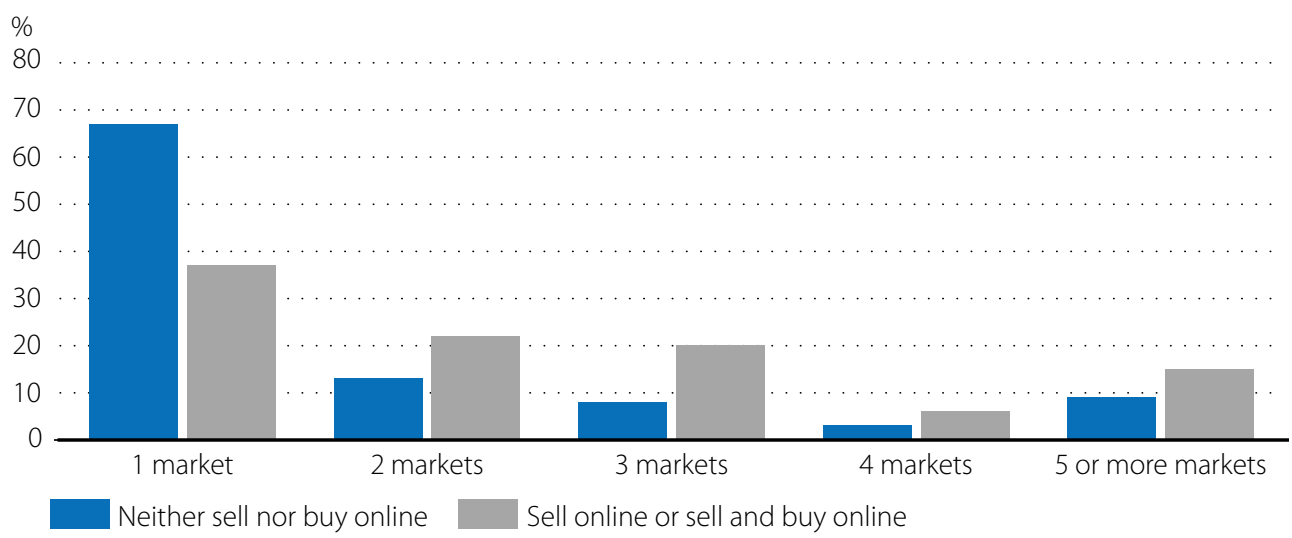

Source: Suominen (2017a), E-commerce development survey and index.

StatLink 게온 http://dx.doi.org/10.1787/888933526899 
Figure 10.3. Merchants' perception of obstacles to cross-border e-commerce, by company size

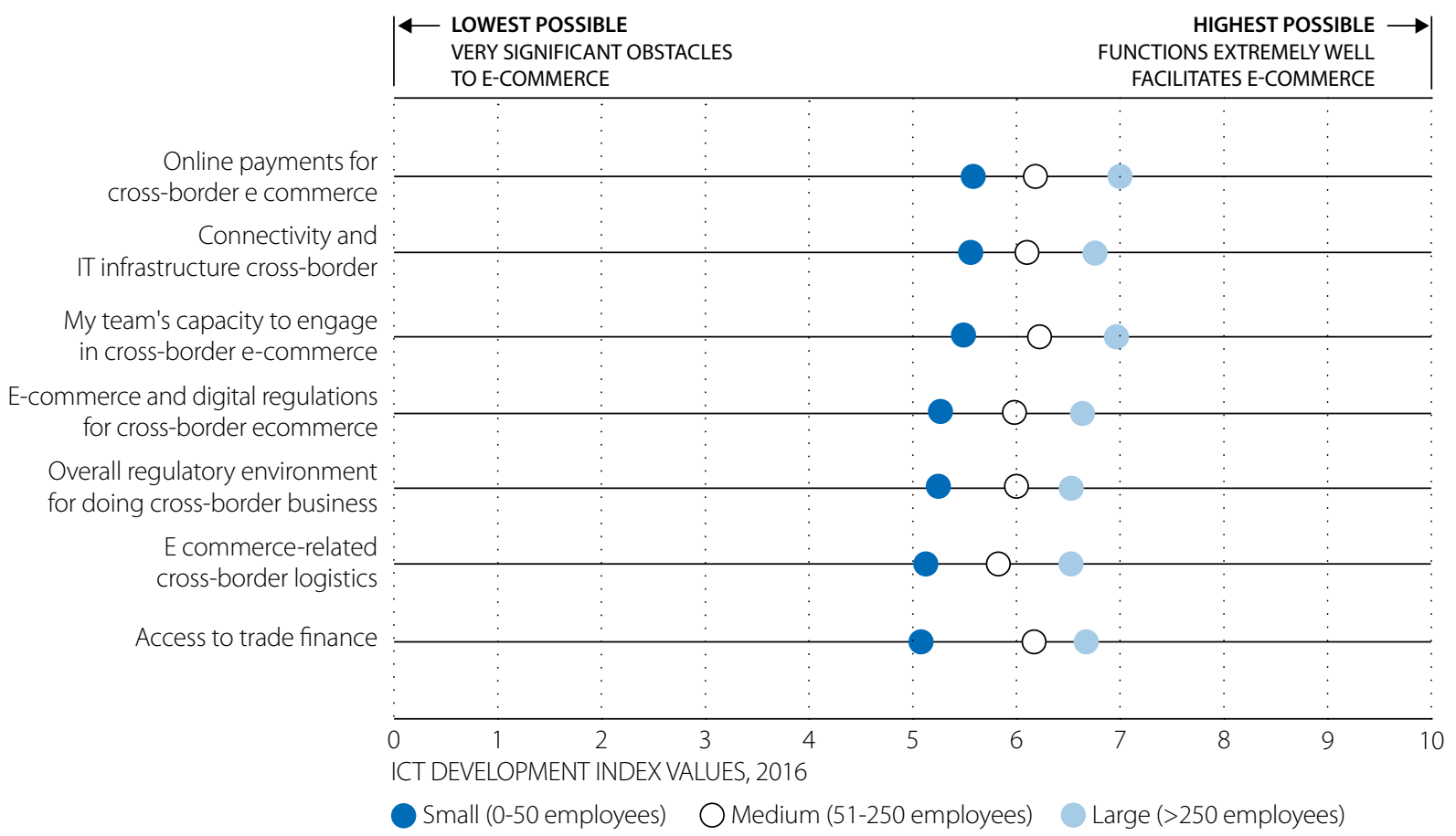

Source: Suominen (2017a) E-commerce development survey and index.

As expected on the basis of firm-level studies in international trade, company characteristics shape companies' perceptions of barriers to e-commerce, with small businesses reporting that they are particularly hampered. In every country, small companies tend to be considerably more affected by the various potential barriers to e-commerce than large companies, with access to finance and e-commerce logistics posing particularly steep challenges for small businesses (Figure 10.4). Midsize and large companies, meanwhile, wrestle most with logistics, and with digital and other regulations. The gaps are significant between small and large companies: for example, some $60 \%$ of the surveyed small companies rate the e-commerce enabling environment at 5/10 or below, while only one-third of large companies do so. These differences are echoed in the responses to questions about cross-border e-commerce (Figure 10.3).

- Perceived challenges to e-commerce vary significantly across and within countries; every country has its idiosyncratic challenges, which means that policy recommendations and interventions need to be tailored to each country. The study asked companies to rank the functioning of the enabling environment for e-commerce from 1 (very poor, significant barriers to e-commerce) to 10 (excellent, facilitates e-commerce), both in broad categories (such as logistics) and in narrow subcategories that are helpful for designing policy interventions (such as, under logistics, last-mile delivery and customs procedures for e-commerce imports). The results show substantial variation. For example, in countries such as Bangladesh, online payments are a leading hindrance to e-commerce; in others, such as Argentina and Kenya, crossborder logistics and customs procedures are the most challenging issues (Figure 10.4). In other countries, such as Brazil, e-commerce and digital regulations, and the overall regulatory environment, complicate e-commerce. In Nigeria, access to finance and logistics issues dominate the list of problems. In Pakistan, the high cost of broadband and lack of Internet connectivity are reported to hamper e-commerce. 
Figure 10.4. Rating of the enabling environment for e-commerce and cross-border e-commerce, selected countries

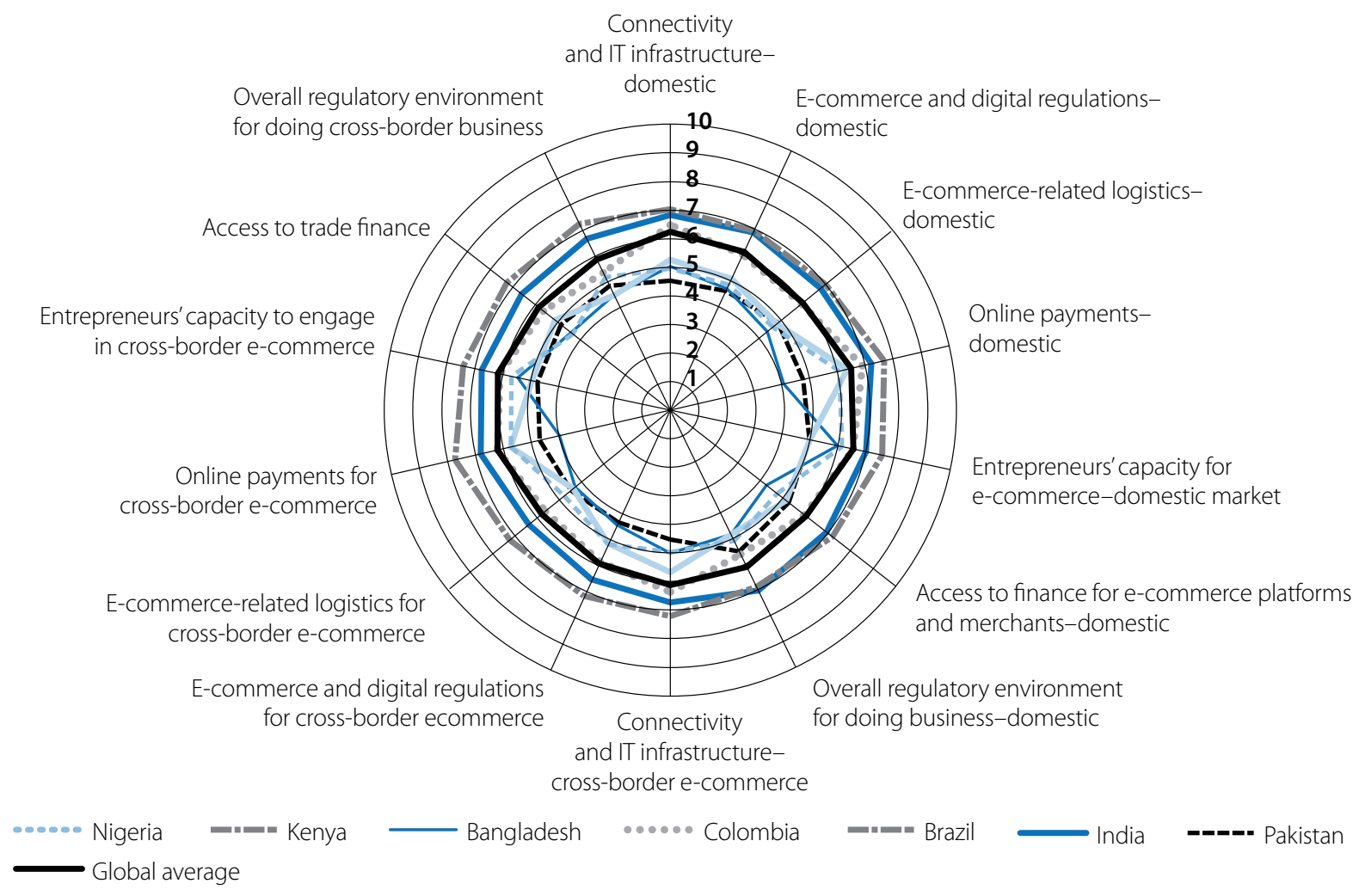

Note: 1 = very poor; $10=$ excellent.

Source: Suominen (2017a), E-commerce development survey and index.

StatLink न्तls/s http://dx.doi.org/10.1787/888933526937

- Driving e-commerce development requires actionable insights into specific bottlenecks. While it is useful to know that e-commerce logistics require improvements, it is even more useful for policy purposes to know the specific aspects of logistics that need work, such as urban last-mile delivery, or customs procedures specific to e-commerce imports. When asked about specific challenges, developing country merchants name total cost of delivery, legal liability rules, and customs procedures for e-commerce imports as key challenges in cross-border e-commerce (Table 10.1). Ecosystem companies, meanwhile, also see logistics as a bottleneck; in addition, they highlight a range of digital regulations as challenges for cross-border e-commerce.

- Companies believe that undoing barriers to e-commerce would result in significant revenue and growth gains. If their top three perceived challenges to e-commerce were removed, developing country companies believe they would perceive annual revenue gains of 34\% in their domestic markets and 30\% in international markets (Figure 10.10). Small companies would expect gains of 37\% domestically and $34 \%$ internationally. 


\section{Table 10.1. Small company rating of the top 15 challenges in enabling environment for cross-border e-commerce, by subcomponent}

\begin{tabular}{|c|c|c|}
\hline $\begin{array}{l}\text { Ranking of } \\
\text { challenges }\end{array}$ & Merchants & Ecosystem \\
\hline 1 & Finance: Availability of trade finance for merchants & $\begin{array}{l}\text { Logistics: Total cost of delivery from my country } \\
\text { to foreign buyers (exports) }\end{array}$ \\
\hline 2 & $\begin{array}{l}\text { Logistics: Customs procedures for } \\
\text { e-commerce imports }\end{array}$ & $\begin{array}{l}\text { Digital regulation: Intellectual property protections } \\
\text { in other markets }\end{array}$ \\
\hline 3 & $\begin{array}{l}\text { Logistics: Cost of logistics for cross-border } \\
\text { transactions }\end{array}$ & $\begin{array}{l}\text { Logistics: Market access (tariffs, trade policy) in } \\
\text { my country's main export markets }\end{array}$ \\
\hline 4 & $\begin{array}{l}\text { Logistics: Total cost of delivery from my country } \\
\text { to foreign buyers (exports) }\end{array}$ & $\begin{array}{l}\text { Logistics: Customs procedures for } \\
\text { e-commerce imports }\end{array}$ \\
\hline 5 & Payments: Cost of cross-border online payments & $\begin{array}{l}\text { Logistics: Customs procedures in main } \\
\text { export markets }\end{array}$ \\
\hline 6 & $\begin{array}{l}\text { Logistics: Market access (tariffs, trade policy) } \\
\text { in main export markets }\end{array}$ & Logistics: Infrastructure for cross-border transactions \\
\hline 7 & $\begin{array}{l}\text { Logistics: Infrastructure for cross-border } \\
\text { e-commerce }\end{array}$ & Digital regulation: Copyright laws in other markets \\
\hline 8 & $\begin{array}{l}\text { Logistics: Postal services for cross-border } \\
\text { e-commerce, import or export }\end{array}$ & Digital regulation: Censorship rules in other markets \\
\hline 9 & $\begin{array}{l}\text { Logistics: Customs procedures in main } \\
\text { export markets }\end{array}$ & $\begin{array}{l}\text { Overall regulatory environment: Tax rules in } \\
\text { other markets }\end{array}$ \\
\hline 10 & $\begin{array}{l}\text { Digital regulation: Consumer protection laws } \\
\text { in other markets }\end{array}$ & $\begin{array}{l}\text { Digital regulation: Internet intermediary liability/safe } \\
\text { harbour in other markets }\end{array}$ \\
\hline 11 & $\begin{array}{l}\text { Digital regulation: Interoperability of digital } \\
\text { and e-commerce regulations with trading } \\
\text { partner markets }\end{array}$ & $\begin{array}{l}\text { Logistics: Postal services for cross-border e-commerce, } \\
\text { import or export }\end{array}$ \\
\hline 12 & $\begin{array}{l}\text { Digital regulation: Legal liability laws for online } \\
\text { sellers in other markets }\end{array}$ & $\begin{array}{l}\text { Digital regulation: Data localization requirements } \\
\text { in other markets }\end{array}$ \\
\hline 13 & $\begin{array}{l}\text { Digital regulation: Copyright laws in } \\
\text { other markets }\end{array}$ & $\begin{array}{l}\text { Over the Top (OTT) regulations (application } \\
\text { of telecom and broadcast rules) in other markets }\end{array}$ \\
\hline 14 & $\begin{array}{l}\text { Digital regulation: Intellectual property protections } \\
\text { in other markets }\end{array}$ & $\begin{array}{l}\text { Digital regulation: Data privacy requirements } \\
\text { in other markets }\end{array}$ \\
\hline 15 & $\begin{array}{l}\text { Overall regulatory environment: Tax rules } \\
\text { in other markets }\end{array}$ & Payments: Cost of cross-border online payments \\
\hline
\end{tabular}


Box 10.1. Internet-based exporters in Latin America: Market access barriers and customs procedures

A study by Suominen (2017b) developed for the Inter-American Development Bank (laDB) shows that the Internet is also a hugely important growth lever for Latin American and Caribbean (LAC) companies: it improves companies' interaction with customers, streamlines their operations, and helps them access new markets for their products and services, among other benefits. The Internet is also ingrained in the daily business of companies in LAC: the bulk of companies in the region would incur a productivity loss of 15\% or more if the Internet were taken away (Figure 10.5).

Figure 10.5. LAC Companies' answers to the question: "What would be the loss on your organization's productivity (measured as the value of sales per employee) if it did not have access to the Internet or other digital networks?"

Estimated productivity loss by company revenue category

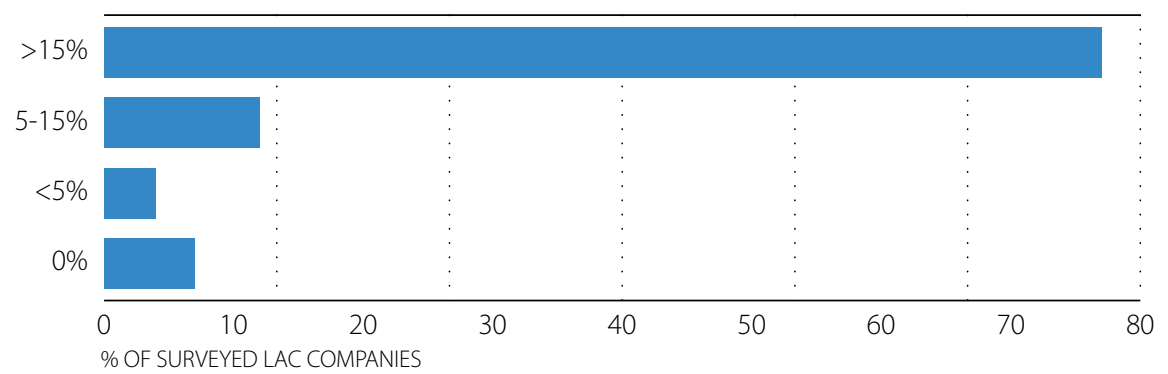

Source: Suominen (2017b), Accelerating Digital Trade in Latin America and the Caribbean.

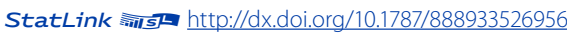

Traditionally, only a small fraction of LAC companies (some 13\%) have exported, and often they have derived only a minor share of their revenues from exports. However, among the surveyed companies that have some online presence and typically some online sales, over 50\% sell and buy online across borders (Figure 10.6), often deriving nearly 50\% of their revenue from export sales. Online presence also has earned developing companies new foreign customers they did not have before selling online.

\section{Figure 10.6. Percentage of online LAC companies with cross-border online sales or purchases in 2016 , by revenue category}

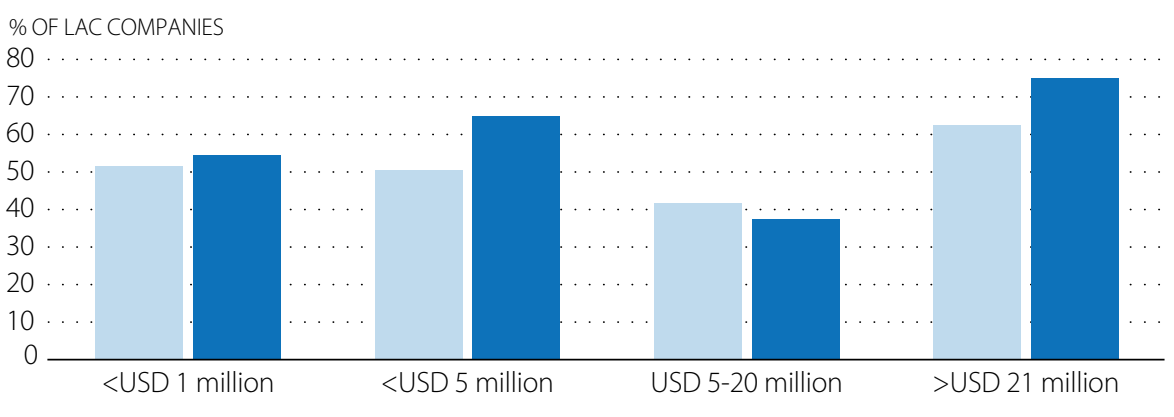

Cross-border online sales

Cross-border online purchases

Source: Suominen (2017b), Accelerating Digital Trade in Latin America and the Caribbean. StatLink न्तार http://dx.doi.org/10.1787/888933526975

When physical goods sold online are shipped across borders, companies still confront the traditional hurdles to trade, such as market access barriers to trade in goods, and trade compliance costs. For example, among Latin American companies that already sell goods and services to, and buy these from, foreign markets, over 50\% find market access barriers a "very significant" obstacle; over 40\% give the same rating to poor logistics in other markets; and 32\% award this rating to compliance with customs procedures (Figure 10.7). One-third of them see too many uncertainties stemming from Internet intermediary liability rules. Notably, these various barriers obstruct small companies much more than large ones. 
Figure 10.7. Challenges to cross-border online sales rated as "very significant" by LAC companies, by type (cross-border sellers)

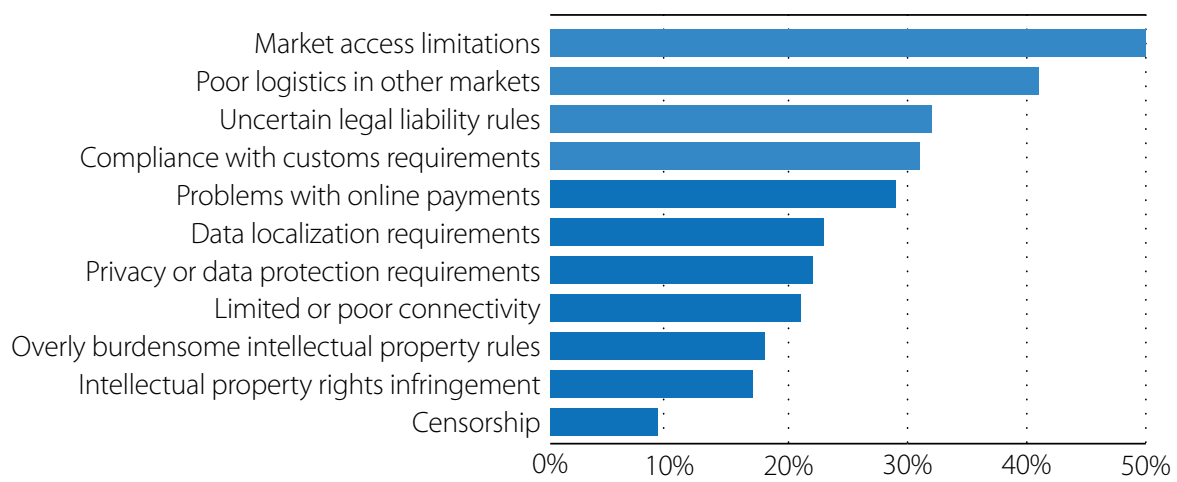

Source: Suominen (2017b), Accelerating Digital Trade in Latin America and the Caribbean.

StatLink नils http://dx.doi.org/10.1787/888933526994

If these obstacles to selling online and across borders were removed, LAC companies report they would score an average of $65 \%$ revenue growth from international sales and 50\% from domestic sales (Figure 10.8). Companies that are intensive digital traders (i.e. that derive over $50 \%$ of their online sales revenue from foreign markets) expect $90 \%$ growth in revenue from foreign markets and $51 \%$ in the home market if these obstacles are removed.

\section{Figure 10.8. LAC companies perceived revenue growth at home and abroad if challenges were removed}

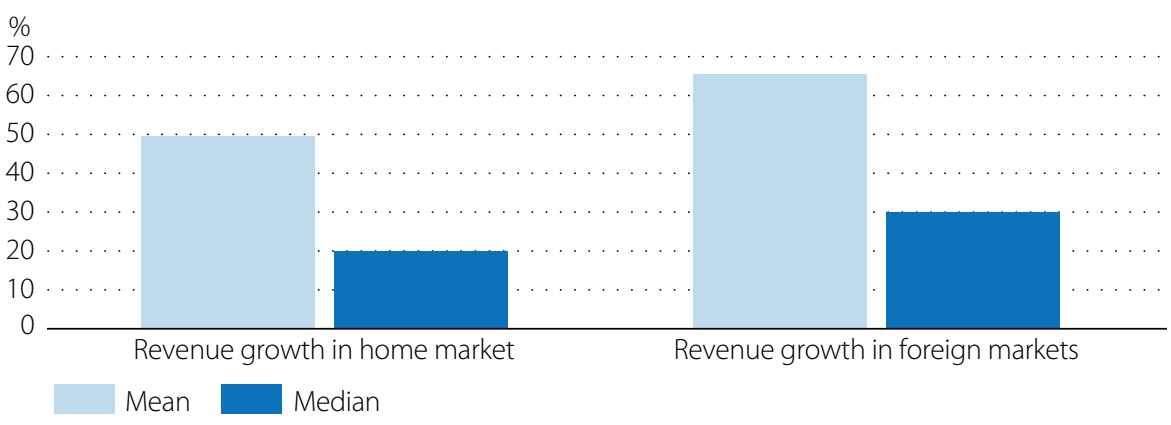

Source: Suominen (2017b), Accelerating Digital Trade in Latin America and the Caribbean.

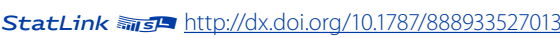

While some of the challenges to digital trade are external to companies, many are internal. LAC companies surveyed for this study find it challenging to grow revenues online due to lack of talent, difficulties in securing employee and management buy-in, and the need to gain knowledge on how to leverage the Internet (Figure 10.9). This, in part, reflects an external constraint: the region's limited ICT skill levels. Regional consumers, meanwhile, are concerned about online fraud and the need to deal with shipping costs of items ordered from overseas.

\section{Figure 10.9. LAC companies' perceived challenges to online sales}

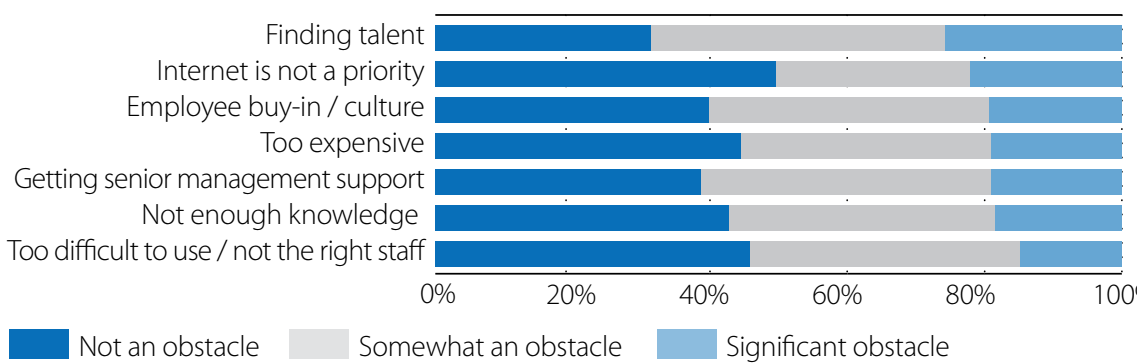

Source: Suominen (2017b), Accelerating Digital Trade in Latin America and the Caribbean. StatLink 겦ㄴ http://dx.doi.org/10.1787/888933527032 
Figure 10.10. Revenue gains to companies if the top three barriers to e-commerce were removed, by market

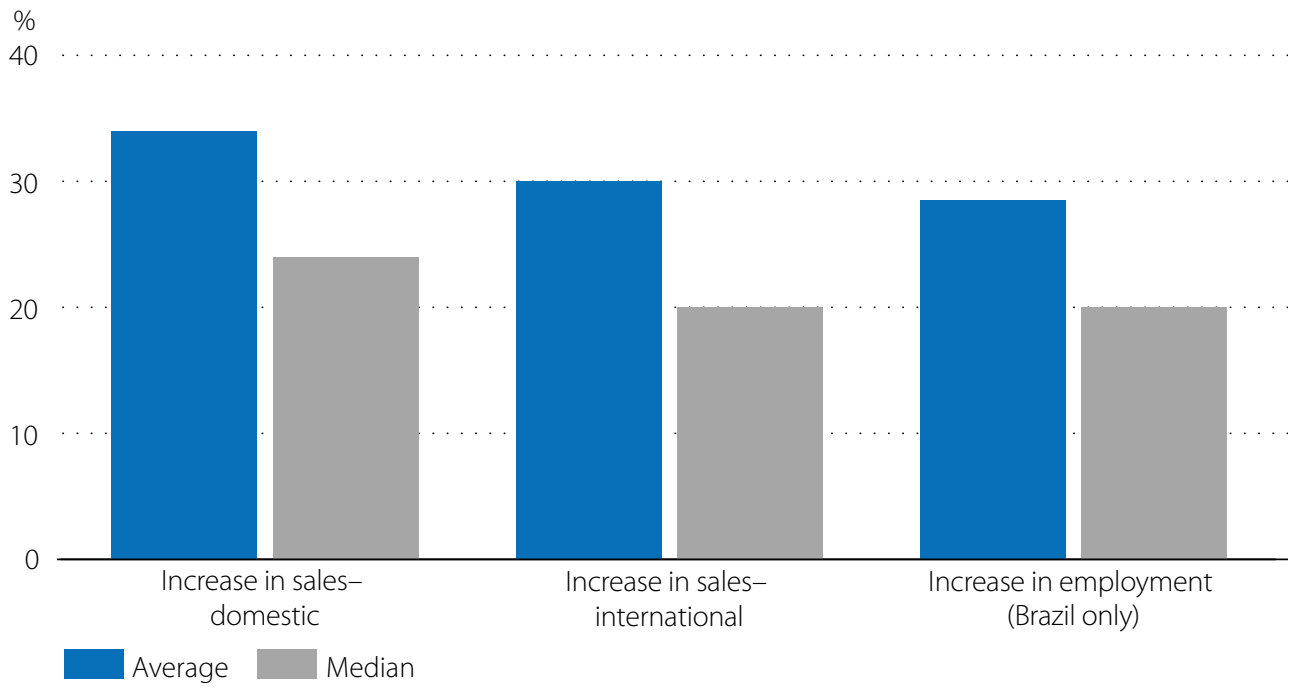

Source: Suominen (2017a), E-commerce development survey and index.

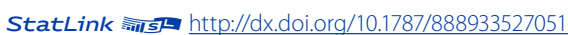

- Companies that have yet to start selling online worry about the complexities involved in exporting using e-commerce and about the uncertainties related to returns on investment (Figure 10.11). Companies in Latin America highlight logistics as a challenge, while companies in Africa mention the obstacle of the small size of the market.

\section{Figure 10.11. Perceived priority barriers to starting to sell online, selected countries}

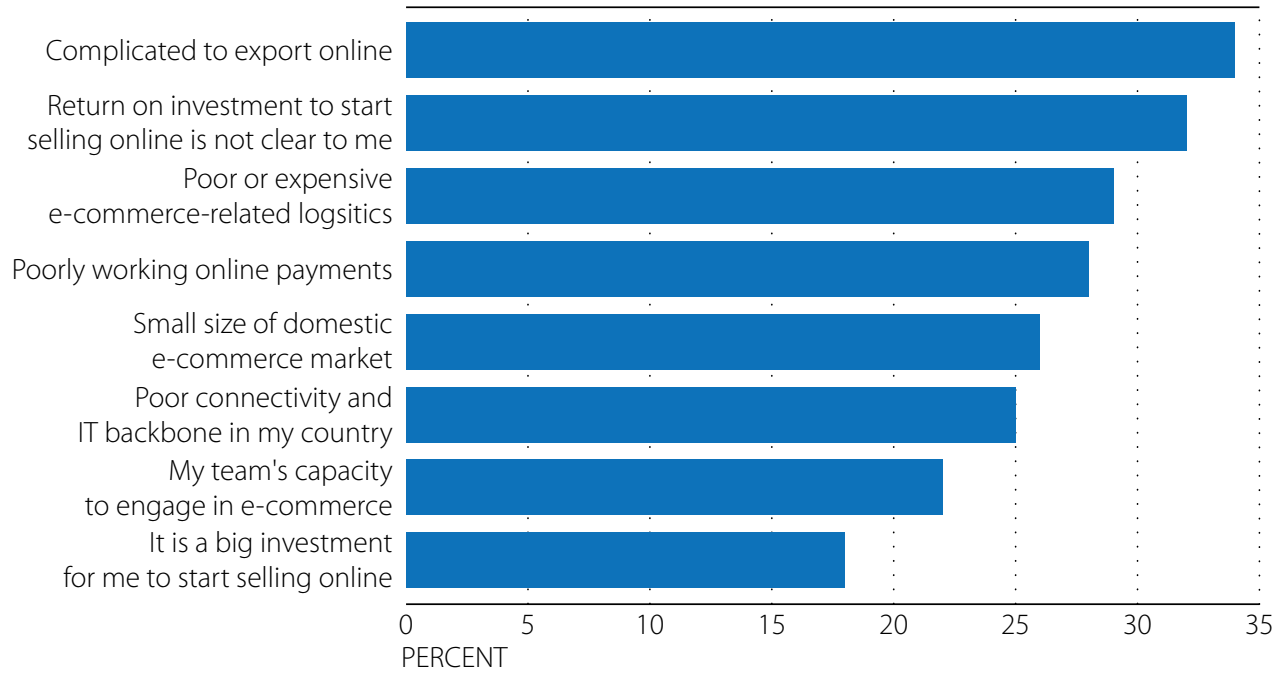

Source: Suominen (2017a), E-commerce development survey and index. 
In sum, the two surveys reviewed here have highlighted that:

- The Internet has become a key means for small companies, in particular, to internationalize. Compared to the broader market of offline sellers, of which only a small fraction export or import, a significant share of the online companies sell and buy online across borders.

- Companies report access to trade finance, logistics and regulations as key challenges to their engagement in cross-border e-commerce. In practically every economy surveyed, small companies tend to be considerably more affected than large companies.

- Perceived challenges to e-commerce vary significantly across countries, which means that policies and investments need to be tailored to each country. Universally, companies see the nature of the overall business environment, e.g. tax policies, as critical for e-commerce success.

- Removing barriers to e-commerce would result in significant revenue and growth gains. The barriers surveyed here matter. If the top three barriers to e-commerce identified here were overcome, companies believe they could achieve annual revenue gains of over $30 \%$.

The next section discusses some ways in which the private sector is seeking to address these challenges.

\section{HOW THE PRIVATE SECTOR CREATES NEW E-COMMERCE ECONOMIES}

Private sector entities are observing a number of challenges to e-commerce in their own economies, but they are also taking action. Businesses big and small are actively pursuing solutions, including efforts to connect the more marginalized segments of business and society in developing countries_-small businesses, women entrepreneurs, and rural populations - to the online economy. These efforts have typically involved significant investments by the private sector and yielded results that should be of interest to donors and international agencies seeking to produce similar results. They can also pave the way for collaboration between the public and private sectors. Several of these initiatives are summarised below, as reported by the companies themselves.

\section{The e-commerce industry has shown results in the Caribbean, Africa, Turkey and China}

E-commerce is a relatively new industry that local entrepreneurs have often built from scratch, overcoming many of the issues cited in the above surveys.

One example is Trini Trolley, an online shopping platform in the Caribbean that has been in operation since 2009. Trini Trolley was motivated by the lack of online shopping platforms in the Caribbean. Orders from international companies had long delivery times and high costs; customers experienced difficulties with returns; and some international providers did not see a profit in shipping low volumes to the Caribbean region. Furthermore, international websites would not accept Caribbean credit cards and local customers risked losing money on fraudulent websites. In addition, fewer than $20 \%$ of Caribbean people had access to a credit card.

Trini Trolley initially learnt from international companies such as Amazon, subsequently developing innovative solutions for the local and regional markets. The company also carried out campaigns to educate the public on the ease and security of e-commerce. It responded to regional challenges to online shopping with its online platform, offering a 24/7 online store with over 12000 products from international and local suppliers and delivering as quickly as within 24-48 hours to customers in Caribbean. The company also provided safe payment facilities and faster, more affordable delivery service and return options. 
Trini Trolley introduced payment by cash or hand-held card-processing terminals for debit or credit cards, as customers were sceptical about providing credit card information online. International customers were offered the option of using PayPal to facilitate purchases for family and friends in the Caribbean. By 2011, the company expanded to offer shipping to the rest of the Caribbean and the world. Trini Trolley opened up its e-commerce platform at no cost to local entrepreneurs and others who did not have the knowledge or funds to create their own websites, or physical stores to display their items for sale.

When it started out, the company had to overcome several challenges, such as high start-up costs for inventory, marketing, and logistics; limited access to capital from commercial banks; scant regulatory guidance for the industry; unclear consumer protection laws; and inadequate payment systems. Trini Trolley is currently enabling exports to the United States (US), United Kingdom (UK), South and Central America and the Caribbean. The company foresees its main challenges as having to do with transportation and logistics, cybersecurity, and access to venture capital (OECD-WTO aid-fortrade monitoring exercise 2017, Private sector case story 85).

A 2010 survey of use of the Internet in Burundi, conducted by Burundi Internet General Applications Network (BIGAN), showed that more than $70 \%$ of respondents in rural communities felt that e-commerce could effectively address some of their business challenges, such as inadequate supply of inputs in remote areas. At the same time, the study identified several challenges to unlocking this opportunity, such as lack of Internet connectivity and skills; poor online payment systems; lack of logistics services for small businesses; and lack of trust in online transactions.

Burundi Shop has worked to address these gaps by setting up an online business distribution centre, where products and services of East African companies can be easily found and sold online as well as through agents operating across the country. The project locates "national agents" to help small traders build their online stores free of charge and enable customers to track their goods using the Internet or text messages. The agents are connected to four major East African platforms. Burundi Shop uses Isoko Courier Services to affordably deliver small shipments door-to-door. The main expected benefit from the project is that it will enable companies to order supplies directly from a manufacturer and thereby bypass brokers. Reduction in supply chain costs thanks to one-stop shopping will also reduce overall costs, with some of the savings passed on to the consumers.

There are also bilateral initiatives to build e-commerce markets in areas where they have yet to be opened. One example is the China-Turkey cross-border e-commerce pilot, launched by the Turkish Ministry of Transport, Maritime and Communications and the People's Republic of China's (hereafter China) National Development and Reform Commission. The effort was kicked off in November 2015 in Antalya, in the margins of the G20 Summit. The World SME Forum and DHGate were designated as the private sector implementing partners. The pilot's objective is to enable a larger number of SMEs in both China and Turkey to engage in cross-border e-trade, for example by developing collaborative city pairs for cross-border e-commerce; boosting the development of cross-border e-commerce platforms; and strengthening the e-commerce and logistics infrastructures in both economies. The pilot project is aligned with the 2016 B20 Presidency's priority of promoting the global e-commerce activity of SMEs by setting up cross-border e-commerce experiment zones based on international experiences and best practices.

\section{Connecting rural areas helps to power e-commerce for their populations}

E-commerce has provided a wonderful means of accessing retailers for rural populations, allowing their companies to access suppliers that are not present in their geographic vicinity. It is also enabling rural companies to "export" to major cities in their own countries and beyond.

The private sector is pursuing a number of projects to systematically unlock rural e-commerce. In China, Alibaba Group has fuelled the development of e-commerce in rural areas through the Rural Taobao initiative, which promotes trade between China's rural and urban regions by removing bottlenecks in logistics and information flow. Alibaba Group 
does this by building up rural e-commerce infrastructure, talent, and ecosystems, giving villagers access to a broad range of consumer products and services at a lower cost; offering them a convenient channel to procure much needed agricultural tools and resources; and enabling them to sell their specialty products beyond their regions. In turn, brands and retailers secure a new channel to unlock rural purchasing power.

As part of the Rural Taobao initiative, in October 2014, Alibaba Group announced that it would invest RMB10 billion (USD 1.6 billion) over the coming three to five years in building 1000 county-level "Taobao rural operations centres" and 100 000 village-level "Taobao rural service centres" throughout China. These e-commerce outposts allow villagers to buy and receive the goods they need from Alibaba Group's online marketplaces, and to start their own online businesses. As of mid-February 2016, more than 14000 village-level service centres were opened in some 300 counties across more than 20 provinces. Alibaba has also empowered Taobao couriers working in both rural and urban areas (OECD-WTO aidfor-trade monitoring exercise 2017, Private sector case stories 21 and 22).

In Africa, the GSoko (Grain Soko Market) platform, a flagship initiative of the DFID-funded FoodTrade East and Southern Africa programme, aims to link small-holder farmers to grain buyers across East Africa. The Eastern Africa Grain Council, in partnership with various industry stakeholders (grain traders and buyers; policy and research bodies; trade and information agencies) has developed this private sector-driven market platform. The system uses innovative technology to provide information on market opportunities, track goods, enhance transparency and connect buyers and sellers. The GSoko platform is bringing structure to trade in grains by facilitating title transfer, market transparency, and price discovery. The objective is to ensure that farmers growing grains have access to regional markets (OECD-WTO aid-for-trade monitoring exercise 2017, Public sector case story 70).

There are also companies connecting rural regions to the Internet. For example, through its Wireless Reach project, Qualcomm has worked with various partners, including companies, government agencies, NGOs, and universities, to extend the benefits of wireless technology to underserved communities around the world. Qualcomm's Taroworks project delivers new wireless tools for data collection and analysis to social entrepreneurs and NGOs working in rural areas in over 20 countries in Africa, Latin America, and Asia. As of March 2014, TaroWorks solutions supported more than 52,000 low-income microentrepreneurs and served more than 2 million beneficiaries. One example is Honey Care, which works to increase economic opportunities for Kenya's smallholder farmers (OECD-WTO aid-for-trade monitoring exercise 2017, Private sector case story 51)

In Cambodia, Japan's National Institute of Information Technology has developed and tested a wireless communications technology, NerveNet, that enables high-speed data communication. Using solar power suitable for deployment across rural and remote areas, it specifically addresses affordability issues in rural areas by reducing ancillary costs. Facebook's Express Wifi empowers local entrepreneurs to provide quality Internet access to their communities and earn a steady income. Working with local mobile operators and Internet service providers, local entrepreneurs are able to use software provided by Facebook to connect their communities (ITU, 2017).

\section{Empowering women helps to build the digital economy}

E-commerce, online work platforms, and online payments are especially empowering to women. They help them to work and build companies in cultures where they are discouraged from entering the labour market, or where they may lack access to the professional networks and resources that are available to their male peers (World Bank, 2016b). For example, a 2015 survey of Pacific island exporters showed that firms that are active online are not only smaller and newer, but have a greater concentration of female executives under 45 years of age (ADB, 2015). These women are able to run their online businesses while handling household obligations, and see great potential to expand their market reach and earnings thanks to ICT. 
However, girls and women often lag behind in accessing the Internet. Women are almost 25\% less likely to be online than men; in Sub-Saharan Africa this figure is around $40 \%$. Intel is seeking to change this through the She Will Connect programme and other digital empowerment initiatives, thereby empowering millions of women to connect to a range of new opportunities through technology. The initiative aims to bring five million women online in sub-Saharan Africa (OECD-WTO aid-for-trade monitoring exercise 2017, Public sector case story 18).

According to the GSM Association (GSMA), closing the gender gap in mobile phone ownership and use could unlock an estimated USD 170 billion in market opportunities for the mobile industry in 2015-20. GSMA's Connected Women project, sponsored by the UK Department for International Development (DFID) and the Bill and Melinda Gates Foundation, works with mobile operators and their partners to address the barriers to women's access to and use of mobile Internet and money services. The partners include players such as Airtel India, Orange Mali, and Turkcell. The programme has awarded 11 innovation grants to operators and NGOs in Africa and Asia. These grants act as seed money for the design and launch of products and services that increase women's access to and use of mobile phones and value-added services. The funders of this programme include Orange Mali, Airtel Uganda, Telenor India and Ooredoo Myanmar.

Facebook Innovation Lab's She Means Business programme is helping women entrepreneurs worldwide to grow and promote their businesses online, starting by leveraging their Facebook Pages (OECD-WTO aid-for-trade monitoring exercise 2017, Public sector case story 153).

In India, Telenor India has worked to educate women, youth and children in rural areas as to the use and benefits of Internet in their daily lives. Project Prayaas provides workshop modules to build awareness of the Internet, creating a window to the world that can help farmers to produce better crops, youth to find jobs, women to benefit from safety and healthcare applications and children to access knowledge. Telenor has also addressed gaps in mobile phone use in rural India, where in 2013-14 some 76\% of men owned a mobile phone, compared to only 29\% of women. In 2014, Telenor launched Project Sampark to enable easy-to-use mobile phone services for rural women. The project also was supported by GSMA's Connected Women programme. Telenor identified and trained anganwadi (health workers) to spread the message about why women should own and use mobile phones. These local women were aware of the local reality on the ground, familiar with the social structures, and easily accepted by locals. The approach of women selling telecom services to women has proved to be more successful than women having to buy a phone from a store with a male salesman. Within 18 months, the project had brought on board 72000 female mobile phone owners (OECD-WTO aid-for-trade monitoring exercise 2017, Private sector case stories 45 and 46).

Tranzum Companies \& Services (TCS) a global courier enterprise based in Pakistan, has been rolling out gender diversity initiatives aimed at increasing the participation of women in the workforce in Pakistan, where they make up $49 \%$ of the population but only $25 \%$ of the workforce. TCS has been working on increasing gender parity within its ranks through a series of women's initiatives like Project Aghaz, which provides a focused and customized female induction plan for TCS's corporate, consumer and operations departments. The company is exponentially growing its e-commerce services and understands the importance of improving the technological footprint. That is why a key element of Project Aghaz's four-pronged approach is enabling women to be part of the TCS e-commerce Platform. Through targeted position profiling, countrywide talent sourcing and training, Project Aghaz simultaneously empowers women and builds TCS's e-commerce business capacity.

People in rural Pakistan seldom have bank accounts. Telenor Pakistan and Tameeer Bank are helping to compensate for this with Easypasia, a mobile-phone banking service. This easy and secure way to transfer funds is helping young girls get access to education via mobile phones. Before this technology, the cost of disbursing stipends could sometimes exceed the amount of the stipends itself. Mobile banking has also ensured that the cash stipends reach the intended recipients. 
Box 10.2. Private sector participation in initiatives to extend coverage

To target rural or underserved areas, solutions need to be low-cost, given that lower incomes often coincide with rural areas. Moreover, solutions need to be scalable and replicable to maximize the number of people being brought online. To this effect, a number of pilot projects are at the testing stage. For example, Alphabet's Loon Balloons in Sri Lanka, Indonesia and other countries is meant to provide Internet to rural and hard-to-reach areas at a low cost or for free; and Facebook's Connectivity Lab is developing new methods to deliver Internet, including lasers, drones, and artificial intelligence-enhanced software. Also, enhanced and more cost-effective satellite systems are being developed using high-throughput satellites (HTS) and non-geostationary satellite orbit (NGSO) systems in low-Earth or mid-Earth orbit with embarked digital technology, which is particularly suitable to address the rural-urban divide at a large scale.

Given the large rural offline populations across Africa and Asia and the Pacific, many initiatives in these regions focus on rolling out infrastructure or providing public access in underserved areas using fixed, mobile or satellite technology. For example, the American Tower Corporation is launching partnerships with governments and other stakeholders in Nigeria and India to create Digital Town Squares as primary points of connectivity. South Korea has introduced The Information Network Village, which aims at enabling rural communities to become self-sustainable through the provision of high-speed Internet access.

Vodacom has partnered with Intelsat in the Democratic Republic of Congo to extend its services to over 700 rural sites using satellite broadband. Other satellite initiatives include the project led by Intelsat, together with the Office des Postes et Telecommunications of French Polynesia, to provide KU-band satellite solutions on Intelsat 18; this is designed to enable expansion of wireless infrastructure across French Polynesia. In Myanmar, the Internet service provider Bluewave has introduced a satellite broadband service called Easy IP Solution, which uses capacity on the EUTELSAT 70B satellite. Another solution being pursued by Intelsat, together with SkyNet de Colombia, entails lending support to the Colombian Ministry of Information Technologies and Communications to connect schools in rural areas using satellite solutions.

Source: ITU (2017)

\section{E-commerce can bring small and medium enterprises into world trade}

As the above surveys show, SMEs that have yet to start selling online tend to struggle with in-house skills for e-commerce. And while typically realizing that e-commerce is a great way to access global customers, SMEs at the same time worry about their capabilities to handle export operations. Many private companies have stepped in to fill this gap.

Jumia Market (formerly Kaymu) has helped to economically empower tens of thousands of traders in Africa through e-commerce, improving their digital literacy. This has enabled them to create and manage e-mail accounts, use the platform to update their online shops independently, and deploy social media and instant messaging to promote their activities, among others. Beyond education, Jumia has opened up access by these companies to delivery partners, as a means of helping them deliver their products beyond their own cities; it has also advised them in product sourcing and has shared lessons learnt in similar markets (OECD-WTO aid-for-trade monitoring exercise 2017, Private sector case story 74).

eBay has entered into a partnership with the International Trade Centre (ITC) to help SMEs in developing countries take advantage of the opportunities offered by e-commerce. Under the agreement, the eBay marketplace offers exportready companies supported by ITC's e-Solutions programme the possibility of connecting with over 162 million buyers around the world. Enterprises that participate are given the opportunity to open "anchor stores" on eBay, giving them greater online visibility and enabling them to reach more clients. SMEs participating in ITC's e-Solutions programme also have access to the eBay network of fulfilment centres, making logistics more cost-effective; in addition they can access eBay's e-commerce research, allowing them to leverage this knowledge so as to better position their offerings in selected target markets. Finally, eBay provides training to complement the training offered by ITC; the issues covered include optimisation of product listings, best practices in online promotion, and skills in analytics and inventory management. 
eBay also has a special project in Mexico, where only one in ten SMEs has a website to sell its products or services. Crece Con eBay is a new platform whose main focus is to support the international growth of entrepreneurs and SMES in Mexico. The platform (www.crececonebay.com) focuses on three main objectives: providing useful information to users about the process of exporting their products through eBay; guiding users step by step through interactive programmes; and providing support and chats 24/7 to SMEs (OECD-WTO aid-for-trade monitoring exercise 2017, Private sector case story 28).

The African platform Kopo Kopo helps SMEs overcome what is often the biggest bottleneck for online sales: payments. Kopo Kopo accepts mobile payments and builds relationships with customers. In 2011 it was one of 25 finalists in the Pivot 25 (now Pivot East) mobile startup competition, winning the opportunity to incubate at m:lab's East Africa iHub. Kopo Kopo partnered with Safaricom to bring the Lipa Na M-PESA Buy Goods service to small and medium businesses throughout Kenya. At iHub, what began as a two-man team grew to 12 employees, soon ballooning to a staff of 50 . Today, Kopo Kopo serves 15000 businesses throughout Kenya and recently processed its millionth transaction. Kopo Kopo has designed a robust payment platform with various functionalities and value additions, which have been segmented into products with the aim of positioning them in various market verticals.

\section{The private sector can help open up markets for artisans around the world}

There are countless initiatives across the developing world promoted by the private sector to cultivate certain products for online sales. For example, Earth Divas is a fair-trade company that works with artisans in Nepal to design and produce handbags, hats, backpacks and other accessories made from natural fibre; they are imported into the US and sold via e-commerce channels to consumers and retail stores. It works primarily with women tailors, returning all proceeds to the women via direct cash payments. Earth Divas adds value by removing intermediaries from the various layers between the producer in Nepal and the consumer in the US. Using online, hosted platforms they are able to reduce costs and improve communication and work-flow to ensure that a consistent, high-quality product is delivered to the US market, on time.

Shop Soko is an e-commerce site that sells jewelry made by African artisans on the global market. The start-up received support and training through Nailab, funded by a World Bank Group project. It also participated in the World Bank Infodev's Startup Camp in 2013. Today, Shop Soko is considered one of Kenya's success stories and has become an Etsy for African jewelry. Their site has sold over 100 thousand products, generating over USD 800 thousand in income for the over 1300 artisans with whom it partners.

Fulfillment by Amazon (FBA) has empowered numerous entrepreneurs worldwide to scale their sales. One example is Lanna Clothes Design — a small woman-led business in rural Thailand — which FBA helped to expand internationally through e-commerce. Within ten months of its enrolment in FBA, Lanna Clothes Design grew by $70 \%$, with sales on Amazon comprising 85\% of total sales. Amazon's e-commerce services have enabled the owner of Lanna Clothes Design, Praew, to fulfil her dream of improving the lives of her family, employees and community. Based on her own e-commerce success, Praew plans to help other local designers grow their businesses (OECD-WTO aid-for-trade monitoring exercise 2017, Private sector case story 88). 


\section{BUSINESSES CAN HELP POLICY MAKERS FIND PATHWAYS FOR CATALYSING E-COMMERCE}

For trade policy makers, the challenges articulated by companies engaged in e-commerce require a rethink of the policy toolkit for trade, including trade rules, export promotion, trade facilitation, export credit, and trade infrastructure. In all these areas, trade policy makers intent on catalysing e-commerce need to work closely with ICT, finance ministries and regulators, as well as with the private sector. Businesses have a first-hand grasp of the challenges to e-commerce, as well as the solutions to them. Aid for trade certainly can play a catalytic role in addressing basic connectivity and ICT infrastructure issues, and in overcoming the connectivity challenges faced by the LDCs in particular.

As governments focus on boosting their digital economies, development partners also need to get behind initiatives to address the demand side, working with governments, the private sector and civil society to tackle key Internet adoption barriers related to capability (e.g. ICT skills), relevance (e.g. local language content) and affordability (e.g. costs of devices). They also need to address the many challenges that add to the costs and operational complexities faced by companies that are already selling online and seeking to export and import, such as logistics and customs procedures, and crossborder online payments. The United Nations Conference on Trade and Development's multi-stakeholder eTrade for All initiative brings an important focus on these efforts. It brings together developing economies, 20 agencies participating in the Aid for Trade Initiative (including the WTO), donor economies, and the global private sector to further e-commerce development and cross-border e-commerce globally. eTrade for All and Aid for Trade are powerful underwriters of the development of digital trade worldwide.

Some of the priorities for empowering small businesses in e-commerce follow.

\section{Facilitating e-trade requires new approaches and capacities}

The surveys reviewed here show that online sellers of physical goods are often most hampered by well-established offline trade challenges, such as arcane customs procedures and logistics. As e-commerce and low-value shipments mushroom, and more and more small enterprises with limited trade compliance capacity engage in trade, customs and other border agencies needs to rethink their approaches. The Trade Facilitation Agreement (TFA) is an excellent instrument for addressing problems in the movement of goods worldwide. Implementation of the TFA will need to consider key issues arising from e-commerce, in particular the rising importance of small parcel trade, often shipped by small players.

New approaches, and capacity-building around them, are needed, for example:

- Higher de minimis thresholds. The silver bullet for fuelling SME trade is raising de minimis thresholdsthe ceiling below which goods may enter a country duty- and tax-free. Economists have repeatedly shown that low de minimis thresholds defeat their own purpose, both because the costs of collecting the duties and taxes outweigh the revenue raised, and because the mark-ups of tariffs and taxes are detrimental to consumers and companies importing goods and inputs that are above the de minimis threshold. Numerous studies show that higher de minimis thresholds provide net economic gains (Halloway and Rae, 2012; Rae, 2012). Suominen (2016b, 2017) has proposed a solution to governments' hesitancy to introduce higher de minimis thresholds: a negotiation on de minimis.

- Simplified, paperless, one-stop clearance processes. Governments need to make better use of the established mechanisms to fuel trade, such as increasing customs clearance availability to 24 hours per day; putting in place electronic filing of customs documents via single windows for one-stop compliance; and enabling the collection and remittance of taxes for goods above the de minimis threshold in locations other than the border. Since the ability for the customer to return an item is a pillar for competitiveness among e-commerce retailers, there should also be simplified, duty-free returns on items sold online by domestic sellers to foreign buyers. 
Box 10.3. The Framework Agreement on Facilitation of Cross-border Paperless Trade in Asia and the Pacific

The United Nations Economic and Social Commission for Asia and the Pacific's (UNESCAP) Framework Agreement on Facilitation of Cross-border Paperless Trade in Asia and the Pacific (FA-PT) is intended to enable the exchange and legal recognition of electronic trade data and documents across borders. The FA-PT is a UN treaty open to all interested among the 53 ESCAP member states. Its objective is to "promote cross-border paperless trade by enabling the exchange and mutual recognition of trade-related data and documents in electronic form and facilitating interoperability among national and sub-regional single windows and/or other paperless trade systems, for the purpose of making international trade transactions more efficient and transparent while improving regulatory compliance" (Article 1). The FA-PT was finalized as a UN treaty in May 2016.

It is expected to be a useful tool to support and improve the implementation of the WTO Agreement on Trade Facilitation, building on the fast growing bilateral and regional single window and cross-border paperless trade initiatives. The FA-PT provides a multi-layered institutional arrangement for parties to facilitate mutual recognition of electronic trade-related data and documents and promote interoperability among paperless trade systems, including national single windows.

To date, most of the paperless trade systems in the ESCAP region have focused on facilitating information exchange among stakeholders domestically. However, to facilitate international trade, trade information also needs to flow across borders, along international supply chains, not only among domestic stakeholders. The flow of electronic trade information generated domestically encounters both technical and legal barriers beyond the border, requiring traders to maintain conventional paper-based trade practices and thereby reducing the overall benefits and returns on investment from paperless trade systems.

It is estimated that implementation of cross-border paperless trade in Asia and the Pacific could reduce export costs by $15-30 \%$ on average, increasing the export potential of the region by USD 257 billion when fully implemented.

Source: OECD-WTO aid-for-trade monitoring exercise( 2017), Public sector case story 86, www.oecd.org/aidfortrade/casestories/ casestories-2017/CS-86-Framework-Agreement-on-Facilitation-of-Cross-border-Paperless.pdf

- Trusted eTrader programmes tailored to the needs of SMEs (Suominen, 2015). Trusted eTrader programmes would balance the need for trade facilitation for small shipments with the imperative of securing trade. They can rest on two components: incentivising SMEs' trade compliance; and leveraging anonymised big data held by major online platforms for risk-targeting in trade. These efforts could be tailored along the lines of the Air Cargo Advanced Screening programme that the US piloted a few years ago with major shippers such as FedEx, DHL, and UPS.

\section{Governments can help new traders access finance}

Export credit agencies have traditionally helped exporters to guarantee working capital loans issued by banks. Today, however, small online sellers often need much smaller and faster working capital loans (often just USD 3 000) to respond to surges in demand. They also are typically nascent in their lifecycles and need equity financing, such as venture capital, to accelerate their expansion when there is high demand for their products at home or abroad. Banks do not effectively provide either. There are a number of creative ways for governments to facilitate new traders' access to finance:

- Help back online lenders of small, fast-disbursing working capital loans. FinTech is on a tear.

Developing country export credit agencies could work with FinTech and online lenders to guarantee smaller loans than those banks are usually willing to make, or to make loans to businesses that may not meet the banks' lending criteria (Suominen, 2016a). For example, export credit agencies could guarantee diversified pools of small loans and thus manage their own risks, leveraging the nontraditional but typically effective underwriting criteria and scale of online platforms. This could lower the cost of capital for export-driven SMEs and incentivise the entry into markets by lending platforms. 
- Pay attention to access to growth capital. Another important consideration is the fact that companies worldwide are entering global markets earlier in their life cycles than ever before. These companies are often not in need of trade finance or small loans, but rather require growth capital (Suominen, 2016c). Growth capital is not aimed at any one trade transaction, but rather at expanding a company's production and sales capabilities. When a small company observes strong demand for its products or services in world markets and wants to seize the opportunity quickly, it tends to need more cash on hand that it is able to secure affordably from lenders. Without picking winners, export credit agencies can help investors identify born-global companies that seek equity financing, lowering the per-deal search and transaction costs for the investors and supporting promising globalising companies in the process

- Leverage multilateral development banks. Multilateral development banks are expanding the range of instruments they make available to support banks and companies in developing countries. This is particularly useful for bankable companies. In a recent survey, over $75 \%$ of banks reported that the trade finance programmes of multilateral development banks help to narrow trade finance gaps (WTO, 2016).

\section{It is important to get the regulatory environment for e-commerce right}

Companies benefit from transparent rules, freedom to innovate, a level playing field and interoperability across economies. The surveys referred to above show that even small online merchants often struggle with digital regulations when seeking to export. While there are numerous policy issues to take into account, the following elements can be considered critical for enabling countries to fuel cross-border trade in the digital era:

- Legal liability protections. Internet intermediaries such as e-commerce sites post user reviews of the goods and services sold on their sites, and in doing so need to be protected from liability for this content. To encourage Internet intermediaries to serve local markets, developing countries can create and modernise "safe harbours" that limit intermediary liability from user-generated content. For example, several countries have put in place liability limitations for certain intermediaries regarding unlawful content.

- Intellectual property protections. As products and services digitise, and as millions of microenterprises and consumers create or copy content, designs, and 3D printed products, intellectual property is becoming harder to protect. Case law is already reshaping the rules around intellectual property in the digital era, such as on 3D printable designs. Policy makers need to balance the protection of intellectual property rights with the development of new Internet services and platforms, updating copyright laws to include limitations and exceptions such as fair use, the doctrine that permits limited use of copyrighted material without acquiring permission from the rights holders.

- Consumer protection laws. Consumer trust in products and services sold online, delivery systems, online payments, and other online services is critical for digital economies to grow. Consumer protection laws help build that confidence. Regulations need to be balanced. They need to safeguard consumer rights and information and to combat trade in counterfeit goods, among other measures. Yet they also need to be fashioned with input from the e-commerce industry, with companies' compliance costs in mind.

- Interoperable online payments. Online payments are critical for cross-border online transactions. Online payment platforms have proliferated worldwide - there are to date more payment platforms than there are countries - and this is a positive development. Some countries have made important strides in ensuring the interoperability of payments. However, more work needs to be done, both within and across countries, to enable buyers and sellers to transact regardless of their respective payment methods. 
- Dispute settlement. Dispute settlement is critical in the digital era, enabling governments and market participants to build confidence in online transactions. There are millions of claims for resolution of commercial disputes in e-commerce. Given technological advances, arbitration and resolution can be made swifter and more automatic; the technology of dispute settlement can evolve to provide faster digital arbitration and resolution among private parties.

Critically, policies such as these should be designed and implemented in collaboration between government and industry so as to optimise the policies and mitigate undue compliance costs for market participants. The rules are also ideally set at the regional level so as to ensure interoperability across economies. Building governments' capacity to develop policy frameworks and work together can be an important area of aid-for-trade support.

\section{PUBLIC-PRIVATE PARTNERSHIPS CAN CREATE A NEW DEVELOPMENT PARADIGM}

In numerous countries there are concerted efforts by the public and private sectors to cultivate e-commerce in their economies. For example, in Turkey the two have come together in a specialised e-commerce council that is roadmapping policies and solutions for issues such as e-commerce regulations and SME participation in e-commerce. In Mexico, the export promotion agency and the ministry of the economy are consulting with the e-commerce ecosystem on appropriate regulations and export promotion needs. In Bangladesh, the IT and e-commerce industry associations have fashioned regulatory solutions working in close co-operation with the government. Other countries can learn from these efforts, which illustrate very simple but effective means for development partners to support and systematize e-commerce across developing economies.

\section{Pursue public-private funding partnerships}

For development partners intent on attaining the Sustainable Development Goals, delivering concrete results from each project is essential. In e-commerce, development partners have a terrific opportunity to put in place a new modus operandi that will help them to secure robust results: innovative public-private partnerships that leverage the insight and existing, voluminous work of the private sector. There are three ways in which the public and private sectors can come together to run and finance projects:

\section{The private sector seeds, the public sector scales.}

The range of projects the private sector is driving to connect people to the Internet, create e-commerce markets in rural regions, bring women to the online economy and so on presents a great opportunity for the Aid for Trade Initiative's development partners. These efforts have typically involved significant investment by the private sector and yielded quantifiable results in areas of keen interest to development partners. A low-hanging fruit would be to take the best of these projects, seeded by the private sector, and use public sector funds to scale them up or replicate them. In other words, the private sector identifies problems, then creates and seeds solutions; and then the public sector comes in as a provider of growth capital for proven projects. This is low-risk, high-yield development opportunity for the public sector. A more sophisticated version is to craft entire portfolios of private sector-led projects, complete with performance metrics, and enable the public sector to invest in these portfolios - in the process diversifying their risk.

\section{The private sector provides ideas and data, the public sector funds.}

The public and private sectors can also work together to design and create e-commerce development projects, with the private sector providing guidance; real-time, granular data; and insights to help the public sector optimise its investments. 


\section{Fund e-commerce development via social impact bonds.}

Still another model to follow in funding projects that are conducive to boosting e-commerce and inclusiveness, leveraging the ingenuity and resources of the public and private sectors, is the social impact bond model proposed by Suominen (2016 ). In this model, private foundations, social impact investors, and/or e-commerce platforms make the initial investment in e-commerce projects, such as an SME training programme, and get compensated at a premium by the government and public development agencies if and when the programme meets certain pre-established performance indicators, such as the creation of a target number of e-commerce-related jobs or the generation of an agreed amount of new online exports (Suominem, 2016d).

Social impact bonds (also known as development impact bonds) have been successfully used to help cure malaria and save rhinos. They lend themselves very well to e-commerce, given the considerable interest of the private sector in bringing new online sellers to market, as well as the push for inclusiveness that is behind impact funds. The instrument is superb for incentivising investors and project implementers to deliver the results desired by the public sector. Upon success, backed up by sound metrics, governments secure trade gains as well as economic and social returns. In the case of failure, they incur no cost: this is risk-free, performance-based development. Resting on rigorous measurement of results, this model would by default create transparency in project evaluation. Aid for trade can offer a powerful means of bringing public sector agencies together to support such an instrument.

\section{CONCLUSIONS}

Technology-powered trade is changing the patterns, players and possibilities of world trade. The private sector-from online merchants to e-commerce platforms, logistics companies, payment providers, IT companies, and others—makes digital trade move. The private sector is closest to the opportunities, challenges, and solutions to e-commerce development issues - and thus central to informing and guiding policy making on e-commerce issues around the world. By partnering with the private sector, the public sector can to develop new solutions to unlock e-commerce markets and stimulate cross-border e-commerce.

Yet gaps in data regarding private sector views on the enabling environment for e-commerce, and lack of systematic public-private collaboration, limit the ability of developing countries to prioritise policy choices and investments in digitisation and e-commerce. This chapter has discussed new data that show that trade finance, logistics, and digital regulations are often suboptimal, making it difficult for developing country companies to engage in cross-border e-commerce. The chapter proposes innovative solutions to these challenges, such as pluri-lateral agreements on de minimis thresholds and a new facility for export credit agencies to guarantee micro-working capital loans for e-commerce merchants. This chapter has also highlighted ways of operationalising public-private partnerships in e-commerce development, as well as fresh ways of financing them, such as social impact bonds.

Twenty-first century digital trade offers the opportunity for creating a medieval town square where buyers and sellers come together - at the global level. A market where anyone can sell to anyone, anywhere anytime, and where no one is kept from participating by their location. To realize this aspiration, development partners will need to stay attuned to the concrete challenges online buyers and sellers face, co-create with the private sector practical solutions to these challenges, and partner with companies that have already done the legwork to identify opportunities and craft business models that will bring people to the opportunities of the online economy. 


\section{REFERENCES}

ADB (2015), Aid for Trade in Asia and the Pacific: Thinking Forward About Trade Costs and the Digital Economy, Asian Development Bank, Mandaluyong City, Philippines, www.adb.org/sites/default/files/publication/167344/aftreport-2015.pdf

Amazon Web Services (n.d.), "AWS Case Study: Travelstart", webpage, https://aws.amazon.com/solutions/case-studies/ travelstart/

eBay Mainstreet (October 2013), Commerce 3.0 for Development, www.ebaymainstreet.com/sites/default/files/eBay Commerce-3-for-Development.pdf.

Frechdesk (n.d.), Who We Are, Freshdesk website, accessed 1 January 2017, https://freshdesk.com/company/about

Freund C. and M. D. Pierola (2013), "Export Superstars", The Review of Economics and Statistics, December 2015, Vol. 97, No. 5, Pages: 1023-1032 Posted Online December 8, 2015, doi: 10.1162/REST_a_00511

Holloway, S. and Rae, J. (2012), "De-minimis thresholds in APEC", World Customs Journal, Vol.6 No.2, pp. 31-62, http:// worldcustomsjournal.org/Archives/Volume\%206\%2C\%20Number\%201\%20(Mar\%202012)/04\%20Holloway_Rae.pdf

Jeffrey Rae (23 July 2012), The Economic Impact of Increased de minimis Thresholds on ASEAN Economies, Presentation at the ASEAN Regulatory Reform Symposium, Manila, http://aadcp2.org/wp-content/uploads/The-Economic-Impactof-Increased-De-Minimis-Thresholds-on-ASEAN-Economies.pdf

Zwillenberg, P. , D. Field, and D. Dean (20 January 2014), "Greasing the Wheels of the Internet Economy" Boston Consulting Group, https://www.bcgperspectives.com/content/articles/ digital_economy_telecommunications_greasing_wheels_internet_economy/

Suominen, Kati (2015), "Fueling the Online Trade Revolution: New Customs Security Framework to Secure and Facilitate Small Business Ecommerce": CSISI Policy Paper, Centre for Strategic and International Studies, https://www.csis.org/analysis/fueling-online-trade-revolution

Suominen, Kati (2016a), "Here's What We Really Should Be Debating When It Comes To Trade," GE Reports, www.gereports.com/heres-really-debating-comes-trade/

Suominen, Kati (2016b), "Silver Bullet for Helping Small Businesses Trade: Plurilateral Agreement on de minimis, "E15 Initiative, http://e15initiative.org/blogs/silver-bullet-for-helping-small-businesses-trade-plurilateral-agreement-onde-minimis/.

Suominen, Kati (20 March 2016c), "Growth Capital Gap Vital to Debate on Trade Finance Gap," BRINK News, www.brinknews.com/growth-capital-gap-vital-to-debate-on-trade-finance-gap/

Suominen, Kati (2016d), "How The Global Fund For Ecommerce Is Helping Entrepreneurs In Developing Countries Enter The Digital Era", GE Reports,

http://www.gereports.com/kati-suominen-how-to-help-entrepreneurs-in-developing-countries-enter-theecommerce-era/

Suominen, Kati (2017a) "E-commerce development survey and index", for United States Agency for International Development, http://pdf.usaid.gov/pdf_docs/PA00MP8T.pdf.

Suominen, Kati. (2017b). "Accelerating Digital Trade in Latin America and the Caribbean" IDB Working Paper Series No IDB-WP-790, Inter-American Development Bank https://publications.iadb.org/bitstream/handle/11319/8166/ Accelerating-Digital-Trade-in-Latin-America-and-the-Caribbean.PDF?sequence=1 
World Bank (2016), Exported dynamics database, Word Bank, http://data.worldbank.org/data-catalog/ exporter-dynamics-database

World Bank (2016b), World Development Report 2016: Digital Dividends, World Bank, Washington, DC, www.worldbank.org/en/publication/wdr2016

World Bank (2017), Enterprise Surveys (database), World Bank, www.enterprisesurveys.org/

WTO (2016) Trade finance and SMEs: Bridging the gaps in provision, WTO, Geneva,

www.wto.org/english/res e/booksp e/tradefinsme e.pdf 


\section{NOTES}

1. The selection of the countries was based on: the aim of covering several geographical regions; the ease of reaching large sets of firms; and the initial data that spontaneously came in. The country samples cover companies of all sizes, numerous sectors, various growth trajectories, exporters and non-exporters, as well as online sellers and offline sellers; the respondents range from staff-level employees to senior vice-presidents and chief executive officers. 


\title{
CHAPTER 11
}

\section{FINANCING CONNECTIVITY: AID FOR TRADE PRIORITIES, POLICIES AND PROGRAMMES}

\author{
Contributed by the Organisation for Economic Co-operation \\ and Development
}

\begin{abstract}
This chapter looks at aid-for-trade priorities, policies and programmes, particularly in the areas of physical and digital connectivity. It provides an overview of the financing for development agenda, highlighting the critical role of official development assistance (ODA) for the least developed countries, as well as its catalytic role in higher-income developing countries. The chapter analyses 2002-15 aggregate aidfor-trade disbursements (around USD 300 billion) and takes a detailed look at aid-for-trade programmes that are building physical and digital connectivity. It offers a brief overview of academic findings on the results of aid-for-trade investments, as well as recent evaluations of donor aid-for-trade strategies and programmes. Case stories show how aid for trade is helping countries improve their physical and digital connectivity, turning trade opportunities into trade flows. Finally, the chapter provides an analysis of aidfor-trade commitments in 2015, closing with a series of conclusion.
\end{abstract}




\section{INTRODUCTION}

Digital connectivity and infrastructure development are critical enablers of the Sustainable Development Goals, and are rising on the agendas of development partners. The digital revolution is intensifying interactions among businesses, consumers and governments. It is also cutting transaction costs, which are among the most binding constraints for firms in developing economies. The digital era, therefore, offers developing country firms an opportunity to expand their access to international markets. Infrastructure development is critical for sustainable economic growth and poverty reduction. It underpins private sector and human development by enabling the movement of people, goods and services. It provides access to local, regional and global markets, as well as health, education, water, energy and communications services.

This chapter looks aid-for-trade priorities, policies and programmes, particularly in the areas of physical and digital connectivity. It provides an overview of the financing for development agenda, highlighting the critical role of official development assistance (ODA) in the least developed countries (LDCs), as well as its catalytic role in higher-income developing countries. An analysis of total 2002-15 aggregate aid-for-trade disbursements of around USD 300 billion follows. The chapter then takes a detailed look at specific aid-for-trade programmes that are building trade-related infrastructure and digital connectivity, making use of the case stories submitted in the context of the 2015 and 2017 OECD-WTO monitoring exercises. This is followed by a brief overview of academic findings on the results of aidfor-trade investments, as well as recent evaluations of donor aid-for-trade strategies and programmes. Finally, the chapter provides an analysis of 2015 aid-for-trade commitments and of the prospects for 2016, closing with a series of conclusions.

\section{AID FOR TRADE IS A CRUCIAL COMPONENT OF THE DEVELOPMENT FINANCING CHALLENGE}

The vision underpinning the 2030 Sustainable Development Agenda is broad and ambitious. It calls for an equally broad and ambitious financing strategy. The resources required are immense-as much as USD 4.5 trillion per annum according to some estimates (Sachs et al., 2014). The first International Conference on Financing for Development (2002) highlighted that in many cases trade is the single most important external source of development finance (UN, 2002). The Third International Conference on Financing for Development and the Addis Ababa Action Agenda (AAAA) no longer list trade as a source of development finance. Instead, they emphasise the role of international trade as an engine for inclusive economic growth and poverty reduction. Aid for trade is referenced for its potential contribution to achieving these goals.

\section{There is a need for additional development finance beyond ODA}

In 2015, bilateral ODA - at nearly USD 162 billion-represented only 19.2\% of all official and private flows from the 29 member countries of the OECD Development Assistance Committee (DAC) and the international financial institutions. In addition, developing countries received USD 80.6 billion in other official flows provided by public bodies at close to market terms. Private finance at market terms amounted to USD 137 billion and private grants reached USD 35.6 billion. Remittances stood at USD 427.7 billion (Figure 11.1).

Aggregate flows, however, should be examined with care. The extraordinary period of expanding private flows since the start of the new millennium may not be an indication of future trends; there are a number of reasons to believe that such flows were the result of temporary circumstances. Developing countries will face a much tougher global environment moving forward. The commodity super-cycle of the 2000s, which saw huge inward investment and windfalls for resource-exporting countries, is coming to an end as demand from the People's Republic of China (hereafter "China") slows. The post-crisis response and the exceptional measures taken by OECD countries_including prolonged low interest rates and unconventional monetary policy—distorted the development finance landscape. 
The search for yield in emerging and developing countries lead to over-investment in these countries (as well as assetprice bubbles) and under-investment in OECD countries (OECD, 2015). As international interest rates normalise and conditions in developing countries improve, capital that flowed to developing countries is returning back to developed countries. For instance, in 2015 private flows to developing countries at market prices dropped almost 60\% compared to 2014.

\section{Figure 11.1. Financial flows provided to developing countries by DAC members and international financial institutions, USD billion, 2015 prices}

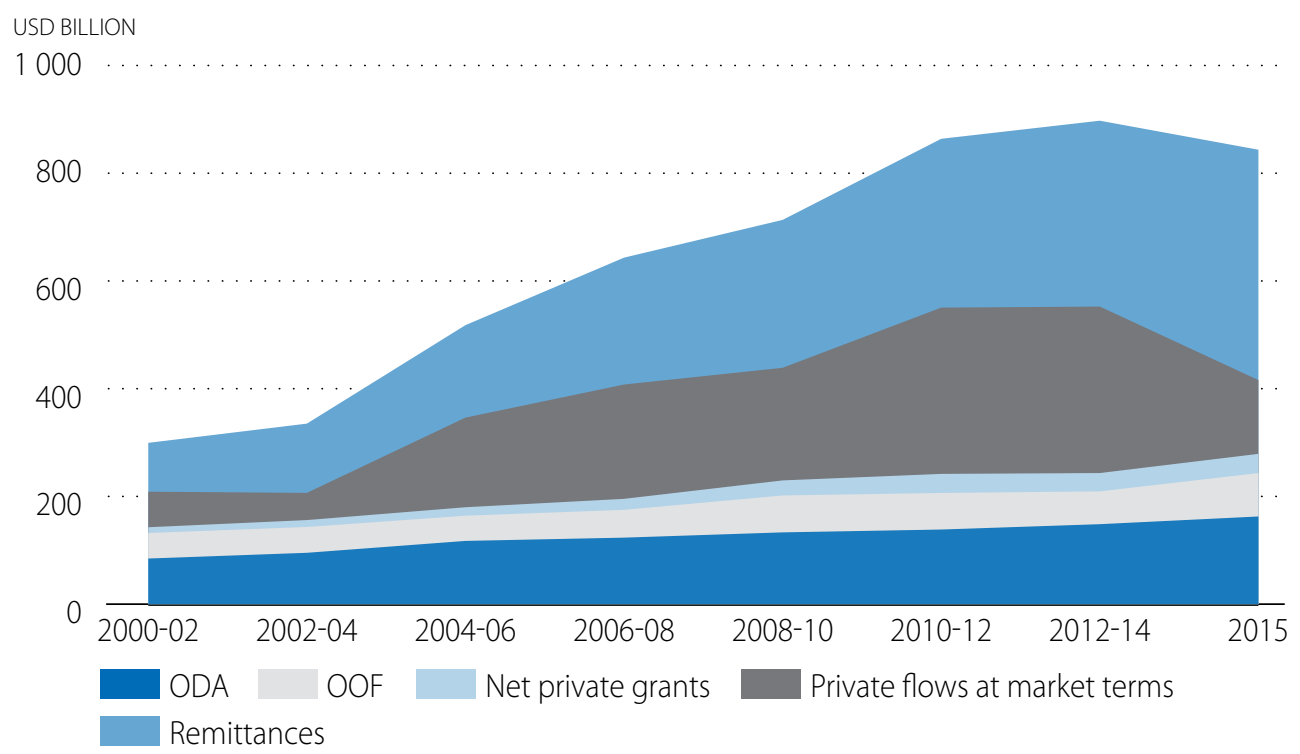

Source: ODA, OOF, Net private grants and Private flows at market terms are extracted from OECD-DAC CRS: aid activity database (2017), DOl: http://dx.doi.org/10.1787/data-00061-en, (accessed on 07 April 2017); World Bank (2017) Personal remittances, received, database, http://data.worldbank.org/indicator/BX.TRF.PWKR.CD.DT (accessed on 07 April 2017)

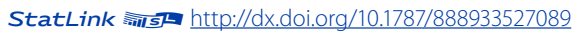

\section{ODA still plays a critical role}

ODA and other forms of official assistance continue to play a significant role in bolstering domestic development efforts in many countries. Used well, aid can generate large payoffs in terms of reducing poverty, meeting basic needs, and helping nations build human and institutional capacity. While aid has eradicated diseases, prevented famines, and done many other good things, its effects on growth are often difficult to establish given the limited data that is available. Arndt et al (2010) found that it was reasonable to assume that aid equivalent to $1 \%$ of a country's gross domestic product raised that country's economic growth by an average of $0.1 \%$ per year during the period $1970-2000$. That is a small, but helpful impact. Clemens et al (2012) found that aid results in some degree of growth in recipient countries, although the magnitude of growth in relation to the amount of aid is in general modest, it varies greatly across recipients, and the results diminish at high levels of aid.

Nonetheless, the distribution and objectives of ODA are very different from other financial flows. Given its unique mandate to directly target development, improve welfare and reduce poverty, ODA remains an essential resource in many countries, especially the poorest-those with limited access to private finance and low levels of domestic resources. ODA remains the largest international resource for countries with a per capita income of less than USD 2000 (Figure 11.2). The switching point where foreign direct investment (FDI) takes on greater relative importance compared to aid for trade and is found around the cut off of GNI that separates the least developed countries from those with a higher GNI, i.e. USD 1.045 . 
Figure 11.2. Share of financial flows to developing countries by DAC and IFIs

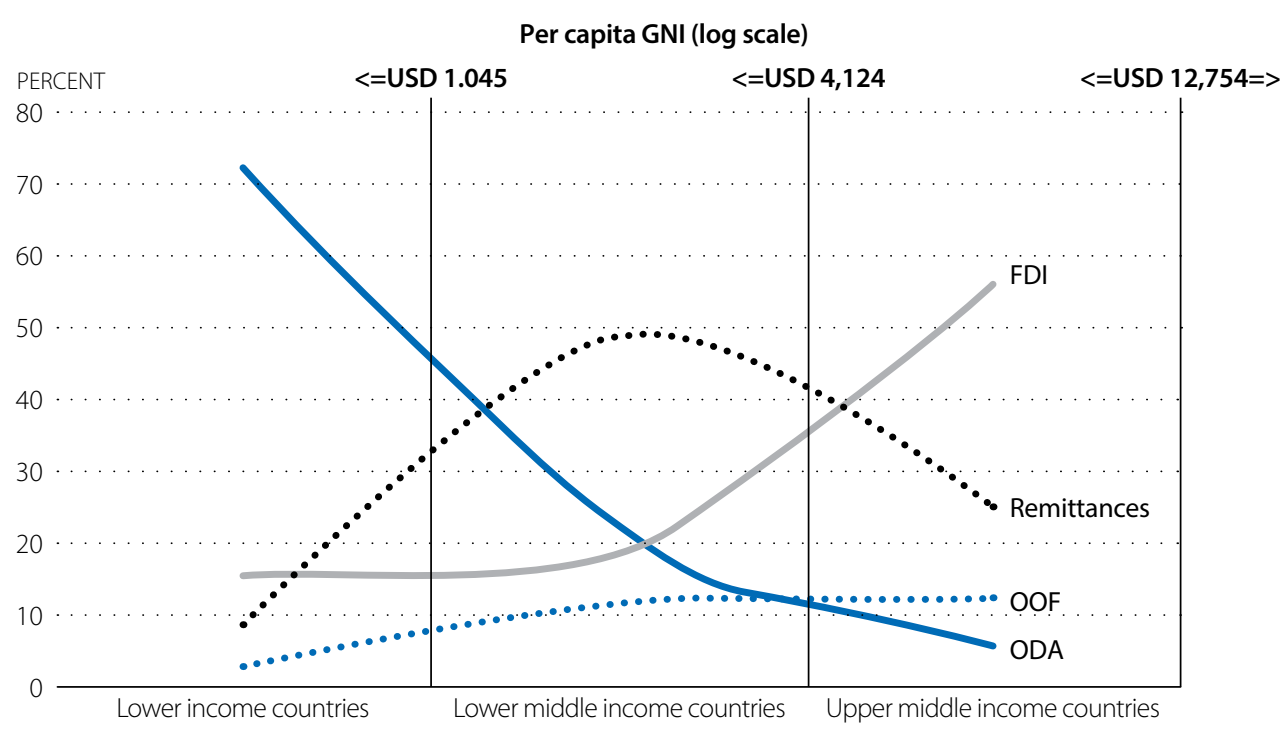

Source: Lammersen, F. and W. Hynes (2016), "Aid for Trade and the Sustainable Development Agenda: Strengthening Synergies"

\section{Mobilising private finance for development calls for adapting aid practices}

Despite the diminishing relative importance of ODA compared to private investments in the lower middle income and upper middle income countries (LMICs and UMICs), it can still contribute to their development by mobilising private flows, leveraging private investment and facilitating trade. Gavas et al. (2011) argue that if developing countries want to attract significant resources for aid for trade, e.g. to cover their infrastructure needs, they need to think outside the box and consider how grants can leverage other resources, such as loans or private finance, to provide blended aid-for-trade finance. According to a recent OECD Survey, in 2012-15 USD 81.1 billion was mobilised through a series of development finance interventions (Figures 11.3 and 11.4). The ultimate development merits of such blended finance, however, will depend on the specific transactions and projects being developed. Also, blended finance carries some inherent risks, for instance by fostering the practice, proven to be ineffective, of tying aid-funded procurement to companies in the donor country.

The challenge is how to adapt current aid practices to make them work with new actors and operators (e.g. the private sector). Their motivations are different from those of traditional donors and their operating mechanisms and modalities may be largely unfamiliar to most development practitioners. The emergence of an increasingly innovative finance agenda will oblige donors to deepen their understanding of private sector involvement in development. It may be important, for example, to explore the distinctions between activities designed to ultimately promote and benefit the local private sector, on the one hand, and those that seek to harness private sector resources for projects (or businesses) that have development-oriented goals, on the other. 
Figure 11.3. Distribution of finance mobilised for development purposes from the private sector in 2012-15, by sector

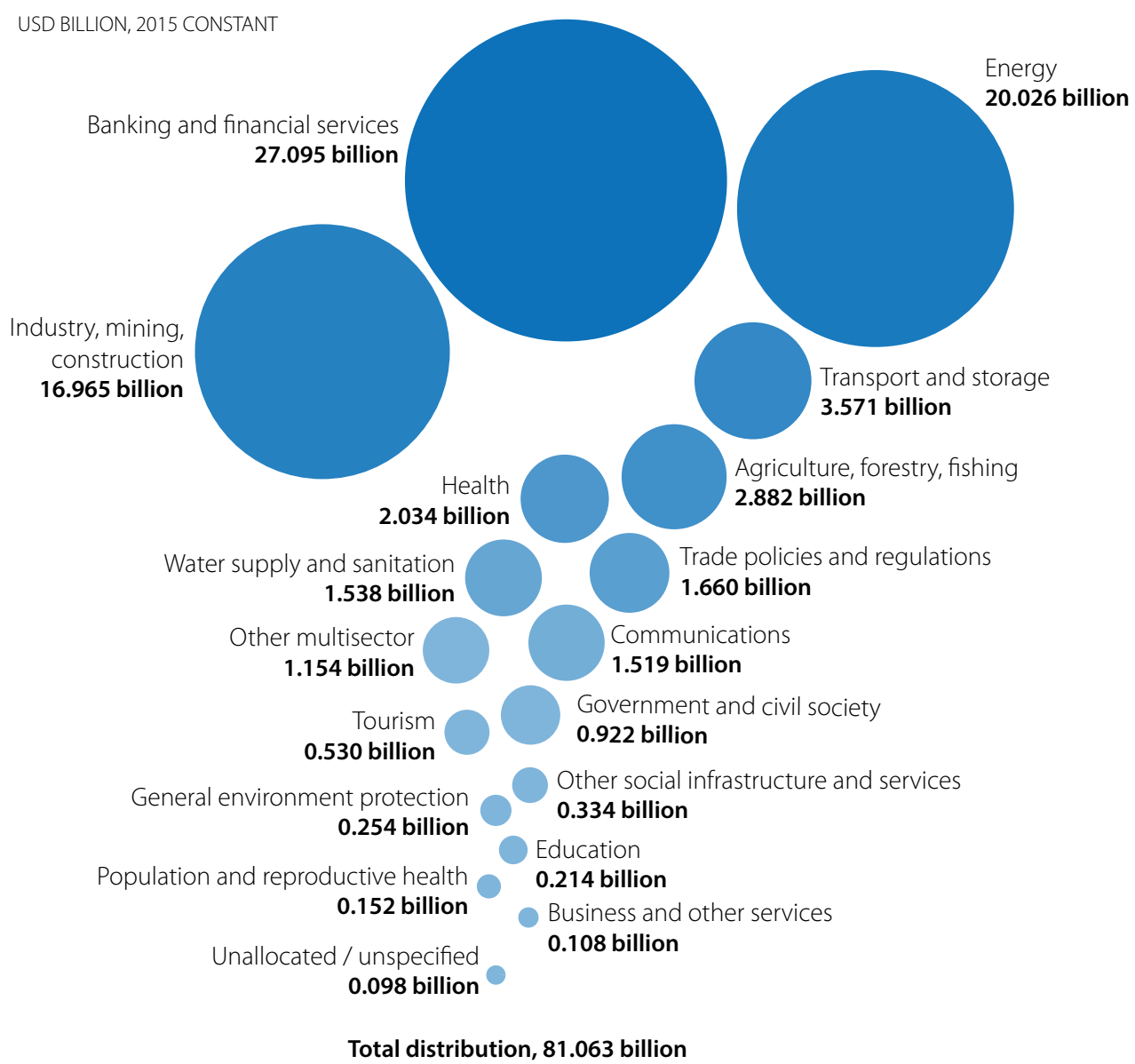

Source: 2016 OECD-DAC survey on amounts mobilised from the private sector by official development finance interventions. For more information, see www.oecd.org/dac/stats/mobilisation.htm StatLink न्ना It http://dx.doi.org/10.1787/888933527108

Figure 11.4. Distribution of finance mobilised for development purposes from the private sector in 2012-15, by income group

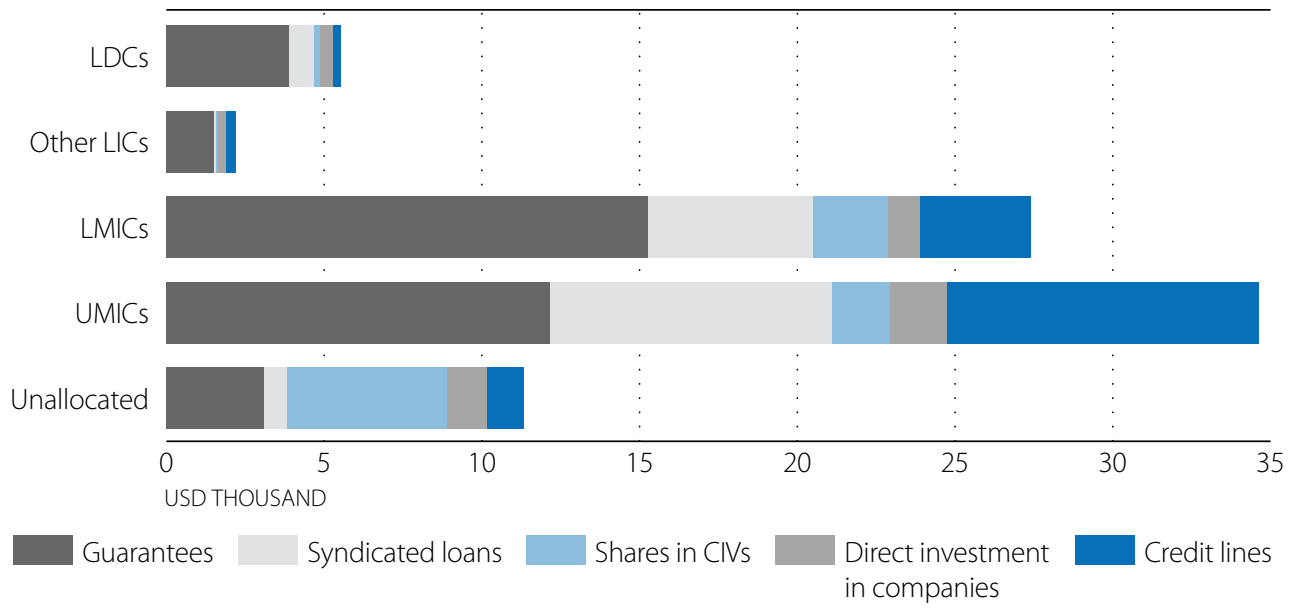

Source: 2016 OECD-DAC survey on amounts mobilised from the private sector by official development finance interventions. For more information, see www.oecd.org/dac/stats/mobilisation.htm 


\section{Aid for trade has supported trade development in 146 countries}

A total of USD 298.3 billion has been disbursed for aid-for-trade programmes and projects since the Aid for Trade Initiative was launched in 2006. Aid-for-trade providers include some 60 bilateral and multilateral donors that report their official development assistance to the OECD-DAC Creditor Reporting System (CRS). Since 2006 bilateral donors have provided almost two-thirds of total support for aid for trade and multilateral donors the rest. The support is equally divided between grants and concessional loans, with LICs, specifically the least developed, receiving most of their support in the form of grants and MICs mostly as loans

Since 2006, 146 developing countries have received aid-for-trade assistance, mainly in Asia (41.5\%) and Africa (38.7\%). Regional and global programmes have attracted almost 15\% of total aid-for-trade disbursements. Over the same time period, middle income countries (MICs) have benefitted more than twice as much as low income countries (LICS) from aid-for-trade funding. To date, more than three-quarters of total aid-for-trade disbursements have financed projects in four sectors (Figure 11.5): transport and storage (28.6\%), energy generation and supply (21.6\%), agriculture (18.3\%), and banking and financial services (11.1\%).

\section{Figure 11.5. Total aid-for-trade disbursements by category, 2006-15}

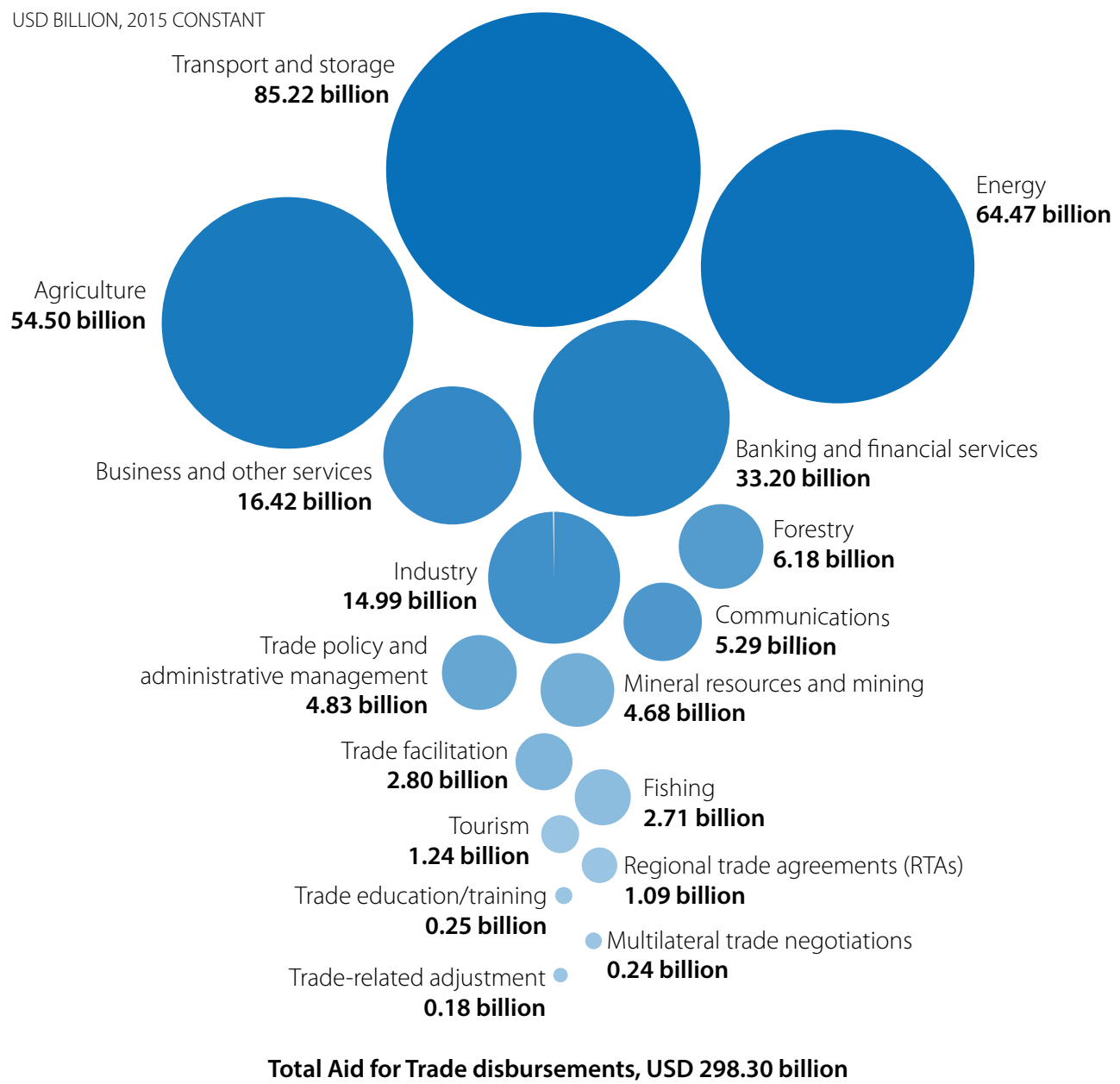


In addition, USD 248.1 billion in trade-related other official flows (OOF)' has been disbursed since 2006, of which 74\% is from international financial institutions (Figure 11.6). Most of this non-concessional funding has been for projects in economic infrastructure (47.5\%) and for building productive capacities (51.6\%); it has been invested almost exclusively in MICs (91.6\%). Asia, the main beneficiary of trade-related OOF, has received USD 103.3 billion or $41.6 \%$ of this total. OOF support to Africa, at USD 40.8 billion, is surpassed by that to MICs in Europe, and to Latin America and the Caribbean (USD 42.2 and USD 58.4 billion respectively).

Figure 11.6. Total trade-related OOF disbursements by category, 2006-15

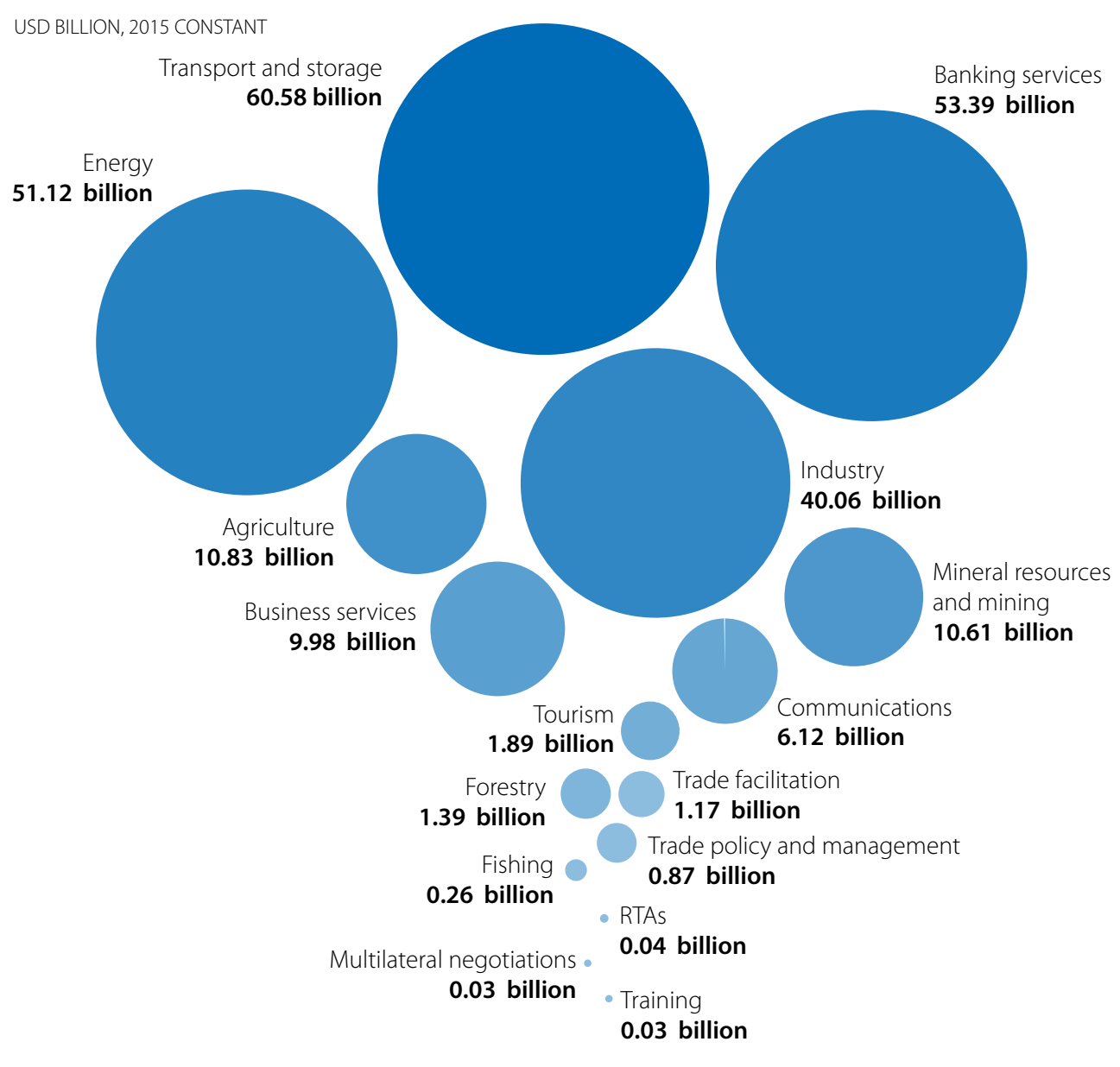

Total trade-related OOF disbursements, USD 248.05 billion 


\section{AID-FOR-TRADE DISBURSEMENTS BY SECTOR, GEOGRAPHIC REGION AND INCOME}

This section looks at aggregate aid-for-trade disbursements since 2006. In particular, it examines the distribution of the disbursements among the different categories that are used as proxies to measure the volume of aid for trade at the global level (i.e. trade policy and regulations, economic infrastructure and productive capacity). Next, the section looks at the countries and regions that receive these funds, and the donors who provide them. Lastly, it examines the financial terms of the disbursements. Throughout, reference is also made to trade-related other official flows.

\section{Aid-for-trade disbursements for infrastructure}

Between 2006 and 2015 a total of USD 155 billion was disbursed to support programmes and projects aimed at reducing the infrastructure gap in developing countries. Transport and storage projects attracted the majority of these funds (55\%), followed by projects in energy generation and supply (41.6\%). Information and telecommunication projects attracted relatively little concessional financing (3.4\%). Asia was the main beneficiary, with USD 69.4 billion, followed by Africa (USD 55.4 billion). Much less support was destined to the transition economies in Eastern Europe (USD 12.9 billion), Latin America and the Caribbean (USD 11.1 billion) and Oceania (USD 2.1 billion).

A total of USD 117.2 billion in OOF was disbursed to finance economic infrastructure programmes: USD 62.6 billion for transport and storage projects and USD 52.1 billion for projects in the energy sector. OOF were predominantly made available by multilateral development banks and Korea for programmes for the most part concentrated in MICs, especially in Asia.

\section{Aid-for-trade disbursements for building productive capacities}

Programmes and projects aimed at building productive capacity in developing countries received USD 133.9 billion in aid between 2006 and 2015. USD 54.5 billion was dedicated to improving agricultural productivity and food security. Banking and financial services, and other business services, received USD 33.2 billion and USD 16.4 billion respectively. Most disbursements for building productive capacity went to Africa (USD 47.8 billion) followed by Asia (USD 41.7 billion), Europe (USD 13.7 billion), Latin America and the Caribbean (USD 11.9 billion), and Oceania (USD 1.2 billion).

A total of USD 128.1 billion in trade-related OOF has been made available since 2006 to finance programmes aimed at building productive capacity. Addressing market failures in banking and financial services, and in other business services, received USD 54 billion and USD 9 billion respectively. Pro-active industry-specific policies in the area of manufacturing, agriculture and mining received USD 40.1 billion, USD 10.8 billion and USD 10.6 billion respectively. The main recipients of these flows were MICs in Asia (37.6\% of total), Latin America and the Caribbean (21.8\%), and Europe (22.5\%). Relatively little went to Africa (16.2\%).

\section{Aid-for-trade disbursements for trade policy and regulation}

Aid for trade in its narrowest sense - support for trade policy and regulation — has attracted a total of USD 9.4 billion, or 3.1\% of total disbursements since 2006. Most of this (USD 4.8 billion) has been for technical support to trade ministries for building capacity in trade policy and management, and for implementing trade agreements (including addressing technical barriers to trade, sanitary and phytosanitary measures). This is followed by support for trade facilitation (USD 2.8 billion), for active participation in regional and multilateral trade negotiations (USD 1.1 billion and USD 239.5 million, respectively), and for training and education (USD 209 million). Support for trade-related adjustments - one of the initial objectives of the Aid for Trade Initiative-only attracted USD 253 million. Only USD 2.1 billion in OOF went to finance projects in trade policy and regulation. This is because this is largely supported through technical assistance. 


\section{Aid-for-trade disbursements to geographic region}

Since 2006, Asian countries have been the main recipients of aid-for-trade disbursements (USD 113.9 billion, with an additional USD 2.2 billion for regional programmes). Most of these funds were for countries in South and Central Asia (51.1\%), followed by East Asia (34.4\%) and the Middle East (12.7\%). Trade-related OOF to Asia totalled USD 103.3 billion, with USD 56.9 billion for programmes in East Asia and USD 40.3 billion for South and Central Asia. Over the same period, aid for trade for Africa reached USD 106.4 billion, almost three-quarters of which was for countries in sub-Saharan Africa. In addition, donors disbursed USD 7 billion for regional programmes in Africa. Overall, only 16.6\% of trade-related OOF were disbursed to countries in Africa, less than the amounts received by Latin America and the Caribbean (23.8\%) and Europe (17.2\%). In fact, trade related OOF has been directed overwhelmingly to MICs (96\%), with only 3.5\%\% going to the least developed (Figure 11.8).

Figure 11.7. Share of total aid-for-trade disbursements by region and income group, 2006-15

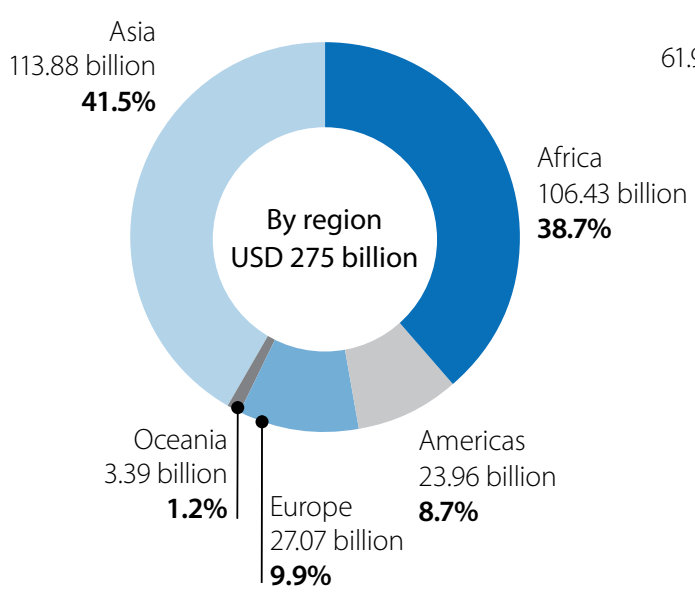

UMICS 61.98 billion $24.6 \%$
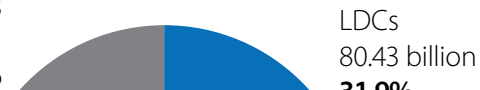

Source: OECD-DAC CRS: aid activity database (2017), DOI: http://dx.doi.org/10.1787/data-00061-en, (accessed 07 April 2017).

StatLink न्तारा http://dx.doi.org/10.1787/888933527184

Figure 11.8. Share of total trade-related OOF disbursements by region and income group, 2006-15

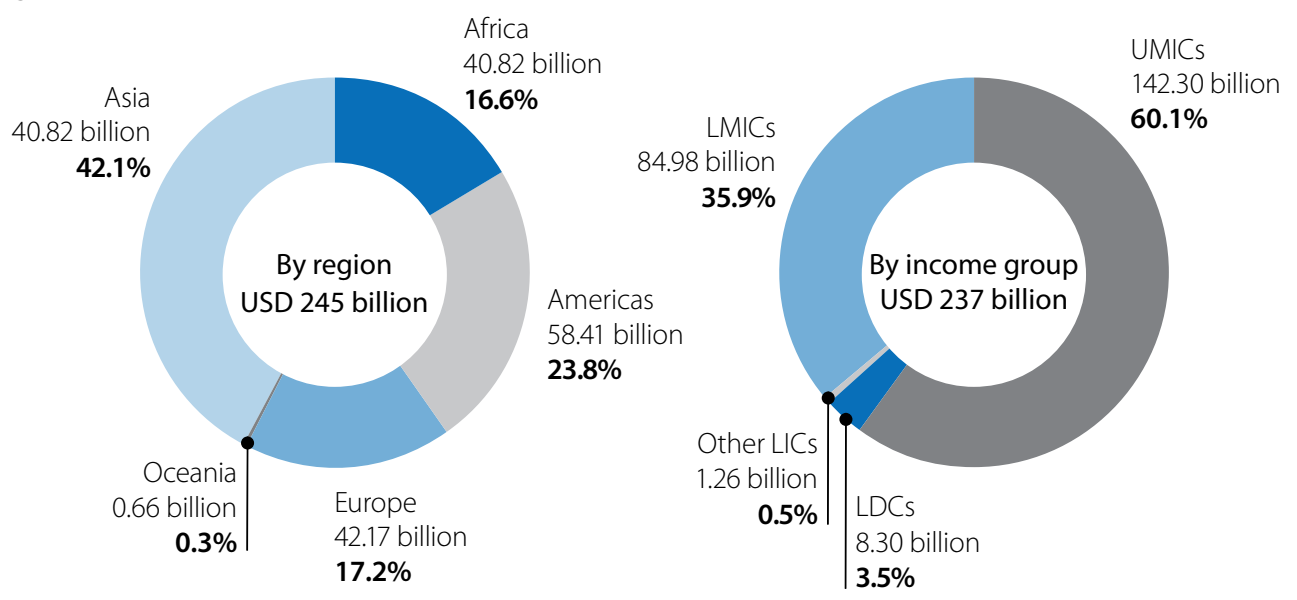

Source: OECD-DAC CRS: aid activity database (2017), DOl: http://dx.doi.org/10.1787/data-00061-en

(accessed 07 April 2017).

StatLink त्राजा http://dx.doi.org/10.1787/888933527203 


\section{Aid-for-trade disbursements by country grouping}

The tendency to provide highly concessional funds, rather than low- or non-concessional OOF, to the poorest countries is reflected in the distribution of loans and grants. At the aggregate level, the shares of loans and grants have been almost equal since 2006. Yet $63.4 \%$ of disbursements to LICs have been made as grants, whereas MICs have received $67.4 \%$ as loans. The share of total country-specific aid-for-trade disbursements for the LDCs was 31.9\%, while other LICs received 2.9\%; 65.3\% went to MICs. Aid for trade per capita, however, is USD 11.1 for the LDCs; USD 12.9 for other LICs; USD 5.7 for LMICs; and USD 2.8 for the UMICs.

The top ten aid-for-trade recipients have received a little over 35\% (USD 104.6 billion) of total country specific aid-fortrade disbursements since 2006 (Figure 11.9). They comprise six countries in Asia, three in Africa and one in Europe. Among these, only Afghanistan is an LDC. To put the $35 \%$ in perspective, it should be noted that the total population of these top ten recipients is close to $30 \%$ of the total population of developing countries. The top ten recipients of traderelated OOF comprise four countries in Asia, two in Europe, two in the Americas and two in Africa (Figure 11.10). All top ten OOF recipients are MICs. Together they received 58\% of total OOF during the period 2006-15.

\section{Figure 11.9. Top ten recipients of total aid-for-trade disbursements 2006-15}

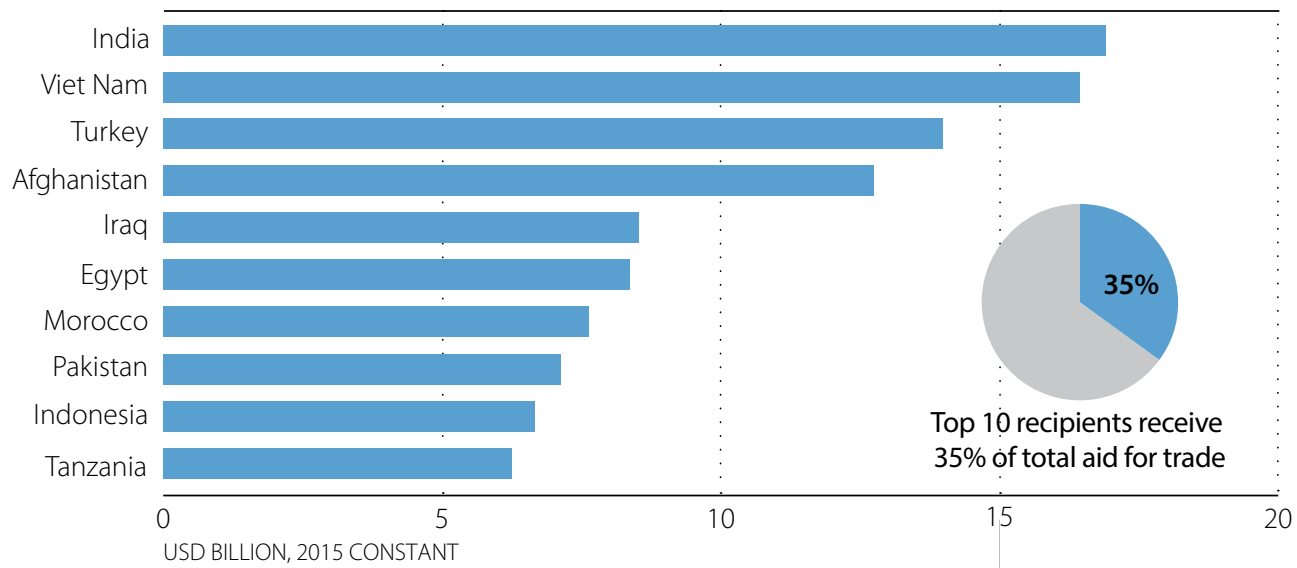

Source: OECD-DAC CRS: aid activity database (2017), DOI: http://dx.doi.org/10.1787/data-00061-en, (accessed 07 April 2017).

Figure 11.10. Top ten recipients of total trade-related OOF, 2006-15

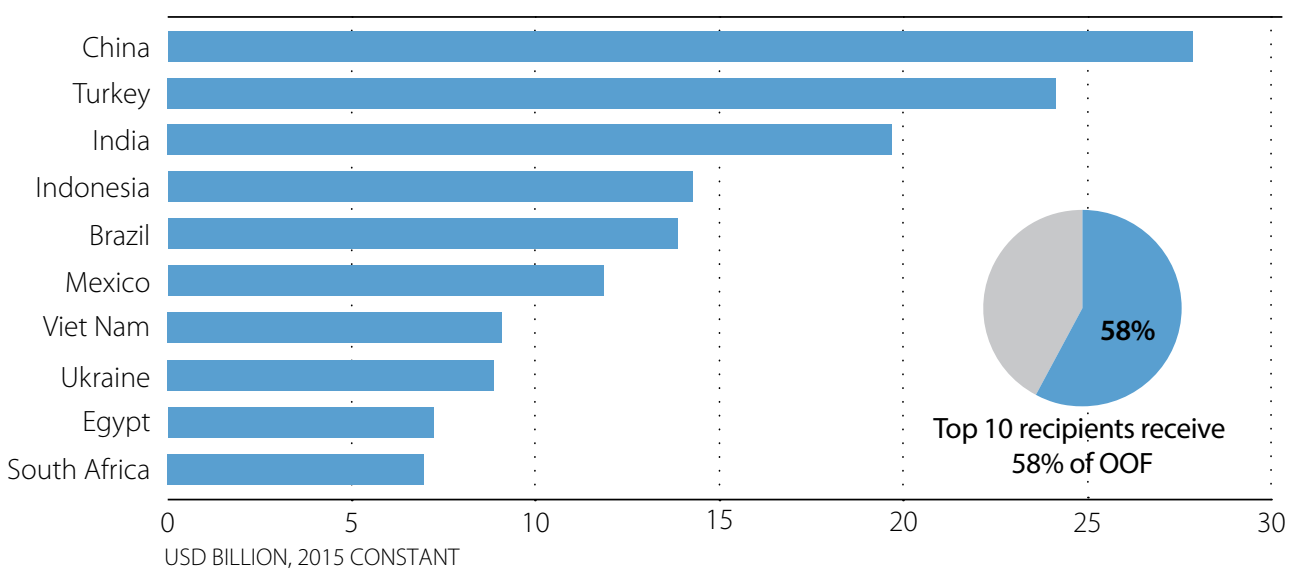

Source: OECD-DAC CRS: aid activity database (2017), DOI: http://dx.doi.org/10.1787/data-00061-en, (accessed 07 April 2017). 


\section{Aid-for-trade disbursements by donor}

Since 2006, bilateral donors have provided $61.5 \%$ of total aid-for-trade disbursements, with the remainder being financed by multilateral donors. Together, the top ten donors (bilateral and multilateral) provide over $81 \%$ of total aid for trade (Figure 11.11). For trade-related OOF, the concentration is even stronger, with the top ten donors providing over $97.2 \%$ of the funds (Figure 11.12).

Figure 11.11. Top ten aid-for-trade providers (total disbursements 2006-15

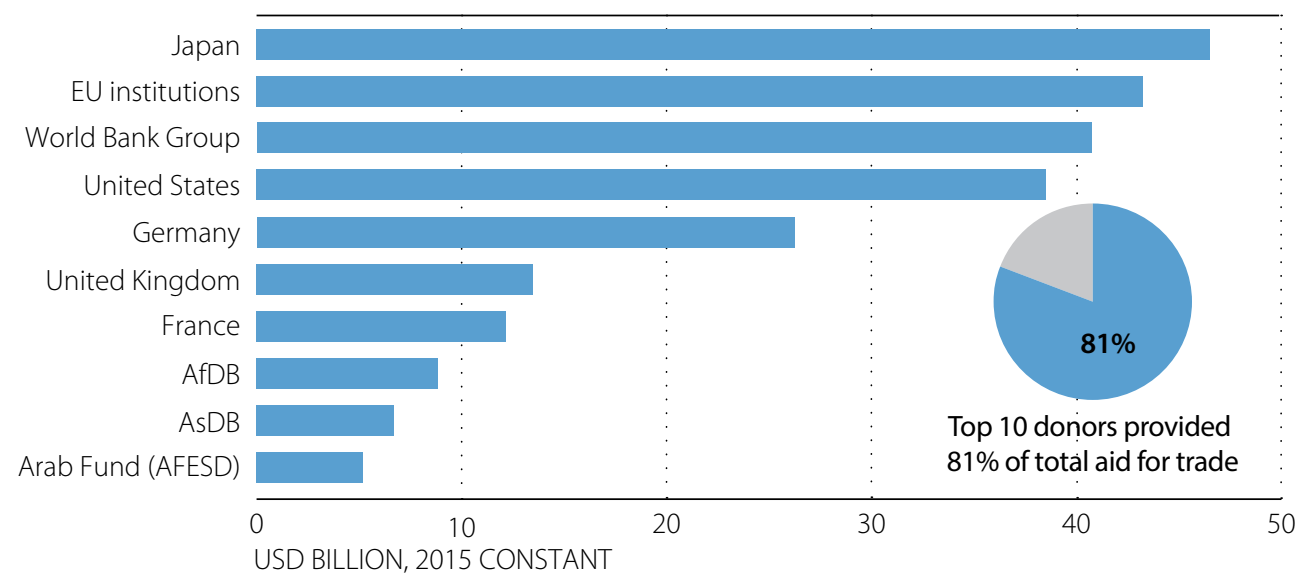

Source: OECD-DAC CRS: aid activity database (2017), DOI: http://dx.doi.org/10.1787/data-00061-en, (accessed 07 April 2017).

Figure 11.12. Top ten providers of trade-related OOF (total disbursements 2006-15

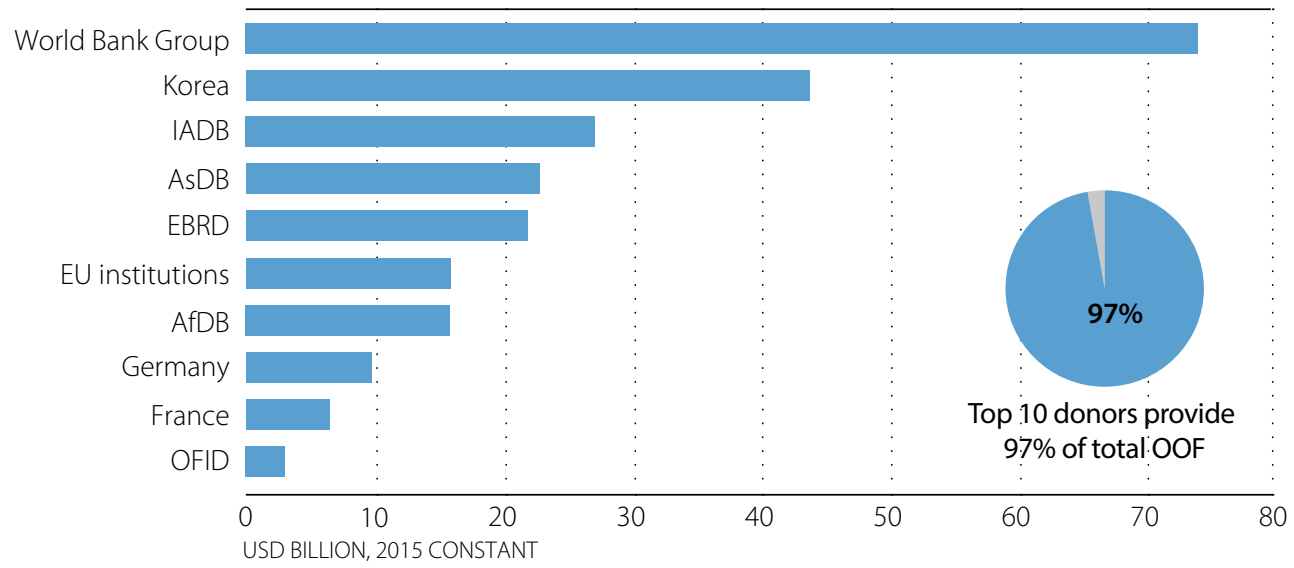

Source: OECD-DAC CRS: aid activity database (2017), DOI: http://dx.doi.org/10.1787/data-00061-en, (accessed 07 April 2017). 


\section{TRADE-RELATED INFRASTRUCTURE IS A DEVELOPMENT ENABLER}

Infrastructure development is critical for sustainable economic growth and poverty reduction. It enables the movement of people, goods and services and provides access to local, regional and global markets as well as health, education, water, energy and communications services. Infrastructure is estimated to have a socioeconomic rate of return of around $20 \%$. This is mainly thanks to increased productivity resulting from reduced travel time and costs, access to reliable electricity, and broadband connectivity that allows individuals and businesses to plug into the digital global economy (MGl, 2016). While the provision of transport is potentially crucial for development, its impact depends on a variety of factors. Setting priorities, especially when resources are scarce, should rely on a detailed analysis of how transport policies can produce growth-inducing effects and reduce social costs (Bielenberg et al., 2016).

Because it is a critical enabler of both direct and indirect societal benefits, infrastructure is a core element of the Sustainable Development Goals, including: access to affordable, reliable, sustainable, and modern energy for all, as well as resilient infrastructure, inclusive and sustainable industrialization, and heightened innovation. Upgrading infrastructure is central to the agendas of many developing countries and regional economic communities (RECs). According to the 2017 OECD-WTO monitoring survey, the issue features in eight out of ten donor dialogues with partner countries and seven out of ten dialogues with RECs. Three quarters of the donor agencies participating in the 2017 monitoring exercise prioritise infrastructure development and half of them operate specific trade-related infrastructure programmes. These place a particular focus on transport and energy related infrastructure ( $78 \%$ and $72 \%$ respectively), and on communication infrastructure (68\%).

This section discusses the use of official development finance for bridging the trade-related infrastructure gap. It starts with a short analysis of the volume of official development finance for infrastructure. Next, it highlights some of the strategies pursued by donors that are particularly active in this area and presents several case stories. It concludes with some observations about how to improve the effectiveness of support for trade-related infrastructure investments.

\section{Infrastructure is a large component of the aid-for-trade portfolio}

Since the start of the Aid for Trade Initiative, more than half of all related funds have been disbursed to build traderelated infrastructure. Together Japan, the World Bank Group, the European Union (EU) institutions, Germany and France disbursed over three quarters of all funds during the period 2006-15. This concentration is explained by the fact that, in general, the size of trade-related infrastructure projects surpasses the financial capacity of smaller donors. Often, these donors work together in multi-donor programmes to finance large-scale infrastructure projects.

In 2015 aid disbursements for trade-related infrastructure reached USD 20.65 billion, double the 2002-05 average baseline (Figure 11.13). Disbursements for transport and storage stood at USD 10.7 billion. For energy projects, they reached USD 9.5 billion, up almost USD 781.8 million compared to 2014. Information and communications technology (ICT) disbursements totalled only USD 443.1 million, mostly in the form of technical assistance for regulatory reform (Figure 11.14). ICT hardware investments were mostly financed by the private sector.

During the period 2006-15, Asia received most of the ODA disbursements for ITC (33\%), followed by Africa (32.9\%), Europe (10.3\%), Latin America and the Caribbean (9.6\%) and Oceania (1.6\%; Figure 11.15). During the same period, 41.2\% of cumulative disbursements went to the LMICs, followed by the LICs with 30.7\% (LDCs 28.2\% and OLICs 2.9\%). The UMICs received $21.7 \%$ of total disbursements.

In 2015, OOF disbursements reached USD 20.9 billion, an increase of 521\% compared to the 2002-05 average baseline. The distribution between the three main infrastructure sectors is comparable with that of ODA. What is very different from the ODA disbursements is that OOF is mainly destined for UMICS (50.8\%) and LMICS (44.6\%), with LICs only receiving $2.8 \%$. 


\section{Figure 11.13 Aid-for-trade disbursements for infrastructure}

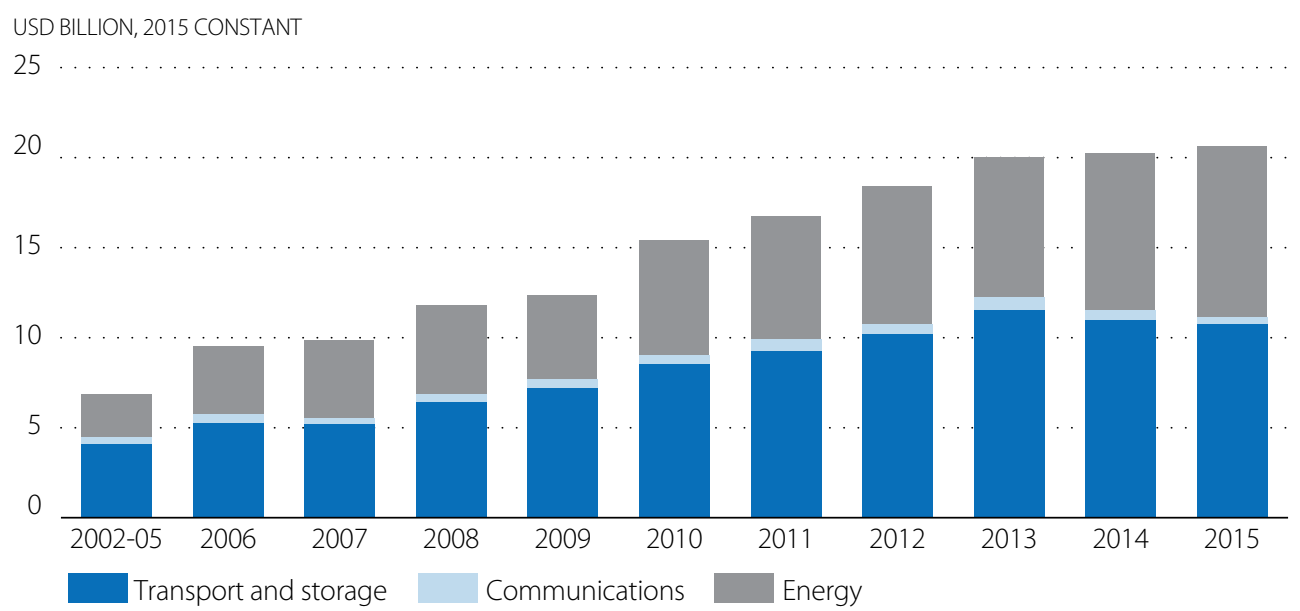

Source: OECD-DAC CRS: aid activity database (2017), DOI: http://dx.doi.org/10.1787/data-00061-en,

(accessed 07 April 2017).

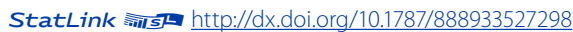

OECD (2015) found that total infrastructure investments in developing countries amounted to roughly USD 1 trillion in 2013, of which more than half was financed by developing country governments and a third by the private sector. Official development partners in general financed between 6-7\% of these infrastructure investments, which amounted to about USD 55 billion, with bilateral donors financing around $46 \%$ and multilaterals $54 \%$ of these amounts. China, India, Turkey and Arab partners provided about 13\% of total official support for infrastructure through South-South development co-operation.

\section{Case stories shed light on infrastructure approaches and priorities}

Donors have diverse strategies for tackling the infrastructure gap. Seeking to address inefficient and costly infrastructure delivery, many governments over the past two decades have turned to public-private partnerships (PPPs) to build and operate infrastructure. The key characteristic of PPPs is the outsourcing and "bundling" of project delivery components (e.g. design, building, financing, operations), to incentivise the builder-operator to incorporate long-term operatingcost considerations into the design and construction phases of a project, and to reduce co-ordination costs. Trebilcock and Rosenstock (2015), reviewing the benefits and drawbacks of PPPs for developing economies, find that relative to traditional procurement, PPPs are complex; they require governments to anticipate and plan for contingencies, and to monitor and enforce contracts over the long term. They argue that institutional capacity is a key determinant of PPP success.

\section{Regional approaches to infrastructure challenges}

The Programme for Infrastructure Development in Africa (PIDA), developed by the African Union, the New Partnership for Africa's Development (NEPAD), the African Development Bank (AfDB), the United Nations Economic Commission for Africa (UNECA) and several regional economic communities, is taking a regional approach, which enables large competitive markets to be created out of smaller, isolated ones, thereby lowering trade and production costs. The price tag for carrying out PIDA between 2011 and 2040 is estimated at around USD 360 billion. This outlay is beyond the financing capacity of African governments or their donors. Attracting private sector financing is therefore essential for the realisation of the various infrastructure projects envisioned under the programme (NEPAD, 2016). 
In 2007, the European Union and several of its member states established the EU-Africa Infrastructure Trust Fund (AIFT). It aims to increase infrastructure investment in sub-Saharan Africa by blending long-term loans and risk capital with grant resources. To date, the fund, with grants of EUR 456 million, has generated investments of EUR 8.9 billion. In 2015, it supported six transport projects in some of sub-Saharan Africa's least connected and most vulnerable areas, such as northern Nigeria and South Sudan. Furthermore, the fund supports projects that are closely aligned with PIDA objectives; more than half of all grants approved under the regional pillar of the fund directly support PIDA projects. The majority of these are in the transport and energy sectors, for example, the North-South Power Transmission Corridor and the West Africa Power Transmission Corridor (EC, 2015).

The members of the Association of Southeast Asian Nations (ASEAN) have renewed their commitment to the Master Plan for Connectivity 2025, which focusses on five areas: sustainable infrastructure, digital innovation, seamless logistics, regulatory excellence and mobility of people. The assessment of the forerunner-the 2010 Master Plan —shows that almost half of the 39 identified infrastructure gaps were tackled. Notable progress has been made on the ASEAN Highway Network, which created integrated, safe, and environmentally sustainable regional land transport corridors linking all ASEAN Member States and neighbouring countries (ASEAN, 2016). Transport and transit infrastructure is also a priority in the Asia-Pacific region.

Transport has been one of the Asian Development Bank's (ADB) main priorities and now receives more than 30\% of total lending. Progressively, the focus of its portfolio for sustainable transport has centred on four key areas: urban transport, low-carbon and climate-resilient transport, cross-border transport and logistics, and integration of safety in road investments. The ADB has established a Sustainable Transport Partnership Facility to enable development partners, research institutes, and nongovernment organizations to provide financing, expertise, and in-kind contributions to enhance and scale-up ADB's sustainable transport operations (ADB, 2010)

The Australian government has recently approved a new strategy for development assistance that prioritises increasing investment in infrastructure. The strategy spotlights investments to enhance trade and connectivity throughout the region and mobilise private sector finance to improve access to infrastructure services and promote women's participation and empowerment. Australia intends to give less priority to financing for infrastructure building, focusing more on providing technical assistance for project preparation and regulatory reform (Australia, 2015).

The United States Agency for International Development (USAID) finances the construction of energy, roads, and communications infrastructure in more than 60 countries. Particular emphasis is placed on construction and rehabilitation of infrastructure in conflict and disaster-affected countries, such as Afghanistan, Pakistan and Haiti, to foster stability and fuel economic recovery. For example, USAID has built or rehabilitated more than 3,000 kilometres of roads in Afghanistan, provided technical assistance for the 2010 Afghanistan-Pakistan Transit-Trade Agreement (APTTA), and supported the Cross-Border Transport Agreement (CBTA) between Kyrgyzstan, Tajikistan and Afghanistan (USAID, 2014).

The infrastructure strategy of the World Bank Group is structured round three pillars: interventions to ensure access to basic infrastructure services; regional projects in the areas of power grids, broadband, transportation corridors and renewable energy; and mobilising private capital. The Bank also manages the Global Infrastructure Facility (GIF), a partnership among governments, multilateral development banks, private sector investors, and financiers to design and implement infrastructure projects that a single agency cannot handle on its own. Working with client governments, the GIF tries to structure infrastructure projects in ways that will attract private capital. Private or public sector entities operating on a commercial basis are tasked with implementing the projects. The partnership focuses on trade enabling projects that facilitate or enhance interconnectivity and trade, including freight rail networks, seaports and inland terminals, airports and toll roads (World Bank, 2016). 


\section{Transport and transit corridors}

Transport and transit corridors have been around for centuries, but it is only in the last few decades that they have been recognized for the value they can add to economic growth—particularly for landlocked countries. While transit corridors are often more effective, they are also politically more challenging because countries bear different shares of the project costs. This creates asymmetric incentives to expend limited funds and resources on the corridor over other domestic projects, particularly when it is difficult to establish ex ante which country "gains the most". An honest broker, such as a development bank or a multi-donor programme, can help overcome this problem. In addition, there might also be downsides related to displacement or conflict. These potential challenges need to be addressed, especially because regional connectivity projects often permeate peripheral areas of nation-state boundaries. The potential largescale environmental impact also needs to be factored in (Yhome and Chaturvedy, 2017).

The infrastructure strategy of the Japanese International Cooperation Agency (JICA) focuses on the development of trunk corridors as key axes to stimulate economic activity. In Africa, Japan is involved in eight economic corridors: the Trans-Maghrebin Corridor, the West Africa Growth Ring, the Northern Corridor, the Nile Corridor, the Djibouti-Addis Ababa Corridor, the Central Corridor and the Nacala Corridor. JICA provides technical assistance for participatory formulation of long-term master plans, which includes environmental and social impact assessment (JICA, 2016). In Asia, JICA and the ADB are building capacity for enhancing cross-border transport and trade across the Great Mekong subregion corridor. The programme builds on progress already made through the Cross Border Transport Facilitation Agreement. By laying the ground for faster, easier, cheaper, compliant, and more inclusive cross-border transport and trade, it is expected to make a significant contribution to the ASEAN Economic Community ((OECD-WTO aid-for-trade monitoring exercise 2017, Public sector case story 124).

Transport corridors have also been developed under the Central Asia Regional Economic Cooperation (CAREC) programme. The 2008 CAREC Transport and Trade Facilitation strategy identified six strategic corridors to be improved: Europe-East Asia; Mediterranean-East Asia; Russian Federation-Middle East and South Asia; Russian FederationEast Asia; East Asia-Middle East and South Asia; Europe-Middle East and South Asia. Although there have been improvements in customs administration, better co-ordination among custom offices is still needed. Furthermore, although intra-regional and extra-regional trade volume grew, the increase remained well below the assessed potential. Consequently, the CAREC countries have refined their strategy by shifting the focus to improving the quality of logistics services and increasing the level of connectivity. For hard infrastructure, there is a new emphasis on longdistance freight movement. In services, the need to connect the six CAREC corridors and major seaports is emphasized. The refined strategy also stresses the importance of extending and completing the six strategic multimodal corridors (OECD-WTO aid-for-trade monitoring exercise 2017, Public sector case story 107).

The German development co-operation agency, GIZ, partnered with the Malian Ministry of Commerce and the Senegalese Ministry of Investment Promotion to implement a trade facilitation programme on the Dakar-Bamako. The project provides advisory services for simplifying Malian and Senegalese custom procedures and transit systems. By engaging private sector actors the project is able to enhance transparency and better disseminate information regarding transit regulations to corridor users. Given the broad variety of actors and interests involved, the establishment of co-ordination committees at different levels has been a major success factor. Anchoring the committees in existing structures also has facilitated the continuation of their activities after the end of the project (OECD-WTO aid-fortrade monitoring exercise 2017, Public sector case story 65). 
Trans-regional corridors are also increasingly attracting attention and investment. The most ambitious is China's revival of the historic Silk Road trade route. Announced in 2013, two new trade corridors—one overland, the other by sea - are planned to connect China with its neighbours in Central Asia, the Middle East and Europe. The aim is to generate USD 2.5 trillion in additional annual trade with the nations along the proposed routes over the next ten years. Fulfilling this ambition will require collaboration among the 40 countries located along the silk routes, both the overland routes from China to Europe and the sea routes. The project requires significant funding —an estimated USD 8 trillion between 2010 and 2020 alone. The Chinese government has announced several commitments, including a USD 40 billion Silk Road Fund for projects in the Central Asia region (Lehmacher and Padilla, 2015).

Asia provides more examples of trans-regional corridor proposals, such as the Indo-Pacific Economic Corridor to connect the Indian and the Pacific Oceans through South and Southeast Asian littorals; initiatives to link East Asia to Africa and Europe through South and Southeast Asia; the Bangladesh, China, India and Myanmar Economic Corridor to connect China's southwest region to India's eastern region through Bangladesh and Myanmar; and the Trans-Himalayan Economic Corridor to link South and Southeast Asia to Central Asia (Yhome and Chaturvedy, 2017).

\section{Railways}

The condition of railway infrastructure and the performance of most rolling stock are generally poor in Africa. However, rail transport has an important role to play in the growth and sustainable development of the African continent over the next few decades (AfDB, 2015). For instance, more than 95\% of Ethiopia's trade passes through the port of Djibouti. The new Addis Ababa-Djibouti railway provides landlocked Ethiopia with railroad access to the sea. The new line was built between 2011 and 2016 and financed by China at around USD 4 billion. The railway has reduced cargo transit times from 3 days by road to 12 hours by train.

The CAREC transport programme includes the construction of 75 kilometres of railway line between Mazar-e-Sharif in Afghanistan and Hairatan on the Uzbekistan border. The railway line cuts through bottlenecks and raises the profile of Afghanistan as a transit route by connecting two CAREC corridors, i.e. the Russian Federation-Middle East corridor, and the South Asia and Europe-Middle East and South Asia corridor. Intensive multiple-donor engagement has been a success factor for the project. This engagement also improved the adaptability of the project to changing conditions during implementation. The ADB provided supervision, both from headquarters and by the resident mission (OECD-WTO, 2015).

The rehabilitation of already existing railway system is also crucial. The European Bank for Reconstruction and Development (EBRD) funds the rehabilitation of railway infrastructure in Bosnia and Herzegovina. The project has been co-financed by the European Investment Bank (EIB) and several other donors. Japan, for example, provided funds to help rebuild the Jedrinje tunnel between Sarajevo and Mostar, while the EU, Italy, United States and Canada supported the project's planning stages. The project also includes support for administrative and regulatory reforms. Greater highlevel policy dialogue, together with strategic engagement with a broad range of stakeholders, is essential to deliver reforms in transport regulation (OECD-WTO aid-for-trade monitoring exercise 2017, Public sector case story 76)

\section{Ports}

Port projects have irreversible effects on the local economy and local community, as well as on the way the regional and national economy operate as a whole, with; in particular, they have major impact on regional transport systems. Investments in port planning should consider these potential broad impacts as part of a national freight transport and logistics strategy. Furthermore, private investment in port terminals is facilitated by the by development of national freight transport and logistics strategies (ITF, 2015). 
The Kenya Ports Authority and TradeMark East Africa have undertaken an infrastructure development project for the port of Mombasa, the principal gateway to Eastern Africa. The key challenges-low performance, particularly at the ship-to-shore interface; lack of capacity; and slow clearing and forwarding arrangements_-all result in high cargo dwell times. Project activities include upgrading the main gates, installing security equipment and the construction of an additional climbing lane. The expansion of the gate has led to improved port access and reduced congestion and truck turnaround times. Surveys show that truck turnaround has been halved, from eight hours in 2014 to four hours in 2016. A user satisfaction survey showed that $86 \%$ of export drivers and $28 \%$ of import drivers were satisfied with the infrastructure changes changes (OECD-WTO aid-for-trade monitoring exercise 2017, Public sector case story 80).

Afghanistan, Iran and India recently finalized the trilateral transport and transit pact that regulates infrastructure improvement in the seaport of Chabahar, located on Iran's South-Eastern coast. India had previously invested USD 135 million to build the Zaranj-Dilaram highway connecting the Kabul-Herat Highway to Chabahar port, providing land-locked Afghanistan with access to the Arabian Sea and the Persian Gulf. The development of the port is expected to revive Afghanistan's historic and natural role as a crossroads connecting Central Asia to South Asia, while making it easier for Afghan goods to reach the lucrative Indian market. Upon completion of the work, Chabahar's capacity should increase to 8 million tons, as compared to the current 2.5 million. Although the project has potential to become a game changer in the region, the political and security situation in Afghanistan and the region may hinder progress (OECD-WTO aid-fortrade monitoring exercise 2017, Public sector case story 61).

\section{Airports}

Transport and communication linkages are crucial for small islands and developing states. To rehabilitate the Bonriki International Airport in Kiribati, one of the most remote countries in the world, Chinese Taipei committed USD 15 million to the World Bank's Kiribati Aviation Investment Project. The project includes investments in infrastructure, sector reform, and training to strengthen airport operations and management capacity, as well as project support. While the project is still ongoing, some challenges have already risen. For example, procurement and contract management require daily on-site technical support to resolve issues, ensure progress and enhance institutional capacity. Local circumstances, such as adverse weather, can also delay the construction schedule (OECD-WTO aid-for-trade monitoring exercise 2017, Public sector case story 12).

\section{Soft infrastructure}

The Czech Republic is running a project to improve road traffic management and regulations in Mongolia. It aims to establish a unified road transport system (including for the transport of goods) with the latest monitoring and control systems. It also aims to improve vehicle registration and technical control, meeting international standards. the project is founded on the transfer of know-how in regulating areas such as transit transport, driving hours and rest periods, and weights and dimensions of load (OECD-WTO aid-for-trade monitoring exercise 2017, Public sector case story 58).

\section{Case stories in trade-related infrastructure offer lessons for the future}

The case stories show that improving trade-related infrastructure helps to reduce transport costs, which in turn increases market access and boosts trade flows. The resulting structural transformation can help farmers, for example, to move from subsistence to commercial agriculture or to non-agricultural activities. These impacts can lead to increased welfare, raising higher incomes and reducing poverty. However, these potential economic gains must be balanced against the possible environmental costs. Road and rail development can lead to deforestation and biodiversity loss. Increased traffic on new roads increases air pollution, which can affect health negatively. 
Nonetheless, financing the required levels of public investment in trade related infrastructure in developing countries faces challenges in today's context of scarce financial resources. Even when the infrastructure is in place, operation also requires funding. Safeguarding debt sustainability requires action on several fronts: boosting public savings by enhancing domestic revenue mobilization and reducing non-priority outlays; ensuring efficient use of funds by strengthening public investment management; developing local capital markets; and tapping into all available sources of concessional financing (IMF, 2016).

Enhancing the role of the private sector in infrastructure delivery also should be promoted where feasible. This requires concerted efforts to improve the regulatory and macroeconomic environment and enhance countries' capacity to negotiate and implement public-private partnerships that will allow them to effectively balance risk-sharing between the public and private partners. Donors also have an important role to play in boosting private sector investment in infrastructure by lending technical support to governments seeking to attract funds, actively engaging their private sector arms in infrastructure projects, and providing effectively-designed risk-mitigation mechanisms.

\section{DONOR SUPPORT FOR ICT IS CRITICAL FOR DEVELOPMENT}

Digital technologies are spreading rapidly in developing countries, offering unprecedented opportunities to tackle development challenges in innovative ways. Many of the challenges faced by local small and medium enterprises are the result of market failures and information asymmetries. These are all domains in which effective ICT applications can make a significant difference (UNCTAD, 2011).

Digital connectivity can help to accelerate the achievement of the 2030 Agenda. Moreover, ICT provides new and more automated means to monitor and assess progresses towards the Sustainable Development Goals (SDGs) and enable evidence-base decision making. Donor agencies have shown an interest in ICT for development since the 1990s (Heeks, 2009). Recently, it has become a more strategic priority for them because ICT offers more innovative, cheaper and affordable ways of delivering development services. The 2017 OECD-WTO monitoring exercise found that ICT is prioritised in the development strategy of two-thirds of the donors, followed by e-government and e-commerce (58\% and $50 \%$ respectively). Donors report that this area is attracting either significant or some growth of demand (44\% for each). Although e-commerce and other digital strategies feature in two-thirds of the country and regional dialogues, less than half of the donors operate special initiatives covering these areas. Half of these special initiatives are undertaken in close co-operation with the private sector.

This section looks at donor strategies for helping to increase connectivity in developing countries, provides data on donor support for ICT, and offers examples of some programmes. The section concludes with some lessons learned.

\section{Disbursements for ICT, by category, region and country grouping}

ODA for ICT is captured in the OECD Creditor Reporting System (CRS) under five categories: 1) technological research and development; 2) radio, television and print media; 3) communication policy and administrative management; 4) information and communications technology; and 5) telecommunication. The 2002-05 annual baseline average was just short of USD 500 million. In 2013, ITC disbursements reached their highest level, at USD 812.5 million; this was largely the result of two large telecommunication projects in Turkey and Romania, both financed by the European Union. Between 2006 and 2015, average overall ICT disbursements fluctuated between USD 650 million and USD 700 million; the largest share (35.2\%) was devoted to financing telecommunication projects, followed by investments in information and telecommunication technology (24.1\%), policy and management (16.6\%) and finally research and development (10.5.2\%; Figure 11.14). 
The relative share of aid for ICT in total aid for trade is small and declining; it went from 3\% during the baseline period to $1.2 \%$ in 2015. The surge in 2013 mentioned above marked a break in this declining trend and the share reached 2.3\%. Most of the aid-for-trade support for ICT is actually provided in the form of technical assistance for institutional and human capacity building in the area of ICT regulations. Investments in physical ICT infrastructure are mostly undertaken by the private sector once the regulatory framework is in place and operating effectively.

\section{Figure 11.14 ODA disbursements for ITC}

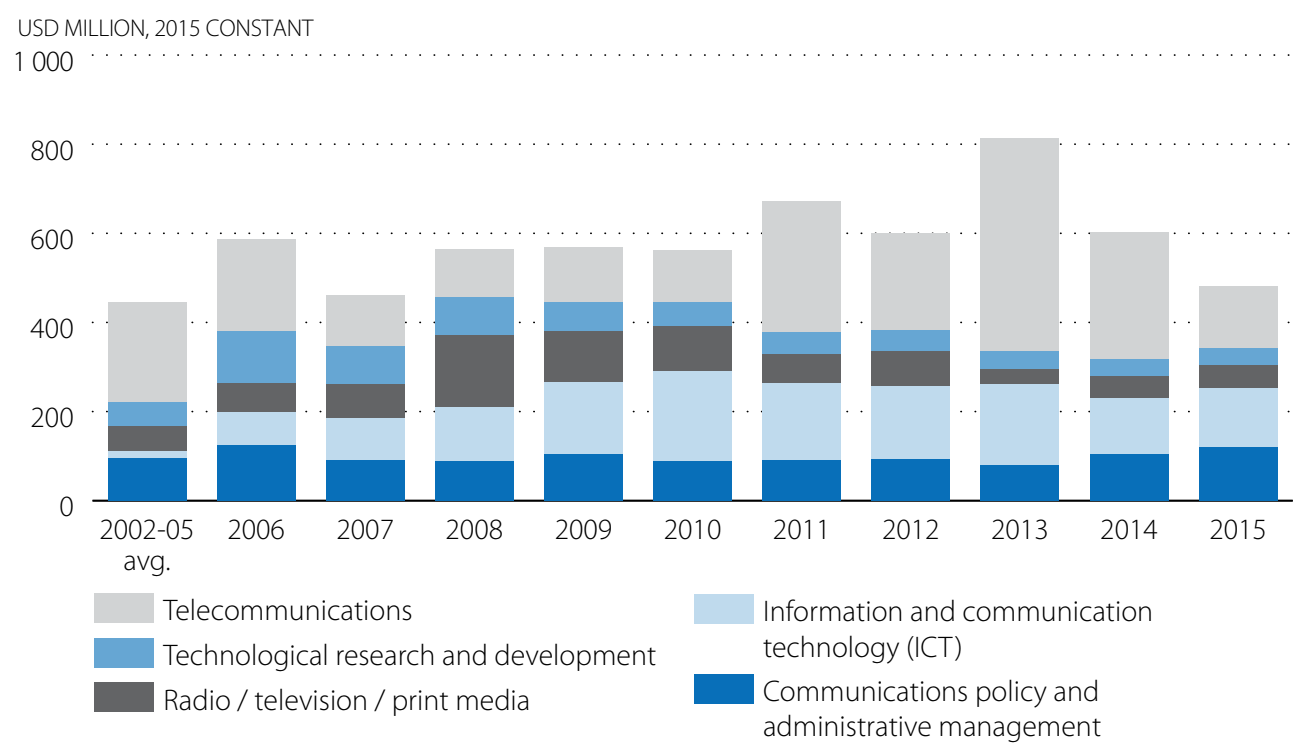

Source: OECD-DAC CRS: aid activity database (2017), DOI: http://dx.doi.org/10.1787/data-00061-en,

(accessed 07 April 2017).

StatLink त्ञाIs http://dx.doi.org/10.1787/888933527317

During the period 2002-15, most of the aggregate ICT disbursements were for Asia and Africa (each USD 2.5 billion), Europe (USD 794.9 million), Latin America and the Caribbean (USD 735.7 million), and Oceania (USD 124.3 million). Regional and global programmes received USD 970 million (Figure 11.15). The UMICs were the largest recipient group, with a share of 29.3\% of total disbursements during the period 2002-15; the LDCs share stood at 24.6\%; OLICs at 2.0\%; and LMICs at $21.2 \%$. The top three donors — the EU institutions, Japan and the World Bank—provided close to half off all disbursements during that period.

Figure 11.15. Cumulative distribution of ODA for ITC by region, 2002-15

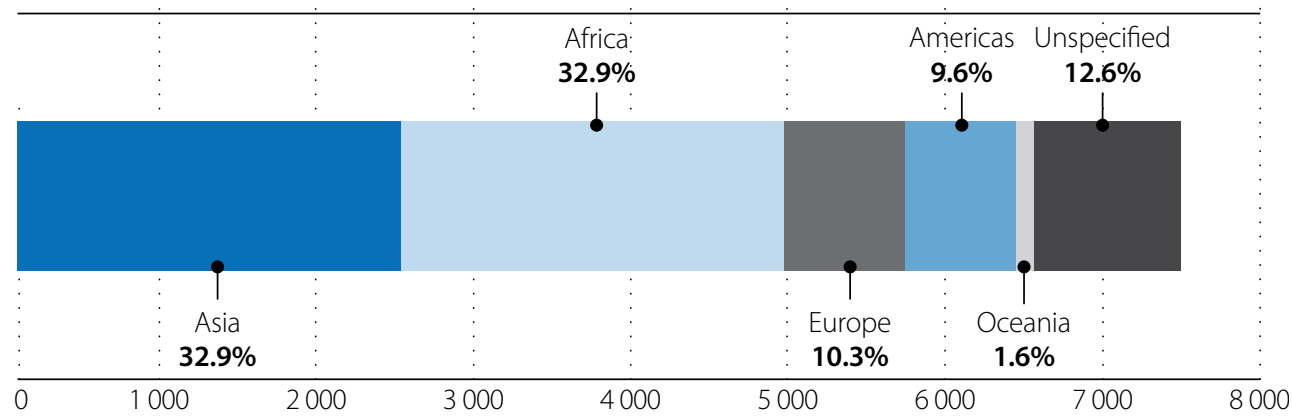

USD MILLION, 2015 CONSTANT

Source: OECD-DAC CRS: aid activity database (2017), DOI: http://dx.doi.org/10.1787/data-00061-en, (accessed 07 April 2017). 


\section{ICT for infrastructure}

The African Development Bank promotes connectivity through the Connect Africa Initiative, a global partnership launched in 2007 that mobilises human, financial, and technical resources to bridge gaps in African ICT infrastructure. It includes fibre connectivity projects with regional and national submarine backbones; policy interventions to promote open, transparent and non-discriminatory access to ICT networks; and simplified licencing procedures for networks and e-applications. An AfDB assessment found that while considerable progress has been made in the area of broadband connectivity, about $87 \%$ of the African population is still unable to connect to the internet (AfDB, 2013). Modest progress has been made in creating the enabling regulatory frameworks; in Kenya, Mauritius, South Africa, Tanzania, and Uganda, the entire telecommunications, broadcasting and information technology sectors have been regulated (OECD-WTO aid-for-trade monitoring exercise 2017, Public sector case story 16).

Public institutions in developing countries are increasingly getting involved in ICT infrastructure development. For instance, the government of Pakistan has embraced the digital economy and now offers a wide range of services online, including social welfare payments, citizen liaison services and automated border control. Some of these services are exported to other developing countries. The Universal Service Fund aims to provide national broadband coverage in every region in Pakistan by 2018. Its main objective is to increase the level of telecom penetration in rural areas by encouraging telecom operators to focus on rural and unserved populations; improve broadband penetration in the country; and significantly boost e-services in both rural and urban parts of the country. As of 2016, the results include: almost half a million contracts signed, more than 700000 broadband subscribers, and the establishment of 1328 educational broadband centres as well as 369 community broadband centres (OECD-WTO aid-for-trade monitoring exercise 2017, Public sector case story 87).

The case of Tonga offers a good example of the potential of ICT infrastructure in providing small islands and landlocked countries with an opportunity to overcome the high transaction costs they face. Under the Pacific Regional Connectivity Program, the ADB, the Government of Tonga, the Tonga Fibre Optic company and the World Bank joined forces to finance an 827-kilometer submarine fibre-optic cable system linking Tonga to Fiji via the Southern Cross Cable - the main trans-Pacific link between Australia and the United States. Thanks to this investment, highspeed broadband internet is transforming everything from health care, business and government services to education, disaster management, and the social life of Tongans. International connectivity costs have already fallen by more than 60\% (OECD-WTO aid-for-trade monitoring exercise 2017, Public sector case story 97.

\section{ICT for productive capacity}

ICT applications have been widely used to improve the life of rural agricultural communities, providing them with better networking opportunities and facilitating access to advanced techniques. Furthermore, ICT enables farmers to enter new markets and gain access to digital services, such as credit or crop failure insurance, or to consult the latest weather report. All of this makes their agricultural activities both more productive, boosting marketing prospects for producers and traders, and more secure. Agricultural market information services can also be effective at the policy level, enabling the tracking of commodity prices and supplies, and ensuring greater transparency $(G I Z, 2015)$.

The GSoko platform links small holders to grain buyers across East Africa. Using digital technology it provides information about market opportunities, tracks goods, enhances transparency and connects buyers and sellers. The platform also issues regional quality certifications and protects farmers against prices falling too low by offering storage facilities that enable them to sell their goods at more favourable prices in the future. The platform, which received a USD 4.4 million DfID grant, is implemented by the Eastern Africa Grain Council in partnership with various industry stakeholders (grain traders and buyers; policy and research bodies; trade and information agencies). Engagement with the private sector has proved critical to the success of the project (OECD-WTO aid-for-trade monitoring exercise 2017, Public sector case story 70). 
Large multinational companies have also been active in promoting access to e-commerce for small and medium enterprises. For instance, Amazon has offered the Fulfilment by Amazon service to producers that want to sell their products online. Using this service, Thailand's Lanna Clothes Design has increased its online business by $70 \%$ after just 10 months; the number of employees has increased from 5 to 20, most of them women from rural Chiang Mai or the neighbouring province. This experience has also had positive externalities in the local community: based on her own e-commerce success, the owner plans to help local designers grow their businesses; at the same time, twice a year her company donates clothing and food to a nearby orphanage with 600 children (OECD-WTO aid-for-trade monitoring exercise 2017, Private sector case story 88).

\section{ICT for trade policies and regulations}

In 2013, the United Nations Conference on Trade and Development (UNCTAD) and the Economic Community of West African States (ECOWAS) supported the implementation of regional e-commerce legislation through a joint capacity building programme. The programme strengthened e-commerce know-how, reviewed the current state of cyber legislation, and discussed ways to achieve regional integration and the harmonization of regional e-commerce legislation. It demonstrated the need for member states to continue the implementation of regional legislation on e-transactions, data protection and cybercrime. At the ECOWAS level, the process of harmonization needs to consider all relevant areas, including e-money, online administration and new issues arising from cloud computing ((OECD-WTO aid-for-trade monitoring exercise 2017, Public sector case story 59).

Certification of origin for exports can be costly for small farmers and entrepreneurs in developing economies. With the support of TradeMark East Africa, the Kenya National Chamber of Commerce and Industry has automated the application for and issuance of certificates of origin. Whereas the manual process took an average of up to three and a half days to complete, automating the process reduced the time to less than one and a half days. The inclusive and consultative project was stakeholder-driven (OECD-WTO aid-for-trade monitoring exercise 2017, Public sector case story 54).

\section{Case stories in support for digital technology offer further lessons}

Several of these case stories illustrate the opportunities provided by digital technologies to increase private sector engagement in development. Most donors have abandoned support for ICT infrastructure, leaving the job to the private sector. The most effective roles for the private sector include investing in ICT infrastructure (which tends to be very capitalintensive), operating ICT networks and delivering ICT services. Companies are interested in ICT-for-development initiatives for both commercial and corporate, social responsibility reasons.

Companies_especially those that provide digital content-can use their know-how to deliver innovative services for development. In addition, they are often able to address the lack of hard and soft ICT infrastructure more efficiently than donors. They might also be more willing to scale-up their ICT infrastructure investments. A fair and transparent regulatory and policy framework helps to secure and promote private-sector involvement.

Yet the development of expertise and technological innovation in developing countries cannot be left to the market alone. It is up to governments to ensure that the poor benefit from ICTs whenever and wherever possible. This can be ensured by formulating policies that specifically focus on the interests of the poor; encouraging network operators to channel part of their investments towards less commercially attractive regions; encouraging and co-financing ICT applications that directly benefit the poor, such as information points in local community centres; and investing in ICT applications in the public sector. 


\section{EMPIRICAL FINDINGS DEMONSTRATE THE EFFECTIVENESS OF AID FOR TRADE}

A review of empirical findings demonstrates the effectiveness of aid for trade in numerous settings and aspects. Velde te et al (2013) confirm that aid for trade, in general, is effective at both the micro and macro levels. They note, however, that the impacts may vary considerably depending on the type of aid-for-trade intervention, the income level of the beneficiaries, the sector to which the support is directed and the geographical region of the recipient country. In the case of sectors, for example, Ferro et al. (2012) find that a 10\% increase in aid to transportation, information, communication and technology, energy, and banking services is associated with increases in the exports of manufactured goods from the recipient countries of $2.0 \%, 0.3 \%, 6.8 \%$ and $4.7 \%$, respectively.

Aid for trade also has great potential to reduce trade costs. Cali and te Velde (2011) examined the impact of aid for trade on trade costs and exports; they found that a USD 1 million increase in aid-for-trade facilitation is associated with a 6\% reduction in the cost of packing, loading and shipping to the transit hub. Busse et al (2012), using panel data on 99 developing countries covering the period 2004-09, show that aid for trade is closely associated with lowering trade costs, and therefore may play an important role in helping developing countries benefit from trade. Cirera and Winters (2014) find that aid for trade has a positive impact on exporting and importing times in sub-Saharan African countries, but other factors explain differing experiences in structural change.

Helble et al. (2012) empirically assess the relationship between different aid-for-trade categories and trade performance. They find that a 1\% increase in aid-for-trade facilitation could generate a USD 415 million increase in global trade. An USAID (2010) evaluation of trade assistance focusing on expansion of exports, trade policy reform, increased participation in trade agreements, and efficiency gains from trade facilitation assistance, finds that each additional US dollar increases the value of developing country exports by USD 42 two years later. OECD-WTO (2013a) finds that one US dollar invested in aid for trade is on average associated with an increase of nearly eight US dollars in exports from all developing countries and an increase of twenty US dollars in exports from the poorest countries. These effects were found to be even higher for exports of parts and components.

On the basis of a literature review, Martuscelli and Winters (2014) conclude that trade liberalisation generally boosts income and thus reduces poverty, with gains for those working in the export sector and losses in the import-competing sector. A fairly common finding is that female workers gain from trade liberalisation. De Melo and Wagner (2015) confirm these findings and observe that aid for trade has also helped reduce poverty through other channels. For example, aid targeted to building productive capacities in agriculture and insurance schemes that remove risks can raise the productivity of households that are close to the poverty line. Road rehabilitation can also reduce the monopolistic power of traders in remote areas, thereby raising the incomes of the poor from sales of their agricultural production.

Ghimire et al (2016) find that aid for trade has positive and significant effects on multiple measures of export performance. However, they also find that aid for trade exhibits diminishing returns. Tadesse et al (2017) find that aid for trade from both bilateral and multilateral donors leads to significant reductions in trade costs for recipients at both the aggregate and sector levels. However, the effectiveness of aid for trade in reducing bilateral trade costs and allowing developing countries' full integration into the global market does not only depend on the size of flows, but also on the co-ordination between bilateral and multilateral donors. They conclude that these observations demonstrate the need for further strengthening of the initiative. This reinforces the findings of Hynes and Holden (2016), who argue that the Aid for Trade Initiative has substantial achievements to its credit and that there is reason to reinforce its positive elements. 
The inquiry into the United Kingdom's (UK) Africa Free Trade Initiative by the All-Party Parliamentary Group for Trade out of Poverty (2016) noted that aid-for-trade programmes have helped individual African governments and regional economic communities lower tariffs, harmonize regional trade arrangements, improve hard and soft trade infrastructure, and cut red tape by modernizing customs systems, procedures and facilities. Most of this progress has been made in East and Southern Africa. Yet despite the progress in improving trade conditions, sustained effort needs to be put into further freeing up trade and boosting the competitiveness of African countries. The evaluation recommends that a successor to the Africa Free Trade Initiative should be part of the UK's strategy (APPG-TOP, 2016).

The 2015 independent evaluation of the Netherlands' Centre for the Promotion of Imports (CBI) from Developing Countries (Netherlands, 2015) concluded that technical assistance to individual companies for strengthening their competitive edge in European markets, and for improvement of business support organisations in developing countries, has been successful in helping companies to overcome scarcity of market information and market entry barriers. This was not always sufficient, however, to increase exports. In some cases, observed export increases could not always be (fully) attributed to CBI programmes and activities. CBI's contribution was, therefore, judged more modest when set against the ultimate intended trade performance goals (Netherlands, 2015).

An independent evaluation of Finland's Aid for Trade Action Plan 2012-15 (Finland, 2016) found that it is not possible to measure the impact at the aggregate level; at the project level, however, there is ample proof that positive results and impact were achieved. Many projects in Finland's priority sectors, such as water, energy, environment, ICT and innovation, forestry and fisheries, have also led to increased involvement of private sector partners in developing countries. The evaluation recommends integrating aid for trade into existing and new development policy strategies, and strengthening private sector involvement and multi-stakeholder participation in aid-for-trade planning and implementation.

The Australian Office of Development Effectiveness examined 24 aid-for-trade projects to identify lessons that could be learned to help guide the scope and focus of the upcoming aid-for-trade evaluation (Australia, 2016). Recalling the findings of Aid for Trade in Action (OECD-WTO, 2013) the report highlights the need for trade to be mainstreamed into a country or region's development strategy, and for donors to align their strategies around recipient countries' existing trade priorities. Identifying bottlenecks and binding constraints are important prerequisites for designing successful aid-for-trade interventions. It is also important for the various interventions to complement each other. Mobilising the support of the private sector and civil society remains critical to effective implementation of trade-related reforms. Furthermore, consideration should be given to how a country or region is connected to global value chains. Given the cross-border nature of trade policy and regulations, regional solutions are often essential.

Half of the donors and one-third of the partner countries participating in the 2017 aid-for-trade monitoring exercise have undertaken aid-for-trade evaluations since the start of the Initiative in 2006. Increasingly, these evaluations are part of broader growth and poverty alleviation programmes. For instance, Germany's Gesellschaft für Internationale Zusammenarbeit $(G I Z, 2015)$ developed a manual to emphasise the role that trade can play in promoting broader growth and, ultimately, poverty alleviation in GIZ initiatives. Taking aid for trade as a catalyst for mainstreaming trade and mobilising resources for the developing and least-developed countries, the manual highlights entry points for aid for trade in a number of sectors, ranging from agriculture to climate change. It contains an updated aid-for-trade results model, which demonstrates the many ways in which other initiatives link up with aid for trade. 


\section{THE WAY FORWARD}

The 2017 OECD-WTO aid-for-trade monitoring exercise offers a view of aid-for-trade priorities among the various respondent groups. Almost $90 \%$ of partner countries give the highest priority to support for trade facilitation, followed by export diversification (63\%), trade policy and regulations (48\%) and transport infrastructure (47\%). Donors, on the other hand, accord the highest priority (74\%) to support for trade policy and regulations, closely flowed by support for trade facilitation (70\%). Regional integration and connecting to value chains follow next on the list of donor priorities (52\% and $40 \%$ respectively). Both partner and donor countries give little priority to e-commerce in their aid-for-trade strategies (13\% and 15\% respectively; Figure 11.16).

According to $88 \%$ of the donors that participated in the 2017 survey, the SDGs will focus prominently in aid-for-trade priority development over the next five years. The aid-for-trade strategy of $60 \%$ of the donors will focus specifically on promoting private sector investment (60\%) and green growth (50\%), while also targeting results (48\%) in areas such as trade facilitation (45\%), gender equality (43\%) and poverty reduction (40\%), especially trough regional programmes (43\%) and in the LDCs (35\%).

\section{Figure 11.16. Partner and donor countries' aid-for-trade priorities}

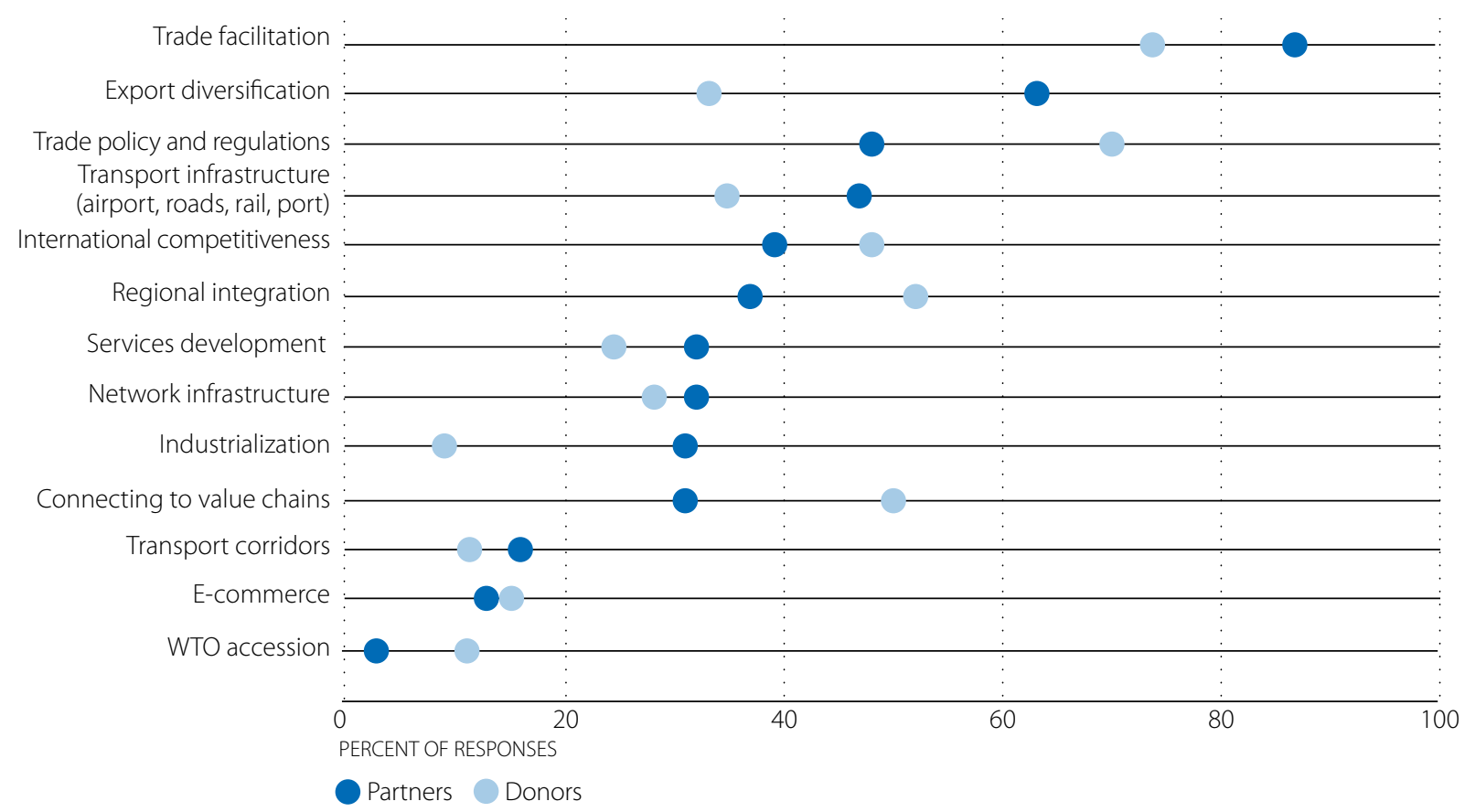

Source: OECD-WTO aid-for-trade monitoring exercise (2017), www.oecd.org/aidfortrade/countryprofiles/

StatLink न्ता St http://dx.doi.org/10.1787/888933527355

The SDGs are less of a game changer for the aid-for trade-strategies of the partner countries, with only $21 \%$ listing them as drivers of change in their strategies since 2014 (Figure 11.17). Changes in these strategies are driven mainly by their national development strategies (64\%), the implementation of the trade facilitation agreements (39\%), efforts to reduce poverty (36\%) and efforts to improve international competitiveness (36\%), amongst others through regional integration (32\%), industrialisation (25\%) and the expansion of services (21\%). 


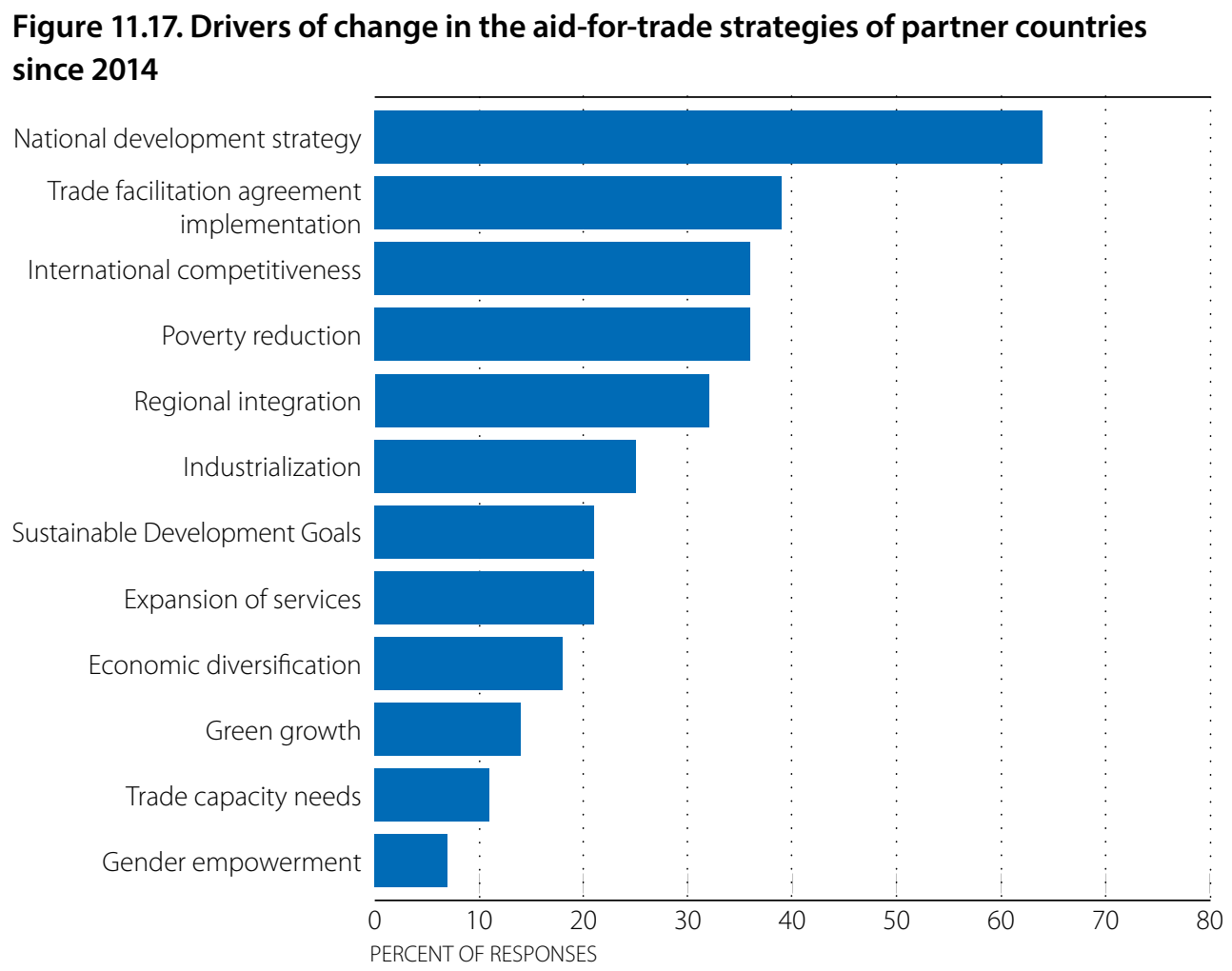

Source: OECD-WTO aid-for-trade monitoring exercise (2017), www.oecd.org/aidfortrade/countryprofiles/

StatLink 尚Is http://dx.doi.org/10.1787/888933527374

\section{Commitments shed light on funding trends}

Aid-for-trade commitments are firm obligations, expressed in writing and backed by the necessary funds, undertaken by an official donor to provide specified assistance to a recipient country or a multilateral organisation. As such, commitments are an expression of the current priorities of the recipient and donor. Commitments are recorded as the full amount of the expected transfer, irrespective of the time required for the completion of disbursements, which in some cases may take many years. Hudson (2013) finds that on average almost all commitments tend to be met within two years, with the overwhelming majority met immediately. There are substantial differences among donors, however, and with respect to individual sectors. Some sectors, such as infrastructure, have very long lags. The remainder of this section provides an analysis of aid-for-trade commitments up to 2015, the latest year for which detailed information is available. It highlights distribution by sector, region and income; donors; and the financial terms of the support committed.

\section{Budgets in 2015}

In 2015, aid-for-trade commitments reached USD 53.9 billion, an increase of USD 5.4 billion in real terms from its 2014 level an additional USD 31.6 billion compared to the 2002-05 baseline average. Trade-related OOF increased by USD 5 billion in 2015 to reach USD 60.1 billion, more than four times the 2002-05 baseline average.

According to the 2017 OECD-WTO aid-for-trade monitoring exercise, ten donors reported a decrease in their aid-fortrade allocations since 2014. No change was reported by eleven donors, while six donors augmented their spending by more than 10\% and another eleven donors did so by less than 10\%. The average annual 9.5\% increase in aid-for-trade commitments has contributed to reversing the trend--which started in early 1980--of a declining share of ODA devoted to promoting economic growth. In 2015, the share of aid for trade in-sector allocable aid stood at 33.3\%. 


\section{Sectoral distribution in 2015}

In 2015, aid commitments for economic infrastructure reached USD 31.8 billion, up 14.3\% compared to 2014 (Figure 11.18). Most of the increase was centred in the area of transport and storage, which rose by USD 3.0 billion, compared to 2014 , and has almost tripled in volume since the 2002-05 average baseline. Support to energy generation and supply also increased by more than USD 1 billion to USD 15.9 billion. The communications sector, however, continued its downward trend with a further decrease of 28\% to USD 560 million. OOF for economic infrastructure decreased 0.9\%, to USD 27.5 billion (Figure 11.21). Most of this decline is due to reductions in support to the communication and energy sectors, which dropped respectively by $25.6 \%$ and $3 \%$.

The building productive capacity category, at USD 21 billion rose by $6.2 \%$ in real terms from its 2014 level. As in past years, the largest share of support is directed to agriculture which attracted USD 9.6 billion, a USD 1.2 billion rise or 15\% growth from 2014. Further increases are noted in the fishing, industry and mining sectors up USD 13.4 million, USD 391.3 million and USD 86.8 million respectively. In contrast, the business and banking sectors fell by USD 291.4 million and USD 9.3 million. Support to tourism now at USD 89.3 million, also recorded a fall of 34\% from 2014.

The trade development marker was introduced to identify those activities in the category of building productive capacity that contribute "principally" or "significantly" to the development of trade. A focus on trade development reveals an increase of USD 1.4 billion in 2015 to USD 6.3 billion covering almost a third of the total amount for building trade capacities. Two-thirds of this support is concentrated in the areas of agriculture and business services.

Aid for trade in its narrowest sense of support to trade policy and regulations attracted USD 1.1 billion in 2015, an increase of 18.2\% compared to 2014 and a 46\% growth from the baseline average. Trade policy management and trade-related education both increased by USD 165 million and USD 18 million respectively, though trade facilitation at USD 420 million saw a small decrease of 5.4\% compared to its 2014 level.

With respect to trade-related OOF, increases were seen in both the trade policy and building productive capacity categories. The latter rose from USD 27 billion in 2014 to USD 31.7 billion in 2015 a 17.3\% increase. In volume terms the main increases were in mining up USD 1.4 billion and industry up USD 1.3 billion. Amounts to trade policy increased by USD 600 million, the bulk of which were allocated to trade facilitation which rose by USD 400 million from its 2014 level. Economic infrastructure remained essentially at its 2014 level at USD 27.5 billion, with a slight decrease of $0.9 \%$. This decline is due to decreases in the communication and energy sectors, which fell by $25.6 \%$ and $3 \%$ respectively.

\section{Regional distribution in 2015}

In 2015, 44.4\% of aid-for-trade commitments were destined for Asia, which amounted to USD 23.9 billion, an increase of USD 4.9 billion compared to 2014. Though amounts to the South and Central Asia region declined by USD 1.2 billion, Far East Asia increased by USD 5.1 billion, mainly due to major commitments to Indonesia (energy) and the Philippines (transport and storage). It should be noted, however, that allocations to Asia fluctuate significantly from one year to the other. In general, this is caused by large biennial commitments from Japan and the ADB towards economic infrastructure. Increases were also noted in Africa up USD 1.9 billion from 2014 to USD 18.2 billion while those to Latin America and Oceania increased by USD 81 million and USD 133 million respectively. Commitments to Europe, however, declined by USD 2 billion (Figure 11.19) 
Regional and global aid-for-trade programmes were allocated USD 6.4 billion in 2015. This is more than a threefold increase compared to the 2002-05 baseline average. Regional aid for trade offers great potential as a catalyst for growth, development and poverty reduction, but projects are often difficult to realise. While regional aid for trade faces many practical implementation challenges, however, experience has shown that associated problems are not insurmountable, but rather require thorough planning, careful project formulation and prioritisation on the part of policy makers (OECD, 2014).

Again, most of the 2015 trade-related OOF was destined for middle income countries in Asia (48.5\%), Latin America and the Caribbean (16.5\%), Europe (12.8\%), Africa (20.1\%) and Oceania (0.6\%) (Figures 11.22 and 11.23). Regional and global programmes only attracted $1.5 \%$ of total trade-related OOF commitments in 2015.

\section{Income group distribution in 2015}

Aid-for-trade commitments to the LDCs increased in 2015 by USD 4.3 billion to reach USD 17.2 billion (Figure 11.20). Other low income countries saw their support double to USD 2.0 billion. The share of commitments to the low income countries as a whole reached $35.8 \%$ of total aid-for-trade flows in 2015, compared to $28.9 \%$ in 2014 . With commitments of USD 19.6 billion, the lower middle income countries were the largest aid-for-trade recipients in 2015, whereas the upper middle income countries saw their commitments drop by USD 600 million, to USD 8.6 billion.

Countries in the middle-income group were by far the largest recipients of trade-related OOF. At USD 51.6 billion or 85\% of total commitments, this group received an increase of USD 5.3 billion from their 2014 levels. To a lesser extent the low-income group also increased by USD 0.6 billion to USD 5.7 billion, with the lion's share being attributed to the least developed countries.

\section{Aid-for-trade providers}

In 2015, bilateral providers committed USD 31.1 billion or 58\% of total aid for trade. Japan, the largest donor, with commitments of USD 11.8 billion directed most of its funding to Asia mainly for transport/storage and energy sectors in Asia. Other main bilateral contributors are Germany, with USD 5.6 billion, followed by the United States with USD 3.4 billion and France with USD 2.8 billion. The United Arab Emirates is also becoming an important aid-for-trade provider, with commitments in 2015 reaching USD 0.9 billion, followed by Kuwait with USD 394.2 million. Most bilateral donors provide the majority of their support in the form of grants, with the exception of Japan and Germany, which also provide a large share in loans. Multilateral providers also increased their commitments by USD 1.9 billion to USD 22.7 billion. The EU Institutions and the World Bank remain the main contributors providing almost two-thirds of multilateral aid for trade. Main increases in 2015 were provided by the Arab Fund, the African Development Bank, EU Institutions and IFAD.

In contrast, multilateral institutions were the largest contributors of trade-related OOF providing USD 45.7 billion or 76\% of the total. Main contributions were noted from the Asian Development Bank, EBRD, the IFC and the World Bank. All of which, apart from the World Bank, increased their allocations in 2015. On the bilateral side, the main OOF contributor by far is Korea. At USD 11.4 billion up by USD 4.5 billion from 2014, Korea's allocation represents 79\% of the total for all bilateral providers of aid for trade. 
Figure 11.18. Aid-for-trade commitments and disbursements by category

USD BILLION (2015 CONSTANT)

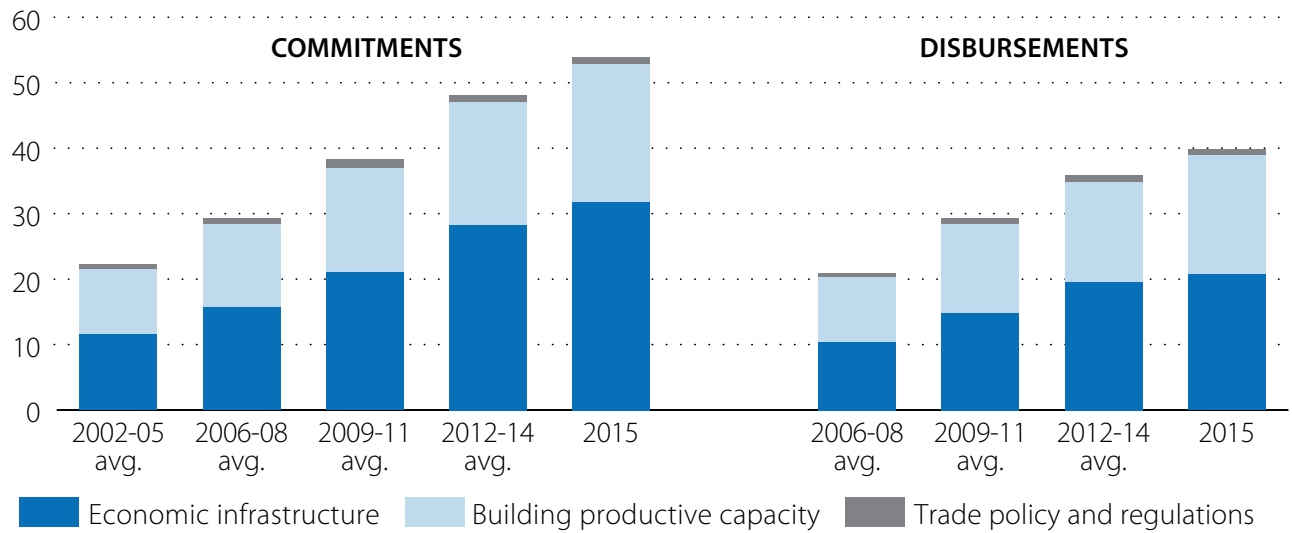

Source: OECD-DAC CRS: aid activity database (2017), DOl: http://dx.doi.org/10.1787/data-00061-en,

(accessed 07 April 2017).

StatLink त्ताजा http://dx.doi.org/10.1787/888933527393

\section{Figure 11.19. Aid-for-trade commitments by region}

USD BILLION (2015 CONSTANT)

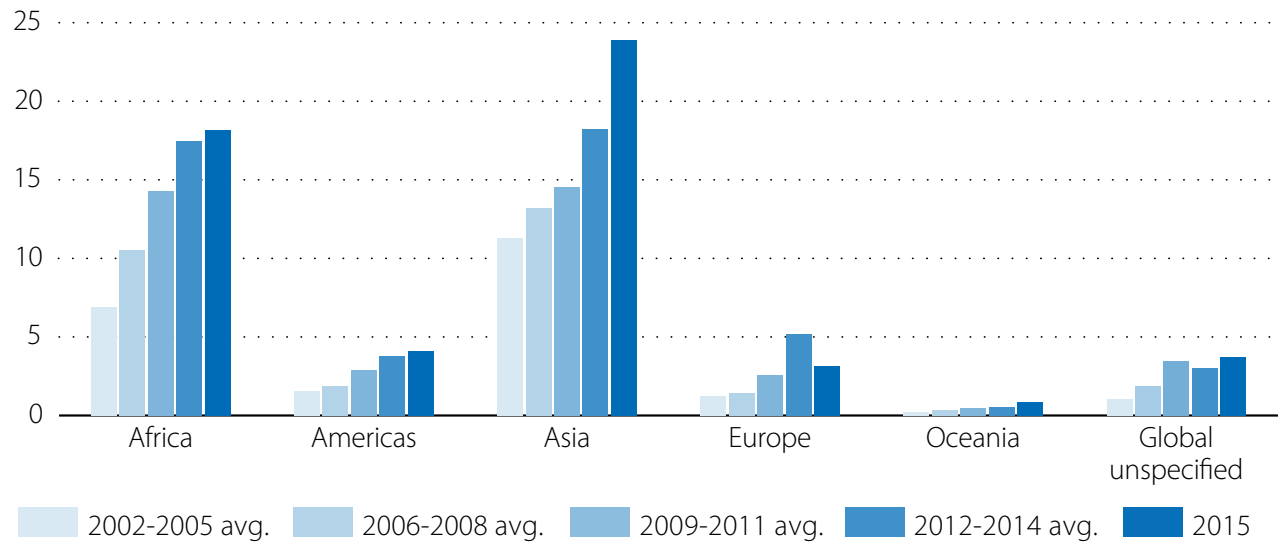

Source: OECD-DAC CRS: aid activity database (2017), DOI: http://dx.doi.org/10.1787/data-00061-en, (accessed 07 April 2017).

StatLink *iाs http://dx.doi.org/10.1787/888933527412

\section{Figure 11.20. Aid-for-trade commitments by income group}

USD BILLION (2015 CONSTANT)

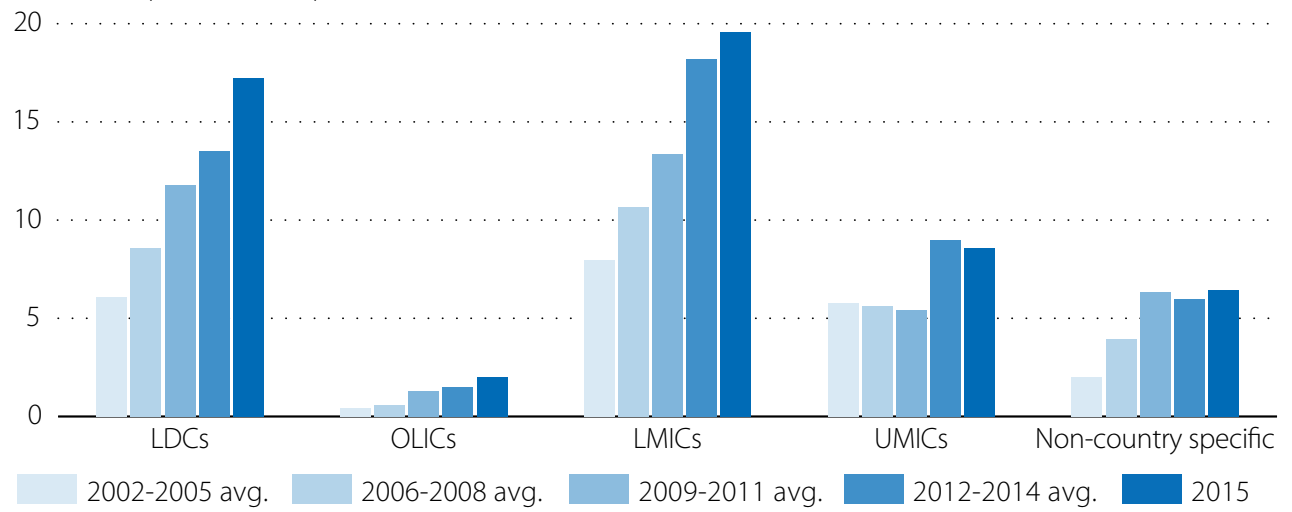

Source: OECD-DAC CRS: aid activity database (2017), DOI: http://dx.doi.org/10.1787/data-00061-en, (accessed 07 April 2017). 
Figure 11.21. Trade-related OOF commitments and disbursements by category

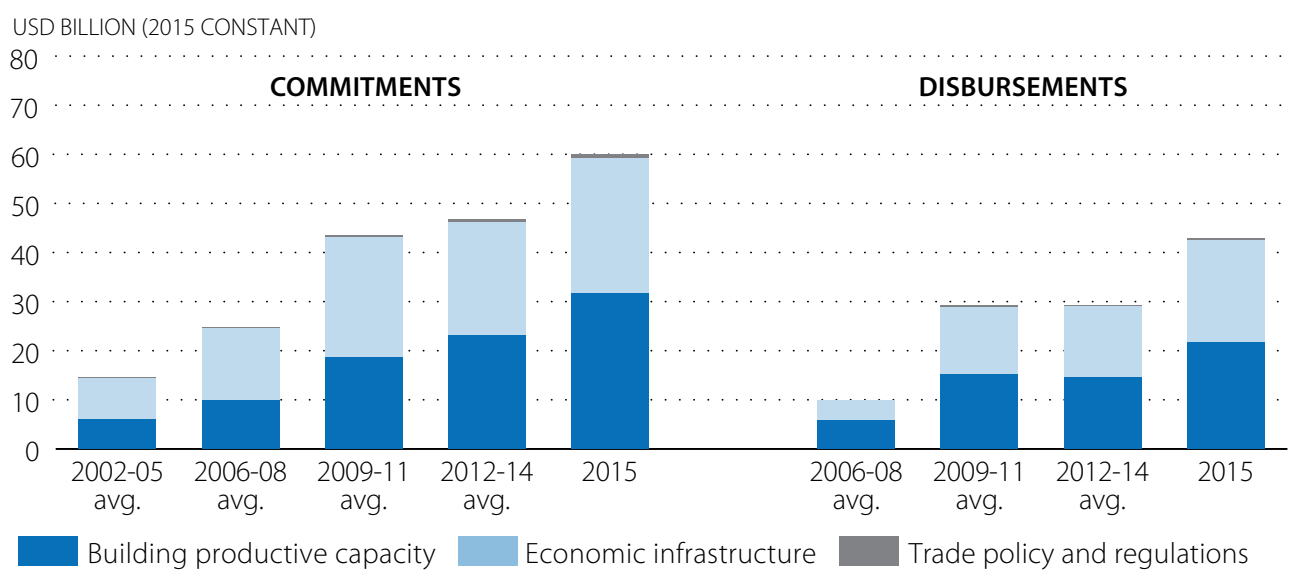

Source: OECD-DAC CRS: aid activity database (2017), DOI: http://dx.doi.org/10.1787/data-00061-en, (accessed 07 April 2017).

StatLink त्गाडs http://dx.doi.org/10.1787/888933527450

\section{Figure 11.22. Trade-related OOF commitments by region}

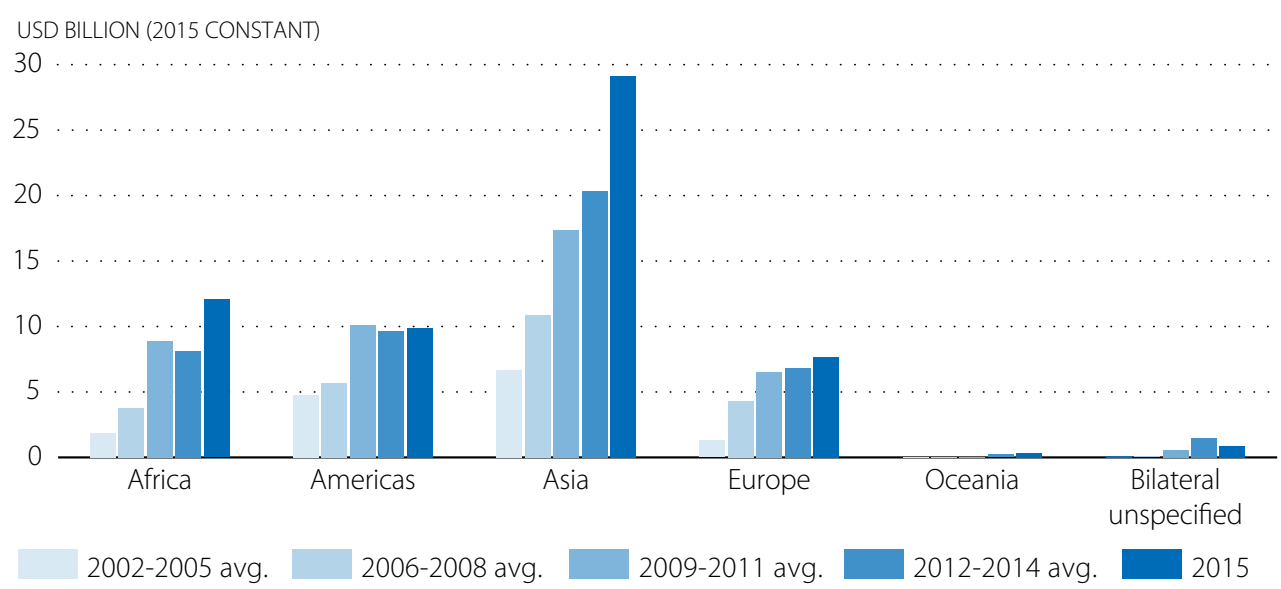

Source: OECD-DAC CRS: aid activity database (2017), DOl: http://dx.doi.org/10.1787/data-00061-en, (accessed 07 April 2017).

Figure 11.23. Trade-related OOF commitments by income group

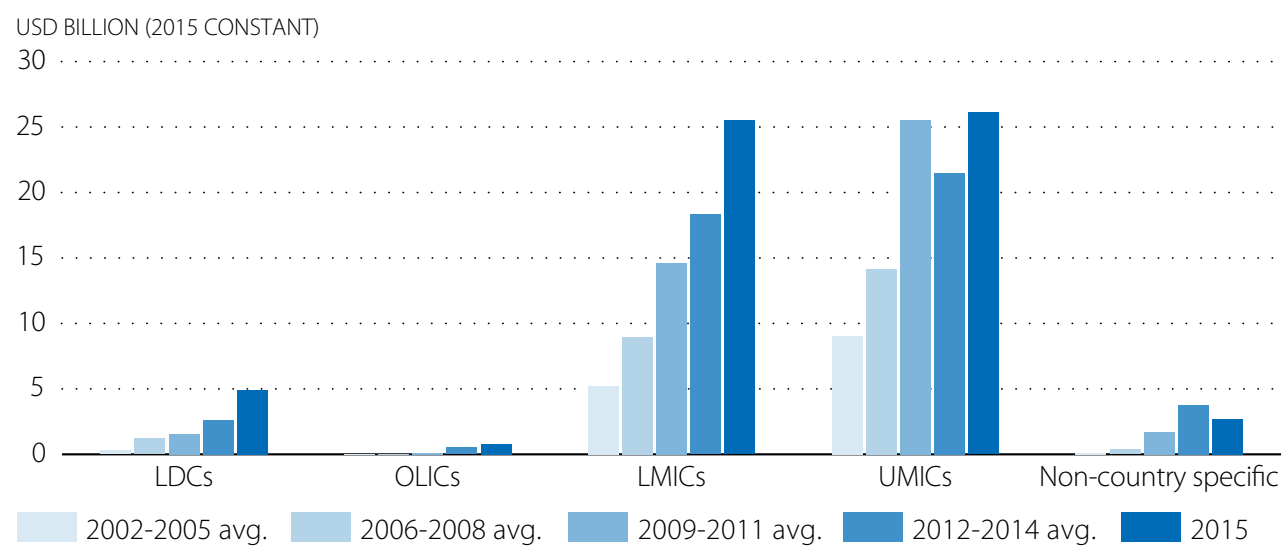

Source: OECD-DAC CRS: aid activity database (2017), DOl: http://dx.doi.org/10.1787/data-00061-en, (accessed 07 April 2017). 


\section{South-South co-operation}

A number of significant providers of development co-operation do not report their development finance flows to the OECD. A conservative estimate by the OECD indicates that total gross concessional development finance by ten nonreporting countries amounted to USD 7.5 billion in 2014 (Table 11.1).

\begin{tabular}{|c|c|c|c|c|c|c|}
\hline Country & 2011 & 2012 & 2013 & 2014 & 2015 & Source \\
\hline Brazil & 469 & 411 & 316 & $\ldots$ & $\ldots$ & $\begin{array}{l}\text { Institute of Applied Economic Research (IPEA) } \\
\text { and Brazilian Cooperation Agency (ABC) }\end{array}$ \\
\hline Chile & 24 & 38 & 44 & 49 & 33 & Ministry of Finance \\
\hline $\begin{array}{l}\text { People's Republic } \\
\text { of China) }\end{array}$ & 2785 & 3123 & 2997 & 3401 & 3113 & Fiscal Yearbook, Ministry of Finance \\
\hline Colombia & 22 & 27 & 42 & 45 & 42 & $\begin{array}{l}\text { Strategic institutional plans, Presidential } \\
\text { Agency of International Cooperation }\end{array}$ \\
\hline Costa Rica & $\ldots$ & $\ldots$ & 21 & 24 & 10 & Annual budget laws, Ministry of Finance \\
\hline India* & 794 & 1077 & 1223 & 1398 & 1772 & Annual budget figures, Ministry of Finance \\
\hline Indonesia & 16 & 26 & 49 & 56 & $\ldots$ & Ministry of National Development Planning \\
\hline Mexico & 99 & 203 & 526 & 169 & $\ldots$ & $\begin{array}{l}\text { Mexican Agency for International } \\
\text { Development Cooperation (AMEXCID) }\end{array}$ \\
\hline Qatar & 733 & 543 & 1344 & $\ldots$ & $\ldots$ & Foreign aid reports, Ministry of Foreign Affairs \\
\hline South Africa* & 229 & 191 & 191 & 148 & 100 & $\begin{array}{l}\text { Estimates of public expenditures, } \\
\text { National Treasury }\end{array}$ \\
\hline
\end{tabular}

Notes: These data are OECD-DAC Secretariat estimates of concessional flows for development from countries that do not report to the DAC statistical systems. Unlike the figures of reporting countries, these estimates are on a gross basis because information on repayments is not available. The estimates are based on publically available information and are therefore not necessarily complete or comparable. For some countries, estimates of funds channelled through multilateral organisations are based on data from the UN Department of Economic and Social Affairs, www.aidflows.org and websites of other multilateral organisations. The data include only development-related contributions. Local resources - financing from a country through multilateral organisations earmarked to programmes within that same country - are excluded. Moreover, as for reporting countries, coefficients are applied to core contributions to multilateral organisations that do not exclusively work in countries eligible for receiving ODA. These coefficients reflect the developmental part of the multilateral organisations' activities.

"..." Not available.

* Figures for India and South Africa are based on their fiscal years. For example, 2012 data correspond to fiscal year 2012/13.

Brazil's development co-operation is estimated by the OECD to have amounted to USD 500 million in 2010, up from USD 362 million in 2009. Brazil has prioritized technical assistance, skills transfer and capacity building over other modalities of co-operation. It is also engaged in triangular co-operation, partnering with several international organisations and members of the OECD Development Assistance Committee (DAC), such as Germany, Japan, Spain and the United States. For instance, the Brazilian government recently signed a Memorandum of Understanding with the International Trade Centre (ITC) to provide technical assistance to African countries on trade facilitation initiatives. As a result, two workshops were held, in Angola and Mozambique, with a focus on the implementation of the WTO Trade Facilitation Agreement. The workshops achieved good results as they allowed for an exchange of experiences among the Brazilian, Angolan and the Mozambican governments with the technical support of the ITC. (OECD-WTO aid-for-trade monitoring exercise 2017, Public sector case story 83). 
China's total concessional finance for development is estimated by the OECD to have reached USD 3.4 billion in 2014, compared to USD 3 billion in 2013. In September 2015, President Xi announced additional commitments of USD 2 billion for South-South co-operation and to implement the SDGs (IDS, 2016). Moreover, Chinese investments in Africa are expected to increase: the Johannesburg Action Plan for comprehensive strategic and co-operative partnership with Africa provides for USD 35 billion in concessional loans and credits in 2016-2018, as well as USD 10 billion for the China-Africa Production Capacity Co-operation Fund; it also increases in the existing China-Africa development fund (for equity investment) from USD 5 billion to USD 10 billion. China's main priority sectors are public facilities, industry and economic infrastructure. The new action plan for Africa also includes the digitalisation of media and communications and the promotion of e-commerce (IDS, 2016). The private sector is also engaged in this area. For instance, ZTE and Huawei provide equipment and technical assistance to enhance e-governance programmes in Rwanda. (IDS, 2015).

India's total concessional development finance is estimated by the OECD to have reached USD 1.4 billion in 2014, compared to USD 1.2 billion in 2013. India's priority partner countries are its neighbours in South Asia. Between 2009 and 2015, Bhutan received 61\% of India's bilateral development co operation, followed by Afghanistan (9\%), Sri Lanka (7\%), Nepal (5\%), Bangladesh (3\%), Myanmar (2\%) and the Maldives (2\%).Co operation with Africa has increased, with the majority of new lines of credit being allocated to Africa in 2014. The main sectors of India's development co-operation are health, education, energy (hydropower) and information technology. In recent years, India has become an important actor in promoting regional integration. , with the main instruments being India's trade concessions through the Free Trade Agreement of the ASEAN, as well as through the South Asian Association for Regional Co-operation and the South Asian Free Trade Area. Furthermore, India is playing a major role in strengthening the existing regional infrastructure and lending support for the development of human resources (OECD-WTO aid-for-trade monitoring exercise 2017, Public sector case story 24).

In 2014 Brazil, Russia, India, China and South Africa created the New Development Bank to mobilize resources for infrastructure and sustainable development projects, complementing the efforts of multilateral and regional financial institutions for global growth and development. In 2016, the Bank approved seven investment projects for a total of over USD 1.5 billion, with more than $75 \%$ of projects dedicated to sustainable infrastructure, mainly for renewable energy generation.

\section{CONCLUSIONS}

Digital connectivity can help to accelerate the achievement of the 2030 Agenda for Sustainable Development. Internet and related technologies can be used to reinforce the partnership approach that is explicitly mandated in SDG 17. However, the real significance of ICT for the SDGs is in helping to realise other targets. Digital technologies can contribute to the achievement of the SDGs related to infrastructure development (Goal 9 - Build resilient infrastructure, promote inclusive and sustainable industrialization and foster innovation; and Goal 11 - Make cities and human settlement inclusive, safe, resilient and sustainable). Satellites, drones and the Internet of Things can generate highly accurate, geo-referenced digital data about human settlements, providing the information needed for infrastructure projects that better match social and economic needs. ICT infrastructure can also help to deliver more affordable and inclusive energy, for instance through home systems such as off-grid solutions or small-scale power grids. These new technologies will contribute to guaranteeing access to energy for all (Goal 7).

Moreover, ICTs provide new and more automated means of monitoring and assessing the progress towards the SDGs, thereby enabling more evidence-base decision making. This is the essence of the "data revolution," called for by the High-Level Panel of Eminent Persons in their 2013 report. Some monitoring tools for tracking progress toward the SDGs are based on the use of big data. However, to garner the full benefits of data revolution, simultaneous improvements in national statistical capacity are required. The United Nations, the European Union, the World Bank and the UK Department for International Development are the largest supporters of statistical capacity building. 
In addition, organisations such as the Partnership in Statistics for Development in the 21st Century (PARIS21) have a significant role in co-ordinating donor efforts. In 2016, more than 150 data champions convened the Global Partnership for Sustainable Development Data to support countries in harnessing the data revolution for development.

Nonetheless, one of the biggest barriers to successful use of ICTs for development is the challenge faced by the poorest in gaining access to quality and affordable Internet connections. Access is not just about infrastructure. It is also about ensuring that digital communication channels, content and delivery are relevant to and understandable for less literate users.

While donor agencies provide relatively little financial support for ICT development, they increasingly use challenge funds to support digital businesses and innovative solutions for poverty reduction. These funds help to channel public financial resources to business activities that have potential development impact but still lack commercial viability. Donor agencies consider these funds a means of engaging the private sector, and in particular small and medium enterprises, as direct partners without creating market distortions. The funds are considered versatile instruments that reduce the risks and costs of private investment while challenging the private sector to innovate for the public good.

For instance, TradeMark East Africa supports the "Logistics Innovation for Trade" challenge fund, with the objective of promoting innovative solutions for East Africa's transport and logistics industry. TradeMark East Africa's risk-sharing support helps the fund co-invest in business projects that have been regarded by other financial investors as too risky. Among the projects recently selected is an online platform where transport and logistics stakeholders can meet and share information. Moreover, it provides users with the opportunity to send out transport requests and to quote, book and deliver with full track-and-trace functionality (including handling, insurance, warehousing, etc.).

Although considerable funding has been allocated through challenge funds, there is still little evidence of their longterm effectiveness and development impact. The focus of evaluations has often been limited to measuring their efficiency of operations - management costs, leverage ratio, etc.- - rather than their development impact. The success and social/environmental impact of a challenge fund depends on: additionality (i.e. serving companies that could not access commercial finance); positive externalities (i.e. the selection of projects with the highest potential development benefit); and systemic impact (i.e. driven by demonstration/imitation effects and the creation of new markets) 


\section{REFERENCES}

AfDB (2013), "Connecting Africa: An Assessment of Progress Towards the Connect Africa Summit Goals" African Development Bank, Abidjan 01, Côte d'Ivoire, https://www.afdb.org/fileadmin/uploads/afdb/Documents/Project-andOperations/Connecting Africa - An Assessment of Progress Towards the Connect Africa Summit Goals Main Report.pdf

AfDB (2015), "Rail Infrastructure in Africa - Financing Policy Options" African Development Bank, Abidjan 01, Côte d'Ivoire https://www.afdb.org/fileadmin/uploads/afdb/Documents/Events/ATFforum/Rail Infrastructure in Africa Financing Policy Options - AfDB.pdf

All Party Parliamentary Group for Trade Out of Poverty (2016, http://tradeoutofpoverty.org (accessed February 2017) Arndt, C., S. Jones and F. Tarp (2010), "Aid, Growth, And Development: Have We Come Full Circle?", WIDER Working Paper 2010/096, UNU-WIDER, Helsinki, https://www.wider.unu.edu/publication/aid-growth-and-development-0.

ADB (2010), "Sustainable transport initiative operational plan" Asian Development Bank, Mandaluyong City, Philippines https://www.adb.org/sites/default/files/institutional-document/31315/sustainable-transport-initiative.pdf

ASEAN (2016), "Master Plan on ASEAN Connectivity 2025", ASEAN Secretariat, Jakarta, Indonesia, http://asean.org/ storage/2016/09/Master-Plan-on-ASEAN-Connectivity-20251.pdf

Australia (2015), "Strategy for Australia's Aid for Trade Investments" Department of Foreign Affairs and Trade (DFAT), Canberra https://dfat.gov.au/about-us/publications/Documents/strategy-for-australias-aid-for-trade-investments.pdf

Australia (2016) "Global and Regional Perspectives: Situation Analysis Report", Department of Foreign Affairs and Trade (DFAT), Canberra http://dfat.gov.au/aid/how-we-measure-performance/ode/Documents/gearing-up-for-trade-situa$\underline{\text { tion-analysis.pdf }}$

Bielenberg, A., Kerlin, M., Roberts, M., and Oppenheim, J. (2016), Financing Change: Mobilizing Private Sector Financing for Sustainable Infrastructure, McKinsey and Company.

Busse, M., Hoekstra, R. and Königer, J. (2012), The Impact of Aid for Trade Facilitation on the Costs of Trading, Kyklos, 65: 143-163, doi: 10.1111/j.1467-6435.2012.00531.x

Cali, M. and Te Velde, D. W. (2011), "Does Aid for Trade Really Improve Trade Performance?" World Development, Elsevier, Vol. 39(5), pages 725-740,

Cirera X and L A Winters (2014), "Aid for Trade and Structural Transformation in Sub-Saharan Africa", Commonwealth Trade Policy Discussion Papers, No 2015/01, Commonwealth Secretariat, London.

Clemens M., S. Radelet, R. Bhavnani and S. Bazzi (2012), "Counting Chickens when they Hatch: Timing and the Effects of Aid on Growth", The Economic Journal, Volume 122, Issue 561, http://onlinelibrary.wiley.com/ doi/10.1111/j.1468-0297.2011.02482.x/suppinfo.

de Melo, J. and Wagner, L. (2015), "Aid For Trade as finance for the Poor", FEDRI, Clermond-Ferrand.

DfID (2017), "Economic Development Strategy: prosperity, poverty and meeting global challenges", The Department for International Development, London https:/www.gov.uk/government/uploads/system/uploads/attachment data/ file/587374/DFID-Economic-Development-Strategy-2017.pdf

European Commission (2015) "EU-Africa Infrastructure Trust Fund 2015 Annual Report", Publications Office of the European Union, Luxembourg http://www.eu-africa-infrastructure-tf.net/attachments/Annual\%20Reports/ eu africa infrastructure trust fund annual report 2015 en.pdf 
Ferro, E., A. Portugal-Perez, and J. Wilson (2012), "Aid to the Services Sector: Does it Affect Manufacturing Exports", paper prepared for the workshop "Aid for Trade: What Have we Learnt? Which way Ahead?" FERDI/ITC Geneva.

Finland (2016), "Evaluation of Finland's Development Cooperation Country Strategies and Country Strategy Modality", Ministry for Foreign Affairs, Helsinki, http://formin.finland.fi/developmentpolicy/evaluations

Gavas, M., M. Geddes, I. Massa and D. te Velde (2011), Aid for Trade and Blended Finance: OECD Aid for Trade Case Study, www.oecd.org/dataoecd/31/55/47722147.pdf.

German Development Institute (2009), "India's Development Cooperation - Opportunities and Challenges for International Development Cooperation", Briefing Paper 3/2009, GDI, Bonn, Germany

Ghimire S., D. Mukherjee, and E. Alvi, (2016), "Aid-for-Trade and Export Performance of Developing Countries Applied Econometrics and International Development" Vol. 16-1

GIZ (2015), Aid for Trade Manual For greater results orientation in the field of trade" Deutsche Gesellschaft für Internationale Zusammenarbeit, Bonn, Germany

Heeks, R. (2009), "The ICT4D 2.0 Manifesto: Where Next for ICTs and International Development?" Development Informatics working paper no. 42, Manchester https://www.oecd.org/ict/4d/43602651.pdf

Helble, M.C., C.L. Mann, and J.S. Wilson (2012), "Aid-for-trade facilitation," Review of World Economics (Weltwirtschaftliches Archiv), Springer, vol. 148(2), pages 357-376, June.

Hudson J., (2013), Promises kept, promises broken? The relationship between aid commitments and disbursements,

Review of Development Finance Volume 3, Issue 3, July-September 2013, Pages 109-120

http://doi.org/10.1016/j.rdf.2013.08.001

Hynes W. and P. Holden (2016), "What future for the Global Aid for Trade Initiative? Towards an assessment of its achievements and limitations", Development Policy Review, 34 (4): 593—619

IDS (2015), "Is China's Role in African Fragile States Exploitative or Developmental?", IDS Policy Briefings no. 91 March 2015, Institute of Development Studies, Brighton, UK

IDS (2016), "China's Comprehensive Strategic and Cooperative Partnership with Africa", IDS Policy Briefings no. 111 February 2016, Institute of Development Studies, Brighton, UK

IMF (2016), "Macroeconomic Prospects and Challenges in LIDCs", Policy Paper, International Monetary Fund, Washington, D.C.

ITF (2015), "Port Investment and Container Shipping Markets", OECD Publishing, Paris. DOI: http://dx.doi. org/10.1787/9789282107850-en

JICA (2016), "Corridor Development Approach: Revitalize the region inclusively and bring strong sustainable economic growth for people" https://www.jica.go.jp/english/publications/brochures/c8h0vm0000avs7w2-att/japan_brand_07. $\underline{\mathrm{pdf}}$

Lehmacher, W. and V. Padilla (2015), "What can the New Silk Road do for global trade", Financial Times, World Economic Forum, Geneva https://www.weforum.org/agenda/2015/09/what-can-the-new-silk-road-do-for-global-trade/

Martuscelli, A and L. Winters (2014), 'Trade Liberalisation and Poverty: What have we learned in a decade?' London, CEPRI. http://www.cepr.org/active/publications/discussion papers/dp.php?dpno=9947

McKinsey Global Institute (2016), "Bridging Global Infrastructure Gaps”, McKinsey \& Company

NEPAD (2016), Programme for Infrastructure Development in Africa (PIDA), Midrand, South Africa, http://www.nepad. org/programme/programme-infrastructure-development-africa-pida 
Netherlands (2015), "Aided trade An evaluation of the Centre for the Promotion of Imports from Developing Countries (2005-2012) Ministry of Foreign Affairs, Policy and Operations Evaluation Department (IOB), The Hague, Netherlands https://www.rijksoverheid.nl/documenten/rapporten/2015/09/01/aided-trade

OECD (2015), "Official Development Finance for Infrastructure Support By Multilateral and Bilateral Development Partners, Report To G20 Finance Ministers and Central Bank Governors", OECD Publishing, Paris. DOI: http://www.oecd. org/g20/topics/development/Official-Development-Finance-for-Infrastructure.pdf

OECD (2017), "OECD-DAC Creditor Reporting System: aid activity”, OECD International Development Statistics (database). DOI: http://dx.doi.org/10.1787/data-00061-en, (accessed on 7 April 2017)

OECD-WTO (2013), "Aid for Trade in Action", OECD Publishing, Paris. DOl: http://dx.doi.org/10.1787/9789264201453-en

OECD-WTO (2015), aid-for-trade monitoring exercise 2015, Public sector case story 46, www.oecd.org/aidfortrade/ casestories/CaseStory2015_46_Asian\%20Development\%20Bank_TransportandStorage.pdf

OECD-WTO (2017), aid-for-trade monitoring exercise 2017 (questionnaires) www.oecd.org/aidfortrade/countryprofiles/ Sachs, J.D. and G. Schmidt-Traub (2014), "Financing Sustainable Development: Implementing the SDGs through Effective Investment Strategies and Partnerships", UN Sustainable Development Solutions Network, New York Tadesse B, E. Shukralla, and B. Fayissa (2017), "Are bilateral and multilateral aid-for-trade complementary?" World Economy, 2017

te Velde, D.W. (2013), Future Directions of Aid for Trade, in: Assessing Aid for Trade; Effectiveness, Current Issues and Future Directions, Commonwealth Secretariat, ODI, London, UK.

TMEA (2017), Logistics innovation for Trade, TradeMark East Africa, www.trademarkea.com/projects/ logistics-innovation-for-trade-lift/

Trebilcock, M., and Rosenstock, M. (2015). "Infrastructure public-private partnerships in the developing world: Lessons from recent experience", The Journal of Development Studies, 51(4), 335-354. doi: 10.1080/00220388.2014.959935

UN (2002), Monterrey Consensus of the International Conference on Financing for Development, http://www.un.org/esa/ffd/monterrey/MonterreyConsensus.pdf

UNCTAD (2011), "Information Economy Report 2011 - ICTs as enabler for private sector development", United Nations Publications, Geneva http://unctad.org/en/PublicationsLibrary/ier2011 en.pdf

USAID (2010), From Aid to Trade: Delivering Results, A Cross-Country Evaluation of USAID Trade Capacity Building, United States Agency for International Development, http://pdf.usaid.gov/pdf docs/PDACR202.pdf.

USAID (2014), "Powering a New Silk Road: Helping Connect Supply with Demand in South and Central Asia" Frontlines Afghanistan November/December 2014, United States Agency for International Development, www.usaid.gov/ news-information/frontlines/afghanistan/powering-new-silk-road-helping-connect-supply-demand-south.

World Bank (2016), "Transformation through infrastructure”, Infrastructure Strategy Update FY2012-2015, World Bank Group, Washington D.C.

World Bank (2017), Personal remittances received, database, http://data.worldbank.org/indicator/BX.TRF.PWKR.CD.DT (accessed on 07 April 2017)

Yhome, K. and R.R. Chaturvedy (2017), "Emerging Trans-Regional Corridors: South and Southeast Asia”, Observer Research Foundation, New Delhi. 


\section{NOTES}

1. Transactions known as OOF are those made by the official sector with countries on the DAC List of ODA

Recipients, but which do not meet the conditions for ODA eligibility, either because they are not primarily aimed at development or because they have a grant element of less than $25 \%$. 


\title{
CHAPTER 12
}

\section{AID FOR INCLUSIVE TRADE \\ AND POVERTY REDUCTION}

Contributed by the World Trade Organization

\begin{abstract}
A growing body of evidence highlights the effectiveness of aid for trade in generating positive trade outcomes. The focus on capturing trade outcomes such as increases in exports or reductions in trade costs, however, is now being complemented by an increasing focus on tracing the direct and indirect impacts of aid interventions on poverty reduction, in particular for women. In that context, this chapter has three main objectives. The first is to demonstrate that poor physical and digital connectivity are among the factors keeping people in poverty. The second is to provide evidence on how infrastructure and digital connectivity are contributing to poverty reduction, market access, financial inclusion and women's economic empowerment. The third is to highlight some of the key points emanating from the 2017 aid-for-trade monitoring and evaluation exercise, including how combined efforts from various stakeholders can facilitate inclusive development and contribute to eradicating poverty.
\end{abstract}




\section{INTRODUCTION}

A growing body of evidence highlights the effectiveness of aid for trade in generating positive trade outcomes. Research has suggested that for every USD 1 invested in aid for trade, there is an increase of approximately USD 8 in exports from developing countries and USD 20 in exports from countries eligible for International Development Association (IDA) ${ }^{1}$ assistance (OECD-WTO, 2013). The focus on capturing trade outcomes (e.g. increases in exports or reductions in trade costs) is now being complemented by an increasing focus on tracing the impacts of aid-for-trade interventions on poverty reduction, in particular for women, on whom the burden of poverty falls heaviest. Eliminating extreme poverty is the first goal of the 2030 Agenda for Sustainable Development and has been integrated into the strategic objectives of development finance institutions. The World Bank's twin target of reducing extreme poverty and boosting shared prosperity is a case in point.

Developmental outcomes can be derived from aid-for-trade projects on at least three levels: 1) direct outcomes, such as improvements in the business environment; 2 ) intermediate outcomes, such as improvements in competitiveness, diversification and trade integration; and 3) final outcomes, such as higher income and more jobs (OECD, 2013). Such a logframe method of evaluation emphasises the range of outcomes that aid for trade can engender for social and economic development at different stages. Establishing direct interactions between aid for trade and poverty reduction is still complex. OECD, for instance, describes a "black box" between inputs and impacts, in which attribution can become lost (OECD, 2006).

Gaps in the availability of quality data concerning poverty reduction further complicate analyses of the impact of aidfor-trade projects on poverty reduction. Nevertheless, efforts are being expended to trace and measure the impacts of aid-for-trade funding on the poor, and on women in particular (Box 12.1). Various metrics have been used, e.g. simple ex-post assessments or randomised controlled trials. The 2015 edition of the present publication also discussed the strengths and weaknesses of Theories of Change in impact evaluations (OECD-WTO, 2015). This edition adds that a combination of different methods is needed to establish a robust evidence base to measure the impact of aid for trade on poverty reduction.

\section{Box 12.1. The UK Department for International Development's approach to trade and poverty}

Recognising that there are winners and losers from trade and trade programmes, the United Kingdom's (UK) Department for International Development (DFID) undertakes assessments of the expected poverty impacts of all its new trade programmes. In addition to ongoing trade and poverty-specific policy support and oversight, detailed guidance-in programme design, during implementation and in reviewing existing programme-helps staff to better understand the distributional effects of trade programmes. This covers analysis of high-level economic indicators - trade patterns, labour market and sector segmentation, tariff revenue change impacts for diverse groups, and adjustment costs-as well as the gathering of qualitative data, which is especially important given the data limitations regarding marginalised groups in developing countries.

Crucially, transmission mechanisms and context are assessed at the country or regional level; this is the only way to properly understand how the linkages among trade, inclusive growth and poverty reduction may play out in any given situation. Recognising the difficulty of anticipating all possible impacts in advance, DFID includes robust monitoring and evaluation arrangements to track impacts, allowing for course adjustment as more is learned.

DFID also recognises that poverty is gendered; since May 2014, all DFID programmes (including trade programmes) must demonstrate that they have meaningfully considered gender issues in line with the Gender Equality Act. DFID will also work closely with the UK Department for International Trade to integrate gender equality throughout the UK trade policy.

Source: The UK Department for International Development 
Figure 12.1. Which SDGs can aid for trade help to achieve?

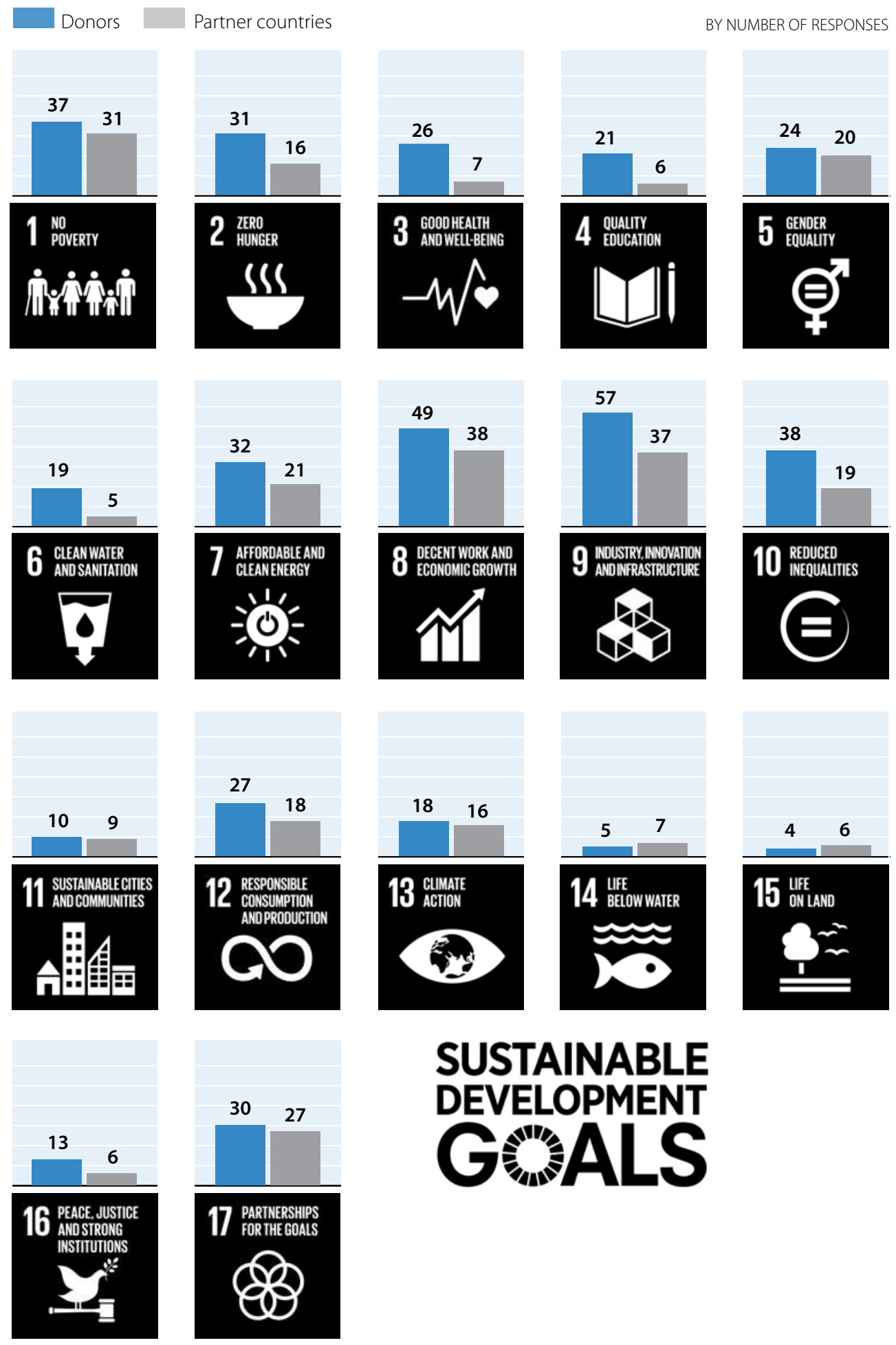

Source: OECD-WTO aid-for-trade monitoring exercise (2017), www.oecd.org/aidfortrade/countryprofiles/. 
Responses to the 2017 OECD-WTO aid-for-trade self-assessment questionnaires demonstrate that poverty eradication ranks high among the objectives that developing countries and their development partners wish to see aid for trade achieve. Questionnaire responses illustrated in Figure 12.1 seem to suggest that developing country governments and donors would like aid for trade to contribute, above all, to achieving Sustainable Development Goals (SDGs) 9 (industry, innovation and infrastructure), 8 (decent work and economic growth), and 1 (no poverty). Industry, innovation and infrastructure were cited 94 times in total, by both partner country and donor respondents, followed by decent work and economic growth (identified 87 times), and poverty eradication (dentified 68 times).

Against this background, this chapter builds on the four characteristics of poverty identified in the 2015 World Bank and World Trade Organisation report on the Role of Trade in Ending Poverty: gender, informality, the poor's location in rural areas, and fragile states. This report proposed actions to make trade opportunities accessible and affordable to the poor, and in particular to micro, small and medium enterprises (MSMEs) and women. These actions included lowering trade costs for the deeper integration of markets; improving the enabling environment and complimentary policies; intensifying the poverty impact of integration policies; managing and mitigating risks faced by the poor; and improving data and analysis to inform policy (WB-WTO, 2015).

This chapter will further explore the relationship between connectivity and poverty reduction by discussing the following:

- How does the incidence of poverty map with that of connectivity—both physical and digital?

- How is connectivity reducing poverty?

What have we learnt from 2017 aid-for-trade programmes and projects?

\section{POOR CONNECTIVITY CAN BE MAPPED AGAINST POVERTY}

Poor connectivity is one of the factors keeping people in poverty. A preliminary step in establishing this relationship is to map the incidences of poverty against physical and digital connectivity. Such mapping can be conducted at two levels: at the national level using aggregate statistics, and at the local level using national data. Importantly, poor connectivity is not offered as a reason why people find themselves in poverty, but rather as a factor keeping them in poverty. Action to address connectivity is therefore one step in removing the binding constraints that keep people in poverty.

In terms of physical connectivity, one observation is that logistics performance scores are lower in regions with higher poverty rates. The World Bank's Logistics Performance Index (LPI) assesses the performance of countries based on components such as trade and transport infrastructure (World Bank, 2016c). Figure 12.2 illustrates the negative correlation between LPI scores and poverty rates by region; as LPI scores improve, poverty rates tend to decrease.

Similarly, Internet connectivity is significantly lower in regions with higher poverty rates. At the global level, there is a strong correlation between income level and key indicators of participation in the digital economy (World Bank, 2016a). The poor are less likely to have access to technology. In African countries, the bottom $40 \%$ of the population, by income, is only one-third as likely to have access to the Internet as the upper 60\% (World Bank, 2016a). Figure 12.3 demonstrates that there is an inverse relationship between Internet usage and poverty rates; as internet usage increases, poverty rates tend to decrease. 
Figure 12.2. Poverty rates by region and logistics performance

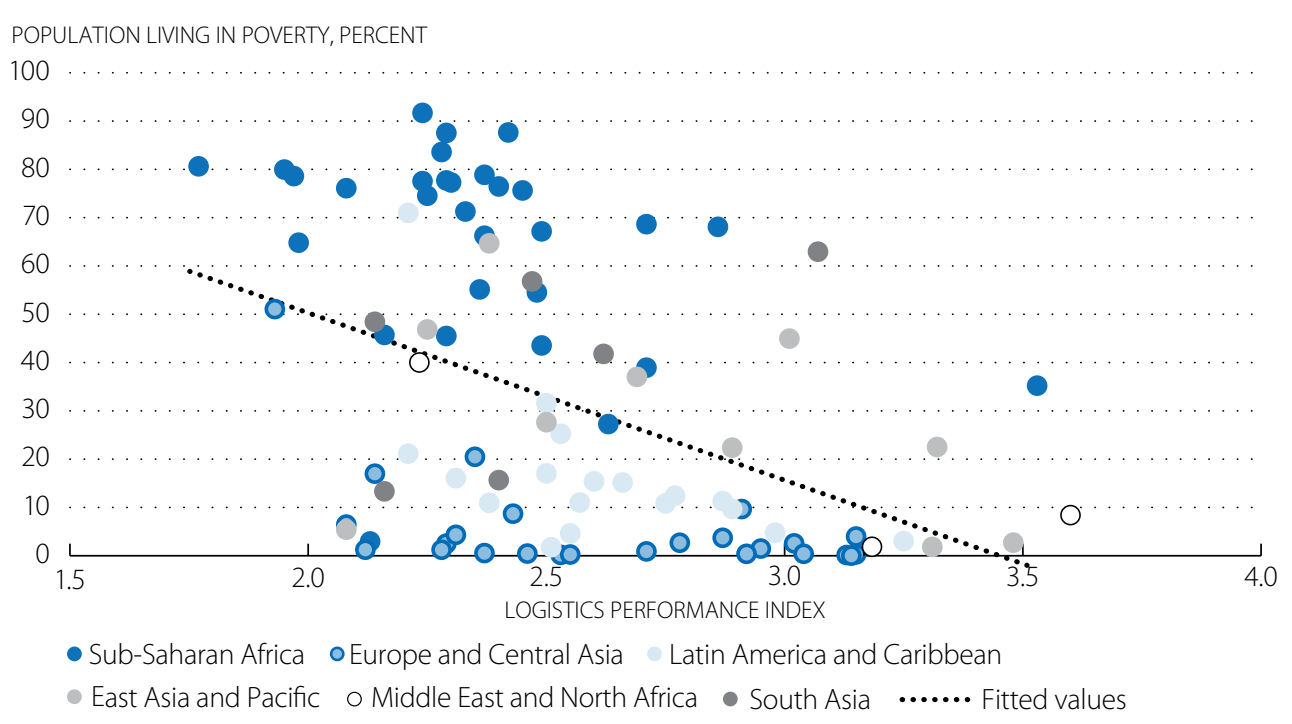

Source: WTO Secretariat based on WB World Development Indicators, Poverty Rates (2008-2014 average) and Logistics performance index (2007). World Bank Regional Classification.

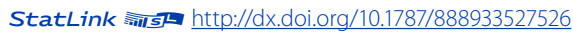

\section{Figure 12.3. Poverty rates by region and percentage of Internet users}

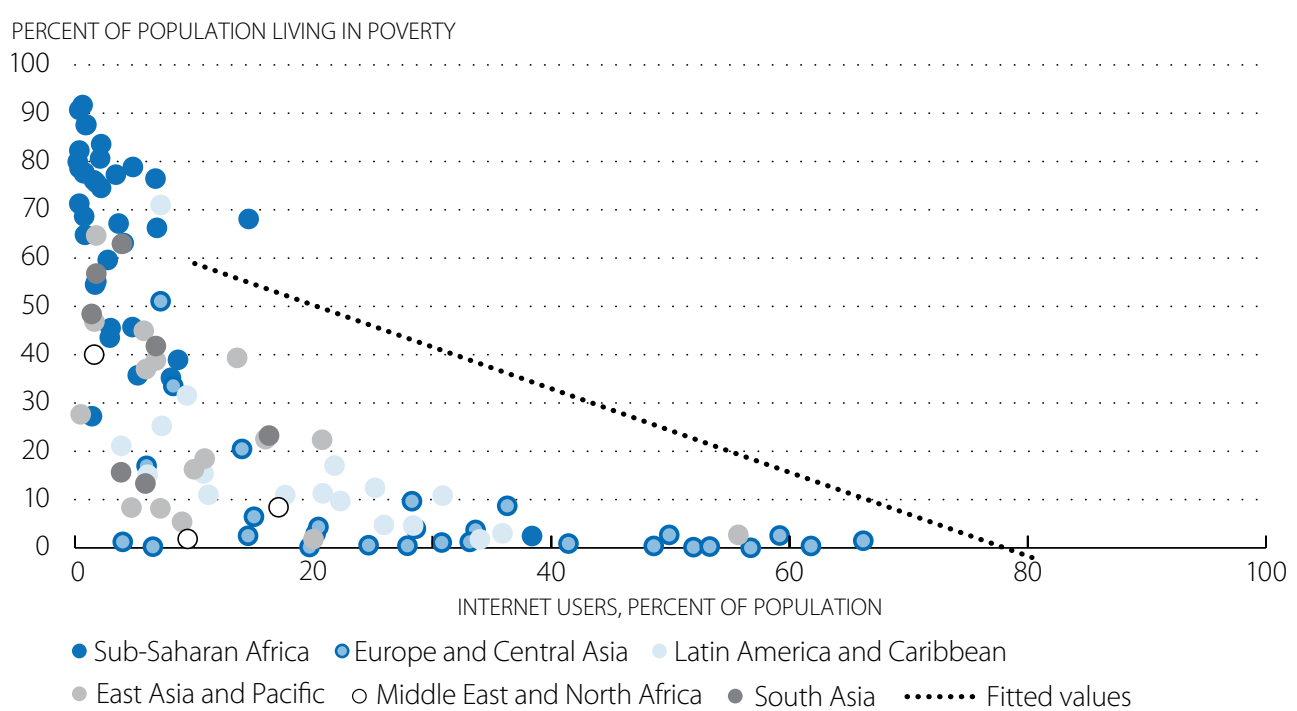

Source: WTO Secretariat based on WB World Development Indicators (2008-2014 average) and ITU World Telecommunications/ICT Indicators, Internet Users (2007). World Bank Regional Classification.

StatLink 需sta http://dx.doi.org/10.1787/888933527545

These findings are complemented by those of the Global Enabling Trade Report 2016 (GATF-WEF, 2016), which ranks seven of the most populous countries, some of which are home to most of the world's extreme poor, very low on the Enabling Trade Index. Research from the Global Enabling Trade Report 2016 indicates that 394 million of the world's 767 million people living below the international poverty line are located in only eight countries, and six of these countries rank lower than 100 on the Enabling Trade Index. Figure 12.4 illustrates the correlation between per capita income and the enabling trade index by region. 
Figure 12.4. GDP per capita and Enabling Trade Index 2016 scores

ENABLING TRADE INDEX (1-7)

6
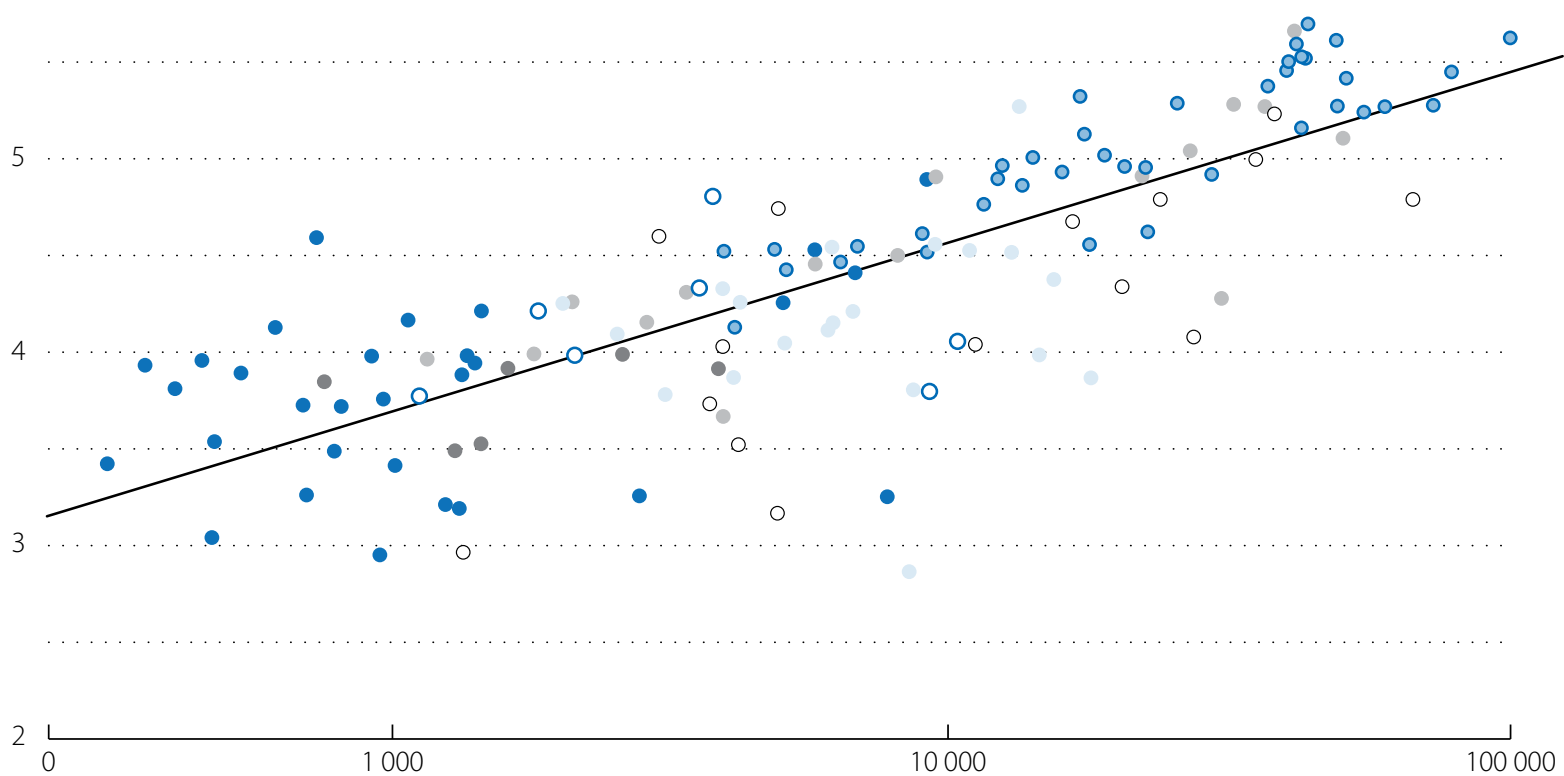

GDP PER CAPITA (USD)

- East Asia and Pacific o Europe and Central Asia - Latin America and Caribbean o Middle East and North Africa

- Sub-Saharan Africa - South Asia o Euraisa

Note: The Global Enabling Trade Report is a joint publication of the World Economic Forum (WEF) and the Global Alliance for Trade Facilitation (GATF).

Source: GATF-WEF (2016), The Global Enabling Trade Report 2016.

StatLink 光is http://dx.doi.org/10.1787/888933527564

Table 12.1. Average tariffs versus income levels in India

\begin{tabular}{cccc}
$\begin{array}{c}\text { Income } \\
\text { decile }\end{array}$ & \multicolumn{2}{c}{ Household weekly consumption } & Average tariff faced (\%) \\
\hline 1 & Rupees & USD & Simple \\
\hline 2 & 511 & 9.6 & 24.4 \\
\hline 3 & 783 & 14.8 & 22.9 \\
\hline 4 & 962 & 18.2 & 22.4 \\
\hline 5 & 1130 & 21.3 & 21.5 \\
\hline 6 & 1305 & 24.6 & 20.3 \\
\hline 7 & 1504 & 28.4 & 19.2 \\
\hline 8 & 1761 & 33.2 & 17.4 \\
\hline 9 & 2118 & 40.0 & 16.0 \\
\hline 10 & 2713 & 51.2 & 14.5 \\
\hline
\end{tabular}

Source: Mendoza et al. (2016), Are the poor getting globalised. 
In practice, approaches based on local-level data are still in their infancy. However intra-country findings have revealed that trade costs tend to decrease as per capita income increases. For instance, one analysis of income levels across deciles in India, home to 30\% of the world's extreme poor (WB-WTO, 2015), found that urban workers faced better market access conditions than their rural counterparts: $22.6 \%$ compared to $11.7 \%$, respectively). In addition, tariffs faced by women were found to be higher than those faced by men: $20.4 \%$ compared to $14.4 \%$, respectively. In the same study, the tariffs faced by enterprises in the formal sector were found to be more liberal than those in the informal sector: $7.2 \%$ compared to 9.8\%, respectively. Market access and income levels were found to be inversely correlated, even within sectors (Table 12.1).

\section{Physical connectivity is strongly related to poverty reduction}

Studies have found that physical connectivity is a strong determinant of poverty reduction. For example, roads and transport-related infrastructure connect people, not only to markets, but also to health services, education and employment opportunities (World Bank, 2014). Furthermore, as most of the poor live in rural areas and a significant share of them depend on agriculture for a living (Cervantes and Dewbre, 2010), physical connectivity can reduce the time and costs associated with the transport of perishable goods, as well as the need for intermediaries, raising the revenue potential of the agricultural sector. Abdi (2004) found that farmers in Kenya's Kisumu and Nyandarua districts faced market access barriers and high production costs, which affected their agricultural performance. These constraints, according to the study, could be addressed by improving infrastructure so as to connect farmers directly to consumers, removing potentially exploitative middlemen, and reducing the costs of intermediation between farmer and consumer.

Fan et al. (2002) found that in rural China, "Estimated elasticities with respect to road density are 0.08 for agricultural GDP per worker, 0.10 for non-agricultural employment, and 0.15 for wages of non-agricultural workers." Furthermore, another study found that rural roads have the most significant impact on the incidence of poverty. It was estimated, for example, that 3.2 persons were lifted out of poverty with every 10000 Yuan invested in rural roads in China (Ali and Pernia, 2003). The framework below (Figure12.5) illustrates the various channels through which infrastructure development can benefit the poor, directly through income distribution effects, and indirectly, through rural economic growth.

While the development of physical infrastructure can drive intra-country, rural-urban linkages, the link between improvements in regional transport corridors and poverty reduction is more complex. One of the reasons is that tradeassociated time and costs tend to be significantly higher across countries, and even more so across developing and least-developed countries (Box 12.2). Some of the 2017 aid-for-trade case stories provided evidence of how lengthy customs clearance procedures between neighbouring countries in Africa have burdened cross-border traders and transporters (e.g. OECD-WTO aid-for-trade monitoring exercise 2017, Public sector case story 65 and 71).

\section{Box 12.2. Intra-regional trade costs in Africa}

If the residents of San Francisco faced the same charges in crossing the Bay Bridge to Oakland as do residents crossing the Congo River between Kinshasa and Brazzaville, a similar distance, they would pay more than USD 1200 for a return trip (...) In southern Africa, a truck serving supermarkets across a border may need to carry up to 1600 documents as a result of permits and licenses and other requirements. Slow and costly customs procedures and delays caused by other agencies operating at the border, such as standards, raise the costs of trading. For example, one supermarket chain in Southern Africa reports that each day one of its trucks is delayed at a border costs USD 500 and it spends USD 20000 per week on securing import permits to distribute meat, milk, and plant-based goods to its stores in one country alone.

Source: Anabel Gonzales for World Bank (2015) 
Figure 12.5. A basic analytical framework depicting the links between infrastructure and poverty reduction

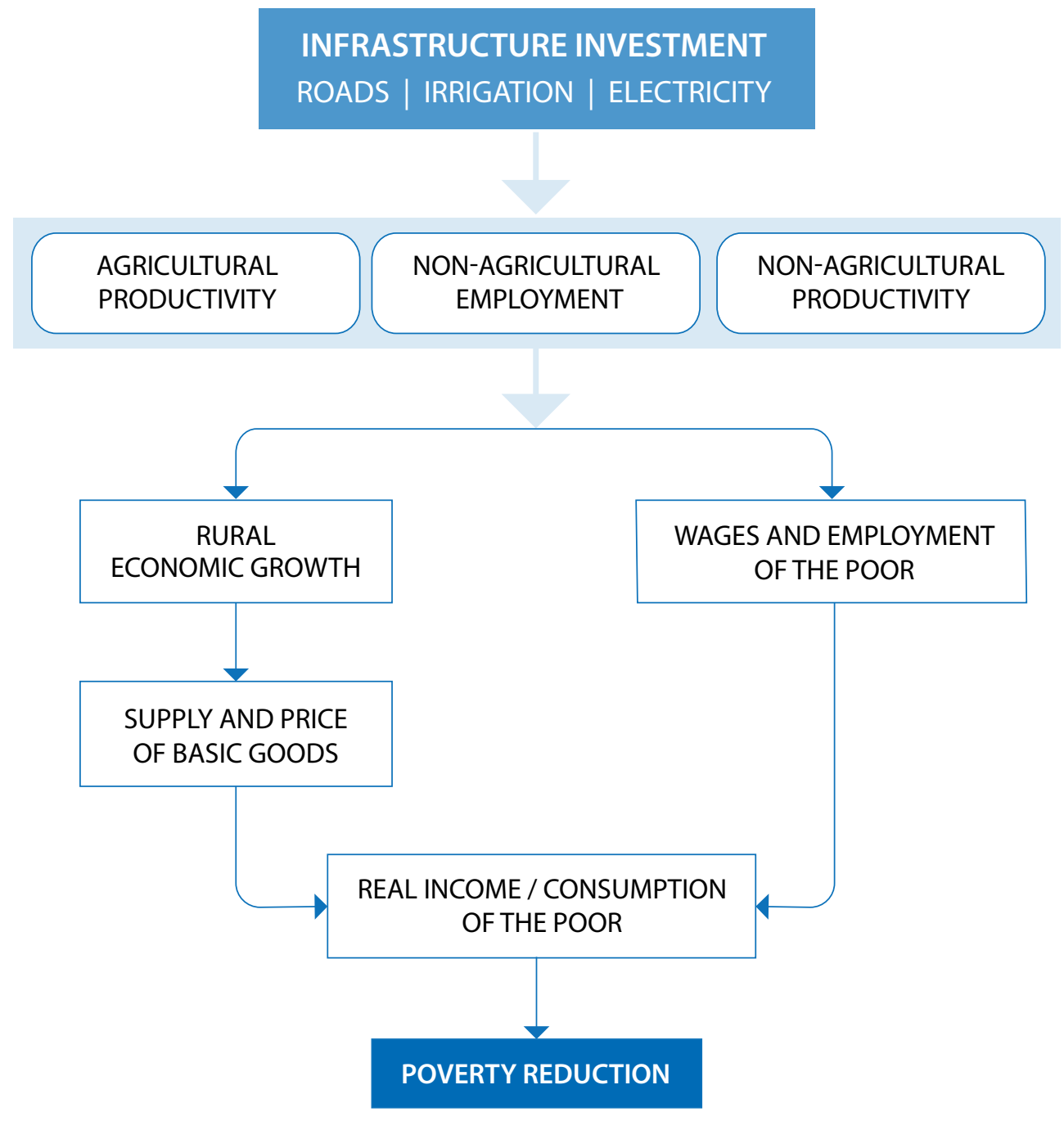

Source: Adapted from Ali and Pernia (2003), Infrastructure and Poverty Reduction-What is the connection? https://www.adb.org/sites/default/files/publication/28071/pb013.pdf

The World Bank's Doing Business database records the time and cost associated with the logistical process of exporting and importing goods. The 2016 Doing Business database shows that the time and cost to clear customs increase as per capita income by region decreases. Figure 12.6 illustrates the comparative advantage of traders in higher income regions in efficiently meeting customs clearance requirements for export. For example, South Asia and sub-Saharan Africa have the lowest per capita income by region, at USD 1542 and USD 1588 respectively, compared to USD 39267 for OECD high-income members, yet in OECD high-income countries the time needed to meet border compliance procedures is more than five times lower than in South Asia, and around eight times less than in sub-Saharan Africa. Similarly, Figure 12.6 shows that the cost of meeting border clearance procedures for export is highest in sub-Saharan Africa and Latin America and the Caribbean, whilst being lowest in Europe and Central Asia, and in OECD high-income countries.

The time and cost to meet documentary compliance procedures for export also increase as per capita income decreases. Figure 12.6 demonstrates that it takes only around 2 hours to complete documentary compliance for export from OECD high-income countries, compared to 78 hours in South Asia and 92 hours in Sub-Saharan Africa. The average cost of 
completing documentary compliance for export is also significantly higher in the Middle East and North Africa (USD 261), sub-Saharan Africa (USD 229), South Asia (USD 182), and East Asia and the Pacific (USD 132) when compared to OECD high-income countries (USD 36). Another practical issue that arises in documentary compliance is the capacity and knowledge of the relevant procedures for export.

\section{Figure 12.6. Time and cost to export and GDP per capita, by region}
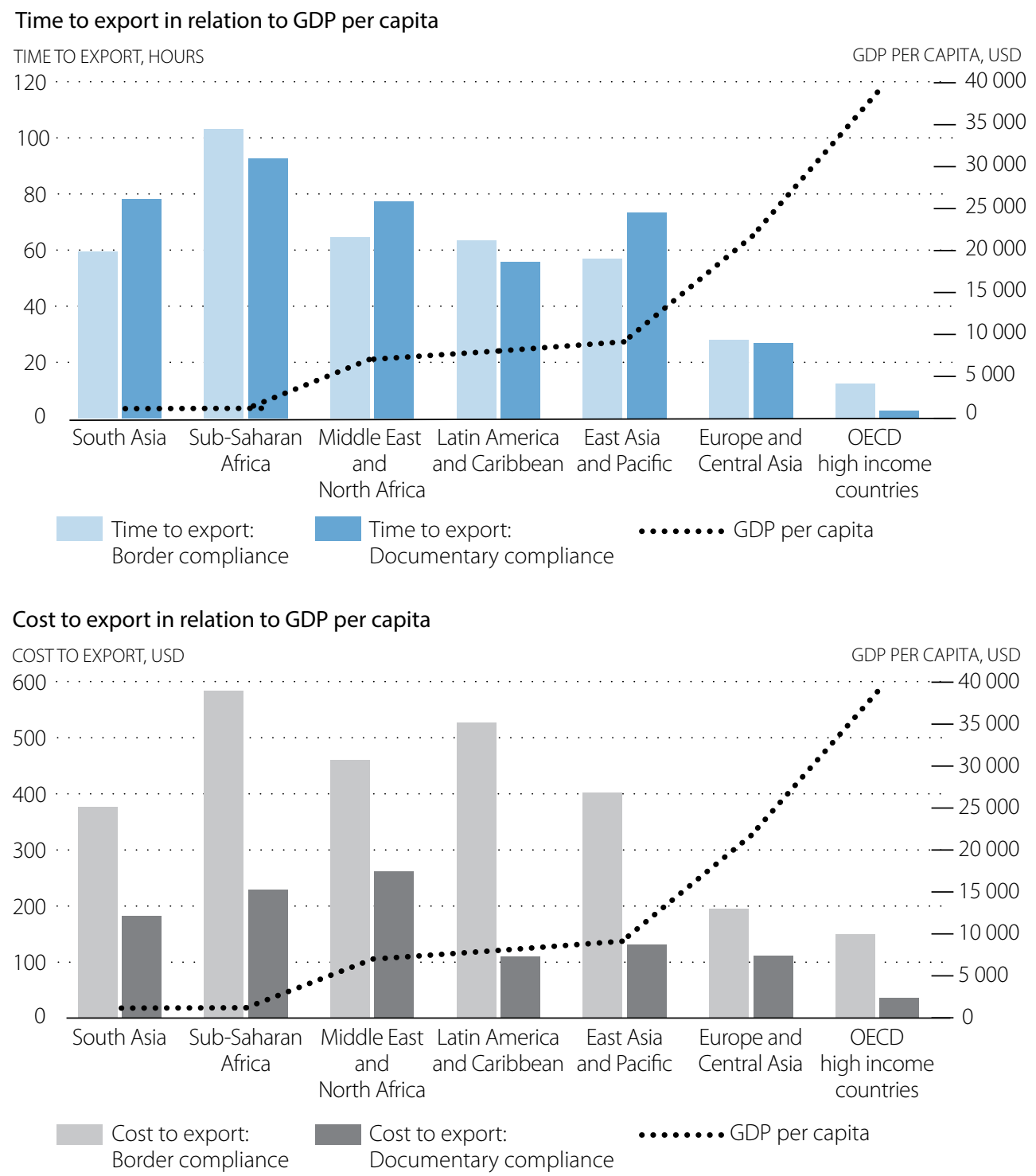

Sources: WTO Secretariat based on WB Doing Business (2016) and World Development Indicators (2015). StatLink 青15口 http://dx.doi.org/10.1787/888933527583

Producers in developing countries benefitting from tariff preferences may also still be faced with high freight costs. For example, the Inter-American Development Bank (IADB, 2008) estimates that Latin America and the Caribbean countries face transport costs that are significantly higher than tariffs for most sectors and markets. Transport costs in Latin America and the Caribbean tend to be higher, largely because of deficiencies in infrastructure and weak competition in shipping services, airfreight in particular. IADB argues that the impact of reductions in freight costs on both the volume and the diversification of of trade in Latin America and the Caribbean can be significantly larger than that of tariff liberalisation. 
Intra-regional trade accounts for only 5\% of South Asia's total trade, compared to 25\% in the Association of Southeast Asian Nations (ASEAN). South Asia, which comprises Afghanistan, Bangladesh, Bhutan, India, Maldives, Nepal, Pakistan, and Sri Lanka, is home to a population of 1.7 billion, among which 262 million people were living under USD 1.90 per day in 2013. Limited transport connectivity, onerous logistics and regulatory barriers make it more costly to trade within South Asia than between South Asia and countries in other regions (World Bank, 2017). Landlocked countries, such as Nepal and Bhutan, also face higher transport costs, as the ability of producers in these countries to trade depends on the affordability of transit costs through neighbouring countries.

Table 12.2 below provides a breakdown of the costs to import from Kolkata to Nepal; it shows that freight costs alone account for 60\% of import costs, at approximately USD 707 per twenty-foot container. Added to these costs are handling charges at the Kolkata-Haldia port—which amount to approximately USD 139-and warehouse charges, at USD 25 per twenty-foot container. High costs to transit, as well as operational inflexibilities (information exchange, logistics or payments), can negatively affect both trade efficiency and the productivity of truck drivers (De, 2015).

Another example of high transport costs is in Rwanda, where smallholders in the coffee sector face a number of logistics and other cost-related challenges. Rwanda's landlocked geographical status and limited infrastructure mean that coffee producers pay higher transport costs than in neighbouring countries. Transporting coffee cherries quickly over Rwandan roads, and moving processed beans out of the country in a timely and cost-effective manner represent some of the practical challenges they face.

\section{Table 12.2. Disaggregated import costs in Nepal (per twenty-foot equivalent unit)}

Procedure

Contact importer / broker

Fix trade terms

Sign and exchange contract

Letter of credit opening service charge

Insurance cost

Obtain approval from concerned ministry

Collect and prepare required document

Hand over document to clearing agent by courier

Handling charge at Kolkata-Haldia port

Customs clearing cost at transit customs

Warehouse charge at Kolkata-Haldia

Freight from Kolkata to factory in Nepal

Cargo transfer

Customs service charge

Clearing cost to Customs House Agent at importer's customs

Other (including informal costs)

Total (import process costs in Nepal)

Source: De, Prabir (2015), Disentangling transit costs and time in South Asia: Lessons from firms in Bhutan and Nepal importing through Kolkata and Haldia ports, www.odi.org/sites/odi.org.uk/files/odi-assets/publications-opinion-files/10260.pdf.

Cost in USD

Share of total costs

(\%)

\begin{tabular}{cc}
0.15 & 0.01 \\
\hline 0.52 & 0.04 \\
\hline 3.16 & 0.61 \\
\hline 49.55 & 3.37 \\
\hline 0.00 & 4.20 \\
\hline 7.24 & 0.00 \\
\hline 6.60 & 0.62 \\
\hline 138.71 & 0.56 \\
\hline 14.50 & 11.82 \\
\hline 24.87 & 1.24 \\
\hline 707.27 & 2.12 \\
\hline 28.78 & 60.26 \\
\hline 30.45 & 2.45 \\
\hline 6.09 & 2.59 \\
\hline 112.56 & 0.52 \\
\hline 173.75 & 9.59 \\
\hline 1000 & 1000 \\
\hline
\end{tabular}


High transit costs can therefore exacerbate the market access divide for producers in landlocked LDCs. While these costs are not exclusive to landlocked LDCs, as pointed out in the 2015 Aid for Trade at a Glance publication, "Consumers in these (isolated) countries cannot take advantage of competitively priced goods from abroad and their firms cannot access high quality foreign inputs or export to overseas markets." Furthermore, high prices tend to disproportionately impact on the incomes, consumption and welfare of the poor (OECD-WTO, 2015).

Transport infrastructure was identified as a priority in the national development strategies of 46 respondents to the 2017 AFT partner country questionnaire. Within countries, as the distance from urban to rural areas increases, so typically do the costs of transport. For the rural poor, the inability to cover distances to service centers or foreign markets and may also negatively affect their overall well-being. In 2014, 85\% of multi-dimensionally poor people lived in rural areas; this is higher than the rural share of income-based poor people, which was estimated at $70-75 \%$ in the same period (OPHDI, 2014).

\section{Connectivity can contribute to tourism development}

Efforts to connect the rural poor can also facilitate the development of trade in services. Tourism and travel is a services sector with high penetration rates in some developing and least-developed countries. In Vanuatu, for instance, the tourism and travel sector contributed to up to one third of GDP in 2013 (WT/COMTD/LDC/W/60). Tourism is also the largest export sector in the Maldives, a recently graduated LDC (in 2011) whose GNI per capita was almost five times the income graduation threshold by 2010 (UN, 2012).

The United Nations World Tourism Organisation (UNWTO) refers to connectivity as an important characteristic of tourism in low-income countries and the poor communities within them. Given the many different activities and inputs that constitute the tourism product, and its large and diversified supply chain, UNWTO finds that tourist spending benefits a wide range of sectors, including agriculture, handicrafts, transport and other services. Tourism is also described as having a multiplier effect through secondary spending by people whose income is supported by tourism (UNWTO, 2017). Box 12.3 lays out seven channels through which the poor can benefit from the development of tourism.

\section{Box 12.3. Transmission channels through which the poor can benefit from tourism development}

The following are seven sustainable tourism-eliminating poverty (ST-EP) mechanisms that can benefit the poor directly: 1. employment of the poor in tourism enterprises

2. supply of goods and services to tourism enterprises by the poor or by enterprises employing the poor

3. direct sales of goods and services to visitors by the poor

4. establishment and running of tourism enterprises by the poor, e.g. MSMEs or community-based enterprises

5. taxes or levies on tourism income or profits with proceeds benefiting the poor

6. voluntary giving/support by tourism enterprises and tourists

7. investment in infrastructure stimulated by tourism and also benefiting the poor in the locality, directly or through support to other sectors

Source: UN Steering Committee on Tourism for Development, "Tourism and Poverty Reduction Strategies in the Integrated Framework for Least Developed Countries" cited in UNDP (2011). 
Challenges in accessing remote areas where the poor tend to be concentrated pose an impediment to the export of touristic and complementary services. For example, 32 partner country respondents cited poor transport infrastructure as a constraint to the growth of their national services capacity. The ST-EP mechanism outlined in Box 12.3 acknowledges the benefits of infrastructure development for the rural poor. On that point, the United Nations Development Programme (UNDP) describes investment in rural infrastructure as having a multiplier effect on poverty reduction: "Tourism development, particularly in a new, remote or rural location, can include investment in new infrastructure, such as roads, water and energy supply, sanitation and communications. With careful planning, such infrastructure can also bring positive benefits to the poor, by providing them with basic services and opening up new and faster routes to access markets" UNDP (2011).

\section{Digital connectivity is high on the list of development concerns}

The 2016 World Bank World Development Report highlights a series of positive characteristics associated with digital innovations, including traceability, market access, food safety, improvements in logistics, quality control in agricultural supply chains, consumer protection, and improved livelihoods for farmers (World Bank, 2016a). Information and communications technology (ICT) is high on the list of national development concerns in developing countries. Also high on this list are infrastructure for road transport and telecommunications, emphasising the importance of both physical and digital connectivity for development.

The extent to which digital connectivity reduces poverty is contingent on the costs of getting the poor online. For persons whose daily income is USD 1.90 or less, it is unlikely that they will be able to meet the basic costs of digital connectivity, including the costs of mobile handsets, computer equipment, electricity and Internet connections. In 2010, the Ghana Census revealed that $47.8 \%$ of Ghanaians own a mobile phone. Going further, the same census revealed that while $63.4 \%$ of urban dwellers own phones, only $29.6 \%$ of rural dwellers do so. Globally, of the 800 million people lacking mobile internet access, 63\% are in the bottom 40\% of global income distribution (World Bank, 2016a).

In 2011, the Broadband Commission aimed for entry-level broadband to be made affordable in developing countries by 2015 - at 5\% of average monthly income - through adequate regulation and market forces. By the end of 2015, 83 developing countries had achieved the Broadband Commission's affordability target. However, only 5 LDCs met the target, leaving a substantial amount of the world's poor without access to affordable broadband Internet (ITU, 2016). Among the partner countries surveyed in the 2017 aid-for-trade monitoring exercise, $61.7 \%$ noted that the cost of broadband subscriptions constrains access to Internet for both enterprises and consumers in their countries, while $41.7 \%$ stated that access is constrained by the cost of mobile phone subscriptions.

In 2015 in Myanmar, one operator's charges for an entry-level (500MB) mobile broadband package represented around $4 \%$ of the average monthly per capita income (USD 4), falling under the Broadband Commission's 5\% target. The Alliance for Affordable Internet (A4AI) notes that for the 26\% of Myanmar's population living under USD 1 per day, this price is still unaffordable, as it represents 13\% of their monthly income. In other LDCs in the region, broadband costs were higher-9.82\% of GNI per capita income in Bangladesh, and 7.92\% in Nepal (OECD-WTO aid-for-trade monitoring exercise 2017, Academia and NGOs case story 05).

Figure 12.7 compares the prices of mobile broadband and fixed broadband across regions, taking into account purchasing power parity (PPP). In LDCs, fixed broadband services are on average more than three times as expensive as mobile broadband services. Not surprisingly, fixed broadband penetration is less than $1 \%$ in the LDCs compared to $8 \%$ in developing countries and 30\% in developed countries. Similarly, mobile penetration rate in the LDCs is an estimated $19 \%$, less than half the penetration rate in developing countries (41\%) and less than one-quarter of the rate in developed countries, which is estimated to be $90 \%$ (ITU, 2016). 
Figure 12.7. Fixed-and mobile-broadband prices in purchasing power parity, 2015

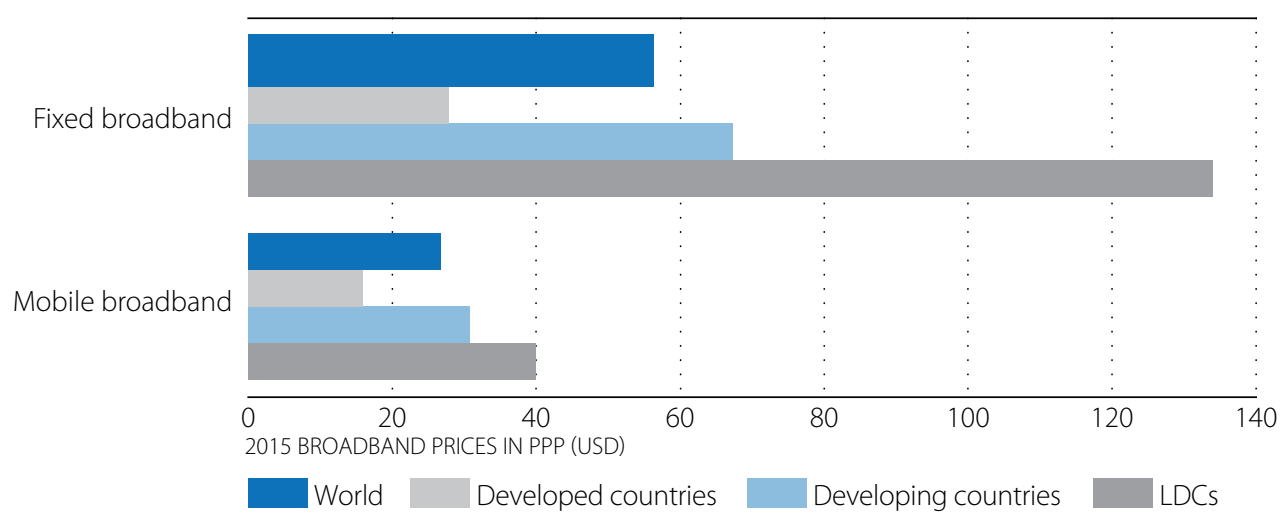

Source: ITU (2016), ICT Facts and Figures 2016

StatLink न्ना5 http://dx.doi.org/10.1787/888933527602

Lack of available, affordable Internet access can impede the poor's direct participation in trade as consumers and as sellers; it also limits their access to information, finance and trade-related capacity building. UNCTAD (2010) noted the importance of mobile technology in addressing information-related market failures among farmers, fisher folk, small manufacturers and service providers. At the same time, including the poor in international trade also requires affordable delivery and logistics services for both supply and demand. In many developing countries and LDCs, particularly in rural areas, addresses and postal services are complicated or unavailable altogether. In that context, the manner in which the digital and physical divides intertwine to hinder the socio-economic integration of the rural poor becomes evident.

For women, traditional constraints in connecting to trade opportunities may be alleviated through digital connectivity. Digital connectivity can reduce interactions and proximity in trade transactions, thereby generating positive outcomes for female traders. For instance, women often face substantial time constraints because of the uneven distribution of responsibilities in the household. A survey of women traders in Africa highlighted shortage of time as a major reason for cancelling trips to markets to sell their household goods, because of the priority placed on work in the home and bearing and caring for children (WB-WTO, 2015). Digital connectivity can reduce the time required to engage in trade, while also lessening the need for women traders to cross borders, lowering the potential risks of harassment and assault—a regular occurrence at many border crossings in Africa (Brenton et al., 2011).

In a similar context, the digitisation of finance-making it possible to conceal the identity of the payee and therefore to make and receive payments independently of men — has helped shift economic decision-making toward women (World Bank, 2016a). In this way, women's economic empowerment may not only be reliant on digital and physical connectivity, but on the inclusion of women in the digital payments economy. In a study by the Bill and Melinda Gates Foundation, it is noted that digital payments can "promote women's economic empowerment by facilitating greater account ownership and asset accumulation and increasing women's economic participation" (World Bank, 2014b ).

One study found that, in Uganda, only $68 \%$ of urban women and 52\% of rural women made decisions on the use of their cash earnings (Table 12.3). Distances to financial centres and unfamiliarity with financial systems are other reasons why digitization of payments can be supportive of women empowerment, as their participation in trade is linked not only to the availability but also to the accessibility of financial resources. In one case story, the Asian Development Bank found that despite the availability of loans, there was low demand for micro-financing from women entrepreneurs in Indonesia, describing cases where women had never been to banks, lacked confidence in borrowing money from banks, or were simply afraid of taking out loans (OECD-WTO aid-for-trade monitoring exercise 2017, Public sector case story 94). The ITC reports that as many as $90 \%$ of female-led enterprises in Latin America are in the informal sector, and noted that the low percentage of women who can access formal financial institutions for business purposes is striking—about 0.2\% in El Salvador (Vergara, 2016). 
Table 12.3. Who makes decisions on how a woman's cash earnings are used in Uganda?

\begin{tabular}{|c|c|c|c|c|c|c|}
\hline & & $\begin{array}{l}\text { Mainly } \\
\text { wife }\end{array}$ & $\begin{array}{l}\text { Mainly } \\
\text { husband }\end{array}$ & $\begin{array}{c}\text { Husband } \\
\text { and wife } \\
\text { jointly }\end{array}$ & $\begin{array}{c}\text { Other/ } \\
\text { information } \\
\text { missing }\end{array}$ & Total \\
\hline \multirow[t]{2}{*}{ Residence } & Urban & 68 & 4.2 & 27 & 0.9 & 100 \\
\hline & Rural & 52 & 15 & 32.7 & 0.3 & 100 \\
\hline \multirow[t]{9}{*}{ Regions } & Central 1 & 71 & 8.1 & 20.3 & 0.5 & 100 \\
\hline & Central 2 & 74.5 & 9.1 & 16.4 & 0 & 100 \\
\hline & Kampala & 79.2 & 1.9 & 18.2 & 0.7 & 100 \\
\hline & East Central & 56.9 & 20.3 & 22.9 & 0 & 100 \\
\hline & Eastern & 24.4 & 18.1 & 57.6 & 0 & 100 \\
\hline & North & 36.7 & 16.9 & 45.6 & 0.1 & 100 \\
\hline & West Nile & 72.4 & 4.9 & 22.4 & 0.3 & 100 \\
\hline & Western & 44.5 & 16.9 & 38.3 & 0.3 & 100 \\
\hline & Southwest & 39.4 & 15.8 & 43.2 & 1.6 & 100 \\
\hline \multirow[t]{2}{*}{ North Sub-Regions } & $\begin{array}{l}\text { Internally Displaced Persons } \\
\text { (IDP) }\end{array}$ & 37.6 & 14.9 & 47 & 0.5 & 100 \\
\hline & Karamoja & 50.4 & 9.7 & 39.9 & 0 & 100 \\
\hline
\end{tabular}

Source: Hisali, Eria, Trade, employment and gender: The case of Uganda, www.oecd.org/site/tadicite/48722379.pdf.

Financial access barriers, in addition to high business start-up costs and lengthy administrative procedures can pose impediments to the participation of women, and micro, small and medium-sized enterprises more generally, in the formal economy. The World Bank's Doing Business data 2016 shows that in sub-Saharan Africa, domestic business startup costs are around 54\% of income per capita and requires approximately one month to start; while in OECD highincome countries, the same start-up costs are around 3\% of income per capita, and requires a little over one week to start (Word Bank, 2016b).

As Internet adoption rates increase, a farmer working his or her own land may be able to take advantage of a price change to sell, or a hairdresser in a large city may spend some of his or her commute time performing simple data-entry services instead through a micro-work platform. However, the challenge is that traders like these-freelancers or individual entrepreneurs - may continue to operate in the informal sector. To date, there is no evidence that trade integration results in growth in the informal sector, but the extent to which this remains so as e-commerce grows will need to be studied further (WB-WTO, 2015).

Governments in developing countries will have to navigate the regulatory complexities of a growing number of individuals and small, potentially informal firms participating in trade. While the objective in all countries may be to support the growth of the formal sector, it is important that this be done gradually and takes into account the importance that trade in general (and increasingly, e-commerce specifically) may have as a source of income for the large number of people working in the informal sector.

An additional challenge for governments is that the lack of data available on e-commerce in general is compounded when many traders are operating informally. Without a more accurate picture of the participation of the informal sector in this type of trade, there is a risk that policies will be designed without an adequate evidence base, incurring a risk of negative impacts. However, as connectivity continues to improve, technology offers a method for gathering better data about the participation of traders operating in the informal sector; this includes through methods such as mobile phone surveys, or through partnerships with online retail platforms or mobile phone operators to gather data on users, while respecting privacy. 


\section{HOW IS CONNECTIVITY REDUCING POVERTY?}

This section focuses on how efforts to improve physical and digital connectivity are reducing poverty. While tracing impacts on poverty reduction is complex, the report The Role of Trade in Ending Poverty describes several actions that can help to make trade more accessible for the poor (WB-WTO, 2015):

- lowering trade costs for deeper integration of markets

a improving the enabling environment and complimentary policies to maximise the gains of openness for the poor.

antensifying the poverty impact of integration policies

- managing and mitigating risks faced by the poor

- improving data and analysis to inform policy.

The discussion in this section is articulated around these actions, and the analysis draws mainly from case stories submitted to the 2017 aid-for-trade monitoring and evaluation exercise.

\section{Physical and digital connectivity are critical for market access}

Streamlining customs processes has contributed to reducing trade costs and increasing revenues in developing countries. Enabling automation and reducing the friction in cross-border trade is essential to lower costs and connect producers to markets and value chains. This can be especially relevant for the typical MSME or individual trader participating in either online or offline trade. A case story submitted by Trademark East Africa describes how the establishment of a one-stop border post (OSBP) connecting Kenya and Uganda led to an increase in revenue collected of around USD 5.5 million, reduced the average time it takes to cross the border by $80 \%$, boosted cross-border trade for small traders and improved the working conditions for staff and transporters. The Busia OSBP warehousing facilities, for instance, have lowered storage costs for small traders as they wait to clear taxes. Transport costs have also been reduced, allowing several small traders whose goods are being transported to a particular destination to consolidate goods and hire one truck driver. The border post also caters to the needs of the physically challenged, as well as women with children (OECD-WTO aid-for-trade monitoring exercise 2017, Public sector case story 71).

Another case story describes how the Uganda Revenue Authority, with support from TradeMark East Africa, rolled out an intervention to improve customs processes and increase the ease of doing business in Uganda, a move which has decreased customs clearance times, increased revenue collection, and improved savings for local traders. For example, improvements in the examination and inspection of goods, as well as the acceptance of pre-arrival import declarations, saves one company USD 150 per day on the 25 containers they receive each month, in addition to administrative savings. The company's savings are reinvested into the business and used to increase employee earnings (OECD-WTO aid-for-trade monitoring exercise 2017, Public sector case story 79).

A trade facilitation initiative along the Dakar-Bamako corridor has helped to reduce escort fees by $50 \%$ for truck drivers in Senegal. The reduction of transport and transaction costs resulting from trade facilitation measures also had spillover effects for local communities, such as enhancing the competitiveness of the local private sector and reducing consumer prices. This initiative has also lessened the stressfulness of working conditions for truck drivers, who suffered from the scarcity of border posts (OECD-WTO aid-for-trade monitoring exercise 2017, Public sector case story 65).

Among the partner countries surveyed, 95\% identified the development of services infrastructure and related services markets as key for achieving the SDGs. The A4Al emphasises the importance of public access to connect the unconnected; its 2017 Affordability Report identifies projects that are being rolled out to promote universal Internet access in developing countries. In Dar es Salaam, Tanzania, for example, Wi-Fi services will be installed in public spaces and recreational venues. In the Philippines, there are plans to make free Wi-Fi available in public areas throughout the country, including schools, hospitals, airports and parks. In India, the government intends to provide free public Wi-Fi hotspots to over 1050 villages across the country as part of its Digital Village programme (A4Al, 2017). 
Efforts to improve Internet connectivity are strongly contingent on infrastructure development. In Tonga, the Asian Development Bank estimates that 22.5\% of the population lives below the national poverty line (AsDB, 2016). A case story presented by the Asian Development Bank describes how an undersea fibre-optic cable has facilitated highspeed Internet connectivity in Tonga (OECD-WTO aid-for-trade monitoring exercise 2017, Public sector case story 97). The cable brings a wide range of benefits to Tongans: international connectivity costs have been reduced by $60 \%$; education and health resources have been improved; iinternational trade opportunities, particularly in tourism and business outsourcing, have increased; and other services (e.g. bill payment, remittances and communication services) have been facilitated at affordable rates.

Internet connectivity is also enabling artisans and entrepreneurs to overcome some of the traditional barriers that impede their access to markets, such as information asymmetries and high business-related and travel costs. In Africa, Jumia Market described how they leveraged the power of the digital economy to help tens of thousands of small traders in Cameroon, some of whom have never used a computer, to gain access to consumers and merchants via their online platform (OECD-WTO aid-for-trade monitoring exercise 2017, Private sector case story 74). The increase in income for small traders resulting from online demand has trickled down to their households, enabled them to save, and has driven their productivity and ambition. Another case story presented by Alibaba described how the Rural Taobao platform has helped rural mountain villagers to earn income by selling products from their remotely located region online (OECD-WTO aid-for-trade monitoring exercise 2017, Private sector case story 21)

Digital connectivity can promote the inclusion of farmers in trade despite their distance from markets and urban centres. A case story submitted by TradeMark East Africa describes how in Kenya, gaining a certificate of origin required travel—which meant additional trade costs, thus decreasing agricultural gains. A new automated system run by the Kenya National Chamber of Commerce and Industry issues certificates of origin online. Prior to automation, agricultural exporters had to undergo a manual process, which had to be completed either in the country's capital, Nairobi, or in the port city, Mombasa. The new automated system is said to have reduced the time needed for application for and issuance of certificates by up to $86 \%$, lowering direct trade costs by up to $75 \%$. The online system is linked to commercial banks for automated payment services, and also includes options for mobile payment services (OECD-WTO aid-for-trade monitoring exercise 2017, Public sector case story 73)

\section{Connectivity contributes to women's economic empowerment}

Case stories have also provided evidence of the importance of mobile connectivity for the rural poor. The Asian Development Bank found that countries in Central Asia are leapfrogging to "mobile first connectivity", noting that "rollout and connectivity policies and programmes do need to recognise that mobile is the agent of change and most people coming online now are doing so via a mobile device" (OECD-WTO aid-for-trade monitoring exercise 2017, Public sector case story 108). According to World Bank estimates, while just $2 \%$ of adults worldwide have mobile money accounts, 12\% of people in sub-Saharan Africa have one.. For the poor, often unbanked and constrained by distances to bank agencies and cash machines, the promotion of financial inclusion via mobile money services is already well documented. One study, for example, found that within eight years, M-PESA had lifted 194000 households out of poverty, helping people develop greater financial resilience and savings, especially among female-headed households (Suri et al, 2016).

Lifting women out of poverty is linked to making available financial services easily accessible to women. The Better than Cash Alliance notes that digital financial services have the potential to be a powerful tool for financial inclusion and can address the needs of women in new and different ways from traditionally provided financial services (Better than Cash Alliance, 2015). For instance, women's limited control over financial resources is among the restraints that may be alleviated through mobile money transfers. Evidence from a cash transfer programme in Niger has shown how the greater control allowed by mobile money transfers and the privacy these afford can shift intra-household decision-making in favour of women (Porter et al, 2015). 
Telenor provided examples of how mobile money initiatives are reducing poverty and gender disparities in rural Pakistan, where education stipends transferred to rural families via mobile transfers help pay for schooling for young girls. Before mobile money technology, the cost of disbursing stipends, at times, exceeded the value of the stipend itself. Pakistan has also been reaching the poor through the use of digitally enabled government-to-citizen (G2C) services. Box 12.4 below describes a universal access programme in Pakistan that has yielded results in both the rural and urban parts of the country (OECD-WTO aid-for-trade monitoring exercise 2017, Public sector case story 33).

\section{Box 12.4. Pakistan's digital economy}

Pakistan has the lowest broadband cost-as-a-percentage-of-income for people living in poverty, and the country ranks eighth out of 30 developing countries in terms of affordability of mobile broadband.

The Universal Service Fund is one of Pakistan's public sector programmes, whose main objective is to increase the level of telecom penetration in rural areas by: encouraging telecom operators to focus on Pakistan's rural and un-served populations; improve broadband penetration in the country; and significantly boost e-services in both rural and urban parts of the country. The results in 2016 included:

- contracts signed for 486896 broadband subscribers

more than 700000 broadband subscribers reached

- 1328 educational broadband centres established

369 community broadband centres established

Source: UN Steering Committee on Tourism for Development, "Tourism and Poverty Reduction Strategies in the Integrated Framework for Least Developed Countries" cited in UNDP (2011).

The Internet is also playing an important role in connecting women to markets. A case story submitted by SPINNA, an organisation offering training, mentoring, and business opportunities for women designers, artisans and entrepreneurs, describes how technology has been an enabler for the inclusion of women artisans in international textile supply chains. It has leapfrogged traditional connectivity methods, helping to reduce even practical communication and language barriers (OECD-WTO aid-for-trade monitoring exercise 2017, Academia and NGOs case story 82). Another case story submitted by the ITC describes the SheTrades initiative, which aims to connect one million women entrepreneurs to markets by 2020. Already, 4600 women businesses have registered on their mobile app platform (OECD-WTO aid-fortrade monitoring exercise 2017, Public sector case story 127).

Greater use of online platforms for trade could support the increased participation of women in trade by reducing gender bias in relationships between buyers and sellers through anonymity, and by allowing for more flexible working hours. On Elance, a freelancing platform that is part of Upwork, 44\% of workers are women, compared with $27 \%$ in the non-agriculture economy more widely (World Bank, 2016a). This contrasts with the situation in traditional trade, where the fact that business networks are male-dominated can result in women traders receiving less returns for their goods and services than male traders. Analysis of male- and female-owned firms suggests that male-owned firms are more likely to find customers through traditional networks of contacts, while women-owned firms tend to secure customers through other channels (Bossuroy et al, 2012).

The UNDP, in its response to the 2017 OECD-WTO donor questionnaire, stated, "The digital economy facilitates forms of economic participation that allow women to better reconcile household demands on their time with gainful economic activities." Similarly, all 63 partner country respondents noted that e-commerce can contribute to women's economic empowerment. Some of the additional information provided by respondents is presented in Box 12.5 . 
Box 12.5. Can growth in e-commerce make a contribution to women's economic empowerment?

Cameroon E-commerce can become an instrument of trade development that can be used by women to lift themselves out of poverty and become economically self-sufficient. (original in French)

El Salvador 'Female entrepreneurship' in the region forms part of the efforts being made to empower women economically. One obvious obstacle to doing business is the disadvantage faced by women compared to men of looking after the family and bearing greater responsibility to care for relatives. Women are therefore less mobile and have fewer opportunities to travel. Technology is clearly a strategy that enables them to do business and mobilise resources without having to leave the home. This is evidenced by the fact that women make greater use of social networks for business purposes. (original in Spanish)

Uganda E-commerce will enable women, especially in rural areas, to conduct businesses and transactions online, for instance mobile money transactions.

Yemen E-commerce will enable women to work and conduct business from their homes. This method of work would enable them to overcome the restrictions imposed by tradition and religion, including interaction with the different sex. E-commerce would empower women by making them economically better and more independent.

Source: OECD-WTO aid-for-trade monitoring exercise (2017), www.oecd.org/aidfortrade/countryprofiles/.

In addition to e-commerce, respondents note that the development of capacity for trade in services is important for women's economic empowerment. Tourism, in particular, has a positive impact on women's lives through the promotion of private sector development and the creation of job and income opportunities. With support from New Zealand, the Enhanced Integrated Framework (EIF) has launched a tourism development project to upgrade tourism infrastructure on Vanuatu's seafront and increase resilience to natural disasters and climate change. An estimated 11000 women working in the handicrafts sector, for example, will earn incomes from this project (EIF, 2016). Figure 12.8 shows the service sectors that partner country respondents identified as contributing most to women's economic empowerment, the most important being tourism and travel-related services.

\section{Figure 12.8. Top ten service sectors expected to contribute to women's economic empowerment}

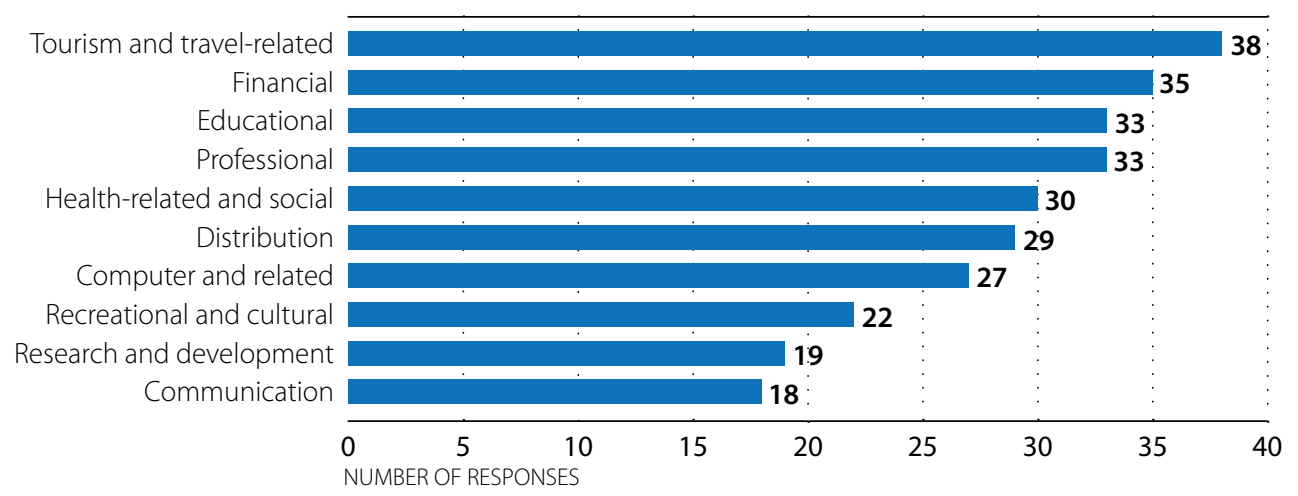

Source: OECD-WTO aid-for-trade monitoring exercise (2017) www.oecd.org/aidfortrade/countryprofiles/.

StatLink ants http://dx.doi.org/10.1787/888933527621 
One concern related to the responses in Figure 12.8 above is that less than 50\% of respondents consider computer and related services to be supportive of women's economic empowerment. Case stories corroborate this finding by affirming that there is a gender gap in the use of and participation by women in computer and related services, mainly the Internet. The A4AI 2015 Affordability Report noted that while in general, the affordability picture appears stark for those living in poverty, the cost for women to connect remains even higher (OECD-WTO aid-for-trade monitoring exercise 2017, Academia and NGOs case story 02). Although e-commerce offers a number of ways of reducing the constraints to maximise trade opportunities, inequality in access to technology must be overcome. In Africa, women are still less likely than men to own a mobile phone, and 18\% of men report using the Internet compared to 12\% of women (World Bank, 2016a).

The foundations of an inclusive digital economy rest on affordable modern telecommunications infrastructure and an educated population that can engage in and contribute to the information society. Initiatives such as Intel's She Will Connect Africa provide insights into how digital education programmes have helped to expand women's technical knowledge, in order for them to take full advantage of Internet usage (OECD-WTO aid-for-trade monitoring exercise 2017, Private sector case story 18). The ITU also co-led a Women's Digital Literacy Campaign with the Philippines-based NGO Telecentre, training unskilled women in over 80 countries to use computers and ICT applications to improve their livelihoods and access opportunities for education, employment and income (ITU, 2017).

\section{Connectivity can help to manage risks}

Another area where connectivity can have positive impacts is in fragile or disaster-affected environments. World Bank research highlights the important environmental impact on poverty, suggesting that extreme weather alone pushes around 26 million people back into poverty each year. In developing countries, the economic cost of disasters since 1980 amounts to USD 1.2 trillion, equivalent to about one-third of all official development aid (Narimatsu-World Bank, 2013). The Inter-Governmental Panel on Climate Change (IPCC, 2001) notes that climate change will intensify poverty, with developing nations most affected because of their geographical and climatic conditions, their high dependence on natural resources, and their limited capacity to adapt to a changing climate: "Within these countries, the poorest, who have the least resources and the least capacity to adapt, are the most vulnerable" (Abeygunawardena et al, 2009).

The welfare of the poor is not only affected by catastrophic earthquakes or tsunamis, but also by frequent or sudden weather variations resulting in flooding and drought. The impact of these events on food security, water scarcity and living conditions can be catastrophic. The 2015 earthquake in Nepal and the 2015 cyclone in Vanuatu have caused major setbacks to the tourism sector in these countries. Health crises can also pose a major setback to sustainable development and poverty reduction. The EIF notes, for example, that an ecotourism project in Sierra Leone was placed on hold due to the outbreak of Ebola, a health crisis that also undermined the development of tourism services in Liberia and Guinea.

In a case story submitted by Japan, the respondent noted the importance of ICT for disaster awareness and management (OECD-WTO aid-for-trade monitoring exercise 2017, Public sector case story 75). Japan has already assisted the Philippines in better predicting tsunamis with satellite technologies and seismographs. After the 2010 earthquake in Haiti, mobile money allowed humanitarian donors to contribute to the recovery of populations in one of the least banked countries in the world, leading to the development of a mobile ecosystem; by 2012, 85\% of Haitian households had access to mobile phones (GSMA, 2012).

Mobile connectivity is also assisting in managing and mitigating risks faced by the poor, and in improving data and analysis to inform policy. The World Bank's Listening to Africa initiative, for example, partners with national statistical offices and NGOs across Africa to gather data on the challenges faced by the poor. Trade professionals interview respondents over the telephone; where necessary, respondents are provided with mobile phones, solar chargers and credit. The survey has already presented timely results on the frequency of power cuts in Togo as well as on food insecurity in Madagascar (Ndip, 2016). 


\section{WHAT HAVE WE LEARNT FROM THE 2017 AID-FOR-TRADE PROGRAMMES?}

Several highlights emerge from the 2017 aid-for-trade monitoring and evaluation exercise:

- Aid-for-trade programmes or projects in both the public and private sectors are inclusive.

There is targeted public and private assistance for women and the rural poor, including those in the agricultural sector. Questionnaire results also evidence a strong connection between the development of services sectors and women's economic empowerment. Going forward, there is focus on collaborative approaches, including private sector engagement, for development and the achievement of the SDGs, notably poverty eradication.

\section{- Both physical and digital connectivity are priorities in developing countries.}

In developing countries, transport and communications infrastructure are top development priorities. Partner countries identified the development of infrastructure as key to the achievement of the SDGs, and case stories showed how improvements in physical infrastructure and facilities at borders have promoted trade, increased revenues and improved working conditions. Partner countries place less emphasis on the development of e-commerce as a stand-alone priority, but acknowledge the positive impact it can have on women's economic empowerment and poverty reduction.

\section{- Aid-for-trade programmes are focusing on reducing trade costs.}

Trade costs associated with physical infrastructure, logistics, transport, and Internet connectivity are critical to the integration of the poor in international trade, and are being addressed in aid-for-trade programmes. The case stories highlight how literacy and regulatory barriers as well as difficulties in meeting customs requirements are also being alleviated through aid-for-trade programmes.

\section{Digital technologies are helping people to earn incomes through trade, financial inclusion and} capacity building.

Access to the Internet and mobile technology is increasing the capacity of entrepreneurs to target consumers and market their products and services. Connectivity is enabling the poor to access information and networks, and reducing distances to consumers. Mobile technology, in particular, is promoting financial inclusion and increasing the participation of women and entrepreneurs in trade.

- Internet connectivity represents a trade cost that is affecting the poor in many aspects of their lives. This year's M\&E results illustrate that barriers to Internet access and affordability limit the participation of the poor as both consumers and suppliers. The Pacific regional initiative described earlier demonstrates the impact of broadband in improving connectivity and promoting social and economic development. Access to the Internet also allows services to be traded cross-border, hence providing opportunities for economic diversification and socio-economic advancement.

\section{Regional initiatives to promote connectivity}

The A4Al's 2017 Affordability Report explains that slow progress in Internet connectivity is placing the poor at the back of the connectivity queue. Less than half the countries surveyed for the A4AI 2017 Affordability Report had developed plans to reduce connectivity costs by facilitating the sharing of infrastructure resources (towers or fibre networks) among telecommunications companies (A4Al, 2017).

The AsDB has recognised the need for investment in regional infrastructure to make the Internet available to all. The Regional Public Goods Initiative of the IADB is also based on the premise that the countries of Latin America and the Caribbean can address shared challenges more effectively and efficiently through regional collective action and cooperation. IADB-funded initiatives include a regional integrated satellite information system and a technology hub for regional competitiveness (IADB, 2017). 
On the African continent, the importance of high-speed Internet connectivity has been highlighted by the AfDB, noting that "the absence of regional connectivity between states with access to the submarine cable and landlocked countries, and more generally the scarcity of cross-border backhaul links, is one of the key broadband access gaps in Africa." The Connect Africa Initiative has mobilised funding for several regional fibre projects, with co-ordination support from the World Bank, to resolve connectivity barriers so that high-speed Internet can be made available to the African population (OECD-WTO aid-for-trade monitoring exercise 2017, Public sector case story 16).

In addition, the AfDB highlighted the importance of national "backbones" in facilitating the widespread use of advanced communication, such as the need for policy and regulatory interventions to abolish exclusivity in market entry, reduce license fees and simplify licensing procedures. AfDB also considers the promotion of open, transparent and nondiscriminatory access to national networks a necessary foundation for improved regional broadband networks in Africa (OECD-WTO aid-for-trade monitoring exercise 2017, Public sector case story 16).

\section{Aid for trade contributes to the SDGs in numerous areas}

Questionnaire responses demonstrate the importance partner countries attribute to aid-for-trade programmes and their contribution to the achievement of the Sustainable Development Goals (Box 12.6). Responses also highlighted how collaborative approaches can complement aid-for-trade efforts for poverty eradication and the achievement of the SDGs. Partner countries, for instance, have indicated their willingness to work with various stakeholders to achieve development objectives.

\section{Box 12.6. How can aid for trade help implement the Sustainable Development Goals?}

Niger Aid for trade can contribute to poverty reduction, to the insertion of youth and to the promotion of women entrepreneurship. (original in French)

Democratic Republic of the Congo The availability of trade-related infrastructure creates effects that contribute to the achievement of the SDGs. More aid for trade contributes to increasing trade, which is the basis for increasing economic growth and, in turn, economic growth is the underpinning factor of economic development favouring the reduction of poverty incidence and undernourishment. (original in French)

Burundi If aid for trade increases, it will significantly reduce the level of poverty. (original in French)

Zambia Aid-for-trade programmes help to unlock existing barriers to trade. Trade as an enabler of Industrial development facilitates the achievement of SDGs.

Colombia Aid for trade contributes to the achievement of the SDGs, through the development of quality, sustainable and reliable infrastructure, including regional and cross-border infrastructure to support economic development and human wellbeing with a focus on affordable and equitable access for all. (original in Spanish)

Indonesia Aid for trade supports enhancing procedure capacity and empowers women through entrepreneurship. Aid for trade is also able to stimulate development partners to take part through triangular mechanism.

Source: OECD-WTO aid-for-trade monitoring exercise (2017) www.oecd.org/aidfortrade/countryprofiles/.

Donors have also highlighted the importance of multi-stakeholder engagement. Canada stated, for example, "In the 2030 Agenda context, all partners must pull together to eradicate poverty, build peace and achieve sustainable development." The ITC works with the private sector to "provide markets for products and services from SMEs; for in-kind and financial partnership in implementation of trade-related projects on the ground; and for supporting public/ private dialogue on trade policy and regulatory issues such as trade facilitation, non-tariff measures and e-solutions." 
Sweden, in its response, stated, "Partnerships with the private sector can help pool sustainable investments in sectors where aid for trade supports policy reforms. However, some key principles must be adhered to. Poverty focus must be at the core (not partnering for the sake of partnering), as must untied aid. Other key criteria include high sustainability standards, ensuring additionality and avoiding market distortion."

What we have learnt from the results of this year's aid-for-trade monitoring exercise is that efforts to improve connectivity are having positive impacts on the wellbeing of the poor in the areas of education (SDG 4), gender equality (SDG 5), industry, innovation and infrastructure (SDG 9), and decent work and economic growth (SDG 8). The extent to which connectivity can contribute directly to eradicating poverty (SDG 1) is, with some exceptions such as mobile money, more complex and difficult to ascertain. This is perhaps due to the multitude of other variable factors that can affect poverty alleviation efforts, including regulatory frameworks, inequalities and gender discrimination.

Notwithstanding these complexities, the results of the 2017 aid-for-trade monitoring exercise demonstrate that there is a relationship between income level, infrastructure, access to the online world and the achievement of the SDGs. This underlines the importance of efforts to increase participation and lower the costs of Internet access through a mix of financing and regulation that attracts public and private resources in telecommunications infrastructure. At the same time, digital connectivity does not make distances disappear, and physical remoteness poses a significant constraint to the poor's participation in the digital economy. Hence, strategies to pursue affordable and reliable physical and digital connectivity, working in tandem, could maximise the impact of poverty eradication efforts, especially for communities in remote, rural areas.

\section{CONCLUSIONS}

Poor connectivity is one of the factors keeping people in poverty. To reduce poverty, the costs of digital and physical connectivity need to be addressed in order to enable the poor to participate in the physical and digital economy.

The first section of this chapter mapped the relationship between connectivity and poverty, demonstrating that regions with higher poverty rates have low physical and digital connectivity. Within and across countries, the costs of doing business tend to increase with distance, thus making physical connectivity a strong determinant of the poor's ability to access basic goods and services, earn an income or integrate into supply chains. A similar association is evident between digital connectivity and poverty - the lower the per capita income, the lower the Internet usage rate. Broadband is also less affordable in least-developed countries, where the majority of the world's poor are concentrated. For women and rural populations, limited digital and physical connectivity together with socio-cultural and other regulatory factors can intensify the burden of poverty.

Efforts to improve physical and digital connectivity are lowering trade costs and reducing poverty. The second section of this chapter provided evidence from 2017 aid-for-trade case stories, which demonstrated that digital approaches to trade facilitation can reduce bottlenecks at borders, increase revenue, and facilitate the participation of small traders and women in cross-border trade. Internet access is also alleviating distance barriers, information asymmetries, and nontariff barriers, helping smallholder farmers, women, and entrepreneurs earn income by selling online. Mobile money has promoted financial inclusion, lifted people out of poverty and increased women's economic empowerment, helping them overcome some of the constraints of traditional financial barriers. 
The third section highlighted some of the key points emanating from the 2017 aid-for-trade monitoring exercise in the context of inclusiveness and poverty reduction. Evidence of trade outputs and outcomes from aid-for-trade projects and programmes is now being complemented by the results of efforts to trace poverty reduction impacts at various stages using targeted indicators. Both the public and private sectors are actively engaged in programmes to connect the poor and help them earn/increase incomes. The case stories submitted emphasise the inclusiveness of connectivity programmes, which target the development of the poor, smallholder farmers and women. Based on the responses to the 2017 aid-for-trade monitoring exercise, both developing countries and donors believe that aid-for-trade support can contribute to eradicating poverty, and have expressed interest in collaborating with various stakeholders, including the private sector, to work towards the achievement of the 2030 SDGs.

As connectivity is multidimensional and is progressing rapidly, there is a need for further research and improved data metrics to understand the challenges facing the poor so as to make sure they are not left behind. With the rapid spread and use of digital technologies in particular, one challenge for developing countries and the LDCs is to make affordable, high-speed Internet connections available to those who are still offline. To that end, mechanisms to improve regulatory environments and mobilise funding for shared infrastructure resources could merit further research and discussion. 


\section{REFERENCES}

A4AI (2017), 2017 Affordability Report, Alliance for Affordable Internet, http://a4ai.org/affordability-report/report/2017/ Abdi, Halima Noor (2004), The Influence of Rural Logistics and Rural Transport Costs on Farm Income and Poverty in Kenya: The Case Of Kisumu and Nyandarua Districts, Kenya, http://siteresources.worldbank.org/INTTLF/Resources/ Kenya Rural Logitcis Report.pdf

Abeygunawardena, Piya et al, (2009), Poverty and climate change: reducing the vulnerability of the poor through adaptation, World Bank, Washington, DC, http://siteresources.worldbank.org/INTTLF/Resources/Kenya Rural Logitcis Report.pdf

ADB (2016), Poverty in Tonga, webpage, Asian Development Bank, www.adb.org/countries/tonga/poverty

Ali, I. and E.M. Pernia (2003), Infrastructure and Poverty Reduction-What is the connection?, in ERD Policy Brief Series, Asian Development Bank, Manila https://www.adb.org/sites/default/files/publication/28071/pb013.pdf

Better than Cash Alliance (11 March 2015), Digital payments can empower women, Better than Cash Alliance, New York, https://www.betterthancash.org/news/blogs-stories/digital-payments-can-empower-women

Bossuroy, T., F. Campos, A. Coville, M. Goldstein, G. Roberts and S. Sequeira (2012), "Shape Up and Ship Out? Gender Constraints to Growth and Exporting in South Africa" in Brenton, P., Gamberoni, E. and Sear, C (eds) Women and Trade in Africa: Realizing the Potential, World Bank, Washington

Boudreaux, C. (2011), "Economic Liberalisation in Rwanda's Coffee Sector: A Better Brew for Success", in Yes, Africa Can: Success Stories from a Dynamic Continent, World Bank Publications, Washington D.C., http://siteresources. worldbank.org/AFRICAEXT/Resources/258643-1271798012256/Rwanda-coffee-11.pdf

Brenton, P., C. Bashinge Bucekuderhwa, C. Hossein, S. Nagaki and J-B Ntagoma, (2011), Risky Business: Poor Women CrossBorder Traders in the Great Lakes Region of Africa, in Africa Trade Policy Note 11, World Bank, Washington, DC.

Cervantes-Godoy, D., and J. Dewbre (2010), Economic importance of agriculture for poverty reduction, OECD Publishing, Paris.

De, Prabir (2015), Disentangling transit costs and time in South Asia: Lessons from firms in Bhutan and Nepal importing through Kolkata and Haldia ports, Overseas Development Institute and UKAID, https://www.odi.org/sites/odi.org.uk/ files/odi-assets/publications-opinion-files/10260.pdf

Enhanced Integrated Framework (2016), EIF Project supports efforts to rebuild Vanuatu's vital tourism infrastructure, www.enhancedif.org/en/publication/2015-08/eif-project-supports-efforts-rebuild-vanuatus-vital-tourism-infrastructure

Fan et al. (2002), cited in Ali, Ifzal and Ernesto M. Pernia (2003), Infrastructure and Poverty Reduction-What is the connection?, in ERD Policy Brief Series, Asian Development Bank, Manila https://www.adb.org/sites/default/files/ publication/28071/pb013.pdf

GATF/WEF (2016), The Global Enabling Trade Report 2016, Global Alliance for Trade Facilitation/World Economic Forum, http://www3.weforum.org/docs/WEF GETR 2016 report.pdf

GSMA (2012), Haiti Mobile Money-A Point in Time Case Study, http://www.gsma.com/mobilefordevelopment/ wp-content/uploads/2012/05/Haiti-Mobile-Money.pdf

Hisali, Eria (Makerere University), Trade, employment and gender: the case of Uganda, OECD website, http://www.oecd. org/site/tadicite/48722379.pdf (accessed February 2017) 
Inter-American Development Bank (2008), Unclogging the Arteries, the Impact of Transport Costs on Latin American and Caribbean Trade, Inter-American Development Bank, Washington D.C., https://publications.iadb.org/bitstream/ handle/11319/264/Unclogging\%20the\%20Arteries.pdf?sequence=1

ITU (2016), ICT Facts and Figures 2016, International Telecommunication Union, www.itu.int/en/ITU-D/Statistics/ Documents/facts/ICTFactsFigures2016.pdf

Junko Narimatsu/World Bank (2013), "Leveraging Technology for Disaster Risk Management", World Bank, http://www.worldbank.org/en/news/feature/2013/04/10/leveraging-technology-disaster-risk-management (accessed February 2017)

Mendoza, A., G. Nayyar, and R. Piermartini (2016), Are the poor getting globalised, http://pubdocs.worldbank.org/ en/714181480467902499/1-Piermartini.pdf

Ndip, Alvin Etang (2016), "The anatomy of a mobile phone survey: Lessons from the Listening to Africa project", World Bank, http://blogs.worldbank.org/africacan/the-anatomy-of-a-mobile-phone-survey-lessons-from-the-listeningto-africa-project

Ndung'u, N., A. Morales, and L. Ndirangu (2016), Cashing in on the Digital Revolution, in International Monetary Fund, Finance and Development, Vol. 53, No. 2, http://www.imf.org/external/pubs/ft/fandd/2016/06/ndungu.htm OECD (2006), Outline of Principles of Impact Evaluation for Development in International Workshop on Impact Evaluation for Development, World Bank and DAC Evaluation Network, www.oecd.org/dac/evaluation/dcdndep/interna tionalworkshoponimpactevaluationfordevelopment15november2006-hostedbytheworldbankandthedacevaluationn etwork.htm

OECD (2013), Aid for Trade and Development Results: A Management Framework, The Development Dimension, OECD Publishing, Paris, http://dx.doi.org/10.1787/9789264112537-en

OECD-WTO (2017), aid-for-trade monitoring exercise 2017 (questionnaires) www.oecd.org/aidfortrade/countryprofiles/ Oxford Poverty and Human Development Initiative (2014), Poverty in Rural and Urban Areas, University of Oxford, www.ophi.org.uk/policy/multidimensional-poverty-index/ (Accessed February 2017)

Porter, B., N. Widjaja, and K. Nowacka (2015), Why technology matters for advancing women's financial inclusion, OECD Observer Special offprint, July 2015, http://oecdobserver.org/news/fullstory.php/aid/4970/Why technology matters for advancing women s financial inclusion.html\#sthash.sfPShDBY.dpuf

Suri, T. and W. Jack (2016), The Long-Run Poverty and Gender Impacts of Mobile Money, Science, http://www.microfinancegateway.org/sites/default/files/publication files/new jack and suri paper 1.pdf UN (2012), Committee for Development Policy, Expert Group Meeting Review of the list of Least Developed Countries 16-17 January 2012, http://www.un.org/en/development/desa/policy/cdp/ldc documents/maldives monitoring report 2012.pdf

UNCTAD (2010), Information Economy Report 2010, United Nations Conference on Trade and Development http://unctad.org/en/docs/ier2010 embargo2010 en.pdf

UNDP (2011), Tourism and Poverty Reduction Strategies in the Integrated Framework for LDCs, UNDP, Geneva, http://unwto. org/sites/all/files/pdf/undp discussion paper tourism and poverty reduction strategies in the integrated framework for least developed countries.pdf

United Nations World Tourism Organisation (n.d.), "The Character of Tourism", in Tourism and Poverty Alleviation, website, http://step.unwto.org/content/tourism-and-poverty-alleviation-1 (accessed February 2017). 
Vergara Carmen Gisela (2016), Ensuring greater participation of women in international trade, International Trade Centre, Geneva, http://www.intracen.org/article/Ensuring-greater-participation-of-women-in-international-trade/

WB-WTO (2015), The Role of Trade in Ending Poverty, World Trade Organisation, Geneva.

World Bank (2014), New roads and irrigation systems improve life in Ecuador, http://www.worldbank.org/en/news/ feature/2014/06/04/nuevas-carreteras-y-sistemas-de-riego-mejoran-la-vida-en-ecuador

World Bank (2014b), Key Findings and Recommendations for Government by Bill \& Melinda Gates Foundation and the Better than Cash Alliance in The opportunities of digitising payments, World Bank, http://siteresources.worldbank.org/ EXTGLOBALFIN/Resources/8519638-1332259343991/G20 Report Final Digital payments.pdf

World Bank (2015), Statement by Anabel Gonzales at the Fourth China-WTO Accessions Roundtable: International Economic Cooperation and African Perspectives on the Future of the Multilateral Trading System, http://www.worldbank.org/en/news/speech/2015/12/14/ deepening-african-integration-intra-africa-trade-for-development-and-poverty-reduction

World Bank (2016a), World Development Report 2016: Digital Dividends, World Bank, Washington DC.

World Bank (2016b), Doing Business (database), http://data.worldbank.org/data-catalog/doing-business-database World Bank (2016c), The Logistics Performance Index (database), http://lpi.worldbank.org

World Bank (2017), Trade and Transport Connectivity: Reducing time and cost of cross border trade, in South Asia Regional Integration, World Bank, http://www.worldbank.org/en/programs/south-asia-regional-integration\#3, (accessed February 2017) 


\section{NOTES}

1. The International Development Association is the part of the World Bank that helps the world's poorest countries; 77 countries are eligible for IDA assistance, including 39 in Africa: http://ida.worldbank.org. 



\section{AID-FOR-TRADE COUNTRY PROFILES}

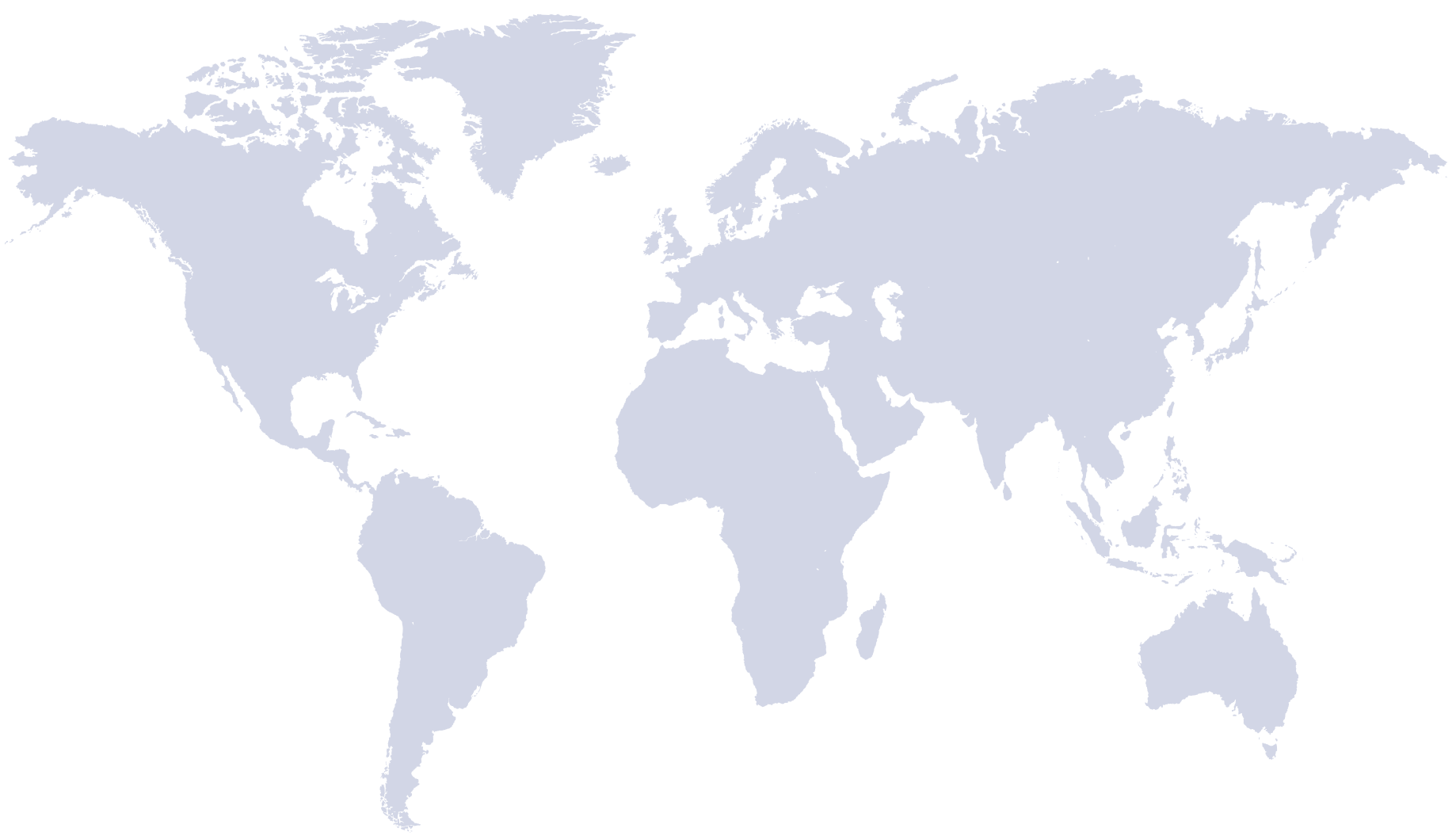





\section{EXPLANATORY NOTES \\ ON AID-FOR-TRADE COUNTRY PROFILES}

The aid-for-trade country profiles provide factual information to stimulate a debate on trends of aid for trade, trade costs, trade performance and development at the country level. The aim is to compare a country's performance in four thematic sections of indicators from 2006 to 2015 and, for selected indicators, against country group benchmarks.

The country profiles are structured according to the results chain framework normally used in project-based development interventions. The results chain framework describes the causal sequence of development interventions based on four main elements: i) inputs and activities produce ii) direct outputs, which in turn lead to iii) intermediate outcomes that contribute to iv) long-term impacts.

The country profiles transpose the idea behind this project-based analytical tool to the macro level and trace a possible causal sequence of aid-for-trade interventions to achieve trade and development objectives. The country profiles therefore present indicators in four sections: A. Development Finance; B. Trade Costs; C. Trade Performance; and D. Development Indicators. Much of aid for trade is aimed at reducing trade costs; lower trade costs increase connectivity and lead to better trade performance in terms of growth and diversification; better trade performance can help improve long-term development indicators, notably through employment creation and poverty alleviation.

The country profiles do not posit a causal link; they do not attempt to test or estimate the causal impact of aid for trade at the macro level. Instead, they give a dynamic perspective on a country's development. In this sense, the sequence traced is one of contribution, not attribution. Where such contribution can be discerned, the country profiles provide ground for further in-depth, country-based research. In this sense, the country profiles contribute to a greater understanding of the important role that aid-for-trade flows play in a country's achievement of the trade and development objectives targeted by these flows.

Most indicators in the country profiles provide a comparison between 2006 and 2015. However, the year coverage is adapted to data availability at the level of both indicators and countries. For a selected number of indicators, comparisons against benchmark groups are shown. The country groups used as benchmarks are least developed countries (LDCs), lower middle income countries (LMICS), upper middle income countries (UMICS) and high income countries (HICS). The country groups are non-overlapping, which means that LDCs are not included in income groups. Zimbabwe, which is a low income country but not an LDC, is benchmarked against LMICs. The country composition of the four country groups differs among indicators according to data availability. The number of countries included in the four groups for a given indicator is provided in the indicator descriptions below.

The country profiles are divided into the following four sections:

\section{A. DEVELOPMENT FINANCE}

Development finance constitutes a vital source of external financing for many developing countries as it comprises inflows of foreign direct investment (FDI), remittances, official development assistance (ODA), and other official flows (OOF). Development finance is used to finance capital investment as well as private and public consumption, which thereby forms the basis for economic growth and development.

This section illustrates how aid-for-trade flows have developed over time, how important they are compared to other flows of development finance and the importance of aid-for-trade for a country compared to other countries. Furthermore, the section shows trends in aid-for-trade disbursements over time at the aggregate level and at the level of sectors and donors. Development finance flows are presented for the periods 2006/08 and 2012/14 (three year averages) and for the year 2015. 


\section{Indicators and sources}

FDI is defined as an investment involving a long-term relationship and reflecting a lasting interest in and control by a resident entity in one economy (foreign direct investor or parent enterprise) of an enterprise resident in a different economy (foreign affiliate). FDI inflows measure the net capital (equity capital, reinvested earnings and intra-company loans) provided by a foreign direct investor to a foreign affiliate. Source: UNCTAD, UNCTADstat.

Remittances comprise personal transfers and compensation of employees. Personal transfers consist of transfers in cash or in kind received by resident households from non-resident households. Compensation of employees refers to the income of border, seasonal, and other short-term workers who are employed in an economy where they are not resident and of residents employed by non-resident entities. Compensation of employees tends to account for a high share of remittances in the case of developing countries which are close to a bigger economy (e.g. Lesotho, Swaziland and Botswana, which border South Africa) or which are characterised by the presence of non-resident institutions (e.g. Afghanistan). Source: World Bank (WB), World Development Indicators.

Official development assistance (ODA) are grants and loans provided by the official sector with the main objective to promote economic development and welfare of developing countries. ODA is concessional in character with a grant element of at least 25 percent (calculated at a discount rate of 10 percent). Aid-for-trade flows are a subset of ODA that fall under the four categories trade policy and regulations, economic infrastructure, building productive capacity and trade-related adjustment. ODA and aid-for-trade flows are reported as gross disbursements. Source: OECD, DAC-CRS Aid Activities Database.

Other official flows (OOF) are transactions by the official sector which do not meet the conditions for eligibility as ODA, either because they are not primarily aimed at development, or because they have a grant element of less than 25 percent. Trade-related OOF are a subset of OOF that fall under the four categories trade policy and regulations, economic infrastructure, building productive capacity and trade-related adjustment. OOF and trade-related OOF flows are reported as gross disbursements. Source: OECD, DAC-CRS Aid Activities Database.

The top three aid-for-trade priorities are based on a ranking of aid-for-trade categories given by countries in selfassessment questionnaires. Source: OECD/WTO Partner Country Questionnaire.

Share of aid for trade in development finance indicates a country's dependence on aid for trade in comparison to other development finance flows. Development finance corresponds to the sum of FDI inflows, remittances, OOF and ODA. For the periods 2006-08 and 2012-14, development finance is calculated as the sum of the three year averages of these four flows. Number of countries included in benchmark groups: LDCs (34), LMICs (30), UMICs (44). Sources: OECD, DAC-CRS Aid Activities Database; UNCTAD, UNCTADstat; WB, World Development Indicators.

Share of aid for trade in gross fixed capital formation indicates the importance of aid for trade for the financing of gross fixed capital formation. Gross fixed capital formation includes land improvements; plant, machinery, and equipment purchases; and the construction of roads, railways, and the like, including schools, offices, hospitals, private residential dwellings, and commercial and industrial buildings. Number of countries included in benchmark groups: LDCs (33), LMICs (27), UMICs (37). Sources: OECD, DAC-CRS Aid Activities Database; WB, World Development Indicators. 


\section{B. TRADE COSTS}

In the results chain, inputs and accompanying activities result in outputs. One of the main objectives of aid-fortrade projects is to reduce trade costs. The trade costs section covers indicators that allow assessing how a country's infrastructure and policy-related trade costs have evolved over time and how high trade costs are in comparison to a benchmark country group.

\section{Indicators and sources}

Tariffs: Import tariffs measure applied most-favoured-nation (MFN) duties calculated either as simple average or as weighted average using import flows at the Harmonized System (HS) six-digit level as weights. The weighted average export tariff faced takes into account preferences and measures the weighted average tariff faced by the country in its top five export markets for agricultural and non-agricultural products, respectively. The share of duty-free exports measures the share of exports reaching these top export markets for agricultural and non-agricultural products dutyfree. Source: WTO, World Tariff Profiles.

Information and Communication Technology (ICT) connectivity (\% of population): Mobile (fixed) broadband subscriptions refer to the percentage of inhabitants with an active mobile (fixed) broadband subscription. Individuals using the internet refer to the percentage of the population using the internet. Source: ITU, World Telecommunication/ ICT Indicators.

Cost and time to trade measure the cost in USD and the time in hours required for documentary and border compliance when an economy imports a standardized shipment of auto parts from its natural import partner or when the economy exports its most important product in value terms (except oil and mining products) to its natural export partner. Documentary compliance captures the cost and time associated with compliance with the documentary requirements of all government agencies of the origin economy, the destination economy and any transit economies. Documentary compliance includes the cost and time for obtaining, preparing, processing, presenting and submitting documents. Border compliance captures the cost and time associated with compliance with the economy's customs regulations and with regulations relating to other mandatory border inspections, for instance regarding sanitary and phytosanitary standards, as well as the cost and time for handling that takes place at its port or border. Number of countries included in benchmark groups: LDCs (45), LMICs (36), UMICs (50), HICs (56). Source: WB, Doing Business.

Logistics performance index (LPI) (1-5): The "Overall LPI" is a perception-based composite indicator of a country's logistics based on six components. These components are efficiency and border clearance ("Customs"), quality of trade and transport infrastructure ("Infrastructure"), ease of arranging competitively priced shipments ("International shipments"), competence and quality of logistics services ("Logistics competence"), ability to track and trace consignments ("Tracking and tracing") and frequency with which shipments reach consignees within scheduled or expected delivery times ("Timeliness"). The index and its components range from 1 to 5 , with a higher score representing better performance. Number of countries included in benchmark groups: LDCs (39), LMICs (28), UMICs (42), HICs (49). Source: WB, Logistics Performance Index.

Competitiveness indicators (1-7): The competitiveness indicators measure the perceptions of business executives regarding the ease of access to loans, the quality of electricity supply, the quality of roads, the quality of port infrastructure and the quality of air transport infrastructure. The ratings range from 1 (low) to 7 (best). Number of countries included in benchmark groups: LDCs (25), LMICs (26), UMICs (36), HICs (50). Source: WEF, Global Competitiveness Index. 
Trade costs (ad valorem, \%): These indicators capture a country's total, intra-regional and extra-regional ad-valorem trade costs in percent. The trade costs measures are calculated as simple averages of bilateral ad valorem trade costs. Given the limited data availability, the number of partners used in the calculation of average trade costs differs across countries. Therefore, the measure is informative regarding a country's evolution of trade costs over time but comparisons between countries should be undertaken with much caution. The bilateral trade costs are derived from observable trade flows representing the geometric mean of international trade costs between two countries relative to domestic trade costs within each country. The intuition of the measure is that if bilateral trade increases relative to domestic trade flows, bilateral trade costs have declined. The database and the bilateral trade cost measure are described in Arvis et al. (2013). To calculate intra- and extra-regional trade costs, trading partners are grouped according to the WTO classifcation into the following regions: Africa, Asia, Commonwealth of Independent States (CIS), Europe, Middle East, North America, South and Central America (including the Caribbean). Source: Author's calculations based on the ESCAP/World Bank Trade Cost Database.

Trade facilitation indicators (0-2): The trade facilitation indicators are composite indicators that measure various dimensions of trade facilitation, most of them closely related to the WTO Trade Facilitation Agreement, on a range from 0 (low) to 2 (best). The country profiles show the following six indicators (out of a total of eleven) for which data coverage is best: Information availability (publication of trade information, including on internet; enquiry points), Advance rulings (prior statements by the administration to requesting traders concerning the classification, origin, valuation method, etc., applied to specific goods at the time of importation; the rules and process applied to such statements), Appeal procedures (the possibility and modalities to appeal administrative decisions by border agencies), Automation (electronic exchange of data; automated border procedures; use of risk management), Procedures (streamlining of border controls; single windows; post-clearance audits; authorised economic operators), Governance and impartiality (customs structures and functions; accountability; ethics policy). Number of countries included in benchmark groups: LDCs (36), LMICS (32), UMICS (43), HICs (51). Source: OECD Trade Facilitation Indicators.

\section{TRADE PERFORMANCE}

Aid for trade interventions aim at improving the trade performance of firms and countries by addressing national supply side constraints to either lower trade costs or improve the productive capacity of firms. This section covers indicators that allow assessing the trade performance of countries in terms of value, growth, structure and diversification.

\section{Indicators and sources}

Trade to GDP ratio is estimated as an economy's total trade of goods and commercial services (exports + imports, balance of payments basis) divided by its GDP. Source: WTO Secretariat.

Commercial services as \% of total exports (imports) refers to the share of commercial services in a country's exports (imports) of commercial services and goods. Trade flows are measured by balance of payments statistics according to the principles of the sixth edition of the Balance of Payments Manual (BPM6). Source: WTO Secretariat.

Non-fuel intermediates (\% of merchandise exports [imports]) refers to the share of non-fuel intermediate goods in merchandise exports (imports) as measured by customs statistics. Intermediates are classified according to the UN Broad Economic Categories (BEC) classification. Fuel products are not classified as intermediates but are included in total merchandise exports. Source: UN Comtrade.

Trade flows (billion current US\$) provide exports and imports of goods and commercial services as measured by balance of payment statistics according to the principles of BPM6. Balance of payment statistics cover transactions between residents of a country and non-residents involving a change of ownership. Source: WTO Secretariat. 
Number of products and markets: The numbers of exported and imported products and the numbers of export and import markets provide simple measures of product and market diversification, respectively. The maximum number of markets is 237 while the maximum number of products, defined at the Harmonized System (HS) 2002 4-digit level, is 1,245. Source: Author's calculations based on UN Comtrade data.

Hirschman-Herfindahl $\mathbf{( H H )}$ concentration indices: The $\mathrm{HH}$ concentration indices measure the concentration, or diversification, of a country's trade in terms of either products or markets. The HH export (import) product concentration index is calculated as the sum of squared product shares in a country's exports (import) and then normalised to lie between zero and one. $\mathrm{HH}$ market concentration indices are calculated analogously. $\mathrm{HH}$ export and import product concentration indices with scores close to zero indicate a diversified, i.e. equally distributed, product portfolio and scores close to one indicate high concentration in a few products. Analogously, in the case of $\mathrm{HH}$ indices of export and import market concentration scores close to zero indicate that trade is diversified, i.e. equally distributed, across markets and scores close concentration on a few markets. It should be noted that the $\mathrm{HH}$ indices inform only about the distribution of trade but not about the underlying numbers of products and markets. The assessment of, for instance, export diversification should therefore take into account both the number of exported products and export markets and the $\mathrm{HH}$ indices indicating how equally distributed trade is across these products and markets. Source: Author's calculations based on UN Comtrade data.

Structure of merchandise trade provides a breakdown of merchandise exports and imports by main commodity groups according to the WTO International Trade Statistics (ITS) definitions: agricultural products refer to food (SITC Rev. 3 sections 0, 1, 4 and division 22) and raw materials (SITC Rev. 3 divisions 21, 23, 24, 25 and 26). Fuels and mining products include ores and other minerals; fuels and non-ferrous metals. Manufactures refer to iron and steel, chemicals, other semi-manufactures, machinery and transport equipment, textiles, clothing and other consumer goods. Shares sum up to 100 percent since trade flows that are not classified in any of those product groups, for instance non-monetary gold, are not taken into account in the calculation. Source: WTO Secretariat.

Structure of services trade shows the shares of travel services, transport services, goods-related services and other commercial services in commercial services exports and imports. Goods-related services, inter alia, include manufacturing activities on a contract basis such as processing, assembly, labelling and packing ("manufacturing services on physical inputs owned by others"). Other commercial services refer to communication, construction, insurance, financial, computer, information, other business, cultural and recreational services, and royalties and license fees. Services trade is measured by balance of payments statistics according to the principles of BPM6. Source: WTO Secretariat.

Top 5 markets for merchandise exports and imports (\%) indicate a country's top five export and import markets as recorded by customs statistics. Trade shares with EU member states are shown at the national level according to the national concept, which can deviate from data harmonized according to the community concept. Unspecified origins or destinations (areas n.e.s., bunkers and free zones) are not shown if they are among the top 5 markets. Source: UN Comtrade.

Top 5 merchandise imports and exports (\%) refer to the percentage shares of a country's top five export and import products as recorded by customs statistics. Products are measured in terms of the Standard International Trade Classification, Rev.3 (SITC Rev. 3). Source: UN Comtrade. 


\section{DEVELOPMENT INDICATORS}

Aid for trade eventually aims to achieve long-term development impacts through increased participation of countries in international trade. This section describes trends in development indicators related to human and economic development, including poverty and inequality.

\section{Indicators and sources}

Unemployment (\% of total labour force) refers to the share of the labour force that is without work but available for and seeking employment. The unemployment rates are harmonized estimates of the International Labour Organization (ILO) allowing comparisons across countries and over time. Source: ILO, ILOSTAT.

Female labour force participation rate (\%) captures to what extent women participate in the labour market. The indicator measures the proportion of a country's female population aged 15 and older that engages actively in the labour market, either by working or looking for work. Source: ILO, ILOSTAT.

ODA (\% of gross national income): The share of net ODA in gross national income (GNI) indicates to what extent a country is dependent on development assistance. Source: OECD, DAC-CRS Aid Activities Database.

Import duties collected (\% of tax revenue): The share of import duties in tax revenue indicates to what extent a country is dependent on import duties in order to finance its government budget. Source: WB, World Development Indicators.

Total debt service (\% of total exports): Total debt service is the sum of principal repayments and interest paid on longterm debt, interest paid on short-term debt, and repayments (repurchases and charges) to the IMF. Both public and private external debt is included. External indebtedness affects a country's creditworthiness and investor perceptions. The share of total debt service to total exports helps assess the sustainability of a country's debt service obligations, in particular regarding a countries' ability to obtain foreign exchange through exports. Source: WB, World Development Indicators.

Human Development Index (HDI): The HDI ranges from zero (minimum level of development) to one (maximum level of development) summarising the three basic development dimensions health, education and living standard. Source: United Nations Development Programme (UNDP), International Human Development Indicators: Human Development Index.

GDP per capita, PPP (constant 2011 international \$): GDP per capita is converted to international dollars using purchasing power parity rates. An international dollar has the same purchasing power over GDP as the U.S. dollar has in the United States. Number of countries included in benchmark groups: LDCs (44), LMICs (34), UMICS (48), HICs (54). Source: WB, World Development Indicators.

Economic structure: The development of a country's economic structure is captured by the shares of agriculture, industry and services in GDP in 2006 and 2015. Source: WB, World Development Indicators.

Poverty: Population living below $\$ 1.90$ (\$3.10) a day measures the percentage of the population living on less than $\$ 1.90$ (\$3.10) a day at 2011 international prices. Source: WB, World Development Indicators.

Inequality: Income held by lowest $20 \%(40 \%)$ is the percentage share of income that accrues to the subgroups of population indicated by the respective quintiles. Source: WB, World Development Indicators.

\section{Legend:}

"-" Not applicable

"..." Data not available or not reported 


\section{REFERENCES}

Arvis, J. F., Y. Duval, B. Shepherd and C. Utoktham (2013), "Trade costs in the developing world: 1995-2010", World Bank Policy Research Working Paper 6309. 
Aid, Trade and Development Indicators for Antigua and Barbuda

\section{A. DEVELOPMENT FINANCE}

\begin{tabular}{lrrrc}
$\begin{array}{l}\text { EXTERNAL FINANCING INFL OWS } \\
\text { (million current USD) }\end{array}$ & $\mathbf{2 0 0 6 / 0 8}$ & $\mathbf{2 0 1 2 / 1 4}$ & $\mathbf{2 0 1 5}$ & $\mathbf{\Delta : 0 6 / 0 8 - 1 5}$ \\
FDl inflows & 287.5 & 131.0 & 154.1 & $-46 \%$ \\
\hline Remittances & 20.6 & 21.0 & 21.8 & $5 \%$ \\
\hline Other official flows (00F) & 0.0 & 0.7 & 42.2 & - \\
\hline of which trade-related 00F & 0.0 & 0.0 & 0.0 & - \\
\hline Official Development Assistance (ODA) & 3.9 & 2.3 & 2.7 & $-30 \%$ \\
\hline of which Aid for Trade & 0.9 & 0.5 & 0.6 & $-32 \%$ \\
\hline
\end{tabular}

Sources: UNCTAD, UNCTADstat; WB, World Development Indicators; OECD,

DAC-CRS Aid Activities Database

\section{TOP 3 AfT PRIORITIES}

\begin{tabular}{|l|l|l|l|l|l|}
\hline $\mathbf{1}$ & Regional integration & $\mathbf{2}$ & Transport infrastructure & $\mathbf{3}$ & Network infrastructure \\
\hline
\end{tabular}

Source: OECD/WTO Partner Questionnaire

SHARE OF AfT IN DEVELOPMENT FINANCE AND FIXED CAPITAL FORMATION (\%)

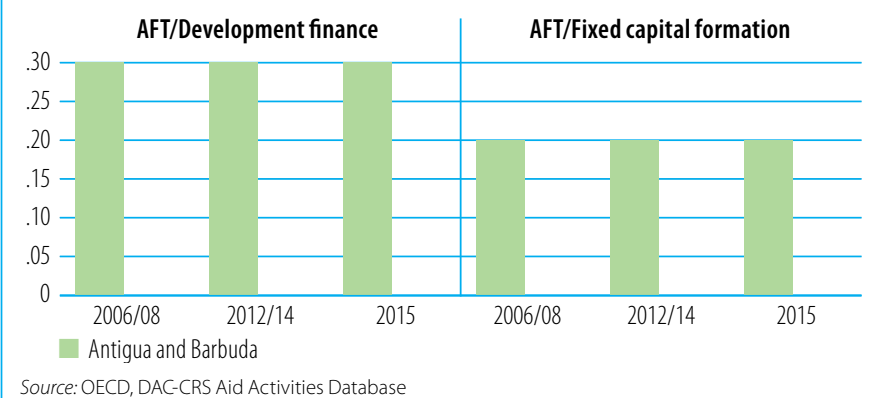

AfT DISBURSEMENTS: TOP DONORS (million current USD)

\begin{tabular}{lrr|lrc}
$\mathbf{2 0 0 6 / 0 8}$ & value & $\%$ & $\mathbf{2 0 1 5}$ & value & $\%$ \\
Japan & 0.9 & 100 & Japan & 0.5 & 84 \\
\hline & & & Global Environment Facility & 0.1 & 16 \\
\hline & & & & \\
\hline & & \multicolumn{3}{|l}{} \\
\hline
\end{tabular}

Source: OECD, DAC-CRS Aid Activities Database

AfT DISBURSEMENTS BY SECTOR (million current USD)

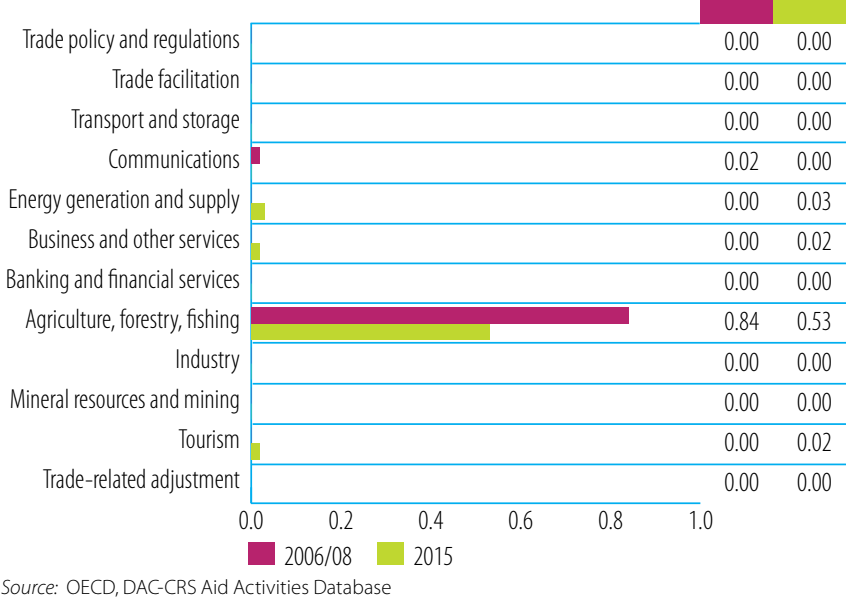

\section{B. TRADE COSTS}

\begin{tabular}{lrc} 
INDICATOR & 2006 & $\mathbf{2 0 1 5}$ \\
Tariffs (\%) & 9.7 & 9.9 \\
\hline Imports: simple avg. MFN applied & $\ldots$ & 13.1 \\
\hline Imports: weighted avg. MFN applied (2006-2014) & 0.8 & 10.7 \\
\hline Exports: weighted avg. faced (2005-2014) & 96.7 & 22.4 \\
\hline Exports: duty free (value in \%) (2005-2014) & & \\
\hline ICT connectivity (\% of population) & 0.0 & 33.8 \\
\hline Mobile broadband subscriptions (2008-2015) & 1.8 & 13.1 \\
\hline Fixed broadband subscriptions & 30.0 & 65.2 \\
\hline Individuals using the internet & &
\end{tabular}
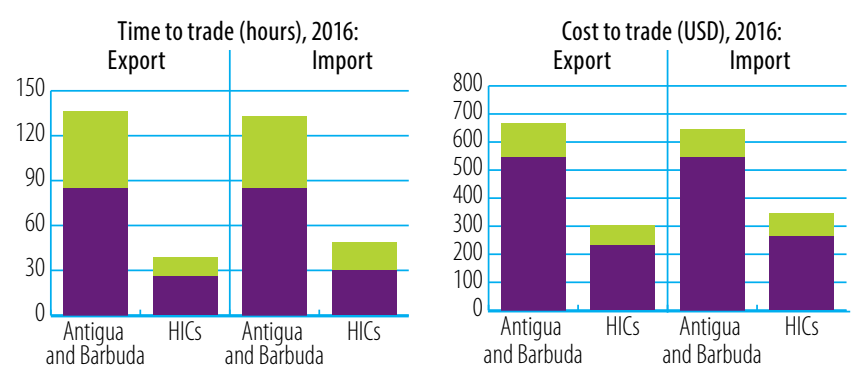

Border compliance Documentary compliance

Source: WB, Doing Business

\section{LOGISTICS PERFORMANCE INDICES (LPI) (1-5)}

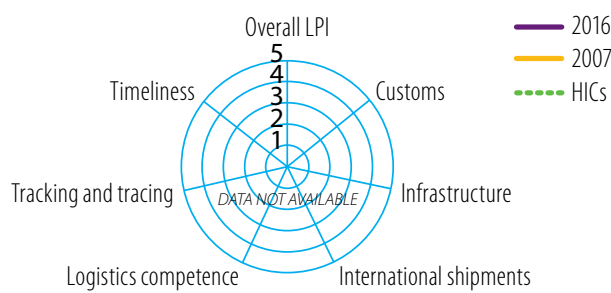

Source: WB Logistics Performance Index (LPI)

GLOBAL COMPETITIVENESS INDICATORS (1-7)

\begin{tabular}{|c|c|c|c|c|c|c|c|c|c|}
\hline \multicolumn{2}{|c|}{ Access to loans } & \multicolumn{2}{|c|}{ Electricity supply } & \multicolumn{2}{|l|}{ Roads } & \multicolumn{2}{|c|}{ Port infrastructure } & \multicolumn{2}{|c|}{ Air transport infrastructure } \\
\hline \multirow{2}{*}{\multicolumn{10}{|c|}{6}} \\
\hline & & & & & & & & & \\
\hline \multicolumn{2}{|c|}{ DATA NOT AVAILABLE } & \multicolumn{2}{|c|}{ DATA NOT AVAILABLE } & \multicolumn{2}{|c|}{ DATANOT AVAILABLE } & \multicolumn{2}{|c|}{ DATA NOT AVAILABLE } & \multicolumn{2}{|c|}{ DATANOT AVAILABLE } \\
\hline \\
\hline \\
\hline $\begin{array}{rr}2006 \quad 2016 \\
\text { Antigua and Barbuda }\end{array}$ & $\begin{array}{l}2016 \\
\text { HICS }\end{array}$ & $\begin{array}{r}2006 \quad 2016 \\
\text { Antigua and Barbuda }\end{array}$ & $\begin{array}{l}2016 \\
\text { HICs }\end{array}$ & $\begin{array}{rr}2006 & 2016 \\
\text { Antigua and Barbuda }\end{array}$ & $\begin{array}{l}2016 \\
\text { HICS }\end{array}$ & $\begin{array}{rr}2006 \quad 2016 \\
\text { Antigua and Barbuda }\end{array}$ & $\begin{array}{l}2016 \\
\text { HICS }\end{array}$ & $\begin{array}{cc}2006 & 2016 \\
\text { Antigua and Barbuda }\end{array}$ & $\begin{array}{l}2016 \\
\text { HICS }\end{array}$ \\
\hline
\end{tabular}

TRADE FACILITATION INDICATORS, 2017 (0-2)

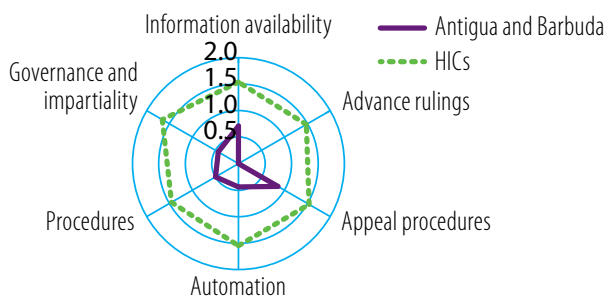

Source: OECD Trade Facilitation Indicators
TRADE COSTS (ad-valorem, \%)

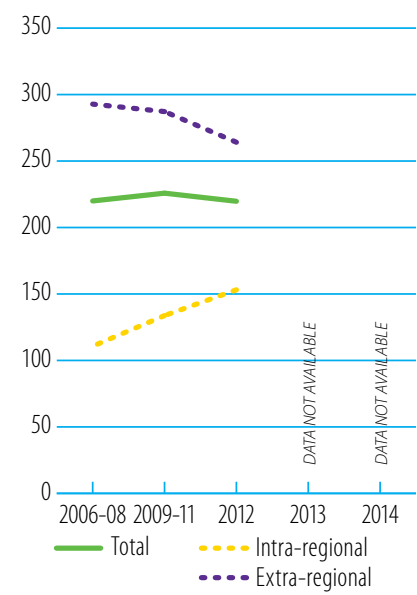

Source: ESCAP-WB Trade Cost Database Note: Number of partners used in the calculation of average trade costs: total (10), intra-regional (4), extra-regional (6) 


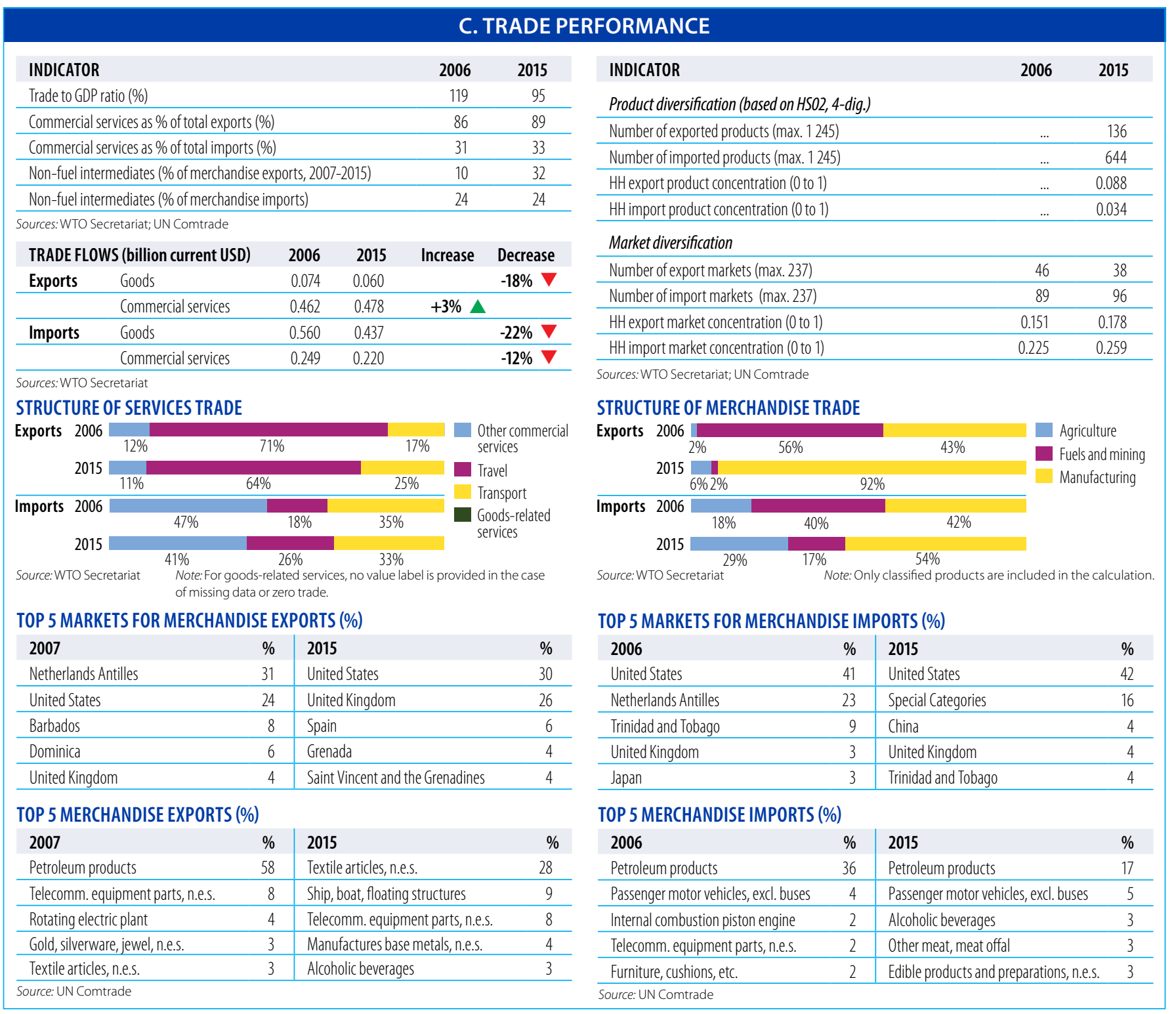

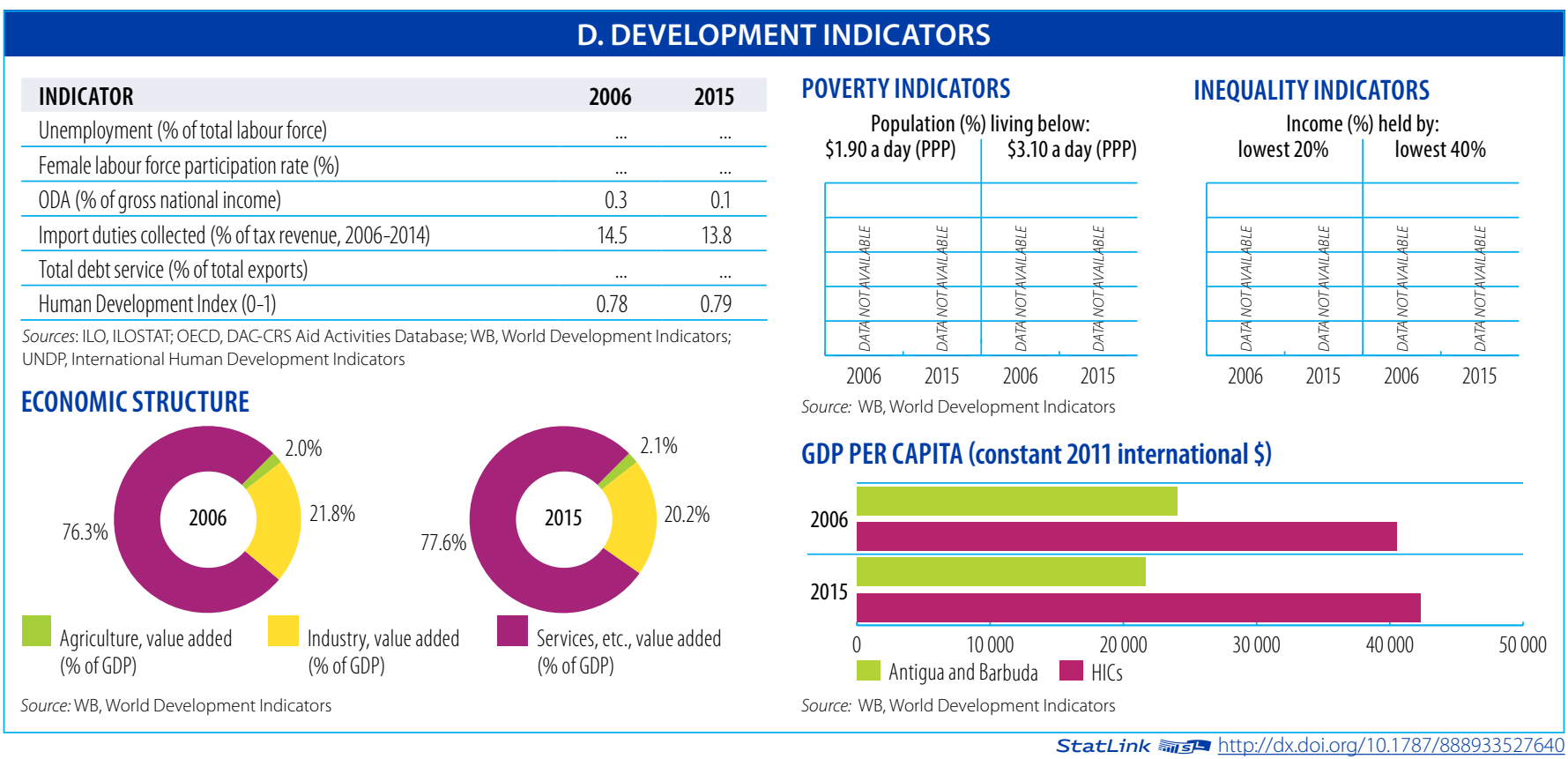




\section{BANGLADESH}

Aid, Trade and Development Indicators for Bangladesh

\section{A. DEVELOPMENT FINANCE}

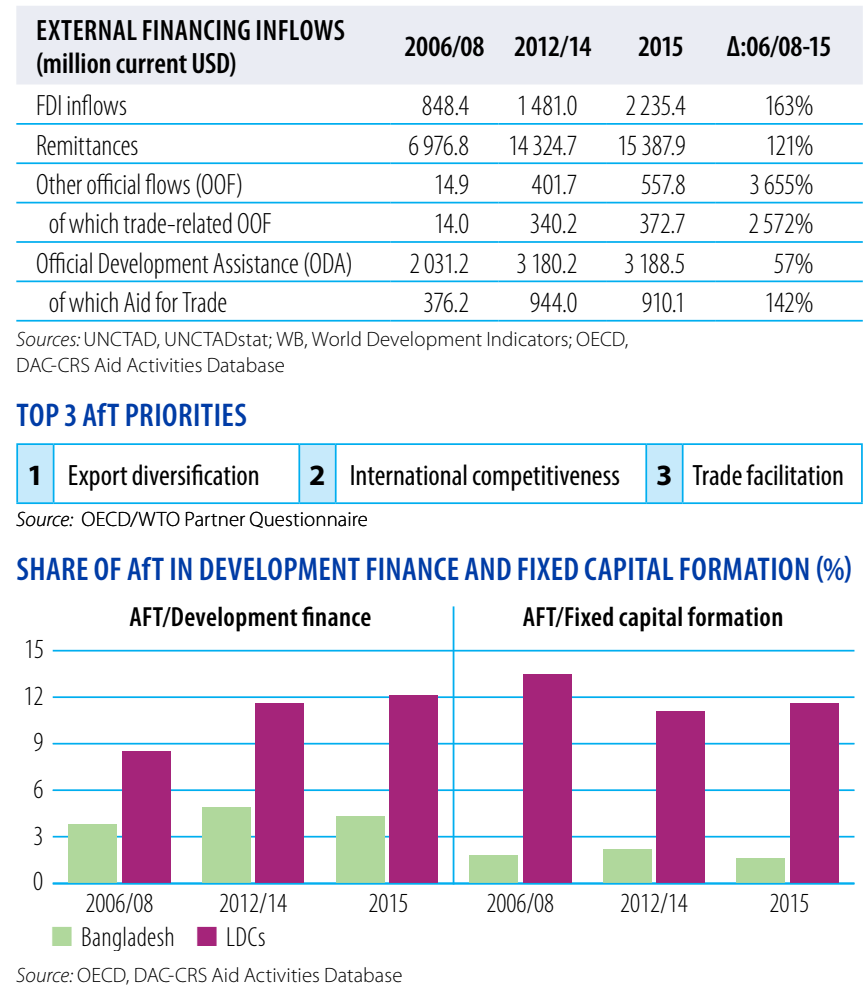

AfT DISBURSEMENTS: TOP DONORS (million current USD)

\begin{tabular}{lcc|lcc}
$\mathbf{2 0 0 6 / 0 8}$ & value & $\%$ & $\mathbf{2 0 1 5}$ & value & $\%$ \\
IDA & 233.8 & 62 & Japan & 359.5 & 40 \\
\hline United Kingdom & 40.1 & 11 & IDA & 292.4 & 32 \\
\hline Germany & 21.5 & 6 & AsDB Special Funds & 88.8 & 10 \\
\hline Denmark & 16.6 & 4 & United States & 50.6 & 6 \\
\hline Japan & 14.1 & 4 & Korea & 35.2 & 4 \\
\hline
\end{tabular}

Source: OECD, DAC-CRS Aid Activities Database

AfT DISBURSEMENTS BY SECTOR (million current USD)

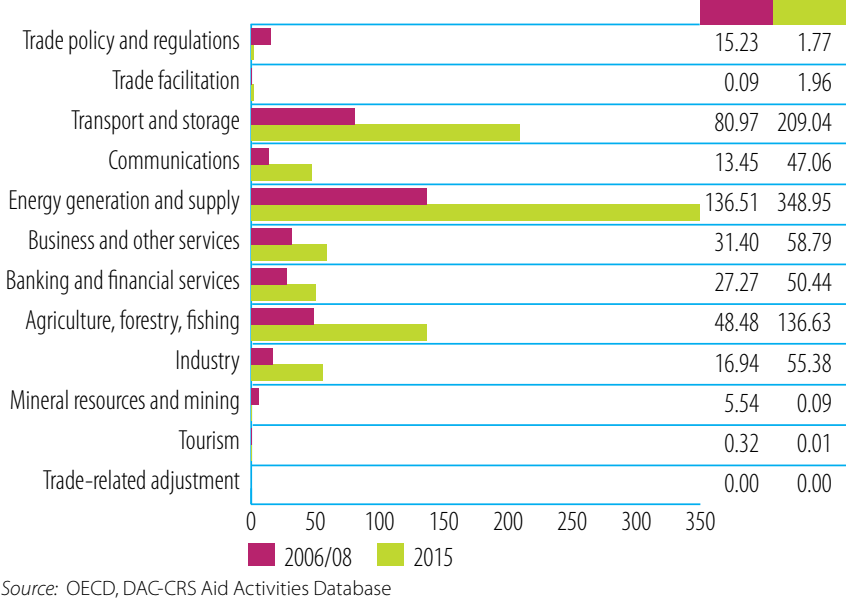

\section{B. TRADE COSTS}

\begin{tabular}{lrc} 
INDICATOR & 2006 & 2015 \\
Tariffs (\%) & & \\
\hline Imports: simple avg. MFN applied & 15.2 & 13.9 \\
\hline Imports: weighted avg. MFN applied & $\ldots$. & $\ldots$ \\
\hline Exports: weighted avg. faced (2005-2014) & 4.9 & 3.4 \\
\hline Exports: duty free (value in \%) (2005-2014) & 69.3 & 78.5 \\
\hline ICT connectivity (\% of population) & $\ldots$ & \\
\hline Mobile broadband subscriptions & $\ldots .0$ & 13.5 \\
\hline Fixed broadband subscriptions (2007-2015) & 2.4 \\
\hline Individuals using the internet & 1.0 & 14.4 \\
\hline Sources: WTO, World Tariff Profiles; ITU, World Telecommunication/ICT Indicators &
\end{tabular}
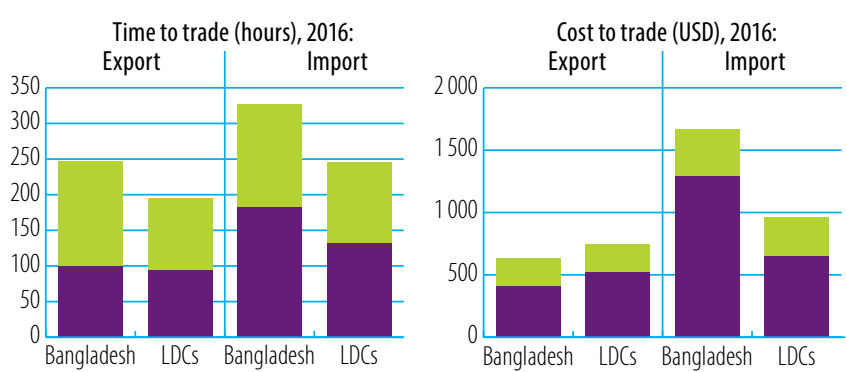

Border compliance Documentary compliance

Source: WB, Doing Business

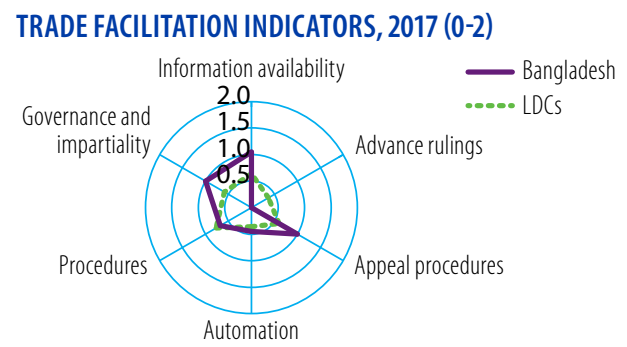

Source: OECD Trade Facilitation Indicators

Source: WB Logistics Performance Index (LPI)

GLOBAL COMPETITIVENESS INDICATORS (1-7)

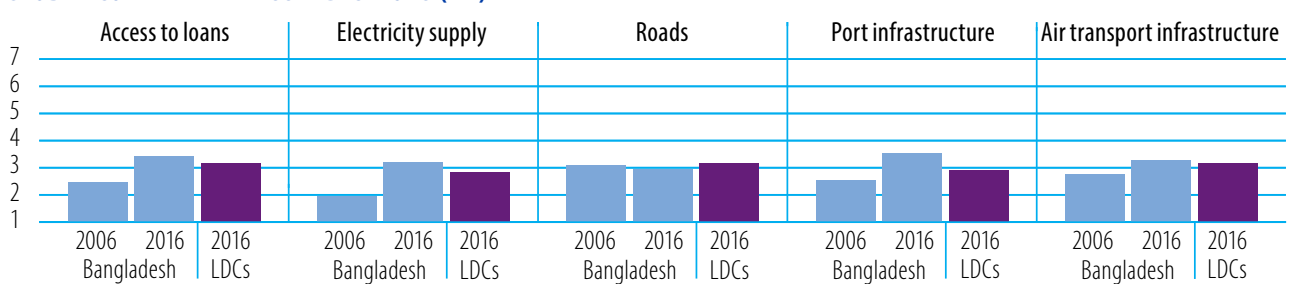

Source: WEF Global Competitiveness Index
TRADE COSTS (ad-valorem, \%)

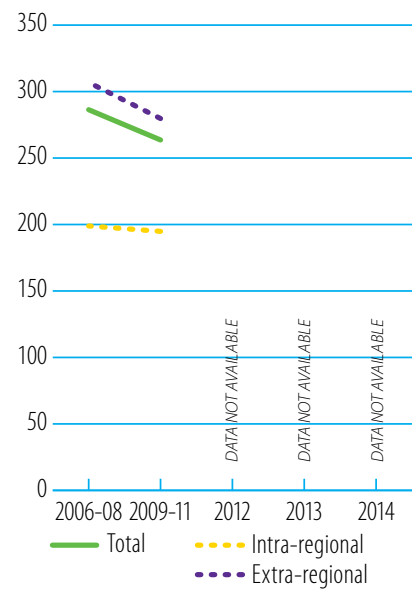

Source: ESCAP-WB Trade Cost Database

Note: Number of partners used in the

calculation of average trade costs: total (100)

intra-regional (19), extra-regional (81) 


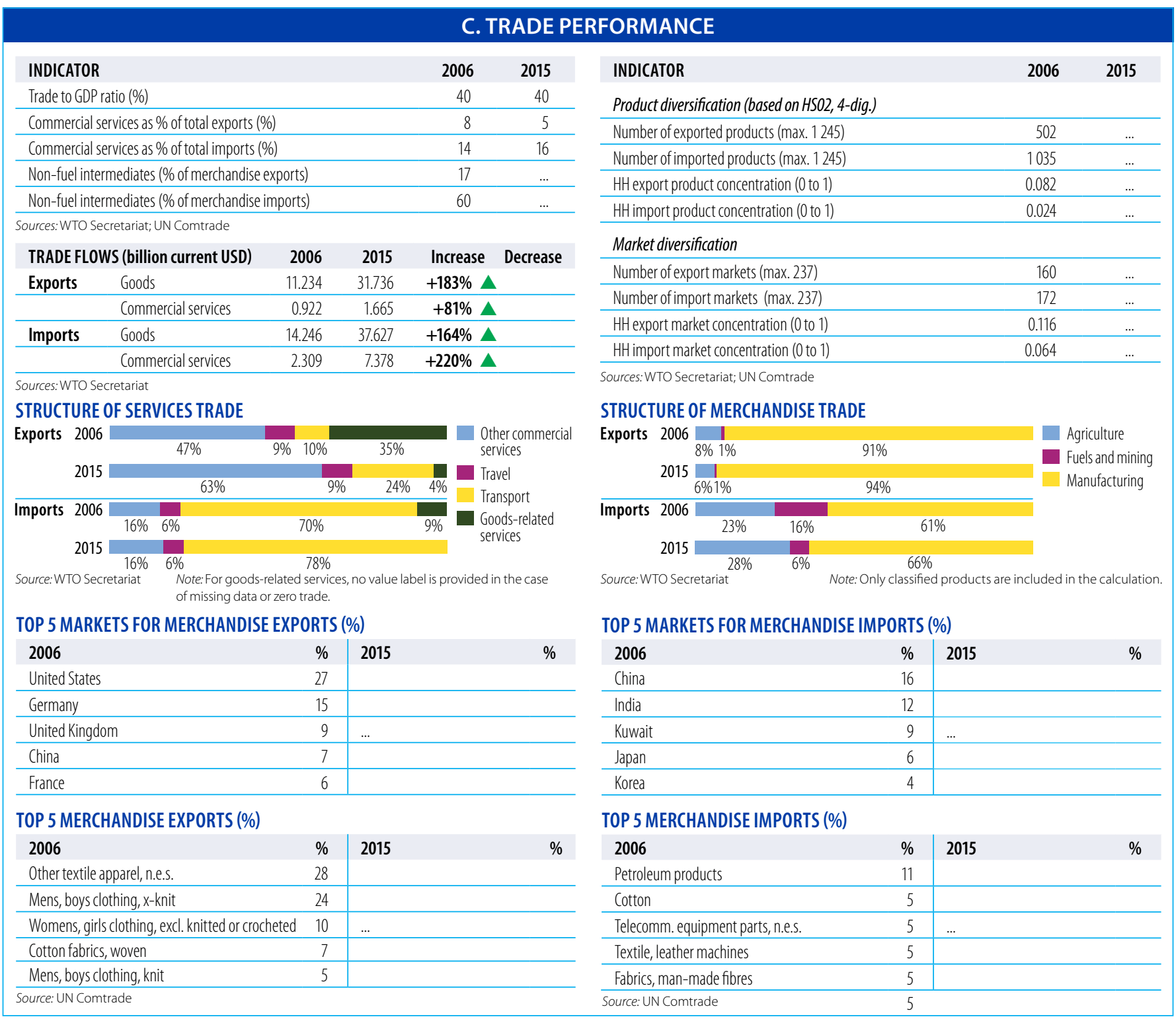

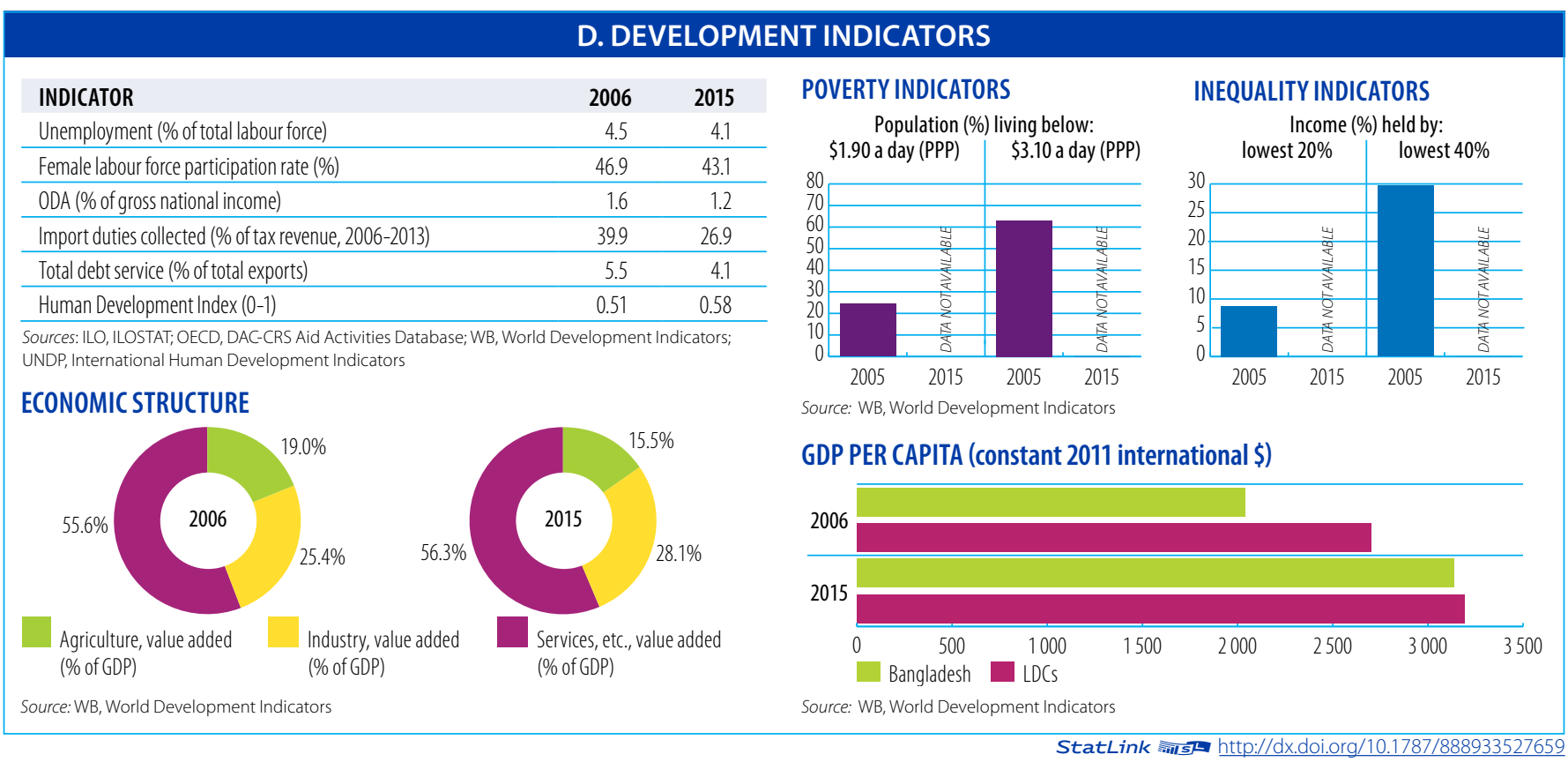




\section{BARBADOS}

Aid, Trade and Development Indicators for Barbados

\section{A. DEVELOPMENT FINANCE}

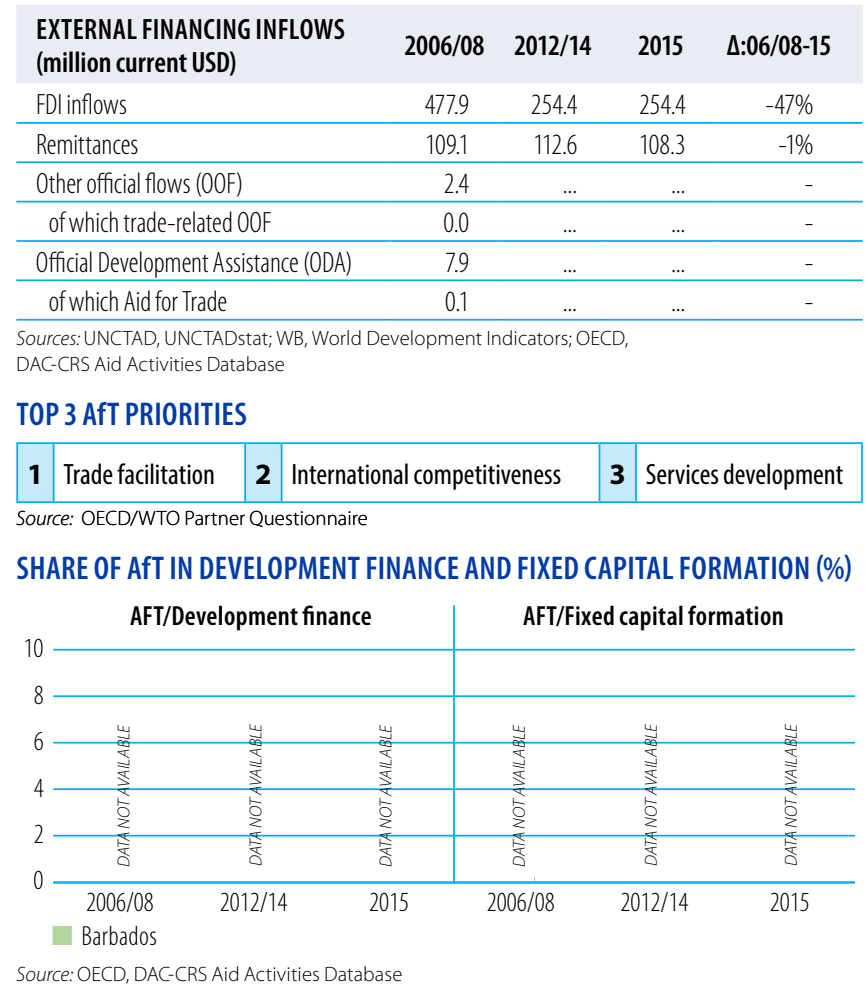

AfT DISBURSEMENTS: TOP DONORS (million current USD)

\begin{tabular}{lrr|ll}
$2006 / 08$ & value & $\%$ & 2015 & value \\
United States & 0.0 & 51 & & \\
\hline Japan & 0.0 & 47 & & \\
\hline Korea & 0.0 & 2 & \\
\hline & & & \\
\hline
\end{tabular}

Source: OECD, DAC-CRS Aid Activities Database

AfT DISBURSEMENTS BY SECTOR (million current USD)

\begin{tabular}{|c|c|c|c|c|c|}
\hline Trade policy and regulations & & & & 0.00 & 0.00 \\
\hline Trade facilitation & & & ש & 0.02 & 0.00 \\
\hline Transport and storage & 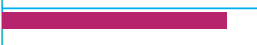 & & & 0.01 & 0.00 \\
\hline Communications & 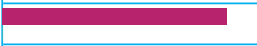 & & & 0.01 & 0.00 \\
\hline Energy generation and supply & & & & 0.00 & 0.00 \\
\hline Business and other services & & & & 0.00 & 0.00 \\
\hline Banking and financial services & & & & 0.00 & 0.00 \\
\hline Agriculture, forestry, fishing & 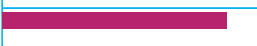 & & & 0.01 & 0.00 \\
\hline Industry & & & & 0.00 & 0.00 \\
\hline Mineral resources and mining & & & & 0.00 & 0.00 \\
\hline Tourism & ב" & & & 0.01 & 0.00 \\
\hline Trade-related adjustment & & & & 0.00 & 0.00 \\
\hline & $0.005 \quad 0.010$ & 0.015 & 0.020 & & \\
\hline
\end{tabular}

\section{B. TRADE COSTS}

\begin{tabular}{lcc} 
INDICATOR & 2006 & 2015 \\
$\begin{array}{l}\text { Tariffs (\%) } \\
\text { Imports: simple avg. MFN applied (2006-2013) }\end{array}$ & 13.5 & 10.7 \\
\hline Imports: weighted avg. MFN applied (2006-2013) & $\ldots$. & 14.2 \\
\hline Exports: weighted avg. faced (2005-2014) & 0.3 & 1.1 \\
\hline Exports: duty free (value in \%) (2005-2014) & 97.8 & 93.0 \\
\hline ICT connectivity (\% of population) & 0.0 & \\
\hline Mobile broadband subscriptions (2008-2015) & 14.1 & 27.2 \\
\hline Fixed broadband subscriptions & 55.3 & 76.1 \\
\hline Individuals using the internet
\end{tabular}
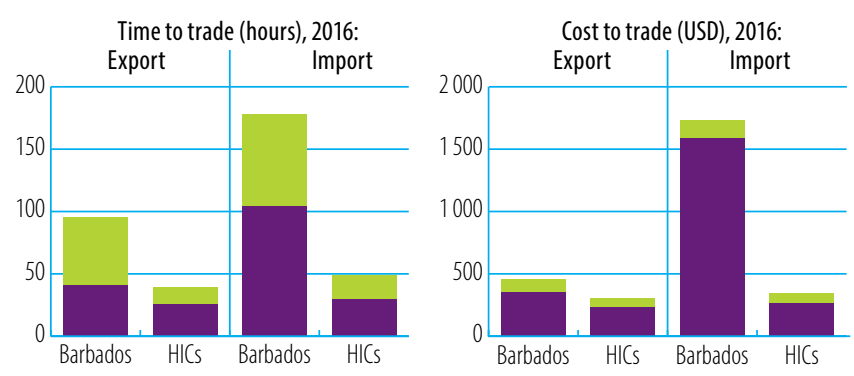

Sources: WTO, World Tariff Profiles; ITU, World Telecommunication/ICT Indicators

LOGISTICS PERFORMANCE INDICES (LPI) (1-5)

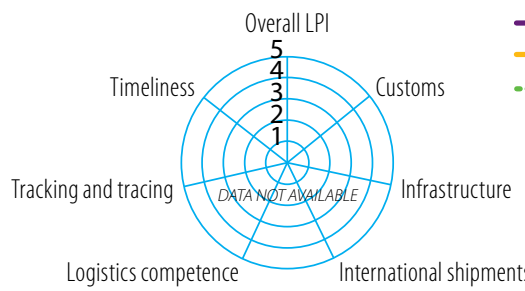

Logistics competence

$$
\text { International shipments }
$$

Source: WB Logistics Performance Index (LPI)

\section{GLOBAL COMPETITIVENESS INDICATORS (1-7)}

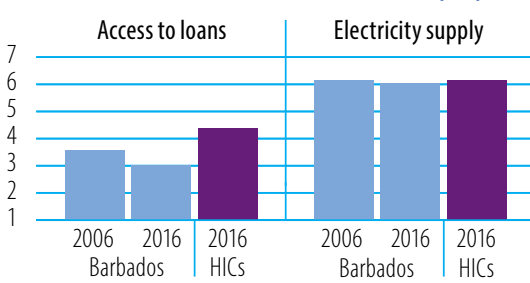

$$
\begin{array}{r}
2016 \\
2007 \\
\ldots \text { HICS }
\end{array}
$$

\section{TR}

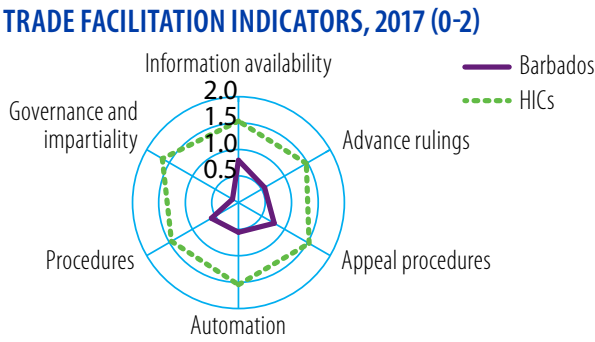

Source: OECD Trade Facilitation Indicators
Border compliance Documentary compliance Source: WB, Doing Business 


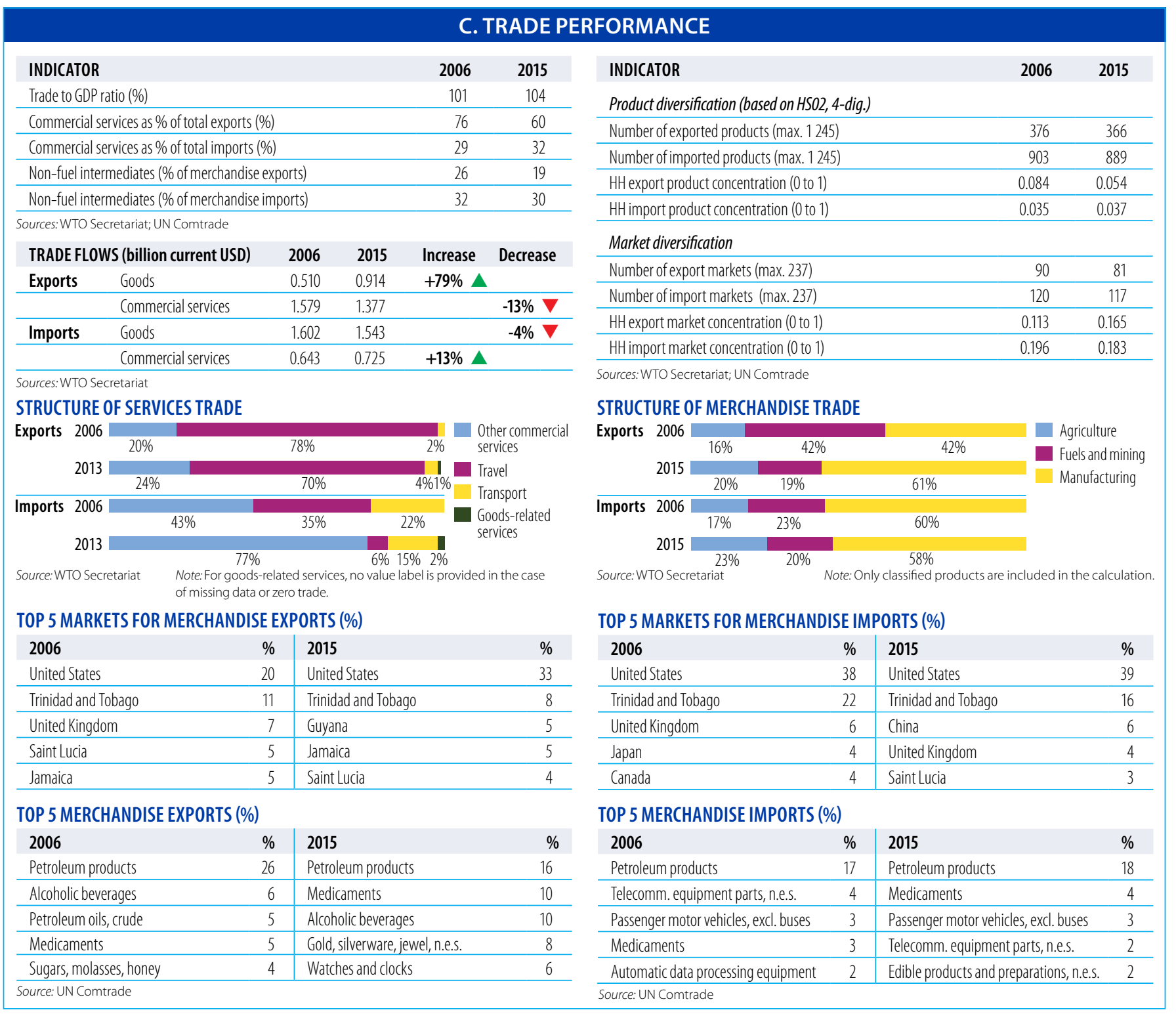

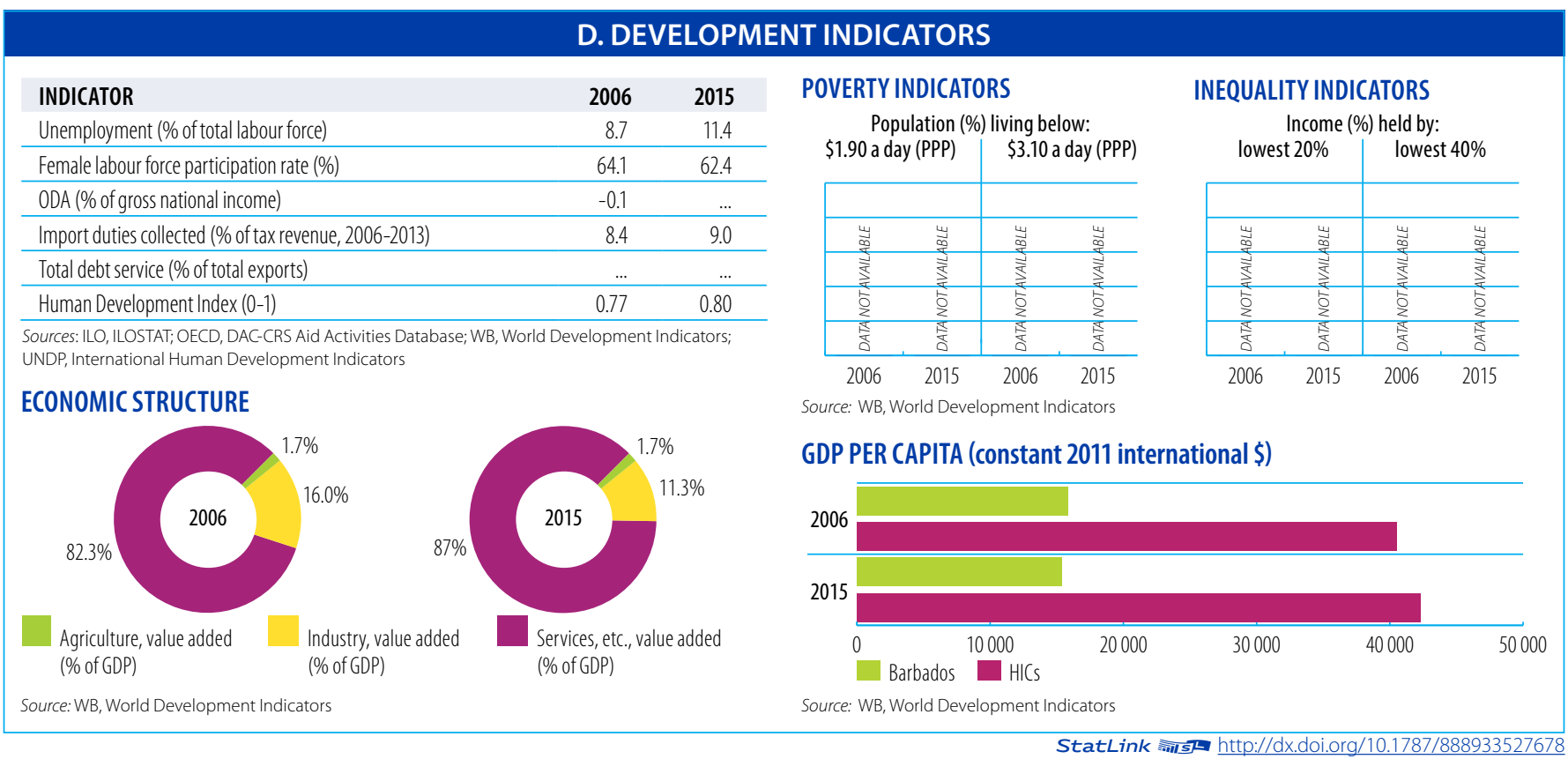


Aid, Trade and Development Indicators for Belize

\section{A. DEVELOPMENT FINANCE}

\begin{tabular}{lrrrc}
$\begin{array}{l}\text { EXTERNAL FINANCING INFL OWS } \\
\text { (million current USD) }\end{array}$ & $\mathbf{2 0 0 6 / 0 8}$ & $\mathbf{2 0 1 2 / 1 4}$ & $\mathbf{2 0 1 5}$ & $\mathbf{\Delta : 0 6 / 0 8 - 1 5}$ \\
\hline FDl inflows & 140.5 & 145.7 & 64.6 & $-54 \%$ \\
\hline Remittances & 71.1 & 76.9 & 84.7 & $19 \%$ \\
\hline Other official flows (00F) & 4.7 & 12.9 & 27.4 & $483 \%$ \\
\hline of which trade-related 00F & 0.0 & 2.8 & 3.8 & $63123 \%$ \\
\hline Official Development Assistance (ODA) & 14.3 & 39.0 & 34.6 & $142 \%$ \\
\hline of which Aid for Trade & 6.1 & 17.4 & 10.8 & $77 \%$ \\
\hline
\end{tabular}

Sources: UNCTAD, UNCTADstat; WB, World Development Indicators; OECD,

DAC-CRS Aid Activities Database

\section{TOP 3 AfT PRIORITIES}

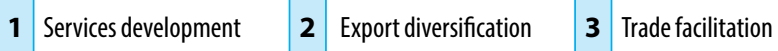
Source: OECD/WTO Partner Questionnaire

SHARE OF AfT IN DEVELOPMENT FINANCE AND FIXED CAPITAL FORMATION (\%)

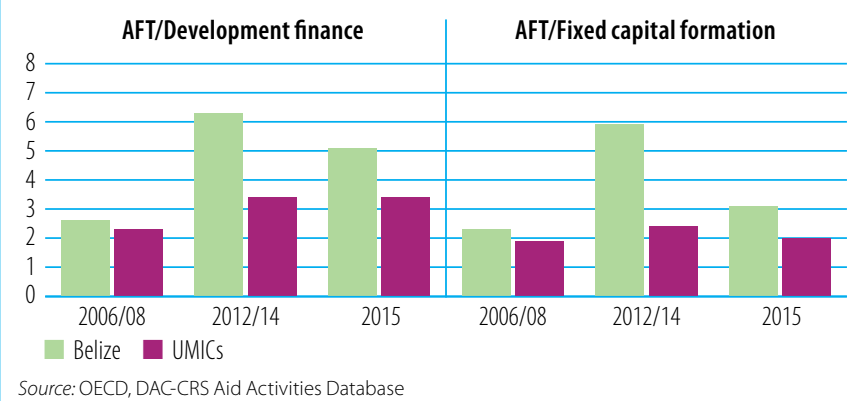

AfT DISBURSEMENTS: TOP DONORS (million current USD)

\begin{tabular}{lrr|lrr} 
2006/08 & value & $\%$ & 2015 & value & $\%$ \\
EU Institutions & 5.8 & 95 & EU Institutions & 8.1 & 75 \\
\hline Japan & 0.2 & 4 & Kuwait (KFAED) & 0.7 & 7 \\
\hline Canada & 0.0 & 1 & OPEC Fund for International Development & 0.5 & 5 \\
\hline Korea & 0.0 & 0 & Inter-American Development Bank & 0.4 & 4 \\
\hline Austria & 0.0 & 0 & IDBSpecial Fund & 0.4 & 4 \\
\hline Source: OECD, DAC-CRS Aid Activities Database & &
\end{tabular}

AfT DISBURSEMENTS BY SECTOR (million current USD)

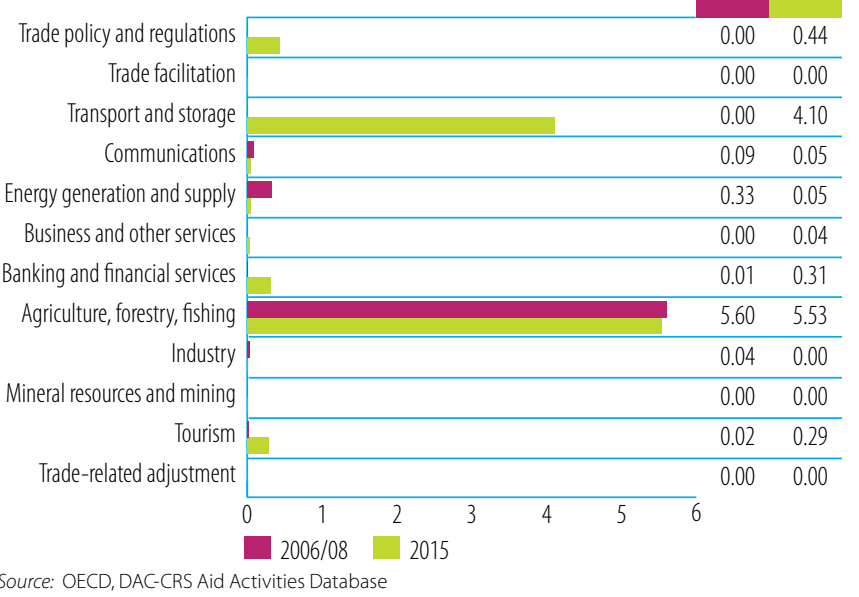

\section{B. TRADE COSTS}

\begin{tabular}{lcc} 
INDICATOR & 2006 & $\mathbf{2 0 1 5}$ \\
Tariffs (\%) & 10.8 & 10.9 \\
\hline Imports: simple avg. MFN applied & $\ldots$ & 13.4 \\
\hline Imports: weighted avg. MFN applied (2006-2014) & 16.2 & 1.9 \\
\hline Exports: weighted avg. faced (2005-2014) & 63.5 & 89.7 \\
\hline Exports: duty free (value in \%) (2005-2014) & & \\
\hline ICT connectivity (\% of population) & $\ldots$ & 30.2 \\
\hline Mobile broadband subscriptions & 2.6 & 2.9 \\
\hline Fixed broadband subscriptions & 24.0 & 41.6 \\
\hline Individuals using the internet & &
\end{tabular}
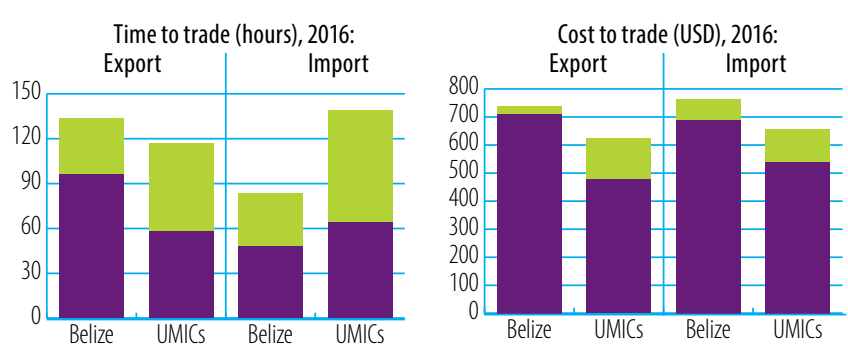

Border compliance Documentary compliance Source: WB, Doing Business
LOGISTICS PERFORMANCE INDICES (LPI) (1-5)

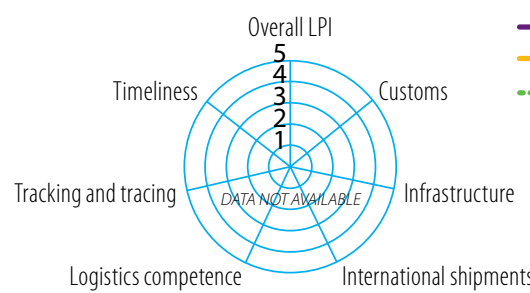

Source: WB Logistics Performance Index (LPI)

GLOBAL COMPETITIVENESS INDICATORS (1-7)

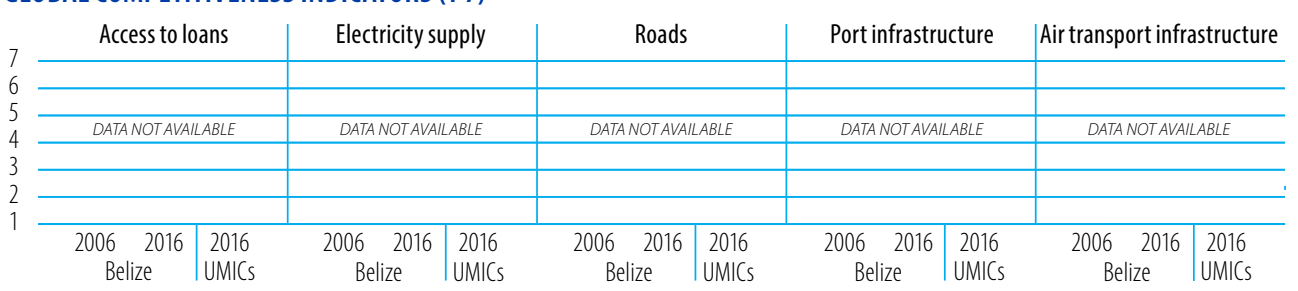

Source: WEF Global Competitiveness Index

TRADE FACILITATION INDICATORS, 2017 (0-2)

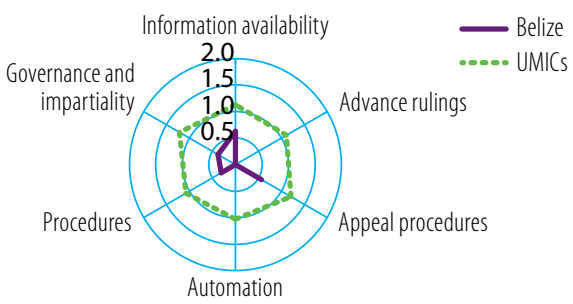

Source: OECD Trade Facilitation Indicators

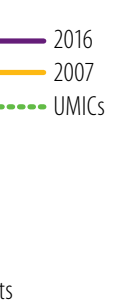

TRADE COSTS (ad-valorem, \%)

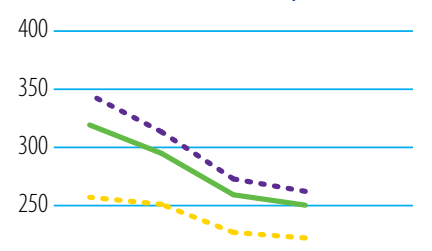

200

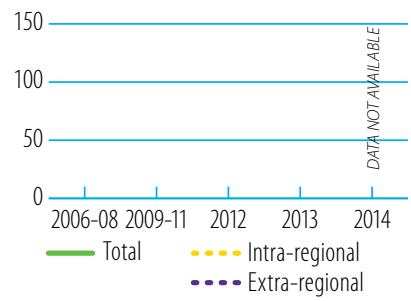

Source: ESCAP-WB Trade Cost Database Note: Number of partners used in the calculation of average trade costs: total (27), intra-regional (8), extra-regional (19) 


\section{TRADE PERFORMANCE}

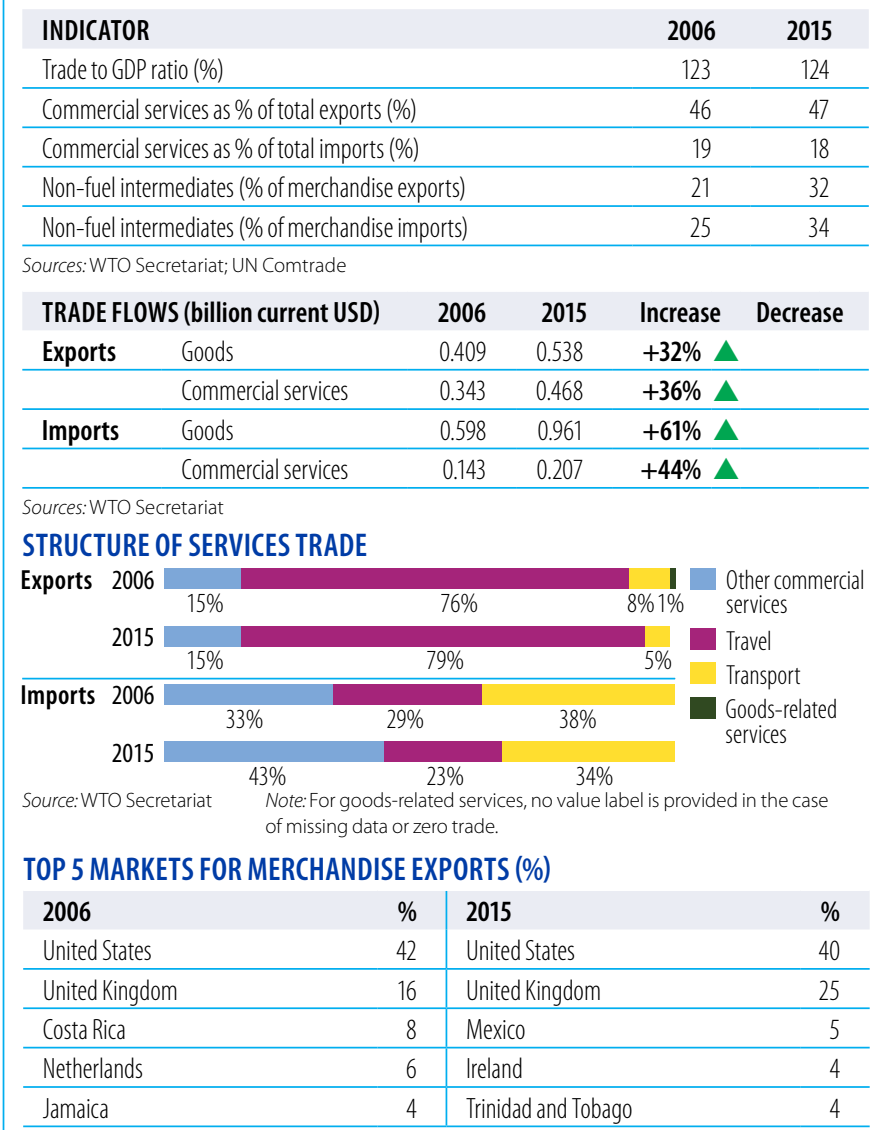

\section{TOP 5 MERCHANDISE EXPORTS (\%)}

\begin{tabular}{lc|lc}
2006 & $\%$ & $\mathbf{2 0 1 5}$ & $\%$ \\
Fruit, veg. juices & 20 & Sugars, molasses, honey & 21 \\
\hline Sugars, molasses, honey & 19 & Special transactions not classified & 15 \\
\hline Petroleum oils, crude & 16 & Fruit, veg. juices & 14 \\
\hline Fruit, nuts excl. oil nuts & 16 & Crustaceans, molluscs, etc. & 13 \\
\hline Crustaceans, molluscs, etc. & 15 & Petroleum oils, crude & 6 \\
\hline Source: UN Comtrade & &
\end{tabular}

\section{INDICATOR}

2006

2015

Product diversification (based on HSO2, 4-dig.)

Number of exported products (max. 1245)

Number of imported products (max. 1245)

HH export product concentration (0 to 1)

HH import product concentration (0 to 1)

\begin{tabular}{|rr|}
\hline 79 & 198 \\
\hline 665 & 750 \\
\hline 0.131 & 0.101 \\
\hline 0.097 & 0.017 \\
\hline
\end{tabular}

Market diversification

Number of export markets (max. 237)

Number of import markets (max. 237)

HH export market concentration (0 to 1)

HH import market concentration (0 to 1)

Sources: WTO Secretariat; UN Comtrade

STRUCTURE OF MERCHANDISE TRADE

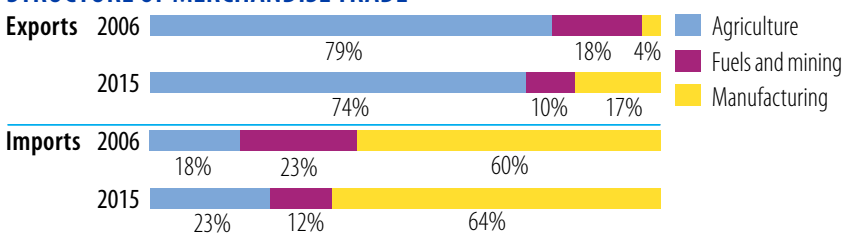

$\begin{array}{ccc}23 \% & 12 \% & 64 \% \\ \text { Source: WTO Secretariat } & \text { Note: Only classified products are included in the calculation. }\end{array}$

TOP 5 MARKETS FOR MERCHANDISE IMPORTS (\%)

\begin{tabular}{lc|lc}
2006 & $\%$ & 2015 & $\%$ \\
United States & 39 & United States & 34 \\
\hline Netherlands Antilles & 11 & Mexico & 11 \\
\hline Panama & 10 & China & 10 \\
\hline Mexico & 9 & Curacao & 9 \\
\hline Guatemala & 6 & Guatemala & 7
\end{tabular}

\section{TOP 5 MERCHANDISE IMPORTS (\%)}

\begin{tabular}{lc|lc}
2006 & $\%$ & 2015 & $\%$ \\
Special transactions not classified & 27 & Petroleum products & 10 \\
\hline Petroleum products & 15 & Tobacco, manufactured & 5 \\
\hline Alcoholic beverages & 2 & Goods, special-purpose transport vehicles & 3 \\
\hline Articles, n.e.s., of plastics & 2 & Edible products and preparations, n.e.s. & 2 \\
\hline Goods, special-purpose transport vehicles & 2 & Animal feed stuff & 2 \\
\hline Source: UN Comtrade & \multicolumn{3}{l}{}
\end{tabular}

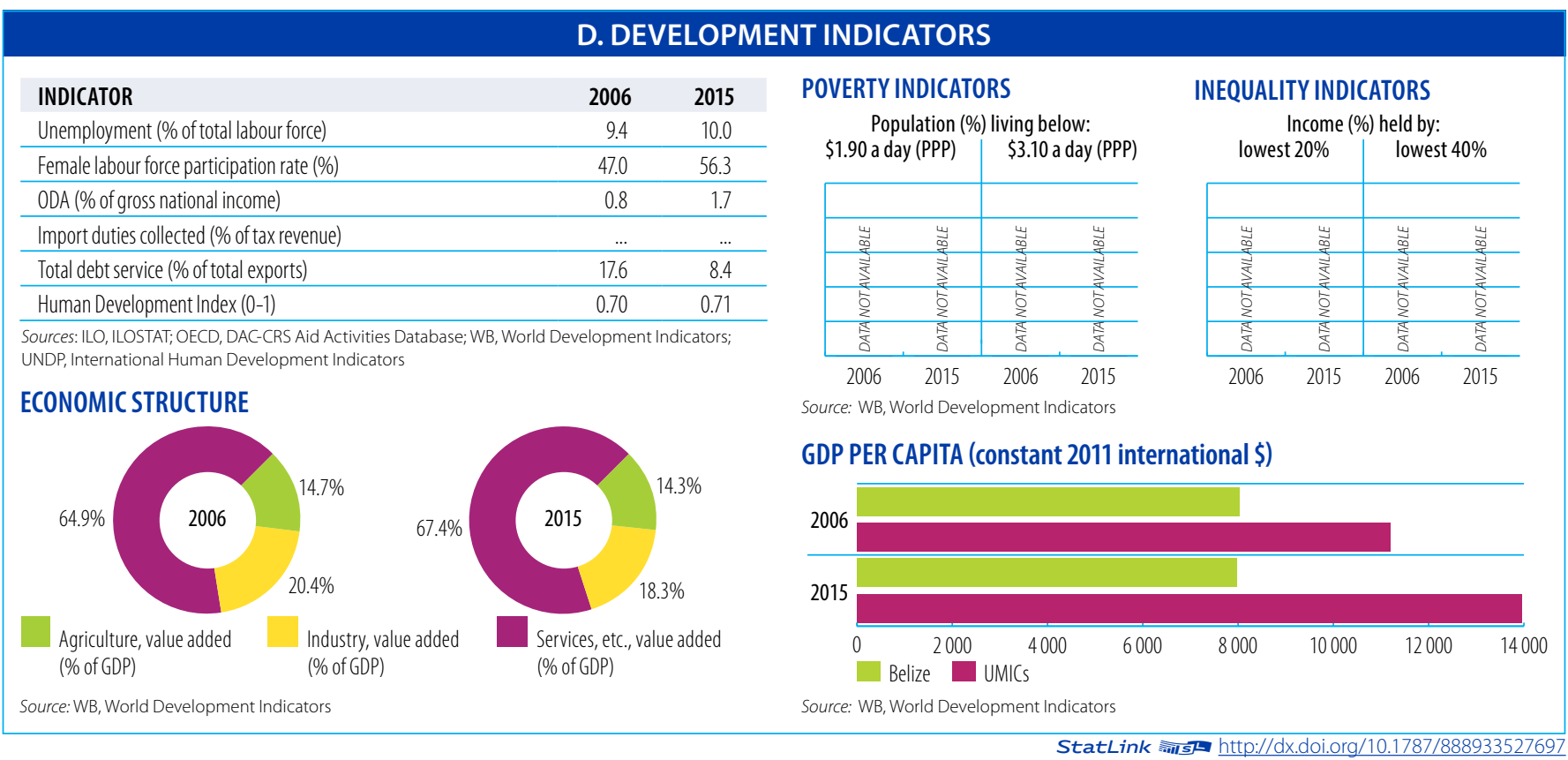




\section{BENIN}

Aid, Trade and Development Indicators for Benin

\section{A. DEVELOPMENT FINANCE}

\begin{tabular}{lrrrc}
$\begin{array}{l}\text { EXTERNAL FINANCING INFLOWS } \\
\text { (million current USD) }\end{array}$ & $\mathbf{2 0 0 6 / 0 8}$ & $\mathbf{2 0 1 2 / 1 4}$ & $\mathbf{2 0 1 5}$ & $\mathbf{\Delta : 0 6 / 0 8 - 1 5}$ \\
FDl inflows & 159.4 & 331.7 & 229.3 & $44 \%$ \\
\hline Remittances & 214.3 & 253.6 & 304.3 & $42 \%$ \\
\hline Other official flows (OOF) & 0.0 & 12.9 & 0.9 & - \\
\hline of which trade-related OOF & 0.0 & 6.0 & 0.2 & - \\
\hline Official Development Assistance (ODA) & 862.2 & 617.6 & 467.5 & $-46 \%$ \\
\hline of which Aid for Trade & 116.2 & 171.5 & 167.1 & $44 \%$ \\
\hline
\end{tabular}

Sources: UNCTAD, UNCTADstat; WB, World Development Indicators; OECD,

DAC-CRS Aid Activities Database

\section{TOP 3 AfT PRIORITIES}

\begin{tabular}{|l|l|l|l|l|l}
\hline & Transport infrastructure & $\mathbf{2}$ & Network infrastructure & $\mathbf{3}$ & Industrialization \\
\hline
\end{tabular}

Source: OECD/WTO Partner Questionnaire

SHARE OF AfT IN DEVELOPMENT FINANCE AND FIXED CAPITAL FORMATION (\%)

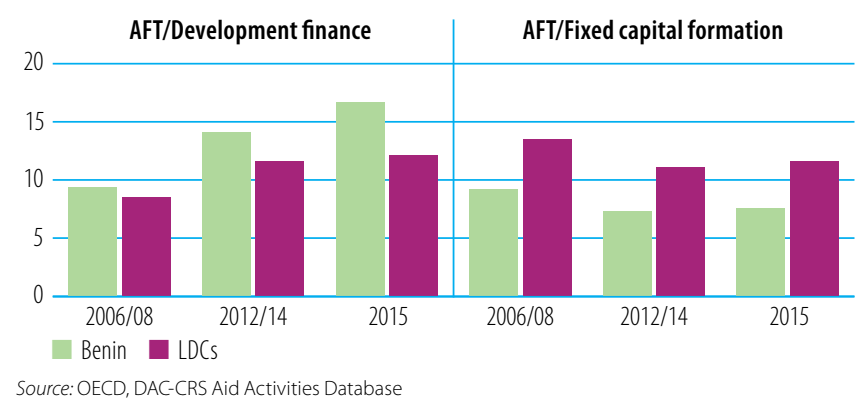

AfT DISBURSEMENTS: TOP DONORS (million current USD)

\begin{tabular}{lrr|lrc}
$\mathbf{2 0 0 6 / 0 8}$ & value & $\mathbf{2}$ & $\mathbf{2 0 1 5}$ & value & $\%$ \\
EU Institutions & 29.7 & 26 & IDA & 45.0 & 27 \\
\hline IDA & 23.6 & 20 & EU Institutions & 38.8 & 23 \\
\hline Denmark & 19.0 & 16 & African Development Fund & 24.7 & 15 \\
\hline African Development Fund & 18.4 & 16 & Germany & 12.4 & 7 \\
\hline France & 8.0 & 7 & Belgium & 8.7 & 5 \\
\hline
\end{tabular}

Source: OECD, DAC-CRS Aid Activities Database

AfT DISBURSEMENTS BY SECTOR (million current USD)

\begin{tabular}{|c|c|c|c|}
\hline Trade policy and regulations & & 0.70 & 0.06 \\
\hline Trade facilitation & & 0.04 & 0.60 \\
\hline Transport and storage & 7 & 55.73 & 70.60 \\
\hline Communications & 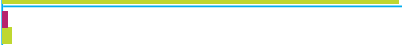 & 0.90 & 1.62 \\
\hline Energy generation and supply & 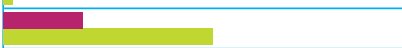 & 14.09 & 37.37 \\
\hline Business and other services & 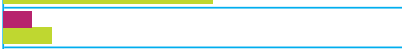 & 5.14 & 8.56 \\
\hline Banking and financial services & $\bar{\sigma}$ & 3.17 & 2.22 \\
\hline Agriculture, forestry, fishing & 7 & 32.38 & 43.53 \\
\hline Industry & $\bar{\theta}$ & 3.98 & 2.55 \\
\hline Mineral resources and mining & & 0.03 & 0.00 \\
\hline Tourism & & 0.02 & 0.03 \\
\hline Trade-related adjustment & & 0.00 & 0.00 \\
\hline & $\begin{array}{llllllll}0 & 10 & 20 & 30 & 40 & 50 & 60 & 70 \\
& 2006 / 08 & 2015 & & & & \end{array}$ & & \\
\hline
\end{tabular}

Source: OECD, DAC-CRS Aid Activities Database

\section{B. TRADE COSTS}

\begin{tabular}{|c|c|c|}
\hline INDICATOR & 2006 & 2015 \\
\hline \multicolumn{3}{|l|}{ Tariffs (\%) } \\
\hline Imports: simple avg. MFN applied & 12.0 & 12.2 \\
\hline Imports: weighted avg. MFN applied (2005-2014) & 12 & 11.1 \\
\hline Exports: weighted avg. faced (2005-2014) & 24.3 & 2.5 \\
\hline Exports: duty free (value in \%) (2005-2014) & 24.7 & 68.1 \\
\hline \multicolumn{3}{|l|}{ ICT connectivity (\% of population) } \\
\hline Mobile broadband subscriptions & $\ldots$ & 4.2 \\
\hline Fixed broadband subscriptions & 0.0 & 0.7 \\
\hline Individuals using the internet & 1.5 & 6.8 \\
\hline
\end{tabular}
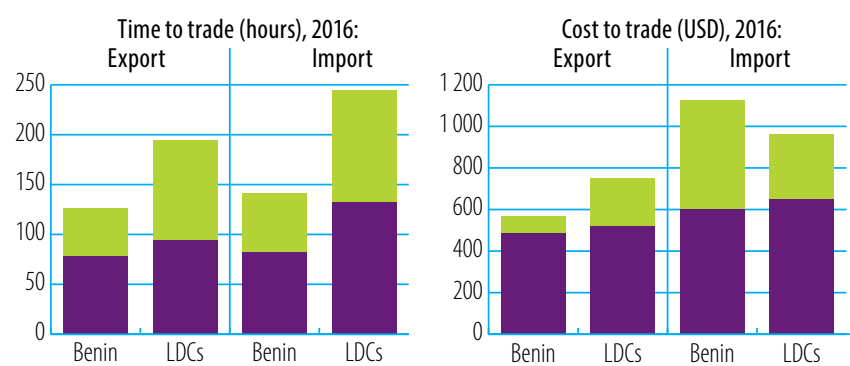

Sources: WTO, World Tariff Profiles; ITU, World Telecommunication/ICT Indicators

LOGISTICS PERFORMANCE INDICES (LPI) (1-5)

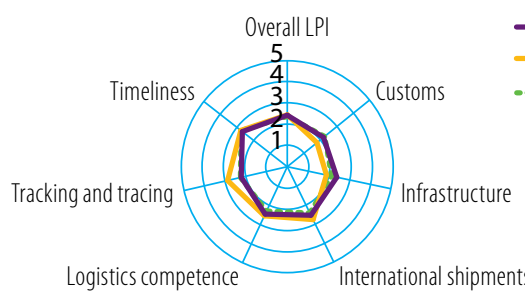

Source: WB Logistics Performance Index (LPI)

GLOBAL COMPETITIVENESS INDICATORS (1-7)

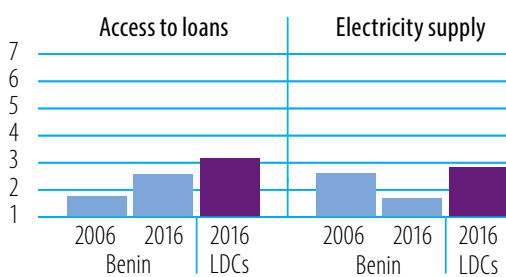

Source: WEF Global Competitiveness Index
TRADE FACILITATION INDICATORS, 2017 (0-2)

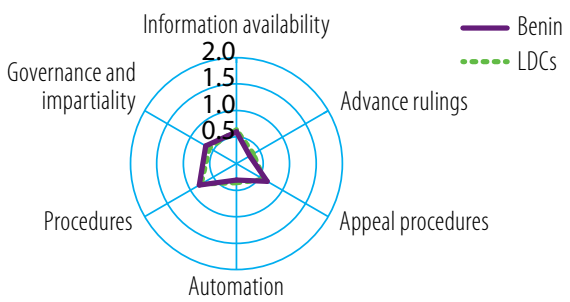

Source: OECD Trade Facilitation Indicators

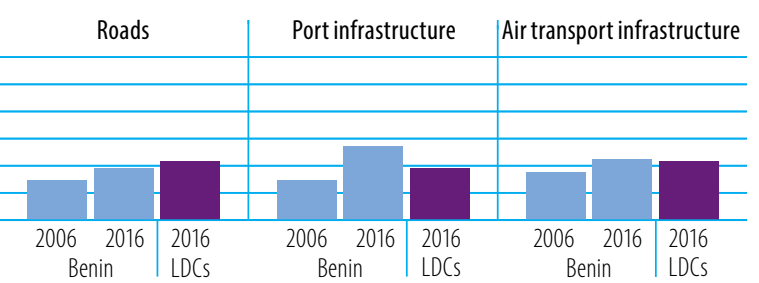

TRADE COSTS (ad-valorem, \%)

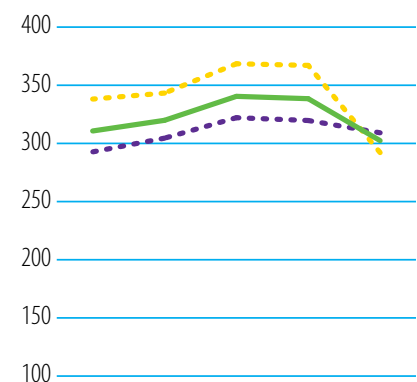

100

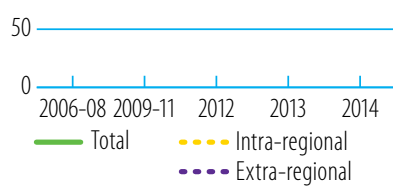

Source: ESCAP-WB Trade Cost Database

Note: Number of partners used in the

calculation of average trade costs: total (48),

intra-regional (19), extra-regional (29) 


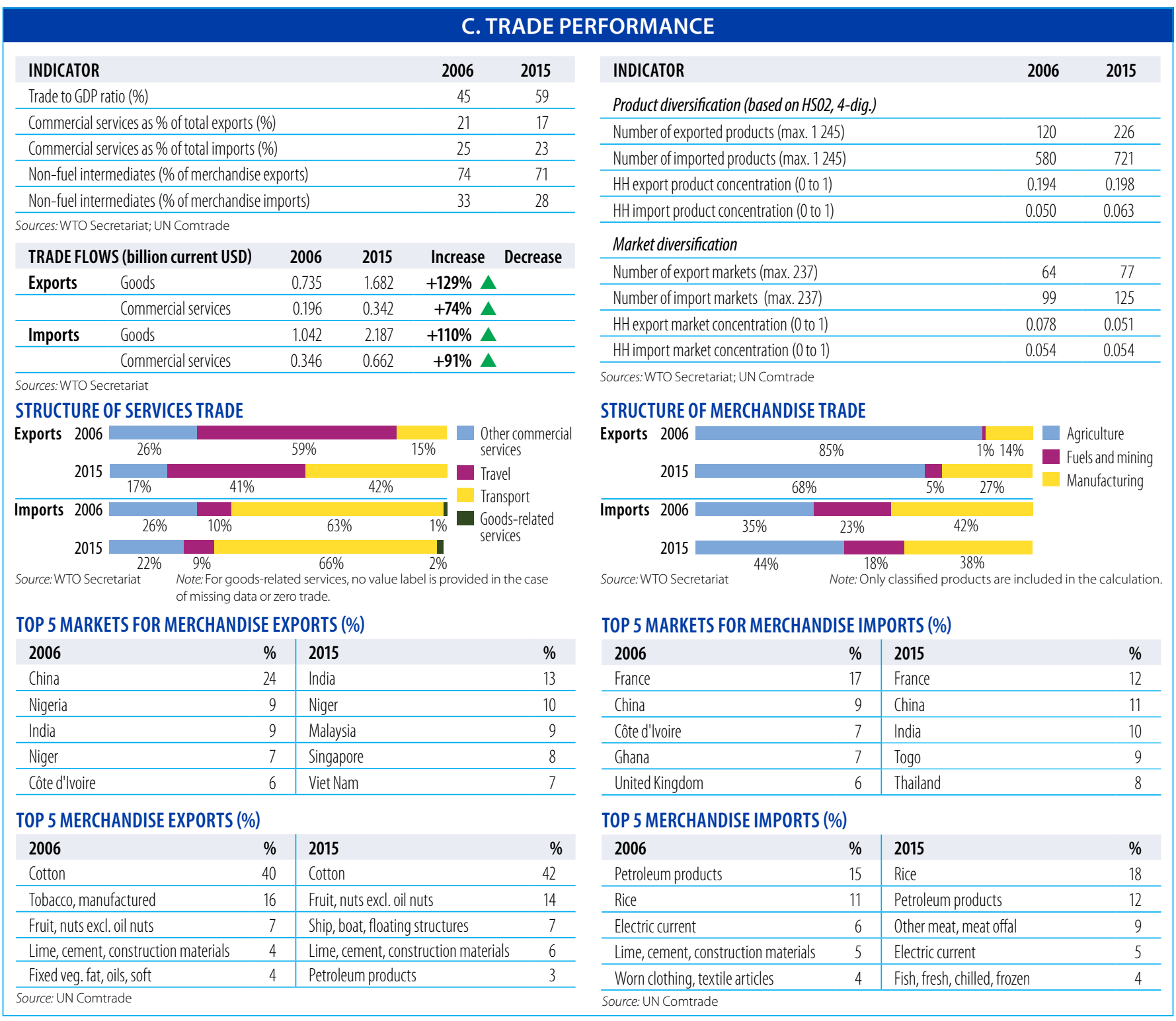

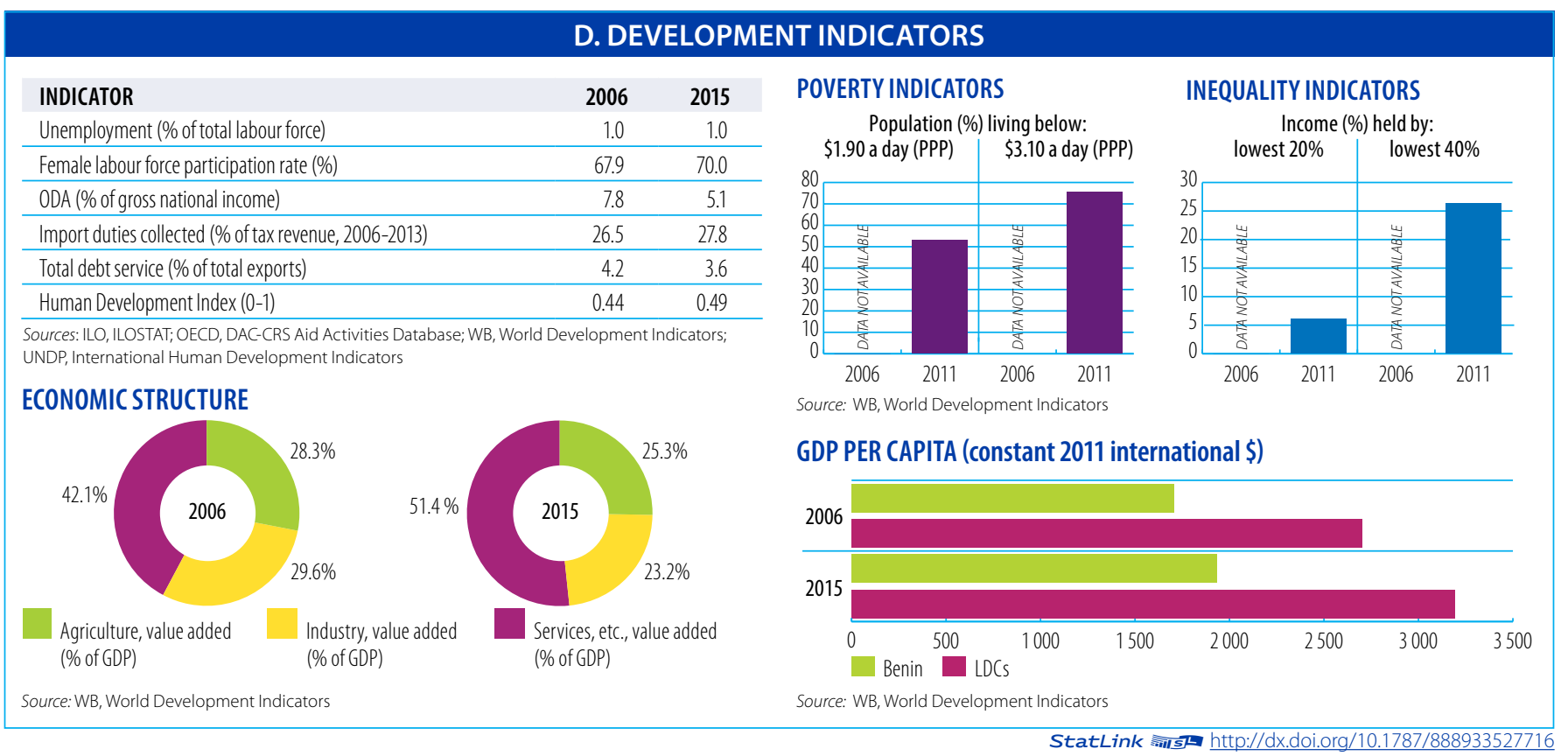


Aid, Trade and Development Indicators for Botswana

\section{A. DEVELOPMENT FINANCE}

\begin{tabular}{lrrrc}
$\begin{array}{l}\text { EXTERNAL FINANCING INFLOWS } \\
\text { (million current USD) }\end{array}$ & $\mathbf{2 0 0 6 / 0 8}$ & $\mathbf{2 0 1 2 / 1 4}$ & $\mathbf{2 0 1 5}$ & $\mathbf{\Delta : 0 6 / 0 8 - 1 5}$ \\
\hline FDl inflows & 500.7 & 466.9 & 393.6 & $-21 \%$ \\
\hline Remittances & 80.9 & 33.4 & 30.5 & $-62 \%$ \\
\hline Other official flows (00F) & 7.7 & 42.8 & 12.2 & $57 \%$ \\
\hline of which trade-related 00F & 2.4 & 25.8 & 11.5 & $373 \%$ \\
\hline Official Development Assistance (ODA) & 313.8 & 114.4 & 81.0 & $-74 \%$ \\
\hline of which Aid for Trade & 11.4 & 11.0 & 4.8 & $-58 \%$ \\
\hline
\end{tabular}

Sources: UNCTAD, UNCTADstat; WB, World Development Indicators; OECD,

DAC-CRS Aid Activities Database

TOP 3 AFT PRIORITIES

\begin{tabular}{|l|l|l|l|l|l|}
\hline $\mathbf{1}$ & Export diversification & $\mathbf{2}$ & International competitiveness & $\mathbf{3}$ & Industrialization \\
\hline
\end{tabular} Source: OECD/WTO Partner Questionnaire

SHARE OF AfT IN DEVELOPMENT FINANCE AND FIXED CAPITAL FORMATION (\%)

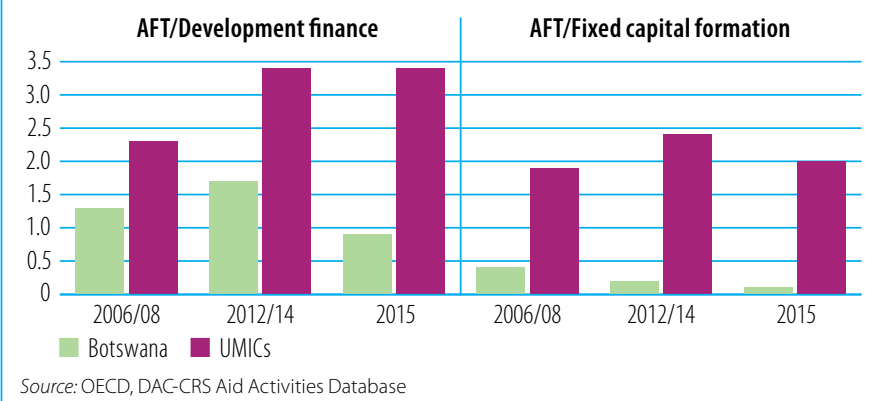

AfT DISBURSEMENTS: TOP DONORS (million current USD)

\begin{tabular}{lrr|lrr}
$\mathbf{2 0 0 6 / 0 8}$ & value & $\%$ & $\mathbf{2 0 1 5}$ & value & $\%$ \\
EU Institutions & 5.8 & 51 & Japan & 3.1 & 65 \\
\hline France & 3.0 & 26 & Global Environment Facility & 0.9 & 19 \\
\hline Japan & 0.9 & 8 & African Development Bank & 0.3 & 6 \\
\hline United States & 0.5 & 4 & New Zealand & 0.2 & 4 \\
\hline Denmark & 0.4 & 4 & France & 0.1 & 2 \\
\hline
\end{tabular}

Source: OECD, DAC-CRS Aid Activities Database

AfT DISBURSEMENTS BY SECTOR (million current USD)

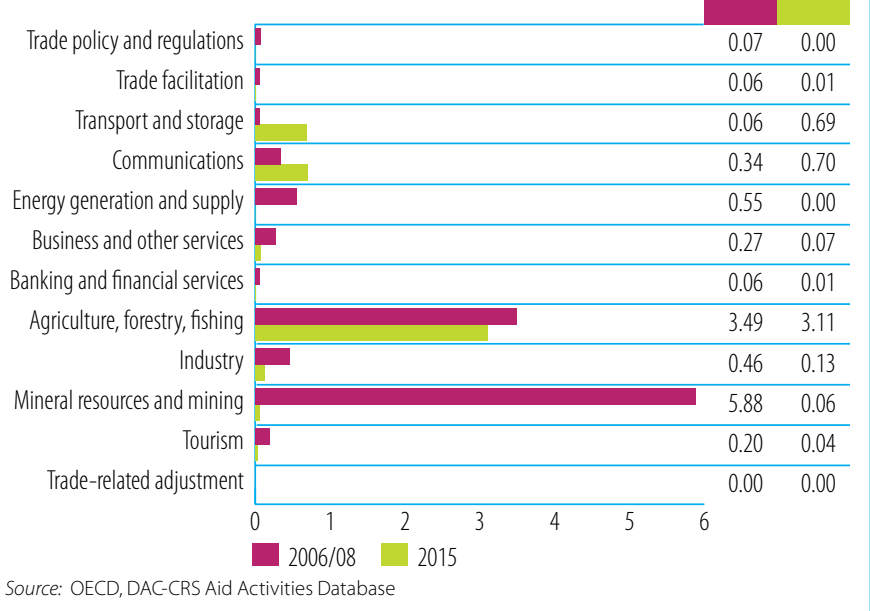

\section{B. TRADE COSTS}

\begin{tabular}{lcc} 
INDICATOR & 2006 & $\mathbf{2 0 1 5}$ \\
Tariffs (\%) & & \\
\hline Imports: simple avg. MFN applied & 8.0 & 7.6 \\
\hline Imports: weighted avg. MFN applied (2006-2014) & $\ldots .8$ & 2.5 \\
\hline Exports: weighted avg. faced (2005-2014) & 98.9 & 78.4 \\
\hline Exports: duty free (value in \%) (2005-2014) & & \\
\hline ICT connectivity (\% of population) & $\ldots$ & 67.3 \\
\hline Mobile broadband subscriptions & 0.1 & 1.8 \\
\hline Fixed broadband subscriptions & 4.3 & 27.5 \\
\hline Individuals using the internet & &
\end{tabular}
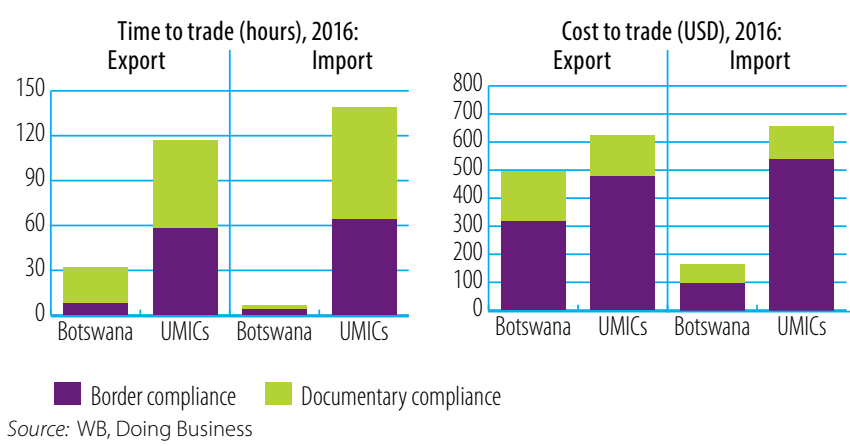

LOGISTICS PERFORMANCE INDICES (LPI) (1-5)

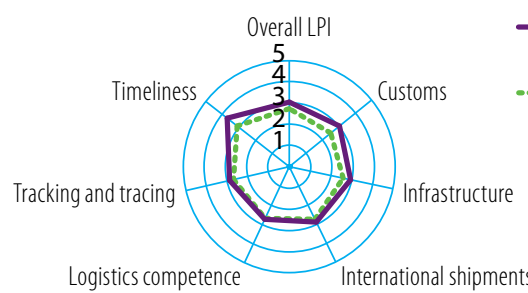

Logistics competence

Source: WB Logistics Performance Index (LPI)

GLOBAL COMPETITIVENESS INDICATORS (1-7)

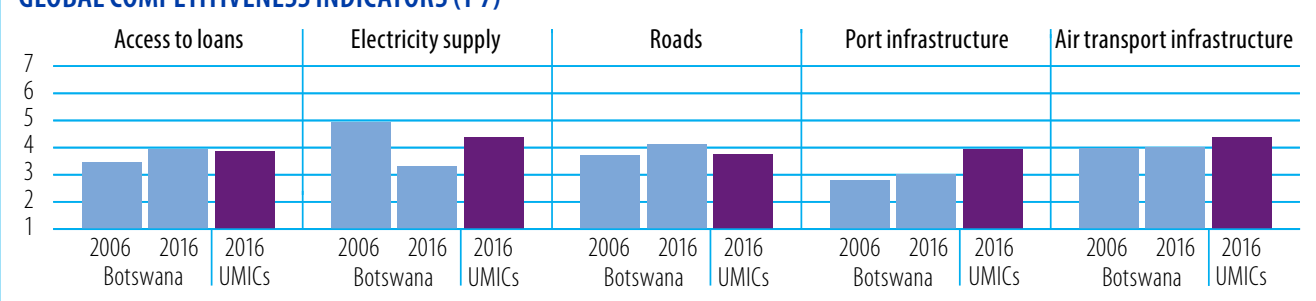

TRADE FACILITATION INDICATORS, 2017 (0-2)

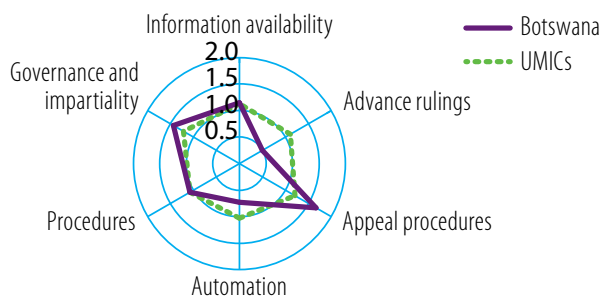

Source: OECD Trade Facilitation Indicators

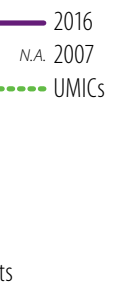

Border compliance Documentary compliance

TRADE COSTS (ad-valorem, \%)

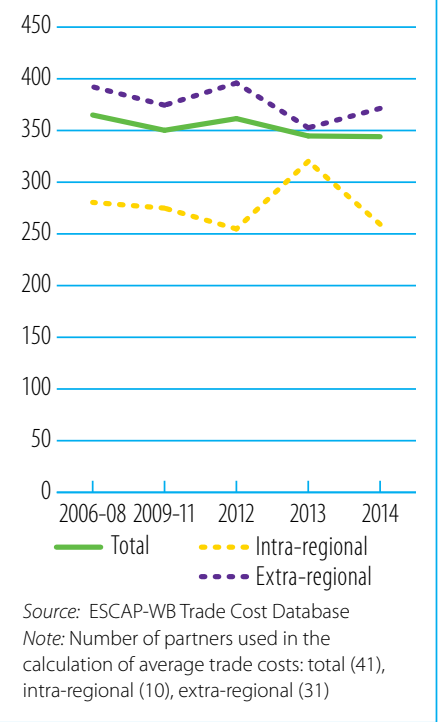




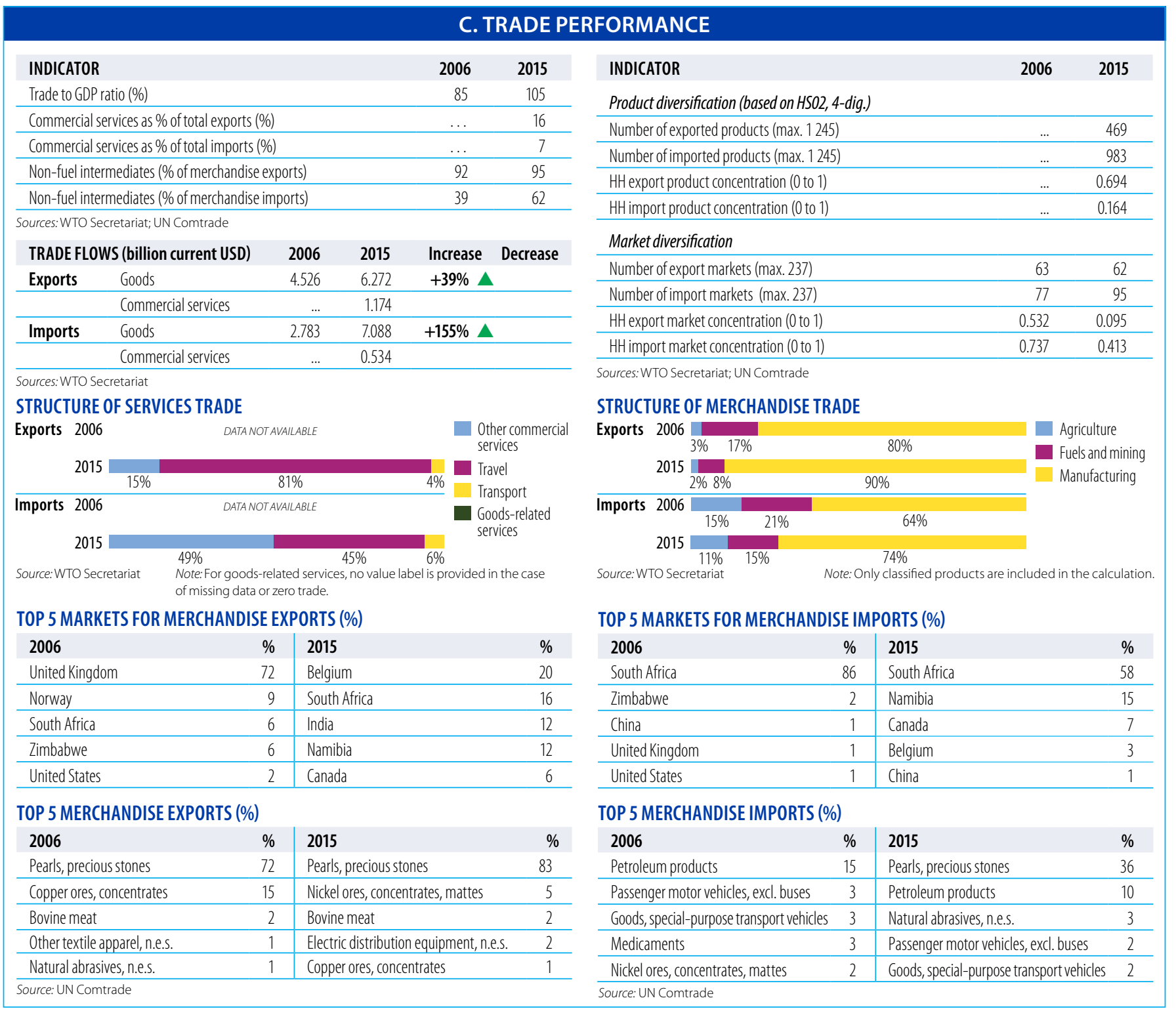

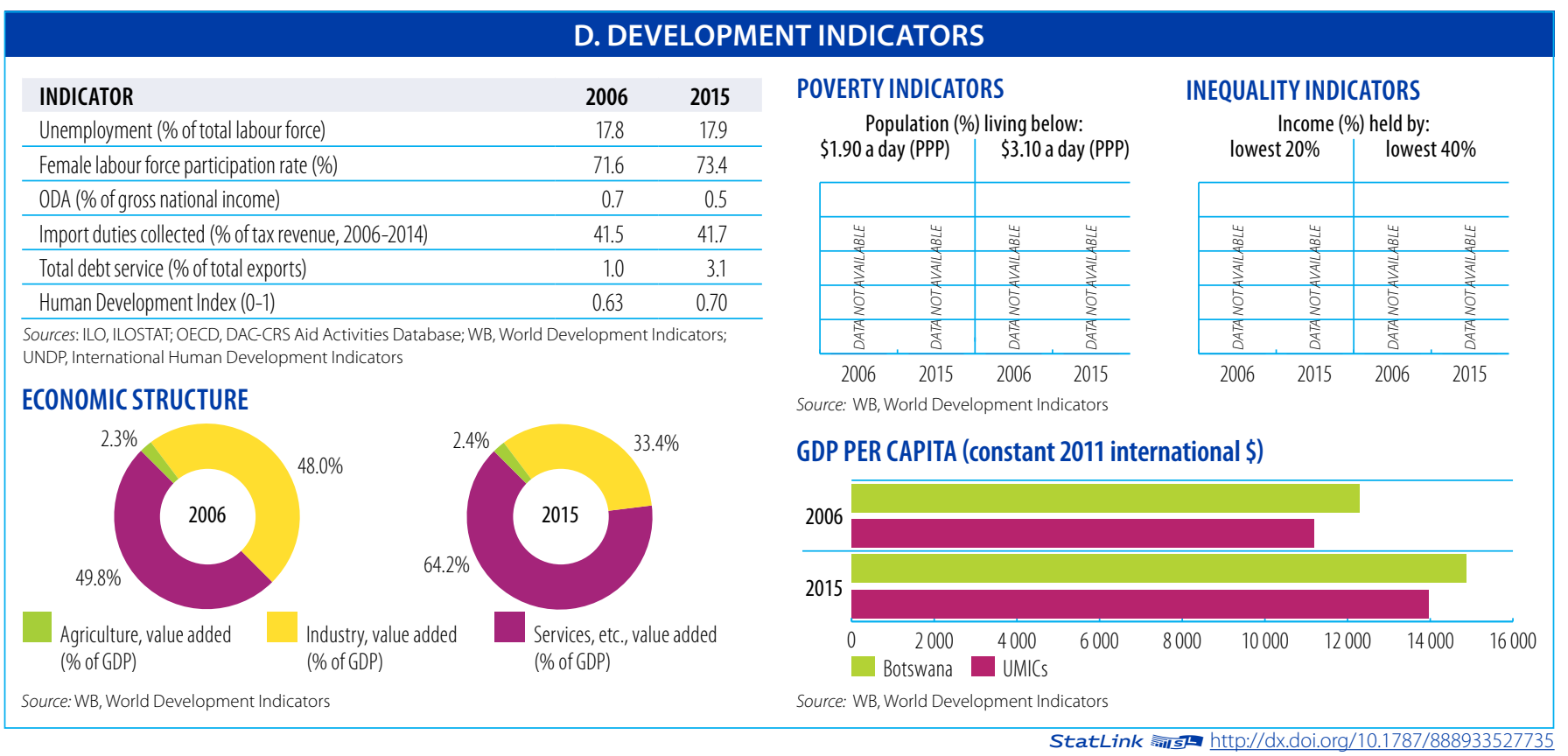




\section{BURKINA FASO}

Aid, Trade and Development Indicators for Burkina Faso

\section{A. DEVELOPMENT FINANCE}

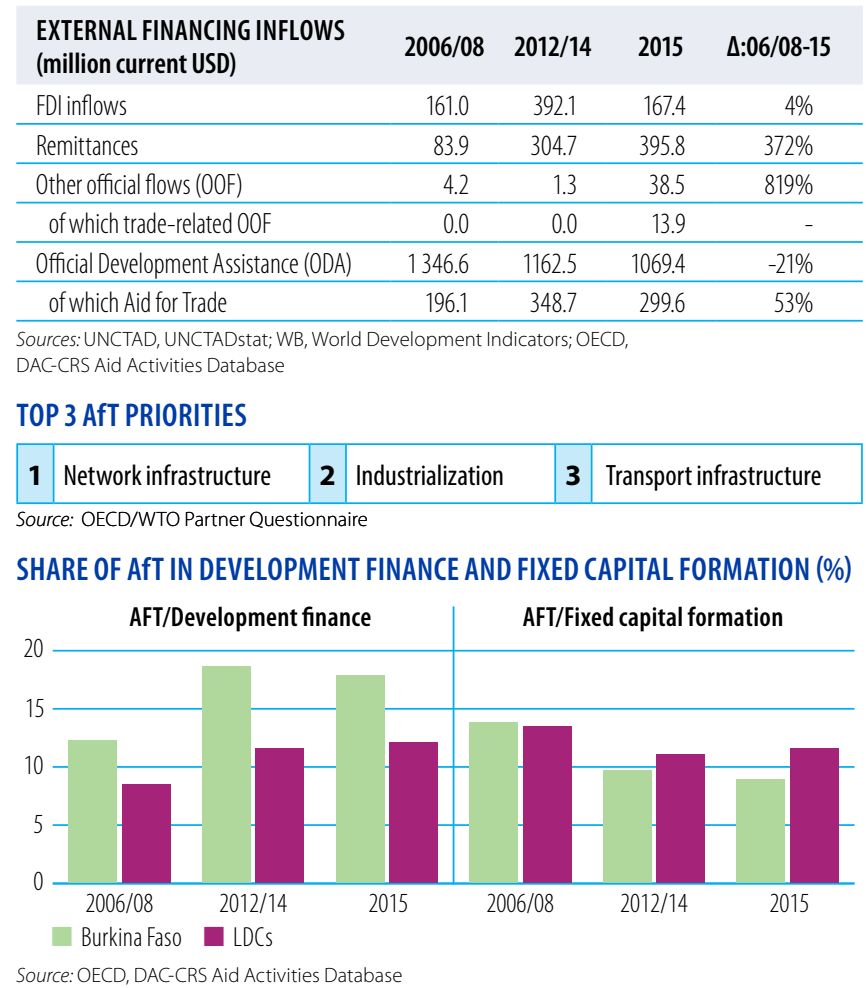

AfT DISBURSEMENTS: TOP DONORS (million current USD)

\begin{tabular}{lrr|lcc}
$\mathbf{2 0 0 6 / 0 8}$ & value & $\%$ & $\mathbf{2 0 1 5}$ & value & $\%$ \\
EU Institutions & 62.0 & 32 & IDA & 142.6 & 48 \\
\hline IDA & 48.3 & 25 & African Development Fund & 38.3 & 13 \\
\hline France & 35.6 & 18 & EU Institutions & 29.7 & 10 \\
\hline African Development Fund & 12.6 & 6 & Germany & 14.9 & 5 \\
\hline Denmark & 8.2 & 4 & France & 14.3 & 5
\end{tabular}

Source: OECD, DAC-CRS Aid Activities Database

AfT DISBURSEMENTS BY SECTOR (million current USD)

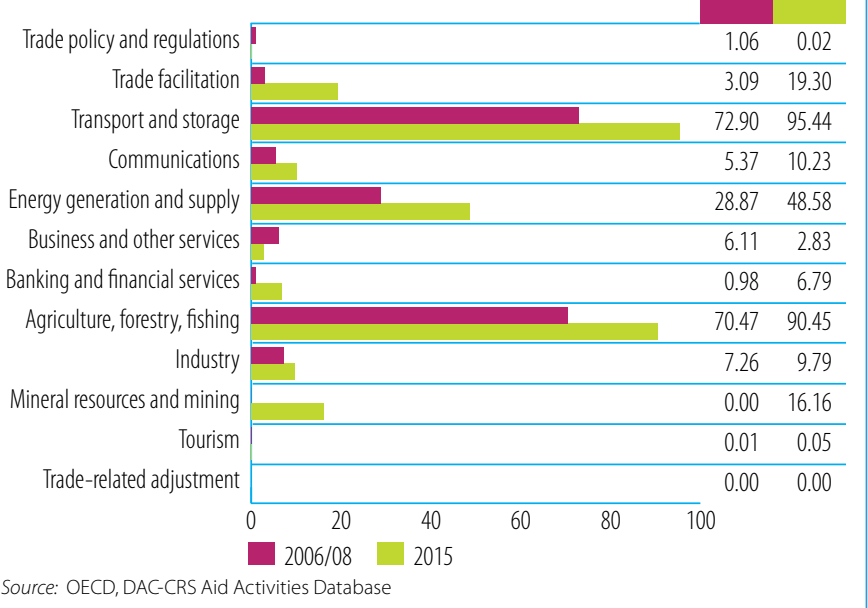

\section{B. TRADE COSTS}

\begin{tabular}{|c|c|c|}
\hline INDICATOR & 2006 & 2015 \\
\hline \multicolumn{3}{|l|}{ Tariffs (\%) } \\
\hline Imports: simple avg. MFN applied & 12.0 & 12.2 \\
\hline Imports: weighted avg. MFN applied (2006-2014) & $\ldots$ & 9.8 \\
\hline Exports: weighted avg. faced (2005-2014) & 26.8 & 0.7 \\
\hline Exports: duty free (value in \%) (2005-2014) & 25.2 & 90.8 \\
\hline \multicolumn{3}{|l|}{ ICT connectivity (\% of population) } \\
\hline Mobile broadband subscriptions & $\ldots$ & 15.4 \\
\hline Fixed broadband subscriptions & 0.0 & 0.0 \\
\hline Individuals using the internet & 0.6 & 11.4 \\
\hline
\end{tabular}
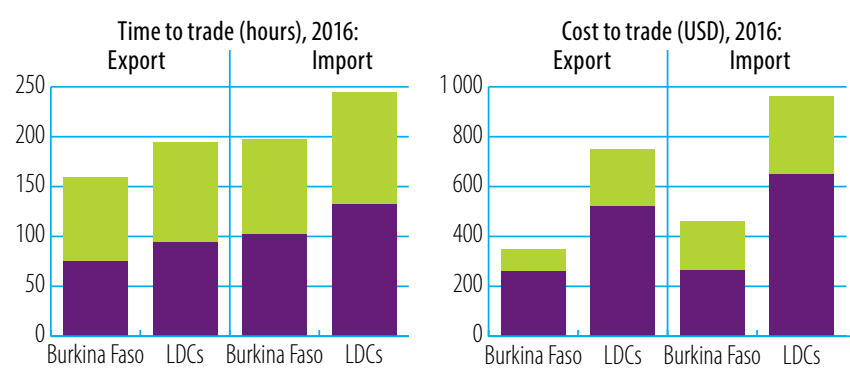

Border compliance Documentary compliance

Source: WB, Doing Business

\section{LOGISTICS PERFORMANCE INDICES (LPI) (1-5)}

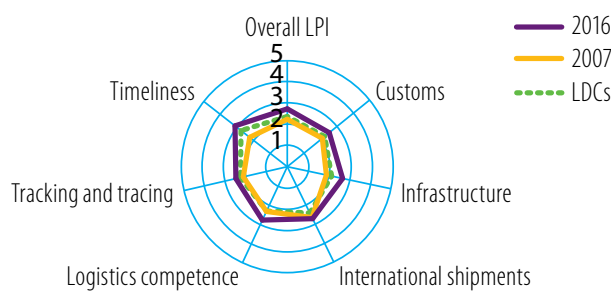

Source: WB Logistics Performance Index (LPI)

GLOBAL COMPETITIVENESS INDICATORS (1-7)

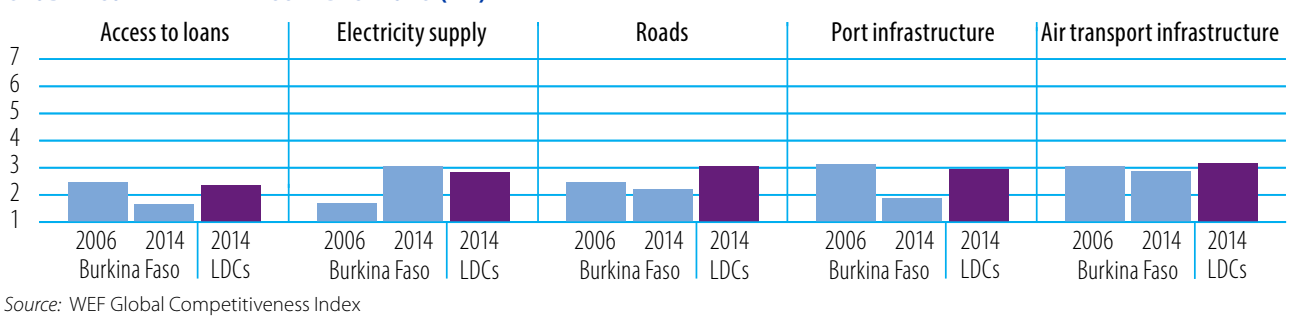

TRADE FACILITATION INDICATORS, 2017 (0-2)

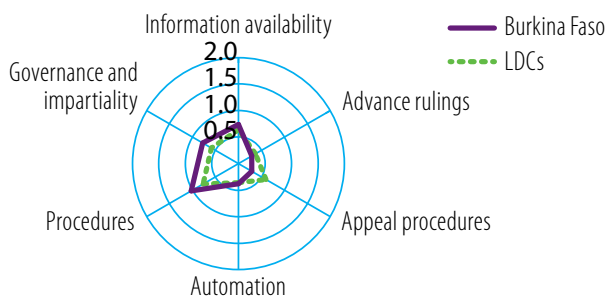

Source: OECD Trade Facilitation Indicators

100

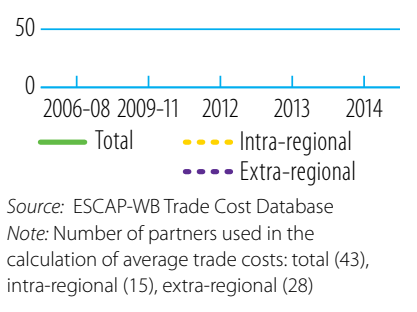




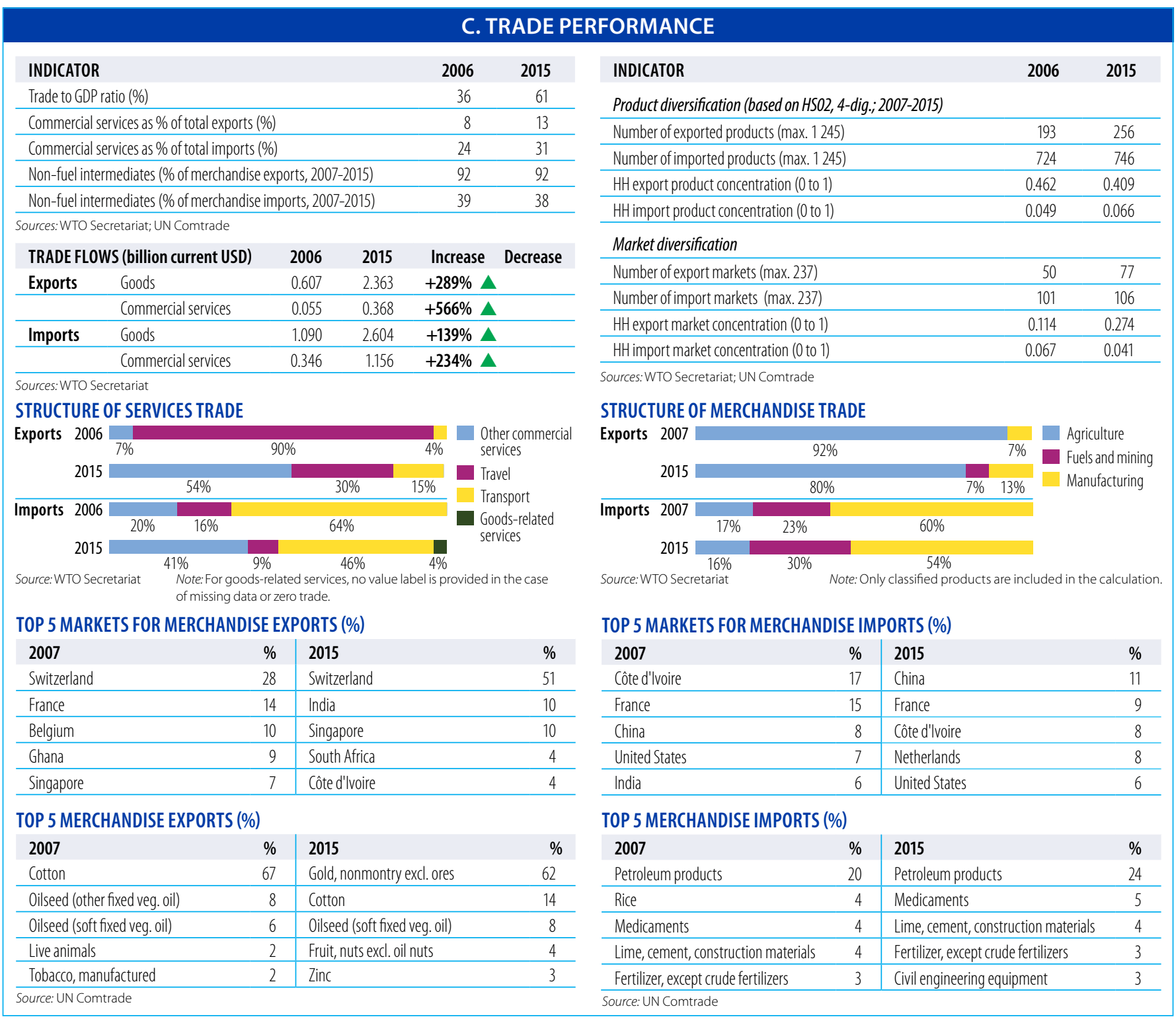

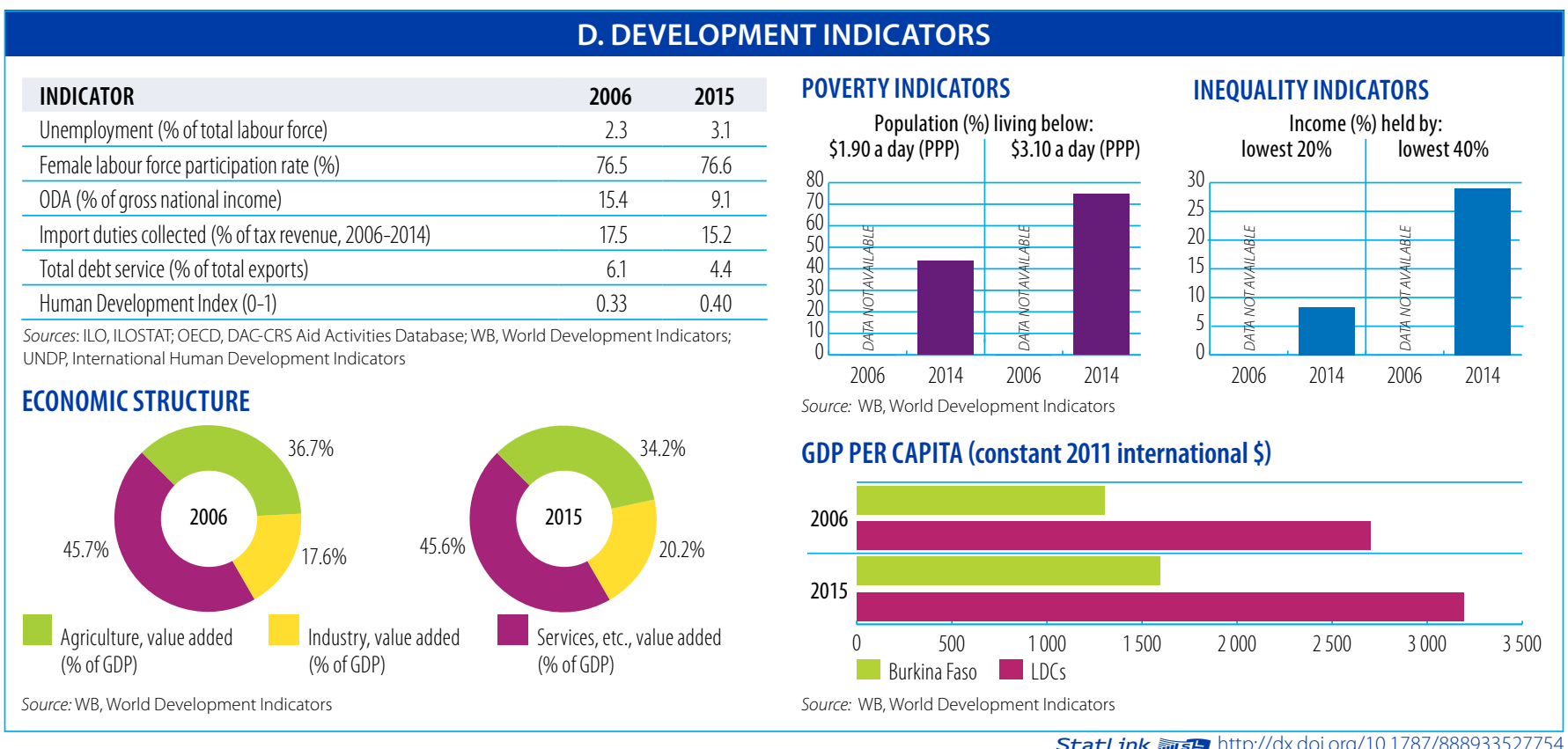




\section{BURUNDI}

Aid, Trade and Development Indicators for Burundi

\section{A. DEVELOPMENT FINANCE}

\begin{tabular}{lrrrc}
$\begin{array}{l}\text { EXTERNAL FINANCING INFLOWS } \\
\text { (million current USD) }\end{array}$ & $\mathbf{2 0 0 6 / 0 8}$ & $\mathbf{2 0 1 2 / 1 4}$ & $\mathbf{2 0 1 5}$ & $\mathbf{\Delta : 0 6 / 0 8 - 1 5}$ \\
FDl inflows & 1.5 & 27.2 & 7.4 & $406 \%$ \\
\hline Remittances & 1.3 & 50.4 & 51.0 & $3880 \%$ \\
\hline Other official flows (00F) & 0.0 & 0.1 & 0.0 & - \\
\hline$\quad$ of which trade-related 00F & 0.0 & 0.0 & 0.0 & - \\
\hline Official Development Assistance (ODA) & 497.3 & 541.8 & 397.1 & $-20 \%$ \\
\hline of which Aid for Trade & 71.9 & 162.6 & 89.7 & $25 \%$ \\
\hline
\end{tabular}

Sources: UNCTAD, UNCTADstat; WB, World Development Indicators; OECD,

DAC-CRS Aid Activities Database

\section{TOP 3 AfT PRIORITIES}

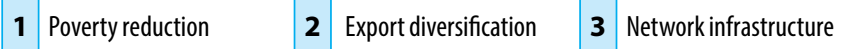

Source: OECD/WTO Partner Questionnaire

SHARE OF AfT IN DEVELOPMENT FINANCE AND FIXED CAPITAL FORMATION (\%)

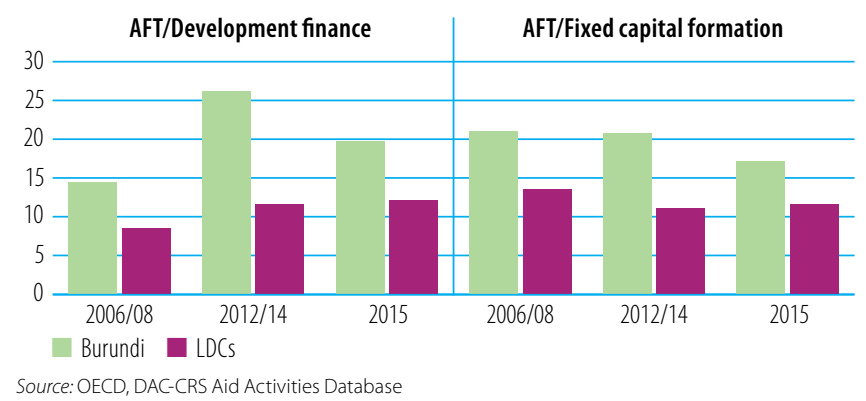

AfT DISBURSEMENTS: TOP DONORS (million current USD)

\begin{tabular}{lrr|lrc}
$\mathbf{2 0 0 6 / 0 8}$ & value & $\%$ & $\mathbf{2 0 1 5}$ & value & $\%$ \\
IDA & 32.1 & 45 & African Development Fund & 19.2 & 21 \\
\hline EU Institutions & 24.7 & 34 & IDA & 17.6 & 20 \\
\hline Belgium & 4.9 & 7 & EU Institutions & 17.4 & 19 \\
\hline Netherlands & 2.0 & 3 & Belgium & 12.0 & 13 \\
\hline African Development Fund & 1.8 & 2 & Netherlands & 10.2 & 11 \\
\hline Source: OECD, DAC-CRS Aid Activities Database & & &
\end{tabular}

AfT DISBURSEMENTS BY SECTOR (million current USD)

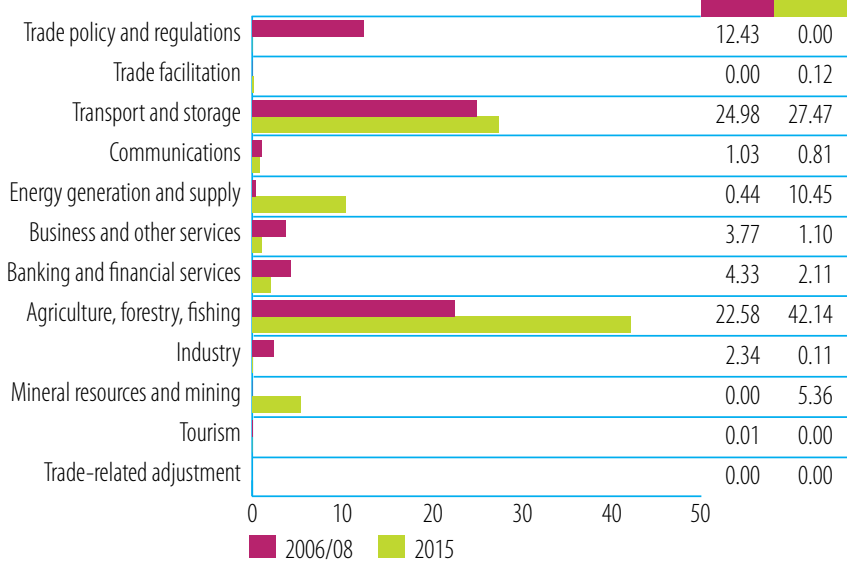

Source: OECD, DAC-CRS Aid Activities Database

\section{B. TRADE COSTS}

\begin{tabular}{lcc} 
INDICATOR & 2006 & $\mathbf{2 0 1 5}$ \\
Tariffs (\%) & & \\
\hline Imports: simple avg. MFN applied & 12.7 & 12.8 \\
\hline Imports: weighted avg. MFN applied (2006-2014) & $\ldots$ & 10.5 \\
\hline Exports: weighted avg. faced (2005-2014) & 0.5 & 0.4 \\
\hline Exports: duty free (value in \%) (2005-2014) & 94.0 & 96.0 \\
\hline ICT connectivity (\% of population) & $\ldots$ & \\
\hline Mobile broadband subscriptions & 0.0 & 0.0 \\
\hline Fixed broadband subscriptions (2008-2015) & 0.7 & 4.9 \\
\hline Individuals using the internet & &
\end{tabular}
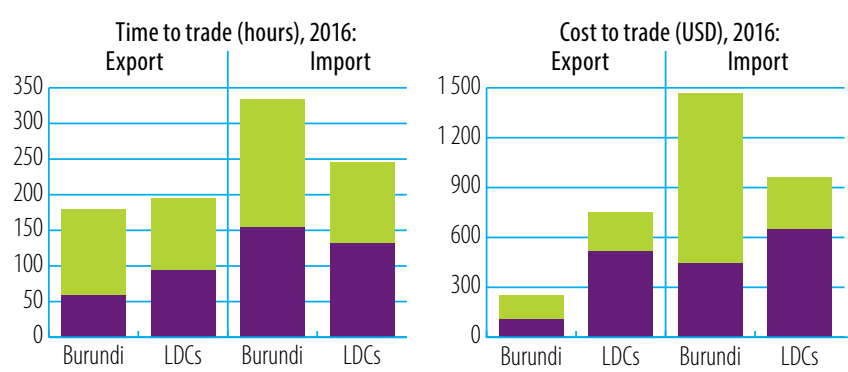

Border compliance Documentary compliance Source: WB, Doing Business

GLOBAL COMPETITIVENESS INDICATORS (1-7)

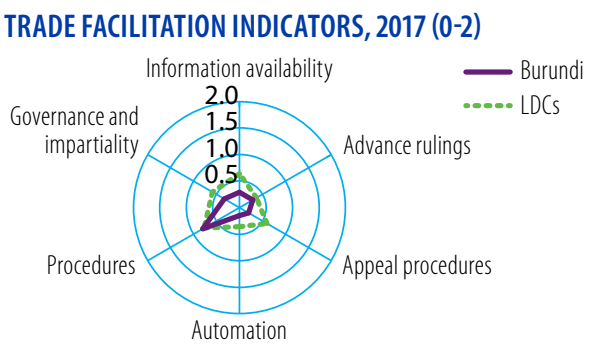

Source: OECD Trade Facilitation Indicators

Source: WB Logistics Performance Index (LPI)

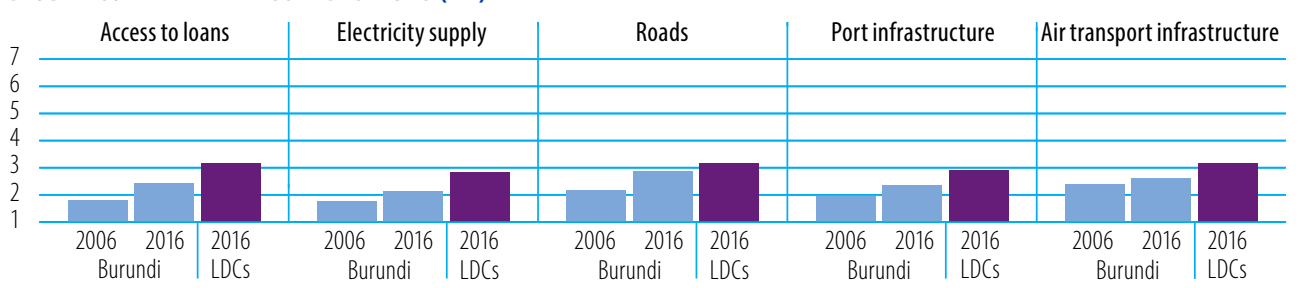

Source: WEF Global Competitiveness Index

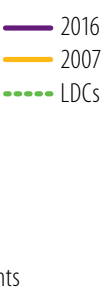

LOGISTICS PERFORMANCE INDICES (LPI) (1-5)

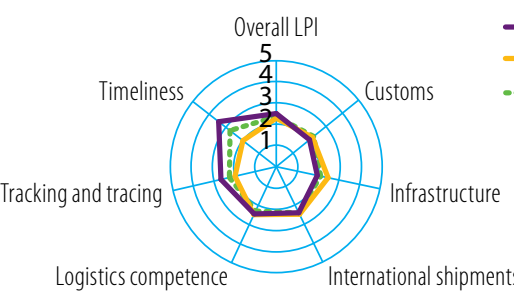

TRADE COSTS (ad-valorem, \%)

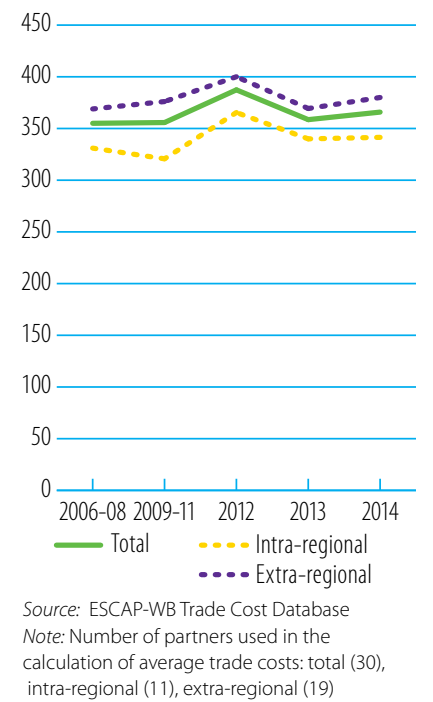




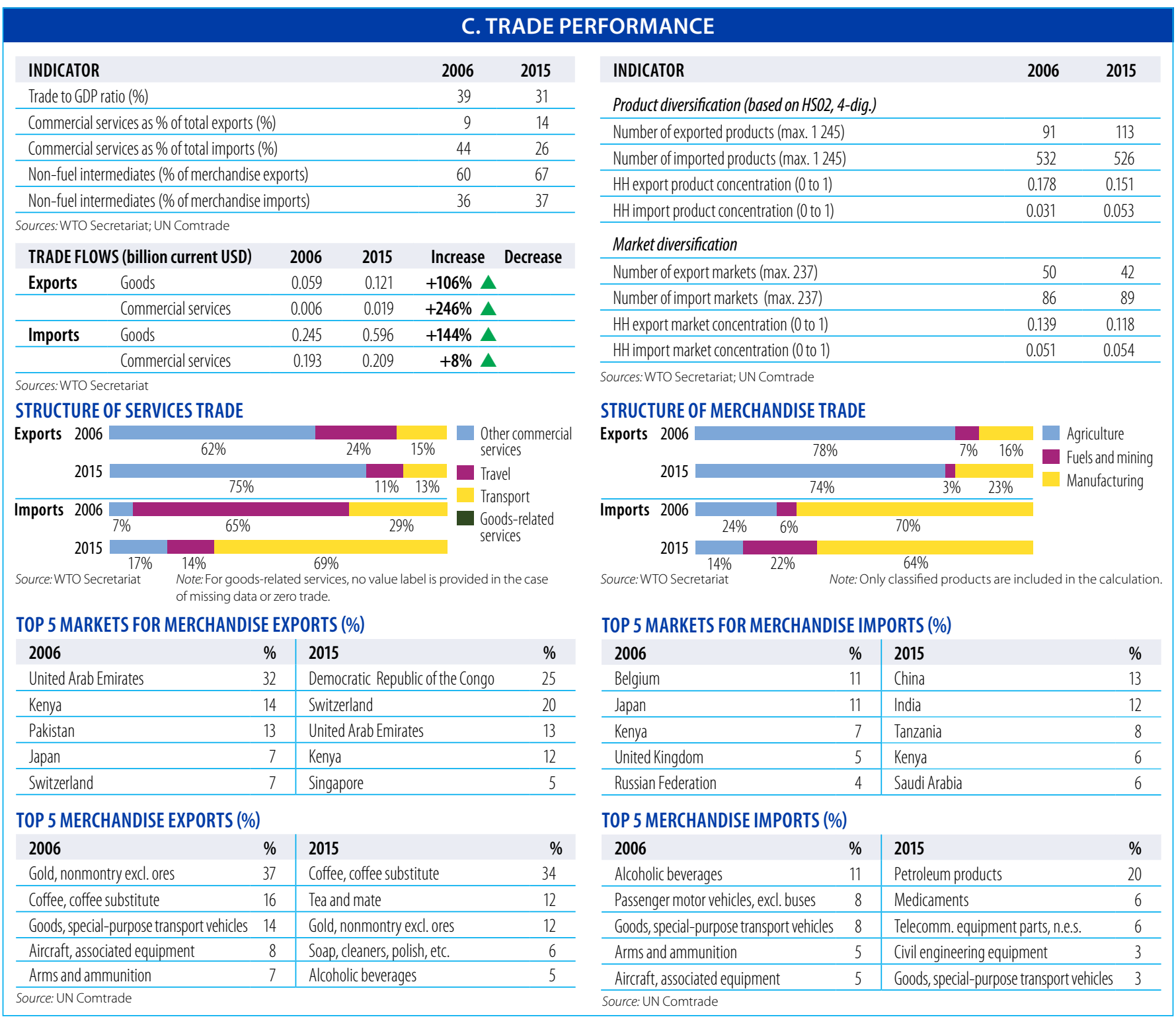

\begin{tabular}{|lrr}
\hline & D. DEVELOPME \\
\hline INDICATOR & $\mathbf{2 0 0 6}$ & $\mathbf{2 0 1 5}$ \\
\hline Unemployment (\% of total labour force) & 1.7 & 1.6 \\
\hline Female labour force participation rate (\%) & 83.9 & 84.6 \\
\hline ODA (\% of gross national income) & 34.2 & 11.9 \\
\hline Import duties collected (\% of tax revenue) & $\ldots$ & $\ldots$ \\
\hline Total debt service (\% of total exports) & 20.4 & 13.5 \\
\hline Human Development Index (0-1) & 0.31 & 0.40 \\
\hline
\end{tabular}

Sources: ILO, ILOSTAT; OECD, DAC-CRS Aid Activities Database; WB, World Development Indicators; UNDP, International Human Development Indicators

\section{ECONOMIC STRUCTURE}

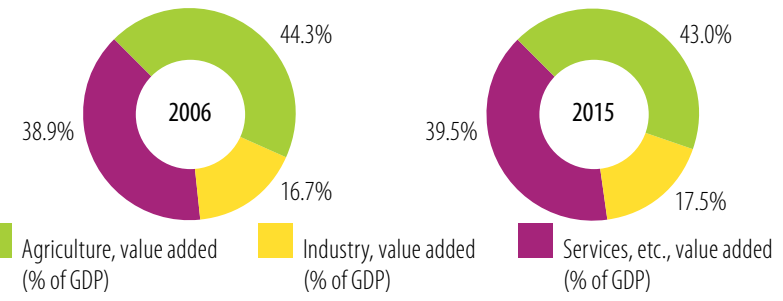

Source: WB, World Development Indicators
POVERTYINDICATORS

\section{Population (\%) living below:}
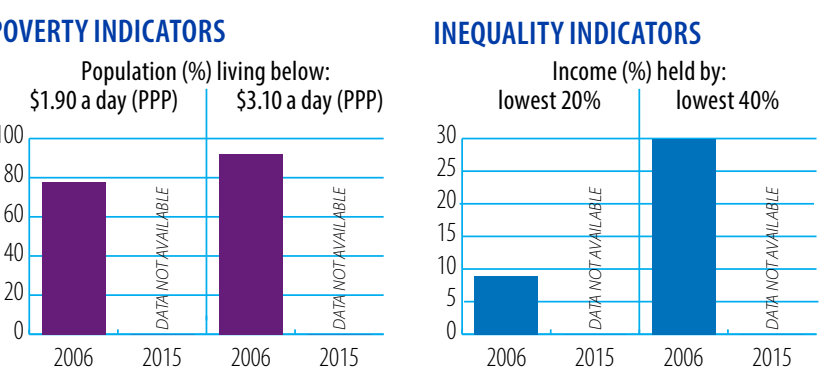

Source: WB, World Development Indicators

GDP PER CAPITA (constant 2011 international \$)

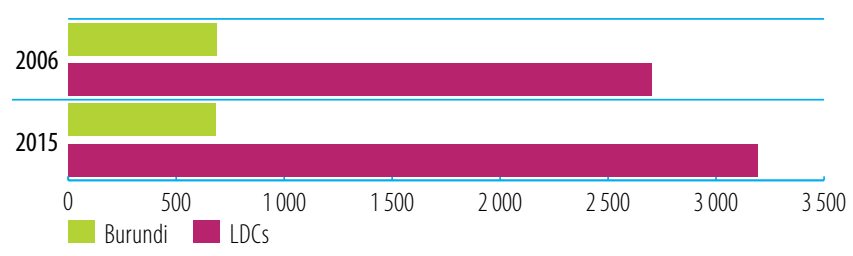

Source: WB, World Development Indicators 
Aid, Trade and Development Indicators for Cameroon

\section{A. DEVELOPMENT FINANCE}

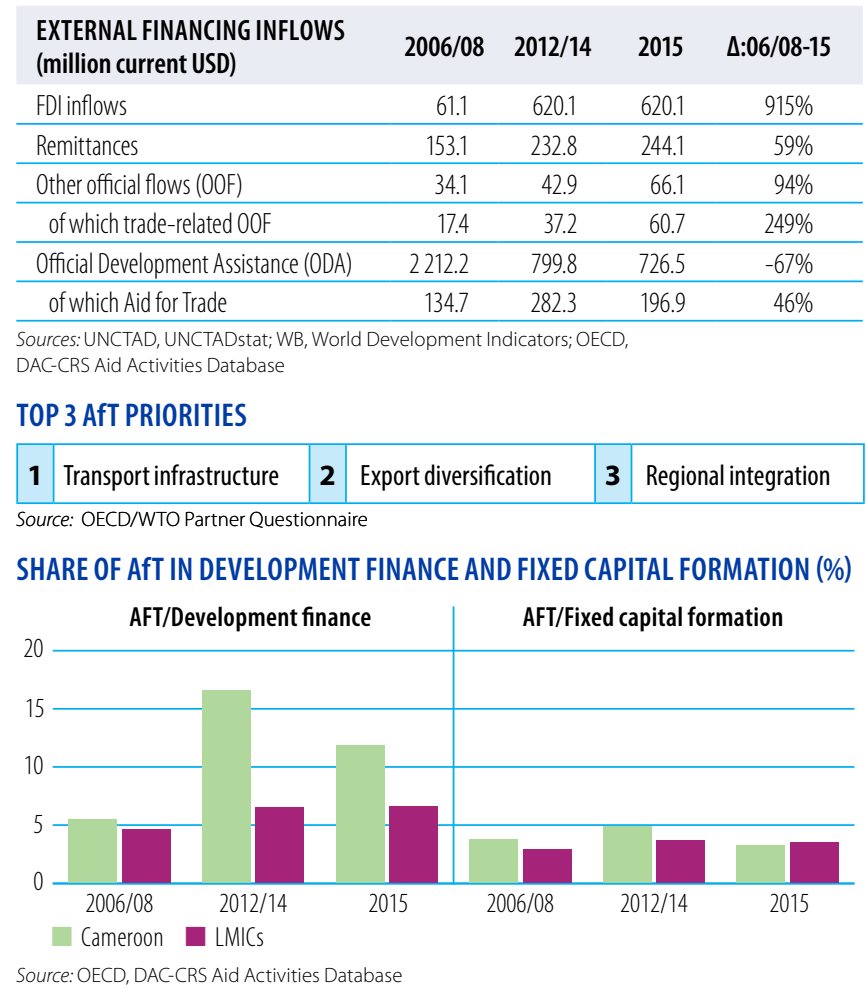

AfT DISBURSEMENTS: TOP DONORS (million current USD)

\begin{tabular}{lrr|lrc}
$\mathbf{2 0 0 6 / 0 8}$ & value & $\%$ & $\mathbf{2 0 1 5}$ & value & $\%$ \\
EU Institutions & 48.2 & 36 & IDA & 74.0 & 38 \\
\hline France & 25.0 & 19 & France & 50.7 & 26 \\
\hline IDA & 22.8 & 17 & EU Institutions & 29.0 & 15 \\
\hline Germany & 12.1 & 9 & African Development Fund & 16.2 & 8 \\
\hline African Development Fund & 8.6 & 6 & Japan & 11.5 & 6 \\
\hline Source: OECD, DAC-CRS Aid Activities Database & & &
\end{tabular}

AfT DISBURSEMENTS BY SECTOR (million current USD)

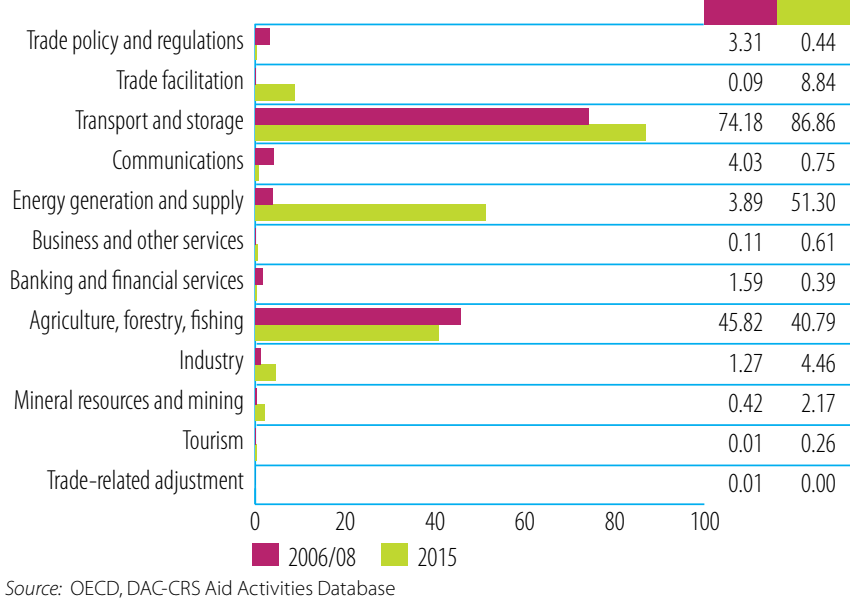

\section{B. TRADE COSTS}

\begin{tabular}{lrc} 
INDICATOR & $\mathbf{2 0 0 6}$ & $\mathbf{2 0 1 5}$ \\
Tariffs (\%) & & \\
\hline Imports: simple avg. MFN applied (2005-2014) & 18.0 & 18.2 \\
\hline Imports: weighted avg. MFN applied (2005-2014) & 14 & 12.9 \\
\hline Exports: weighted avg. faced (2005-2014) & 5.7 & 0.1 \\
\hline Exports: duty free (value in \%) (2005-2014) & 79.6 & 98.3 \\
\hline ICT connectivity (\% of population) & & \\
\hline Mobile broadband subscriptions (2008-2015) & 0.0 & 4.3 \\
\hline Fixed broadband subscriptions & 0.0 & 0.1 \\
\hline Individuals using the internet & 2.0 & 20.7 \\
\hline Sources: WTO, World Tariff Profiles; ITU, World Telecommunication/ICT Indicators &
\end{tabular}
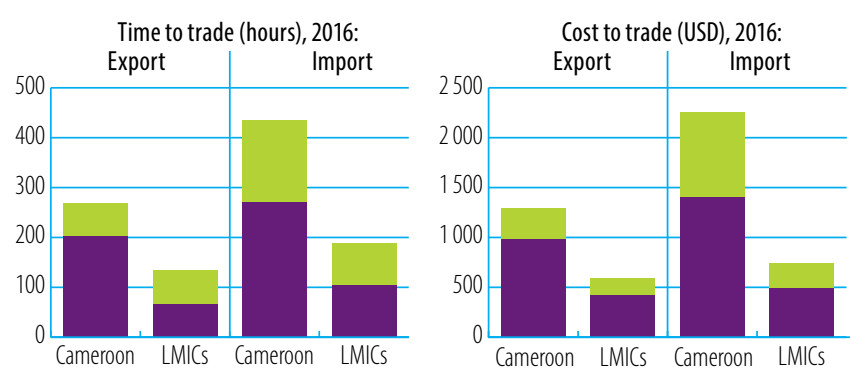

- Border compliance Documentary compliance Source: WB, Doing Business

\section{LOGISTICS PERFORMANCE INDICES (LPI) (1-5)}

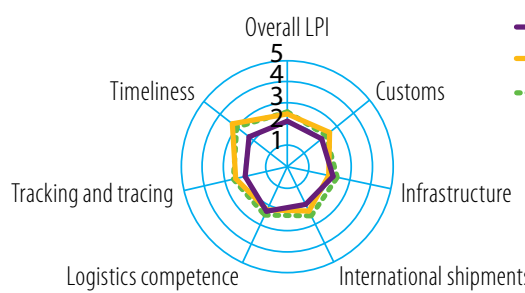

Logistics competence International shipments

Source: WB Logistics Performance Index (LPI)
TRADE FACILITATION INDICATORS, 2017 (0-2)

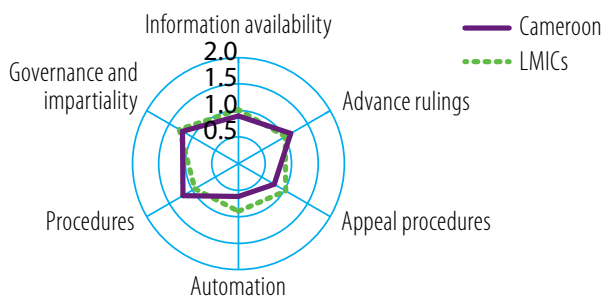

Source: OECD Trade Facilitation Indicators
TRADE COSTS (ad-valorem, \%)

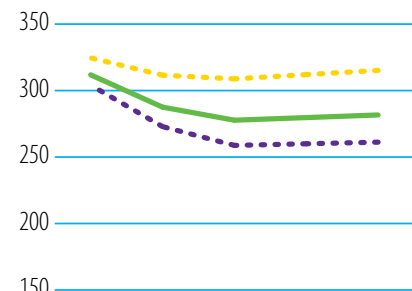

100

\section{GLOBAL COMPETITIVENESS INDICATORS (1-7)}

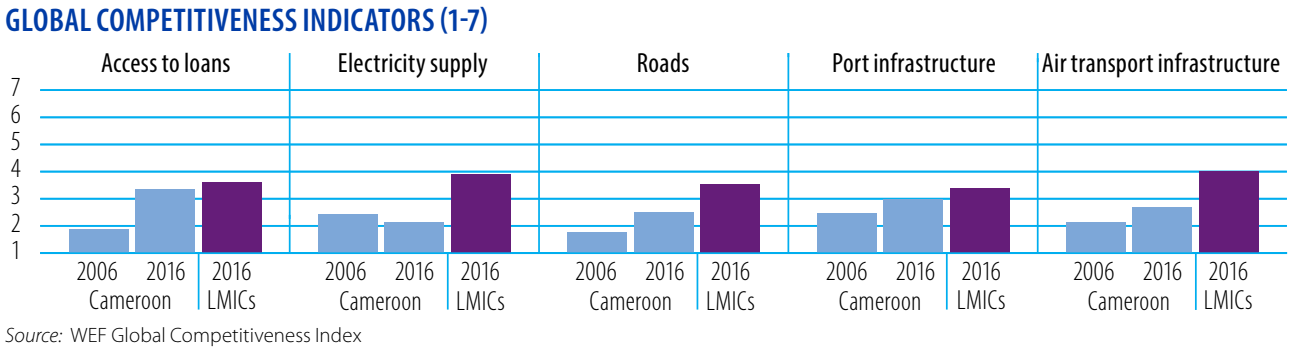

Source: WEF Global Competitiveness Index

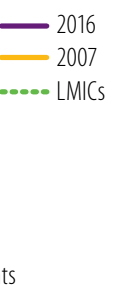

(1) 


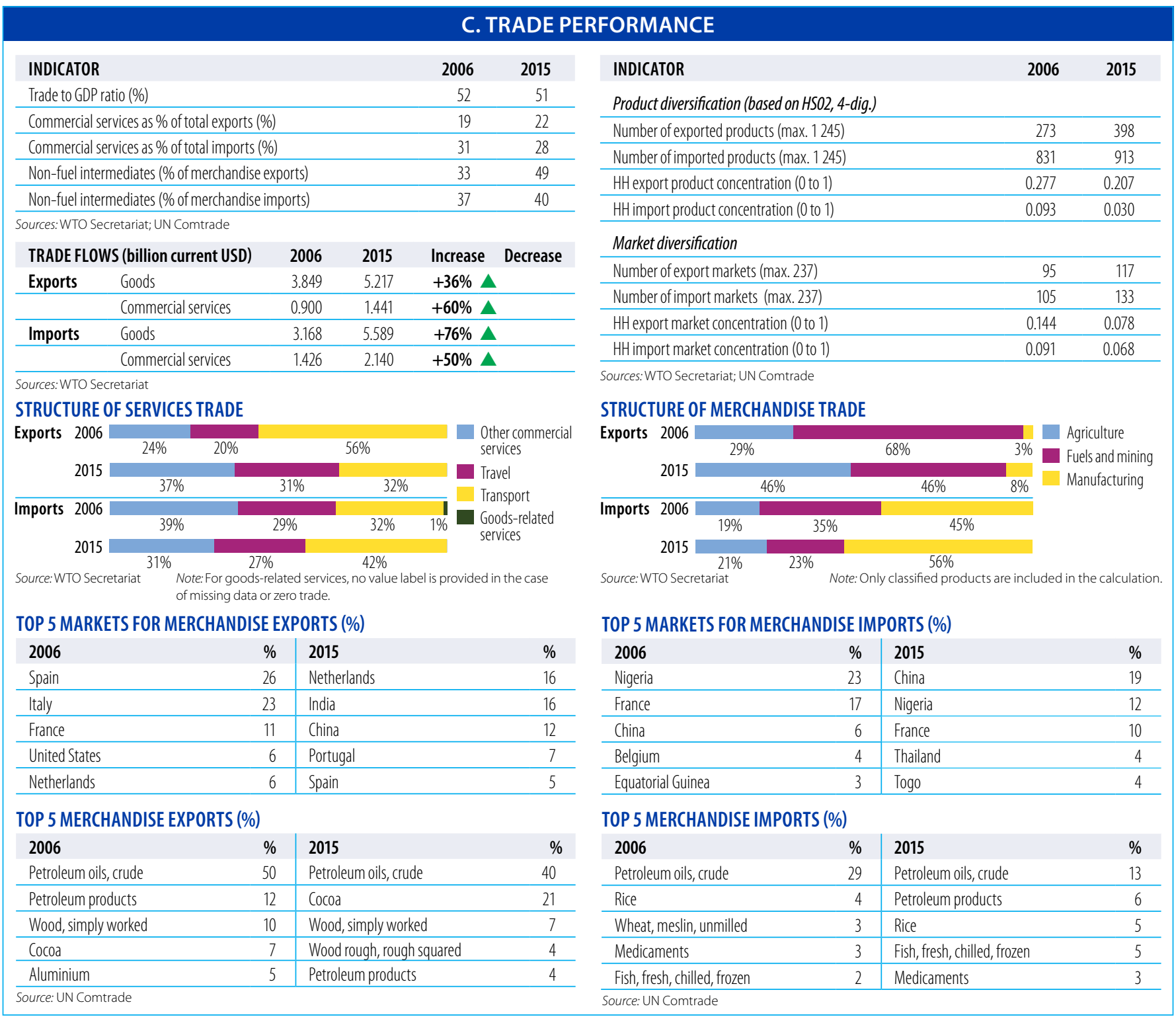

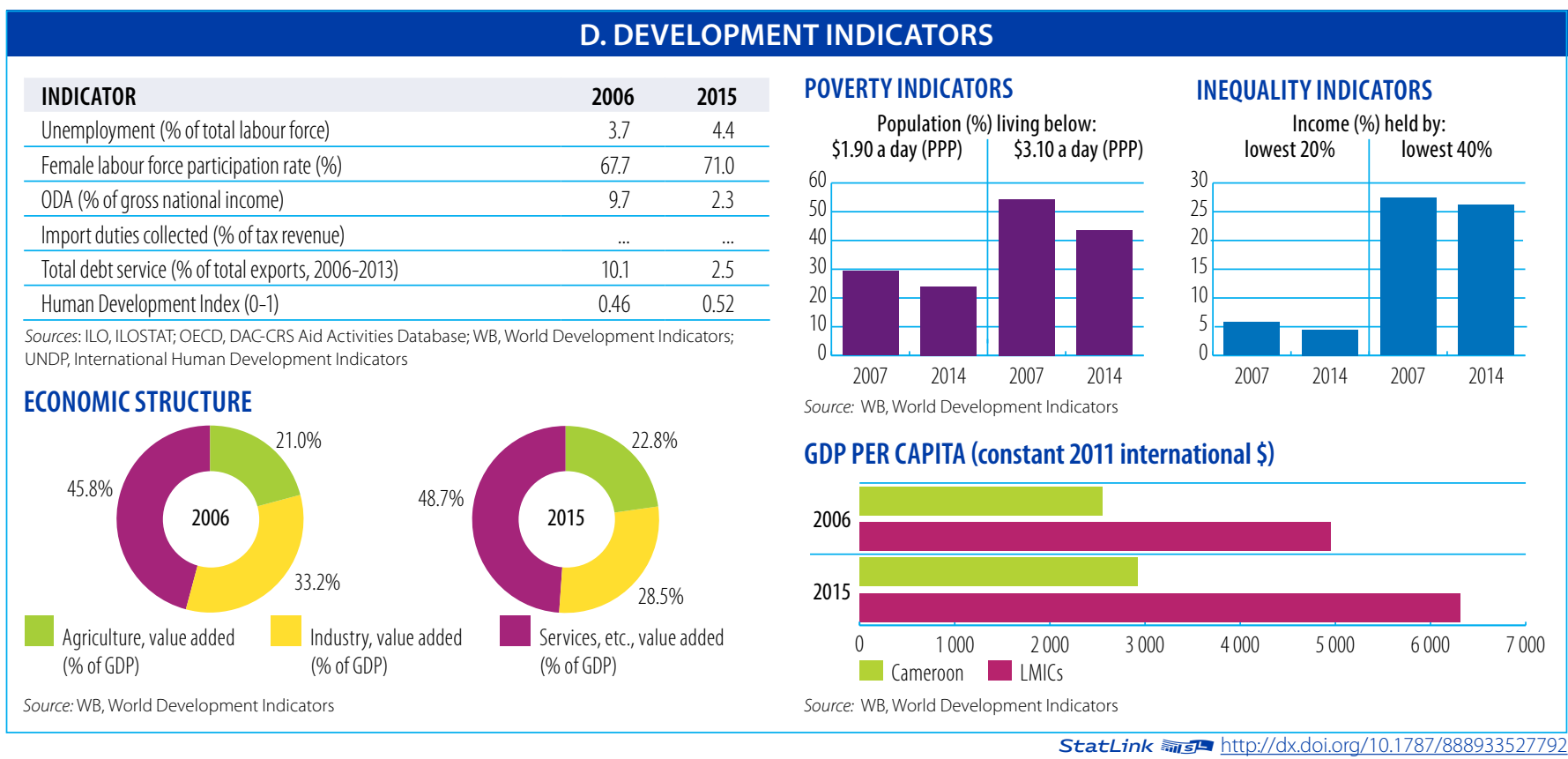




\section{CENTRAL AFRICAN REPUBLIC}

Aid, Trade and Development Indicators for Central African Republic

\section{A. DEVELOPMENT FINANCE}

\begin{tabular}{lrrrc}
$\begin{array}{l}\text { EXTERNAL FINANCING INFLOWS } \\
\text { (million current USD) }\end{array}$ & $\mathbf{2 0 0 6 / 0 8}$ & $\mathbf{2 0 1 2 / 1 4}$ & $\mathbf{2 0 1 5}$ & $\Delta: 06 / 08-15$ \\
FDl inflows & 69.5 & 25.1 & 3.0 & $-96 \%$ \\
\hline Remittances & $\ldots$ & $\ldots$ & $\ldots$ & - \\
\hline Other official flows (0OF) & 20.9 & 0.0 & 0.0 & $-100 \%$ \\
\hline of which trade-related 00F & 0.0 & 0.0 & 0.0 & - \\
\hline Official Development Assistance (ODA) & 231.5 & 353.9 & 505.0 & $118 \%$ \\
\hline of which Aid for Trade & 33.7 & 33.2 & 18.6 & $-45 \%$ \\
\hline
\end{tabular}

Sources: UNCTAD, UNCTADstat; WB, World Development Indicators; OECD,

DAC-CRS Aid Activities Database

\section{TOP 3 AfT PRIORITIES}

1 Connecting to value chains 2 Export diversification 3 Cross-border infrastructure Source: OECD/WTO Partner Questionnaire

SHARE OF AfT IN DEVELOPMENT FINANCE AND FIXED CAPITAL FORMATION (\%)

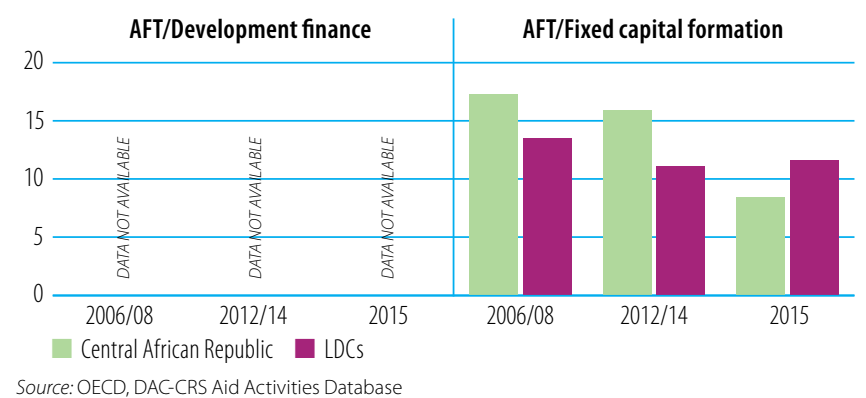

AfT DISBURSEMENTS: TOP DONORS (million current USD)

\begin{tabular}{lrr|lrr}
$\mathbf{2 0 0 6 / 0 8}$ & value & $\%$ & $\mathbf{2 0 1 5}$ & value & $\%$ \\
IDA & 11.8 & 35 & IDA & 10.7 & 58 \\
\hline France & 9.8 & 29 & EU Institutions & 6.0 & 33 \\
\hline United States & 7.6 & 23 & France & 0.9 & 5 \\
\hline Germany & 2.4 & 7 & Kuwait (KFAED) & 0.7 & 4 \\
\hline EU Institutions & 1.8 & 5 & UNICEF & 0.1 & 1 \\
\hline
\end{tabular}

Source: OECD, DAC-CRS Aid Activities Database

AfT DISBURSEMENTS BY SECTOR (million current USD)

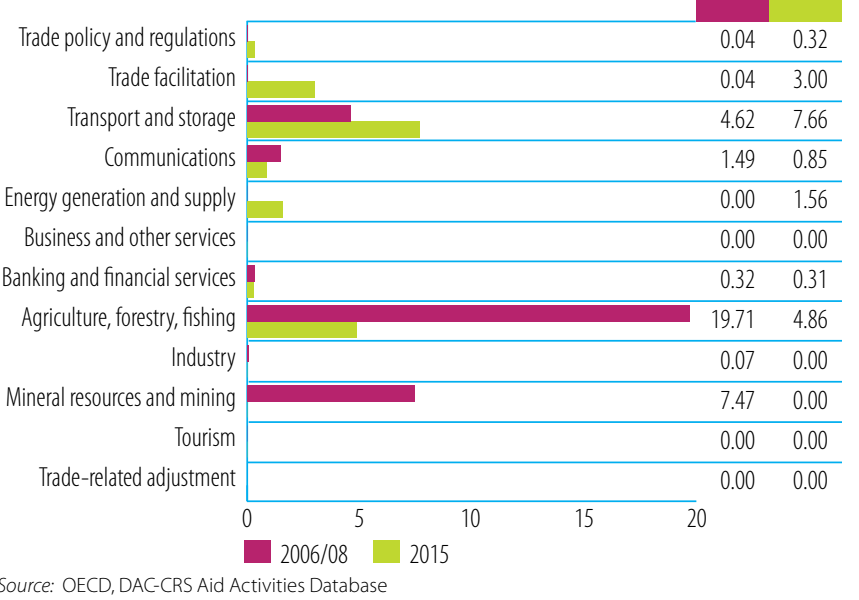

\section{B. TRADE COSTS}

\begin{tabular}{lcc} 
INDICATOR & $\mathbf{2 0 0 6}$ & $\mathbf{2 0 1 5}$ \\
Tariffs (\%) & & \\
\hline Imports: simple avg. MFN applied (2005-2015) & 18.0 & 18.0 \\
\hline Imports: weighted avg. MFN applied (2005-2014) & 21 & 17.5 \\
\hline Exports: weighted avg. faced (2005-2014) & 0.6 & 1.0 \\
\hline Exports: duty free (value in \%) (2005-2014) & 98.2 & 90.2 \\
\hline ICT connectivity (\% of population) & $\ldots$ & \\
\hline Mobile broadband subscriptions & $\ldots$. & 1.1 \\
\hline Fixed broadband subscriptions & $\ldots .3$ & $\ldots .6$ \\
\hline Individuals using the internet & 0.3 & \\
\hline Sources: WTO, World Tariff Profiles; : TU, World Telecommunication/ICT Indicators &
\end{tabular}
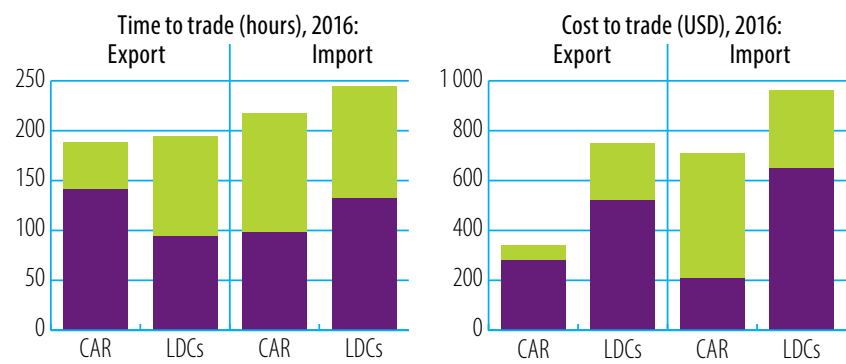

Sources: WTO, World Tariff Profiles; ITU, World Telecommunication/ICT Indicators

LOGISTICS PERFORMANCE INDICES (LPI) (1-5)

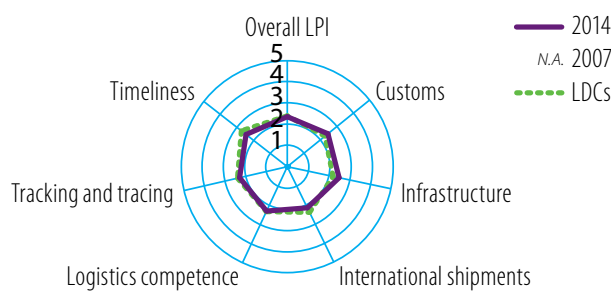

Source: WB Logistics Performance Index (LPI)

GLOBAL COMPETITIVENESS INDICATORS (1-7)

\begin{tabular}{|c|c|c|c|c|c|c|c|c|c|}
\hline \multicolumn{2}{|c|}{ Access to loans } & \multicolumn{2}{|c|}{ Electricity supply } & \multicolumn{2}{|l|}{ Roads } & \multicolumn{2}{|c|}{ Port infrastructure } & \multicolumn{2}{|c|}{ Air transport infrastructure } \\
\hline \\
\hline DATA NOT AVA & \multirow{2}{*}{ DATA NOT AVAILABLE } & \multicolumn{2}{|c|}{ DATA NOT AVAILABLE } & \multicolumn{2}{|c|}{ DATANOT AVAILABLE } & \multicolumn{2}{|c|}{ DATA NOT AVAILABLE } & \multicolumn{2}{|c|}{ DATA NOT AVAILABLE } \\
\hline & \\
\hline \\
\hline & & & & & & & & & \\
\hline $2006{ }_{\text {CAR }}^{2016}$ & $\begin{array}{l}2016 \\
\text { LDCS }\end{array}$ & $\begin{array}{c}2006{ }^{2016} \\
\text { CAR }\end{array}$ & $\begin{array}{l}2016 \\
\text { LDCs }\end{array}$ & $\begin{array}{c}2006{ }^{2016} \\
\text { CAR }\end{array}$ & $\begin{array}{l}2016 \\
\text { LDCs }\end{array}$ & $\begin{array}{c}2006{ }_{\text {CAR }}^{2016} \\
\end{array}$ & $\begin{array}{l}2016 \\
\text { LDCs }\end{array}$ & $\begin{array}{c}2006{ }_{\text {CAR }}^{2016} \\
\end{array}$ & $\begin{array}{l}2016 \\
\text { LDCS }\end{array}$ \\
\hline
\end{tabular}

Source: WEF Global Competitiveness Index
TRADE FACILITATION INDICATORS, 2017 (0-2)

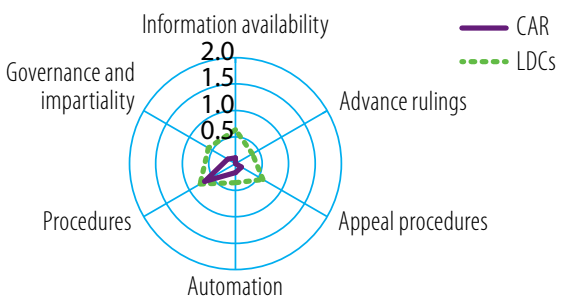

Source: OECD Trade Facilitation Indicators

- Border compliance Documentary compliance

Source: WB, Doing Business

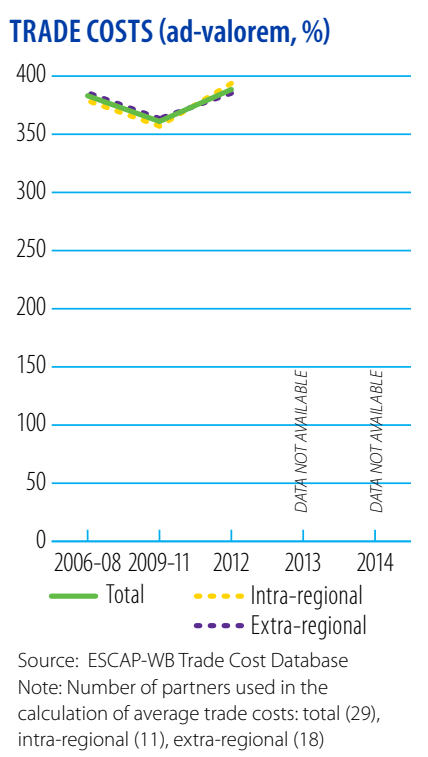




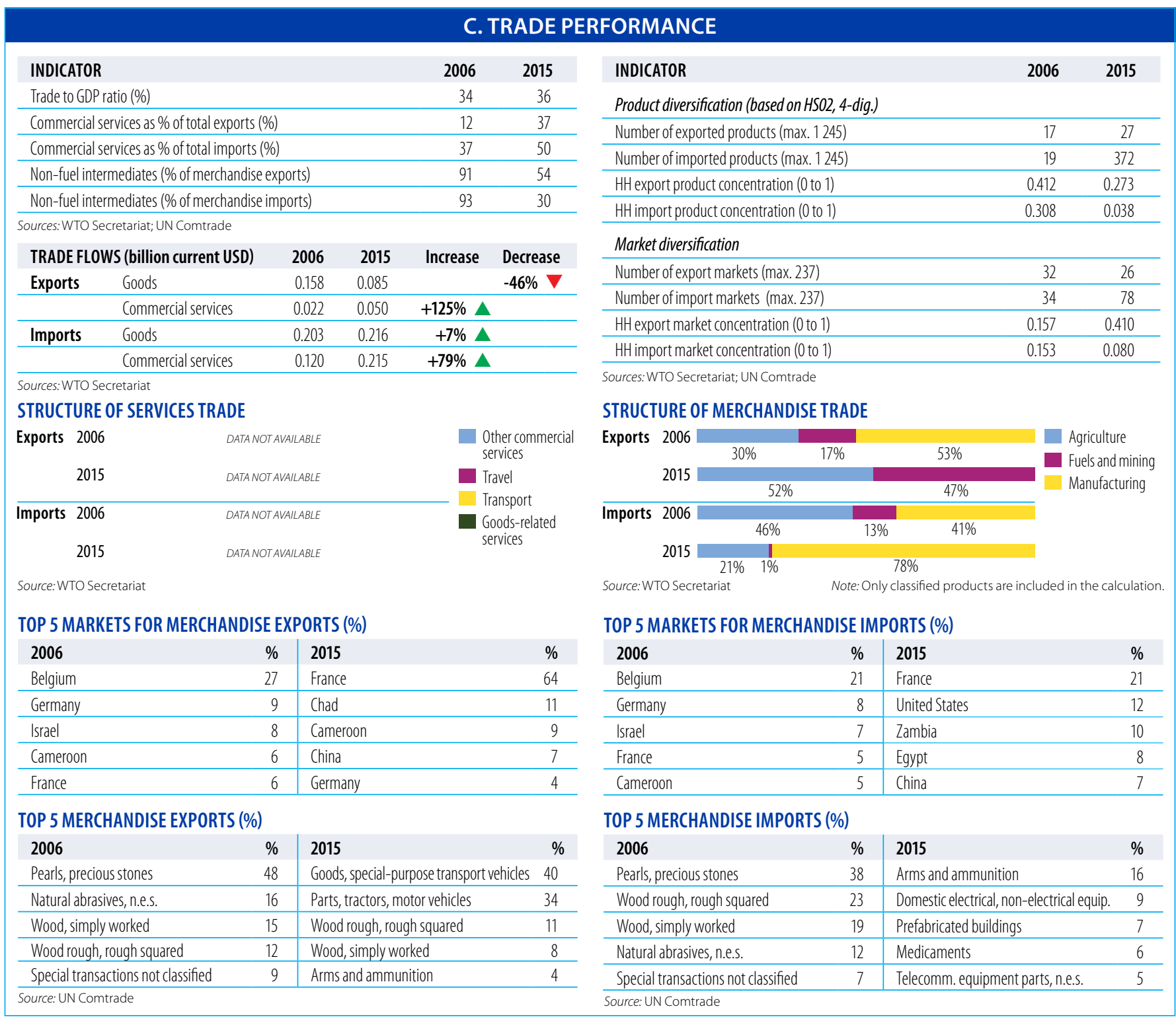

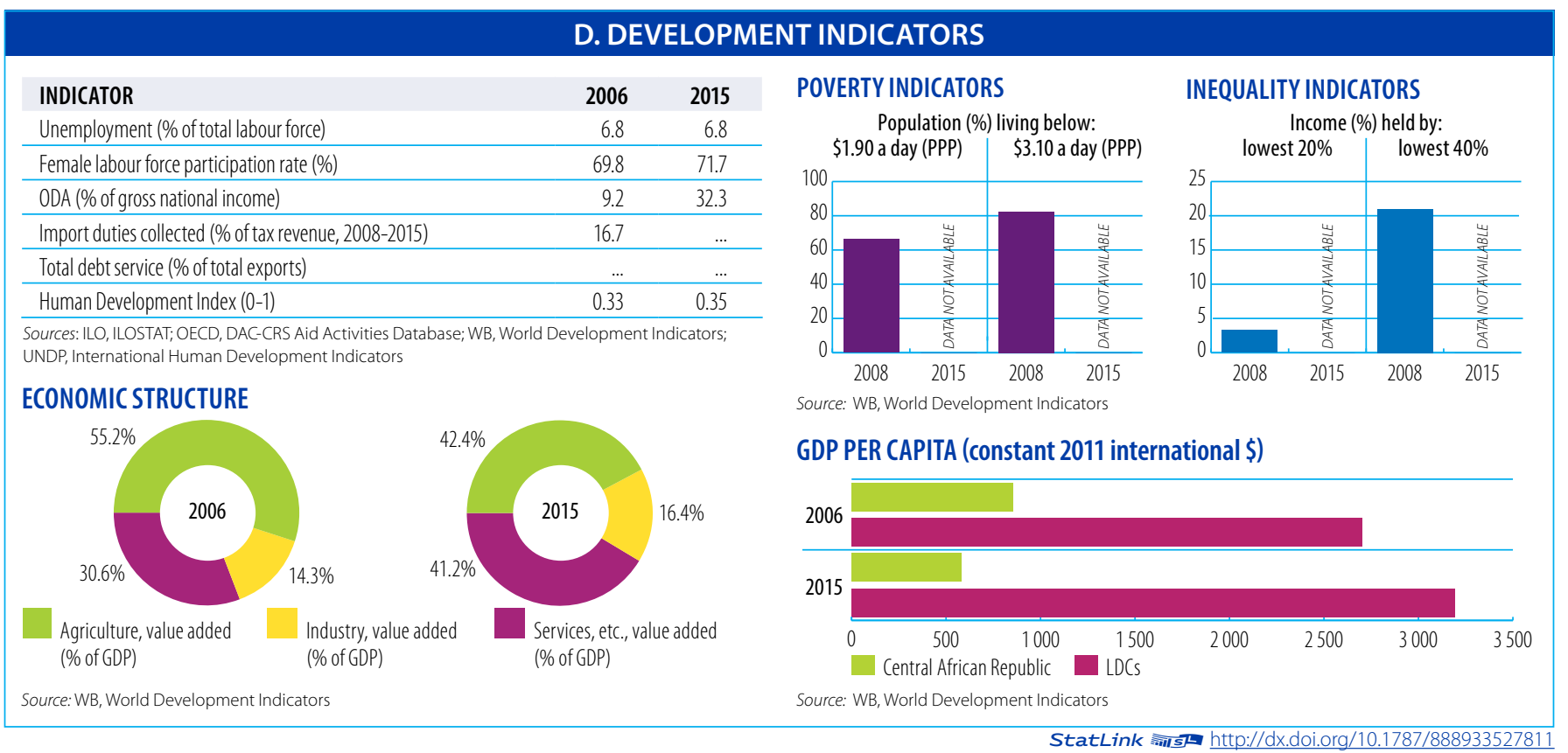


Aid, Trade and Development Indicators for Chad

\section{A. DEVELOPMENT FINANCE}

\begin{tabular}{lrrrc}
\hline $\begin{array}{l}\text { EXTERNAL FINANCING INFL OWS } \\
\text { (million current USD) }\end{array}$ & $\mathbf{2 0 0 6 / 0 8}$ & $\mathbf{2 0 1 2 / 1 4}$ & $\mathbf{2 0 1 5}$ & $\mathbf{\Delta : 0 6 / 0 8 - 1 5}$ \\
\hline FDl inflows & -44.6 & 141.5 & 600.2 & - \\
\hline Remittances & $\ldots$ & $\ldots$ & $\ldots$ & - \\
\hline Other official flows (00F) & 5.1 & 25.1 & 20.4 & $301 \%$ \\
\hline$\quad$ of which trade-related 00F & 5.1 & 0.4 & 0.0 & $-100 \%$ \\
\hline Official Development Assistance (ODA) & 392.4 & 494.7 & 1176.0 & $200 \%$ \\
\hline of which Aid for Trade & 50.2 & 47.9 & 87.8 & $75 \%$ \\
\hline
\end{tabular}

Sources: UNCTAD, UNCTADstat; WB, World Development Indicators; OECD,

DAC-CRS Aid Activities Database

\section{TOP 3 AfT PRIORITIES}

\begin{tabular}{|c|c|c|c|c|c|}
\hline 1 & Trade policy & 2 & Trade facilitation & 3 & Export diversification \\
\hline
\end{tabular}

Source: OECD/WTO Partner Questionnaire

SHARE OF AfT IN DEVELOPMENT FINANCE AND FIXED CAPITAL FORMATION (\%)

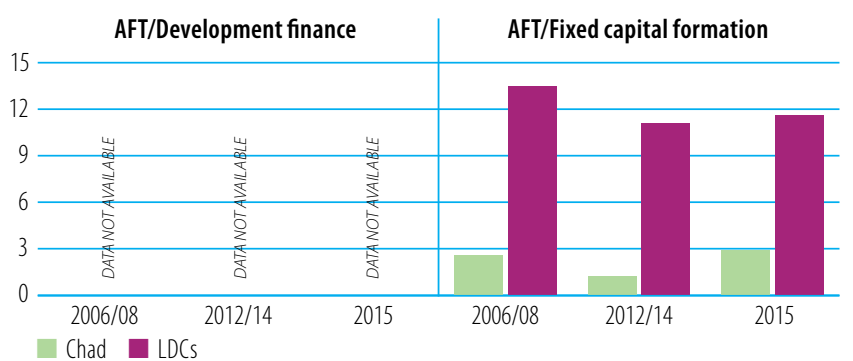

Source: OECD, DAC-CRS Aid Activities Database
AfT DISBURSEMENTS: TOP DONORS (million current USD)

\begin{tabular}{lrr|lrc}
$\mathbf{2 0 0 6 / 0 8}$ & value & $\%$ & $\mathbf{2 0 1 5}$ & value & $\%$ \\
EU Institutions & 29.9 & 60 & EU Institutions & 47.3 & 54 \\
\hline IDA & 11.6 & 23 & IDA & 25.9 & 30 \\
\hline Switzerland & 3.0 & 6 & Switzerland & 5.9 & 7 \\
\hline African Development Fund & 2.7 & 5 & France & 4.5 & 5 \\
\hline France & 1.6 & 3 & African Development Fund & 2.1 & 2 \\
\hline Source. OECD.DAC-CRS Aid Activities Database & \multicolumn{2}{l}{}
\end{tabular}

Source: OECD, DAC-CRS Aid Activities Database

AfT DISBURSEMENTS BY SECTOR (million current USD)

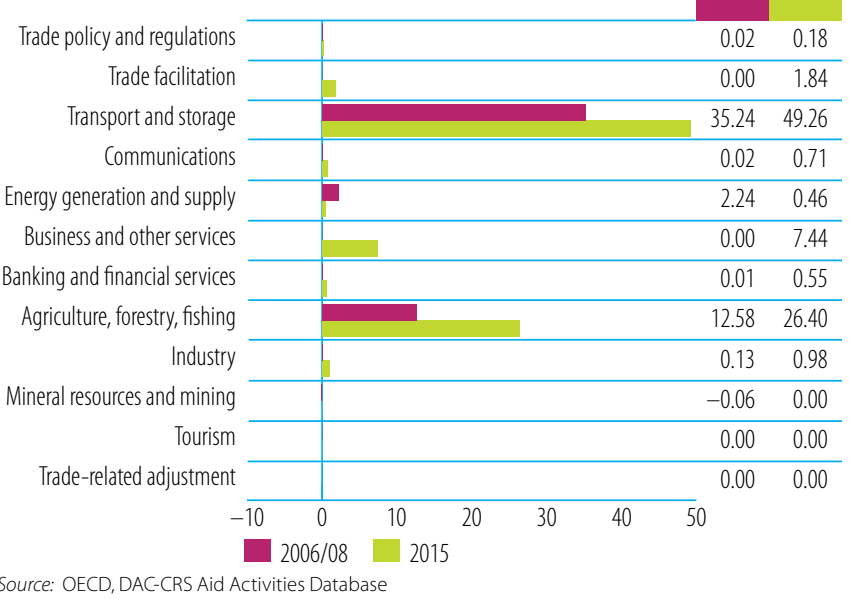

\section{B. TRADE COSTS}

\begin{tabular}{lcc} 
INDICATOR & 2006 & $\mathbf{2 0 1 5}$ \\
Tariffs (\%) & & \\
\hline Imports: simple avg. MFN applied (2005-2015) & 18.0 & 17.9 \\
\hline Imports: weighted avg. MFN applied (2006-2013) & $\ldots$ & 15.6 \\
\hline Exports: weighted avg. faced (2005-2014) & 0.5 & 0.2 \\
\hline Exports: duty free (value in \%) (2005-2014) & 94.7 & 99.3 \\
\hline ICT connectivity (\% of population) & & \\
\hline Mobile broadband subscriptions & $\ldots$ & 1.4 \\
\hline Fixed broadband subscriptions & $\ldots$ & 0.1 \\
\hline Individuals using the internet & 0.6 & 2.7 \\
\hline Sources: WTO, World Tariff Profiles; ITU, World Telecommunication/ICT Indicators &
\end{tabular}
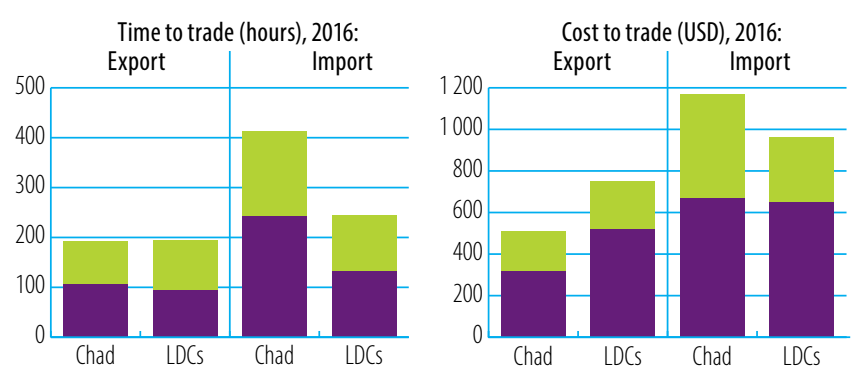

- Border compliance Documentary compliance Source: WB, Doing Business

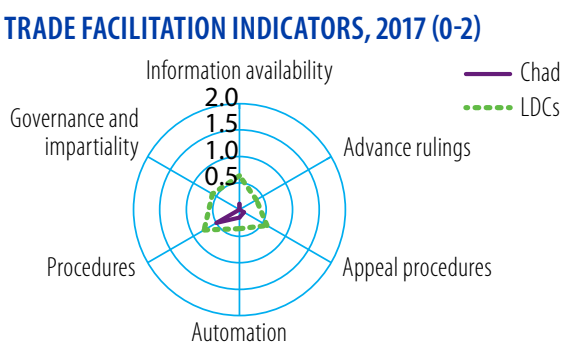

Source: OECD Trade Facilitation Indicators

Source: WB Logistics Performance Index (LPI)

GLOBAL COMPETITIVENESS INDICATORS (1-7)

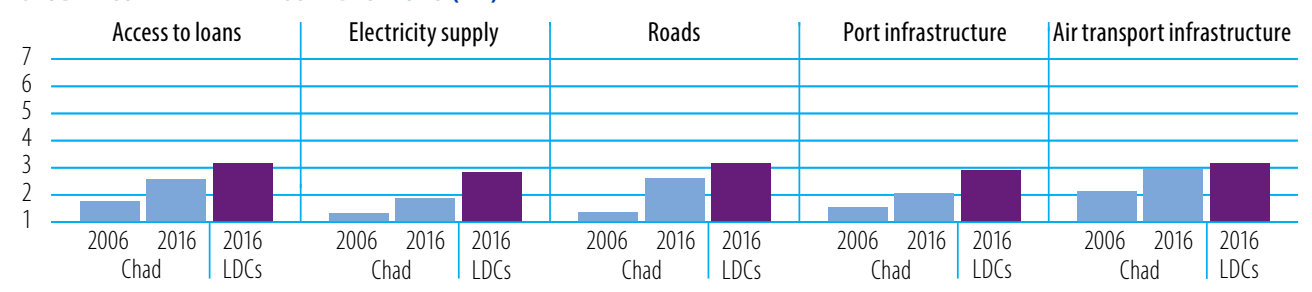

Source: WEF Global Competitiveness Index

LOGISTICS PERFORMANCE INDICES (LPI) (1-5)

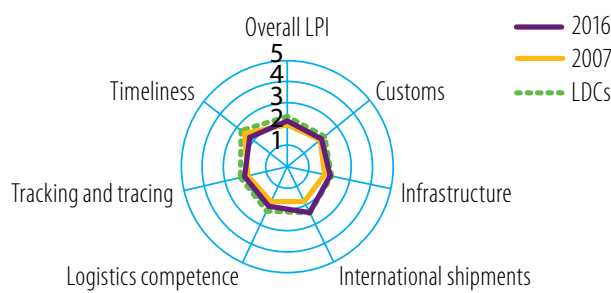




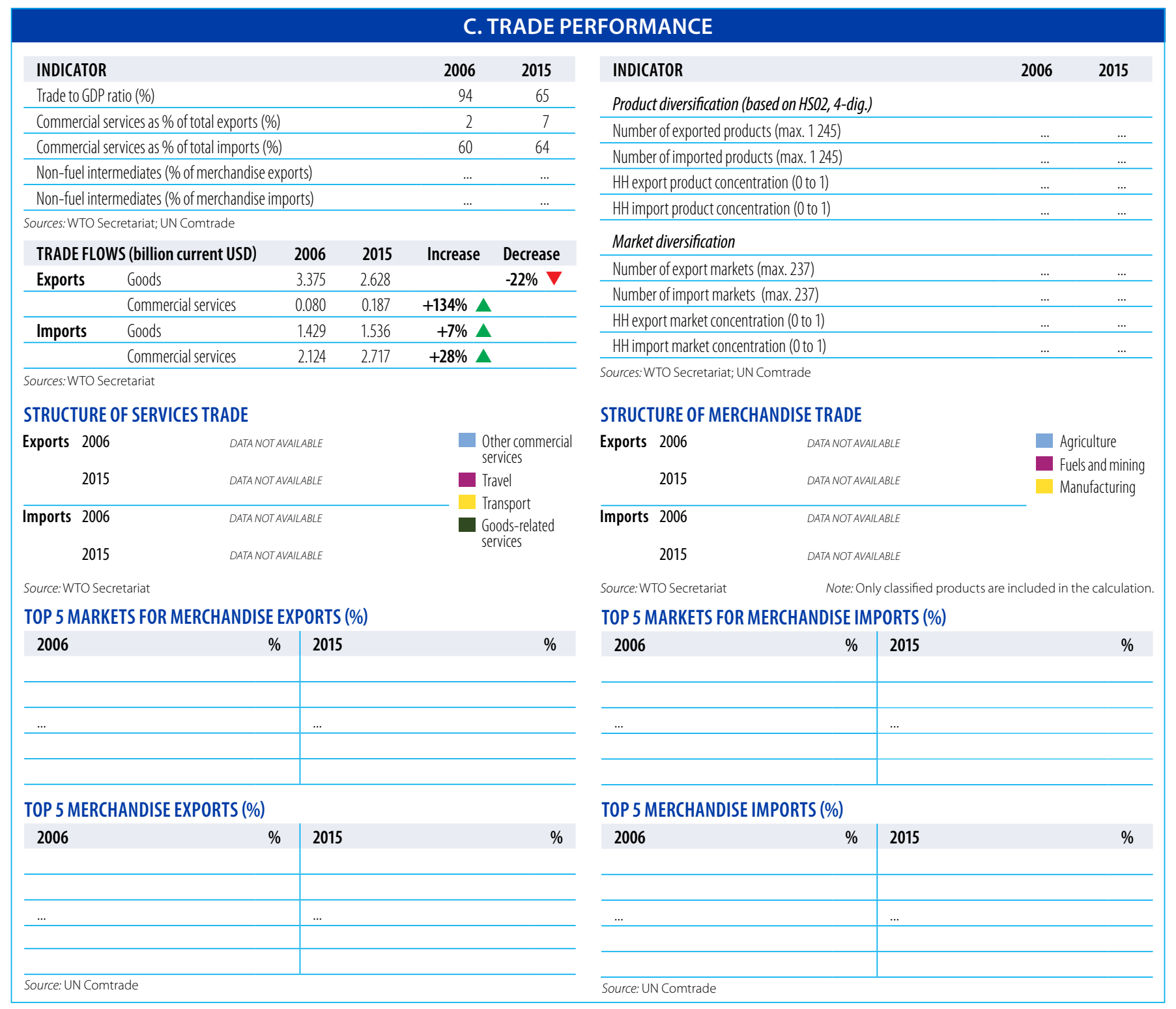

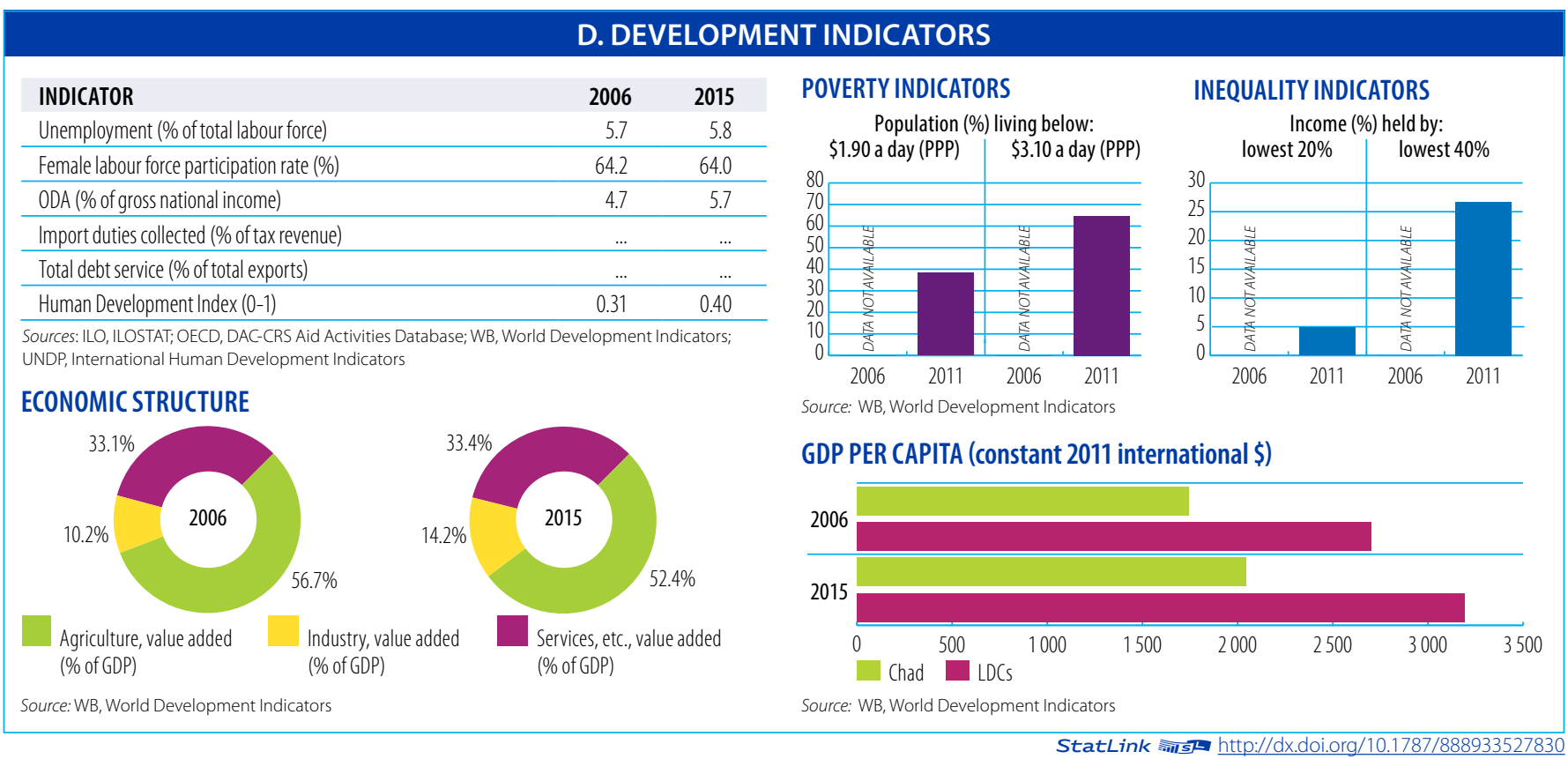


Aid, Trade and Development Indicators for Colombia

\section{A. DEVELOPMENT FINANCE}

\begin{tabular}{|c|c|c|c|c|c|c|}
\hline $\begin{array}{l}\text { EXTERNAL FINANCING INFLOWS } \\
\text { (million current USD) }\end{array}$ & & 2006/08 & $2012 / 14$ & & 2015 & $\Delta: 06 / 08-15$ \\
\hline FDl inflows & & 8733.7 & 15857.5 & & 2107.6 & $39 \%$ \\
\hline Remittances & & 4395.4 & 4211.4 & & 4679.7 & $6 \%$ \\
\hline Other official flows (00F) & & 814.2 & 1559.2 & & 2151.0 & $164 \%$ \\
\hline of which trade-related 00F & & 313.5 & 486.6 & & 868.9 & $177 \%$ \\
\hline Official Development Assistance (ODA) & & 918.1 & 997.2 & & 1417.6 & $54 \%$ \\
\hline of which Aid for Trade & & 123.9 & 165.8 & & 213.5 & $72 \%$ \\
\hline \multicolumn{7}{|c|}{$\begin{array}{l}\text { Sources: UNCTAD, UNCTADstat; WB, World Development Indicators; OECD, } \\
\text { DAC-CRS Aid Activities Database }\end{array}$} \\
\hline \multicolumn{7}{|l|}{ TOP 3 AfT PRIORITIES } \\
\hline 1 International competitiveness & 2 & Trade pc & olicy & 3 & Trade & cilitation \\
\hline
\end{tabular}

SHARE OF AfT IN DEVELOPMENT FINANCE AND FIXED CAPITAL FORMATION (\%)

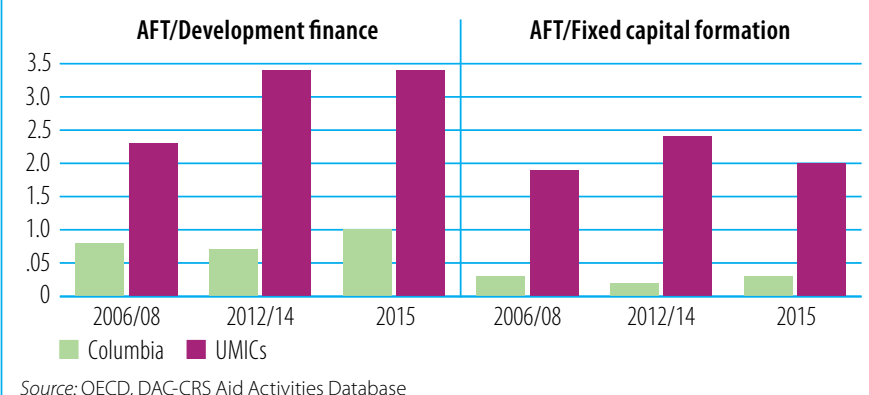

AfT DISBURSEMENTS: TOP DONORS (million current USD)

\begin{tabular}{lrr|lrc}
$\mathbf{2 0 0 6 / 0 8}$ & value & $\%$ & $\mathbf{2 0 1 5}$ & value & $\%$ \\
United States & 89.3 & 72 & United States & 79.7 & 37 \\
\hline Spain & 11.6 & 9 & United Kingdom & 47.4 & 22 \\
\hline Netherlands & 7.3 & 6 & Germany & 27.9 & 13 \\
\hline EU Institutions & 3.4 & 3 & Canada & 18.7 & 9 \\
\hline France & 3.3 & 3 & EU Institutions & 10.3 & 5 \\
\hline
\end{tabular}

Source: OECD, DAC-CRS Aid Activities Database

AfT DISBURSEMENTS BY SECTOR (million current USD)

\begin{tabular}{|c|c|c|c|}
\hline Trade policy and regulations & & 2.46 & 3.14 \\
\hline Trade facilitation & & 0.21 & 0.03 \\
\hline Transport and storage & 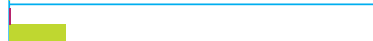 & 0.66 & 24.97 \\
\hline Communications & & 0.89 & 1.13 \\
\hline Energy generation and supply & 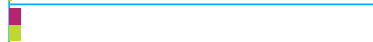 & 5.09 & 5.28 \\
\hline Business and other services & 1 & 2.91 & 8.49 \\
\hline Banking and financial services & $\bar{F}$ & 6.41 & 0.85 \\
\hline Agriculture, forestry, fishing & 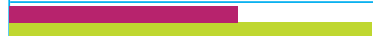 & 101.72 & 161.10 \\
\hline Industry & 1 & 2.92 & 7.29 \\
\hline Mineral resources and mining & & 0.06 & 0.87 \\
\hline Tourism & & 0.60 & 0.35 \\
\hline Trade-related adjustment & & 0.00 & 0.00 \\
\hline & 50 & 200 & \\
\hline
\end{tabular}

\section{B. TRADE COSTS}

\begin{tabular}{lcc} 
INDICATOR & $\mathbf{2 0 0 6}$ & $\mathbf{2 0 1 5}$ \\
Tariffs (\%) & 12.5 & 5.7 \\
\hline Imports: simple avg. MFN applied & $\ldots$ & 6.6 \\
\hline Imports: weighted avg. MFN applied (2006-2014) & 5.7 & 0.2 \\
\hline Exports: weighted avg. faced (2005-2014) & 91.0 & 97.9 \\
\hline Exports: duty free (value in \%) (2005-2014) & & \\
\hline ICT connectivity (\% of population) & 0.3 & 41.0 \\
\hline Mobile broadband subscriptions (2008-2015) & 1.4 & 11.2 \\
\hline Fixed broadband subscriptions & 15.3 & 55.9 \\
\hline Individuals using the internet & &
\end{tabular}
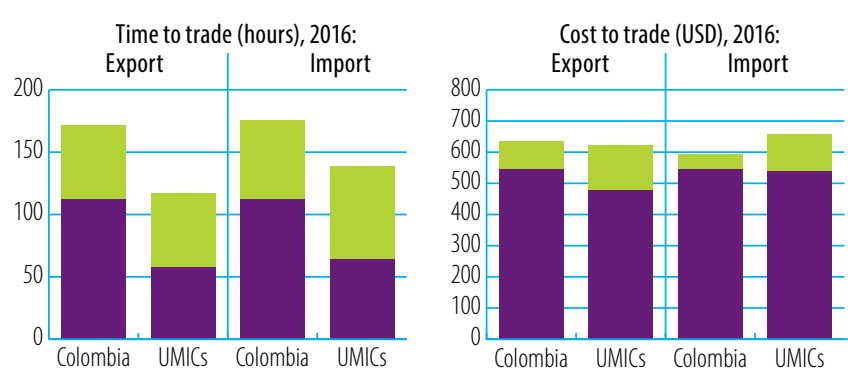

Border compliance Documentary compliance Source: WB, Doing Business

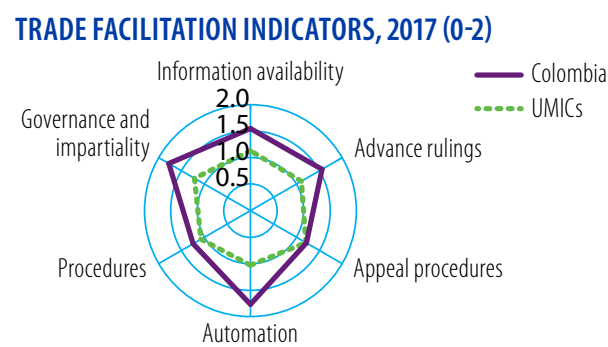

GLOBAL COMPETITIVENESS INDICATORS (1-7)

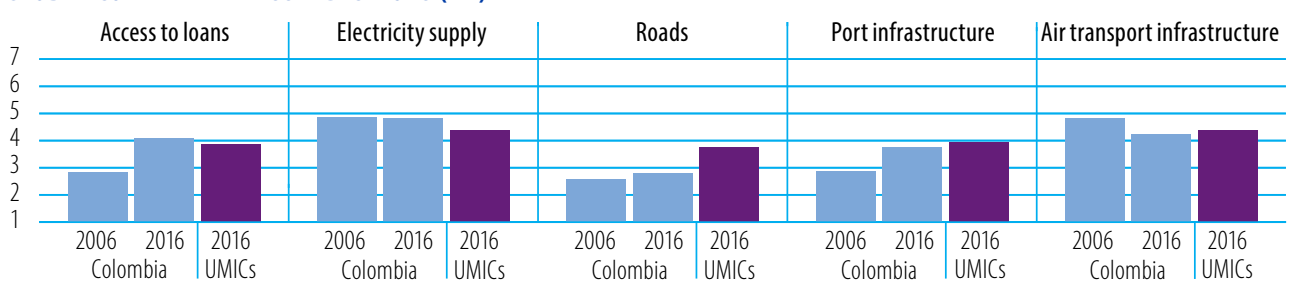

Source: WEF Global Competitiveness Index
Source: OECD Trade Facilitation Indicators

Source: WB Logistics Performance Index (LPI)

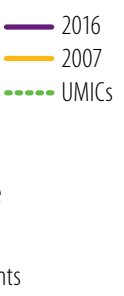

LOGISTICS PERFORMANCE INDICES (LPI) (1-5)

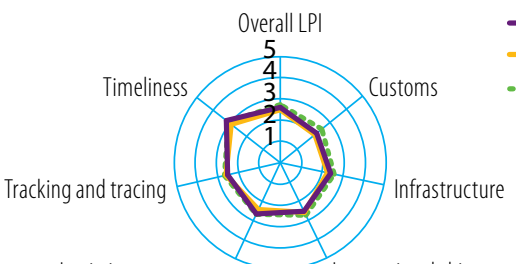

Logistics competence

$$
\text { ternational shipments }
$$

Colombia UMICS
TRADE COSTS (ad-valorem, \%)

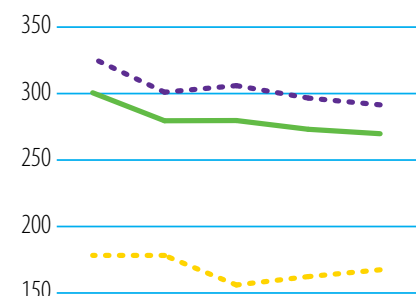

100

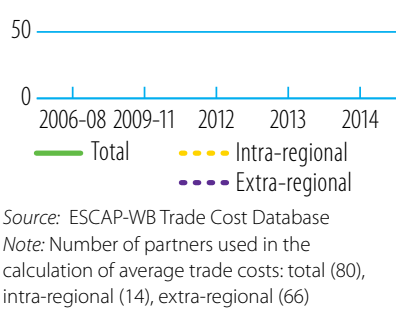




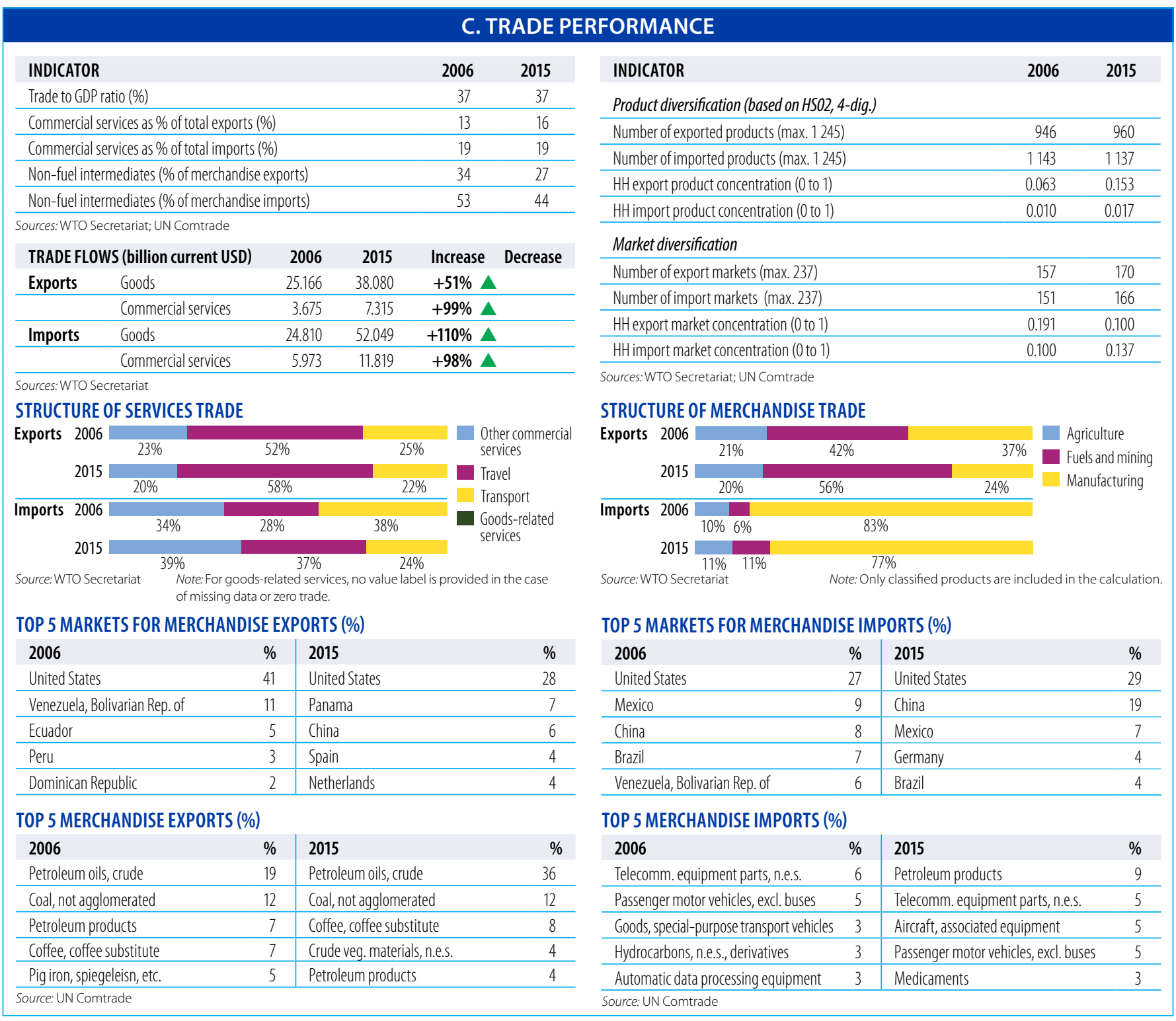

\begin{tabular}{|lrr}
\hline & D. DEVELOPMEN \\
\hline INDICATOR & $\mathbf{2 0 0 6}$ & $\mathbf{2 0 1 5}$ \\
\hline Unemployment (\% of total labour force) & 11.7 & 9.0 \\
\hline Female labour force participation rate (\%) & 51.6 & 57.9 \\
\hline ODA (\% of gross national income) & 0.6 & 0.5 \\
\hline Import duties collected (\% of tax revenue, 2008-2014) & 8.9 & 4.1 \\
\hline Total debt service (\% of total exports) & 34.0 & 28.1 \\
\hline Human Development Index (0-1) & 0.68 & 0.73 \\
\hline
\end{tabular}

Sources: ILO, ILOSTAT; OECD, DAC-CRS Aid Activities Database; WB, World Development Indicators; UNDP, International Human Development Indicators

\section{ECONOMIC STRUCTURE}

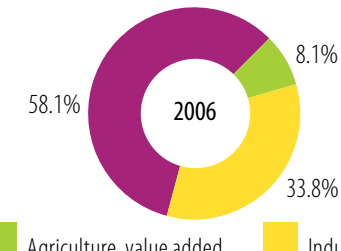

Agriculture, value added (\% of GDP)
Industry, value added (\% of GDP)

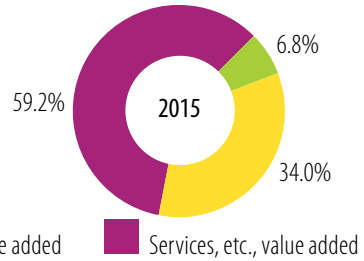

(\% of GDP)
Source: WB, World Development Indicators

\section{POVERTY INDICATORS}

Population (\%) living below:

$\$ 1.90$ a day (PPP) $\quad \$ 3.10$ a day (PPP)

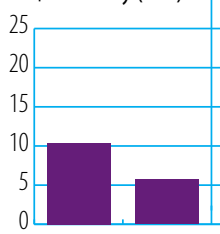

20052014

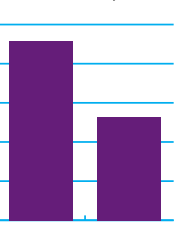

$2005 \quad 2014$

Source: WB, World Development Indicators

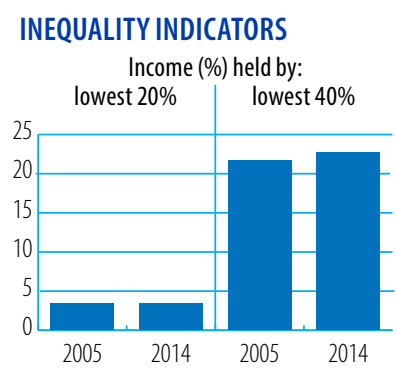

GDP PER CAPITA (constant 2011 international \$)

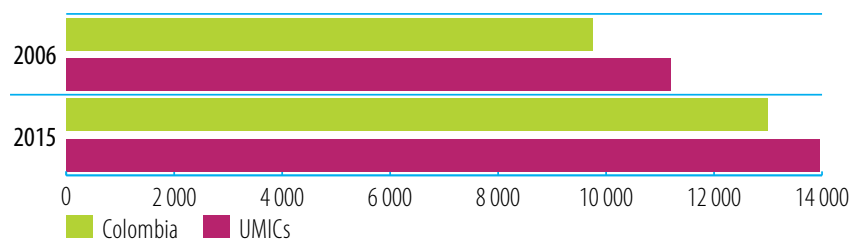

Source: WB, World Development Indicators 
Aid, Trade and Development Indicators for Comoros

\section{A. DEVELOPMENT FINANCE}

\begin{tabular}{lrrrc}
$\begin{array}{l}\text { EXTERNAL FINANCING INFLOWS } \\
\text { (million current USD) }\end{array}$ & $\mathbf{2 0 0 6 / 0 8}$ & $\mathbf{2 0 1 2 / 1 4}$ & $\mathbf{2 0 1 5}$ & $\mathbf{\Delta : 0 6 / 0 8 - 1 5}$ \\
\hline FDl inflows & 4.4 & 6.4 & 5.1 & $18 \%$ \\
\hline Remittances & 79.3 & 117.4 & 128.8 & $62 \%$ \\
\hline Other official flows (00F) & 0.0 & 0.1 & 0.0 & - \\
\hline$\quad$ of which trade-related 00F & 0.0 & 0.0 & 0.0 & - \\
\hline Official Development Assistance (ODA) & 40.0 & 122.0 & 70.0 & $75 \%$ \\
\hline$\quad$ of which Aid for Trade & 3.6 & 12.6 & 13.6 & $278 \%$ \\
\hline
\end{tabular}

Sources: UNCTAD, UNCTADstat; WB, World Development Indicators; OECD,

DAC-CRS Aid Activities Database

TOP 3 AFT PRIORITIES

\begin{tabular}{|l|l|l|l|l|l|}
\hline $\mathbf{1}$ & WTO accession & $\mathbf{2}$ & International competitiveness & $\mathbf{3}$ & Trade facilitation \\
\hline
\end{tabular}

Source: OECD/WTO Partner Questionnaire

SHARE OF AfT IN DEVELOPMENT FINANCE AND FIXED CAPITAL FORMATION (\%)

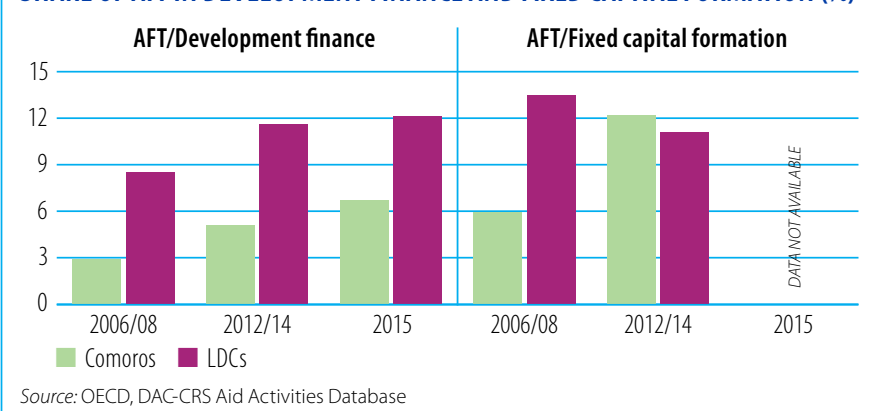

AfT DISBURSEMENTS: TOP DONORS (million current USD)

\begin{tabular}{lrr|lrc}
$\mathbf{2 0 0 6 / 0 8}$ & value & $\%$ & $\mathbf{2 0 1 5}$ & value & $\%$ \\
France & 2.0 & 55 & IDA & 4.0 & 29 \\
\hline EU Institutions & 0.9 & 24 & EU Institutions & 3.1 & 23 \\
\hline IDA & 0.5 & 14 & African Development Fund & 2.0 & 15 \\
\hline Belgium & 0.1 & 3 & Global Environment Facility & 1.8 & 13 \\
\hline UNDP & 0.1 & 2 & New Zealand & 1.0 & 7 \\
\hline
\end{tabular}

Source: OECD, DAC-CRS Aid Activities Database

AfT DISBURSEMENTS BY SECTOR (million current USD)

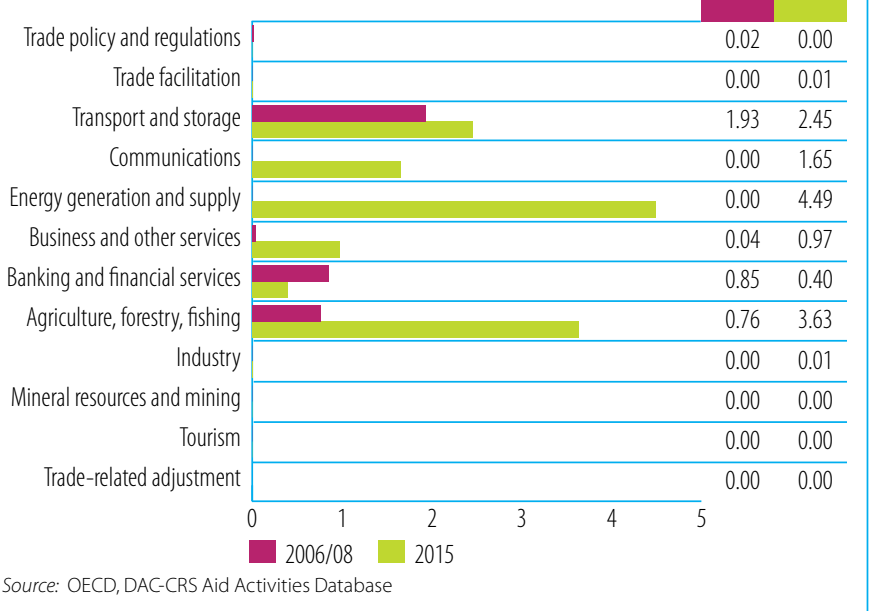

\section{B. TRADE COSTS}

\begin{tabular}{lcc} 
INDICATOR & $\mathbf{2 0 0 6}$ & $\mathbf{2 0 1 5}$ \\
Tariffs (\%) & & \\
\hline Imports: simple avg. MFN applied & 28.9 & 15.3 \\
\hline Imports: weighted avg. MFN applied (2006-2013) & $\ldots$ & 6.9 \\
\hline Exports: weighted avg. faced (2005-2014) & 0.6 & 5.3 \\
\hline Exports: duty free (value in \%) (2005-2014) & 82.5 & 47.0 \\
\hline ICT connectivity (\% of population) & $\ldots$ & \\
\hline Mobile broadband subscriptions (2006-2014) & 0.0 & 0.3 \\
\hline Fixed broadband subscriptions (2007-2015) & 2.2 & 7.5 \\
\hline Individuals using the internet & &
\end{tabular}
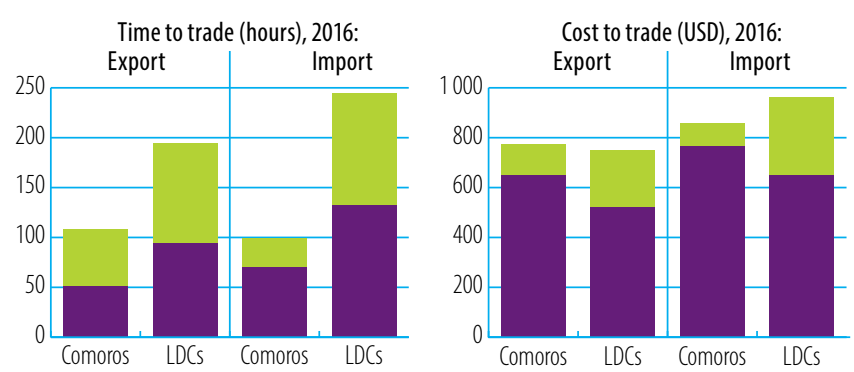

Sources: WTO, World Tariff Profiles; ITU, World Telecommunication/ICT Indicators

LOGISTICS PERFORMANCE INDICES (LPI) (1-5)

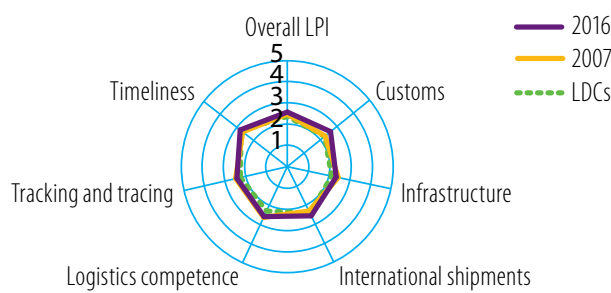

Source: WB Logistics Performance Index (LPI)

GLOBAL COMPETITIVENESS INDICATORS (1-7)

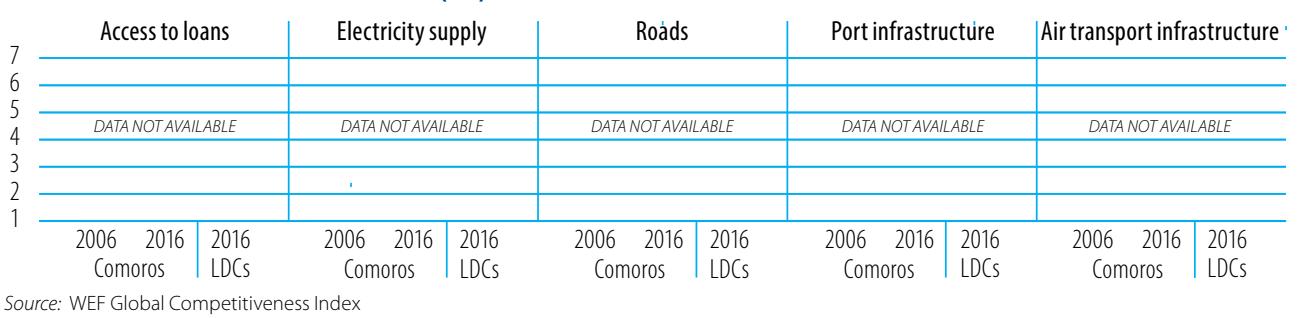

TRADE FACILITATION INDICATORS, 2017 (0-2)

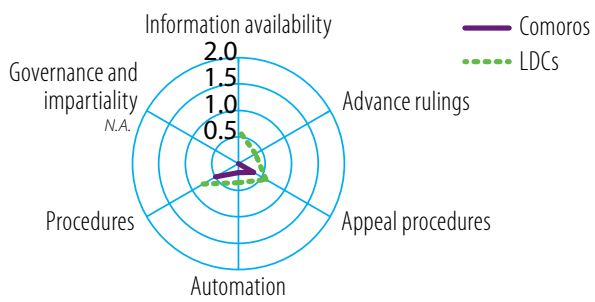

Source: OECD Trade Facilitation Indicators

Border compliance Documentary compliance

Source: WB, Doing Business 


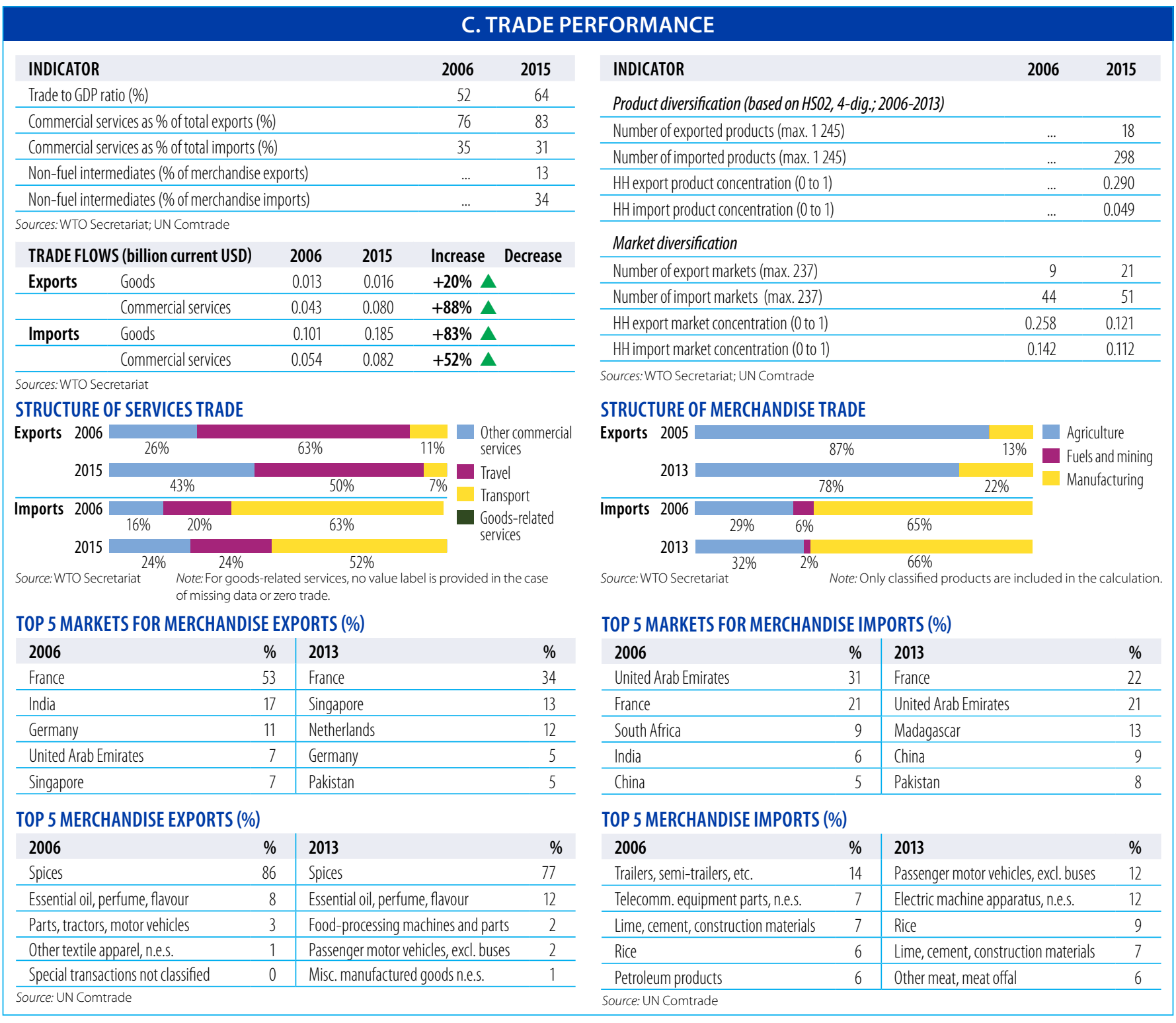

\begin{tabular}{|lrc}
\hline & D. DEVELOPME \\
\hline INDICATOR & 2006 & 2015 \\
Unemployment (\% of total labour force) & 20.2 & 19.9 \\
\hline Female labour force participation rate (\%) & 32.6 & 35.3 \\
\hline ODA (\% of gross national income, 2006-2014) & 7.9 & 12.1 \\
\hline Import duties collected (\% of tax revenue) & $\ldots$ & $\ldots$ \\
\hline Total debt service (\% of total exports, 2006-2014) & 5.9 & 0.6 \\
\hline Human Development Index (0-1) & 0.46 & 0.50 \\
\hline
\end{tabular}

Sources: ILO, ILOSTAT: OECD, DAC-CRS Aid Activities Database; WB, World Development Indicators; UNDP, International Human Development Indicators

\section{ECONOMIC STRUCTURE}

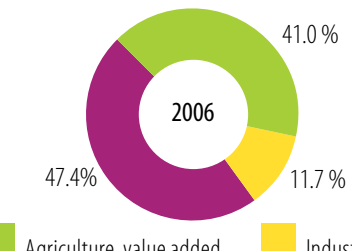

Agriculture, value added (\% of GDP)

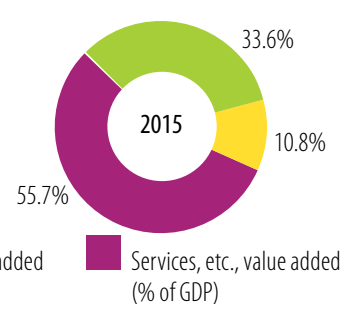

(\% of GDP)

Source: WB, World Development Indicators

\section{POVERTY INDICATORS}

Population (\%) living below:

$\$ 1.90$ a day (PPP) $\quad \$ 3.10$ a day (PPP)

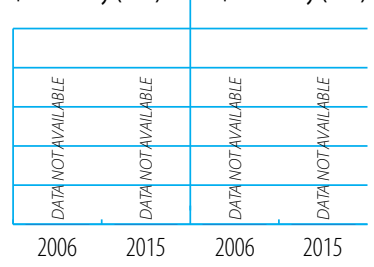

Source: WB, World Development Indicators

\section{INEQUALITY INDICATORS}

Income (\%) held by:

lowest 20\% | lowest 40\%

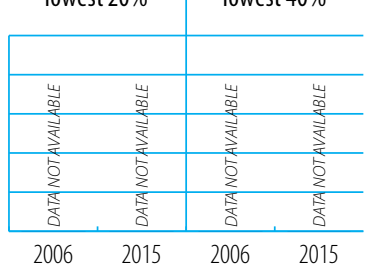

GDP PER CAPITA (constant 2011 international \$)

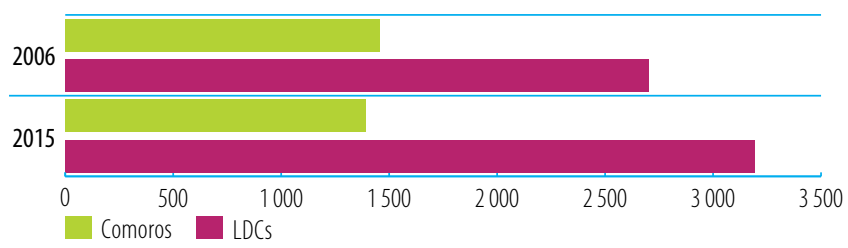

Source: WB, World Development Indicators 


\section{CONGO}

Aid, Trade and Development Indicators for Congo

\section{A. DEVELOPMENT FINANCE}

\begin{tabular}{lrrrc}
$\begin{array}{l}\text { EXTERNAL FINANCING INFLOWS } \\
\text { (million current USD) }\end{array}$ & $\mathbf{2 0 0 6 / 0 8}$ & $\mathbf{2 0 1 2 / 1 4}$ & $\mathbf{2 0 1 5}$ & $\mathbf{\Delta : 0 6 / 0 8 - 1 5}$ \\
FDl inflows & 1351.0 & 3522.7 & 1486.2 & $10 \%$ \\
\hline Remittances & 14.0 & $\ldots$ & $\ldots$ & - \\
\hline Other official flows (OOF) & 6.1 & 0.0 & 0.1 & $-98 \%$ \\
\hline$\quad$ of which trade-related O0F & 0.0 & 0.0 & 0.1 & - \\
\hline Official Development Assistance (ODA) & 353.2 & 164.5 & 131.6 & $-63 \%$ \\
\hline$\quad$ of which Aid for Trade & 29.3 & 37.8 & 27.6 & $-6 \%$ \\
\hline
\end{tabular}

Sources: UNCTAD, UNCTADstat; WB, World Development Indicators; OECD,

DAC-CRS Aid Activities Database

\section{TOP 3 AfT PRIORITIES}

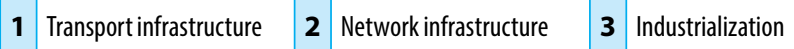

Source: OECD/WTO Partner Questionnaire

SHARE OF AfT IN DEVELOPMENT FINANCE AND FIXED CAPITAL FORMATION (\%)

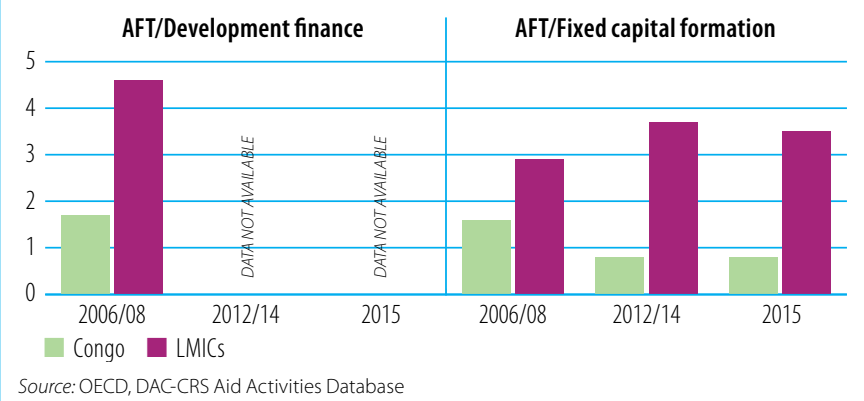

AfT DISBURSEMENTS: TOP DONORS (million current USD)

\begin{tabular}{lrr|lrr} 
2006/08 & value & $\%$ & 2015 & value & $\%$ \\
EU Institutions & 22.3 & 76 & EU Institutions & 15.0 & 55 \\
\hline France & 3.4 & 12 & IDA & 8.1 & 29 \\
\hline IDA & 2.9 & 10 & OPEC Fund for International Development & 1.8 & 6 \\
\hline Spain & 0.2 & 1 & France & 1.2 & 4 \\
\hline Luxembourg & 0.2 & 1 & Japan & 0.5 & 2 \\
\hline \multicolumn{2}{l}{ Source: OECD,DAC-CRS Aid Activities Database }
\end{tabular}

AfT DISBURSEMENTS BY SECTOR (million current USD)

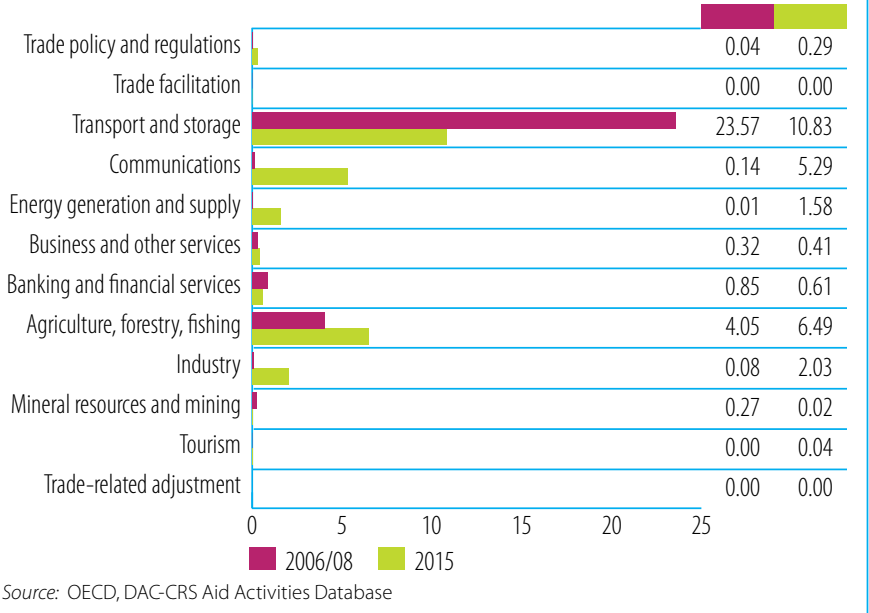

\section{B. TRADE COSTS}

\begin{tabular}{lcc} 
INDICATOR & 2006 & $\mathbf{2 0 1 5}$ \\
Tariffs (\%) & 18.4 & 11.9 \\
\hline Imports: simple avg. MFN applied & $\ldots$ & 11.8 \\
\hline Imports: weighted avg. MFN applied (2006-2014) & 0.6 & 0.8 \\
\hline Exports: weighted avg. faced (2005-2014) & 85.3 & 83.0 \\
\hline Exports: duty free (value in \%) (2005-2014) & & \\
\hline ICT connectivity (\% of population) & 0.0 & 10.8 \\
\hline Mobile broadband subscriptions (2008-2014) & $\ldots$ & 0.0 \\
\hline Fixed broadband subscriptions (2006-2014) & 2.0 & 7.6 \\
\hline Individuals using the internet & &
\end{tabular}
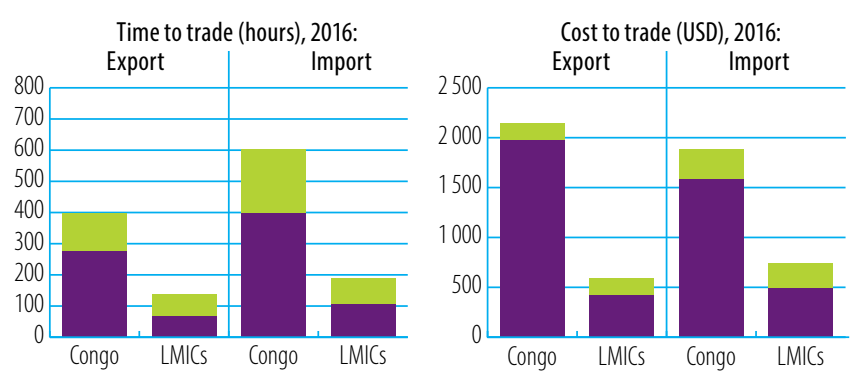

Sources: WTO, World Tariff Profiles; ITU, World Telecommunication/ICT Indicators

LOGISTICS PERFORMANCE INDICES (LPI) (1-5)

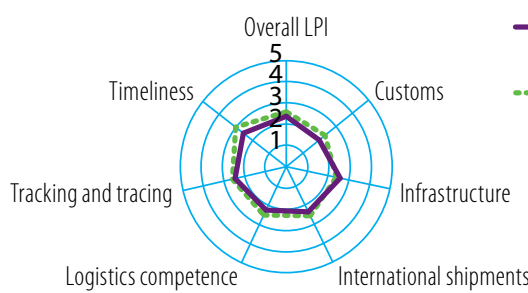

Source: WB Logistics Performance Index (LPI)

GLOBAL COMPETITIVENESS INDICATORS (1-7)

\begin{tabular}{|c|c|c|c|c|c|c|c|c|c|}
\hline \multicolumn{2}{|c|}{ Access to loans } & \multicolumn{2}{|c|}{ Electricity supply } & \multicolumn{2}{|l|}{ Roàds } & \multicolumn{2}{|c|}{ Port infrastructure } & \multicolumn{2}{|c|}{ Air transport infrastructure } \\
\hline \multirow{2}{*}{\multicolumn{10}{|c|}{6}} \\
\hline & & & & & & & & & \\
\hline \multicolumn{2}{|c|}{ DATA NOT AVAILABLE } & \multicolumn{2}{|c|}{ DATA NOT AVAILABLE } & \multicolumn{2}{|c|}{ DATANOT AVAILABLE } & \multicolumn{2}{|c|}{ DATA NOT AVAILABLE } & \multicolumn{2}{|c|}{ DATA NOT AVAILABLE } \\
\hline \\
\hline 2 & & \multicolumn{2}{|l|}{. } & & & & & & \\
\hline \multicolumn{10}{|c|}{ 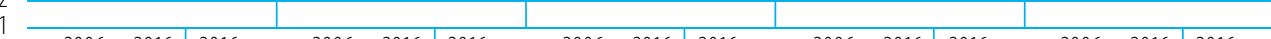 } \\
\hline $\begin{array}{c}2006 \quad 2016 \\
\text { Congo }\end{array}$ & $\begin{array}{l}2016 \\
\text { LMICS }\end{array}$ & $\begin{array}{c}2006 \quad 2016 \\
\text { Congo }\end{array}$ & $\begin{array}{l}2016 \\
\text { LMICs }\end{array}$ & $\begin{array}{c}2006 \quad 2016 \\
\text { Congo }\end{array}$ & $\begin{array}{l}2016 \\
\text { LMICS }\end{array}$ & $\begin{array}{c}2006 \quad 2016 \\
\text { Congo }\end{array}$ & $\begin{array}{l}2016 \\
\text { LMICs }\end{array}$ & $\begin{array}{c}2006 \quad 2016 \\
\text { Congo }\end{array}$ & $\begin{array}{l}2016 \\
\text { LMICS }\end{array}$ \\
\hline
\end{tabular}

Source: WEF Global Competitiveness Index

TRADE FACILITATION INDICATORS, 2017 (0-2)

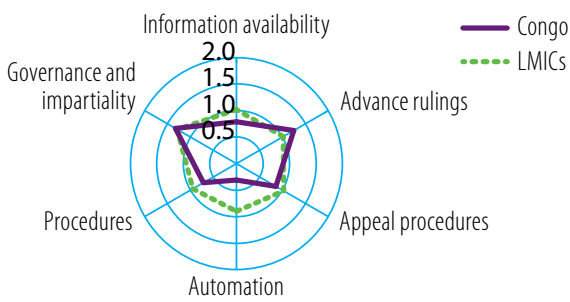

Source: OECD Trade Facilitation Indicators

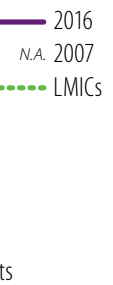

- Border compliance Documentary compliance Source: WB, Doing Business

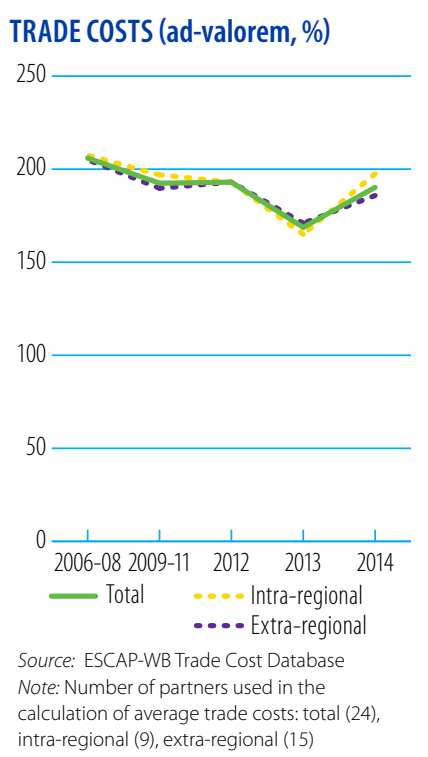




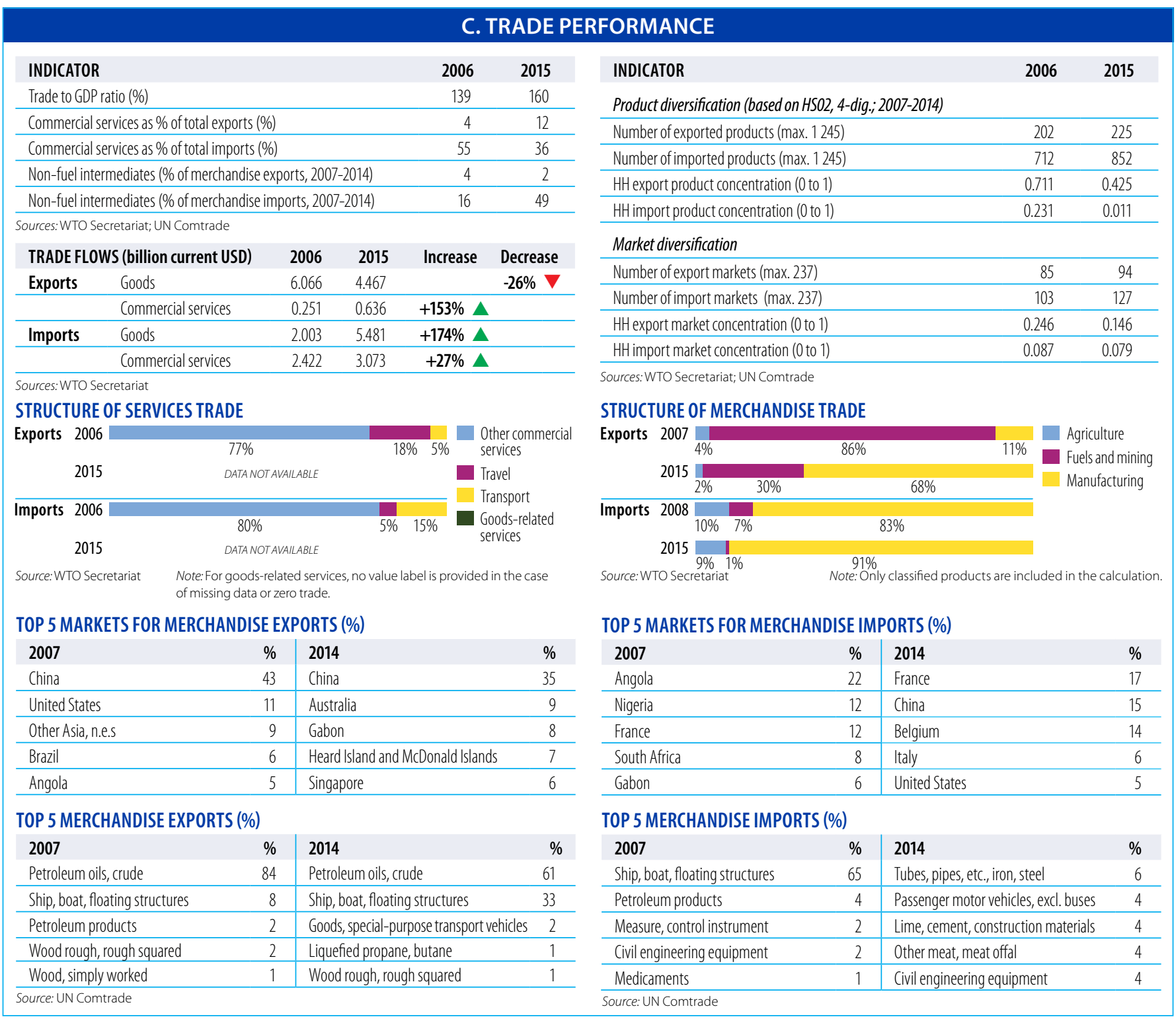

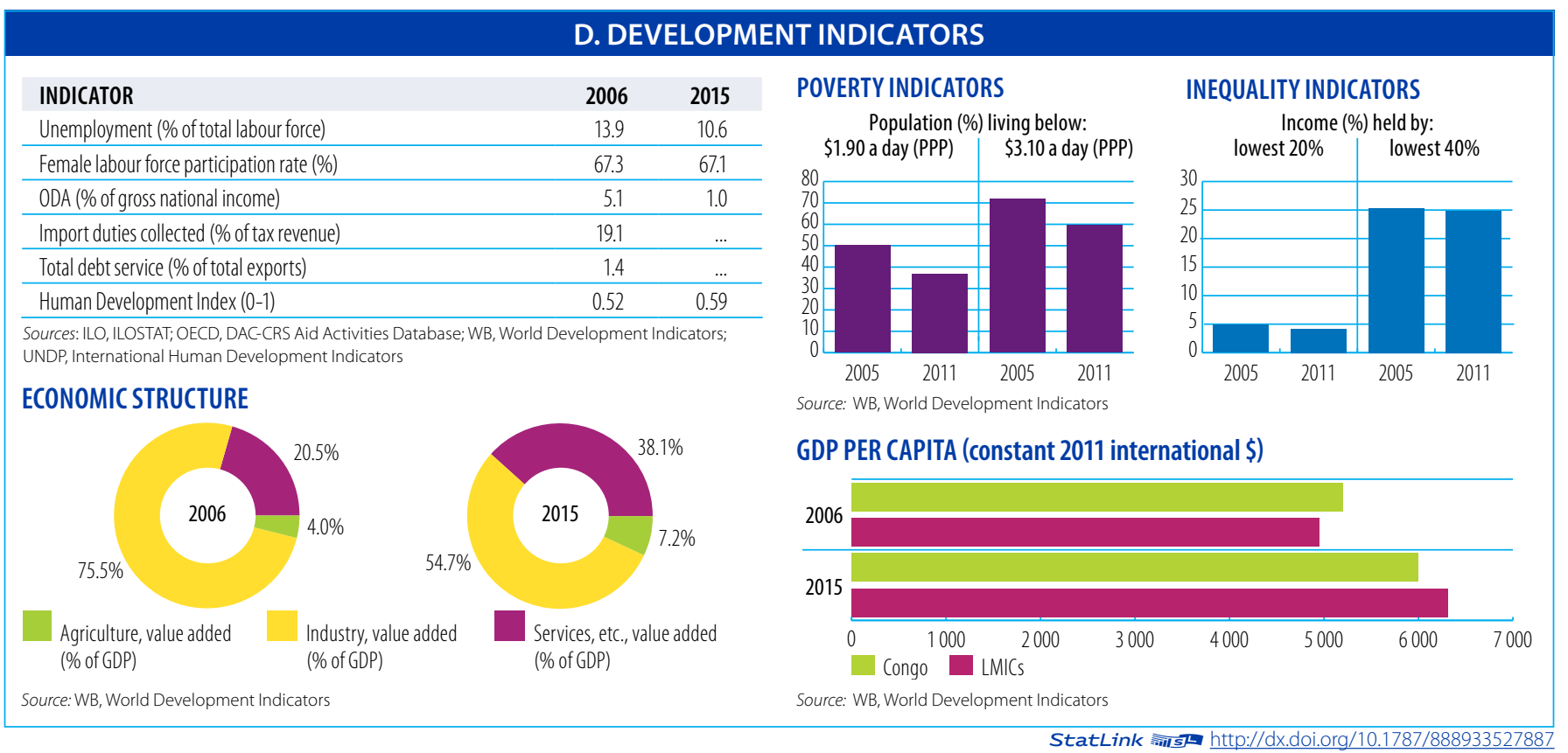




\section{DEMOCRATIC REPUBLIC OF THE CONGO}

Aid, Trade and Development Indicators for the Democratic Republic of the Congo

\section{A. DEVELOPMENT FINANCE}

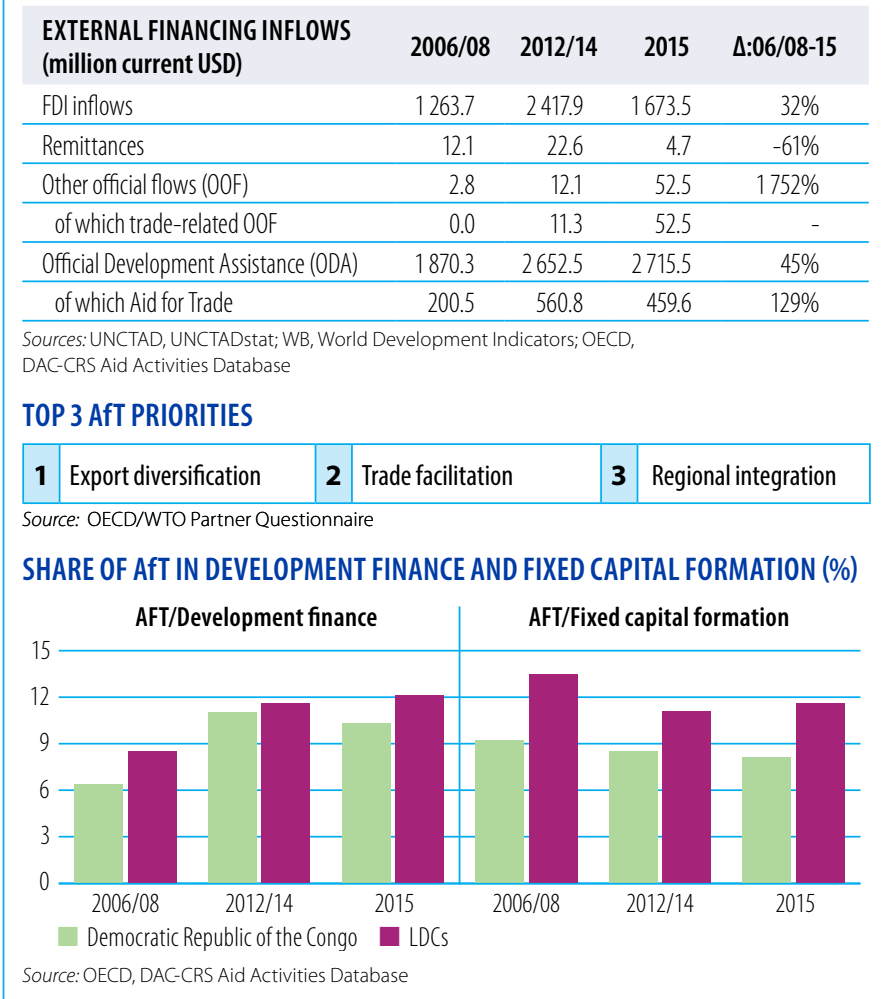

AfT DISBURSEMENTS: TOP DONORS (million current USD)

\begin{tabular}{lrr|lrc}
$\mathbf{2 0 0 6 / 0 8}$ & value & $\%$ & $\mathbf{2 0 1 5}$ & value & $\%$ \\
IDA & 120.6 & 60 & IDA & 263.5 & 57 \\
\hline EU Institutions & 36.5 & 18 & African Development Fund & 65.0 & 14 \\
\hline Belgium & 15.5 & 8 & EU Institutions & 54.7 & 12 \\
\hline United Kingdom & 8.8 & 4 & Belgium & 27.6 & 6 \\
\hline Germany & 6.3 & 3 & United Kingdom & 14.3 & 3 \\
\hline
\end{tabular}

Source: OECD, DAC-CRS Aid Activities Database

AfT DISBURSEMENTS BY SECTOR (million current USD)

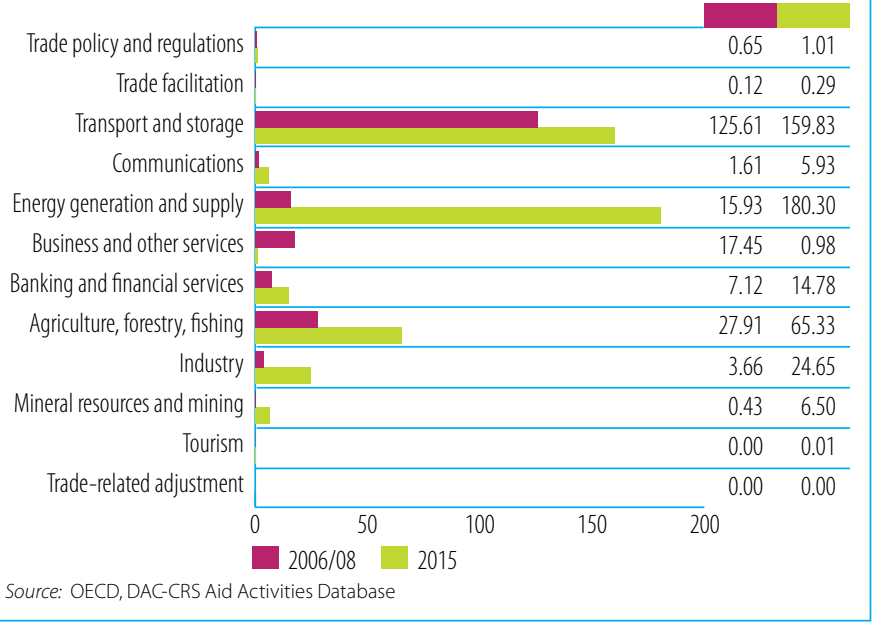

\section{B. TRADE COSTS}

\begin{tabular}{lcc} 
INDICATOR & 2006 & 2015 \\
Tariffs (\%) & & \\
\hline Imports: simple avg. MFN applied & 12.0 & 10.9 \\
\hline Imports: weighted avg. MFN applied & $\ldots$ & $\ldots$ \\
\hline Exports: weighted avg. faced (2005-2014) & 0.4 & 0.4 \\
\hline Exports: duty free (value in \%) (2005-2014) & 98.7 & 94.1 \\
\hline ICT connectivity (\% of population) & \multicolumn{2}{c}{} \\
\hline Mobile broadband subscriptions & $\ldots$ & 8.5 \\
\hline Fixed broadband subscriptions & $\ldots$ & 0.0 \\
\hline Individuals using the internet & 0.3 & 3.8 \\
\hline Sources: WTO, World Tariff Profiles; ITU, World Telecommunication/ICT Indicators &
\end{tabular}
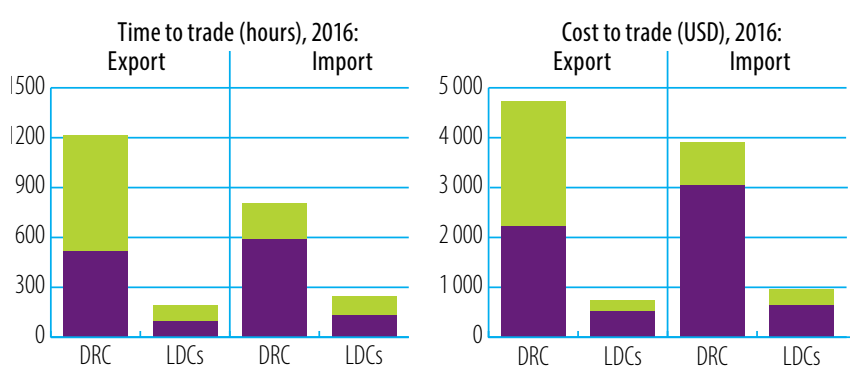

Border compliance Documentary compliance Source: WB, Doing Business

TRADE FACILITATION INDICATORS, 2017 (0-2)

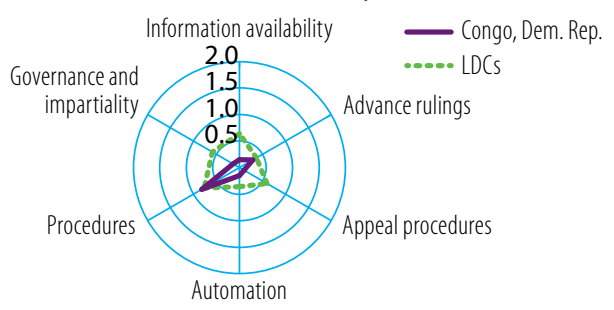

Source: OECD Trade Facilitation Indicators

Source: WB Logistics Performance Index (LPI)

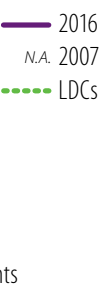

\section{GLOBAL COMPETITIVENESS INDICATORS (1-7)}

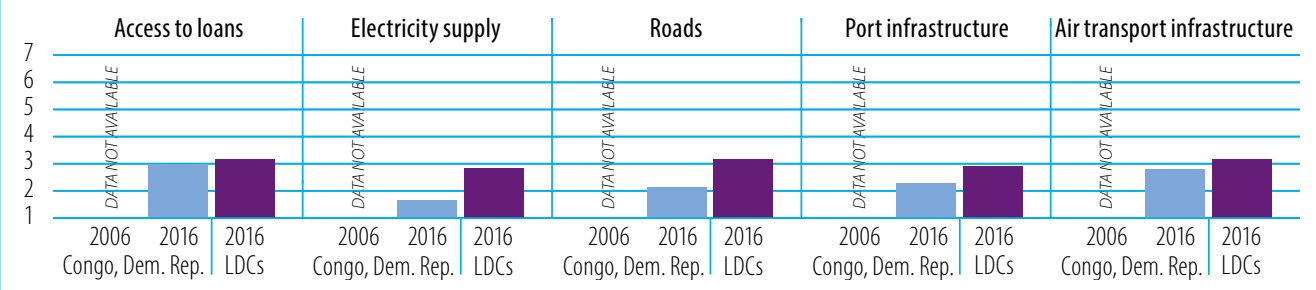

Source: WEF Global Competitiveness Index
TRADE COSTS (ad-valorem, \%)
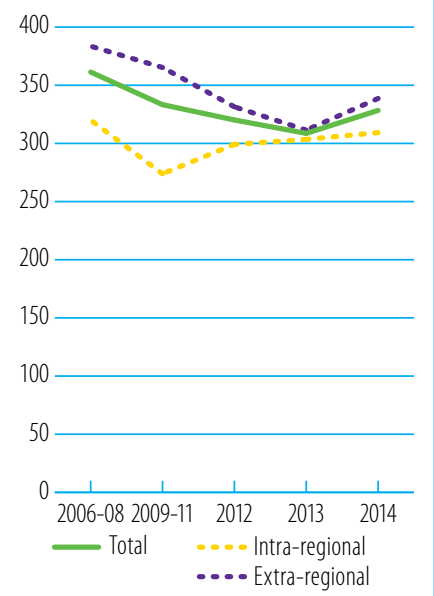

Source: ESCAP-WB Trade Cost Database Note: Number of partners used in the calculation of average trade costs: total (60), intra-regional (21), extra-regional (39) 


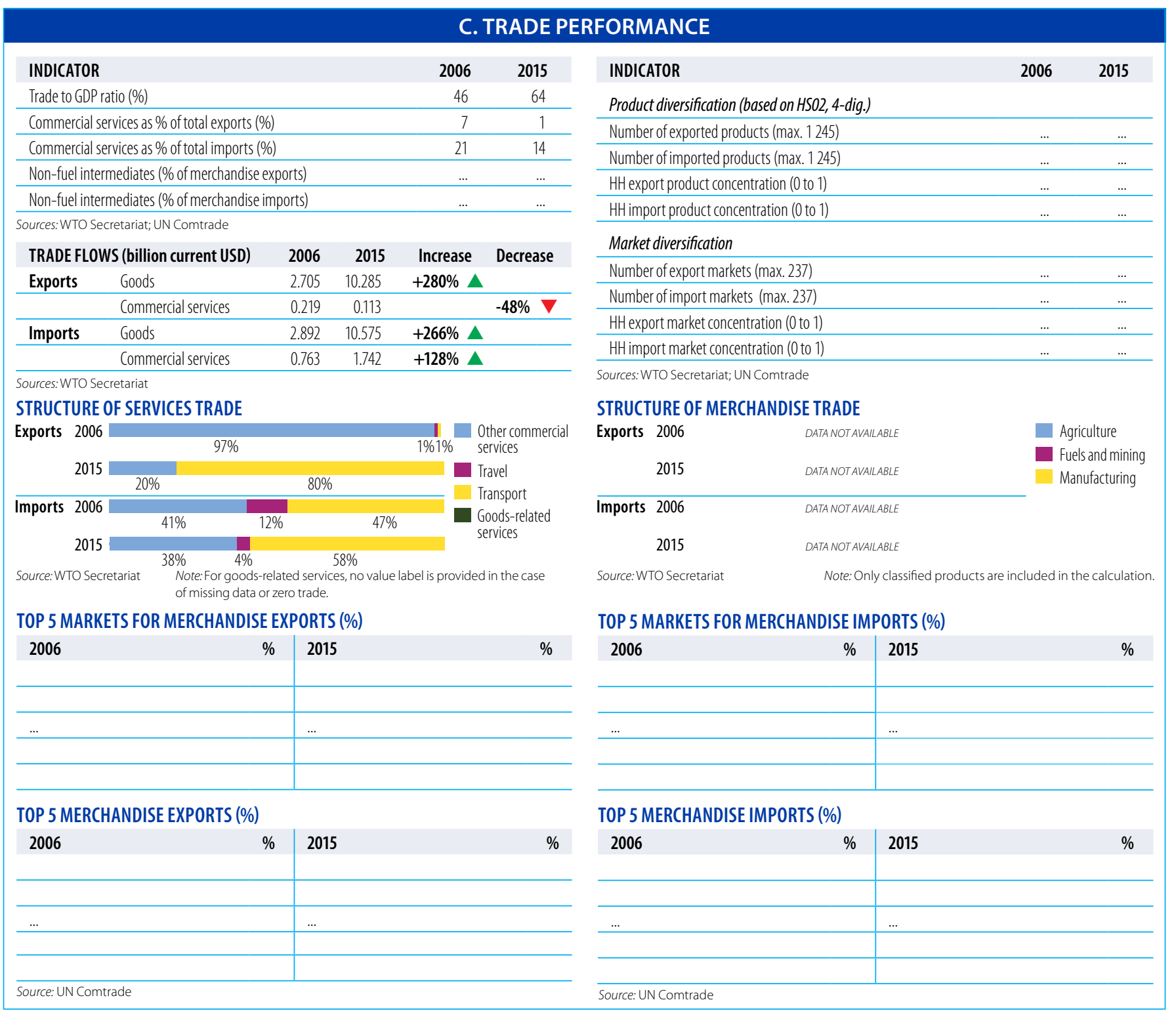

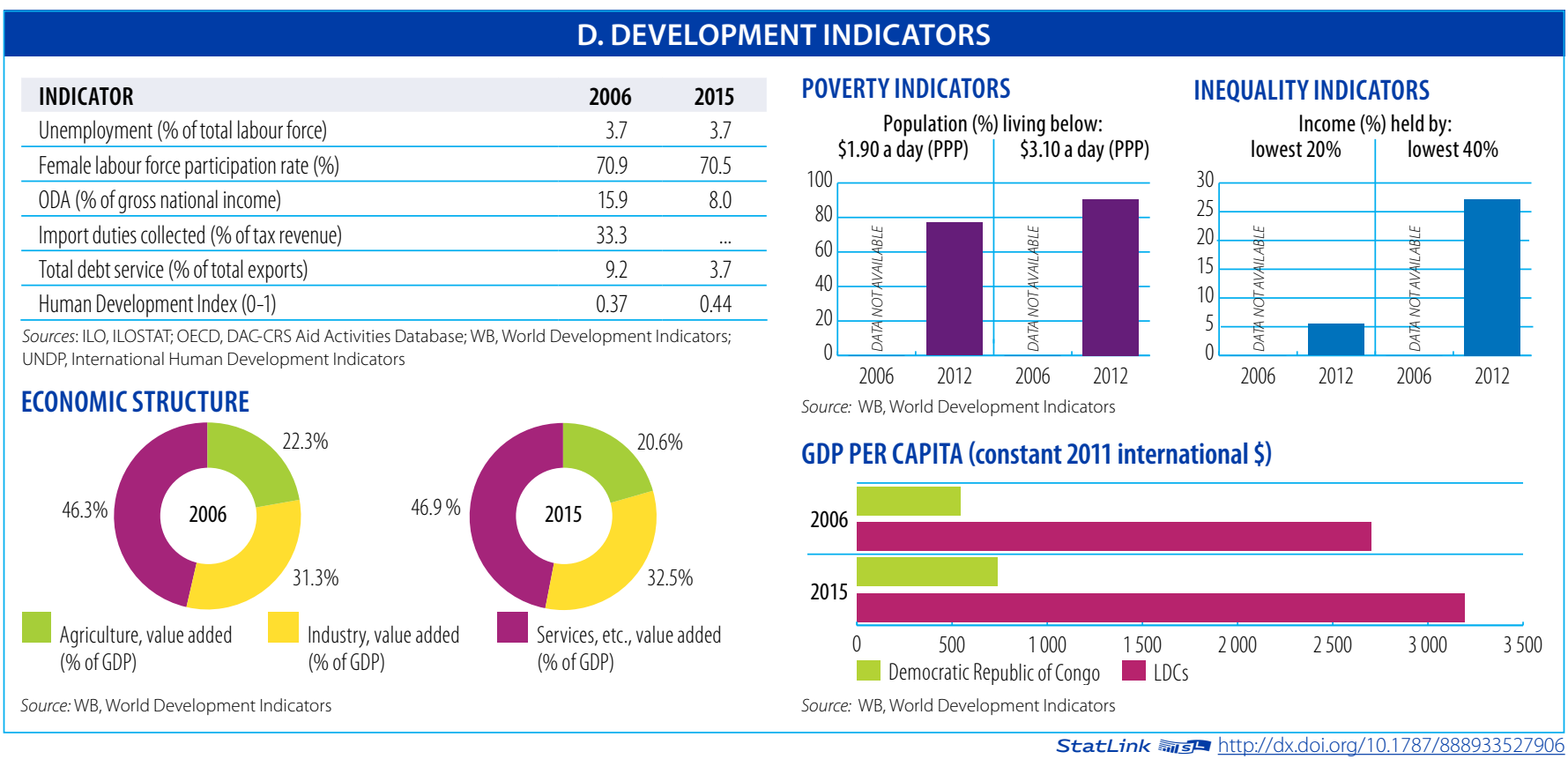


Aid, Trade and Development Indicators for Costa Rica

\section{A. DEVELOPMENT FINANCE}

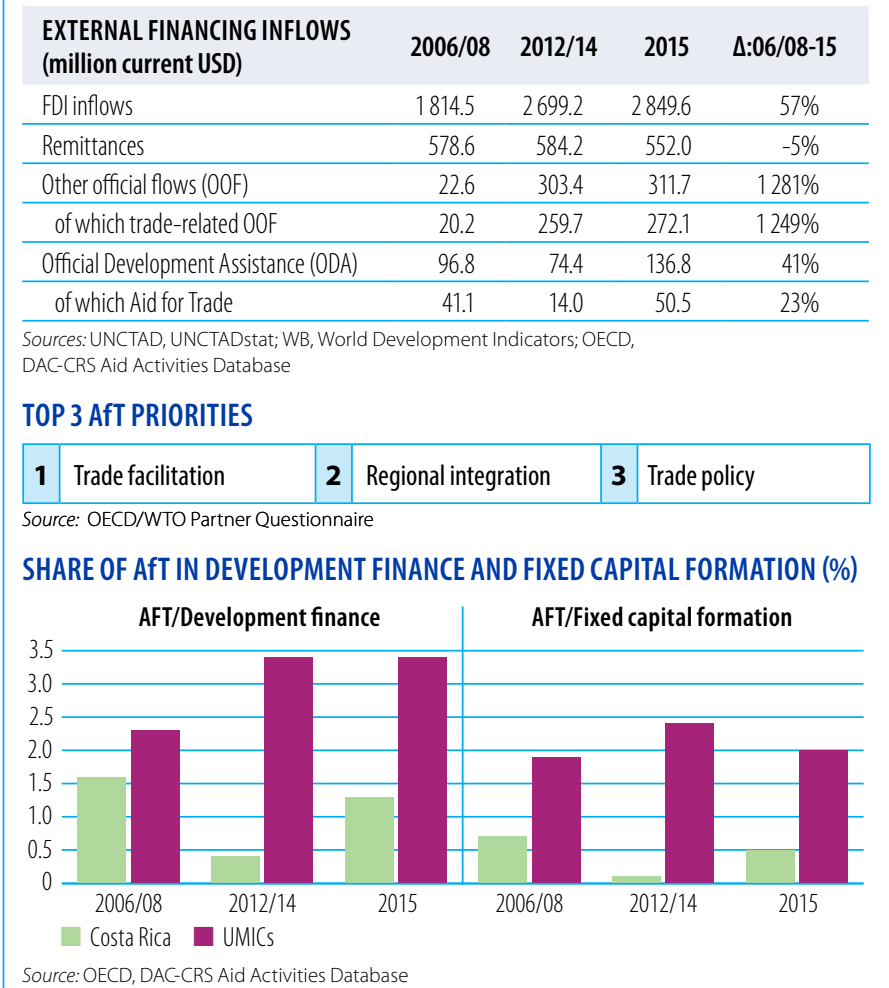

AfT DISBURSEMENTS: TOP DONORS (million current USD)

\begin{tabular}{lrr|lrc}
$\mathbf{2 0 0 6 / 0 8}$ & value & $\%$ & $\mathbf{2 0 1 5}$ & value & $\%$ \\
Japan & 19.0 & 46 & Japan & 24.1 & 48 \\
\hline Germany & 9.9 & 24 & Germany & 12.1 & 24 \\
\hline France & 7.0 & 17 & EU Institutions & 8.9 & 18 \\
\hline EU Institutions & 1.8 & 4 & France & 2.4 & 5 \\
\hline Spain & 1.2 & 3 & IADB & 1.3 & 3 \\
\hline
\end{tabular}

Source: OECD, DAC-CRS Aid Activities Database

AfT DISBURSEMENTS BY SECTOR (million current USD)

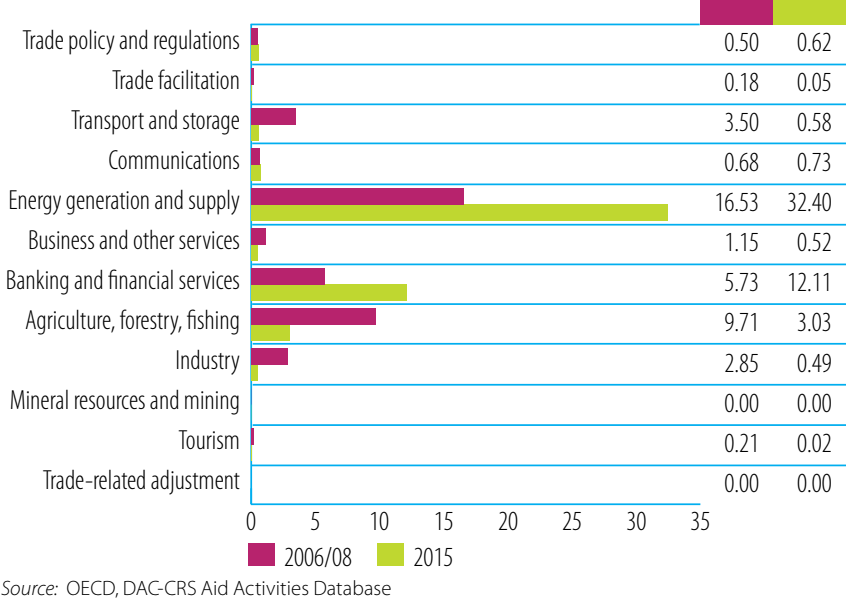

\section{B. TRADE COSTS}

\begin{tabular}{lcc} 
INDICATOR & 2006 & $\mathbf{2 0 1 5}$ \\
$\begin{array}{l}\text { Tariffs (\%) } \\
\text { Imports: simple avg. MFN applied (2005-2014) }\end{array}$ & 5.9 & 5.6 \\
\hline Imports: weighted avg. MFN applied (2006-2014) & $\ldots$. & 4.4 \\
\hline Exports: weighted avg. faced (2005-2014) & 7.3 & 0.4 \\
\hline Exports: duty free (value in \%) (2005-2014) & 86.7 & 93.9 \\
\hline ICT connectivity (\% of population) & 0.0 & \\
\hline Mobile broadband subscriptions (2008-2015) & 1.9 & 11.2 \\
\hline Fixed broadband subscriptions & 25.1 & 59.8 \\
\hline Individuals using the internet &
\end{tabular}
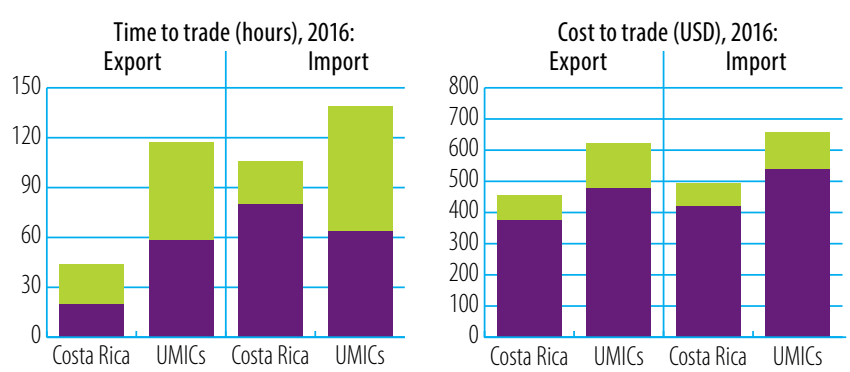

Border compliance Documentary compliance

Source: WB, Doing Business

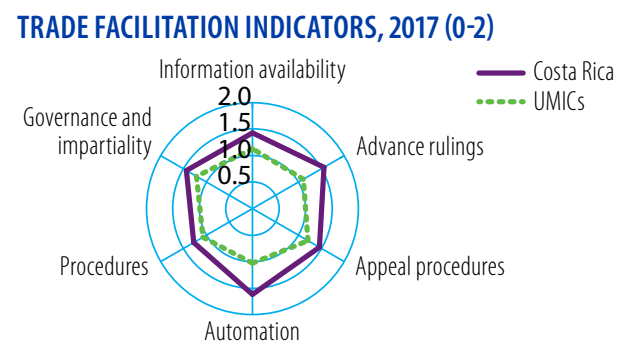

Source: OECD Trade Facilitation Indicators

Source: WB Logistics Performance Index (LPI)

GLOBAL COMPETITIVENESS INDICATORS (1-7)

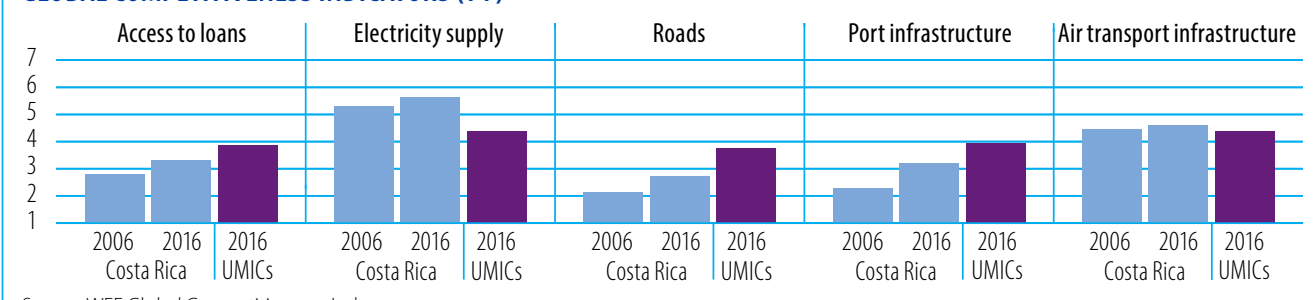

Source: WEF Global Competitiveness Index

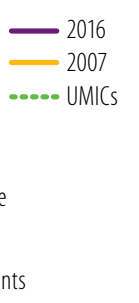

LOGISTICS PERFORMANCE INDICES (LPI) (1-5)

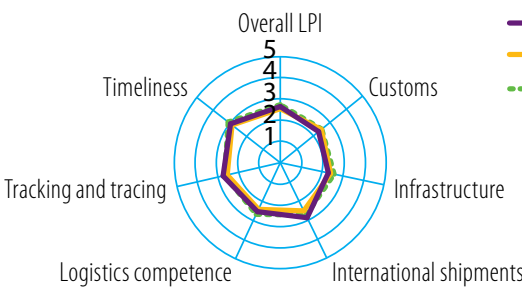

TRADE COSTS (ad-valorem, \%)

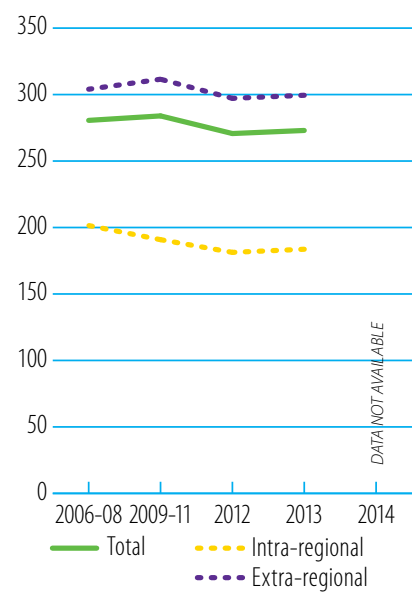

Source: ESCAP-WB Trade Cost Database Note: Number of partners used in the calculation of average trade costs: total (70), intra-regional (16), extra-regional (54) 


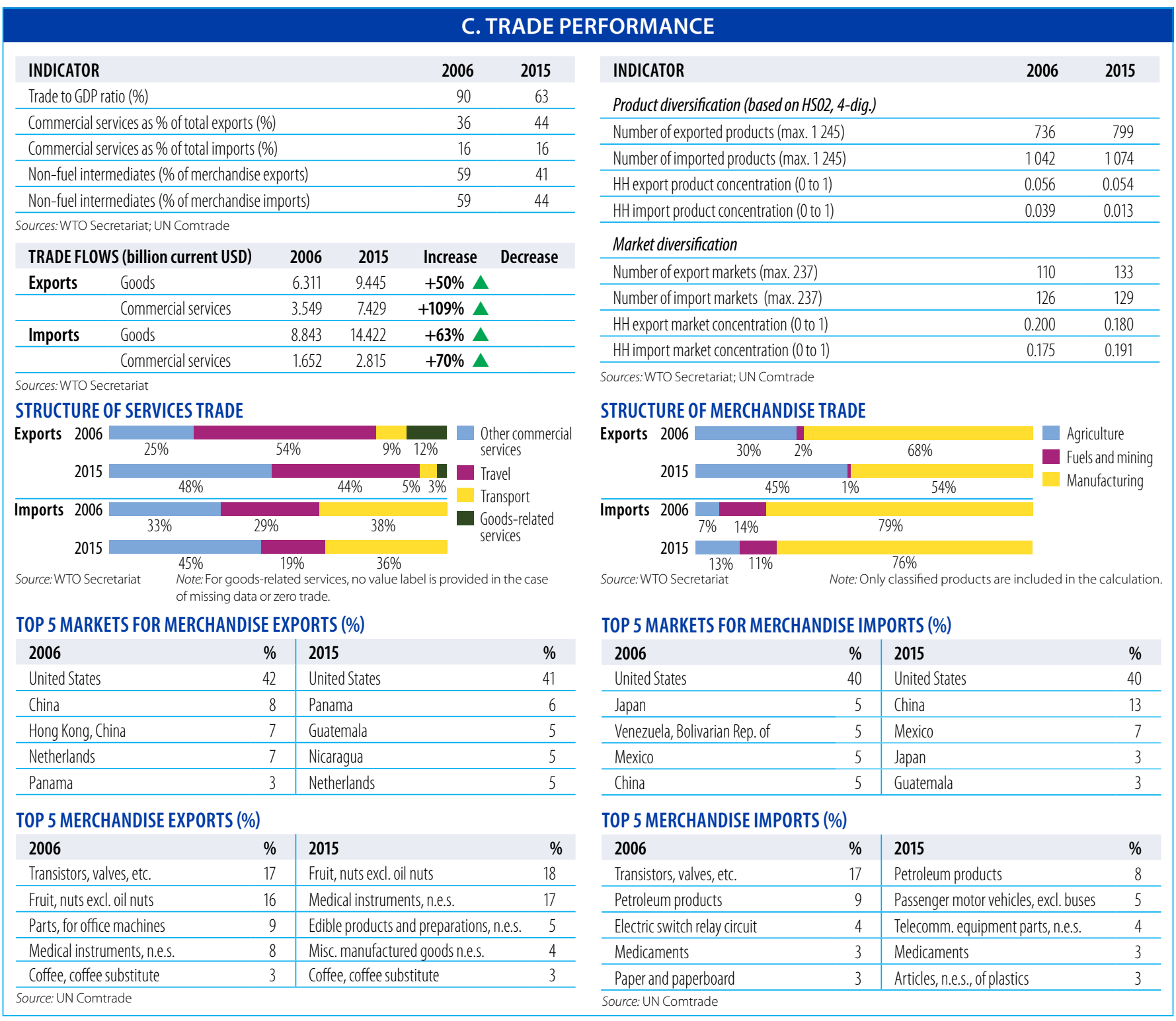

\begin{tabular}{|lrr}
\hline & D. DEVELOPME \\
\hline INDICATOR & $\mathbf{2 0 0 6}$ & $\mathbf{2 0 1 5}$ \\
Unemployment (\% of total labour force) & 5.7 & 9.6 \\
\hline Female labour force participation rate (\%) & 43.6 & 46.8 \\
\hline ODA (\% of gross national income) & 0.1 & 0.2 \\
\hline Import duties collected (\% of tax revenue, 2006-2014) & 6.6 & 4.7 \\
\hline Total debt service (\% of total exports) & 7.6 & 16.0 \\
\hline Human Development Index (0-1) & 0.73 & 0.78 \\
\hline
\end{tabular}

Sources: ILO, ILOSTAT; OECD, DAC-CRS Aid Activities Database; WB, World Development Indicators; UNDP, International Human Development Indicators

\section{ECONOMIC STRUCTURE}

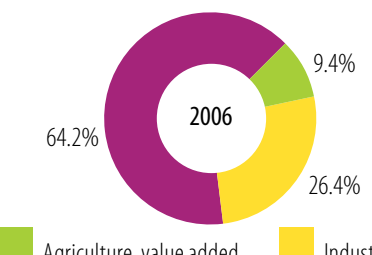

Agriculture, value added (\% of GDP)

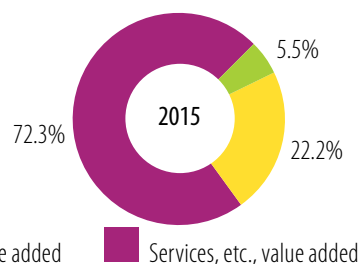

(\% of GDP)

Source: WB, World Development Indicators $\%$ of GDP)

\section{POVERTY INDICATORS}

Population (\%) living below:

$\$ 1.90$ a day (PPP) $\quad \$ 3.10$ a day (PPP)

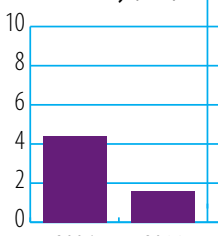

$2006 \quad 2014$

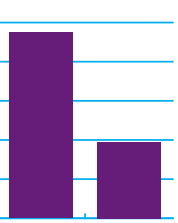

20062014

Source: WB, World Development Indicators

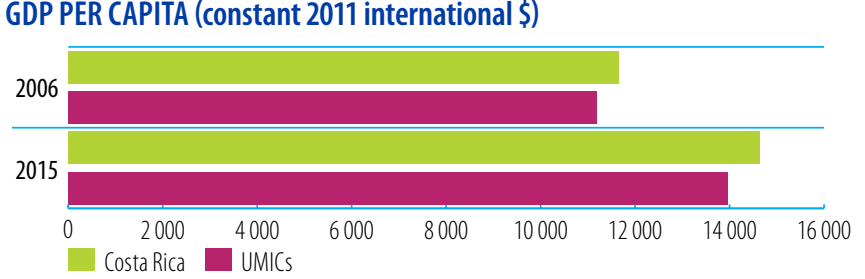

Source: WB, World Development Indicators

\section{INEQUALITY INDICATORS}

Income (\%) held by:

lowest 20\% | lowest 40\%

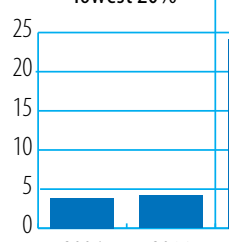

$2006 \quad 2014 \quad 2006 \quad 2014$

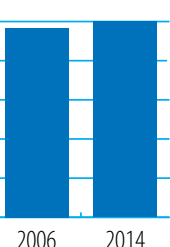




\section{CÔTE D'IVOIRE}

Aid, Trade and Development Indicators for Côte d'Ivoire

\section{A. DEVELOPMENT FINANCE}

\begin{tabular}{lrrrc}
$\begin{array}{l}\text { EXTERNAL FINANCING INFLOWS } \\
\text { (million current USD) }\end{array}$ & $\mathbf{2 0 0 6 / 0 8}$ & $\mathbf{2 0 1 2 / 1 4}$ & $\mathbf{2 0 1 5}$ & $\mathbf{\Delta : 0 6 / 0 8 - 1 5}$ \\
FDl inflows & 397.3 & 392.2 & 430.2 & $8 \%$ \\
\hline Remittances & 183.5 & 378.8 & 384.7 & $110 \%$ \\
\hline Other official flows (0OF) & 86.9 & 91.1 & 167.6 & $93 \%$ \\
\hline$\quad$ of which trade-related 00F & 1.7 & 64.1 & 149.5 & $8867 \%$ \\
\hline Official Development Assistance (ODA) & 479.5 & 2670.6 & 988.2 & $106 \%$ \\
\hline of which Aid for Trade & 95.9 & 128.0 & 218.2 & $128 \%$ \\
\hline
\end{tabular}

Sources: UNCTAD, UNCTADstat; WB, World Development Indicators; OECD,

DAC-CRS Aid Activities Database

\section{TOP 3 AfT PRIORITIES}

\begin{tabular}{|l|l|l|l|l|l|}
\hline 1 & Export diversification & $\mathbf{2}$ & Trade facilitation & $\mathbf{3}$ & Transport infrastructure \\
\hline
\end{tabular}

Source: OECD/WTO Partner Questionnaire

SHARE OF AfT IN DEVELOPMENT FINANCE AND FIXED CAPITAL FORMATION (\%)

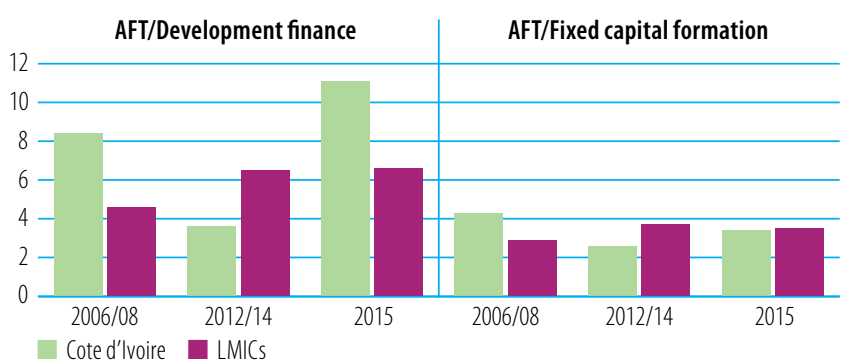

Source: OECD, DAC-CRS Aid Activities Database

AfT DISBURSEMENTS: TOP DONORS (million current USD)

\begin{tabular}{lrr|lrr}
$\mathbf{2 0 0 6 / 0 8}$ & value & $\%$ & $\mathbf{2 0 1 5}$ & value & $\%$ \\
IDA & 76.2 & 79 & IDA & 165.4 & 76 \\
\hline EU Institutions & 12.2 & 13 & EU Institutions & 32.2 & 15 \\
\hline France & 3.8 & 4 & Germany & 5.1 & 2 \\
\hline Belgium & 1.1 & 1 & Japan & 4.2 & 2 \\
\hline Japan & 0.7 & 1 & African Development Fund & 3.8 & 2 \\
\hline
\end{tabular}

Source: OECD, DAC-CRS Aid Activities Database

AfT DISBURSEMENTS BY SECTOR (million current USD)

\begin{tabular}{|c|c|c|c|}
\hline Trade policy and regulations & 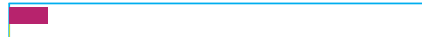 & 6.78 & 0.04 \\
\hline Trade facilitation & & 0.05 & 21.66 \\
\hline Transport and storage & 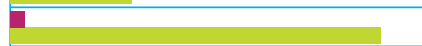 & 2.62 & 65.90 \\
\hline Communications & & 1.06 & 1.05 \\
\hline Energy generation and supply & 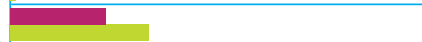 & 17.08 & 24.74 \\
\hline Business and other services & 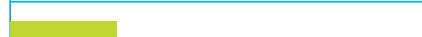 & 0.00 & 18.92 \\
\hline Banking and financial services & 0 & 14.63 & 0.55 \\
\hline Agriculture, forestry, fishing & 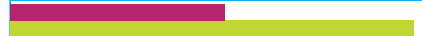 & 38.14 & 71.91 \\
\hline Industry & 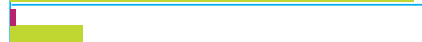 & 0.96 & 12.93 \\
\hline Mineral resources and mining & & 14.60 & 0.49 \\
\hline Tourism & & 0.00 & 0.02 \\
\hline Trade-related adjustment & & 0.00 & 0.00 \\
\hline & $\begin{array}{llllllll}0 & 10 & 20 & 30 & 40 & 50 & 60 & 70\end{array}$ & 80 & \\
\hline
\end{tabular}

Source: OECD, DAC-CRS Aid Activities Database

\section{B. TRADE COSTS}

\begin{tabular}{lcc} 
INDICATOR & $\mathbf{2 0 0 6}$ & $\mathbf{2 0 1 5}$ \\
Tariffs (\%) & & \\
\hline Imports: simple avg. MFN applied & 12.0 & 12.2 \\
\hline Imports: weighted avg. MFN applied (2006-2014) & $\ldots$ & 7.2 \\
\hline Exports: weighted avg. faced (2005-2014) & 3.5 & 0.8 \\
\hline Exports: duty free (value in \%) (2005-2014) & 87.0 & 90.5 \\
\hline ICT connectivity (\% of population) & $\ldots$ & \\
\hline Mobile broadband subscriptions & $\ldots .1$ & 0.5 \\
\hline Fixed broadband subscriptions & 1.5 & 21.0 \\
\hline Individuals using the internet & &
\end{tabular}

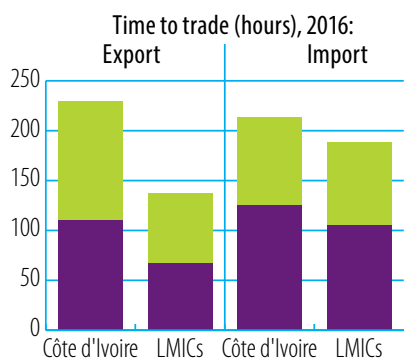

- Border compliance Documentary complian

Source: WB, Doing Business
LOGISTICS PERFORMANCE INDICES (LPI) (1-5)

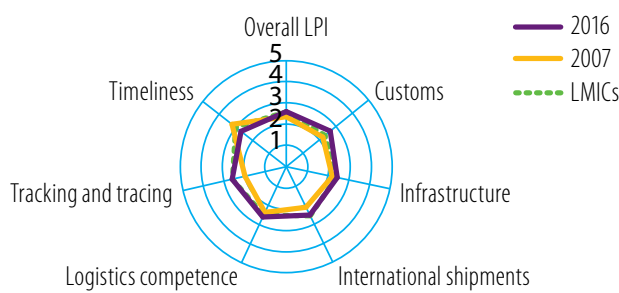

Source: WB Logistics Performance Index (LPI)

GLOBAL COMPETITIVENESS INDICATORS (1-7)

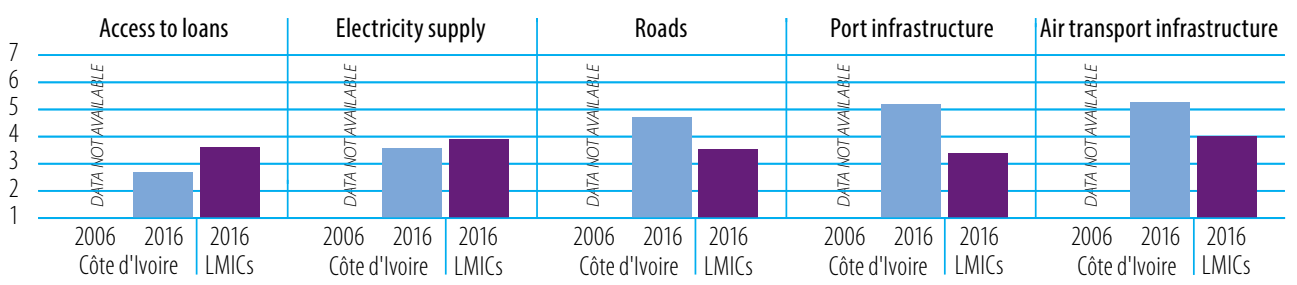

TRADE FACILITATION INDICATORS, 2017 (0-2)

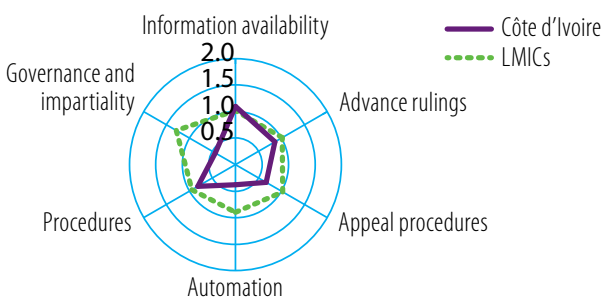

Source: OECD Trade Facilitation Indicators
Cost to trade (USD), 2016:

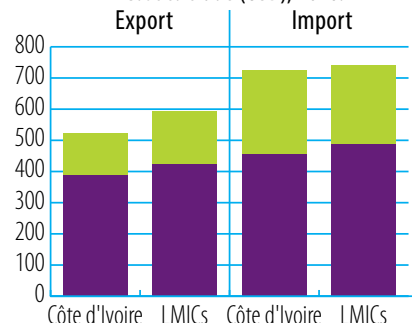

WEF Global Competitiveness Index 


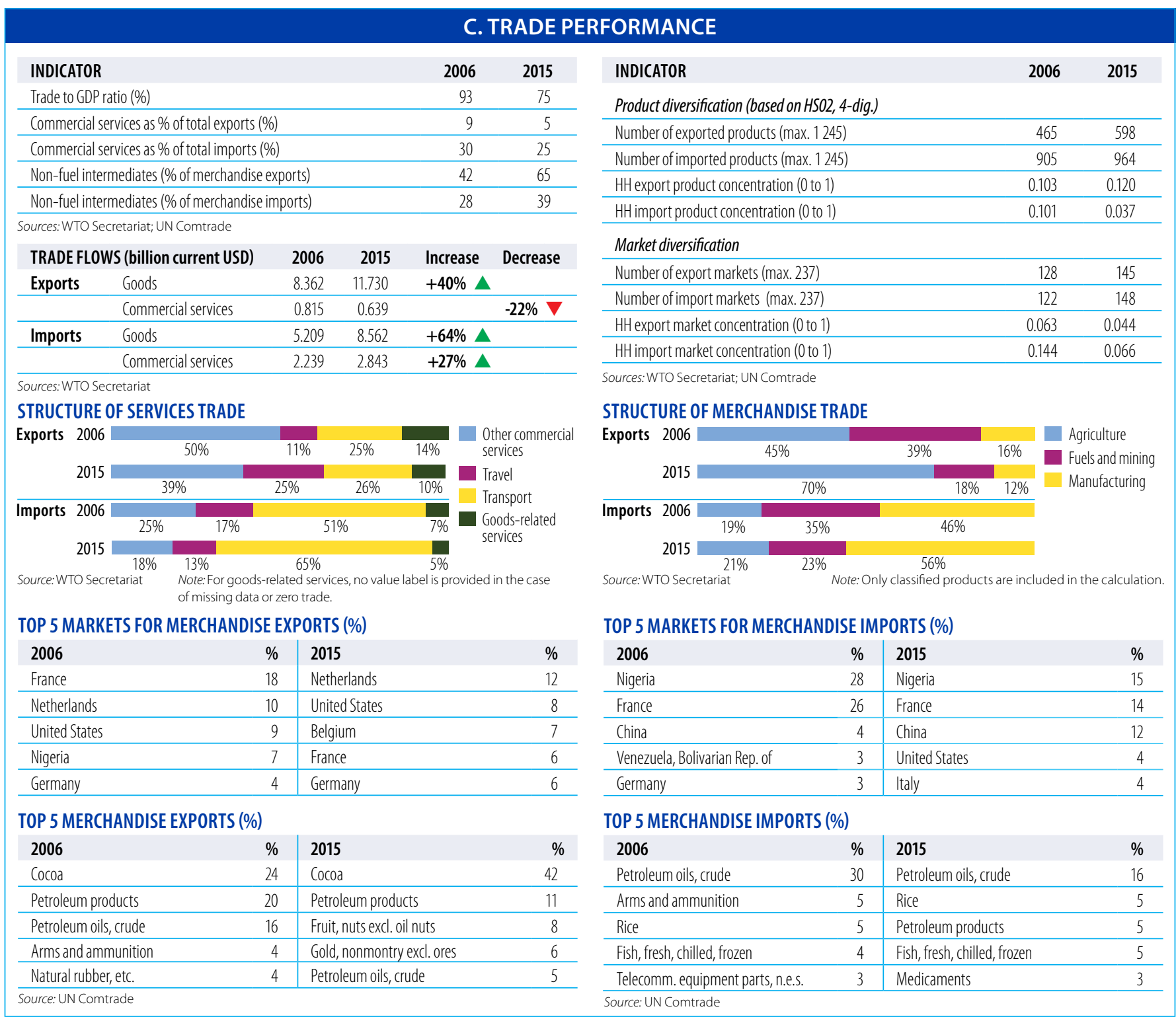

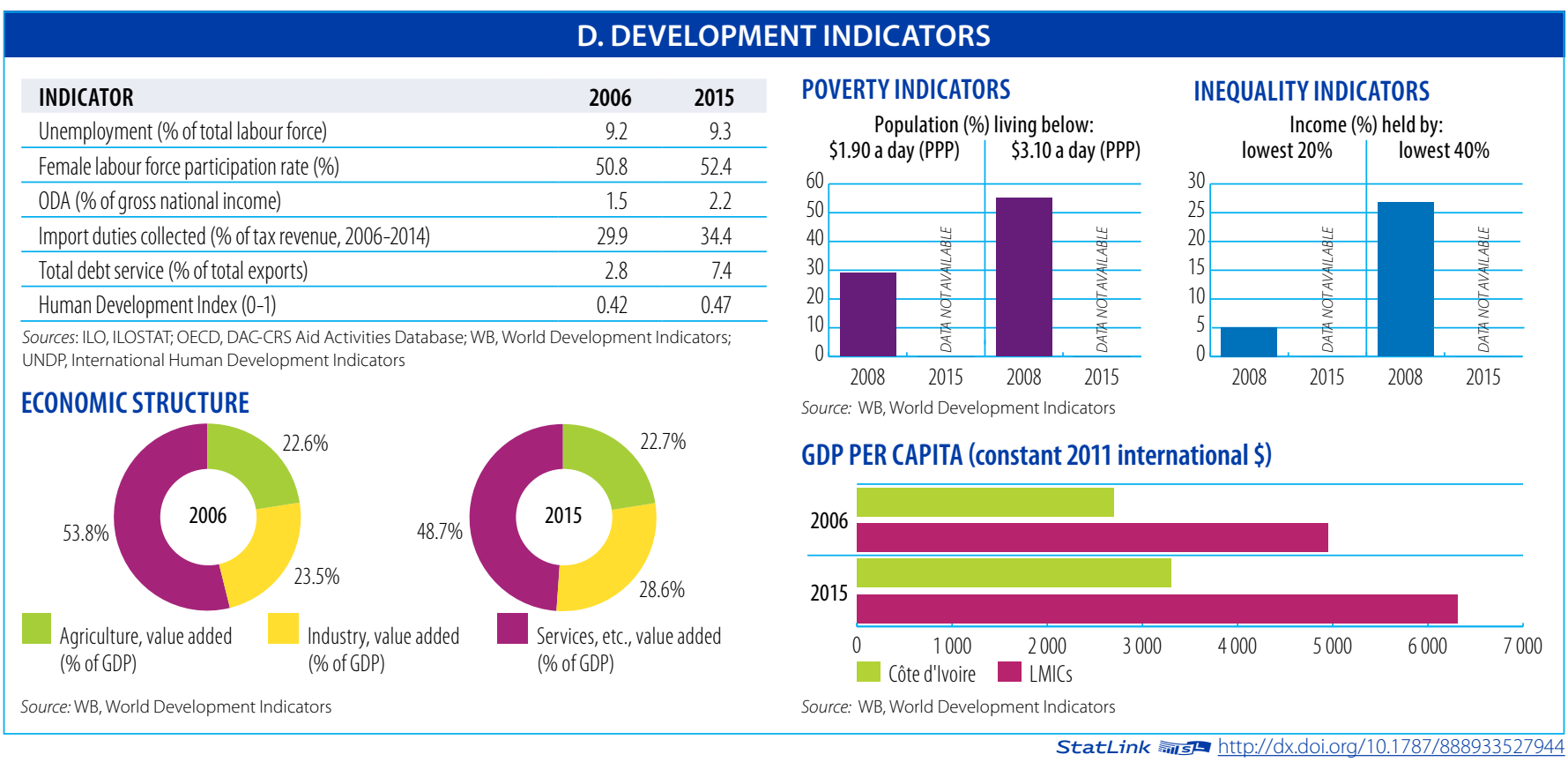


Aid, Trade and Development Indicators for Dominica

\section{A. DEVELOPMENT FINANCE}

\begin{tabular}{lrrrc}
$\begin{array}{l}\text { EXTERNAL FINANCING INFLOWS } \\
\text { (million current USD) }\end{array}$ & $\mathbf{2 0 0 6 / 0 8}$ & $\mathbf{2 0 1 2 / 1 4}$ & $\mathbf{2 0 1 5}$ & $\mathbf{\Delta : 0 6 / 0 8 - 1 5}$ \\
\hline FDl inflows & 44.5 & 39.8 & 36.0 & $-19 \%$ \\
\hline Remittances & 22.4 & 23.5 & 23.6 & $5 \%$ \\
\hline Other official flows (00F) & 0.0 & 3.0 & 0.5 & - \\
\hline of which trade-related O0F & 0.0 & 3.0 & 0.0 & - \\
\hline Official Development Assistance (ODA) & 21.0 & 22.8 & 21.2 & $1 \%$ \\
\hline$\quad$ of which Aid for Trade & 9.2 & 12.7 & 3.8 & $-59 \%$ \\
\hline
\end{tabular}

Sources: UNCTAD, UNCTADstat; WB, World Development Indicators; OECD,

DAC-CRS Aid Activities Database

\section{TOP 3 AfT PRIORITIES}

\begin{tabular}{|l|l|l|l|l|l|}
\hline 1 & Regional integration & $\mathbf{2}$ & Trade policy & $\mathbf{3}$ & Trade facilitation \\
\hline
\end{tabular}

SHARE OF AfT IN DEVELOPMENT FINANCE AND FIXED CAPITAL FORMATION (\%)

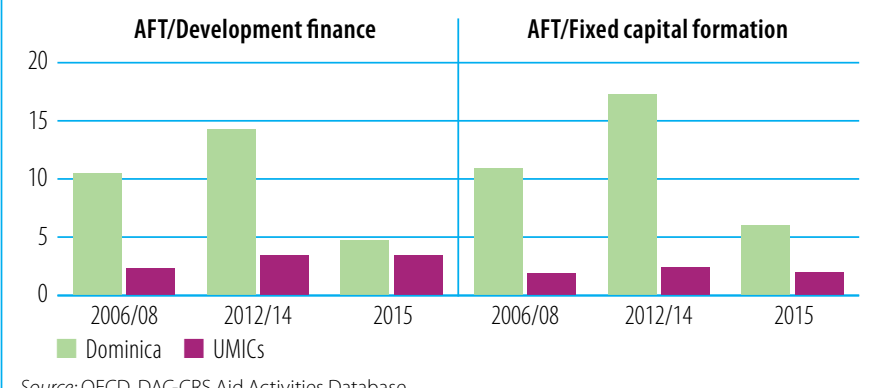

AfT DISBURSEMENTS: TOP DONORS (million current USD)

\begin{tabular}{lrr|lrc}
$\mathbf{2 0 0 6 / 0 8}$ & value & $\%$ & $\mathbf{2 0 1 5}$ & value & $\%$ \\
EU Institutions & 8.6 & 94 & France & 2.2 & 57 \\
\hline Japan & 0.3 & 4 & EU Institutions & 0.8 & 20 \\
\hline IDA & 0.1 & 2 & IDA & 0.6 & 16 \\
\hline France & 0.1 & 1 & Japan & 0.2 & 5 \\
\hline & & & Global Environment Facility & 0.0 & 1 \\
\hline
\end{tabular}

Source: OECD, DAC-CRS Aid Activities Database

AfT DISBURSEMENTS BY SECTOR (million current USD)

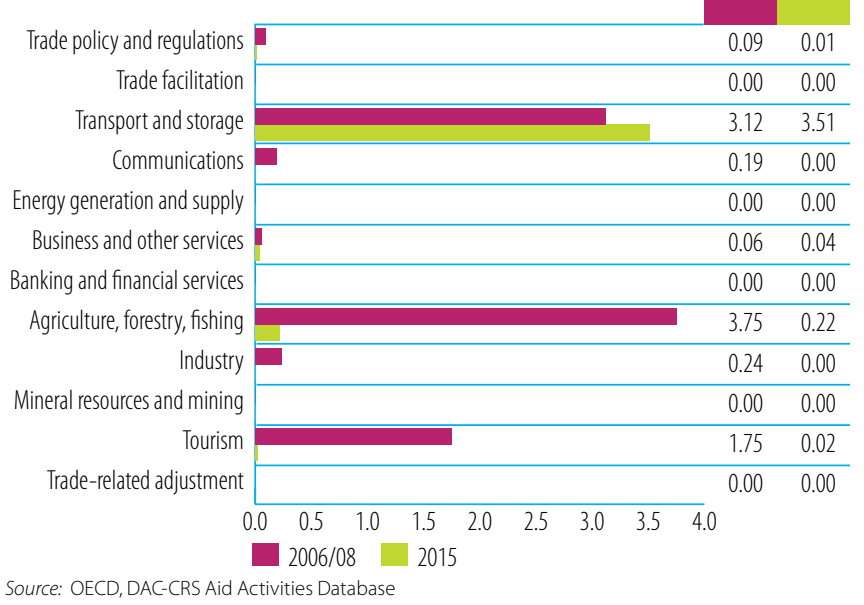

\section{B. TRADE COSTS}

\begin{tabular}{lcc} 
INDICATOR & 2006 & $\mathbf{2 0 1 5}$ \\
Tariffs (\%) & & \\
\hline Imports: simple avg. MFN applied & $\ldots .9$ & 10.0 \\
\hline Imports: weighted avg. MFN applied (2006-2013) & 14.7 \\
\hline Exports: weighted avg. faced (2005-2014) & 16.8 & 1.1 \\
\hline Exports: duty free (value in \%) (2005-2014) & 50.0 & 83.4 \\
\hline ICT connectivity (\% of population) & & \\
\hline Mobile broadband subscriptions (2008-2015) & 0.0 & 42.2 \\
\hline Fixed broadband subscriptions & 6.1 & 20.9 \\
\hline Individuals using the internet & 39.4 & 67.6 \\
\hline Sources: WTO, World Tariff Profiles; ITU, World Telecommunication/ICT Indicators &
\end{tabular}
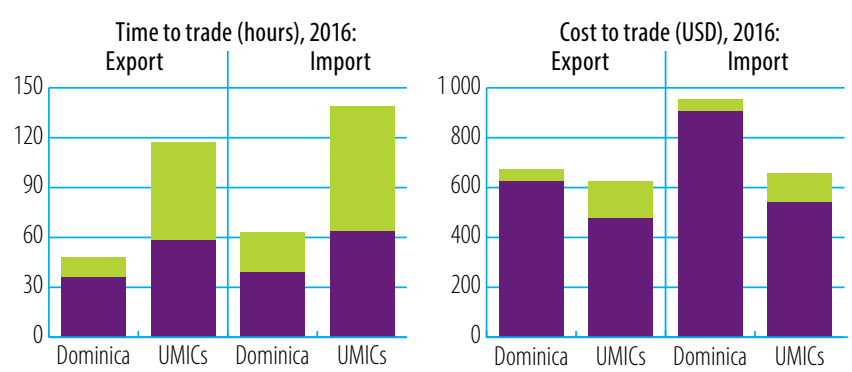

Border compliance Documentary compliance

Source: WB, Doing Business

\section{LOGISTICS PERFORMANCE INDICES (LPI) (1-5)}

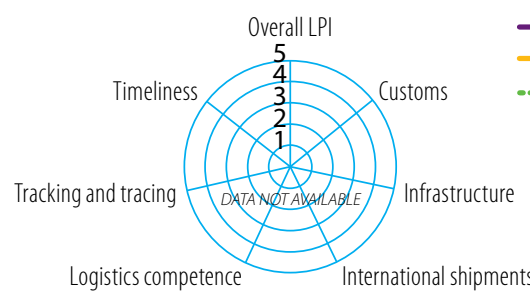

Source: WB Logistics Performance Index (LPI)

GLOBAL COMPETITIVENESS INDICATORS (1-7)

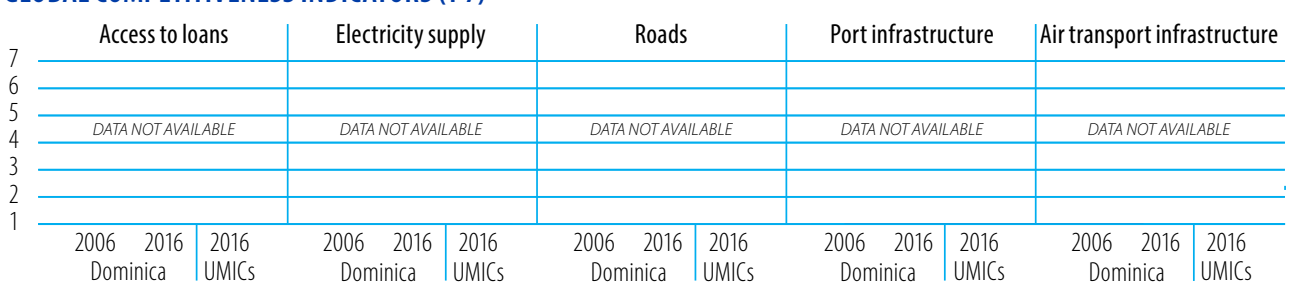

TRADE FACILITATION INDICATORS, 2017 (0-2)

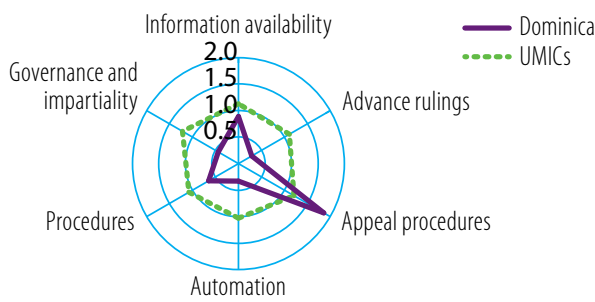

Source: OECD Trade Facilitation Indicators
TRADE COSTS (ad-valorem, \%)

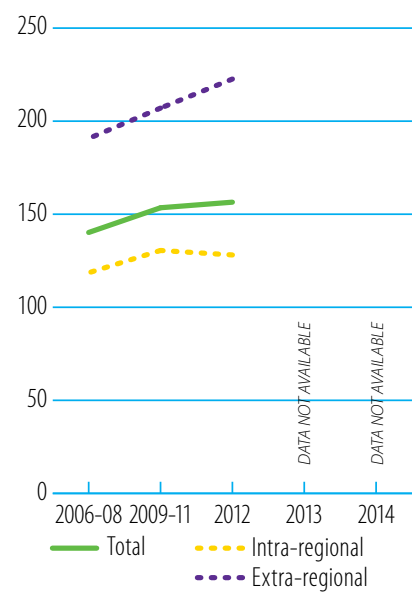

Source: ESCAP-WB Trade Cost Database Note: Number of partners used in the calculation of average trade costs: total (10), intra-regional (7), extra-regional (3) 


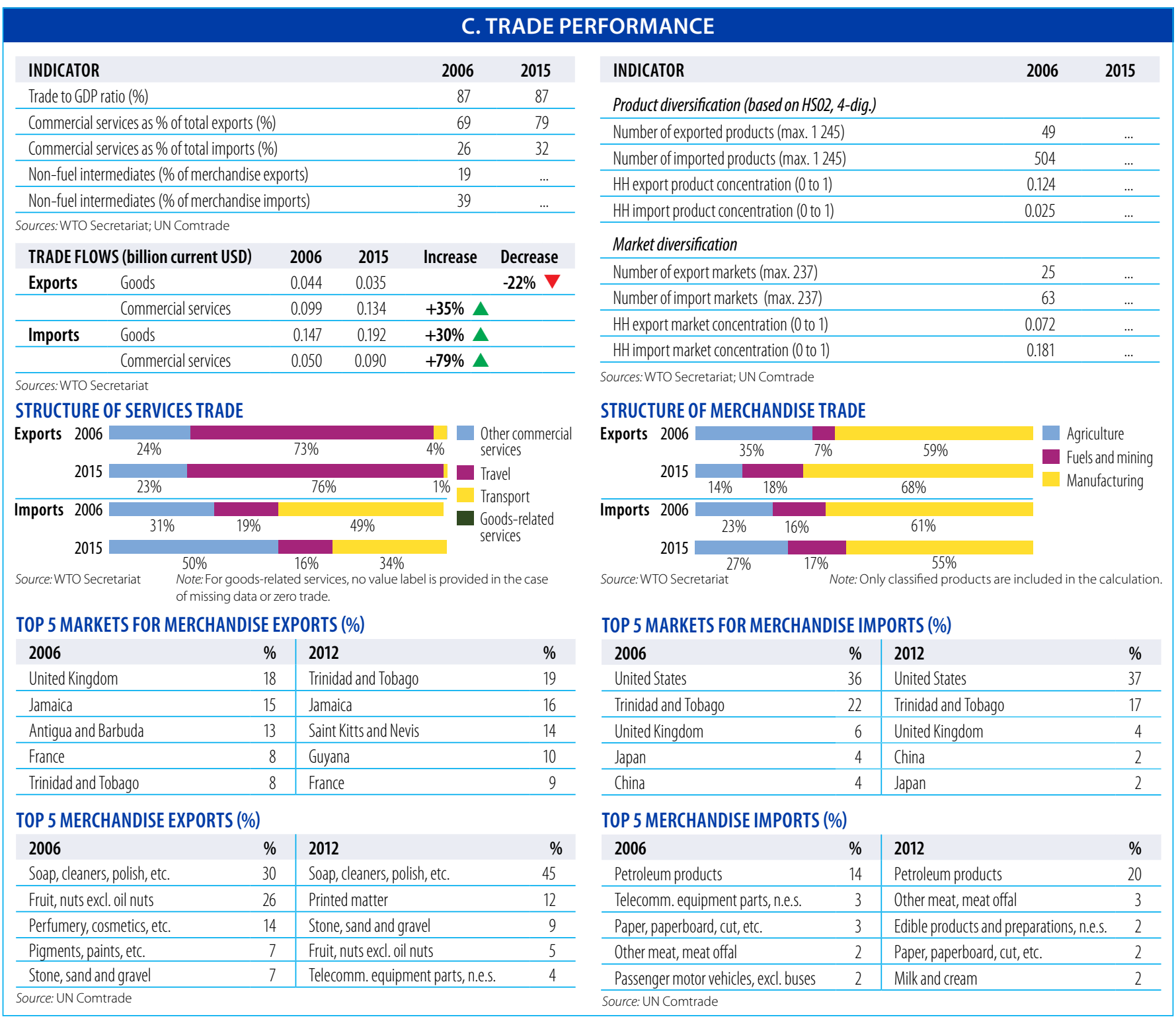

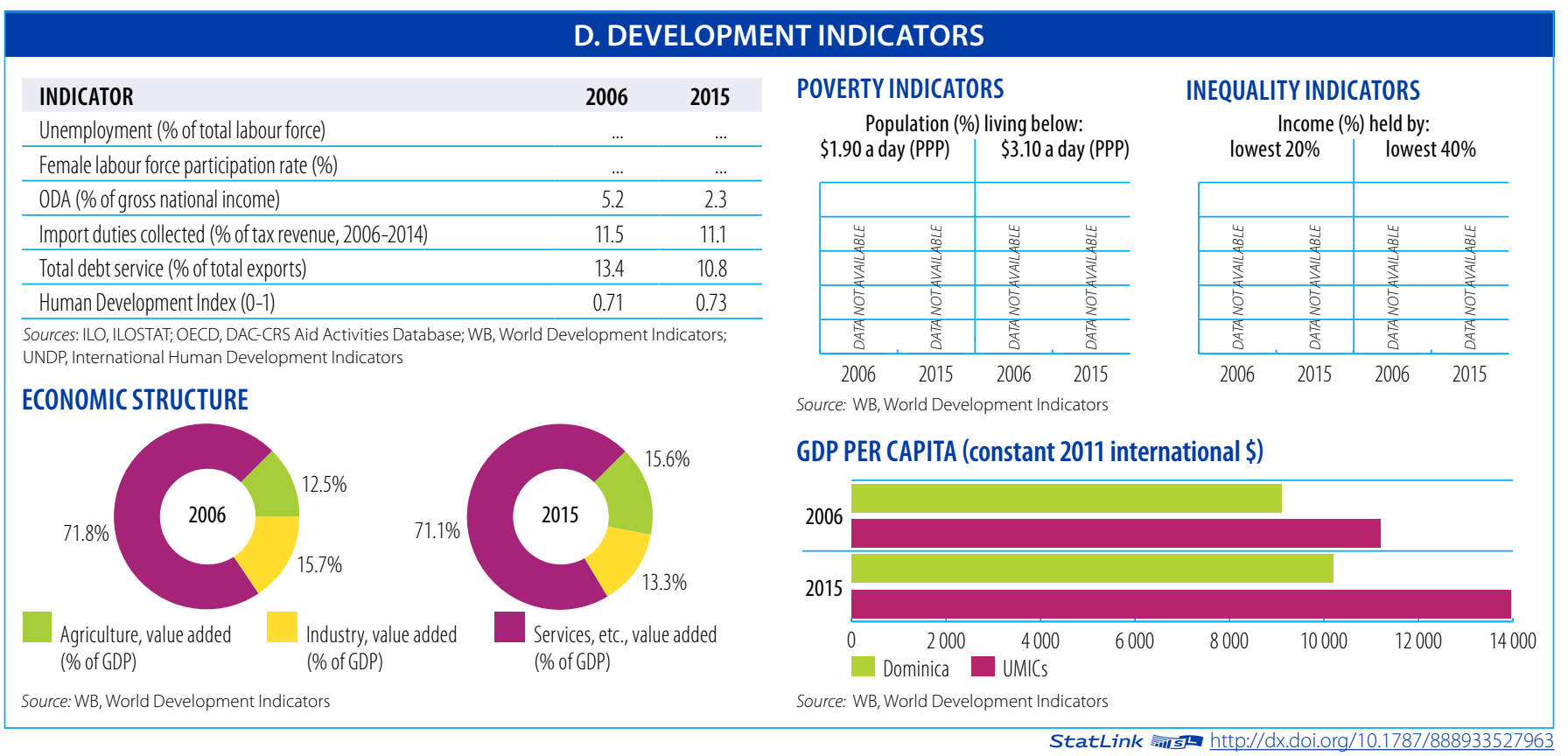




\section{DOMINICAN REPUBLIC}

Aid, Trade and Development Indicators for the Dominican Republic

\section{A. DEVELOPMENT FINANCE}

\begin{tabular}{lrrrc}
$\begin{array}{l}\text { EXTERNAL FINANCING INFLOWS } \\
\text { (million current USD) }\end{array}$ & $\mathbf{2 0 0 6 / 0 8}$ & $\mathbf{2 0 1 2 / 1 4}$ & $\mathbf{2 0 1 5}$ & $\mathbf{\Delta : 0 6 / 0 8 - 1 5}$ \\
\hline FDl inflows & 1874.0 & 2447.0 & 2221.5 & $19 \%$ \\
\hline Remittances & 3352.1 & 4519.3 & 5196.2 & $55 \%$ \\
\hline Other official flows (00F) & 80.4 & 387.4 & 744.1 & $825 \%$ \\
\hline of which trade-related 00F & 45.6 & 56.7 & 321.0 & $604 \%$ \\
\hline Official Development Assistance (ODA) & 229.0 & 261.9 & 347.8 & $52 \%$ \\
\hline of which Aid for Trade & 53.7 & 81.6 & 28.1 & $-48 \%$ \\
\hline
\end{tabular}

Sources: UNCTAD, UNCTADstat; WB, World Development Indicators; OECD,

DAC-CRS Aid Activities Database

\section{TOP 3 AfT PRIORITIES}

\begin{tabular}{|l|l|l|l|l|l|}
\hline 1 & Trade policy & $\mathbf{2}$ & Export diversification & $\mathbf{3}$ & 3. Trade facilitation \\
\hline
\end{tabular}

Source: OECD/WTO Partner Questionnaire

SHARE OF AfT IN DEVELOPMENT FINANCE AND FIXED CAPITAL FORMATION (\%)

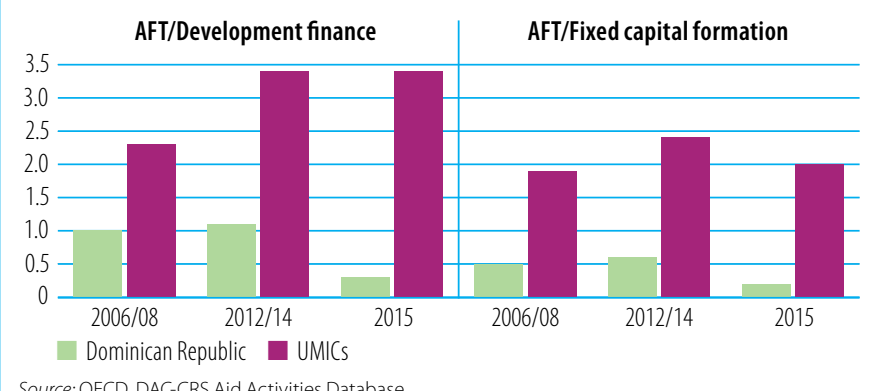

AfT DISBURSEMENTS: TOP DONORS (million current USD)

\begin{tabular}{lcc|lcc}
$\mathbf{2 0 0 6 / 0 8}$ & value & $\%$ & $\mathbf{2 0 1 5}$ & value & $\%$ \\
EU Institutions & 15.2 & 28 & OPEC Fund for International Development & 13.0 & 46 \\
\hline Germany & 7.3 & 14 & EU Institutions & 6.8 & 24 \\
\hline United States & 6.0 & 11 & United States & 3.8 & 14 \\
\hline Japan & 5.9 & 11 & Korea & 0.8 & 3 \\
\hline France & 5.6 & 10 & Japan & 0.7 & 2 \\
\hline
\end{tabular}

Source: OECD, DAC-CRS Aid Activities Database

AfT DISBURSEMENTS BY SECTOR (million current USD)

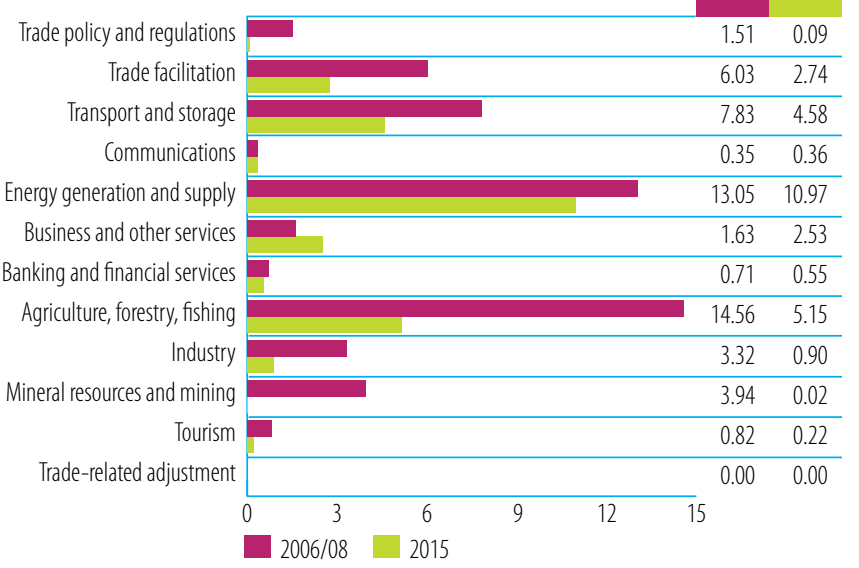

Source: OECD, DAC-CRS Aid Activities Database

\section{B. TRADE COSTS}

\begin{tabular}{lcc} 
INDICATOR & $\mathbf{2 0 0 6}$ & $\mathbf{2 0 1 5}$ \\
Tariffs (\%) & & \\
\hline Imports: simple avg. MFN applied & 8.5 & 7.3 \\
\hline Imports: weighted avg. MFN applied (2006-2014) & $\ldots$. & 6.8 \\
\hline Exports: weighted avg. faced (2005-2014) & 9.0 & 0.9 \\
\hline Exports: duty free (value in \%) (2005-2014) & 54.1 & 93.5 \\
\hline ICT connectivity (\% of population) & & \\
\hline Mobile broadband subscriptions (2007-2015) & 0.4 & 39.6 \\
\hline Fixed broadband subscriptions & 1.1 & 6.4 \\
\hline Individuals using the internet & 14.8 & 51.9 \\
\hline Sources: WTO, World Tariff Profiles; ITU, World Telecommunication/ICT Indicators &
\end{tabular}
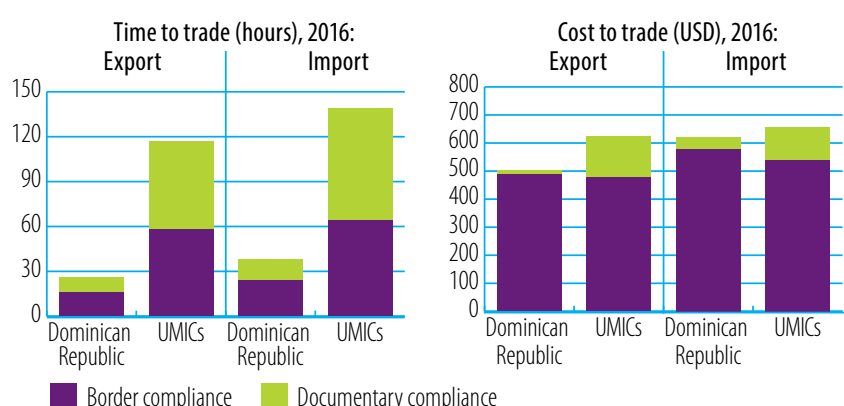

Border compliance Documentary compliance

Source: WB, Doing Business

TRADE FACILITATION INDICATORS, 2017 (0-2)

LOGISTICS PERFORMANCE INDICES (LPI) (1-5)

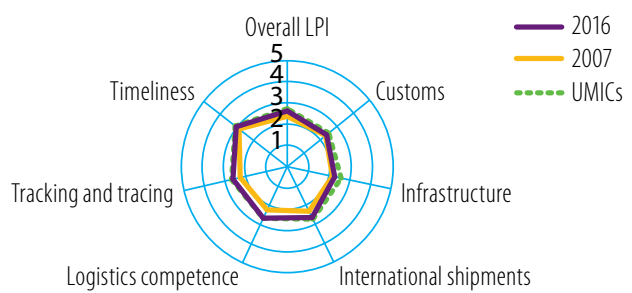

Source: WB Logistics Performance Index (LPI)

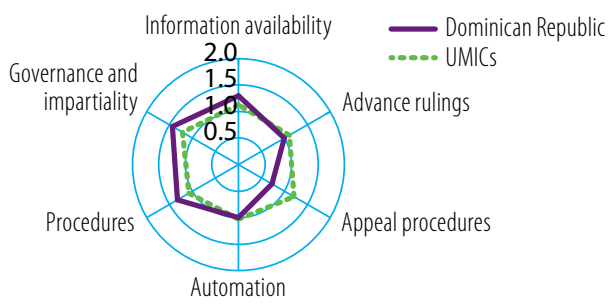

Source: OECD Trade Facilitation Indicators

\section{GLOBAL COMPETITIVENESS INDICATORS (1-7)}

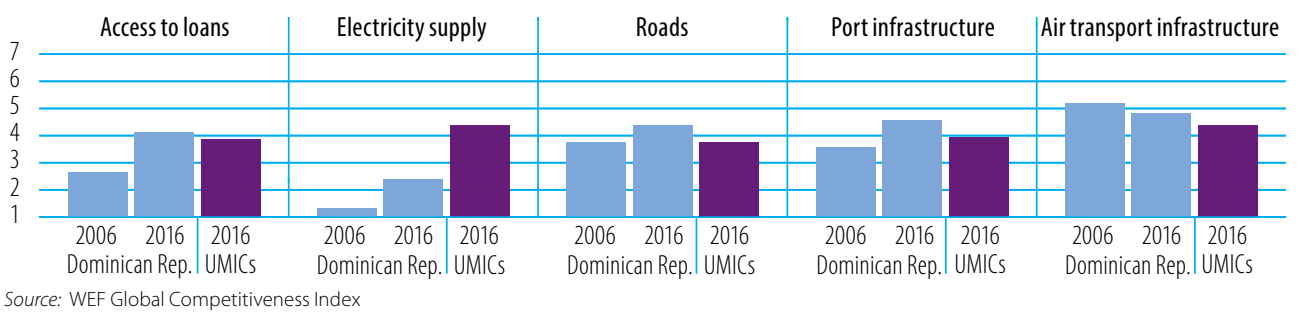

TRADE COSTS (ad-valorem, \%)

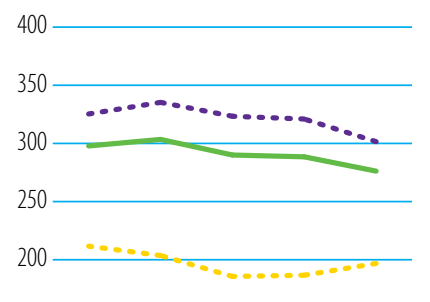

150

100

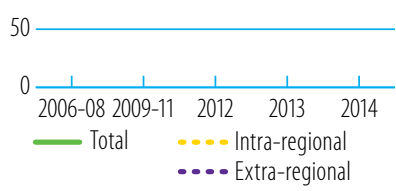

Source: ESCAP-WB Trade Cost Database

Note: Number of partners used in the

intra-regional (15), extra-regional (47) calculation of average trade costs: total (62), 


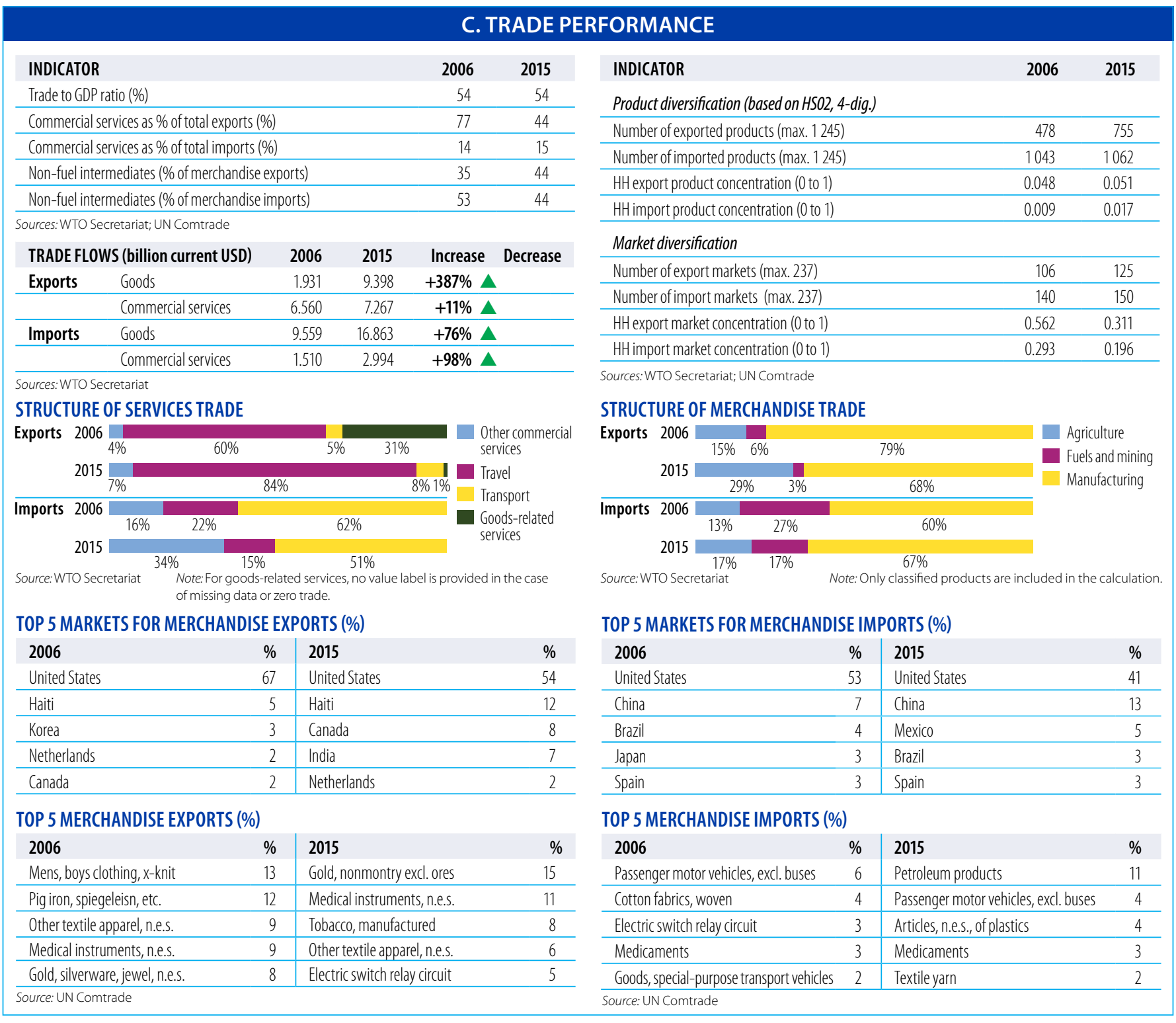

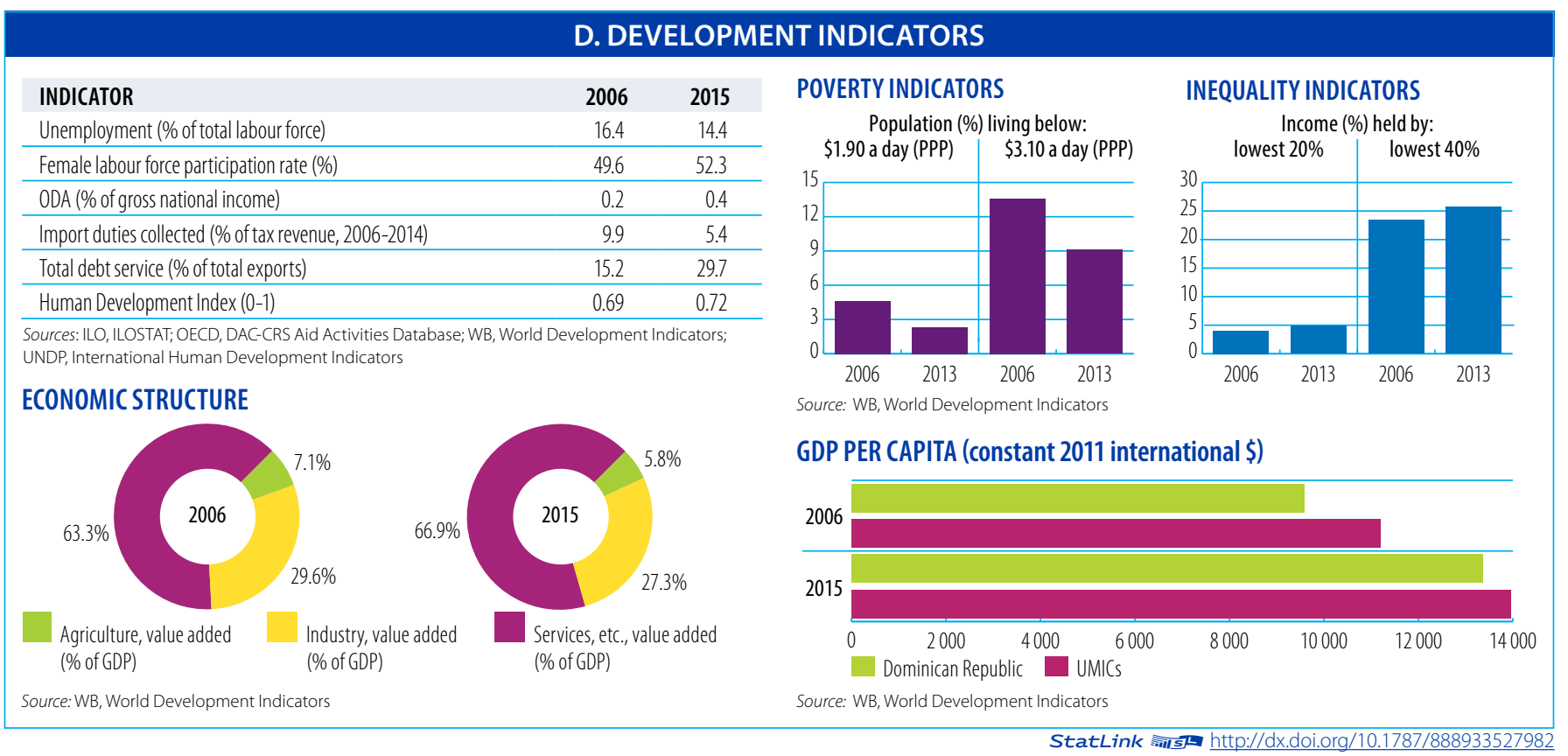




\section{EL SALVADOR}

Aid, Trade and Development Indicators for El Salvador

\section{A. DEVELOPMENT FINANCE}

\begin{tabular}{lrrrc}
$\begin{array}{l}\text { EXTERNAL FINANCING INFLOWS } \\
\text { (million current USD) }\end{array}$ & $\mathbf{2 0 0 6 / 0 8}$ & $\mathbf{2 0 1 2 / 1 4}$ & $\mathbf{2 0 1 5}$ & $\mathbf{\Delta : 0 6 / 0 8 - 1 5}$ \\
\hline FDl inflows & 898.3 & 324.1 & 428.7 & $-52 \%$ \\
\hline Remittances & 3648.8 & 4000.7 & 4285.2 & $17 \%$ \\
\hline Other official flows (OOF) & 43.7 & 231.9 & 198.6 & $355 \%$ \\
\hline of which trade-related 00F & 7.7 & 83.6 & 128.5 & $1567 \%$ \\
\hline Official Development Assistance (ODA) & 229.8 & 227.9 & 149.7 & $-35 \%$ \\
\hline of which Aid for Trade & 51.0 & 70.4 & 20.0 & $-61 \%$ \\
\hline
\end{tabular}

Sources:UNCTAD, UNCTADstat; WB, World Development Indicators; OECD,

DAC-CRS Aid Activities Database

\section{TOP 3 AfT PRIORITIES}

\section{\begin{tabular}{|l|l|l|l|l|l|}
\hline & Trade facilitation & $\mathbf{2}$ & Export diversification & $\mathbf{3}$ & Trade policy
\end{tabular}}

Source: OECD/WTO Partner Questionnaire

SHARE OF AfT IN DEVELOPMENT FINANCE AND FIXED CAPITAL FORMATION (\%)

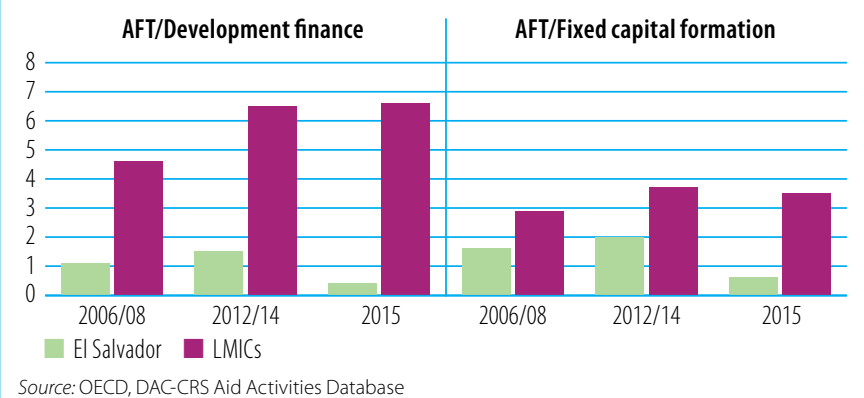

AfT DISBURSEMENTS: TOP DONORS (million current USD)

\begin{tabular}{lrr|lrr}
$\mathbf{2 0 0 6 / 0 8}$ & value & $\%$ & $\mathbf{2 0 1 5}$ & value & $\%$ \\
Japan & 27.8 & 55 & United States & 5.2 & 26 \\
\hline Spain & 9.9 & 19 & Germany & 3.4 & 17 \\
\hline United States & 3.7 & 7 & Japan & 2.5 & 12 \\
\hline EU Institutions & 3.1 & 6 & OPEC Fund for International Development & 1.7 & 9 \\
\hline Germany & 2.7 & 5 & Spain & 1.0 & 5 \\
\hline
\end{tabular}

Source: OECD, DAC-CRS Aid Activities Database

AfT DISBURSEMENTS BY SECTOR (million current USD)

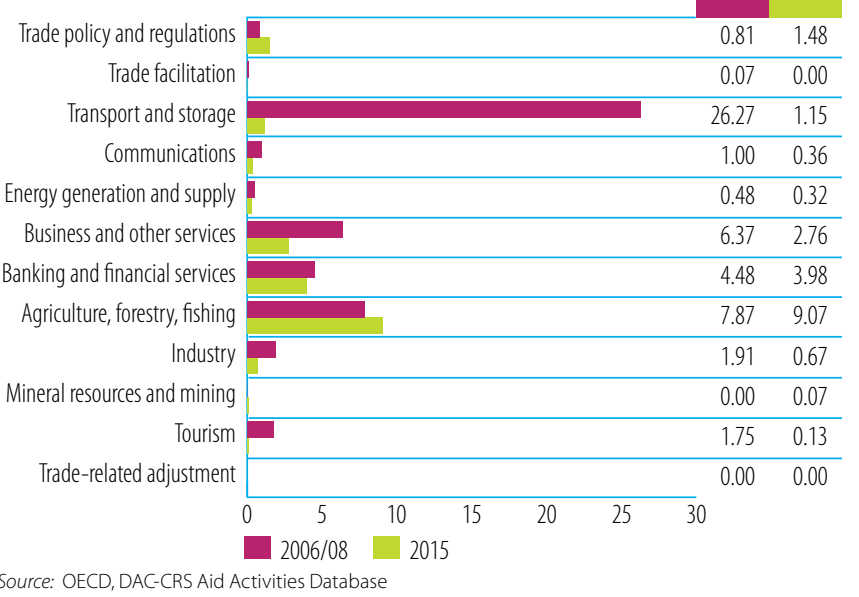

\section{B. TRADE COSTS}

\begin{tabular}{lcc} 
INDICATOR & 2006 & $\mathbf{2 0 1 5}$ \\
Tariffs (\%) & & \\
\hline Imports: simple avg. MFN applied (2005-2015) & 5.9 & 6.0 \\
\hline Imports: weighted avg. MFN applied (2006-2014) & $\ldots$ & 6.7 \\
\hline Exports: weighted avg. faced (2005-2014) & 10.1 & 0.9 \\
\hline Exports: duty free (value in \%) (2005-2014) & 43.2 & 98.0 \\
\hline ICT connectivity (\% of population) & $\ldots$ & \\
\hline Mobile broadband subscriptions & 1.0 & 19.9 \\
\hline Fixed broadband subscriptions & 5.5 \\
\hline Individuals using the internet & 5.5 & 26.9 \\
\hline Sources: WTO, World Tariff Profiles; ITU, World Telecommunication/ICT Indicators &
\end{tabular}

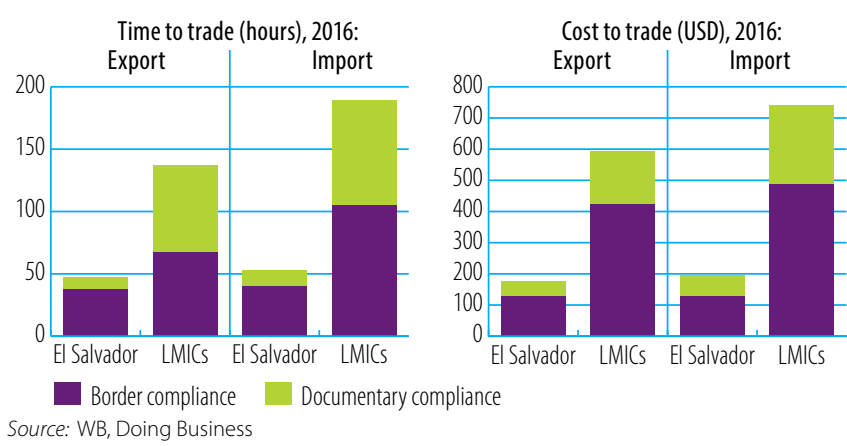

LOGISTICS PERFORMANCE INDICES (LPI) (1-5)

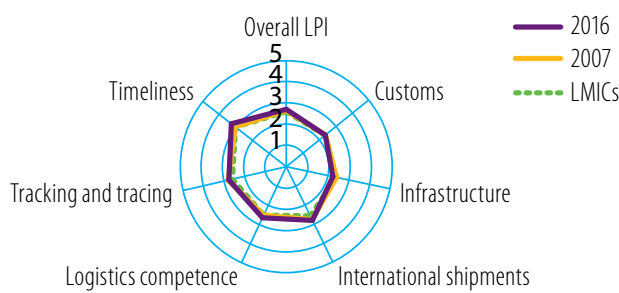

Source: WB Logistics Performance Index (LPI)

\section{GLOBAL COMPETITIVENESS INDICATORS (1-7)}

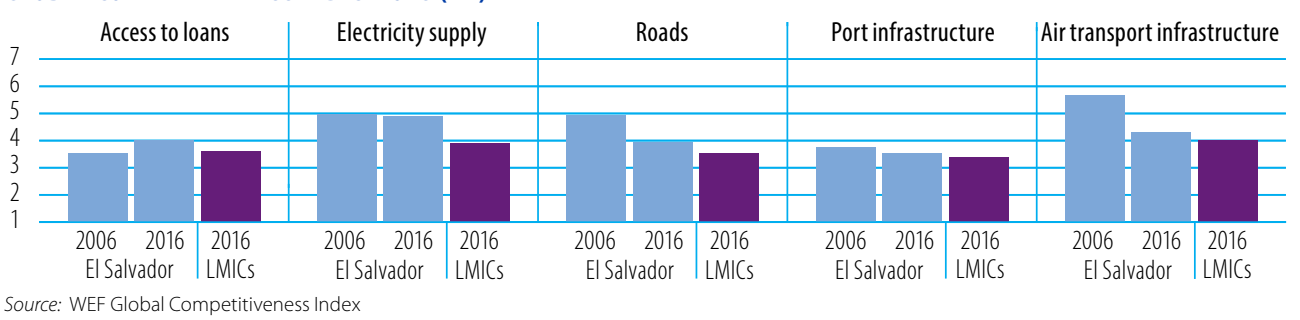

TRADE FACILITATION INDICATORS, 2017 (0-2)

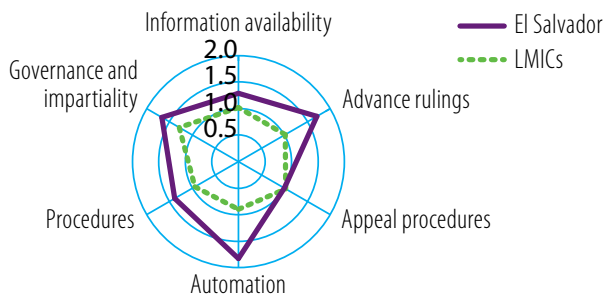

Source: OECD Trade Facilitation Indicators
TRADE COSTS (ad-valorem, \%)

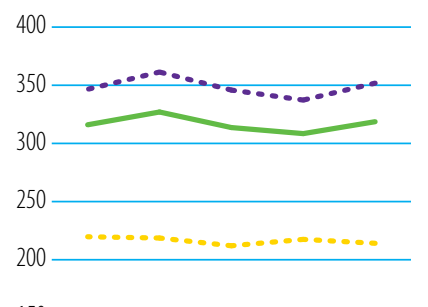

150

100

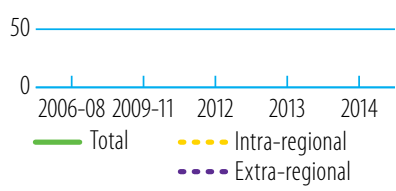

Source: ESCAP-WB Trade Cost Database

Note: Number of partners used in the

calculation of average trade costs: total (54),

intra-regional (13), extra-regional (41) 


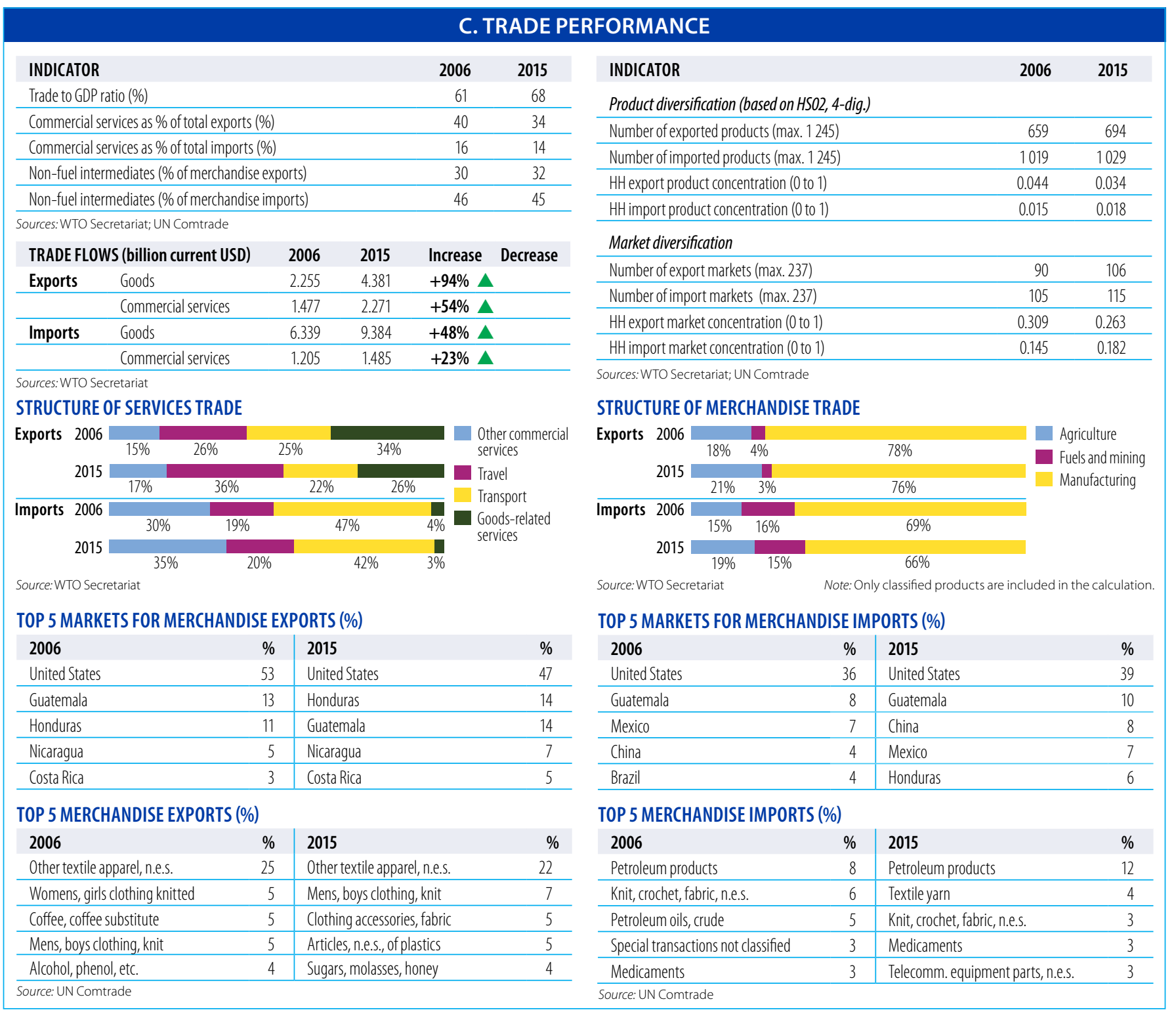

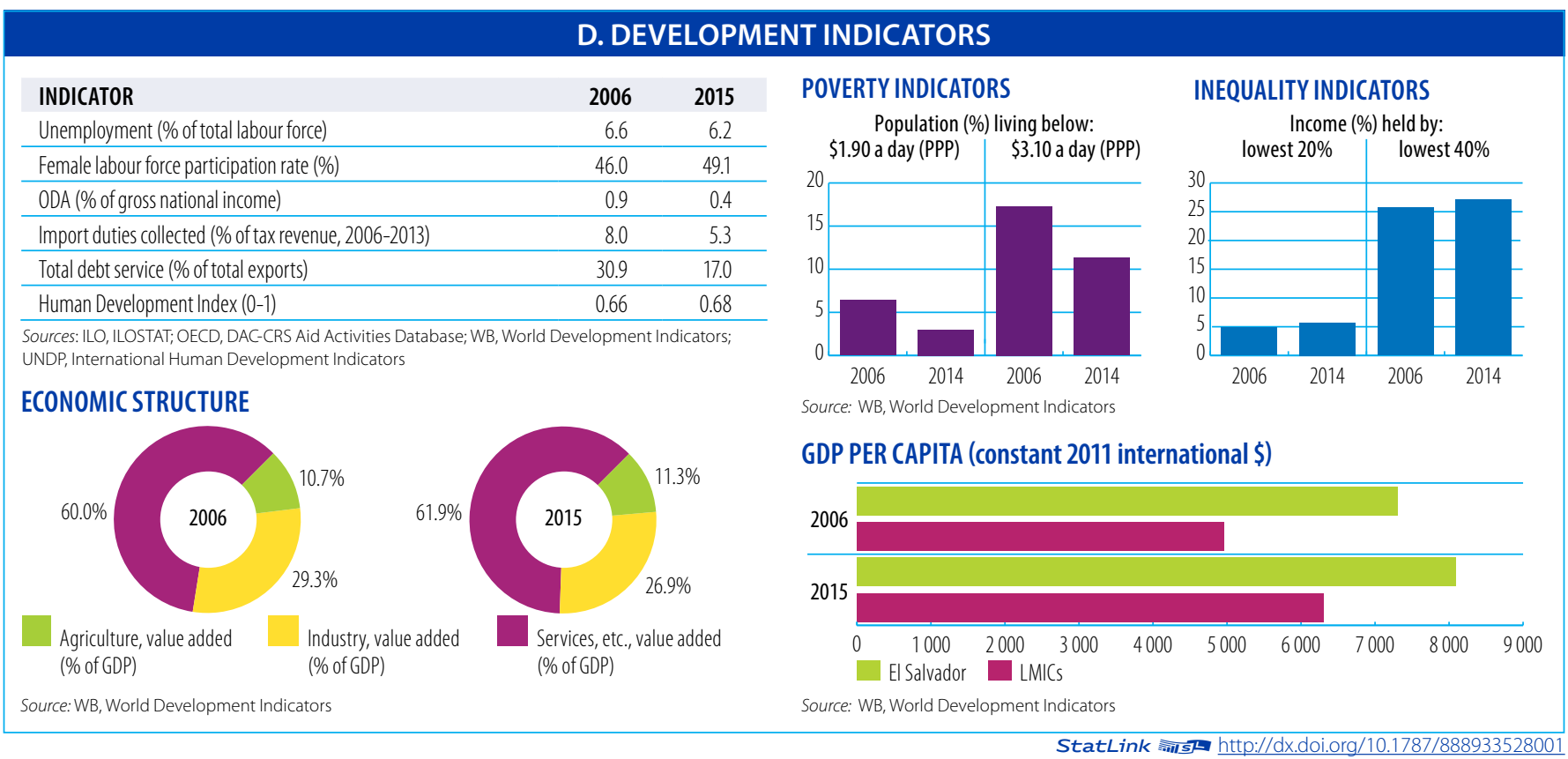


Aid, Trade and Development Indicators for Gabon

\section{A. DEVELOPMENT FINANCE}

\begin{tabular}{lrrrc}
\hline $\begin{array}{l}\text { EXTERNAL FINANCING INFL OWS } \\
\text { (million current USD) }\end{array}$ & $\mathbf{2 0 0 6 / 0 8}$ & $\mathbf{2 0 1 2 / 1 4}$ & $\mathbf{2 0 1 5}$ & $\mathbf{\Delta : 0 6 / 0 8 - 1 5}$ \\
\hline FDl inflows & 436.7 & 871.7 & 623.9 & $43 \%$ \\
\hline Remittances & $\ldots$ & $\ldots$ & $\ldots$ & - \\
\hline Other official flows (00F) & 23.7 & 97.7 & 58.5 & $147 \%$ \\
\hline$\quad$ of which trade-related 00F & 9.5 & 56.9 & 20.0 & $110 \%$ \\
\hline Official Development Assistance (ODA) & 91.0 & 109.4 & 116.5 & $28 \%$ \\
\hline of which Aid for Trade & 23.4 & 36.6 & 65.5 & $180 \%$ \\
\hline
\end{tabular}

Sources: UNCTAD, UNCTADstat; WB, World Development Indicators; OECD,

DAC-CRS Aid Activities Database

\section{TOP 3 AfT PRIORITIES}

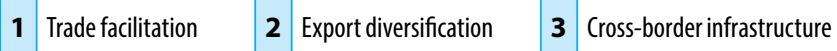
Source: OECD/WTO Partner Questionnaire

SHARE OF AfT IN DEVELOPMENT FINANCE AND FIXED CAPITAL FORMATION (\%)

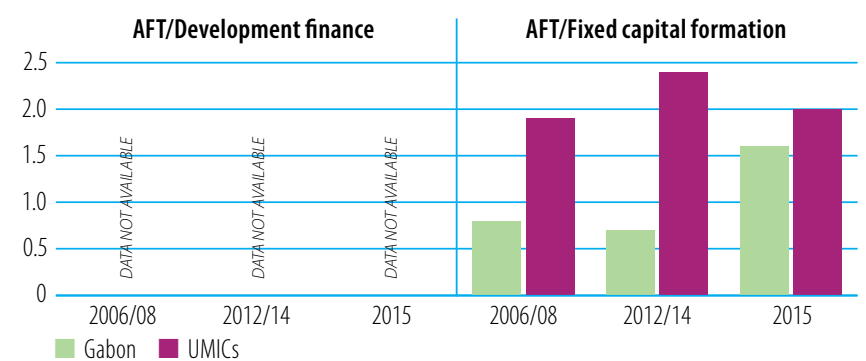

Source: OECD, DAC-CRS Aid Activities Database

AfT DISBURSEMENTS: TOP DONORS (million current USD)

\begin{tabular}{lrr|lrc}
$\mathbf{2 0 0 6 / 0 8}$ & value & $\%$ & $\mathbf{2 0 1 5}$ & value & $\%$ \\
France & 13.0 & 56 & France & 61.8 & 94 \\
\hline EU Institutions & 8.4 & 36 & EU Institutions & 2.2 & 3 \\
\hline Japan & 1.9 & 8 & Japan & 0.9 & 1 \\
\hline Belgium & 0.1 & 0 & Kuwait (KFAED) & 0.3 & 0 \\
\hline United States & 0.0 & 0 & Korea & 0.2 & 0 \\
\hline
\end{tabular}

Source: OECD, DAC-CRS Aid Activities Database

AfT DISBURSEMENTS BY SECTOR (million current USD)

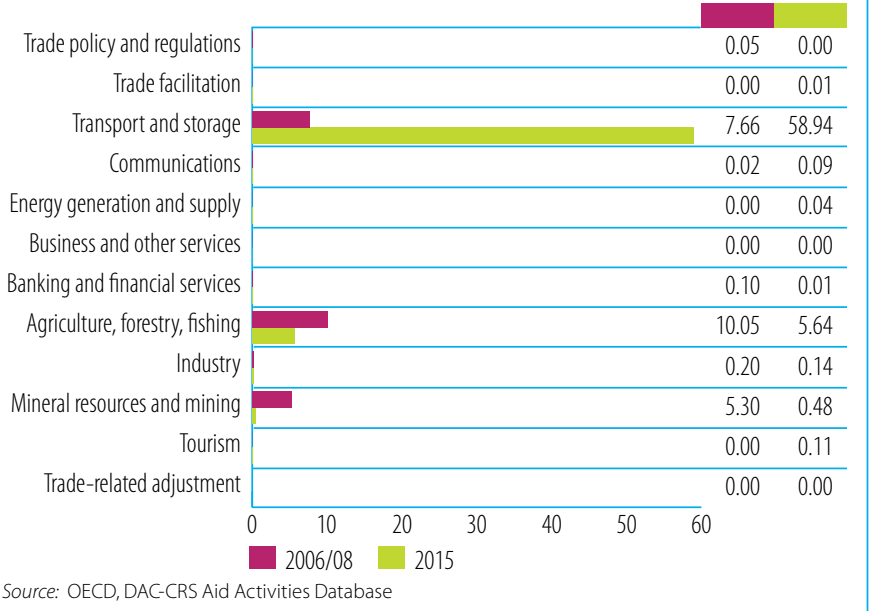

\section{B. TRADE COSTS}

\begin{tabular}{lcc} 
INDICATOR & $\mathbf{2 0 0 6}$ & $\mathbf{2 0 1 5}$ \\
Tariffs (\%) & & \\
\hline Imports: simple avg. MFN applied (2005-2015) & 18.0 & 17.7 \\
\hline Imports: weighted avg. MFN applied (2006-2012) & $\ldots$ & 14.1 \\
\hline Exports: weighted avg. faced (2005-2014) & 0.0 & 0.1 \\
\hline Exports: duty free (value in \%) (2005-2014) & 99.9 & 98.3 \\
\hline ICT connectivity (\% of population) & & \\
\hline Mobile broadband subscriptions & $\ldots$ & 33.1 \\
\hline Fixed broadband subscriptions & 0.1 & 0.6 \\
\hline Individuals using the internet & 5.5 & 23.5 \\
\hline Sources: WTO, World Tariff Profiles; ITU, World Telecommunication/ICT Indicators &
\end{tabular}
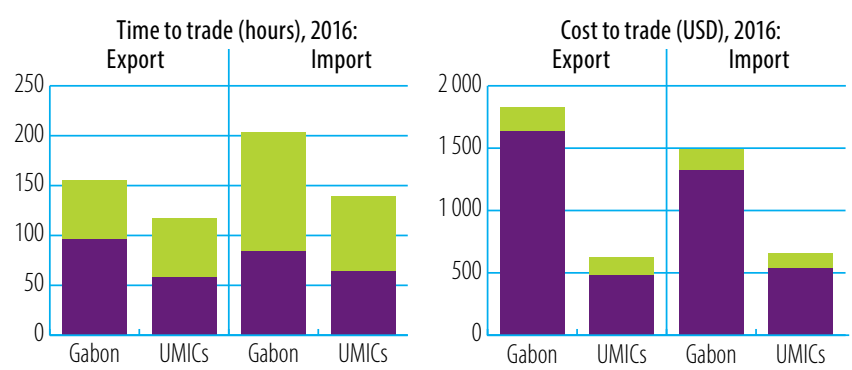

Sources: WTO, World Tariff Profiles; ITU, World Telecommunication/ICT Indicators

LOGISTICS PERFORMANCE INDICES (LPI) (1-5)

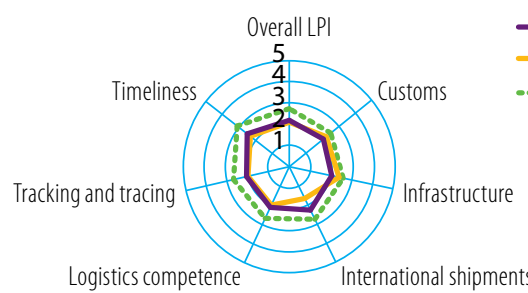

Source: WB Logistics Performance Index (LPI)

GLOBAL COMPETITIVENESS INDICATORS (1-7)

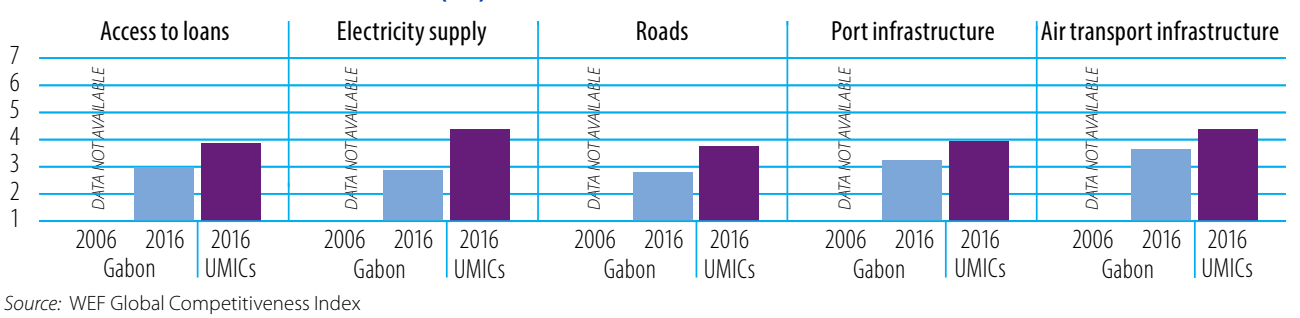

TRADE FACILITATION INDICATORS, 2017 (0-2)

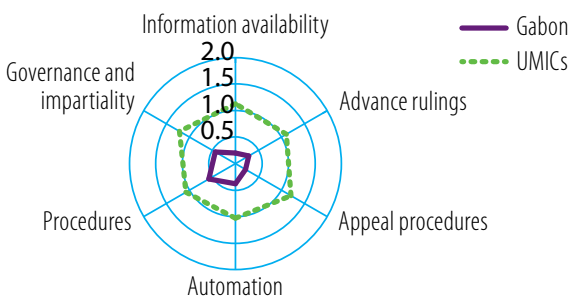

Source: OECD Trade Facilitation Indicators

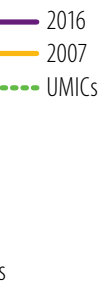

Border compliance Documentary compliance Border compliance
Source: WB, Doing Business 


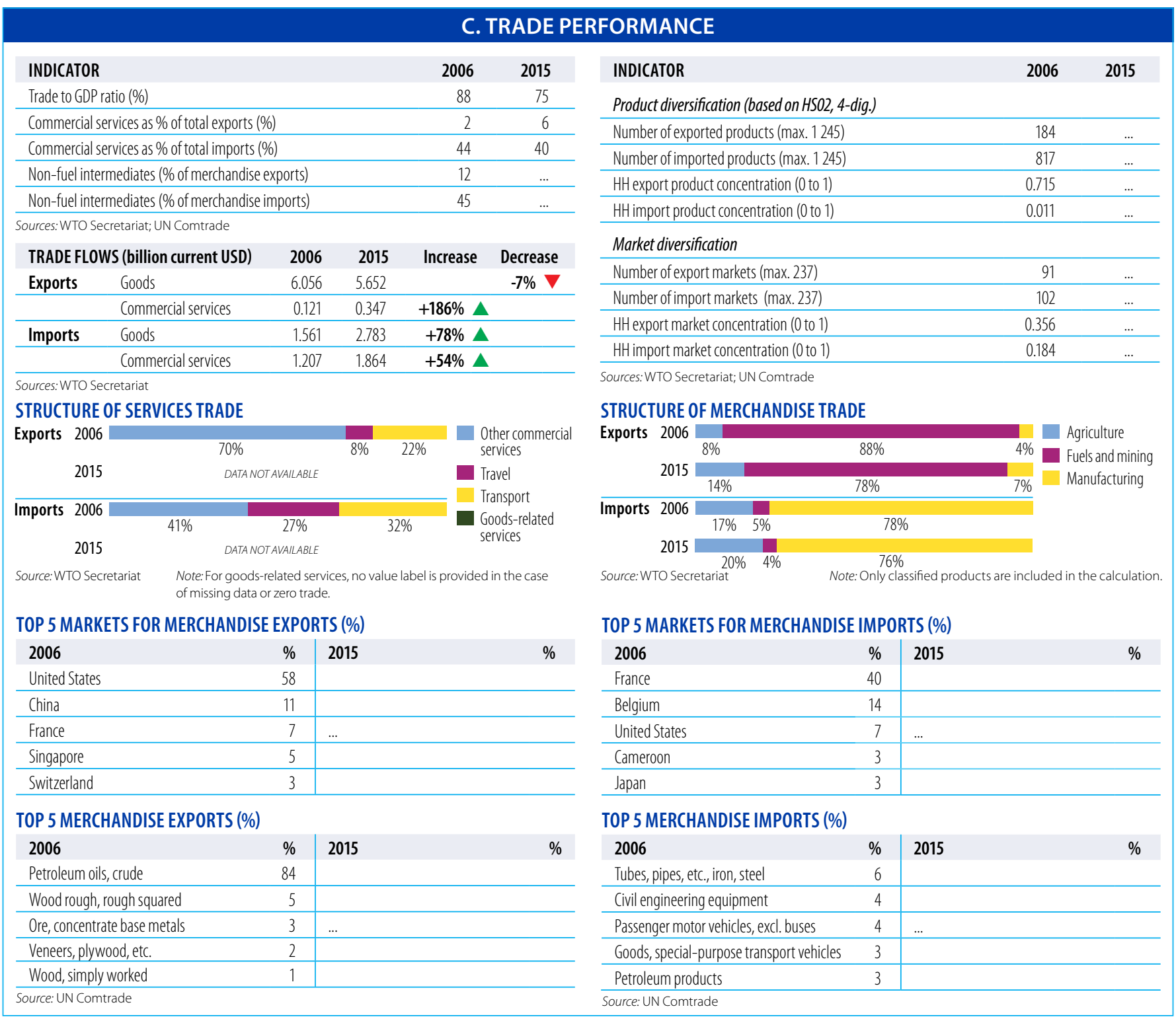

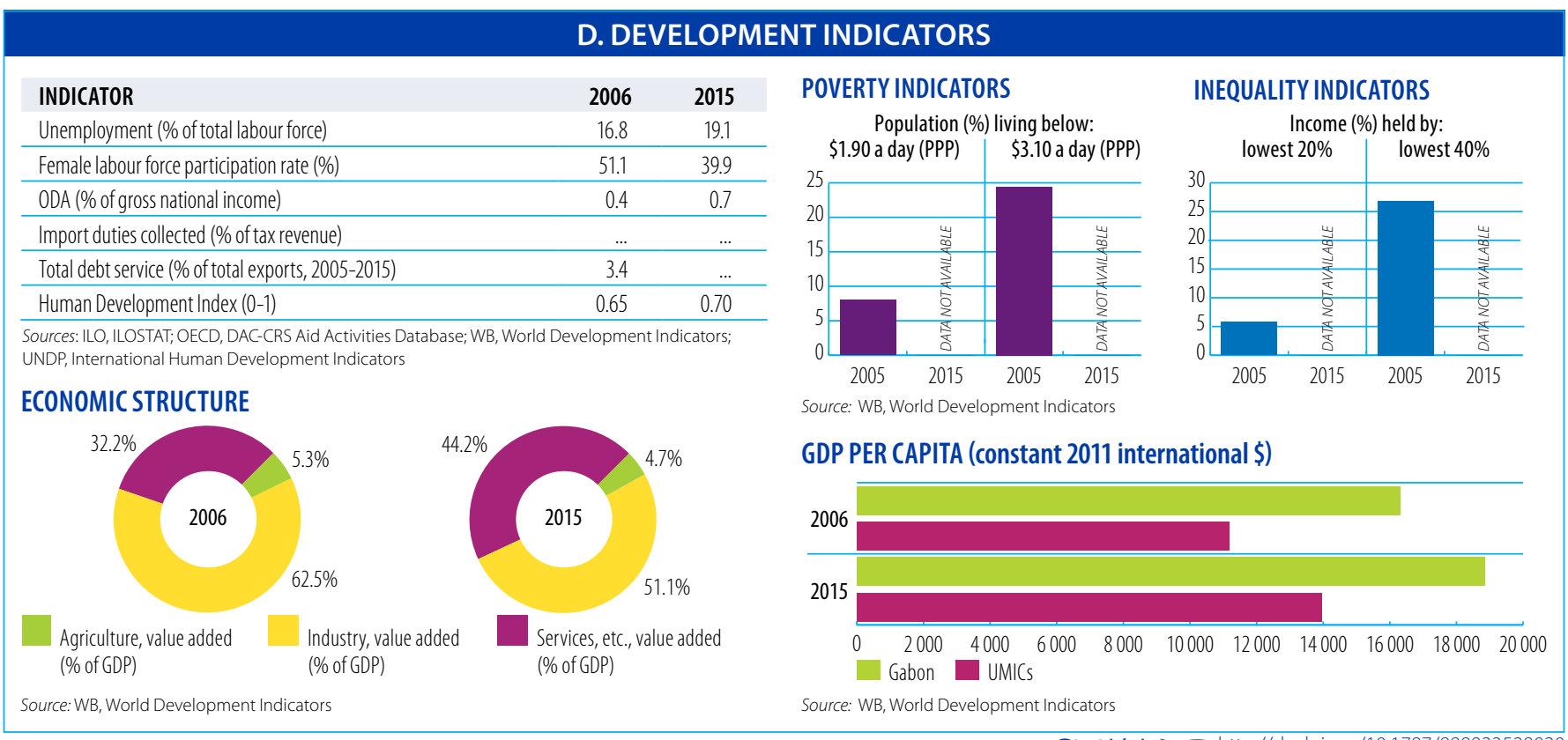


Aid, Trade and Development Indicators for Gambia

\section{A. DEVELOPMENT FINANCE}

\begin{tabular}{lrrrc}
$\begin{array}{l}\text { EXTERNAL FINANCING INFLOWS } \\
\text { (million current USD) }\end{array}$ & $\mathbf{2 0 0 6 / 0 8}$ & $\mathbf{2 0 1 2 / 1 4}$ & $\mathbf{2 0 1 5}$ & $\mathbf{\Delta : 0 6 / 0 8 - 1 5}$ \\
\hline FDl inflows & 56.7 & 53.1 & 10.6 & $-81 \%$ \\
\hline Remittances & 61.4 & 167.5 & 180.7 & $194 \%$ \\
\hline Other official flows (OOF) & 0.0 & 10.7 & 21.7 & - \\
\hline of which trade-related 0OF & 0.0 & 8.2 & 2.8 & - \\
\hline Official Development Assistance (ODA) & 218.8 & 127.8 & 128.8 & $-41 \%$ \\
\hline of which Aid for Trade & 15.1 & 44.5 & 36.6 & $143 \%$ \\
\hline
\end{tabular}

Sources: UNCTAD, UNCTADstat; WB, World Development Indicators; OECD,

DAC-CRS Aid Activities Database

\section{TOP 3 AfT PRIORITIES}

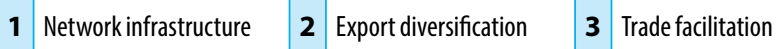

Source: OECD/WTO Partner Questionnaire

SHARE OF AfT IN DEVELOPMENT FINANCE AND FIXED CAPITAL FORMATION (\%)

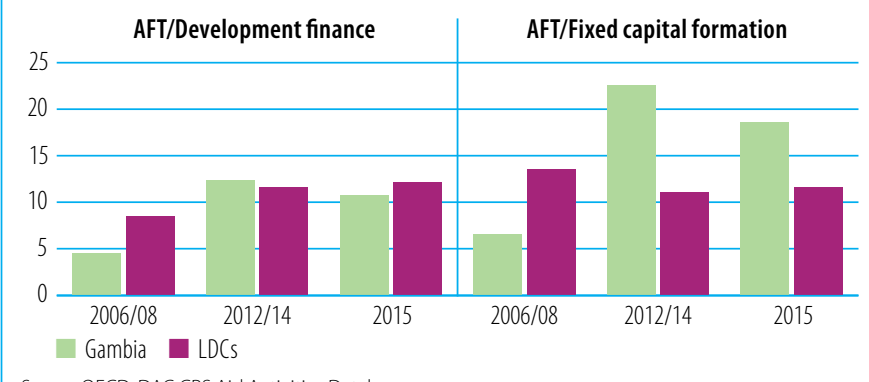

AfT DISBURSEMENTS: TOP DONORS (million current USD)

\begin{tabular}{lrr|lrc}
$\mathbf{2 0 0 6 / 0 8}$ & value & $\%$ & $\mathbf{2 0 1 5}$ & value & $\%$ \\
EU Institutions & 4.4 & 29 & OPEC Fund for Int. Development & 11.2 & 31 \\
\hline African Development Fund & 4.0 & 27 & Kuwait (KFAED) & 8.4 & 23 \\
\hline IDA & 3.3 & 22 & IDA & 8.0 & 22 \\
\hline Japan & 1.6 & 11 & EU Institutions & 3.8 & 10 \\
\hline Belgium & 0.5 & 3 & $\begin{array}{l}\text { Arab Bankfor Economic Development } \\
\text { in Africa }\end{array}$ & 2.7 & 7
\end{tabular}

Source: OECD, DAC-CRS Aid Activities Database

AfT DISBURSEMENTS BY SECTOR (million current USD)

\begin{tabular}{|c|c|c|c|}
\hline Trade policy and regulations & & 0.07 & 0.00 \\
\hline Trade facilitation & & 0.00 & 0.00 \\
\hline Transport and storage & 9 & 5.15 & 16.04 \\
\hline Communications & 5 & 0.60 & 1.13 \\
\hline Energy generation and supply & 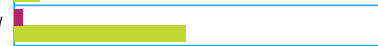 & 0.36 & 7.61 \\
\hline Business and other services & $\overline{0}$ & 1.19 & 1.40 \\
\hline Banking and financial services & & 0.09 & 0.05 \\
\hline Agriculture, forestry, fishing & 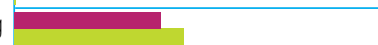 & 6.50 & 7.53 \\
\hline Industry & $\overline{0}$ & 0.95 & 1.91 \\
\hline Mineral resources and mining & & 0.04 & 0.00 \\
\hline Tourism & 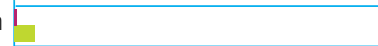 & 0.13 & 0.91 \\
\hline Trade-related adjustment & & 0.00 & 0.00 \\
\hline & $\begin{array}{ll}5 & 10\end{array}$ & 20 & \\
\hline
\end{tabular}

\section{B. TRADE COSTS}

\begin{tabular}{lcc} 
INDICATOR & 2006 & $\mathbf{2 0 1 5}$ \\
Tariffs (\%) & $\ldots$ & 14.1 \\
\hline Imports: simple avg. MFN applied (2006-2013) & $\ldots$ & 13.1 \\
\hline Imports: weighted avg. MFN applied (2006-2013) & 15.1 & 0.7 \\
\hline Exports: weighted avg. faced (2005-2014) & 36.7 & 87.9 \\
\hline Exports: duty free (value in \%) (2005-2014) & & \\
\hline ICT connectivity (\% of population) & $\ldots$ & 10.0 \\
\hline Mobile broadband subscriptions & 0.0 & 0.2 \\
\hline Fixed broadband subscriptions (2007-2015) & 5.2 & 17.1 \\
\hline Individuals using the internet & &
\end{tabular}
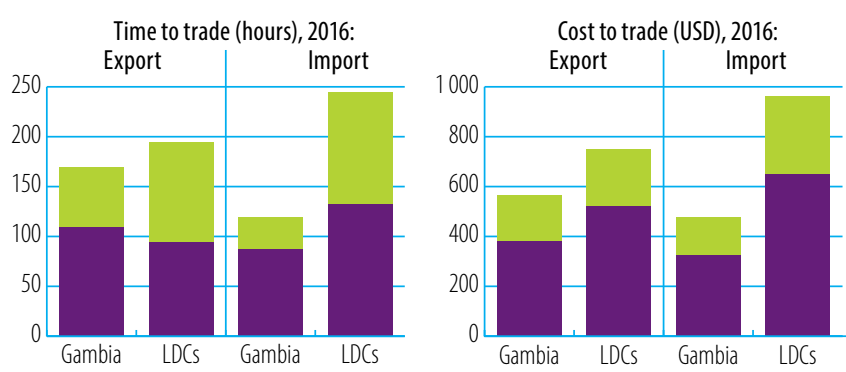

- Border compliance Documentary compliance Source: WB, Doing Business

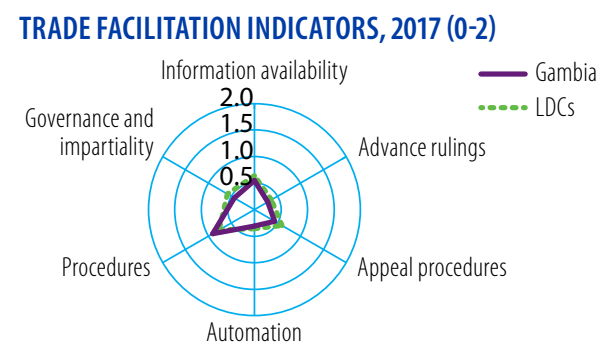

Source: OECD Trade Facilitation Indicators

Source: WB Logistics Performance Index (LPI)

GLOBAL COMPETITIVENESS INDICATORS (1-7)

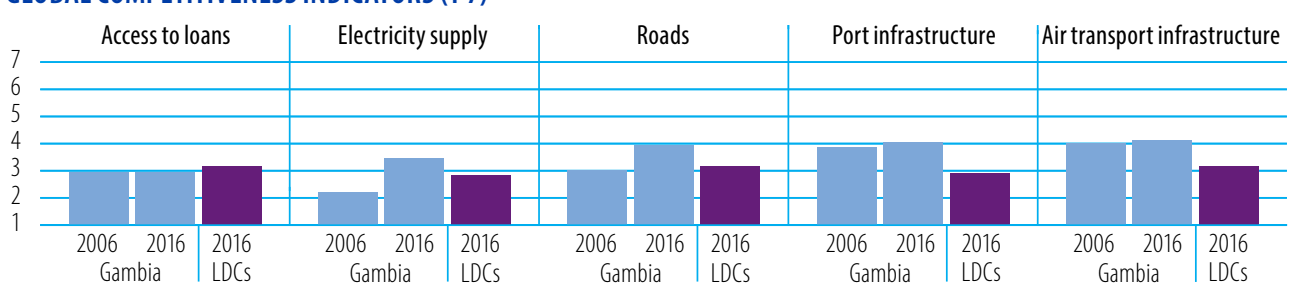

Source: WEF Global Competitiveness Index

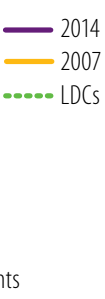

LOGISTICS PERFORMANCE INDICES (LPI) (1-5)

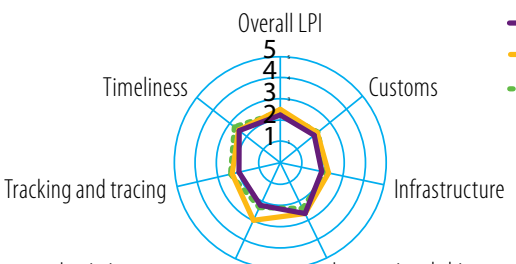

Logistics competence ternational shipments 


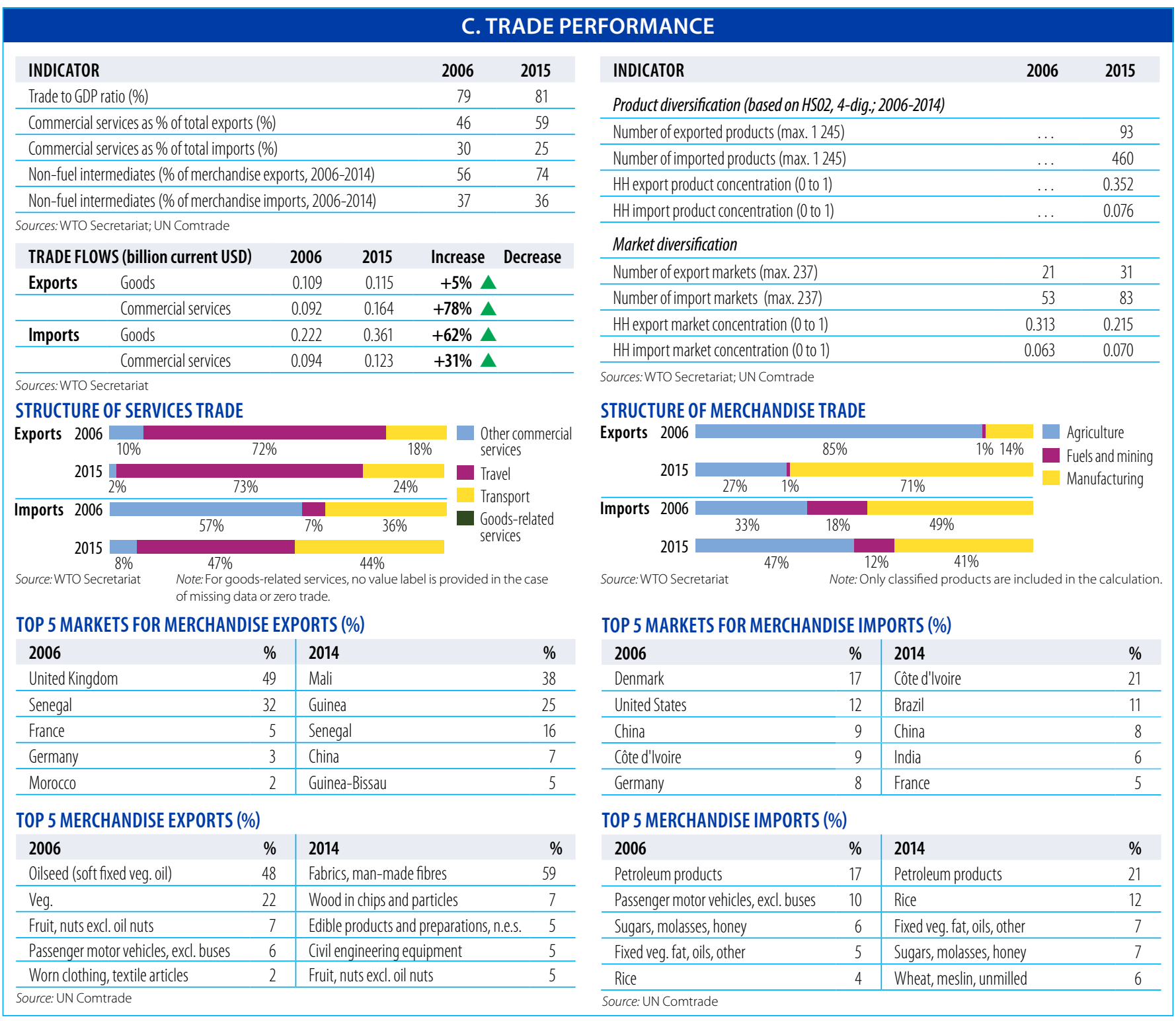

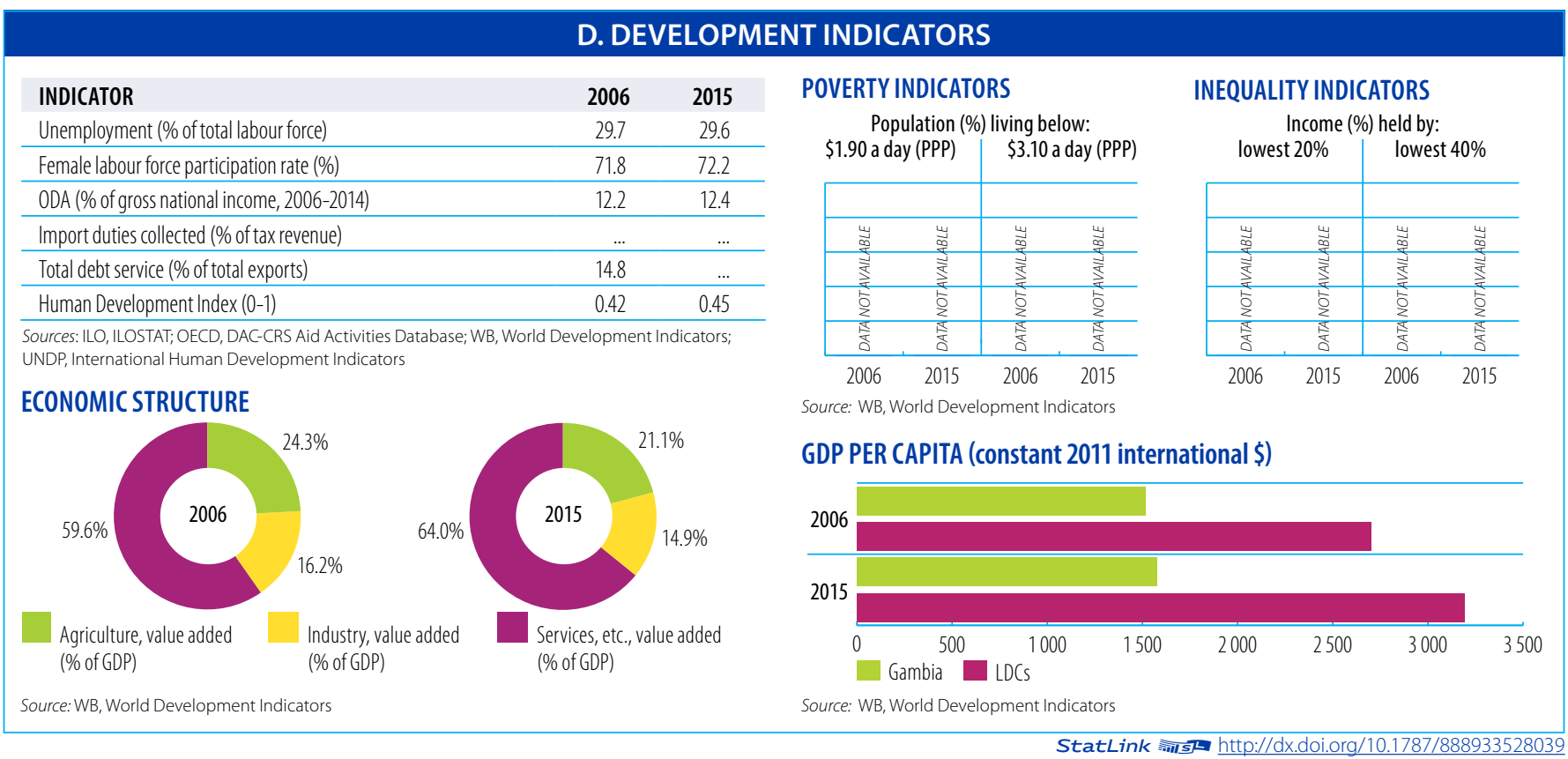


Aid, Trade and Development Indicators for Grenada

\section{A. DEVELOPMENT FINANCE}

\begin{tabular}{lrrrr}
$\begin{array}{l}\text { EXTERNAL FINANCING INFL OWS } \\
\text { (million current USD) }\end{array}$ & $\mathbf{2 0 0 6 / 0 8}$ & $\mathbf{2 0 1 2 / 1 4}$ & $\mathbf{2 0 1 5}$ & $\mathbf{\Delta : 0 6 / 0 8 - 1 5}$ \\
FDl inflows & 136.2 & 62.0 & 60.7 & $-55 \%$ \\
\hline Remittances & 28.6 & 29.5 & 29.6 & $4 \%$ \\
\hline Other official flows (00F) & 5.1 & 2.5 & 22.7 & $349 \%$ \\
\hline of which trade-related 0OF & 0.0 & 1.6 & 5.0 & $11230 \%$ \\
\hline Official Development Assistance (ODA) & 15.2 & 20.9 & 35.8 & $136 \%$ \\
\hline of which Aid for Trade & 1.0 & 4.6 & 12.3 & $1112 \%$ \\
\hline
\end{tabular}

Sources: UNCTAD, UNCTADstat; WB, World Development Indicators; OECD,

DAC-CRS Aid Activities Database

\section{TOP 3 AfT PRIORITIES}

\begin{tabular}{|l|l|l|l|l|l|}
\hline $\mathbf{1}$ & Trade policy & $\mathbf{2}$ & Services development & $\mathbf{3}$ & Export diversification \\
\hline
\end{tabular}

Source: OECD/WTO Partner Questionnaire

SHARE OF AfT IN DEVELOPMENT FINANCE AND FIXED CAPITAL FORMATION (\%)

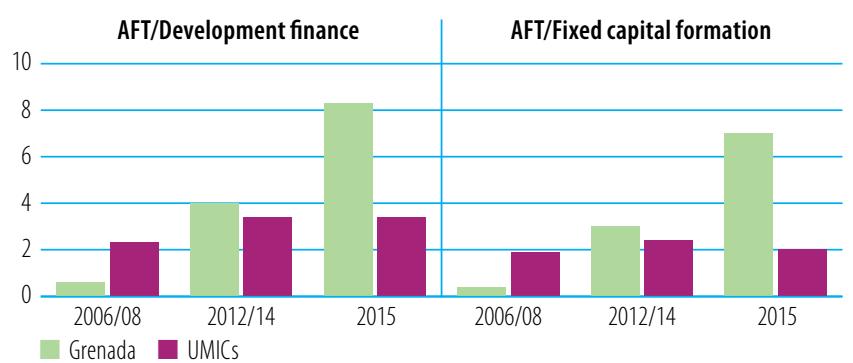

Source: OECD, DAC-CRS Aid Activities Database
AfT DISBURSEMENTS: TOP DONORS (million current USD)

\begin{tabular}{lrr|lrr}
$\mathbf{2 0 0 6 / 0 8}$ & value & $\%$ & $\mathbf{2 0 1 5}$ & value & $\%$ \\
EU Institutions & 0.7 & 69 & IDA & 8.9 & 72 \\
\hline Japan & 0.2 & 17 & Kuwait (KFAED) & 2.8 & 22 \\
\hline IDA & 0.1 & 6 & Japan & 0.3 & 2 \\
\hline Canada & 0.1 & 5 & Germany & 0.3 & 2 \\
\hline United Kingdom & 0.0 & 1 & Korea & 0.1 & 1 \\
\hline
\end{tabular}

Source: OECD, DAC-CRS Aid Activities Database

AfT DISBURSEMENTS BY SECTOR (million current USD)

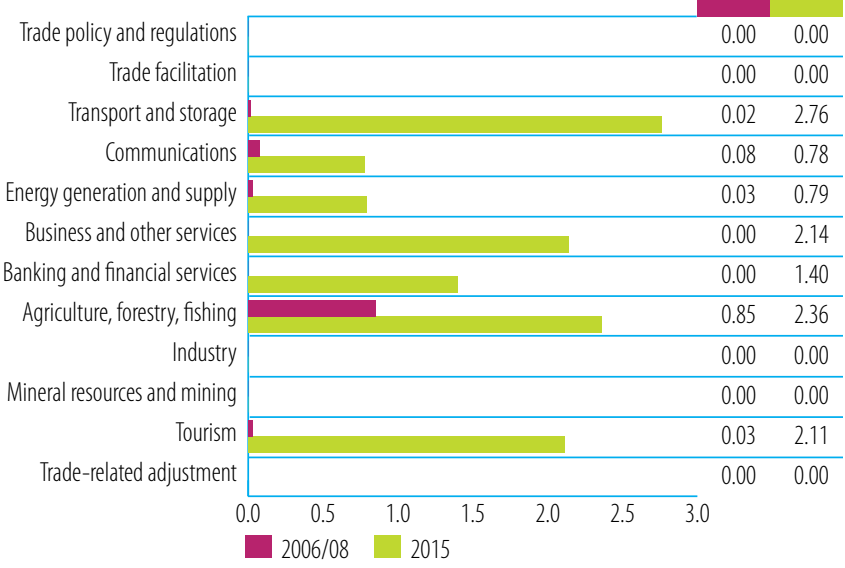

Source: OECD, DAC-CRS Aid Activities Database

\section{B. TRADE COSTS}

\begin{tabular}{lcc} 
INDICATOR & $\mathbf{2 0 0 6}$ & $\mathbf{2 0 1 5}$ \\
Tariffs (\%) & & \\
\hline Imports: simple avg. MFN applied & 10.2 & 11.0 \\
\hline Imports: weighted avg. MFN applied & $\ldots$ & $\ldots$ \\
\hline Exports: weighted avg. faced (2005-2014) & 0.5 & 0.3 \\
\hline Exports: duty free (value in \%) (2005-2014) & 92.9 & 94.9 \\
\hline ICT connectivity (\% of population) & $\ldots$ & \\
\hline Mobile broadband subscriptions & 5.4 & 28.8 \\
\hline Fixed broadband subscriptions & 21.4 & 53.5 \\
\hline Individuals using the internet & 53.8 \\
\hline Sources: WTO, World Tariff Profiles; ITU, World Telecommunication/ICT Indicators &
\end{tabular}
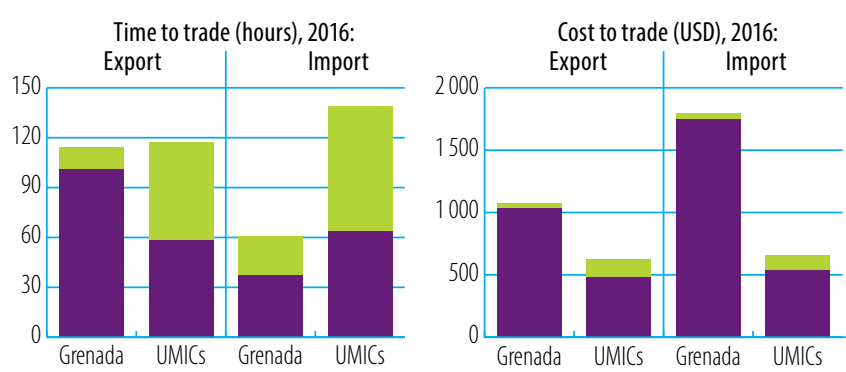

Border compliance Documentary compliance Source: WB, Doing Business

\section{LOGISTICS PERFORMANCE INDICES (LPI) (1-5)}

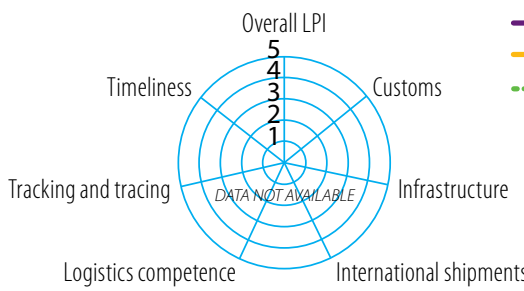

Logistics competence International shipments

Source: WB Logistics Performance Index (LPI)
TRADE FACILITATION INDICATORS, 2017 (0-2)

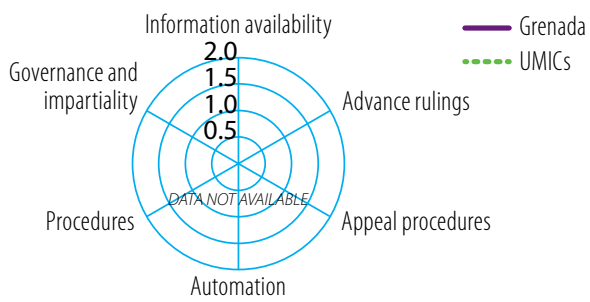

Source: OECD Trade Facilitation Indicators
GLOBAL COMPETITIVENESS INDICATORS (1-7)

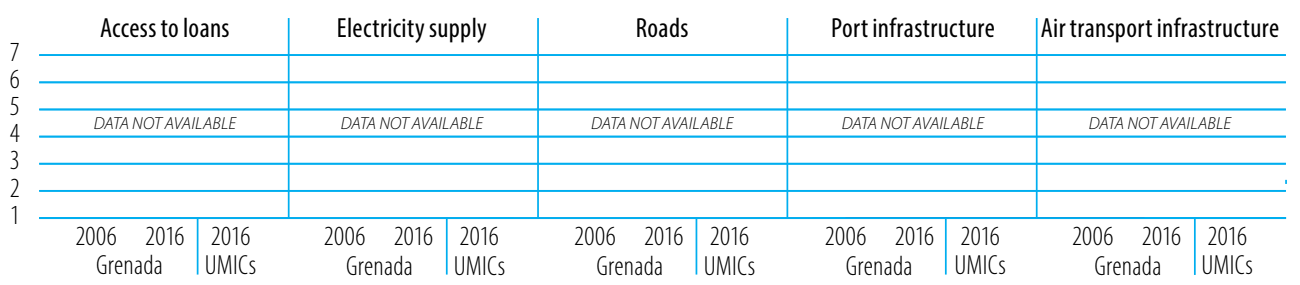

Source: WEF Global Competitiveness Index

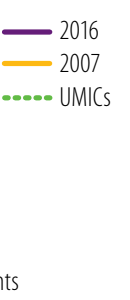

Grenada UMICs
Grenada 1 UMIC

Grenada UMICS
TRADE COSTS (ad-valorem, \%)

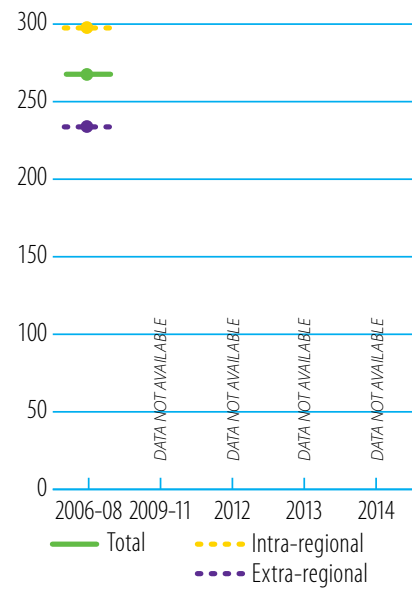

Source: ESCAP-WB Trade Cost Database Note: Number of partners used in the calculation of average trade costs: total (29), intra-regional (14), extra-regional (15) 


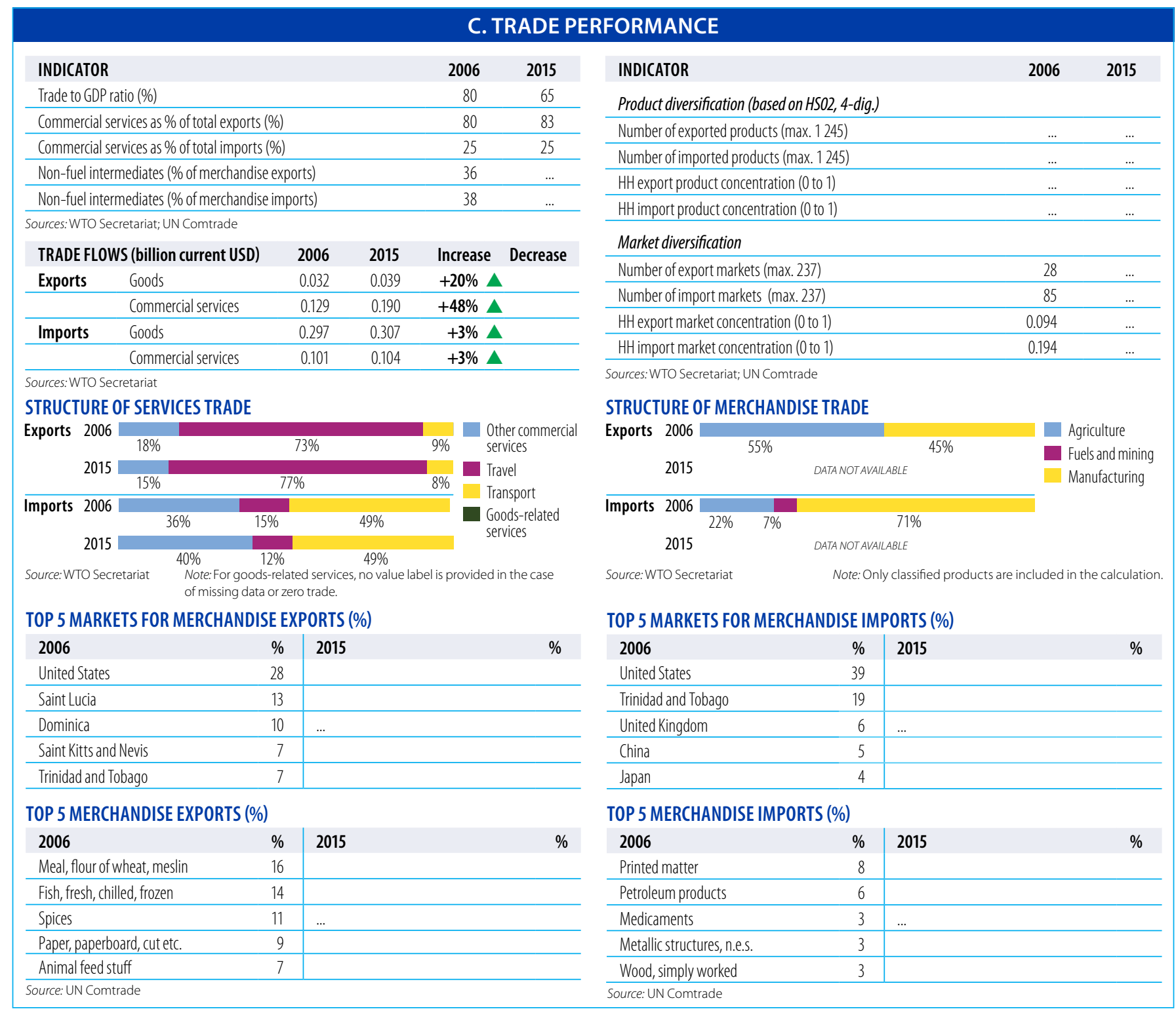

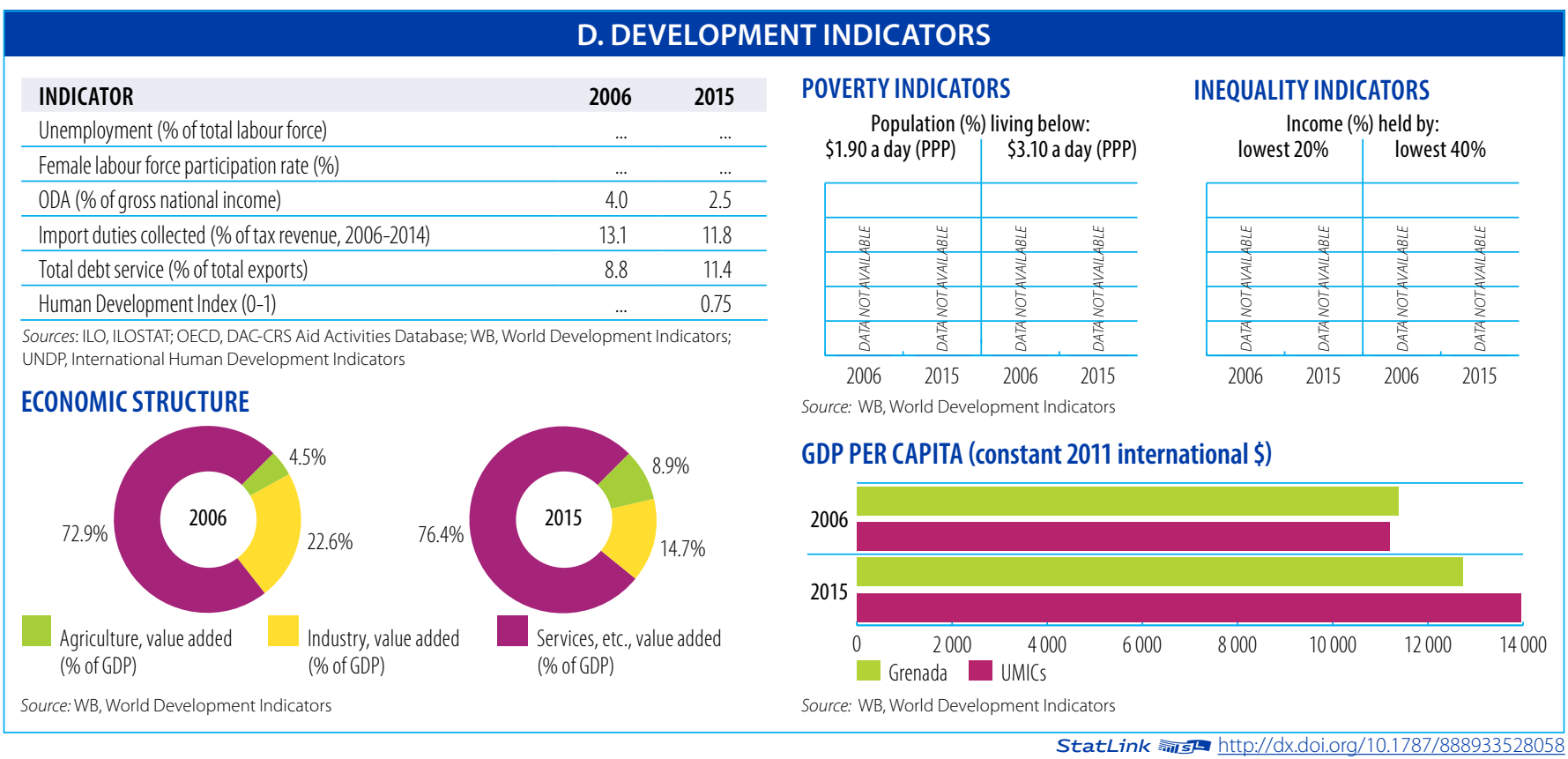


Aid, Trade and Development Indicators for Guatemala

\section{A. DEVELOPMENT FINANCE}

\begin{tabular}{lrrrc}
$\begin{array}{l}\text { EXTERNAL FINANCING INFLOWS } \\
\text { (million current USD) }\end{array}$ & $\mathbf{2 0 0 6 / 0 8}$ & $\mathbf{2 0 1 2 / 1 4}$ & $\mathbf{2 0 1 5}$ & $\mathbf{\Delta : 0 6 / 0 8 - 1 5}$ \\
\hline FDl inflows & 696.9 & 1309.7 & 1208.4 & $73 \%$ \\
\hline Remittances & 4132.0 & 5415.9 & 6572.8 & $59 \%$ \\
\hline Other official flows (00F) & 156.8 & 307.1 & 571.9 & $265 \%$ \\
\hline of which trade-related 00F & 73.3 & 69.6 & 24.8 & $-66 \%$ \\
\hline Official Development Assistance (ODA) & 538.3 & 407.8 & 455.3 & $-15 \%$ \\
\hline of which Aid for Trade & 26.7 & 88.1 & 55.5 & $108 \%$ \\
\hline
\end{tabular}

Sources: UNCTAD, UNCTADstat; WB, World Development Indicators; OECD,

DAC-CRS Aid Activities Database

TOP 3 AfT PRIORITIES

\begin{tabular}{|l|l|l|l|l|l|}
\hline & Trade facilitation & $\mathbf{2}$ & Regional integration & $\mathbf{3}$ & International competitiveness
\end{tabular} Source: OECD/WTO Partner Questionnaire

SHARE OF AfT IN DEVELOPMENT FINANCE AND FIXED CAPITAL FORMATION (\%)

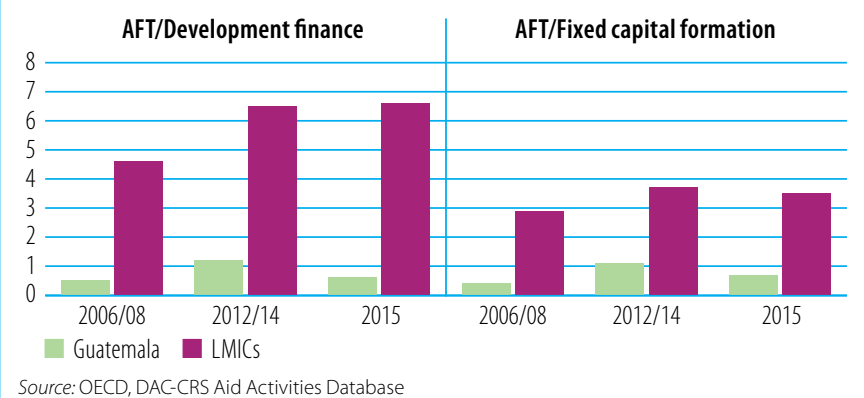

AfT DISBURSEMENTS: TOP DONORS (million current USD)

\begin{tabular}{lrr|lrc}
$\mathbf{2 0 0 6 / 0 8}$ & value & $\%$ & $\mathbf{2 0 1 5}$ & value & $\%$ \\
Spain & 5.0 & 19 & United States & 32.6 & 59 \\
\hline EU Institutions & 4.7 & 18 & Sweden & 3.2 & 6 \\
\hline Japan & 4.4 & 16 & Germany & 3.1 & 6 \\
\hline Netherlands & 3.1 & 12 & Belgium & 2.6 & 5 \\
\hline United States & 2.3 & 9 & Japan & 2.3 & 4 \\
\hline
\end{tabular}

Source: OECD, DAC-CRS Aid Activities Database

AfT DISBURSEMENTS BY SECTOR (million current USD)

\begin{tabular}{|c|c|c|c|c|}
\hline Trade policy and regulations & $\square$ & & 2.26 & 1.37 \\
\hline Trade facilitation & $\mathbf{E}$ & & 2.10 & 0.00 \\
\hline Transport and storage & $\bar{\square}$ & & 3.33 & 1.94 \\
\hline Communications & $\bar{\beta}$ & & 1.47 & 0.16 \\
\hline Energy generation and supply & & & 0.74 & 0.74 \\
\hline Business and other services & 1 & & 1.32 & 4.51 \\
\hline Banking and financial services & & & 0.70 & 1.09 \\
\hline Agriculture, forestry, fishing & ב & & 12.33 & 41.29 \\
\hline Industry & 1 & & 1.79 & 3.95 \\
\hline Mineral resources and mining & & & 0.00 & 0.00 \\
\hline Tourism & & & 0.63 & 0.40 \\
\hline Trade-related adjustment & & & 0.00 & 0.00 \\
\hline & 20 & 30 & 50 & \\
\hline
\end{tabular}

\section{B. TRADE COSTS}

\begin{tabular}{lcc} 
INDICATOR & 2006 & $\mathbf{2 0 1 5}$ \\
Tariffs (\%) & 5.6 & 5.6 \\
\hline Imports: simple avg. MFN applied (2005-2015) & $\ldots$ & 4.7 \\
\hline Imports: weighted avg. MFN applied (2006-2014) & 8.6 & 1.1 \\
\hline Exports: weighted avg. faced (2005-2014) & 54.3 & 97.8 \\
\hline Exports: duty free (value in \%) (2005-2014) & & \\
\hline ICT connectivity (\% of population) & $\ldots$. & 10.1 \\
\hline Mobile broadband subscriptions & 0.3 & 2.8 \\
\hline Fixed broadband subscriptions & 6.5 & 27.1 \\
\hline Individuals using the internet & &
\end{tabular}

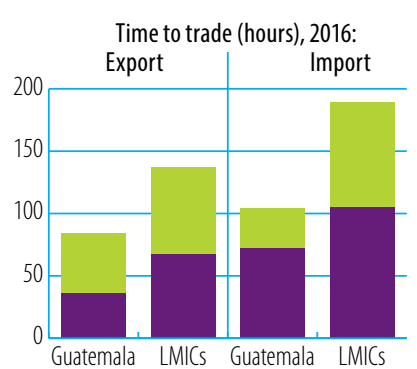

Border compliance Documentary compliance Source: WB, Doing Business

\section{LOGISTICS PERFORMANCE INDICES (LPI) (1-5)}

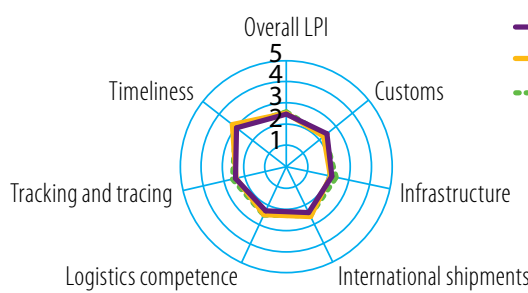

Source: WB Logistics Performance Index (LPI)

\section{GLOBAL COMPETITIVENESS INDICATORS (1-7)}

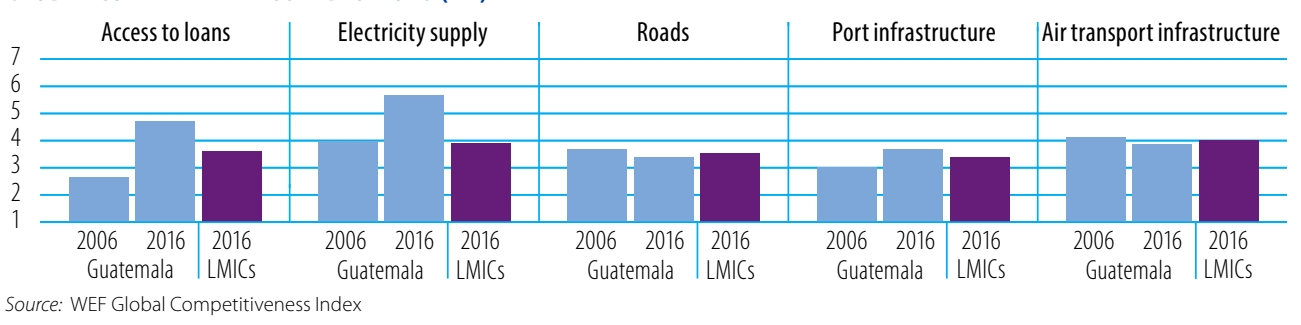

TRADE FACILITATION INDICATORS, 2017 (0-2)

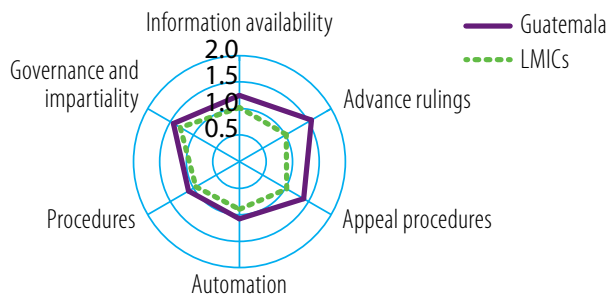

Source: OECD Trade Facilitation Indicators

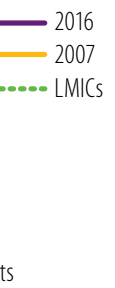




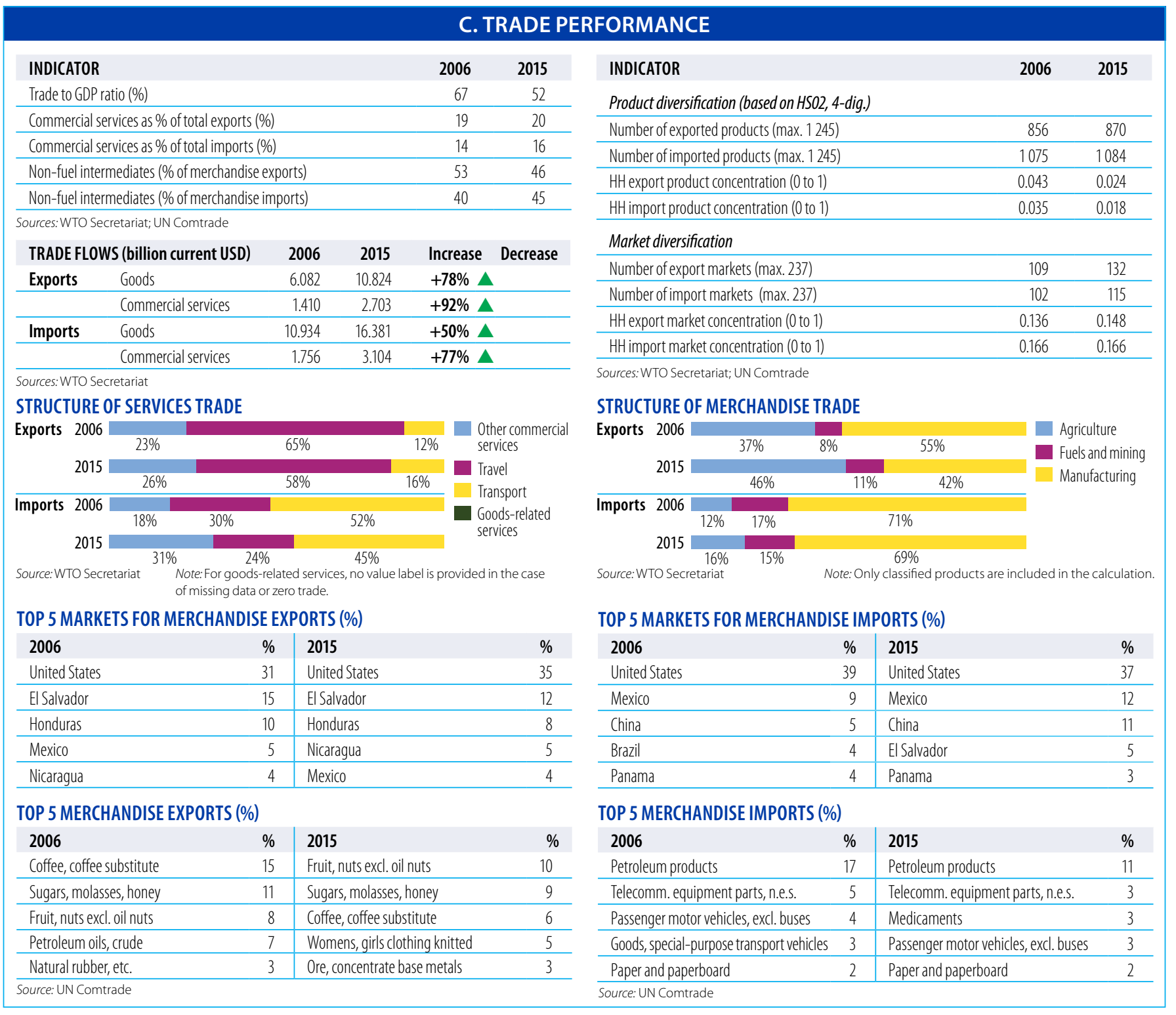

\begin{tabular}{|lrr}
\hline & D. DEVELOPMEN \\
\hline INDICATOR & $\mathbf{2 0 0 6}$ & $\mathbf{2 0 1 5}$ \\
\hline Unemployment (\% of total labour force) & 1.8 & 2.4 \\
\hline Female labour force participation rate (\%) & 47.5 & 41.3 \\
\hline ODA (\% of gross national income) & 1.6 & 0.7 \\
\hline Import duties collected (\% of tax revenue, 2006-2013) & 9.6 & 4.3 \\
\hline Total debt service (\% of total exports) & 15.8 & 15.2 \\
\hline Human Development Index (0-1) & 0.58 & 0.64 \\
\hline
\end{tabular}

Sources: ILO, ILOSTAT; OECD, DAC-CRS Aid Activities Database; WB, World Development Indicators; UNDP, International Human Development Indicators

\section{ECONOMIC STRUCTURE}

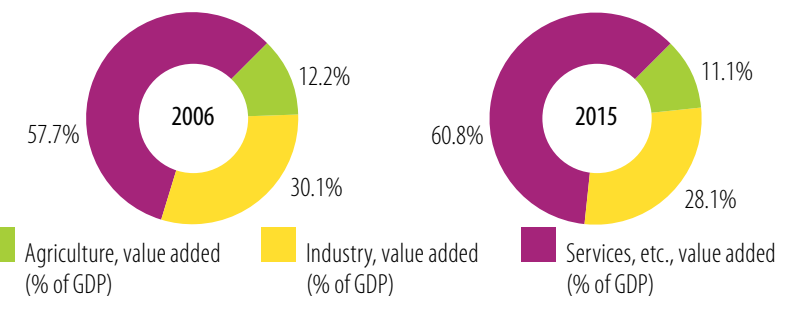

POVERTY INDICATORS

Population (\%) living below:

$\$ 1.90$ a day (PPP) $\quad \$ 3.10$ a day (PPP)

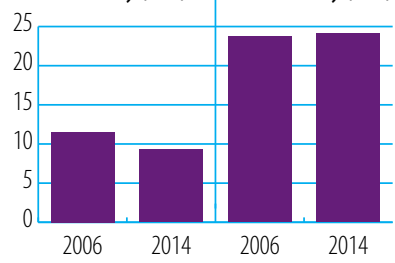

Source: WB, World Development Indicators

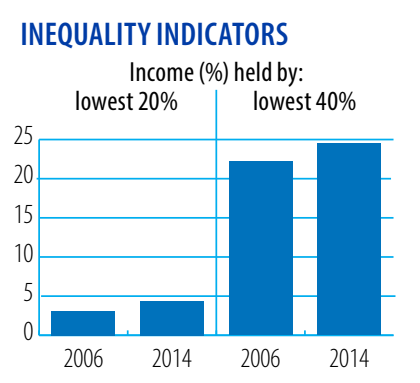

GDP PER CAPITA (constant 2011 international \$)

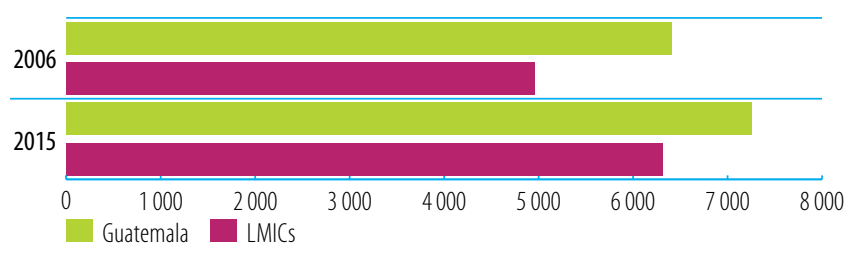

Source: WB, World Development Indicators 
Aid, Trade and Development Indicators for Guinea

\section{A. DEVELOPMENT FINANCE}

\begin{tabular}{|c|c|c|c|c|c|c|}
\hline \multicolumn{2}{|c|}{$\begin{array}{l}\text { EXTERNAL FINANCING INFLOWS } \\
\text { (million current USD) }\end{array}$} & $2006 / 08$ & \multicolumn{2}{|l|}{ 2012/14 } & 2015 & $\Delta: 06 / 08-15$ \\
\hline \multicolumn{2}{|c|}{ FDl inflows } & 297.6 & \multicolumn{2}{|l|}{269.6} & 85.0 & $-71 \%$ \\
\hline \multicolumn{2}{|c|}{ Remittances } & 35.4 & \multicolumn{2}{|l|}{84.1} & 93.0 & $163 \%$ \\
\hline \multicolumn{2}{|c|}{ Other official flows (OOF) } & 0.9 & \multicolumn{2}{|l|}{1.5} & 0.7 & $-27 \%$ \\
\hline \multicolumn{2}{|c|}{ of which trade-related 00F } & 0.0 & \multicolumn{2}{|l|}{0.1} & 0.7 & - \\
\hline \multicolumn{2}{|c|}{ Official Development Assistance (ODA) } & 324.9 & \multicolumn{2}{|l|}{1004.0} & 601.6 & $85 \%$ \\
\hline \multicolumn{2}{|c|}{ of which Aid for Trade } & 44.1 & \multicolumn{2}{|l|}{72.9} & 53.1 & $20 \%$ \\
\hline \multicolumn{7}{|c|}{$\begin{array}{l}\text { Sources: UNCTAD, UNCTADstat; WB, World Development Indicators; OECD, } \\
\text { DAC-CRS Aid Activities Database }\end{array}$} \\
\hline \multicolumn{7}{|c|}{ TOP 3 AfT PRIORITIES } \\
\hline 1. & 2 & & & 3 & $\ldots$ & \\
\hline
\end{tabular}

SHARE OF AfT IN DEVELOPMENT FINANCE AND FIXED CAPITAL FORMATION (\%)

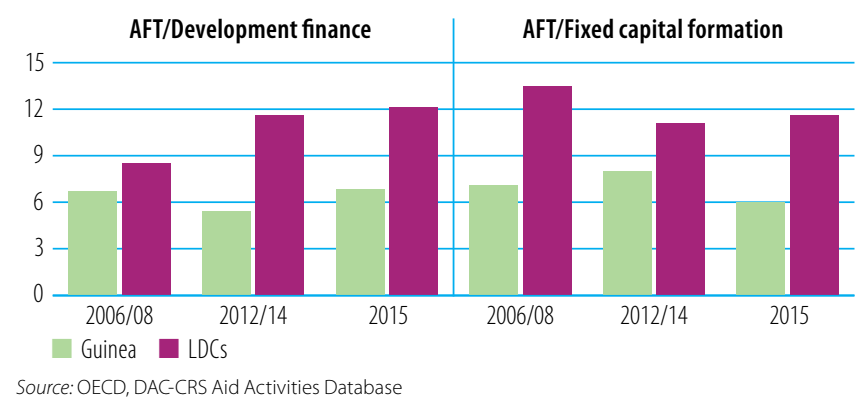

AfT DISBURSEMENTS: TOP DONORS (million current USD)

\begin{tabular}{lcc|lcc}
$\mathbf{2 0 0 6 / 0 8}$ & value & $\%$ & $\mathbf{2 0 1 5}$ & value & $\%$ \\
EU Institutions & 14.6 & 33 & EU Institutions & 15.5 & 29 \\
\hline African Development Fund & 6.8 & 15 & International Development Association & 14.3 & 27 \\
\hline France & 6.7 & 15 & African Development Fund & 7.6 & 14 \\
\hline IDA & 6.2 & 14 & OPEC Fund for International Development & 3.8 & 7 \\
\hline Japan & 3.4 & 8 & Kuwait (KFAED) & 3.1 & 6 \\
\hline Source: OECD, DAC-CRS Aid Activities Database & &
\end{tabular}

AfT DISBURSEMENTS BY SECTOR (million current USD)

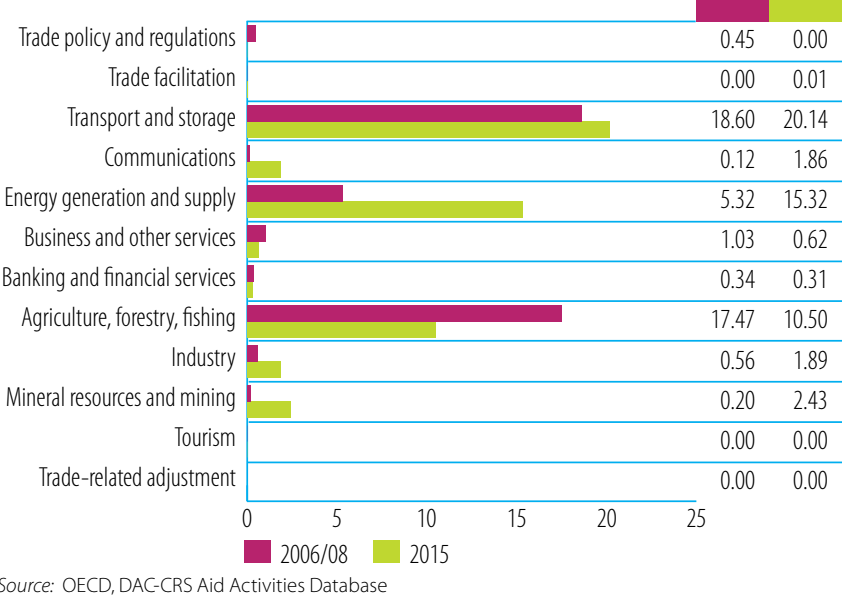

\section{B. TRADE COSTS}

\begin{tabular}{|c|c|c|}
\hline INDICATOR & 2006 & 2015 \\
\hline \multicolumn{3}{|l|}{ Tariffs (\%) } \\
\hline Imports: simple avg. MFN applied (2005-2012) & 11.9 & 11.9 \\
\hline Imports: weighted avg. MFN applied (2006-2012) & $\ldots$ & 11.3 \\
\hline Exports: weighted avg. faced (2005-2014) & 1.6 & 2.3 \\
\hline Exports: duty free (value in \%) (2005-2014) & 60.8 & 52.4 \\
\hline \multicolumn{3}{|l|}{ ICT connectivity (\% of population) } \\
\hline Mobile broadband subscriptions & $\ldots$ & 13.9 \\
\hline Fixed broadband subscriptions & $\ldots$ & 0.0 \\
\hline Individuals using the internet & 0.6 & 4.7 \\
\hline
\end{tabular}
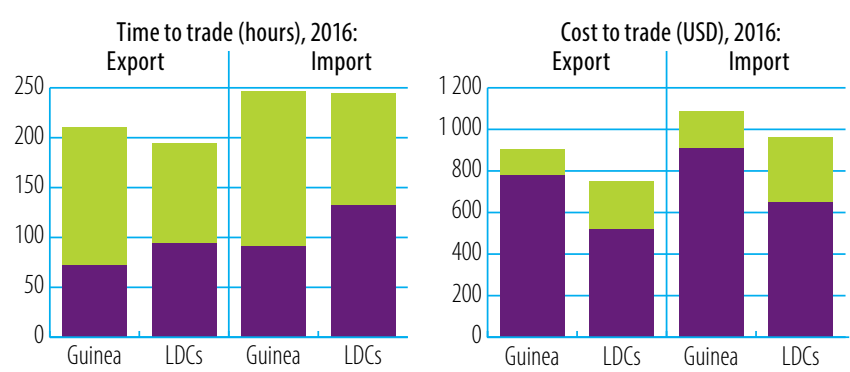

Border compliance Documentary compliance Source: WB, Doing Business

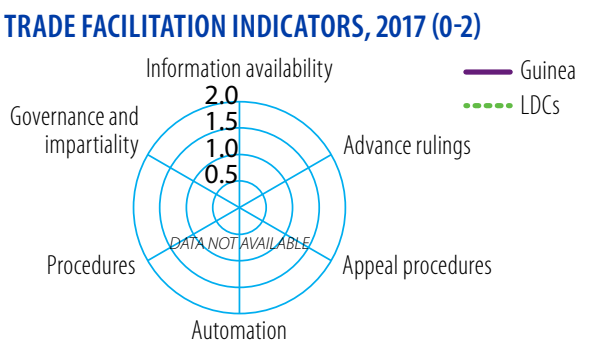

Source: OECD Trade Facilitation Indicators

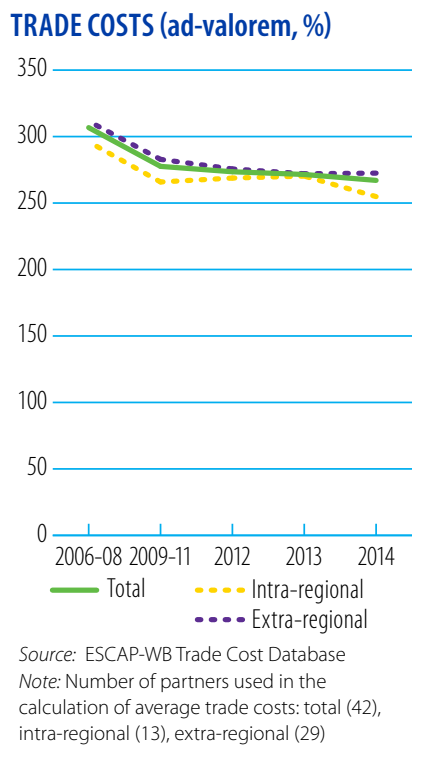




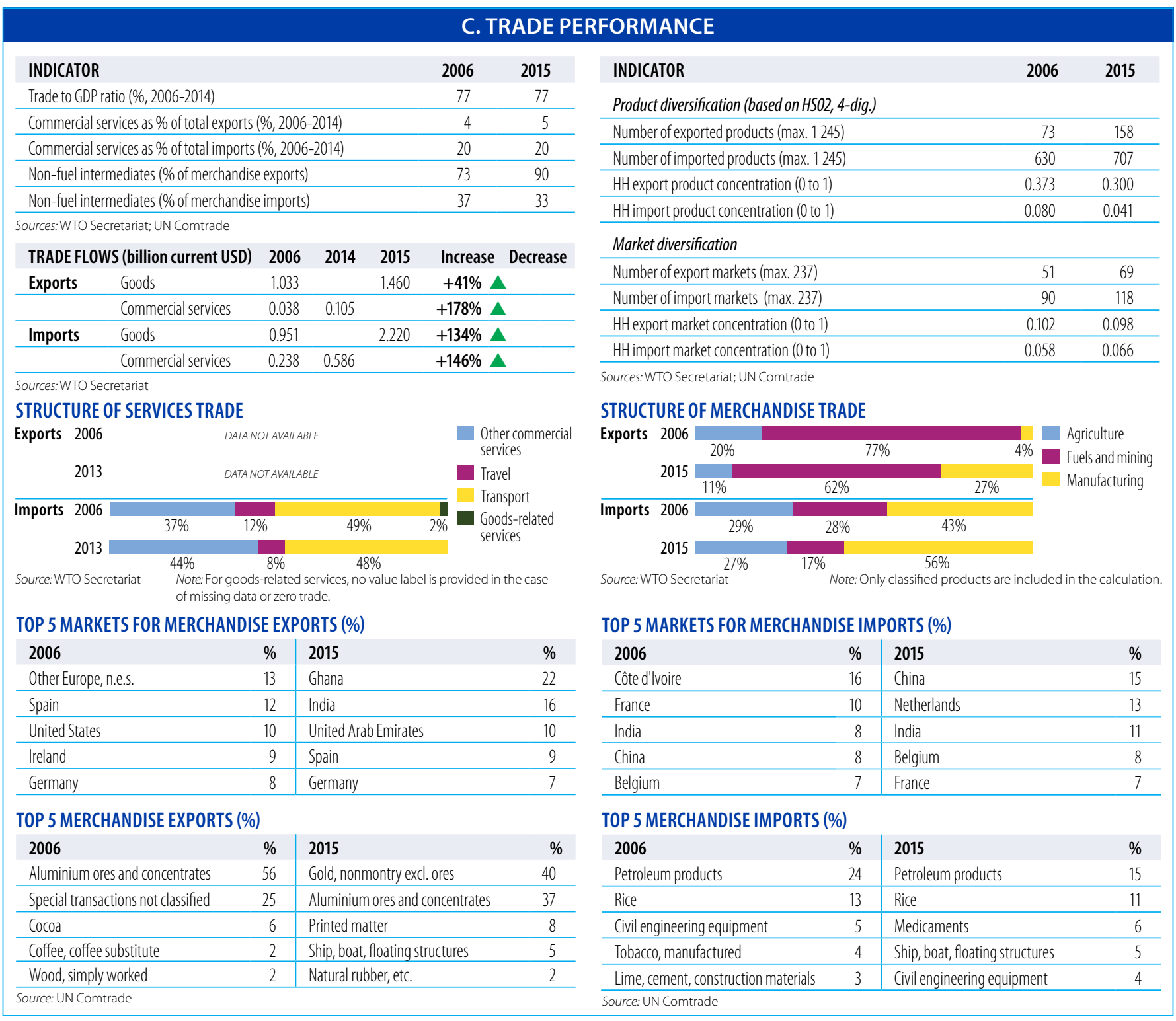

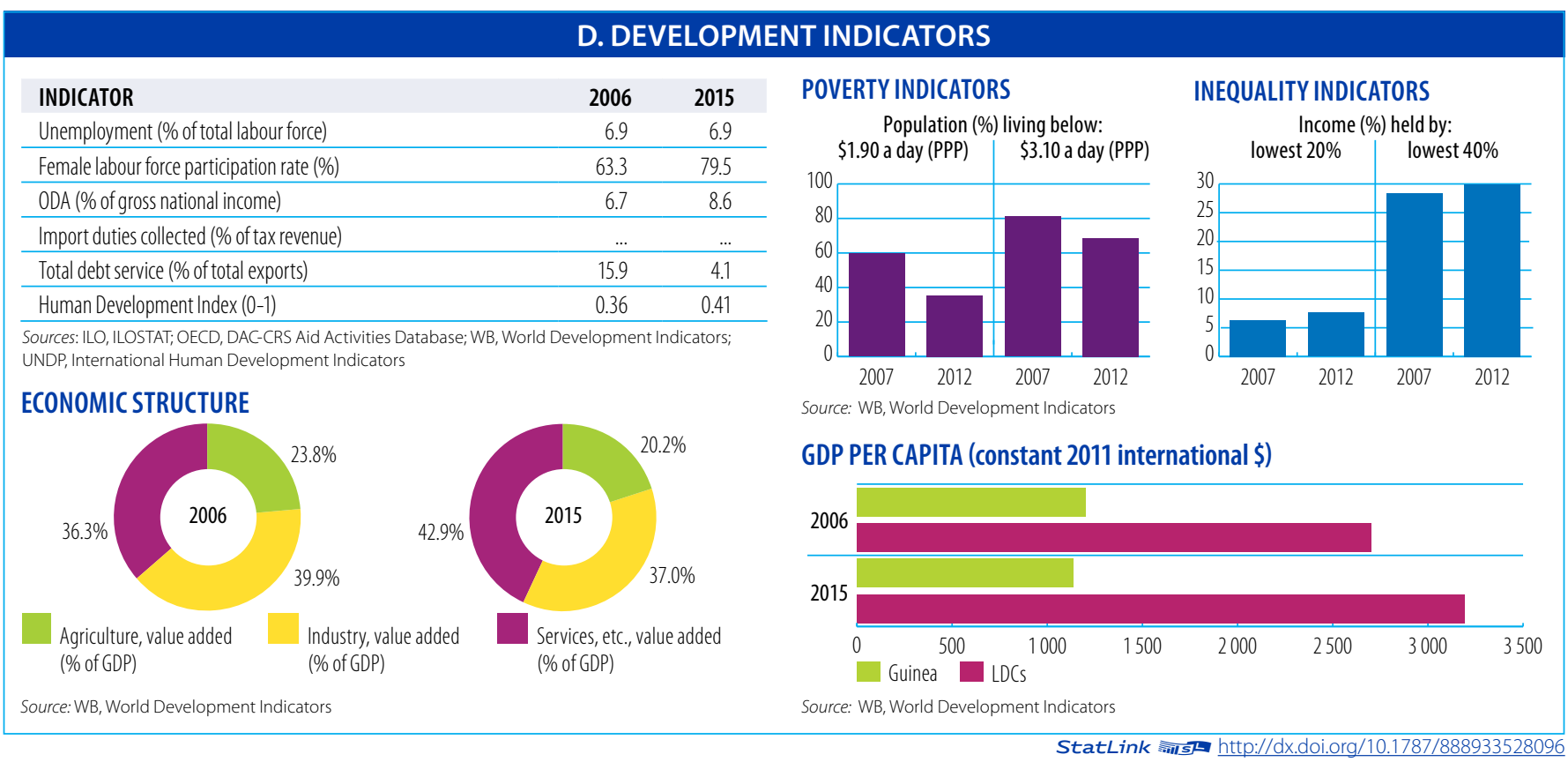




\section{GUINEA-BISSAU}

Aid, Trade and Development Indicators for Guinea-Bissau

\section{A. DEVELOPMENT FINANCE}

\begin{tabular}{lrrrc}
$\begin{array}{l}\text { EXTERNAL FINANCING INFL OWS } \\
\text { (million current USD) }\end{array}$ & $\mathbf{2 0 0 6 / 0 8}$ & $\mathbf{2 0 1 2 / 1 4}$ & $\mathbf{2 0 1 5}$ & $\mathbf{\Delta : 0 6 / 0 8 - 1 5}$ \\
\hline FDl inflows & 13.7 & 18.4 & 18.3 & $34 \%$ \\
\hline Remittances & 39.3 & 57.7 & 63.8 & $62 \%$ \\
\hline Other official flows (00F) & 0.0 & 1.5 & 0.0 & - \\
\hline of which trade-related 00F & 0.0 & 0.0 & 0.0 & - \\
\hline Official Development Assistance (ODA) & 125.3 & 101.1 & 99.2 & $-21 \%$ \\
\hline of which Aid for Trade & 33.1 & 11.9 & 10.0 & $-70 \%$ \\
\hline
\end{tabular}

Sources: UNCTAD, UNCTADstat; WB, World Development Indicators; OECD,

DAC-CRS Aid Activities Database

\section{TOP 3 AfT PRIORITIES}

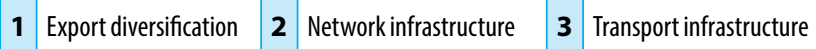
Source: OECD/WTO Partner Questionnaire

\section{SHARE OF AfT IN DEVELOPMENT FINANCE AND FIXED CAPITAL FORMATION (\%)}

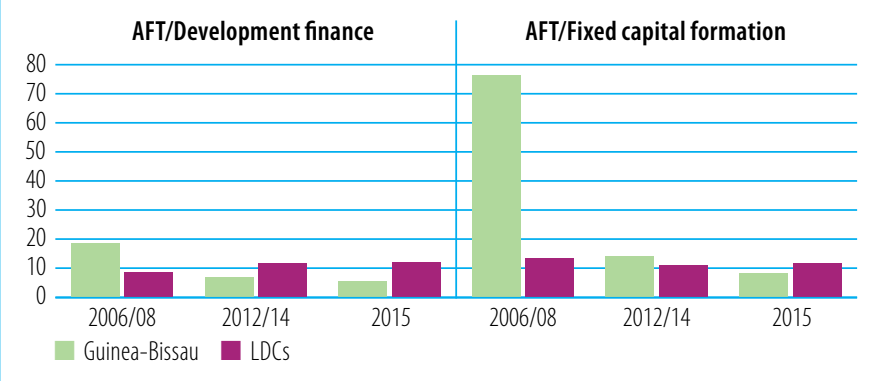

AfT DISBURSEMENTS: TOP DONORS (million current USD)

\begin{tabular}{lrr|lrr}
$\mathbf{2 0 0 6 / 0 8}$ & value & $\%$ & $\mathbf{2 0 1 5}$ & value & $\%$ \\
EU Institutions & 23.5 & 71 & EU Institutions & 4.2 & 42 \\
\hline IDA & 5.1 & 16 & IDA & 3.9 & 39 \\
\hline African Development Fund & 1.5 & 4 & Spain & 0.8 & 8 \\
\hline Spain & 1.4 & 4 & Belgium & 0.4 & 4 \\
\hline Portugal & 0.5 & 1 & Portugal & 0.3 & 3 \\
\hline
\end{tabular}

Source: OECD, DAC-CRS Aid Activities Database

AfT DISBURSEMENTS BY SECTOR (million current USD)

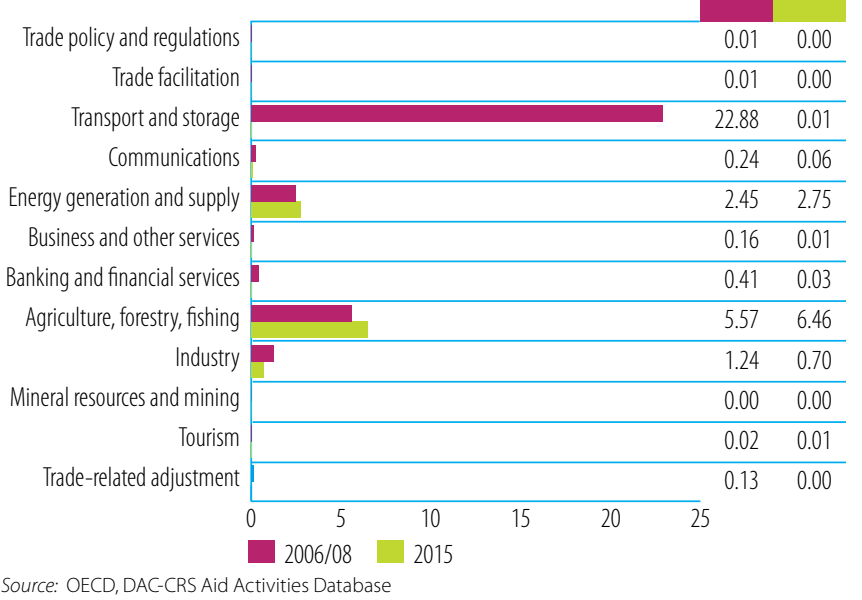

\section{B. TRADE COSTS}

\begin{tabular}{lcc} 
INDICATOR & 2006 & 2015 \\
Tariffs (\%) & & \\
\hline Imports: simple avg. MFN applied (2006-2014) & 12.0 & 11.9 \\
\hline Imports: weighted avg. MFN applied & $\ldots$ & $\ldots$ \\
\hline Exports: weighted avg. faced (2005-2014) & 26.5 & 0.8 \\
\hline Exports: duty free (value in \%) (2005-2014) & 4.7 & 87.7 \\
\hline ICT connectivity (\% of population) & $\ldots$ & \\
\hline Mobile broadband subscriptions & $\ldots .0$ & 0.1 \\
\hline Fixed broadband subscriptions & 2.1 & 3.5 \\
\hline Individuals using the internet & $\ldots$ &
\end{tabular}
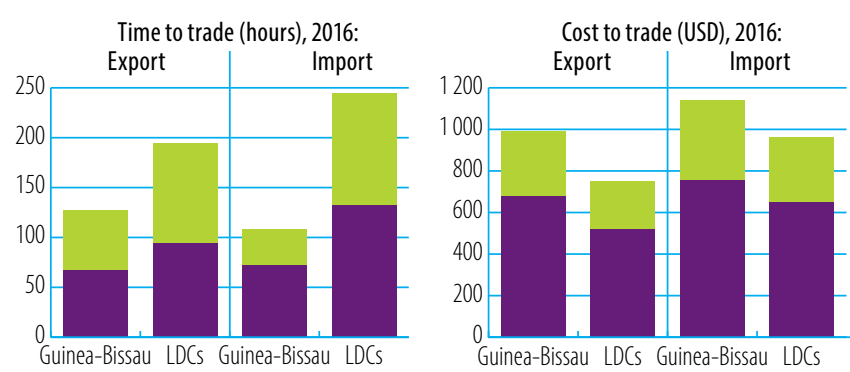

Border compliance Documentary compliance

Source: WB, Doing Business

TRADE FACILITATION INDICATORS, 2017 (0-2)

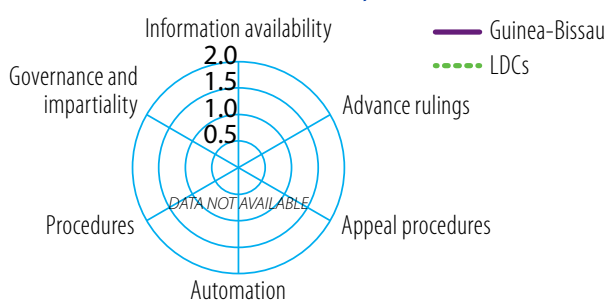

TRADE COSTS (ad-valorem, \%)
LOGISTICS PERFORMANCE INDICES (LPI) (1-5)

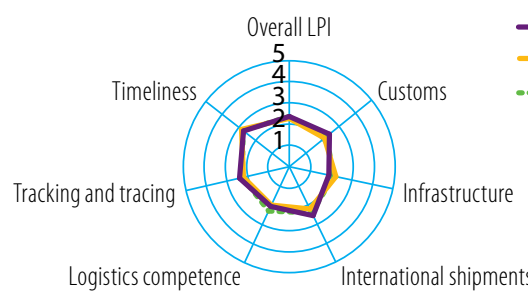

Source: WB Logistics Performance Index (LPI)

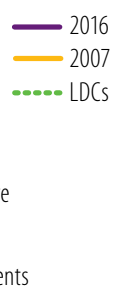

Source: OECD Trade Facilitation Indicators

GLOBAL COMPETITIVENESS INDICATORS (1-7)

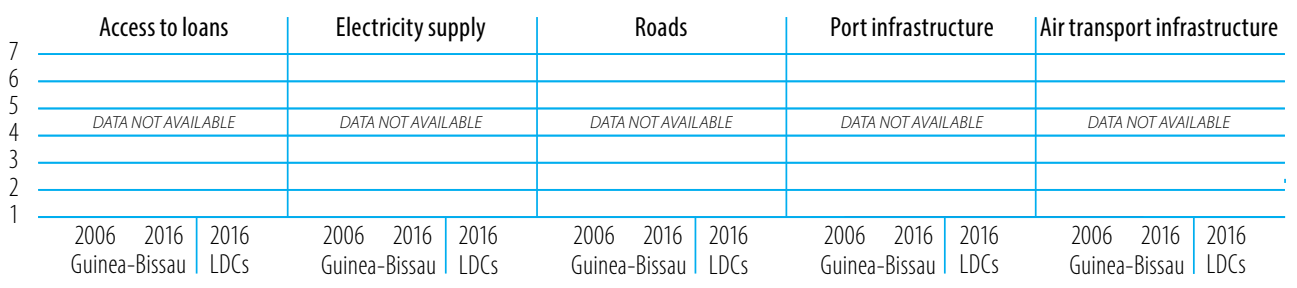

2006-08 2009-11 $2012 \quad 2013 \quad 2014$ - Total $\quad \ldots . .$. Intra-regional .... Extra-regional

Source: ESCAP-WB Trade Cost Database Note: Number of partners used in the calculation of average trade costs: total (0) intra-regional (0), extra-regional (0) 


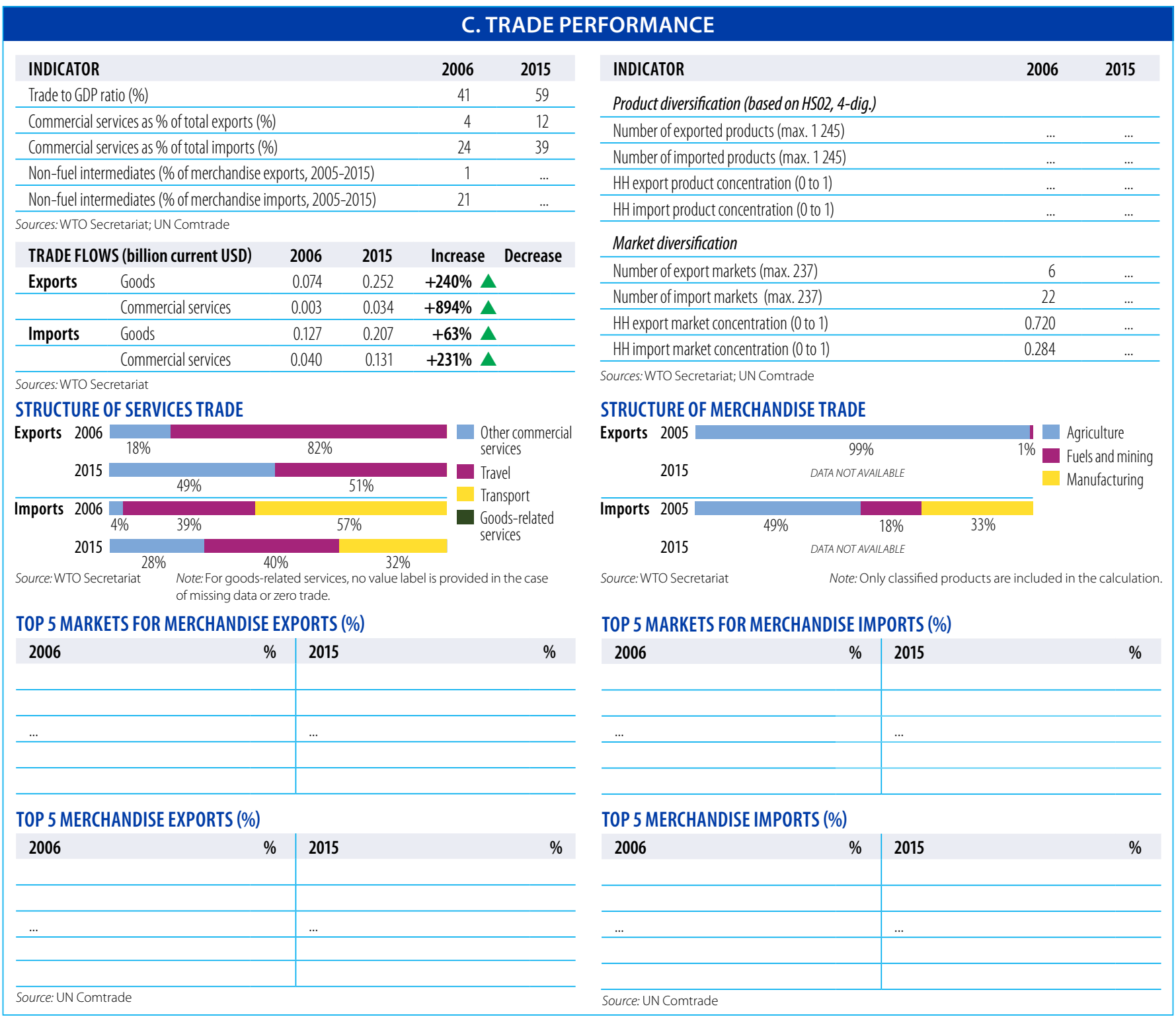

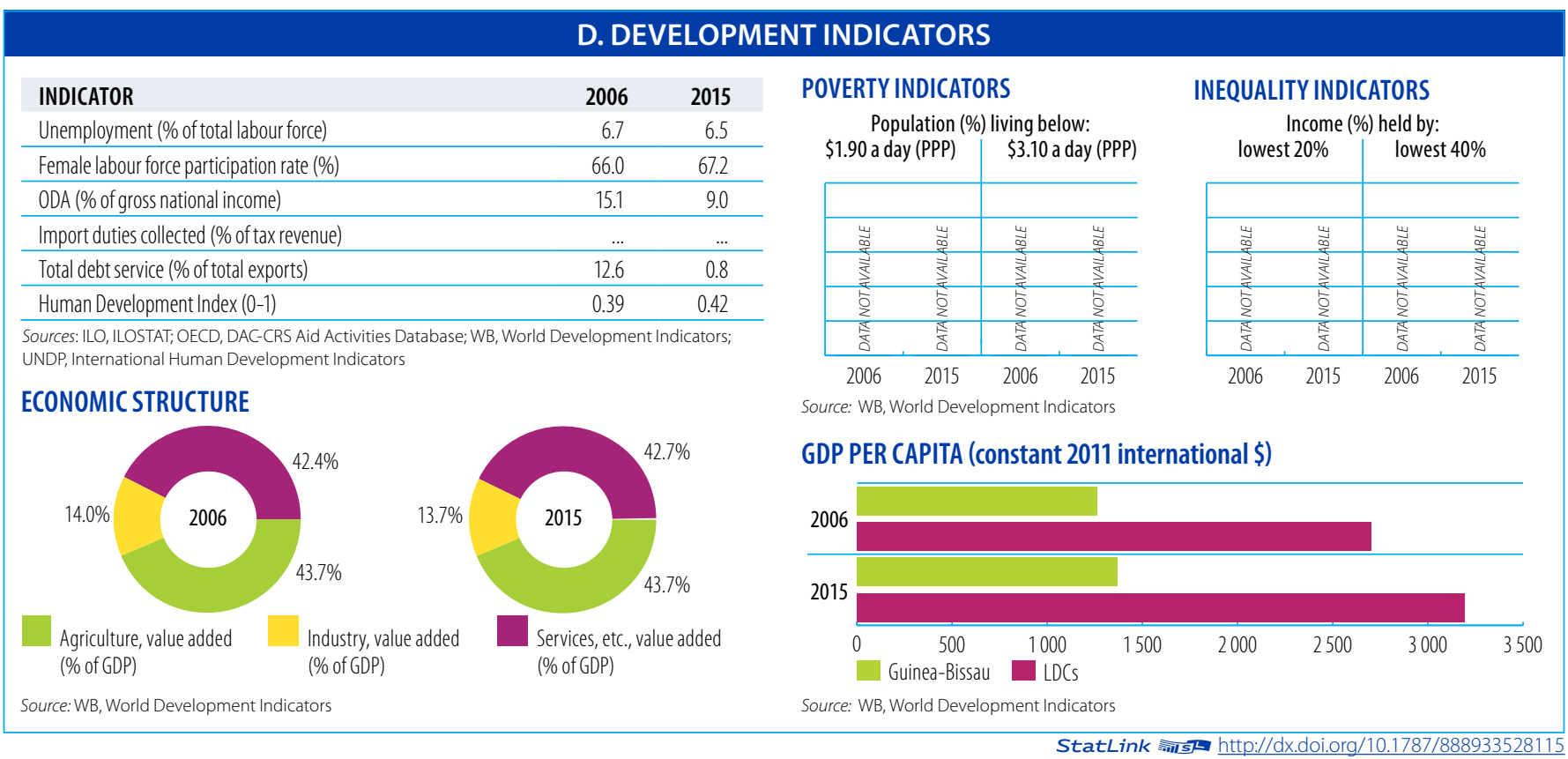


Aid, Trade and Development Indicators for Honduras

\section{A. DEVELOPMENT FINANCE}

\begin{tabular}{lrrrc}
$\begin{array}{l}\text { EXTERNAL FINANCING INFLOWS } \\
\text { (million current USD) }\end{array}$ & $\mathbf{2 0 0 6 / 0 8}$ & $\mathbf{2 0 1 2 / 1 4}$ & $\mathbf{2 0 1 5}$ & $\mathbf{\Delta : 0 6 / 0 8 - 1 5}$ \\
FDl inflows & 867.7 & 1087.4 & 1203.5 & $39 \%$ \\
\hline Remittances & 2590.7 & 3129.4 & 3666.2 & $42 \%$ \\
\hline Other official flows (OOF) & 11.9 & 60.1 & 157.8 & $1223 \%$ \\
\hline of which trade-related O0F & 3.9 & 27.4 & 90.3 & $2203 \%$ \\
\hline Official Development Assistance (ODA) & 918.7 & 642.3 & 599.5 & $-35 \%$ \\
\hline of which Aid for Trade & 73.1 & 250.0 & 144.0 & $97 \%$ \\
\hline
\end{tabular}

Sources: UNCTAD, UNCTADstat; WB, World Development Indicators; OECD,

DAC-CRS Aid Activities Database

TOP 3 AFT PRIORITIES

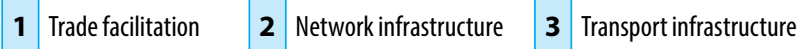

Source: OECD/WTO Partner Questionnaire

SHARE OF AfT IN DEVELOPMENT FINANCE AND FIXED CAPITAL FORMATION (\%)

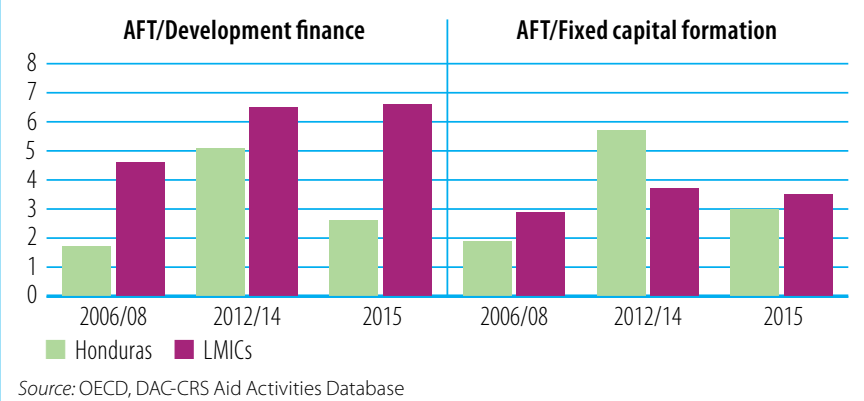

AfT DISBURSEMENTS: TOP DONORS (million current USD)

\begin{tabular}{lrr|lrr}
$\mathbf{2 0 0 6 / 0 8}$ & value & $\%$ & $\mathbf{2 0 1 5}$ & value & $\%$ \\
IDA & 26.7 & 37 & IDB Special Fund & 60.6 & 42 \\
\hline United States & 18.5 & 25 & International Development Association & 26.8 & 19 \\
\hline Japan & 10.1 & 14 & United States & 14.4 & 10 \\
\hline Spain & 6.5 & 9 & OPEC Fund for International Development & 10.3 & 7 \\
\hline Germany & 3.3 & 5 & Canada & 7.1 & 5 \\
\hline Source: OECD DAC-CRS Aid Activities Database & &
\end{tabular}

AfT DISBURSEMENTS BY SECTOR (million current USD)

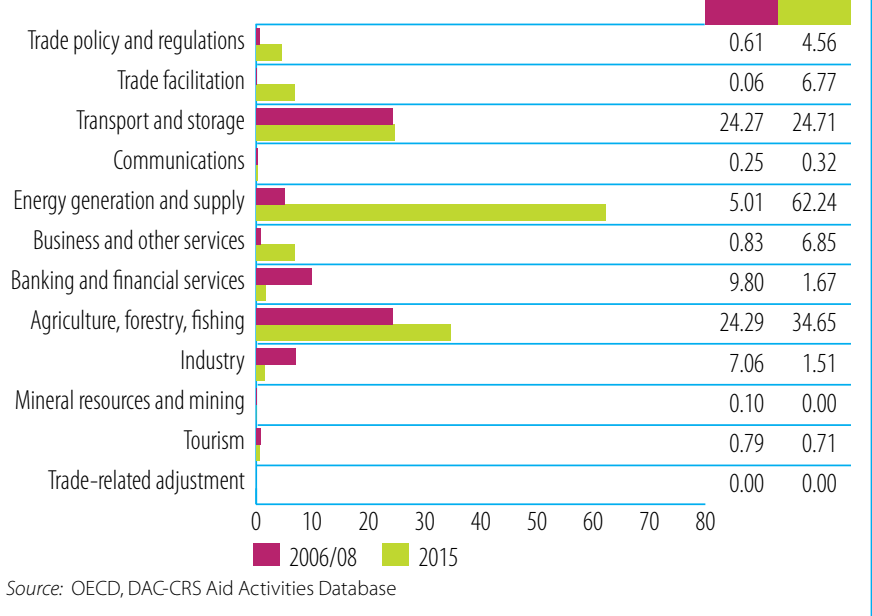

\section{B. TRADE COSTS}

\begin{tabular}{lcc} 
INDICATOR & 2006 & $\mathbf{2 0 1 5}$ \\
Tariffs (\%) & 5.6 & 5.7 \\
\hline Imports: simple avg. MFN applied (2005-2015) & $\ldots$ & 6.0 \\
\hline Imports: weighted avg. MFN applied (2006-2014) & 11.5 & 0.2 \\
\hline Exports: weighted avg. faced (2005-2014) & 38.9 & 99.4 \\
\hline Exports: duty free (value in \%) (2005-2014) & & \\
\hline ICT connectivity (\% of population) & $\ldots$ & 17.2 \\
\hline Mobile broadband subscriptions & $\ldots$ & 2.3 \\
\hline Fixed broadband subscriptions & 7.8 & 20.4 \\
\hline Individuals using the internet & &
\end{tabular}
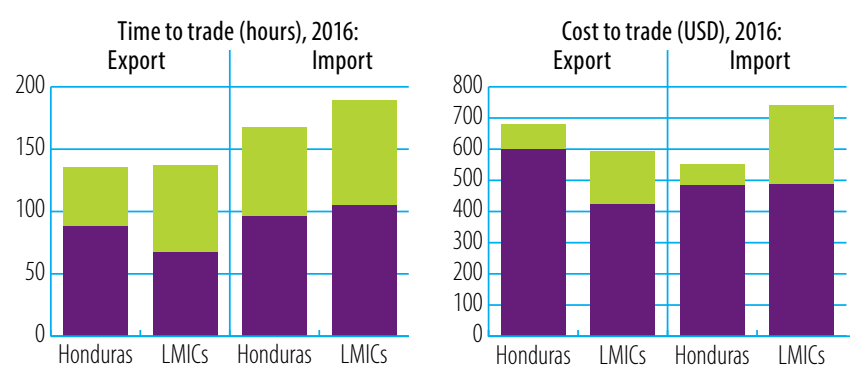

Border compliance Documentary compliance

Source: WB, Doing Business

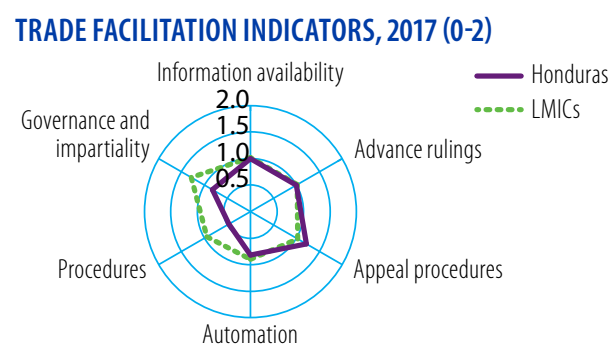

Source: WB Logistics Performance Index (LPI)

Source: WEF Global Competitiveness Index
Source: OECD Trade Facilitation Indicators

GLOBAL COMPETITIVENESS INDICATORS (1-7)

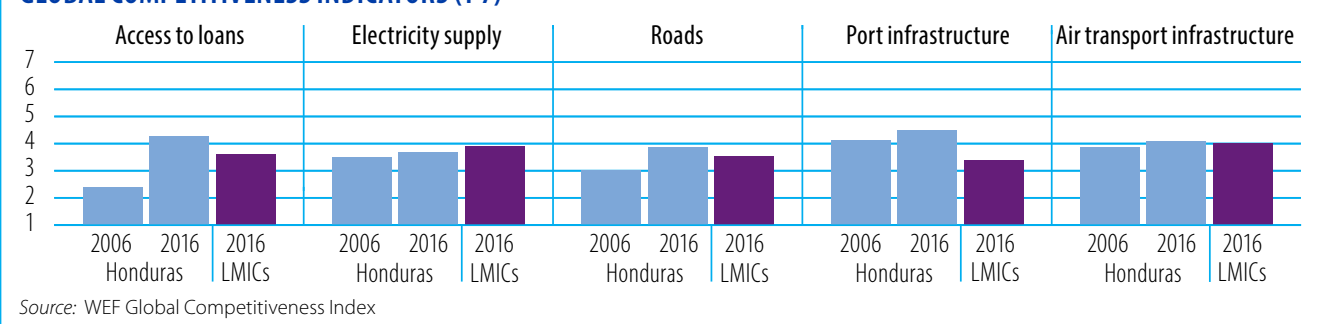

LOGISTICS PERFORMANCE INDICES (LPI) (1-5)

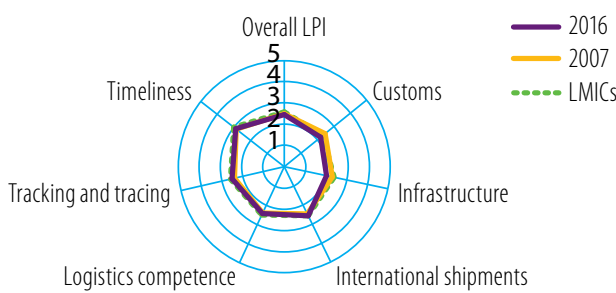

TRADE COSTS (ad-valorem, \%)

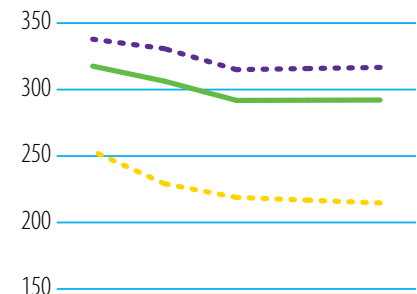

150

100

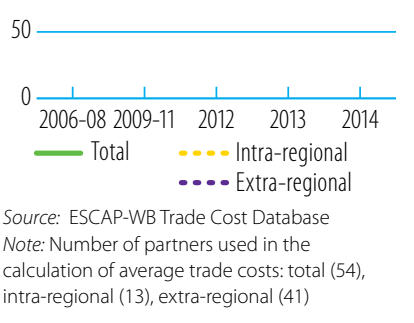




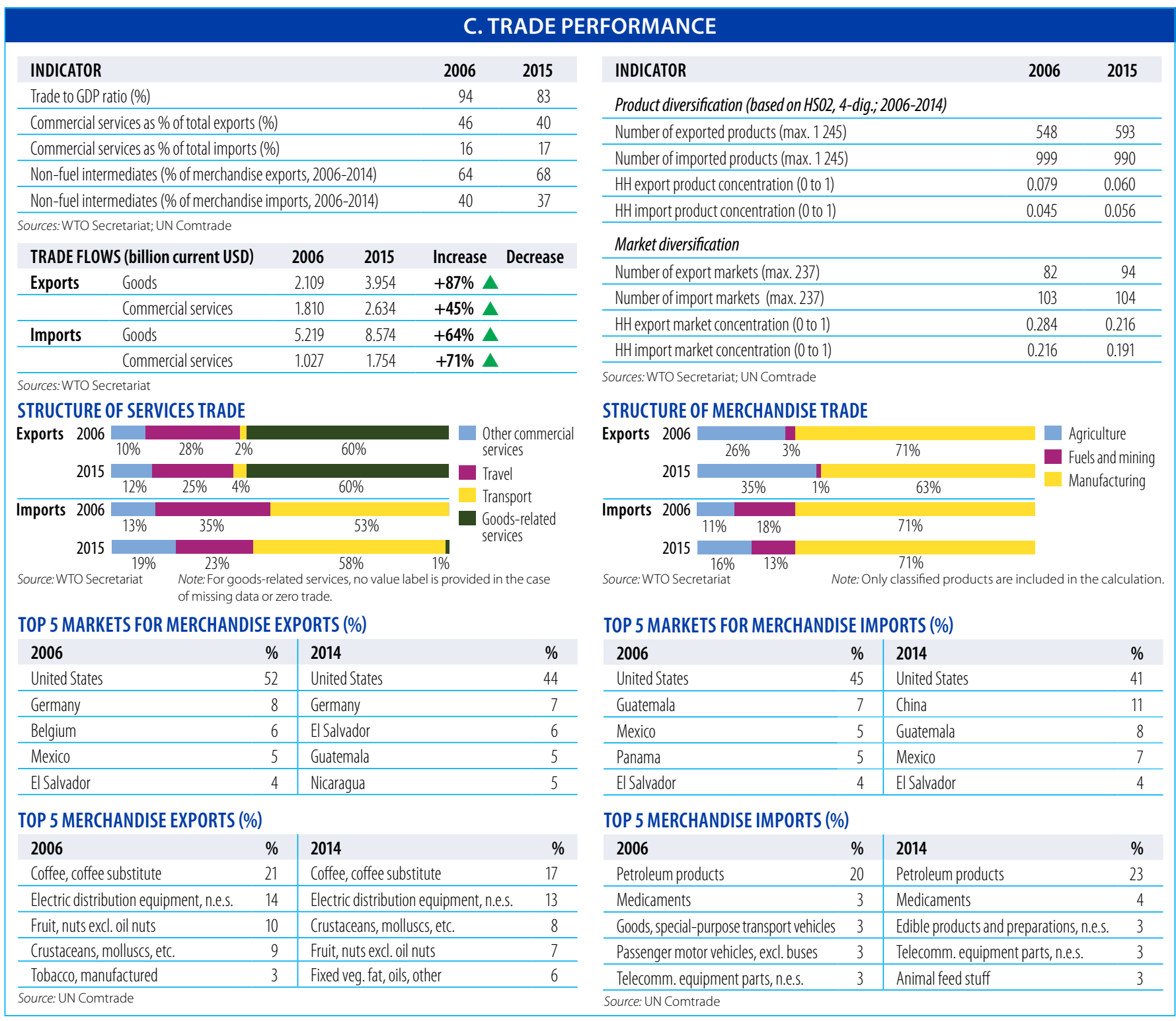

\begin{tabular}{|lrr}
\hline & D. DEVELOPME \\
\hline INDICATOR & $\mathbf{2 0 0 6}$ & $\mathbf{2 0 1 5}$ \\
Unemployment (\% of total labour force) & 3.1 & 7.4 \\
\hline Female labour force participation rate (\%) & 40.2 & 47.2 \\
\hline ODA (\% of gross national income) & 5.8 & 2.9 \\
\hline Import duties collected (\% of tax revenue) & 7.5 & 4.4 \\
\hline Total debt service (\% of total exports) & 7.9 & 19.2 \\
\hline Human Development Index (0-1) & 0.59 & 0.63 \\
\hline
\end{tabular}

Sources: ILO, ILOSTAT; OECD, DAC-CRS Aid Activities Database; WB, World Development Indicators; UNDP, International Human Development Indicators

\section{ECONOMIC STRUCTURE}

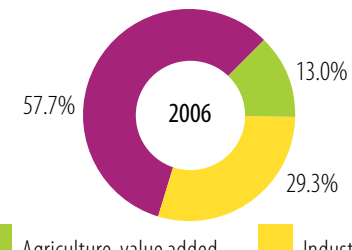

Agriculture, value added (\% of GDP)

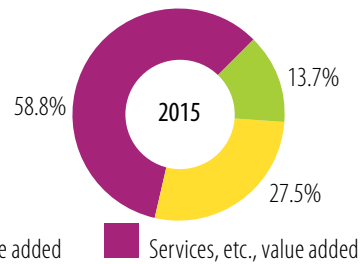
( $\%$ of GDP)

Source: WB, World Development Indicators

try, value added $\%$ of GDP)

\section{POVERTY INDICATORS}

Population (\%) living below:

$\$ 1.90$ a day (PPP) $\quad \$ 3.10$ a day (PPP)

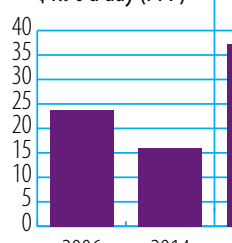

$2006 \quad 2014$
$\$ 3.10$ a day (PPP)

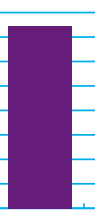

2006201
INEQUALITY INDICATORS

Income (\%) held by:

lowest 20\% lowest 40\%

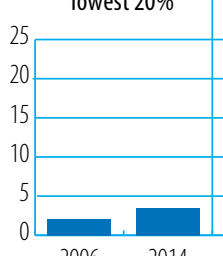

$2006 \quad 2014$

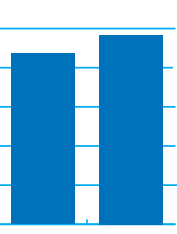

$2006 \quad 2014$

GDP PER CAPITA (constant 2011 international \$)

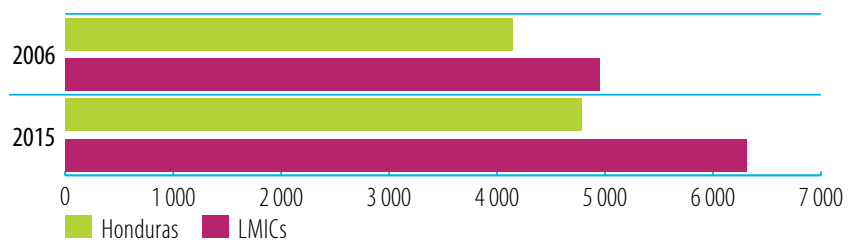

Source: WB, World Development Indicators 
Aid, Trade and Development Indicators for Indonesia

\section{A. DEVELOPMENT FINANCE}

\begin{tabular}{lrrrc}
$\begin{array}{l}\text { EXTERNAL FINANCING INFLOWS } \\
\text { (million current USD) }\end{array}$ & $\mathbf{2 0 0 6 / 0 8}$ & $\mathbf{2 0 1 2 / 1 4}$ & $\mathbf{2 0 1 5}$ & $\mathbf{\Delta : 0 6 / 0 8 - 1 5}$ \\
\hline FDl inflows & 7053.7 & 19940.1 & 15508.2 & $120 \%$ \\
\hline Remittances & 6230.3 & 7792.6 & 9659.2 & $55 \%$ \\
\hline Other official flows (00F) & 1261.4 & 2708.2 & 6890.8 & $446 \%$ \\
\hline of which trade-related 00F & 652.7 & 1680.8 & 4803.2 & $636 \%$ \\
\hline Official Development Assistance (ODA) & 2953.9 & 2281.6 & 2026.6 & $-31 \%$ \\
\hline of which Aid for Trade & 755.7 & 640.1 & 878.0 & $16 \%$ \\
\hline
\end{tabular}

Sources: UNCTAD, UNCTADstat; WB, World Development Indicators; OECD,

DAC-CRS Aid Activities Database

\section{TOP 3 AfT PRIORITIES}

\begin{tabular}{|l|l|l|l|l|l|}
\hline 1 & Trade policy & $\mathbf{2}$ & Export diversification & $\mathbf{3}$ & Trade facilitation \\
\hline
\end{tabular}

Source: OECD/WTO Partner Questionnaire

SHARE OF AfT IN DEVELOPMENT FINANCE AND FIXED CAPITAL FORMATION (\%)

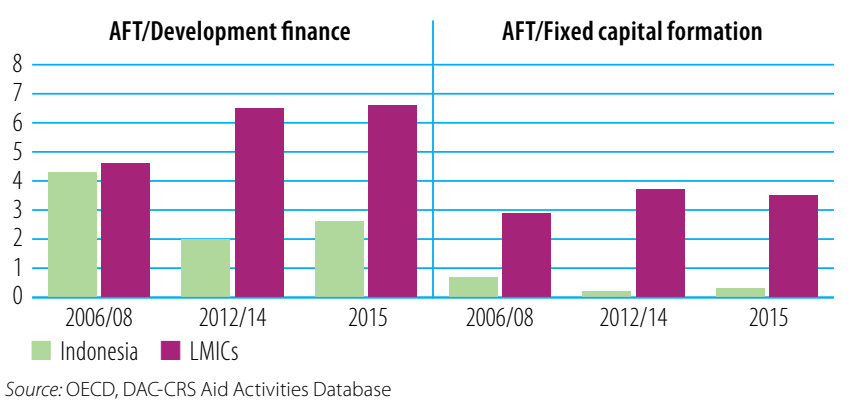

AfT DISBURSEMENTS: TOP DONORS (million current USD)

\begin{tabular}{lrr|lrr}
$\mathbf{2 0 0 6 / 0 8}$ & value & $\%$ & $\mathbf{2 0 1 5}$ & value & $\%$ \\
Japan & 524.6 & 69 & Japan & 339.9 & 39 \\
\hline Germany & 55.9 & 7 & Germany & 238.8 & 27 \\
\hline Australia & 38.8 & 5 & France & 179.0 & 20 \\
\hline IDA & 34.9 & 5 & Australia & 31.7 & 4 \\
\hline United Kingdom & 25.2 & 3 & Korea & 19.9 & 2 \\
\hline
\end{tabular}

Source: OECD, DAC-CRS Aid Activities Database

AfT DISBURSEMENTS BY SECTOR (million current USD)

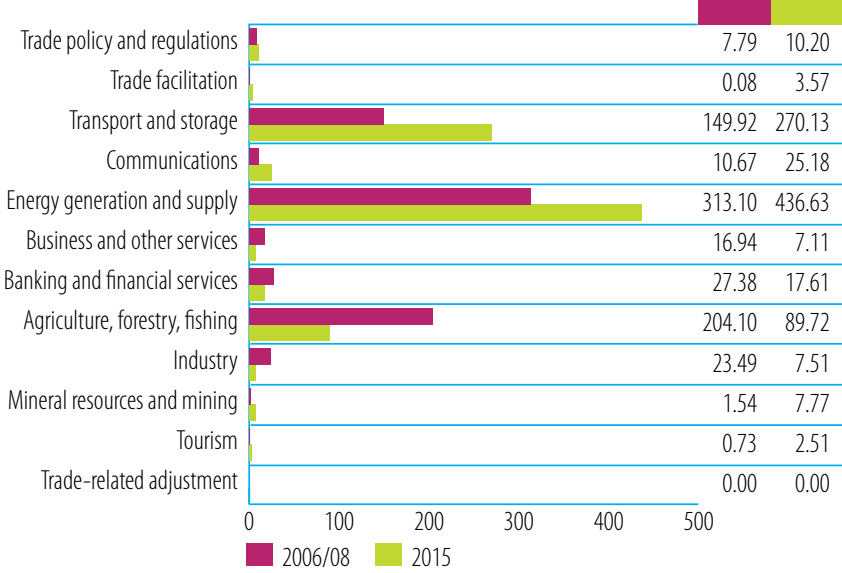

Source: OECD, DAC-CRS Aid Activities Database

\section{B. TRADE COSTS}

\begin{tabular}{lrc} 
INDICATOR & $\mathbf{2 0 0 6}$ & $\mathbf{2 0 1 5}$ \\
Tariffs (\%) & & \\
\hline Imports: simple avg. MFN applied (2006-2014) & 6.9 & 6.9 \\
\hline Imports: weighted avg. MFN applied (2005-2014) & 2.5 & 4.3 \\
\hline Exports: weighted avg. faced (2005-2014) & 71.3 & 79.1 \\
\hline Exports: duty free (value in \%) (2005-2014) & & \\
\hline ICT connectivity (\% of population) & $\ldots .1$ & 42.0 \\
\hline Mobile broadband subscriptions & 0.1 & 1.1 \\
\hline Fixed broadband subscriptions & 4.8 & 22.0 \\
\hline Individuals using the internet & &
\end{tabular}
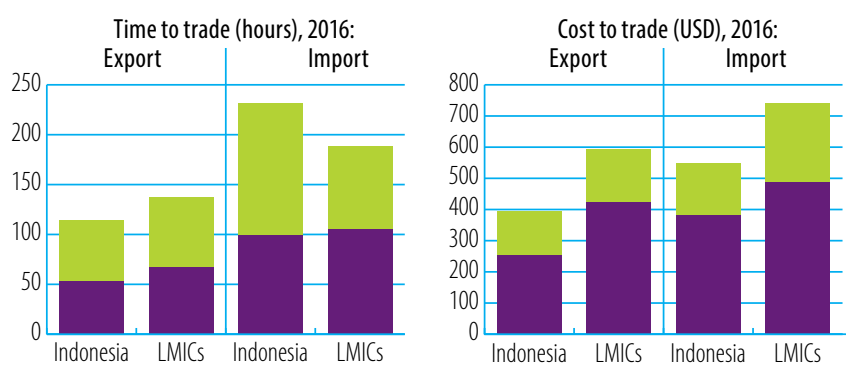

Border compliance Documentary compliance Source: WB, Doing Business

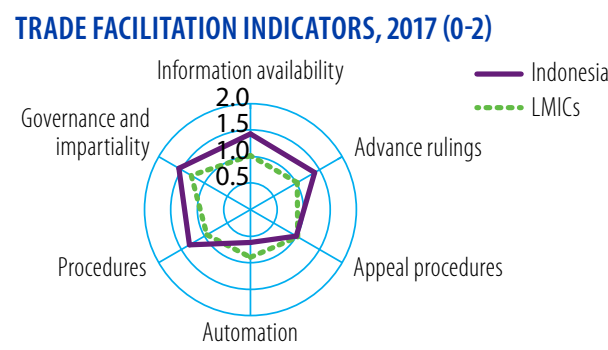

TRADE COSTS (ad-valorem, \%)

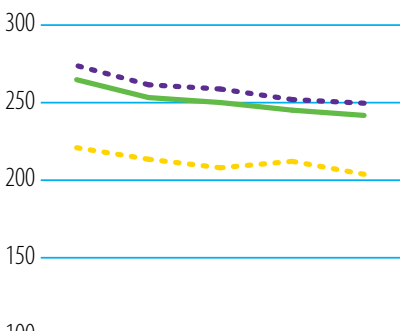

100

GLOBAL COMPETITIVENESS INDICATORS (1-7)

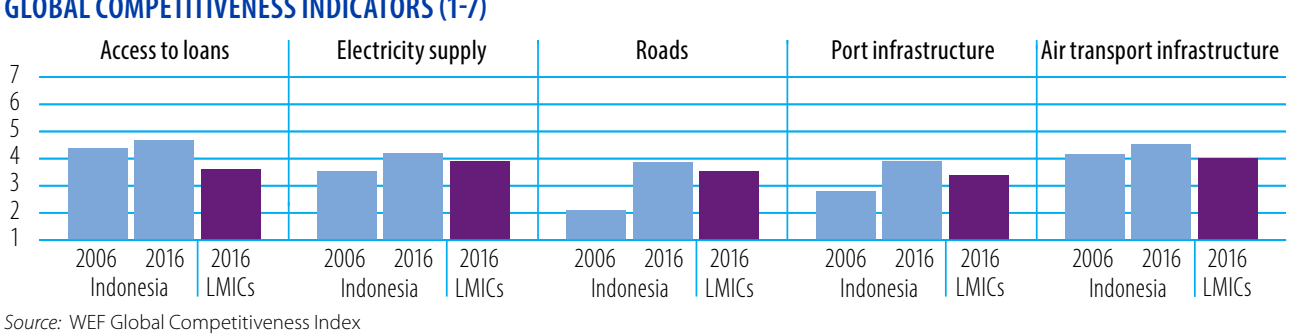

Source: WEF Global Competitiveness Index
Source: OECD Trade Facilitation Indicators

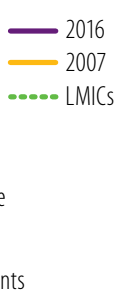

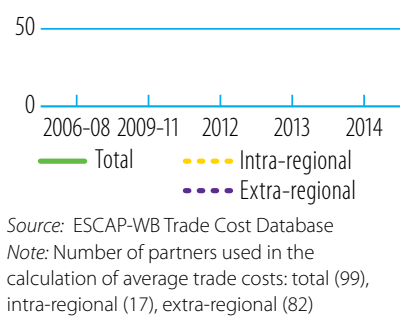
intra-regional (17), extra-regional (82) 


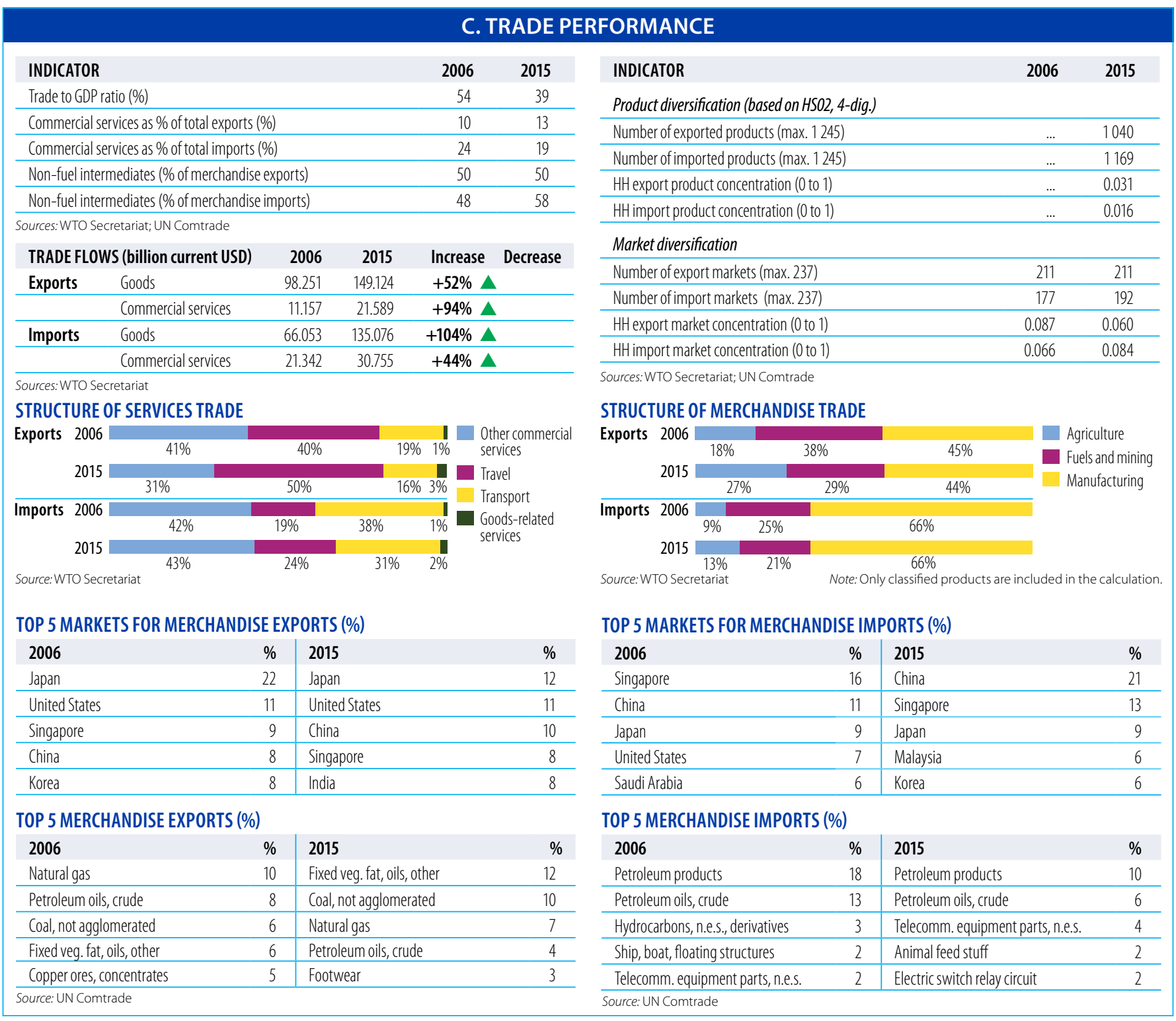

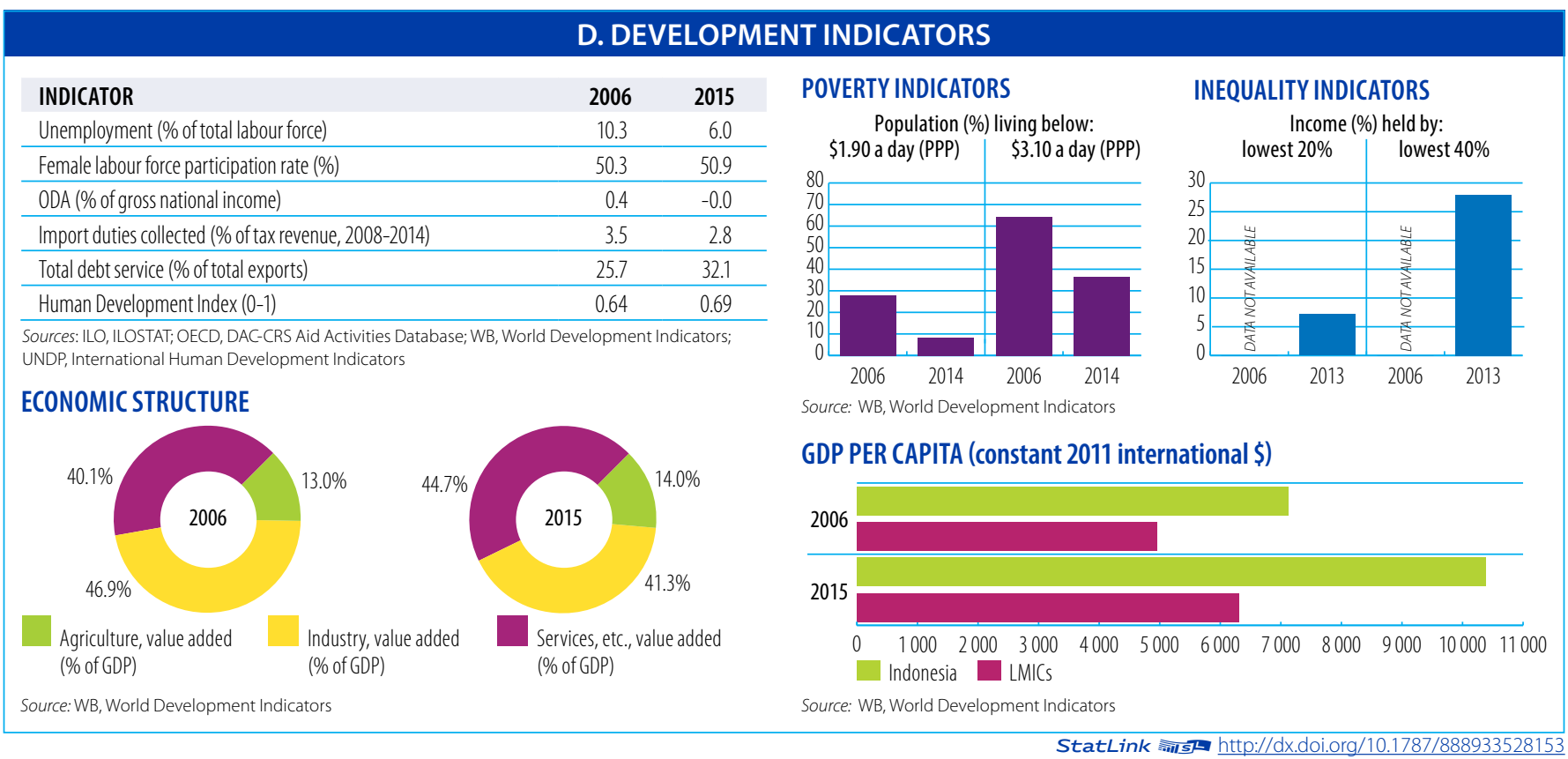




\section{LAO PEOPLE'S DEMOCRATIC REPUBLIC}

Aid, Trade and Development Indicators for Lao People's Democratic Republic

\section{A. DEVELOPMENT FINANCE}

\begin{tabular}{lrrrc}
$\begin{array}{l}\text { EXTERNAL FINANCING INFLOWS } \\
\text { (million current USD) }\end{array}$ & $\mathbf{2 0 0 6 / 0 8}$ & $\mathbf{2 0 1 2 / 1 4}$ & $\mathbf{2 0 1 5}$ & $\mathbf{\Delta : 0 6 / 0 8 - 1 5}$ \\
\hline FDl inflows & 246.2 & 480.6 & 1219.8 & $395 \%$ \\
\hline Remittances & 9.4 & 52.8 & 93.0 & $889 \%$ \\
\hline Other official flows (00F) & 23.3 & 61.4 & 6.5 & $-72 \%$ \\
\hline of which trade-related 00F & 12.5 & 39.3 & 6.3 & $-49 \%$ \\
\hline Official Development Assistance (ODA) & 303.7 & 471.8 & 538.4 & $77 \%$ \\
\hline of which Aid for Trade & 113.2 & 148.1 & 201.8 & $78 \%$ \\
\hline
\end{tabular}

Sources: UNCTAD, UNCTADstat; WB, World Development Indicators; OECD,

DAC-CRS Aid Activities Database

\section{TOP 3 AfT PRIORITIES}

\begin{tabular}{|l|l|l|l|l|l|}
\hline 1 & Export diversification & $\mathbf{2}$ & Regional integration & $\mathbf{3}$ & Trade policy \\
\hline
\end{tabular}

Source: OECD/WTO Partner Questionnaire

SHARE OF AfT IN DEVELOPMENT FINANCE AND FIXED CAPITAL FORMATION (\%)

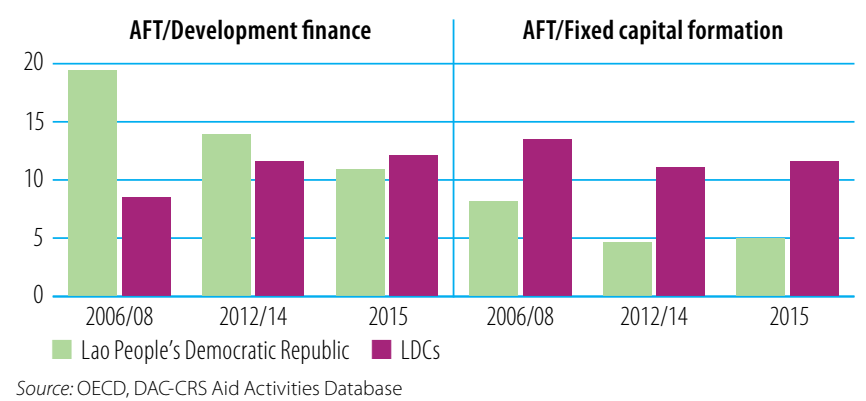

AfT DISBURSEMENTS: TOP DONORS (million current USD)

\begin{tabular}{lrr|lrc}
$\mathbf{2 0 0 6 / 0 8}$ & value & $\%$ & $\mathbf{2 0 1 5}$ & value & $\%$ \\
Japan & 32.2 & 28 & Korea & 71.0 & 35 \\
\hline IDA & 21.4 & 19 & Japan & 52.3 & 26 \\
\hline France & 12.4 & 11 & AsDB Special Funds & 23.2 & 12 \\
\hline Sweden & 10.5 & 9 & Germany & 12.4 & 6 \\
\hline Germany & 10.4 & 9 & IDA & 12.0 & 6 \\
\hline
\end{tabular}

Source: OECD, DAC-CRS Aid Activities Database

AfT DISBURSEMENTS BY SECTOR (million current USD)

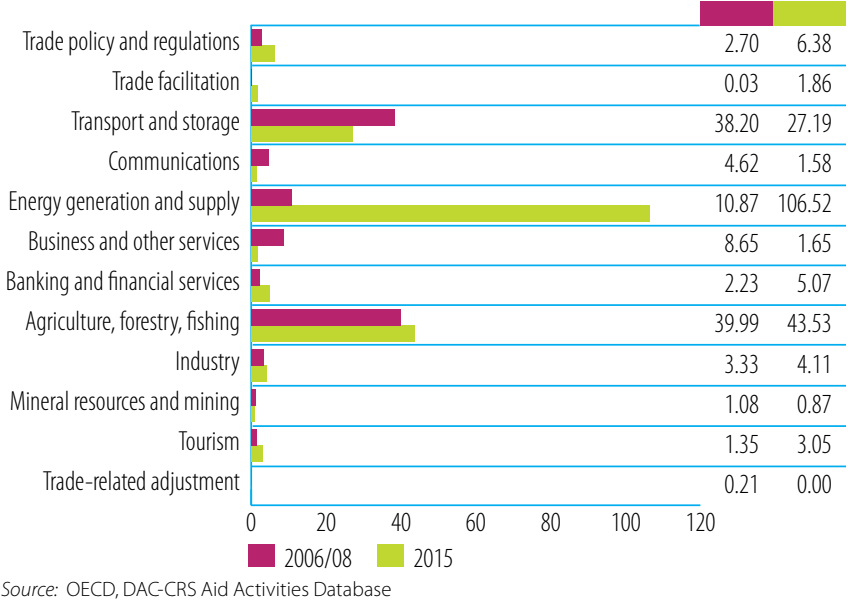

\section{B. TRADE COSTS}

\begin{tabular}{lrc} 
INDICATOR & 2006 & 2015 \\
Tariffs (\%) & 9.7 & 10.0 \\
\hline Imports: simple avg. MFN applied (2005-2015) & $\ldots$ & $\ldots$ \\
\hline Imports: weighted avg. MFN applied & 2.2 & 0.8 \\
\hline Exports: weighted avg. faced (2005-2014) & 60.7 & 95.5 \\
\hline Exports: duty free (value in \%) (2005-2014) & & \\
\hline ICT connectivity (\% of population) & $\ldots$ & 14.2 \\
\hline Mobile broadband subscriptions & 0.0 & 0.5 \\
\hline Fixed broadband subscriptions & 1.2 & 18.2 \\
\hline Individuals using the internet & &
\end{tabular}

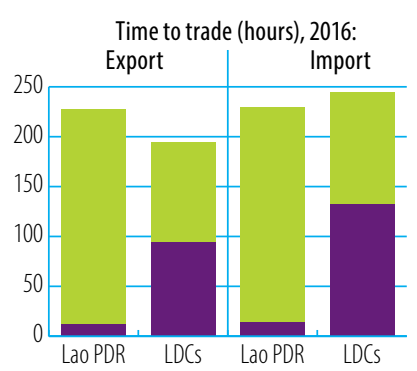

Border compliance Documentary compliance Source: WB, Doing Business

\section{LOGISTICS PERFORMANCE INDICES (LPI) (1-5)}

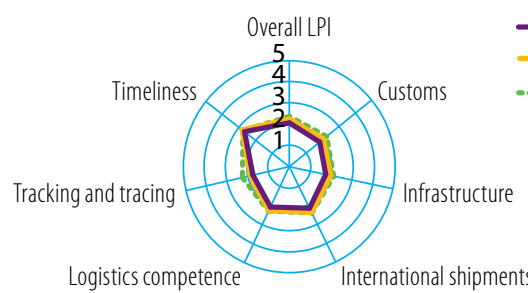

Source: WB Logistics Performance Index (LPI)

GLOBAL COMPETITIVENESS INDICATORS (1-7)

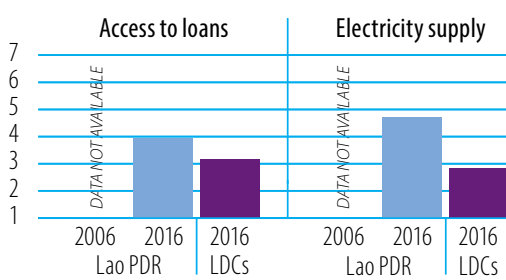

Lao PDR

Lao
TRADE FACILITATION INDICATORS, 2017 (0-2)

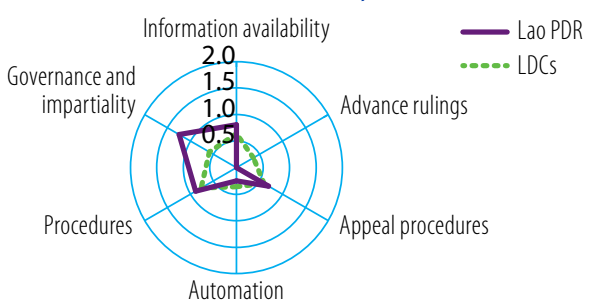

Source: OECD Trade Facilitation Indicators
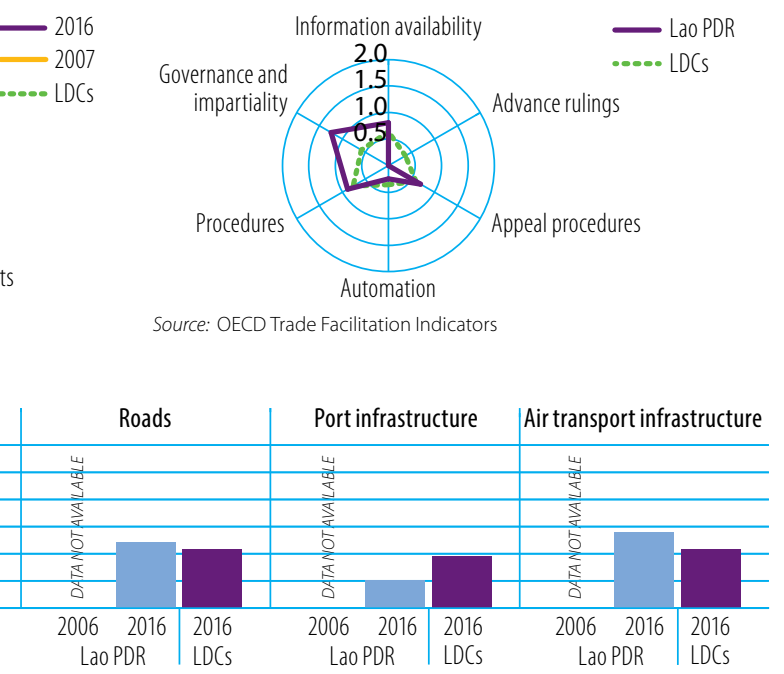

TRADE COSTS (ad-valorem, \%)

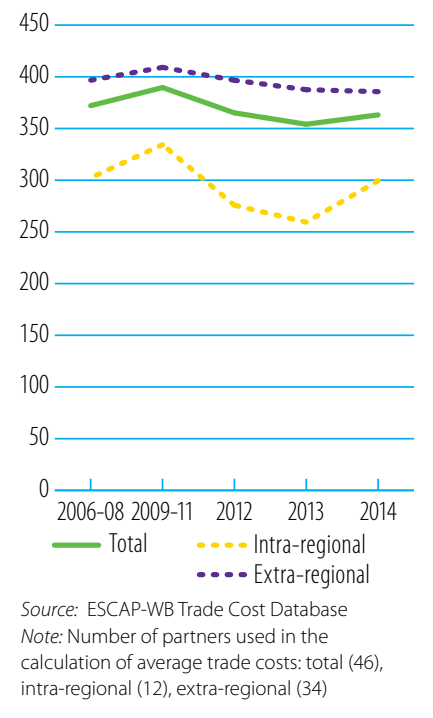




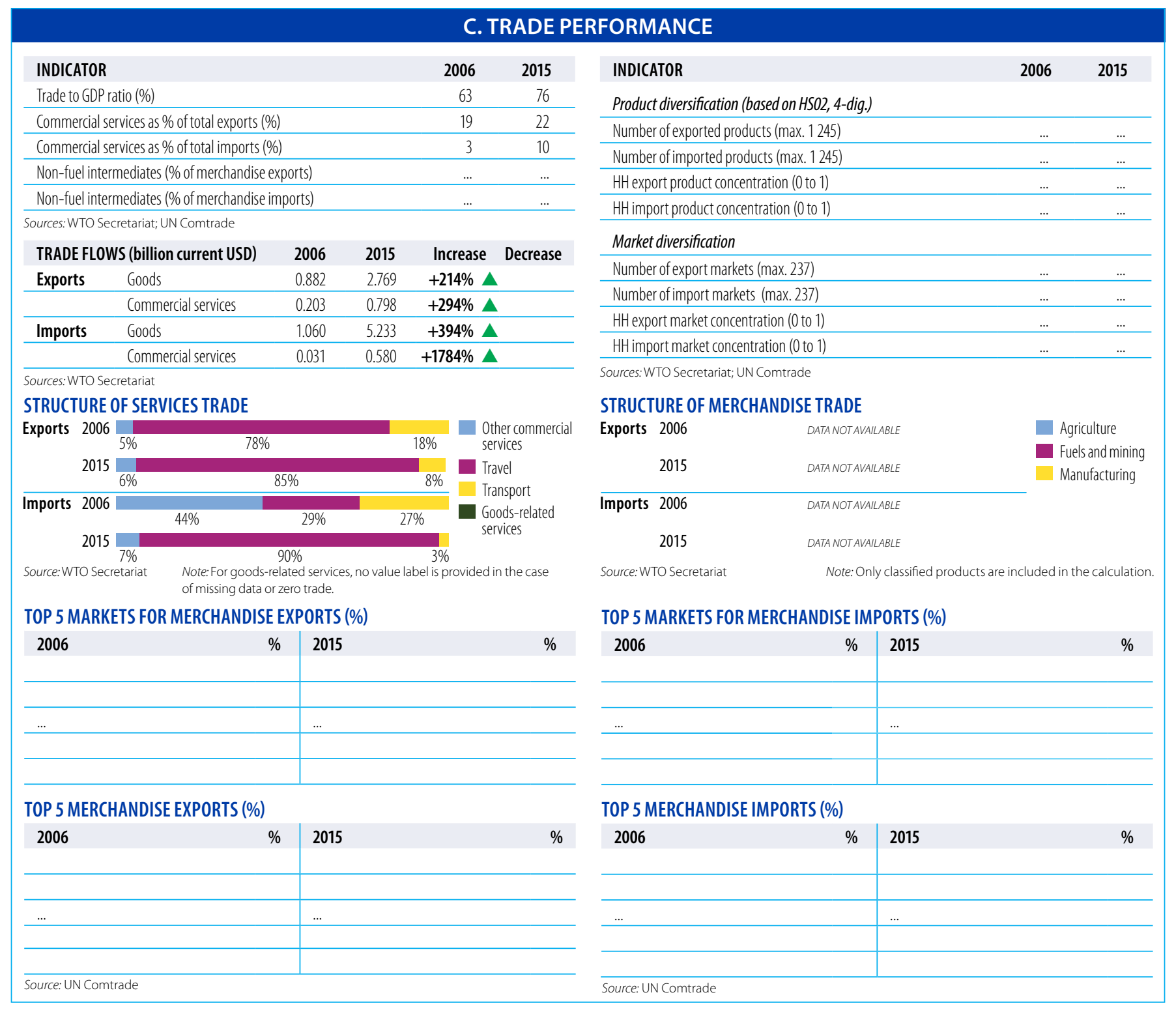

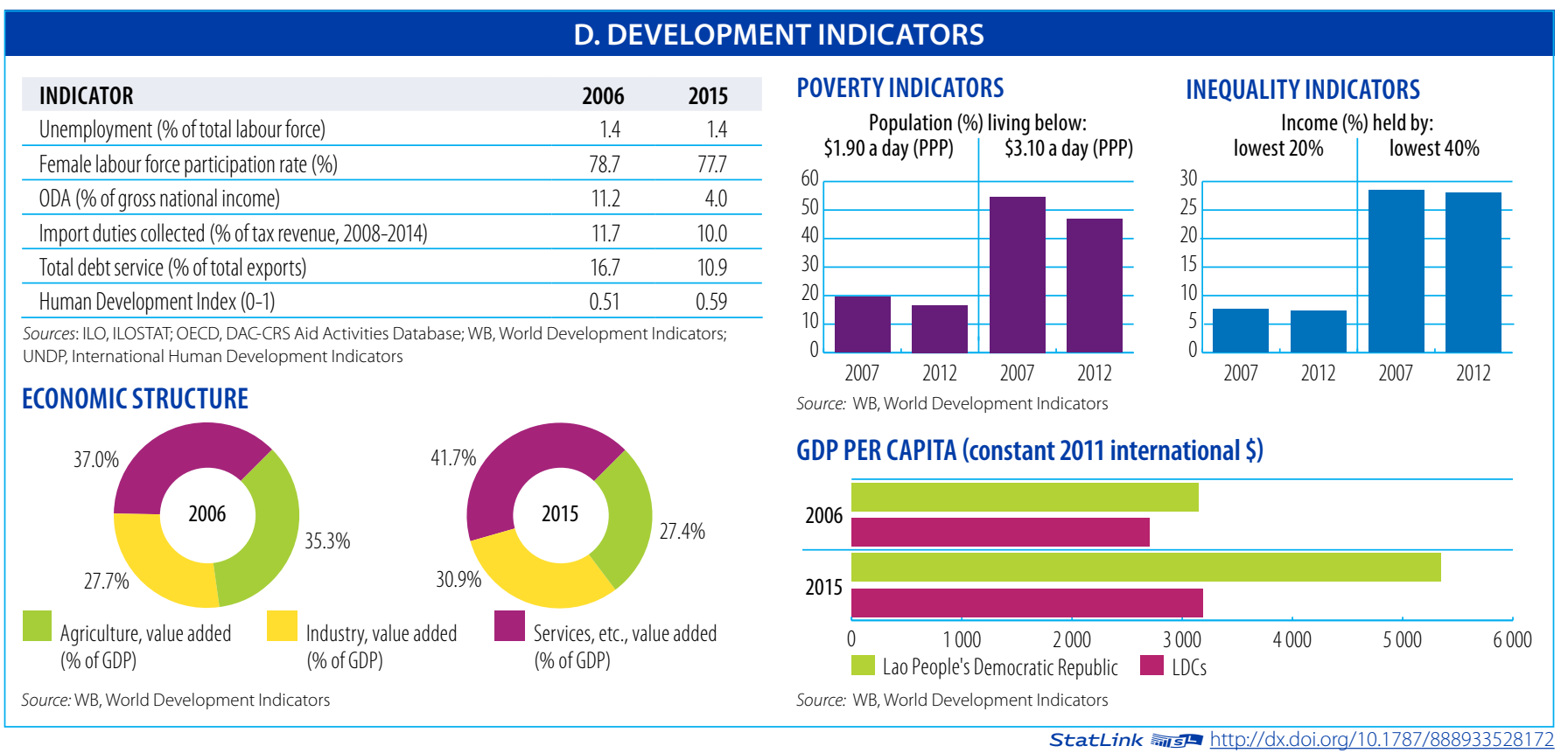


Aid, Trade and Development Indicators for Lesotho

\section{A. DEVELOPMENT FINANCE}

\begin{tabular}{lrrrc}
$\begin{array}{l}\text { EXTERNAL FINANCING INFLOWS } \\
\text { (million current USD) }\end{array}$ & $\mathbf{2 0 0 6 / 0 8}$ & $\mathbf{2 0 1 2 / 1 4}$ & $\mathbf{2 0 1 5}$ & $\mathbf{\Delta : 0 6 / 0 8 - 1 5}$ \\
\hline FDl inflows & 118.9 & 141.0 & 169.0 & $42 \%$ \\
\hline Remittances & 609.3 & 465.9 & 365.6 & $-40 \%$ \\
\hline Other official flows (O0F) & -0.4 & 13.3 & 0.0 & - \\
\hline of which trade-related 00F & 0.0 & 0.0 & 0.0 & - \\
\hline Official Development Assistance (ODA) & 118.4 & 260.9 & 103.6 & $-12 \%$ \\
\hline of which Aid for Trade & 17.5 & 18.5 & 14.5 & $-17 \%$ \\
\hline
\end{tabular}

Sources: UNCTAD, UNCTADstat; WB, World Development Indicators; OECD,

DAC-CRS Aid Activities Database

\section{TOP 3 AfT PRIORITIES}

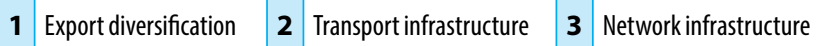
Source: OECD/WTO Partner Questionnaire

SHARE OF AfT IN DEVELOPMENT FINANCE AND FIXED CAPITAL FORMATION (\%)

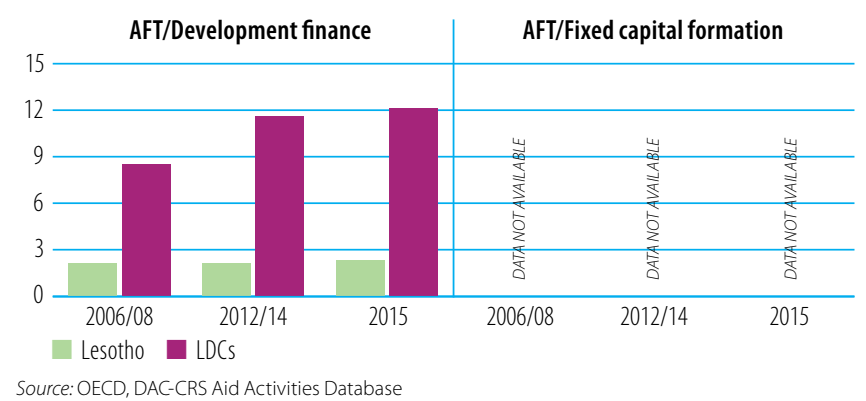

AfT DISBURSEMENTS: TOP DONORS (million current USD)

\begin{tabular}{lcc|lcc}
$\mathbf{2 0 0 6 / 0 8}$ & value & $\%$ & $\mathbf{2 0 1 5}$ & value & $\%$ \\
IDA & 6.7 & 38 & International Development Association & 10.1 & 69 \\
\hline African Development Fund & 6.1 & 35 & $\begin{array}{l}\text { Arab Bank for Economic Development } \\
\text { in Africa }\end{array}$ & 1.3 & 9 \\
\hline EU Institutions & 3.1 & 18 & Global Environment Facility & 0.9 & 6 \\
\hline Germany & 0.7 & 4 & OPEC Fund for International Development & 0.8 & 6 \\
\hline United States & 0.2 & 1 & United Kingdom & 0.3 & 2 \\
\hline Source: OECD, DAC-CRS Aid Activities Database &
\end{tabular}

AfT DISBURSEMENTS BY SECTOR (million current USD)

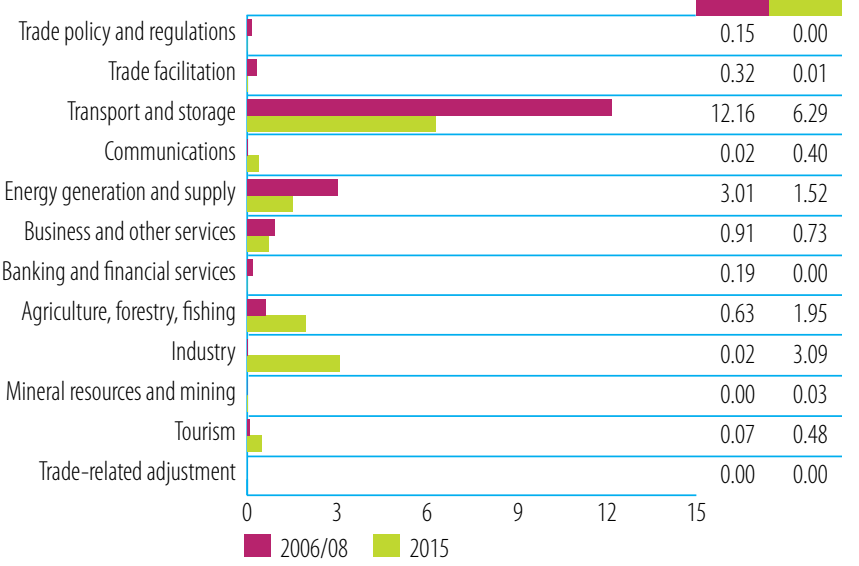

Source: OECD, DAC-CRS Aid Activities Database

\section{B. TRADE COSTS}

\begin{tabular}{lrc} 
INDICATOR & 2006 & 2015 \\
Tariffs (\%) & 7.9 & 7.6 \\
\hline Imports: simple avg. MFN applied & $\ldots$ & 12.3 \\
\hline Imports: weighted avg. MFN applied (2006-2013) & 0.0 & 0.3 \\
\hline Exports: weighted avg. faced (2005-2014) & 99.9 & 99.0 \\
\hline Exports: duty free (value in \%) (2005-2014) & & \\
\hline ICT connectivity (\% of population) & $\ldots$ & 37.7 \\
\hline Mobile broadband subscriptions & 0.0 & 0.1 \\
\hline Fixed broadband subscriptions (2007-2015) & 3.0 & 16.1 \\
\hline Individuals using the internet & &
\end{tabular}
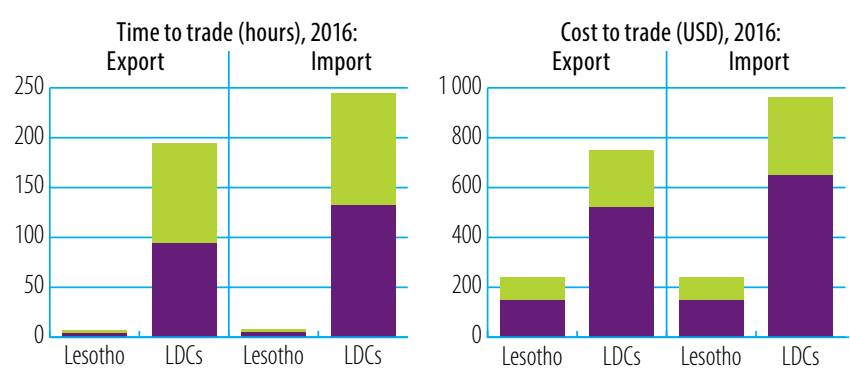

Sources: WTO, World Tariff Profiles; ITU, World Telecommunication/ICT Indicators

LOGISTICS PERFORMANCE INDICES (LPI) (1-5)

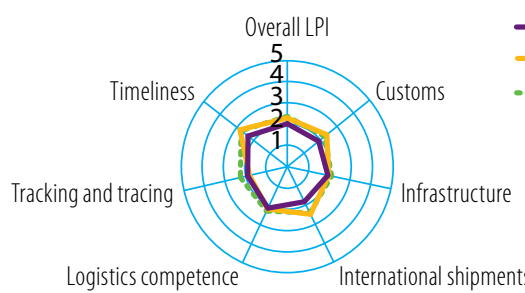

Source: WB Logistics Performance Index (LPI)

GLOBAL COMPETITIVENESS INDICATORS (1-7)

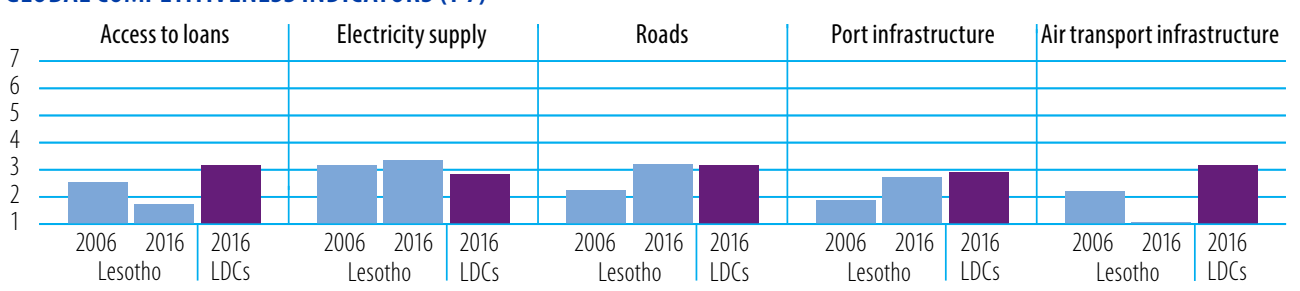

TRADE FACILITATION INDICATORS, 2017 (0-2)

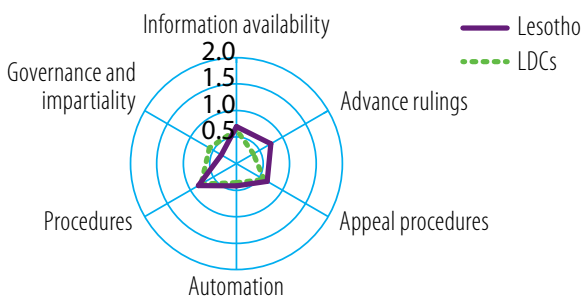

Source: OECD Trade Facilitation Indicators

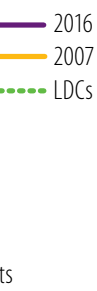

Source: WEF Global Competitiveness Index 


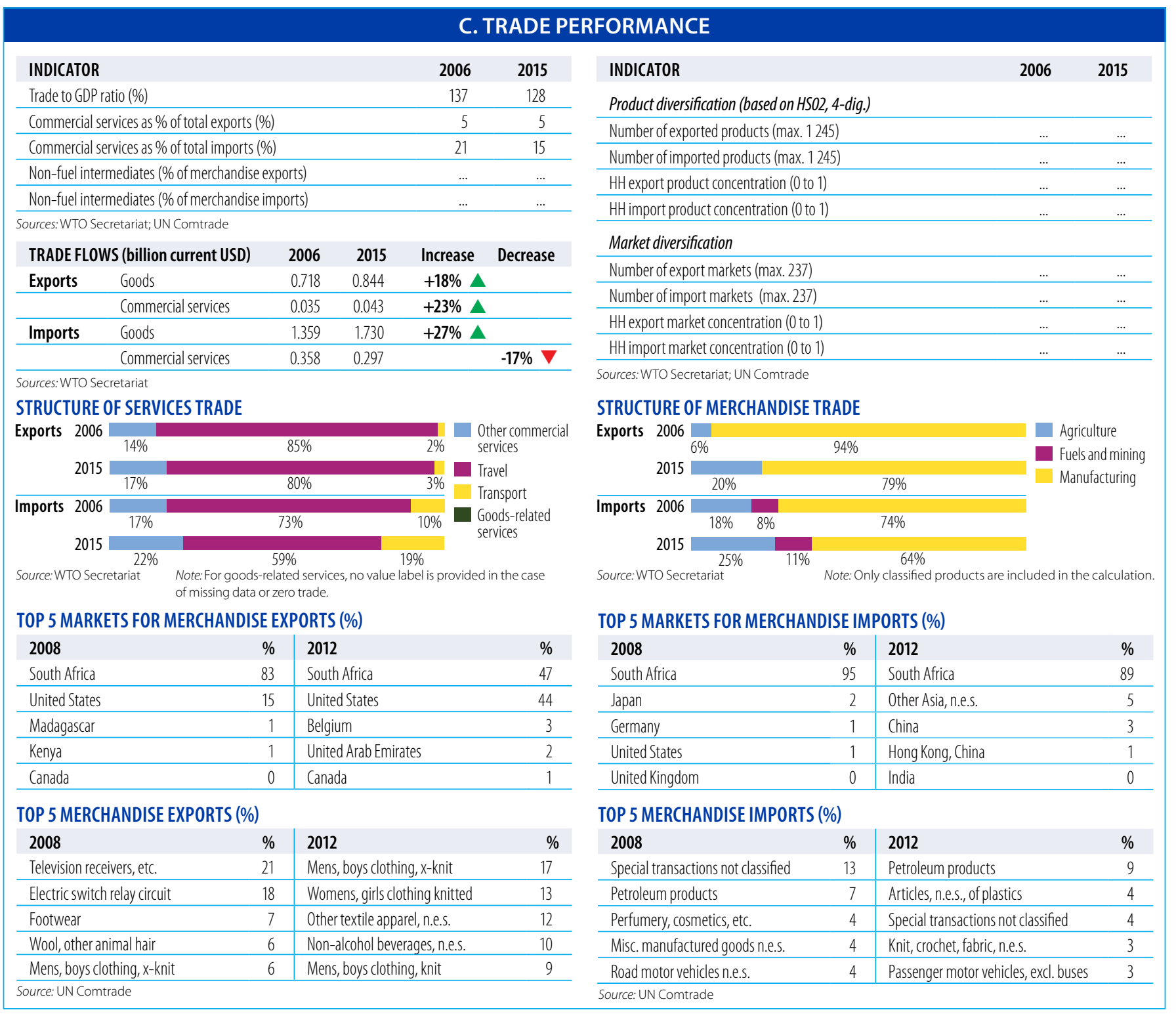

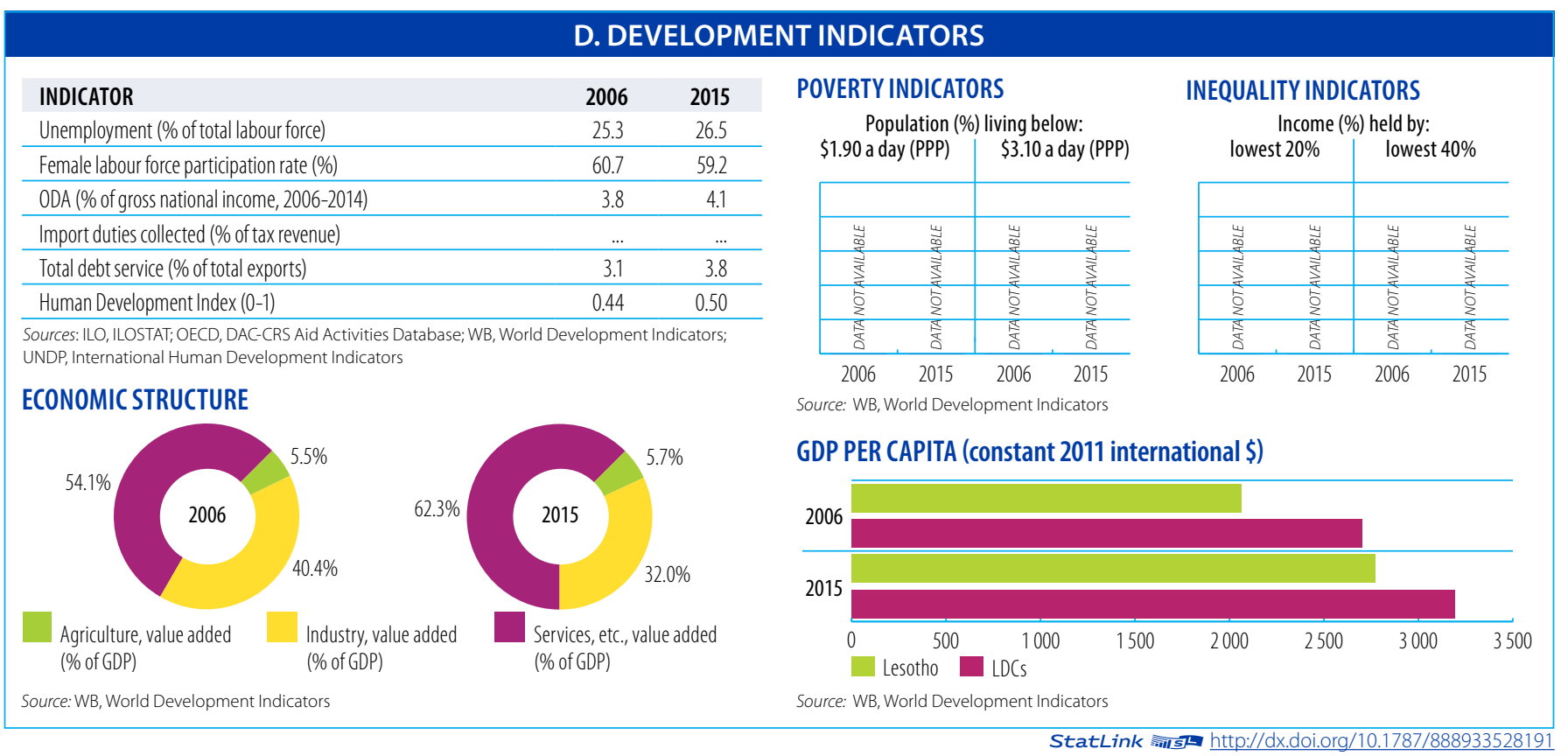


Aid, Trade and Development Indicators for Madagascar

\section{A. DEVELOPMENT FINANCE}

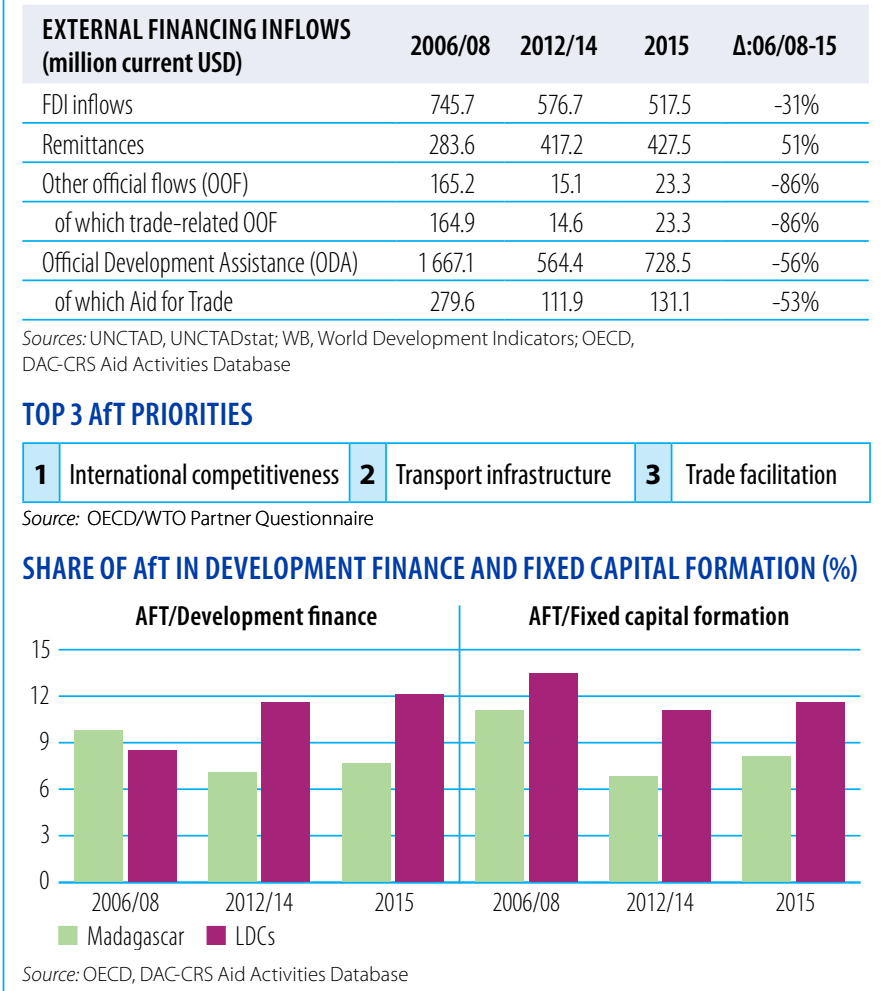

AfT DISBURSEMENTS: TOP DONORS (million current USD)

\begin{tabular}{lcc|lrc}
$\mathbf{2 0 0 6 / 0 8}$ & value & $\%$ & $\mathbf{2 0 1 5}$ & value & $\%$ \\
IDA & 118.6 & 42 & IDA & 50.3 & 38 \\
\hline EU Institutions & 81.0 & 29 & EU Institutions & 39.0 & 30 \\
\hline France & 32.7 & 12 & African Development Fund & 20.6 & 16 \\
\hline African Development Fund & 12.0 & 4 & France & 8.4 & 6 \\
\hline United States & 10.4 & 4 & Germany & 3.0 & 2 \\
\hline Source: OECD, DAC-CRS Aid Activities Database & & &
\end{tabular}

AfT DISBURSEMENTS BY SECTOR (million current USD)

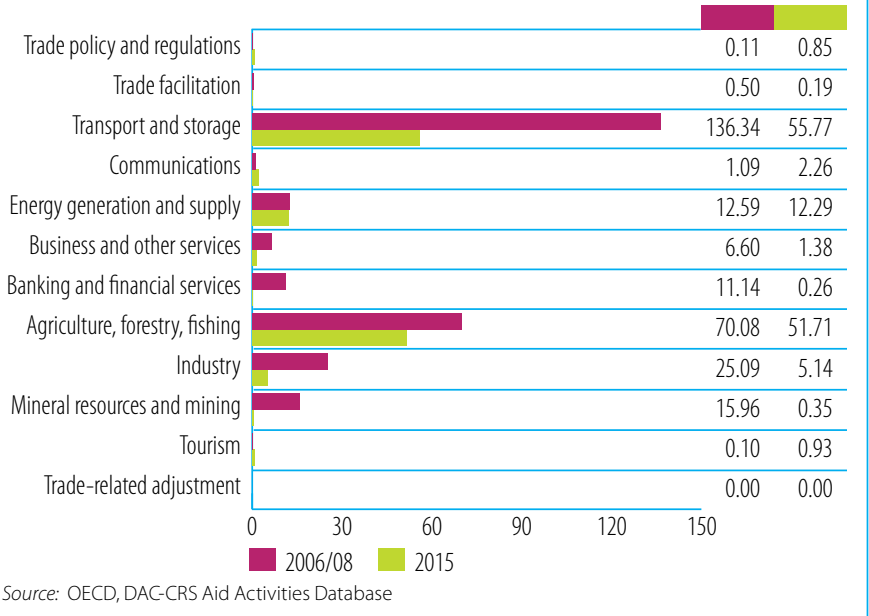

\section{B. TRADE COSTS}

\begin{tabular}{|c|c|c|}
\hline INDICATOR & 2006 & 2015 \\
\hline \multicolumn{3}{|l|}{ Tariffs (\%) } \\
\hline Imports: simple avg. MFN applied & 13.3 & 11.7 \\
\hline Imports: weighted avg. MFN applied (2006-2014) & $\ldots$ & 9.2 \\
\hline Exports: weighted avg. faced (2005-2014) & 0.3 & 0.8 \\
\hline Exports: duty free (value in \%) (2005-2014) & 99.3 & 96.9 \\
\hline \multicolumn{3}{|l|}{ ICT connectivity (\% of population) } \\
\hline Mobile broadband subscriptions & $\ldots$ & 9.0 \\
\hline Fixed broadband subscriptions & 0.0 & 0.1 \\
\hline Individuals using the internet & 0.6 & 4.2 \\
\hline
\end{tabular}
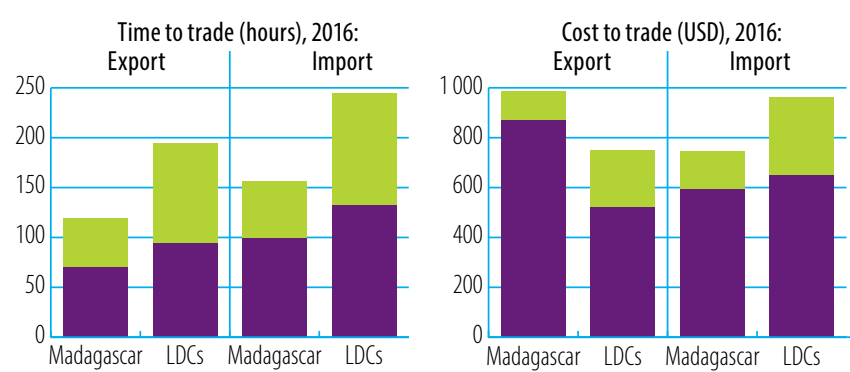

Border compliance Documentary compliance

Source: WB, Doing Business

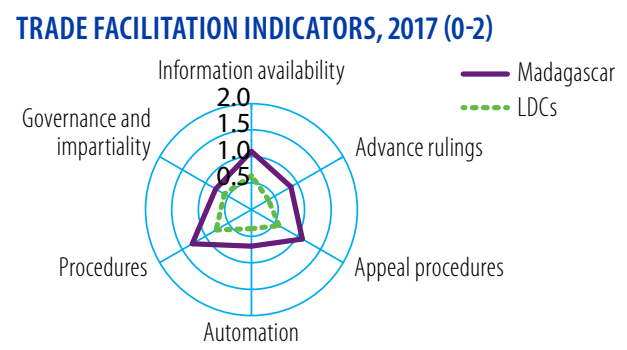

Source: OECD Trade Facilitation Indicators

Source: WB Logistics Performance Index (LPI)

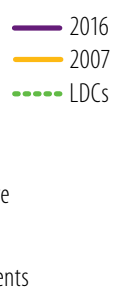

\section{GLOBAL COMPETITIVENESS INDICATORS (1-7)}

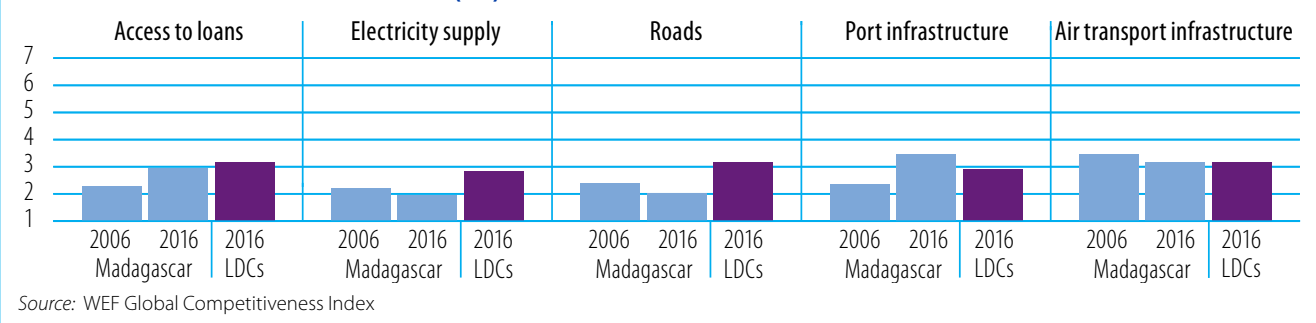

TRADE COSTS (ad-valorem, \%)

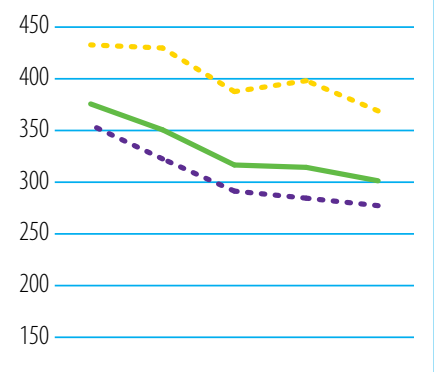

100

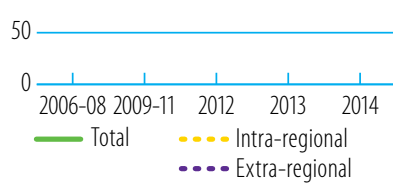

Source: ESCAP-WB Trade Cost Database Note: Number of partners used in the calculation of average trade costs: total (61), intra-regional (16), extra-regional (45) 


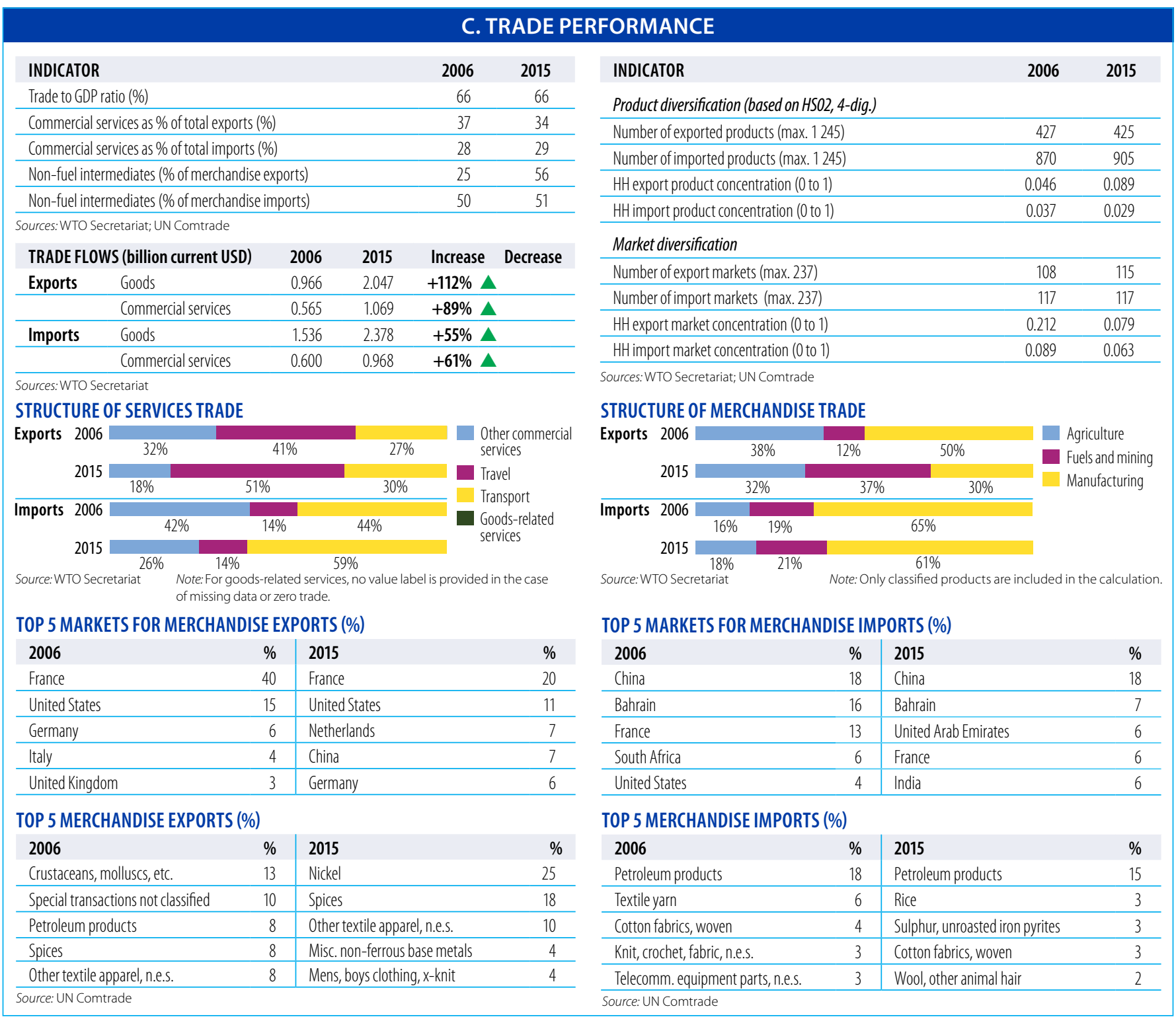

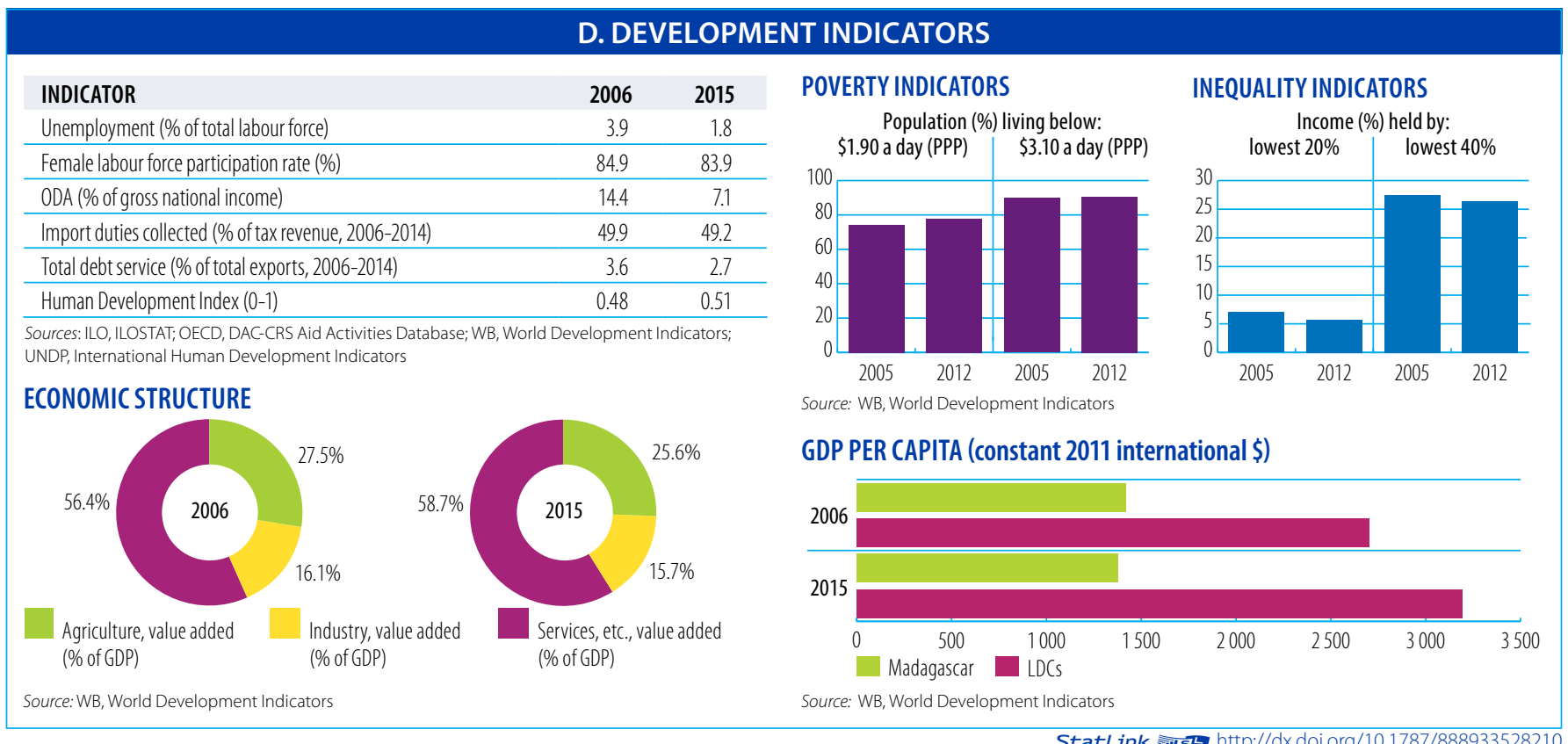


Aid, Trade and Development Indicators for Malawi

\section{A. DEVELOPMENT FINANCE}

\begin{tabular}{lrrrc}
$\begin{array}{l}\text { EXTERNAL FINANCING INFLOWS } \\
\text { (million current USD) }\end{array}$ & $\mathbf{2 0 0 6 / 0 8}$ & $\mathbf{2 0 1 2 / 1 4}$ & $\mathbf{2 0 1 5}$ & $\mathbf{\Delta : 0 6 / 0 8 - 1 5}$ \\
FDl inflows & 118.5 & 126.3 & 142.5 & $\mathbf{2 0 \%}$ \\
\hline Remittances & 17.5 & 33.6 & 34.2 & $96 \%$ \\
\hline Other official flows (OOF) & 1.7 & 0.0 & 0.1 & $-95 \%$ \\
\hline of which trade-related 00F & 1.7 & 0.0 & 0.1 & $-96 \%$ \\
\hline Official Development Assistance (ODA) & 1912.6 & 1125.0 & 1104.0 & $-42 \%$ \\
\hline of which Aid for Trade & 99.6 & 217.3 & 244.2 & $145 \%$ \\
\hline
\end{tabular}

Sources:UNCTAD, UNCTADstat; WB, World Development Indicators; OECD,

DAC-CRS Aid Activities Database

\section{TOP 3 AfT PRIORITIES}

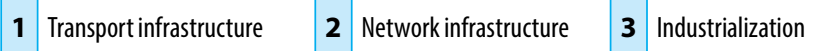
Source: OECD/WTO Partner Questionnaire

SHARE OF AfT IN DEVELOPMENT FINANCE AND FIXED CAPITAL FORMATION (\%)

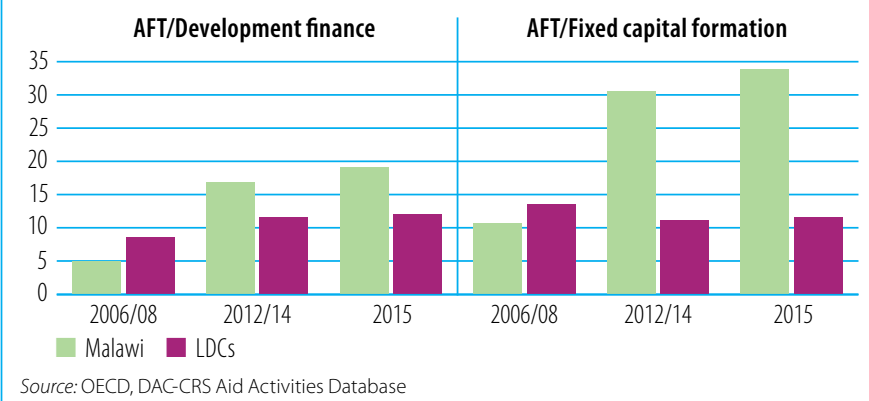

AfT DISBURSEMENTS: TOP DONORS (million current USD)

\begin{tabular}{lrr|lrc}
$\mathbf{2 0 0 6 / 0 8}$ & value & $\%$ & $\mathbf{2 0 1 5}$ & value & $\%$ \\
IDA & 24.4 & 24 & United States & 61.1 & 25 \\
\hline EU Institutions & 23.5 & 24 & IDA & 39.5 & 16 \\
\hline Japan & 12.4 & 12 & African Development Fund & 35.1 & 14 \\
\hline Norway & 11.2 & 11 & EU Institutions & 26.7 & 11 \\
\hline African Development Fund & 9.6 & 10 & Norway & 19.7 & 8 \\
\hline Source. OECD.DAC-CRS Aid Activities Database & & &
\end{tabular}

Source: OECD, DAC-CRS Aid Activities Database

AfT DISBURSEMENTS BY SECTOR (million current USD)

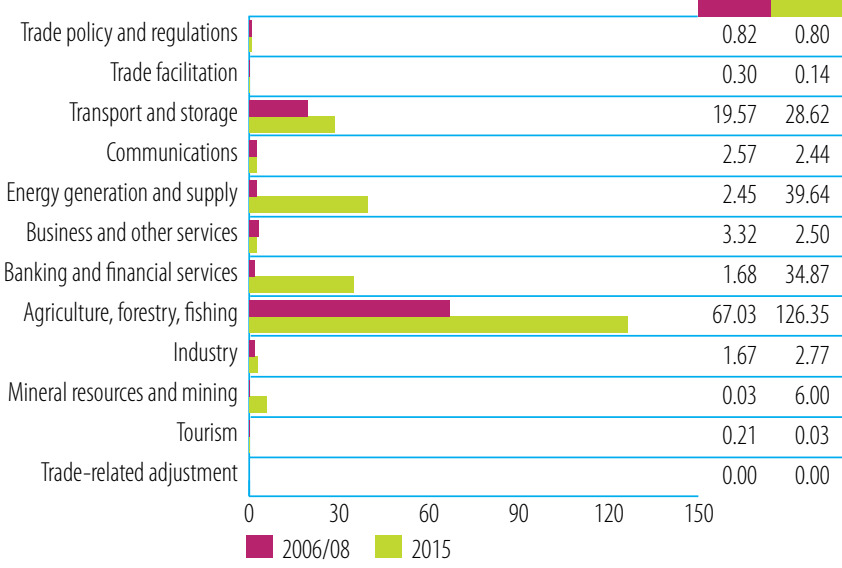

Source: OECD, DAC-CRS Aid Activities Database

\section{B. TRADE COSTS}

\begin{tabular}{lcc} 
INDICATOR & $\mathbf{2 0 0 6}$ & $\mathbf{2 0 1 5}$ \\
Tariffs (\%) & & \\
\hline Imports: simple avg. MFN applied & 13.5 & 12.6 \\
\hline Imports: weighted avg. MFN applied (2006-2014) & $\ldots$ & 7.9 \\
\hline Exports: weighted avg. faced (2005-2014) & 14.7 & 13.6 \\
\hline Exports: duty free (value in \%) (2005-2014) & 85.7 & 90.7 \\
\hline ICT connectivity (\% of population) & & \\
\hline Mobile broadband subscriptions & $\ldots$ & 16.6 \\
\hline Fixed broadband subscriptions (2007-2015) & 0.0 & 0.0 \\
\hline Individuals using the internet & 0.4 & 9.3 \\
\hline Sources: WTO, World Tariff Profiles; ITU, World Telecommunication/ICT Indicators &
\end{tabular}
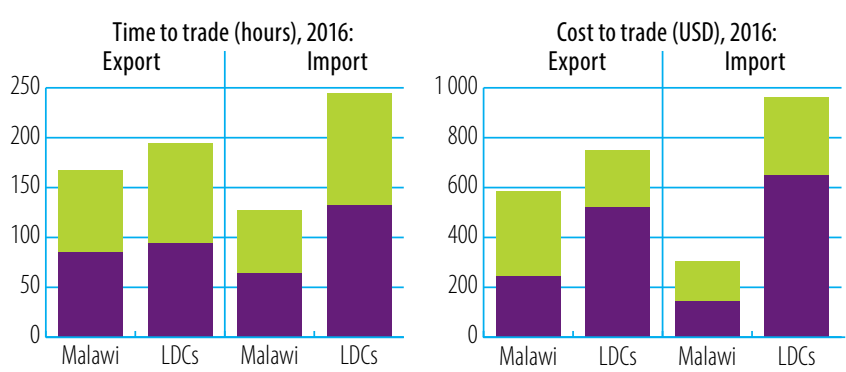

Border compliance Documentary compliance Source: WB, Doing Business

\section{LOGISTICS PERFORMANCE INDICES (LPI) (1-5)}

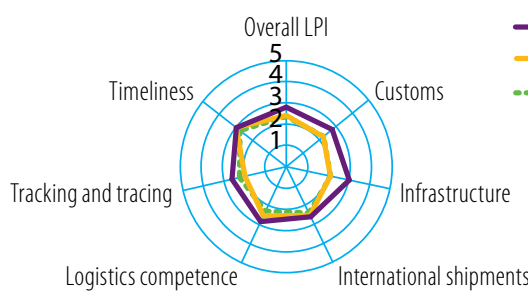

Source: WB Logistics Performance Index (LPI)

GLOBAL COMPETITIVENESS INDICATORS (1-7)
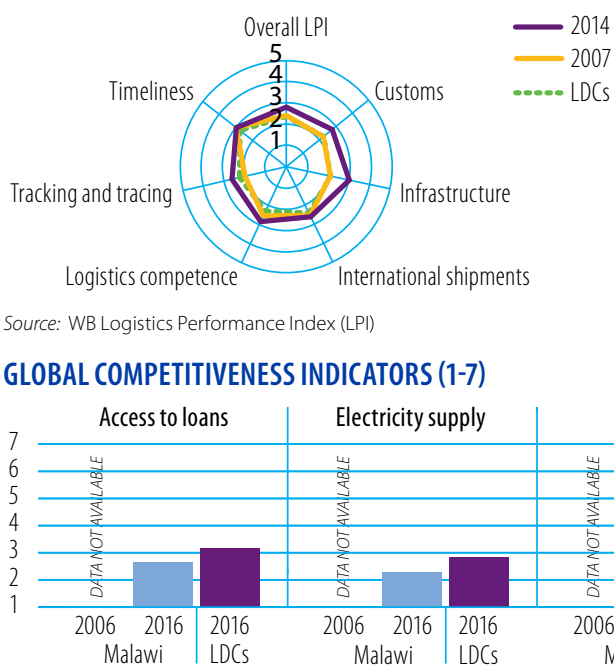

TRADE FACILITATION INDICATORS, 2017 (0-2)

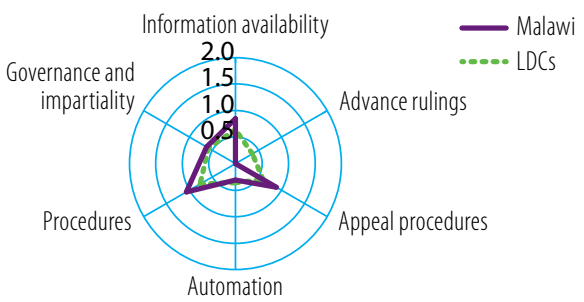

Source: OECD Trade Facilitation Indicators
TRADE COSTS (ad-valorem, \%)

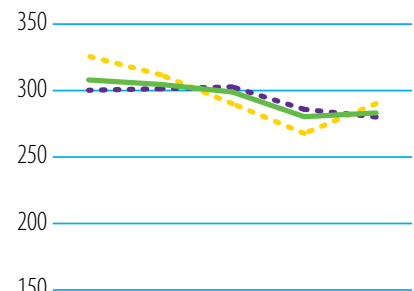

100

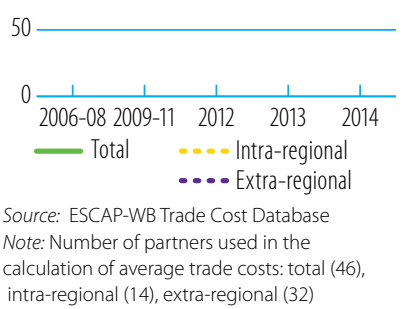

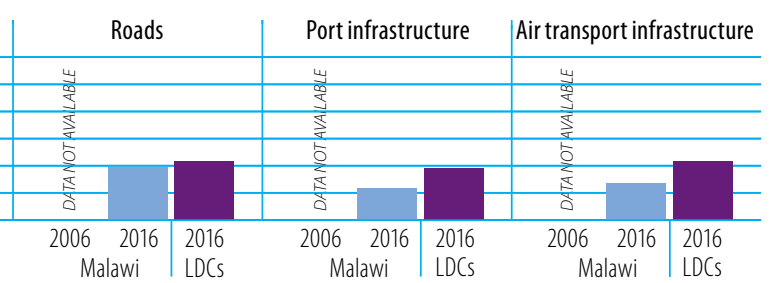

\begin{tabular}{ll|l}
\hline 6 & 2016 & 2016 \\
\hline Malawi & IDCs
\end{tabular} 


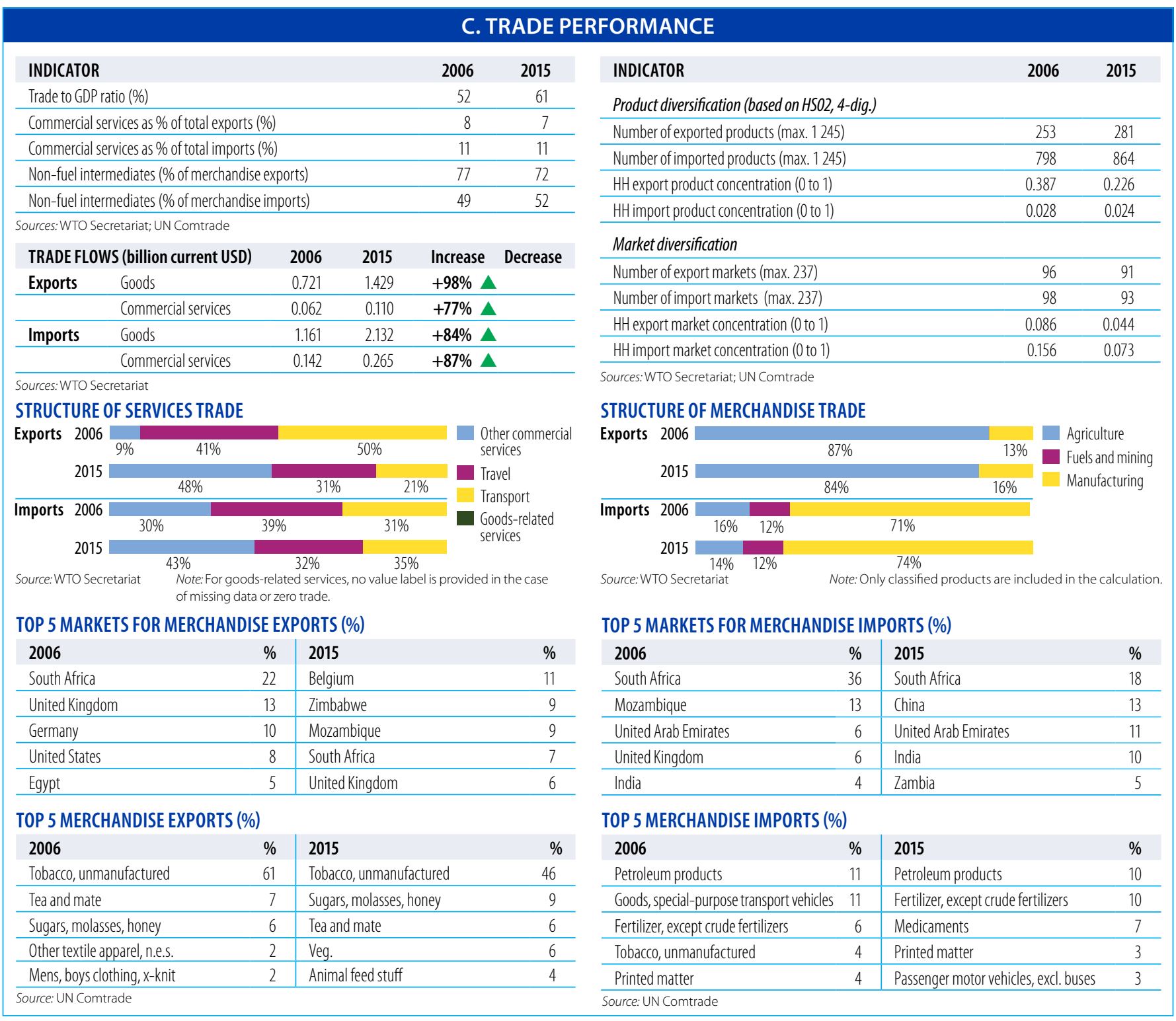

\begin{tabular}{|lrr}
\hline & D. DEVELOPMEN \\
\hline INDICATOR & $\mathbf{2 0 0 6}$ & $\mathbf{2 0 1 5}$ \\
Unemployment (\% of total labour force) & 6.7 & 6.6 \\
\hline Female labour force participation rate (\%) & 81.3 & 81.2 \\
\hline ODA (\% of gross national income) & 18.3 & 16.5 \\
\hline Import duties collected (\% of tax revenue) & $\ldots$ & 9.5 \\
\hline Total debt service (\% of total exports) & 8.9 & 4.3 \\
\hline Human Development Index (0-1) & 0.39 & 0.48 \\
\hline
\end{tabular}

Sources: ILO, ILOSTAT; OECD, DAC-CRS Aid Activities Database; WB, World Development Indicators; UNDP, International Human Development Indicators

\section{ECONOMIC STRUCTURE}

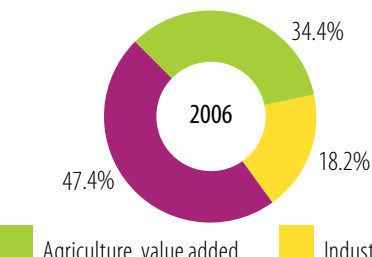

(\% of GDP)

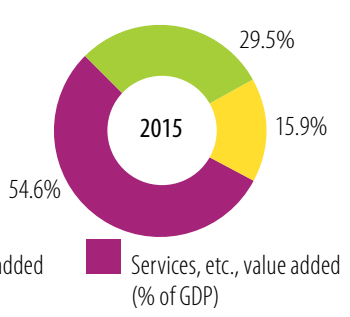

$(\%$ of GDP)

Source: WB, World Development Indicators

\section{POVERTY INDICATORS}

Population (\%) living below:

$\$ 1.90$ a day (PPP) $\quad$ \$3.10 a day (PPP)

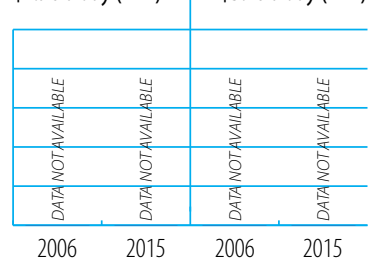

Source: WB, World Development Indicators

GDP PER CAPITA (constant 2011 international \$)

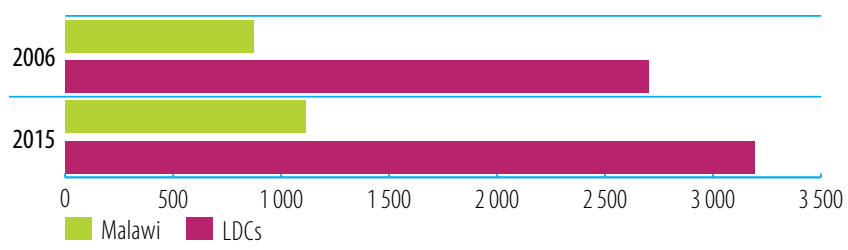

Source: WB, World Development Indicators
INEQUALITY INDICATORS

Income (\%) held by:

lowest 20\% | lowest 40\%

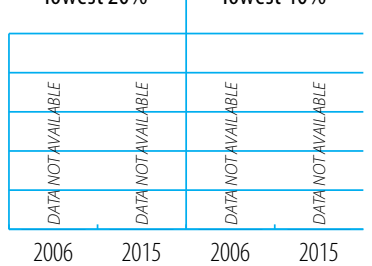


Aid, Trade and Development Indicators for Mali

\section{A. DEVELOPMENT FINANCE}

\begin{tabular}{lrrrc}
\hline $\begin{array}{l}\text { EXTERNAL FINANCING INFLOWS } \\
\text { (million current USD) }\end{array}$ & $\mathbf{2 0 0 6 / 0 8}$ & $\mathbf{2 0 1 2 / 1 4}$ & $\mathbf{2 0 1 5}$ & $\mathbf{\Delta : 0 6 / 0 8 - 1 5}$ \\
\hline FDl inflows & 112.2 & 283.2 & 152.9 & $36 \%$ \\
\hline Remittances & 328.9 & 880.7 & 894.5 & $172 \%$ \\
\hline Other official flows (OOF) & 0.0 & 11.2 & 45.2 & - \\
\hline of which trade-related 0OF & 0.0 & 0.0 & 12.2 & - \\
\hline Official Development Assistance (ODA) & 1590.1 & 1262.2 & 1281.9 & $-19 \%$ \\
\hline of which Aid for Trade & 237.2 & 286.9 & 250.9 & $6 \%$ \\
\hline
\end{tabular}

Sources: UNCTAD, UNCTADstat; WB, World Development Indicators; OECD,

DAC-CRS Aid Activities Database

TOP 3 AfT PRIORITIES

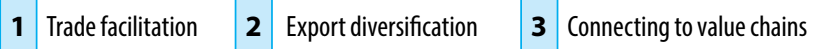
Source: OECD/WTO Partner Questionnaire

SHARE OF AfT IN DEVELOPMENT FINANCE AND FIXED CAPITAL FORMATION (\%)

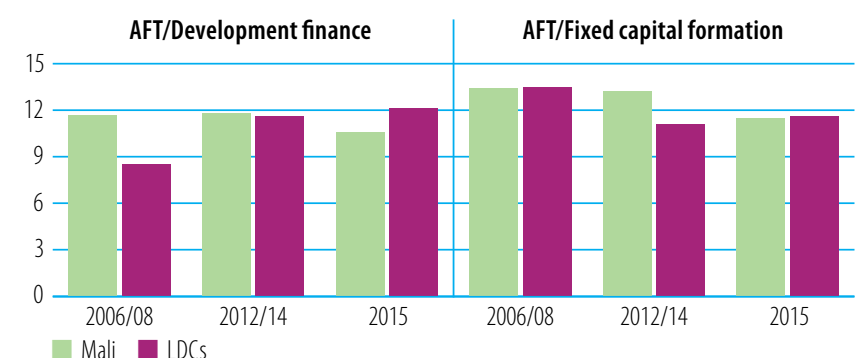

Mali $\square$ LDCS

Source: OECD, DAC-CRS Aid Activities Database
AfT DISBURSEMENTS: TOP DONORS (million current USD)

\begin{tabular}{lrr|lrc}
$\mathbf{2 0 0 6 / 0 8}$ & value & $\%$ & $\mathbf{2 0 1 5}$ & value & $\%$ \\
IDA & 79.8 & 34 & IDA & 99.8 & 40 \\
\hline EU Institutions & 76.0 & 32 & EU Institutions & 24.7 & 10 \\
\hline France & 15.8 & 7 & United States & 21.3 & 8 \\
\hline African Development Fund & 13.8 & 6 & Kuwait (KFAED) & 11.9 & 5 \\
\hline Germany & 11.3 & 5 & France & 10.7 & 4 \\
\hline
\end{tabular}

Source: OECD, DAC-CRS Aid Activities Database

AfT DISBURSEMENTS BY SECTOR (million current USD)

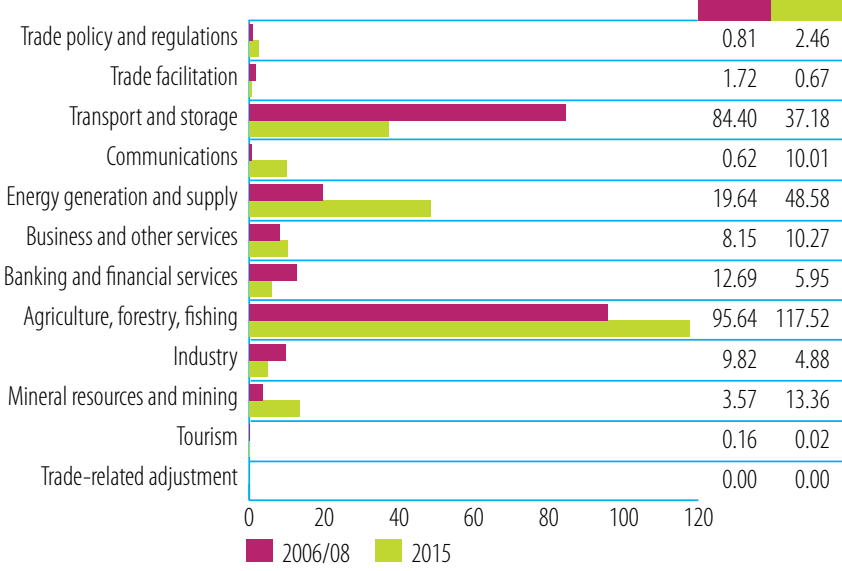

Source: OECD, DAC-CRS Aid Activities Database

\section{B. TRADE COSTS}

\begin{tabular}{lcc} 
INDICATOR & 2006 & $\mathbf{2 0 1 5}$ \\
Tariffs (\%) & & \\
\hline Imports: simple avg. MFN applied & 12.0 & 12.2 \\
\hline Imports: weighted avg. MFN applied (2006-2012) & $\ldots$ & 9.8 \\
\hline Exports: weighted avg. faced (2005-2014) & 17.1 & 0.1 \\
\hline Exports: duty free (value in \%) (2005-2014) & 51.3 & 98.6 \\
\hline ICT connectivity (\% of population) & $\ldots$ & \\
\hline Mobile broadband subscriptions & $\ldots .0$ & 0.0 \\
\hline Fixed broadband subscriptions & 0.7 & 10.3 \\
\hline Individuals using the internet & &
\end{tabular}

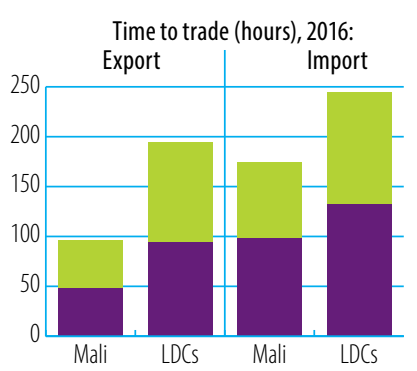

Border compliance Documentary compliance Source: WB, Doing Business

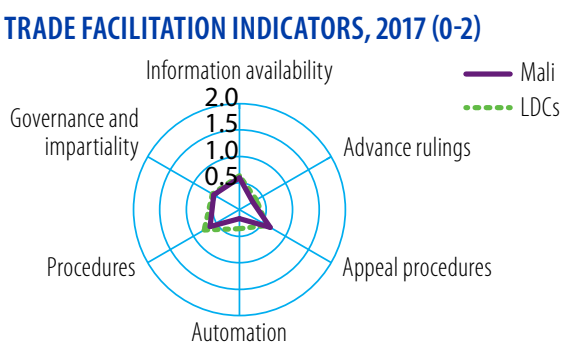

Source: OECD Trade Facilitation Indicators

Source: WB Logistics Performance Index (LPI)

GLOBAL COMPETITIVENESS INDICATORS (1-7)

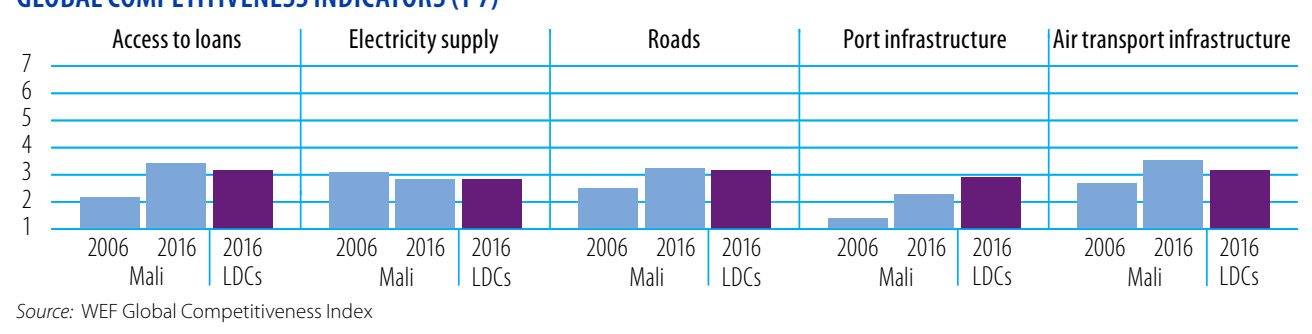

Source: WEF Global Competitiveness Index

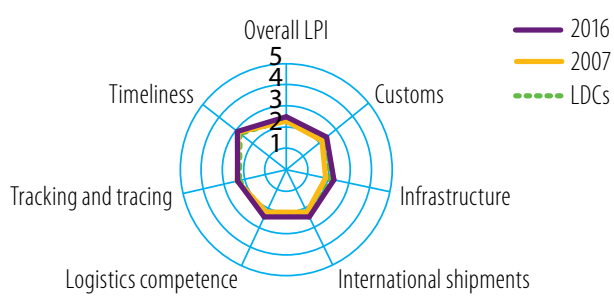

LOGISTICS PERFORMANCE INDICES (LPI) (1-5)
TRADE COSTS (ad-valorem, \%)

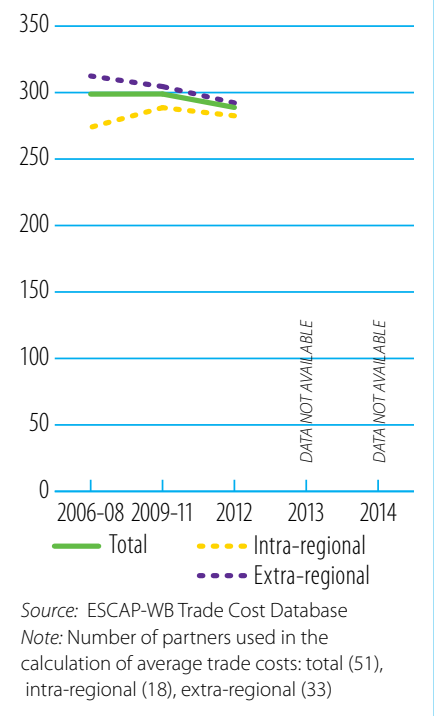




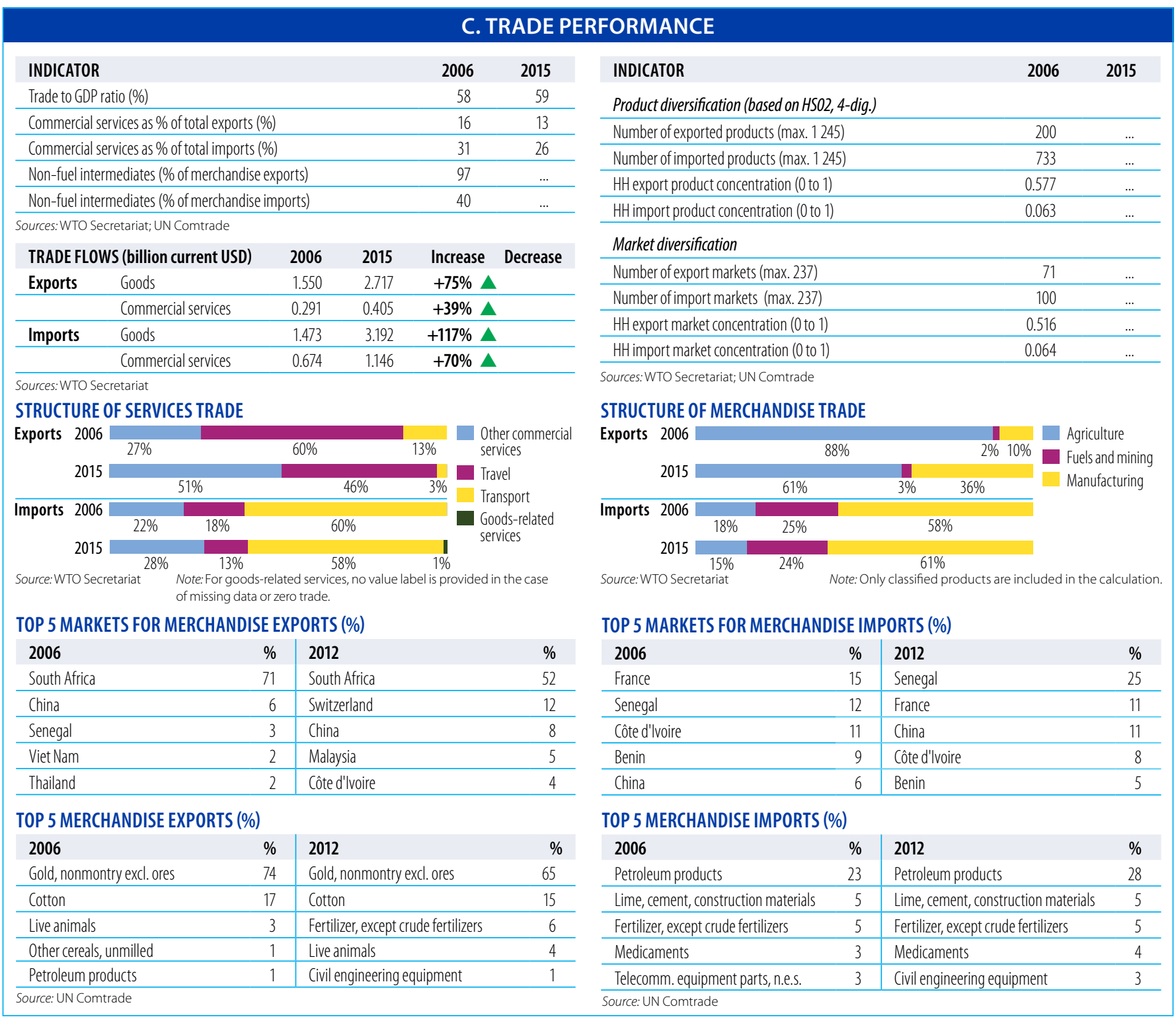

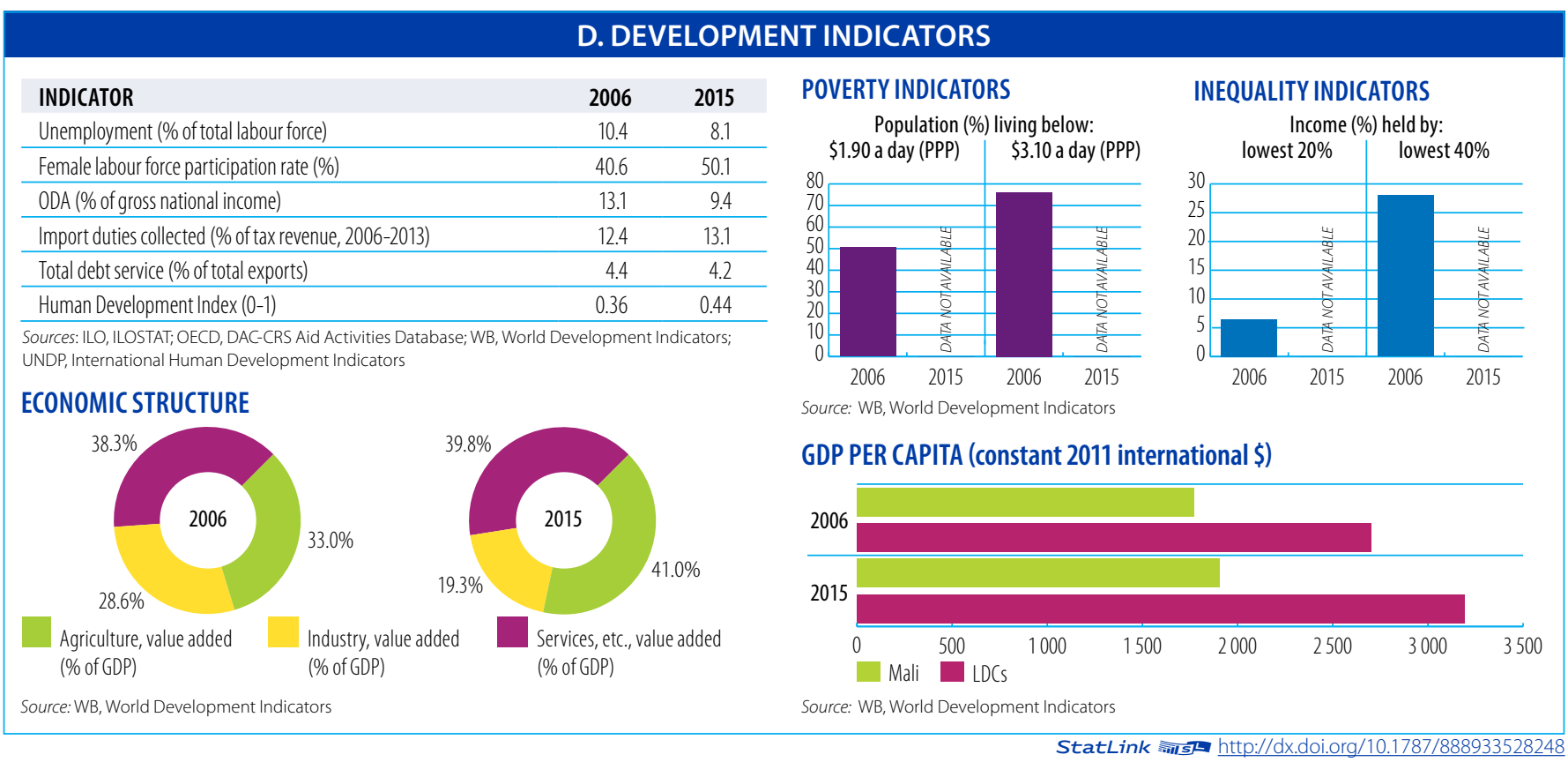


Aid, Trade and Development Indicators for Mauritius

\section{A. DEVELOPMENT FINANCE}

\begin{tabular}{lrrrc}
$\begin{array}{l}\text { EXTERNAL FINANCING INFLOWS } \\
\text { (million current USD) }\end{array}$ & $\mathbf{2 0 0 6 / 0 8}$ & $\mathbf{2 0 1 2 / 1 4}$ & $\mathbf{2 0 1 5}$ & $\mathbf{\Delta : 0 6 / 0 8 - 1 5}$ \\
\hline FDl inflows & 275.8 & 433.6 & 208.3 & $-24 \%$ \\
\hline Remittances & 0.7 & 0.8 & 1.3 & $91 \%$ \\
\hline Other official flows (OOF) & 44.6 & 189.7 & 44.6 & $0 \%$ \\
\hline of which trade-related O0F & 9.1 & 58.1 & 43.8 & $384 \%$ \\
\hline Official Development Assistance (ODA) & 103.2 & 164.4 & 119.4 & $16 \%$ \\
\hline of which Aid for Trade & 6.5 & 75.8 & 67.6 & $945 \%$ \\
\hline
\end{tabular}

Sources: UNCTAD, UNCTADstat; WB, World Development Indicators; OECD,

DAC-CRS Aid Activities Database

\section{TOP 3 AfT PRIORITIES}

\section{International competitiveness \\ 2 Trade policy \\ 3 Export diversification}

Source: OECD/WTO Partner Questionnaire

SHARE OF AfT IN DEVELOPMENT FINANCE AND FIXED CAPITAL FORMATION (\%)

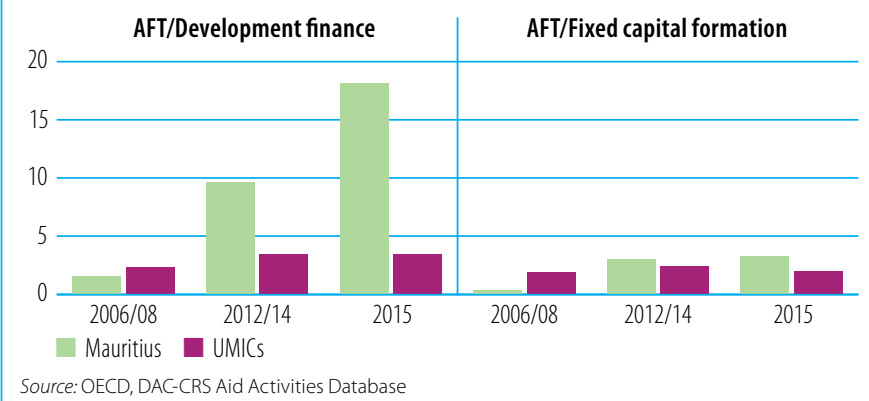

AfT DISBURSEMENTS: TOP DONORS (million current USD)

\begin{tabular}{lrr|lrr}
$\mathbf{2 0 0 6 / 0 8}$ & value & \multicolumn{1}{c|}{$\%$} & $\mathbf{2 0 1 5}$ & value & $\%$ \\
EU Institutions & 6.5 & 100 & France & 45.4 & 67 \\
\hline Greece & 0.3 & 4 & EU Institutions & 20.9 & 31 \\
\hline Japan & 0.2 & 4 & Finland & 0.8 & 1 \\
\hline Germany & 0.1 & 1 & Global Environment Facility & 0.4 & 1 \\
\hline UNDP & 0.1 & 1 & United States & 0.1 & 0 \\
\hline
\end{tabular}

Source: OECD, DAC-CRS Aid Activities Database

AfT DISBURSEMENTS BY SECTOR (million current USD)

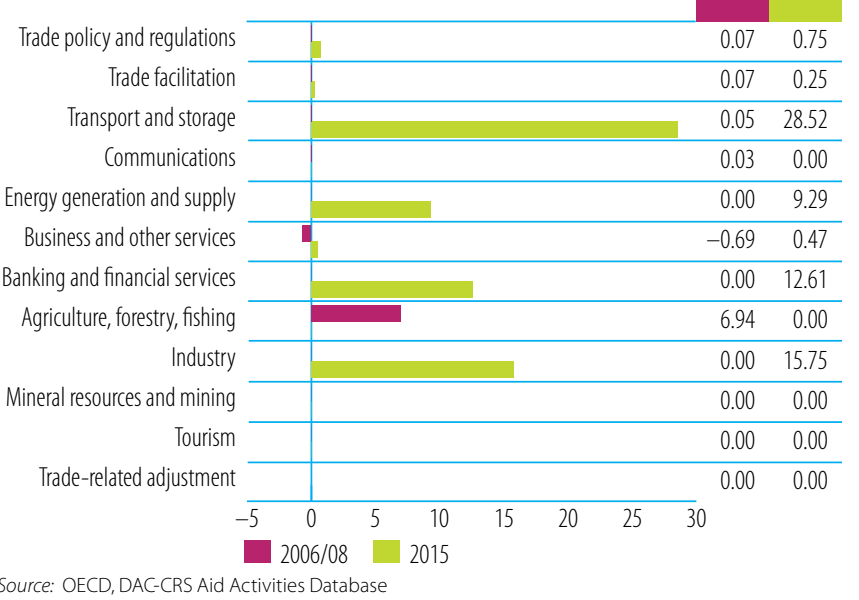

\section{B. TRADE COSTS}

\begin{tabular}{lrc} 
INDICATOR & $\mathbf{2 0 0 6}$ & $\mathbf{2 0 1 5}$ \\
Tariffs (\%) & 3.5 & 1.0 \\
\hline Imports: simple avg. MFN applied & 2 & 0.9 \\
\hline Imports: weighted avg. MFN applied (2005-2014) & 1.6 & 0.1 \\
\hline Exports: weighted avg. faced (2005-2014) & 95.3 & 99.8 \\
\hline Exports: duty free (value in \%) (2005-2014) & 3.2 & \\
\hline ICT connectivity (\% of population) & 2.3 & 15.7 \\
\hline Mobile broadband subscriptions (2007-2015) & 16.7 & 50.1 \\
\hline Fixed broadband subscriptions & &
\end{tabular}
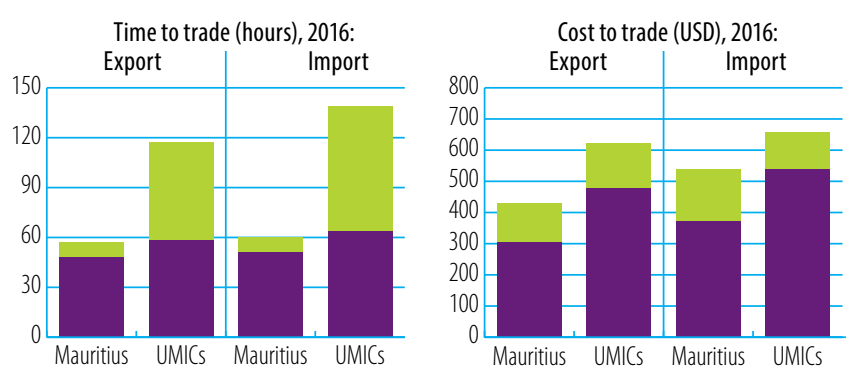

Border compliance Documentary compliance

Source: WB, Doing Business

\section{LOGISTICS PERFORMANCE INDICES (LPI) (1-5)}

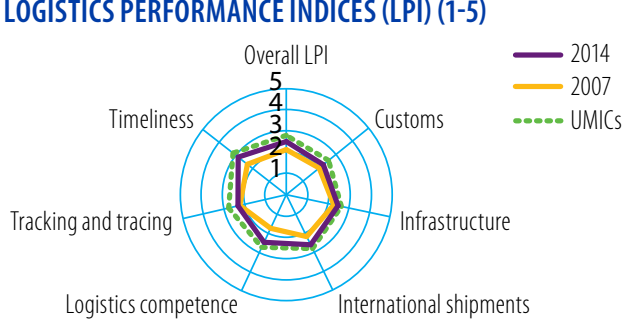

Source: WB Logistics Performance Index (LPI)

TRADE FACILITATION INDICATORS, 2017 (0-2)

\section{GLOBAL COMPETITIVENESS INDICATORS (1-7)}

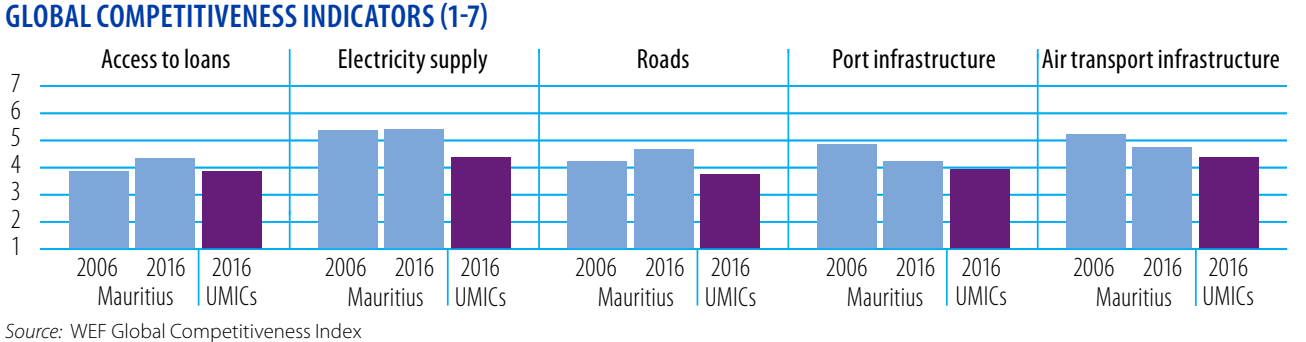

Source: WEF Global Competitiveness Index

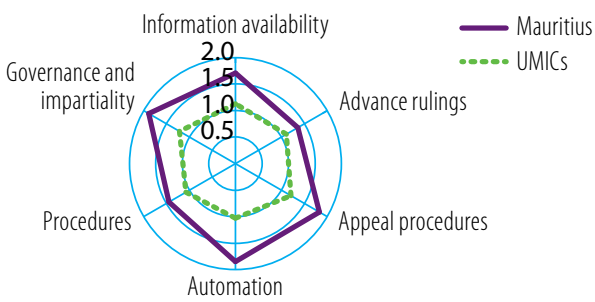

Source: OECD Trade Facilitation Indicators
TRADE COSTS (ad-valorem, \%)

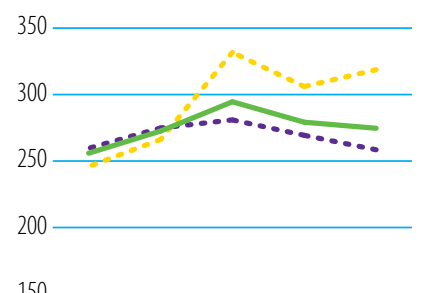

100

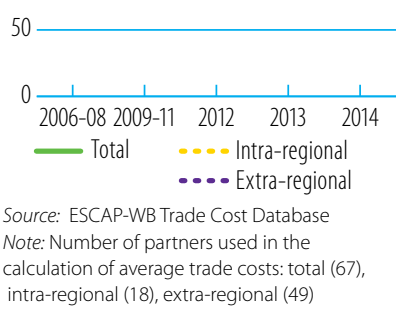




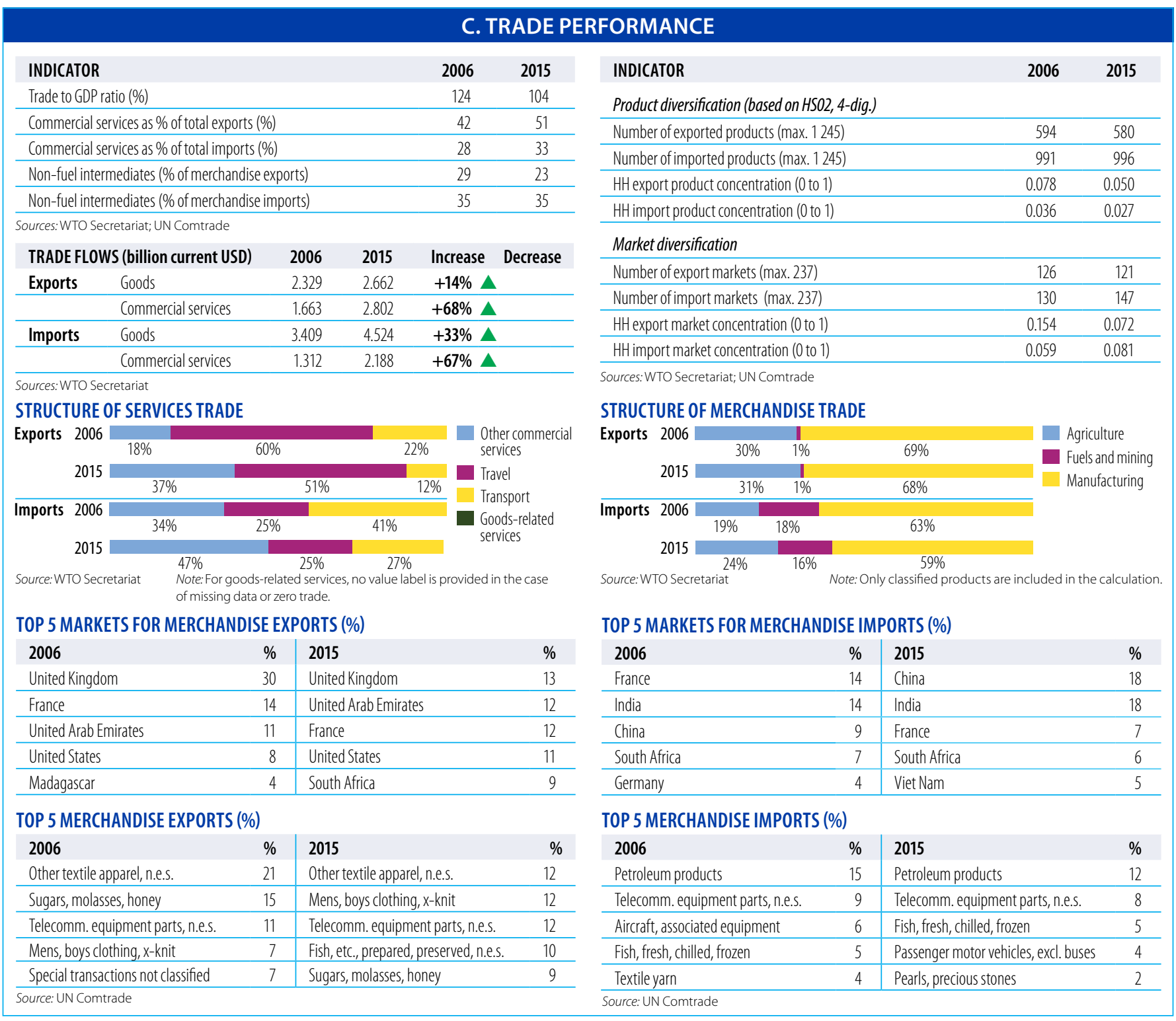

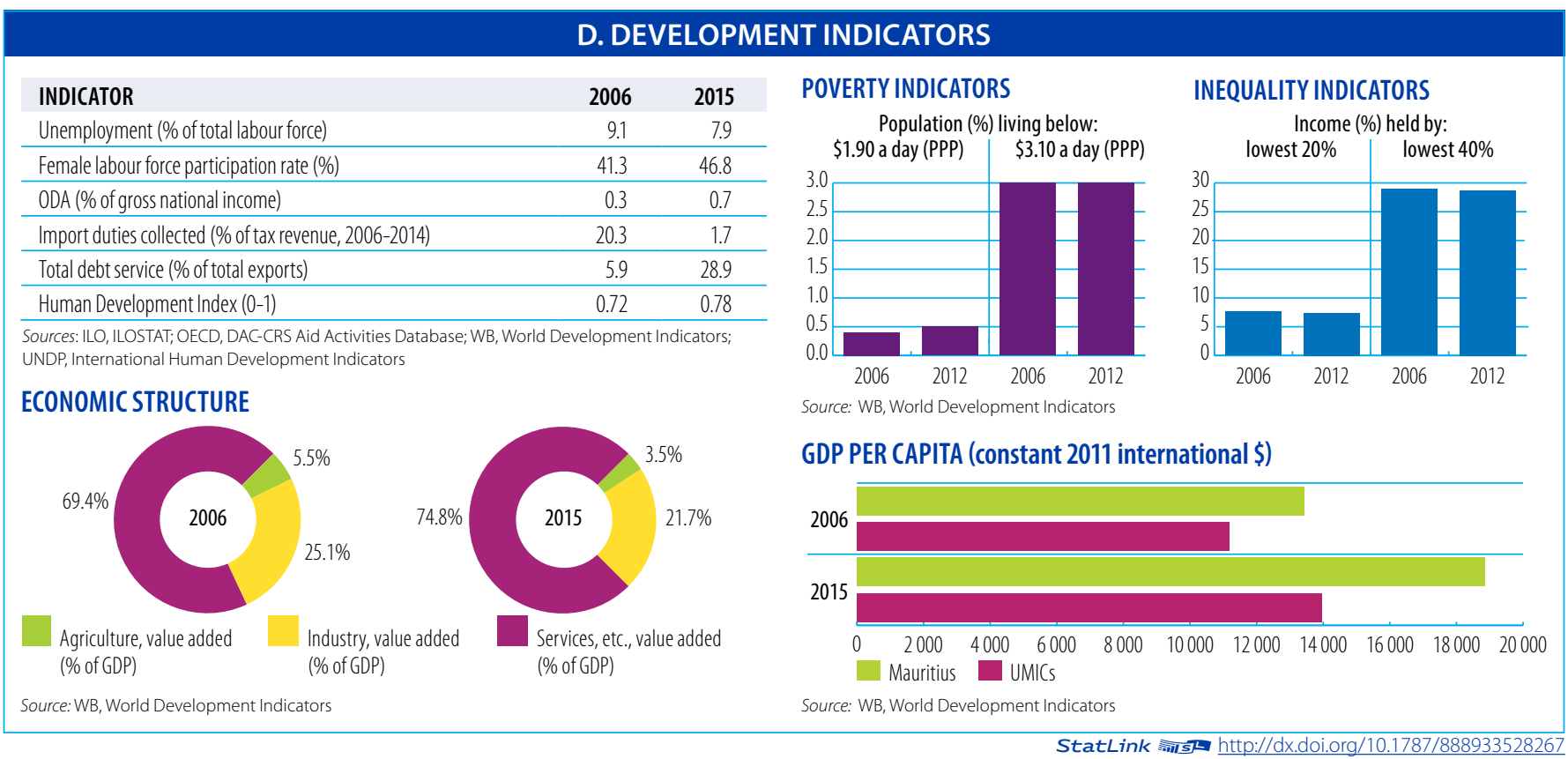


Aid, Trade and Development Indicators for Mexico

\section{A. DEVELOPMENT FINANCE}

\begin{tabular}{lrrrc}
\hline $\begin{array}{l}\text { EXTERNAL FINANCING INFLOWS } \\
\text { (million current USD) }\end{array}$ & $\mathbf{2 0 0 6 / 0 8}$ & $\mathbf{2 0 1 2 / 1 4}$ & $\mathbf{2 0 1 5}$ & $\mathbf{\Delta : 0 6 / 0 8 - 1 5}$ \\
\hline FDl inflows & 27531.9 & 30655.6 & 30284.6 & $10 \%$ \\
\hline Remittances & 26488.1 & 23753.7 & 26164.4 & $-1 \%$ \\
\hline Other official flows (00F) & 1517.8 & 2875.8 & 2174.1 & $43 \%$ \\
\hline of which trade-related 00F & 493.3 & 1087.3 & 848.6 & $72 \%$ \\
\hline Official Development Assistance (ODA) & 283.9 & 749.8 & 503.9 & $77 \%$ \\
\hline of which Aid for Trade & 25.9 & 252.3 & 102.3 & $295 \%$ \\
\hline
\end{tabular}

Sources:UNCTAD, UNCTADstat; WB, World Development Indicators; OECD,

DAC-CRS Aid Activities Database

\section{TOP 3 AfT PRIORITIES}

\begin{tabular}{|l|l|l|l|l|l|}
\hline 1 & Trade policy & $\mathbf{2}$ & Regional integration & $\mathbf{3}$ & Trade facilitation \\
\hline
\end{tabular}

Source: OECD/WTO Partner Questionnaire

SHARE OF AfT IN DEVELOPMENT FINANCE AND FIXED CAPITAL FORMATION (\%)

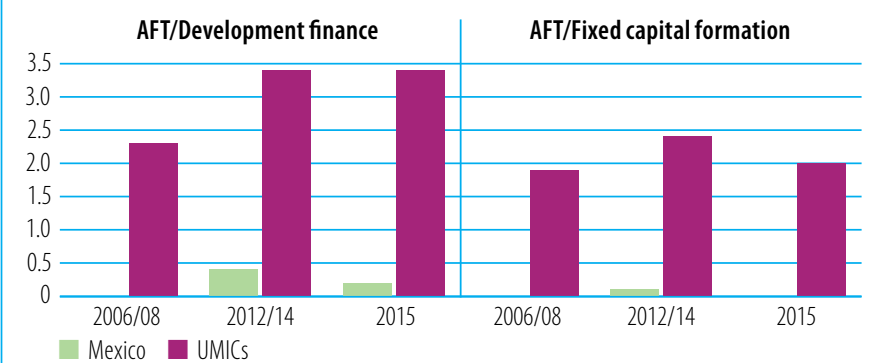

Source: OECD, DAC-CRS Aid Activities Database
AfT DISBURSEMENTS: TOP DONORS (million current USD)

\begin{tabular}{lrr|lrr}
$\mathbf{2 0 0 6 / 0 8}$ & value & $\%$ & $\mathbf{2 0 1 5}$ & value & $\%$ \\
EU Institutions & 5.7 & 22 & Germany & 66.9 & 65 \\
\hline United States & 5.4 & 21 & United States & 8.9 & 9 \\
\hline Japan & 4.5 & 17 & Finland & 4.5 & 4 \\
\hline France & 2.9 & 11 & Inter-American Development Bank & 4.3 & 4 \\
\hline Germany & 2.4 & 9 & United Kingdom & 3.4 & 3 \\
\hline
\end{tabular}

Source: OECD, DAC-CRS Aid Activities Database

AfT DISBURSEMENTS BY SECTOR (million current USD)

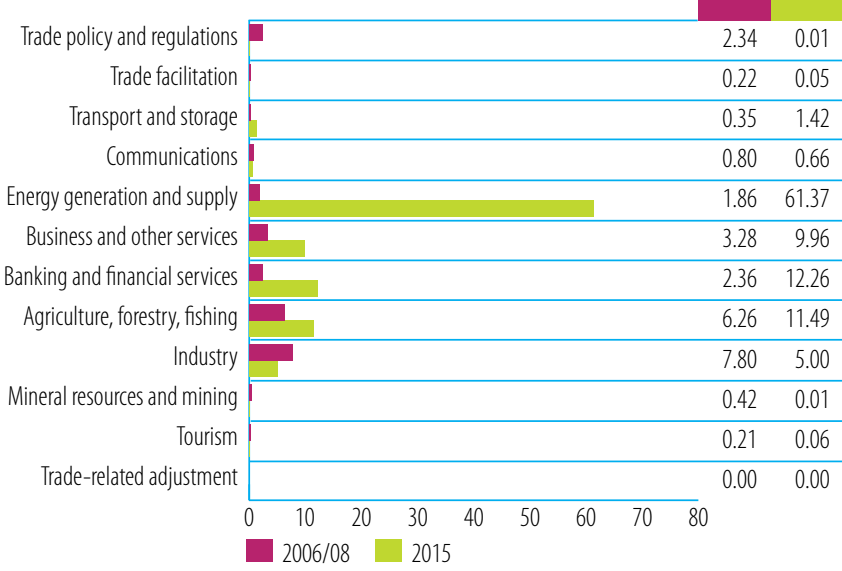

Source: OECD, DAC-CRS Aid Activities Database

\section{B. TRADE COSTS}

\begin{tabular}{lrc} 
INDICATOR & $\mathbf{2 0 0 6}$ & $\mathbf{2 0 1 5}$ \\
Tariffs (\%) & & \\
\hline Imports: simple avg. MFN applied & 14.0 & 7.1 \\
\hline Imports: weighted avg. MFN applied (2005-2014) & 12 & 4.7 \\
\hline Exports: weighted avg. faced (2005-2014) & 0.2 & 0.3 \\
\hline Exports: duty free (value in \%) (2005-2014) & 98.6 & 98.0 \\
\hline ICT connectivity (\% of population) & & \\
\hline Mobile broadband subscriptions (2008-2015) & 0.0 & 50.4 \\
\hline Fixed broadband subscriptions & 2.7 & 11.6 \\
\hline Individuals using the internet & 19.5 & 57.4 \\
\hline Sources: WTO, World Tariff Profiles; ITU, World Telecommunication/ICT Indicators &
\end{tabular}
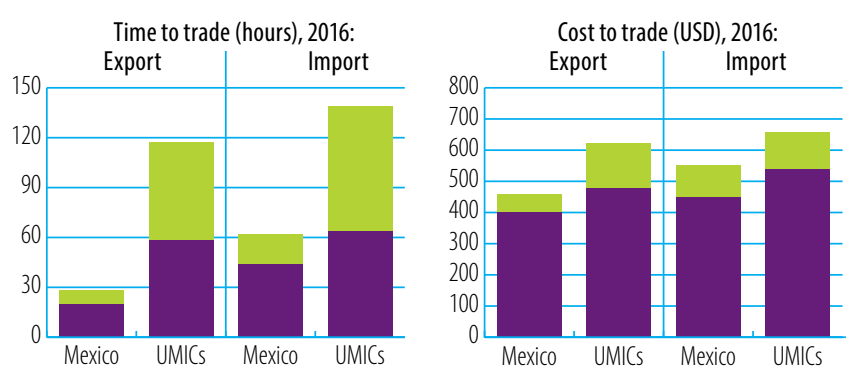

- Border compliance Documentary compliance Source: WB, Doing Business

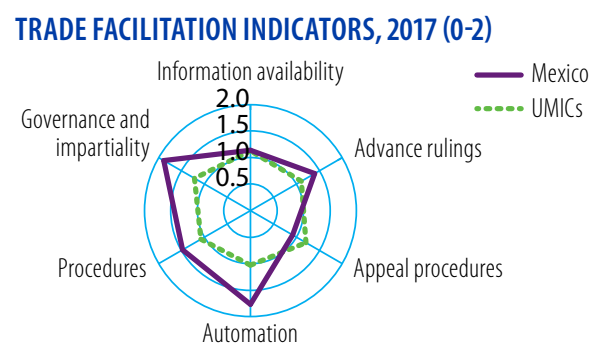

GLOBAL COMPETITIVENESS INDICATORS (1-7)

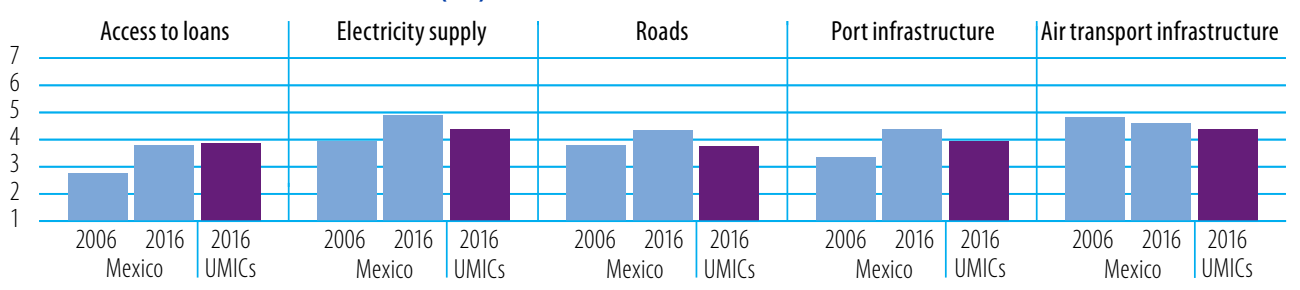

Source: WEF Global Competitiveness Index
Source: OECD Trade Facilitation Indicators

Source: WB Logistics Performance Index (LPI)

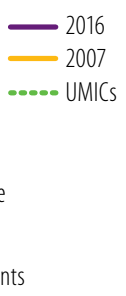

LOGISTICS PERFORMANCE INDICES (LPI) (1-5)

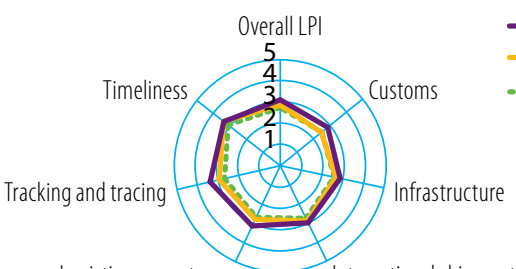

Logistics competence International shipment

Mexico 1 UMICs
TRADE COSTS (ad-valorem, \%)

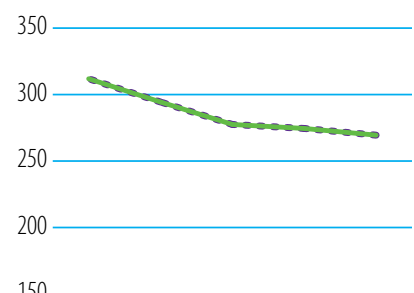

150

100

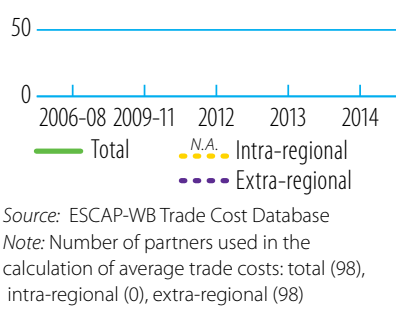




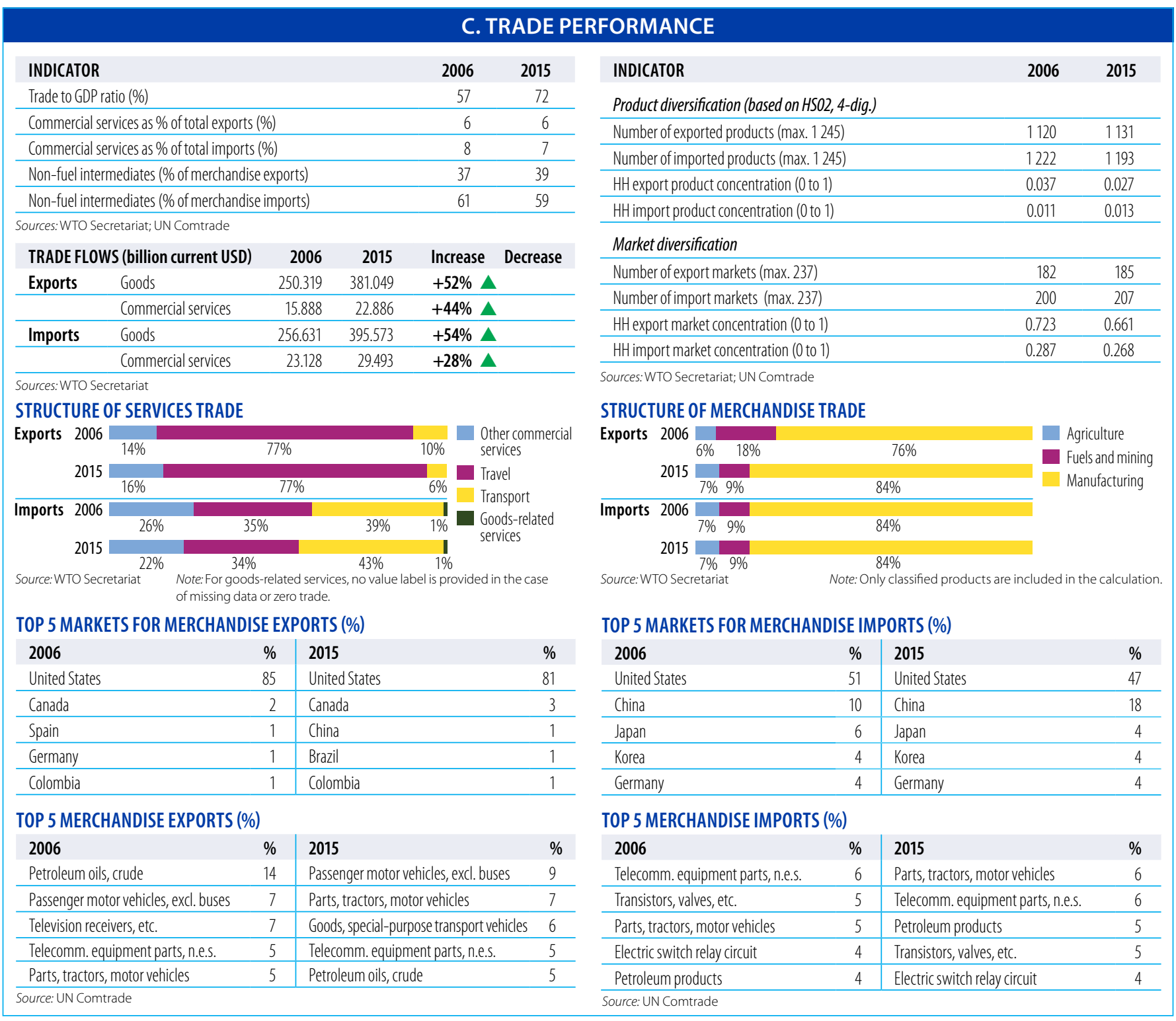

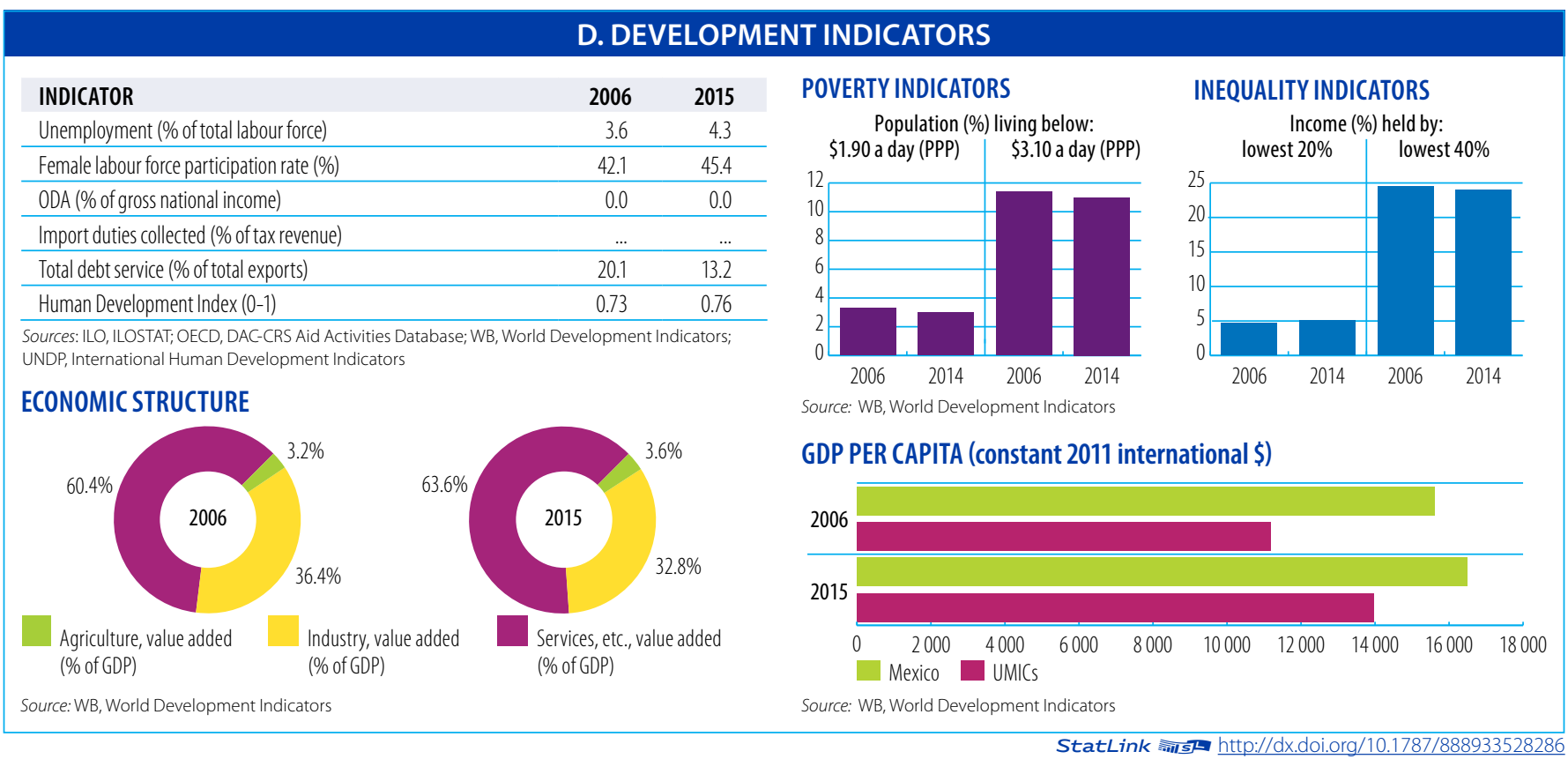


Aid, Trade and Development Indicators for Myanmar

\section{A. DEVELOPMENT FINANCE}

\begin{tabular}{lrrrc}
$\begin{array}{l}\text { EXTERNAL FINANCING INFLOWS } \\
\text { (million current USD) }\end{array}$ & $\mathbf{2 0 0 6 / 0 8}$ & $\mathbf{2 0 1 2 / 1 4}$ & $\mathbf{2 0 1 5}$ & $\mathbf{\Delta : 0 6 / 0 8 - 1 5}$ \\
\hline FDl inflows & 443.3 & 675.8 & 2824.0 & $537 \%$ \\
\hline Remittances & 83.6 & 732.5 & 386.8 & $362 \%$ \\
\hline Other official flows (00F) & 0.9 & 369.4 & 66.7 & $7489 \%$ \\
\hline$\quad$ of which trade-related 00F & 0.0 & 4.9 & 2.4 & - \\
\hline Official Development Assistance (ODA) & 286.3 & 3423.2 & 1222.8 & $327 \%$ \\
\hline$\quad$ of which Aid for Trade & 16.1 & 190.7 & 319.3 & $1887 \%$ \\
\hline
\end{tabular}

Sources: UNCTAD, UNCTADstat; WB, World Development Indicators; OECD,

DAC-CRS Aid Activities Database

\section{TOP 3 AfT PRIORITIES}

\begin{tabular}{|l|l|l|l|l|l|}
\hline 1 & Trade policy & $\mathbf{2}$ & Trade facilitation & $\mathbf{3}$ & Export diversification \\
\hline
\end{tabular}

Source: OECD/WTO Partner Questionnaire

SHARE OF AfT IN DEVELOPMENT FINANCE AND FIXED CAPITAL FORMATION (\%)

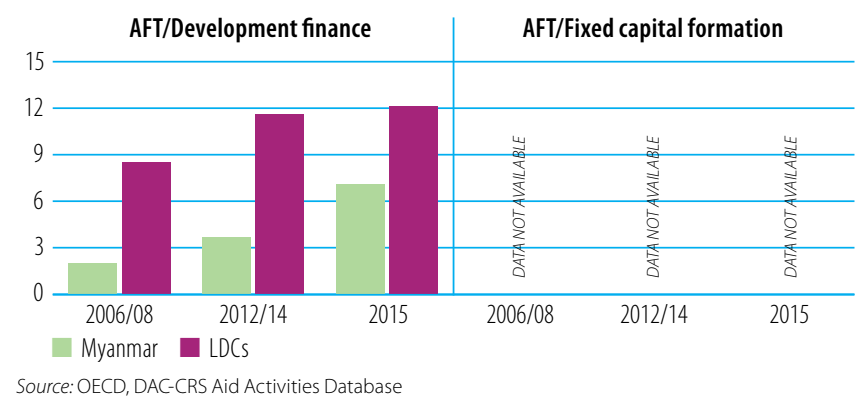

AfT DISBURSEMENTS: TOP DONORS (million current USD)

\begin{tabular}{lrr|lrc}
$\mathbf{2 0 0 6 / 0 8}$ & value & $\%$ & $\mathbf{2 0 1 5}$ & value & $\%$ \\
Japan & 8.0 & 49 & Japan & 179.7 & 56 \\
\hline Korea & 1.8 & 11 & United Kingdom & 60.7 & 19 \\
\hline UNDP & 1.5 & 10 & United States & 12.8 & 4 \\
\hline Australia & 1.4 & 9 & Australia & 10.8 & 3 \\
\hline Italy & 1.2 & 8 & Korea & 10.0 & 3 \\
\hline
\end{tabular}

Source: OECD, DAC-CRS Aid Activities Database

AfT DISBURSEMENTS BY SECTOR (million current USD)

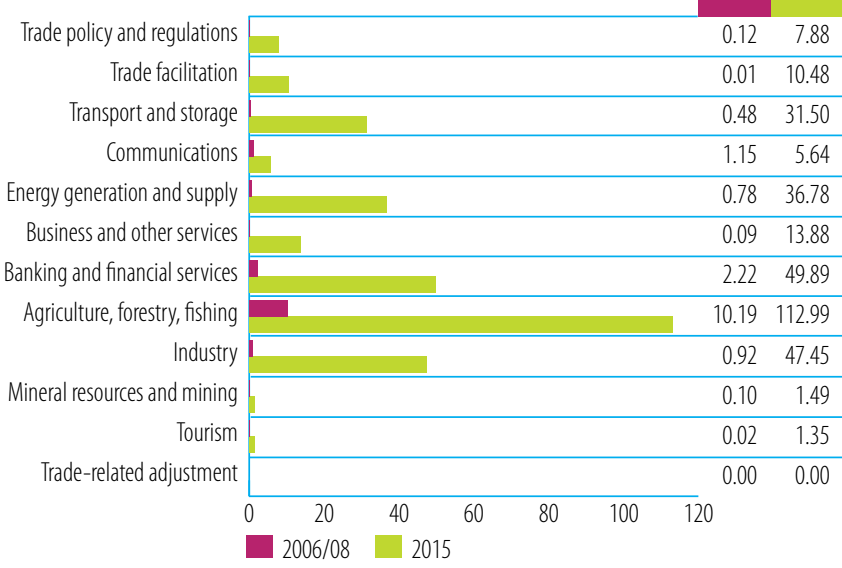

Source: OECD, DAC-CRS Aid Activities Database

\section{B. TRADE COSTS}

\begin{tabular}{lcc} 
INDICATOR & 2006 & $\mathbf{2 0 1 5}$ \\
Tariffs (\%) & & \\
\hline Imports: simple avg. MFN applied & 5.6 & 5.6 \\
\hline Imports: weighted avg. MFN applied & $\ldots .1$ & $\ldots .6$ \\
\hline Exports: weighted avg. faced (2005-2014) & 16.7 & 94.1 \\
\hline Exports: duty free (value in \%) (2005-2014) & & \\
\hline ICT connectivity (\% of population) & 0.0 & 29.5 \\
\hline Mobile broadband subscriptions (2008-2015) & 0.0 & 0.3 \\
\hline Fixed broadband subscriptions & 0.2 & 21.8 \\
\hline Individuals using the internet & &
\end{tabular}
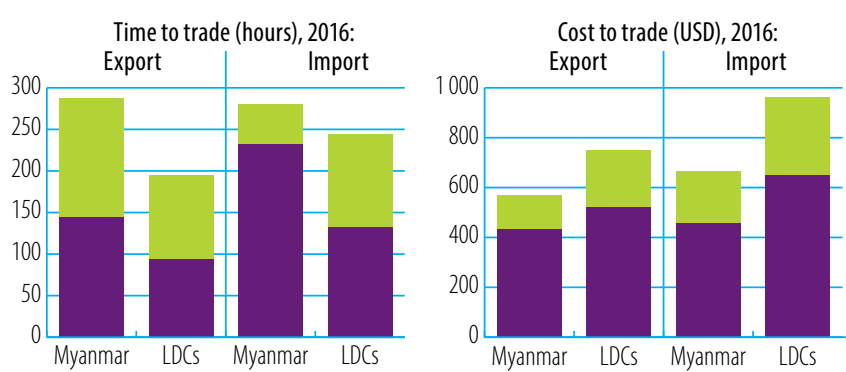

Border compliance Documentary compliance

Source: WB, Doing Business

TRADE FACILITATION INDICATORS, 2017 (0-2)

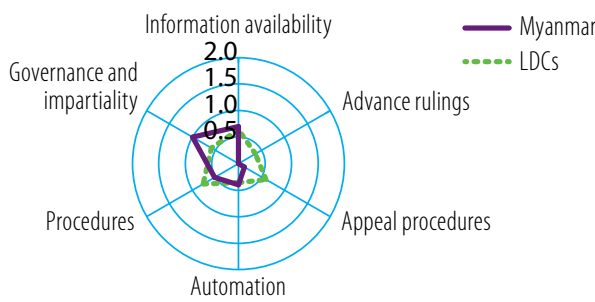

TRADE COSTS (ad-valorem, \%)
LOGISTICS PERFORMANCE INDICES (LPI) (1-5)

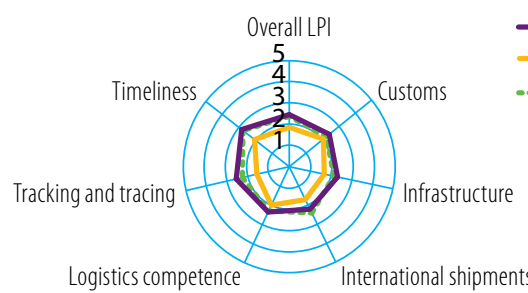

Source: WB Logistics Performance Index (LPI)

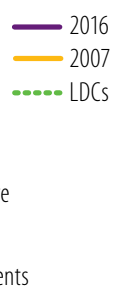

GLOBAL COMPETITIVENESS INDICATORS (1-7)

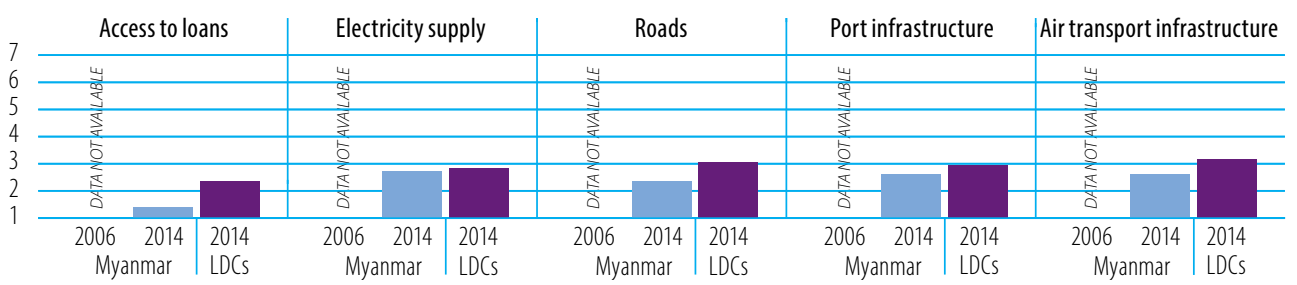

Source: OECD Trade Facilitation Indicators

2006-08 2009-11 $2012 \quad 2013 \quad 2014$ Total $\quad \ldots .$. Intra-regional .... Extra-regiona

Source: ESCAP-WB Trade Cost Database Note: Number of partners used in the calculation of average trade costs: total (0) intra-regional (0), extra-regional (0) 


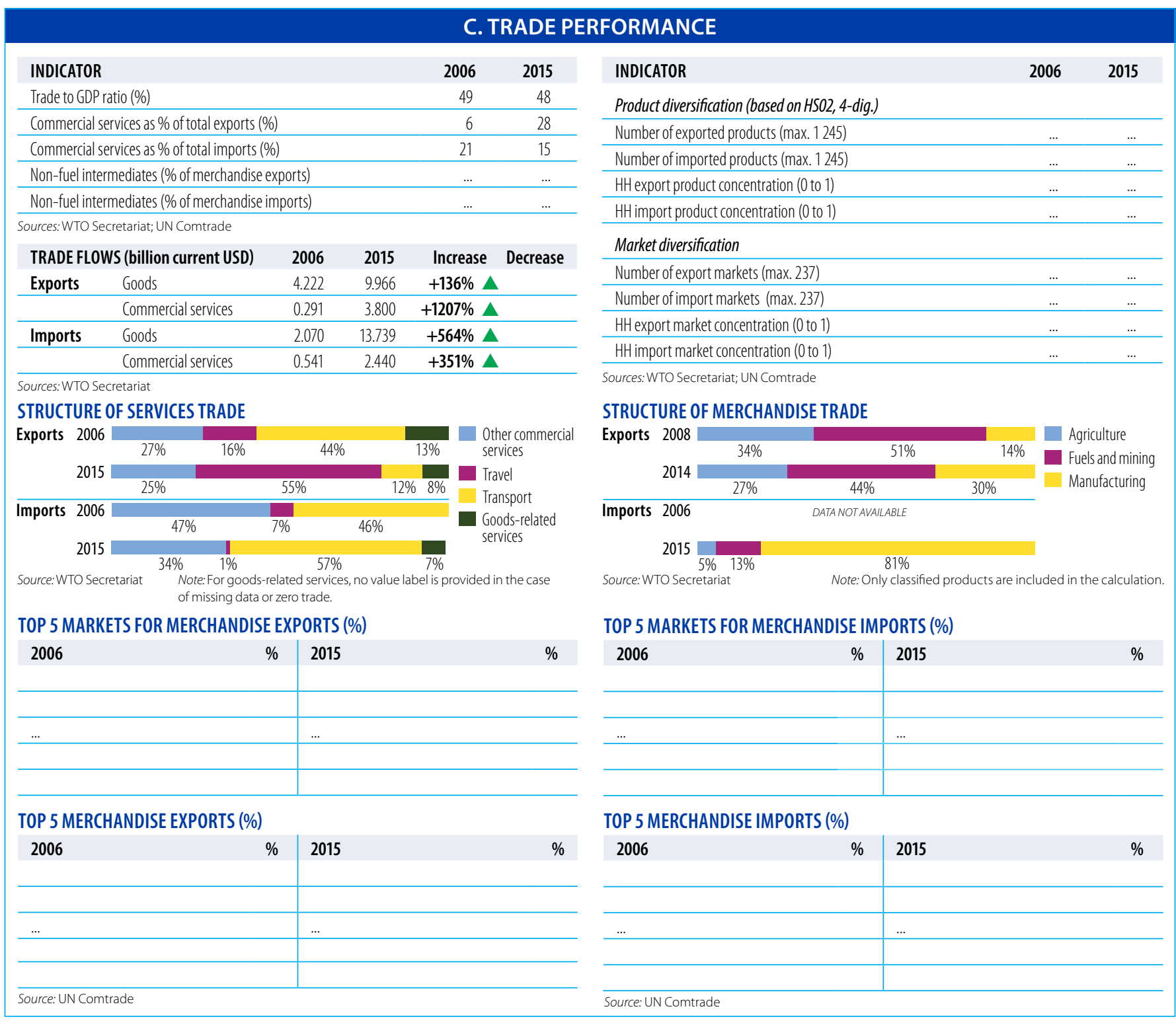

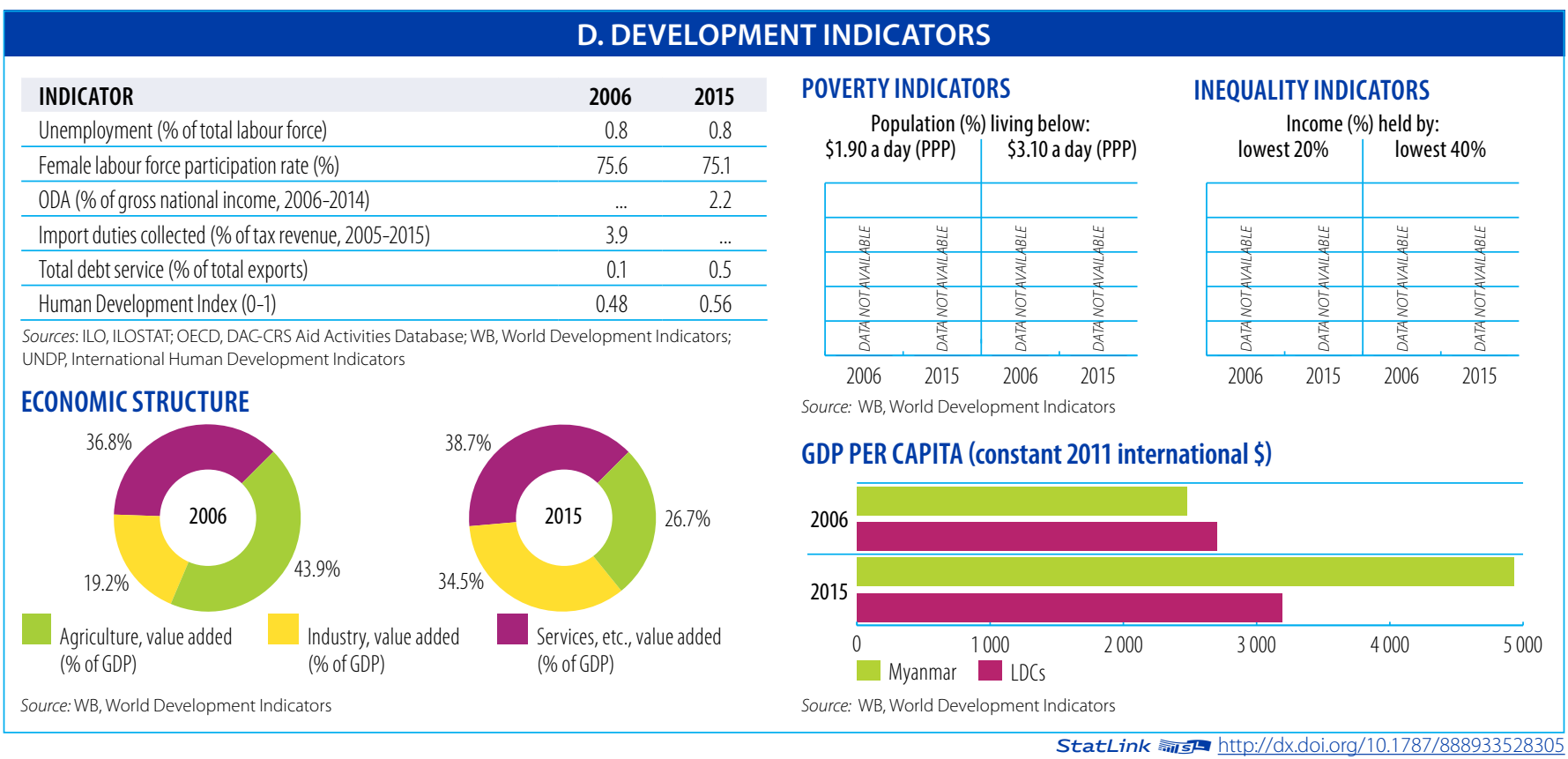


Aid, Trade and Development Indicators for Namibia

\section{A. DEVELOPMENT FINANCE}

\begin{tabular}{lrrrc}
$\begin{array}{l}\text { EXTERNAL FINANCING INFL OWS } \\
\text { (million current USD) }\end{array}$ & $\mathbf{2 0 0 6 / 0 8}$ & $\mathbf{2 0 1 2 / 1 4}$ & $\mathbf{2 0 1 5}$ & $\mathbf{\Delta : 0 6 / 0 8 - 1 5}$ \\
\hline FDl inflows & 613.3 & 788.6 & 1077.8 & $76 \%$ \\
\hline Remittances & 15.2 & 11.7 & 8.7 & $-43 \%$ \\
\hline Other official flows (O0F) & 23.3 & 27.0 & 92.5 & $296 \%$ \\
\hline of which trade-related 00F & 20.8 & 27.0 & 92.5 & $344 \%$ \\
\hline Official Development Assistance (ODA) & 192.8 & 289.5 & 180.4 & $-6 \%$ \\
\hline of which Aid for Trade & 30.1 & 59.2 & 51.0 & $69 \%$ \\
\hline
\end{tabular}

Sources: UNCTAD, UNCTADstat; WB, World Development Indicators; OECD,

DAC-CRS Aid Activities Database

\section{TOP 3 AfT PRIORITIES}

\begin{tabular}{|c|c|c|c|c|c|}
\hline 1 & Industrialization & 2 & Trade policy & 3 & Trade facilitation \\
\hline
\end{tabular}

SHARE OF AfT IN DEVELOPMENT FINANCE AND FIXED CAPITAL FORMATION (\%)

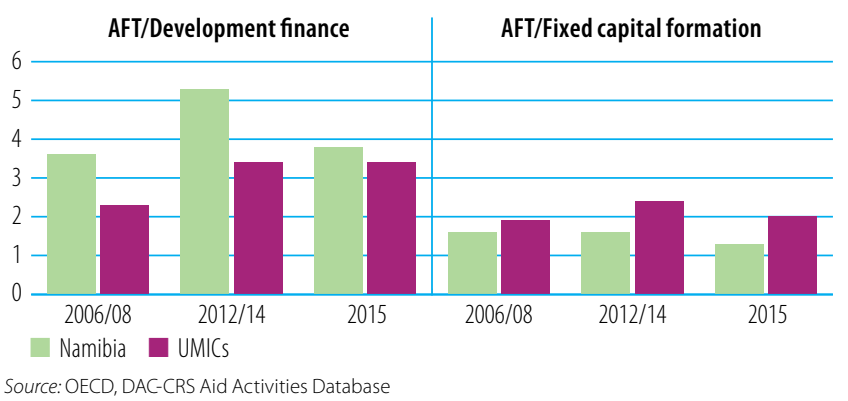

AfT DISBURSEMENTS: TOP DONORS (million current USD)

\begin{tabular}{lrr|lrc}
$\mathbf{2 0 0 6 / 0 8}$ & value & $\%$ & $\mathbf{2 0 1 5}$ & value & $\%$ \\
Germany & 10.3 & 34 & Germany & 42.3 & 83 \\
\hline Spain & 6.5 & 21 & Japan & 2.1 & 4 \\
\hline Japan & 4.2 & 14 & Finland & 1.8 & 4 \\
\hline Norway & 2.7 & 9 & United States & 1.8 & 3 \\
\hline Global Environment Facility & 1.5 & 5 & Global Environment Facility & 1.2 & 2 \\
\hline Source: OECD, DAC-CRS Aid Activities Database & & &
\end{tabular}

AfT DISBURSEMENTS BY SECTOR (million current USD)

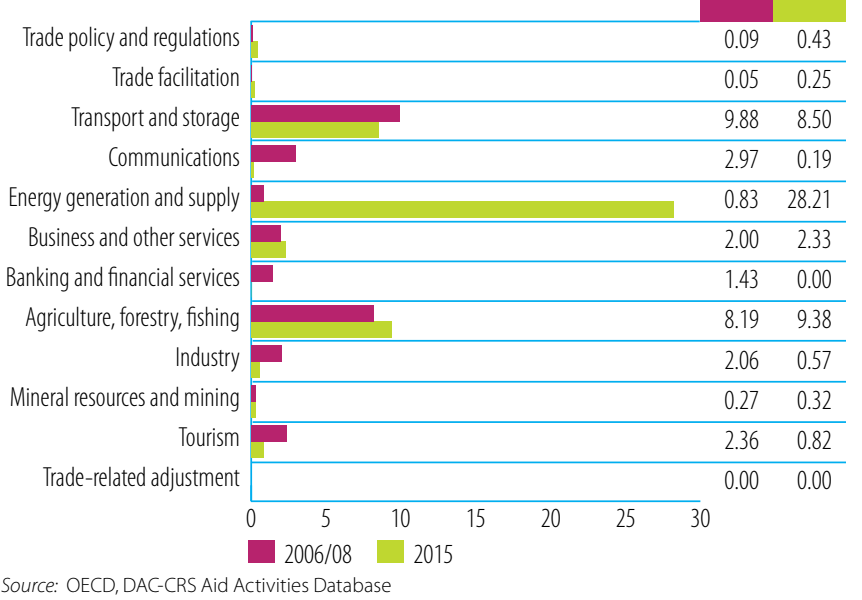

\section{B. TRADE COSTS}

\begin{tabular}{lcc} 
INDICATOR & $\mathbf{2 0 0 6}$ & $\mathbf{2 0 1 5}$ \\
Tariffs (\%) & & \\
\hline Imports: simple avg. MFN applied & 8.0 & 7.6 \\
\hline Imports: weighted avg. MFN applied (2006-2014) & $\ldots$ & 7.5 \\
\hline Exports: weighted avg. faced (2005-2014) & 2.7 & 1.1 \\
\hline Exports: duty free (value in \%) (2005-2014) & 90.5 & 94.0 \\
\hline ICT connectivity (\% of population) & $\ldots$ & \\
\hline Mobile broadband subscriptions & $\ldots .0$ & 1.7 \\
\hline Fixed broadband subscriptions & 4.4 & 22.3 \\
\hline Individuals using the internet & &
\end{tabular}
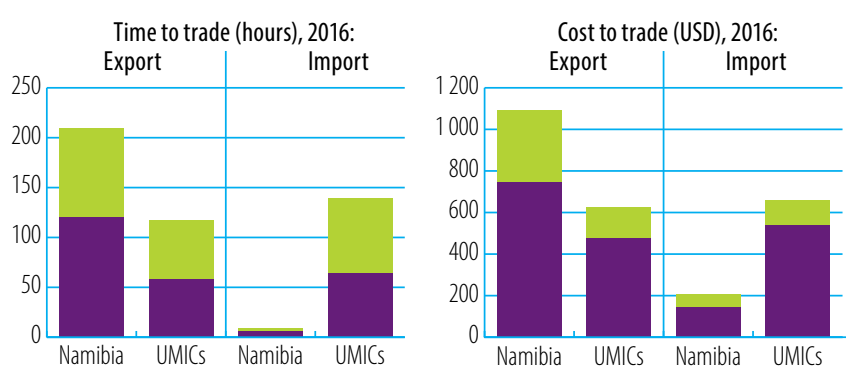

Border compliance Documentary compliance Source: WB, Doing Business

\section{LOGISTICS PERFORMANCE INDICES (LPI) (1-5)}

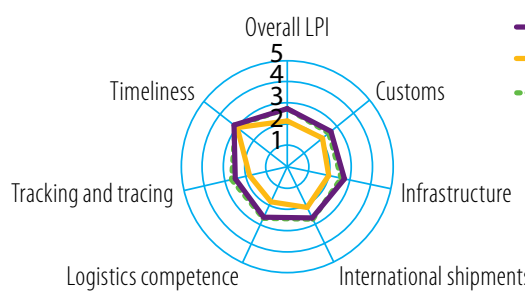

Logistics competence

$$
\text { International shipments }
$$

Source: WB Logistics Performance Index (LPI)

TRADE FACILITATION INDICATORS, 2017 (0-2)

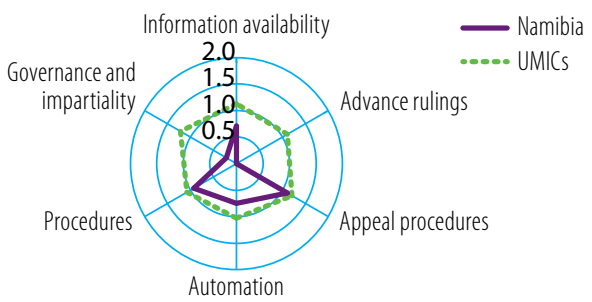

Source: OECD Trade Facilitation Indicators
TRADE COSTS (ad-valorem, \%)

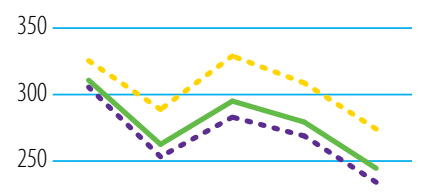

200

150

100

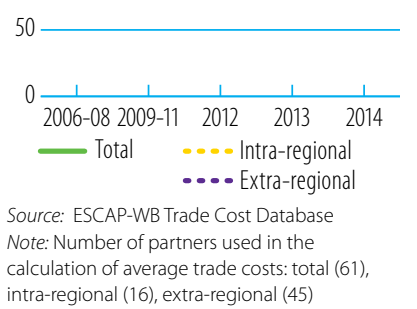

GLOBAL COMPETITIVENESS INDICATORS (1-7)

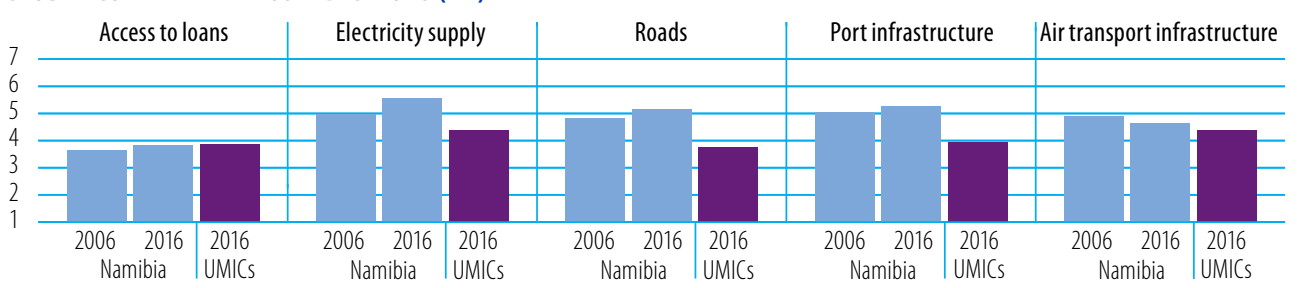

Source: WEF Global Competitiveness Index 


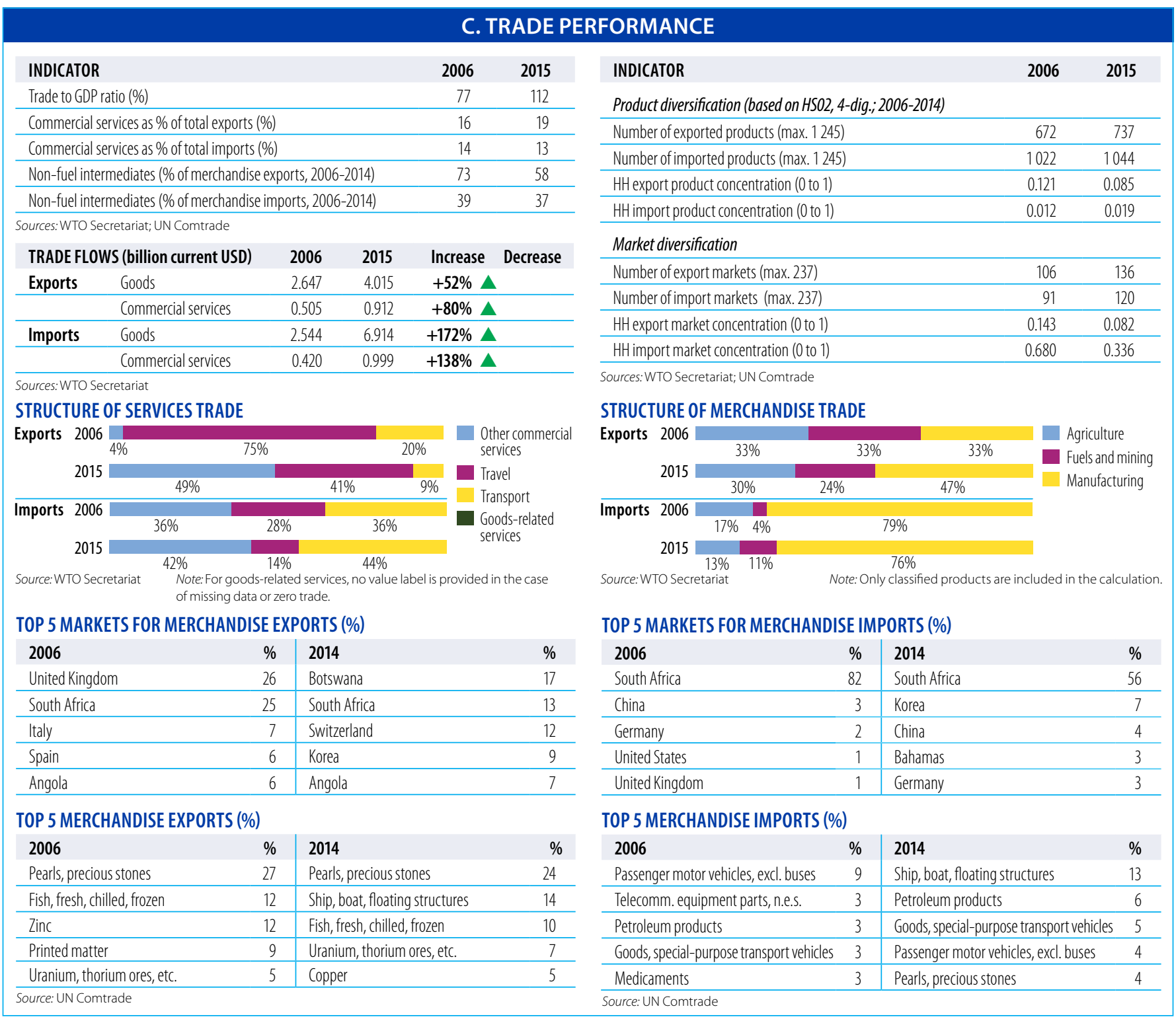

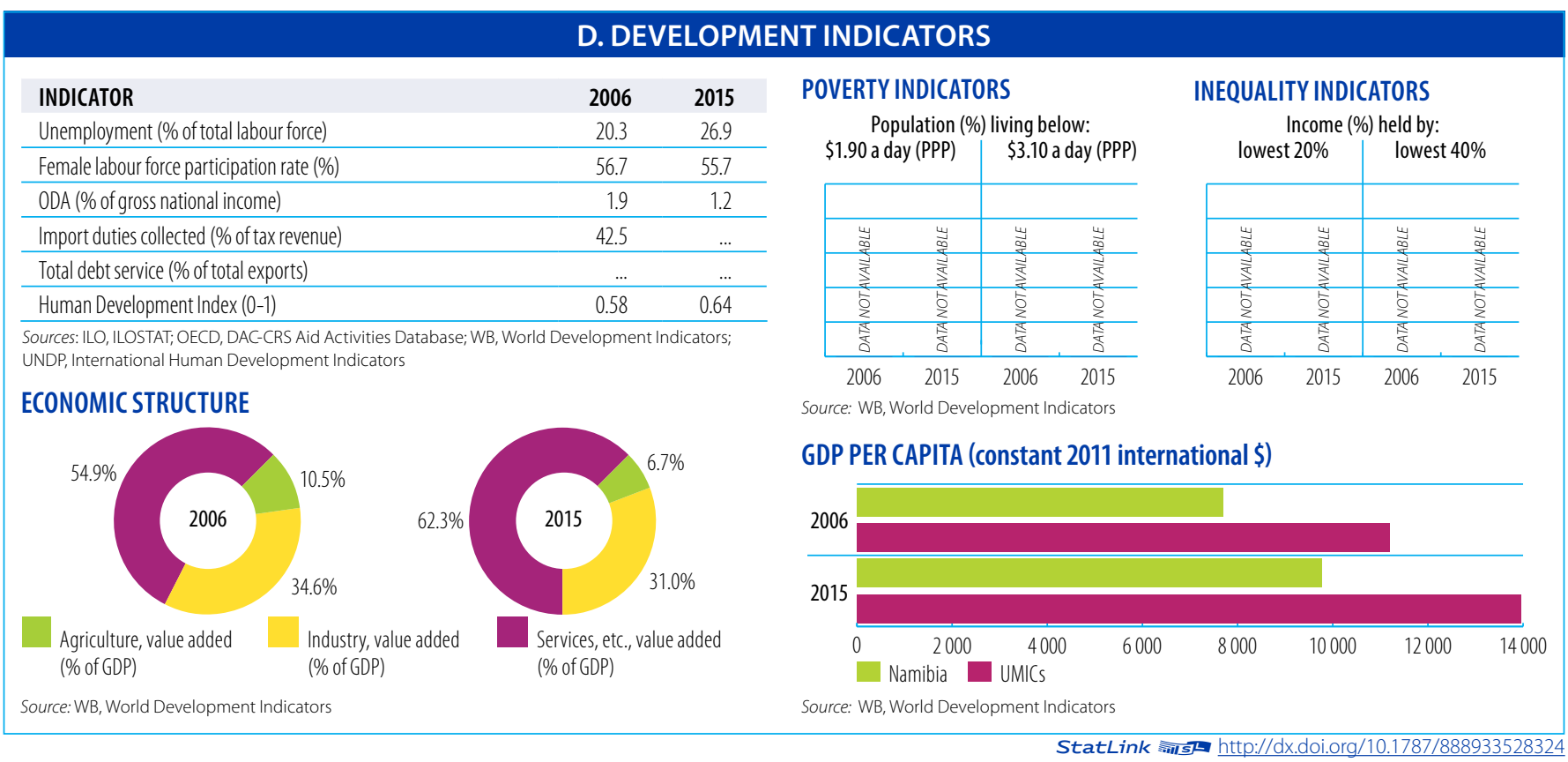


Aid, Trade and Development Indicators for Nepal

\section{A. DEVELOPMENT FINANCE}

\begin{tabular}{|c|c|c|c|c|c|c|}
\hline \multicolumn{2}{|r|}{$\begin{array}{l}\text { EXTERNAL FINANCING INFLOWS } \\
\text { (million current USD) }\end{array}$} & $2006 / 08$ & 2012/14 & & 015 & $\Delta: 06 / 08-15$ \\
\hline \multicolumn{2}{|r|}{ FDl inflows } & 0.1 & 64.3 & & 51.4 & $60932 \%$ \\
\hline \multicolumn{2}{|c|}{ Remittances } & 1971.4 & 5423.7 & 672 & 29.9 & $241 \%$ \\
\hline \multicolumn{2}{|c|}{ Other official flows (OOF) } & 0.4 & 0.4 & & 0.2 & $-40 \%$ \\
\hline \multicolumn{2}{|r|}{ of which trade-related 00F } & 0.0 & 0.0 & & 0.0 & - \\
\hline \multicolumn{2}{|r|}{ Official Development Assistance (ODA) } & 589.0 & 1001.6 & 135 & 55.8 & $130 \%$ \\
\hline \multicolumn{2}{|r|}{ of which Aid for Trade } & 125.3 & 305.2 & & 97.9 & $217 \%$ \\
\hline \multicolumn{7}{|c|}{$\begin{array}{l}\text { Sources: UNCTAD, UNCTADstat; WB, World Development Indicators; OECD, } \\
\text { DAC-CRS Aid Activities Database }\end{array}$} \\
\hline \multicolumn{7}{|c|}{ TOP 3 AfT PRIORITIES } \\
\hline & Export diversification & \multicolumn{2}{|c|}{ Industrialization } & \multicolumn{3}{|c|}{3 Trade policy } \\
\hline
\end{tabular}

SHARE OF AfT IN DEVELOPMENT FINANCE AND FIXED CAPITAL FORMATION (\%)

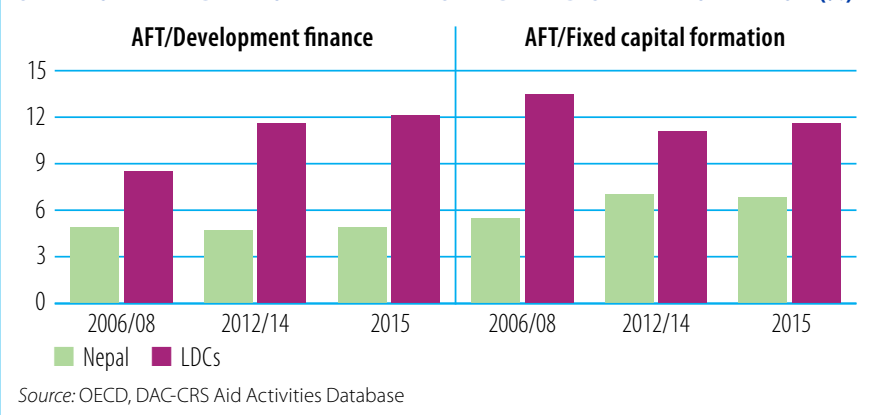

AfT DISBURSEMENTS: TOP DONORS (million current USD)

\begin{tabular}{lrr|lrr}
$\mathbf{2 0 0 6 / 0 8}$ & value & $\%$ & $\mathbf{2 0 1 5}$ & value & $\%$ \\
IDA & 31.1 & 25 & IDA & 188.3 & 47 \\
\hline United Kingdom & 24.6 & 20 & AsDB Special Funds & 79.5 & 20 \\
\hline Germany & 21.4 & 17 & United Kingdom & 26.9 & 7 \\
\hline Japan & 16.4 & 13 & Switzerland & 21.3 & 5 \\
\hline Norway & 10.4 & 8 & Norway & 17.0 & 4 \\
\hline
\end{tabular}

Source: OECD, DAC-CRS Aid Activities Database

AfT DISBURSEMENTS BY SECTOR (million current USD)

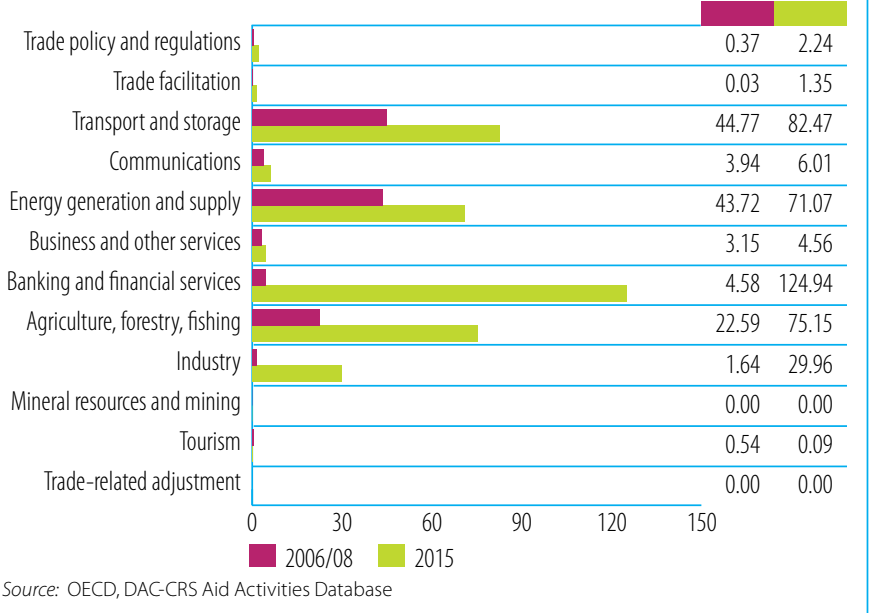

\section{B. TRADE COSTS}

\begin{tabular}{lcc} 
INDICATOR & 2006 & 2015 \\
Tariffs (\%) & & \\
\hline Imports: simple avg. MFN applied (2005-2015) & 13.9 & 12.3 \\
\hline Imports: weighted avg. MFN applied (2006-2014) & $\ldots$ & 12.7 \\
\hline Exports: weighted avg. faced (2005-2014) & 11.8 & 0.3 \\
\hline Exports: duty free (value in \%) (2005-2014) & 37.8 & 97.2 \\
\hline ICT connectivity (\% of population) & $\ldots$ & \\
\hline Mobile broadband subscriptions & $\ldots .0$ & 1.1 \\
\hline Fixed broadband subscriptions & 0.0 & 1.1 \\
\hline Individuals using the internet & 17.6 \\
\hline Sources: WTO, World Tariff Profiles; ITU, World Telecommunication/ICT Indicators &
\end{tabular}
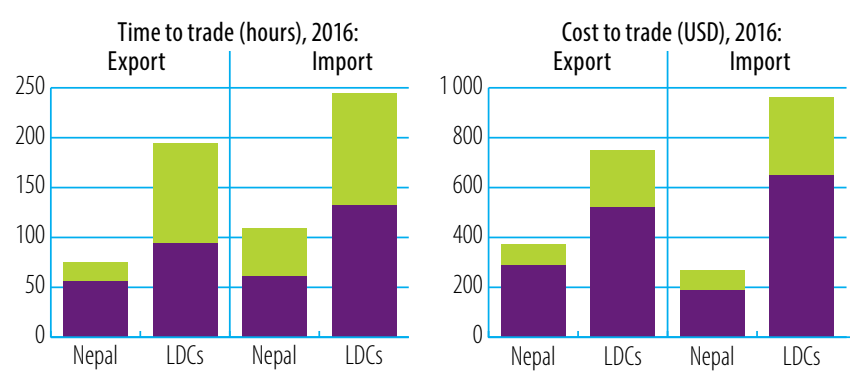

Border compliance Documentary compliance Source: WB, Doing Business

TRADE FACILITATION INDICATORS, 2017 (0-2)

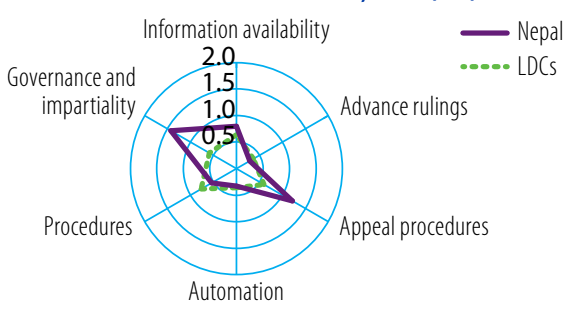

Source: OECD Trade Facilitation Indicators

TRADE COSTS (ad-valorem, \%)

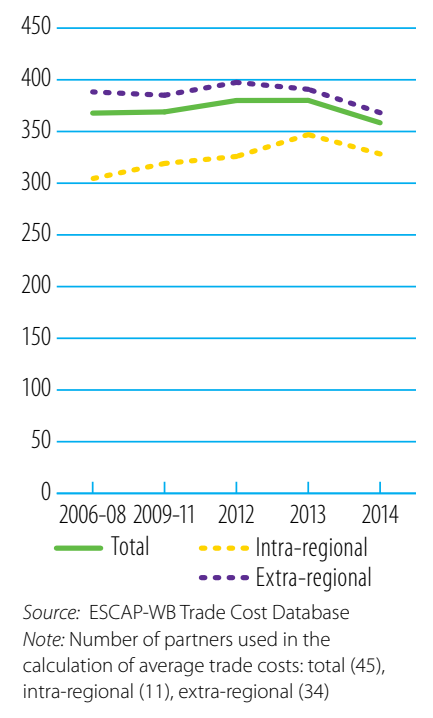




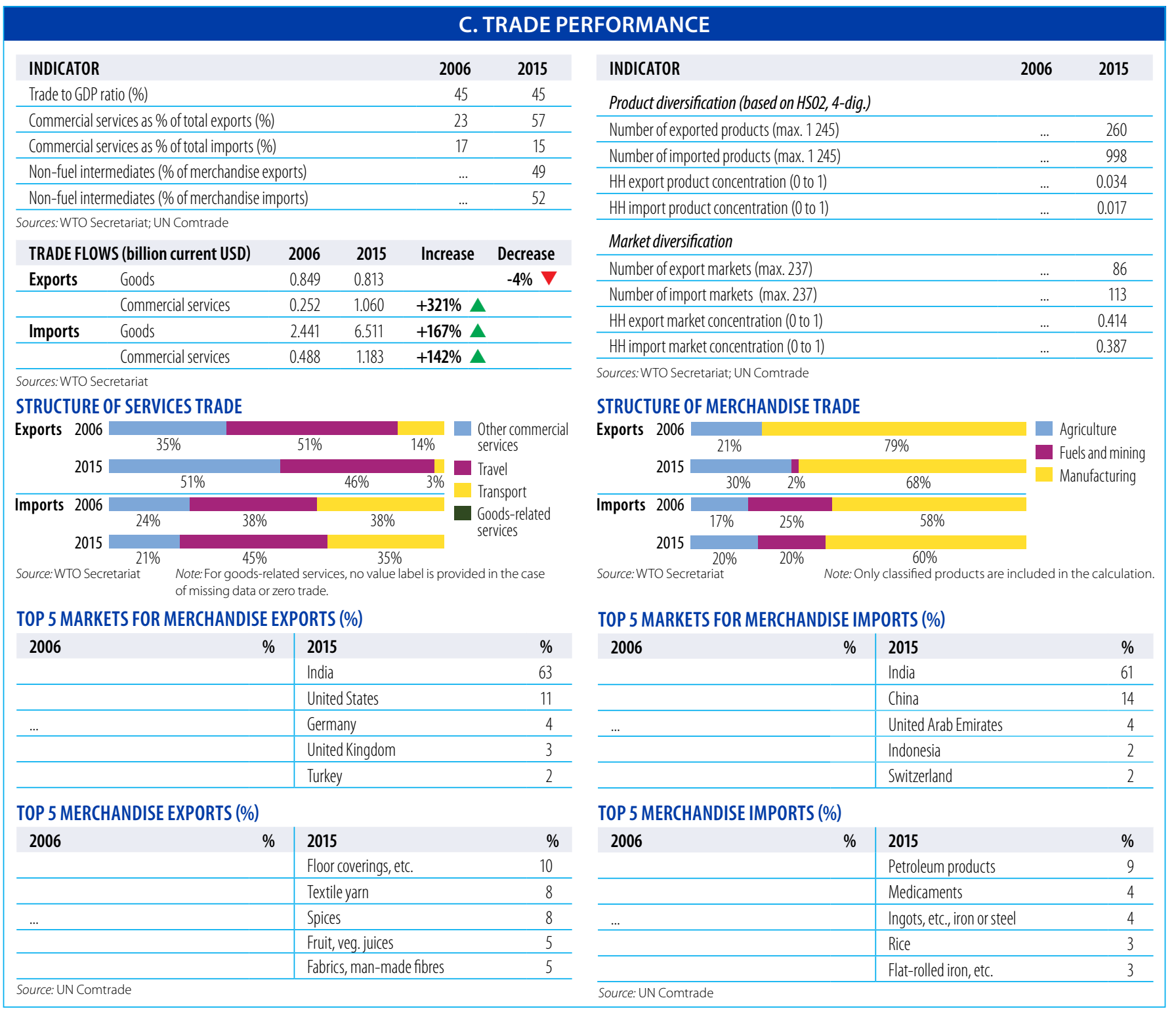

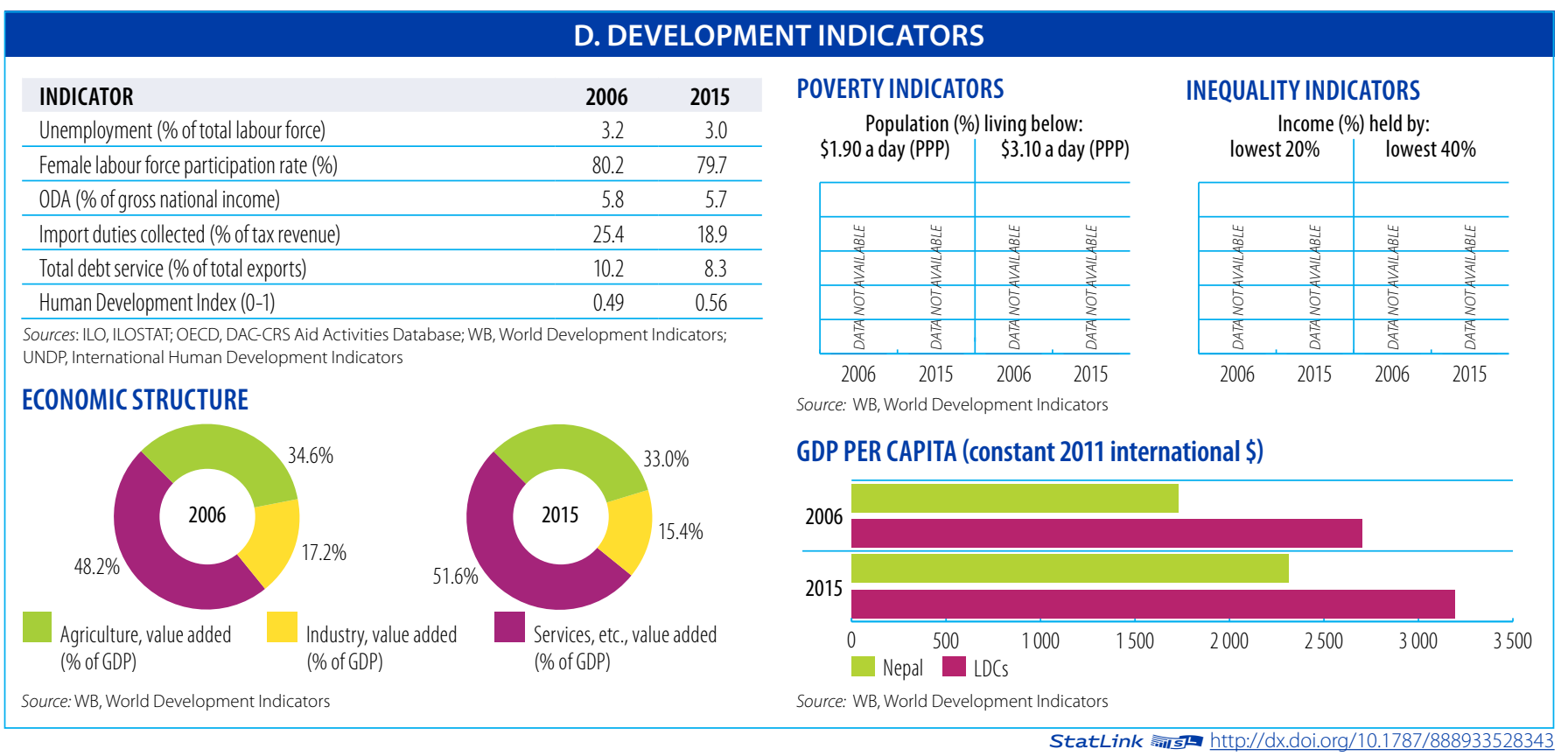


Aid, Trade and Development Indicators for Niger

\section{A. DEVELOPMENT FINANCE}

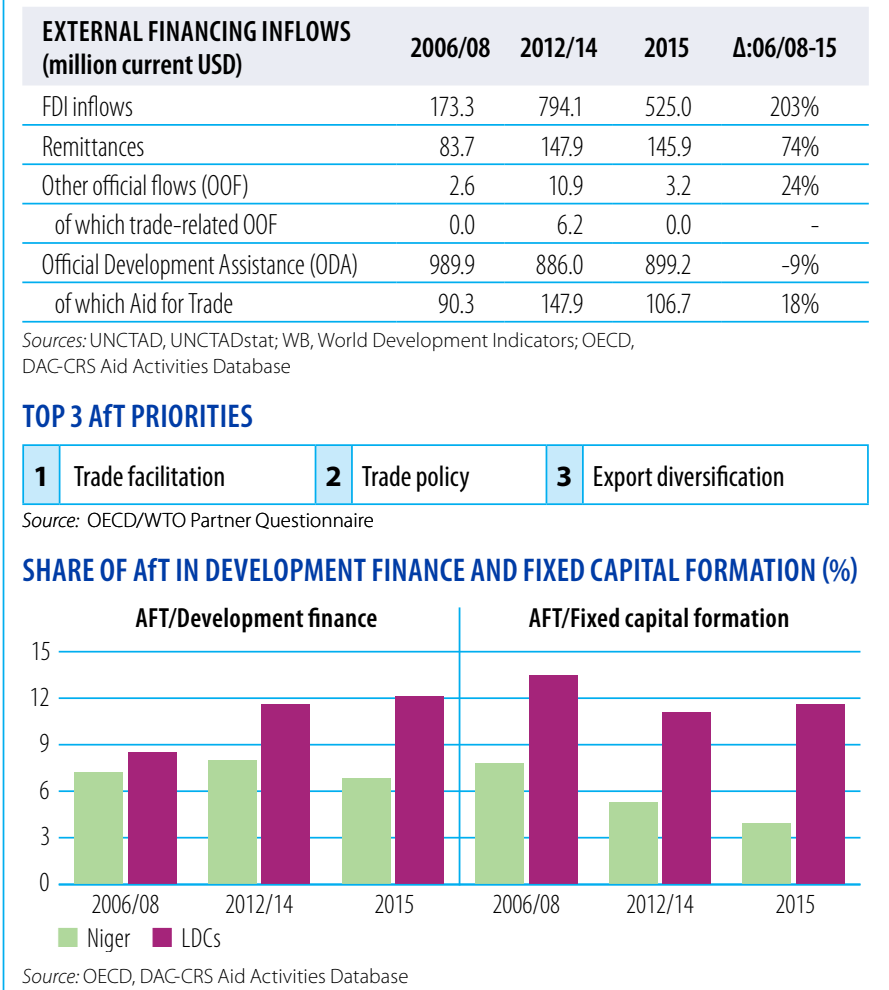

AfT DISBURSEMENTS: TOP DONORS (million current USD)

\begin{tabular}{lrr|lrr}
$\mathbf{2 0 0 6 / 0 8}$ & value & $\%$ & $\mathbf{2 0 1 5}$ & value & $\%$ \\
EU Institutions & 48.8 & 54 & IDA & 32.0 & 30 \\
\hline IDA & 16.0 & 18 & EU Institutions & 22.5 & 21 \\
\hline African Development Fund & 6.6 & 7 & United States & 10.0 & 9 \\
\hline France & 5.0 & 6 & African Development Fund & 9.2 & 9 \\
\hline Japan & 3.3 & 4 & Switzerland & 6.5 & 6 \\
\hline Source: OECD DAC-CRS Aid Activities Database & & &
\end{tabular}

Source: OECD, DAC-CRS Aid Activities Database

AfT DISBURSEMENTS BY SECTOR (million current USD)

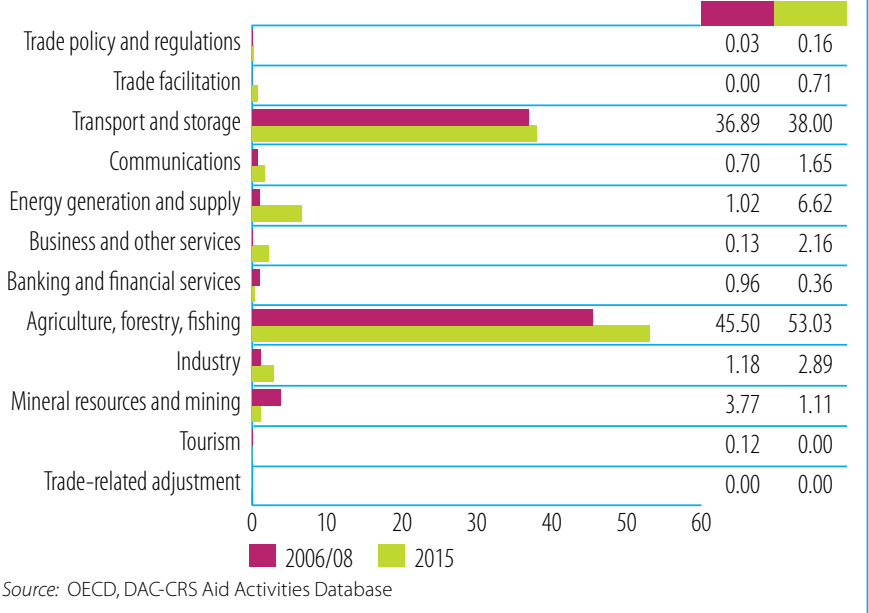

\section{B. TRADE COSTS}

\begin{tabular}{lcc} 
INDICATOR & 2006 & 2015 \\
Tariffs (\%) & & \\
\hline Imports: simple avg. MFN applied & 12.0 & 12.2 \\
\hline Imports: weighted avg. MFN applied (2006-2014) & $\ldots$. & 11.3 \\
\hline Exports: weighted avg. faced (2005-2014) & 0.0 & 4.7 \\
\hline Exports: duty free (value in \%) (2005-2014) & 99.6 & 72.4 \\
\hline ICT connectivity (\% of population) & $\ldots$ & \\
\hline Mobile broadband subscriptions & $\ldots .0$ & 0.1 \\
\hline Fixed broadband subscriptions & 0.3 & 2.2 \\
\hline Individuals using the internet & 0.3
\end{tabular}
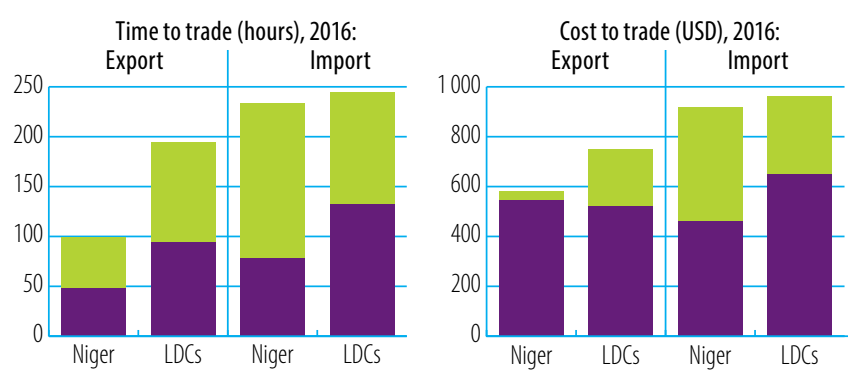

Border compliance Documentary compliance Source: WB, Doing Business

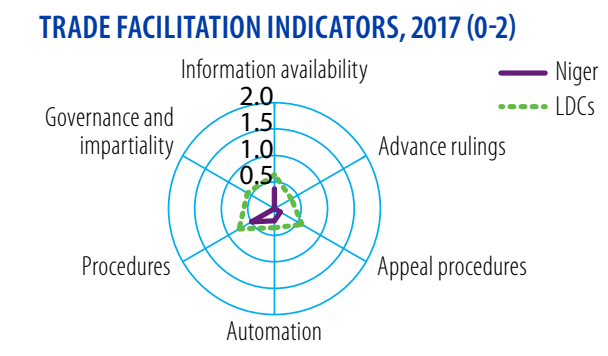

Source: OECD Trade Facilitation Indicators

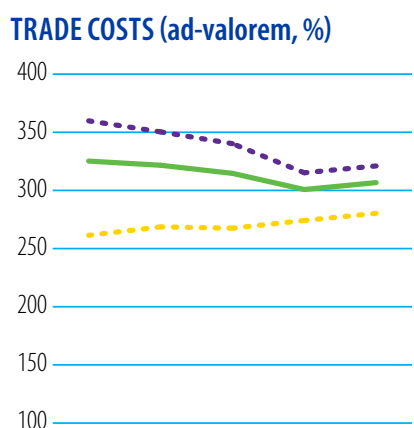

\section{GLOBAL COMPETITIVENESS INDICATORS (1-7)}

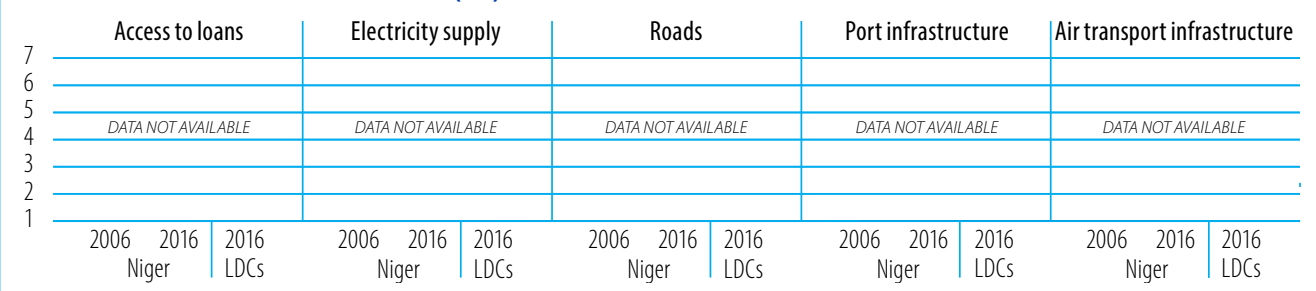

Source: WEF Global Competitiveness Index

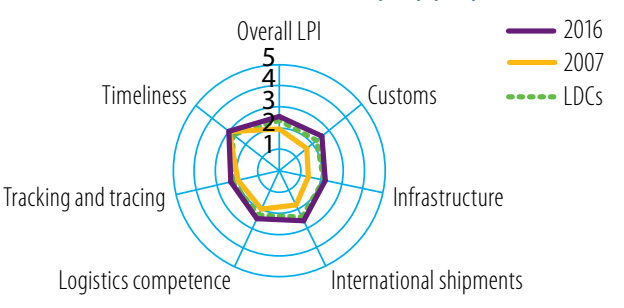

LOGISTICS PERFORMANCE INDICES (LPI) (1-5)

Source: WB Logistics Performance Index (LPI)

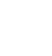




\section{TRADE PERFORMANCE}

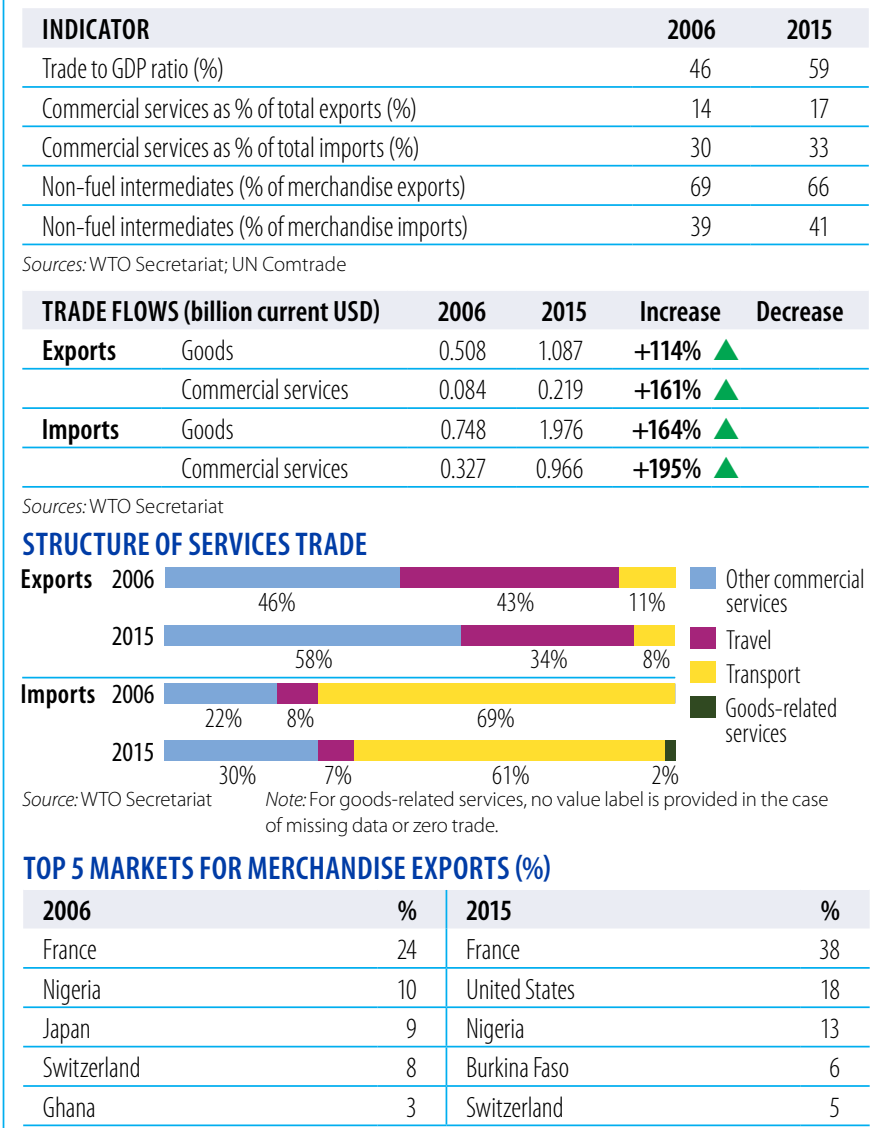

\section{TOP 5 MERCHANDISE EXPORTS (\%)}

\begin{tabular}{lc|lc}
2006 & $\%$ & 2015 & $\%$ \\
Uranium, thorium ores, etc. & 32 & Uranium, thorium ores, etc. & 51 \\
\hline Live animals & 16 & Petroleum products & 18 \\
\hline Veg. & 11 & Gold, nonmontry excl. ores & 5 \\
\hline Gold, nonmontry excl. ores & 8 & Goods, special-purpose transport vehicles & 5 \\
\hline Passenger motor vehicles, excl. buses & 6 & Fixed veg. fat, oils, other & 4 \\
\hline Source: Un Comtrade & &
\end{tabular}

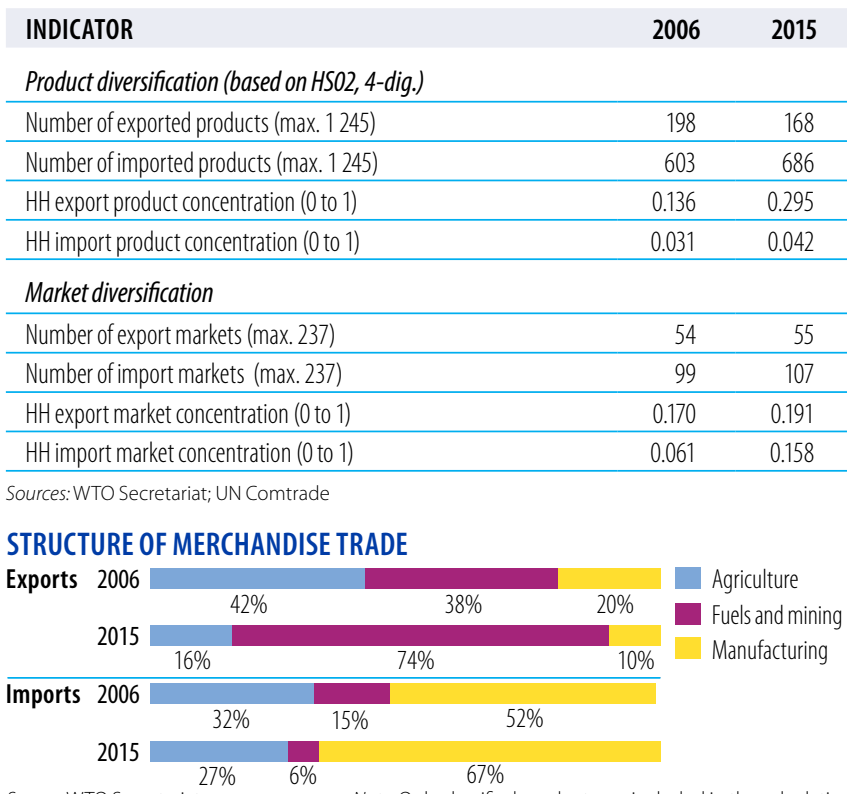

Source:WTO Secretariat Note: Only classified products are included in the calculation.

\section{TOP 5 MARKETS FOR MERCHANDISE IMPORTS (\%)}

\begin{tabular}{lc|lc}
2006 & $\%$ & 2015 & $\%$ \\
France & 15 & France & 32 \\
\hline China & 12 & China & 23 \\
\hline United States & 10 & United States & 5 \\
\hline Coted'Ivoire & 6 & India & 4 \\
\hline Nigeria & 6 & Nigeria & 4 \\
\hline
\end{tabular}

\section{TOP 5 MERCHANDISE IMPORTS (\%)}

\begin{tabular}{lc|lr}
2006 & $\%$ & 2015 & $\%$ \\
Petroleum products & 12 & Aircraft, associated equipment & 25 \\
\hline Rice & 7 & Rice & 7 \\
\hline Lime, cement, construction materials & 4 & Lime, cement, construction materials & 3 \\
\hline Worn clothing, textile articles & 4 & Petroleum products & 3 \\
\hline Civil engineering equipment & 4 & Civil engineering equipment & 3 \\
\hline Source: UN Comtrade & \multicolumn{3}{|r}{}
\end{tabular}

\begin{tabular}{lrr} 
& \multicolumn{2}{c}{ D. DEVELOPMEN } \\
\hline INDICATOR & 2006 & 2015 \\
Unemployment (\% of total labour force) & 2.9 & 2.6 \\
\hline Female labour force participation rate (\%) & 39.3 & 40.2 \\
\hline ODA (\% of gross national income) & 14.9 & 12.2 \\
\hline Import duties collected (\% of tax revenue) & $\ldots$ & $\ldots$ \\
\hline Total debt service (\% of total exports) & 26.7 & 7.5 \\
\hline Human Development Index (0-1) & 0.29 & 0.35 \\
\hline
\end{tabular}

Sources: ILO, ILOSTAT; OECD, DAC-CRS Aid Activities Database; WB, World Development Indicators; UNDP, International Human Development Indicators

\section{ECONOMIC STRUCTURE}

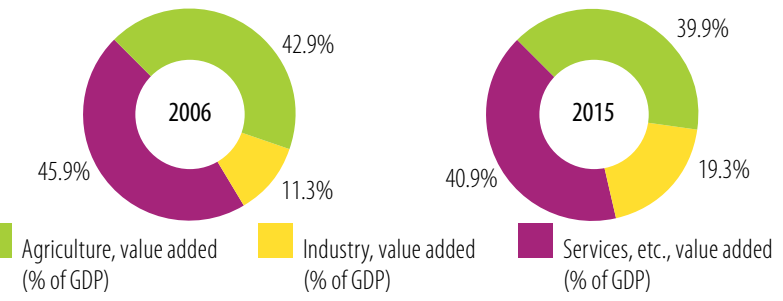

Source: WB, World Development Indicators
(\% of GDP)

\section{INEQUALITY INDICATORS}

POVERTY INDICATORS

Population (\%) living below:

$\$ 1.90$ a day (PPP) $\quad \$ 3.10$ a day (PPP)

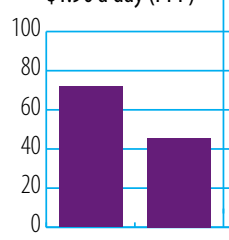

$2007 \quad 2014$

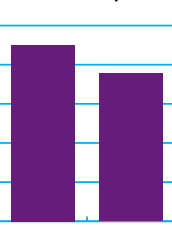

$2007 \quad 2014$

Source: WB, World Development Indicators

GDP PER CAPITA (constant 2011 international \$)

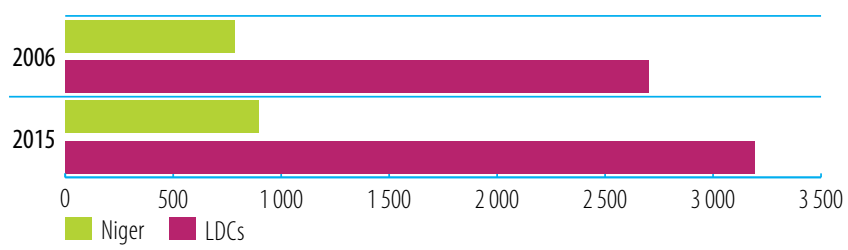

Source: WB, World Development Indicators

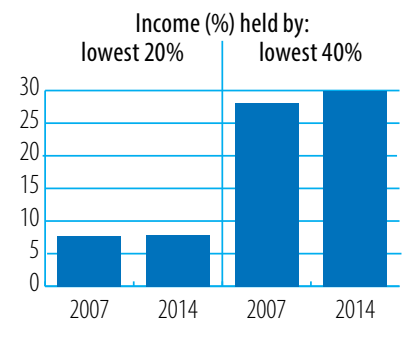


Aid, Trade and Development Indicators for Pakistan

\section{A. DEVELOPMENT FINANCE}

\begin{tabular}{lrrrc}
\hline $\begin{array}{l}\text { EXTERNAL FINANCING INFLOWS } \\
\text { (million current USD) }\end{array}$ & $\mathbf{2 0 0 6 / 0 8}$ & $\mathbf{2 0 1 2 / 1 4}$ & $\mathbf{2 0 1 5}$ & $\mathbf{\Delta : 0 6 / 0 8 - 1 5}$ \\
\hline FDl inflows & 5100.3 & 1352.3 & 864.7 & $-83 \%$ \\
\hline Remittances & 6052.7 & 15293.3 & 19306.0 & $219 \%$ \\
\hline Other official flows (OOF) & 163.7 & 785.1 & 658.4 & $302 \%$ \\
\hline of which trade-related 0OF & 138.2 & 453.5 & 445.2 & $222 \%$ \\
\hline Official Development Assistance (ODA) & 1900.7 & 3398.8 & 4359.2 & $129 \%$ \\
\hline of which Aid for Trade & 338.9 & 1153.6 & 1729.9 & $410 \%$ \\
\hline
\end{tabular}

Sources: UNCTAD, UNCTADstat; WB, World Development Indicators; OECD,

DAC-CRS Aid Activities Database

\section{TOP 3 AfT PRIORITIES}

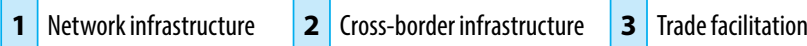
Source: OECD/WTO Partner Questionnaire

SHARE OF AfT IN DEVELOPMENT FINANCE AND FIXED CAPITAL FORMATION (\%)

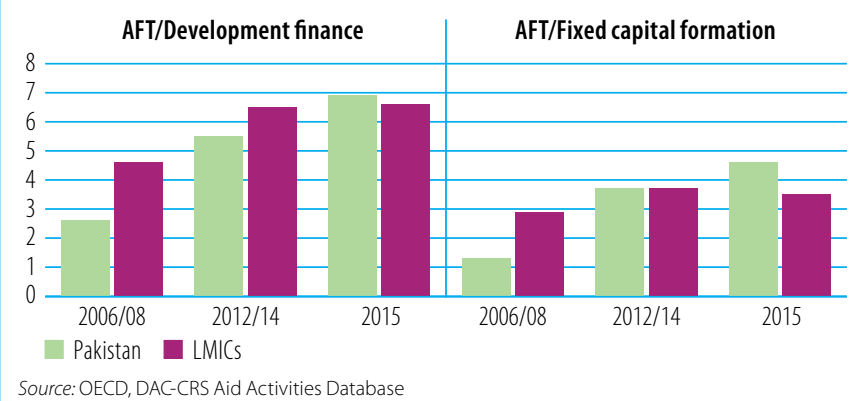

AfT DISBURSEMENTS: TOP DONORS (million current USD)

\begin{tabular}{lcc|lcc}
$\mathbf{2 0 0 6 / 0 8}$ & value & $\mathbf{\%}$ & $\mathbf{2 0 1 5}$ & value & $\%$ \\
IDA & 190.0 & 56 & IDA & 801.2 & 46 \\
\hline United States & 47.1 & 14 & AsDB Special Funds & 344.8 & 20 \\
\hline Japan & 37.3 & 11 & United States & 272.8 & 16 \\
\hline Germany & 29.6 & 9 & Japan & 140.8 & 8 \\
\hline United Kingdom & 12.5 & 4 & United Kingdom & 56.6 & 3 \\
\hline
\end{tabular}

Source: OECD, DAC-CRS Aid Activities Database

AfT DISBURSEMENTS BY SECTOR (million current USD)

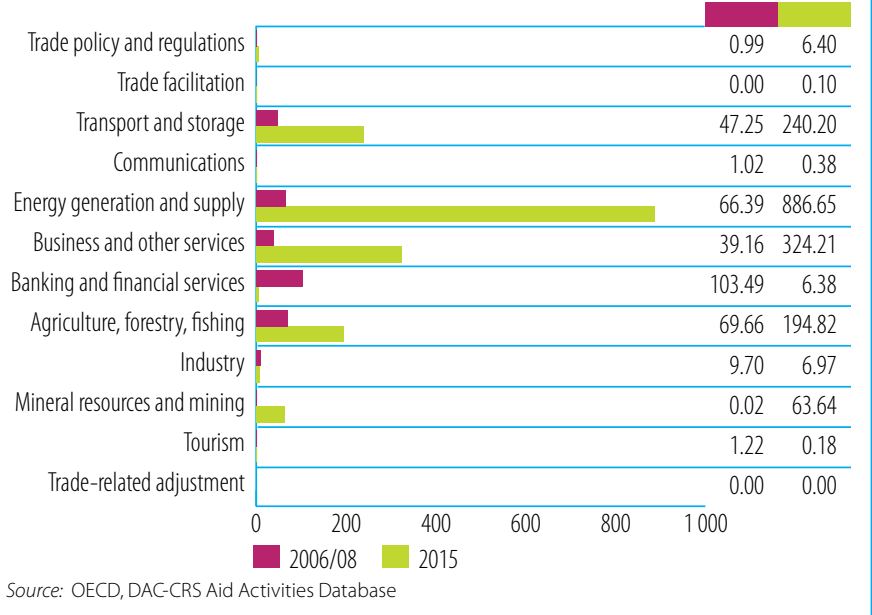

\section{B. TRADE COSTS}

\begin{tabular}{lrc} 
INDICATOR & $\mathbf{2 0 0 6}$ & $\mathbf{2 0 1 5}$ \\
Tariffs (\%) & & \\
\hline Imports: simple avg. MFN applied & 14.3 & 12.4 \\
\hline Imports: weighted avg. MFN applied (2005-2014) & 13 & 9.9 \\
\hline Exports: weighted avg. faced (2005-2014) & 7.6 & 3.9 \\
\hline Exports: duty free (value in \%) (2005-2014) & 19.0 & 61.9 \\
\hline ICT connectivity (\% of population) & & \\
\hline Mobile broadband subscriptions (2008-2015) & 0.0 & 13.0 \\
\hline Fixed broadband subscriptions & 0.0 & 1.0 \\
\hline Individuals using the internet & 6.5 & 18.0 \\
\hline Sources: WTO, World Tariff Profiles; ITU, World Telecommunication/ICT Indicators &
\end{tabular}
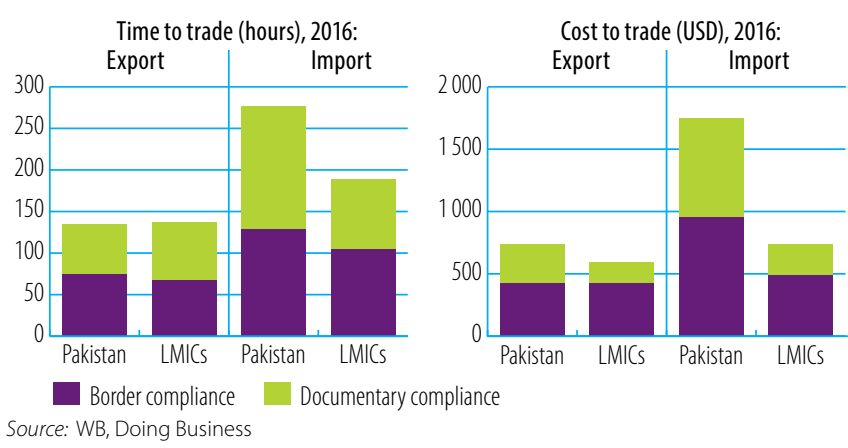

LOGISTICS PERFORMANCE INDICES (LPI) (1-5)

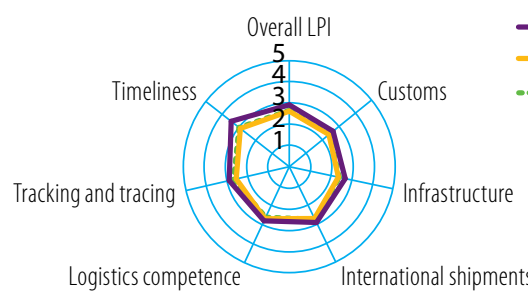

Source: WB Logistics Performance Index (LPI)

GLOBAL COMPETITIVENESS INDICATORS (1-7)

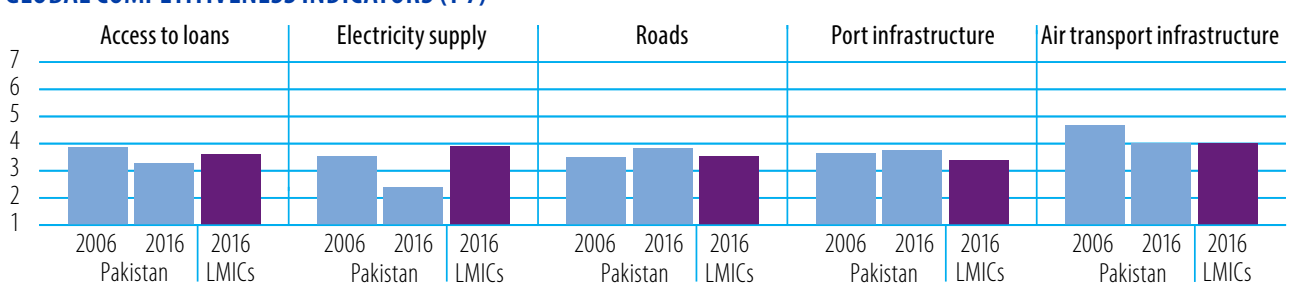

TRADE FACILITATION INDICATORS, 2017 (0-2)

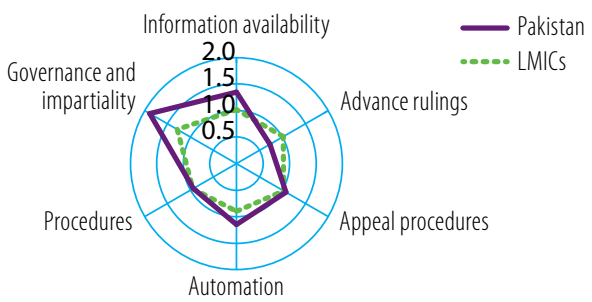

Source: OECD Trade Facilitation Indicators

TRADE COSTS (ad-valorem, \%)

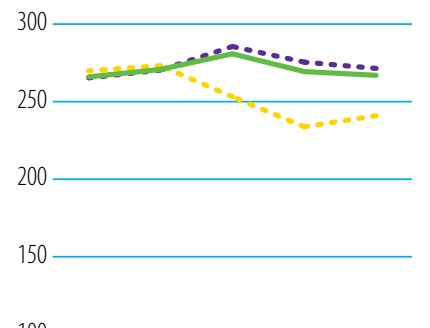

100

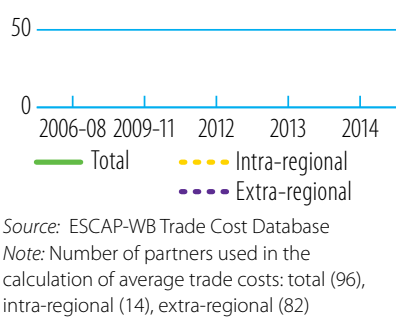

Source: WEF Global Competitiveness Index 


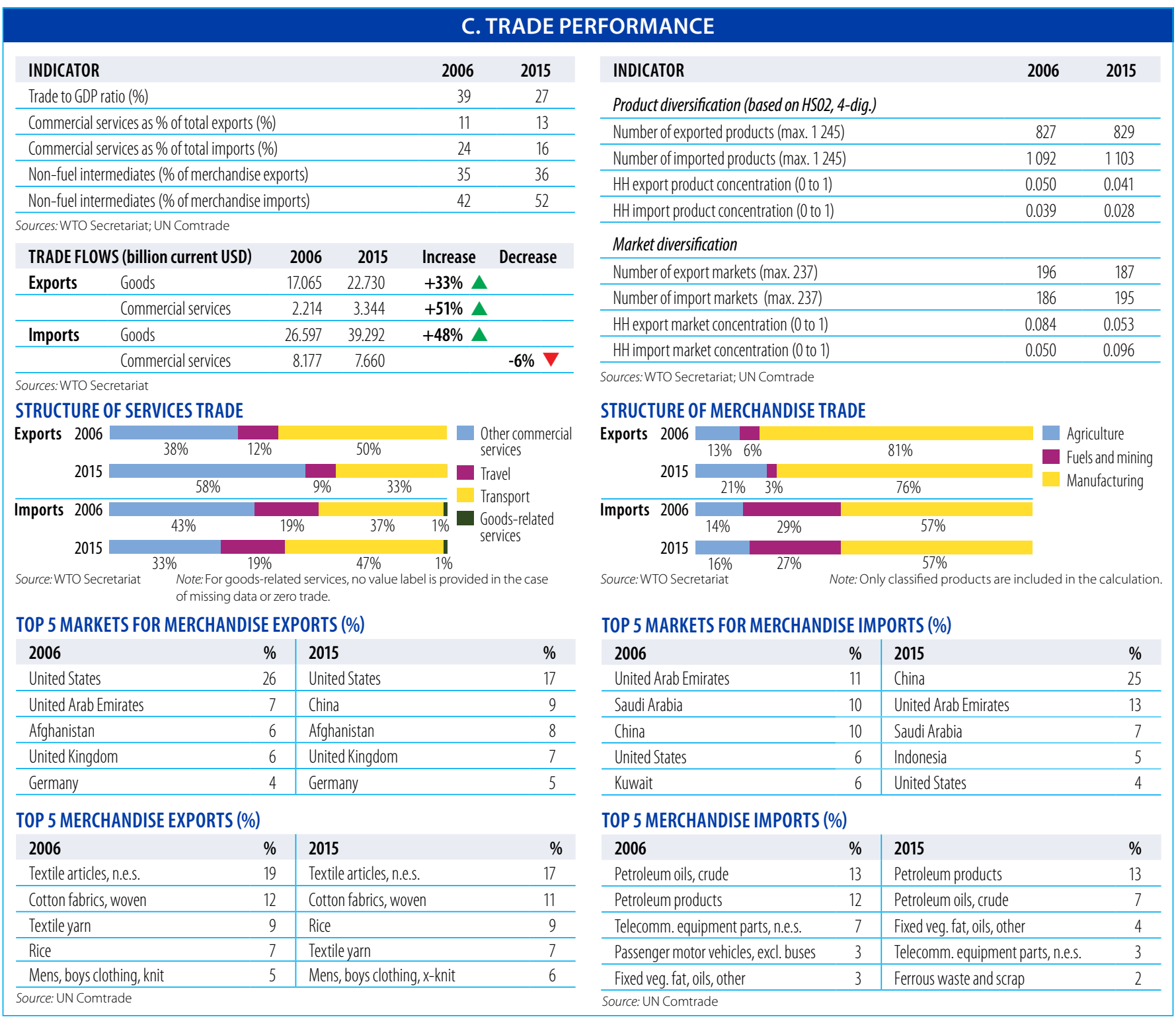

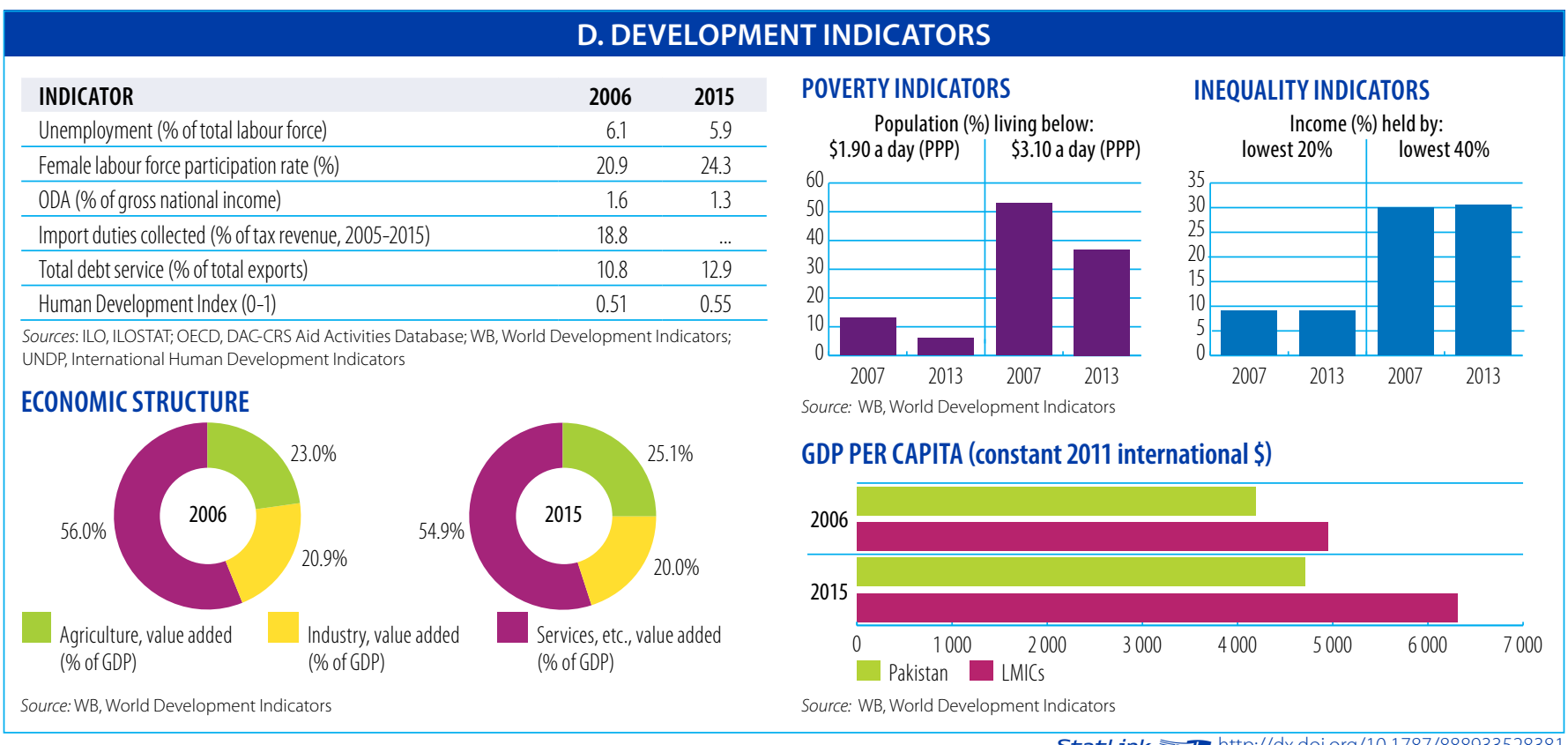


Aid, Trade and Development Indicators for Papua New Guinea

\section{A. DEVELOPMENT FINANCE}

\begin{tabular}{lrrrc}
$\begin{array}{l}\text { EXTERNAL FINANCING INFLOWS } \\
\text { (million current USD) }\end{array}$ & $\mathbf{2 0 0 6 / 0 8}$ & $\mathbf{2 0 1 2 / 1 4}$ & $\mathbf{2 0 1 5}$ & $\mathbf{\Delta : 0 6 / 0 8 - 1 5}$ \\
FDl inflows & 19.5 & 4.4 & -27.8 & - \\
\hline Remittances & 6.5 & 12.9 & 10.5 & $62 \%$ \\
\hline Other official flows (00F) & 15.8 & 69.1 & 107.4 & $580 \%$ \\
\hline$\quad$ of which trade-related 00F & 10.1 & 58.6 & 74.9 & $641 \%$ \\
\hline Official Development Assistance (ODA) & 353.0 & 679.3 & 627.6 & $78 \%$ \\
\hline of which Aid for Trade & 87.7 & 180.1 & 186.7 & $113 \%$ \\
\hline
\end{tabular}

Sources: UNCTAD, UNCTADstat; WB, World Development Indicators; OECD,

DAC-CRS Aid Activities Database

\section{TOP 3 AfT PRIORITIES}

\begin{tabular}{|c|c|c|c|c|c|}
\hline 1 & Trade policy & 2 & Adjustment costs & 3 & Trade facilitation \\
\hline
\end{tabular}

SHARE OF AfT IN DEVELOPMENT FINANCE AND FIXED CAPITAL FORMATION (\%)

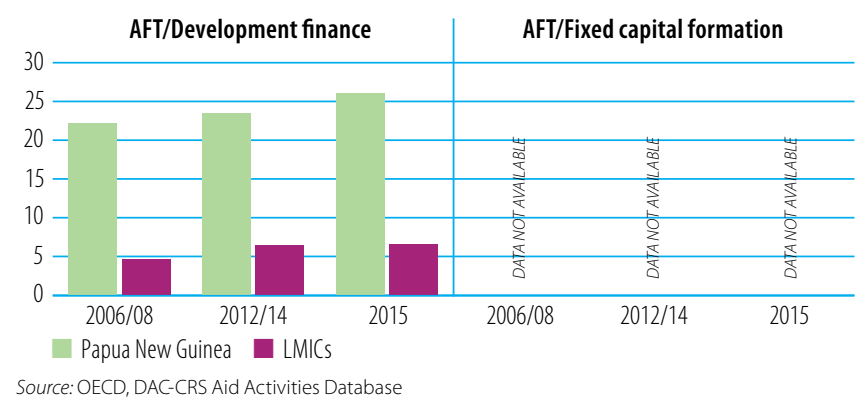

AfT DISBURSEMENTS: TOP DONORS (million current USD)

\begin{tabular}{lrr|lrc}
$\mathbf{2 0 0 6 / 0 8}$ & value & $\mathbf{\%}$ & $\mathbf{2 0 1 5}$ & value & $\%$ \\
Australia & 67.5 & 77 & Australia & 80.6 & 43 \\
\hline EU Institutions & 12.3 & 14 & AsDB Special Funds & 65.5 & 35 \\
\hline Japan & 4.7 & 5 & IDA & 18.1 & 10 \\
\hline New Zealand & 1.6 & 2 & New Zealand & 8.8 & 5 \\
\hline IDA & 0.7 & 1 & Japan & 8.8 & 5 \\
\hline
\end{tabular}

Source: OECD, DAC-CRS Aid Activities Database

AfT DISBURSEMENTS BY SECTOR (million current USD)

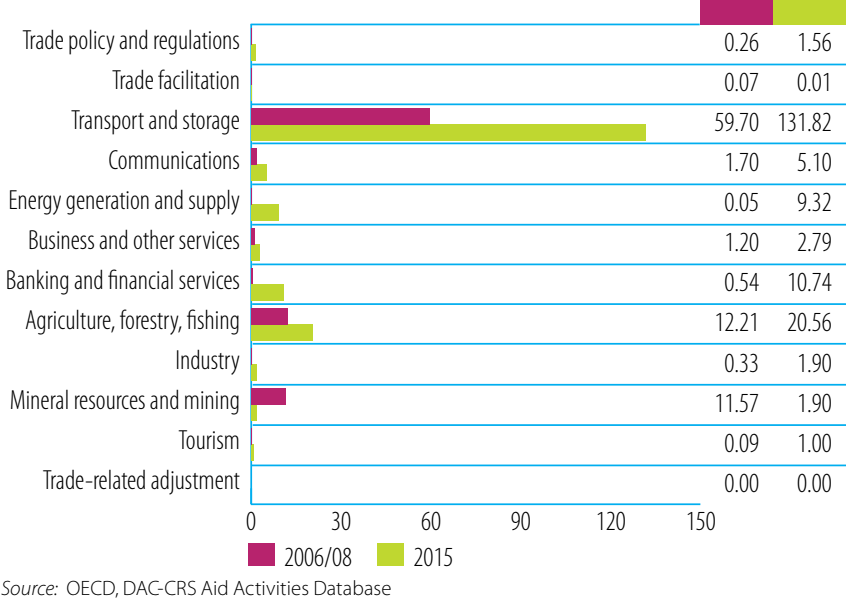

\section{B. TRADE COSTS}

\begin{tabular}{lrc} 
INDICATOR & 2006 & $\mathbf{2 0 1 5}$ \\
Tariffs (\%) & & \\
\hline Imports: simple avg. MFN applied (2006-2014) & 5.5 & 4.7 \\
\hline Imports: weighted avg. MFN applied (2006-2012) & $\ldots$ & 2.2 \\
\hline Exports: weighted avg. faced (2005-2014) & 0.2 & 0.0 \\
\hline Exports: duty free (value in \%) (2005-2014) & 92.5 & 98.5 \\
\hline ICT connectivity (\% of population) & $\ldots$ & \\
\hline Mobile broadband subscriptions & 0.0 & 0.1 \\
\hline Fixed broadband subscriptions (2008-2015) & 1.8 & 7.9 \\
\hline Individuals using the internet & &
\end{tabular}
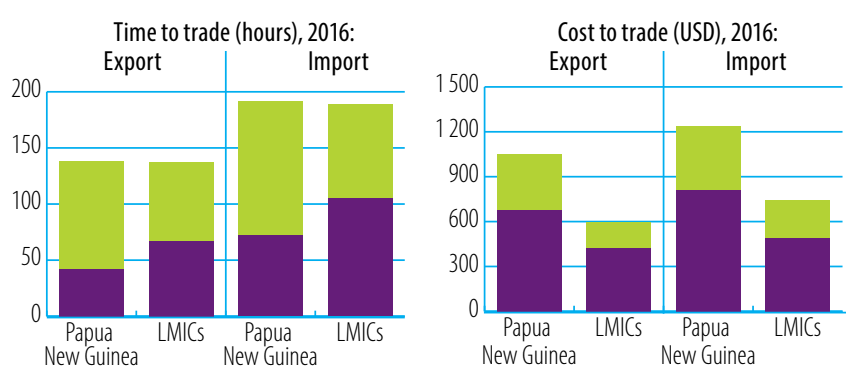

Border compliance Documentary compliance

Source: WB, Doing Business

\section{LOGISTICS PERFORMANCE INDICES (LPI) (1-5)}

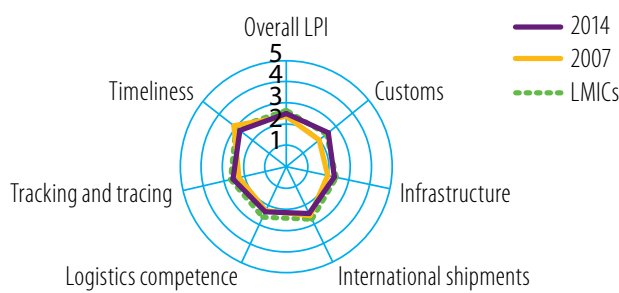

Source: WB Logistics Performance Index (LPI)

GLOBAL COMPETITIVENESS INDICATORS (1-7)

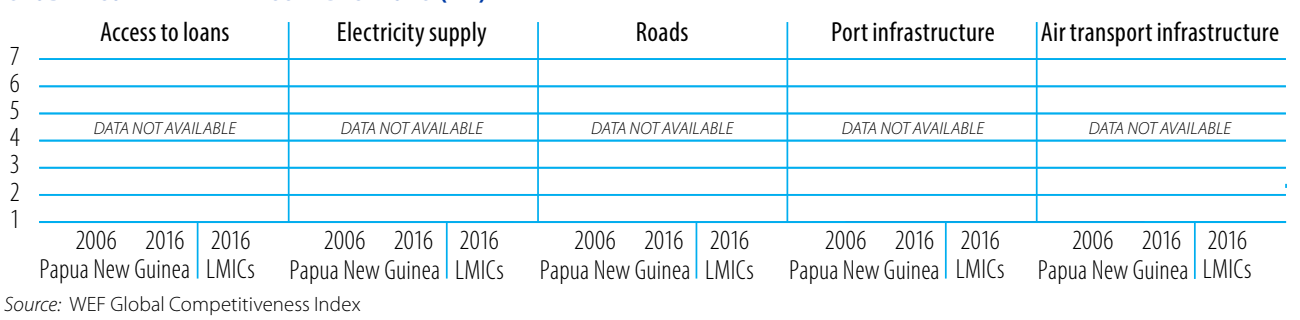

TRADE FACILITATION INDICATORS, 2017 (0-2)

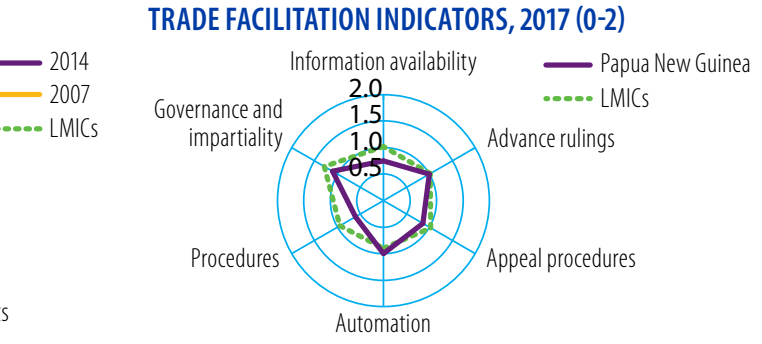

Source: OECD Trade Facilitation Indicators

TRADE COSTS (ad-valorem, \%)

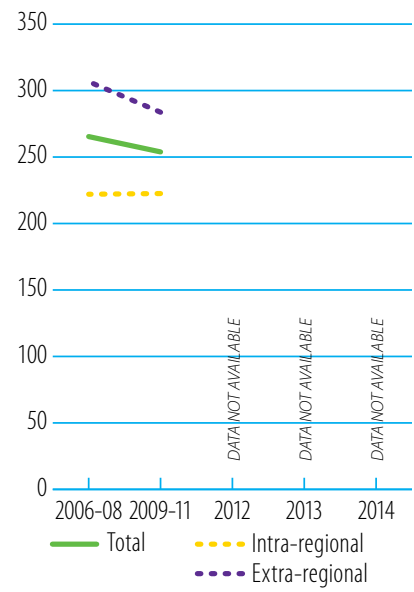

Source: ESCAP-WB Trade Cost Database Note: Number of partners used in the calculation of average trade costs: total (41), intra-regional (20), extra-regional (21) 


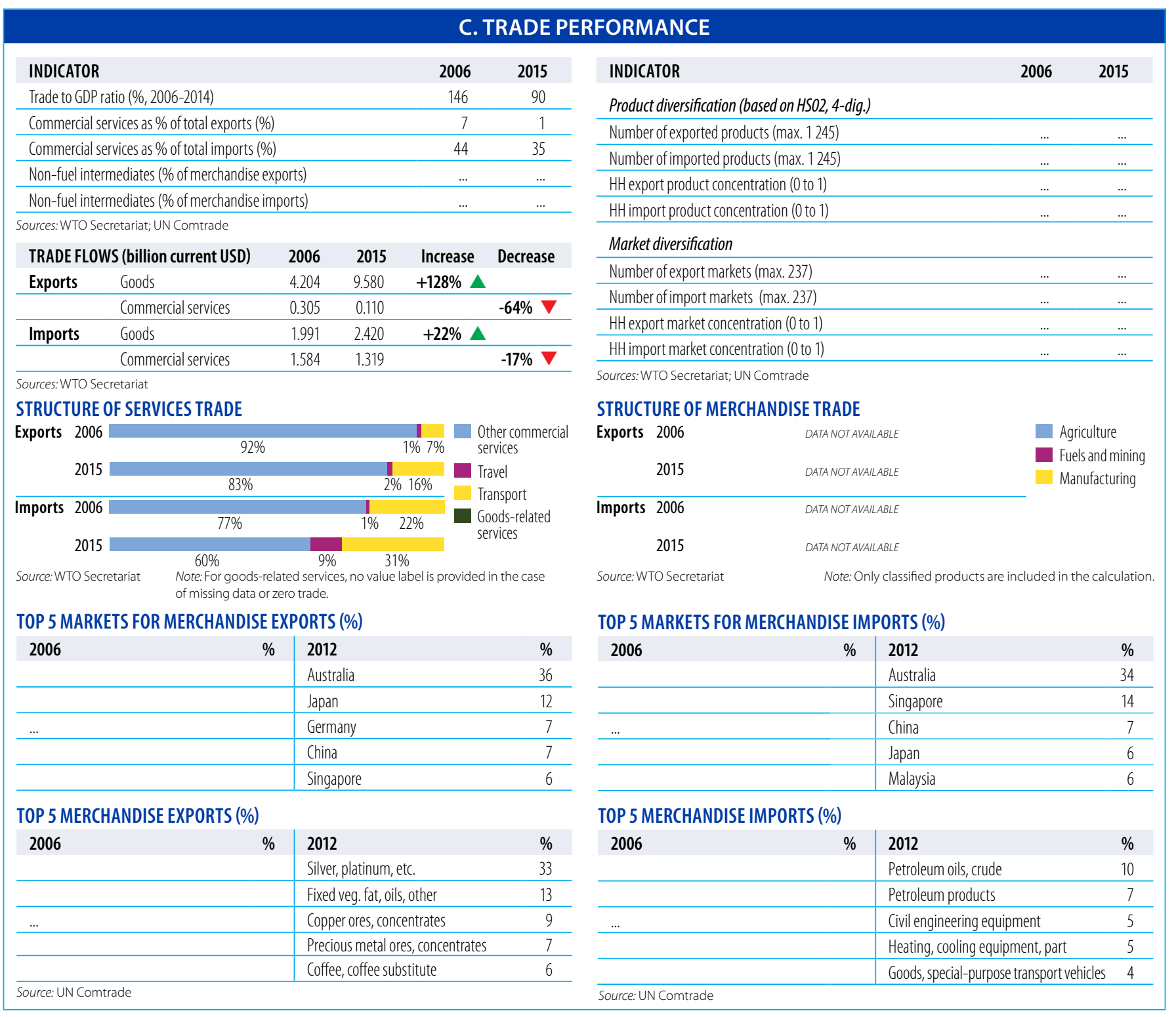

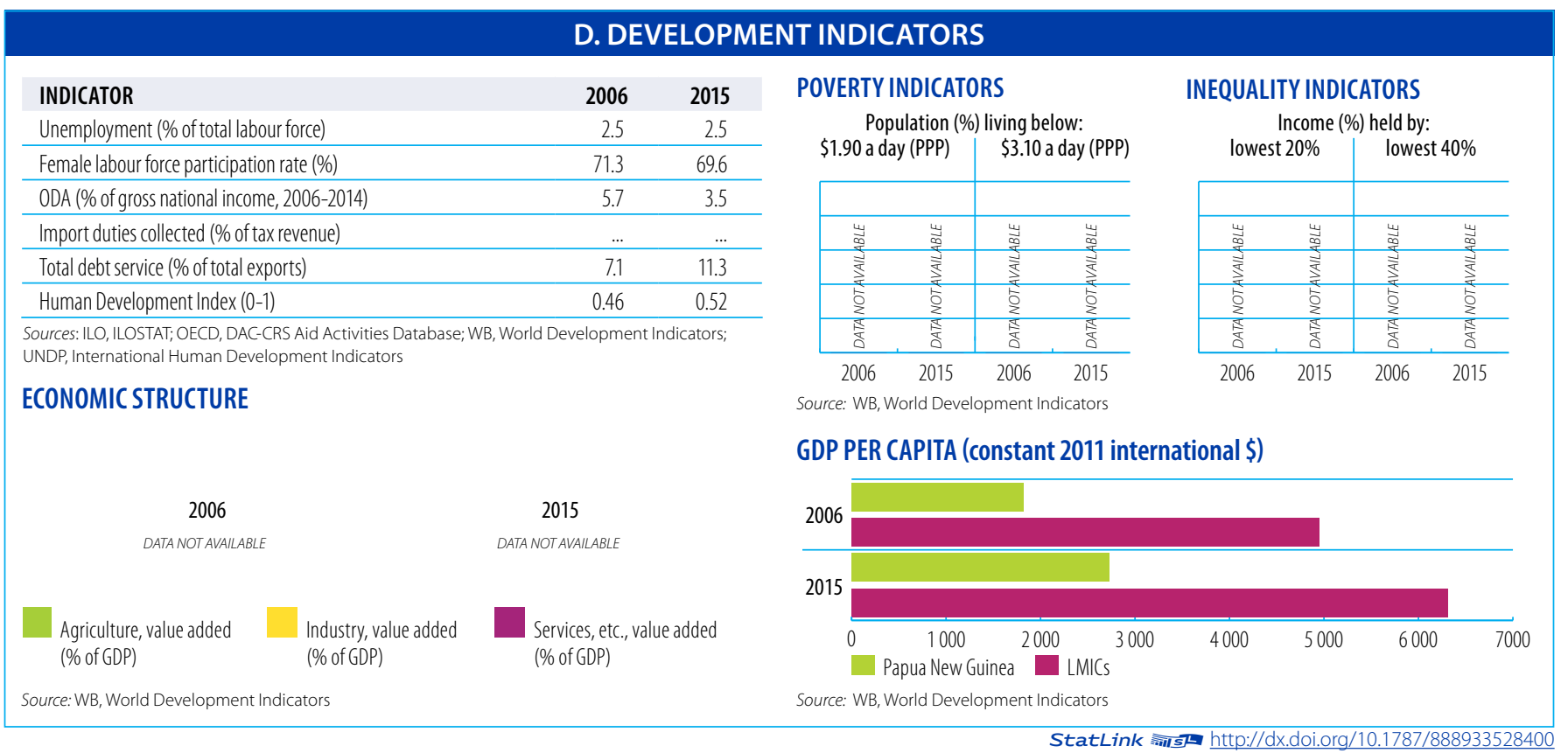


Aid, Trade and Development Indicators for Paraguay

\section{A. DEVELOPMENT FINANCE}

\begin{tabular}{lrrrc}
$\begin{array}{l}\text { EXTERNAL FINANCING INFLOWS } \\
\text { (million current USD) }\end{array}$ & $\mathbf{2 0 0 6 / 0 8}$ & $\mathbf{2 0 1 2 / 1 4}$ & $\mathbf{2 0 1 5}$ & $\mathbf{\Delta : 0 6 / 0 8 - 1 5}$ \\
\hline FDl inflows & 175.1 & 385.0 & 282.7 & $61 \%$ \\
\hline Remittances & 346.5 & 588.0 & 553.6 & $60 \%$ \\
\hline Other official flows (00F) & 33.4 & 215.0 & 203.7 & $509 \%$ \\
\hline$\quad$ of which trade-related 00F & 20.9 & 147.7 & 173.3 & $729 \%$ \\
\hline Official Development Assistance (ODA) & 150.5 & 165.1 & 129.7 & $-14 \%$ \\
\hline of which Aid for Trade & 35.0 & 50.5 & 42.6 & $22 \%$ \\
\hline
\end{tabular}

Sources: UNCTAD, UNCTADstat; WB, World Development Indicators; OECD,

DAC-CRS Aid Activities Database

TOP 3 AFT PRIORITIES

\section{\begin{tabular}{|l|l|l|l|l|l|}
\hline & Poverty reduction & $\mathbf{2}$ & Inclusive growth & $\mathbf{3}$ & International competitiveness
\end{tabular}}

Source: OECD/WTO Partner Questionnaire

SHARE OF AfT IN DEVELOPMENT FINANCE AND FIXED CAPITAL FORMATION (\%)

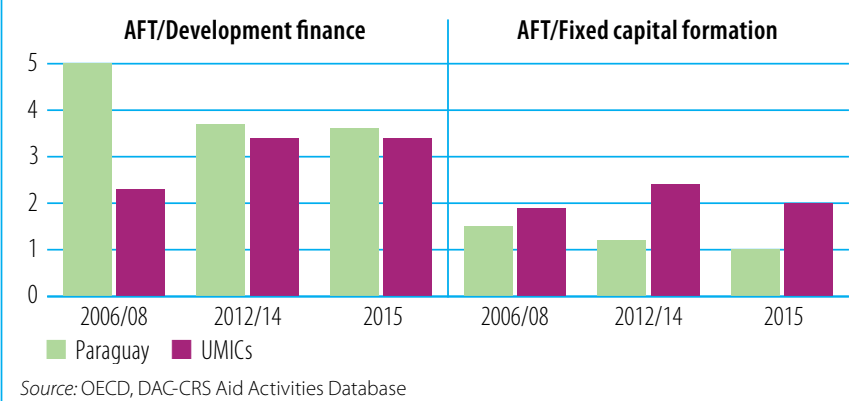

AfT DISBURSEMENTS: TOP DONORS (million current USD)

\begin{tabular}{lrr|lrc}
$\mathbf{2 0 0 6 / 0 8}$ & value & $\%$ & $\mathbf{2 0 1 5}$ & value & $\%$ \\
Japan & 23.4 & 67 & IDB Special Fund & 20.1 & 47 \\
\hline EU Institutions & 3.7 & 11 & Japan & 9.2 & 22 \\
\hline Korea & 2.0 & 6 & Korea & 5.8 & 14 \\
\hline Spain & 1.7 & 5 & EU Institutions & 1.8 & 4 \\
\hline Germany & 1.3 & 4 & United States & 1.7 & 4 \\
\hline
\end{tabular}

Source: OECD, DAC-CRS Aid Activities Database

AfT DISBURSEMENTS BY SECTOR (million current USD)

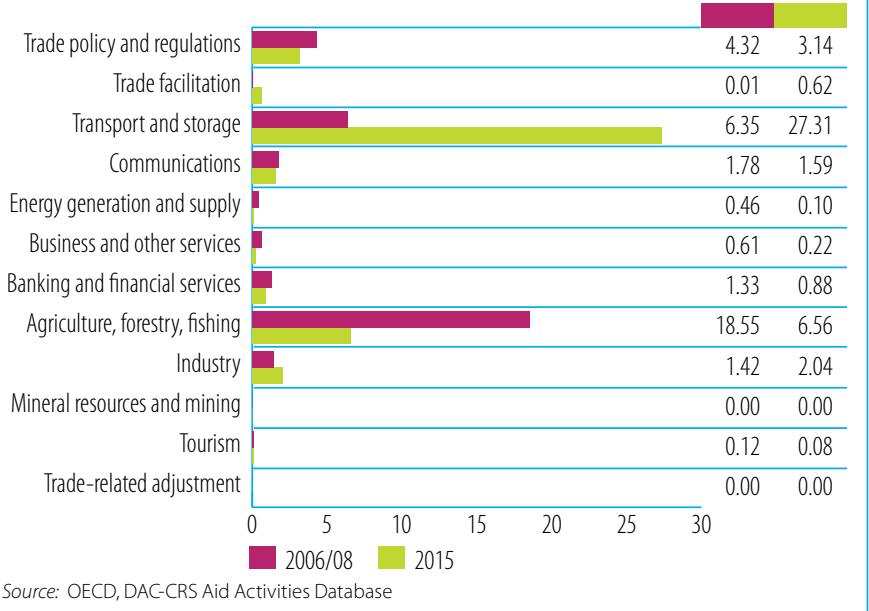

\section{B. TRADE COSTS}

\begin{tabular}{lcc} 
INDICATOR & 2006 & $\mathbf{2 0 1 5}$ \\
Tariffs (\%) & & \\
\hline Imports: simple avg. MFN applied & 9.9 & 9.8 \\
\hline Imports: weighted avg. MFN applied (2006-2014) & $\ldots$. & 6.5 \\
\hline Exports: weighted avg. faced (2005-2014) & 0.4 & 2.2 \\
\hline Exports: duty free (value in \%) (2005-2014) & 93.2 & 77.4 \\
\hline ICT connectivity (\% of population) & $\ldots$ & \\
\hline Mobile broadband subscriptions & 0.1 & 39.2 \\
\hline Fixed broadband subscriptions & 8.0 & 44.4 \\
\hline Individuals using the internet & &
\end{tabular}
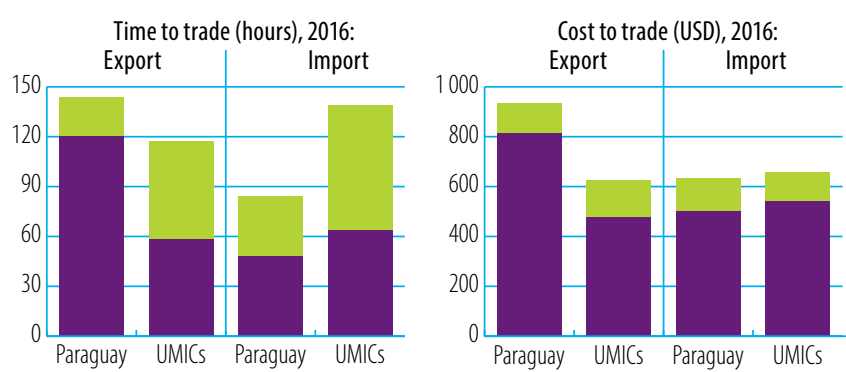

Border compliance Documentary compliance

Source: WB, Doing Business

\section{LOGISTICS PERFORMANCE INDICES (LPI) (1-5)}

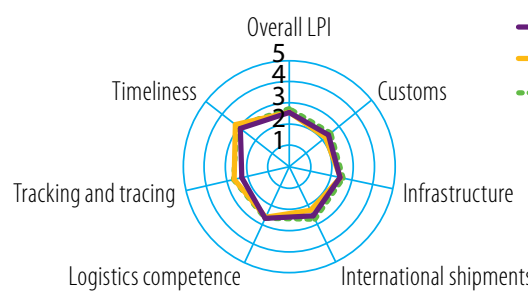

Source: WB Logistics Performance Index (LPI)

\section{GLOBAL COMPETITIVENESS INDICATORS (1-7)}

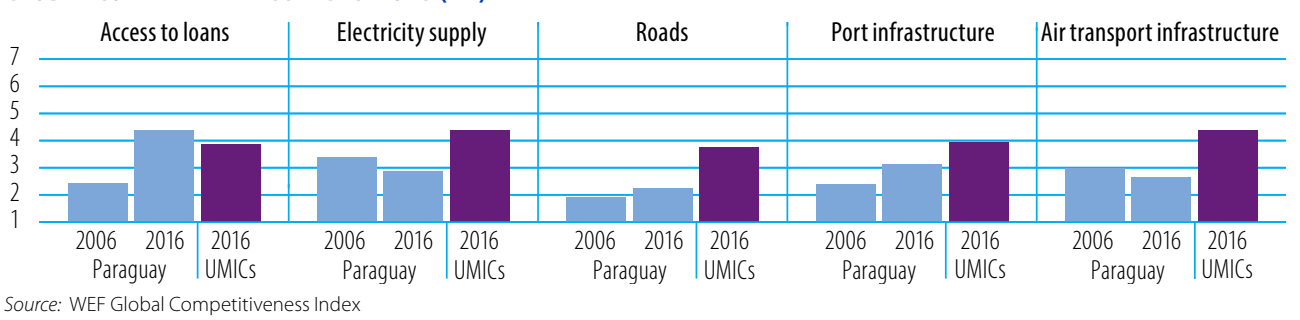

TRADE FACILITATION INDICATORS, 2017 (0-2)

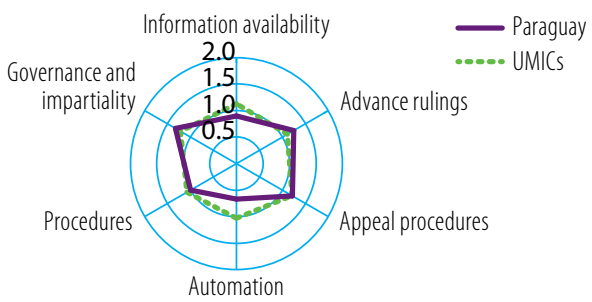

Source: OECD Trade Facilitation Indicators
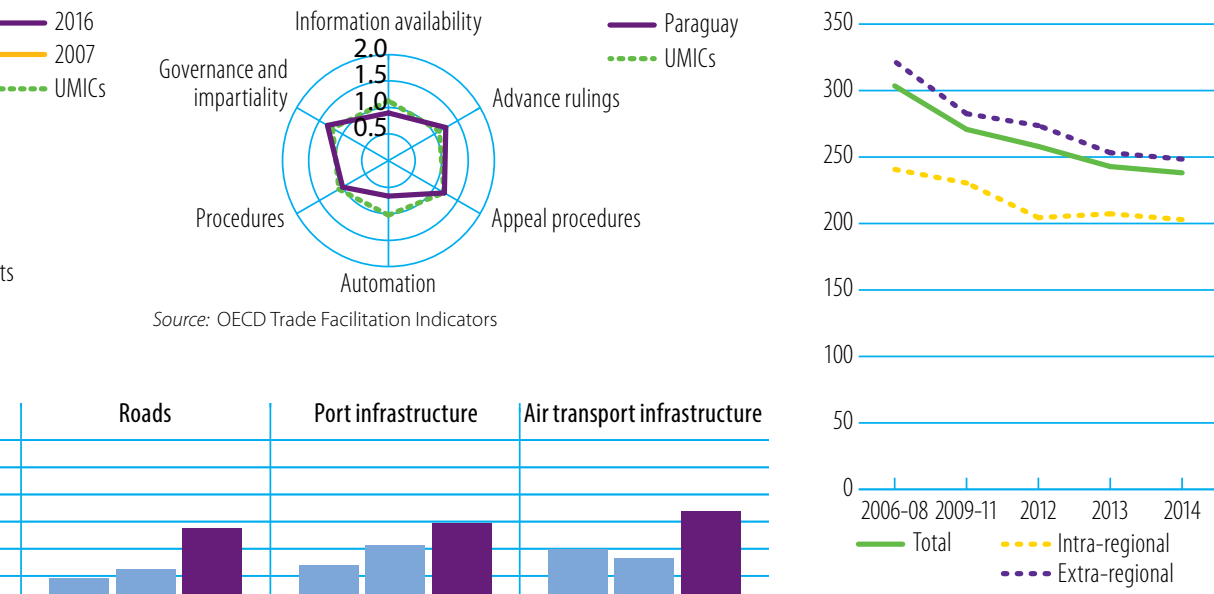

Source: ESCAP-WB Trade Cost Database Note: Number of partners used in the calculation of average trade costs: total (53), intra-regional (12), extra-regional (41) 


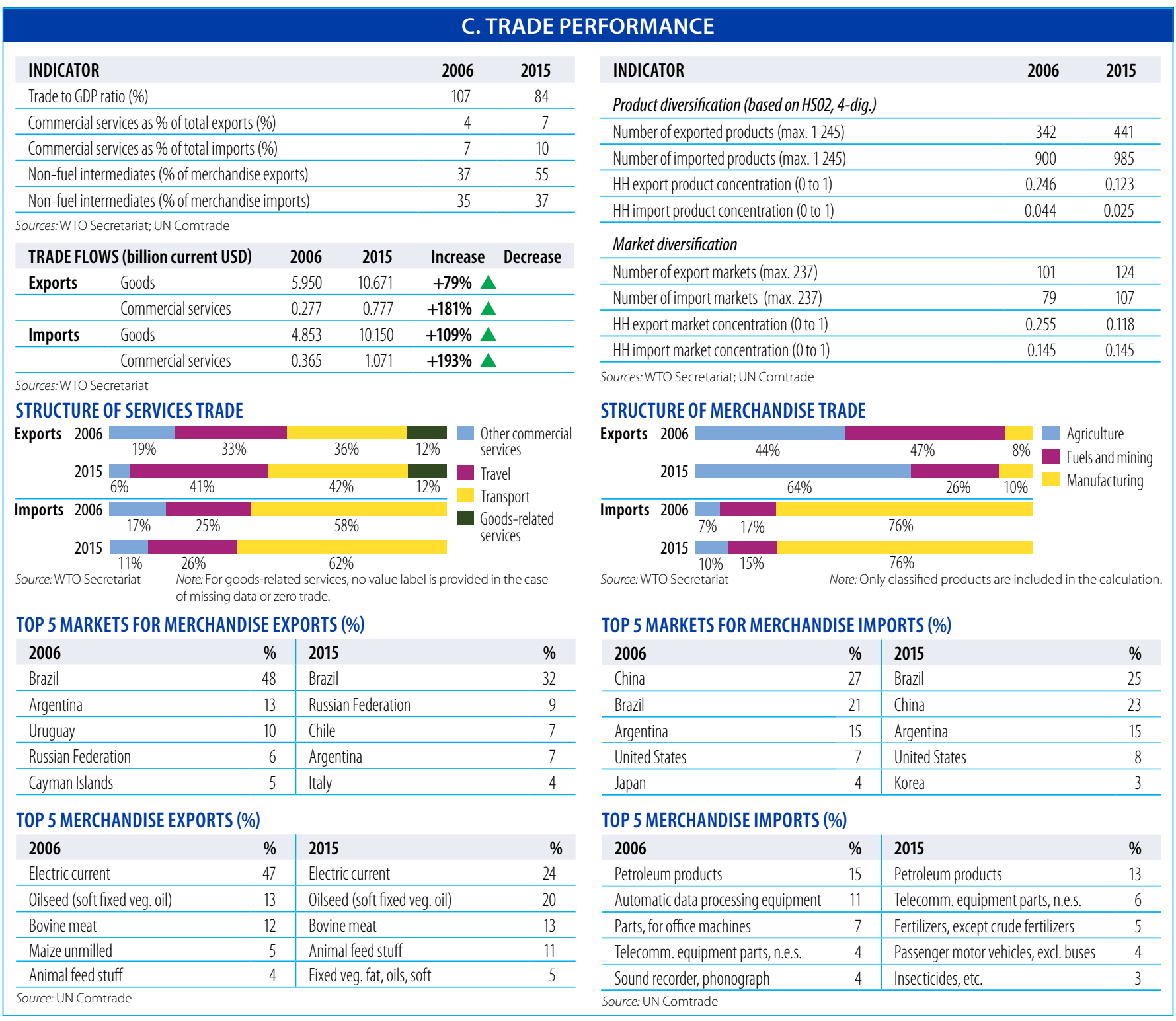

\begin{tabular}{|lrr} 
& \multicolumn{2}{c}{ D. DEVELOPMEN } \\
\hline INDICATOR & $\mathbf{2 0 0 6}$ & $\mathbf{2 0 1 5}$ \\
\hline Unemployment (\% of total labour force) & 6.7 & 5.3 \\
\hline Female labour force participation rate (\%) & 55.1 & 58.1 \\
\hline ODA (\% of gross national income) & 0.6 & 0.2 \\
\hline Import duties collected (\% of tax revenue, 2006-2014) & 14.5 & 10.2 \\
\hline Total debt service (\% of total exports) & 6.5 & 18.6 \\
\hline Human Development Index (0-1) & 0.65 & 0.69 \\
\hline
\end{tabular}

Sources: ILO, ILOSTAT; OECD, DAC-CRS Aid Activities Database; WB, World Development Indicators; UNDP, International Human Development Indicators

\section{ECONOMIC STRUCTURE}

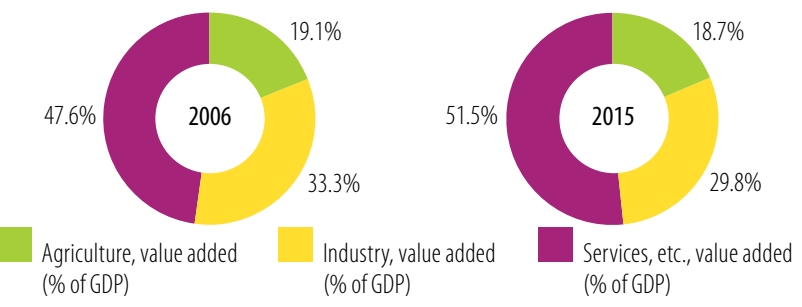

Source: WB, World Development Indicators

\section{POVERTY INDICATORS}

Population (\%) living below:

$\$ 1.90$ a day (PPP) $\quad \$ 3.10$ a day (PPP)

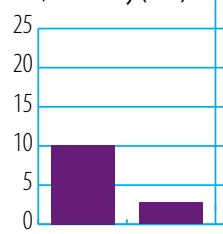

$2006 \quad 2014$

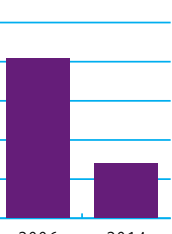

Source: WB, World Development Indicators

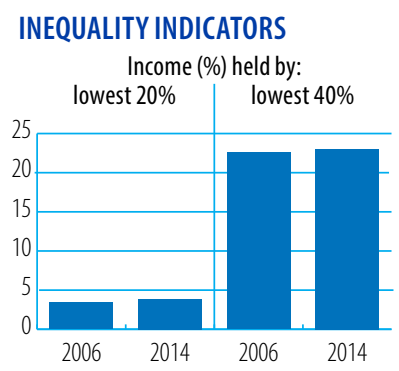

GDP PER CAPITA (constant 2011 international \$)

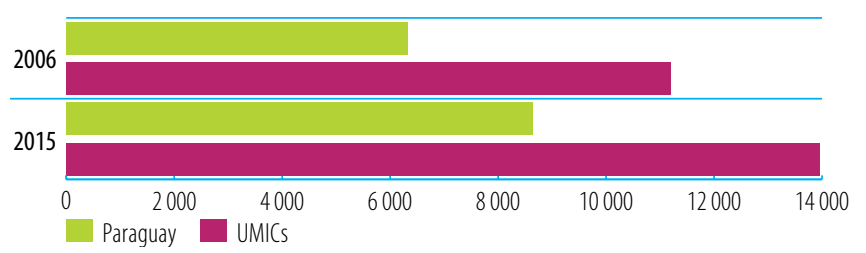

Source: WB, World Development Indicators 
Aid, Trade and Development Indicators for Peru

\section{A. DEVELOPMENT FINANCE}

\begin{tabular}{lcccc}
\hline $\begin{array}{l}\text { EXTERNAL FINANCING INFLOWS } \\
\text { (million current USD) }\end{array}$ & $\mathbf{2 0 0 6 / 0 8}$ & $\mathbf{2 0 1 2 / 1 4}$ & $\mathbf{2 0 1 5}$ & $\mathbf{\Delta : 0 6 / 0 8 - 1 5}$ \\
\hline FDl inflows & 5293.7 & 9700.1 & 6861.2 & $30 \%$ \\
\hline Remittances & 2137.3 & 2710.6 & 2725.1 & $27 \%$ \\
\hline Other official flows (00F) & 316.5 & 399.4 & 1405.4 & $344 \%$ \\
\hline of which trade-related 00F & 158.9 & 228.3 & 670.7 & $322 \%$ \\
\hline Official Development Assistance (ODA) & 684.9 & 539.6 & 523.4 & $-24 \%$ \\
\hline of which Aid for Trade & 179.8 & 135.6 & 96.0 & $-47 \%$ \\
\hline
\end{tabular}

Sources: UNCTAD, UNCTADstat; WB, World Development Indicators; OECD,

DAC-CRS Aid Activities Database

\section{TOP 3 AfT PRIORITIES}

\section{\begin{tabular}{|l|l|l|l|l|l|}
\hline 1 & $\begin{array}{l}\text { International } \\
\text { competitiveness }\end{array}$ & $\mathbf{2}$ & Connecting to value chains & $\mathbf{3}$ & Export diversification \\
\hline
\end{tabular}} Source: OECD/WTO Partner Questionnaire

SHARE OF AfT IN DEVELOPMENT FINANCE AND FIXED CAPITAL FORMATION (\%)

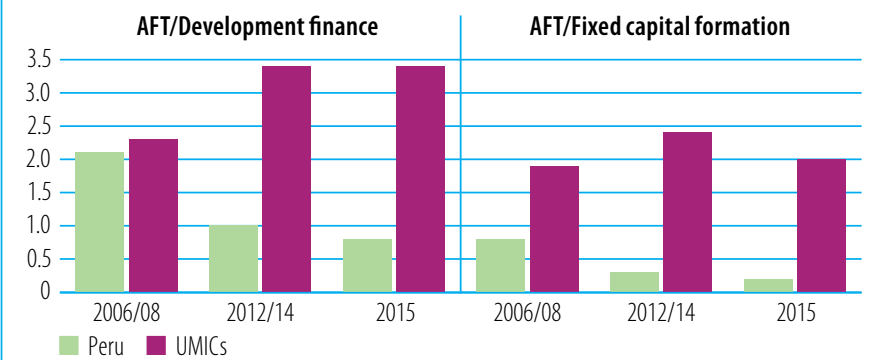

Source: OECD, DAC-CRS Aid Activities Database
AfT DISBURSEMENTS: TOP DONORS (million current USD)

\begin{tabular}{lrr|lrc}
$\mathbf{2 0 0 6 / 0 8}$ & value & $\%$ & $\mathbf{2 0 1 5}$ & value & $\%$ \\
Norway & 45.3 & 25 & United States & 26.7 & 28 \\
\hline United States & 44.4 & 25 & Germany & 22.4 & 23 \\
\hline EU Institutions & 27.4 & 15 & Canada & 10.4 & 11 \\
\hline Spain & 21.4 & 12 & Switzerland & 7.4 & 8 \\
\hline Japan & 9.8 & 5 & EU Institutions & 7.1 & 7 \\
\hline
\end{tabular}

Source: OECD, DAC-CRS Aid Activities Database

AfT DISBURSEMENTS BY SECTOR (million current USD)

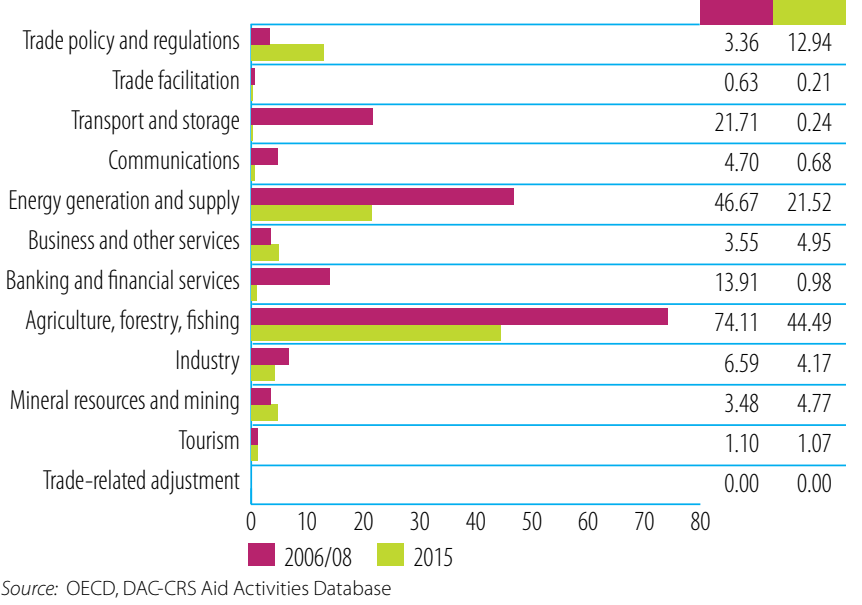

\section{B. TRADE COSTS}

\begin{tabular}{lcc} 
INDICATOR & $\mathbf{2 0 0 6}$ & $\mathbf{2 0 1 5}$ \\
Tariffs (\%) & & \\
\hline Imports: simple avg. MFN applied & 10.2 & 2.4 \\
\hline Imports: weighted avg. MFN applied (2006-2014) & $\ldots$ & 1.9 \\
\hline Exports: weighted avg. faced (2005-2014) & 1.6 & 0.2 \\
\hline Exports: duty free (value in \%) (2005-2014) & 84.0 & 94.6 \\
\hline ICT connectivity (\% of population) & $\ldots$ & \\
\hline Mobile broadband subscriptions & 1.7 & 36.7 \\
\hline Fixed broadband subscriptions & 20.7 & 40.9 \\
\hline Individuals using the internet & &
\end{tabular}

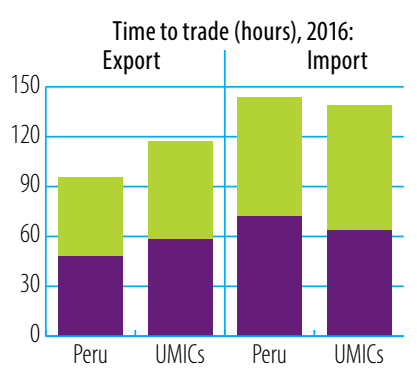

Border compliance Documentary compliance Source: WB, Doing Business

\section{LOGISTICS PERFORMANCE INDICES (LPI) (1-5)}

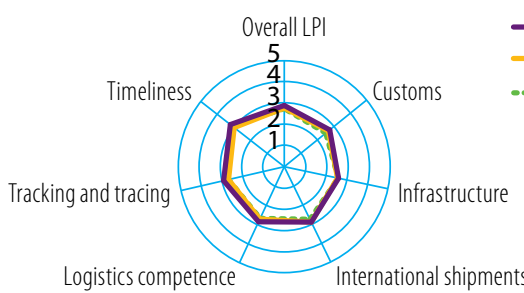

Source: WB Logistics Performance Index (LPI)

\section{GLOBAL COMPETITIVENESS INDICATORS (1-7)}

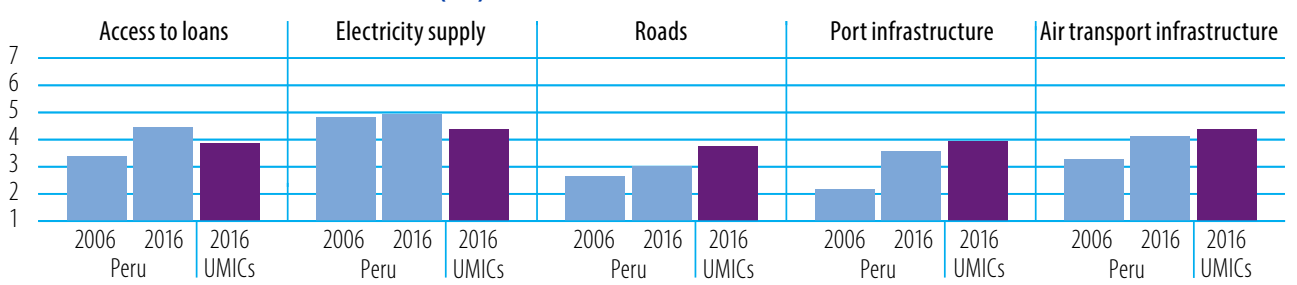

TRADE FACILITATION INDICATORS, 2017 (0-2)

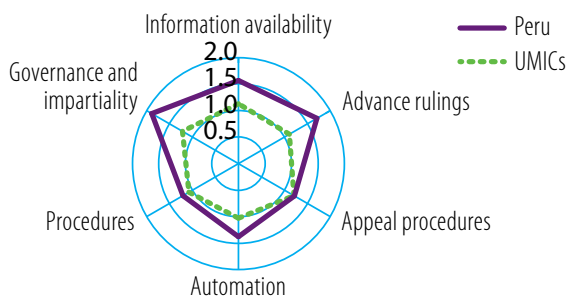

Source: OECD Trade Facilitation Indicators

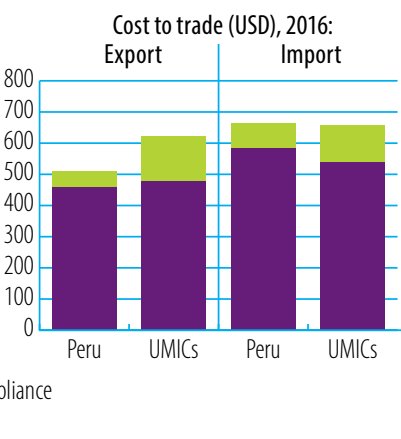

TRADE COSTS (ad-valorem, \%)

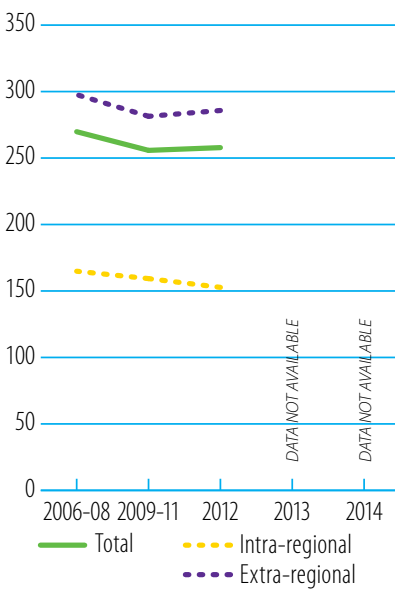

Source: ESCAP-WB Trade Cost Database Note: Number of partners used in the calculation of average trade costs: total (81), intra-regional (17), extra-regional (64) 


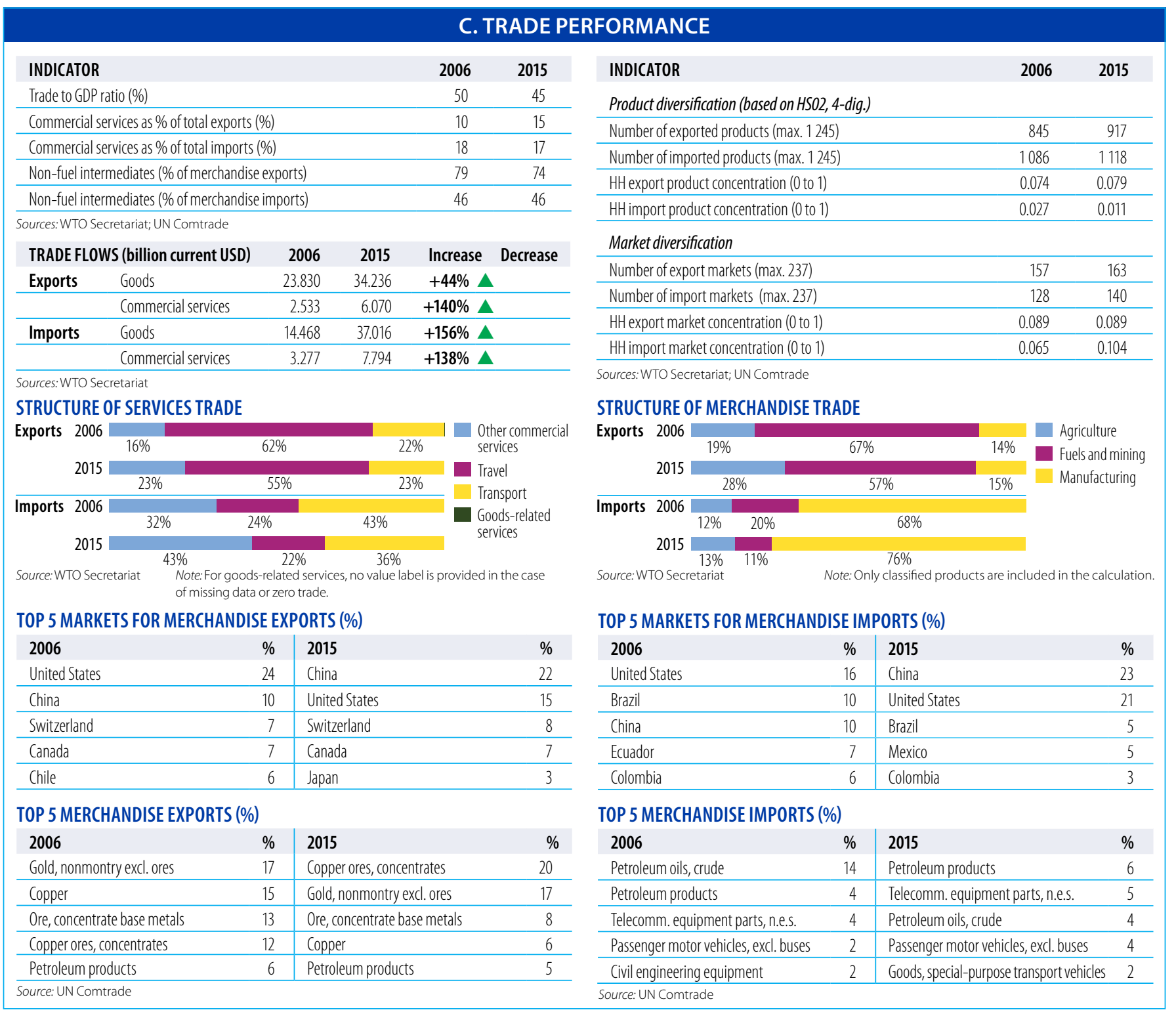

\begin{tabular}{|lrr}
\hline & D. DEVELOPME \\
\hline INDICATOR & $\mathbf{2 0 0 6}$ & $\mathbf{2 0 1 5}$ \\
\hline Unemployment (\% of total labour force) & 7.2 & 4.4 \\
\hline Female labour force participation rate (\%) & 58.0 & 65.7 \\
\hline ODA (\% of gross national income) & 0.6 & 0.2 \\
\hline Import duties collected (\% of tax revenue) & 5.2 & 2.0 \\
\hline Total debt service (\% of total exports) & 13.1 & 11.5 \\
\hline Human Development Index (0-1) & 0.70 & 0.74 \\
\hline
\end{tabular}

Sources: ILO,ILOSTAT: OECD, DAC-CRS Aid Activities Database: WB, World Development Indicators: UNDP, International Human Development Indicators

\section{ECONOMIC STRUCTURE}

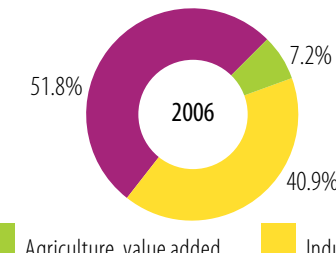

(\% of GDP)

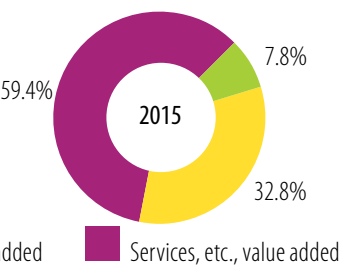

(\% of GDP)

Source: WB, World Development Indicators

Industry, value added (\% of GDP)

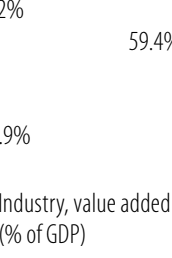

$$
\text { ors }
$$

\section{ENT INDICATORS}

\section{POVERTY INDICATORS}

Population (\%) living below:

$\$ 1.90$ a day (PPP) $\quad \$ 3.10$ a day (PPP)

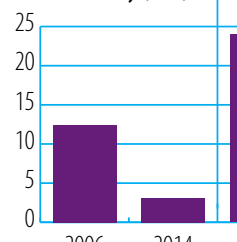

20062014

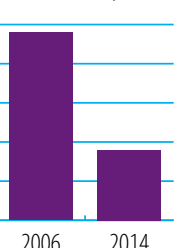

Source: WB, World Development Indicators

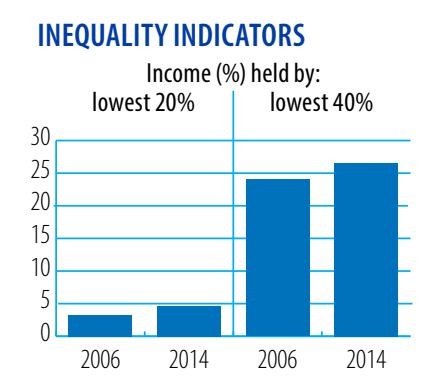

GDP PER CAPITA (constant 2011 international \$)

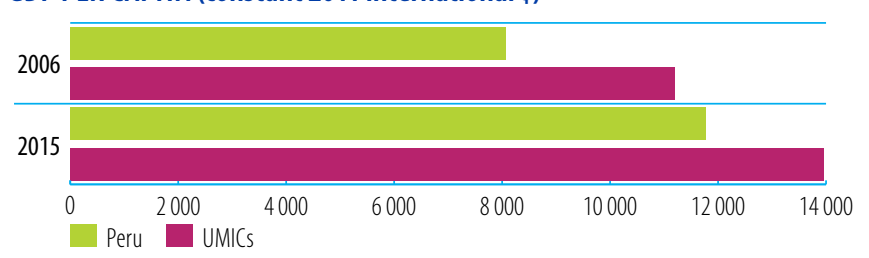

Source: WB, World Development Indicators 


\section{PHILIPPINES}

Aid, Trade and Development Indicators for the Philippines

\section{A. DEVELOPMENT FINANCE}

\begin{tabular}{lrrrc}
$\begin{array}{l}\text { EXTERNAL FINANCING INFLOWS } \\
\text { (million current USD) }\end{array}$ & $\mathbf{2 0 0 6 / 0 8}$ & $\mathbf{2 0 1 2 / 1 4}$ & $\mathbf{2 0 1 5}$ & $\mathbf{\Delta : 0 6 / 0 8 - 1 5}$ \\
\hline FDl inflows & 2460.2 & 3897.2 & 5234.0 & $113 \%$ \\
\hline Remittances & 16928.1 & 26672.4 & 29799.4 & $76 \%$ \\
\hline Other official flows (0OF) & 392.7 & 1188.6 & 2428.9 & $519 \%$ \\
\hline of which trade-related 00F & 141.3 & 316.8 & 1040.1 & $636 \%$ \\
\hline Official Development Assistance (ODA) & 1096.6 & 1195.5 & 1200.0 & $9 \%$ \\
\hline of which Aid for Trade & 468.9 & 241.3 & 345.1 & $-26 \%$ \\
\hline
\end{tabular}

Sources: UNCTAD, UNCTADstat; WB, World Development Indicators; OECD,

DAC-CRS Aid Activities Database

\section{TOP 3 AfT PRIORITIES}

\begin{tabular}{|l|l|l|l|l|l|}
\hline $\mathbf{1}$ & Transport infrastructure & $\mathbf{2}$ & Cross-border infrastructure & $\mathbf{3}$ & $\begin{array}{l}\text { International } \\
\text { competitiveness }\end{array}$ \\
\hline
\end{tabular} Source: OECD/WTO Partner Questionnaire

SHARE OF AfT IN DEVELOPMENT FINANCE AND FIXED CAPITAL FORMATION (\%)

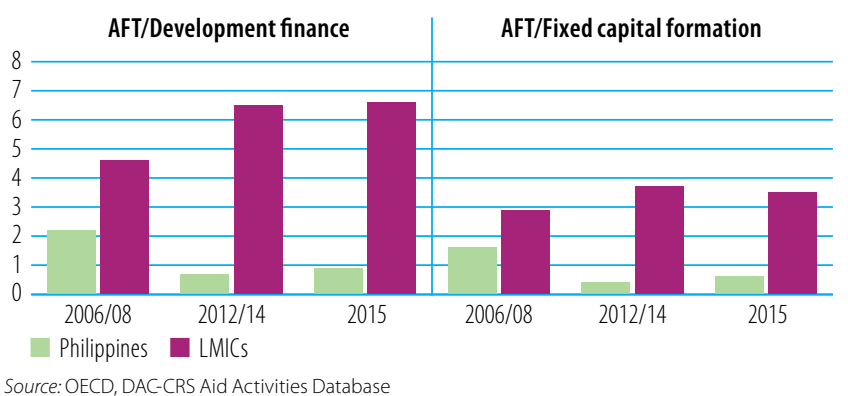

AfT DISBURSEMENTS: TOP DONORS (million current USD)

\begin{tabular}{lcc|lrc}
$\mathbf{2 0 0 6 / 0 8}$ & value & $\%$ & $\mathbf{2 0 1 5}$ & value & $\%$ \\
Japan & 349.8 & 75 & Japan & 202.0 & 59 \\
\hline Germany & 25.8 & 6 & United States & 60.9 & 18 \\
\hline Norway & 22.9 & 5 & Korea & 29.1 & 8 \\
\hline United States & 20.3 & 4 & Australia & 15.1 & 4 \\
\hline Korea & 17.7 & 4 & OPEC Fund for International Development & 10.1 & 3 \\
\hline
\end{tabular}

Source: OECD, DAC-CRS Aid Activities Database

AfT DISBURSEMENTS BY SECTOR (million current USD)

\begin{tabular}{|c|c|c|c|}
\hline Trade policy and regulations & & 2.79 & 4.49 \\
\hline Trade facilitation & & 0.05 & 6.46 \\
\hline Transport and storage & & 309.40 & 249.79 \\
\hline Communications & & 4.58 & 4.08 \\
\hline Energy generation and supply & 0 & 38.94 & 10.04 \\
\hline Business and other services & 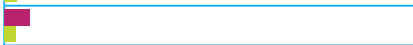 & 20.11 & 9.19 \\
\hline Banking and financial services & 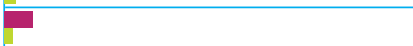 & 21.96 & 6.69 \\
\hline Agriculture, forestry, fishing & $\overline{0}$ & 59.62 & 46.50 \\
\hline Industry & $\bar{\square}$ & 10.59 & 4.98 \\
\hline Mineral resources and mining & & 0.51 & 0.81 \\
\hline Tourism & & 0.34 & 2.07 \\
\hline Trade-related adjustment & & 0.00 & 0.00 \\
\hline & $\begin{array}{lrrrrrr}0 & 50 & 100 & 150 & 200 & 250 & 300\end{array}$ & 350 & \\
\hline
\end{tabular}

\section{B. TRADE COSTS}

\begin{tabular}{lrc} 
INDICATOR & 2006 & $\mathbf{2 0 1 5}$ \\
Tariffs (\%) & 6.3 & 6.3 \\
\hline Imports: simple avg. MFN applied & 4 & 4.8 \\
\hline Imports: weighted avg. MFN applied (2005-2014) & 1.6 & 0.8 \\
\hline Exports: weighted avg. faced (2005-2014) & 86.4 & 94.9 \\
\hline Exports: duty free (value in \%) (2005-2014) & & \\
\hline ICT connectivity (\% of population) & $\ldots$ & 41.6 \\
\hline Mobile broadband subscriptions & 0.3 & 3.4 \\
\hline Fixed broadband subscriptions & 5.7 & 40.7 \\
\hline Individuals using the internet & &
\end{tabular}
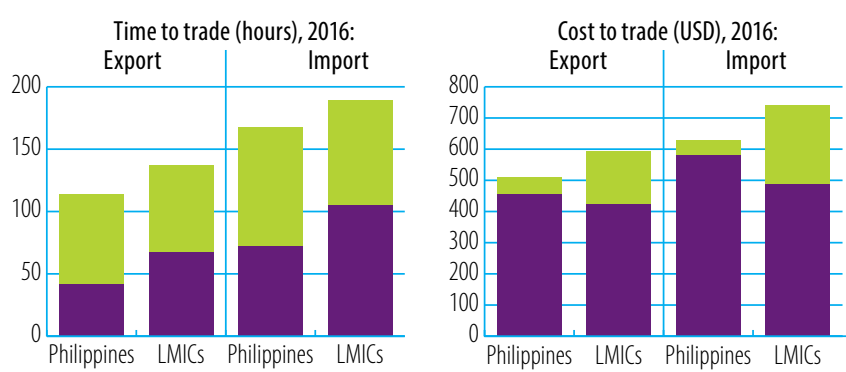

Border compliance Documentary compliance

Source: WB, Doing Business

\section{LOGISTICS PERFORMANCE INDICES (LPI) (1-5)}

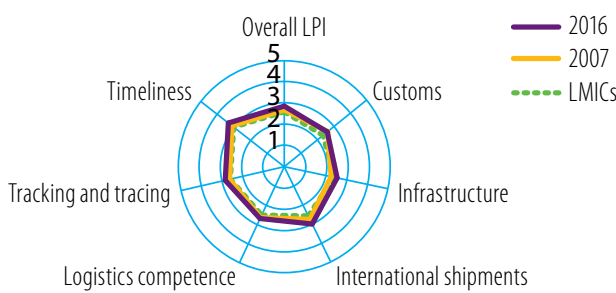

Source: WB Logistics Performance Index (LPI)

GLOBAL COMPETITIVENESS INDICATORS (1-7)

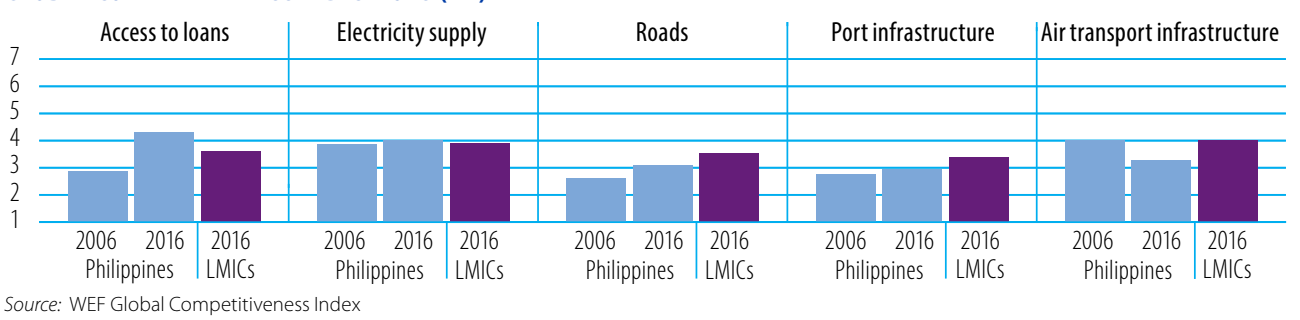

TRADE FACILITATION INDICATORS, 2017 (0-2)

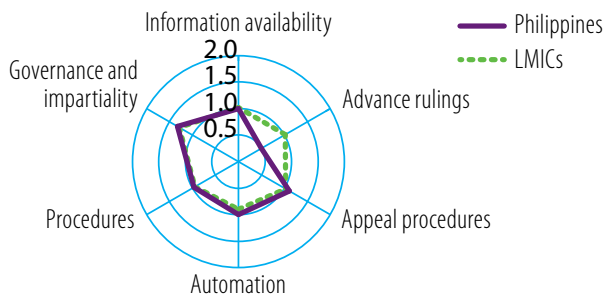

Source: OECD Trade Facilitation Indicators

100

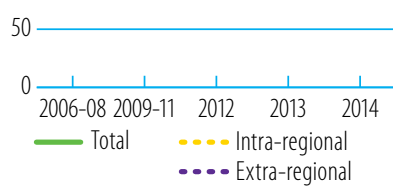

Source: ESCAP-WB Trade Cost Database

Note: Number of partners used in the

calculation of average trade costs: total (90),

intra-regional (17), extra-regional (73) 


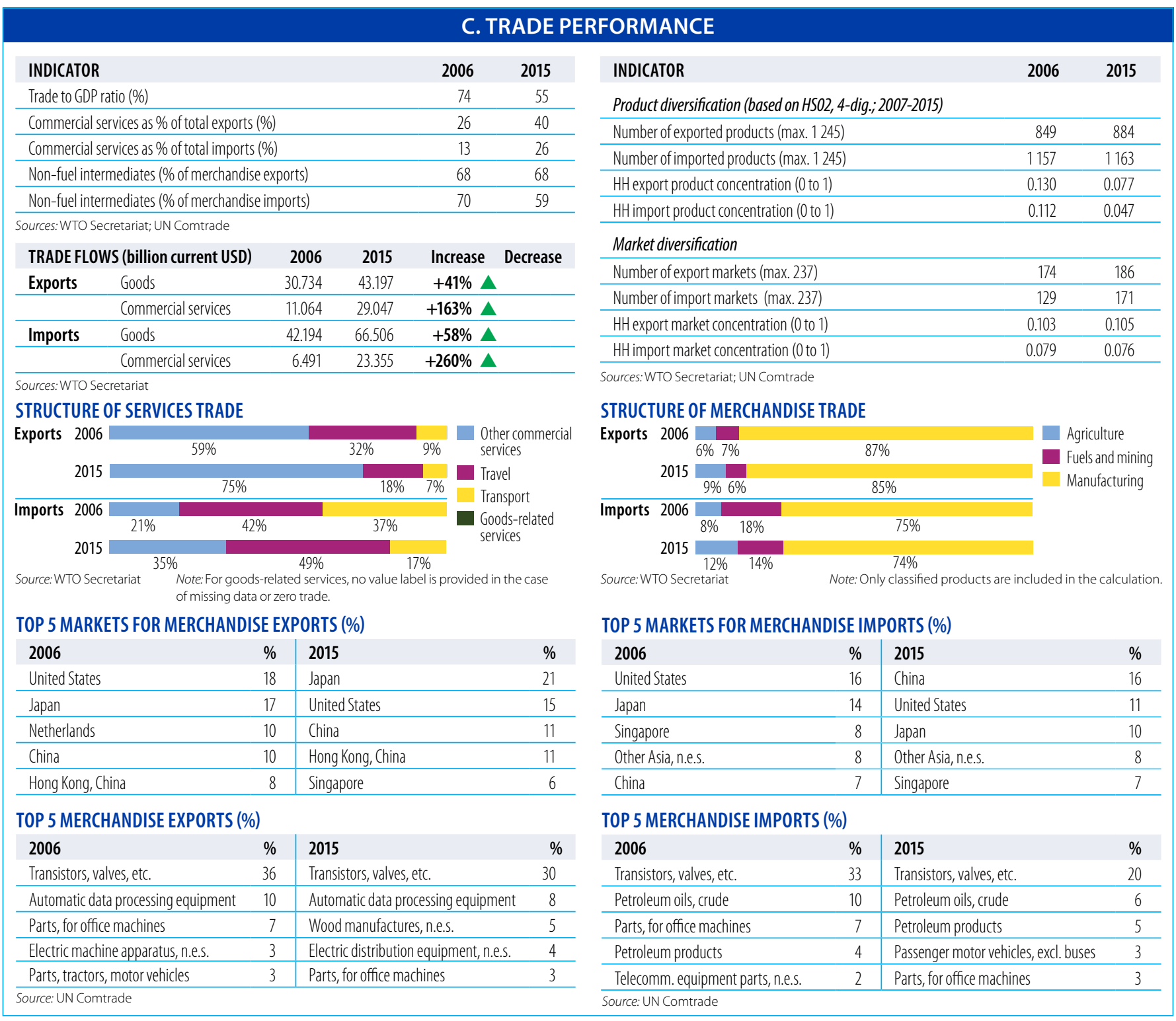

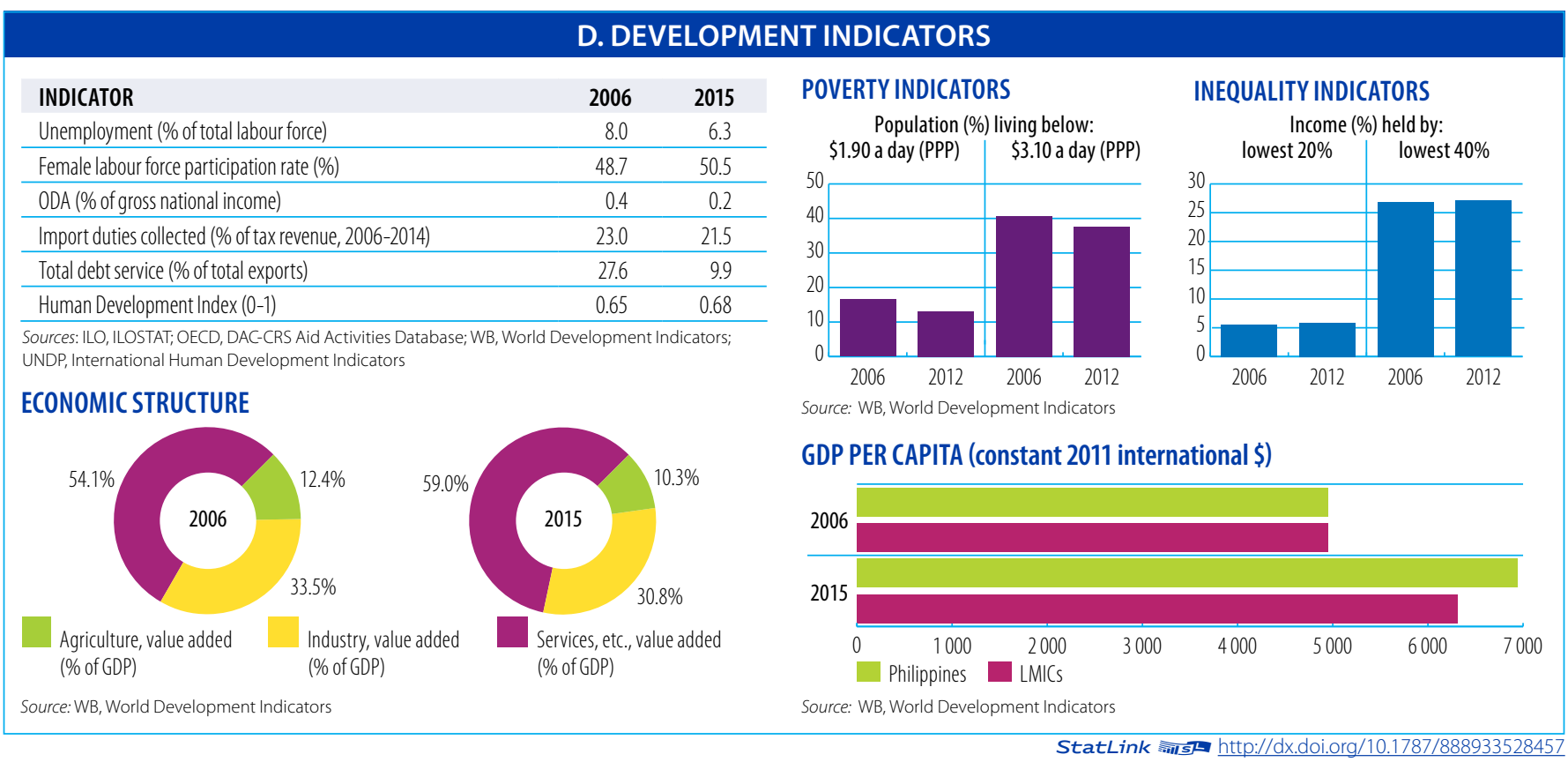


Aid, Trade and Development Indicators for Rwanda

\section{A. DEVELOPMENT FINANCE}

\begin{tabular}{|c|c|c|c|c|c|c|}
\hline \multicolumn{3}{|c|}{$\begin{array}{l}\text { EXTERNAL FINANCING INFLOWS } \\
\text { (million current USD) }\end{array}$} & $2006 / 08$ & $2012 / 14$ & 2015 & $\Delta: 06 / 08-15$ \\
\hline \multicolumn{3}{|c|}{ FDl inflows } & 71.7 & 323.8 & 471.2 & $557 \%$ \\
\hline \multicolumn{3}{|c|}{ Remittances } & 72.8 & 144.6 & 161.4 & $122 \%$ \\
\hline \multicolumn{3}{|c|}{ Other official flows (00F) } & 4.0 & 27.2 & 5.4 & $36 \%$ \\
\hline \multicolumn{3}{|c|}{ of which trade-related $00 \mathrm{~F}$} & 0.4 & 24.3 & 5.4 & $1229 \%$ \\
\hline \multicolumn{3}{|c|}{ Official Development Assistance (ODA) } & 1159.2 & 1007.1 & 1108.5 & $-4 \%$ \\
\hline \multicolumn{3}{|c|}{ of which Aid for Trade } & 102.3 & 217.6 & 340.7 & $233 \%$ \\
\hline \multicolumn{7}{|c|}{$\begin{array}{l}\text { Sources: UNCTAD, UNCTADstat; WB, World Development Indicators; OECD, } \\
\text { DAC-CRS Aid Activities Database }\end{array}$} \\
\hline \multicolumn{7}{|c|}{ TOP 3 AfT PRIORITIES } \\
\hline 1 & Export diversification & 2 & Transport infras & ructure & 3 Indust & ialization \\
\hline
\end{tabular}

Source: OECD/WTO Partner Questionnaire

SHARE OF AfT IN DEVELOPMENT FINANCE AND FIXED CAPITAL FORMATION (\%)

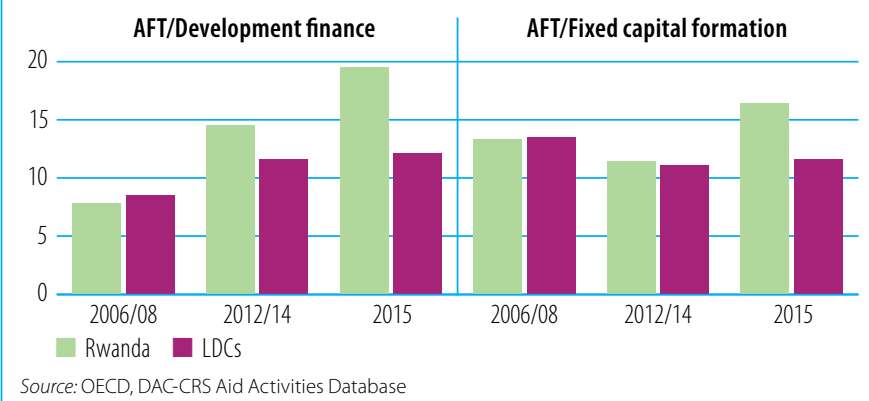

AfT DISBURSEMENTS: TOP DONORS (million current USD)

\begin{tabular}{lrr|lrc}
$\mathbf{2 0 0 6 / 0 8}$ & value & $\%$ & $\mathbf{2 0 1 5}$ & value & $\%$ \\
IDA & 31.9 & 31 & IDA & 77.9 & 23 \\
\hline EU Institutions & 17.4 & 17 & United States & 76.5 & 22 \\
\hline African Development Fund & 13.8 & 14 & United Kingdom & 65.9 & 19 \\
\hline Belgium & 10.4 & 10 & African Development Fund & 34.3 & 10 \\
\hline Japan & 5.0 & 5 & EU Institutions & 20.2 & 6 \\
\hline
\end{tabular}

Source: OECD, DAC-CRS Aid Activities Database

AfT DISBURSEMENTS BY SECTOR (million current USD)

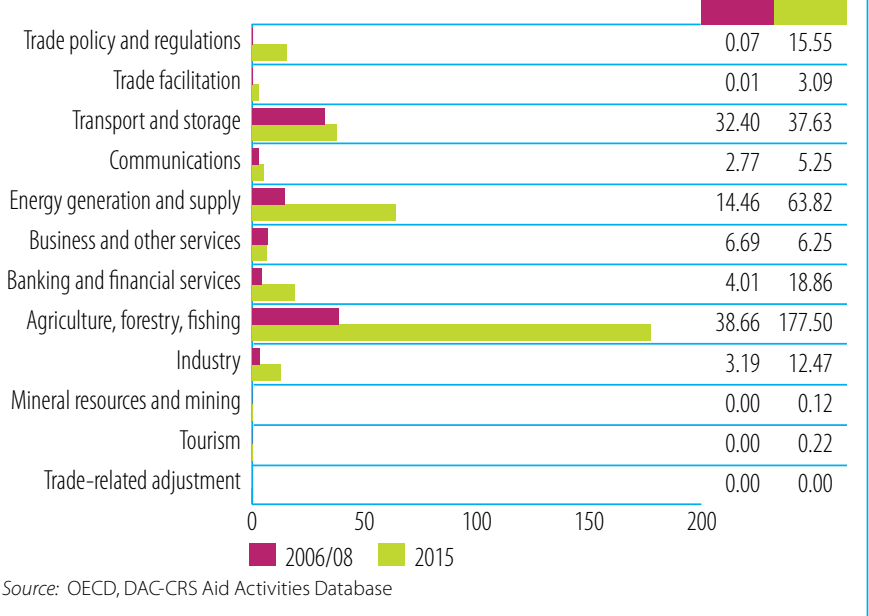

\section{B. TRADE COSTS}

\begin{tabular}{lcc} 
INDICATOR & 2006 & 2015 \\
Tariffs (\%) & & \\
\hline Imports: simple avg. MFN applied & 18.7 & 12.8 \\
\hline Imports: weighted avg. MFN applied (2006-2014) & $\ldots$ & 14.9 \\
\hline Exports: weighted avg. faced (2005-2014) & 0.9 & 0.8 \\
\hline Exports: duty free (value in \%) (2005-2014) & 90.5 & 79.6 \\
\hline ICT connectivity (\% of population) & $\ldots$ & \\
\hline Mobile broadband subscriptions & 0.0 & 25.9 \\
\hline Fixed broadband subscriptions & 0.2 \\
\hline Individuals using the internet (2007-2015) & 2.1 & 18.0 \\
\hline Sources: WTO, World Tariff Profiles; ITU, World Telecommunication/ICT Indicators &
\end{tabular}
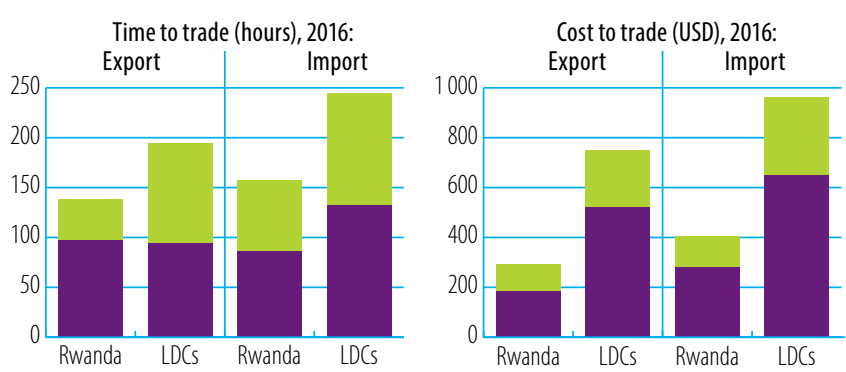

Border compliance Documentary compliance

Source: WB, Doing Business

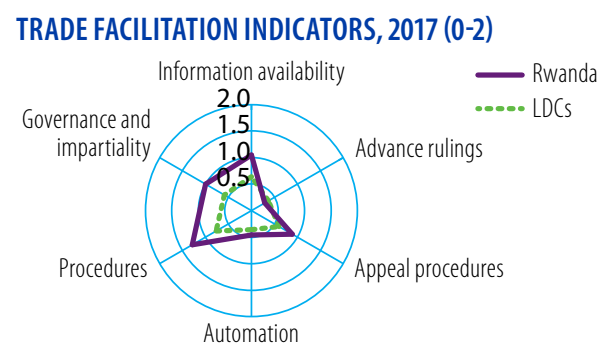

Source: OECD Trade Facilitation Indicators

GLOBAL COMPETITIVENESS INDICATORS (1-7)

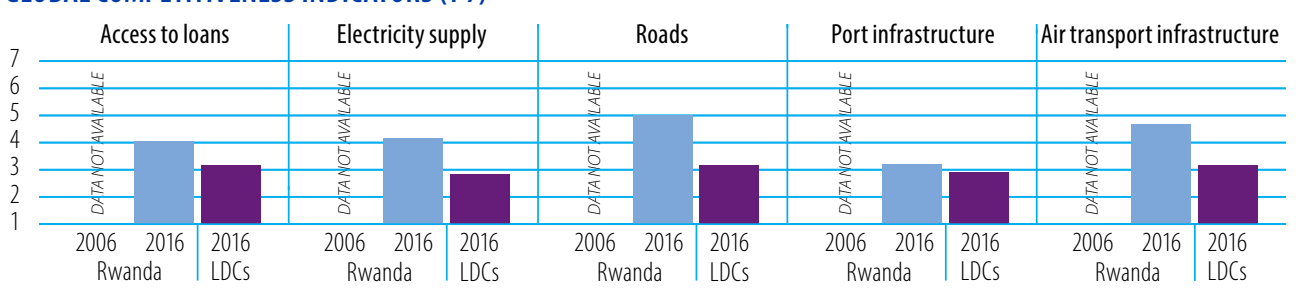

Source: WEF Global Competitiveness Index
Source: WB Logistics Performance Index (LPI)

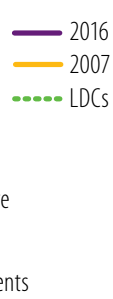

LOGISTICS PERFORMANCE INDICES (LPI) (1-5)

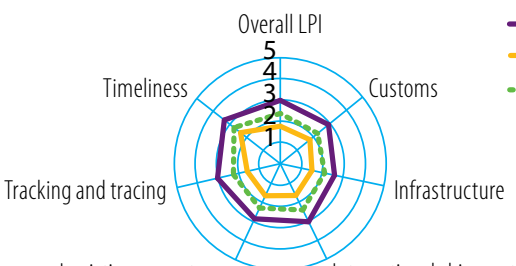

Logistics competence

\begin{tabular}{l|l}
2006 Rwanda & 2016 \\
\hline
\end{tabular}

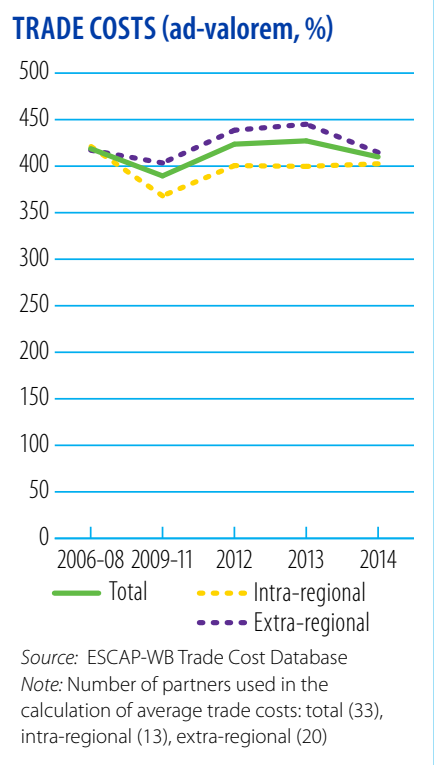




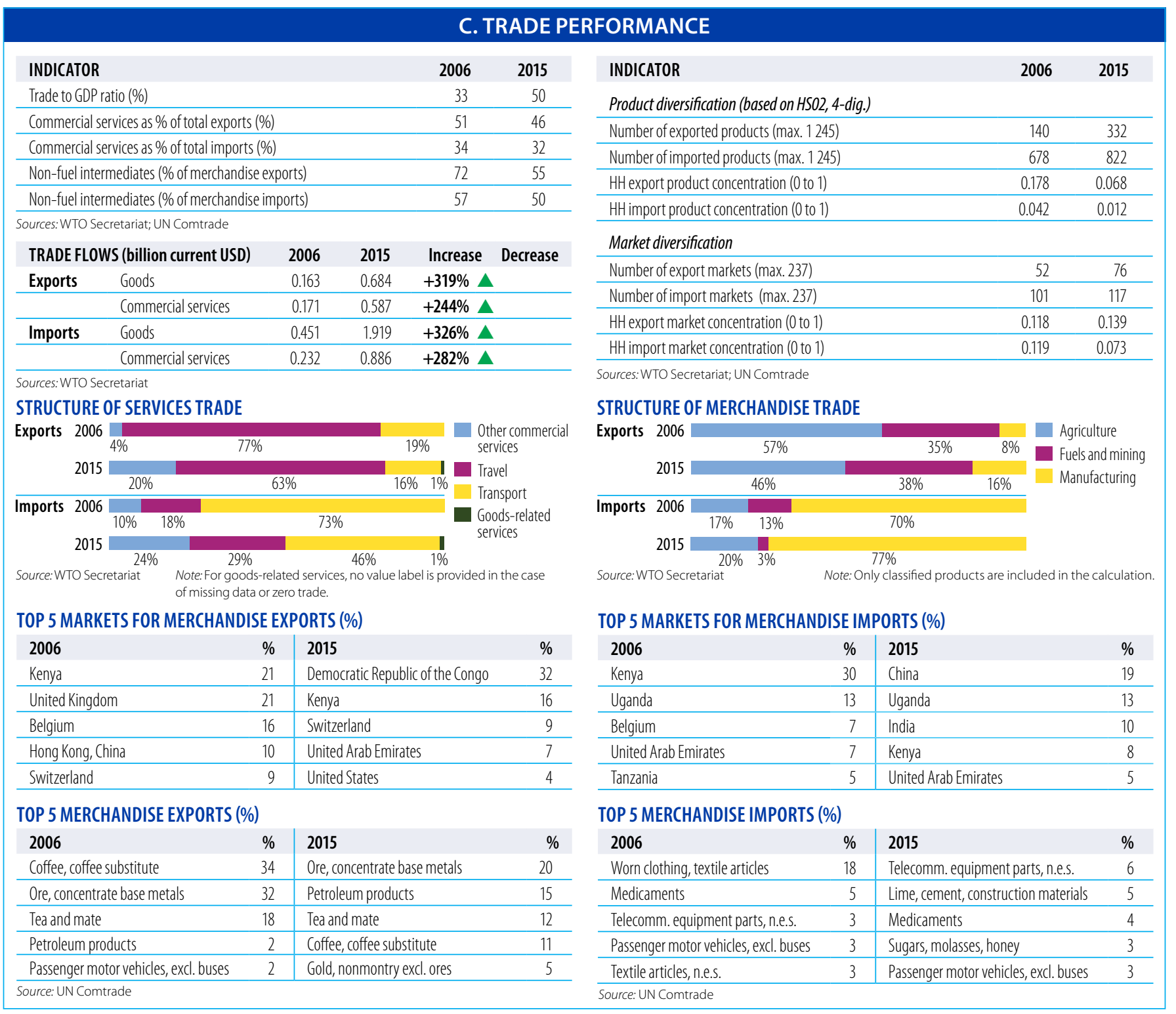

\begin{tabular}{|lrr}
\hline & D. DEVELOPME \\
\hline INDICATOR & $\mathbf{2 0 0 6}$ & $\mathbf{2 0 1 5}$ \\
\hline Unemployment (\% of total labour force) & 2.7 & 2.8 \\
\hline Female labour force participation rate (\%) & 85.7 & 86.4 \\
\hline ODA (\% of gross national income) & 19.6 & 13.7 \\
\hline Import duties collected (\% of tax revenue, 2008-2015) & 12.7 & 7.8 \\
\hline Total debt service (\% of total exports) & 6.7 & 7.7 \\
\hline Human Development Index (0-1) & 0.42 & 0.50 \\
\hline
\end{tabular}

Sources: ILO, ILOSTAT; OECD, DAC-CRS Aid Activities Database; WB, World Development Indicators; UNDP, International Human Development Indicators

\section{ECONOMIC STRUCTURE}

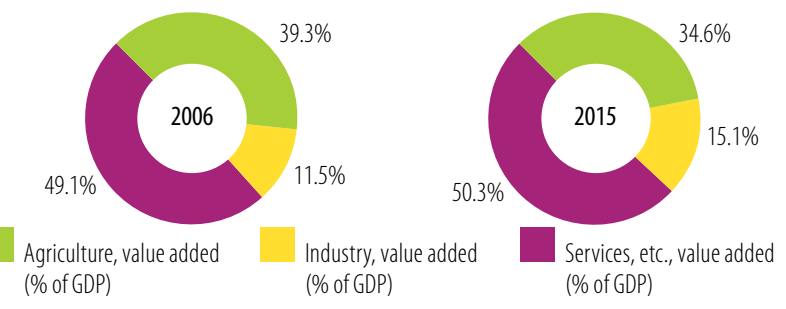

Source: WB, World Development Indicators
POVERTY INDICATORS

Population (\%) living below:

$\$ 1.90$ a day (PPP) $\quad \$ 3.10$ a day (PPP)

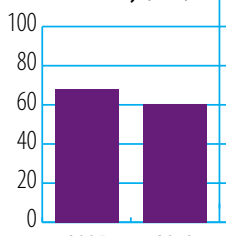

20052013

Source: W

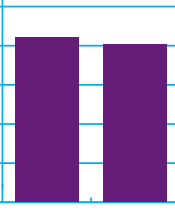

20052013
INEQUALITY INDICATORS

Income (\%) held by:

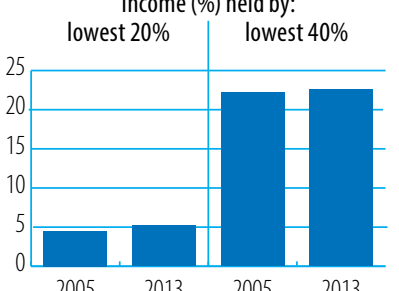

2005
GDP PER CAPITA (constant 2011 international \$)

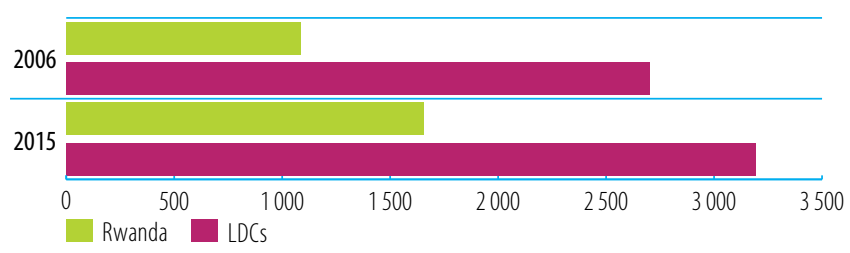

Source: WB, World Development Indicators 


\section{SAINT KITTS AND NEVIS}

Aid, Trade and Development Indicators for Saint Kitts and Nevis

\section{A. DEVELOPMENT FINANCE}

\begin{tabular}{lrrrc}
$\begin{array}{l}\text { EXTERNAL FINANCING INFL OWS } \\
\text { (million current USD) }\end{array}$ & $\mathbf{2 0 0 6 / 0 8}$ & $\mathbf{2 0 1 2 / 1 4}$ & $\mathbf{2 0 1 5}$ & $\mathbf{\Delta : 0 6 / 0 8 - 1 5}$ \\
FDl inflows & 146.4 & 122.9 & 78.2 & $-47 \%$ \\
\hline Remittances & 36.4 & 51.4 & 51.8 & $42 \%$ \\
\hline Other official flows (00F) & 2.1 & 0.1 & $\ldots$ & - \\
\hline of which trade-related 00F & 0.5 & 0.1 & $\ldots$ & - \\
\hline Official Development Assistance (ODA) & 17.6 & 20.2 & $\ldots$ & - \\
\hline of which Aid for Trade & 1.8 & 0.2 & $\ldots$ & - \\
\hline
\end{tabular}

Sources: UNCTAD, UNCTADstat; WB, World Development Indicators; OECD,

DAC-CRS Aid Activities Database

\section{TOP 3 AfT PRIORITIES}

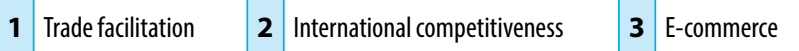

Source: OECD/WTO Partner Questionnaire

SHARE OF AfT IN DEVELOPMENT FINANCE AND FIXED CAPITAL FORMATION (\%)

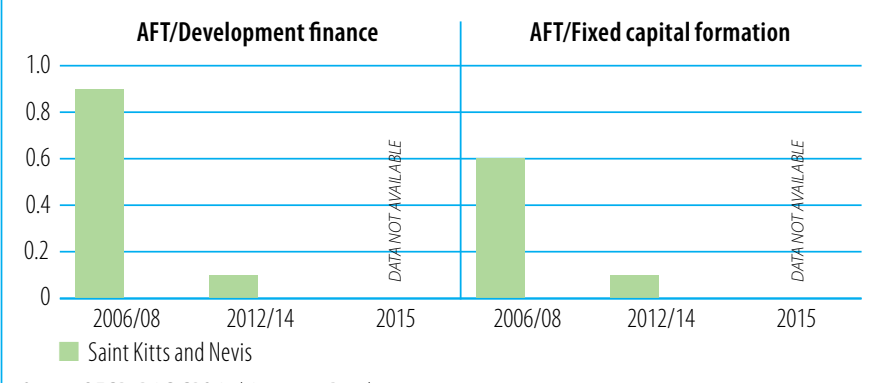

AfT DISBURSEMENTS: TOP DONORS (million current USD)

\begin{tabular}{lrr|rr}
$2006 / 08$ & value & $\%$ & 2015 & value \\
Japan & 1.6 & 92 & & \\
\hline EUInstitutions & 0.1 & 8 & & \\
\hline & & & & \\
\hline & &
\end{tabular}

Source: OECD, DAC-CRS Aid Activities Database

AfT DISBURSEMENTS BY SECTOR (million current USD)

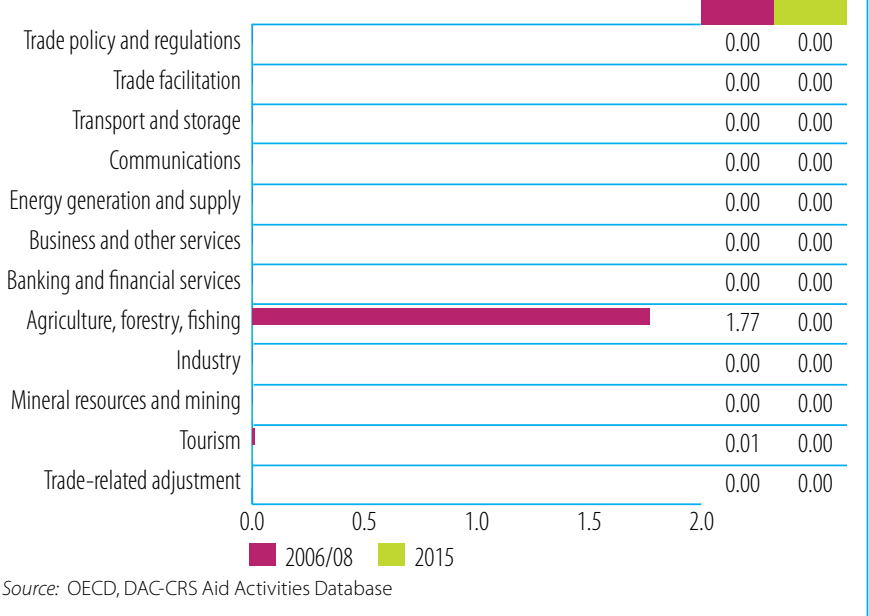

Source: OECD, DAC-CRS Aid Activities Database

\section{B. TRADE COSTS}

\begin{tabular}{lrc} 
INDICATOR & 2006 & 2015 \\
Tariffs (\%) & & \\
\hline Imports: simple avg. MFN applied & 9.2 & 9.1 \\
\hline Imports: weighted avg. MFN applied & $\ldots .2$ & $\ldots .8$ \\
\hline Exports: weighted avg. faced (2005-2014) & 98.6 & 91.8 \\
\hline Exports: duty free (value in \%) (2005-2014) & & \\
\hline ICT connectivity (\% of population) & $\ldots$ & 71.0 \\
\hline Mobile broadband subscriptions & 17.7 & 29.6 \\
\hline Fixed broadband subscriptions & 38.5 & 75.7 \\
\hline Individuals using the internet & &
\end{tabular}
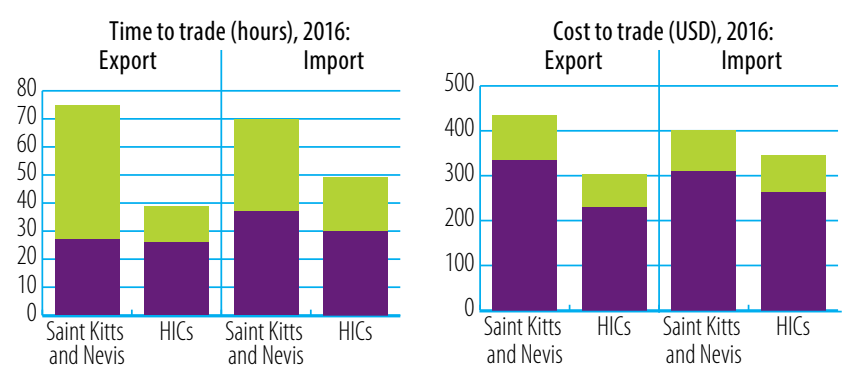

Border compliance Documentary compliance

Source: WB, Doing Business

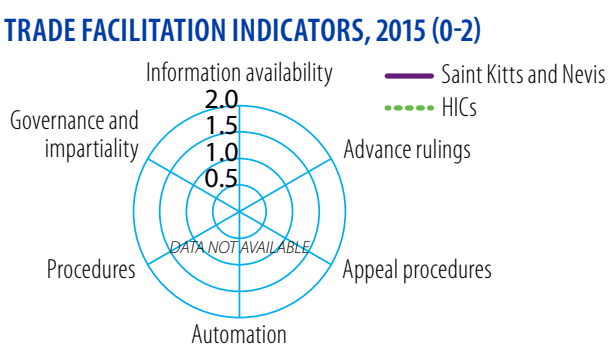

Source: OECD Trade Facilitation Indicators

Source: WB Logistics Performance Index (LPI)

GLOBAL COMPETITIVENESS INDICATORS (1-7)

\begin{tabular}{|c|c|c|c|c|c|c|c|c|c|c|}
\hline & \multicolumn{2}{|c|}{ Access to loans } & \multicolumn{2}{|c|}{ Electricity supply } & \multicolumn{2}{|l|}{ Roads } & \multicolumn{2}{|c|}{ Port infrastructure } & \multicolumn{2}{|c|}{ Air transport infrastructure } \\
\hline \\
\hline & & & & & & & & & & \\
\hline & \multicolumn{2}{|c|}{ DATA NOT AVAILABLE } & \multicolumn{2}{|c|}{ DATA NOT AVAILABLE } & \multicolumn{2}{|c|}{ DATANOT AVAILABLE } & \multicolumn{2}{|c|}{ DATANOT AVAILABLE } & \multicolumn{2}{|c|}{ DATANOT AVAILABLE } \\
\hline \\
\hline \\
\hline & & & & & & & & & & \\
\hline & $\begin{array}{rr}2006 & 2016 \\
\text { Saint Kitts and Nevis }\end{array}$ & $\begin{array}{l}2016 \\
\text { UMICs }\end{array}$ & $\begin{array}{c}20062016 \\
\text { Saint Kitts and Nevis }\end{array}$ & \begin{tabular}{|l}
2016 \\
UMICS
\end{tabular} & $\begin{array}{cc}2006 & 2016 \\
\text { Saint Kitts and Nevis }\end{array}$ & $\begin{array}{l}2016 \\
\text { UMICS }\end{array}$ & $\begin{array}{cr}2006 & 2016 \\
\text { Saint Kitts and Nevis }\end{array}$ & \begin{tabular}{|l|}
2016 \\
UMICS
\end{tabular} & $\begin{array}{c}20062016 \\
\text { Saint Kitts and Nevis }\end{array}$ & $\begin{array}{l}2016 \\
\text { UMICs }\end{array}$ \\
\hline
\end{tabular}

TRADE COSTS (ad-valorem, \%)

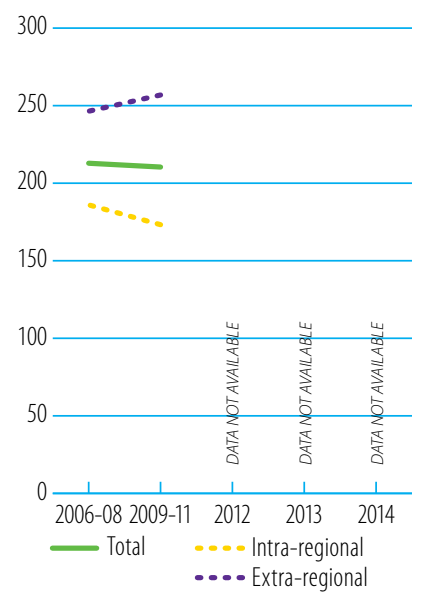

Source: ESCAP-WB Trade Cost Database Note: Number of partners used in the calculation of average trade costs: total (9), intra-regional (5), extra-regional (4) 


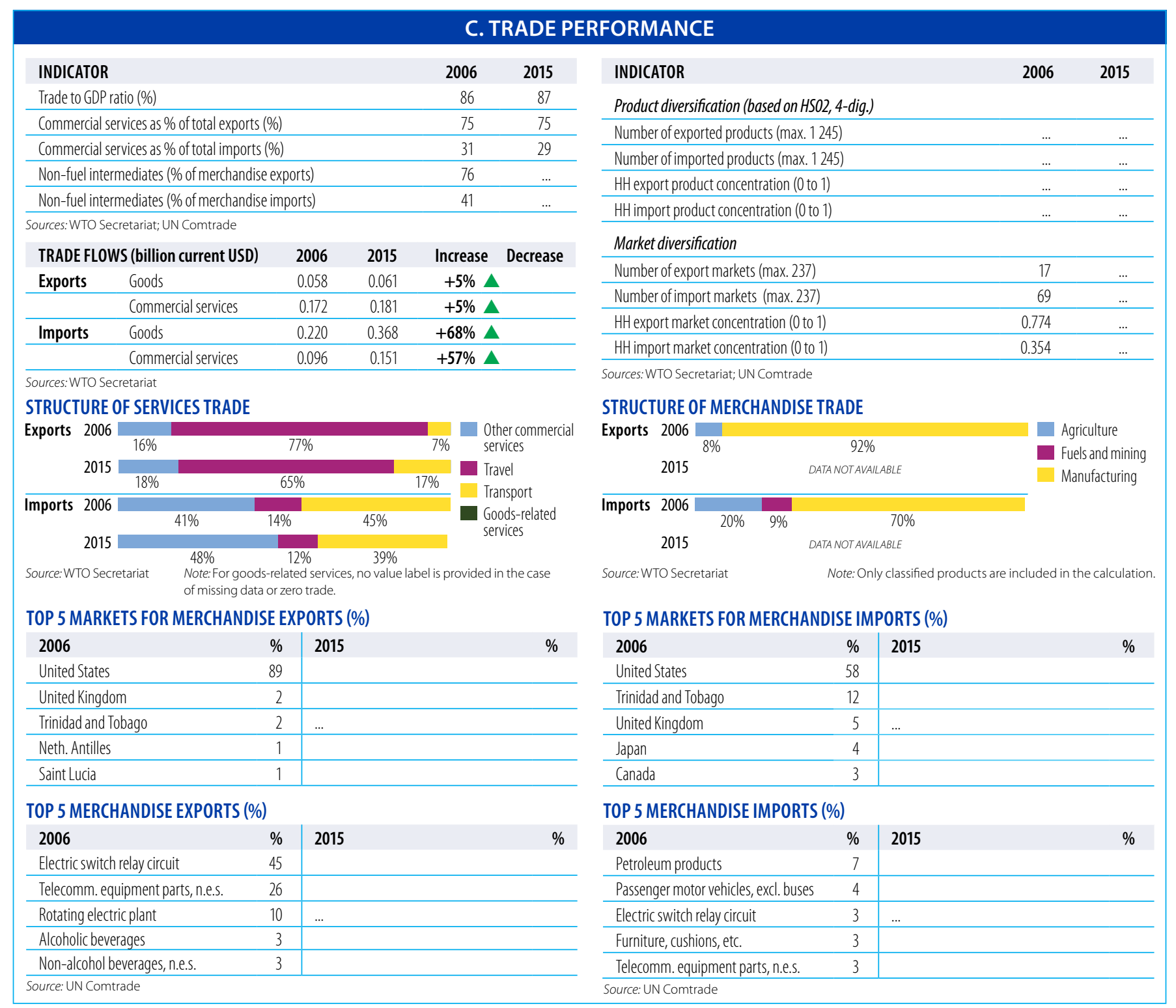

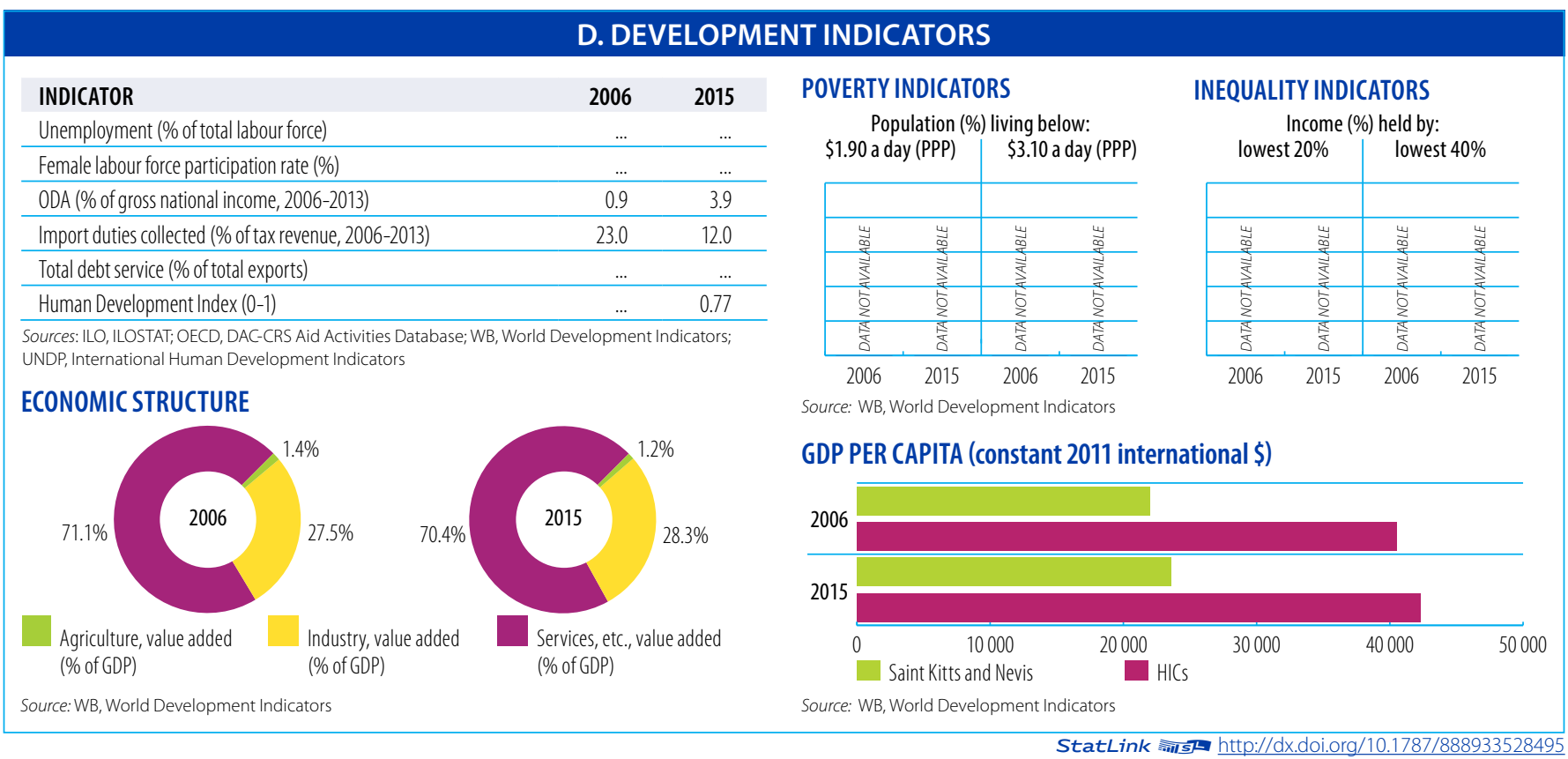




\section{SAINT LUCIA}

Aid, Trade and Development Indicators for Saint Lucia

\section{A. DEVELOPMENT FINANCE}

\begin{tabular}{lrrrc}
$\begin{array}{l}\text { EXTERNAL FINANCING INFL OWS } \\
\text { (million current USD) }\end{array}$ & $\mathbf{2 0 0 6 / 0 8}$ & $\mathbf{2 0 1 2 / 1 4}$ & $\mathbf{2 0 1 5}$ & $\mathbf{\Delta : 0 6 / 0 8 - 1 5}$ \\
\hline FDl inflows & 227.1 & 88.7 & 95.0 & $-58 \%$ \\
\hline Remittances & 28.4 & 30.0 & 30.1 & $6 \%$ \\
\hline Other official flows (00F) & 6.2 & 0.0 & 3.0 & $-52 \%$ \\
\hline$\quad$ of which trade-related 00F & 0.1 & 0.0 & 0.0 & $-100 \%$ \\
\hline Official Development Assistance (ODA) & 19.2 & 25.7 & 23.0 & $20 \%$ \\
\hline of which Aid for Trade & 7.3 & 7.2 & 3.9 & $-46 \%$ \\
\hline
\end{tabular}

Sources: UNCTAD, UNCTADstat; WB, World Development Indicators; OECD,

DAC-CRS Aid Activities Database

\section{TOP 3 AfT PRIORITIES}

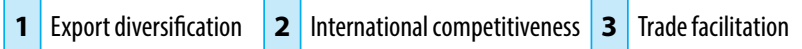
Source: OECD/WTO Partner Questionnaire

SHARE OF AfT IN DEVELOPMENT FINANCE AND FIXED CAPITAL FORMATION (\%)

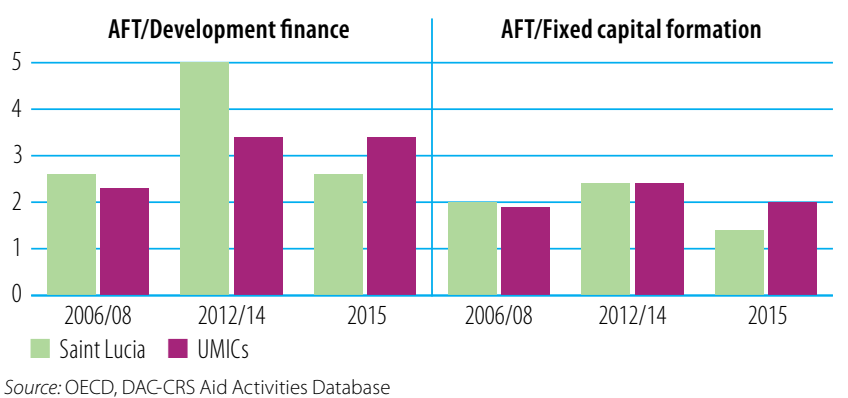

AfT DISBURSEMENTS: TOP DONORS (million current USD)

\begin{tabular}{lrr|lrc}
$\mathbf{2 0 0 6 / 0 8}$ & value & $\%$ & $\mathbf{2 0 1 5}$ & value & $\%$ \\
EU Institutions & 4.6 & 63 & IDA & 2.1 & 53 \\
\hline France & 1.7 & 24 & EU Institutions & 1.2 & 30 \\
\hline Japan & 0.9 & 12 & Japan & 0.4 & 11 \\
\hline IDA & 0.1 & 1 & Kuwait (KFAED) & 0.1 & 4 \\
\hline United Kingdom & 0.0 & 0 & Global Environment Facility & 0.0 & 1 \\
\hline
\end{tabular}

Source: OECD, DAC-CRS Aid Activities Database

AfT DISBURSEMENTS BY SECTOR (million current USD)

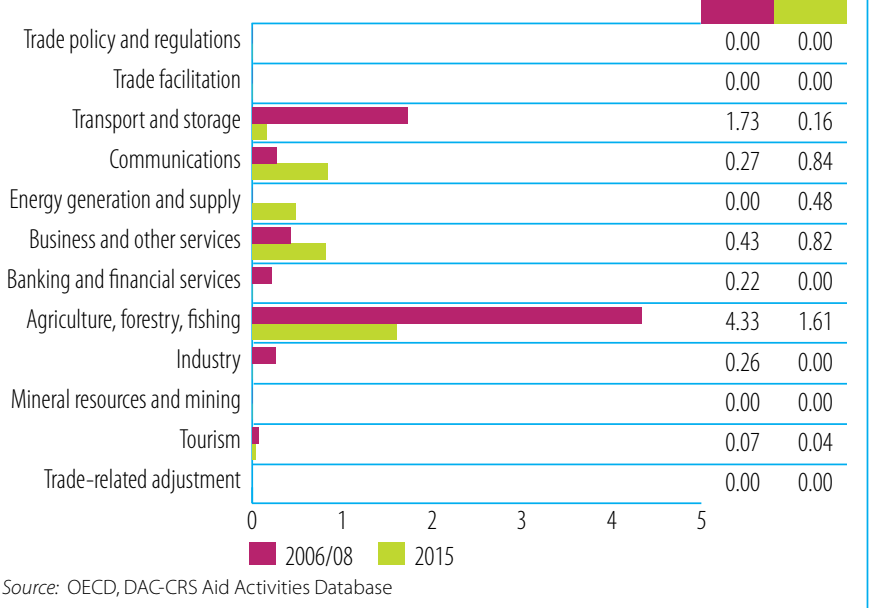

\section{B. TRADE COSTS}

\begin{tabular}{lrr} 
INDICATOR & 2006 & $\mathbf{2 0 1 5}$ \\
Tariffs (\%) & & \\
\hline Imports: simple avg. MFN applied & 8.9 & 9.1 \\
\hline Imports: weighted avg. MFN applied (2006-2014) & $\ldots$ & 12.6 \\
\hline Exports: weighted avg. faced (2005-2014) & 12.3 & 0.0 \\
\hline Exports: duty free (value in \%) (2005-2014) & 56.7 & 100.0 \\
\hline ICT connectivity (\% of population) & & \\
\hline Mobile broadband subscriptions & $\ldots$ & 33.6 \\
\hline Fixed broadband subscriptions & 4.3 & 15.4 \\
\hline Individuals using the internet & 24.5 & 52.3 \\
\hline
\end{tabular}

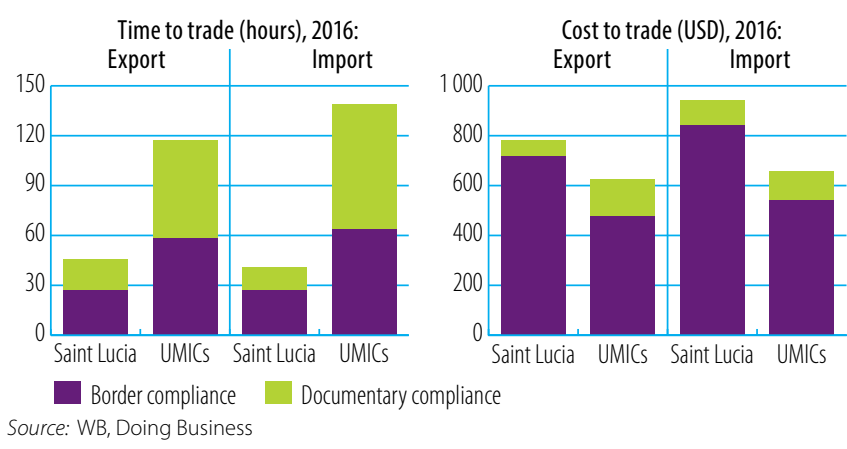

Sources: WTO, World Tariff Profiles; ITU, World Telecommunication/ICT Indicators

LOGISTICS PERFORMANCE INDICES (LPI) (1-5)

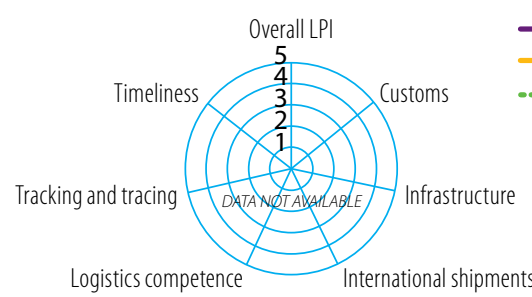

Source: WB Logistics Performance Index (LPI)

GLOBAL COMPETITIVENESS INDICATORS (1-7)

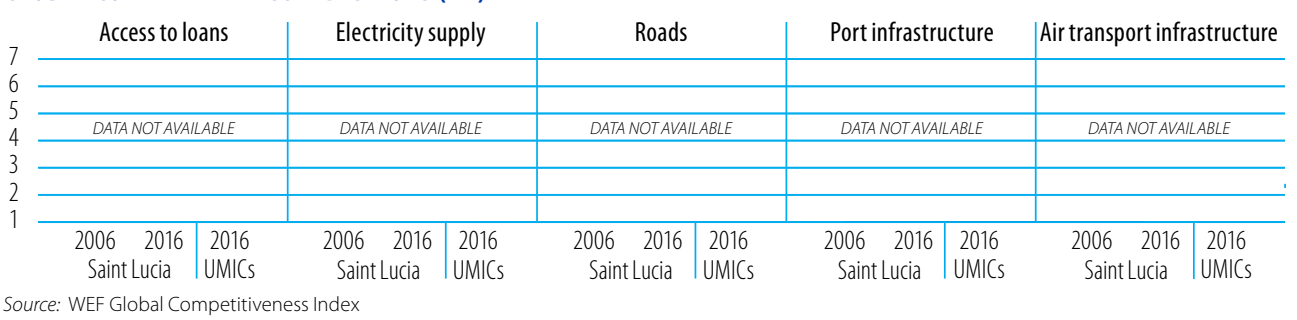

TRADE FACILITATION INDICATORS, 2015 (0-2)

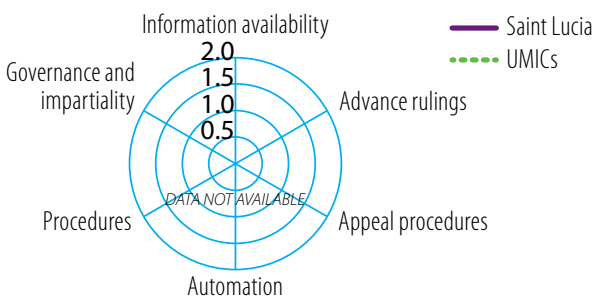

Source: OECD Trade Facilitation Indicators

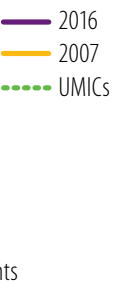

TRADE COSTS (ad-valorem, \%)

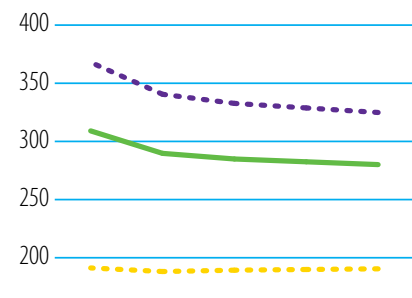

150

100

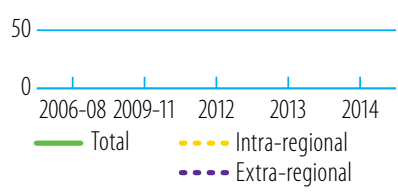

Source: ESCAP-WB Trade Cost Database

Note: Number of partners used in the

calculation of average trade costs: total (15),

intra-regional (5), extra-regional (10) 


\section{TRADE PERFORMANCE}

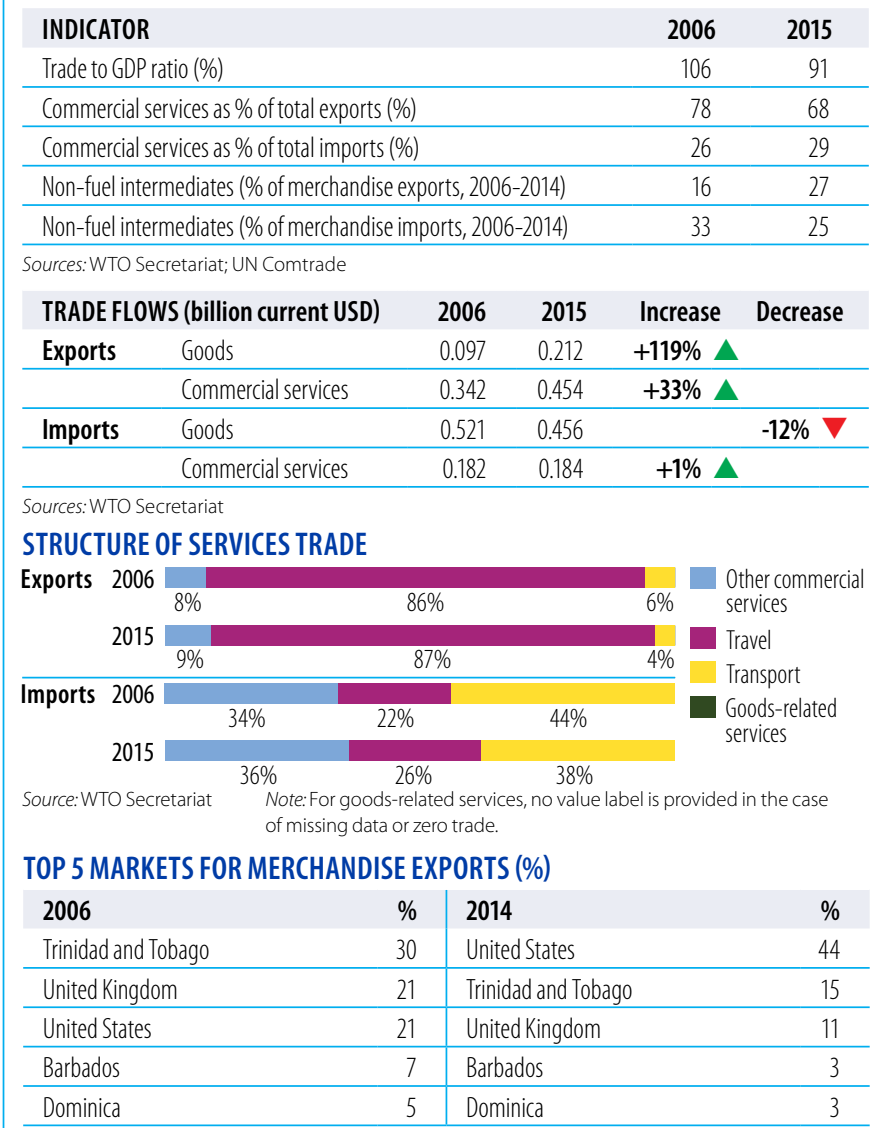

\section{TOP 5 MERCHANDISE EXPORTS (\%)}

\begin{tabular}{lc|lc}
2006 & $\%$ & 2014 & $\%$ \\
Petroleum products & 22 & Petroleum products & 21 \\
\hline Fruit, nuts excl. oil nuts & 19 & Alcoholic beverages & 15 \\
\hline Alcoholic beverages & 15 & Gold, silverware, jewel, n.e.s. & 11 \\
\hline Gold, silverware, jewel, n.e.s. & 6 & Telecomm. equipment parts, n.e.s. & 10 \\
\hline Paper, paperboard, cut, etc. & 5 & Special transactions not classified & 4 \\
\hline Source: UN Comtrade & &
\end{tabular}

\section{INDICATOR}

2006

2015

Product diversification (based on HSO2, 4-dig.; 2006-2014)

Number of exported products (max. 1245)

Number of imported products (max. 1245)

HH export product concentration (0 to 1)

HH import product concentration (0 to 1)

Market diversification

Number of export markets (max. 237)

Number of import markets (max. 237)

HH export market concentration (0 to 1)

HH import market concentration (0 to 1)

Sources: WTO Secretariat; UN Comtrade

STRUCTURE OF MERCHANDISE TRADE

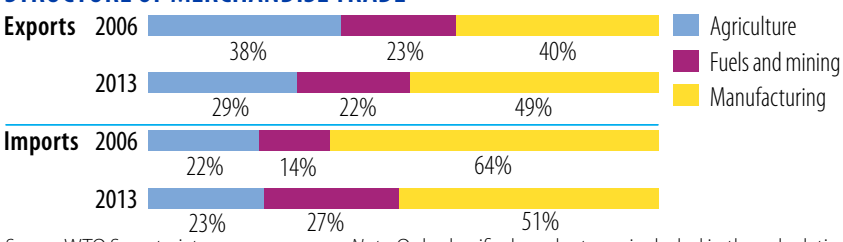

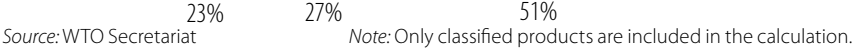

TOP 5 MARKETS FOR MERCHANDISE IMPORTS (\%)

\begin{tabular}{lc|lr}
2006 & $\%$ & 2014 & $\%$ \\
United States & 39 & United States & 45 \\
\hline Trinidad and Tobago & 17 & Trinidad and Tobago & 21 \\
\hline United Kingdom & 7 & United Kingdom & 4 \\
\hline Japan & 6 & Barbados & 3 \\
\hline Barbados & 4 & Jamaica & 2 \\
\hline
\end{tabular}

\section{TOP 5 MERCHANDISE IMPORTS (\%)}

\begin{tabular}{lc|lr}
2006 & $\%$ & 2014 & $\%$ \\
Petroleum products & 12 & Petroleum products & 23 \\
\hline Passenger motor vehicles, excl. buses & 5 & Special transactions not classified & 3 \\
\hline Goods, special-purpose transport vehicles & 3 & Other meat, meat offal & 3 \\
\hline Furniture, cushions, etc. & 2 & Passenger motor vehicles, excl. buses & 2 \\
\hline Other meat, meat offal & 2 & Telecomm. equipment parts, n.e.s. & 2 \\
\hline Source: UN Comtrade & &
\end{tabular}

\section{DEVELOPMENT INDICATORS}

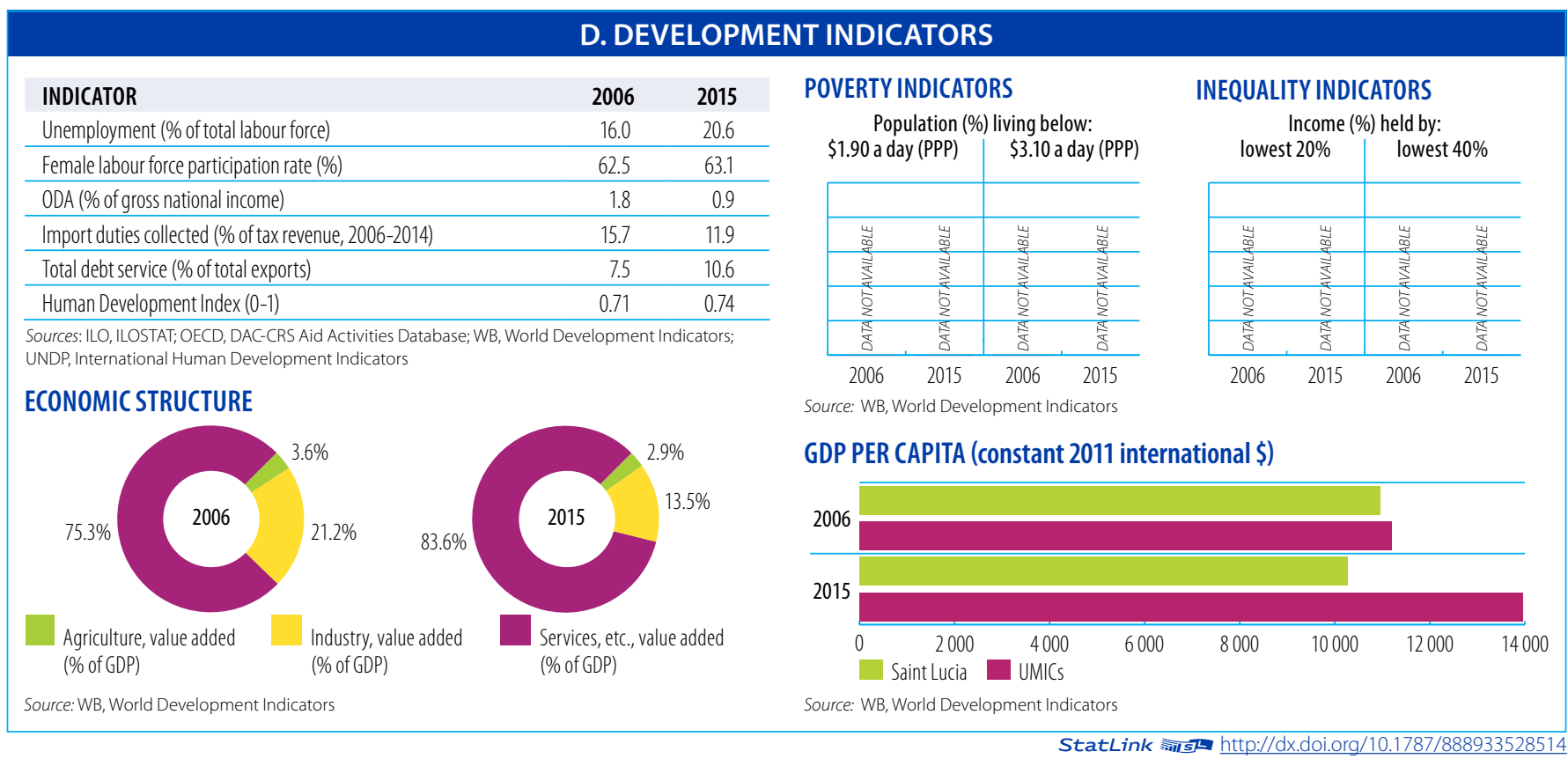




\section{SAINT VINCENT AND THE GRENADINES}

Aid, Trade and Development Indicators for Saint Vincent and the Grenadines

\section{A. DEVELOPMENT FINANCE}

\begin{tabular}{lrrrc}
$\begin{array}{l}\text { EXTERNAL FINANCING INFLOWS } \\
\text { (million current USD) }\end{array}$ & $\mathbf{2 0 0 6 / 0 8}$ & $\mathbf{2 0 1 2 / 1 4}$ & $\mathbf{2 0 1 5}$ & $\mathbf{\Delta : 0 6 / 0 8 - 1 5}$ \\
\hline FDl inflows & 130.0 & 128.4 & 120.7 & $-7 \%$ \\
\hline Remittances & 27.1 & 31.4 & 31.6 & $17 \%$ \\
\hline Other official flows (00F) & 2.3 & 0.0 & 3.7 & $59 \%$ \\
\hline of which trade-related O0F & 0.8 & 0.0 & 0.0 & $-100 \%$ \\
\hline Official Development Assistance (ODA) & 31.3 & 11.4 & 18.5 & $-41 \%$ \\
\hline of which Aid for Trade & 9.6 & 1.7 & 1.8 & $-81 \%$ \\
\hline
\end{tabular}

Sources: UNCTAD, UNCTADstat; WB, World Development Indicators; OECD,

DAC-CRS Aid Activities Database

\section{TOP 3 AfT PRIORITIES}

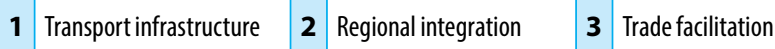

Source: OECD/WTO Partner Questionnaire

SHARE OF AfT IN DEVELOPMENT FINANCE AND FIXED CAPITAL FORMATION (\%)

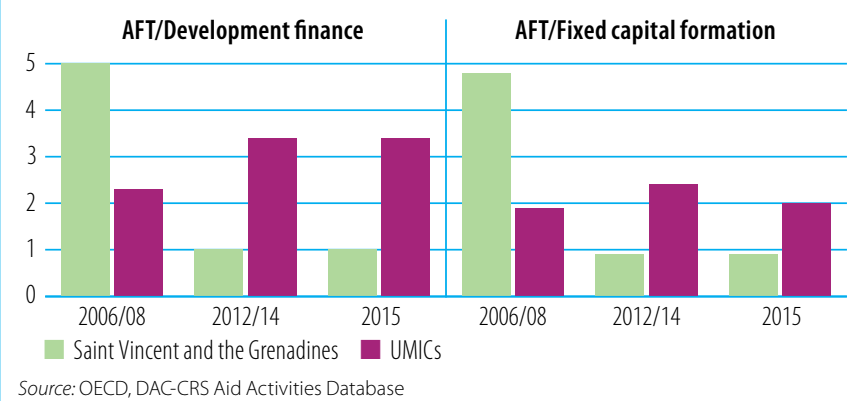

AfT DISBURSEMENTS: TOP DONORS (million current USD)

\begin{tabular}{lrr|lrr}
$\mathbf{2 0 0 6 / 0 8}$ & value & $\%$ & $\mathbf{2 0 1 5}$ & value & $\%$ \\
EU Institutions & 5.2 & 54 & EU Institutions & 0.8 & 44 \\
\hline Japan & 4.0 & 42 & Japan & 0.5 & 28 \\
\hline IDA & 0.2 & 2 & IDA & 0.5 & 26 \\
\hline Germany & 0.1 & 1 & Austria & 0.0 & 1 \\
\hline Austria & 0.1 & 1 & New Zealand & 0.0 & 0 \\
\hline
\end{tabular}

Source: OECD, DAC-CRS Aid Activities Database

AfT DISBURSEMENTS BY SECTOR (million current USD)

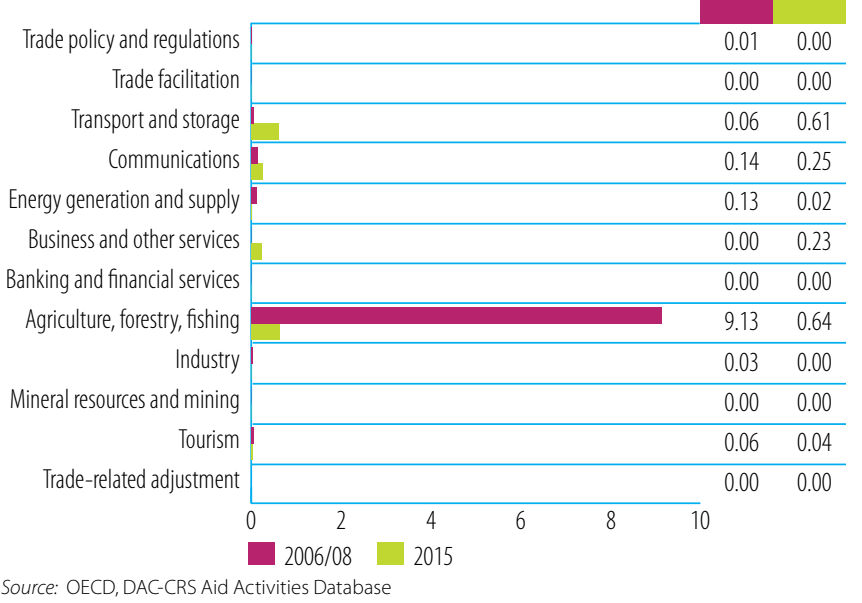

\section{B. TRADE COSTS}

\begin{tabular}{lrc} 
INDICATOR & 2006 & $\mathbf{2 0 1 5}$ \\
Tariffs (\%) & & \\
\hline Imports: simple avg. MFN applied & 9.8 & 10.0 \\
\hline Imports: weighted avg. MFN applied (2006-2012) & 2.4 & 12.4 \\
\hline Exports: weighted avg. faced (2005-2014) & 95.3 & 100.0 \\
\hline Exports: duty free (value in \%) (2005-2014) & & \\
\hline ICT connectivity (\% of population) & 0.0 & 39.0 \\
\hline Mobile broadband subscriptions (2008-2015) & 5.2 & 15.5 \\
\hline Fixed broadband subscriptions & 12.0 & 51.8 \\
\hline Individuals using the internet & &
\end{tabular}
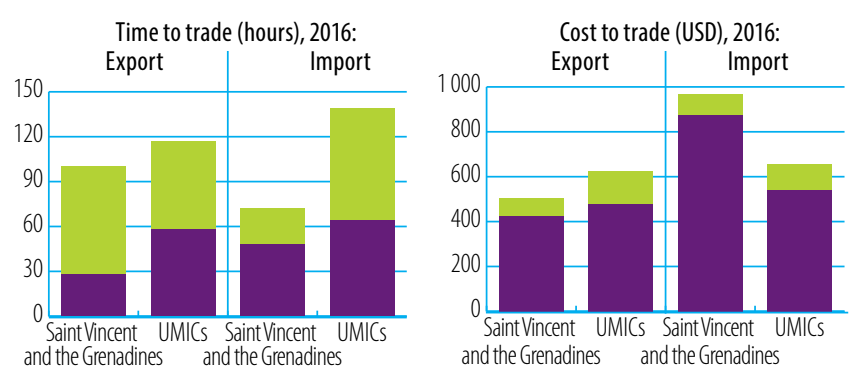

Border compliance Documentary compliance

Source: WB, Doing Business

\section{LOGISTICS PERFORMANCE INDICES (LPI) (1-5)}

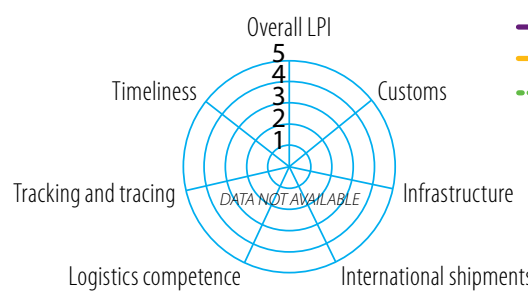

Source: WB Logistics Performance Index (LPI)

\section{GLOBAL COMPETITIVENESS INDICATORS (1-7)}

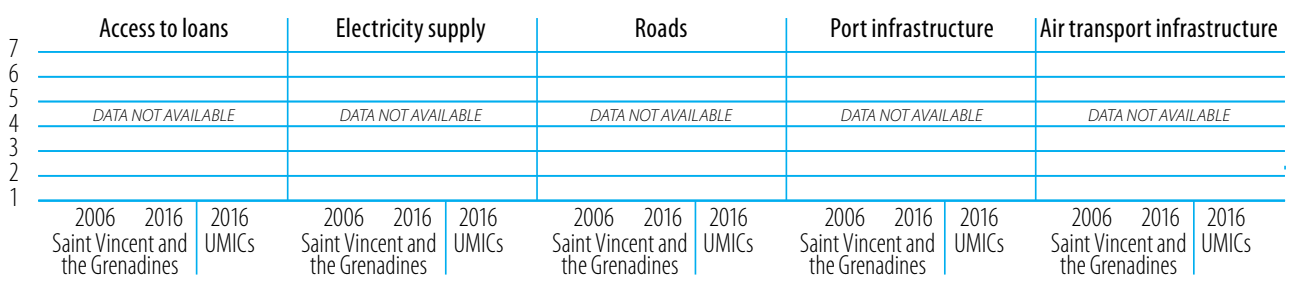

TRADE FACILITATION INDICATORS, 2015 (0-2)

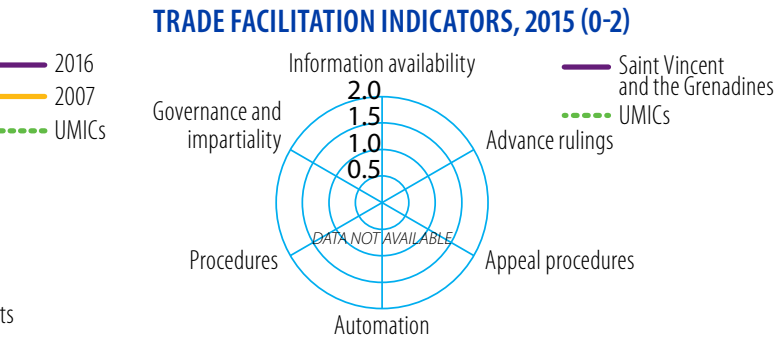

Source: OECD Trade Facilitation Indicators

Source: WEF Global Competitiveness Index
TRADE COSTS (ad-valorem, \%)
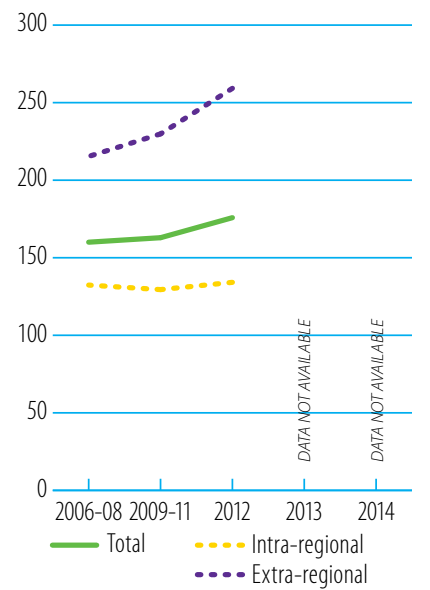

Source: ESCAP-WB Trade Cost Database Note: Number of partners used in the calculation of average trade costs: total (9) intra-regional (6), extra-regional (3) 


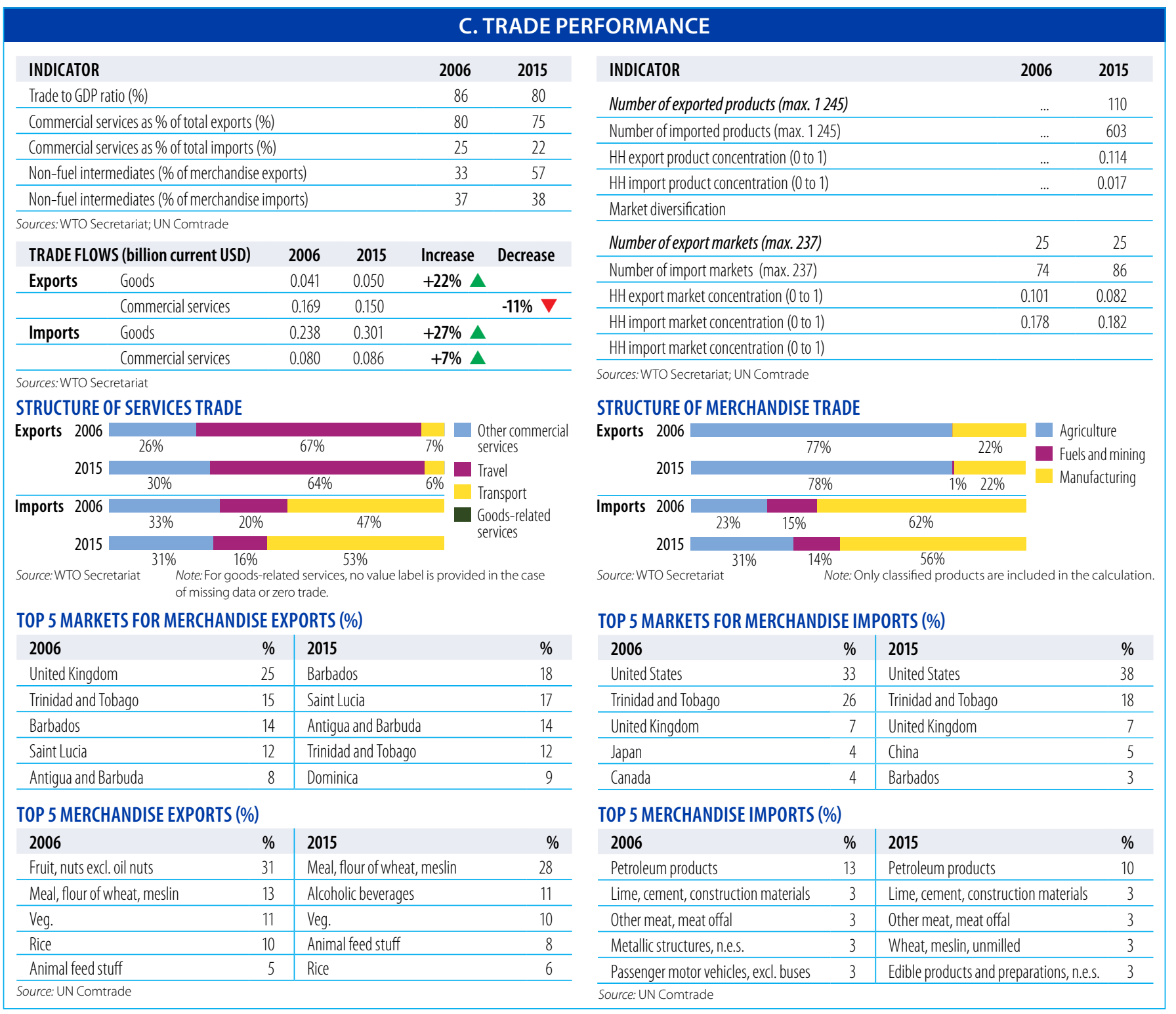

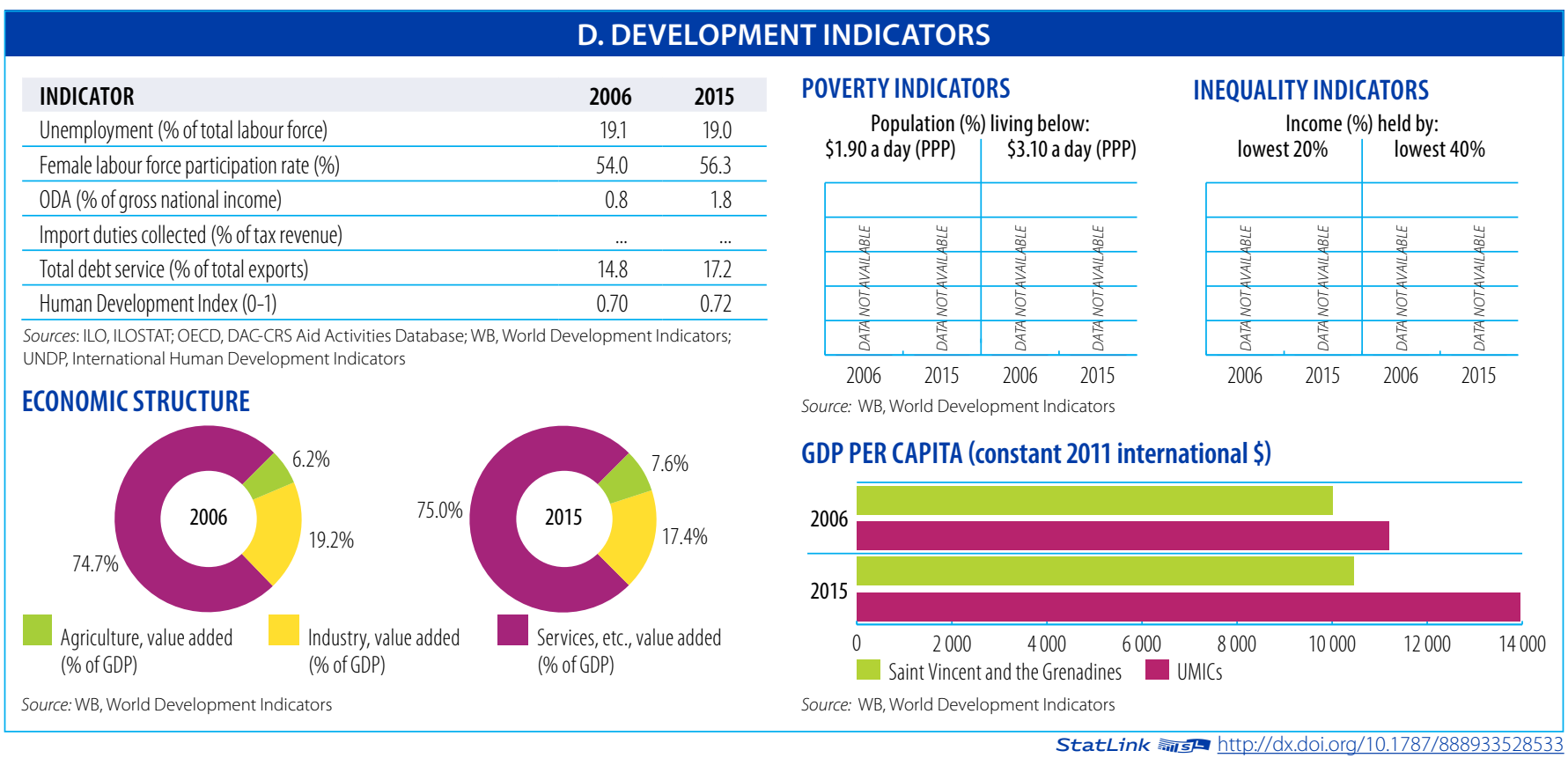


Aid, Trade and Development Indicators for Samoa

\section{A. DEVELOPMENT FINANCE}

\begin{tabular}{lrrrc}
$\begin{array}{l}\text { EXTERNAL FINANCING INFLOWS } \\
\text { (million current USD) }\end{array}$ & $\mathbf{2 0 0 6 / 0 8}$ & $\mathbf{2 0 1 2 / 1 4}$ & $\mathbf{2 0 1 5}$ & $\mathbf{\Delta : 0 6 / 0 8 - 1 5}$ \\
FDl inflows & 26.1 & 21.1 & 15.6 & $-40 \%$ \\
\hline Remittances & 97.6 & 160.9 & 154.2 & $58 \%$ \\
\hline Other official flows (00F) & 0.5 & 1.0 & 0.2 & $-65 \%$ \\
\hline of which trade-related 0OF & 0.0 & 0.0 & 0.1 & - \\
\hline Official Development Assistance (ODA) & 42.8 & 115.5 & 102.1 & $139 \%$ \\
\hline of which Aid for Trade & 8.4 & 29.3 & 31.5 & $275 \%$ \\
\hline
\end{tabular}

Sources: UNCTAD, UNCTADstat; WB, World Development Indicators; OECD,

DAC-CRS Aid Activities Database

\section{TOP 3 AfT PRIORITIES}

\begin{tabular}{|l|l|l|l|l|l|}
\hline $\mathbf{1}$ & Network infrastructure & $\mathbf{2}$ & Transport infrastructure & $\mathbf{3}$ & Trade policy \\
\hline
\end{tabular}

Source: OECD/WTO Partner Questionnair

SHARE OF AfT IN DEVELOPMENT FINANCE AND FIXED CAPITAL FORMATION (\%)

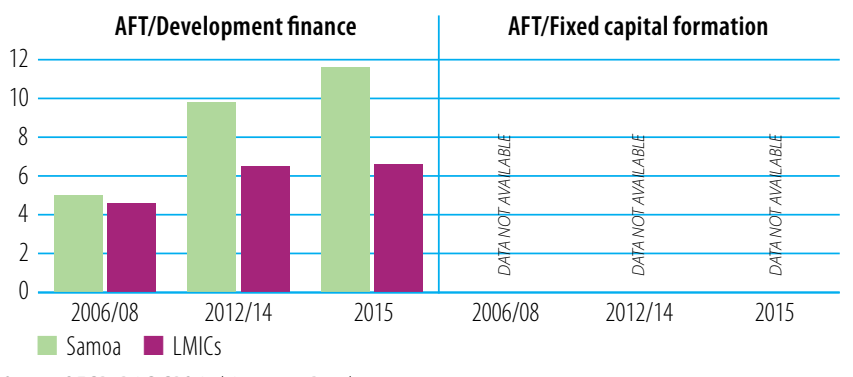

AfT DISBURSEMENTS: TOP DONORS (million current USD)

\begin{tabular}{lrr|lrc}
$\mathbf{2 0 0 6 / 0 8}$ & value & $\%$ & $\mathbf{2 0 1 5}$ & value & $\%$ \\
Japan & 3.5 & 42 & IDA & 12.9 & 41 \\
\hline IDA & 2.6 & 31 & New Zealand & 3.3 & 11 \\
\hline Australia & 1.8 & 22 & Japan & 3.3 & 10 \\
\hline New Zealand & 0.4 & 4 & EU Institutions & 3.3 & 10 \\
\hline UNDP & 0.0 & 0 & AsDB Special Funds & 2.9 & 9 \\
\hline
\end{tabular}

Source: OECD, DAC-CRS Aid Activities Database

AfT DISBURSEMENTS BY SECTOR (million current USD)

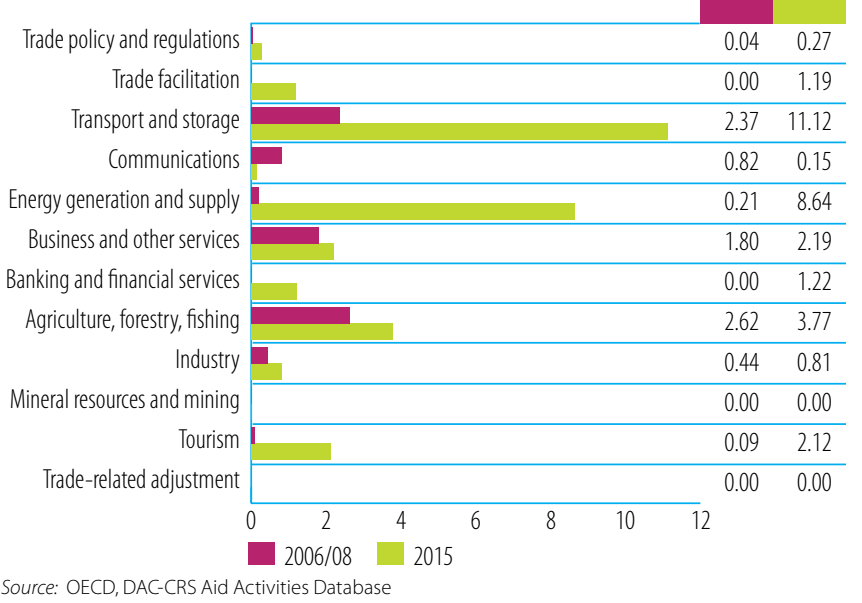

\section{B. TRADE COSTS}

\begin{tabular}{lcc} 
INDICATOR & 2006 & 2015 \\
Tariffs (\%) & & \\
\hline Imports: simple avg. MFN applied & $\ldots$ & 11.4 \\
\hline Imports: weighted avg. MFN applied (2006-2014) & $\ldots$ & 10.0 \\
\hline Exports: weighted avg. faced (2006-2014) & $\ldots$ & 1.2 \\
\hline Exports: duty free (value in \%) (2006-2014) & $\ldots$ & 87.9 \\
\hline ICT connectivity (\% of population) & $\ldots$ & \\
\hline Mobile broadband subscriptions & $\ldots .1$ & 1.1 \\
\hline Fixed broadband subscriptions & 4.5 & 25.4 \\
\hline Individuals using the internet & $\ldots .6$ &
\end{tabular}
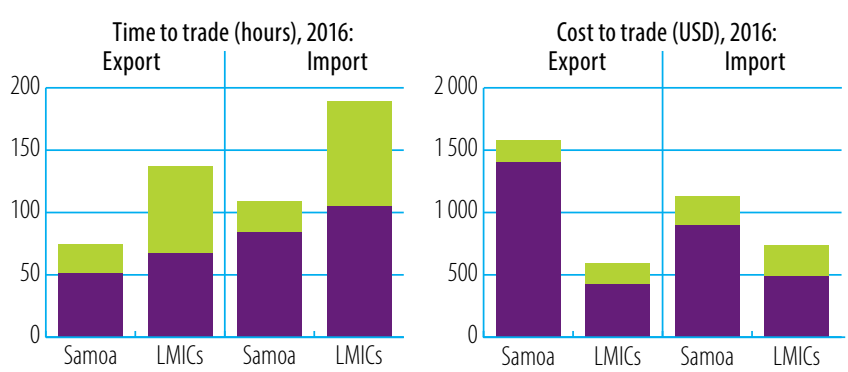

- Border compliance Documentary compliance Source: WB, Doing Business
LOGISTICS PERFORMANCE INDICES (LPI) (1-5)

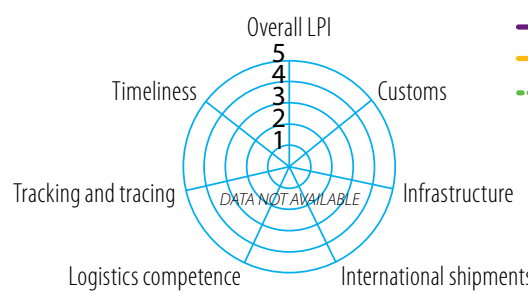

Source: WB Logistics Performance Index (LPI)

GLOBAL COMPETITIVENESS INDICATORS (1-7)

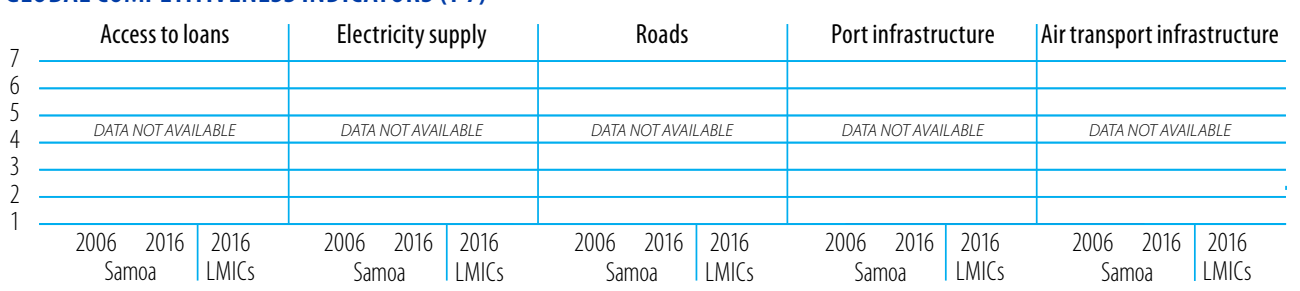

TRADE FACILITATION INDICATORS, 2015 (0-2)

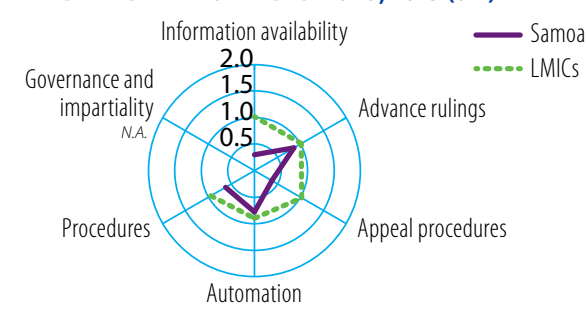

Source: OECD Trade Facilitation Indicators

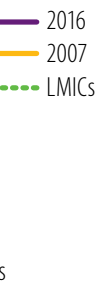

Source: WEF Global Competitiveness Index 


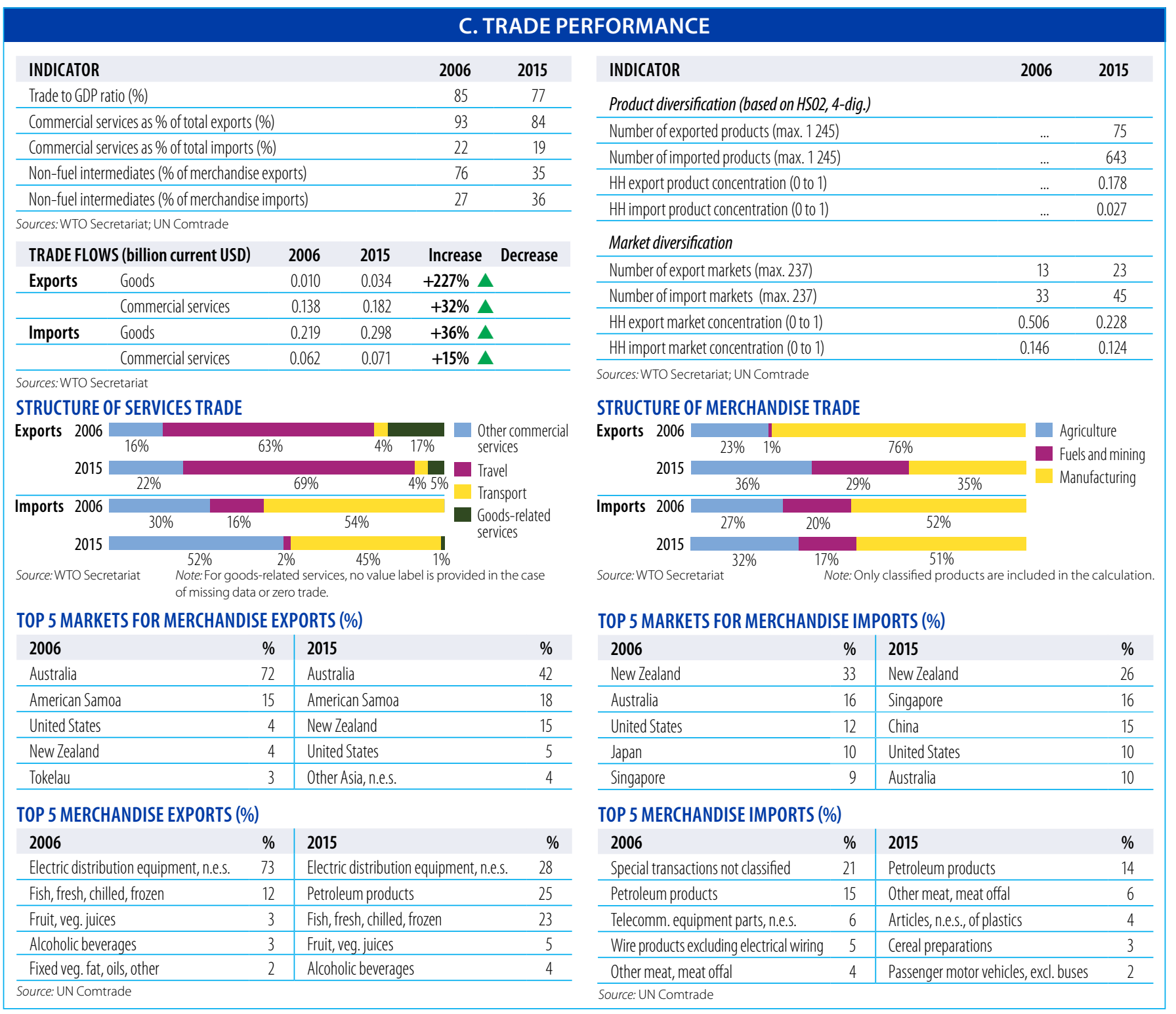

\begin{tabular}{|lrr}
\hline & D. DEVELOPME \\
\hline INDICATOR & $\mathbf{2 0 0 6}$ & $\mathbf{2 0 1 5}$ \\
\hline Unemployment (\% of total labour force) & 1.3 & 7.7 \\
\hline Female labour force participation rate (\%) & 27.4 & 23.1 \\
\hline ODA (\% of gross national income) & 10.0 & 12.8 \\
\hline Import duties collected (\% of tax revenue, 2006-2014) & $\ldots$ & 12.3 \\
\hline Total debt service (\% of total exports) & 4.6 & 11.0 \\
\hline Human Development Index (0-1) & 0.68 & 0.70 \\
\hline
\end{tabular}

Sources: ILO, ILOSTAT; OECD, DAC-CRS Aid Activities Database; WB, World Development Indicators; UNDP, International Human Development Indicators

\section{ECONOMIC STRUCTURE}

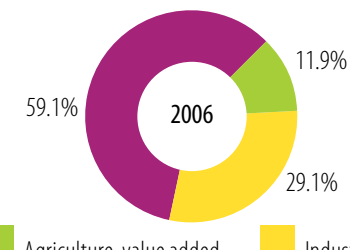

Agriculture, value added (\% of GDP)
Industry, value added (\% of GDP)

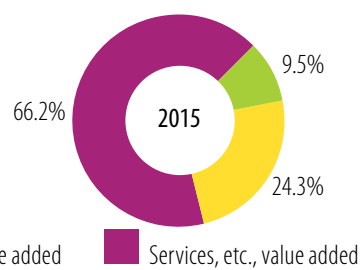

( $\%$ of GDP)
Source: WB, World Development Indicators

\section{POVERTY INDICATORS}

Population (\%) living below:

$\$ 1.90$ a day (PPP) $\quad \$ 3.10$ a day (PPP)

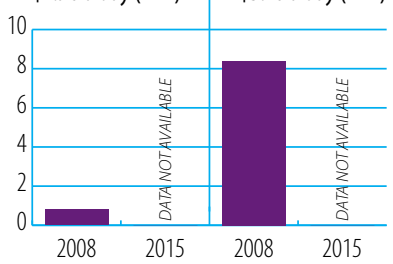

Source: WB, World Development Indicators

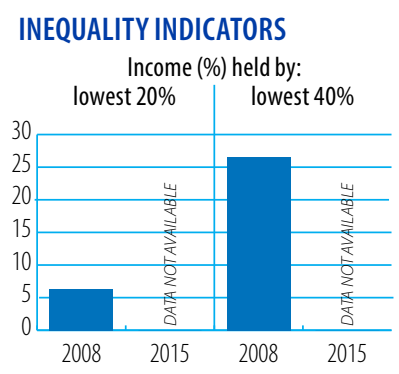

GDP PER CAPITA (constant 2011 international \$)

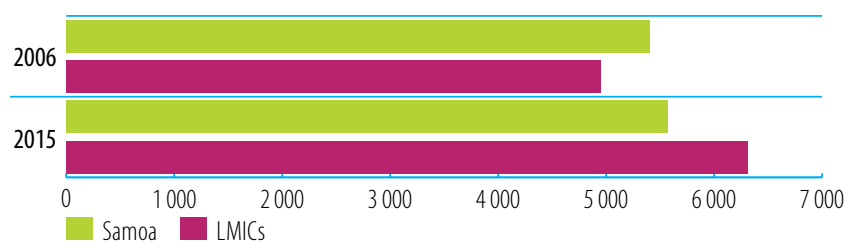

Source: WB, World Development Indicators 
Aid, Trade and Development Indicators for Senegal

\section{A. DEVELOPMENT FINANCE}

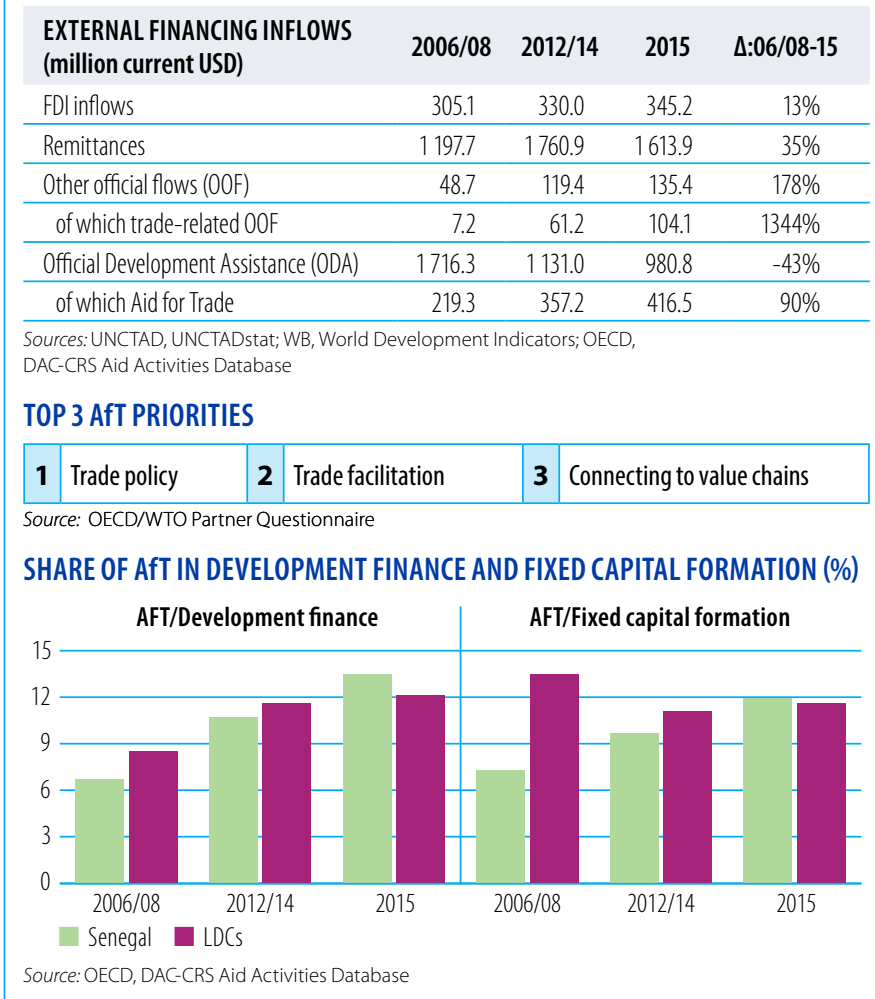

AfT DISBURSEMENTS: TOP DONORS (million current USD)

\begin{tabular}{lrr|lrr}
$\mathbf{2 0 0 6 / 0 8}$ & value & $\%$ & $\mathbf{2 0 1 5}$ & value & $\%$ \\
IDA & 62.6 & 29 & United States & 184.8 & 44 \\
\hline EU Institutions & 45.3 & 21 & IDA & 85.9 & 21 \\
\hline France & 44.9 & 20 & France & 36.7 & 9 \\
\hline African Development Fund & 10.6 & 5 & EU Institutions & 22.6 & 5 \\
\hline Germany & 10.6 & 5 & African Development Fund & 15.6 & 4 \\
\hline Source: OECD, DAC-CRS Aid Activities Database & \multicolumn{3}{l}{}
\end{tabular}

AfT DISBURSEMENTS BY SECTOR (million current USD)

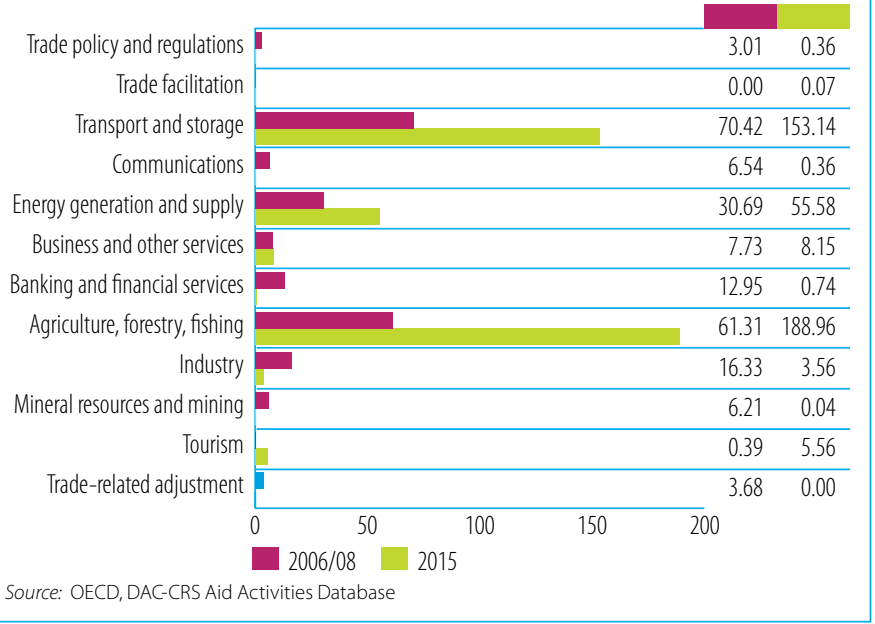

\section{B. TRADE COSTS}

\begin{tabular}{lrr} 
INDICATOR & 2006 & 2015 \\
Tariffs (\%) & & \\
\hline Imports: simple avg. MFN applied & 12.0 & 12.2 \\
\hline Imports: weighted avg. MFN applied (2005-2014) & 9 & 9.4 \\
\hline Exports: weighted avg. faced (2005-2014) & 3.4 & 0.9 \\
\hline Exports: duty free (value in \%) (2005-2014) & 75.7 & 84.8 \\
\hline ICT connectivity (\% of population) & $\ldots$ & \\
\hline Mobile broadband subscriptions & $\ldots .2$ & 0.7 \\
\hline Fixed broadband subscriptions & 0.2 & 21.7 \\
\hline Individuals using the internet & 5.6 &
\end{tabular}
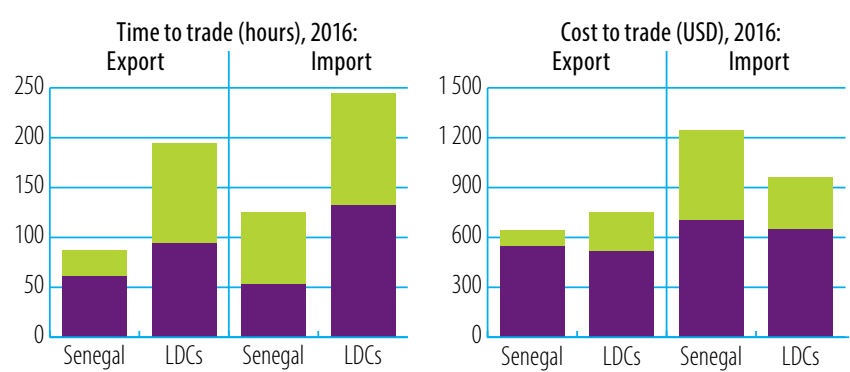

Border compliance Documentary compliance

Source: WB, Doing Business
LOGISTICS PERFORMANCE INDICES (LPI) (1-5)

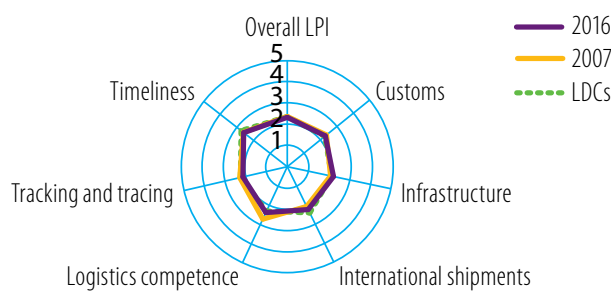

Source: WB Logistics Performance Index (LPI)

GLOBAL COMPETITIVENESS INDICATORS (1-7)

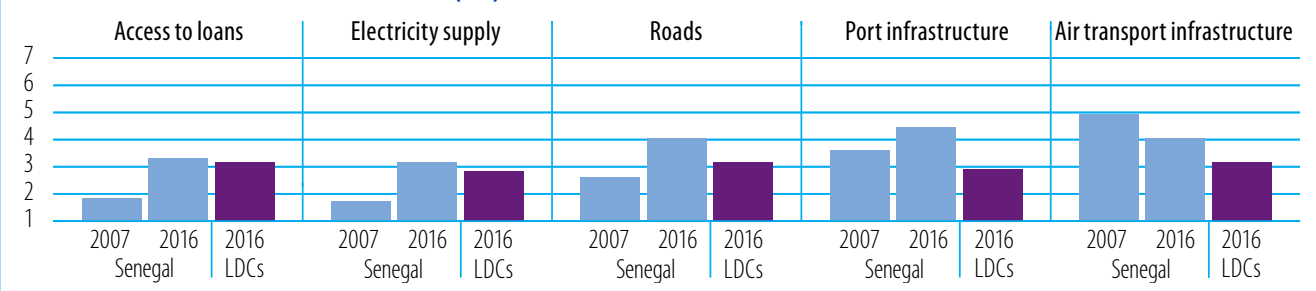

TRADE FACILITATION INDICATORS, 2015 (0-2)

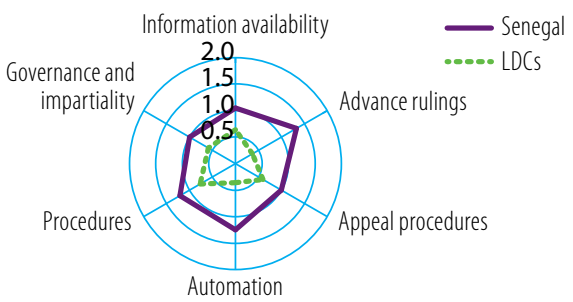

Source: OECD Trade Facilitation Indicators
TRADE COSTS (ad-valorem, \%)

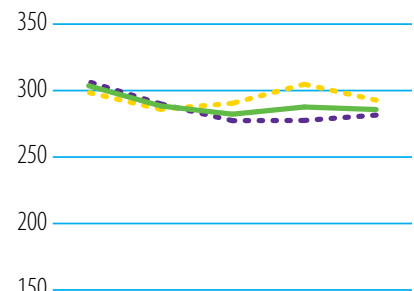

100

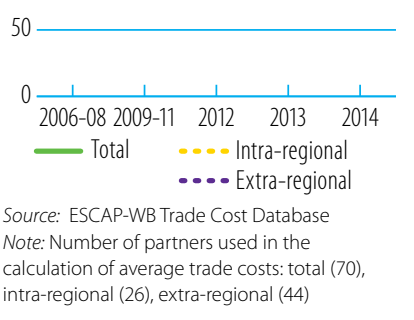




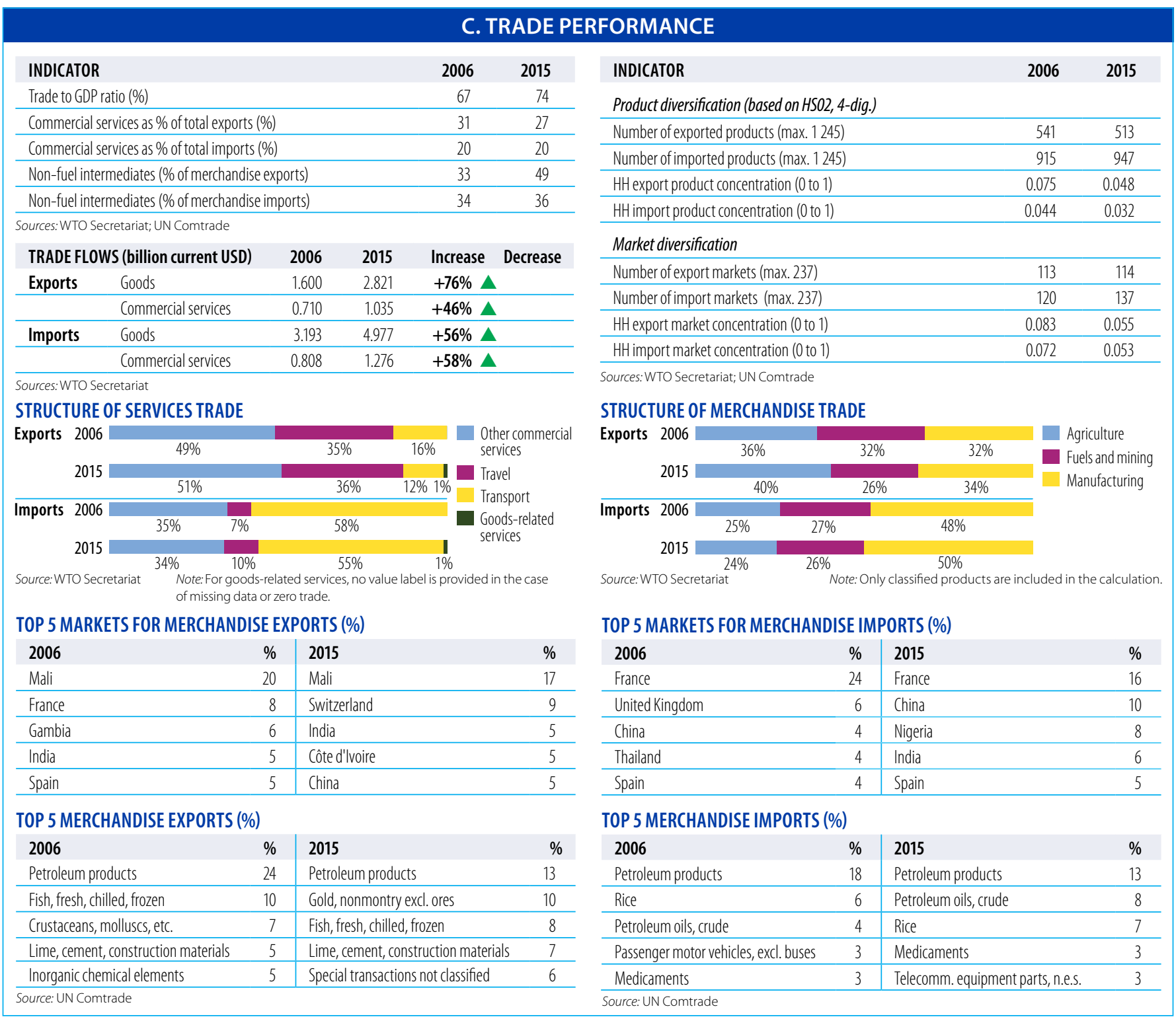

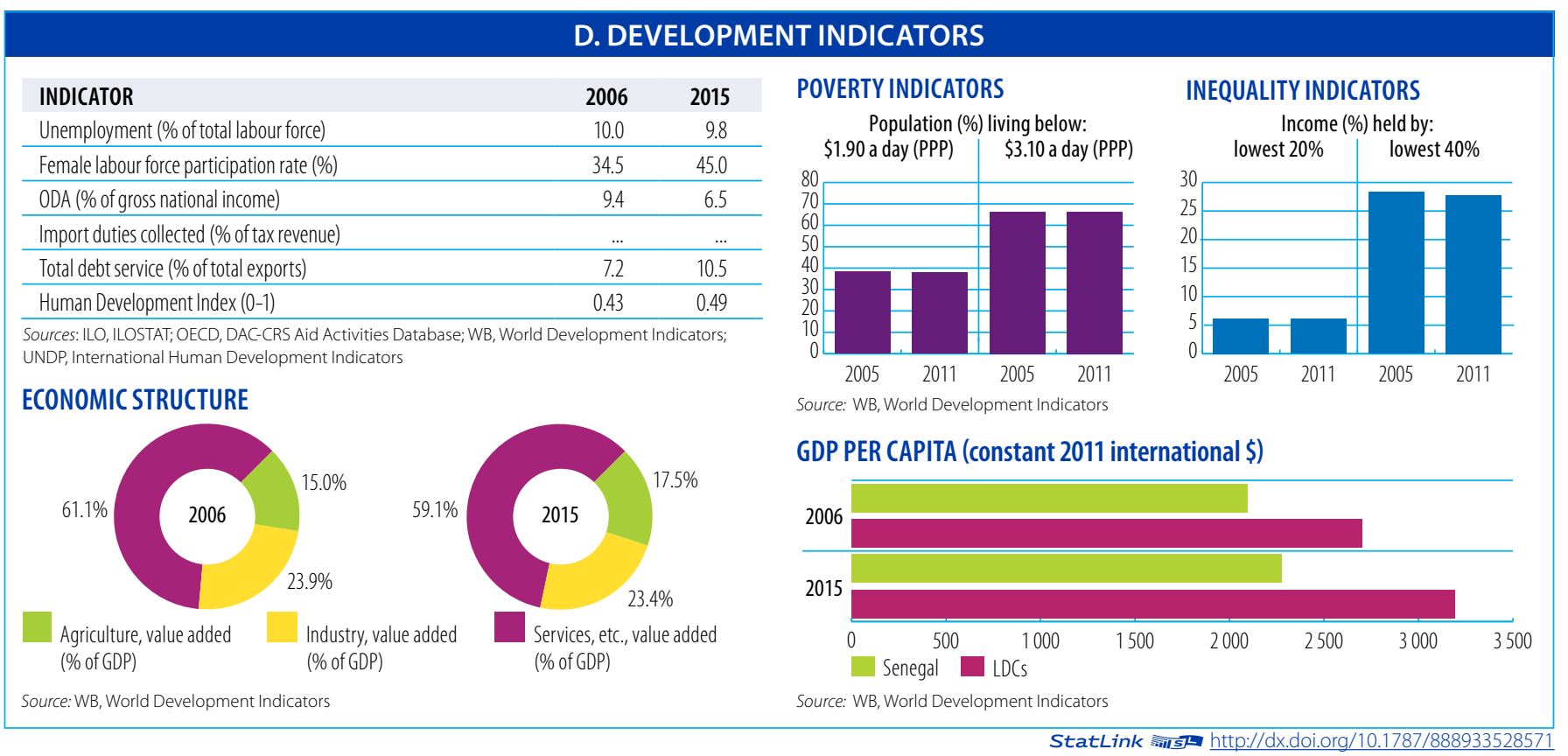




\section{SIERRA LEONE}

Aid, Trade and Development Indicators for Sierra Leone

\section{A. DEVELOPMENT FINANCE}

\begin{tabular}{lrrrc}
$\begin{array}{l}\text { EXTERNAL FINANCING INFLOWS } \\
\text { (million current USD) }\end{array}$ & $\mathbf{2 0 0 6 / 0 8}$ & $\mathbf{2 0 1 2 / 1 4}$ & $\mathbf{2 0 1 5}$ & $\mathbf{\Delta : 0 6 / 0 8 - 1 5}$ \\
\hline FDl inflows & 71.0 & 518.7 & 518.7 & $631 \%$ \\
\hline Remittances & 26.7 & 65.5 & 66.2 & $148 \%$ \\
\hline Other official flows (00F) & 0.3 & 22.1 & 9.7 & $3241 \%$ \\
\hline$\quad$ of which trade-related 00F & 0.0 & 18.8 & 0.0 & - \\
\hline Official Development Assistance (ODA) & 736.6 & 633.8 & 1015.0 & $38 \%$ \\
\hline$\quad$ of which Aid for Trade & 54.0 & 101.6 & 65.4 & $21 \%$ \\
\hline
\end{tabular}

Sources: UNCTAD, UNCTADstat; WB, World Development Indicators; OECD,

DAC-CRS Aid Activities Database

\section{TOP 3 AfT PRIORITIES}

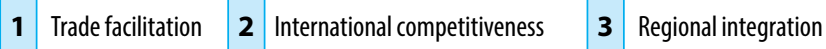
Source: OECD/WTO Partner Questionnaire

SHARE OF AfT IN DEVELOPMENT FINANCE AND FIXED CAPITAL FORMATION (\%)

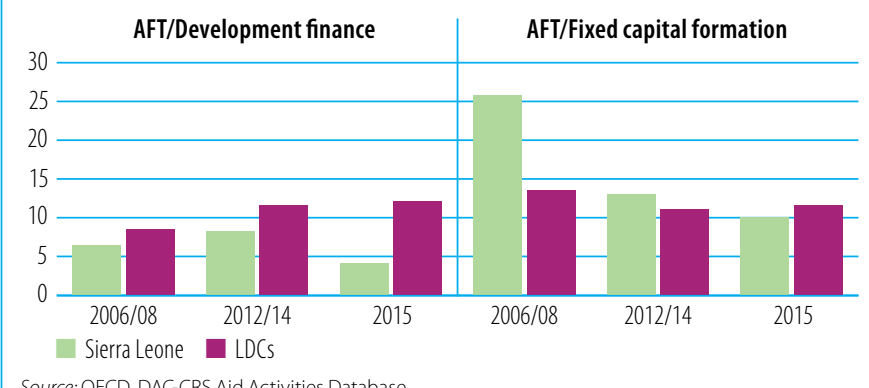

AfT DISBURSEMENTS: TOP DONORS (million current USD)

\begin{tabular}{lrr|lrr}
$\mathbf{2 0 0 6 / 0 8}$ & value & $\%$ & $\mathbf{2 0 1 5}$ & value & $\%$ \\
IDA & 14.9 & 28 & EU Institutions & 15.9 & 24 \\
\hline EU Institutions & 12.3 & 23 & United Kingdom & 10.5 & 16 \\
\hline United Kingdom & 11.1 & 20 & African Development Fund & 10.5 & 16 \\
\hline Italy & 5.5 & 10 & Japan & 10.5 & 16 \\
\hline Germany & 2.7 & 5 & OPEC Fund for International Development & 6.0 & 9 \\
\hline Source: OECD, DAC-CRS Aid Activities Database & &
\end{tabular}

AfT DISBURSEMENTS BY SECTOR (million current USD)

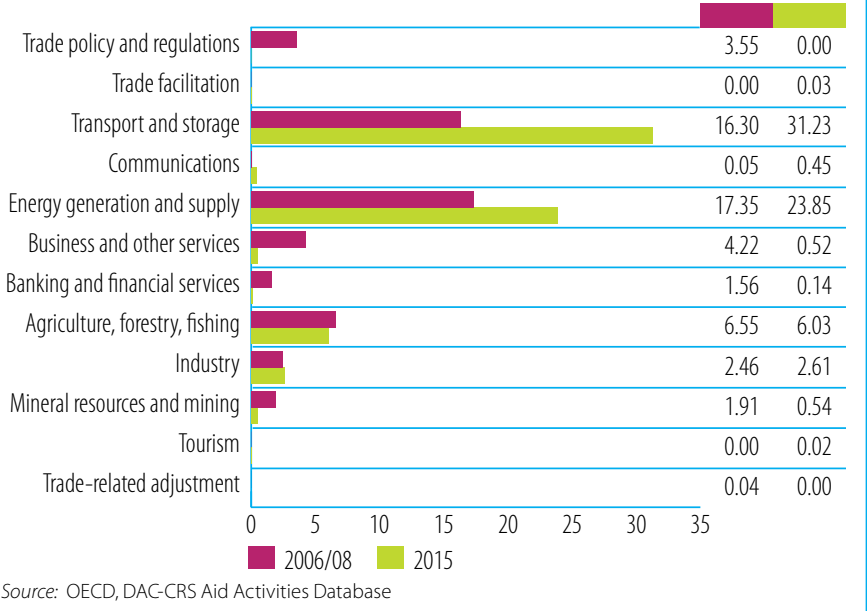

\section{B. TRADE COSTS}

\begin{tabular}{lcc} 
INDICATOR & 2006 & 2015 \\
Tariffs (\%) & & \\
\hline Imports: simple avg. MFN applied (2006-2012) & 13.6 & 11.9 \\
\hline Imports: weighted avg. MFN applied & $\ldots$ & $\ldots$ \\
\hline Exports: weighted avg. faced (2005-2014) & 1.3 & 0.1 \\
\hline Exports: duty free (value in \%) (2005-2014) & 93.2 & 97.7 \\
\hline ICT connectivity (\% of population) & $\ldots$ & 15.2 \\
\hline Mobile broadband subscriptions & $\ldots$ & $\ldots$ \\
\hline Fixed broadband subscriptions & 0.2 & 2.5 \\
\hline Individuals using the internet & $\ldots$ &
\end{tabular}
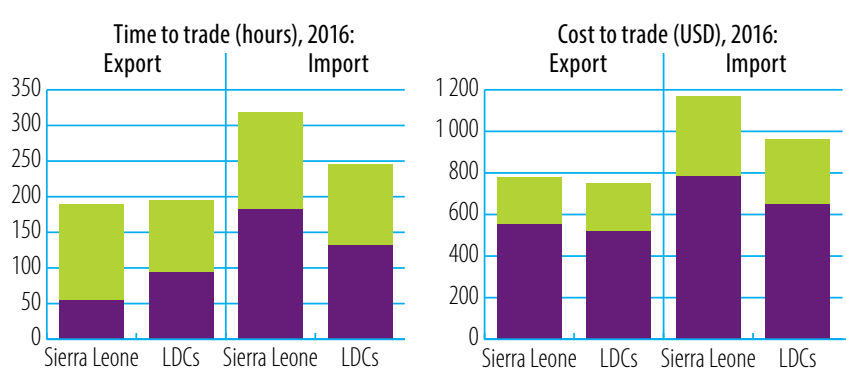

Border compliance Documentary compliance

Source: WB, Doing Business

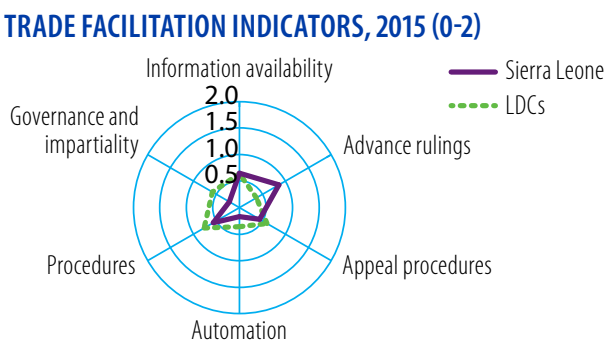

Source: OECD Trade Facilitation Indicators

Source: WB Logistics Performance Index (LPI)

GLOBAL COMPETITIVENESS INDICATORS (1-7)

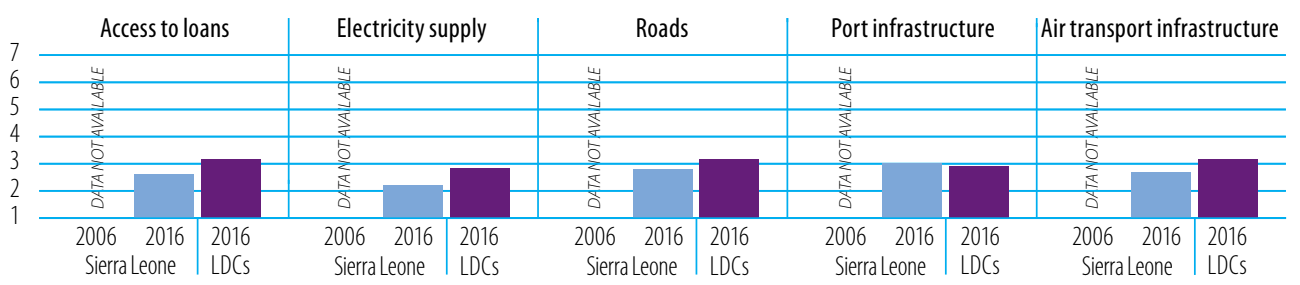

Source: WEF Global Competitiveness Index
TRADE COSTS (ad-valorem, \%)

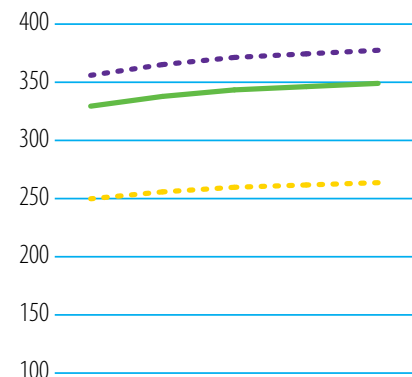

100

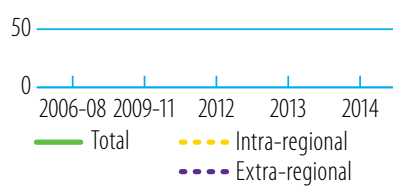

Source: ESCAP-WB Trade Cost Database

Note: Number of partners used in the

calculation of average trade costs: total (12),

intra-regional (3), extra-regional (9) 


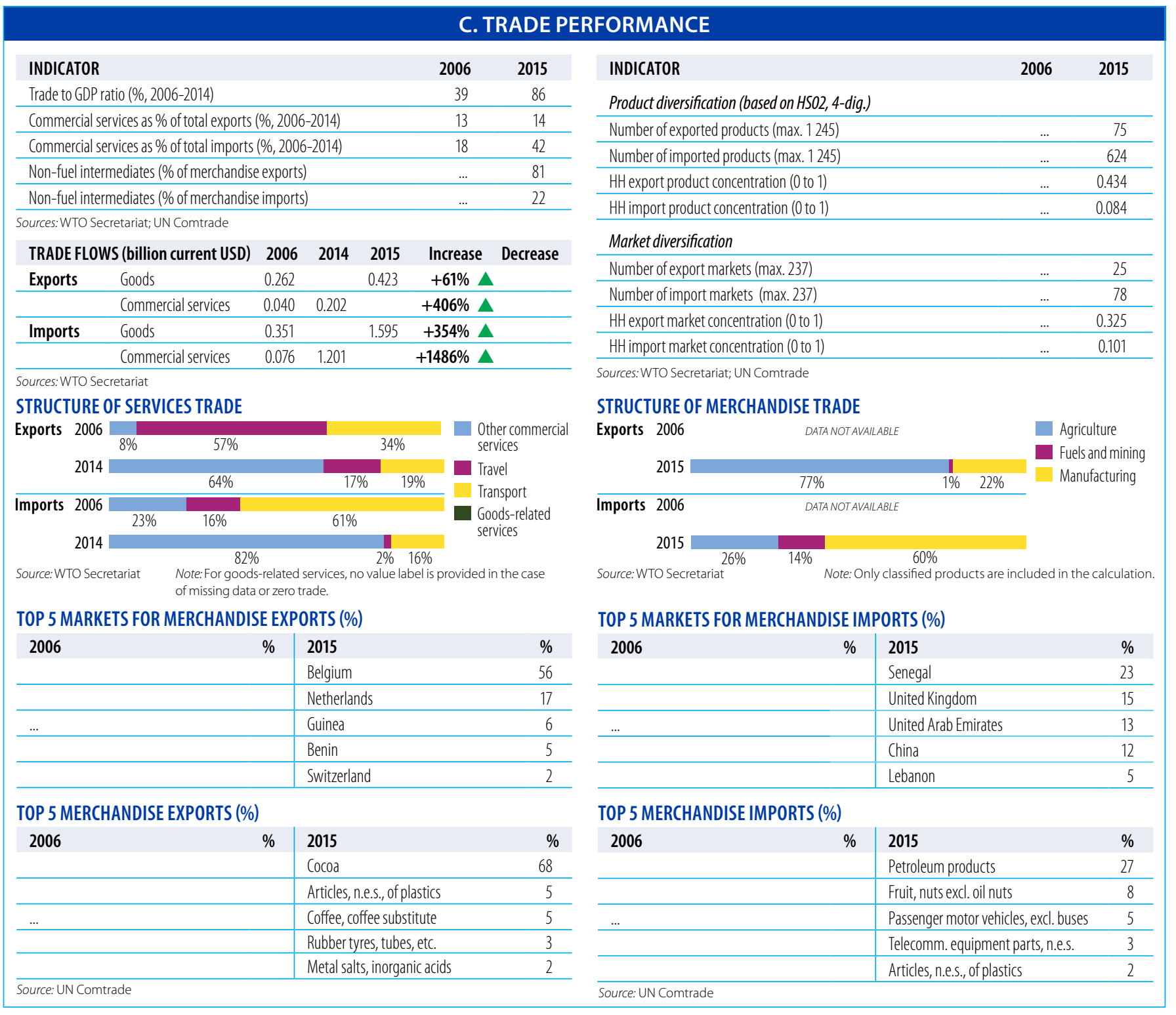

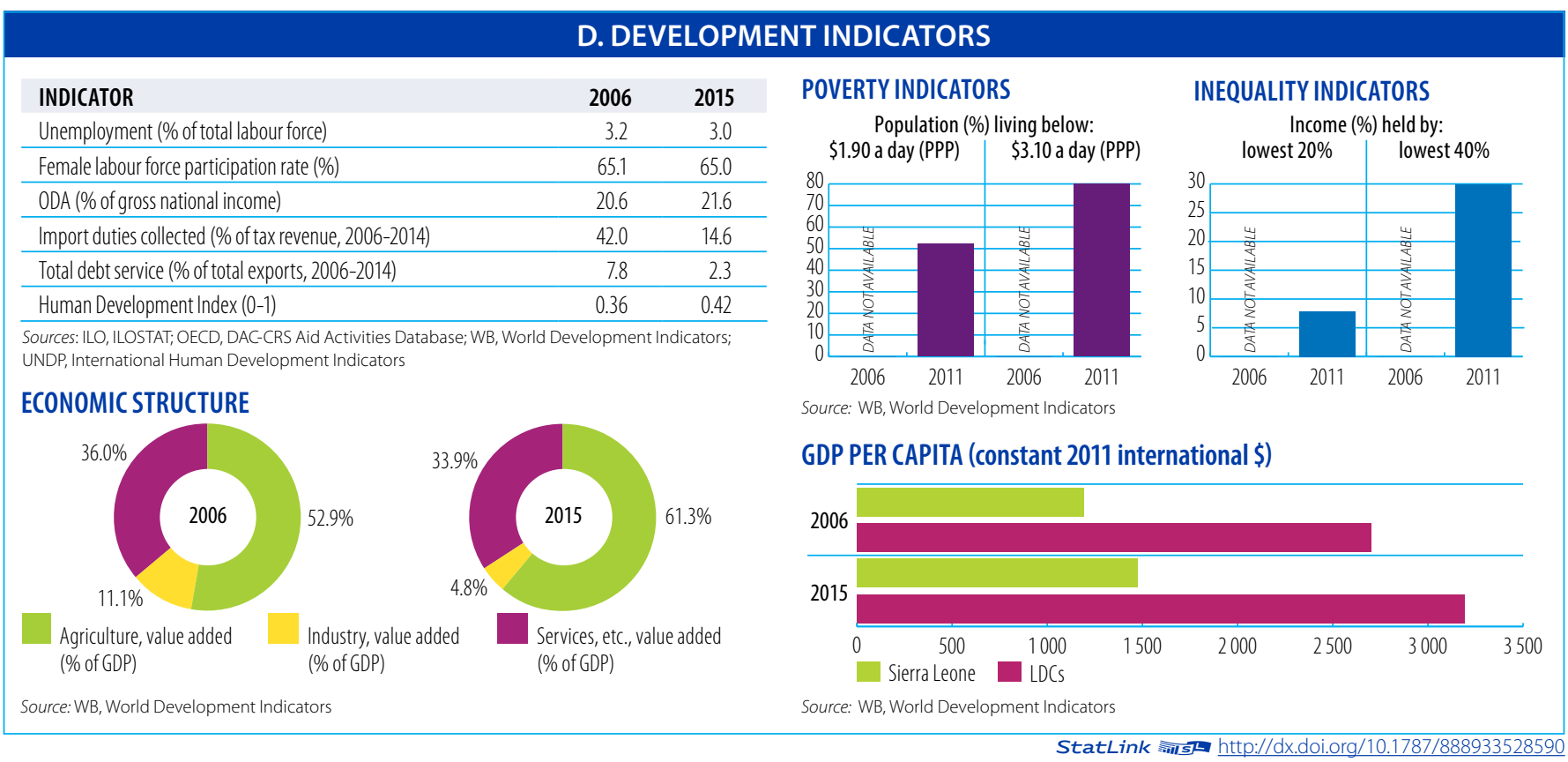


Aid, Trade and Development Indicators for Sri Lanka

\section{A. DEVELOPMENT FINANCE}

\begin{tabular}{lrrrc}
$\begin{array}{l}\text { EXTERNAL FINANCING INFLOWS } \\
\text { (million current USD) }\end{array}$ & $\mathbf{2 0 0 6 / 0 8}$ & $\mathbf{2 0 1 2 / 1 4}$ & $\mathbf{2 0 1 5}$ & $\mathbf{\Delta : 0 6 / 0 8 - 1 5}$ \\
FDl inflows & 611.9 & 922.4 & 681.2 & $11 \%$ \\
\hline Remittances & 2532.9 & 6486.0 & 6999.7 & $176 \%$ \\
\hline Other official flows (00F) & 48.9 & 277.8 & 373.0 & $664 \%$ \\
\hline of which trade-related 00F & 9.7 & 207.9 & 206.2 & $2023 \%$ \\
\hline Official Development Assistance (ODA) & 930.4 & 944.5 & 824.5 & $-11 \%$ \\
\hline of which Aid for Trade & 283.3 & 440.9 & 373.8 & $32 \%$ \\
\hline
\end{tabular}

Sources: UNCTAD, UNCTADstat; WB, World Development Indicators; OECD,

DAC-CRS Aid Activities Database

TOP 3 AFT PRIORITIES

\begin{tabular}{|l|l|l|l|l|l|}
\hline $\mathbf{1}$ & Trade facilitation & $\mathbf{2}$ & Connecting to value chains & $\mathbf{3}$ & Regional integration \\
\hline
\end{tabular} Source: OECD/WTO Partner Questionnaire

SHARE OF AfT IN DEVELOPMENT FINANCE AND FIXED CAPITAL FORMATION (\%)

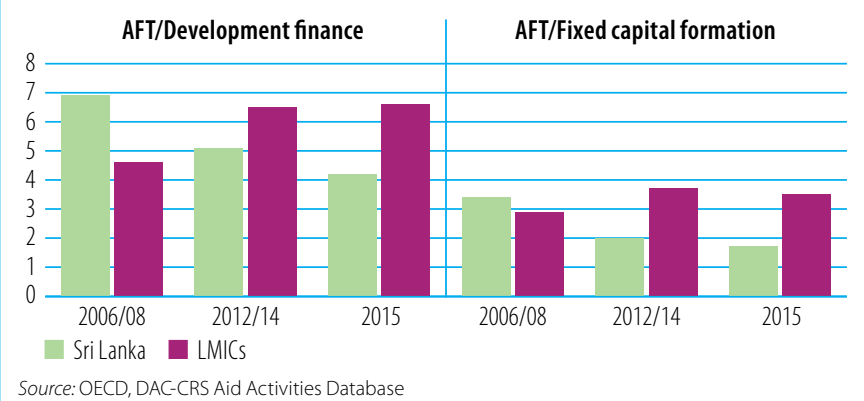

AfT DISBURSEMENTS: TOP DONORS (million current USD)

\begin{tabular}{lrr|lrc} 
2006/08 & value & $\%$ & $\mathbf{2 0 1 5}$ & value & $\%$ \\
Japan & 146.4 & 52 & Japan & 132.1 & 35 \\
\hline IDA & 55.4 & 20 & EU Institutions & 87.3 & 23 \\
\hline Germany & 22.6 & 8 & AsDB Special Funds & 75.6 & 20 \\
\hline Spain & 7.6 & 3 & IDA & 24.4 & 7 \\
\hline Korea & 7.0 & 2 & Korea & 17.2 & 5 \\
\hline
\end{tabular}

Source: OECD, DAC-CRS Aid Activities Database

AfT DISBURSEMENTS BY SECTOR (million current USD)

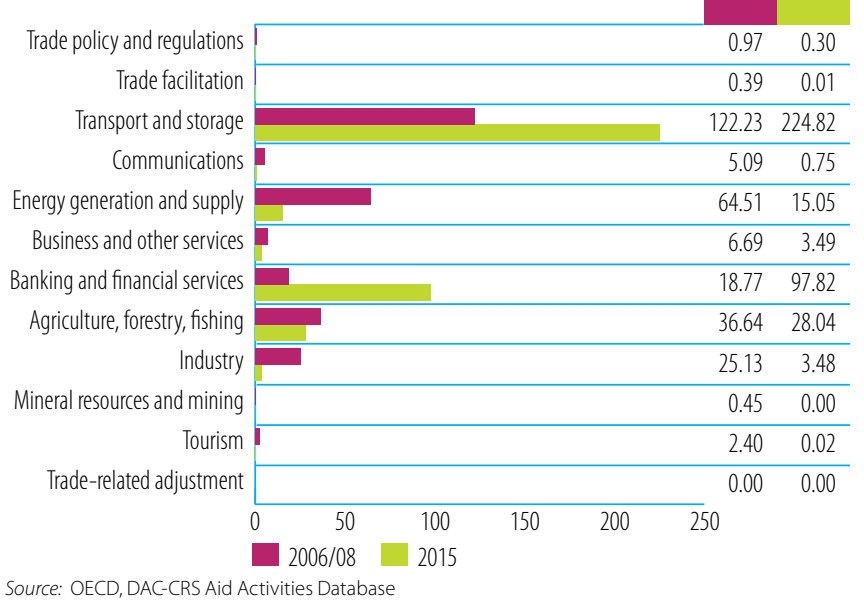

\section{B. TRADE COSTS}

\begin{tabular}{lcc} 
INDICATOR & $\mathbf{2 0 0 6}$ & $\mathbf{2 0 1 5}$ \\
Tariffs (\%) & & \\
\hline Imports: simple avg. MFN applied & 11.2 & 9.3 \\
\hline Imports: weighted avg. MFN applied (2006-2014) & $\ldots$ & 8.2 \\
\hline Exports: weighted avg. faced (2005-2014) & 7.1 & 8.3 \\
\hline Exports: duty free (value in \%) (2005-2014) & 54.3 & 44.0 \\
\hline ICT connectivity (\% of population) & $\ldots$ & \\
\hline Mobile broadband subscriptions & 0.1 & 3.1 \\
\hline Fixed broadband subscriptions & 2.5 & 30.0 \\
\hline Individuals using the internet & &
\end{tabular}
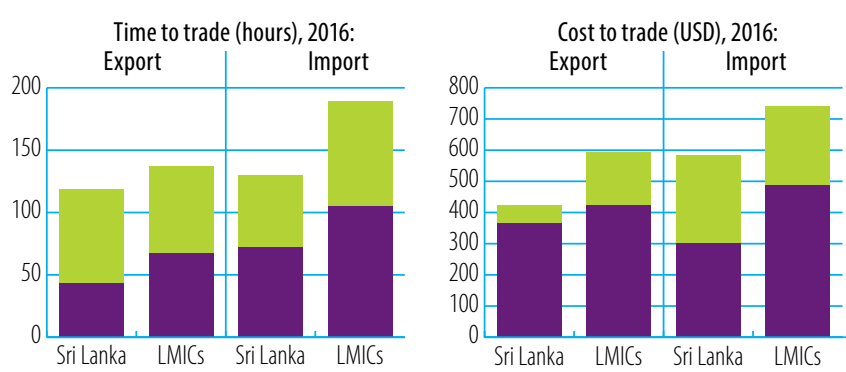

- Border compliance Documentary compliance

Source: WB, Doing Business

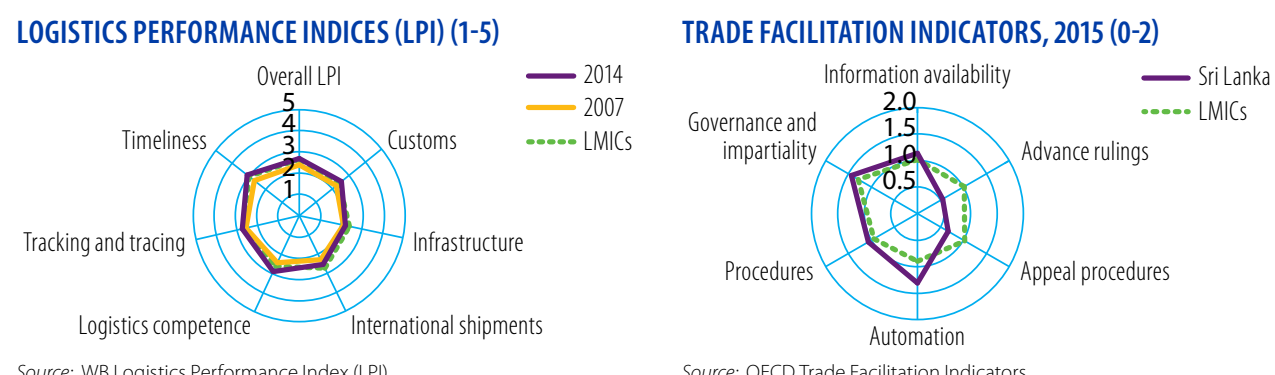

TRADE COSTS (ad-valorem, \%)

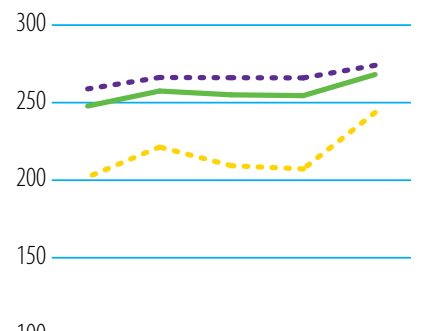

Source: WB Logistics Performance Index (LPI)

Source: OECD Trade Facilitation Indicators

100

\section{GLOBAL COMPETITIVENESS INDICATORS (1-7)}

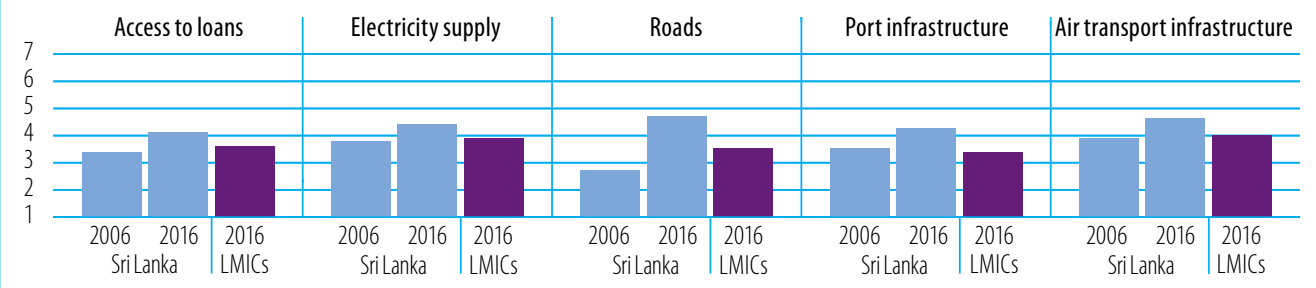

Source: WEF Global Competitiveness Index 


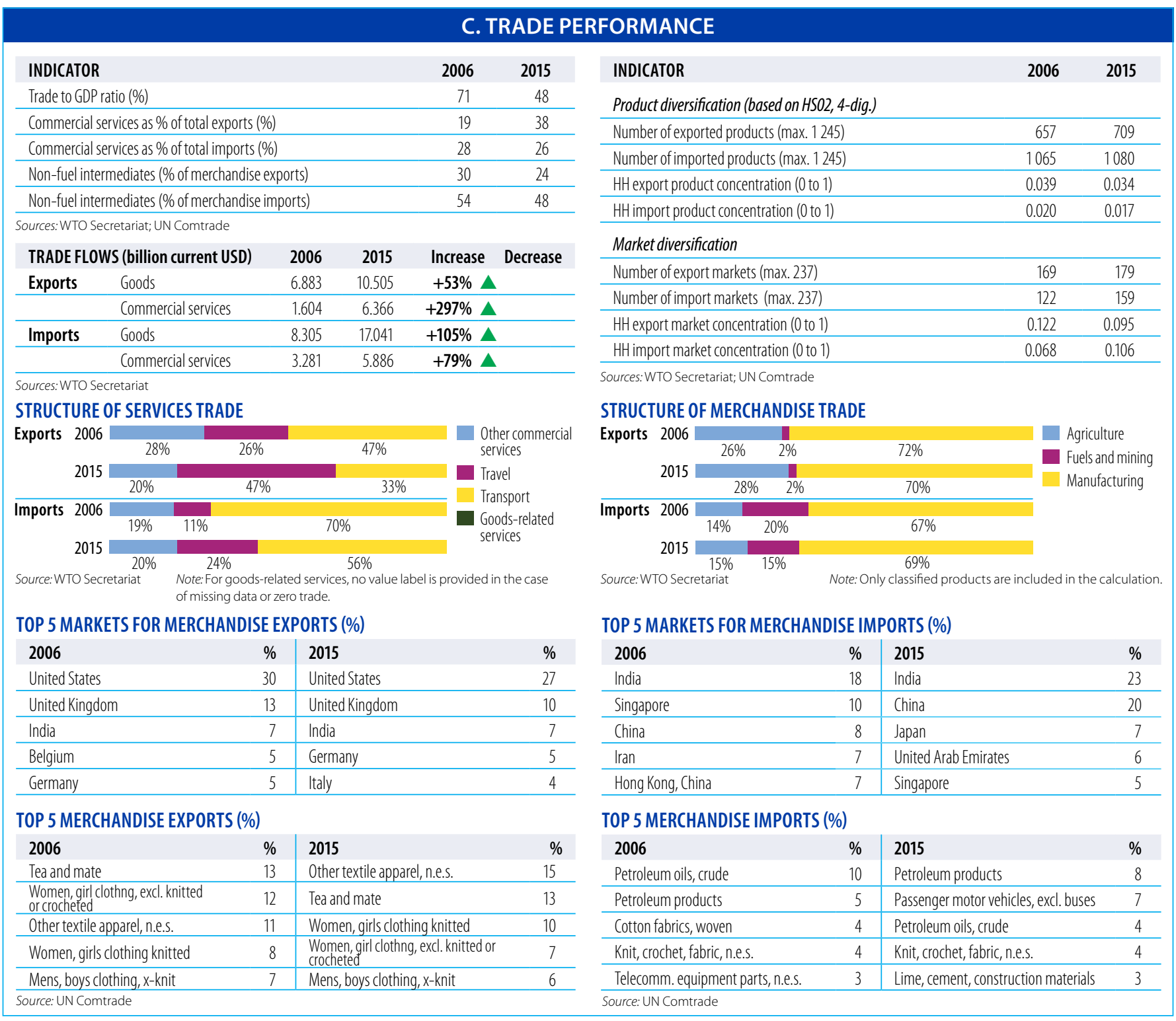

\begin{tabular}{|lrr}
\hline & D. DEVELOPMEN \\
\hline INDICATOR & $\mathbf{2 0 0 6}$ & $\mathbf{2 0 1 5}$ \\
\hline Unemployment (\% of total labour force) & 6.5 & 4.7 \\
\hline Female labour force participation rate (\%) & 36.4 & 30.2 \\
\hline ODA (\% of gross national income) & 2.8 & 0.5 \\
\hline Import duties collected (\% of tax revenue, 2006-2014) & 12.3 & 18.9 \\
\hline Total debt service (\% of total exports) & 10.8 & 18.7 \\
\hline Human Development Index (0-1) & 0.73 & 0.77 \\
\hline
\end{tabular}

Sources: ILO, ILOSTAT; OECD, DAC-CRS Aid Activities Database; WB, World Development Indicators; UNDP, International Human Development Indicators

\section{ECONOMIC STRUCTURE}

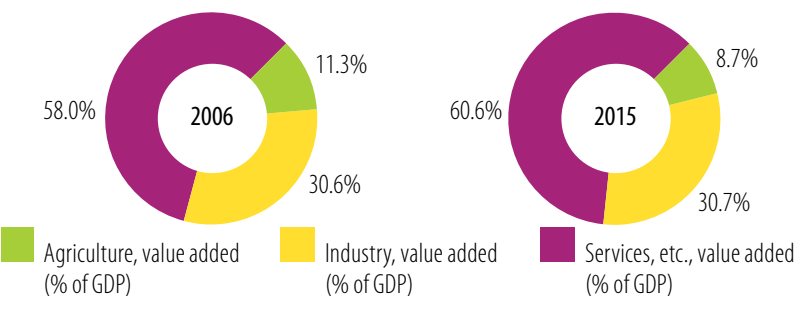

\section{POVERTY INDICATORS}

Population (\%) living below:

$\$ 1.90$ a day (PPP) $\quad \$ 3.10$ a day (PPP)

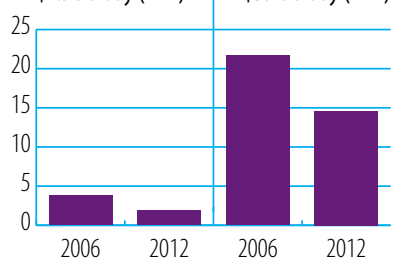

Source: WB, World Development Indicators

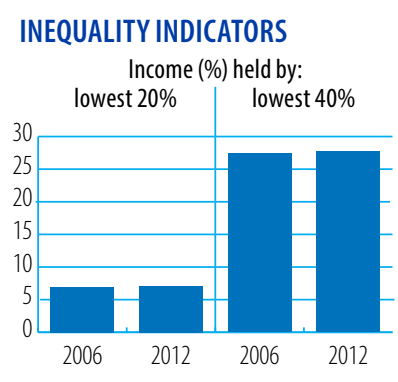

GDP PER CAPITA (constant 2011 international \$)

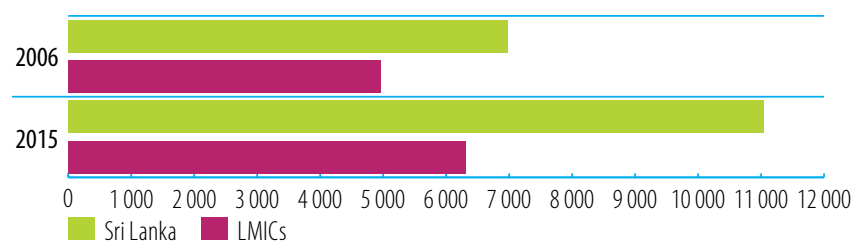

Source: WB, World Development Indicators

Source: WB, World Development Indicators 


\section{SUDAN}

Aid, Trade and Development Indicators for Sudan

\section{A. DEVELOPMENT FINANCE}

\begin{tabular}{lrrrc}
$\begin{array}{l}\text { EXTERNAL FINANCING INFLOWS } \\
\text { (million current USD) }\end{array}$ & $\mathbf{2 0 0 6 / 0 8}$ & $\mathbf{2 0 1 2 / 1 4}$ & $\mathbf{2 0 1 5}$ & $\mathbf{\Delta : 0 6 / 0 8 - 1 5}$ \\
\hline FDl inflows & $\ldots$ & 1750.1 & 1736.8 & - \\
\hline Remittances & 1130.4 & 574.0 & 151.4 & $-87 \%$ \\
\hline Other official flows (00F) & 3.6 & 50.7 & 14.9 & $307 \%$ \\
\hline$\quad$ of which trade-related 00F & 2.9 & 7.6 & 0.0 & $-100 \%$ \\
\hline Official Development Assistance (ODA) & 2066.1 & 1286.1 & 1049.2 & $-49 \%$ \\
\hline$\quad$ of which Aid for Trade & 84.7 & 194.6 & 265.2 & $213 \%$ \\
\hline
\end{tabular}

Sources: UNCTAD, UNCTADstat; WB, World Development Indicators; OECD,

DAC-CRS Aid Activities Database

\section{TOP 3 AfT PRIORITIES}

\begin{tabular}{|l|l|l|l|l|l|}
\hline $\mathbf{1}$ & WTO accession & $\mathbf{2}$ & Trade facilitation & $\mathbf{3}$ & Transport infrastructure \\
\hline
\end{tabular}

Source: OECD/WTO Partner Questionnaire

SHARE OF AfT IN DEVELOPMENT FINANCE AND FIXED CAPITAL FORMATION (\%)

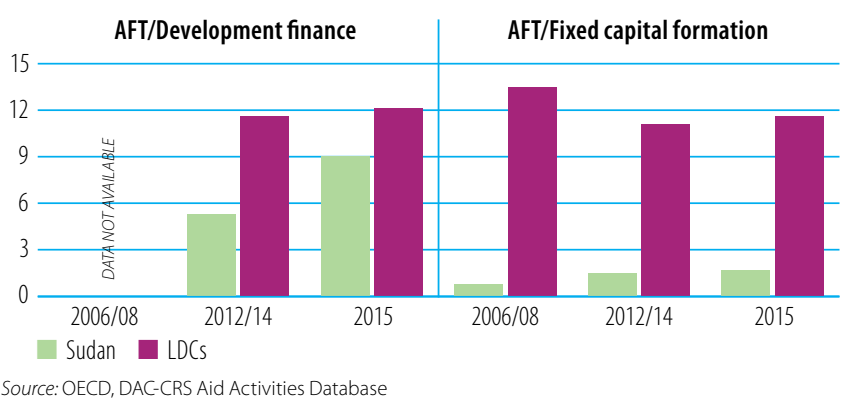

AfT DISBURSEMENTS: TOP DONORS (million current USD)

\begin{tabular}{lrr|lrr}
$\mathbf{2 0 0 6 / 0 8}$ & value & $\%$ & 2015 & value & $\%$ \\
Arab Fund (AFESD) & 52.9 & 62 & Arab Fund (AFESD) & 93.7 & 35 \\
\hline United States & 11.1 & 13 & Kuwait (KFAED) & 81.1 & 31 \\
\hline United Kingdom & 7.0 & 8 & United Arab Emirates & 59.8 & 23 \\
\hline EU Institutions & 4.6 & 5 & Japan & 14.0 & 5 \\
\hline Norway & 3.9 & 5 & EU Institutions & 4.3 & 2 \\
\hline
\end{tabular}

Source: OECD, DAC-CRS Aid Activities Database

AfT DISBURSEMENTS BY SECTOR (million current USD)

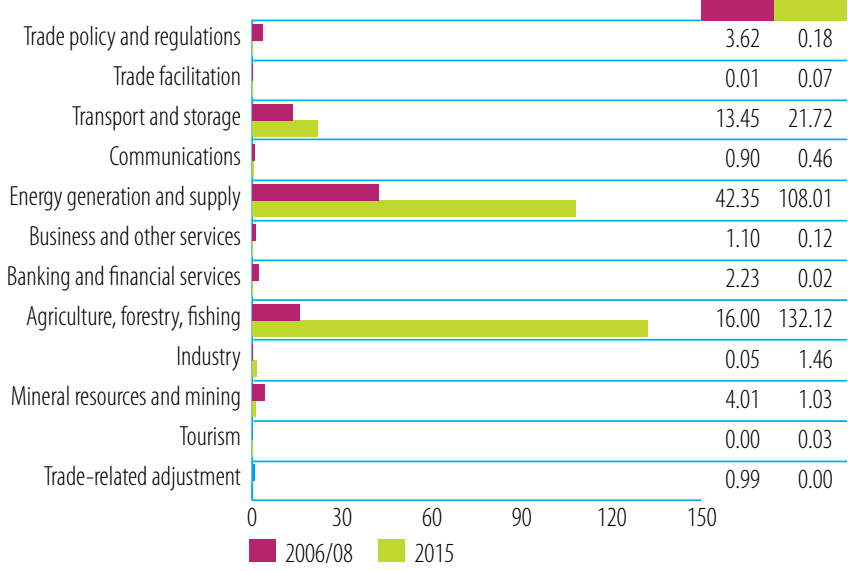

Source: OECD, DAC-CRS Aid Activities Database

\section{B. TRADE COSTS}

\begin{tabular}{lcc} 
INDICATOR & 2006 & 2015 \\
Tariffs (\%) & & \\
\hline Imports: simple avg. MFN applied (2006-2013) & 20.1 & 21.2 \\
\hline Imports: weighted avg. MFN applied (2006-2012) & $\ldots$ & 16.3 \\
\hline Exports: weighted avg. faced (2005-2013) & 1.3 & 0.4 \\
\hline Exports: duty free (value in \%) (2005-2013) & 59.2 & 95.4 \\
\hline ICT connectivity (\% of population) & $\ldots$ & \\
\hline Mobile broadband subscriptions & 0.0 & 29.4 \\
\hline Fixed broadband subscriptions & 8.7 & 26.6 \\
\hline Individuals using the internet (2007-2015) & &
\end{tabular}
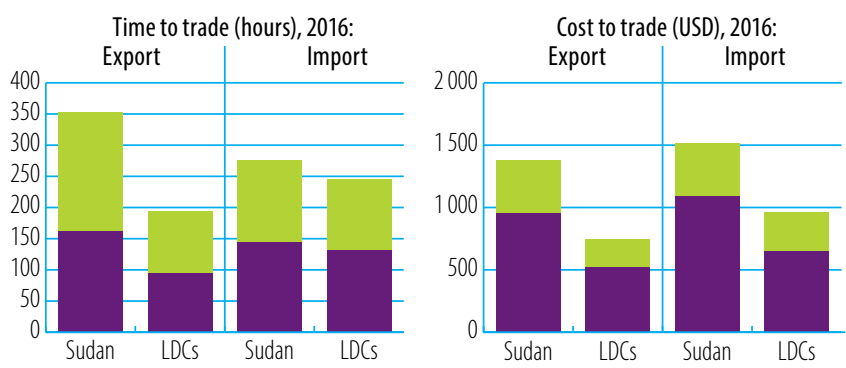

Border compliance Documentary compliance Source: WB, Doing Business

TRADE FACILITATION INDICATORS, 2015 (0-2)

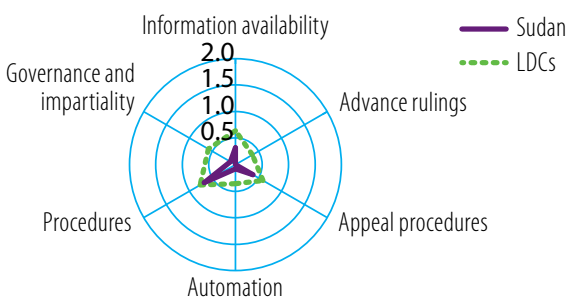

Source: OECD Trade Facilitation Indicators

Source: WB Logistics Performance Index (LPI)

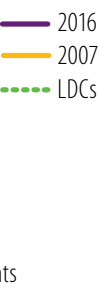

GLOBAL COMPETITIVENESS INDICATORS (1-7)

\begin{tabular}{|c|c|c|c|c|c|c|c|c|c|}
\hline \multicolumn{2}{|c|}{ Access to loans } & \multicolumn{2}{|c|}{ Electricity supply } & \multicolumn{2}{|l|}{ Roads } & \multicolumn{2}{|c|}{ Port infrastructure } & \multicolumn{2}{|c|}{ Air transport infrastructure } \\
\hline \multicolumn{10}{|l|}{6} \\
\hline 5 & & & & & & & & & \\
\hline \multicolumn{2}{|c|}{ DATA NOT AVAILABLE } & \multicolumn{2}{|c|}{ DATA NOT AVAILABLE } & \multicolumn{2}{|c|}{ DATANOT AVAILABLE } & \multicolumn{2}{|c|}{ DATA NOT AVAILABLE } & \multicolumn{2}{|c|}{ DATANOT AVAILABLE } \\
\hline \\
\hline \multirow{2}{*}{\multicolumn{10}{|c|}{2}} \\
\hline 1 & & & & & & & & & \\
\hline 20062016 & 2016 & $2006 \quad 2016$ & 2016 & $2006 \quad 2016$ & 2016 & $2006 \quad 2016$ & 2016 & $2006 \quad 2016$ & 2016 \\
\hline Sudan & LDCs & Sudan & LDCS & Sudan & LDCs & Sudan & LDCs & Sudan & LDCs \\
\hline
\end{tabular}

Source: WEF Global Competitiveness Index
TRADE COSTS (ad-valorem, \%)

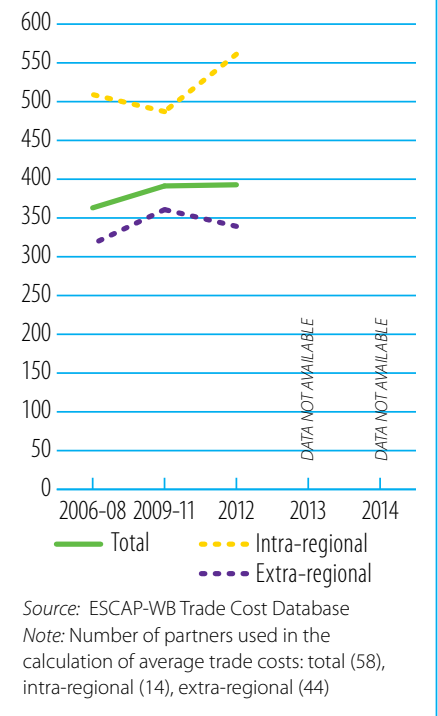




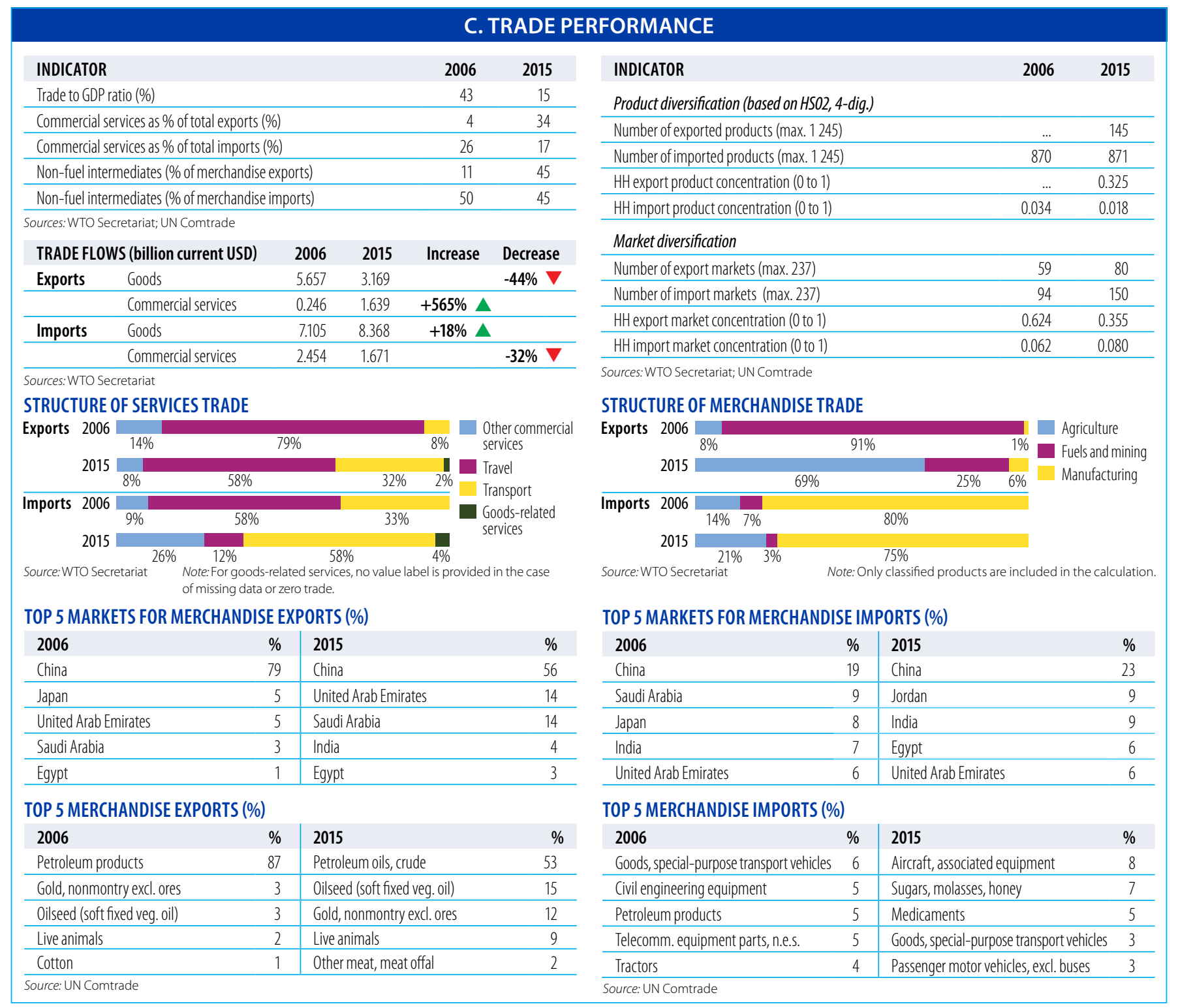

\begin{tabular}{|lrc} 
& \multicolumn{3}{c}{ D. DEVELOPMEN } \\
\hline INDICATOR & $\mathbf{2 0 0 6}$ & $\mathbf{2 0 1 5}$ \\
Unemployment (\% of total labour force) & 14.1 & 13.2 \\
\hline Female labour force participation rate (\%) & 24.1 & 24.3 \\
\hline ODA (\% of gross national income) & 6.1 & 1.1 \\
\hline Import duties collected (\% of tax revenue) & $\ldots$ & $\ldots$ \\
\hline Total debt service (\% of total exports) & 5.0 & 10.5 \\
\hline Human Development Index (0-1) & 0.44 & 0.49 \\
\hline
\end{tabular}

Sources: ILO, ILOSTAT; OECD, DAC-CRS Aid Activities Database; WB, World Development Indicators; UNDP, International Human Development Indicators

\section{ECONOMIC STRUCTURE}

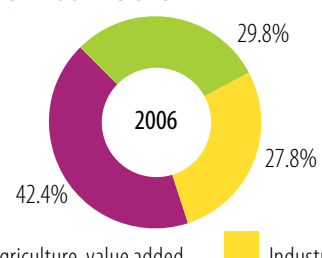

Agriculture, value added (\% of GDP)

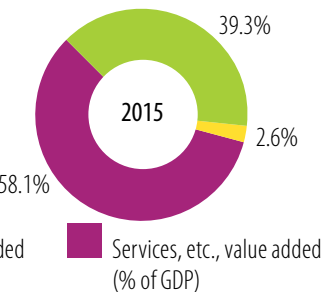

$(\%$ of GDP)

Source: WB, World Development Indicators

Industry, value added (\% of GDP)
POVERTY INDICATORS

Population (\%) living below:

$\$ 1.90$ a day (PPP) $\$ 3.10$ a day (PPP)

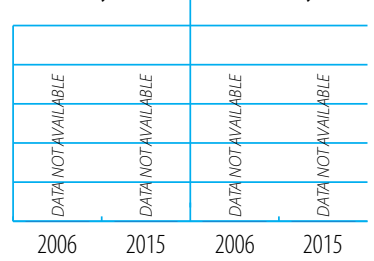

Source: WB, World Development Indicators

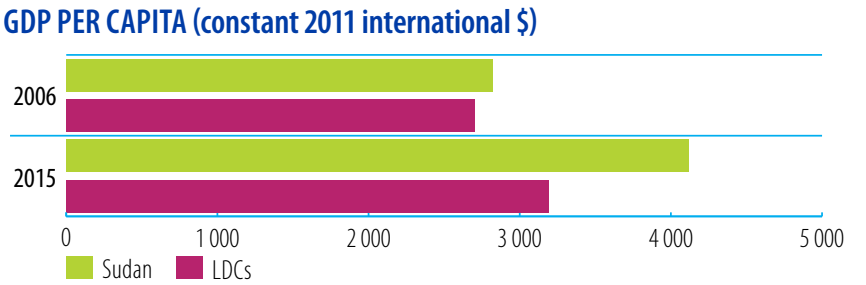

Source: WB, World Development Indicators

INEQUALITY INDICATORS

Income (\%) held by:

lowest 20\% | lowest 40\%

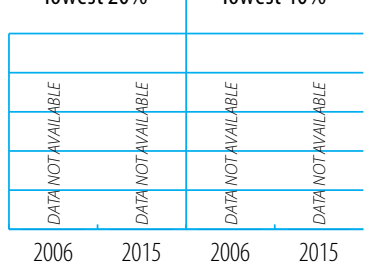




\section{SURINAME}

Aid, Trade and Development Indicators for Suriname

\section{A. DEVELOPMENT FINANCE}

\begin{tabular}{lrrrc}
$\begin{array}{l}\text { EXTERNAL FINANCING INFLOWS } \\
\text { (million current USD) }\end{array}$ & $\mathbf{2 0 0 6 / 0 8}$ & $\mathbf{2 0 1 2 / 1 4}$ & $\mathbf{2 0 1 5}$ & $\mathbf{\Delta : 0 6 / 0 8 - 1 5}$ \\
FDl inflows & -213.8 & 174.9 & 276.4 & - \\
\hline Remittances & 2.4 & 8.0 & 6.7 & $183 \%$ \\
\hline Other official flows (OOF) & 0.0 & 73.3 & 43.9 & - \\
\hline$\quad$ of which trade-related 00F & 0.0 & 47.1 & 30.3 & - \\
\hline Official Development Assistance (ODA) & 106.6 & 29.7 & 17.5 & $-84 \%$ \\
\hline$\quad$ of which Aid for Trade & 23.6 & 15.1 & 2.0 & $-91 \%$ \\
\hline
\end{tabular}

Sources: UNCTAD, UNCTADstat; WB, World Development Indicators; OECD,

DAC-CRS Aid Activities Database

\section{TOP 3 AfT PRIORITIES}

\section{\begin{tabular}{ll|l|l|l|l}
1 & Trade facilitation & $\mathbf{2}$ & Export diversification & $\mathbf{3}$ & Connecting to value chains
\end{tabular}}

Source: OECD/WTO Partner Questionnaire

SHARE OF AfT IN DEVELOPMENT FINANCE AND FIXED CAPITAL FORMATION (\%)

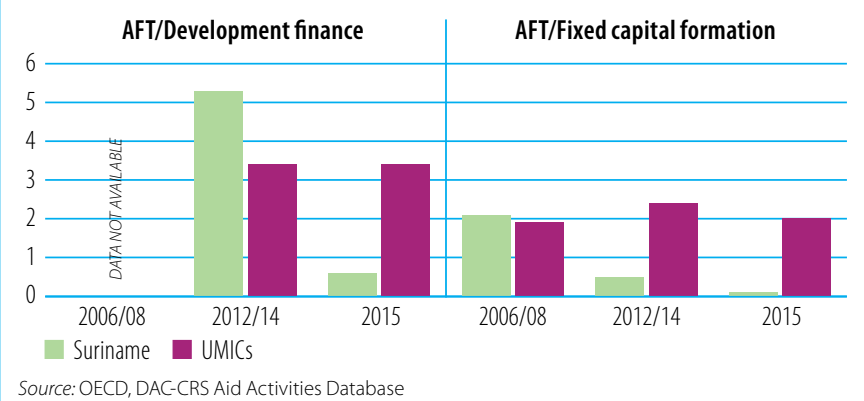

AfT DISBURSEMENTS: TOP DONORS (million current USD)

\begin{tabular}{lrr|lrc}
$\mathbf{2 0 0 6 / 0 8}$ & value & $\%$ & $\mathbf{2 0 1 5}$ & value & $\%$ \\
EU Institutions & 14.6 & 62 & EU Institutions & 1.6 & 80 \\
\hline Netherlands & 6.6 & 28 & Inter-American Development Bank & 0.3 & 12 \\
\hline Japan & 2.3 & 10 & Austria & 0.1 & 3 \\
\hline Korea & 0.0 & 0 & IDB Special Fund & 0.0 & 2 \\
\hline Belgium & 0.0 & 0 & Canada & 0.0 & 1 \\
\hline
\end{tabular}

Source: OECD, DAC-CRS Aid Activities Database

AfT DISBURSEMENTS BY SECTOR (million current USD)

\begin{tabular}{|c|c|c|c|c|}
\hline Trade policy and regulations & & & 0.00 & 0.00 \\
\hline Trade facilitation & & & 0.00 & 0.00 \\
\hline Transport and storage & 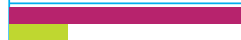 & & 10.71 & 1.56 \\
\hline Communications & & & 0.03 & 0.01 \\
\hline Energy generation and supply & 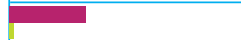 & & 2.04 & 0.13 \\
\hline Business and other services & ( & & 0.66 & 0.04 \\
\hline Banking and financial services & & & 0.11 & 0.00 \\
\hline Agriculture, forestry, fishing & & ב & 9.52 & 0.25 \\
\hline Industry & & & 0.20 & 0.04 \\
\hline Mineral resources and mining & & & 0.00 & 0.00 \\
\hline Tourism & $\bar{F}$ & & 0.34 & 0.00 \\
\hline Trade-related adjustment & & & 0.00 & 0.00 \\
\hline & 2 & 10 & 12 & \\
\hline
\end{tabular}

\section{B. TRADE COSTS}

\begin{tabular}{lrc} 
INDICATOR & 2006 & 2015 \\
Tariffs (\%) & $\ldots$ & 10.4 \\
\hline Imports: simple avg. MFN applied (2006-2013) & $\ldots$ & $\ldots$ \\
\hline Imports: weighted avg. MFN applied & 2.2 & 0.2 \\
\hline Exports: weighted avg. faced (2005-2014) & 93.0 & 99.2 \\
\hline Exports: duty free (value in \%) (2005-2014) & & \\
\hline ICT connectivity (\% of population) & $\ldots$ & 75.8 \\
\hline Mobile broadband subscriptions & 0.5 & 9.5 \\
\hline Fixed broadband subscriptions & 9.5 & 42.8 \\
\hline Individuals using the internet & &
\end{tabular}
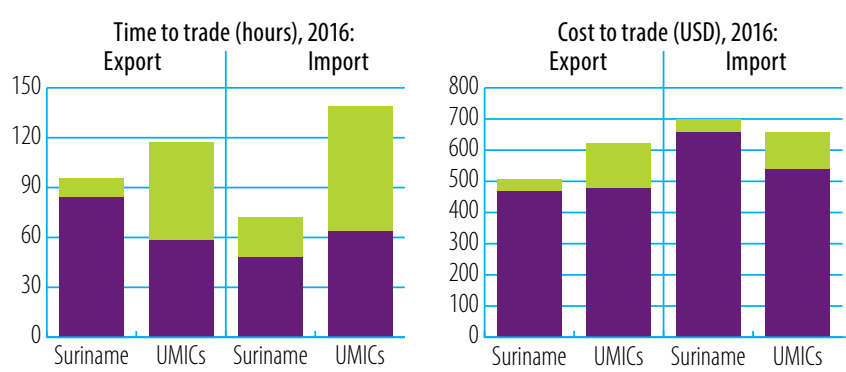

Border compliance Documentary compliance

Source: WB, Doing Business

\section{LOGISTICS PERFORMANCE INDICES (LPI) (1-5)}

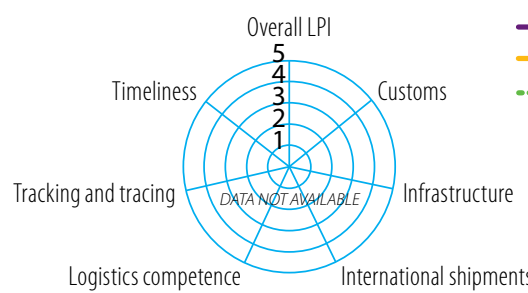

Source: WB Logistics Performance Index (LPI)

GLOBAL COMPETITIVENESS INDICATORS (1-7)

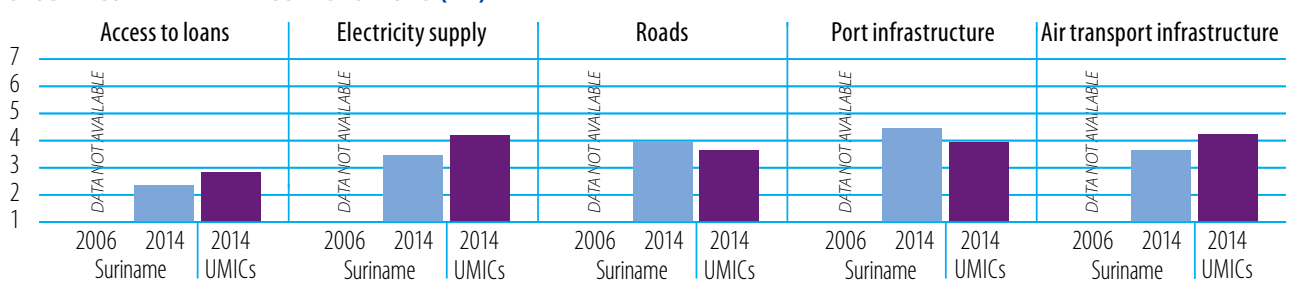

TRADE FACILITATION INDICATORS, 2015 (0-2)

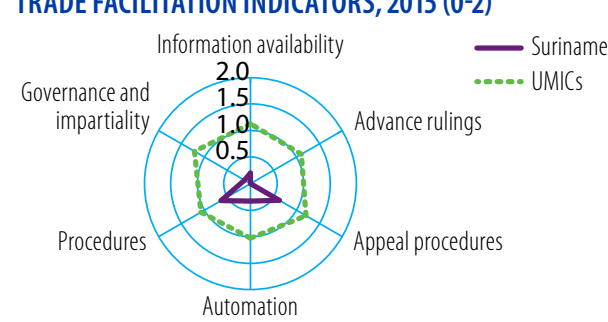

Source: OECD Trade Facilitation Indicators

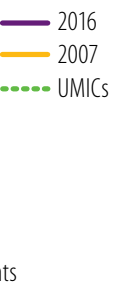

Source: WEF Global Competitiveness Index

TRADE COSTS (ad-valorem, \%)

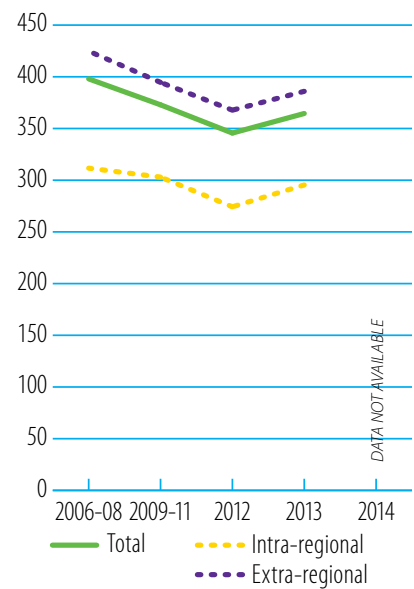

Source: ESCAP-WB Trade Cost Database Note: Number of partners used in the calculation of average trade costs: total (38), intra-regional (9), extra-regional (29) 


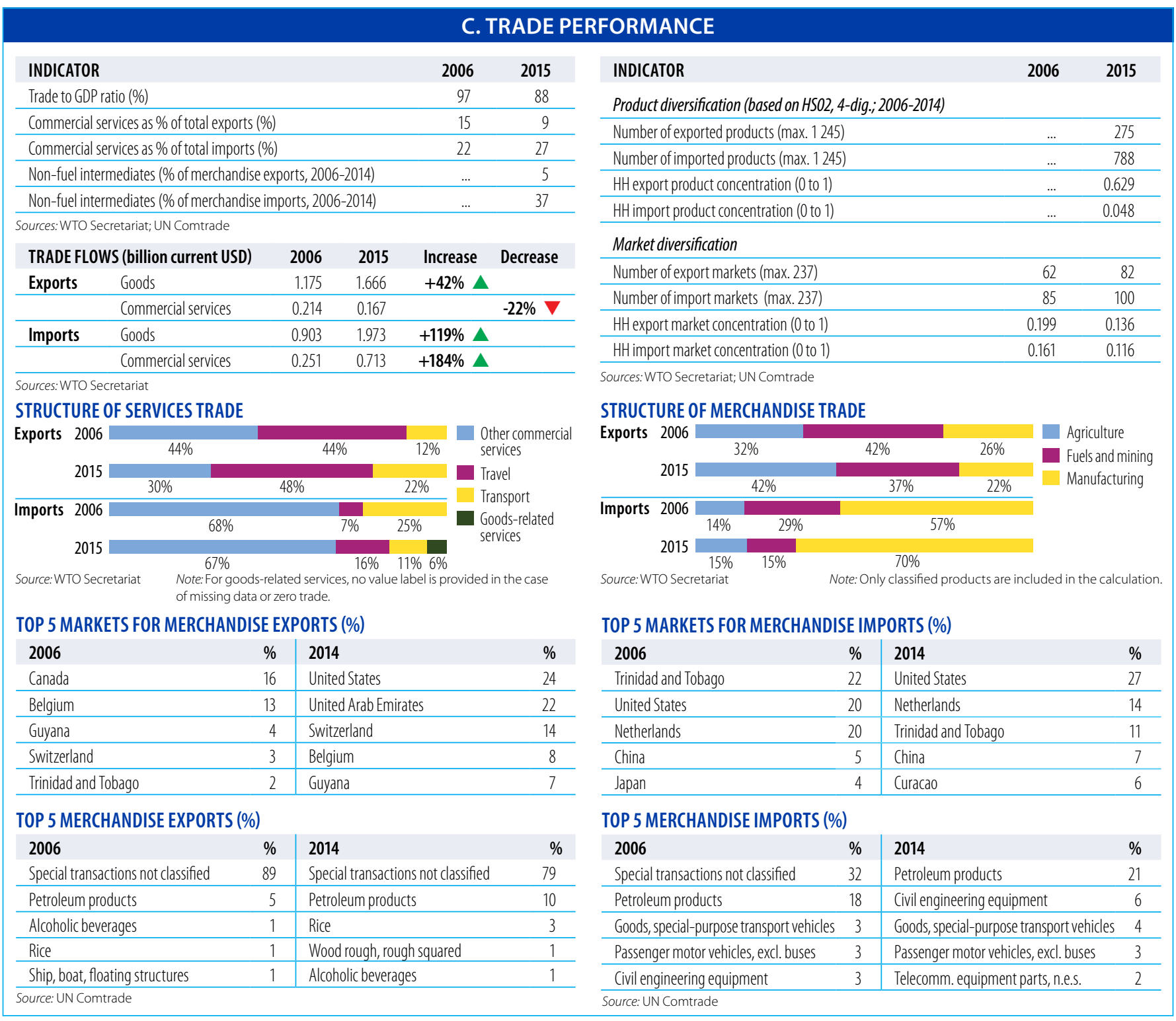

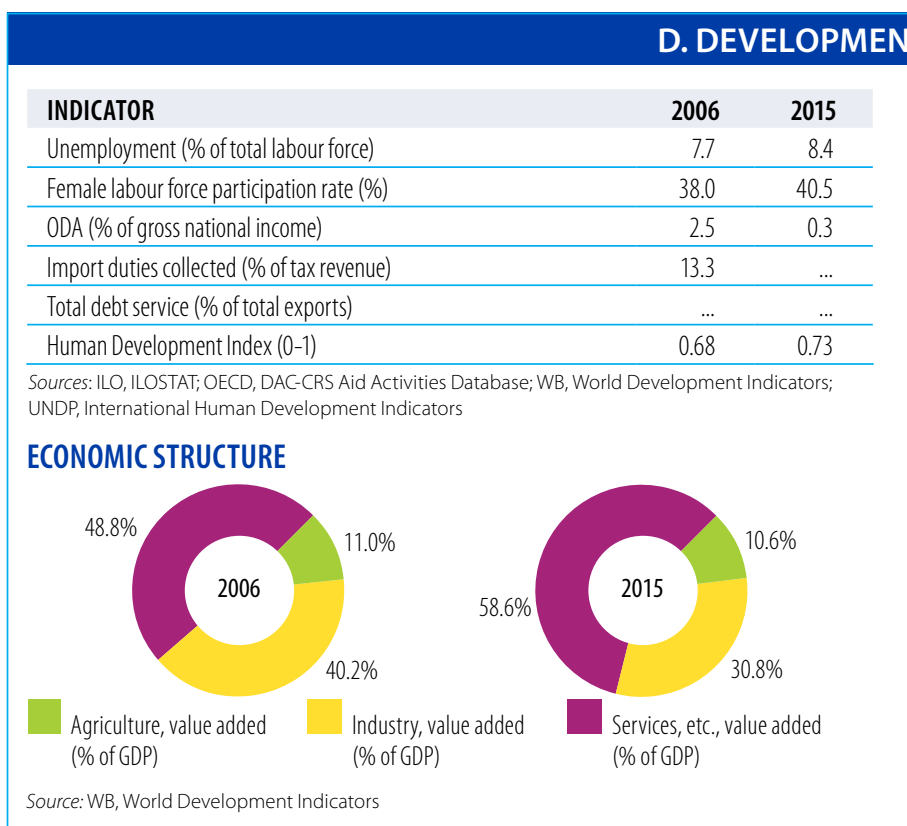

POVERTYINDICATORS

Population (\%) living below:

$\$ 1.90$ a day (PPP) $\$ 3.10$ a day (PPP)

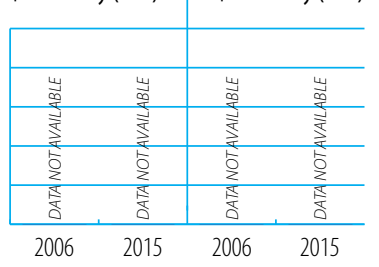

Source: WB, World Development Indicators

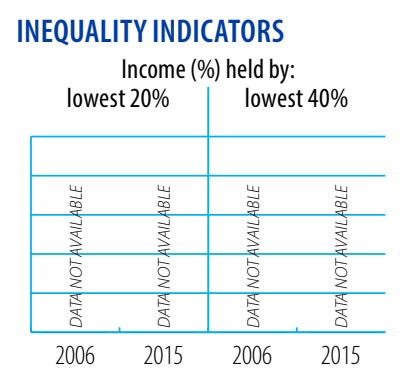

GDP PER CAPITA (constant 2011 international \$)

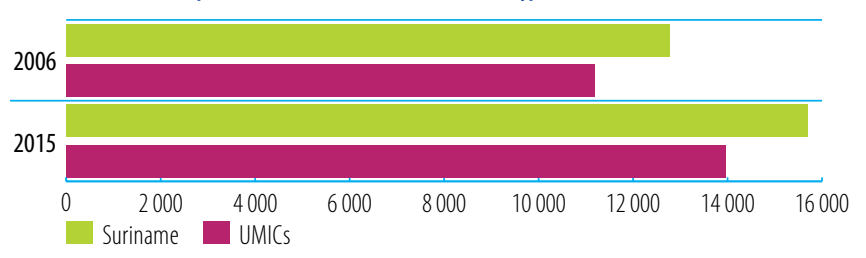

Source: WB, World Development Indicators 
Aid, Trade and Development Indicators for Tanzania

\section{A. DEVELOPMENT FINANCE}

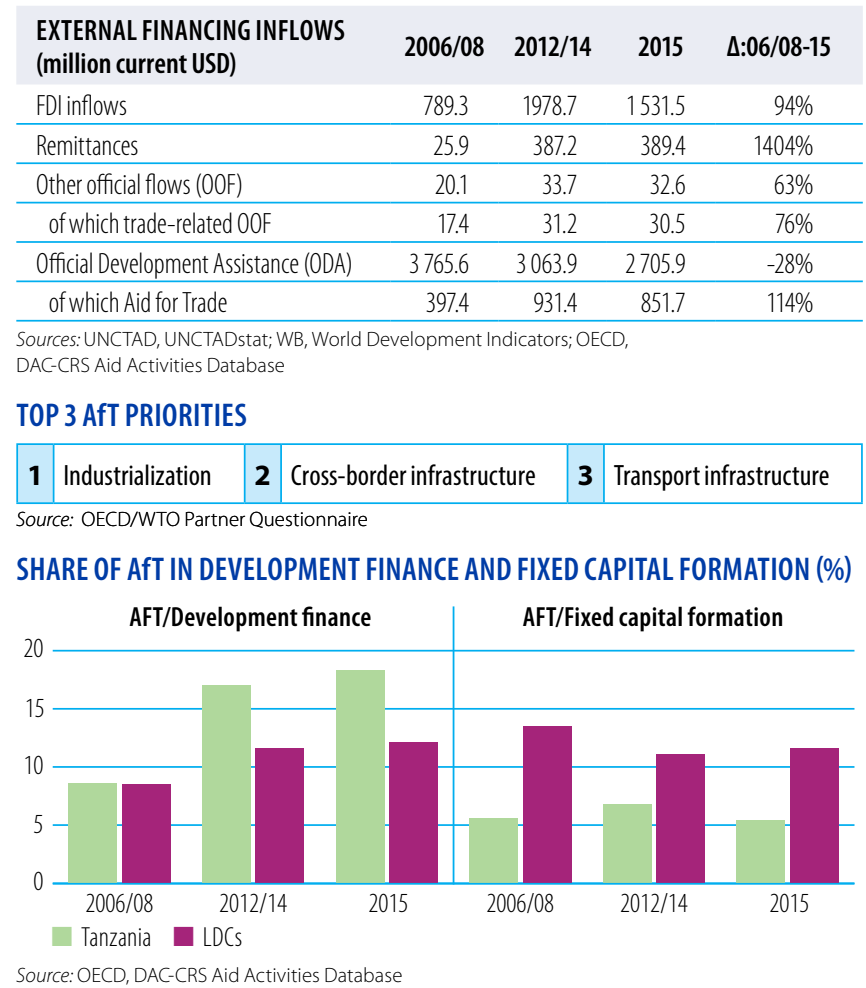

AfT DISBURSEMENTS: TOP DONORS (million current USD)

\begin{tabular}{lrr|lrr}
$\mathbf{2 0 0 6 / 0 8}$ & value & $\%$ & $\mathbf{2 0 1 5}$ & value & $\%$ \\
IDA & 153.7 & 39 & IDA & 234.8 & 28 \\
\hline EU Institutions & 62.2 & 16 & African Development Fund & 194.2 & 23 \\
\hline African Development Fund & 33.8 & 9 & Japan & 73.9 & 9 \\
\hline Denmark & 32.2 & 8 & United Kingdom & 71.8 & 8 \\
\hline Sweden & 23.8 & 6 & United States & 57.4 & 7 \\
\hline
\end{tabular}

Source: OECD, DAC-CRS Aid Activities Database

AfT DISBURSEMENTS BY SECTOR (million current USD)

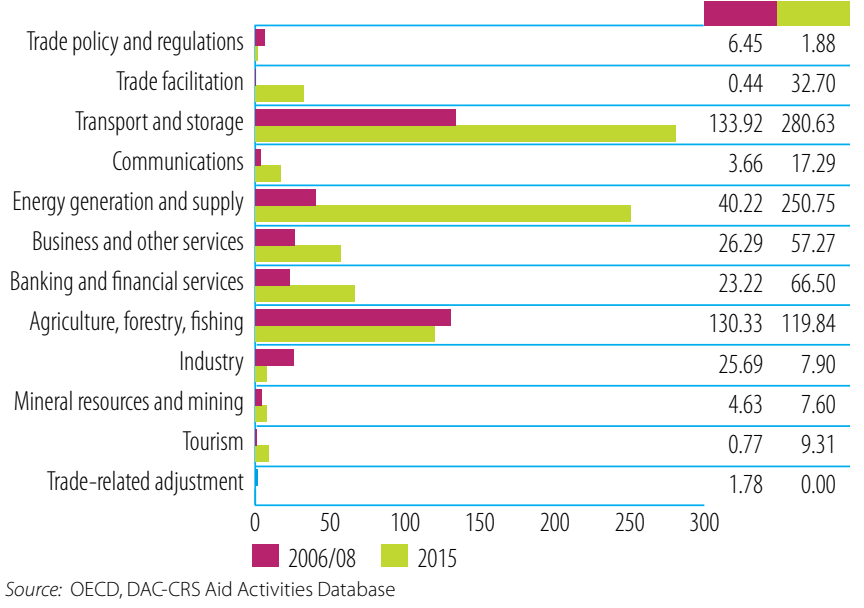

\section{B. TRADE COSTS}

\begin{tabular}{lcc} 
INDICATOR & 2006 & $\mathbf{2 0 1 5}$ \\
Tariffs (\%) & & \\
\hline Imports: simple avg. MFN applied & 12.7 & 12.9 \\
\hline Imports: weighted avg. MFN applied (2005-2014) & 10 & 8.4 \\
\hline Exports: weighted avg. faced (2005-2014) & 5.0 & 1.4 \\
\hline Exports: duty free (value in \%) (2005-2014) & 81.6 & 93.4 \\
\hline ICT connectivity (\% of population) & 0.5 & \\
\hline Mobile broadband subscriptions (2008-2015) & 3.2 \\
\hline Fixed broadband subscriptions & 0.0 & 0.2 \\
\hline Individuals using the internet & 1.3 & 5.4 \\
\hline Sources: WTO, World Tariff Profiles; ITU, World Telecommunication/ICT Indicators &
\end{tabular}
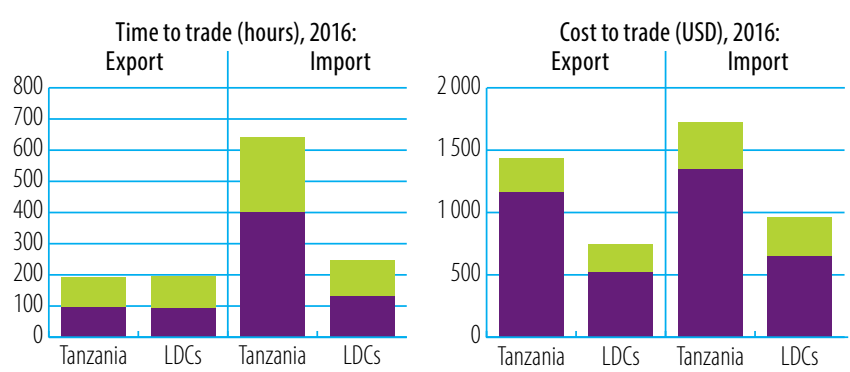

Border compliance Documentary compliance

Source: WB, Doing Business

LOGISTICS PERFORMANCE INDICES (LPI) (1-5)

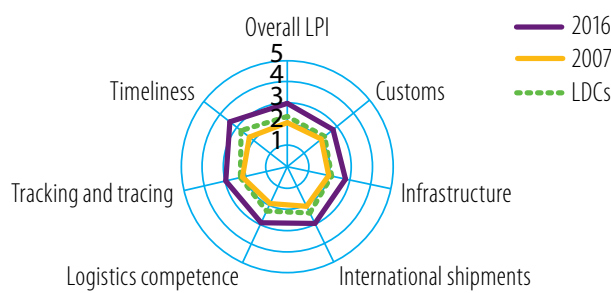

Source: WB Logistics Performance Index (LPI)

GLOBAL COMPETITIVENESS INDICATORS (1-7)

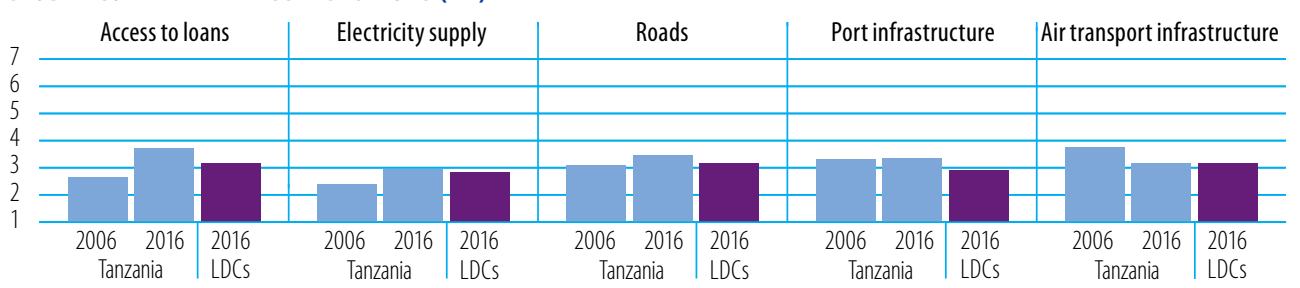

TRADE FACILITATION INDICATORS, 2015 (0-2)

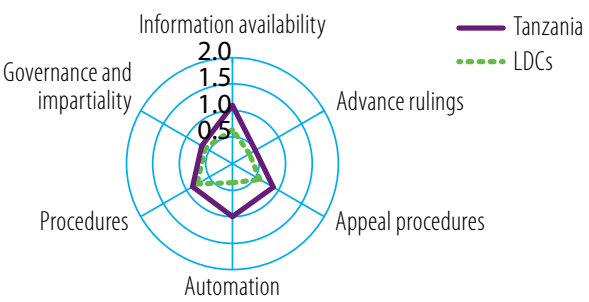

Source: OECD Trade Facilitation Indicators
TRADE COSTS (ad-valorem, \%)

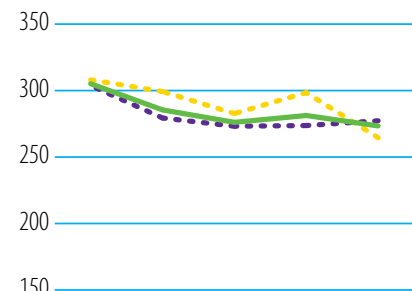

150

100

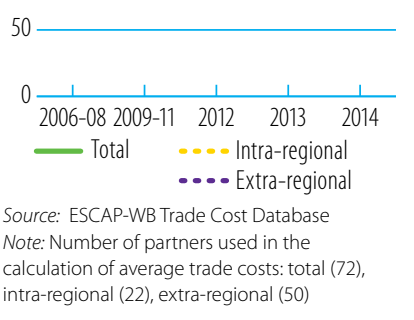




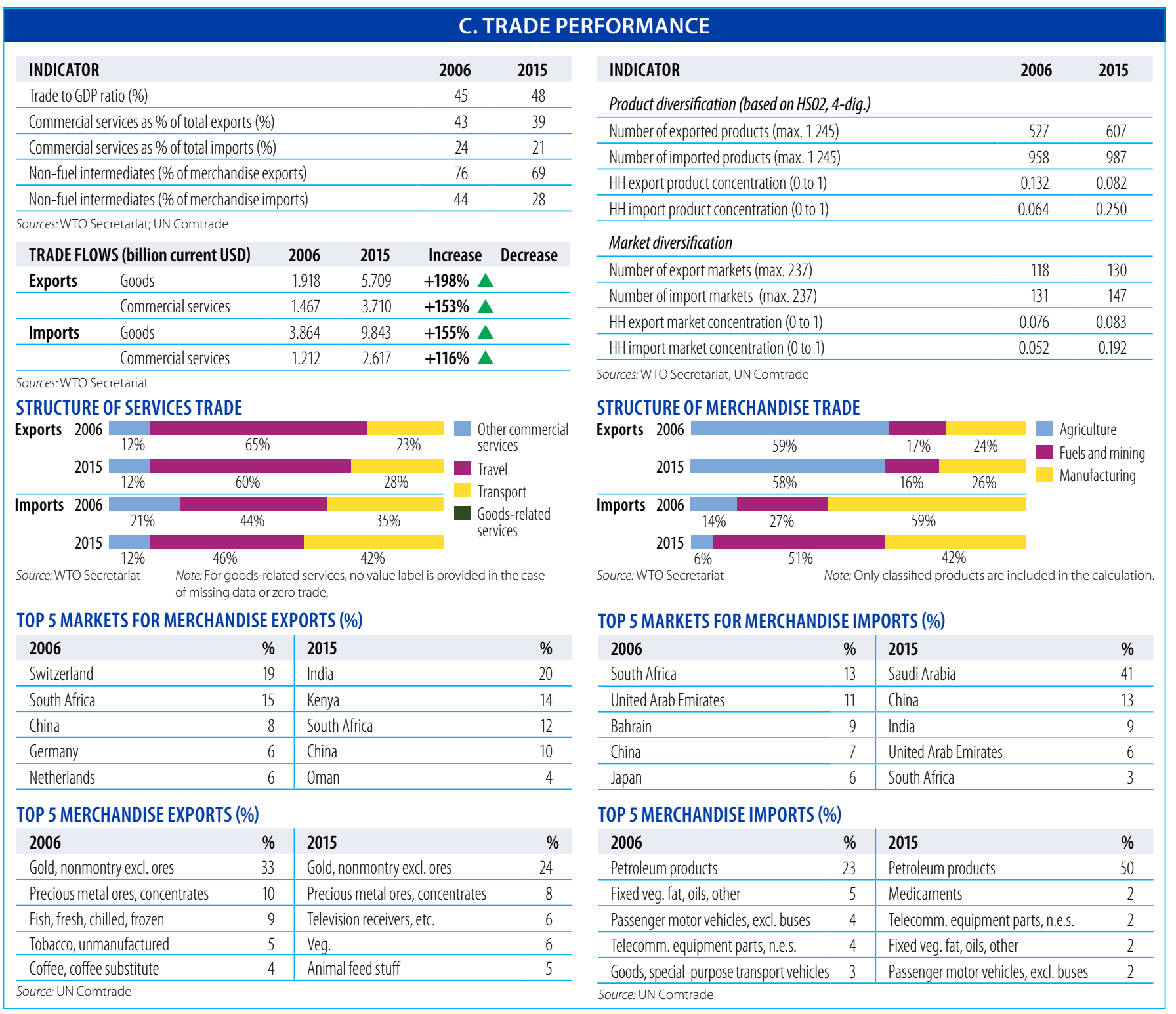

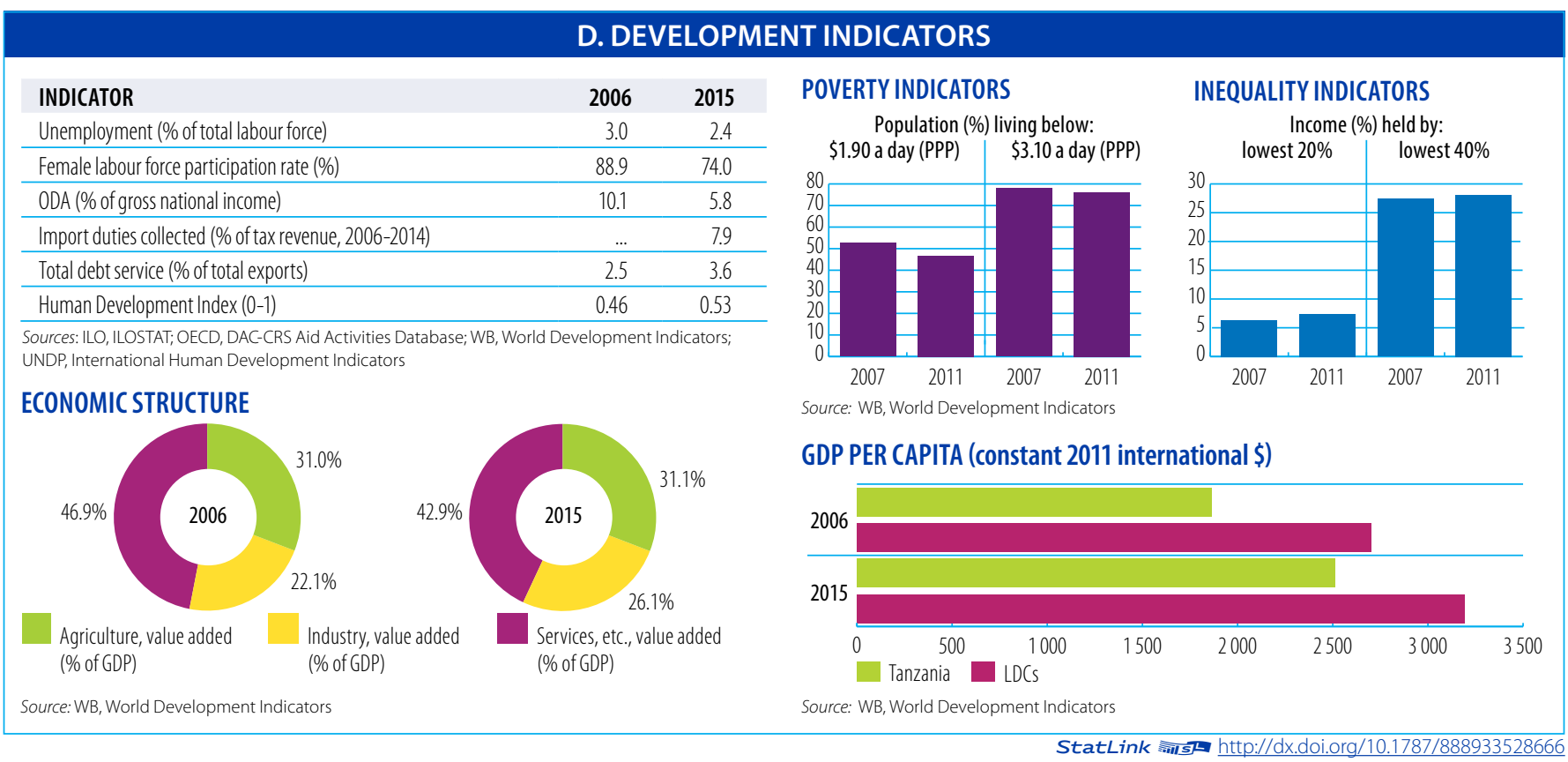


Aid, Trade and Development Indicators for Togo

\section{A. DEVELOPMENT FINANCE}

\begin{tabular}{lrrrc}
$\begin{array}{l}\text { EXTERNAL FINANCING INFLOWS } \\
\text { (million current USD) }\end{array}$ & $\mathbf{2 0 0 6 / 0 8}$ & $\mathbf{2 0 1 2 / 1 4}$ & $\mathbf{2 0 1 5}$ & $\mathbf{\Delta : 0 6 / 0 8 - 1 5}$ \\
FDl inflows & 50.1 & 119.7 & 52.7 & $5 \%$ \\
\hline Remittances & 284.6 & 389.8 & 397.4 & $40 \%$ \\
\hline Other official flows (00F) & 48.1 & 41.7 & 23.1 & $-52 \%$ \\
\hline$\quad$ of which trade-related 00F & 0.0 & 40.0 & 23.1 & - \\
\hline Official Development Assistance (ODA) & 225.3 & 240.5 & 228.1 & $1 \%$ \\
\hline of which Aid for Trade & 36.5 & 50.6 & 81.7 & $124 \%$ \\
\hline
\end{tabular}

Sources: UNCTAD, UNCTADstat; WB, World Development Indicators; OECD,

DAC-CRS Aid Activities Database

\section{TOP 3 AfT PRIORITIES}

\begin{tabular}{|l|l|l|l|l|l|}
\hline 1 & Transport infrastructure & $\mathbf{2}$ & Export diversification & $\mathbf{3}$ & Poverty reduction \\
\hline
\end{tabular}

Source: OECD/WTO Partner Questionnaire

SHARE OF AfT IN DEVELOPMENT FINANCE AND FIXED CAPITAL FORMATION (\%)

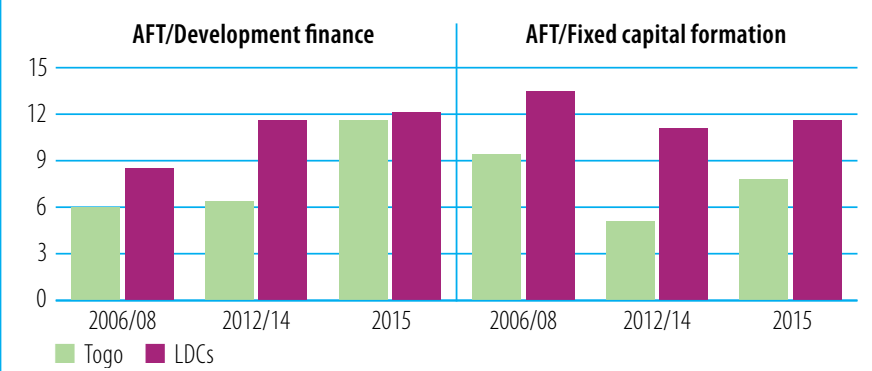

$\square$ Togo $\square$ LDC

Source: OECD, DAC-CRS Aid Activities Database

AfT DISBURSEMENTS: TOP DONORS (million current USD)

\begin{tabular}{lrr|lrc}
$\mathbf{2 0 0 6 / 0 8}$ & value & $\%$ & $\mathbf{2 0 1 5}$ & value & $\%$ \\
IDA & 27.2 & 74 & Germany & 22.7 & 28 \\
\hline United Kingdom & 2.9 & 8 & African Development Fund & 20.1 & 25 \\
\hline EU Institutions & 2.4 & 7 & Belgium & 10.1 & 12 \\
\hline France & 2.1 & 6 & IDA & 9.6 & 12 \\
\hline Germany & 0.6 & 2 & Kuwait (KFAED) & 8.8 & 11 \\
\hline
\end{tabular}

Source: OECD, DAC-CRS Aid Activities Database

AfT DISBURSEMENTS BY SECTOR (million current USD)

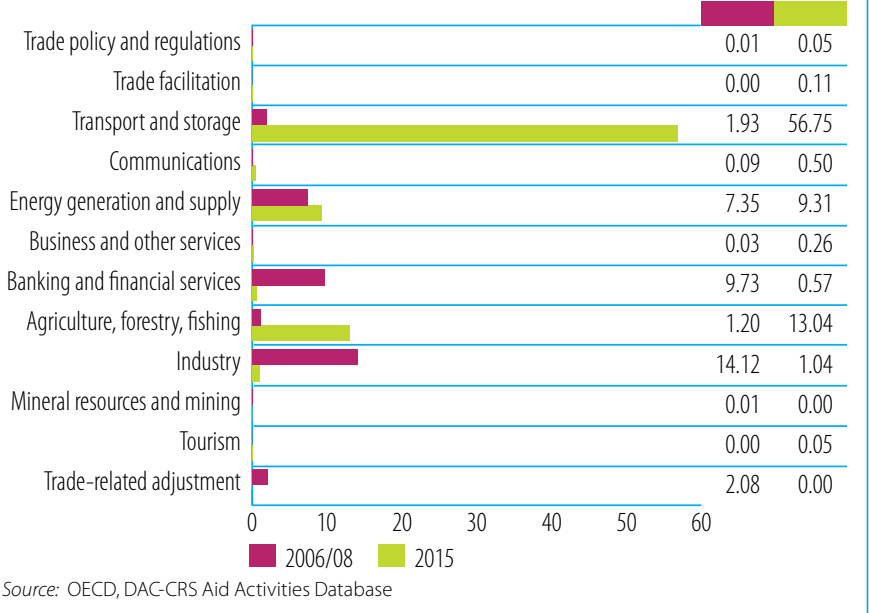

\section{B. TRADE COSTS}

\begin{tabular}{lrc} 
INDICATOR & $\mathbf{2 0 0 6}$ & $\mathbf{2 0 1 5}$ \\
Tariffs (\%) & & \\
\hline Imports: simple avg. MFN applied & 12.0 & 12.2 \\
\hline Imports: weighted avg. MFN applied (2005-2014) & 10 & 11.1 \\
\hline Exports: weighted avg. faced (2005-2014) & 6.9 & 2.9 \\
\hline Exports: duty free (value in \%) (2005-2014) & 66.5 & 65.7 \\
\hline ICT connectivity (\% of population) & & \\
\hline Mobile broadband subscriptions (2008-2015) & 0.0 & 6.0 \\
\hline Fixed broadband subscriptions (2007-2015) & 0.0 & 0.9 \\
\hline Individuals using the internet & 2.0 & 7.1 \\
\hline Sources: WTO, World Tariff Profiles; ITU, World Telecommunication/ICT Indicators &
\end{tabular}
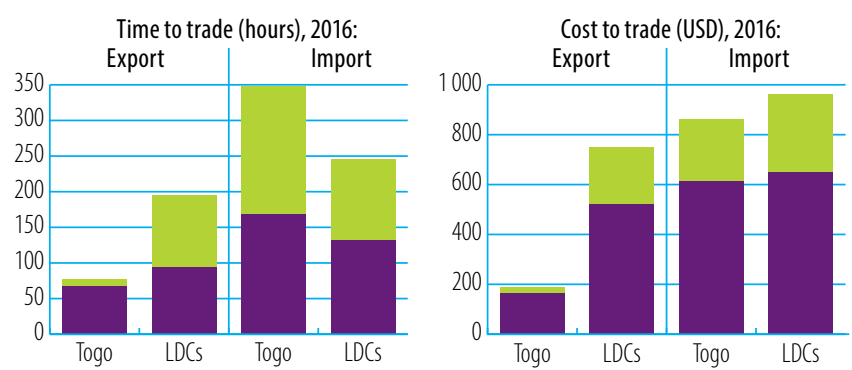

Border compliance Documentary compliance

Source: WB, Doing Business

\section{LOGISTICS PERFORMANCE INDICES (LPI) (1-5)}

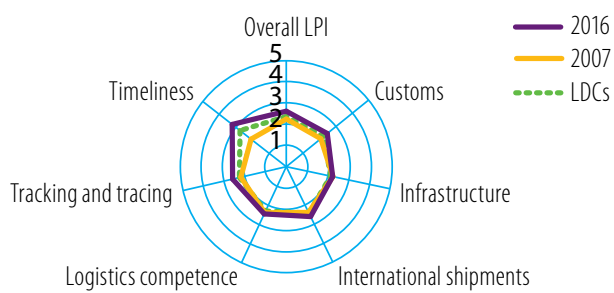

Source: WB Logistics Performance Index (LPI)

GLOBAL COMPETITIVENESS INDICATORS (1-7)

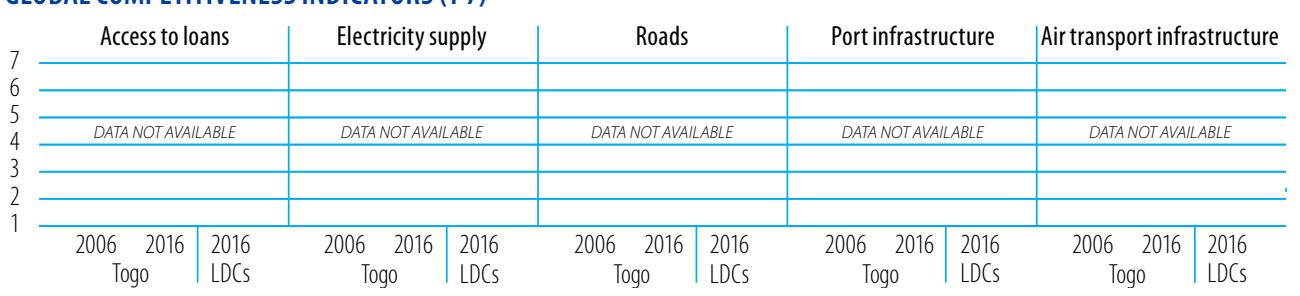

Source: WEF Global Competitiveness Index
TRADE FACILITATION INDICATORS, 2015 (0-2)

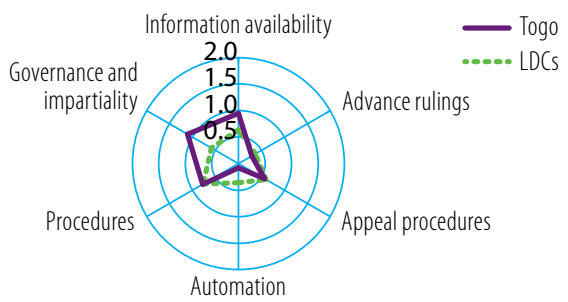

Source: OECD Trade Facilitation Indicators

100

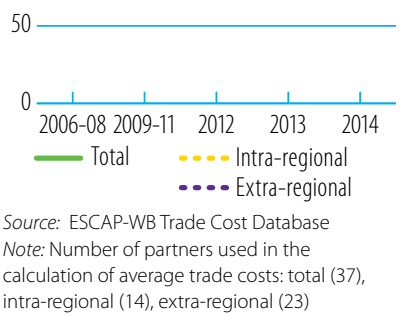




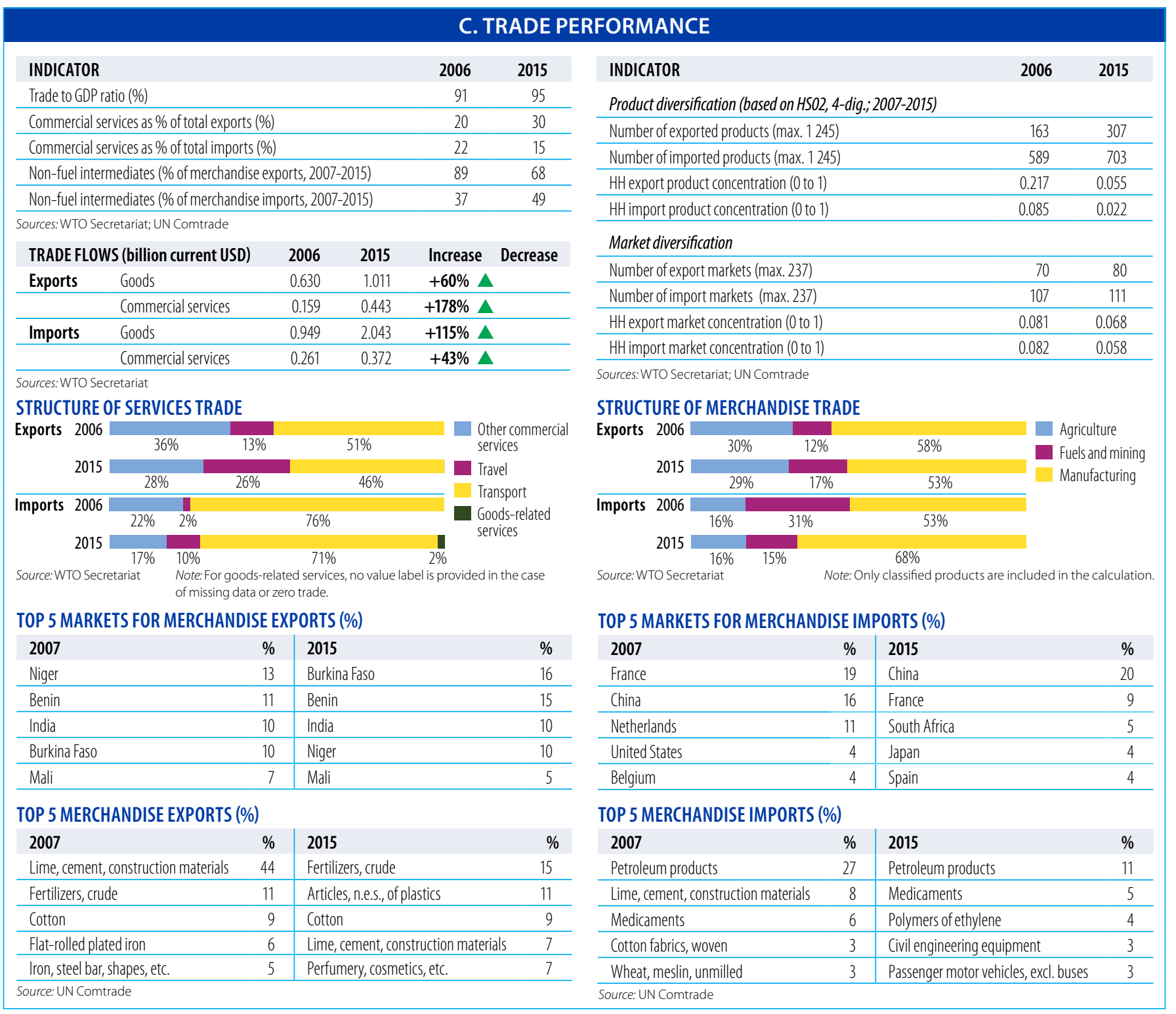

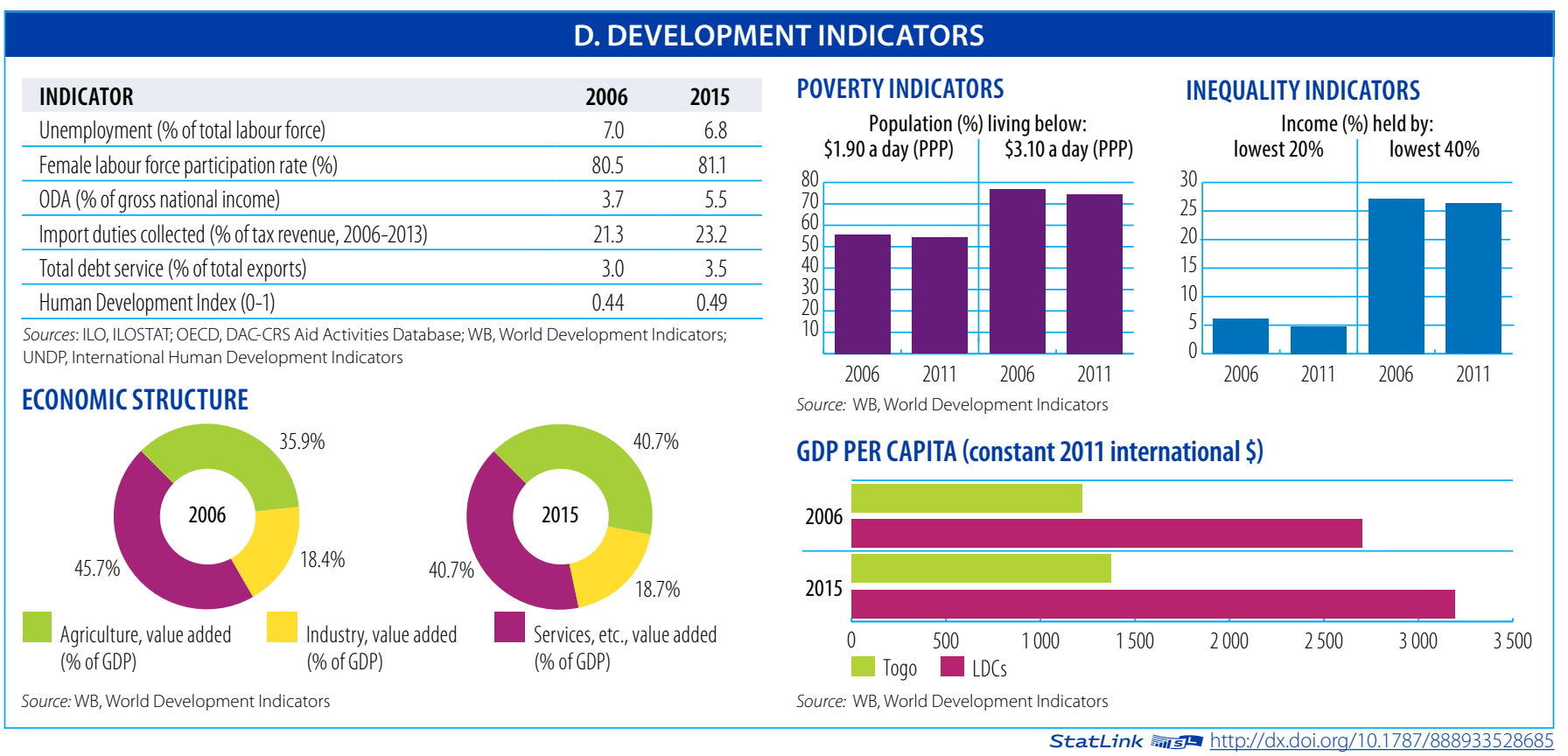


Aid, Trade and Development Indicators for Tonga

\section{A. DEVELOPMENT FINANCE}

\begin{tabular}{lrrrc}
$\begin{array}{l}\text { EXTERNAL FINANCING INFL OWS } \\
\text { (million current USD) }\end{array}$ & $\mathbf{2 0 0 6 / 0 8}$ & $\mathbf{2 0 1 2 / 1 4}$ & $\mathbf{2 0 1 5}$ & $\mathbf{\Delta : 0 6 / 0 8 - 1 5}$ \\
FDl inflows & 29.2 & 46.2 & 12.6 & $-57 \%$ \\
\hline Remittances & 91.2 & 118.7 & 117.6 & $29 \%$ \\
\hline Other official flows (00F) & 0.3 & 0.5 & 2.1 & $600 \%$ \\
\hline of which trade-related 0OF & 0.0 & 0.0 & 2.1 & - \\
\hline Official Development Assistance (ODA) & 26.9 & 82.1 & 71.1 & $165 \%$ \\
\hline of which Aid for Trade & 5.9 & 30.7 & 27.2 & $359 \%$ \\
\hline
\end{tabular}

Sources: UNCTAD, UNCTADstat; WB, World Development Indicators; OECD,

DAC-CRS Aid Activities Database

\section{TOP 3 AfT PRIORITIES}

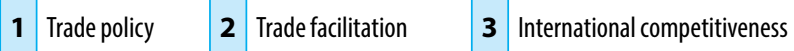

Source: OECD/WTO Partner Questionnaire

SHARE OF AfT IN DEVELOPMENT FINANCE AND FIXED CAPITAL FORMATION (\%)

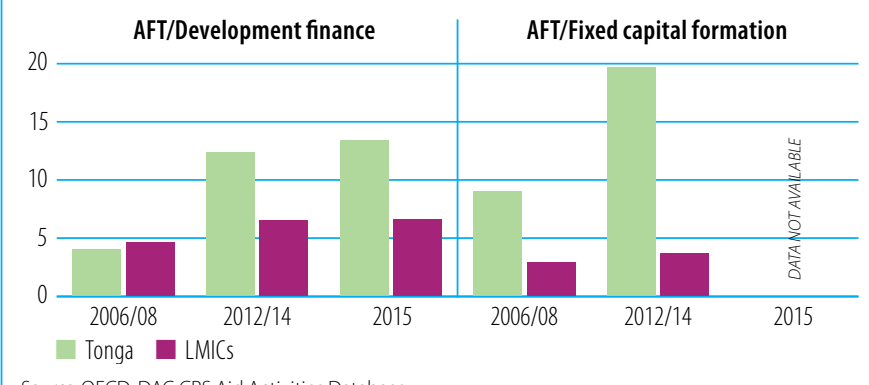

AfT DISBURSEMENTS: TOP DONORS (million current USD)

\begin{tabular}{lrr|lrl}
$\mathbf{2 0 0 6 / 0 8}$ & value & $\mathbf{\%}$ & $\mathbf{2 0 1 5}$ & value & $\%$ \\
Australia & 3.3 & 55 & IDA & 9.6 & 35 \\
\hline New Zealand & 1.7 & 29 & Japan & 4.8 & 18 \\
\hline Japan & 0.8 & 13 & New Zealand & 4.6 & 17 \\
\hline United Kingdom & 0.2 & 3 & EU Institutions & 4.1 & 15 \\
\hline EU Institutions & 0.0 & 1 & Australia & 2.7 & 10 \\
\hline
\end{tabular}

Source: OECD, DAC-CRS Aid Activities Database

AfT DISBURSEMENTS BY SECTOR (million current USD)

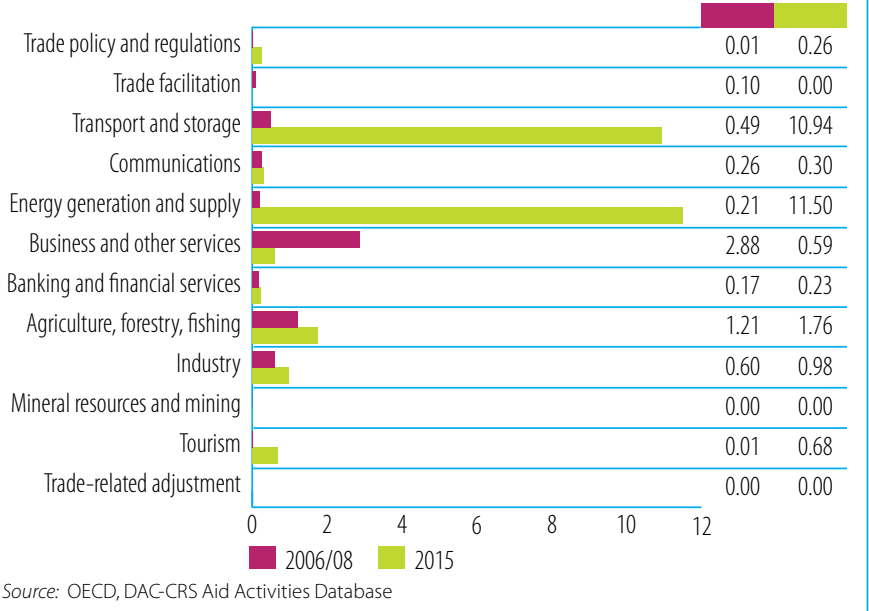

\section{B. TRADE COSTS}

\begin{tabular}{lcc} 
INDICATOR & 2006 & 2015 \\
Tariffs (\%) & 17.0 & 11.7 \\
\hline Imports: simple avg. MFN applied & $\ldots$ & 5.7 \\
\hline Imports: weighted avg. MFN applied (2006-2014) & 2.6 & 3.6 \\
\hline Exports: weighted avg. faced (2005-2014) & 45.3 & 72.9 \\
\hline Exports: duty free (value in \%) (2005-2014) & & \\
\hline ICT connectivity (\% of population) & $\ldots$ & 29.5 \\
\hline Mobile broadband subscriptions & 0.6 & 1.9 \\
\hline Fixed broadband subscriptions & 5.9 & 45.0 \\
\hline Individuals using the internet & &
\end{tabular}
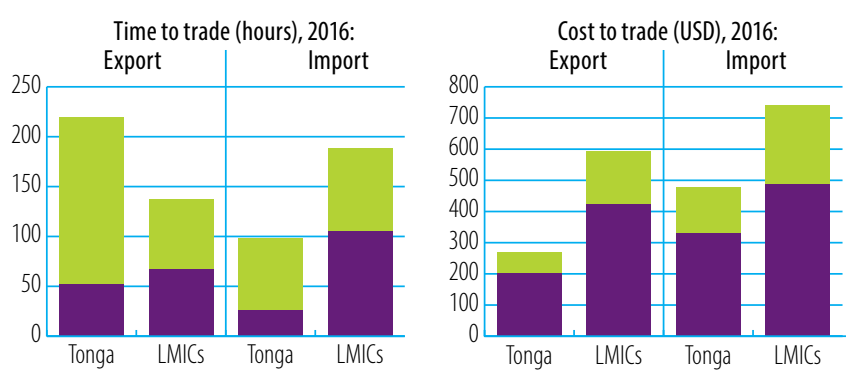

- Border compliance Documentary compliance Source: WB, Doing Business

\section{LOGISTICS PERFORMANCE INDICES (LPI) (1-5)}

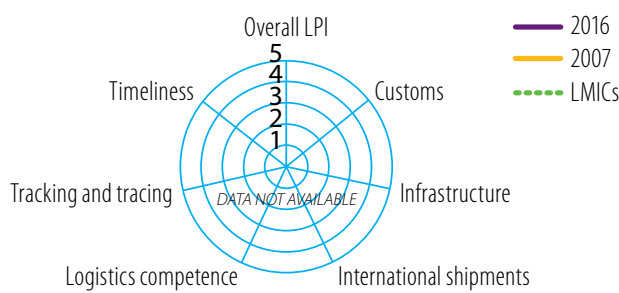

Source: WB Logistics Performance Index (LPI)

\section{GLOBAL COMPETITIVENESS INDICATORS (1-7)}

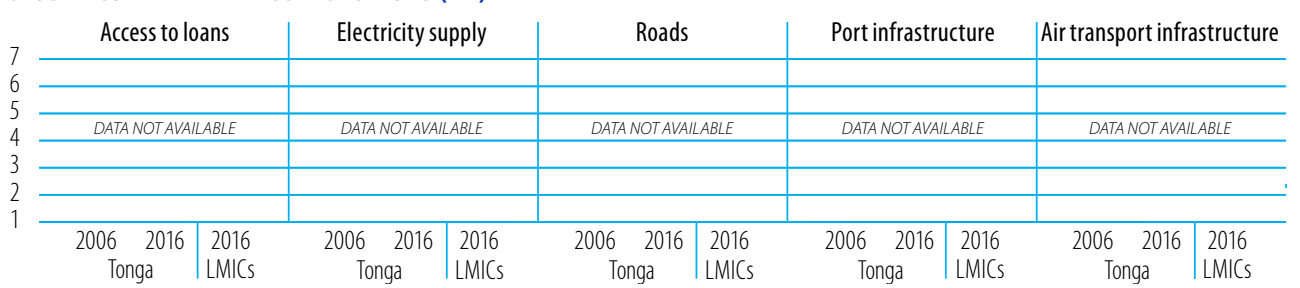

Source: WEF Global Competitiveness Index

TRADE FACILITATION INDICATORS, 2015 (0-2)

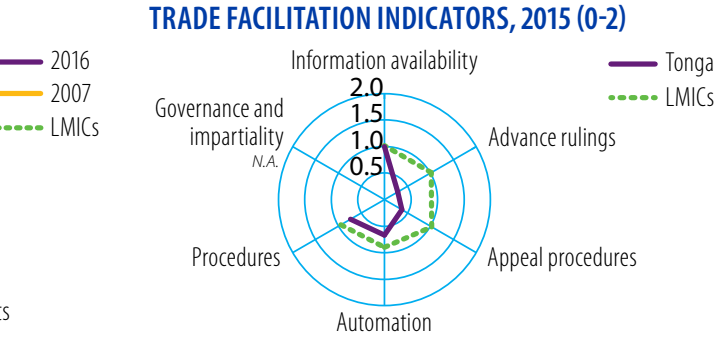

Source: OECD Trade Facilitation Indicators 


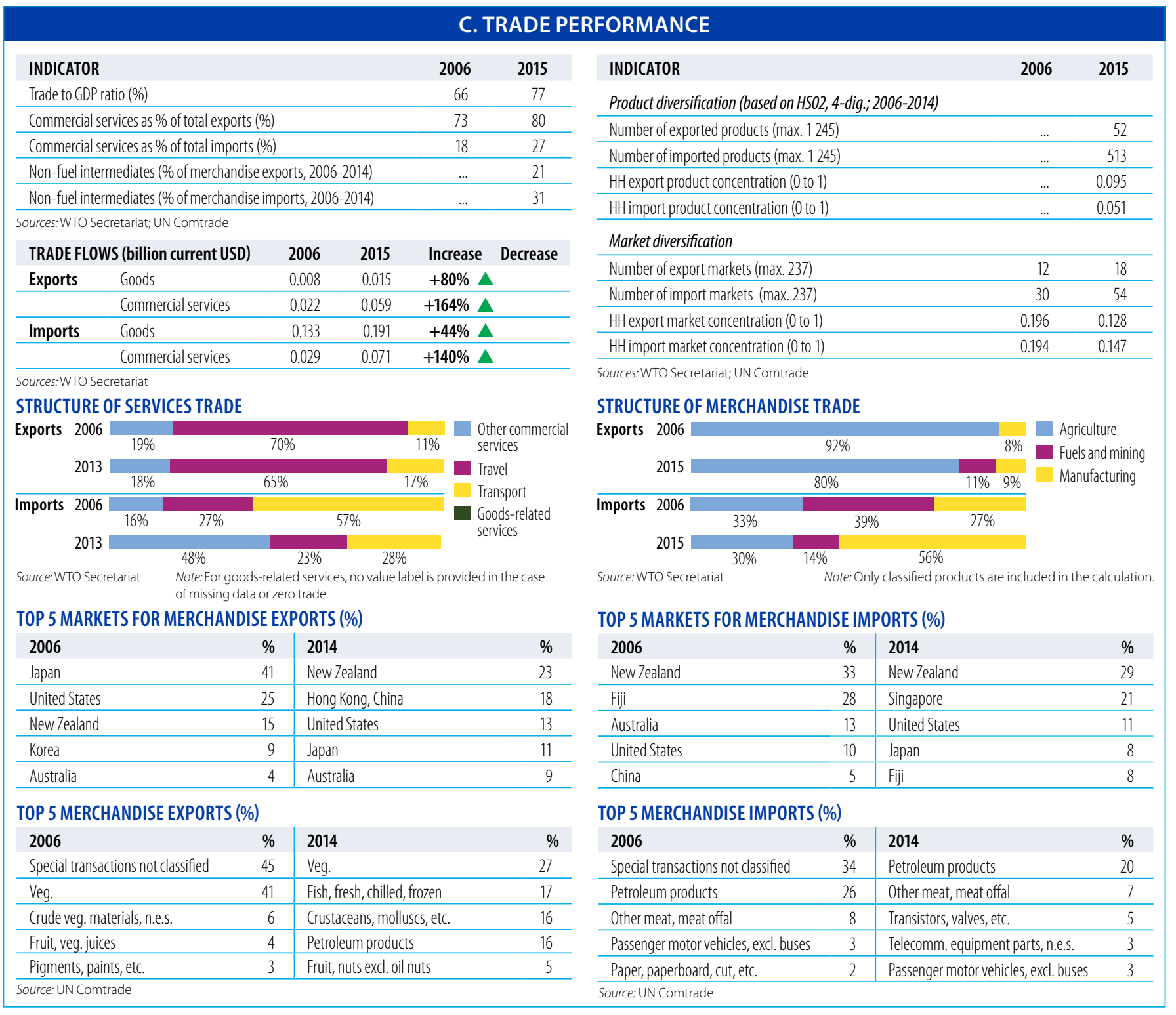

\begin{tabular}{|lrr}
\hline & D. DEVELOPMEN \\
\hline INDICATOR & $\mathbf{2 0 0 6}$ & $\mathbf{2 0 1 5}$ \\
Unemployment (\% of total labour force) & 5.1 & 5.0 \\
\hline Female labour force participation rate (\%) & 53.3 & 52.8 \\
\hline ODA (\% of gross national income, 2006-2014) & 7.4 & 18.3 \\
\hline Import duties collected (\% of tax revenue) & $\ldots$ & $\ldots$ \\
\hline Total debt service (\% of total exports) & 10.3 & 20.2 \\
\hline Human Development Index (0-1) & 0.70 & 0.72 \\
\hline
\end{tabular}

Sources: ILO, ILOSTAT; OECD, DAC-CRS Aid Activities Database; WB, World Development Indicators; UNDP, International Human Development Indicators

\section{ECONOMIC STRUCTURE}

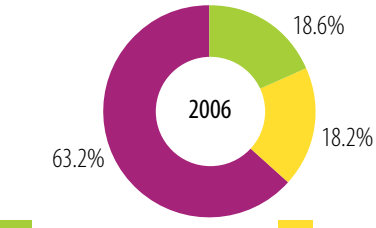

Agriculture, value added (\% of GDP)

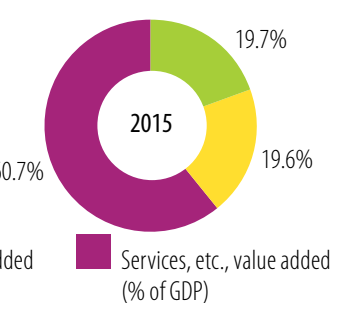

(\% of GDP)

Source: WB, World Development Indicators

ndustry, value added (\% of GDP)
POVERTYINDICATORS

Population (\%) living below:

$\$ 1.90$ a day (PPP) $\quad \$ 3.10$ a day (PPP)

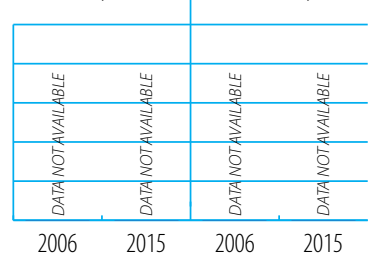

Source: WB, World Development Indicators

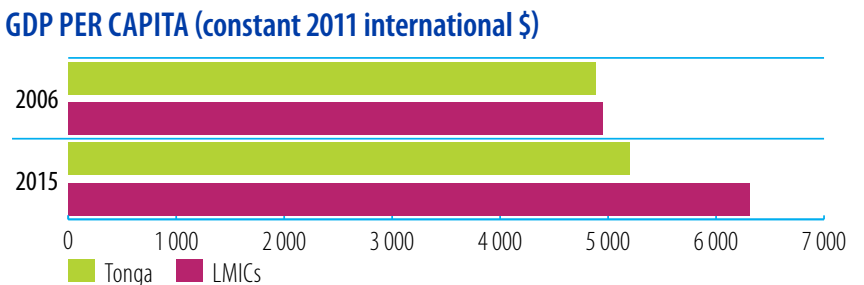

Source: WB, World Development Indicators

INEQUALITY INDICATORS

Income (\%) held by:

lowest 20\% | lowest 40\%

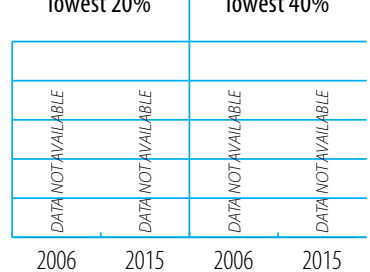


Aid, Trade and Development Indicators for Uganda

\section{A. DEVELOPMENT FINANCE}

\begin{tabular}{lrrrc}
$\begin{array}{l}\text { EXTERNAL FINANCING INFLOWS } \\
\text { (million current USD) }\end{array}$ & $\mathbf{2 0 0 6 / 0 8}$ & $\mathbf{2 0 1 2 / 1 4}$ & $\mathbf{2 0 1 5}$ & $\mathbf{\Delta : 0 6 / 0 8 - 1 5}$ \\
\hline FDl inflows & $\mathbf{7 2 1 . 8}$ & 1120.0 & 1057.3 & $46 \%$ \\
\hline Remittances & 528.7 & 913.8 & 1049.3 & $98 \%$ \\
\hline Other official flows (O0F) & 37.0 & 61.0 & 36.6 & $-1 \%$ \\
\hline of which trade-related 00F & 33.2 & 56.8 & 36.5 & $10 \%$ \\
\hline Official Development Assistance (ODA) & 2801.6 & 1744.1 & 1693.4 & $-40 \%$ \\
\hline of which Aid for Trade & 386.0 & 468.5 & 432.4 & $12 \%$ \\
\hline
\end{tabular}

Sources: UNCTAD, UNCTADstat; WB, World Development Indicators; OECD,

DAC-CRS Aid Activities Database

\section{TOP 3 AfT PRIORITIES}

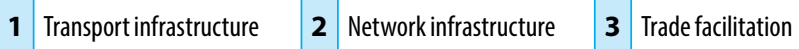

Source: OECD/WTO Partner Questionnaire

SHARE OF AfT IN DEVELOPMENT FINANCE AND FIXED CAPITAL FORMATION (\%)

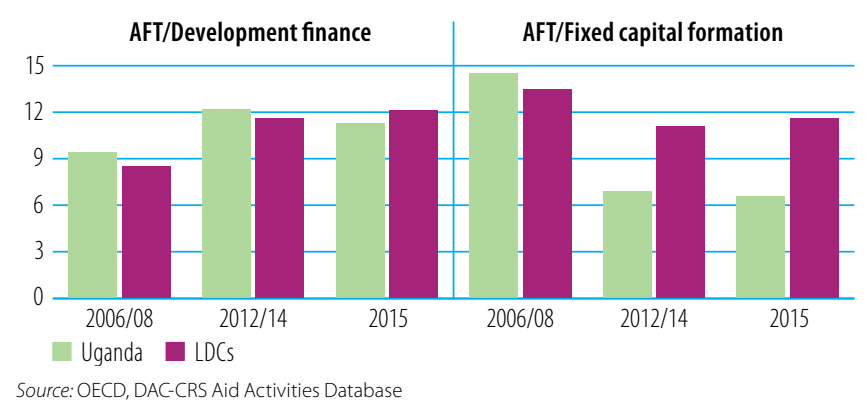

AfT DISBURSEMENTS: TOP DONORS (million current USD)

\begin{tabular}{lrr|lrc}
$\mathbf{2 0 0 6 / 0 8}$ & value & $\%$ & $\mathbf{2 0 1 5}$ & value & $\%$ \\
IDA & 169.5 & 44 & IDA & 107.0 & 25 \\
\hline EU Institutions & 71.1 & 18 & EU Institutions & 55.0 & 13 \\
\hline African Development Fund & 47.8 & 12 & United Kingdom & 54.0 & 12 \\
\hline United States & 16.3 & 4 & United States & 46.3 & 11 \\
\hline Norway & 15.3 & 4 & Japan & 45.8 & 11 \\
\hline
\end{tabular}

Source: OECD, DAC-CRS Aid Activities Database

AfT DISBURSEMENTS BY SECTOR (million current USD)

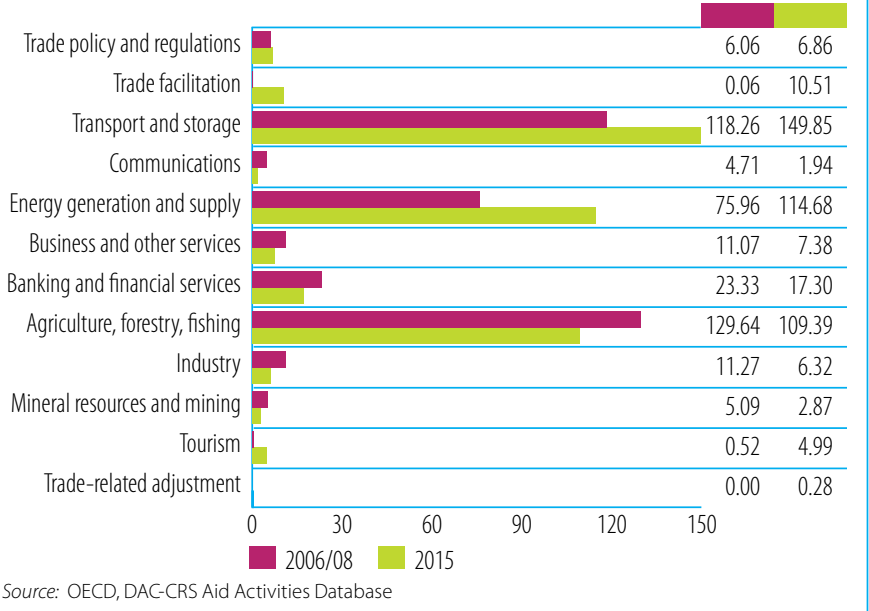

\section{B. TRADE COSTS}

\begin{tabular}{lrc} 
INDICATOR & 2006 & $\mathbf{2 0 1 5}$ \\
Tariffs (\%) & 12.7 & 12.8 \\
\hline Imports: simple avg. MFN applied & 12 & 11.0 \\
\hline Imports: weighted avg. MFN applied (2005-2014) & 1.1 & 0.0 \\
\hline Exports: weighted avg. faced (2005-2014) & 96.8 & 99.5 \\
\hline Exports: duty free (value in \%) (2005-2014) & & \\
\hline ICT connectivity (\% of population) & $\ldots$. & 18.3 \\
\hline Mobile broadband subscriptions & 0.0 & 0.3 \\
\hline Fixed broadband subscriptions & 2.5 & 19.2 \\
\hline Individuals using the internet & &
\end{tabular}
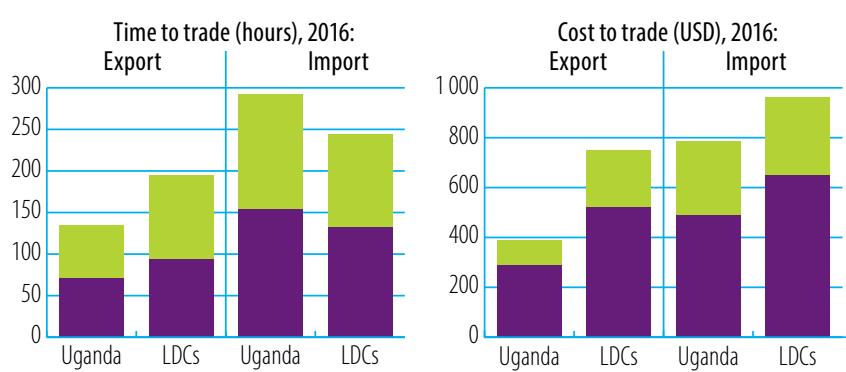

Border compliance Documentary compliance Source: WB, Doing Business

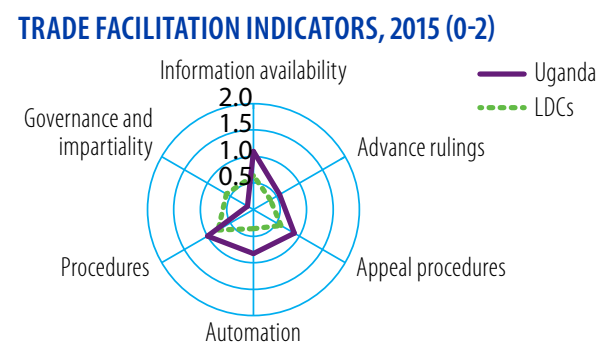

Source: OECD Trade Facilitation Indicators

Source: WB Logistics Performance Index (LPI)

GLOBAL COMPETITIVENESS INDICATORS (1-7)

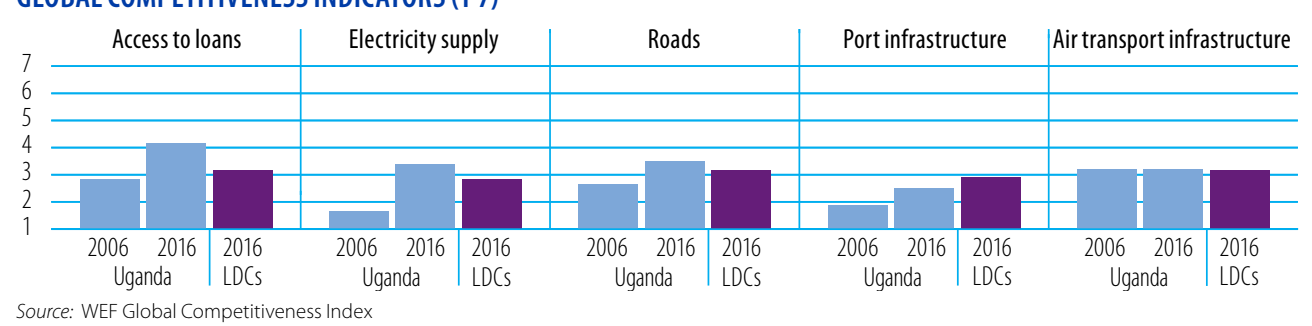

Source: WEF Global Competitiveness Index

LOGISTICS PERFORMANCE INDICES (LPI) (1-5)

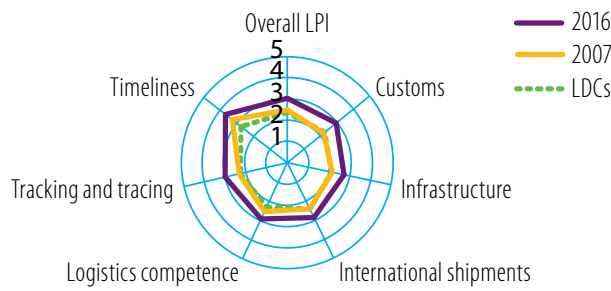

TRADE COSTS (ad-valorem, \%)

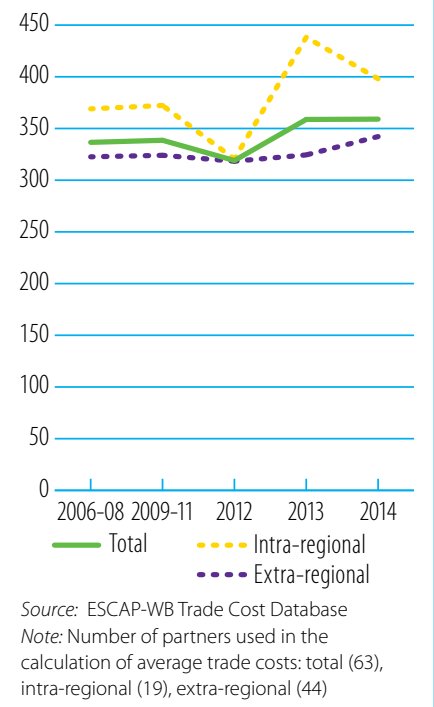




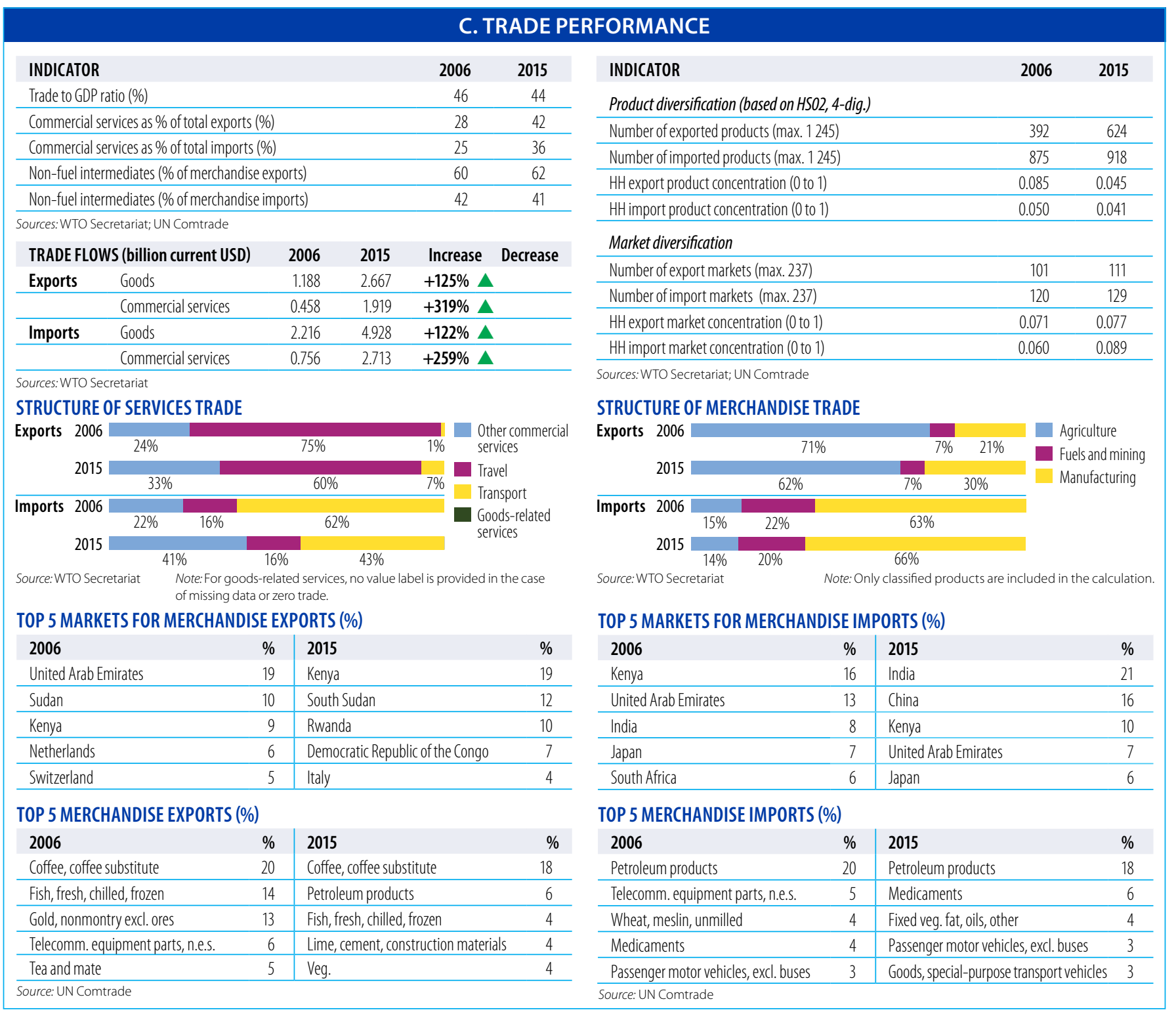

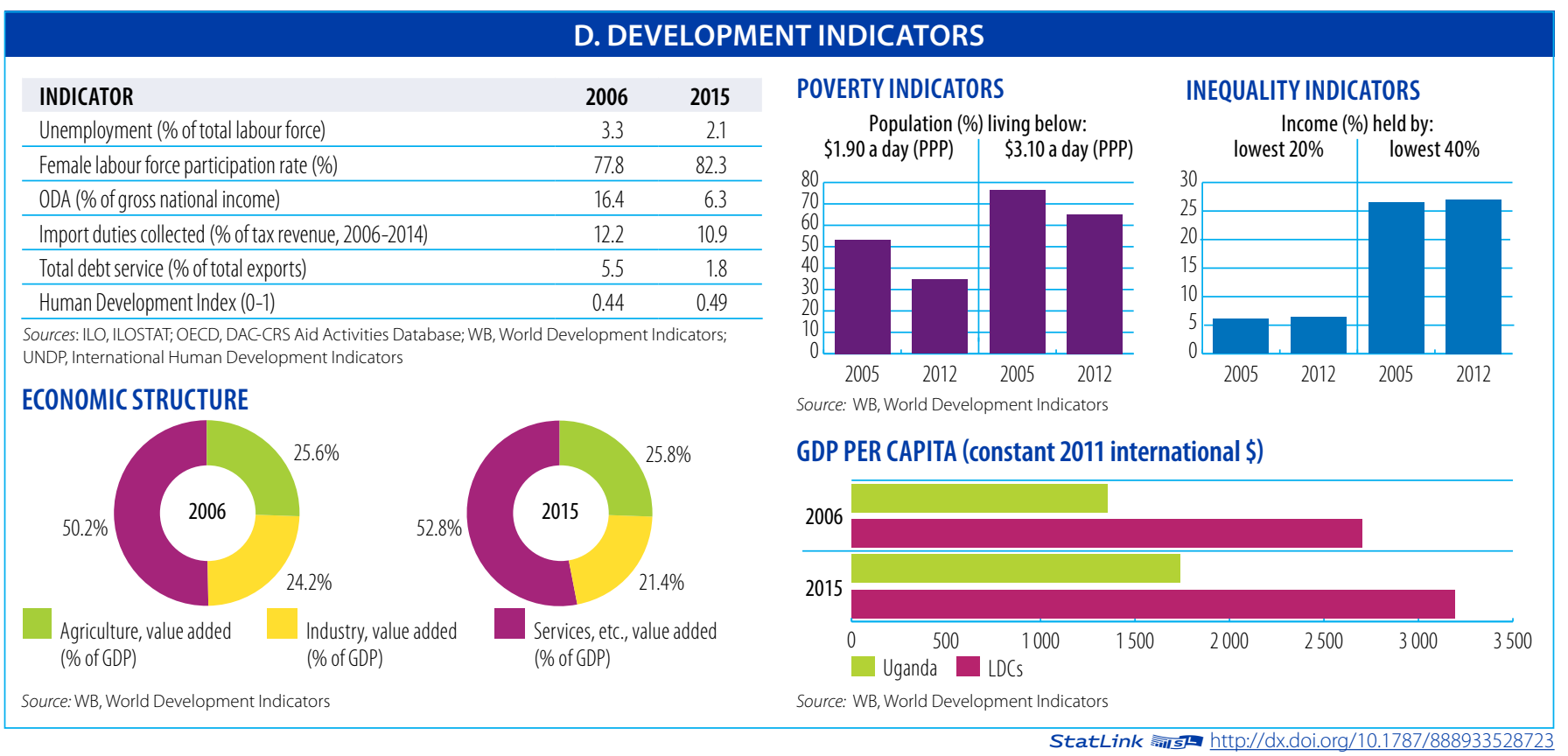


Aid, Trade and Development Indicators for Uruguay

\section{A. DEVELOPMENT FINANCE}

\begin{tabular}{lrrrc}
\hline $\begin{array}{l}\text { EXTERNAL FINANCING INFLOWS } \\
\text { (million current USD) }\end{array}$ & $\mathbf{2 0 0 6 / 0 8}$ & $\mathbf{2 0 1 2 / 1 4}$ & $\mathbf{2 0 1 5}$ & $\mathbf{\Delta : 0 6 / 0 8 - 1 5}$ \\
\hline FDl inflows & 1642.9 & 2585.2 & 1647.2 & $0 \%$ \\
\hline Remittances & 97.8 & 123.3 & 116.8 & $19 \%$ \\
\hline Other official flows (OOF) & 109.2 & 335.6 & 296.3 & $171 \%$ \\
\hline of which trade-related 00F & 65.3 & 205.9 & 181.2 & $177 \%$ \\
\hline Official Development Assistance (ODA) & 39.6 & 56.5 & 48.2 & $22 \%$ \\
\hline$\quad$ of which Aid for Trade & 6.0 & 32.1 & 25.0 & $315 \%$ \\
\hline
\end{tabular}

Sources: UNCTAD, UNCTADstat; WB, World Development Indicators; OECD,

DAC-CRS Aid Activities Database

\section{TOP 3 AfT PRIORITIES}

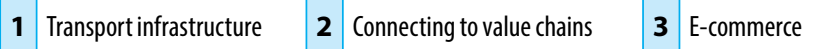

Source: OECD/WTO Partner Questionnaire

SHARE OF AfT IN DEVELOPMENT FINANCE AND FIXED CAPITAL FORMATION (\%)

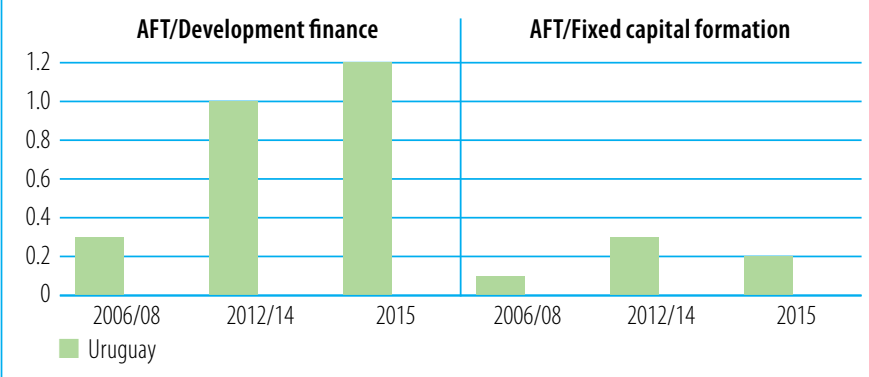

AfT DISBURSEMENTS: TOP DONORS (million current USD)

\begin{tabular}{lrr|lrr}
$\mathbf{2 0 0 6 / 0 8}$ & value & \% & 2015 & value & $\%$ \\
EU Institutions & 3.1 & 51 & Germany & 22.0 & 88 \\
\hline Japan & 1.2 & 20 & IDB Special Fund & 1.3 & 5 \\
\hline Spain & 0.4 & 7 & New Zealand & 0.7 & 3 \\
\hline Italy & 0.4 & 7 & Japan & 0.3 & 1 \\
\hline United States & 0.3 & 5 & Inter-American Development Bank & 0.3 & 1
\end{tabular}

Source: OECD, DAC-CRS Aid Activities Database

AfT DISBURSEMENTS BY SECTOR (million current USD)

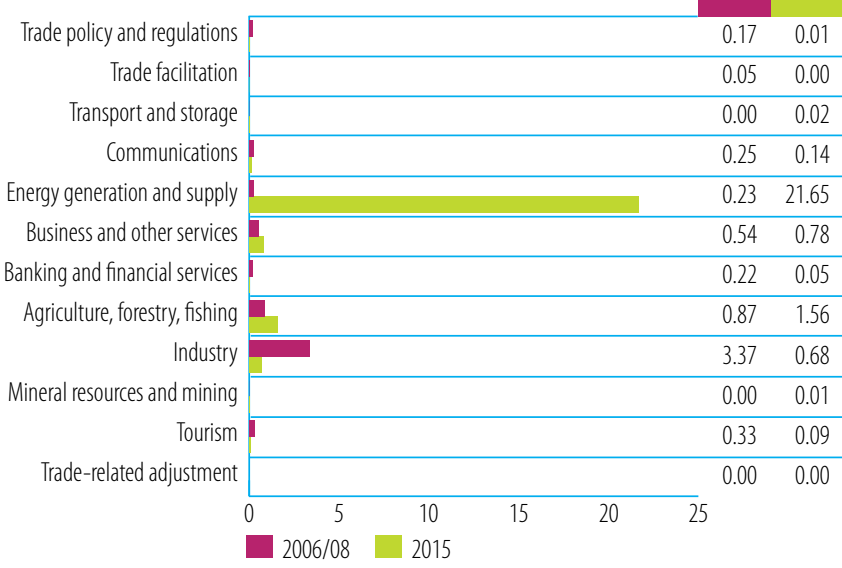

\section{B. TRADE COSTS}

\begin{tabular}{lcc} 
INDICATOR & 2006 & $\mathbf{2 0 1 5}$ \\
Tariffs (\%) & & \\
\hline Imports: simple avg. MFN applied & 10.6 & 10.5 \\
\hline Imports: weighted avg. MFN applied (2006-2014) & $\ldots .7$ & 8.2 \\
\hline Exports: weighted avg. faced (2005-2014) & 67.8 & 56.9 \\
\hline Exports: duty free (value in \%) (2005-2014) & & \\
\hline ICT connectivity (\% of population) & $\ldots$ & 77.7 \\
\hline Mobile broadband subscriptions & 3.2 & 26.3 \\
\hline Fixed broadband subscriptions & 29.4 & 64.6 \\
\hline Individuals using the internet & &
\end{tabular}
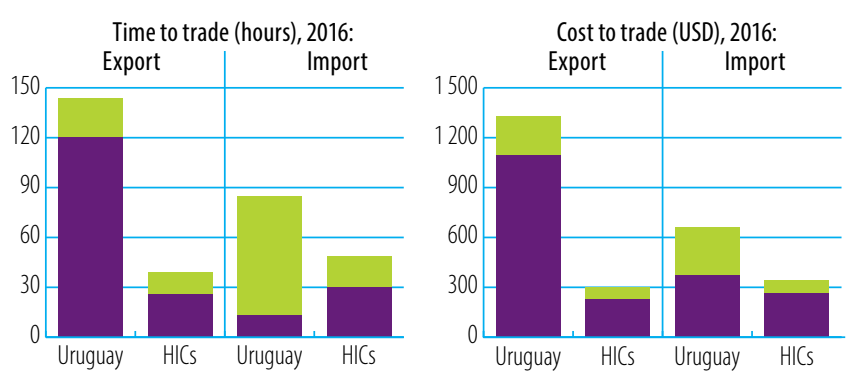

Border compliance Documentary compliance Source: WB, Doing Business

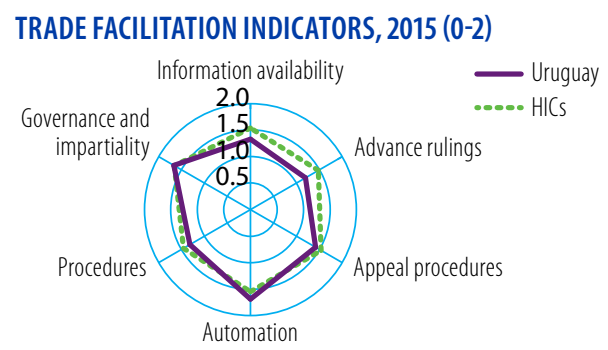

Source: OECD Trade Facilitation Indicators

Source: WB Logistics Performance Index (LPI)

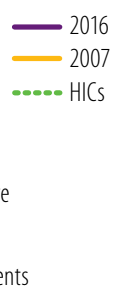

\section{GLOBAL COMPETITIVENESS INDICATORS (1-7)}

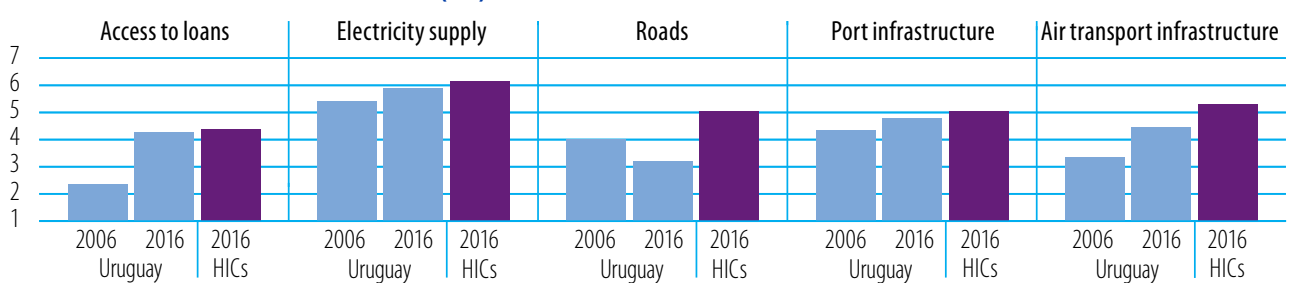

Source: WEF Global Competitiveness Index

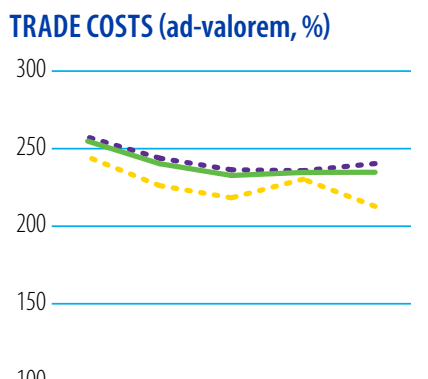

100

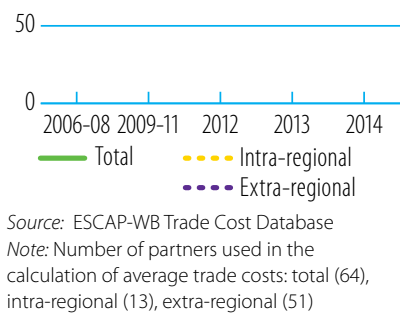




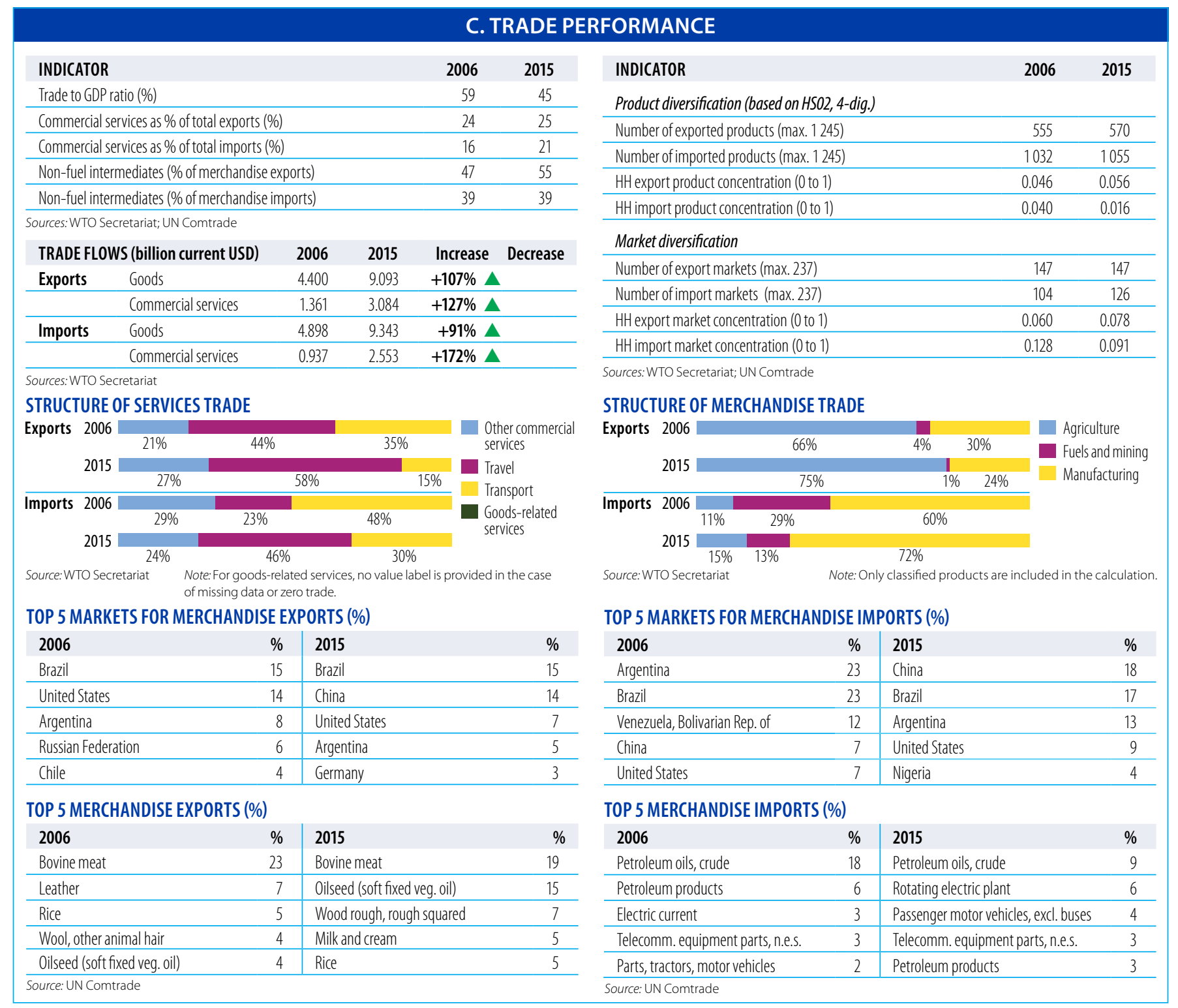

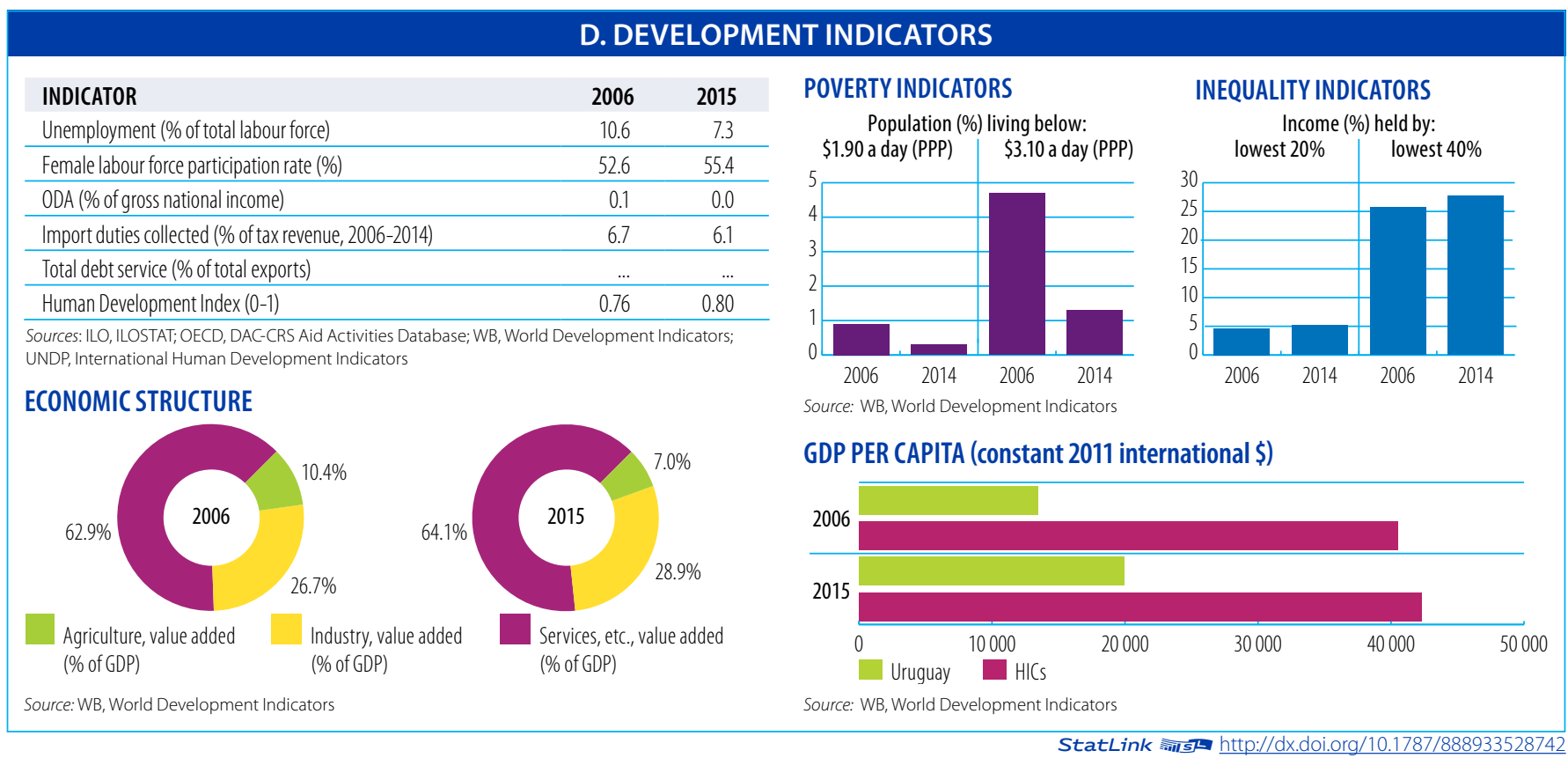


Aid, Trade and Development Indicators for Viet Nam

\section{A. DEVELOPMENT FINANCE}

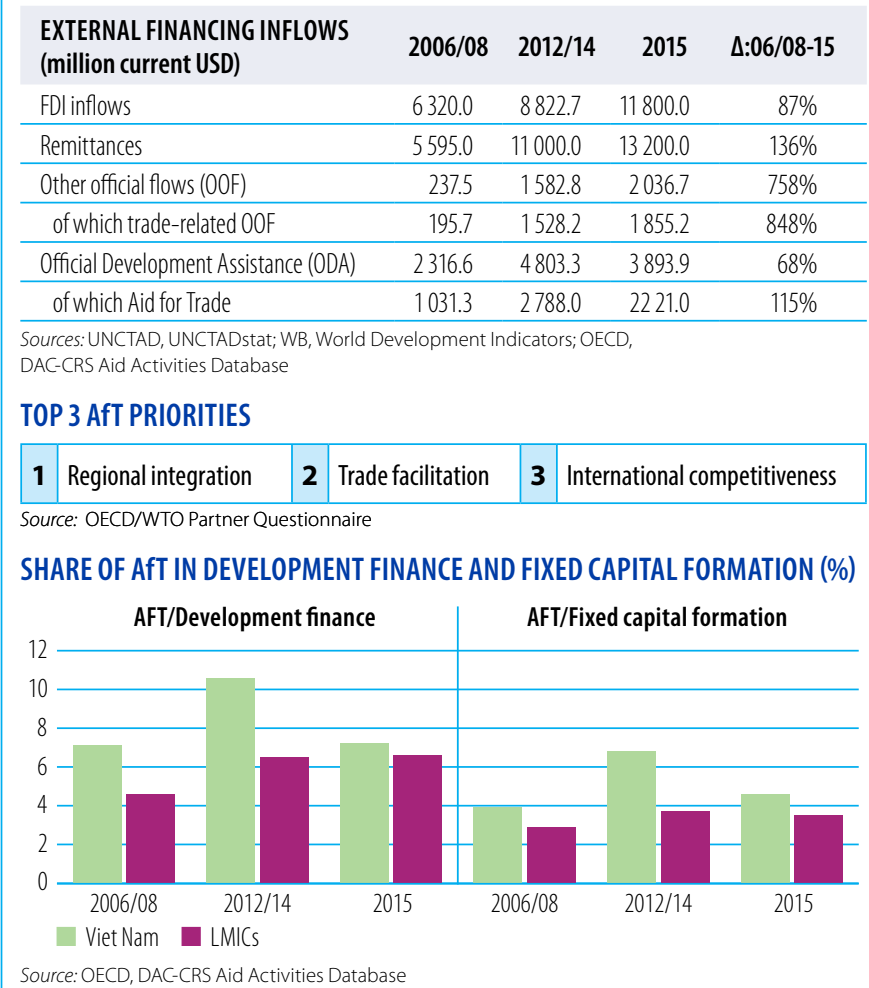

AfT DISBURSEMENTS: TOP DONORS (million current USD)

\begin{tabular}{lrr|lrc}
$\mathbf{2 0 0 6 / 0 8}$ & value & $\%$ & $\mathbf{2 0 1 5}$ & value & $\%$ \\
Japan & 516.3 & 50 & Japan & 1094.3 & 49 \\
\hline IDA & 299.5 & 29 & IDA & 461.5 & 21 \\
\hline France & 64.2 & 6 & AsDB Special Funds & 226.5 & 10 \\
\hline Germany & 20.9 & 2 & Korea & 136.0 & 6 \\
\hline Denmark & 18.0 & 2 & France & 86.8 & 4 \\
\hline
\end{tabular}

Source: OECD, DAC-CRS Aid Activities Database

AfT DISBURSEMENTS BY SECTOR (million current USD)

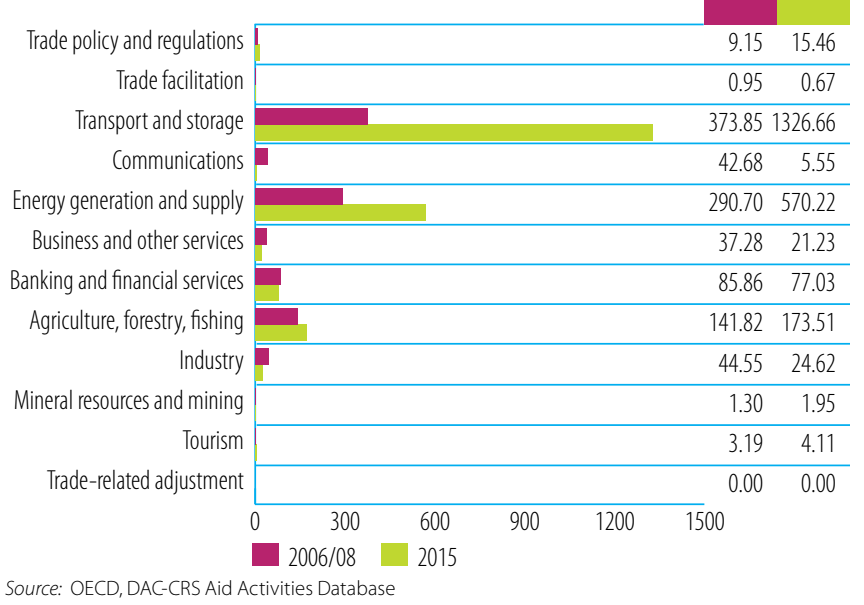

\section{B. TRADE COSTS}

\begin{tabular}{|c|c|c|}
\hline INDICATOR & 2006 & 2015 \\
\hline \multicolumn{3}{|l|}{ Tariffs (\%) } \\
\hline Imports: simple avg. MFN applied & 16.8 & 9.5 \\
\hline Imports: weighted avg. MFN applied (2006-2014) & $\ldots$ & 5.8 \\
\hline Exports: weighted avg. faced (2005-2014) & 5.8 & 3.4 \\
\hline Exports: duty free (value in \%) (2005-2014) & 48.1 & 73.2 \\
\hline \multicolumn{3}{|l|}{ ICT connectivity (\% of population) } \\
\hline Mobile broadband subscriptions & $\ldots$ & 39.0 \\
\hline Fixed broadband subscriptions & 0.6 & 8.1 \\
\hline Individuals using the internet & 17.3 & 52.7 \\
\hline
\end{tabular}
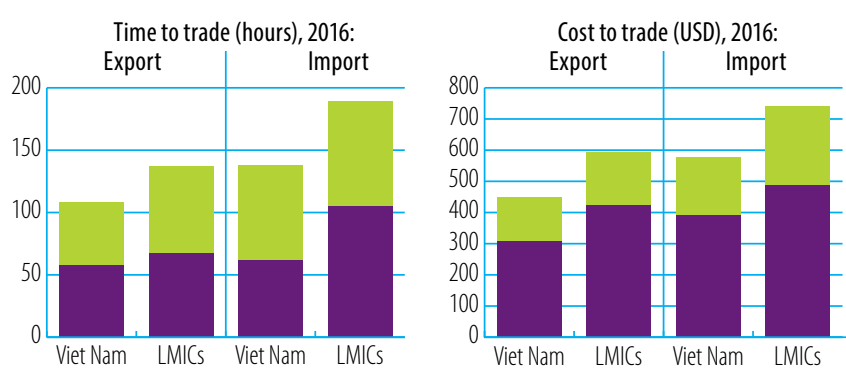

Border compliance Documentary compliance Source: WB, Doing Business

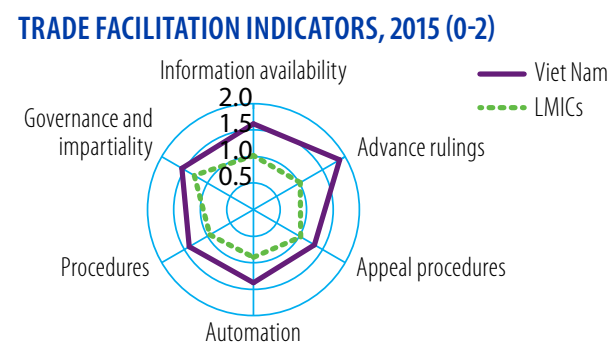

Source: OECD Trade Facilitation Indicators

TRADE COSTS (ad-valorem, \%)

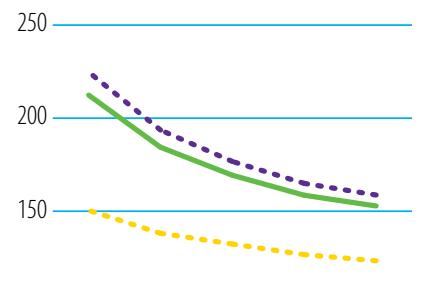

100

50

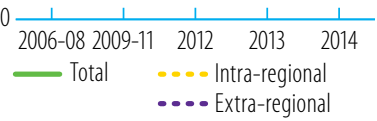

Source: ESCAP-WB Trade Cost Database Note: Number of partners used in the calculation of average trade costs: total (90), intra-regional (15), extra-regional (75) 


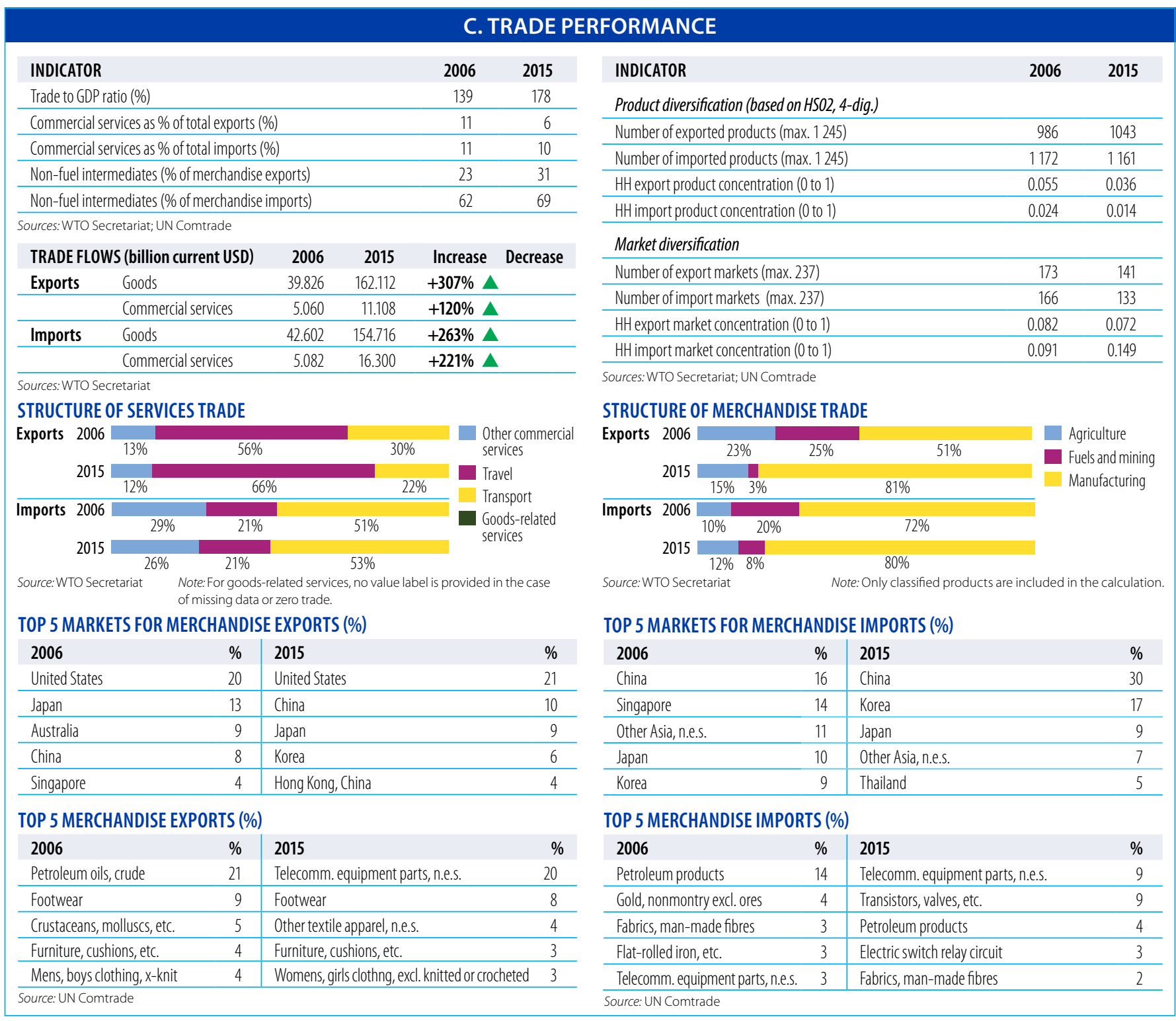

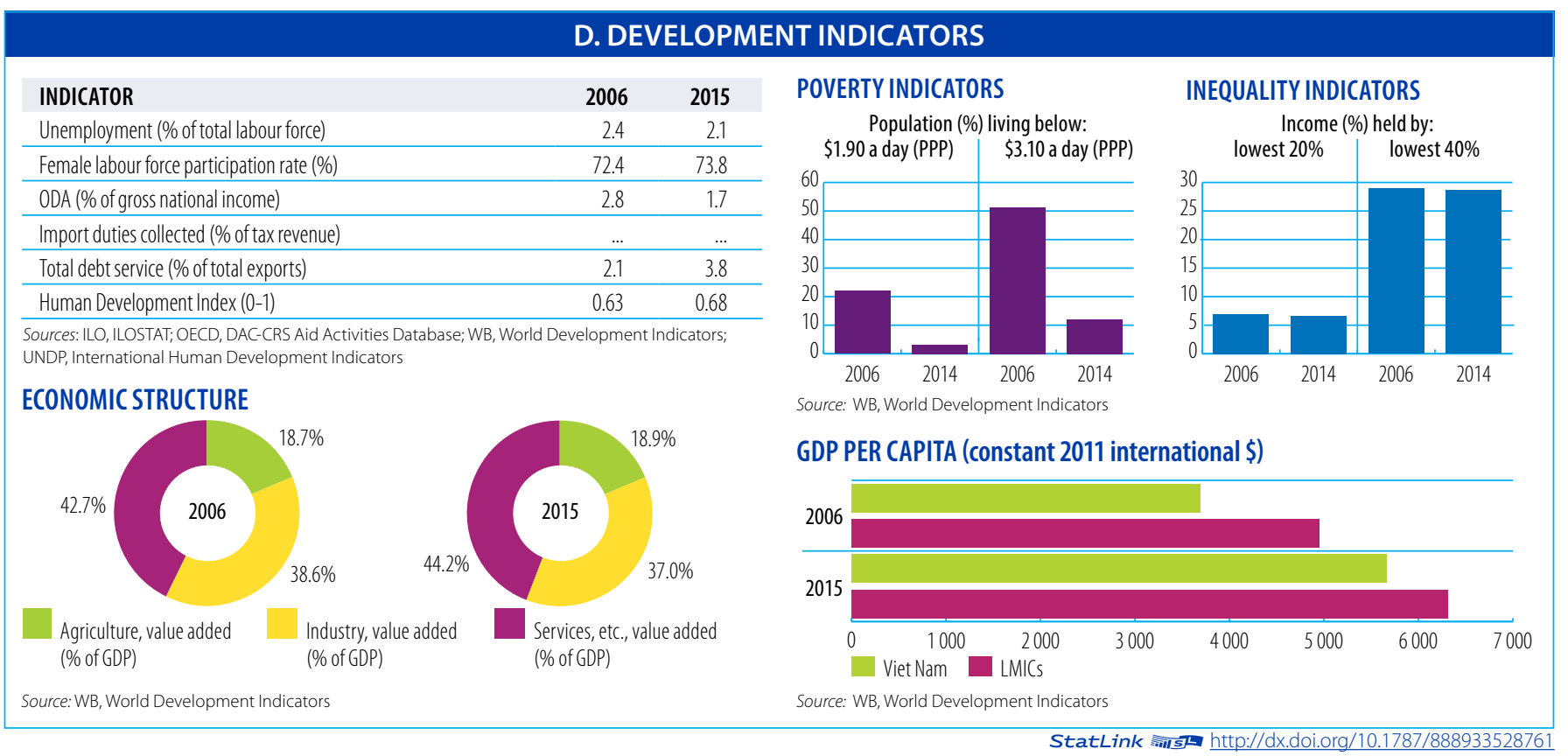


Aid, Trade and Development Indicators for Yemen

\section{A. DEVELOPMENT FINANCE}

\begin{tabular}{lcrrc}
$\begin{array}{l}\text { EXTERNAL FINANCING INFLOWS } \\
\text { (million current USD) }\end{array}$ & $\mathbf{2 0 0 6 / 0 8}$ & $\mathbf{2 0 1 2 / 1 4}$ & $\mathbf{2 0 1 5}$ & $\mathbf{\Delta : 0 6 / 0 8 - 1 5}$ \\
FDl inflows & 1197.6 & -817.2 & -1191.0 & - \\
\hline Remittances & 1338.2 & 3348.0 & 3350.5 & $150 \%$ \\
\hline Other official flows (00F) & 162.6 & 2.4 & 3.2 & $-98 \%$ \\
\hline of which trade-related 00F & 162.6 & 0.4 & 0.0 & $-100 \%$ \\
\hline Official Development Assistance (ODA) & 417.6 & 1091.9 & 1645.8 & $294 \%$ \\
\hline of which Aid for Trade & 75.2 & 156.4 & 357.0 & $375 \%$ \\
\hline
\end{tabular}

Sources: UNCTAD, UNCTADstat; WB, World Development Indicators; OECD,

DAC-CRS Aid Activities Database

\section{TOP 3 AfT PRIORITIES}

\section{\begin{tabular}{|l|l|l|l|l|l|}
\hline & Transport infrastructure & $\mathbf{2}$ & International competitiveness & $\mathbf{3}$ & Trade policy
\end{tabular}} Source: OECD/WTO Partner Questionnaire

\section{SHARE OF AfT IN DEVELOPMENT FINANCE AND FIXED CAPITAL FORMATION (\%)}

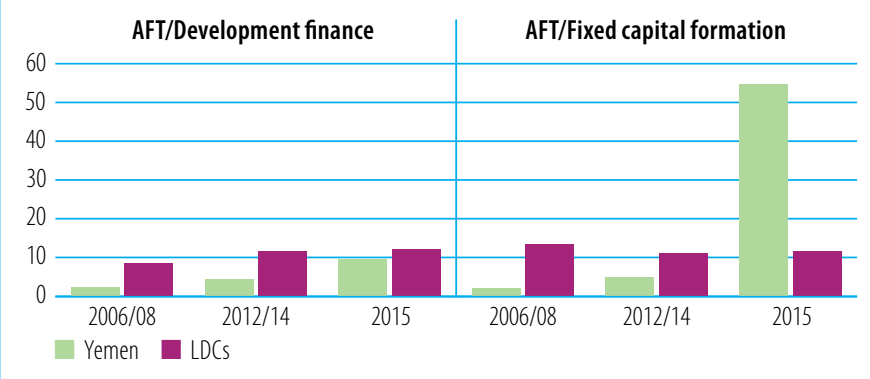

AfT DISBURSEMENTS: TOP DONORS (million current USD)

\begin{tabular}{lrr|lrc}
$\mathbf{2 0 0 6 / 0 8}$ & value & $\%$ & $\mathbf{2 0 1 5}$ & value & $\%$ \\
IDA & 32.0 & 43 & United Arab Emirates & 299.5 & 84 \\
\hline Arab Fund (AFESD) & 26.9 & 36 & Arab Fund (AFESD) & 23.6 & 7 \\
\hline Italy & 4.0 & 5 & IDA & 17.7 & 5 \\
\hline EU Institutions & 3.3 & 4 & EU Institutions & 6.9 & 2 \\
\hline Korea & 2.7 & 4 & United States & 4.2 & 1 \\
\hline
\end{tabular}

Source: OECD, DAC-CRS Aid Activities Database

AfT DISBURSEMENTS BY SECTOR (million current USD)

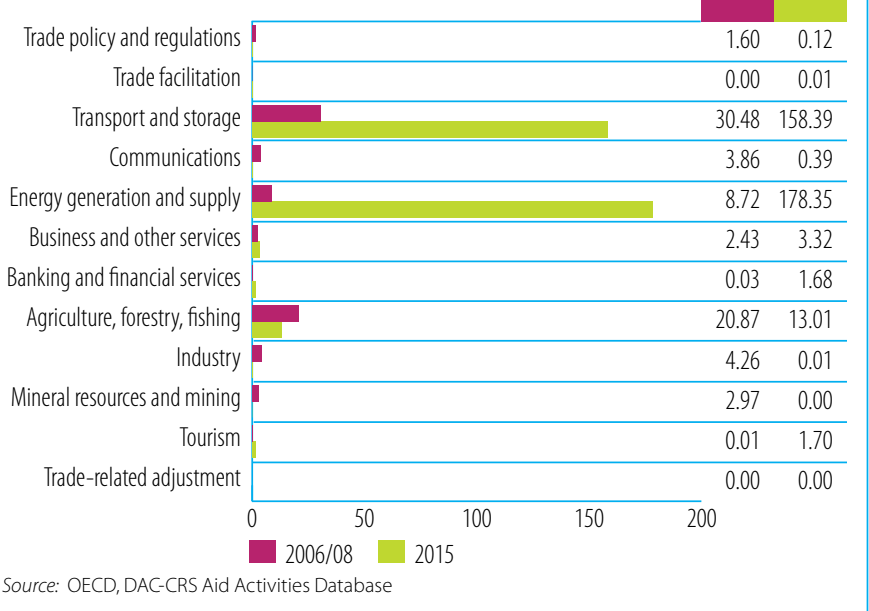

\section{B. TRADE COSTS}

\begin{tabular}{lcc} 
INDICATOR & $\mathbf{2 0 0 6}$ & $\mathbf{2 0 1 5}$ \\
Tariffs (\%) & 7.1 & 7.5 \\
\hline Imports: simple avg. MFN applied & $\ldots$ & 6.2 \\
\hline Imports: weighted avg. MFN applied (2006-2014) & 0.5 & 0.3 \\
\hline Exports: weighted avg. faced (2005-2014) & 83.2 & 94.0 \\
\hline Exports: duty free (value in \%) (2005-2014) & & \\
\hline ICT connectivity (\% of population) & $\ldots$ & 5.9 \\
\hline Mobile broadband subscriptions & 0.0 & 1.5 \\
\hline Fixed broadband subscriptions & 1.2 & 25.1 \\
\hline Individuals using the internet & &
\end{tabular}

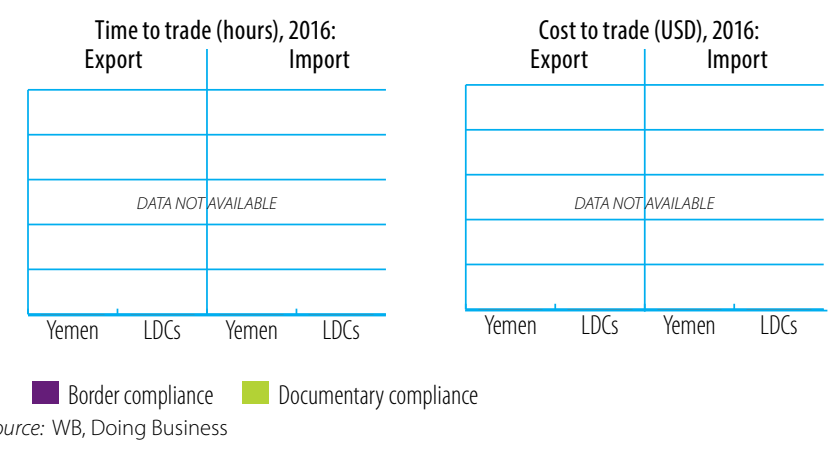

LOGISTICS PERFORMANCE INDICES (LPI) (1-5)

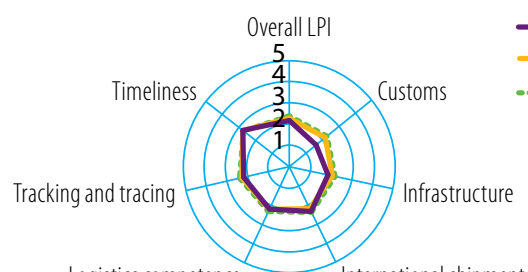

Logistics competence

$$
\text { International shipments }
$$

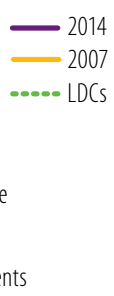

Source: WB Logistics Performance Index (LPI)

TRADE FACILITATION INDICATORS, 2015 (0-2)

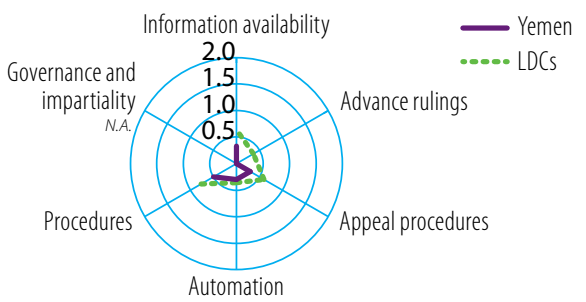

Source: OECD Trade Facilitation Indicators

\section{GLOBAL COMPETITIVENESS INDICATORS (1-7)}

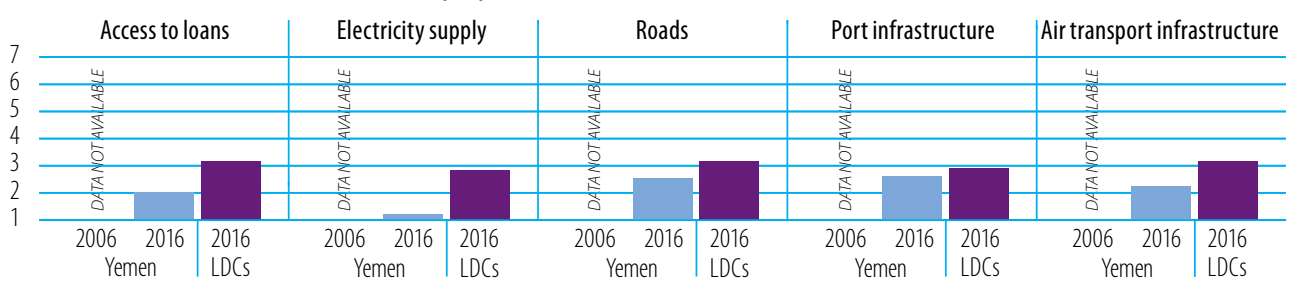

Source: WEF Global Competitiveness Index
TRADE COSTS (ad-valorem, \%)

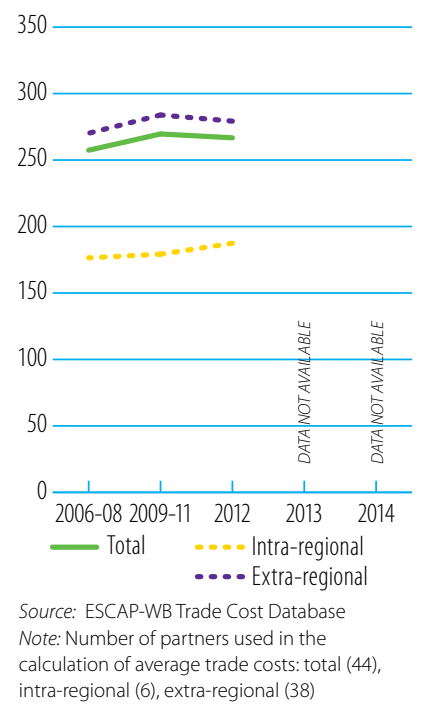




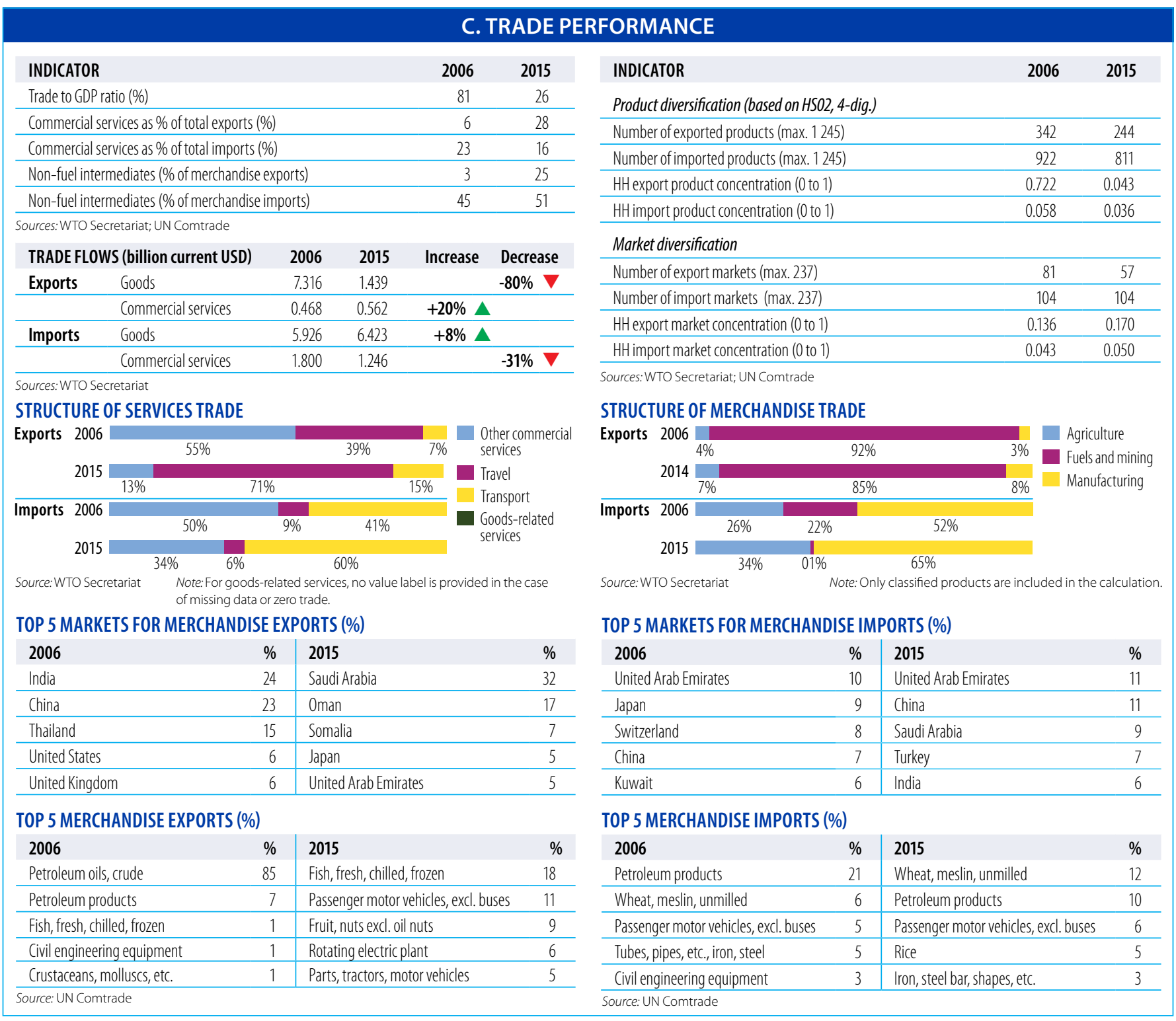

\begin{tabular}{|lrc} 
& \multicolumn{2}{c}{ D. DEVELOPMEN } \\
\hline INDICATOR & 2006 & 2015 \\
Unemployment (\% of total labour force) & 15.7 & 18.1 \\
\hline Female labour force participation rate (\%) & 23.9 & 25.8 \\
\hline ODA (\% of gross national income, 2006-2013) & 1.6 & 3.0 \\
\hline Import duties collected (\% of tax revenue) & $\ldots$ & $\ldots$ \\
\hline Total debt service (\% of total exports) & 2.9 & 18.8 \\
\hline Human Development Index (0-1) & 0.48 & 0.48 \\
\hline
\end{tabular}

Sources: ILO, ILOSTAT; OECD, DAC-CRS Aid Activities Database; WB, World Development Indicators; UNDP, International Human Development Indicators

\section{ECONOMIC STRUCTURE}

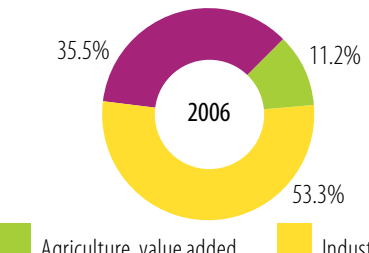

(\% of GDP)

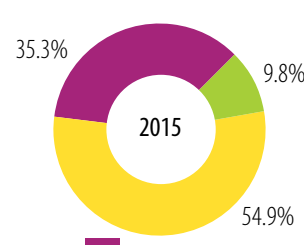

Services, etc., value added (\% of GDP)

Source: WB, World Development Indicators

Industry, value added (\% of GDP)
POVERTY INDICATORS

Population (\%) living below: $\$ 1.90$ a day (PPP) $\quad \$ 3.10$ a day (PPP)

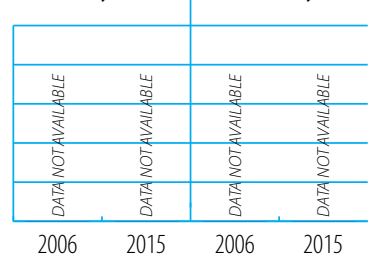

Source: WB, World Development Indicators
INEQUALITY INDICATORS

Income (\%) held by:

lowest 20\% lowest $40 \%$

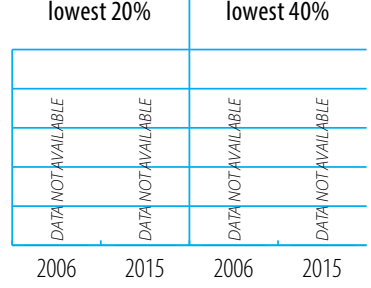

GDP PER CAPITA (constant 2011 international \$)

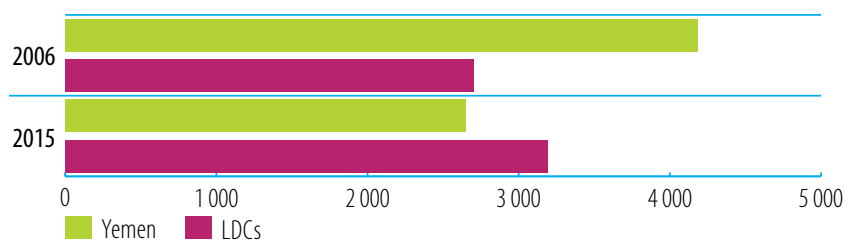

Source: WB, World Development Indicators 
Aid, Trade and Development Indicators for Zambia

\section{A. DEVELOPMENT FINANCE}

\begin{tabular}{lrrrc}
\hline $\begin{array}{l}\text { EXTERNAL FINANCING INFLOWS } \\
\text { (million current USD) }\end{array}$ & $\mathbf{2 0 0 6 / 0 8}$ & $\mathbf{2 0 1 2 / 1 4}$ & $\mathbf{2 0 1 5}$ & $\mathbf{\Delta : 0 6 / 0 8 - 1 5}$ \\
\hline FDl inflows & 931.1 & 2479.3 & 1653.0 & $78 \%$ \\
\hline Remittances & 61.7 & 61.7 & 47.0 & $-24 \%$ \\
\hline Other official flows (OOF) & 67.9 & 12.8 & 78.7 & $16 \%$ \\
\hline of which trade-related 0OF & 32.6 & 11.2 & 78.3 & $140 \%$ \\
\hline Official Development Assistance (ODA) & 2308.4 & 1067.7 & 883.1 & $-62 \%$ \\
\hline of which Aid for Trade & 144.4 & 219.2 & 266.8 & $85 \%$ \\
\hline
\end{tabular}

Sources: UNCTAD, UNCTADstat; WB, World Development Indicators; OECD,

DAC-CRS Aid Activities Database

TOP 3 AfT PRIORITIES

\section{\begin{tabular}{l|l|l|l|l|l}
1 & Industrialization & $\mathbf{2}$ & Trade facilitation & $\mathbf{3}$ & Cross-border infrastructure
\end{tabular}}

Source: OECD/WTO Partner Questionnaire

SHARE OF AfT IN DEVELOPMENT FINANCE AND FIXED CAPITAL FORMATION (\%)

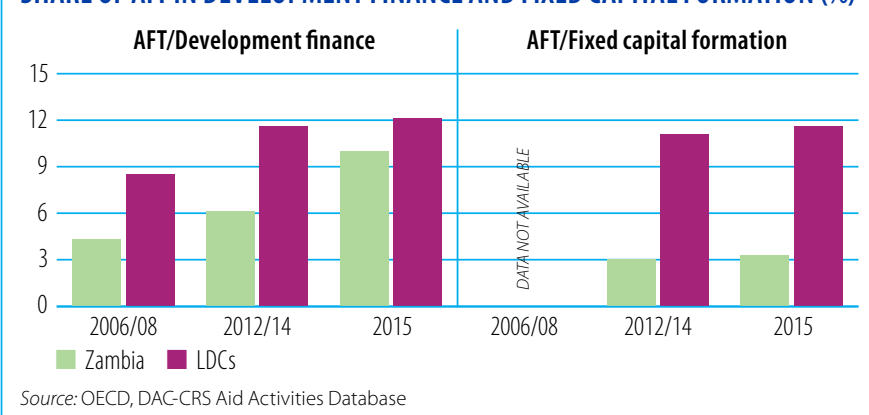

AfT DISBURSEMENTS: TOP DONORS (million current USD)

\begin{tabular}{lrr|lrc}
$\mathbf{2 0 0 6 / 0 8}$ & value & $\%$ & $\mathbf{2 0 1 5}$ & value & $\%$ \\
EU Institutions & 41.6 & 29 & IDA & 58.8 & 22 \\
\hline IDA & 29.3 & 20 & African Development Fund & 49.0 & 18 \\
\hline Denmark & 12.2 & 8 & EU Institutions & 38.5 & 14 \\
\hline Japan & 11.9 & 8 & France & 26.5 & 10 \\
\hline Norway & 10.7 & 7 & Sweden & 26.1 & 10 \\
\hline Source: OECD, DAC-CRS Aid Activities Database & & &
\end{tabular}

AfT DISBURSEMENTS BY SECTOR (million current USD)

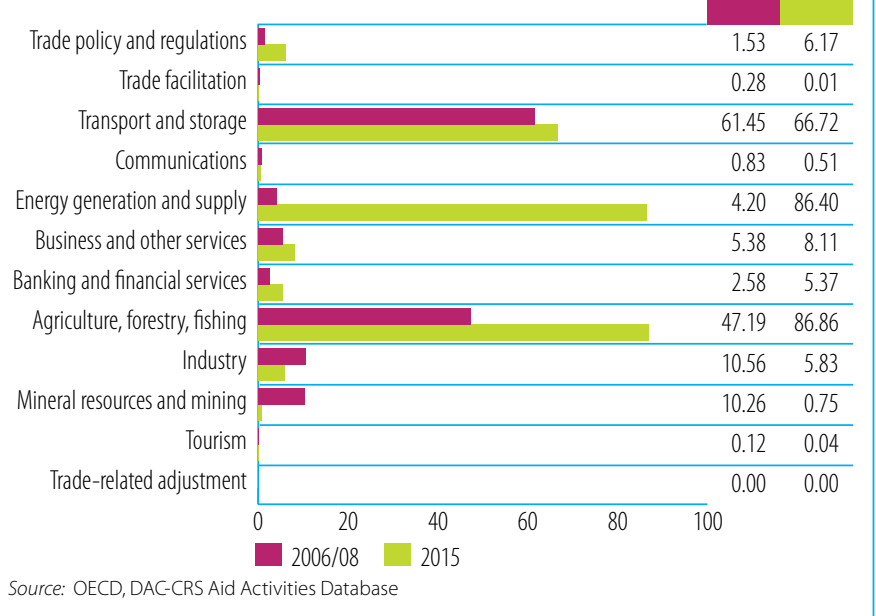

\section{B. TRADE COSTS}

\begin{tabular}{lrc} 
INDICATOR & 2006 & $\mathbf{2 0 1 5}$ \\
Tariffs (\%) & 13.9 & 13.6 \\
\hline Imports: simple avg. MFN applied (05-15) & 11 & 9.4 \\
\hline Imports: weighted avg. MFN applied (2005-2014) & 2.9 & 2.0 \\
\hline Exports: weighted avg. faced (2005-2014) & 84.5 & 69.5 \\
\hline Exports: duty free (value in \%) (2005-2014) & & \\
\hline ICT connectivity (\% of population) & $\ldots$. & 13.8 \\
\hline Mobile broadband subscriptions & 0.0 & 0.1 \\
\hline Fixed broadband subscriptions & 4.2 & 21.0 \\
\hline Individuals using the internet & &
\end{tabular}
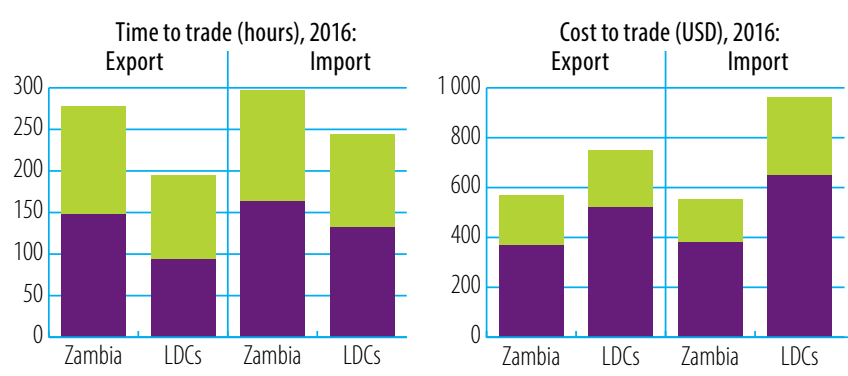

- Border compliance Documentary compliance Source: WB, Doing Business

\section{LOGISTICS PERFORMANCE INDICES (LPI) (1-5)}

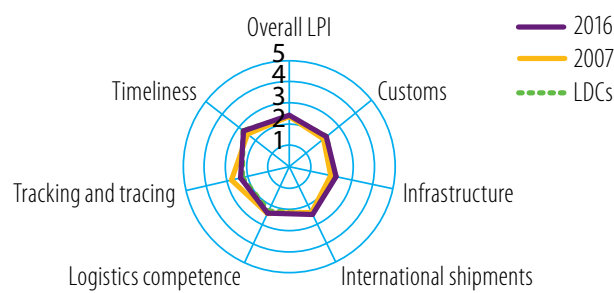

Source: WB Logistics Performance Index (LPI)

\section{GLOBAL COMPETITIVENESS INDICATORS (1-7)}

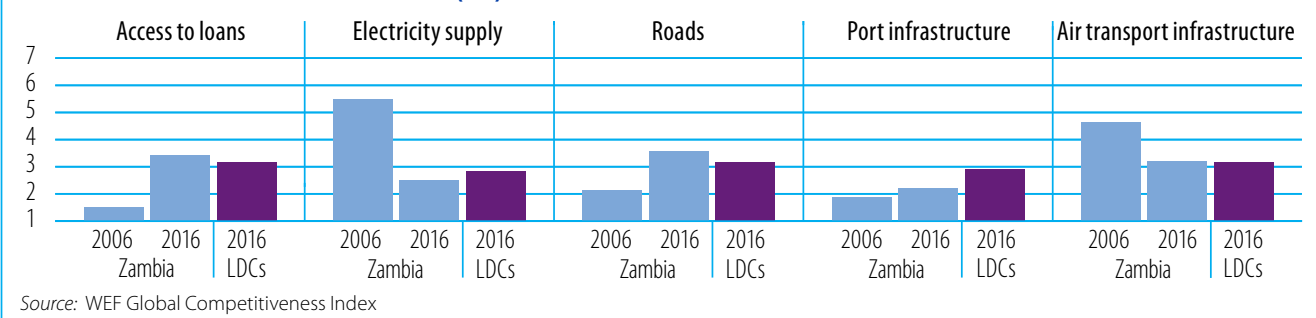

TRADE FACILITATION INDICATORS, 2015 (0-2)

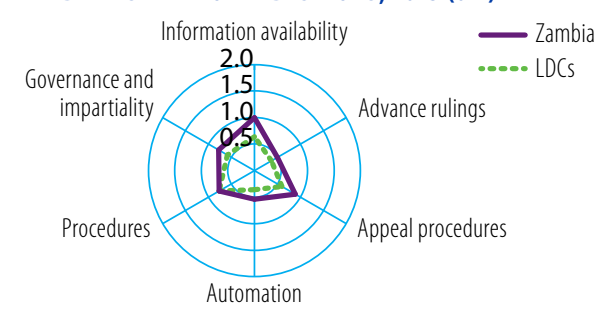

Source: OECD Trade Facilitation Indicators

TRADE COSTS (ad-valorem, \%)

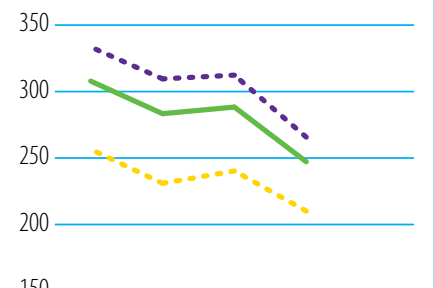

150

100

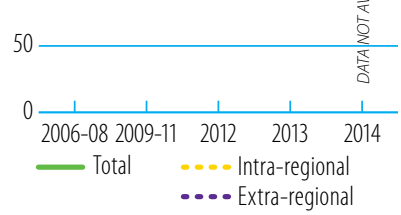

Source: ESCAP-WB Trade Cost Database Note: Number of partners used in the calculation of average trade costs: total (63), intra-regional (21), extra-regional (42) 


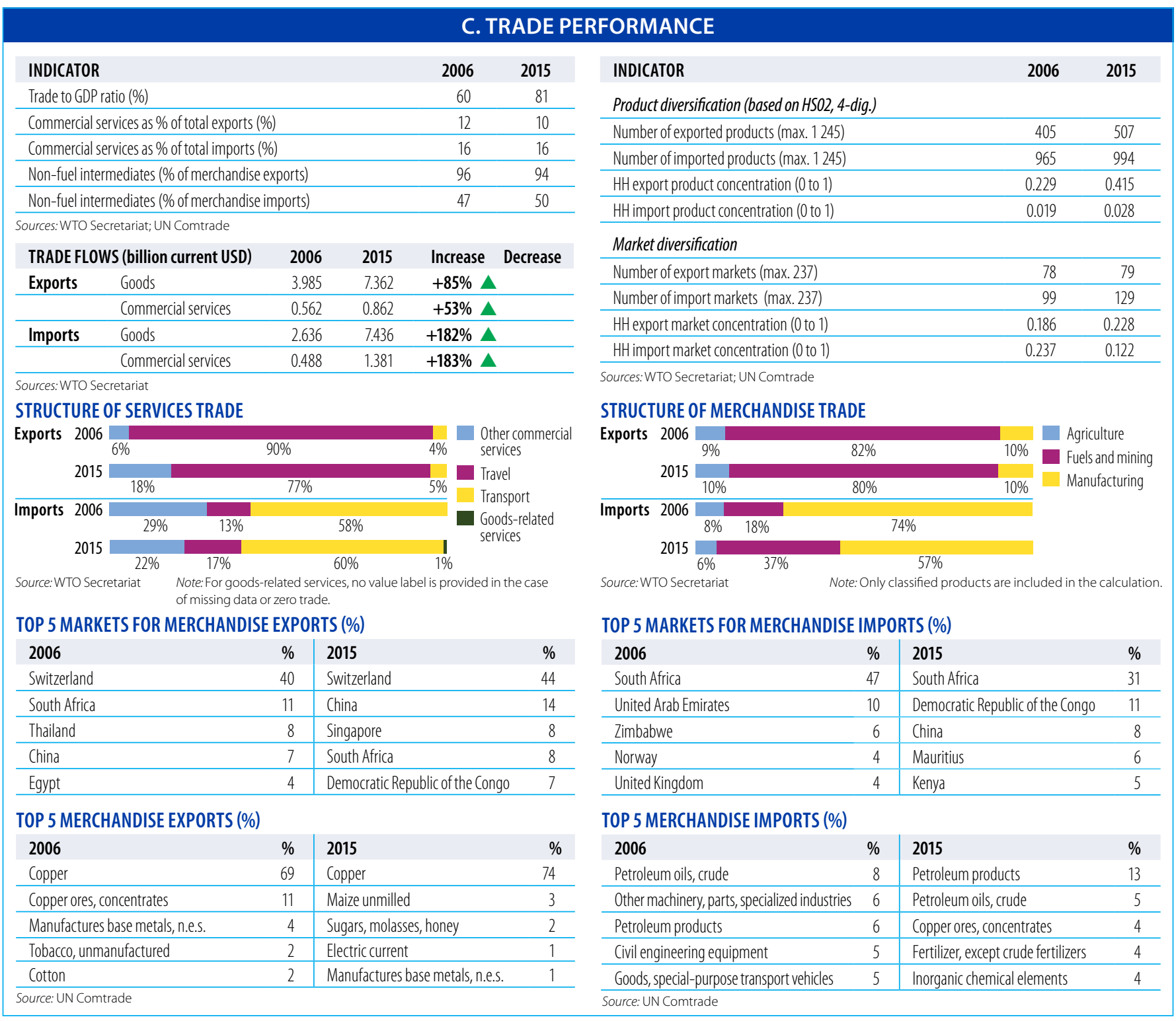

\begin{tabular}{|lrr}
\hline & D. DEVELOPMEN \\
\hline INDICATOR & $\mathbf{2 0 0 6}$ & $\mathbf{2 0 1 5}$ \\
Unemployment (\% of total labour force) & 14.3 & 7.6 \\
\hline Female labour force participation rate (\%) & 72.6 & 69.8 \\
\hline ODA (\% of gross national income) & 12.7 & 4.0 \\
\hline Import duties collected (\% of tax revenue, 2007-2015) & 10.5 & $\ldots$ \\
\hline Total debt service (\% of total exports) & 3.2 & 6.2 \\
\hline Human Development Index (0-1) & 0.49 & 0.58 \\
\hline
\end{tabular}

Sources: ILO, ILOSTAT; OECD, DAC-CRS Aid Activities Database; WB, World Development Indicators; UNDP, International Human Development Indicators

\section{ECONOMIC STRUCTURE}

$52.1 \%$

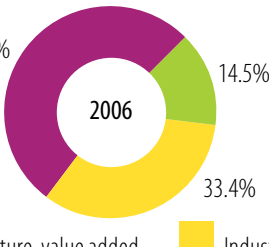

Agriculture, value added (\% of GDP)

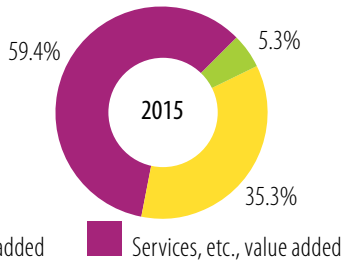

( $\%$ of GDP)

\section{POVERTY INDICATORS}

Population (\%) living below:

$\$ 1.90$ a day (PPP) $\quad$ \$3.10 a day (PPP)

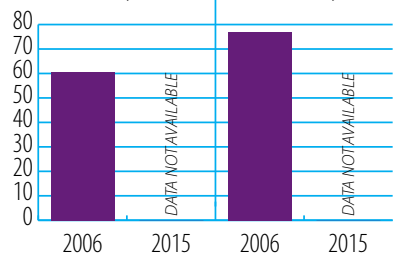

Source: WB, World Development Indicators

\section{GDP PER CAPITA (constant 2011 international \$)}

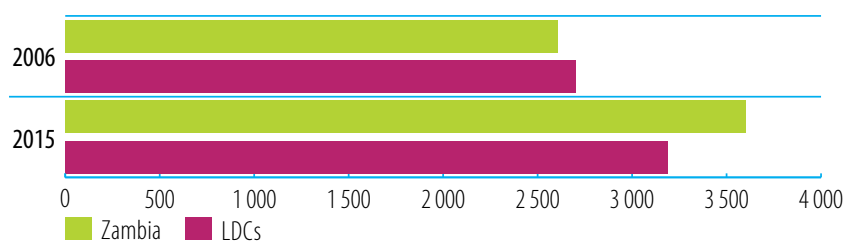

Source: WB, World Development Indicators

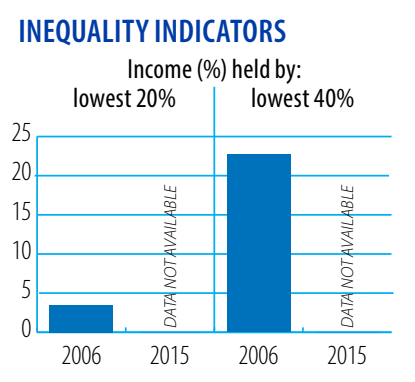

StatLink *iाlsh http://dx.doi.org/10.1787/888933528799 
Aid, Trade and Development Indicators for Zimbabwe

\section{A. DEVELOPMENT FINANCE}

\begin{tabular}{lrrrc}
$\begin{array}{l}\text { EXTERNAL FINANCING INFLOWS } \\
\text { (million current USD) }\end{array}$ & $\mathbf{2 0 0 6 / 0 8}$ & $\mathbf{2 0 1 2 / 1 4}$ & $\mathbf{2 0 1 5}$ & $\mathbf{\Delta : 0 6 / 0 8 - 1 5}$ \\
FDl inflows & 53.5 & 448.1 & 421.0 & $687 \%$ \\
\hline Remittances & $\ldots$ & 1969.3 & 2046.6 & - \\
\hline Other official flows (00F) & 1.5 & 10.6 & 0.2 & $-87 \%$ \\
\hline$\quad$ of which trade-related 00F & 0.0 & 9.6 & 0.0 & - \\
\hline Official Development Assistance (ODA) & 446.2 & 876.5 & 815.0 & $83 \%$ \\
\hline of which Aid for Trade & 11.4 & 84.9 & 59.7 & $423 \%$ \\
\hline
\end{tabular}

Sources: UNCTAD, UNCTADstat; WB, World Development Indicators; OECD,

DAC-CRS Aid Activities Database

\section{TOP 3 AfT PRIORITIES}

\begin{tabular}{|l|l|l|l|l|l|}
\hline 1 & Industrialization & $\mathbf{2}$ & Connecting to value chains & $\mathbf{3}$ & Trade facilitation \\
\hline
\end{tabular}

Source: OECD/WTO Partner Questionnaire

SHARE OF AfT IN DEVELOPMENT FINANCE AND FIXED CAPITAL FORMATION (\%)

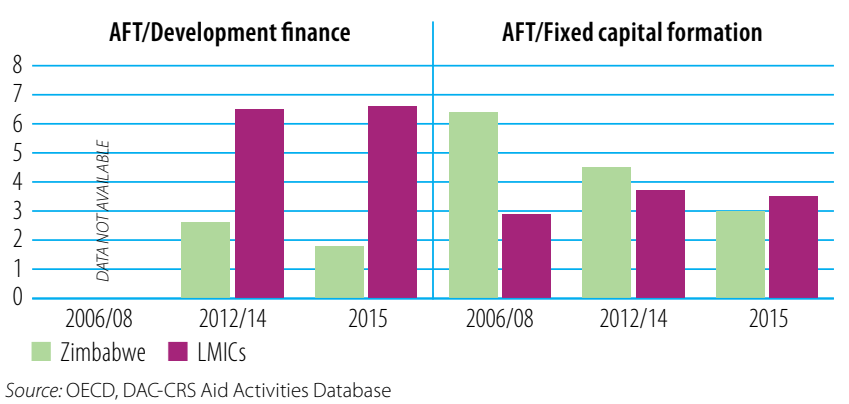

AfT DISBURSEMENTS: TOP DONORS (million current USD)

\begin{tabular}{lrr|lrc}
$\mathbf{2 0 0 6 / 0 8}$ & value & $\%$ & $\mathbf{2 0 1 5}$ & value & $\%$ \\
France & 4.8 & 42 & United Kingdom & 20.7 & 35 \\
\hline Germany & 1.6 & 14 & EU Institutions & 11.9 & 20 \\
\hline EU Institutions & 1.4 & 12 & Denmark & 9.8 & 16 \\
\hline Japan & 1.0 & 9 & United States & 7.6 & 13 \\
\hline Ireland & 1.0 & 9 & Germany & 2.0 & 3 \\
\hline
\end{tabular}

Source: OECD, DAC-CRS Aid Activities Database

AfT DISBURSEMENTS BY SECTOR (million current USD)

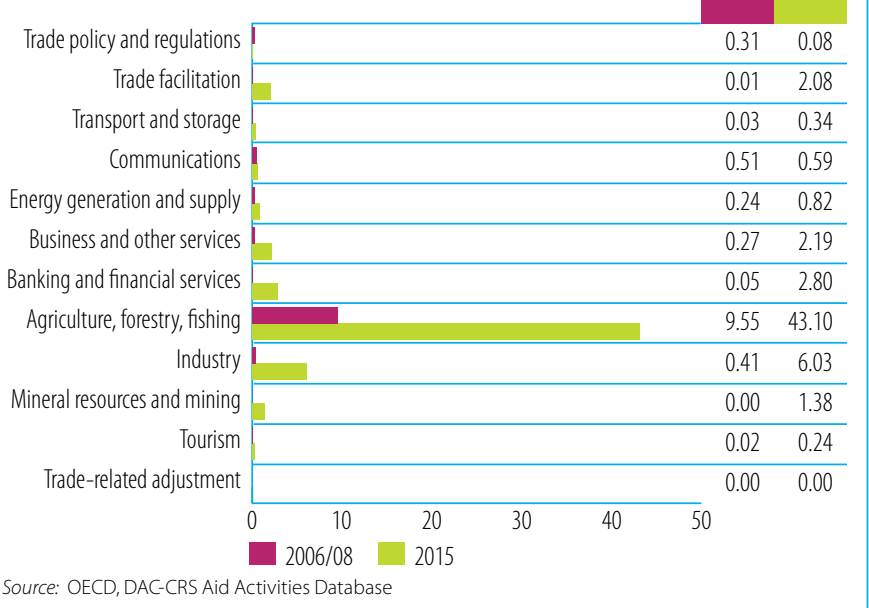

\section{B. TRADE COSTS}

\begin{tabular}{lcc} 
INDICATOR & 2006 & $\mathbf{2 0 1 5}$ \\
Tariffs (\%) & $\ldots$ & 16.8 \\
\hline Imports: simple avg. MFN applied & $\ldots$ & 13.7 \\
\hline Imports: weighted avg. MFN applied (2006-2014) & 3.8 & 9.4 \\
\hline Exports: weighted avg. faced (2005-2014) & 73.9 & 60.2 \\
\hline Exports: duty free (value in \%) (2005-2014) & & \\
\hline ICT connectivity (\% of population) & $\ldots$ & 39.0 \\
\hline Mobile broadband subscriptions & 0.1 & 1.1 \\
\hline Fixed broadband subscriptions & 2.4 & 16.4 \\
\hline Individuals using the internet & &
\end{tabular}
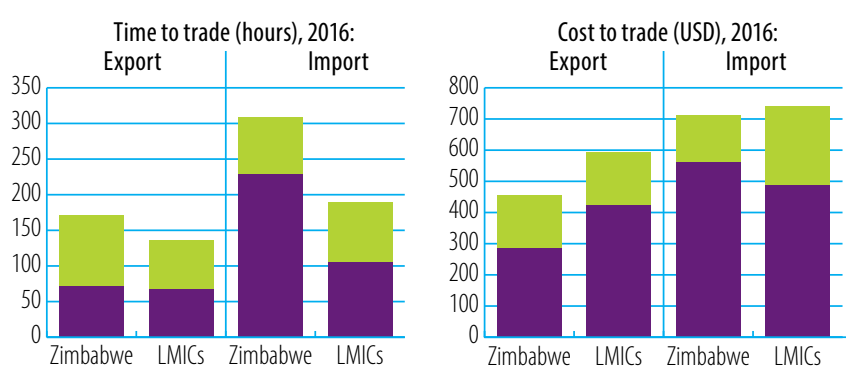

Border compliance Documentary compliance

Source: WB, Doing Business

\section{LOGISTICS PERFORMANCE INDICES (LPI) (1-5)}

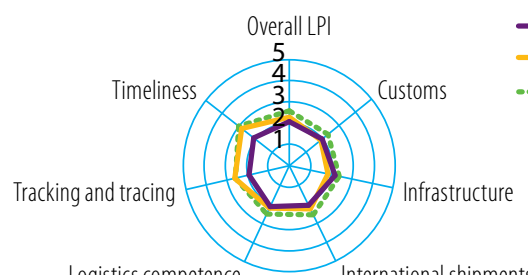

Logistics competence

ource: WB Logistics Performance Index (LPI)

\section{GLOBAL COMPETITIVENESS INDICATORS (1-7)}
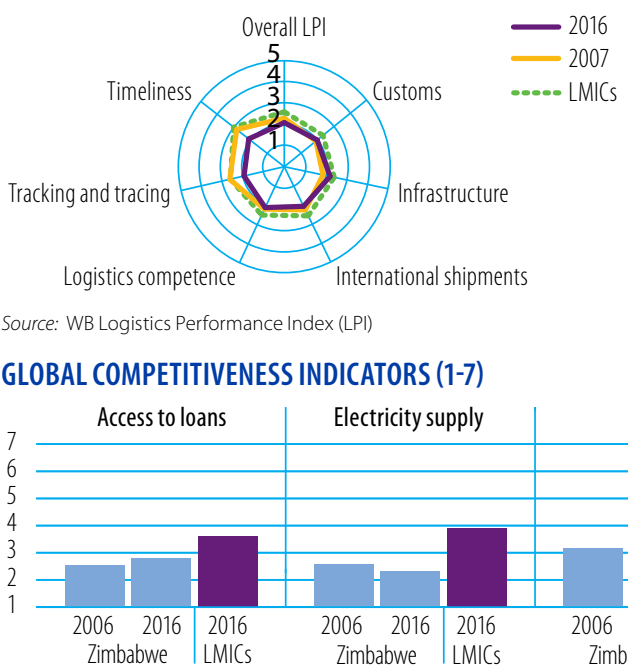

TRADE FACILITATION INDICATORS, 2015 (0-2)

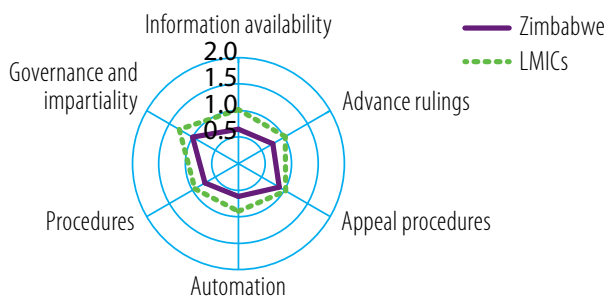

Source: OECD Trade Facilitation Indicators

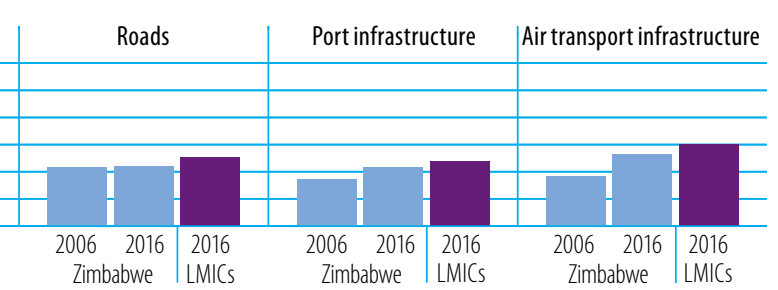

TRADE COSTS (ad-valorem, \%)

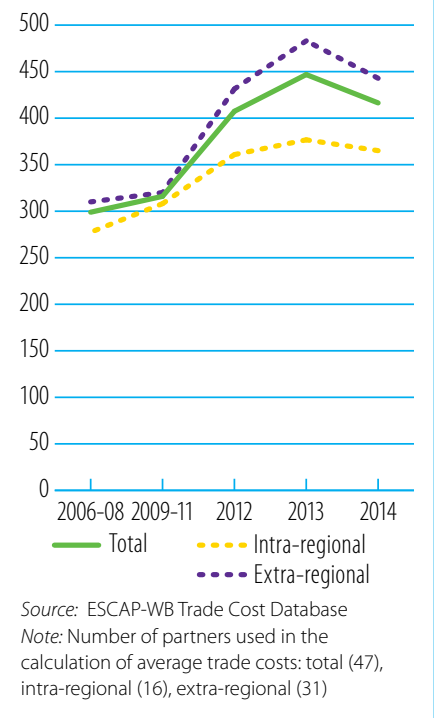




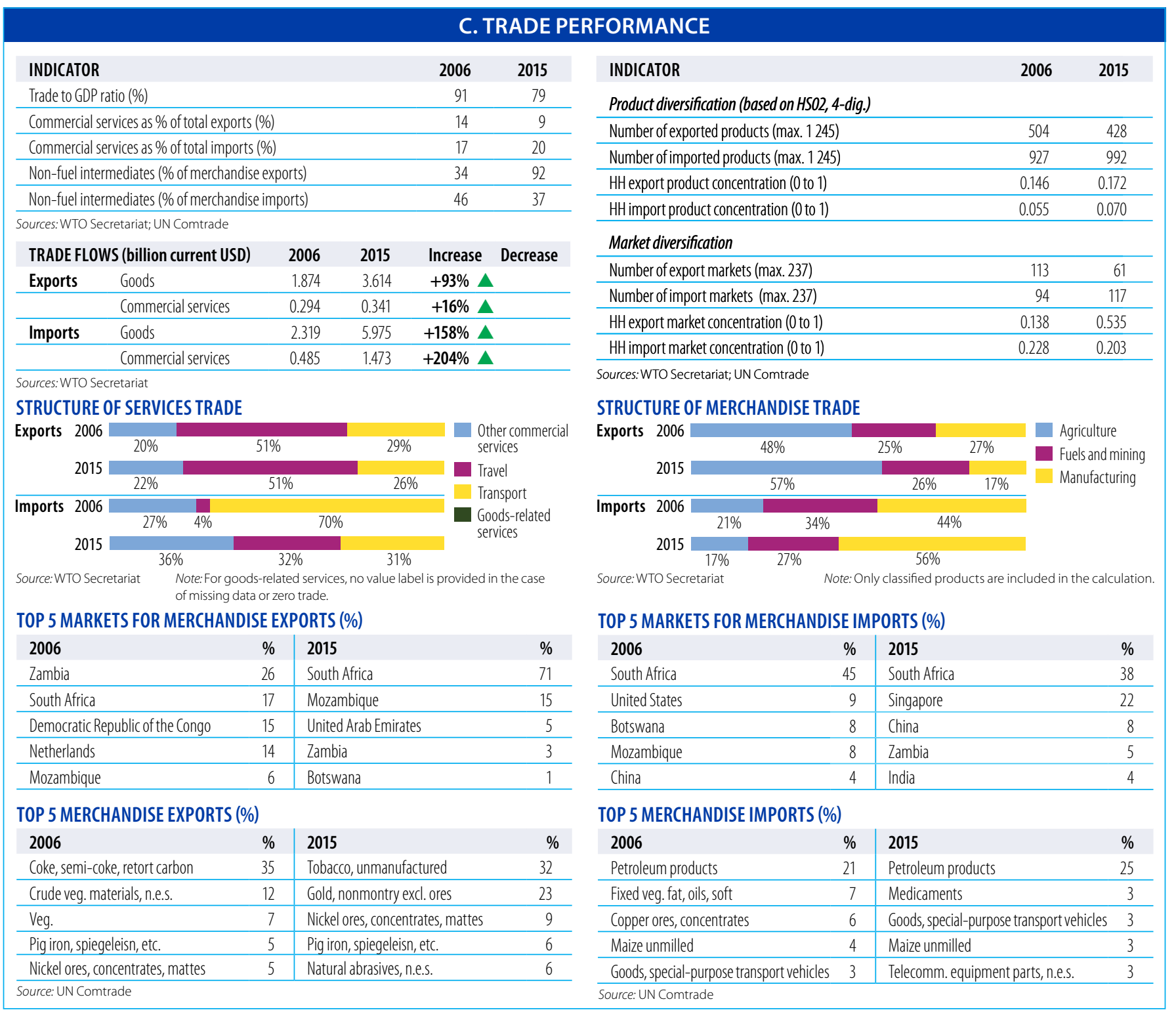

\begin{tabular}{|lrr} 
& \multicolumn{2}{c}{ D. DEVELOPMEN } \\
\hline INDICATOR & $\mathbf{2 0 0 6}$ & $\mathbf{2 0 1 5}$ \\
Unemployment (\% of total labour force) & 5.7 & 5.1 \\
\hline Female labour force participation rate (\%) & 81.6 & 77.8 \\
\hline ODA (\% of gross national income) & 5.4 & 6.0 \\
\hline Import duties collected (\% of tax revenue) & $\ldots$ & $\ldots$ \\
\hline Total debt service (\% of total exports) & $\ldots$ & 13.4 \\
\hline Human Development Index (0-1) & 0.41 & 0.52 \\
\hline
\end{tabular}

Sources: ILO, ILOSTAT; OECD, DAC-CRS Aid Activities Database; WB, World Development Indicators: UNDP, International Human Development Indicators

\section{ECONOMIC STRUCTURE}

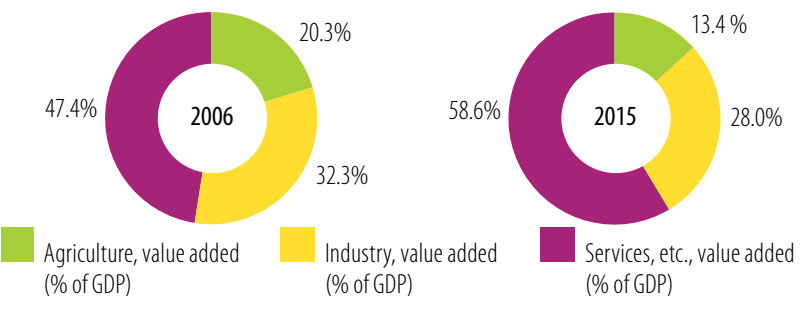

POVERTYINDICATORS

\section{POVERTYINDICATORS}

Population (\%) living below:

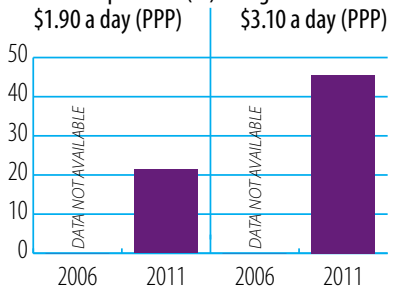

Source: WB, World Development Indicators

GDP PER CAPITA (constant 2011 international \$)

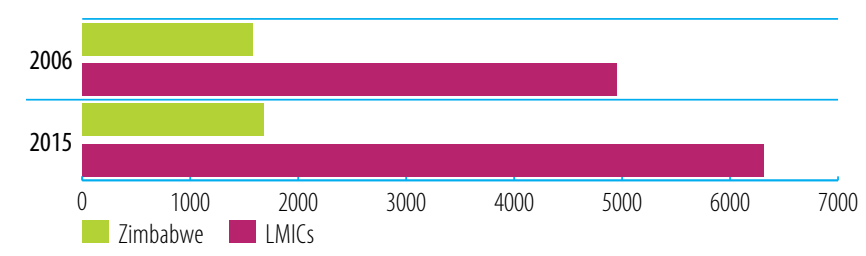

Source: WB, World Development Indicators

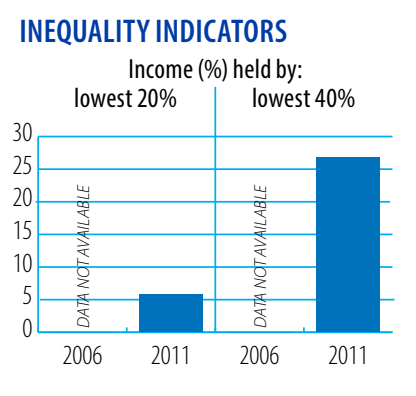

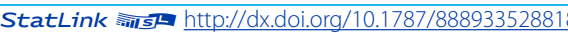





\section{STATISTICAL NOTES}

According to the WTO Task Force on Aid for Trade, projects and programmes are part of aid for trade if these activities have been identified as trade related development priorities in the partner country's national development strategies. Furthermore, the WTO Task Force concluded that to measure aid for trade flows the following categories should be included:

a) Technical assistance for trade policy and regulations: for example, helping countries to develop trade strategies, negotiate trade agreements, and implement their outcomes;

b) Trade-related infrastructure: for example, building roads, ports, and telecommunications networks to connect domestic markets to the global economy;

c) Productive capacity building (including trade development): for example, supporting the private sector to exploit their comparative advantages and diversify their exports;

d) Trade-related adjustment: helping developing countries with the costs associated with trade liberalisation, such as tariff reductions, preference erosion, or declining terms of trade; and,

e) Other trade-related needs: if identified as trade-related development priorities in partner countries' national development strategies.

The OECD DAC aid activity database (CRS) - a database covering around 90\% of all ODA - is recognised as the best available data source for tracking global aid-for-trade flows. The CRS was established in 1967 and collects information on official development assistance (ODA) and other official flows (OOF) to developing countries. It is the internationally recognised source of data on aid activities (geographical and sectoral breakdowns) and is widely used by governments, organisations and researchers active in the field of development. For the OECD, the CRS serves as a tool for monitoring specific policy issues, including aid for trade. The CRS enables the tracking of aid commitments and disbursements, and provides comparable data over time and across countries. The use of this existing database led to significant savings of time and resources to effectively track aid-for-trade flows. The policy and guidelines for CRS reporting are approved by DAC members as represented at the DAC Working Party on Statistics (WP-STAT). The OECD collects, collates and verifies the consistency of the data, and maintains the database.

It should be kept in mind that the CRS does not provide data that match exactly all of the above aid-for-trade categories. In fact, the CRS provides proxies under four headings:

- Trade policy and regulations. In the CRS, five purpose codes are used to cover trade policy and regulations activities. These five sub-categories are: trade policy and administrative management; trade facilitation; regional trade agreements; multilateral trade negotiations; and trade education/training.

- Economic infrastructure. Amounts relating to trade-related infrastructure are provided in the CRS by data under the heading "Economic Infrastructure and Services" and cover the sectors transport and storage, communications and energy generation and supply.

- Building Productive capacity (BPC), including trade development. The CRS captures full data on all activities in the productive and services sectors, such as agriculture; industry; mineral resources and mining; business; and banking. Trade development activities are identified through the Trade Development policy marker and have been separately identified in the CRS data collection since 
2007 flows. These activities are an "of which" of Building productive capacity and are scored as either principally or significantly contributing to trade development. However, at time of reporting, some donors may have difficulty in identifying aid activities that have a defined trade component. This may reflect upon the accuracy of these data and, as such, amounts shown under trade development can only at best be used as approximations.

- Trade-related adjustment. Was introduced in the CRS as a separate data item in 2007 to track flows corresponding to trade-related adjustment. This category identifies contributions to developing country budgets to assist the implementation of trade reforms and adjustments to trade policy measures by other countries, and alleviate shortfalls in balance-of-payments due to changes in the world trading environment.

The CRS covers all ODA, but only those activities reported under the above four categories can be identified as aid for trade. It is not possible to distinguish activities in the context of 'Other trade-related needs'. To estimate the volume of such 'other' activities, it would be necessary to examine aid projects in sectors other than those considered so far - for example in health and education - and indicate what share, if any, of these activities have an important trade component. A health programme, for instance, might permit increased trade from localities where the disease burden was previously a constraint on trade. Consequently, accurate monitoring of aid for trade would require comparison of the CRS data with providers and partner countries' self-assessments of their aid for trade.

\section{FOOTNOTES TO TABLES IN ANNEX A}

Most of the data shown in Annex A are sourced from the CRS. To view the full set of CRS data please visit: www.oecd.org/dac/stats/idsonline

\section{Providers of aid for trade and trade-related other official flows:}

The list of aid providers is split into DAC member countries, other bilateral donors and multilateral organisations. The full names of organisations are listed under the Acronyms section.

Korea became a member of the DAC in 2010 and was joined in 2013 by the Czech Republic, Iceland, Poland, the Slovak Republic and Slovenia. Data shown in previous years for these countries may be partial. Data collected from the EIF, FAO, IMF, ITC UNESCAP, UNESCWA, UNIDO, WTO and Turkey comprise specialised reporting as from 2007 on Aid for Trade flows and may not constitute the totality of their individual aid funding.

The Inter-American Development Bank (IDB) changed its reporting methodology to the CRS as from 2009 flows.

"Other multilateral donors" include small amounts from several multilateral agencies (GGGI, AITIC, Nordic Development Fund, UNPBF, UNICEF).

\section{Aid recipients:}

The DAC List of ODA Recipients represents all countries and territories eligible to receive official development assistance (ODA). These ODA-eligible recipients consist of low and middle income countries based on gross national income (GNI) per capita as published by the World Bank, with the exception of G8 members, EU members, and countries with a firm date for entry into the EU. The low-income countries include the Least Developed Countries (LDCS) as defined by the United Nations. 
In the latest revision of the list, effective from 1 January 2015 for reporting on 2014, 2015 and 2016 flows, there remains a total of 146 ODA-eligible countries (52 low-income countries of which 48 least developed, 36 lower middle-income and 58 upper middle-income). The next review of the DAC List will take place in 2017.

See the Annexes to view the DAC List of Aid Recipients by income group and region. A full historic of graduations to and from the DAC List can be viewed at: http://www.oecd.org/dac/stats/daclist.htm

\section{Channels of delivery:}

The list shown in Table A.11 represents major headings for channels of delivery in the CRS. The full list under each category (updated in 6 July 2016), is accessible at: http://www.oecd.org/dac/stats/annex2.htm. The category "Other" represents channels of delivery such as: Universities, colleges, or other teaching institutions, research institutes or think-tanks.

\section{Sector allocable aid:}

As from 2010 the method used to calculate sector allocable aid has changed. In order to measure donors' intention, the calculation is now based on types of aid. This allows the inclusion of unpredictable aid that has a specific policy. For example, humanitarian aid is unpredictable but allows practices targeting gender equality. Aid where the donor has no control on the spending has been removed such as sector budget support and core support to NGOs.

\section{Legend:}

".." denotes zero.

0.0 denotes amounts of less than USD 0.5 million.

$0.0 \%$ denotes a percentage of less than $0.5 \%$ 

ANNEX A

AID-FOR-TRADE KEY DATA

USD million (2015 constant)

Table A.1. Aid for trade by category

COMMITMENTS

DISBURSEMENTS

\begin{tabular}{|l|l|l|l|l|l|l|l|l|}
\hline 2002-05 avg. & $2006-08$ avg. & 2009-11 avg. & $2012-14$ avg. & 2015 & $2006-08$ avg. & $2009-11$ avg. & 2012-14 avg. & 2015
\end{tabular}

\section{Trade policy and regulations}

\begin{tabular}{|c|c|c|c|c|c|c|c|c|c|}
\hline Trade policy and admin. management & 567.8 & 653.1 & 625.3 & 517.5 & 659.5 & 461.0 & 517.1 & 491.9 & 418.2 \\
\hline Trade facilitation & 65.7 & 166.2 & 392.4 & 502.2 & 320.3 & 108.2 & 263.4 & 422.8 & 419.1 \\
\hline Regional trade agreements & 72.2 & 111.2 & 227.9 & 169.8 & 39.9 & 61.7 & 124.2 & 144.7 & 93.8 \\
\hline Multilateral trade negotiations & 13.8 & 38.7 & 17.6 & 9.4 & 8.0 & 23.2 & 31.7 & 19.4 & 16.6 \\
\hline Trade education/training & 9.4 & 29.3 & 32.1 & 21.1 & 34.2 & 20.1 & 30.1 & 23.2 & 33.0 \\
\hline Sub-total & 729.0 & 998.4 & 1295.3 & 1220.1 & 1061.8 & 674.3 & 966.5 & 1102.0 & 980.6 \\
\hline
\end{tabular}

\section{Economic infrastructure}

\begin{tabular}{|c|c|c|c|c|c|c|c|c|c|}
\hline Transport and storage & 6006.7 & 8908.4 & 11587.0 & 14115.9 & 15333.8 & 5614.5 & 8327.7 & 10889.4 & 10729.4 \\
\hline Communications & 580.3 & 457.2 & 602.0 & 793.1 & 559.8 & 442.7 & 544.4 & 629.3 & 443.1 \\
\hline Energy generation and supply & 4980.3 & 6305.9 & 8879.9 & 13346.3 & 15890.7 & 4331.0 & 5960.9 & 8041.8 & 9473.7 \\
\hline Sub-total & 11567.4 & 15671.5 & 21068.9 & 28255.3 & 31784.3 & 10388.2 & 14833.1 & 19560.5 & 20646.2 \\
\hline \multicolumn{10}{|l|}{ Building productive capacity } \\
\hline Business and other services & 1268.0 & 1899.2 & 1835.2 & 1674.4 & 1920.1 & 1729.5 & 1517.8 & 1550.4 & 2024.6 \\
\hline Banking and financial services & 1605.9 & 2313.6 & 3033.1 & 4757.3 & 5338.0 & 2024.2 & 3143.9 & 4042.5 & 5563.7 \\
\hline Agriculture & 3793.0 & 5515.3 & 7494.5 & 8507.0 & 9623.7 & 3764.9 & 5856.4 & 6126.7 & 7259.6 \\
\hline Forestry & 489.8 & 565.0 & 654.4 & 723.6 & 760.4 & 495.3 & 696.1 & 617.4 & 753.3 \\
\hline Fishing & 230.9 & 318.8 & 414.1 & 326.4 & 339.8 & 246.0 & 310.7 & 270.4 & 226.5 \\
\hline Industry & 1727.5 & 1506.1 & 1882.0 & 2078.3 & 2392.5 & 1151.6 & 1571.7 & 1691.6 & 1743.5 \\
\hline Mineral resources and mining & 808.6 & 365.2 & 418.1 & 536.9 & 566.6 & 418.6 & 277.5 & 717.6 & 442.6 \\
\hline Tourism & 90.0 & 188.9 & 165.4 & 113.3 & 89.3 & 63.7 & 130.6 & 164.3 & 161.9 \\
\hline Sub-total & 10013.7 & 12672.0 & 15896.9 & 18717.2 & 21030.5 & 9893.8 & 13504.7 & 15181.0 & 18175.6 \\
\hline \multicolumn{10}{|l|}{ Trade-related adjustment } \\
\hline Trade-related adjustment & .. & 1.9 & 20.1 & 2.1 & 2.2 & 7.6 & 35.1 & 14.0 & 13.1 \\
\hline Sub-total & .. & 1.9 & 20.1 & 2.1 & 2.2 & 7.6 & 35.1 & 14.0 & 13.1 \\
\hline TOTAL AID FOR TRADE & 22310.1 & 29343.8 & 38281.2 & 48194.7 & 53878.8 & 20963.9 & 29339.4 & 35857.5 & 39815.5 \\
\hline \multicolumn{10}{|l|}{ Focus on trade development } \\
\hline Principal objective & .. & 835.4 & 2115.5 & 2924.1 & 3802.5 & 757.2 & 1821.9 & 2918.9 & 3693.2 \\
\hline Significant objective & .. & 1303.7 & 2572.3 & 1756.0 & 2522.7 & 555.5 & 2074.0 & 1663.2 & 2219.1 \\
\hline TOTAL & .. & 2139.0 & 4687.8 & 4680.1 & 6325.2 & 1312.7 & 3895.9 & 4582.1 & 5912.2 \\
\hline \multicolumn{10}{|l|}{ Share in total Aid for trade } \\
\hline Trade policy and regulations & $3.3 \%$ & $3.4 \%$ & $3.4 \%$ & $2.5 \%$ & $2.0 \%$ & $3.2 \%$ & $3.3 \%$ & $3.1 \%$ & $2.5 \%$ \\
\hline Economic infrastructure & $51.8 \%$ & $53.4 \%$ & $55.0 \%$ & $58.6 \%$ & $59.0 \%$ & $49.6 \%$ & $50.6 \%$ & $54.6 \%$ & $51.9 \%$ \\
\hline Building productive capacity & $44.9 \%$ & $43.2 \%$ & $41.5 \%$ & $38.8 \%$ & $39.0 \%$ & $47.2 \%$ & $46.0 \%$ & $42.3 \%$ & $45.6 \%$ \\
\hline Trade-related adjustment & .. & $0.0 \%$ & $0.1 \%$ & $0.0 \%$ & $0.0 \%$ & $0.0 \%$ & $0.1 \%$ & $0.0 \%$ & $0.0 \%$ \\
\hline Share in sector allocable ODA & $32.1 \%$ & $31.1 \%$ & $30.8 \%$ & $34.3 \%$ & $33.3 \%$ & $28.4 \%$ & $27.9 \%$ & $29.7 \%$ & $27.6 \%$ \\
\hline Share in total ODA & $18.8 \%$ & $20.0 \%$ & $25.3 \%$ & $30.2 \%$ & $29.7 \%$ & $15.4 \%$ & $19.8 \%$ & $22.1 \%$ & $22.5 \%$ \\
\hline
\end{tabular}


USD million (2015 constant)

Table A.2. Aid for trade by category and region

COMMITMENTS

2002-05 avg. $\quad$ 2006-08 avg. $\quad$ 2009-11 avg. $2012-14$ avg.
DISBURSEMENTS

\begin{tabular}{l|l|l|l|}
2015 & $2006-08$ avg. $2009-11$ avg. & 2012-14 avg. & 2015
\end{tabular}

\section{Africa}

\begin{tabular}{|c|c|c|c|c|c|c|c|c|c|}
\hline Trade policy and regulations & 361.7 & 344.4 & 428.2 & 421.0 & 481.1 & 199.0 & 321.5 & 385.0 & 375.5 \\
\hline Economic infrastructure & 3357.4 & 5783.8 & 7961.1 & 10072.5 & 10138.1 & 3447.7 & 5207.3 & 7241.6 & 7743.9 \\
\hline Building productive capacity & 3186.9 & 4417.8 & 5903.2 & 7010.9 & 7541.0 & 3276.7 & 4954.9 & 5717.8 & 5950.7 \\
\hline Trade-related adjustment &.. & 1.4 & 4.8 & 0.0 &. & 7.2 & 25.3 & 1.2 & 0.3 \\
\hline Sub-total & 6906.1 & 10547.4 & 14297.2 & 17504.4 & 18160.3 & 6930.5 & 10509.0 & 13345.6 & 14070.4 \\
\hline \multicolumn{10}{|l|}{ America } \\
\hline Trade policy and regulations & 61.7 & 106.6 & 164.6 & 73.6 & 69.9 & 81.1 & 91.6 & 92.4 & 87.9 \\
\hline Economic infrastructure & 443.6 & 692.2 & 1279.0 & 2310.8 & 2575.1 & 406.2 & 1109.4 & 1673.4 & 1546.8 \\
\hline Building productive capacity & 1060.6 & 1088.2 & 1452.6 & 1373.8 & 1465.1 & 990.9 & 1378.0 & 1209.5 & 1175.5 \\
\hline Trade-related adjustment &. & 0.3 & 12.3 & 0.0 &. &.. & 5.5 & 8.9 & 11.0 \\
\hline Sub-total & 1566.0 & 1887.3 & 2908.5 & 3758.3 & 4110.1 & 1478.2 & 2584.5 & 2984.2 & 2821.1 \\
\hline \multicolumn{10}{|l|}{ Asia } \\
\hline Trade policy and regulations & 147.4 & 241.8 & 292.0 & 353.0 & 175.9 & 168.9 & 258.1 & 275.7 & 239.8 \\
\hline Economic infrastructure & 6790.2 & 8005.6 & 9431.2 & 12566.4 & 17119.0 & 5599.9 & 6273.0 & 8208.5 & 9579.0 \\
\hline Building productive capacity & 4354.1 & 4976.3 & 4803.3 & 5288.8 & 6624.7 & 3925.7 & 4264.8 & 4008.4 & 5092.2 \\
\hline Trade-related adjustment &. & 0.2 & 2.8 & 0.3 &. & 0.4 & 2.9 & 2.0 & 0.1 \\
\hline Sub-total & 11291.6 & 13223.9 & 14529.3 & 18208.6 & 23919.6 & 9694.9 & 10798.9 & 12494.6 & 14911.1 \\
\hline
\end{tabular}

Europe

\begin{tabular}{|c|c|c|c|c|c|c|c|c|c|}
\hline Trade policy and regulations & 24.2 & 73.7 & 61.1 & 70.4 & 22.9 & 24.7 & 48.4 & 49.6 & 38.5 \\
\hline Economic infrastructure & 663.7 & 743.2 & 1408.1 & 2547.0 & 885.8 & 636.9 & 1424.2 & 1841.3 & 1229.2 \\
\hline Building productive capacity & 562.4 & 629.6 & 1134.6 & 2543.9 & 2222.1 & 485.6 & 1063.2 & 2171.7 & 2557.7 \\
\hline Trade-related adjustment & .. & .. & 0.2 & 1.8 & 2.2 & .. & 1.1 & 2.0 & 1.7 \\
\hline Sub-total & 1250.4 & 1446.4 & 2604.0 & 5163.0 & 3133.1 & 1147.2 & 2536.9 & 4064.5 & 3827.1 \\
\hline \multicolumn{10}{|l|}{ Oceania } \\
\hline Trade policy and regulations & 3.0 & 4.3 & 31.7 & 14.9 & 10.3 & 2.2 & 9.4 & 18.3 & 20.0 \\
\hline Economic infrastructure & 122.7 & 206.5 & 276.1 & 372.8 & 663.2 & 128.5 & 189.2 & 269.2 & 344.1 \\
\hline Building productive capacity & 101.2 & 124.7 & 148.3 & 150.4 & 160.1 & 108.8 & 106.5 & 120.0 & 171.1 \\
\hline Trade-related adjustment &. & 0.0 & 0.0 & 0.0 &. &. & 0.3 & 0.0 & .. \\
\hline Sub-total & 227.0 & 335.5 & 456.1 & 538.1 & 833.6 & 239.6 & 305.4 & 407.5 & 535.2 \\
\hline \multicolumn{10}{|l|}{ Non-region specific } \\
\hline Trade policy and regulations & 130.8 & 227.6 & 317.7 & 287.1 & 301.7 & 198.5 & 237.6 & 281.0 & 218.9 \\
\hline Economic infrastructure & 189.8 & 240.3 & 713.5 & 385.7 & 403.1 & 169.0 & 629.9 & 326.6 & 203.2 \\
\hline Building productive capacity & 748.5 & 1435.4 & 2454.9 & 2349.4 & 3017.4 & 1106.0 & 1737.3 & 1953.6 & 3228.4 \\
\hline Trade-related adjustment & .. & .. & .. & 0.0 & 0.0 &. & 0.0 & 0.0 & 0.0 \\
\hline Sub-total & 1069.1 & 1903.3 & 3486.0 & 3022.3 & 3722.2 & 1473.5 & 2604.8 & 2561.2 & 3650.5 \\
\hline TOTAL AID FOR TRADE & 22310.1 & 29343.8 & 38281.2 & 48194.7 & 53878.8 & 20963.9 & 29339.4 & 35857.5 & 39815.5 \\
\hline
\end{tabular}


USD million (2015 constant)

Table A.3. Aid for trade by category and income group

Least developed countries

\begin{tabular}{|c|c|c|c|c|c|c|c|c|c|}
\hline Trade policy and regulations & 82.7 & 205.6 & 224.4 & 328.4 & 235.2 & 116.1 & 147.3 & 243.1 & 253.4 \\
\hline Economic infrastructure & 3339.3 & 5013.1 & 6754.4 & 8250.2 & 10608.2 & 2927.1 & 4327.5 & 5307.5 & 5951.0 \\
\hline Building productive capacity & 2658.9 & 3344.1 & 4833.5 & 4955.0 & 6401.1 & 2578.8 & 3811.3 & 3800.5 & 4345.4 \\
\hline Trade-related adjustment &. & 1.4 & 2.3 & 0.0 &. & 7.4 & 23.8 & 1.9 & 0.3 \\
\hline Sub-total & 6081.0 & 8564.2 & 11814.6 & 13533.6 & 17244.5 & 5629.4 & 8309.9 & 9353.0 & 10550.0 \\
\hline \multicolumn{10}{|l|}{ Other low-income countries } \\
\hline Trade policy and regulations & 20.1 & 3.1 & 10.2 & 26.0 & 25.2 & 3.3 & 7.7 & 21.2 & 12.0 \\
\hline Economic infrastructure & 243.5 & 362.9 & 890.8 & 1097.6 & 1460.6 & 156.4 & 300.4 & 763.1 & 834.5 \\
\hline Building productive capacity & 161.8 & 212.1 & 396.8 & 366.7 & 545.4 & 168.6 & 254.5 & 338.5 & 378.5 \\
\hline Trade-related adjustment &. & 0.0 & 0.0 & 0.0 &.. &.. & 1.2 & 0.0 & .. \\
\hline Sub-total & 425.5 & 578.3 & 1297.8 & 1490.2 & 2031.2 & 328.3 & 563.8 & 1122.8 & 1225.0 \\
\hline \multicolumn{10}{|c|}{ Lower middle-income countries } \\
\hline Trade policy and regulations & 294.3 & 192.2 & 219.9 & 254.1 & 246.4 & 145.3 & 171.4 & 207.9 & 179.5 \\
\hline Economic infrastructure & 4377.7 & 6256.5 & 8752.5 & 12498.6 & 13848.8 & 3807.3 & 5952.8 & 8327.7 & 9588.4 \\
\hline Building productive capacity & 3315.1 & 4198.8 & 4415.1 & 5436.8 & 5496.9 & 2841.3 & 3744.0 & 4186.1 & 4803.4 \\
\hline Trade-related adjustment &. & 0.0 & 2.1 & 1.1 & .. & 0.0 & 2.7 & 2.2 & 0.4 \\
\hline Sub-total & 7987.0 & 10647.6 & 13389.6 & 18190.6 & 19592.1 & 6793.9 & 9870.9 & 12723.8 & 14571.8 \\
\hline
\end{tabular}

\section{Upper middle-income countries}

Trade policy and regulations

Economic infrastructure

Building productive capacity

Trade-related adjustment

Sub-total

\section{Non-country specific}

Trade policy and regulations

Economic infrastructure

Building productive capacity

Trade-related adjustment

Sub-total

TOTAL AID FOR TRADE

Source: OECD-DAC/CRS aid activity database
COMMITMENTS

DISBURSEMENTS

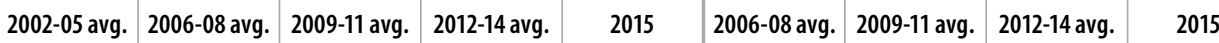


USD million (2015 constant)

Table A.4. Aid for trade by individual provider

COMMITMENTS

2002-05 avg. 2006-08 avg. 2009-11 avg. 2012-14 avg.
DISBURSEMENTS

2015 2006-08 avg. 2009-11 avg. 2012-14 avg. 2015

\begin{tabular}{|c|c|c|c|c|c|c|c|c|c|}
\hline \multicolumn{10}{|l|}{ DAC countries } \\
\hline Australia & 193.0 & 291.1 & 463.6 & 361.2 & 386.0 & 237.4 & 366.8 & 361.2 & 386.0 \\
\hline Austria & 43.1 & 50.2 & 70.7 & 82.4 & 68.2 & 36.8 & 57.0 & 56.1 & 45.5 \\
\hline Belgium & 219.0 & 242.4 & 410.7 & 175.6 & 205.0 & 167.3 & 363.8 & 194.1 & 203.9 \\
\hline Canada & 323.2 & 354.9 & 545.1 & 497.8 & 713.2 & 269.1 & 558.5 & 435.6 & 342.7 \\
\hline Czech Republic & & & 3.3 & 7.2 & 10.4 & & 3.2 & 7.3 & 10.3 \\
\hline Denmark & 398.3 & 259.6 & 291.9 & 357.8 & 119.8 & 250.8 & 318.1 & 323.8 & 258.6 \\
\hline Finland & 76.2 & 122.8 & 282.7 & 127.6 & 89.2 & 59.2 & 132.1 & 150.3 & 151.1 \\
\hline France & 637.8 & 1364.6 & 1307.0 & 2427.4 & 2842.9 & 814.4 & 1060.4 & 1694.7 & 1467.6 \\
\hline Germany & 1164.8 & 1945.2 & 3173.1 & 4653.2 & 5629.1 & 1600.6 & 2447.5 & 3043.3 & 4965.7 \\
\hline Greece & 11.0 & 16.2 & 15.0 & 0.1 & 0.0 & 16.2 & 15.0 & 0.1 & 0.0 \\
\hline Hungary & 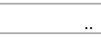 & .. & & & 0.4 & .. & & 1.9 & 0.4 \\
\hline Iceland & & & 2.6 & 9.5 & 6.6 & & 2.6 & 9.5 & 6.6 \\
\hline Ireland & 26.7 & 42.4 & 58.0 & 45.8 & 32.6 & 42.4 & 58.0 & 45.8 & 32.6 \\
\hline Italy & 241.2 & 220.9 & 159.3 & 113.4 & 184.2 & 231.9 & 138.0 & 84.2 & 194.9 \\
\hline Japan & 4080.1 & 5183.7 & 5580.7 & 7690.4 & 11754.6 & 3698.6 & 4374.4 & 5457.5 & 5938.4 \\
\hline Korea & & 469.0 & 900.2 & 839.5 & 892.0 & 192.0 & 357.1 & 496.0 & 587.6 \\
\hline Luxembourg & 16.1 & 30.0 & 32.3 & 37.1 & 32.3 & 30.0 & 32.3 & 37.1 & 32.3 \\
\hline Netherlands & 514.0 & 661.4 & 671.2 & 831.3 & 588.2 & 459.2 & 455.9 & 594.4 & 523.3 \\
\hline New Zealand & 20.9 & 42.4 & 90.8 & 112.3 & 135.2 & 28.8 & 49.7 & 91.2 & 106.6 \\
\hline Norway & 247.4 & 400.8 & 504.7 & 529.2 & 337.6 & 380.3 & 385.3 & 485.9 & 481.7 \\
\hline Poland & & & & 8.6 & 31.2 & & & 8.7 & 31.1 \\
\hline Portugal & 41.3 & 26.8 & 48.6 & 26.5 & 24.1 & 33.9 & 50.0 & 39.2 & 22.4 \\
\hline Slovak Republic & .. & .. & & 0.6 & 0.9 & .. & & 0.5 & 0.8 \\
\hline Slovenia & & & 2.0 & 1.1 & 0.1 & & 2.0 & 0.8 & 0.5 \\
\hline Spain & 348.4 & 637.2 & 791.3 & 87.1 & 50.4 & 445.9 & 782.7 & 108.0 & 67.5 \\
\hline Sweden & 219.8 & 318.1 & 322.2 & 364.6 & 285.0 & 320.0 & 337.4 & 386.8 & 329.1 \\
\hline Switzerland & 304.0 & 274.8 & 292.4 & 387.7 & 315.5 & 253.9 & 232.4 & 306.0 & 383.0 \\
\hline United Kingdom & 736.1 & 918.6 & 1261.6 & 968.1 & 1724.8 & 942.4 & 1341.7 & 1471.6 & 2234.0 \\
\hline United States & 4147.2 & 5900.2 & 4544.8 & 3363.9 & 3385.2 & 4262.6 & 4192.4 & 3442.5 & 2836.6 \\
\hline Sub-total & 14009.8 & 19773.4 & 21825.9 & 24106.9 & 29844.8 & 14773.7 & 18114.3 & 19334.0 & 21640.8 \\
\hline \multicolumn{10}{|l|}{ Other bilateral } \\
\hline Azerbaijan & .. & .. & .. & & & .. & .. & 0.1 & 0.2 \\
\hline Estonia & & & & 1.4 & 1.1 & ... & & 0.9 & 1.3 \\
\hline Kazakhstan & .. & .. & & & & .. & & 0.1 & 0.7 \\
\hline Kuwait (KFAED) & & .. & 308.0 & 526.5 & 394.2 & .. & 246.6 & 265.7 & 403.6 \\
\hline Lithuania & .. & .. & 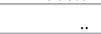 & 0.0 & 0.7 & & 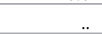 & 0.0 & 0.6 \\
\hline Romania & .. & .. & & 0.1 & 0.5 & .. & & 0.3 & 0.5 \\
\hline Turkey & & ... & 38.3 & & & & 38.3 & & \\
\hline United Arab Emirates & .. & .. & 229.0 & 879.5 & 895.9 & .. & 87.0 & 694.5 & 886.4 \\
\hline Sub-total & .. & .. & 575.3 & 1407.6 & 1292.4 & .. & 371.9 & 961.6 & 1293.2 \\
\hline \multicolumn{10}{|l|}{ Multilateral } \\
\hline AfDB & 145.5 & 690.7 & 1470.2 & 1555.2 & 1662.9 & 371.4 & 1182.4 & 990.3 & 1223.1 \\
\hline Arab Fund (AFESD) & & 379.9 & 991.6 & 757.7 & 1334.3 & 228.6 & 683.8 & 661.0 & 486.9 \\
\hline AsDB & 729.8 & 509.6 & 1176.3 & 1758.8 & 1668.9 & & 477.8 & 1234.5 & 1553.4 \\
\hline BADEA & 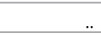 & 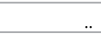 & 24.4 & 98.8 & & & 14.7 & 62.8 & 61.0 \\
\hline Caribbean Development Bank & .. & .. & .. & .. & 4.1 & ... & & & \\
\hline CEB & & & & & 2.8 & & 12.4 & 2.0 & 1.4 \\
\hline Climate Investment Funds (CIF) & & & & 773.0 & 660.3 & & & 64.1 & 207.7 \\
\hline Enhanced Integrated Framework (EIF) & & & 12.9 & 25.9 & 18.4 & & 10.0 & 15.8 & 7.5 \\
\hline EU Institutions & 2367.0 & 2903.8 & 4160.5 & 8319.6 & 6715.9 & 2134.7 & 3716.5 & 6469.3 & 6269.7 \\
\hline FAO & & 128.8 & 268.6 & 267.7 & 312.7 & 128.8 & 268.6 & 267.7 & 312.7 \\
\hline GEF & & & 117.9 & 270.9 & 111.1 & 64.3 & 94.3 & 124.0 & 162.5 \\
\hline IDB & 236.5 & 108.4 & 425.2 & 577.5 & 787.9 & . & 348.3 & 555.6 & 514.7 \\
\hline IFAD & 262.4 & 367.5 & 570.2 & 533.1 & 915.7 & & .. & & \\
\hline ILO & & & & 12.8 & 14.9 & .. & .. & 12.8 & 14.9 \\
\hline IMF & & 9.9 & 13.3 & 9.3 & & & & 0.7 & \\
\hline Islamic Development Bank & 185.9 & 246.8 & 185.4 & 136.1 & 233.8 & & & & \\
\hline ITC & & 29.4 & 53.2 & 64.0 & 68.0 & 28.9 & 50.9 & 57.2 & 65.4 \\
\hline OFID & & & 340.4 & 413.0 & 508.7 & & 165.1 & 220.9 & 294.2 \\
\hline UNDP & 11.6 & 23.5 & 32.9 & 30.2 & 25.9 & 2.1 & 6.6 & 36.1 & 51.9 \\
\hline UNECE & & 1.3 & 4.1 & 3.4 & 5.1 & 22.8 & 32.8 & 30.2 & 25.9 \\
\hline UNESCAP & & 0.3 & 0.5 & 0.6 & 0.7 & 1.3 & 4.1 & 3.4 & 5.1 \\
\hline UNESCWA & & 0.1 & 0.2 & 0.3 & 0.4 & 0.2 & 0.5 & 0.5 & 0.7 \\
\hline UNIDO & & 26.5 & 60.4 & 12.7 & & 0.1 & 0.2 & 0.3 & 0.3 \\
\hline World Bank & 4360.5 & 4127.5 & 5934.3 & 7012.1 & 7621.4 & & & & \\
\hline WTO & & 12.4 & 15.3 & 11.8 & 11.5 & 3194.7 & 3769.1 & 4741.0 & 5611.0 \\
\hline Other multilateral donors & 1.0 & 4.1 & 22.6 & 35.6 & 56.2 & 12.4 & 15.3 & 11.8 & 11.5 \\
\hline Sub-total & 8300.3 & 9570.4 & 15880.1 & 22680.2 & 22741.6 & 6190.2 & 10853.2 & 15561.9 & 16881.5 \\
\hline TOTAL AID FOR TRADE & 22310.1 & 29343.8 & 38281.2 & 48194.7 & 53878.8 & 20963.9 & 29339.4 & 35857.5 & 39815.5 \\
\hline \multicolumn{10}{|l|}{ Shares in total aid for trade } \\
\hline DAC countries & $62.8 \%$ & $67.4 \%$ & $57.0 \%$ & $50.0 \%$ & $55.4 \%$ & $70.5 \%$ & $61.7 \%$ & $53.9 \%$ & $54.4 \%$ \\
\hline Other bilateral & & & $1.5 \%$ & $2.9 \%$ & $2.4 \%$ & & $1.3 \%$ & $2.7 \%$ & $3.2 \%$ \\
\hline Multilateral & $37.2 \%$ & $32.6 \%$ & $41.5 \%$ & $47.1 \%$ & $42.2 \%$ & $29.5 \%$ & $37.0 \%$ & $43.4 \%$ & $42.4 \%$ \\
\hline
\end{tabular}

Source: OECD-DAC/CRS aid activity database. 
USD million (2015 constant)

Table A.5a. Top 20 providers of aid for trade in 2015, commitments

COMMITMENTS

\begin{tabular}{|c|c|c|c|c|c|}
\hline & 2002-05 avg. & 2006-08 avg. & 2009-11 avg. & 2012-14 avg. & 2015 \\
\hline Japan & 4080.1 & 5183.7 & 5580.7 & 7690.4 & 11754.6 \\
\hline World Bank & 4360.5 & 4127.5 & 5934.3 & 7012.1 & 7621.4 \\
\hline EU Institutions & 2367.0 & 2903.8 & 4160.5 & 8319.6 & 6715.9 \\
\hline Germany & 1164.8 & 1945.2 & 3173.1 & 4653.2 & 5629.1 \\
\hline United States & 4147.2 & 5900.2 & 4544.8 & 3363.9 & 3385.2 \\
\hline France & 637.8 & 1364.6 & 1307.0 & 2427.4 & 2842.9 \\
\hline United Kingdom & 736.1 & 918.6 & 1261.6 & 968.1 & 1724.8 \\
\hline AsDB & 729.8 & 509.6 & 1176.3 & 1758.8 & 1668.9 \\
\hline AfDB & 145.5 & 690.7 & 1470.2 & 1555.2 & 1662.9 \\
\hline Arab Fund (AFESD) & .. & 379.9 & 991.6 & 757.7 & 1334.3 \\
\hline IFAD & 262.4 & 367.5 & 570.2 & 533.1 & 915.7 \\
\hline United Arab Emirates & .. & .. & 229.0 & 879.5 & 895.9 \\
\hline Korea & .. & 469.0 & 900.2 & 839.5 & 892.0 \\
\hline IDB & 236.5 & 108.4 & 425.2 & 577.5 & 787.9 \\
\hline Canada & 323.2 & 354.9 & 545.1 & 497.8 & 713.2 \\
\hline Climate Investment Funds & .. & .. & .. & 773.0 & 660.3 \\
\hline Netherlands & 514.0 & 661.4 & 671.2 & 831.3 & 588.2 \\
\hline OFID & .. & .. & 340.4 & 413.0 & 508.7 \\
\hline Kuwait (KFAED) & .. &. & 308.0 & 526.5 & 394.2 \\
\hline Australia & 193.0 & 291.1 & 463.6 & 361.2 & 386.0 \\
\hline Sub-total & 19898.1 & 26176.3 & 34053.1 & 44739.0 & 51082.2 \\
\hline TOTAL AID FOR TRADE & 22310.1 & 29343.8 & 38281.2 & 48194.7 & 53878.8 \\
\hline Top 20 share in total AFT & $89.2 \%$ & $89.2 \%$ & $89.0 \%$ & $92.8 \%$ & $94.8 \%$ \\
\hline
\end{tabular}

USD million (2015 constant)

Table A.5b. Top 20 providers of aid for trade in 2015, disbursements

DISBURSEMENTS

\begin{tabular}{|c|c|c|c|c|}
\hline & \\
\hline & 2006-08 avg. & 2009-11 avg. & 2012-14 avg. & 2015 \\
\hline EU Institutions & 2134.7 & 3716.5 & 6469.3 & 6269.7 \\
\hline Japan & 3698.6 & 4374.4 & 5457.5 & 5938.4 \\
\hline World Bank & 3194.7 & 3769.1 & 4741.0 & 5611.0 \\
\hline Germany & 1600.6 & 2447.5 & 3043.3 & 4965.7 \\
\hline United States & 4262.6 & 4192.4 & 3442.5 & 2836.6 \\
\hline United Kingdom & 942.4 & 1341.7 & 1471.6 & 2234.0 \\
\hline AsDB & .. & 477.8 & 1234.5 & 1553.4 \\
\hline France & 814.4 & 1060.4 & 1694.7 & 1467.6 \\
\hline AfDB & 371.4 & 1182.4 & 990.3 & 1223.1 \\
\hline United Arab Emirates & .. & 87.0 & 694.5 & 886.4 \\
\hline Korea & 192.0 & 357.1 & 496.0 & 587.6 \\
\hline Netherlands & 459.2 & 455.9 & 594.4 & 523.3 \\
\hline IADB & .. & 348.3 & 555.6 & 514.7 \\
\hline Arab Fund (AFESD) & 228.6 & 683.8 & 661.0 & 486.9 \\
\hline Norway & 380.3 & 385.3 & 485.9 & 481.7 \\
\hline Kuwait (KFAED) & .. & 246.6 & 265.7 & 403.6 \\
\hline Australia & 237.4 & 366.8 & 361.2 & 386.0 \\
\hline Switzerland & 253.9 & 232.4 & 306.0 & 383.0 \\
\hline Canada & 269.1 & 558.5 & 435.6 & 342.7 \\
\hline Sweden & 320.0 & 337.4 & 386.8 & 329.1 \\
\hline Sub-total & 19359.7 & 26621.5 & 33787.3 & 37424.3 \\
\hline TOTAL AID FOR TRADE & 20963.9 & 29339.4 & 35857.5 & 39815.5 \\
\hline Top 20 share in total AFT & $92.3 \%$ & $90.7 \%$ & $94.2 \%$ & $94.0 \%$ \\
\hline
\end{tabular}

Source: OECD-DAC/CRS aid activity database.

StatLink 刑Is http://dx.doi.org/10.1787/888933528913 
USD million (2015 constant)

\section{Table A.6. Aid for trade by individual recipient country (page 2 of 3 )}

\section{COMMITMENTS}

2002-05 avg. 2006-08 avg. 2009-11 avg. 2012-14 avg.

Guinea-Bissau

Guyana

Haiti

Honduras

India

Indonesia

Iran

Iraq

Jamaica

Jordan

Kazakhstan

Kenya

Kiribati

Kosovo

Kyrgyzstan

Lao People's Democratic Republic

Lebanon

Lesotho

Liberia

Libya

Madagascar

Malawi

Malaysia

Maldives

Mali

Marshall Islands

Mauritania

Mauritius

Mexico

Micronesia

Moldova

Mongolia

Montenegro

Montserrat

Morocco

Mozambique

Myanmar

Namibia

Nauru

Nepal

Nicaragua

Niger

Nigeria

Niue

Pakistan

Palau

Panama

Papua New Guinea

Paraguay

Peru

Philippines

Rwanda

Saint Helena

Source: OECD-DAC/CRS aid activity database

\begin{tabular}{|r|r|r|r|}
\hline 928.5 & 716.5 & 734.3 & 493.1 \\
\hline 4.2 & 2.9 & 6.1 & 2.6 \\
\hline
\end{tabular}

$4.2 \quad 29$

\begin{tabular}{r|r|r}
\hline 2280.5 & 2093.8 & 401.4 \\
\hline 3
\end{tabular}

$30.9 \quad 32.4$

\begin{tabular}{l|l}
38.2 & 112.7 \\
\hline 38.1 & 111.5
\end{tabular}

\begin{tabular}{r|r}
38.1 & 111.5 \\
\hline 282.2 & 440.3
\end{tabular}

$112.7 \quad 174.2$

\begin{tabular}{r|r}
112.7 & 174.2 \\
\hline 111.5 & 81.4
\end{tabular}

\begin{tabular}{|r|r|r}
\hline 6.3 & 6.6 & 33.9 \\
\hline
\end{tabular}

\begin{tabular}{|r|r|r|}
\hline 0.0 & 0.0 & 80.1 \\
\hline 50.7 & 90.5 & 1527 \\
\hline
\end{tabular}

50.7

50.7
139.8

\begin{tabular}{|l|l|r|}
\hline 139.8 & 113.6 & 183.5 \\
\hline
\end{tabular}

152.7

\begin{tabular}{l|l}
183.5 & 236.5 \\
51.0 & 58.0
\end{tabular}

\begin{tabular}{|r|r|r|}
\hline 6.2 & 30.0 & 26.6 \\
\hline 0.9 & 71.2 & 189.7 \\
\hline
\end{tabular}

$26.6 \quad 24.9$

2.0

$268.6 \quad 236.8$

\begin{tabular}{|l|l|}
\hline 103.6 & 125.4 \\
\hline
\end{tabular}

\begin{tabular}{r|r}
\hline 10.5 & 41.6 \\
\hline 9.5 & 14.3 \\
\hline
\end{tabular}

\begin{tabular}{r|r|r}
\hline 170.9 & 497.1 & 371.6 \\
\hline
\end{tabular}

\begin{tabular}{r|r}
17.7 & 1.1 \\
\hline 1117 & 134.7 \\
\hline
\end{tabular}

\begin{tabular}{r|r}
1.1 & 6.3 \\
\hline 1347 & 128.8
\end{tabular}

\begin{tabular}{r|r}
111.7 & 134.7 \\
\hline 54.2 & 30.5 \\
\hline
\end{tabular}

23.5

\begin{tabular}{l|l}
12.5 & 15.0 \\
\hline 617 & -42.2 \\
\hline
\end{tabular}

\begin{tabular}{l|r}
63.1 & 238.2 \\
6.2
\end{tabular}

\begin{tabular}{|r|r|r|}
\hline 61.7 & 42.2 & 182. \\
\hline 53.1 & 238.2 & 162 \\
\hline 6.2 & 27.7 & 23.5 \\
\hline 7.6 & 11.0 & 1.6 \\
\hline
\end{tabular}

$280.5 \quad 800.9$

$312.2 \quad 429.1$

\begin{tabular}{l|l}
9.2 & 14.5
\end{tabular}

\begin{tabular}{r|r}
\hline 11.0 & 1.6 \\
8009 & 872.2 \\
\hline
\end{tabular}

\begin{tabular}{r|r|r} 
& 872.2 & 1570.7 \\
\hline 229.1 & 4075 & 579.6
\end{tabular}

\begin{tabular}{|c|c|c|}
\hline 29.2 & 14.5 & 32.2 \\
\hline 29.2 & 68.6 & 88.3 \\
\hline
\end{tabular}

\begin{tabular}{r|r}
32.2 & 663.1
\end{tabular}

\begin{tabular}{r|r|r}
\hline 2.2 & 68.6 & 88.3 \\
\hline 2.0 & 9.4 & 2.5 \\
\hline
\end{tabular}

\begin{tabular}{l|l}
155.2 & 194.1 \\
\hline 177.7 & 192.8 \\
\hline
\end{tabular}

\begin{tabular}{l|r}
177.7 & 192.8 \\
\hline
\end{tabular}

\begin{tabular}{|l|l}
\hline 104.8 & 102.1 \\
\hline 223.1 & 327.3 \\
\hline
\end{tabular}

223.1

\begin{tabular}{r|r}
2.2 & \\
\hline 547.5 & 65.5 \\
\hline 5.5 & \\
\hline
\end{tabular}

\begin{tabular}{|r|r|r|}
\hline 194.1 & 355.2 & 618.0 \\
\hline 192.8 & 209.1 & 216.3 \\
\hline 102.1 & 1066 & 2629 \\
\hline
\end{tabular}

\begin{tabular}{|l|r|r|}
\hline 327.3 & 557.8 & 262.9 \\
\hline 1.8 & 884.7 \\
\hline
\end{tabular}

\begin{tabular}{r|r}
\hline 1.8 & 5.5 \\
\hline 654.5 & 729.4
\end{tabular}

\begin{tabular}{r|r}
\hline 654.5 & 729.4 \\
\hline
\end{tabular}

\begin{tabular}{r|r}
729.4 & 3.6 \\
\hline 3.3 & 1503.0 \\
\hline
\end{tabular}

\begin{tabular}{r|r}
5.5 & 5.3 \\
\hline 9.0 & 11.6 \\
\hline
\end{tabular}

\begin{tabular}{r|r}
115.0 & 125.5 \\
\hline 14.5 & 77.3 \\
\hline 129.3 & 119.8 \\
\hline
\end{tabular}

\begin{tabular}{|l|r|}
\hline 129.3 & 119.8 \\
\hline 290.2 & 208.9 \\
\hline
\end{tabular}

\begin{tabular}{r|r}
290.2 & 208.9 \\
\hline 69.5 & 118.2 \\
\hline 41.4
\end{tabular}

\begin{tabular}{r|r}
\hline 41.4 & 13.9
\end{tabular}

\begin{tabular}{r|r}
11.6 & 16.9 \\
\hline & 185.3
\end{tabular}

$125.5 \quad 185.3$

\begin{tabular}{|r|r|}
\hline 16.9 & 6.7 \\
\hline 185.3 & 188.5 \\
\hline 81.2 & 87.5 \\
\hline 139.1 & 166.5 \\
\hline
\end{tabular}

\begin{tabular}{|r|r|r|}
\hline 77.3 & 81.2 & 87.5 \\
\hline 119.8 & 139.1 & 166.5 \\
\hline 208.9 & 539.3 & 592.9 \\
\hline 118.2 & 278.8 & 303.9 \\
\hline
\end{tabular}

\begin{tabular}{|r|r|r|}
\hline 13.9 & 278.8 & 303.9 \\
\hline
\end{tabular}

DISBURSEMENTS

\begin{tabular}{|r|r|r|r|r|}
\hline 23.5 & 14.1 & 15.8 & 11.3 & 114.6 \\
\hline 39.9 & 50.4 & 51.4 & 41.6 & 2.9 \\
\hline 79.0 & 88.4 & 361.5 & 264.7 & 358.9 \\
\hline 175.6 & 63.9 & 190.2 & 224.0 & 332.6 \\
\hline 1365.5 & 2030.8 & 2346.2 & 4018.7 & 2804.8 \\
\hline
\end{tabular}

\begin{tabular}{|r|r|}
\hline 503.0 & 3.6 \\
\hline 6.3 & \\
\hline 6.7 & \\
\hline 188.5 & \\
\hline 87.5 & \\
\hline 166.5 & \\
\hline 592.9 & \\
\hline 303.9 & \\
\hline 14.2 & \\
\hline
\end{tabular}

\begin{tabular}{|r|}
\hline 1732.7 \\
\hline 5.9 \\
\hline 6.4 \\
\hline 354.0 \\
\hline 62.4 \\
\hline 94.3 \\
\hline 2648.9 \\
\hline 339.8 \\
\hline 27.5 \\
\hline
\end{tabular}

\begin{tabular}{|r|r|}
\hline 9.2 & 2.1 \\
\hline 5.9 & 330.7 \\
\hline 6.4 & 6.9 \\
\hline 54.0 & 7.0 \\
\hline 62.4 & 90.4 \\
\hline 94.3 & 30.6 \\
\hline 2648.9 & 172.2 \\
\hline 339.8 & 429.2 \\
\hline 27.5 & 94.7 \\
\hline
\end{tabular}

206-08 avg. 2009-11 avg.

2012-14 avg. 2015

\begin{tabular}{|r|r|r|r|}
\hline 30.3 & 21.2 & 10.9 & 10.0 \\
\hline 15.7 & 52.0 & 43.4 & 4.6 \\
\hline 52.4 & 244.2 & 242.4 & 249.8 \\
\hline
\end{tabular}

\begin{tabular}{|r|r|r|r|}
\hline 52.4 & 244.2 & 242.4 & 249.8 \\
\hline 71.7 & 175.8 & 224.1 & 144.0 \\
\hline
\end{tabular}

\begin{tabular}{|r|r|r|r}
\hline 1098.1 & 1724.0 & 1782.2 & 3085.6 \\
\hline
\end{tabular}

\begin{tabular}{|r|r|r|r|}
\hline 688.2 & 716.6 & 522.8 & 878.0 \\
\hline 1.9 & 3.5 & 4.8 & 6.1 \\
\hline
\end{tabular}

\begin{tabular}{|r|r|r|r|}
\hline 1947.1 & 410.3 & 418.9 & 201.2 \\
\hline 41.3 & 45.4 & 32.0 & 25.9 \\
\hline
\end{tabular}

\begin{tabular}{|r|r|r|r|}
\hline 41.3 & 45.4 & 32.0 & 25.9 \\
\hline 62.9 & 207.4 & 264.7 & 286.1 \\
\hline 96.8 & 56.7 & 32.1 & 15.4 \\
\hline
\end{tabular}

\begin{tabular}{|r|r|r|r|}
\hline 62.9 & 207.4 & 264.7 & 286.1 \\
\hline 96.8 & 56.7 & 32.1 & 15.4 \\
\hline
\end{tabular}


USD million (2015 constant)

Table A.6. Aid for trade by individual recipient country (page 3 of 3)

COMMITMENTS

DISBURSEMENTS

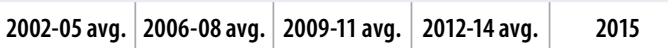

2006-08 avg. 2009-11 avg. 2012-14 avg. 2015

Saint Lucia

Saint Vincent and the Grenadines

Samoa

Sao Tome and Principe

Senegal

Serbia

Seychelles

Sierra Leone

Solomon Islands

Somalia

South Africa

South Sudan

Sri Lanka

Sudan

Suriname

Swaziland

Syrian Arab Republic

Tajikistan

Tanzania

Thailand

Timor-Leste

Togo

Tokelau

Tonga

Tunisia

Turkey

Turkmenistan

Tuvalu

Uganda

Ukraine

Uruguay

Uzbekistan

Vanuatu

Venezuela

Viet Nam

Wallis and Futuna

West Bank and Gaza Strip

Yemen

Zambia

Zimbabwe

Total recipient countries

Non-country specific

TOTAL AID FOR TRADE

\begin{tabular}{|r|r|r|}
\hline 85 avg. & $\mathbf{2 0 0 6 - 0 8 ~ a v g . ~}$ & $\mathbf{2 0 0}$ \\
\hline 8.1 & 7.3 & \\
\hline 5.8 & 6.3 & \\
\hline 13.7 & 23.8 & \\
\hline 6.9 & 5.9 & \\
\hline 175.2 & 225.2 & \\
\hline 398.8 & 266.8 & \\
\hline 27 & & \\
\hline
\end{tabular}

\begin{tabular}{|r|r|}
\hline 3.4 & 17.4 \\
\hline 0.7 & 8.4 \\
\hline 17.3 & 40.8 \\
\hline
\end{tabular}

15.6

\begin{tabular}{|l|l|}
\hline 469.6 & 341.4 \\
\hline
\end{tabular}

567.8

2.7

90.0

10.8
3.9

\begin{tabular}{l|l}
3.9 & 13.1
\end{tabular}

\begin{tabular}{l|l}
4.8 & 1.4 \\
\hline
\end{tabular}

1.4
88.6

689.4

4.7
119.4

\begin{tabular}{|l|l|}
\hline 2.4 & 33.8 \\
\hline
\end{tabular}

\begin{tabular}{l|l}
37.9 \\
\hline
\end{tabular}

27.9

52.9

52.9
66.6
227.4

\begin{tabular}{|r|r|r|}
\hline 0.0 & 0.0 & 21.1 \\
\hline 429.2 & 325.6 & 373.3 \\
\hline
\end{tabular}

\begin{tabular}{l|r|}
\hline 27.1 & 214.8 \\
\hline
\end{tabular}

20.4

\begin{tabular}{r|r}
325.6 & 395.2 \\
\hline
\end{tabular}

\begin{tabular}{l|l}
373.3 & 563.7 \\
\hline
\end{tabular}

\begin{tabular}{|r|r}
\hline 37.3 & 563.7 \\
\hline 95.2 & 252.4 \\
\hline
\end{tabular}

Source: OECD-DAC/CRS aid activity database.

15.9

15.0

15.0
98.7

15.0
98.7

19.4

\begin{tabular}{r|r}
175.5 & 173.5 \\
\hline
\end{tabular}

\begin{tabular}{l|l|l}
\hline 38.7 & 114.7 & 183.5 \\
\hline 366.6 & 730.3 & 828.7
\end{tabular}

\begin{tabular}{l|l|l}
\hline 299.2 & 205.5 & 283.5
\end{tabular}

\begin{tabular}{l|l}
29.7 & 30.3
\end{tabular}

8.0

1.5

2.5

380.5

359.2

\begin{tabular}{l|l}
30.3 & 52.2 \\
\hline
\end{tabular}

\begin{tabular}{r|r}
37.7 & 92.0 \\
\hline 12 & 3.5
\end{tabular}

\begin{tabular}{|r|r|}
\hline 1.2 & 3.5 \\
\hline 12.3 & 33.2 \\
\hline 246.3 & 318.1 \\
\hline
\end{tabular}

359.2

\begin{tabular}{r|r}
318.1 & 26.2 \\
\hline & 965.3
\end{tabular}

\begin{tabular}{r|r|r|r}
\hline 2.6 & 1.8 & 8.6 & 6.6 \\
\hline
\end{tabular}

\begin{tabular}{|r|r|r|r|}
\hline 3.6 & 4.9 & 5.9 & 20.1 \\
\hline 238.4 & 399.5 & 663.4 & 501.9 \\
\hline
\end{tabular}

\begin{tabular}{r|r|r}
\hline 238.4 & 399.5 & 663.4 \\
\hline 74.6 & 222.5 & 221.1 \\
\hline
\end{tabular}

\begin{tabular}{r|r|}
\hline 12.0 & 6.4 \\
\hline 0.5 & 8.3 \\
\hline
\end{tabular}

\begin{tabular}{|r|r|r|}
\hline 14.7 & 6.3 & 4.0 \\
\hline 7.0 & 1.4 & 1.8 \\
\hline
\end{tabular}


USD million (2015 constant)

\section{Table A.7a. Top 20 recipients of aid for trade in 2015, commitments}

\begin{tabular}{|c|c|c|c|c|c|c|c|}
\hline & & & & MITMENTS & & & \\
\hline & Region & Income group & 2002-05 avg. & 2006-08 avg. & 2009-11 avg. & 2012-14 avg. & 2015 \\
\hline India & Asia & LMIC & 1365.5 & 2030.8 & 2346.2 & 4018.7 & 2804.8 \\
\hline Philippines & Asia & LMIC & 290.2 & 208.9 & 539.3 & 592.9 & 2648.9 \\
\hline Bangladesh & Asia & LDC & 724.4 & 749.7 & 1127.5 & 1340.1 & 2424.3 \\
\hline Viet Nam & Asia & LMIC & 1344.0 & 1605.4 & 2115.4 & 2401.6 & 2236.0 \\
\hline Indonesia & Asia & LMIC & 928.5 & 716.5 & 734.3 & 493.1 & 2218.2 \\
\hline Myanmar & Asia & LDC & 9.2 & 14.5 & 32.2 & 663.1 & 2163.3 \\
\hline Pakistan & Asia & LMIC & 547.5 & 654.5 & 729.4 & 1503.0 & 1732.7 \\
\hline Kenya & Africa & OLIC & 282.2 & 440.3 & 1014.9 & 1222.8 & 1662.9 \\
\hline Turkey & Europe & UMIC & 380.5 & 359.2 & 946.9 & 2857.3 & 1642.0 \\
\hline Egypt & Africa & LMIC & 554.1 & 756.6 & 919.4 & 1595.4 & 1521.1 \\
\hline Ethiopia & Africa & LDC & 476.0 & 687.7 & 646.1 & 1203.0 & 1387.4 \\
\hline Afghanistan & Asia & LDC & 756.1 & 1540.6 & 1797.9 & 1592.7 & 1204.1 \\
\hline Tanzania & Africa & $L D C$ & 366.6 & 730.3 & 828.7 & 938.7 & 1042.6 \\
\hline South Africa & Africa & UMIC & 116.9 & 147.2 & 146.4 & 227.4 & 962.7 \\
\hline Morocco & Africa & LMIC & 280.5 & 800.9 & 872.2 & 1570.7 & 931.7 \\
\hline Uganda & Africa & LDC & 238.4 & 399.5 & 663.4 & 501.9 & 813.6 \\
\hline Brazil & America & UMIC & 45.4 & 60.6 & 214.0 & 644.3 & 758.4 \\
\hline Mozambique & Africa & LDC & 312.2 & 429.1 & 407.5 & 579.6 & 689.1 \\
\hline Iraq & Asia & UMIC & 2280.5 & 2093.8 & 401.4 & 332.4 & 619.6 \\
\hline Liberia & Africa & LDC & 0.9 & 71.2 & 189.7 & 259.6 & 603.7 \\
\hline Sub-total & & & 11299.7 & 14497.5 & 16672.6 & 24538.4 & 30067.1 \\
\hline TOTAL AID FOR TRADE & & & 22310.1 & 29343.8 & 38281.2 & 48194.7 & 53878.8 \\
\hline Top 20 share in total AFT & & & $50.6 \%$ & $49.4 \%$ & $43.6 \%$ & $50.9 \%$ & $55.8 \%$ \\
\hline
\end{tabular}

Table A.7b. Top 20 recipients of aid for trade in 2015, disbursements

USD million (2015 constant)

\section{DISBURSEMENTS}

\begin{tabular}{|c|c|c|c|c|c|c|}
\hline & \\
\hline & Region & Income group & $2006-08$ avg. & 2009-11 avg. & 2012-14 avg. & 2015 \\
\hline India & Asia & LMIC & 1098.1 & 1724.0 & 1782.2 & 3085.6 \\
\hline Turkey & Europe & UMIC & 333.4 & 1144.0 & 2429.0 & 2259.0 \\
\hline Viet Nam & Asia & LMIC & 953.1 & 1431.6 & 2351.9 & 2221.0 \\
\hline Pakistan & Asia & LMIC & 330.7 & 412.4 & 1056.6 & 1730.0 \\
\hline Morocco & Africa & LMIC & 384.6 & 695.9 & 1140.0 & 969.5 \\
\hline Kenya & Africa & OLIC & 264.8 & 380.4 & 890.5 & 931.6 \\
\hline Bangladesh & Asia & LDC & 353.6 & 371.2 & 824.1 & 910.1 \\
\hline Indonesia & Asia & LMIC & 688.2 & 716.6 & 522.8 & 878.0 \\
\hline Egypt & Africa & LMIC & 536.2 & 650.9 & 1314.5 & 857.5 \\
\hline Tanzania & Africa & LDC & 372.3 & 583.0 & 845.4 & 852.7 \\
\hline Afghanistan & Asia & LDC & 1017.7 & 1803.2 & 1147.2 & 843.2 \\
\hline Ethiopia & Africa & LDC & 465.8 & 671.4 & 678.2 & 763.6 \\
\hline Brazil & America & UMIC & 70.8 & 226.3 & 468.8 & 661.9 \\
\hline Nigeria & Africa & LMIC & 230.4 & 325.0 & 467.7 & 594.1 \\
\hline South Africa & Africa & UMIC & 181.1 & 153.9 & 196.9 & 594.1 \\
\hline Mozambique & Africa & LDC & 320.4 & 312.0 & 487.4 & 555.6 \\
\hline Ghana & Africa & LMIC & 310.3 & 519.7 & 512.6 & 466.0 \\
\hline Democratic Republic of the Congo & Africa & LDC & 188.8 & 350.8 & 502.4 & 460.7 \\
\hline Uganda & Africa & LDC & 361.2 & 405.6 & 415.3 & 432.4 \\
\hline Senegal & Africa & LDC & 201.9 & 231.1 & 327.9 & 416.9 \\
\hline \multicolumn{3}{|l|}{ Sub-total } & 8663.3 & 13109.0 & 18361.5 & 20483.3 \\
\hline \multicolumn{3}{|l|}{ TOTAL AID FOR TRADE } & 20963.9 & 29339.4 & 35857.5 & 39815.5 \\
\hline \multicolumn{3}{|l|}{ Top 20 share in total AFT } & $41.3 \%$ & $44.7 \%$ & $51.2 \%$ & $51.4 \%$ \\
\hline
\end{tabular}


USD million (2015 constant)

Table A.8. Aid-for-trade regional and global programmes

\begin{tabular}{|c|c|c|c|c|c|c|c|c|c|}
\hline & \multicolumn{5}{|c|}{ COMMITMENTS } & \multicolumn{4}{|c|}{ DISBURSEMENTS } \\
\hline & $2002-05$ avg. & 2006-08 avg. & 2009-11 avg. & 2012-14 avg. & 2015 & $2006-08$ avg. & 2009-11 avg. & 2012-14 avg. & 2015 \\
\hline Africa & 540.6 & 1084.1 & 1797.8 & 1851.2 & 1587.3 & 648.9 & 1634.1 & 1504.0 & 1631.9 \\
\hline America & 175.6 & 361.9 & 438.4 & 477.1 & 401.0 & 253.1 & 396.1 & 479.8 & 273.9 \\
\hline Asia & 166.7 & 329.5 & 397.1 & 502.1 & 450.4 & 305.4 & 322.2 & 407.9 & 450.3 \\
\hline Europe & 49.4 & 209.6 & 152.3 & 97.5 & 216.2 & 170.5 & 194.1 & 104.2 & 223.2 \\
\hline Oceania & 26.5 & 54.1 & 73.8 & 46.0 & 58.9 & 44.1 & 45.3 & 45.2 & 75.3 \\
\hline Non-region specific & 1069.1 & 1903.3 & 3486.0 & 3022.3 & 3722.2 & 1473.5 & 2604.8 & 2561.2 & 3650.5 \\
\hline TOTAL & 2027.9 & 3942.4 & 6345.4 & 5996.1 & 6435.9 & 2895.5 & 5196.5 & 5102.3 & 6305.1 \\
\hline \multicolumn{10}{|l|}{ Share in total } \\
\hline Africa & $26.7 \%$ & $27.5 \%$ & $28.3 \%$ & $30.9 \%$ & $24.7 \%$ & $22.4 \%$ & $31.4 \%$ & $29.5 \%$ & $25.9 \%$ \\
\hline America & $8.7 \%$ & $9.2 \%$ & $6.9 \%$ & $8.0 \%$ & $6.2 \%$ & $8.7 \%$ & $7.6 \%$ & $9.4 \%$ & $4.3 \%$ \\
\hline Asia & $8.2 \%$ & $8.4 \%$ & $6.3 \%$ & $8.4 \%$ & $7.0 \%$ & $10.5 \%$ & $6.2 \%$ & $8.0 \%$ & $7.1 \%$ \\
\hline Europe & $2.4 \%$ & $5.3 \%$ & $2.4 \%$ & $1.6 \%$ & $3.4 \%$ & $5.9 \%$ & $3.7 \%$ & $2.0 \%$ & $3.5 \%$ \\
\hline Oceania & $1.3 \%$ & $1.4 \%$ & $1.2 \%$ & $0.8 \%$ & $0.9 \%$ & $1.5 \%$ & $0.9 \%$ & $0.9 \%$ & $1.2 \%$ \\
\hline Non-region specific & $52.7 \%$ & $48.3 \%$ & $54.9 \%$ & $50.4 \%$ & $57.8 \%$ & $50.9 \%$ & $50.1 \%$ & $50.2 \%$ & $57.9 \%$ \\
\hline
\end{tabular}

Table A.9. Aid for trade regional and global programmes by category

COMMITMENTS

\begin{tabular}{|c|c|c|c|c|c|c|c|c|c|}
\hline & \multicolumn{5}{|c|}{ COMMITMENTS } & \multicolumn{4}{|c|}{ DISBURSEMENTS } \\
\hline & 2002-05 avg. & 2006-08 avg. & 2009-11 avg. & 2012-14 avg. & 2015 & 2006-08 avg. & 2009-11 avg. & 2012-14 avg. & 2015 \\
\hline Trade policy and regulations & 241.3 & 455.8 & 714.6 & 518.8 & 508.1 & 321.7 & 528.9 & 525.6 & 465.9 \\
\hline Economic infrastructure & 441.9 & 863.1 & 1674.1 & 1438.1 & 1111.3 & 453.0 & 1282.4 & 1112.9 & 753.0 \\
\hline Building productive capacity & 1344.7 & 2623.5 & 3953.4 & 4039.0 & 4814.7 & 2120.8 & 3384.8 & 3463.6 & 5085.5 \\
\hline Trade-related adjustment &. & 0.1 & 3.4 & 0.2 & 1.8 & 0.0 & 0.4 & 0.2 & 0.8 \\
\hline TOTAL & 2027.9 & 3942.4 & 6345.4 & 5996.1 & 6435.9 & 2895.5 & 5196.5 & 5102.3 & 6305.1 \\
\hline \multicolumn{10}{|l|}{ Share in total } \\
\hline Trade policy and regulations & $11.9 \%$ & $11.6 \%$ & $11.3 \%$ & $8.7 \%$ & $7.9 \%$ & $11.1 \%$ & $10.2 \%$ & $10.3 \%$ & $7.4 \%$ \\
\hline Economic infrastructure & $21.8 \%$ & $21.9 \%$ & $26.4 \%$ & $24.0 \%$ & $17.3 \%$ & $15.6 \%$ & $24.7 \%$ & $21.8 \%$ & $11.9 \%$ \\
\hline Building productive capacity & $66.3 \%$ & $66.5 \%$ & $62.3 \%$ & $67.4 \%$ & $74.8 \%$ & $73.2 \%$ & $65.1 \%$ & $67.9 \%$ & $80.7 \%$ \\
\hline Trade-related adjustment & .. & $0.0 \%$ & $0.1 \%$ & $0.0 \%$ & $0.0 \%$ & $0.0 \%$ & $0.0 \%$ & $0.0 \%$ & $0.0 \%$ \\
\hline
\end{tabular}


USD million (2015 constant)

Table A.10. Aid-for-trade grants and loans by category

\begin{tabular}{|c|c|c|c|c|c|c|c|c|c|}
\hline & & & DMITMEN & & & & DISBURS & EMENTS & \\
\hline & $2002-05$ avg. & 2006-08 avg. & 2009-11 avg. & 2012-14 avg. & 2015 & $2006-08$ avg. & 2009-11 avg. & 2012-14 avg. & 2015 \\
\hline Trade policy and regula & & & & & & & & & \\
\hline Grants & 653.5 & 958.2 & 1231.4 & 1068.8 & 842.0 & 642.5 & 904.1 & 986.3 & 859.3 \\
\hline Loans & 75.5 & 40.2 & 63.9 & 151.3 & 219.8 & 31.9 & 62.4 & 115.7 & 121.3 \\
\hline Sub-total & 729.0 & 998.4 & 1295.3 & 1220.1 & 1061.8 & 674.3 & 966.5 & 1102.0 & 980.6 \\
\hline Economic infrastructure & & & & & & & & & \\
\hline Grants & 4771.3 & 7014.9 & 7144.2 & 6662.4 & 5969.3 & 4983.4 & 5775.8 & 5977.9 & 5604.0 \\
\hline Loans & 6796.0 & 8656.6 & 13924.7 & 21592.8 & 25815.0 & 5404.9 & 9057.3 & 13582.6 & 15042.3 \\
\hline Sub-total & 11567.4 & 15671.5 & 21068.9 & 28255.3 & 31784.3 & 10388.2 & 14833.1 & 19560.5 & 20646.2 \\
\hline Building productive cap & & & & & & & & & \\
\hline Grants & 5961.6 & 7636.1 & 9777.3 & 9372.7 & 9992.5 & 6486.5 & 8544.1 & 8339.1 & 9656.8 \\
\hline Loans & 4052.2 & 5035.9 & 6119.7 & 9344.5 & 11038.0 & 3407.3 & 4960.6 & 6841.9 & 8518.8 \\
\hline Sub-total & 10013.7 & 12672.0 & 15896.9 & 18717.2 & 21030.5 & 9893.8 & 13504.7 & 15181.0 & 18175.6 \\
\hline Trade-related adjustme & & & & & & & & & \\
\hline Grants &.. & 1.9 & 17.0 & 2.1 & 2.2 & 7.6 & 34.7 & 14.0 & 13.1 \\
\hline Loans & .. & .. & 3.1 & .. & .. & .. & 0.4 & .. & .. \\
\hline Sub-total & .. & 1.9 & 20.1 & 2.1 & 2.2 & 7.6 & 35.1 & 14.0 & 13.1 \\
\hline TOTAL AID FOR TRADE & 22310.1 & 29343.8 & 38281.2 & 48194.7 & 53878.8 & 20963.9 & 29339.4 & 35857.5 & 39815.5 \\
\hline Share in total & & & & & & & & & \\
\hline Total grants & $51.0 \%$ & $53.2 \%$ & $47.5 \%$ & $35.5 \%$ & $31.2 \%$ & $57.8 \%$ & $52.0 \%$ & $42.7 \%$ & $40.5 \%$ \\
\hline Total loans & $49.0 \%$ & $46.8 \%$ & $52.5 \%$ & $64.5 \%$ & $68.8 \%$ & $42.2 \%$ & $48.0 \%$ & $57.3 \%$ & $59.5 \%$ \\
\hline
\end{tabular}

USD million (2015 constant)

Table A.11. Aid-for-trade channels of delivery

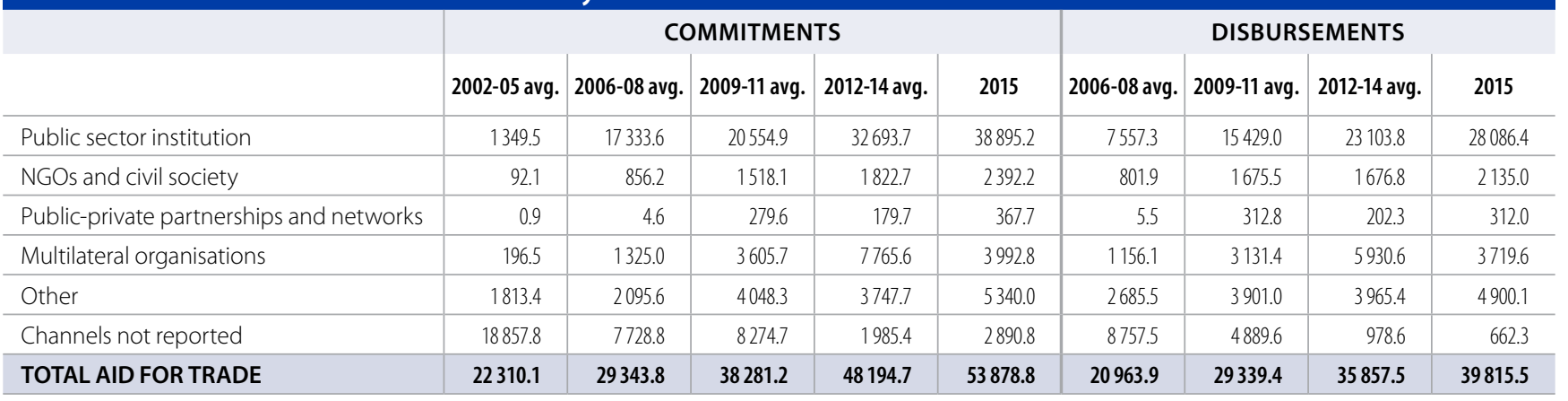

Source: OECD-DAC/CRS aid activity database. 
USD million (2015 constant)

Table A.12. Aid for trade by provider and category, commitments (page 1 of 2)

\section{DAC countries}

Australia

Austria

Belgium

Canada

Czech Republic

Denmark

Finland

France

Germany

Greece

Hungary

Iceland

Ireland

Italy

Japan

Korea

Luxembourg

Netherlands

New Zealand

Norway

Poland

Portugal

Slovak Republic

Slovenia

Spain

Sweden

Switzerland

United Kingdom

United States

Sub-total

Other bilateral

Azerbaijan

Estonia

Kazakhstan

Kuwait (KFAED)

Lithuania

Romania

Turkey

United Arab Emirates

Sub-total

Multilateral

AfDB

Arab Fund (AFESD)

AsDB

BADEA

Caribbean Development Bank

CEB

Climate Investment Funds (CIF)

Enhanced Integrated Framework (EIF)

EU Institutions

$\mathrm{FAO}$

GEF

IDB

IFAD

ILO

Islamic Development Bank

ITC

OFID

UNDP

UNECE

UNESCAP

UNESCWA

UNIDO

World Bank

WTO

Other multilateral donors

Sub-total

TOTAL AID FOR TRADE

Source: OECD-DAC/CRS aid activity database.
TOTAL AID FOR TRADE

2002-05 avg. 2006-08 avg. 2009-11 avg. 2012-14 avg. 2015

TRADE POLICY AND REGULATIONS

2002-05 avg. 2006-08 avg. 2009-11 avg. 2012-14 avg. 2015

\begin{tabular}{|c|c|c|c|c|c|c|c|c|c|}
\hline 193.0 & 291.1 & 463.6 & 361.2 & 386.0 & 9.0 & 5.7 & 26.7 & 17.4 & 36.3 \\
\hline 43.1 & 50.2 & 70.7 & 82.4 & 68.2 & 0.1 & 1.2 & 0.1 & 0.0 & 0.1 \\
\hline 219.0 & 242.4 & 410.7 & 175.6 & 205.0 & 3.7 & 4.6 & 10.0 & 10.2 & 0.7 \\
\hline 323.2 & 354.9 & 545.1 & 497.8 & 713.2 & 18.3 & 19.7 & 29.8 & 16.4 & 34.7 \\
\hline .. & .. & 3.3 & 7.2 & 10.4 & .. & .. & 0.0 & 0.1 & 0.0 \\
\hline 398.3 & 259.6 & 291.9 & 357.8 & 119.8 & 0.4 & 2.8 & 11.0 & 4.9 & 2.0 \\
\hline 76.2 & 122.8 & 282.7 & 127.6 & 89.2 & 2.3 & 6.1 & 11.2 & 7.8 & 21.3 \\
\hline 637.8 & 1364.6 & 1307.0 & 2427.4 & 2842.9 & 4.0 & 2.5 & 1.2 & 3.0 & 9.7 \\
\hline 1164.8 & 1945.2 & 3173.1 & 4653.2 & 5629.1 & 13.1 & 32.7 & 32.3 & 36.7 & 41.4 \\
\hline 11.0 & 16.2 & 15.0 & 0.1 & 0.0 & 0.3 & 0.5 & 0.2 & .. & .. \\
\hline .. & & .. & .. & 0.4 & .. & .. & .. & .. & 0.0 \\
\hline .. & & 2.6 & 9.5 & 6.6 & .. & .. & .. & .. & .. \\
\hline 26.7 & 42.4 & 58.0 & 45.8 & 32.6 & 0.1 & 1.0 & 0.3 & 1.0 & 0.6 \\
\hline 241.2 & 220.9 & 159.3 & 113.4 & 184.2 & 1.7 & 0.4 & 0.1 & 0.1 & 0.2 \\
\hline 4080.1 & 5183.7 & 5580.7 & 7690.4 & 11754.6 & 43.5 & 46.3 & 45.7 & 99.9 & 41.4 \\
\hline .. & 469.0 & 900.2 & 839.5 & 892.0 & .. & 6.8 & 4.2 & 7.8 & 9.2 \\
\hline 16.1 & 30.0 & 32.3 & 37.1 & 32.3 & 0.1 & 0.3 & 1.2 & .. & \\
\hline 514.0 & 661.4 & 671.2 & 831.3 & 588.2 & 16.6 & 58.6 & 132.4 & 82.3 & 126.5 \\
\hline 20.9 & 42.4 & 90.8 & 112.3 & 135.2 & 1.7 & 3.0 & 4.7 & 3.4 & 2.3 \\
\hline 247.4 & 400.8 & 504.7 & 529.2 & 337.6 & 8.9 & 24.8 & 11.2 & 13.4 & 9.8 \\
\hline & .. & & 8.6 & 31.2 & . & .. & .. & & . \\
\hline 41.3 & 26.8 & 48.6 & 26.5 & 24.1 & 0.1 & 0.1 & 0.0 & 0.0 & \\
\hline & .. & .. & 0.6 & 0.9 & .. & .. & .. & 0.0 & 0.0 \\
\hline & .. & 2.0 & 1.1 & 0.1 & .. & .. & 0.4 & 0.0 & \\
\hline 348.4 & 637.2 & 791.3 & 87.1 & 50.4 & 1.2 & 4.0 & 3.2 & 0.5 & 0.0 \\
\hline 219.8 & 318.1 & 322.2 & 364.6 & 285.0 & 15.8 & 31.1 & 48.9 & 35.6 & 34.1 \\
\hline 304.0 & 274.8 & 292.4 & 387.7 & 315.5 & 38.4 & 17.6 & 34.7 & 36.4 & 15.9 \\
\hline 736.1 & 918.6 & 1261.6 & 968.1 & 1724.8 & 27.2 & 63.0 & 140.9 & 63.9 & 32.5 \\
\hline 4147.2 & 5900.2 & 4544.8 & 3363.9 & 3385.2 & 262.7 & 261.7 & 194.4 & 304.8 & 187.6 \\
\hline 14009.8 & 19773.4 & 21825.9 & 24106.9 & 29844.8 & 469.1 & 594.6 & 744.8 & 745.7 & 606.2 \\
\hline
\end{tabular}


USD million (2015 constant)

Table A.12. Aid for trade by provider and category, commitments (page 2 of 2) ECONOMIC INFRASTRUCTURE BUILDING PRODUCTIVE CAPACITY

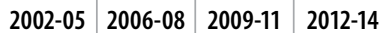
2015 2002-05 2006-08 $2009-11 \mid 2012-14$ 2015 TRADE-RELATED ADJUSTMENT \begin{tabular}{l|c|c|c|} 
avg. & avg. & avg. & avg.
\end{tabular}

DAC countries

Australia

Austria

Belgium

Canada

Czech Republic

Denmark

Finland

\begin{tabular}{|r|r|r|r|r|r|r|r|r|r|}
\hline 65.3 & 135.1 & 229.2 & 150.0 & 171.1 & 118.7 & 150.1 & 207.3 & 193.8 & 178.5 \\
\hline 22.6 & 17.9 & 24.8 & 28.9 & 33.7 & 20.3 & 31.1 & 45.9 & 53.5 & 34.4 \\
\hline 50.3 & 70.5 & 84.8 & 40.7 & 33.7 & 164.9 & 17.3 & 315.9 & 124.7 & 170.7 \\
\hline
\end{tabular}

France

Germany

Greece

Hungary

Iceland

Ireland

Italy

Japan

Luxembourg

Netherlands

New Zealand

Norway

Poland

Portugal

Slovak Republic

Slovenia

Spain

Sweden

Switzerland

United Kingdom

United States

\begin{tabular}{|r|r|r|}
\hline 22.6 & 17.9 \\
\hline 50.3 & 70.5 & 2 \\
43.0 & 72.5 & 8 \\
\hline
\end{tabular}

\begin{tabular}{|l|l|}
\hline 84.8 & 40.7 \\
\hline 89.5 & 91.8 \\
\hline 1.3 & 2.2 \\
\hline
\end{tabular}

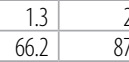

\begin{tabular}{r|r}
9.7 & 18 \\
\hline & 39.2 \\
2.2 & 4.9 \\
\hline
\end{tabular}

\begin{tabular}{r|r}
33.7 \\
39.2
\end{tabular}

\begin{tabular}{|r|r|r|r|r|r|}
\hline 164.9 & 167.3 & 315.9 & 124.7 & 170.7 \\
\hline
\end{tabular}

Sub-total

\begin{tabular}{|r|r|r|r|}
\hline 28.5 & 19.0 & 86.4 & 43.6 \\
\hline 320.7 & 766.8 & 707.4 & 1983.3 \\
\hline 532.3 & 835.6 & 1658.6 & 2341.6 \\
\hline
\end{tabular}

\begin{tabular}{|r|r|}
\hline 2.2 & 4.6 \\
\hline 87.1 & 7.6 \\
\hline
\end{tabular}

\begin{tabular}{|r|r|r|r|r|}
\hline 532.3 & 835.6 & 1658.6 & 2341.6 & 2992.1 \\
\hline
\end{tabular}

\begin{tabular}{|r|r|r|r|r|}
\hline 205.3 & 151.7 & 214.7 & 265.7 & 110.1 \\
\hline
\end{tabular}

Other bilateral

Azerbaijan

Estonia

Kazakhstan

Kuwait (KFAED)

Lithuania

Romania

Turkey

United Arab Emirates

6.3

$6.7 \quad 12.5$

\begin{tabular}{|r|r|r|}
\hline 2.5 & 0.1 & 0.0 \\
\hline.. &.. & 0.0 \\
\hline 0.9 & 3.9 & 3.1 \\
\hline
\end{tabular}

\begin{tabular}{|r|r|r|r|}
\hline 6.9 & 2.6 & 1.3 & 0.3 \\
\hline 141.5 & 110.4 & 47.0 & 28.9 \\
\hline
\end{tabular}

\begin{tabular}{r|r|}
\hline .3 & 0.0 \\
\hline .9 & 59.8 \\
\hline
\end{tabular}

\begin{tabular}{|r|r|r|r|r|}
\hline 3214.5 & 3660.1 & 4700.9 & 6407.8 & 10287.1 \\
\hline & 386.1 & 783.2 & 607.5 & 745.5 \\
\hline
\end{tabular}

\begin{tabular}{|r|r|r|r|r|r|}
\hline 313.2 & 595.3 & 598.5 & 441.1 & 766.5 \\
\hline 619.4 & 1076.8 & 1482.3 & 2274.8 & 2595.6 \\
\hline
\end{tabular}

Multilateral

\begin{tabular}{r|r}
1.1 & 5 \\
\hline 131.2 & 162 \\
\hline 4.1
\end{tabular}

\begin{tabular}{|r|r|r|r|}
\hline 131.2 & 162.7 & 150.1 & 64.8 \\
\hline 4.1 & 14.9 & 43.1 & 49.9 \\
\hline
\end{tabular}

\begin{tabular}{|r|}
\hline 2.5 \\
\hline 51.8 \\
\hline
\end{tabular}

\begin{tabular}{|r|r|r|r|r|}
\hline.. &.. & 1.7 & 5.6 & 3.5 \\
\hline 19.8 & 38.9 & 56.4 & 44.5 & 31.9 \\
\hline 98.1 & 110.1 & 112.2 & 84.4 & 124.2 \\
\hline
\end{tabular}

\begin{tabular}{|r|r|r|r|r|}
\hline 822.2 & 1477.3 & 834.0 & 1182.6 & 1426.1 \\
\hline.. & 76.1 & 112.9 & 224.2 & 137.3 \\
\hline
\end{tabular}

\begin{tabular}{|r|r|r|r|r|}
\hline.. & 76.1 & 112.9 & 224.2 & 137.3 \\
\hline 14.9 & 24.2 & 28.8 & 31.3 & 29.8 \\
\hline 366.3 & 440.2 & 388.7 & 684.2 & 410.0 \\
\hline
\end{tabular}

\begin{tabular}{|r|r|r|r|r|r|r|r|r|r|r|}
\hline 4.1 & 14.9 & 43.1 & 49.9 & 28.5 & 15.1 & 24.5 & 42.9 & 59.0 & 104.3 \\
\hline
\end{tabular}

\begin{tabular}{|r|r|r|r|r|}
86.9 & 148.9 & 195.6 & 195.7 & 44.5 \\
\hline
\end{tabular}

\begin{tabular}{l|l}
151.7 & 227 \\
\hline
\end{tabular}

\begin{tabular}{c|c|c}
$\begin{array}{c}2006-08 \\
\text { avg. }\end{array}$ & $\begin{array}{c}2009-11 \\
\text { avg. }\end{array}$ & $\begin{array}{c}2012-14 \\
\text { avg. }\end{array}$
\end{tabular}

2015

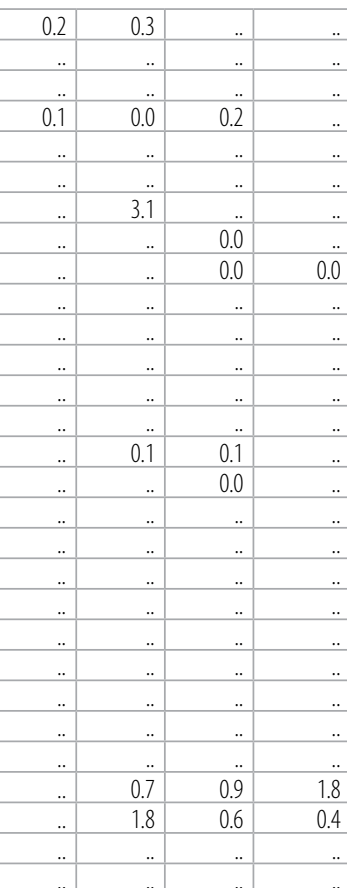

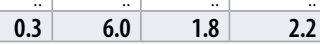

AfDB

Arab Fund (AFESD)

AsDB

BADEA

Caribbean Development Bank

CEB

Climate Investment Funds (CIF)

Enhanced Integrated Framework (EIF)

EU Institutions

$\mathrm{FAO}$

GEF

IDB

IFAD

ILO

IMF

Islamic Development Bank

ITC

OFID

UNDP

UNECE

UNESCAP

UNESCWA

UNIDO

World Bank

WTO

Other multilateral donors

Sub-total

TOTAL

\begin{tabular}{|r|r|r|r|r|r|r|r|r|r|r|}
\hline.. &.. &.. & 0.6 & 2.1 &.. &.. &.. & 8.1 & 29.1 \\
\hline 34.2 & 23.5 & 45.2 & 24.7 & 21.1 & 6.9 & 3.2 & 3.4 & 1.8 & 3.1 \\
\hline.. &.. &.. & 0.1 & 0.2 &.. &.. &.. & 0.5 & 0.7 \\
\hline.. &.. & 0.5 & 0.3 & -0.1 &.. &.. & 1.2 & 0.7 & 0.2 \\
\hline 100.1 & 392.3 & 248.0 & 6.3 & 14.6 & 135.1 & 240.8 & 540.0 & 80.4 & 35.9 \\
\hline 41.2 & 87.6 & 63.8 & 50.3 & 128.2 & 103.9 & 199.3 & 208.8 & 277.8 & 120.8 \\
\hline 301.9 & 172.6 & 45.0 & 66.1 & 59.3 & 224.4 & 208.7 & 210.9 & 284.5 & 239.9 \\
\hline 1923.0 & 3134.2 & 1898.3 & 391.0 & 303.1 & 407.0 & 682.7 & 711.4 & 513.2 & 1389.3 \\
\hline $\mathbf{4 6 0 . 3}$ & $\mathbf{1 0 3 7 9 . 4}$ & $\mathbf{1 1 5 9 5 . 8}$ & $\mathbf{1 3 7 9 9 . 3}$ & $\mathbf{1 8 3 1 2 . 2}$ & $\mathbf{6 0 8 0 . 3}$ & $\mathbf{8 7 9 9 . 0}$ & $\mathbf{9 4 7 9 . 2}$ & $\mathbf{9 5 6 0 . 0}$ & $\mathbf{1 0 9 2 4 . 1}$ \\
\hline
\end{tabular}
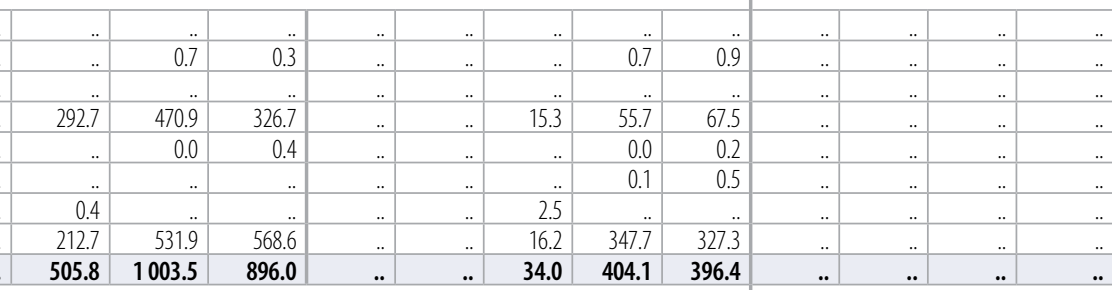

Source: OECD-DAC/CRS aid activity database

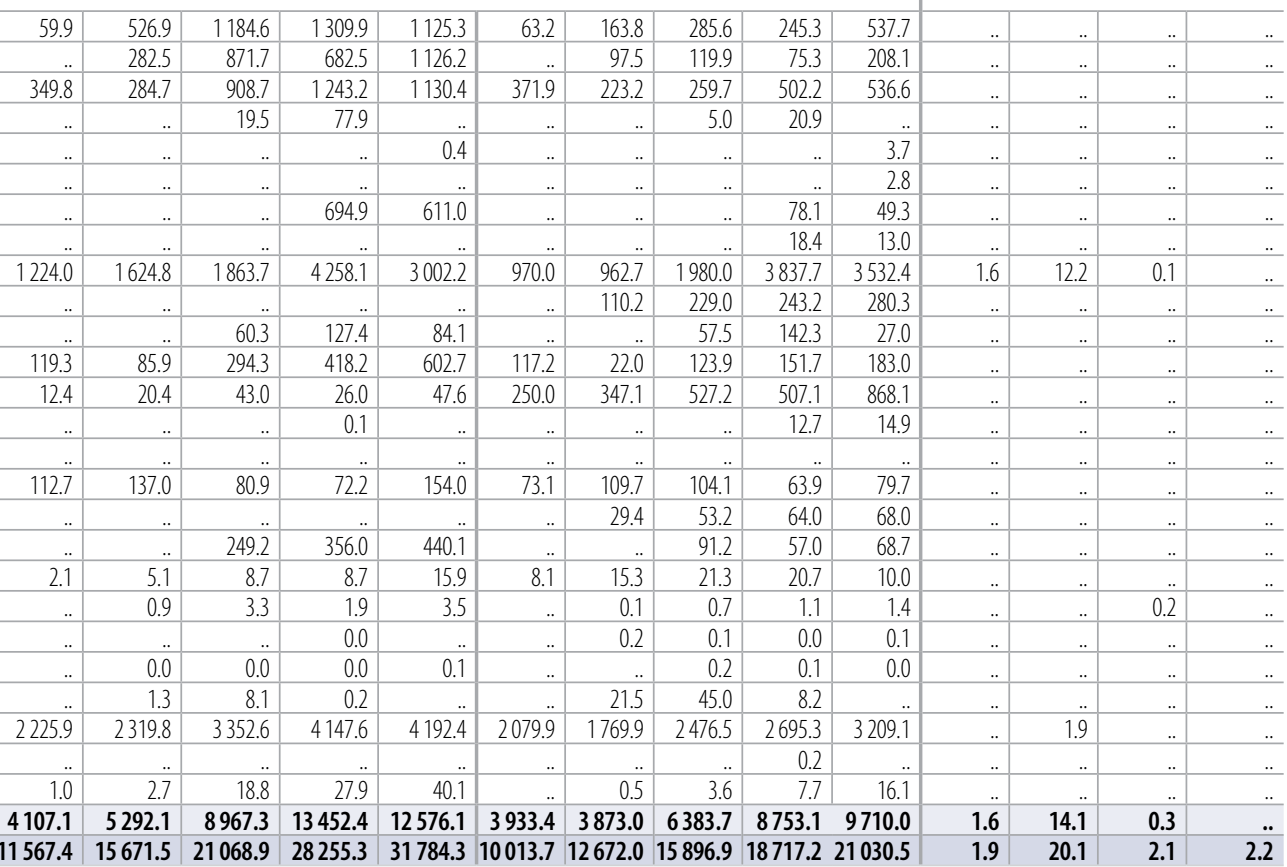


USD million (2015 constant)

Table A.13. Aid for trade by provider and by category, disbursements (page 1 of 2)

TOTAL AID FOR TRADE

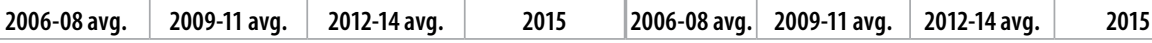

DAC countries

\begin{tabular}{|c|c|c|c|c|c|c|c|c|}
\hline \\
\hline Australia & 237.4 & 366.8 & 361.2 & 386.0 & 5.3 & 11.2 & 17.4 & 36.3 \\
\hline Austria & 36.8 & 57.0 & 56.1 & 45.5 & 1.2 & 0.1 & 0.0 & 0.0 \\
\hline Belgium & 167.3 & 363.8 & 194.1 & 203.9 & 3.6 & 8.7 & 6.7 & 1.8 \\
\hline Canada & 269.1 & 558.5 & 435.6 & 342.7 & 14.6 & 29.8 & 20.7 & 18.2 \\
\hline Czech Republic & & 3.2 & 7.3 & 10.3 & & 0.0 & 0.1 & 0.0 \\
\hline Denmark & 250.8 & 318.1 & 323.8 & 258.6 & 0.6 & 3.2 & 12.1 & 4.7 \\
\hline Finland & 59.2 & 132.1 & 150.3 & 151.1 & 5.1 & 6.7 & 7.2 & 8.3 \\
\hline France & 814.4 & 1060.4 & 1694.7 & 1467.6 & 2.1 & 3.4 & 2.5 & 4.2 \\
\hline Germany & 1600.6 & 2447.5 & 3043.3 & 4965.7 & 23.0 & 26.7 & 30.5 & 36.1 \\
\hline Greece & 16.2 & 15.0 & 0.1 & 0.0 & 0.5 & 0.2 & .. & \\
\hline Hungary & .. & .. & 1.9 & 0.4 & .. & .. & .. & 0.0 \\
\hline Iceland & & 2.6 & 9.5 & 6.6 & 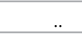 & & 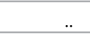 & \\
\hline Ireland & 42.4 & 58.0 & 45.8 & 32.6 & 1.0 & 0.3 & 1.0 & 0.6 \\
\hline Italy & 231.9 & 138.0 & 84.2 & 194.9 & 0.3 & 0.2 & 0.1 & 0.1 \\
\hline Japan & 3698.6 & 4374.4 & 5457.5 & 5938.4 & 43.8 & 45.2 & 87.9 & 49.5 \\
\hline Korea & 192.0 & 357.1 & 496.0 & 587.6 & 9.4 & 6.8 & 8.2 & 6.9 \\
\hline Luxembourg & 30.0 & 32.3 & 37.1 & 32.3 & 0.3 & 1.2 & & \\
\hline Netherlands & 459.2 & 455.9 & 594.4 & 523.3 & 41.8 & 52.9 & 81.9 & 62.0 \\
\hline New Zealand & 28.8 & 49.7 & 91.2 & 106.6 & 2.4 & 2.9 & 3.8 & 4.3 \\
\hline Norway & 380.3 & 385.3 & 485.9 & 481.7 & 15.9 & 16.2 & 11.6 & 11.6 \\
\hline Poland & & & 8.7 & 31.1 & & & & .. \\
\hline Portugal & 33.9 & 50.0 & 39.2 & 22.4 & 0.1 & 0.0 & 0.0 & .. \\
\hline Slovak Republic & .. & .. & 0.5 & 0.8 & .. & .. & 0.0 & 0.0 \\
\hline Slovenia & & 2.0 & 0.8 & 0.5 & .. & 0.4 & 0.0 & .. \\
\hline Spain & 445.9 & 782.7 & 108.0 & 67.5 & 3.9 & 2.9 & 0.3 & 0.2 \\
\hline Sweden & 320.0 & 337.4 & 386.8 & 329.1 & 25.0 & 41.0 & 41.8 & 45.7 \\
\hline Switzerland & 253.9 & 232.4 & 306.0 & 383.0 & 24.9 & 22.3 & 39.9 & 33.5 \\
\hline United Kingdom & 942.4 & 1341.7 & 1471.6 & 2234.0 & 48.7 & 125.3 & 101.8 & 82.1 \\
\hline United States & 4262.6 & 4192.4 & 3442.5 & 2836.6 & 147.3 & 198.6 & 260.3 & 194.5 \\
\hline Sub-total & 14773.7 & 18114.3 & 19334.0 & 21640.8 & 421.0 & 606.2 & 735.6 & 600.7 \\
\hline \multicolumn{9}{|l|}{ Other bilateral } \\
\hline Azerbaijan & .. & .. & 0.1 & 0.2 & .. & .. & 0.1 & 0.1 \\
\hline Estonia & .. & .. & 0.9 & 1.3 & .. & .. & 0.0 & 0.0 \\
\hline Kazakhstan & .. & & 0.1 & 0.7 & .. & .. & .. & .. \\
\hline Kuwait (KFAED) & .. & 246.6 & 265.7 & 403.6 & .. & .. & .. & ... \\
\hline Lithuania & .. & .. & 0.0 & 0.6 & .. & .. & 0.0 & 0.1 \\
\hline Romania & .. & & 0.3 & 0.5 & .. & .. & .. & 0.0 \\
\hline Turkey & .. & 38.3 & & & .. & 35.4 & .. & .. \\
\hline United Arab Emirates & .. & 87.0 & 694.5 & 886.4 & .. & & 3.4 & .. \\
\hline Sub-total & .. & 371.9 & 961.6 & 1293.2 & .. & 35.4 & 3.4 & 0.2 \\
\hline \multicolumn{9}{|l|}{ Multilateral } \\
\hline AfDB & 371.4 & 1182.4 & 990.3 & 1223.1 & 0.4 & 0.6 & 0.1 & .. \\
\hline Arab Fund (AFESD) & 228.6 & 683.8 & 661.0 & 486.9 & .. & 0.3 & .. & .. \\
\hline AsDB & .. & 477.8 & 1234.5 & 1553.4 & .. & 3.2 & 4.2 & 3.9 \\
\hline BADEA & .. & 14.7 & 62.8 & 61.0 & .. & .. & .. & .. \\
\hline Caribbean Development Bank & .. & & & & .. & .. & .. & .. \\
\hline CEB & & 12.4 & 2.0 & 1.4 & .. & .. & .. & \\
\hline Climate Investment Funds (CIF) & & & 64.1 & 207.7 & .. & & & \\
\hline Enhanced Integrated Framework (EIF) & & 10.0 & 15.8 & 7.5 & & 10.0 & 9.5 & 3.7 \\
\hline EU Institutions & 2134.7 & 3716.5 & 6469.3 & 6269.7 & 188.9 & 193.3 & 179.7 & 182.4 \\
\hline FAO & 128.8 & 268.6 & 267.7 & 312.7 & 18.6 & 39.6 & 24.5 & 32.4 \\
\hline GEF & 64.3 & 94.3 & 124.0 & 162.5 & .. & & & \\
\hline IDB & .. & 348.3 & 555.6 & 514.7 & .. & 5.1 & 9.1 & 14.6 \\
\hline \multicolumn{9}{|l|}{ IFAD } \\
\hline ILO & & .. & 12.8 & 14.9 & .. & ... & & .. \\
\hline IMF & & .. & 0.7 & .. & .. & .. & 0.7 & .. \\
\hline Islamic Development Bank & & & & & .. &.. & .. & .. \\
\hline ITC & 28.9 & 50.9 & 57.2 & 65.4 & .. & .. & .. & .. \\
\hline OFID & & 165.1 & 220.9 & 294.2 & - & 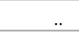 & & \\
\hline UNDP & 2.1 & 6.6 & 36.1 & 51.9 & 2.9 & 2.9 & 0.8 & 0.0 \\
\hline UNECE & 22.8 & 32.8 & 30.2 & 25.9 & 0.3 & 0.1 & 0.2 & 0.2 \\
\hline UNESCAP & 1.3 & 4.1 & 3.4 & 5.1 & 0.1 & 0.4 & 0.5 & 0.6 \\
\hline UNESCWA & 0.2 & 0.5 & 0.5 & 0.7 & 0.1 & 0.0 & 0.1 & 0.2 \\
\hline UNIDO & 0.1 & 0.2 & 0.3 & 0.3 & & & & \\
\hline World Bank & & & & & 28.9 & 54.2 & 121.9 & 130.1 \\
\hline WTO & 3194.7 & 3769.1 & 4741.0 & 5611.0 & 12.4 & 15.3 & 11.6 & 11.5 \\
\hline Other multilateral donors & 12.4 & 15.3 & 11.8 & 11.5 & 0.8 & 0.2 & & \\
\hline Sub-total & 6190.2 & 10853.2 & 15561.9 & 16881.5 & 253.3 & 325.0 & 362.9 & 379.7 \\
\hline TOTAL AID FOR TRADE & 20963.9 & 29339.4 & 35857.5 & 39815.5 & 674.3 & 966.5 & 1102.0 & 980.6 \\
\hline
\end{tabular}


USD million (2015 constant)

Table A.13. Aid for trade by provider and by category, disbursements (page 2 of 2)

\begin{tabular}{|c|c|c|c|c|c|c|c|c|c|c|c|}
\hline \multicolumn{4}{|c|}{ ECONOMIC INFRASTRUCTURE } & \multicolumn{4}{|c|}{ BUILDING PRODUCTIVE CAPACITY } & \multicolumn{4}{|c|}{ TRADE-RELATED ADJUSTMENT } \\
\hline avg. & $\begin{array}{c}2009-11 \\
\text { avg. }\end{array}$ & $\begin{array}{c}2012-14 \\
\text { avg. }\end{array}$ & 2015 & $\begin{array}{c}2006-08 \\
\text { avg. }\end{array}$ & $\begin{array}{c}2009-11 \\
\text { avg. }\end{array}$ & $\begin{array}{c}2012-14 \\
\text { avg. }\end{array}$ & 2015 & $\begin{array}{c}2006-08 \\
\text { avg. }\end{array}$ & & & \\
\hline
\end{tabular}

\section{DAC countries}

\begin{tabular}{|c|c|c|c|c|c|c|c|c|c|c|c|c|}
\hline Australia & 98.3 & 164.3 & 150.0 & 171.1 & 133.6 & 191.0 & 193.8 & 178.5 & 0.2 & 0.3 & & \\
\hline Austria & 8.9 & 14.2 & 14.1 & 17.7 & 26.7 & 42.6 & 42.0 & 27.8 & -1 & .. & & \\
\hline Belgium & 30.7 & 78.9 & 43.9 & 39.4 & 133.1 & 276.3 & 143.4 & 162.7 & & & & \\
\hline Canada & 46.3 & 116.5 & 90.3 & 40.8 & 208.2 & 412.2 & 324.7 & 283.7 & 0.0 & 0.0 & & \\
\hline Czech Republic & & 1.3 & 2.3 & 4.6 & & 1.9 & 4.9 & 5.7 & & & & \\
\hline Denmark & 123.9 & 121.1 & 99.5 & 42.8 & 126.3 & 193.8 & 212.2 & 211.0 & .. & & & \\
\hline Finland & 12.5 & 32.2 & 44.5 & 37.4 & 41.6 & 92.8 & 98.6 & 105.4 & ... & 0.4 & & \\
\hline France & 325.2 & 547.3 & 1237.9 & 1083.4 & 487.1 & 509.7 & 454.2 & 380.0 & .. & 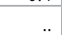 & 0.0 & \\
\hline Germany & 593.6 & 1175.0 & 1298.4 & 2307.0 & 984.1 & 1245.8 & 1713.9 & 2622.2 & .. & & 0.5 & 0.4 \\
\hline Greece & 6.7 & 12.5 & 0.1 & 0.0 & 9.0 & 2.3 & & & & & .. & \\
\hline Hungary & .. & & 0.0 & 0.0 & .. & 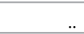 & 1.9 & 0.4 & .. & & .. & \\
\hline Iceland & & 0.9 & 3.9 & 3.1 & & 1.7 & 5.6 & 3.5 & ... & .. & .. & \\
\hline Ireland & 2.6 & 1.3 & 0.3 & 0.0 & 38.9 & 56.4 & 44.5 & 31.9 & ... & .. & .. & \\
\hline Italy & 139.8 & 64.4 & 29.7 & 61.6 & 91.8 & 73.4 & 54.5 & 133.1 & .. & & 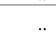 & \\
\hline Japan & 2630.4 & 3279.0 & 4313.8 & 4703.4 & 1024.4 & 1050.0 & 1055.7 & 1185.5 & .. & 0.1 & 0.1 & \\
\hline Korea & 131.2 & 278.9 & 371.0 & 439.7 & 51.3 & 71.4 & 116.8 & 141.0 & ... & . & 0.0 & \\
\hline Luxembourg & 5.4 & 2.3 & 5.7 & 2.5 & 24.2 & 28.8 & 31.3 & 29.8 & .. & .. & .. & \\
\hline Netherlands & 109.7 & 123.9 & 96.9 & 48.0 & 307.6 & 279.1 & 415.6 & 413.2 & .. & 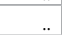 & .. & \\
\hline New Zealand & 7.8 & 21.4 & 47.1 & 36.9 & 18.6 & 25.4 & 40.3 & 65.4 & ... & & .. & \\
\hline Norway & 193.9 & 143.4 & 196.2 & 120.6 & 170.5 & 225.7 & 278.1 & 349.5 & ... & .. & .. & \\
\hline Poland & & & 0.6 & 2.1 & & & 8.1 & 29.0 & .. & .. & .. & \\
\hline Portugal & 30.6 & 46.6 & 37.4 & 19.5 & 3.2 & 3.4 & 1.8 & 2.9 & ... & .. & .. & \\
\hline Slovak Republic & .. & & 0.1 & 0.1 & .. & & 0.4 & 0.6 & .. & 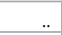 & .. & \\
\hline Slovenia & & 0.5 & 0.4 & 0.0 & & 1.1 & 0.4 & 0.5 & ... & ... & ... & \\
\hline Spain & 240.9 & 329.6 & 16.7 & 11.0 & 201.1 & 450.2 & 91.0 & 56.3 & .. & & ... & \\
\hline Sweden & 86.2 & 82.6 & 89.1 & 109.2 & 208.7 & 213.8 & 255.7 & 173.4 & ... & 0.0 & 0.2 & 0.8 \\
\hline Switzerland & 41.8 & 29.6 & 49.6 & 41.2 & 187.3 & 179.6 & 216.4 & 308.1 & .. & 0.9 & 0.1 & 0.2 \\
\hline United Kingdom & 146.1 & 422.7 & 556.1 & 411.1 & 747.5 & 793.7 & 813.7 & 1740.8 & ... & .. & .. & \\
\hline United States & 2085.8 & 1830.1 & 1197.0 & 827.3 & 2029.5 & 2163.7 & 1985.3 & 1814.8 & & & & \\
\hline Sub-total & 7098.1 & 8920.4 & 9992.7 & 10581.7 & 7254.4 & 8586.1 & 8605.0 & 10457.0 & 0.2 & 1.7 & 0.8 & 1.4 \\
\hline
\end{tabular}

\section{Other bilateral}

Azerbaijan

Estonia

Kazakhstan

Kuwait (KFAED)

Lithuania

Romania

Turkey

United Arab Emirates

Sub-total

Multilateral

AfDB

Arab Fund (AFESD)

AsDB

BADEA

Caribbean Development Bank

CEB

Climate Investment Funds (CIF)

Enhanced Integrated Framework (EIF)

EU Institutions

FAO

GEF

IFAD

ILO

IMF

Islamic Development Bank

ITC

OFID

UNDP

UNECE

UNESCAP

UNESCWA

UNIDO

World Bank

WTO

Other multilateral donors

Sub-total

\begin{tabular}{r|r|r|r|}
.. &.. & 0.0 & 0.1 \\
\hline. &.. & 0.5 & 0.4 \\
.. &.. & 0.1 & 0.5 \\
.. & 223.3 & 222.3 & 380.0 \\
\hline. &.. & 0.0 & 0.3 \\
.. &.. &.. &.. \\
.. & 0.4 &.. &.. \\
.. & 71.3 & 265.1 & 617.1 \\
\hline. & 295.1 & 488.1 & 998.3 \\
\hline
\end{tabular}
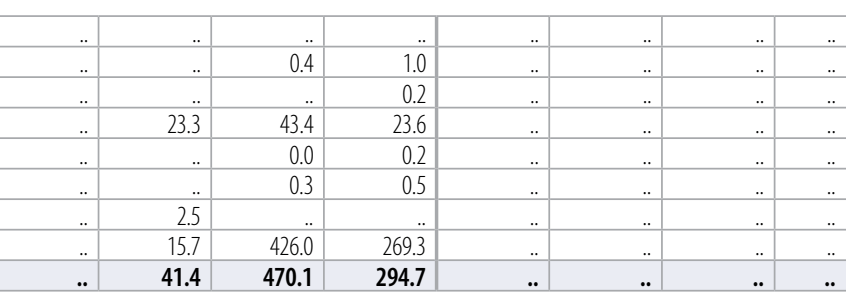

TOTAL

\begin{tabular}{|c|c|c|c|}
\hline 173.1 & 544.4 & 792.3 & 1049.8 \\
\hline 201.8 & 580.0 & 552.3 & 389.1 \\
\hline .. & 329.6 & 856.1 & 1159.6 \\
\hline & 9.5 & 52.1 & 51.6 \\
\hline ... & .. & & \\
\hline & 12.4 & 2.0 & \\
\hline & .. & 61.8 & 202.3 \\
\hline & & & \\
\hline 1190.6 & 1828.1 & 3285.3 & 2560.6 \\
\hline \multirow{8}{*}{8.8} & 160 & 240 & $\ddot{77}$ \\
\hline & 207.6 & 3725 & 3971 \\
\hline & .. & .. & \\
\hline & .. & 0.1 & \\
\hline & .. & .. &.. \\
\hline & .. & .. & .. \\
\hline & & .. & \\
\hline & 120.7 & 170.0 & 219.7 \\
\hline 5.0 & 8.7 & 8.7 & 15.9 \\
\hline \multirow[t]{2}{*}{0.9} & 3.3 & 1.9 & 3.5 \\
\hline & & 0.0 & \\
\hline 0.0 & 0.0 & 0.0 & 0.0 \\
\hline 1708.7 & 1950.8 & 28625 & 29316 \\
\hline & & & \\
\hline 1.2 & 5.6 & 27.8 & 41.7 \\
\hline 3290.2 & 5617.6 & 9079.8 & 9066.2 \\
\hline 10388.2 & 14833.1 & 19560.5 & 20646.2 \\
\hline
\end{tabular}

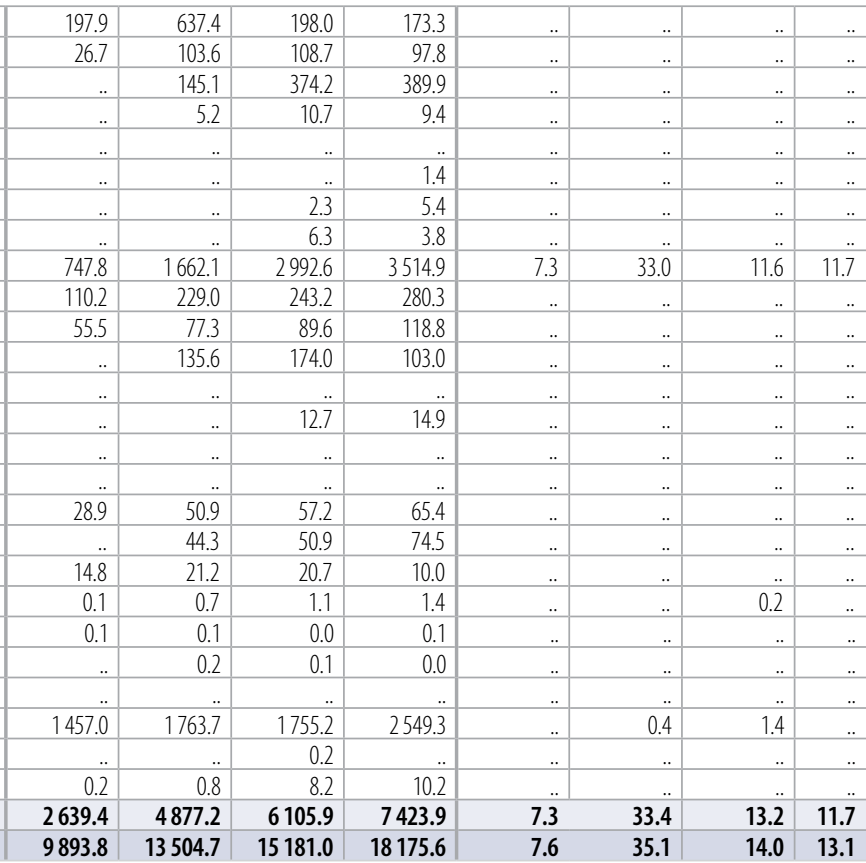

Source: OECD-DAC/CRS aid activity database.

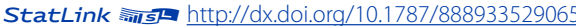




\section{DAC countries}

Australia

Austria

Belgium

Canada

Czech Republic

Denmark

Finland

France

Germany

Greece

Hungary

Iceland

Ireland

Italy

Japan

Luxembourg

Netherlands

New Zealand

Norway

Poland

Portugal

Slovak Republic

Slovenia

Spain

Sweden

Switzerland

United Kingdom

United States

Sub-total

Other bilateral

Azerbaijan

Estonia

Kazakhstan

Kuwait (KFAED)

Lithuania

Romania

Turkey

United Arab Emirates

\section{Sub-total}

Multilateral

AfDB

Arab Fund (AFESD)

AsDB

BADEA

Caribbean Development Bank

CEB

Climate Investment Funds (CIF)

Enhanced Integrated Framework (EIF)

EU Institutions

FAO

GEF

IDB

IFAD

ILO

IMF

Islamic Development Bank

ITC

OFID

UNDP

UNECE

UNESCAP

UNESCWA

UNIDO

World Bank

WTO

Other multilateral donors

Sub-total

TOTAL AID FOR TRADE

Source: OECD-DAC/CRS aid activity database.
AFRICA

2002-05 avg. 2006-08 avg. 2009-11 avg. 2012-14 avg. 2015

\begin{tabular}{|r|r|r|r|r|}
\hline 9.6 & 0.6 & 21.1 & 30.9 & 11.5 \\
\hline 8.7 & 14.1 & 17.6 & 30.4 & 23.4 \\
\hline 106.2 & 155.4 & 214.9 & 110.7 & 140.7 \\
\hline 135.2 & 113.5 & 240.5 & 229.6 & 344.7 \\
\hline.. &.. & 0.6 & 1.0 & 1.2 \\
\hline 226.1 & 159.5 & 209.6 & 210.6 & 88.6 \\
\hline 20.3 & 46.0 & 149.4 & 51.8 & 60.8 \\
\hline 364.7 & 769.8 & 710.5 & 1244.7 & 1359.5 \\
\hline 359.6 & 403.4 & 709.7 & 1404.8 & 1820.2 \\
\hline 0.7 & 0.9 & 0.7 &.. &.. \\
\hline.. &.. &.. &.. & 0.0 \\
\hline 21.7 & 29.1 & 1.2 & 4.3 & 2.4 \\
\hline 131.8 & 91.7 & 22.0 & 34.1 & 28.1 \\
\hline 291.1 & 807.6 & 869.3 & 64.7 & 84.5 \\
\hline.. & 71.2 & 222.0 & 186.7 & 1695.6 \\
\hline 7.4 & 16.2 & 11.3 & 15.9 & 134.7 \\
\hline 78.2 & 100.8 & 102.1 & 208.0 & 300.8 \\
\hline 0.2 & 0.1 & 0.8 & 5.9 & 1.3 \\
\hline 117.3 & 169.9 & 270.5 & 298.1 & 75.7 \\
\hline.. &.. &.. & 6.6 & 27.0 \\
\hline 22.9 & 24.6 & 47.0 & 24.7 & 23.1 \\
\hline.. &.. &.. & 0.4 & 0.6 \\
\hline.. &.. & 0.0 &.. &.. \\
\hline 102.9 & 288.3 & 343.3 & 28.1 & 9.7 \\
\hline 82.7 & 137.4 & 124.6 & 102.8 & 141.1 \\
\hline 72.5 & 67.6 & 59.4 & 146.1 & 117.0 \\
\hline 235.8 & 292.6 & 568.9 & 391.1 & 430.3 \\
\hline 580.2 & 1493.3 & 1230.6 & 936.9 & 1176.9 \\
\hline 2975.9 & 5253.6 & $\mathbf{6 1 9 0 . 7}$ & $\mathbf{6 7 0 2 . 5}$ & $\mathbf{8} 109.8$ \\
\hline & & & & \\
\hline
\end{tabular}

2002-05 avg. 2006-08 avg. 2009-11 avg. 2012-14 avg.

2015

\section{AMERICA}

\begin{tabular}{|l|l|l|l|l|}
\hline 0.2 & 0.2 & 2.9 & 3.7 & 0.2 \\
\hline
\end{tabular}

\begin{tabular}{|r|r|r|r|r}
\hline 0.2 & 0.2 & 2.9 & 3.7 & 0.2 \\
\hline 4.4 & 5.1 & 6.4 & 5.8 & 2.5 \\
\hline 42.0 & 31.8 & 43.1 & 13.5 & 13.6 \\
\hline 61.5 & 88.5 & 105.9 & 138.2 & 161.7 \\
\hline.. &.. & 0.1 & 0.0 & 0.0 \\
\hline 36.9 & 5.2 & 15.3 & 15.5 & 1.7 \\
\hline 10.7 & 8.8 & 27.7 & 15.2 & 0.7 \\
\hline 28.0 & 52.5 & 172.0 & 417.5 & 212.7 \\
\hline 82.3 & 246.5 & 342.0 & 727.3 & 671.7 \\
\hline.. & 0.0 &.. &.. &.. \\
\hline.. &.. &.. &.. &.. \\
\hline 0.6 & 2. & 0.2 & 0.4 &.. \\
\hline 36.3 & 11.5 & 19.1 & 1.9 & 1.7 \\
\hline 88.4 & 193.4 & 154.2 & 331.8 & 23.9 \\
\hline.. & 14.8 & 85.1 & 61.0 & 209.5 \\
\hline 38.4 & 3.3 & 3.6 & 3.3 & 3.5 \\
\hline 0.5 & 1.9 & 23.6 & 4.5 & 0.7 \\
\hline 18.7 & 17.9 & 0.5 & 2.8 & 6.8 \\
\hline.. &.. & 35.6 & 25.9 & 5.3 \\
\hline 0.2 & 0.0 &.. & 0.0 & 0.0 \\
\hline.. &.. &.. & 0.2 & 0.2 \\
\hline.. &.. &.. & 0.0 &.. \\
\hline 87.3 & 110.5 & 189.9 & 4.0 &.. \\
\hline 13.0 & 8.2 & 13.9 & 15.4 & 38.4 \\
\hline 47.2 & 40.1 & 41.2 & 33.8 & 10.9 \\
\hline 69.3 & 19.9 & 66.2 & 84.0 & 113.0 \\
\hline 293.9 & 531.3 & 426.6 & 301.7 & 465.8 \\
\hline 961.6 & 1430.5 & 1779.2 & 2259.3 & 2034.7 \\
\hline & & & & \\
\hline
\end{tabular}


USD million (2015 constant)

Table A.14. Aid for trade by provider and by region, commitments (page 2 of 3)

ASIA

2002-05 avg. 2006-08 avg. 2009-11 avg. $2012-14$ avg. 2015

DAC countries

\begin{tabular}{|c|c|c|c|c|c|}
\hline Australia & 90.2 & 145.7 & 267.9 & 183.8 & 200.0 \\
\hline Austria & 26.0 & 15.4 & 15.0 & 31.3 & 16.5 \\
\hline Belgium & 28.9 & 17.8 & 30.8 & 11.8 & 5.0 \\
\hline Canada & 113.1 & 116.8 & 86.9 & 102.0 & 182.8 \\
\hline Czech Republic & .. & .. & 1.5 & 3.4 & 4.7 \\
\hline Denmark & 111.3 & 81.5 & 43.1 & 100.6 & 10.1 \\
\hline Finland & 32.0 & 37.0 & 53.6 & 24.4 & 5.4 \\
\hline France & 160.0 & 327.4 & 195.3 & 530.4 & 1119.6 \\
\hline Germany & 558.2 & 903.9 & 1135.0 & 1650.2 & 2001.9 \\
\hline Greece & 2.8 & 4.3 & 1.2 & 0.0 & 0.0 \\
\hline Hungary & .. & .. & .. & .. & 0.3 \\
\hline Iceland & .. & .. & .. & .. & .. \\
\hline Ireland & 2.1 & 7.8 & 5.6 & 2.9 & 1.0 \\
\hline Italy & 28.1 & 62.4 & 99.8 & 28.2 & 38.5 \\
\hline Japan & 3357.1 & 4029.1 & 4227.7 & 6060.1 & 9371.5 \\
\hline Korea & .. & 374.7 & 587.0 & 580.4 & 683.7 \\
\hline Luxembourg & 3.0 & 4.4 & 5.9 & 4.5 & 5.2 \\
\hline Netherlands & 98.4 & 68.0 & 46.8 & 29.1 & 8.9 \\
\hline New Zealand & 6.9 & 8.8 & 19.5 & 20.8 & 46.0 \\
\hline Norway & 61.0 & 103.3 & 73.8 & 75.5 & 21.9 \\
\hline Poland & & .. & .. & 0.5 & 0.5 \\
\hline Portugal & 2.6 & 1.5 & 0.8 & 0.4 & 0.1 \\
\hline Slovak Republic & & .. & .. & 0.0 & 0.0 \\
\hline Slovenia & & .. & 0.1 & 0.0 & .. \\
\hline Spain & 91.5 & 93.1 & 72.5 & 7.3 & 1.6 \\
\hline Sweden & 55.3 & 47.3 & 31.9 & 45.0 & 12.6 \\
\hline Switzerland & 105.3 & 85.7 & 81.0 & 110.9 & 85.2 \\
\hline United Kingdom & 312.8 & 380.1 & 437.7 & 270.8 & 230.5 \\
\hline United States & 2957.3 & 3534.5 & 2402.8 & 1667.4 & 1304.0 \\
\hline Sub-total & 8204.0 & 10450.6 & 9923.3 & 11541.7 & 15357.8 \\
\hline
\end{tabular}

Other bilateral

\begin{tabular}{l|}
\hline Azerbaijan \\
\hline Estonia \\
\hline Kazakhstan \\
\hline Kuwait (KFAED) \\
\hline Lithuania \\
\hline Romania \\
\hline Turkey \\
\hline United Arab Emirates \\
\hline Sub-total
\end{tabular}

\begin{tabular}{|r|r|r|r|r|}
\hline. &.. &.. &.. &.. \\
\hline. &.. &.. & 0.6 & 0.5 \\
\hline. &.. &.. &.. &.. \\
\hline. &.. & 103.7 & 127.6 & 109.1 \\
\hline. &.. &.. & 0.0 & 0.3 \\
\hline. &.. &.. &.. & 0.1 \\
\hline.. &.. & 36.7 &.. &.. \\
\hline.. &.. & 134.6 & 246.0 & 427.6 \\
\hline. &.. & $\mathbf{2 7 5 . 0}$ & $\mathbf{3 7 4 . 2}$ & $\mathbf{5 3 7 . 5}$ \\
\hline
\end{tabular}

Sub-total

AfDB

Arab Fund (AFESD)

AsDB

BADEA

Caribbean Development Bank

CEB

Climate Investment Funds (CIF)

Enhanced Integrated Framework (EIF)

EU Institutions

$\mathrm{FAO}$

GEF

IFAD

IMF

Islamic Development Bank

ITC

OFID

UNDP

UNECE

UNESCAP

UNESCWA

UNIDO

World Bank

WTO

Other multilateral donors

Sub-total

TOTAL AID FOR TRADE

Source: OECD-DAC/CRS aid activity database.
EUROPE

2002-05 avg. 2006-08 avg. $2009-11$ avg. $2012-14$ avg. 2015 
USD million (2015 constant)

Table A.14. Aid for trade by provider and by region, commitments (page 3 of 3)

OCEANIA

2002-05 avg. 2006-08 avg. 2009-11 avg. $2012-14$ avg. 2015

\section{DAC countries}

\begin{tabular}{|c|c|c|c|c|c|c|c|c|c|c|}
\hline \\
\hline Australia & 89.2 & 101.4 & 95.7 & 98.6 & 140.4 & 3.9 & 43.3 & 76.1 & 44.3 & 33.8 \\
\hline Austria & 0.0 & 0.1 & 0.3 & 0.1 & & 1.2 & 4.4 & 16.4 & 11.4 & 16.0 \\
\hline Belgium & 0.0 & & 0.0 & & & 40.3 & 34.9 & 121.0 & 39.5 & 45.6 \\
\hline Canada & 0.2 & 0.0 & 1.3 & 0.1 & 0.2 & 12.0 & 26.7 & 98.6 & 10.2 & 10.7 \\
\hline Czech Republic & .. & .. & .. & .. & .. & & & 0.0 & 0.2 & 0.1 \\
\hline Denmark & .. & .. & .. & .. & .. & 23.9 & 12.6 & 6.6 & 19.7 & 9.2 \\
\hline Finland & & 0.0 & 0.0 & 0.1 & & 10.7 & 28.5 & 46.9 & 34.8 & 21.7 \\
\hline France & 11.1 & 3.0 & 6.1 & 6.6 & 3.6 & 54.6 & 91.5 & 198.2 & 188.5 & 133.0 \\
\hline Germany & 1.5 & 0.6 & 2.5 & 1.6 & 17.2 & 67.4 & 131.7 & 607.0 & 345.6 & 548.1 \\
\hline Greece & .. & 0.0 & .. & .. & .. & .. & 0.4 & 0.2 & .. & \\
\hline Hungary & .. & .. & .. & .. & .. & .. & .. & ... & & 0.0 \\
\hline Iceland & & & .. & & & & & 1.2 & 4.8 & 4.2 \\
\hline Ireland & 0.0 & .. & .. & .. & & 2.1 & 2.4 & 5.4 & 6.9 & 1.8 \\
\hline Italy & & & & 0.5 & 0.7 & 3.2 & 0.5 & 0.2 & 2.6 & 34.5 \\
\hline Japan & 36.3 & 96.7 & 43.0 & 93.3 & 395.3 & 40.2 & 43.6 & 46.3 & 80.8 & 74.6 \\
\hline Korea & & 1.1 & 2.0 & 2.0 & 3.5 & & 3.5 & 3.6 & 8.8 & 16.4 \\
\hline Luxembourg & & .. & .. & 0.0 & .. & 0.8 & 3.5 & 8.4 & 11.7 & 13.1 \\
\hline Netherlands & 0.1 & & & & & 282.8 & 441.9 & 497.3 & 589.7 & 277.8 \\
\hline New Zealand & 12.7 & 31.3 & 68.9 & 81.6 & 81.0 & 0.5 & 0.8 & 1.1 & 1.2 & \\
\hline Norway & 0.0 & 0.0 & .. & .. & .. & 30.1 & 90.0 & 109.3 & 118.0 & 226.0 \\
\hline Poland & & .. & .. & .. & .. & & & & 0.4 & 0.4 \\
\hline Portugal & .. & .. & .. & .. & .. & 1.4 & 0.7 & 0.7 & 1.1 & 0.7 \\
\hline \multicolumn{11}{|l|}{ Slovak Republic } \\
\hline Slovenia & & .. & .. & .. & .. & & & 0.2 & 0.3 & 0.0 \\
\hline Spain & 0.0 & .. & .. & .. & .. & 7.8 & 12.2 & 131.1 & 0.7 & 0.8 \\
\hline Sweden &.. & .. & .. & .. & .. & 42.8 & 101.6 & 124.1 & 183.7 & 92.0 \\
\hline Switzerland & & & & & .. & 50.8 & 55.8 & 84.6 & 70.1 & 45.7 \\
\hline United Kingdom & 8.1 & 0.8 & 0.8 & 0.0 & .. & 103.4 & 219.1 & 186.2 & 220.8 & 949.8 \\
\hline United States & 4.7 & 28.3 & 14.1 & 1.4 & 3.4 & 160.8 & 169.3 & 224.1 & 374.0 & 360.0 \\
\hline Sub-total & 164.0 & 263.4 & 234.7 & 286.0 & 645.2 & 940.6 & 1518.9 & 2594.7 & 2369.5 & 2916.0 \\
\hline \multicolumn{11}{|l|}{ Other bilateral } \\
\hline Azerbaijan & .. & .. & .. & .. & .. & .. & .. & .. & .. & .. \\
\hline Estonia & .. & .. & ... & .. & .. & .. & .. & .. & 0.2 & \\
\hline Kazakhstan & .. & .. & .. & .. & .. & .. & .. & .. & .. & ... \\
\hline Kuwait (KFAED) & .. & .. & .. & .. & .. & .. & .. & 0.0 & .. & 1.0 \\
\hline Lithuania & .. & .. & .. & & .. & & & .. & ... & 0.0 \\
\hline Romania & .. & .. & & & & .. & ... & & ... & 0.0 \\
\hline Turkey & .. & .. & 0.1 & .. & & .. & .. & 0.0 & .. & .. \\
\hline United Arab Emirates & .. & .. & 1.5 & 14.9 & 20.5 & .. & ... & 1.3 & 2.4 & \\
\hline Sub-total & .. & .. & 1.6 & 14.9 & 20.5 & .. & .. & 1.3 & 2.6 & 1.0 \\
\hline \multicolumn{11}{|l|}{ Multilateral } \\
\hline \multicolumn{11}{|l|}{ AfDB } \\
\hline Arab Fund (AFESD) & & & & & & ... & 0.0 & 5.4 & 1.3 & \\
\hline AsDB & 23.3 & 18.2 & 99.0 & 62.5 & 52.7 & .. & .. & .. & .. & \\
\hline \multicolumn{11}{|l|}{ BADEA } \\
\hline Caribbean Development Bank & .. & .. & .. & .. & .. & .. & .. & .. & .. & \\
\hline CEB & .. & .. & .. & & 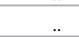 & .. & & .. & & \\
\hline Climate Investment Funds (CIF) & .. & .. & .. & 4.5 & 8.9 & .. & .. & .. & 11.6 & 145.0 \\
\hline Enhanced Integrated Framework (EIF) & & & 0.4 & 2.2 & 3.7 & & & .. & & \\
\hline EU Institutions & 34.4 & 21.8 & 38.5 & 47.3 & 22.2 & 125.7 & 210.5 & 515.4 & 258.2 & 233.2 \\
\hline FAO & .. & .. & & & & .. & 128.8 & 268.6 & 267.7 & 312.7 \\
\hline GEF & .. & .. & 3.2 & 6.2 & 9.9 & .. & .. & 19.1 & 18.5 & 24.1 \\
\hline IDB & .. & .. & & & & .. & & .. & .. & \\
\hline IFAD & .. & .. & 4.7 & 7.3 & 4.5 & .. & .. & .. & .. & \\
\hline ILO & .. & .. & .. & 0.1 & 0.1 & .. & ... & .. & 9.6 & 10.0 \\
\hline IMF & .. & 0.2 & 0.6 & 0.2 & .. & & 0.2 & & & \\
\hline Islamic Development Bank & .. & .. & .. & .. & .. & 2.7 & 8.0 & 6.6 & 3.5 & 1.8 \\
\hline ITC & & .. & & .. & .. & .. & 29.4 & 53.2 & 64.0 & 68.0 \\
\hline OFID & & & 3.5 & & & & & 0.8 & 1.1 & 1.2 \\
\hline UNDP & 0.2 & 0.2 & 0.1 & 0.0 & 0.1 & .. & & 3.6 & 3.0 & 0.4 \\
\hline UNECE & .. & .. & .. & .. & .. & .. & & .. & .. &.. \\
\hline UNESCAP & & .. & & .. & .. & .. & 0.2 & .. & & \\
\hline UNESCWA & .. & .. & .. & .. & .. & .. & 0.0 & 0.2 & 0.1 & .. \\
\hline UNIDO & & .. & & & & ... & 3.3 & 9.8 & 1.7 & .. \\
\hline World Bank & 5.0 & 31.6 & 69.6 & 106.4 & 65.0 & & & & & \\
\hline WTO & & 0.3 & 0.2 & 0.2 & 0.0 & & 3.5 & 7.3 & 7.1 & 6.2 \\
\hline Other multilateral donors & 0.1 & 0.0 & 0.0 & 0.1 & 0.6 & & 0.5 & 0.1 & 2.8 & 2.5 \\
\hline Sub-total & 62.9 & 72.1 & 219.8 & 237.2 & 167.8 & 128.4 & 384.3 & 890.0 & 650.2 & 805.2 \\
\hline TOTAL AID FOR TRADE & 227.0 & 335.5 & 456.1 & 538.1 & 833.6 & 1069.1 & 1903.3 & 3486.0 & 3022.3 & 3722.2 \\
\hline
\end{tabular}

Source: OECD-DAC/CRS aid activity database.

NON-REGION SPECIFIC

2002-05 avg. 2006-08 avg. 2009-11 avg. 2012-14 avg. 2015

StatLink न्ञाIs http://dx.doi.org/10.1787/888933529084 
USD million (2015 constant)

Table A.15. Aid for trade by provider and by region, disbursements (page 1 of 3 )

AFRICA

AMERICA

\begin{tabular}{|l|l|l|l|l|l|l|r|} 
2006-08 avg. & $2009-11$ avg. & $2012-14$ avg. & 2015 & $2006-08$ avg. & $2009-11$ avg. & $2012-14$ avg. & 2015
\end{tabular}

\section{DAC countries}

\begin{tabular}{|c|c|c|c|c|c|c|c|c|}
\hline Australia & 2.7 & 18.9 & 30.9 & 11.5 & 0.2 & 2.9 & 3.7 & 0.2 \\
\hline Austria & 12.7 & 14.2 & 14.5 & 17.3 & 4.9 & 6.5 & 3.5 & 2.3 \\
\hline Belgium & 87.5 & 163.1 & 123.4 & 131.8 & 26.7 & 47.7 & 24.1 & 20.3 \\
\hline Canada & 97.0 & 236.0 & 193.8 & 170.8 & 50.4 & 101.8 & 124.9 & 92.4 \\
\hline Czech Republic & & 0.6 & 1.0 & 1.2 & & 0.1 & 0.0 & 0.0 \\
\hline Denmark & 162.7 & 208.1 & 202.9 & 134.3 & 25.9 & 21.5 & 11.7 & 13.7 \\
\hline Finland & 18.8 & 52.2 & 78.2 & 92.5 & 6.8 & 17.5 & 15.0 & 9.7 \\
\hline France & 417.2 & 493.4 & 816.2 & 744.1 & 53.2 & 109.6 & 379.1 & 221.5 \\
\hline Germany & 460.1 & 477.7 & 774.0 & 1397.4 & 179.4 & 346.0 & 566.4 & 477.2 \\
\hline Greece & 0.9 & 0.7 & & & 0.0 & .. & .. & 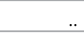 \\
\hline Hungary & & & 0.0 & 0.0 & .. & & & \\
\hline Iceland & & 1.2 & 4.3 & 2.4 & ... & 0.2 & 0.4 & \\
\hline Ireland & 29.1 & 43.1 & 34.1 & 28.1 & 2.8 & 3.9 & 1.9 & 1.7 \\
\hline Italy & 142.9 & 45.2 & 34.9 & 55.7 & 19.2 & 13.6 & 5.9 & 9.1 \\
\hline Japan & 487.8 & 600.7 & 783.6 & 1142.1 & 152.2 & 197.1 & 91.8 & 92.4 \\
\hline Korea & 35.8 & 56.2 & 136.6 & 134.4 & 21.9 & 17.4 & 28.6 & 41.7 \\
\hline Luxembourg & 16.2 & 11.3 & 15.9 & 10.3 & 3.3 & 3.6 & 3.3 & 3.5 \\
\hline Netherlands & 85.0 & 89.3 & 168.1 & 154.6 & 31.6 & 33.4 & 10.6 & 2.7 \\
\hline New Zealand & 0.1 & 0.5 & 1.8 & 3.9 & 0.8 & 0.8 & 0.9 & 4.3 \\
\hline Norway & 123.9 & 187.3 & 219.0 & 165.6 & 74.1 & 40.6 & 66.5 & 9.9 \\
\hline Poland & & & 6.6 & 27.0 & & & 0.0 & 0.0 \\
\hline Portugal & 22.5 & 47.5 & 37.4 & 21.3 & 0.0 & 0.1 & 0.2 & 0.2 \\
\hline Slovak Republic & .. & .. & 0.4 & 0.6 & .. & .. & 0.0 & .. \\
\hline Slovenia & & 0.0 & & & & & 0.0 & \\
\hline Spain & 138.8 & 319.4 & 48.0 & 30.7 & 115.5 & 164.5 & 42.3 & 32.3 \\
\hline Sweden & 132.1 & 120.5 & 124.8 & 145.9 & 14.8 & 12.4 & 13.7 & 7.1 \\
\hline Switzerland & 65.7 & 47.8 & 92.3 & 124.5 & 37.8 & 38.7 & 33.3 & 43.9 \\
\hline United Kingdom & 322.8 & 591.9 & 673.4 & 692.1 & 23.8 & 69.6 & 90.3 & 79.2 \\
\hline United States & 521.6 & 1046.4 & 1232.2 & 986.5 & 288.3 & 459.1 & 327.9 & 276.9 \\
\hline Sub-total & 3383.9 & 4873.4 & 5848.1 & 6426.5 & 1133.7 & 1708.8 & 1846.3 & 1442.2 \\
\hline \multicolumn{9}{|l|}{ Other bilateral } \\
\hline Azerbaijan & ... & .. & & 0.0 & ... & .. & .. & \\
\hline Estonia & .. & .. & 0.1 & 0.1 & .. & .. & .. & 0.0 \\
\hline \multicolumn{9}{|l|}{ Kazakhstan } \\
\hline Kuwait (KFAED) & .. & 177.5 & 186.2 & 290.0 & & 4.5 & 7.6 & 4.2 \\
\hline \multicolumn{9}{|l|}{ Lithuania } \\
\hline Romania & .. & & & 0.1 & .. & .. & .. & .. \\
\hline Turkey & .. & 0.5 & & & .. & .. & .. & .. \\
\hline United Arab Emirates & .. & 28.8 & 548.0 & 368.5 & & & & \\
\hline Sub-total & .. & 206.8 & 734.3 & 658.6 & .. & 4.5 & 7.6 & 4.2 \\
\hline \multicolumn{9}{|l|}{ Multilateral } \\
\hline AfDB & 371.4 & 1182.4 & 990.3 & 1223.1 & .. & .. & .. & .. \\
\hline Arab Fund (AFESD) & 151.6 & 472.3 & 485.0 & 427.4 & ... & .. & .. & .. \\
\hline \multicolumn{9}{|l|}{ AsDB } \\
\hline BADEA & & 14.7 & 62.8 & 61.0 & .. & .. & .. & .. \\
\hline Caribbean Development Bank &.. & .. & .. & .. & .. & .. & .. & .. \\
\hline CEB & .. & .. & . & .. & .. & .. & .. & . \\
\hline Climate Investment Funds (CIF) & .. & & 45.1 & 200.0 & .. & .. & 0.7 & 4.8 \\
\hline Enhanced Integrated Framework (EIF) & & 5.6 & 10.7 & 6.5 & .. & 0.1 & 0.1 & \\
\hline EU Institutions & 1315.9 & 1468.7 & 2350.7 & 1938.3 & 261.3 & 385.7 & 387.7 & 610.5 \\
\hline \multicolumn{9}{|l|}{$\mathrm{FAO}$} \\
\hline GEF & 33.5 & 47.3 & 33.1 & 35.8 & 10.4 & 17.0 & 24.1 & 29.6 \\
\hline IDB & .. & .. & .. & .. & .. & 348.3 & 555.6 & 514.7 \\
\hline IFAD & .. & .. & .. & .. & .. & .. & .. & 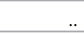 \\
\hline ILO &.. & .. & 1.0 & 1.1 & .. & .. & 1.3 & 2.2 \\
\hline IMF & .. & .. & 0.3 & .. & .. & .. & 0.2 & .. \\
\hline Islamic Development Bank & .. & .. & .. & .. & .. & .. & .. & \\
\hline \multicolumn{9}{|l|}{ ITC } \\
\hline OFID & & 89.8 & 107.2 & 137.0 & .. & 22.4 & 42.9 & 61.0 \\
\hline UNDP & 12.1 & 15.3 & 16.0 & 15.8 & 0.6 & 0.6 & 1.3 & 2.0 \\
\hline UNECE & .. & .. & .. & .. & .. & .. & .. & .. \\
\hline UNESCAP & .. & .. & . & .. & .. & .. & .. & .. \\
\hline UNESCWA & .. & .. & 0.0 & .. & .. & .. & .. & \\
\hline \multicolumn{9}{|l|}{ UNIDO } \\
\hline World Bank & 1656.3 & 2125.3 & 2646.5 & 2909.1 & 69.8 & 94.5 & 104.1 & 140.6 \\
\hline WTO & 4.4 & 4.1 & 2.0 & 1.7 & 2.5 & 1.6 & 0.9 & 1.4 \\
\hline Other multilateral donors & 1.5 & 3.4 & 12.4 & 28.5 & 0.1 & 1.0 & 11.3 & 7.9 \\
\hline Sub-total & 3546.7 & 5428.9 & 6763.2 & 6985.4 & 344.6 & 871.3 & 1130.3 & 1374.7 \\
\hline TOTAL AID FOR TRADE & 6930.5 & 10509.0 & 13345.6 & 14070.4 & 1478.2 & 2584.5 & 2984.2 & 2821.1 \\
\hline
\end{tabular}

Source: OECD-DAC/CRS aid activity database. 
USD million (2015 constant)

Table A.15. Aid for trade by provider and region, disbursements (page 2 of 3 )

ASIA

EUROPE

\begin{tabular}{|l|l|l|l|l|l|l|l|}
\hline 2006-08 avg. & $2009-11$ avg. & $2012-14$ avg. & 2015 & $2006-08$ avg. & $2009-11$ avg. & $2012-14$ avg. & 2015 \\
\hline
\end{tabular}

\section{DAC countries}

\begin{tabular}{|c|c|c|c|c|c|c|c|c|}
\hline Australia & 108.5 & 176.6 & 183.8 & 200.0 & 0.0 & & & \\
\hline Austria & 4.6 & 10.1 & 19.9 & 9.8 & 10.8 & 14.4 & 5.1 & 4.7 \\
\hline Belgium & 17.4 & 30.6 & 11.9 & 5.5 & 2.5 & 0.9 & 0.0 & 0.1 \\
\hline Canada & 98.2 & 111.0 & 89.4 & 57.0 & 6.6 & 10.7 & 17.0 & 11.5 \\
\hline Czech Republic & & 1.5 & 3.4 & 4.7 & & 1.0 & 2.6 & 4.3 \\
\hline Denmark & 53.3 & 69.5 & 81.1 & 60.2 & 0.1 & 6.5 & 12.4 & 20.8 \\
\hline Finland & 14.3 & 28.7 & 25.7 & 25.0 & 1.1 & 3.0 & 2.8 & 1.9 \\
\hline France & 162.2 & 188.7 & 290.7 & 360.8 & 76.0 & 63.1 & 18.2 & 3.6 \\
\hline Germany & 682.5 & 914.0 & 1099.5 & 1899.5 & 168.3 & 241.4 & 347.0 & 629.3 \\
\hline Greece & 4.3 & 1.2 & 0.0 & 0.0 & 10.5 & 12.9 & 0.0 & \\
\hline Hungary & .. & ... & 0.1 & 0.3 & ... & .. & 0.1 & 0.0 \\
\hline Iceland & & & & & & & 0.0 & 0.0 \\
\hline Ireland & 7.8 & 5.6 & 2.9 & 1.0 & 0.2 & 0.0 & & \\
\hline Italy & 44.2 & 38.9 & 28.5 & 77.8 & 24.7 & 40.1 & 11.8 & 19.4 \\
\hline Japan & 2778.4 & 3173.8 & 4332.2 & 4501.8 & 167.6 & 295.6 & 116.1 & 60.8 \\
\hline Korea & 115.9 & 262.1 & 319.6 & 394.5 & 13.8 & 16.3 & 0.7 & 0.6 \\
\hline Luxembourg & 4.4 & 5.9 & 4.5 & 5.2 & 2.5 & 3.0 & 1.7 & 0.2 \\
\hline Netherlands & 72.1 & 55.5 & 27.4 & 21.7 & 14.0 & 8.2 & 0.1 & \\
\hline New Zealand & 6.7 & 8.4 & 17.7 & 25.1 & & & & \\
\hline Norway & 90.7 & 68.0 & 60.4 & 51.0 & 16.2 & 13.9 & 10.3 & 10.5 \\
\hline Poland & & & 0.6 & 0.5 & & & 1.1 & 3.3 \\
\hline Portugal & 1.5 & 0.8 & 0.4 & 0.1 & 9.2 & 0.9 & 0.1 & 0.1 \\
\hline Slovak Republic & 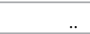 & & 0.0 & 0.0 & .. & & 0.1 & 0.2 \\
\hline Slovenia & & 0.1 & 0.0 & & .. & 1.7 & 0.5 & 0.5 \\
\hline Spain & 80.2 & 86.0 & 13.2 & 3.5 & 98.8 & 78.5 & 0.5 & 0.5 \\
\hline Sweden & 50.3 & 41.4 & 43.6 & 40.0 & 24.4 & 33.6 & 27.8 & 31.5 \\
\hline Switzerland & 73.2 & 67.0 & 90.5 & 120.9 & 22.8 & 21.0 & 26.5 & 20.0 \\
\hline United Kingdom & 406.8 & 493.5 & 363.8 & 387.0 & 7.4 & 1.7 & 1.4 & 0.9 \\
\hline United States & 3137.7 & 2314.9 & 1434.9 & 1107.6 & 141.2 & 140.8 & 162.3 & 134.1 \\
\hline Sub-total & 8015.2 & 8153.7 & 8545.9 & 9360.8 & 818.8 & 1009.1 & 766.2 & 958.9 \\
\hline \multicolumn{9}{|l|}{ Other bilateral } \\
\hline Azerbaijan & .. & .. & & & .. & .. & & 0.0 \\
\hline Estonia & & & 0.4 & 0.6 & .. & .. & 0.3 & 0.5 \\
\hline Kazakhstan & ... & & 0.0 & 0.4 & .. & .. & & \\
\hline Kuwait (KFAED) & .. & 62.4 & 65.4 & 82.7 & .. & 2.3 & 6.5 & 26.7 \\
\hline Lithuania & .. & .. & 0.0 & 0.1 & .. & .. & 0.0 & 0.4 \\
\hline Romania & .. & & & 0.1 & .. & & 0.3 & 0.4 \\
\hline Turkey & .. & 36.7 & & & .. & 1.0 & ... & \\
\hline United Arab Emirates & .. & 56.9 & 124.3 & 475.3 & .. & & 14.4 & 16.8 \\
\hline Sub-total & .. & 155.9 & 190.1 & 559.1 & .. & 3.2 & 21.6 & 44.8 \\
\hline \multicolumn{9}{|l|}{ Multilateral } \\
\hline \multicolumn{9}{|l|}{ AfDB } \\
\hline Arab Fund (AFESD) & 76.7 & 207.7 & 173.0 & 59.5 & .. & .. & .. & .. \\
\hline $\mathrm{AsDB}$ & .. & 461.7 & 1152.9 & 1474.8 & .. & .. & .. & \\
\hline \multicolumn{9}{|l|}{ BADEA } \\
\hline Caribbean Development Bank & .. & .. & .. & .. & .. & & .. & \\
\hline CEB & .. & .. & .. & .. & .. & 12.4 & 2.0 & 1.4 \\
\hline Climate Investment Funds (CIF) & .. & & 18.1 & 2.6 & .. & .. & .. & .. \\
\hline Enhanced Integrated Framework (EIF) & & 4.2 & 4.3 & 0.5 & & & & \\
\hline EU Institutions & 199.6 & 284.6 & 386.2 & 813.7 & 239.8 & 1420.0 & 3212.0 & 2774.4 \\
\hline \multicolumn{9}{|l|}{$\mathrm{FAO}$} \\
\hline GEF & 13.1 & 18.7 & 39.5 & 60.6 & 0.5 & 2.1 & 7.9 & 11.4 \\
\hline IDB & .. & .. & .. & .. & .. & .. & .. & .. \\
\hline IFAD & .. & .. & & .. & .. & .. & & \\
\hline ILO & .. & .. & 0.7 & 1.6 & .. & ... & 0.1 & 0.1 \\
\hline IMF & .. & .. & 0.1 & .. & .. & .. & .. & .. \\
\hline Islamic Development Bank & ... & & .. & .. & .. & ... & .. & \\
\hline \multicolumn{9}{|l|}{ ITC } \\
\hline OFID & & 45.7 & 57.8 & 88.9 & .. & 6.8 & 8.7 & 5.0 \\
\hline UNDP & 9.3 & 12.5 & 8.9 & 6.9 & 0.6 & 0.6 & 0.8 & 0.6 \\
\hline UNECE & 0.0 & 0.1 & 0.2 & & 1.3 & 4.0 & 3.3 & 5.1 \\
\hline UNESCAP & 0.1 & 0.5 & 0.5 & 0.7 & .. & .. & .. & .. \\
\hline UNESCWA & 0.0 & & 0.2 & 0.3 & .. & .. & .. & \\
\hline \multicolumn{9}{|l|}{ UNIDO } \\
\hline World Bank & 1379.4 & 1449.4 & 1905.3 & 2467.3 & 86.0 & 78.6 & 41.7 & 24.9 \\
\hline WTO & 1.4 & 2.0 & 1.6 & 2.2 & 0.4 & 0.1 & 0.0 & 0.0 \\
\hline Other multilateral donors & 0.1 & 2.0 & 9.3 & 11.7 & & 0.0 & 0.2 & 0.5 \\
\hline Sub-total & 1679.7 & 2489.2 & 3758.6 & 4991.2 & 328.5 & 1524.6 & 3276.7 & 2823.4 \\
\hline TOTAL AID FOR TRADE & 9694.9 & 10798.9 & 12494.6 & 14911.1 & 1147.2 & 2536.9 & 4064.5 & 3827.1 \\
\hline
\end{tabular}

Source: OECD-DAC/CRS aid activity database. 
USD million (2015 constant)

Table A.15. Aid for trade by provider and by region, disbursements (page 3 of 3 )

OCEANIA

NON-REGION SPECIFIC

\begin{tabular}{l|l|l|l|l|l|l|l|}
\hline 2006-08 avg. & $2009-11$ avg. & $2012-14$ avg. & 2015 & $2006-08$ avg. & $2009-11$ avg. & $2012-14$ avg. & 2015 \\
\hline
\end{tabular}

\section{DAC countries}

\begin{tabular}{|c|c|c|c|c|c|c|c|c|}
\hline Australia & 100.5 & 102.2 & 98.6 & 140.4 & 25.6 & 66.2 & 44.3 & 33.8 \\
\hline Austria & 0.1 & 0.3 & 0.0 & 0.1 & 3.8 & 11.4 & 13.1 & 11.4 \\
\hline Belgium & & 0.0 & & 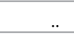 & 33.2 & 121.5 & 34.7 & 46.4 \\
\hline Canada & 0.0 & 1.0 & 0.4 & 0.2 & 16.9 & 98.1 & 10.1 & 10.8 \\
\hline Czech Republic & .. & .. & .. & .. & & 0.0 & 0.2 & 0.1 \\
\hline Denmark & & & & .. & 8.9 & 12.4 & 15.7 & 29.6 \\
\hline Finland & 0.0 & 0.0 & 0.1 & & 18.3 & 30.7 & 28.5 & 22.0 \\
\hline France & 5.5 & 6.2 & 5.8 & 5.9 & 100.2 & 199.5 & 184.6 & 131.7 \\
\hline Germany & 0.3 & 0.9 & 2.1 & 17.8 & 110.1 & 467.5 & 254.3 & 544.4 \\
\hline Greece & 0.0 & .. & .. & .. & 0.4 & 0.2 & & \\
\hline Hungary & .. & .. & .. & .. & .. & & 1.7 & 0.0 \\
\hline Iceland & .. & .. & .. & .. & & 1.2 & 4.8 & 4.2 \\
\hline Ireland & & .. & & & 2.4 & 5.4 & 6.9 & 1.8 \\
\hline Italy & 0.1 & & 0.5 & 0.7 & 0.8 & 0.2 & 2.7 & 32.2 \\
\hline Japan & 69.3 & 61.5 & 53.6 & 66.9 & 43.4 & 45.7 & 80.3 & 74.4 \\
\hline Korea & 1.1 & 1.8 & 1.8 & 2.5 & 3.5 & 3.3 & 8.8 & 13.9 \\
\hline Luxembourg & & .. & 0.0 & .. & 3.5 & 8.4 & 11.7 & 13.1 \\
\hline Netherlands & 0.0 & & & & 256.5 & 269.4 & 388.2 & 344.3 \\
\hline New Zealand & 20.6 & 39.1 & 69.8 & 72.7 & 0.5 & 0.9 & 1.0 & 0.6 \\
\hline Norway & 0.0 & .. & .. & .. & 75.3 & 75.6 & 129.7 & 244.6 \\
\hline Poland & .. & .. & .. & .. & & & 0.4 & 0.3 \\
\hline Portugal & .. & .. & .. & .. & 0.7 & 0.7 & 1.1 & 0.7 \\
\hline \multicolumn{9}{|l|}{ Slovak Republic } \\
\hline Slovenia & ... & .. & .. & .. & ... & 0.2 & 0.3 & 0.1 \\
\hline Spain & e & & .. & .. & 12.6 & 134.4 & 4.0 & 0.5 \\
\hline Sweden & 0.0 & 0.0 & .. & .. & 98.4 & 129.6 & 176.9 & 104.6 \\
\hline Switzerland & & 0.0 & & .. & 54.4 & 57.9 & 63.3 & 73.7 \\
\hline United Kingdom & 1.0 & 0.8 & 0.0 & & 180.6 & 184.2 & 342.7 & 1074.7 \\
\hline United States & 12.0 & 27.1 & 0.9 & 0.7 & 161.7 & 204.1 & 284.3 & 330.7 \\
\hline Sub-total & 210.6 & 240.9 & 233.6 & 307.9 & 1211.7 & 2128.5 & 2094.0 & 3144.6 \\
\hline \multicolumn{9}{|l|}{ Other bilateral } \\
\hline Azerbaijan & .. & .. &.. & .. & .. & & 0.1 & 0.1 \\
\hline Estonia & & & .. & & & & 0.1 & 0.1 \\
\hline Kazakhstan & .. & .. & .. & .. & .. & & 0.0 & 0.3 \\
\hline Kuwait (KFAED) & .. & .. & .. & ... & ... & 0.0 & 0.0 & \\
\hline Lithuania & .. & ... & .. & .. & .. & .. & .. & 0.0 \\
\hline Romania & .. & & & & & & & 0.0 \\
\hline Turkey & .. & 0.1 & & & ... & 0.0 & 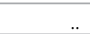 & - \\
\hline United Arab Emirates & .. & & 4.4 & 25.8 & .. & 1.3 & 3.4 & \\
\hline Sub-total & .. & 0.1 & 4.4 & 25.8 & .. & 1.3 & 3.6 & 0.6 \\
\hline \multicolumn{9}{|l|}{ Multilateral } \\
\hline \multicolumn{9}{|l|}{ AfDB } \\
\hline Arab Fund (AFESD) & .. & & & & 0.4 & 3.8 & 2.9 & .. \\
\hline AsDB & .. & 16.1 & 81.7 & 78.7 & .. & .. & .. & .. \\
\hline BADEA & .. & .. & .. & .. & .. & .. &. & .. \\
\hline Caribbean Development Bank & .. & .. & .. & .. & .. & .. & .. & .. \\
\hline \multicolumn{9}{|l|}{ CEB } \\
\hline Climate Investment Funds (CIF) &.. &.. & 0.3 & 0.4 & .. & .. & 0.0 & .. \\
\hline Enhanced Integrated Framework (EIF) & .. & 0.1 & 0.6 & 0.5 & & & & \\
\hline EU Institutions & 25.4 & 23.1 & 32.6 & 43.8 & 92.8 & 134.5 & 100.0 & 88.9 \\
\hline FAO & .. & & & & 128.8 & 268.6 & 267.7 & 312.7 \\
\hline GEF & .. & 3.2 & 6.9 & 6.8 & 6.9 & 5.9 & 12.5 & 18.3 \\
\hline IDB & .. & .. & .. & .. & .. & .. & .. & .. \\
\hline \multicolumn{9}{|l|}{ IFAD } \\
\hline ILO &.. & .. & 0.1 & 0.1 & .. & .. & 9.6 & 10.0 \\
\hline \multicolumn{9}{|l|}{ IMF } \\
\hline \multicolumn{9}{|l|}{ Islamic Development Bank } \\
\hline ITC & .. & & & & 28.9 & 50.9 & 57.2 & 65.4 \\
\hline OFID & & 0.3 & 3.6 & 1.5 & .. & 0.2 & 0.7 & 0.9 \\
\hline UNDP & 0.2 & 0.1 & 0.0 & 0.1 & .. & 3.6 & 3.0 & 0.4 \\
\hline \multicolumn{9}{|l|}{ UNECE } \\
\hline UNESCAP & & & & 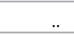 & 0.1 & & & \\
\hline UNESCWA & & .. & & .. & 0.0 & 0.2 & 0.0 & \\
\hline \multicolumn{9}{|l|}{ UNIDO } \\
\hline World Bank & 3.2 & 21.2 & 43.4 & 69.1 & & & & \\
\hline WTO & 0.3 & 0.2 & 0.2 & 0.0 & 3.5 & 7.3 & 7.1 & 6.2 \\
\hline Other multilateral donors & 0.0 & 0.0 & 0.1 & 0.6 & 0.5 & 0.1 & 2.8 & 2.5 \\
\hline Sub-total & 29.0 & 64.3 & 169.6 & 201.5 & 261.8 & 475.0 & 463.6 & 505.3 \\
\hline TOTAL AID FOR TRADE & 239.6 & 305.4 & 407.5 & 535.2 & 1473.5 & 2604.8 & 2561.2 & 3650.5 \\
\hline
\end{tabular}

Source: OECD-DAC/CRS aid activity database. 
USD million (2015 constant)

Table A.16. Aid for trade by provider and by income group, commitments (page 1 of 3)

LEAST DEVELOPED COUNTRIES

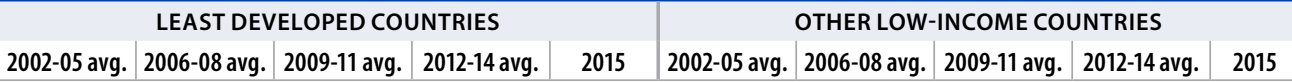

\section{DAC countries}

\begin{tabular}{|c|c|c|c|c|c|c|c|c|c|c|}
\hline \\
\hline Australia & 22.4 & 27.7 & 69.8 & 99.7 & 88.7 & 1.5 & 0.0 & 9.7 & 6.4 & 3.0 \\
\hline Austria & 15.2 & 9.5 & 6.3 & 20.1 & 10.6 & 0.2 & 0.3 & 0.3 & 2.5 & 0.2 \\
\hline Belgium & 61.9 & 95.8 & 169.5 & 90.7 & 121.9 & 3.6 & 6.3 & 15.6 & 5.3 & 12.7 \\
\hline Canada & 85.1 & 163.5 & 230.6 & 144.1 & 263.2 & 8.0 & 5.8 & 3.6 & 1.7 & 22.9 \\
\hline Czech Republic & & & 1.1 & 2.1 & 1.8 & .. & .. & 0.0 & 0.0 & 0.0 \\
\hline Denmark & 203.9 & 163.6 & 93.0 & 257.1 & 40.2 & 8.6 & 13.0 & 35.4 & 14.9 & 19.1 \\
\hline Finland & 8.7 & 27.5 & 82.3 & 28.9 & 26.1 & 7.3 & 3.9 & 17.9 & 15.3 & 0.5 \\
\hline France & 122.3 & 178.9 & 199.8 & 277.2 & 560.8 & 17.8 & 36.6 & 108.7 & 103.6 & 91.3 \\
\hline Germany & 201.2 & 198.6 & 264.5 & 415.4 & 483.4 & 21.6 & 25.8 & 75.2 & 65.0 & 50.8 \\
\hline Greece & 0.1 & 0.1 & 0.2 & .. & .. & 0.0 & 0.0 & .. & .. & \\
\hline Hungary & .. & .. & .. & .. & 0.3 & .. & .. & .. & .. & 0.0 \\
\hline Iceland & .. & .. & 1.0 & 3.2 & 1.4 & .. & .. & .. & .. & .. \\
\hline Ireland & 21.8 & 31.1 & 42.5 & 31.9 & 23.7 & 0.7 & 2.3 & 3.5 & 2.2 & 3.7 \\
\hline Italy & 95.2 & 64.8 & 46.8 & 51.1 & 47.7 & 0.8 & 5.4 & 0.6 & 1.1 & 18.9 \\
\hline Japan & 283.3 & 454.1 & 952.9 & 1699.2 & 3399.1 & 28.8 & 111.5 & 182.8 & 112.9 & 308.5 \\
\hline Korea & .. & 183.4 & 334.7 & 407.4 & 433.1 & .. & 1.6 & 1.0 & 1.5 & 2.7 \\
\hline Luxembourg & 4.7 & 8.8 & 9.7 & 14.4 & 11.2 & .. & 0.0 & .. & .. & .. \\
\hline Netherlands & 71.3 & 64.5 & 76.9 & 132.6 & 143.0 & 1.4 & 1.3 & 1.4 & 10.2 & 10.1 \\
\hline New Zealand & 3.8 & 17.4 & 37.4 & 32.2 & 53.8 & 0.0 & 0.0 & 0.1 & 1.0 & \\
\hline Norway & 111.5 & 149.7 & 204.0 & 283.9 & 64.9 & 2.7 & 2.7 & 7.3 & 5.5 & 2.7 \\
\hline Poland & .. & .. & .. & 6.6 & 27.0 & .. & .. & .. & 0.2 & 0.0 \\
\hline Portugal & 8.3 & 5.0 & 4.7 & 3.1 & 16.0 & .. & .. & ... & .. & ... \\
\hline Slovak Republic & .. & .. & .. & 0.2 & 0.0 & .. & .. & .. & 0.3 & 0.6 \\
\hline Slovenia & .. & & 0.1 & 0.0 & .. & .. & .. & .. & .. & ... \\
\hline Spain & 36.6 & 49.4 & 99.7 & 22.8 & 9.7 & 0.1 & 4.9 & 0.9 & 0.2 & 0.2 \\
\hline Sweden & 63.7 & 89.0 & 92.6 & 72.6 & 129.4 & 8.1 & 26.4 & 5.4 & 16.0 & 1.3 \\
\hline Switzerland & 64.1 & 56.3 & 54.4 & 90.5 & 72.7 & 14.8 & 3.6 & 5.0 & 4.8 & 12.7 \\
\hline United Kingdom & 175.9 & 241.0 & 270.9 & 204.4 & 309.0 & 14.4 & 6.2 & 49.6 & 40.3 & 25.4 \\
\hline United States & 571.5 & 2027.0 & 2008.5 & 1487.4 & 1639.3 & 49.3 & 24.7 & 74.7 & 75.1 & 97.4 \\
\hline Sub-total & 2232.6 & 4306.6 & 5353.8 & 5878.7 & 7977.9 & 189.7 & 282.4 & 598.7 & 485.9 & 684.7 \\
\hline \multicolumn{11}{|l|}{ Other bilateral } \\
\hline Azerbaijan & .. &.. & .. & .. &.. & .. & .. & .. & .. & .. \\
\hline Estonia & .. & .. & .. & 0.1 & ... & .. &.. & .. & 0.0 & 0.1 \\
\hline Kazakhstan & .. & .. & .. & .. & .. & ... & .. & .. & .. & .. \\
\hline Kuwait (KFAED) & .. & .. & 110.6 & 270.3 & 157.2 & .. & .. & 12.2 & 6.8 & ... \\
\hline Lithuania & .. & .. & .. & & & .. & .. & ... & ... & 0.0 \\
\hline \multicolumn{11}{|l|}{ Romania } \\
\hline Turkey &.. &.. & 0.6 & .. & .. &.. & .. & 0.0 & .. & .. \\
\hline United Arab Emirates &.. & .. & 139.8 & 102.7 & 424.7 & .. & .. & 7.8 & 0.2 & \\
\hline Sub-total & .. & .. & 251.0 & 373.0 & 582.0 & .. & .. & 20.1 & 7.0 & 0.1 \\
\hline \multicolumn{11}{|l|}{ Multilateral } \\
\hline AfDB & 108.0 & 355.5 & 797.4 & 877.0 & 1187.3 & 23.0 & 79.5 & 62.4 & 252.7 & 150.4 \\
\hline Arab Fund (AFESD) & .. & 253.2 & 353.9 & 260.6 & 232.7 & .. & ... & .. & .. & .. \\
\hline AsDB & 353.3 & 147.3 & 532.6 & 881.2 & 778.0 & 32.1 & 36.0 & 73.6 & 98.7 & 79.0 \\
\hline BADEA & .. & .. & 16.6 & 82.4 & .. & .. & .. & 4.5 & 0.9 & .. \\
\hline Caribbean Development Bank & .. & .. & .. & .. & .. & .. & .. & .. & .. & .. \\
\hline CEB & .. & .. & .. & & .. & .. & .. & .. & .. & .. \\
\hline Climate Investment Funds (CIF) & .. & .. & .. & 75.6 & 85.0 & .. & .. & .. & .. & 7.5 \\
\hline Enhanced Integrated Framework (EIF) & .. & .. & 12.2 & 24.2 & 18.2 & .. & .. & .. & .. & .. \\
\hline EU Institutions & 935.3 & 1009.8 & 786.4 & 887.2 & 837.1 & 42.7 & 36.7 & 123.7 & 120.1 & 120.9 \\
\hline $\mathrm{FAO}$ & .. & .. & .. & .. & .. & .. & .. & .. & .. & .. \\
\hline GEF & .. & .. & 19.2 & 66.7 & 27.2 & .. & .. & 2.2 & 0.9 & .. \\
\hline IDB & 36.3 & 5.8 & 97.3 & 116.6 & 152.1 & & .. & & .. & .. \\
\hline IFAD & 142.5 & 179.8 & 331.5 & 306.5 & 604.5 & 5.0 & 10.0 & 9.4 & 8.0 & 104.5 \\
\hline ILO & .. & .. & .. & 0.6 & 1.1 & .. & .. & .. & 0.1 & 0.0 \\
\hline IMF & .. & 3.5 & 5.4 & 3.7 & .. & .. & 0.2 & 0.4 & 0.3 & .. \\
\hline Islamic Development Bank & 137.3 & 163.1 & 106.4 & 88.2 & 77.0 & 7.3 & 8.5 & 16.5 & 7.7 & 70.0 \\
\hline ITC & .. & .. & .. & & .. & .. & .. & .. & .. & .. \\
\hline OFID & .. & & 138.8 & 143.5 & 232.9 & & .. & 15.5 & 8.9 & .. \\
\hline UNDP & 5.6 & 14.2 & 18.1 & 17.8 & 16.2 & 0.6 & 1.3 & 1.4 & 2.0 & 0.8 \\
\hline UNECE & .. & 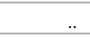 & .. & 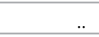 & .. & .. & .. & .. & .. & .. \\
\hline UNESCAP &.. & 0.0 &.. & 0.0 & 0.1 & .. &.. & .. &.. & .. \\
\hline UNESCWA & .. & 0.0 & .. & 0.0 & .. & .. & .. & .. & .. & .. \\
\hline UNIDO & .. & 10.5 & 12.3 & 5.2 & & & 0.0 & 0.7 & 0.0 & .. \\
\hline World Bank & 2129.6 & 2108.9 & 2970.4 & 3427.6 & 4405.4 & 125.0 & 123.7 & 366.7 & 496.1 & 811.9 \\
\hline WTO & .. & 2.5 & 1.0 & 0.5 & 0.3 & .. & 0.1 & 0.2 & 0.0 & 0.0 \\
\hline Other multilateral donors & 0.5 & 3.4 & 10.3 & 16.7 & 29.5 & .. & 0.0 & 1.8 & 0.9 & 1.4 \\
\hline Sub-total & 3848.3 & 4257.5 & 6209.8 & 7281.9 & 8684.6 & 235.8 & 295.9 & 679.0 & 997.3 & 1346.4 \\
\hline TOTAL AID FOR TRADE & 6081.0 & 8564.2 & 11814.6 & 13533.6 & 17244.5 & 425.5 & 578.3 & 1297.8 & 1490.2 & 2031.2 \\
\hline
\end{tabular}

Source: OECD-DAC/CRS aid activity database. 
USD million (2015 constant)

Table A.16. Aid for trade by provider and by income group, commitments (page 2 of 3) LOWER MIDDLE-INCOME COUNTRIES

UPPER MIDDLE-INCOME COUNTRIES

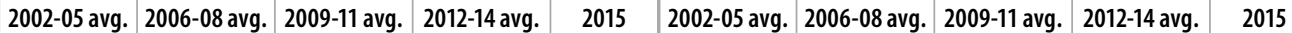

\begin{tabular}{|c|c|c|c|c|c|c|c|c|c|c|}
\hline \multicolumn{11}{|l|}{ DAC countries } \\
\hline Australia & 111.1 & 174.8 & 243.0 & 155.6 & 195.8 & 27.8 & 28.8 & 20.1 & 20.5 & 14.2 \\
\hline Austria & 16.7 & 10.2 & 15.2 & 19.1 & 22.3 & 7.8 & 10.9 & 10.7 & 2.8 & 0.5 \\
\hline Belgium & 49.5 & 44.4 & 61.8 & 22.1 & 11.1 & 44.6 & 44.5 & 25.1 & 9.7 & 9.6 \\
\hline Canada & 95.3 & 83.6 & 101.1 & 107.7 & 189.1 & 62.3 & 14.9 & 22.0 & 51.6 & 74.7 \\
\hline Czech Republic & & & 1.2 & 2.8 & 3.4 & & & 1.0 & 1.9 & 4.4 \\
\hline Denmark & 128.2 & 54.4 & 84.9 & 38.5 & 41.3 & 22.9 & 13.1 & 15.8 & 9.3 & 4.2 \\
\hline Finland & 19.4 & 20.0 & 44.7 & 17.5 & 2.9 & 20.8 & 13.2 & 20.7 & 8.7 & 0.8 \\
\hline France & 213.1 & 701.3 & 479.0 & 1052.8 & 1411.8 & 204.3 & 353.6 & 310.9 & 787.8 & 592.6 \\
\hline Germany & 484.1 & 583.2 & 925.7 & 1864.8 & 1983.1 & 357.6 & 607.6 & 836.3 & 1185.6 & 1691.7 \\
\hline Greece & 2.8 & 3.8 & 1.7 & 0.0 & 0.0 & 8.0 & 11.5 & 13.0 & 0.0 & \\
\hline Hungary & ... & ... & & ... & 0.0 & ... & ... & 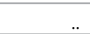 & 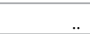 & 0.0 \\
\hline Iceland & & & 0.2 & 0.2 & 0.0 & & & 0.0 & 0.0 & \\
\hline Ireland & 1.5 & 5.4 & 5.0 & 3.2 & 2.4 & 0.7 & 1.0 & 0.4 & 0.3 & 0.2 \\
\hline Italy & 47.1 & 49.8 & 31.1 & 9.7 & 52.8 & 87.8 & 97.3 & 77.5 & 46.6 & 23.4 \\
\hline Japan & 2691.5 & 3390.7 & 3501.9 & 4824.8 & 6618.4 & 1016.8 & 1007.1 & 800.3 & 810.9 & 1036.0 \\
\hline Korea & & 245.0 & 518.2 & 393.8 & 418.7 & & 32.8 & 40.3 & 24.0 & 16.3 \\
\hline Luxembourg & 5.4 & 9.3 & 6.9 & 7.3 & 7.4 & 4.6 & 4.7 & 2.8 & 2.3 & 0.6 \\
\hline Netherlands & 98.3 & 62.3 & 43.3 & 24.0 & 5.6 & 33.1 & 29.0 & 6.9 & 2.1 & 0.9 \\
\hline New Zealand & 7.7 & 9.0 & 16.1 & 28.7 & 27.9 & 5.1 & 5.3 & 20.9 & 27.7 & 24.8 \\
\hline Norway & 31.6 & 59.6 & 50.3 & 27.8 & 21.3 & 31.1 & 27.0 & 44.2 & 22.0 & 13.4 \\
\hline Poland & & & & 1.4 & 3.8 & 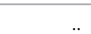 & & & 0.1 & 0.0 \\
\hline Portugal & 16.0 & 20.6 & 42.7 & 22.0 & 7.2 & 14.6 & 0.0 & 0.1 & 0.2 & 0.1 \\
\hline Slovak Republic & 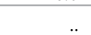 & 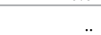 & & 0.0 & 0.2 & .. & .. & .. & 0.1 & 0.0 \\
\hline Slovenia & & & 0.1 & 0.2 & & & & 1.7 & 0.7 & 0.1 \\
\hline Spain & 91.0 & 161.4 & 132.8 & 23.9 & 14.0 & 200.8 & 385.5 & 198.4 & 23.1 & 12.2 \\
\hline Sweden & 36.0 & 23.7 & 35.1 & 30.0 & 32.1 & 28.9 & 20.5 & 21.5 & 9.4 & 13.4 \\
\hline Switzerland & 81.4 & 67.0 & 67.5 & 73.6 & 56.7 & 41.9 & 39.6 & 30.1 & 44.7 & 39.5 \\
\hline United Kingdom & 164.4 & 212.2 & 298.2 & 261.7 & 150.6 & 232.8 & 110.1 & 191.4 & 127.5 & 155.4 \\
\hline United States & 711.8 & 1648.6 & 1373.5 & 937.1 & 812.1 & 2516.8 & 1894.7 & 695.7 & 360.0 & 260.5 \\
\hline Sub-total & 5104.1 & 7640.2 & 8080.7 & 9950.6 & 12091.8 & 4971.0 & 4752.7 & 3407.9 & 3579.6 & 3989.7 \\
\hline \multicolumn{11}{|l|}{ Other bilateral } \\
\hline Azerbaijan & .. & .. & .. & & & .. & .. & .. & .. & \\
\hline Estonia & .. & & .. & 1.0 & 1.0 & ... & & ... & 0.1 & 0.0 \\
\hline \multicolumn{11}{|l|}{ Kazakhstan } \\
\hline Kuwait (KFAED) & $\ldots$ & & 161.3 & 168.6 & 159.5 & $\ldots$ & $\ldots$ & 23.9 & 80.8 & 76.5 \\
\hline Lithuania & $\ldots$ & ... & .. & 0.0 & 0.4 & $\ldots$ & ... & .. & 0.0 & 0.2 \\
\hline Romania & .. & .. & & 0.1 & 0.5 & .. & .. & & .. & \\
\hline Turkey & .. & & 0.4 & & & & .. & 1.1 & & \\
\hline United Arab Emirates & ... & & 63.8 & 546.2 & 284.5 & .. & .. & 16.2 & 228.1 & 186.6 \\
\hline Sub-total &.. & .. & 225.5 & 716.0 & 445.9 & .. &.. & 41.2 & 309.1 & 263.3 \\
\hline \multicolumn{11}{|l|}{ Multilateral } \\
\hline AfDB & 7.1 & 37.4 & 142.4 & 167.1 & 234.1 & & & 0.5 & 4.2 & 8.6 \\
\hline Arab Fund (AFESD) & & 85.6 & 485.9 & 309.3 & 648.3 & & 41.1 & 146.4 & 184.8 & 446.5 \\
\hline $\mathrm{AsDB}$ & 336.3 & 320.4 & 562.2 & 743.7 & 779.9 & 8.2 & 5.9 & 7.9 & 22.4 & 17.9 \\
\hline BADEA & .. & .. & 3.0 & 7.1 & .. & .. & .. & 0.0 & 3.6 & \\
\hline Caribbean Development Bank & & .. & & .. & & &.. & .. & .. & 1.4 \\
\hline CEB & .. & .. & .. & ... & & .. & .. & .. & & 2.8 \\
\hline Climate Investment Funds (CIF) & ... &.. & & 402.3 & 173.6 & .. & .. & .. & 209.2 & 247.3 \\
\hline Enhanced Integrated Framework (EIF) & & & 0.3 & 1.2 & 0.2 & & & 0.4 & 0.5 & \\
\hline EU Institutions & 397.8 & 569.7 & 726.8 & 2026.0 & 1707.7 & 536.0 & 549.5 & 1553.3 & 4341.7 & 3485.2 \\
\hline \multicolumn{11}{|l|}{ FAO } \\
\hline GEF & & & 17.3 & 67.3 & 30.2 & .. & .. & 43.1 & 110.1 & 29.6 \\
\hline IDB & 200.2 & 102.7 & 248.6 & 380.6 & 559.0 & & & 44.2 & 38.6 & 40.5 \\
\hline IFAD & 88.1 & 126.0 & 210.0 & 166.6 & 206.6 & 26.8 & 51.7 & 19.4 & 52.0 & \\
\hline ILO & .. & & .. & 0.5 & 1.4 & .. & & .. & 1.2 & 1.7 \\
\hline IMF & & 2.7 & 3.9 & 2.7 & & & 2.7 & 3.7 & 2.6 & .. \\
\hline Islamic Development Bank & 23.6 & 45.1 & 45.3 & 30.6 & 85.0 & 15.0 & 21.9 & 9.5 & 6.2 & \\
\hline \multicolumn{11}{|l|}{ ITC } \\
\hline OFID & & & 103.5 & 185.4 & 247.9 & & & 50.1 & 72.2 & 24.0 \\
\hline UNDP & 3.6 & 4.8 & 7.1 & 4.6 & 4.8 & 1.8 & 3.2 & 2.4 & 2.4 & 2.6 \\
\hline UNECE & .. & .. & & & & .. & .. & 0.1 & 0.1 & 0.0 \\
\hline UNESCAP & .. & & 0.0 & 0.0 & 0.0 & .. & .. & .. & 0.0 & .. \\
\hline UNESCWA & .. & 0.0 & & 0.0 & .. & .. & & & 0.0 & \\
\hline UNIDO & & 5.6 & 15.9 & 0.4 & & .. & 4.5 & 16.8 & 4.5 & \\
\hline World Bank & 1825.7 & 1705.4 & 2506.5 & 3020.3 & 2366.2 & 229.9 & 174.3 & 85.4 & 37.0 & 11.0 \\
\hline WTO & & 2.0 & 1.1 & 0.3 & 0.2 & & 3.8 & 1.5 & 0.5 & 0.3 \\
\hline Other multilateral donors & 0.4 & 0.0 & 3.6 & 8.0 & 9.3 & 0.1 & 0.0 & 0.2 & 1.8 & 2.8 \\
\hline Sub-total & 2882.9 & 3007.4 & 5083.4 & 7524.1 & 7054.3 & 817.8 & 858.7 & 1984.8 & 5095.5 & 4322.2 \\
\hline TOTAL AID FOR TRADE & 7987.0 & 10647.6 & 13389.6 & 18190.6 & 19592.1 & 5788.8 & 5611.4 & 5433.9 & 8984.2 & 8575.1 \\
\hline
\end{tabular}

Source: OECD-DAC/CRS aid activity database. 
USD million (2015 constant)

Table A.16. Aid for trade by provider and by income group, commitments (page 3 of 3 )

NON-COUNTRY SPECIFIC

\section{DAC countries}

\begin{tabular}{l|l}
$2002-05$ avg. & $2006-08$ avg.
\end{tabular}

2009-11 avg.

2012-14 avg.

2015

\begin{tabular}{|c|c|c|c|c|c|}
\hline Australia & 30.3 & 59.8 & 121.0 & 79.0 & 84.3 \\
\hline Austria & 3.2 & 19.4 & 38.3 & 37.9 & 34.7 \\
\hline Belgium & 59.4 & 51.4 & 138.8 & 47.8 & 49.7 \\
\hline Canada & 72.5 & 87.1 & 187.7 & 192.8 & 163.3 \\
\hline Czech Republic & & & 0.0 & 0.4 & 0.8 \\
\hline Denmark & 34.7 & 15.6 & 62.7 & 37.9 & 15.0 \\
\hline Finland & 19.9 & 58.3 & 117.1 & 57.3 & 59.0 \\
\hline France & 80.3 & 94.3 & 208.6 & 206.1 & 186.4 \\
\hline Germany & 100.4 & 529.9 & 1071.4 & 1122.3 & 1420.1 \\
\hline Greece & 0.1 & 0.8 & 0.2 & .. & \\
\hline Hungary & .. & .. & & & 0.0 \\
\hline Iceland & & & 1.4 & 6.0 & 5.2 \\
\hline Ireland & 2.1 & 2.5 & 6.7 & 8.2 & 2.6 \\
\hline Italy & 10.3 & 3.6 & 3.4 & 4.9 & 41.4 \\
\hline Japan & 59.7 & 220.2 & 142.9 & 242.5 & 392.6 \\
\hline Korea & & 6.3 & 6.1 & 12.7 & 21.2 \\
\hline Luxembourg & 1.3 & 7.1 & 12.9 & 13.1 & 13.2 \\
\hline Netherlands & 310.0 & 504.3 & 542.7 & 662.4 & 428.6 \\
\hline New Zealand & 4.2 & 10.7 & 16.4 & 22.7 & 28.7 \\
\hline Norway & 70.6 & 161.8 & 198.9 & 190.0 & 235.4 \\
\hline Poland & & & & 0.4 & 0.4 \\
\hline Portugal & 2.4 & 1.3 & 1.1 & 1.2 & 0.8 \\
\hline Slovak Republic & .. & .. & . & 0.0 & 0.0 \\
\hline Slovenia & & & 0.2 & 0.3 & 0.0 \\
\hline Spain & 19.9 & 36.0 & 359.5 & 17.2 & 14.4 \\
\hline Sweden & 83.2 & 158.4 & 167.6 & 236.6 & 108.7 \\
\hline Switzerland & 101.8 & 108.4 & 135.4 & 174.0 & 133.9 \\
\hline United Kingdom & 148.5 & 349.1 & 451.4 & 334.3 & 1084.5 \\
\hline United States & 297.7 & 305.3 & 392.4 & 504.4 & 575.8 \\
\hline Sub-total & 1512.3 & 2791.4 & 4384.8 & 4212.1 & 5100.6 \\
\hline \multicolumn{6}{|l|}{ Other bilateral } \\
\hline Azerbaijan & .. & .. & .. & .. & .. \\
\hline Estonia & .. & .. & .. & 0.2 & .. \\
\hline \multicolumn{6}{|l|}{ Kazakhstan } \\
\hline Kuwait (KFAED) & .. & .. & 0.0 & .. & 1.0 \\
\hline Lithuania & .. & .. & .. & 0.0 & 0.1 \\
\hline Romania & .. & .. & & .. & 0.0 \\
\hline Turkey & .. & .. & 36.2 & .. & .. \\
\hline United Arab Emirates & .. & .. & 1.3 & 2.4 & 0.1 \\
\hline Sub-total & .. & .. & 37.5 & 2.6 & 1.2 \\
\hline \multicolumn{6}{|l|}{ Multilateral } \\
\hline AfDB & 7.3 & 218.3 & 467.5 & 254.1 & 82.6 \\
\hline Arab Fund (AFESD) & .. & 0.0 & 5.4 & 3.1 & 6.8 \\
\hline AsDB & & & & 12.6 & 14.1 \\
\hline BADEA & .. & .. & 0.3 & 4.7 & \\
\hline Caribbean Development Bank & .. & .. & .. & .. & 2.7 \\
\hline CEB & & & .. & .. & .. \\
\hline Climate Investment Funds (CIF) & .. & .. & .. & 85.9 & 146.9 \\
\hline Enhanced Integrated Framework (EIF) & & & & & \\
\hline EU Institutions & 455.3 & 738.1 & 970.3 & 944.5 & 565.0 \\
\hline $\mathrm{FAO}$ & 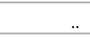 & 128.8 & 268.6 & 267.7 & 312.7 \\
\hline GEF & & .. & 35.9 & 26.0 & 24.1 \\
\hline IDB & .. & .. & 35.1 & 41.7 & 36.3 \\
\hline IFAD & & .. & .. & .. & .. \\
\hline ILO & .. & .. & .. & 10.4 & 10.7 \\
\hline IMF & & 0.9 & .. & .. & .. \\
\hline Islamic Development Bank & 2.7 & 8.1 & 7.6 & 3.5 & 1.8 \\
\hline ITC & & 29.4 & 53.2 & 64.0 & 68.0 \\
\hline OFID & .. & .. & 32.5 & 3.0 & 4.0 \\
\hline UNDP & .. & & 3.8 & 3.4 & 1.4 \\
\hline UNECE & & 1.3 & 4.1 & 3.4 & 5.1 \\
\hline UNESCAP & .. & 0.3 & 0.5 & 0.5 & 0.6 \\
\hline UNESCWA & .. & 0.1 & 0.2 & 0.3 & 0.4 \\
\hline UNIDO & & 5.8 & 14.7 & 2.6 & \\
\hline World Bank & 50.2 & 15.2 & 5.3 & 31.1 & 27.0 \\
\hline WTO & & 4.1 & 11.5 & 10.5 & 10.7 \\
\hline Other multilateral donors & 0.0 & 0.6 & 6.7 & 8.2 & 13.3 \\
\hline Sub-total & 515.5 & 1151.0 & 1923.1 & 1781.4 & 1334.1 \\
\hline TOTAL AID FOR TRADE & 2027.9 & 3942.4 & 6345.4 & 5996.1 & 6435.9 \\
\hline
\end{tabular}

Source: OECD-DAC/CRS aid activity database. 
USD million (2015 constant)

Table A.17. Aid for trade by provider and by income group, disbursements (page 1 of 2)

LEAST DEVELOPED COUNTRIES

\begin{tabular}{|l|l|l|l|l|l|l|r|}
$2006-08$ avg. & $2009-11$ avg. & $2012-14$ avg. & 2015 & $2006-08$ avg. & $2009-11$ avg. & $2012-14$ avg. & 2015
\end{tabular}

\begin{tabular}{|c|c|c|c|c|c|c|c|c|}
\hline \multicolumn{9}{|l|}{ DAC countries } \\
\hline Australia & 27.4 & 64.0 & 99.7 & 88.7 & 0.0 & 9.8 & 6.4 & 3.0 \\
\hline Austria & 8.8 & 8.1 & 9.8 & 11.3 & 0.3 & 0.3 & 2.3 & 0.3 \\
\hline Belgium & 57.1 & 121.8 & 100.1 & 110.2 & 1.4 & 7.4 & 6.1 & 6.5 \\
\hline Canada & 102.0 & 242.3 & 119.8 & 128.4 & 5.7 & 3.4 & 2.8 & 5.8 \\
\hline Czech Republic & & 1.1 & 2.1 & 1.8 & & & 0.0 & 0.0 \\
\hline Denmark & 123.6 & 163.7 & 165.3 & 121.2 & 12.4 & 22.0 & 27.6 & 24.5 \\
\hline Finland & 8.5 & 27.8 & 39.8 & 41.8 & 2.9 & 7.0 & 14.6 & 16.0 \\
\hline France & 176.9 & 115.4 & 183.9 & 214.1 & 30.8 & 35.5 & 75.6 & 68.0 \\
\hline Germany & 200.7 & 209.2 & 249.6 & 312.6 & 16.3 & 38.3 & 66.3 & 34.4 \\
\hline Greece & 0.1 & 0.2 & & & 0.0 & .. & & \\
\hline Hungary & & & 0.1 & 0.3 & .. & .. & 0.0 & 0.0 \\
\hline Iceland & & 1.0 & 3.2 & 1.4 & .. & 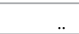 & & \\
\hline Ireland & 31.1 & 42.5 & 31.9 & 23.7 & 2.3 & 3.5 & 2.2 & 3.7 \\
\hline Italy & 103.4 & 39.5 & 35.0 & 54.4 & 2.0 & 1.1 & 0.8 & 2.1 \\
\hline Japan & 286.3 & 453.9 & 856.8 & 1256.5 & 35.2 & 43.0 & 132.0 & 170.4 \\
\hline Korea & 52.3 & 143.2 & 209.4 & 271.9 & 5.6 & 2.5 & 1.9 & 2.3 \\
\hline Luxembourg & 8.8 & 9.7 & 14.4 & 11.2 & 0.0 & .. & & \\
\hline Netherlands & 58.0 & 59.1 & 101.8 & 74.4 & 1.4 & 1.6 & 5.9 & 6.2 \\
\hline New Zealand & 8.7 & 17.1 & 34.4 & 33.9 & 0.0 & 0.1 & 0.2 & 0.7 \\
\hline Norway & 121.4 & 161.1 & 188.2 & 169.2 & 2.9 & 5.0 & 5.0 & 2.5 \\
\hline Poland & & & 6.6 & 26.9 & .. & .. & 0.2 & 0.0 \\
\hline Portugal & 5.0 & 4.7 & 3.1 & 14.2 & .. & .. & .. & .. \\
\hline Slovak Republic & 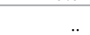 & & 0.1 & 0.1 & .. & .. & 0.3 & 0.4 \\
\hline Slovenia & & 0.1 & 0.0 & & & & & \\
\hline Spain & 33.8 & 78.7 & 30.5 & 18.3 & 0.6 & 5.1 & 0.0 & 0.3 \\
\hline Sweden & 89.7 & 85.9 & 94.6 & 124.5 & 19.5 & 17.4 & 12.4 & 12.9 \\
\hline Switzerland & 50.0 & 42.1 & 64.7 & 90.2 & 6.8 & 4.6 & 4.7 & 4.5 \\
\hline United Kingdom & 152.8 & 331.3 & 319.1 & 542.9 & 15.2 & 32.3 & 70.4 & 79.2 \\
\hline United States & 986.9 & 1925.5 & 1541.4 & 1243.4 & 23.7 & 33.4 & 75.1 & 73.0 \\
\hline Sub-total & 2693.2 & 4349.0 & 4505.6 & 4987.6 & 185.2 & 273.2 & 512.7 & 516.8 \\
\hline \multicolumn{9}{|l|}{ Other bilateral } \\
\hline Azerbaijan & .. & .. & & 0.0 & .. & .. & . & \\
\hline Estonia & & .. & 0.0 & 0.1 & .. & .. & 0.0 & 0.0 \\
\hline \multicolumn{9}{|l|}{ Kazakhstan } \\
\hline Kuwait (KFAED) & .. & 59.3 & 80.7 & 168.4 & .. & 0.7 & 5.6 & 5.5 \\
\hline Lithuania & 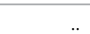 & .. & & .. & .. & .. & .. & 0.0 \\
\hline \multicolumn{9}{|l|}{ Romania } \\
\hline Turkey & & 0.6 & & & $\ldots$ & 0.0 & & \\
\hline United Arab Emirates & .. & 37.2 & 52.8 & 390.7 & .. & & 2.7 & 0.9 \\
\hline Sub-total &.. & 97.0 & 133.6 & 559.2 &.. & 0.7 & 8.3 & 6.5 \\
\hline \multicolumn{9}{|l|}{ Multilateral } \\
\hline AfDB & 284.3 & 597.4 & 559.2 & 772.1 & 16.7 & 76.9 & 144.7 & 209.5 \\
\hline Arab Fund (AFESD) & 80.1 & 176.4 & 229.9 & 195.4 & . & & & \\
\hline $\mathrm{AsDB}$ & & 242.6 & 524.5 & 433.1 & .. & 29.0 & 65.1 & 152.1 \\
\hline BADEA & .. & 11.7 & 43.9 & 48.2 & .. & 0.4 & 0.1 & 0.8 \\
\hline Caribbean Development Bank & & & & .. & .. & .. & .. & .. \\
\hline CEB & .. & ... & & & .. & .. & .. & .. \\
\hline Climate Investment Funds (CIF) & .. & & 2.7 & 2.2 & .. & ... & 3.1 & 4.5 \\
\hline Enhanced Integrated Framework (EIF) & & 9.5 & 15.2 & 7.5 & & & & \\
\hline EU Institutions & 892.5 & 805.9 & 761.4 & 756.8 & 28.9 & 38.8 & 124.6 & 98.6 \\
\hline \multicolumn{9}{|l|}{ FAO } \\
\hline GEF & 17.0 & 28.2 & 25.7 & 32.8 & 3.6 & 3.7 & 2.1 & 2.1 \\
\hline IDB & ... & 72.0 & 101.7 & 114.5 & .. & .. & .. & .. \\
\hline IFAD & .. & .. & & .. & .. & .. & .. & \\
\hline ILO & .. & .. & 0.6 & 1.1 & .. & .. & 0.1 & 0.0 \\
\hline IMF & .. & .. & 0.1 & .. & .. & .. & 0.0 & .. \\
\hline Islamic Development Bank & & .. & . & .. & $\ldots$ & .. & .. & ... \\
\hline \multicolumn{9}{|l|}{ ITC } \\
\hline OFID & & 66.7 & 80.1 & 110.5 & & 10.8 & 4.4 & 6.3 \\
\hline UNDP & 13.8 & 18.1 & 17.8 & 16.2 & 1.3 & 1.4 & 2.0 & 0.8 \\
\hline UNECE & & .. & & & .. & .. & .. & .. \\
\hline UNESCAP & 0.0 & .. & 0.0 & 0.1 & .. & .. & .. & ... \\
\hline UNESCWA & 0.0 & .. & 0.0 & .. & .. & .. & .. & .. \\
\hline \multicolumn{9}{|l|}{ UNIDO } \\
\hline World Bank & 1644.3 & 1831.0 & 2335.8 & 2487.1 & 92.5 & 128.5 & 255.3 & 225.5 \\
\hline WTO & 2.5 & 1.0 & 0.5 & 0.3 & 0.1 & 0.2 & 0.0 & 0.0 \\
\hline Other multilateral donors & 1.5 & 3.3 & 14.8 & 25.4 & 0.0 & 0.2 & 0.3 & 1.4 \\
\hline Sub-total & 2936.2 & 3863.9 & 4713.8 & 5003.3 & 143.1 & 289.9 & 601.8 & 701.7 \\
\hline TOTAL AID FOR TRADE & 5629.4 & 8309.9 & 9353.0 & 10550.0 & 328.3 & 563.8 & 1122.8 & 1225.0 \\
\hline
\end{tabular}

Source: OECD-DAC/CRS aid activity database. 
USD million (2015 constant)

Table A.17. Aid for trade by provider and income group, disbursements (page 2 of 2)

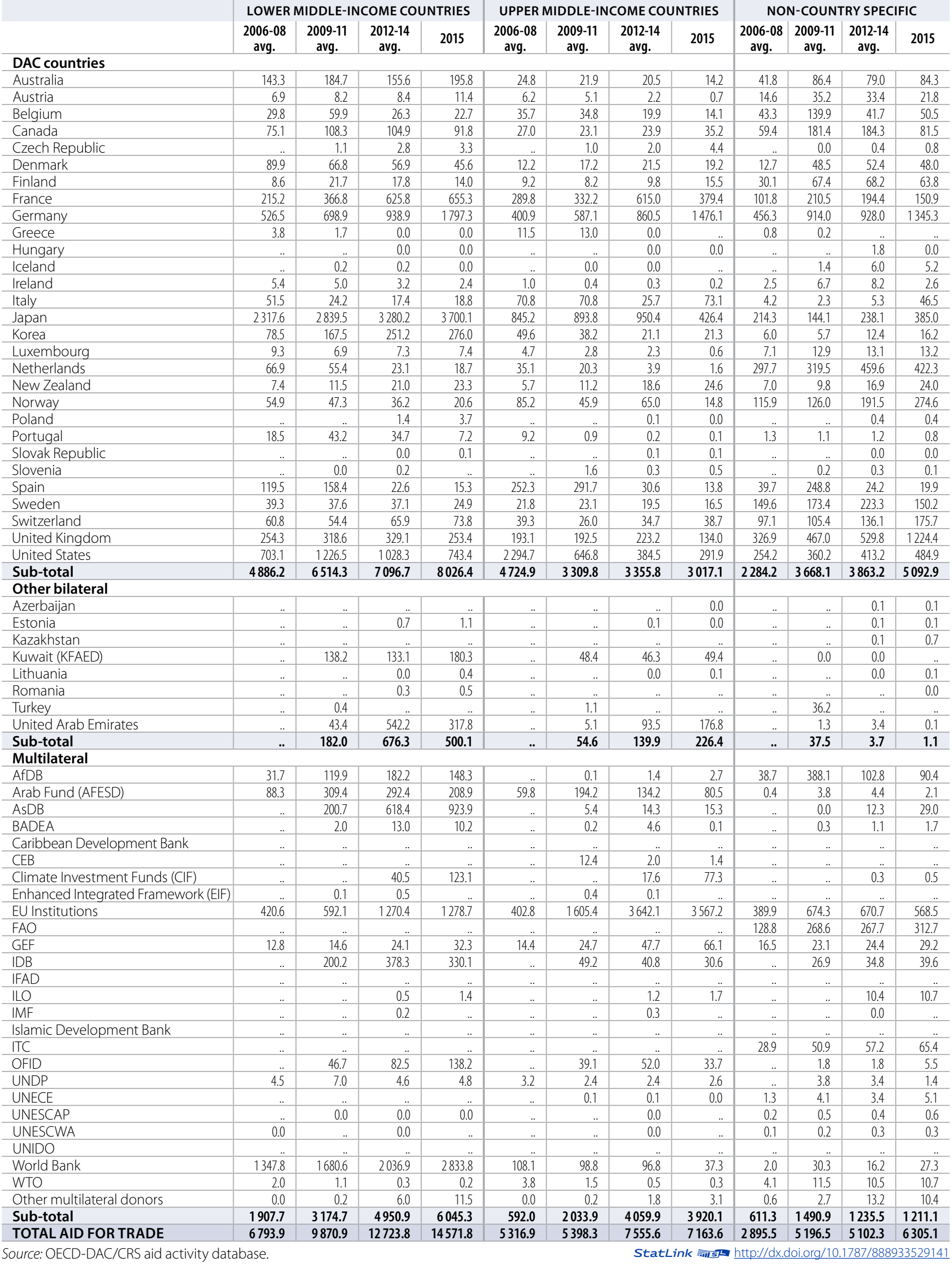


USD million (2015 constant)

Table A.18. Trade-related other official flows by category

\section{COMMITMENTS}

2002-05 avg. $2006-08$ avg. $2009-011$ avg. $2012-14$ avg.
DISBURSEMENTS

2015 2006-08 avg. 2009-011 avg. 2012-14 avg. 2015

\begin{tabular}{|c|c|c|c|c|c|c|c|c|c|}
\hline \multicolumn{10}{|l|}{ Trade policy and regulations } \\
\hline Trade policy and admin. management & 268.0 & 135.1 & 277.8 & 263.0 & 135.7 & 54.6 & 147.5 & 71.8 & 52.0 \\
\hline Trade facilitation & 76.2 & 28.0 & 210.8 & 66.7 & 495.5 & 16.0 & 154.6 & 71.5 & 446.3 \\
\hline Regional trade agreements & 60.7 &. & 13.2 & .. &. &. & 14.6 &. &. \\
\hline Multilateral trade negotiations & .. & 11.5 & 3.2 & .. & .. & 11.0 &. &. &. \\
\hline Trade education/training &.. &.. &.. & 212.0 & 247.0 & & & 7.3 & 4.3 \\
\hline Sub-total & 404.9 & 174.5 & 505.1 & 541.6 & 878.2 & 81.6 & 316.7 & 150.5 & 502.5 \\
\hline \multicolumn{10}{|l|}{ Economic infrastructure } \\
\hline Transport and storage & 5515.2 & 8086.8 & 11574.9 & 11678.4 & 13167.0 & 2567.6 & 6814.5 & 7746.0 & 9199.7 \\
\hline Communications & 566.9 & 668.0 & 662.9 & 1209.7 & 1059.8 & 329.9 & 680.5 & 830.5 & 596.4 \\
\hline Energy generation and supply & 2131.8 & 5877.8 & 12222.9 & 10230.0 & 13264.3 & 1185.4 & 6241.0 & 5927.8 & 11055.3 \\
\hline Sub-total & 8213.9 & 14632.7 & 24460.7 & 23118.0 & 27491.1 & 4082.9 & 13736.0 & 14504.4 & 20851.3 \\
\hline \multicolumn{10}{|l|}{ Building productive capacity } \\
\hline Business and other services & 561.3 & 1281.9 & 1988.4 & 612.8 & 1867.2 & 694.7 & 1343.4 & 627.3 & 1041.6 \\
\hline Banking and financial services & 2362.7 & 2517.2 & 8036.9 & 11130.3 & 14952.1 & 1638.1 & 7193.0 & 6068.8 & 9315.4 \\
\hline Agriculture & 1192.5 & 1103.5 & 2033.6 & 2300.3 & 2519.0 & 700.7 & 1086.5 & 1369.4 & 1361.1 \\
\hline Forestry & 82.8 & 66.6 & 315.8 & 298.4 & 126.3 & 50.9 & 170.2 & 193.8 & 147.6 \\
\hline Fishing & 7.4 & 1.4 & 46.0 & 203.6 & 117.7 & 1.5 & 20.8 & 31.0 & 98.2 \\
\hline Industry & 1535.8 & 4046.8 & 4044.6 & 6248.3 & 8660.4 & 1965.8 & 3872.3 & 4868.4 & 7936.2 \\
\hline Mineral resources and mining & 248.6 & 860.8 & 1864.4 & 1668.3 & 3237.4 & 630.1 & 1397.2 & 968.8 & 1617.1 \\
\hline Tourism & 111.7 & 79.0 & 236.6 & 580.2 & 204.4 & 52.6 & 92.5 & 444.0 & 119.1 \\
\hline Sub-total & 6102.9 & 9957.3 & 18566.3 & 23042.3 & 31684.3 & 5734.4 & 15175.8 & 14571.6 & 21636.4 \\
\hline TOTAL TRADE-RELATED OOF & 14721.7 & 24764.5 & 43532.1 & 46701.9 & 60053.6 & 9898.9 & 29228.5 & 29226.5 & 42990.3 \\
\hline \multicolumn{10}{|l|}{ Share in total } \\
\hline Trade policy and regulations & $2.8 \%$ & $0.7 \%$ & $1.2 \%$ & $1.2 \%$ & $1.5 \%$ & $0.8 \%$ & $1.1 \%$ & $0.5 \%$ & $1.2 \%$ \\
\hline Economic infrastructure & $55.8 \%$ & $59.1 \%$ & $56.2 \%$ & $49.5 \%$ & $45.8 \%$ & $41.2 \%$ & $47.0 \%$ & $49.6 \%$ & $48.5 \%$ \\
\hline Building productive capacity & $41.5 \%$ & $40.2 \%$ & $42.6 \%$ & $49.3 \%$ & $52.8 \%$ & $57.9 \%$ & $51.9 \%$ & $49.9 \%$ & $50.3 \%$ \\
\hline Share in sector allocable OOF & $51.6 \%$ & $63.5 \%$ & $64.8 \%$ & $71.8 \%$ & $69.3 \%$ & $59.3 \%$ & $61.5 \%$ & $68.8 \%$ & $70.3 \%$ \\
\hline Share in total OOF & $49.0 \%$ & $58.5 \%$ & $61.8 \%$ & $68.8 \%$ & $63.9 \%$ & $46.5 \%$ & $58.3 \%$ & $62.5 \%$ & $60.1 \%$ \\
\hline
\end{tabular}


USD million (2015 constant)

Table A.19. Trade-related other official flows by individual provider

\section{COMMITMENTS}

2002-05 avg. 2006-08 avg. 2009-011 avg. 2012-14 avg.
DISBURSEMENTS

2015 2006-08 avg. 2009-011 avg. 2012-14 avg. 2015

\section{DAC countries}

\begin{tabular}{|c|c|c|c|c|c|c|c|c|c|}
\hline Australia &.. & 0.9 & 12.7 & 27.0 & 11.1 & 2.5 & 12.7 & 27.0 & 11.1 \\
\hline Austria & 1.3 & & & .. & .. &.. &.. & & \\
\hline Belgium &.. &.. & 0.0 & 47.3 & 86.4 &. & .. & 88.7 & 86.4 \\
\hline Canada &. &. & 4.0 & 15.9 &. & .. & 4.0 & 15.9 & .. \\
\hline Denmark & 6.9 &. &.. &. &. &.. &. & 12.7 & 30.9 \\
\hline Finland & 15.5 & 29.1 & 39.7 & 30.7 & 41.2 & 28.9 & 38.7 & 25.5 & 44.7 \\
\hline France & 228.4 & 271.7 & 885.3 & 1204.1 & 1033.5 & 255.3 & 604.1 & 944.8 & 1082.8 \\
\hline Germany &. & 991.1 & 1028.2 & 996.3 & 849.5 & 813.5 & 1121.6 & 1021.3 & 914.8 \\
\hline Greece &. & 1.3 &.. &.. & .. & 1.3 &. &.. & .. \\
\hline Italy &. &. & 0.4 & 1.5 &. &. & 0.4 &. &.. \\
\hline Japan & 835.7 & 1263.0 &. &. &. & 23.0 &. &. & .. \\
\hline Korea &. & 1785.8 & 4192.6 & 5946.2 & 11400.2 & 1630.0 & 3628.5 & 5308.3 & 12211.7 \\
\hline Netherlands & 7.6 & .. &.. &. &. &.. &. &.. & .. \\
\hline Norway & .. &. &.. & 59.1 & 578.0 &.. &.. & 126.1 & 778.2 \\
\hline Portugal &. &. & 0.3 & 2.7 & 1.7 &.. & 0.3 & 2.1 & 1.4 \\
\hline Spain &. & 2.0 &. & 4.3 & 0.0 &. &. & 4.8 & 0.0 \\
\hline Sweden & 1.6 & 0.0 &. & 27.5 & 54.4 & 0.1 &. & 15.3 & 36.5 \\
\hline Switzerland &.. &. &. & 6.8 &. &. &. & 6.8 & 27.0 \\
\hline United Kingdom & 209.0 & 15.1 & 116.5 & 72.3 & .. & -5.7 & 116.5 & 72.3 & .. \\
\hline United States & 183.1 & 386.6 & 710.0 & 454.8 & 339.2 & 122.6 & 350.9 & 253.4 & 288.2 \\
\hline Sub-total & 1489.0 & 4746.6 & 6989.6 & 8896.6 & 14395.2 & 2871.4 & 5877.7 & 7924.9 & 15513.7 \\
\hline \multicolumn{10}{|l|}{ Other bilateral } \\
\hline United Arab Emirates & .. &. & .. & .. & .. & .. & 12.5 & 20.8 & 33.3 \\
\hline \multicolumn{10}{|l|}{ Multilateral } \\
\hline AfDB & 330.0 & 918.0 & 3453.1 & 1763.6 & 2252.5 & 476.4 & 2089.6 & 2077.8 & 1969.2 \\
\hline AsDB & 3270.7 & 3702.6 & 4369.6 & 6244.5 & 8488.0 &. & 2135.8 & 3841.7 & 4936.7 \\
\hline Caribbean Development Bank &.. & .. &.. & .. & 9.0 &.. &. &.. & .. \\
\hline CEB &. &. & 147.8 & 203.5 & 130.9 &. & 131.1 & 202.4 & 231.9 \\
\hline Climate Investment Funds & .. & .. & .. & .. & .. & .. & .. & 38.0 & .. \\
\hline EU Institutions & 1915.2 & 4572.7 & 2678.8 & 913.1 & 632.7 & 1385.8 & 2935.3 & 838.3 & 474.8 \\
\hline $\begin{array}{l}\text { European Bank for Reconstruction } \\
\text { and Development }\end{array}$ &. &. & 3701.7 & 4049.5 & 6945.2 & .. & 2608.7 & 3154.9 & 4639.6 \\
\hline IDB & 1693.0 & 2629.1 & 5087.5 & 4928.0 & 4116.7 &. & 3973.1 & 3419.9 & 5012.7 \\
\hline IFAD & 21.9 & 34.3 & 63.1 & 87.0 & 264.9 &. & .. & .. & .. \\
\hline International Finance Corporation & .. & .. &. & 7753.5 & 8329.7 &. &.. &. & .. \\
\hline Islamic Development Bank & 508.2 & 1191.1 & 2270.4 & 2545.4 & 3110.9 &. & & .. & .. \\
\hline OFID & .. &. & 442.8 & 555.2 & 493.6 & .. & 361.8 & 480.4 & 518.2 \\
\hline World Bank & 5493.6 & 6970.1 & 14327.7 & 8762.2 & 10884.1 & 5165.4 & 9102.9 & 7227.3 & 9660.2 \\
\hline Sub-total & 13232.7 & 20017.9 & 36542.4 & 37805.4 & 45658.4 & 7027.5 & 23338.3 & 21280.8 & 27443.2 \\
\hline TOTAL TRADE-RELATED OOF & 14721.7 & 24764.5 & 43532.1 & 46701.9 & 60053.6 & 9898.9 & 29228.5 & 29226.5 & 42990.3 \\
\hline
\end{tabular}

Source: OECD-DAC/CRS aid activity database. 
USD million (2015 constant)

Table A.20. Trade-related other official flows by individual recipient country (page 1 of 3 )

\section{COMMITMENTS}

2002-05 avg. 2006-08 avg. 2009-011 avg. 2012-14 avg.

Afghanistan

Albania

Algeria

Angola

Argentina

Armenia

Azerbaijan

Bangladesh

Belarus

Belize

Benin

Bhutan

Bolivia

Bosnia and Herzegovina

Botswana

Brazil

Burkina Faso

Burundi

Cabo Verde

Cambodia

Cameroon

Central African Republic

Chad

Chile

China (People's Republic of)

Colombia

Comoros

Congo

Cook Islands

Costa Rica

Côte d'Ivoire

Cuba

Democratic People's Republic of Korea

Democratic Republic of the Congo

Djibouti

Dominica

Dominican Republic

Ecuador

Egypt

El Salvador

Equatorial Guinea

Ethiopia

Fiji

Former Yugoslav Republic of Macedonia

Gabon

Gambia

Georgia

Ghana

Grenada

Guatemala

Guinea

Guinea-Bissau

Guyana

Haiti

Honduras

India

Source: OECD-DAC/CRS aid activity database.

\begin{tabular}{|r|r|r|r|}
\hline 8.7 & 25.2 & 22.1 & 24.4 \\
\hline 11.1 & 40.4 & 169.9 & 245.2 \\
\hline
\end{tabular}

\begin{tabular}{|l|l|r|r|}
\hline 109.2 & 0.0 & 195.3 & 90.9 \\
\hline
\end{tabular}

\begin{tabular}{r|r}
\hline.. & 6.1 \\
\hline 513.4 & 1326.5 \\
\hline
\end{tabular}

\begin{tabular}{r|r}
\hline.. & 17.2 \\
\hline 23.3 & 473.3 \\
\hline 110.4 & 247.1 \\
\hline
\end{tabular}

\begin{tabular}{l|r}
110.4 & 247.1 \\
\hline
\end{tabular}

\begin{tabular}{r|r}
\hline.. & 23.3 \\
\hline 2.3 & 0.9 \\
\hline
\end{tabular}

7.8

\begin{tabular}{r|r}
6.1 & 27.0
\end{tabular}

\begin{tabular}{l|r|r}
\hline 6.1 & 27.0 & 322.0 \\
\hline 1326.5 & 812.8 & 503.8 \\
\hline
\end{tabular}

\begin{tabular}{l|l|l|}
\hline 14.2 & 226.3 & 221.4 \\
\hline
\end{tabular}

\begin{tabular}{|l|r|r|}
\hline 43.3 & 467.2 & 635.8 \\
\hline
\end{tabular}

0.9

\begin{tabular}{r|r}
\hline 14.4 & 10.5 \\
\hline 48.7 & 175.7 \\
\hline 12.8 & \\
\hline 1631.0 \\
\hline
\end{tabular}

1631.5

1361.0

\begin{tabular}{|r|r|r|r|}
\hline 2.4 & 4.9 & 10.1 & 76.6 \\
\hline.. &.. &.. &.. \\
\hline.. & 18.7 & 31.9 & 39.8 \\
\hline 5.0 & 1.4 & 20.4 & 124.9 \\
\hline .3 & 9.8 & 45.5 & 104.3 \\
\hline
\end{tabular}

189.1

\begin{tabular}{l|r}
89.1 & 314.1
\end{tabular}

10.5

\begin{tabular}{r|r}
\hline 6.6 \\
\hline 16.1 \\
\hline 38.2
\end{tabular}

66.6

66.6
8.8

\begin{tabular}{|r|r|}
\hline 38.2 & 14.0 \\
\hline 186.9 & 220.4 \\
\hline 680.8 & 0.6 \\
\hline 2641.0 & 2546.9 \\
\hline 10.1 & 76.6 \\
\hline.. &.. \\
\hline 31.9 & 39.8 \\
\hline 20.4 & 124.9 \\
\hline 45.5 & 104.3 \\
\hline
\end{tabular}

\begin{tabular}{|c|c|}
\hline 4.3 & 9.8 \\
\hline .. & . \\
\hline 8.1 & 20.7 \\
\hline 56.9 & 254.2 \\
\hline 2105.5 & 2937.5 \\
\hline 357.7 & 448.5 \\
\hline
\end{tabular}

\begin{tabular}{|r|r|r}
\hline.. &.. & \\
\hline 51.4 & 66.9 & \\
\hline 134.5 & 453.7 & \\
\hline 3458.0 & 4281.5 & 5 \\
\hline 703.7 & 692.5 \\
\hline
\end{tabular}

\begin{tabular}{r|r|r}
\hline.. &.. \\
\hline. & 0.6 \\
\hline.. &.. \\
\hline 53.5
\end{tabular}

\begin{tabular}{|r|r|}
703.7 & 692.5 \\
\hline 1.5 &.. \\
\hline.. & 6.8 \\
\hline 4.1 &.. \\
\hline
\end{tabular}

DISBURSEMENTS

2015

2006-08 avg. 2009-011 avg. 2012-14 avg. 2015

3.2

\begin{tabular}{r|}
91.2 \\
454.1 \\
\hline 4.5 \\
\hline 392.1
\end{tabular}

13.9

18.6

\begin{tabular}{|r|r|}
\hline 5.4 & 3.1 \\
\hline 80.3 & 28.8 \\
\hline 75.8 & 327.6 \\
\hline 188.3 & 0.1 \\
\hline
\end{tabular}

\begin{tabular}{|r|r|r|r|}
\hline 4.2 & 195.3 & 75.8 & 327.6 \\
\hline 2.9 & 28.0 & 188.3 & 0.1 \\
\hline 161.4 & 952.8 & 717.5 & 654.1 \\
\hline
\end{tabular}

\begin{tabular}{|r|r|r|}
\hline 392.1 & 161.4 \\
\hline
\end{tabular}

470.2
787.5

1178.3

88.2

15.0

15.0
123.1

\begin{tabular}{|r|r|}
\hline 79.5 &.. \\
\hline 256.7 & 6.0 \\
\hline
\end{tabular}

\begin{tabular}{|l|}
\hline 14.8 \\
\hline 30.1 \\
\hline
\end{tabular}

\begin{tabular}{|l|l|}
\hline 952.8 & 717.5 \\
\hline 142.1 & 110.8 \\
\hline
\end{tabular}

\begin{tabular}{r|r}
\hline 162.3 \\
\hline 22.2 \\
1267.5
\end{tabular}

\begin{tabular}{|r|r|}
\hline 12.7 & 105.9 \\
\hline 10.5 & 67.1 \\
\hline
\end{tabular}

\begin{tabular}{|l|l|}
\hline 110.8 & 200.6 \\
\hline 461.3 & 497.4 \\
\hline
\end{tabular}

\begin{tabular}{r|r}
\hline \\
\hline
\end{tabular}

\begin{tabular}{|r|r|r|r|}
\hline 54.6 & 3.0 & 6.5 & 52.6 \\
\hline 2.0 & 326.9 & 219.0 & 206.5 \\
\hline 506.1 & 2145.7 & 23.4 & 11.5 \\
\hline
\end{tabular}

\begin{tabular}{|r|r|r|r|r|}
\hline 205.5 &.. & 1.3 &.. & 13.9 \\
\hline.. &.. &.. & 0.0 &.. \\
\hline.. &.. & 37.0 & 14.2 & 14.0 \\
\hline 147.1 & 4.5 & 16.9 & 61.0 & 103.7 \\
\hline 415.9 & 16.5 & 40.7 & 33.1 & 60.7 \\
\hline
\end{tabular}

\begin{tabular}{|r|r|}
\hline 151.2 & \\
\hline 313.0 & \\
\hline 5661.0 & \\
14097 & \\
\hline
\end{tabular}

\begin{tabular}{|r|r|r|r}
\hline.. &.. &.. &.. \\
\hline 62.0 &.. & 0.3 &.. \\
\hline 1529.5 & 2726.9 & 178.6 & 309.4 \\
\hline 305.7 & 443.2 & 3348.9 & 5041.4 \\
\hline.. & 0.8 & 436.5 & 868.9 \\
\hline & &.. & \\
\hline
\end{tabular}

1409.7


USD million (2015 constant)

Table A.20. Trade-related other official flows by individual recipient country (page 2 of 3 )

\section{COMMITMENTS}

2002-05 avg. 2006-08 avg. 2009-011 avg. 2012-14 avg. 2015

Indonesia

Iran

Iraq

Jamaica

Jordan

Kazakhstan

Kenya

Kiribati

Kosovo

Kyrgyzstan

Lao People's Democratic Republic

Lebanon

Lesotho

Liberia

Libya

Madagascar

Malawi

Malaysia

Maldives

Mali

Marshall Islands

Mauritania

Mauritius

Mexico

Micronesia

Moldova

Mongolia

Montenegro

Morocco

Mozambique

Myanmar

Namibia

Nauru

Nepal

Nicaragua

Niger

Nigeria

Pakistan

Palau

Panama

Papua New Guinea

Paraguay

Peru

Philippines

Rwanda

Saint Lucia

Saint Vincent and the Grenadines

Samoa

Sao Tome and Principe

Senegal

Serbia

Seychelles

Sierra Leone

Solomon Islands

Somalia

South Africa

Source: OECD-DAC/CRS aid activity database.

4928.6

\begin{tabular}{|l|l|r|r|r|}
\hline 189.3 & 128.9 & 288.9 & 92.4 \\
\hline
\end{tabular}

189.3

128.9

288.9

28.9

30.9

\begin{tabular}{|c|c|}
\hline 20.7 & 114.8 \\
\hline
\end{tabular}

63.2

110.3

202.9

242.9

$1720.0-264.4$

\begin{tabular}{|r|r|}
\hline 81.7 & 4005.7 \\
\hline
\end{tabular}

\begin{tabular}{l|l}
12.6 & 40.4
\end{tabular}

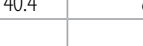

\begin{tabular}{r|r}
\hline.. & \\
\hline.. & \\
24.0 & \\
90.0 &
\end{tabular}

\begin{tabular}{r|r}
.. & \\
6.1 & 30.4 \\
78.1
\end{tabular}

\begin{tabular}{r|r}
\hline.. & \\
\hline. & \\
9.2 & \\
142.5 &
\end{tabular}

\begin{tabular}{|r|r|}
\hline 78.1 & 74.5 \\
\hline 7.2 & 84.8 \\
\hline
\end{tabular}

\begin{tabular}{|l|r|r|r|}
\hline 90.0 & 142.5 & 45.3 & 129.1 \\
\hline
\end{tabular}

\begin{tabular}{l|l}
9.4 \\
\hline
\end{tabular}

\begin{tabular}{|l|l|}
\hline 264.4 & 396.4 \\
\hline
\end{tabular}

\begin{tabular}{r|r}
465.1 & 625.0 \\
\hline
\end{tabular}

\begin{tabular}{r|r}
\hline. & \\
\hline. & 21.0 \\
\hline. & 2. \\
\hline
\end{tabular}

\begin{tabular}{|r|r|r|}
\hline.. & 8.2 & \\
\hline 21.0 & 77.0 & 10.3 \\
\hline 2.4 & 0.0 & 15.1 \\
\hline 361.0 & 211.4 & 1.4 \\
\hline
\end{tabular}

\begin{tabular}{|r|r|r|r|}
\hline 0.7 & 361.0 & 211.4 & 1.4 \\
\hline 0.7 & 0.4 & 3.0 & 4.5 \\
\hline 27.5 & 76.7 & 11.3 & 81.6 \\
\hline
\end{tabular}

\begin{tabular}{|c|c|c|c|c|}
\hline 0.1 & 0.4 & 3.0 & 4.5 & 0.0 \\
\hline 127.5 & 76.7 & 11.3 & 81.6 & 297.0 \\
\hline .. & 25.5 & .. & 3.6 & .. \\
\hline 0.3 & 19.2 & 23.9 & 25.8 & 41.4 \\
\hline .. & .. & 3.1 & 62.1 & 250.3 \\
\hline 7.1 & 21.6 & 138.3 & 69.9 & .. \\
\hline 6.8 & 20.9 & 94.6 & 97.2 & 0.3 \\
\hline 1168.3 & 562.2 & 2235.6 & 1353.4 & 1358.0 \\
\hline .. & &. & 1.4 & 0.1 \\
\hline 0.9 & 22.3 & 73.1 & 152.0 & 129.5 \\
\hline.. & & 114.6 & 287.6 & 990.1 \\
\hline. & 18.5 & 158.0 & 82.3 & 123.5 \\
\hline
\end{tabular}

11.3

\begin{tabular}{|r|r|r|r|r|r|}
\hline 0.7 & 0.4 & 3.0 & 4.5 & 0.0 & \\
\hline 127.5 & 76.7 & 11.3 & 81.6 & 297.0 &.. \\
\hline.. & 25.5 &.. & 3.6 &.. & \\
\hline 0.3 & 19.2 & 23.9 & 25.8 & 41.4 & \\
\hline.. &.. & 3.1 & 62.1 & 250.3 & \\
\hline 7.1 & 21.6 & 138.3 & 69.9 &.. & \\
\hline 6.8 & 20.9 & 94.6 & 97.2 & 0.3 & \\
\hline 1168.3 & 562.2 & 2235.6 & 1353.4 & 1358.0 & \\
\hline.. &.. &.. & 1.4 & 0.1 & \\
\hline 0.9 & 22.3 & 73.1 & 152.0 & 129.5 & \\
\hline. &.. & 114.6 & 287.6 & 990.1 & \\
.. & 18.5 & 158.0 & 82.3 & 123.5 & \\
\hline 11.0 & 587.2 & 957.9 & 1208.0 & 1645.5 & \\
\hline
\end{tabular}

\begin{tabular}{|c|c|c|c|c|}
\hline 0.1 & 0.4 & 3.0 & 4.5 & 0.0 \\
\hline 127.5 & 76.7 & 11.3 & 81.6 & 297.0 \\
\hline .. & 25.5 & .. & 3.6 & .. \\
\hline 0.3 & 19.2 & 23.9 & 25.8 & 41.4 \\
\hline .. & .. & 3.1 & 62.1 & 250.3 \\
\hline 7.1 & 21.6 & 138.3 & 69.9 & .. \\
\hline 6.8 & 20.9 & 94.6 & 97.2 & 0.3 \\
\hline 1168.3 & 562.2 & 2235.6 & 1353.4 & 1358.0 \\
\hline .. & &. & 1.4 & 0.1 \\
\hline 0.9 & 22.3 & 73.1 & 152.0 & 129.5 \\
\hline.. & & 114.6 & 287.6 & 990.1 \\
\hline. & 18.5 & 158.0 & 82.3 & 123.5 \\
\hline
\end{tabular}

\begin{tabular}{|r|r|r|}
\hline.. &.. & 114.6 \\
\hline.. & 18.5 & 158.0 \\
\hline 411.0 & 587.2 & 957.9 \\
\hline 42.9 & 9.4 & 45.0 \\
\hline.. &.. &.. \\
\hline
\end{tabular}

1208.0

\begin{tabular}{|l|l|}
\hline 46.8 \\
\hline 30.3 \\
\hline 90.9
\end{tabular}

1645.5
266.5

\section{DISBURSEMENTS}

2006-08 avg. 2009-011 avg. 2012-14 avg. 2015

649.5

899.9

1601.7

\begin{tabular}{r|r}
\hline.. \\
940.9 \\
244.5 \\
\hline 396.4
\end{tabular}

\begin{tabular}{r|r}
33.3 \\
\hline 18.3 \\
0.9
\end{tabular}

15.7

\begin{tabular}{|r|r|r}
\hline 15.7 & 4.4 &.. \\
\hline 56.9 & 109.5 & 814.8 \\
\hline 130.3 & 88.3 & 104.5 \\
\hline
\end{tabular}

\begin{tabular}{|r|}
\hline 0.2 \\
\hline 62.7 \\
\hline 50.7 \\
\hline 141.3 \\
\hline 70.6 \\
\hline
\end{tabular}

\begin{tabular}{r|r}
\hline 11.6 \\
\hline 101.4 \\
\hline 28.8
\end{tabular}

$\begin{array}{r}130.3 \\ 195.8 \\ \hline\end{array}$

\begin{tabular}{r|r}
195.8 \\
859.3 \\
\hline 65.2
\end{tabular}

\begin{tabular}{|r|r|}
\hline 88.3 & 104.5 \\
\hline 196.3 & 361.0 \\
\hline
\end{tabular}

\begin{tabular}{|l|l|}
\hline 196.3 & 361.0 \\
\hline 988.8 & 851.9 \\
\hline 140.0
\end{tabular}

\begin{tabular}{|l|r|}
\hline 988.8 & 851.9 \\
\hline 140.0 & 371.5 \\
\hline
\end{tabular}

\begin{tabular}{|r|r|r|r|}
\hline.. &.. &.. & 0.2 \\
\hline.. & 2.8 & 4.4 & 7.7 \\
\hline 11.1 & 31.2 & 64.4 & 23.8 \\
\hline 75.1 & 9.7 & 31.3 & 6.3 \\
\hline
\end{tabular}

..
175.6

\begin{tabular}{r|r}
\hline$\cdot$. & \\
0.9 & 0.2 \\
\hline
\end{tabular}

\begin{tabular}{|r|}
\hline 266.5 \\
\hline 331.0 \\
\hline 99.5
\end{tabular}

\begin{tabular}{r|}
\hline .2 \\
\hline 164.0 \\
1.6 \\
\hline 0.3
\end{tabular}

\begin{tabular}{|r|r|r|}
\hline 20.7 & 13.9 & 162.5 \\
\hline 0.0 & 0.0 &.. \\
\hline 331.4 & 14.8 & 23.3 \\
\hline.. &.. & 0.1 \\
\hline
\end{tabular}


Table A.20. Trade-related other official flows by individual recipient country (page 3 of 3 )

COMMITMENTS

2002-05 avg. 2006-08 avg. 2009-011 avg. 2012-14 avg. 2015

South Sudan

Sri Lanka

Sudan

Suriname

Swaziland

Syrian Arab Republic

Tajikistan

Tanzania

Thailand

Timor-Leste

Togo

Tonga

Tunisia

Turkey

Turkmenistan

Tuvalu

Uganda

Ukraine

Uruguay

Uzbekistan

Vanuatu

Venezuela

Viet Nam

Wallis and Futuna

West Bank and Gaza Strip

Yemen

Zambia

Zimbabwe

Total recipient countries

Non country specific

TOTAL TRADE-RELATED OOF

Source: OECD-DAC/CRS aid activity database.

\begin{tabular}{|r|r|r|r|}
\hline 17.9 & 44.7 & 64.4 & 55.5 \\
\hline 5.4 & 1.4 & 13.5 & 58.4 \\
\hline
\end{tabular}

\begin{tabular}{r|r}
58.4 & $\cdot \cdot$ \\
13.9 & 38.6
\end{tabular}

196.9

\begin{tabular}{r|r}
.. & \\
82.5 &
\end{tabular}

\begin{tabular}{|r|r|r|r|}
\hline 196.9 & 82.5 & 71.0 &.. \\
\hline.. &.. & 17.8 & 50.5 \\
\hline 6.8 & 17.5 & 8.3 & 97.4 \\
\hline 25.1 & 53.2 & 213.8 & 262.0 \\
\hline
\end{tabular}

\begin{tabular}{|r|r|r|r|}
\hline 25.1 & 53.2 & 213.8 & 262.0 \\
\hline.. &.. &.. & 26.1 \\
\hline 0.0 & 54.0 & 23.5 & 22.0 \\
\hline
\end{tabular}

\begin{tabular}{|r|r|r|r|}
\hline 0.0 & 54.0 & 23.5 & 22.0 \\
\hline.. &.. &.. &.. \\
\hline 307.4 & 493.4 & 826.9 & 339.7 \\
\hline 1134.8 & 3287.5 & 3196.4 & 3261.6 \\
\hline
\end{tabular}

\begin{tabular}{|c|c|c|c|c|}
\hline ט. & 政 & (3) & J 201.0 & J 027.2 \\
\hline .. & & 260.5 & 13.6 & 12.7 \\
\hline .. & .. & .. & .. & 0.2 \\
\hline 2.8 & 93.6 & 23.2 & 193.2 & 523.7 \\
\hline 57.2 & 409.8 & 1411.0 & 1590.5 & 2354.4 \\
\hline 228.6 & 132.9 & 212.9 & 605.6 & 772.7 \\
\hline 120.8 & 91.3 & 361.9 & 1085.7 & 778.5 \\
\hline
\end{tabular}

\begin{tabular}{|r|r|r|r|}
\hline 120.8 & 91.3 & 361.9 & 1085.7 \\
\hline 0.1 &.. & 1.7 & 1.1 \\
\hline 12.7 & 259.8 & 534.7 & 2.1 \\
\hline 27.1 & 714.3 & 1547.2 & 1584.5 \\
\hline 0.0 &.. &.. &.. \\
\hline.. & 120.1 & 10.9 & 16.0 \\
\hline.. & 157.0 & 10.9 & 15.1 \\
\hline 16.3 & 29.8 & 20.9 & 53.1 \\
\hline.. &.. &.. & 17.2 \\
\hline $\mathbf{1 4 5 9 1 . 8}$ & $\mathbf{2 4 3 9 4 . 9}$ & $\mathbf{4 1 8 2 6 . 9}$ & $\mathbf{4 2 9 3 7 . 5}$ \\
\hline 129.9 & 369.5 & 1705.1 & 3764.4 \\
\hline $\mathbf{1 4 7 2 1 . 7}$ & $\mathbf{2 4 7 6 4 . 5}$ & $\mathbf{4 3 5 3 2 . 1}$ & $\mathbf{4 6 7 0 1 . 9}$ \\
\hline
\end{tabular}

USD million (2015 constant)

DISBURSEMENTS

2006-08 avg. 2009-011 avg. 2012-14 avg. 2015

\begin{tabular}{ccc}
\hline & 2015 \\
\hline
\end{tabular}

482.1

\begin{tabular}{|r|r|r|r|r|r|r|r|r|r|}
\hline 122.5 & 230.6 & 155.8 & 176.9 & 482.1 & 8.8 & 119.5 & 187.5 & 206.2 \\
\hline
\end{tabular}

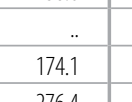

276.4

\begin{tabular}{r|r|r|}
11.8 & 215.2 & \\
2.1 & &
\end{tabular}

\begin{tabular}{|r|r|r|r|r|}
\hline 1188.0 & 197.4 & 593.7 & 285.1 & 682.0 \\
\hline 3627.2 & 1656.9 & 3135.9 & 2355.2 & 2696.7 \\
\hline 12.7 &.. & 11.4 & 38.9 & 19.4 \\
\hline
\end{tabular}

\begin{tabular}{|r|r|r|r|}
\hline.. & 42.6 & 30.3 \\
\hline 9.5 & 4.0 & 0.1 & 3.4 \\
\hline.. & 45.8 &.. &.. \\
\hline.. & 16.5 & 11.9 & 70.5 \\
\hline
\end{tabular}

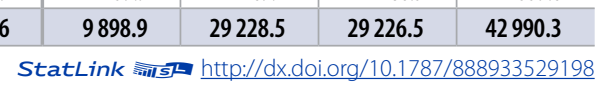





\section{ANNEX B \\ DAC LIST OF ODA RECIPIENTS BY INCOME GROUP}

\section{LEAST DEVELOPED COUNTRIES}

$\begin{array}{llll}\text { Afghanistan } & \text { Djibouti } & \text { Madagascar } & \text { Somalia } \\ \text { Angola } & \text { Equatorial Guinea } & \text { Malawi } & \text { South Sudan } \\ \text { Bangladesh } & \text { Eritrea } & \text { Mali } & \text { Sudan } \\ \text { Benin } & \text { Ethiopia } & \text { Mauritania } & \text { Tanzania } \\ \text { Bhutan } & \text { Gambia } & \text { Mozambique } & \text { Timor-Leste } \\ \text { Burkina Faso } & \text { Guinea } & \text { Myanmar } & \text { Togo } \\ \text { Burundi } & \text { Guinea-Bissau } & \text { Nepal } & \text { Tuvalu } \\ \text { Cambodia } & \text { Haiti } & \text { Niger } & \text { Uganda } \\ \text { Central African Republic } & \text { Kiribati } & \text { Rwanda } & \text { Vanuatu } \\ \text { Chad } & \text { Lao People's Democratic } & \text { SaoTome and Principe } & \text { Yemen } \\ \text { Comoros } & \text { Republic } & \text { Senegal } & \text { Zambia } \\ \text { Democratic Republic } & \text { Lesotho } & \text { Sierra Leone } & \\ \text { Of the Congo } & \text { Liberia } & \text { Solomon Islands } & \end{array}$

\section{OTHER LOW INCOME COUNTRIES}

(GNI per capita <=\$1 045 in 2013)

Democratic People's

Kenya

Tajikistan

Zimbabwe

Republic of Korea

\section{LOWER MIDDLE INCOME COUNTRIES AND TERRITORIES}

(GNI per capita $<=\$ 1046$ to $\$ 4125$ in 2013)

$\begin{array}{llll}\text { Armenia } & \text { Guatemala } & \text { Mongolia } & \text { Sri Lanka } \\ \text { Bolivia } & \text { Guyana } & \text { Morocco } & \text { Swaziland } \\ \text { Cabo Verde } & \text { Honduras } & \text { Nicaragua } & \text { Syrian Arab Republic } \\ \text { Cameroon } & \text { India } & \text { Nigeria } & \text { Tokelau* } \\ \text { Congo } & \text { Indonesia } & \text { Pakistan } & \text { Ukraine } \\ \text { Côte d'Ivoire } & \text { Kosovo' } & \text { Papua New Guinea } & \text { Uzbekistan } \\ \text { Egypt } & \text { Kyrgyzstan } & \text { Paraguay } & \text { Viet Nam } \\ \text { El Salvador } & \text { Micronesia } & \text { Philippines } & \text { West Bank and Gaza Strip } \\ \text { Georgia } & \text { Moldova } & \text { Samoa } & \end{array}$


UPPER MIDDLE INCOME COUNTRIES

(GNI per capita <= \$4 126 to $\$ 12745$ in 2013)

$\begin{array}{llll}\text { Albania } & \text { Cuba } & \text { Libya } & \text { Saint Lucia } \\ \text { Algeria } & \text { Dominica } & \text { Malaysia } & \text { Saint Vincent } \\ \text { Antigua and Barbuda } & \text { Dominican Republic } & \text { Maldives } & \text { and the Grenadines } \\ \text { Argentina } & \text { Ecuador } & \text { Marshall Islands } & \text { Serbia } \\ \text { Azerbaijan } & \text { Fiji } & \text { Mauritius } & \text { Seychelles } \\ \text { Belarus } & \text { Former Yugoslav } & \text { Mexico } & \text { South Africa } \\ \text { Belize } & \text { Republic of Macedonia } & \text { Montenegro } & \text { Suriname } \\ \text { Bosnia and Herzegovina } & \text { Gabon } & \text { Montserrat* } & \text { Thailand } \\ \text { Botswana } & \text { Grenada } & \text { Namibia } & \text { Tonga } \\ \text { Brazil } & \text { Iran } & \text { Nauru } & \text { Tunisia } \\ \text { Chile } & \text { Iraq } & \text { Niue } & \text { Turkey } \\ \text { People's Republic of China } & \text { Jamaica } & \text { Palau } & \text { Turkmenistan } \\ \text { Colombia } & \text { Jordan } & \text { Panama } & \text { Uruguay } \\ \text { Cook Islands } & \text { Kazakhstan } & \text { Peru } & \text { Venezuela } \\ \text { Costa Rica } & \text { Lebanon } & \text { Saint Helena* } & \text { Wallis and Futuna* } \\ \text { Notes: } & & \end{array}$




\section{ANNEX C DAC LIST OF ODA-ELIGIBLE COUNTRIES BY REGION}

AFRICA

\section{North of Sahara}

Algeria

Egypt

Libya

Morocco

Tunisia

South of Sahara
Angola
Benin
Botswana
Burkina Faso
Burundi
Cabo Verde
Cameroon
Central African Republic
Chad
Comoros
Congo
Côte d'Ivoire
Democratic Republic
of the Congo
Djibouti
Equatorial Guinea
Eritrea

\section{AMERICA}

North and Central America

Antigua and Barbuda

Belize

Costa Rica

Cuba

Dominica

Dominican Republic

El Salvador

Grenada

Guatemala

Haiti
Honduras

Jamaica

Mexico

Montserrat

Nicaragua

Panama

Saint Lucia

Saint Vincent

and the Grenadines

West Indies, regionals
Ethiopia

Gabon

Gambia

Ghana

Guinea

Guinea-Bissau

Kenya

Lesotho

Liberia

Madagascar

Malawi

Mali

Mauritania

Mauritius

Mozambique

Namibia

Niger
Nigeria

Rwanda

Saint Helena

Sao Tome and Principe Senegal

Seychelles

Sierra Leone

Somalia

South Africa

South Sudan

Sudan

Swaziland

Tanzania

Togo

Uganda

Zambia

Zimbabwe

\section{South America}

$\begin{array}{ll}\text { Argentina } & \text { Guyana } \\ \text { Bolivia } & \text { Paraguay } \\ \text { Brazil } & \text { Peru } \\ \text { Chile } & \text { Suriname } \\ \text { Colombia } & \text { Uruguay } \\ \text { Ecuador } & \text { Venezuela }\end{array}$


ASIA

South and Central Asia

Afghanistan

Armenia

Azerbaijan

Bangladesh

Bhutan

Georgia

India

Kazakhstan

Kyrgyzstan
Maldives

Myanmar

Nepal

Pakistan

Sri Lanka

Tajikistan

Turkmenistan

Uzbekistan
Middle East

Iran

Iraq

Jordan

Lebanon

Syrian Arab Republic

West Bank and Gaza Strip

Yemen
Far East Asia

Cambodia

China (People's Republic of)

Democratic People's

Republic of Korea

Indonesia

Lao People's

Democratic Republic

Malaysia

Mongolia

Philippines

Thailand

Timor-Leste

Viet Nam

Moldova

Montenegro

Serbia

Papua New Guinea

Tonga

Samoa

Tuvalu

Solomon Islands

Tokelau
Turkey

Ukraine
Vanuatu

Wallis and Futuna

Nive

Palau 


\section{ANNEX D}

\section{AID FOR TRADE: SECTORS AND DEFINITIONS}

\section{CRS PURPOSE CODE DESCRIPTION}

Trade policy and regulations and trade-related adjustment

\section{CLARIFICATIONS / ADDITIONAL NOTES ON COVERAGE}

Economic infrastructure

TRANSPORT AND STORAGE

\begin{tabular}{|l|l|l|}
\hline 21010 & $\begin{array}{l}\text { Transport policy and } \\
\text { administrative management }\end{array}$ & $\begin{array}{l}\text { Transport sector policy, planning and programmes; aid to transport } \\
\text { ministries; institution capacity building and advice; unspecified transport; } \\
\text { activities that combine road, rail, water and/or air transport. }\end{array}$ \\
\hline 21020 & Road transport & $\begin{array}{l}\text { Road infrastructure, road vehicles; passenger road transport, motor } \\
\text { passenger cars. }\end{array}$ \\
\hline 21030 & Rail transport & $\begin{array}{l}\text { Rail infrastructure, rail equipment, locomotives, other rolling stock; } \\
\text { including light rail (tram) and underground systems. }\end{array}$ \\
\hline
\end{tabular}




\begin{tabular}{|c|c|c|}
\hline 21040 & Water transport & $\begin{array}{l}\text { Harbours and docks, harbour guidance systems, ships and boats; river } \\
\text { and other inland water transport, inland barges and vessels. }\end{array}$ \\
\hline 21050 & Air transport & $\begin{array}{l}\text { Airports, airport guidance systems, aeroplanes, aeroplane maintenance } \\
\text { equipment. }\end{array}$ \\
\hline 21061 & Storage & Whether or not related to transportation. \\
\hline 21081 & $\begin{array}{l}\text { Education and training in } \\
\text { transport and storage }\end{array}$ & \\
\hline \multicolumn{3}{|c|}{ COMMUNICATIONS } \\
\hline 22010 & $\begin{array}{l}\text { Communications policy and } \\
\text { administrative management }\end{array}$ & $\begin{array}{l}\text { Communications sector policy, planning and programmes; institution } \\
\text { capacity building and advice; including postal services development; } \\
\text { unspecified communications activities. }\end{array}$ \\
\hline 22020 & Telecommunications & Telephone networks, telecommunication satellites, earth stations. \\
\hline 22030 & Radio/television/print media & Radio and TV links, equipment; newspapers; printing and publishing. \\
\hline 22040 & $\begin{array}{l}\text { Information and communication } \\
\text { technology (ICT) }\end{array}$ & $\begin{array}{l}\text { Computer hardware and software; internet access; IT training. When } \\
\text { sector cannot be specified. }\end{array}$ \\
\hline \multicolumn{3}{|c|}{ ENERGY GENERATION AND SUPPLY } \\
\hline 23110 & $\begin{array}{l}\text { Energy policy and administrative } \\
\text { management }\end{array}$ & $\begin{array}{l}\text { Energy sector policy, planning; aid to energy ministries; institution } \\
\text { capacity building and advice; unspecified energy activities. }\end{array}$ \\
\hline 23111 & $\begin{array}{l}\text { Energy sector policy, planning and } \\
\text { administration }\end{array}$ & \\
\hline 23112 & Energy regulation & $\begin{array}{l}\text { Regulation of the energy sector, including wholesale and retail electricity } \\
\text { provision. }\end{array}$ \\
\hline 23181 & Energy education/training & All levels of training not included elsewhere. \\
\hline 23182 & Energy research & Including general inventories, surveys. \\
\hline 23183 & $\begin{array}{l}\text { Energy conservation and } \\
\text { demand-side efficiency }\end{array}$ & $\begin{array}{l}\text { All projects in support of energy demand reduction, e.g. building and } \\
\text { industry upgrades, smart grids, metering and tariffs. Also includes } \\
\text { efficient cook-stoves and biogas projects. }\end{array}$ \\
\hline 23210 & $\begin{array}{l}\text { Energy generation, renewable } \\
\text { sources - multiple technologies }\end{array}$ & $\begin{array}{l}\text { Renewable energy generation programmes that cannot be attributed to } \\
\text { one single technology (codes } 23220 \text { through } 23280 \text { below). Fuelwood/ } \\
\text { charcoal production should be included under forestry } 31261 \text {. }\end{array}$ \\
\hline 23220 & Hydro-electric power plants & Including energy generating river barges. \\
\hline 23230 & Solar energy & Including photo-voltaic cells, solar thermal applications and solar heating. \\
\hline 23240 & Wind energy & Wind energy for water lifting and electric power generation. \\
\hline 23250 & Marine energy & Including ocean thermal energy conversion, tidal and wave power. \\
\hline 23260 & Geothermal energy & $\begin{array}{l}\text { Use of geothermal energy for generating electric power or directly as } \\
\text { heat for agriculture, etc. }\end{array}$ \\
\hline
\end{tabular}




\begin{tabular}{|c|c|c|}
\hline 23270 & Biofuel-fired power plants & $\begin{array}{l}\text { Use of solids and liquids produced from biomass for direct power } \\
\text { generation. Also includes biogases from anaerobic fermentation (e.g. } \\
\text { landfill gas, sewage sludge gas, fermentation of energy crops and } \\
\text { manure) and thermal processes (also known as syngas); waste-fired } \\
\text { power plants making use of biodegradable municipal waste (household } \\
\text { waste and waste from companies and public services that resembles } \\
\text { household waste, collected at installations specifically designed for their } \\
\text { disposal with recovery of combustible liquids, gases or heat). See code } \\
23360 \text { for non- renewable waste-fired power plants. }\end{array}$ \\
\hline 23310 & $\begin{array}{l}\text { Energy generation, non- } \\
\text { renewable sources, unspecified }\end{array}$ & $\begin{array}{l}\text { Thermal power plants including when energy source cannot be } \\
\text { determined; combined gas-coal power plants. }\end{array}$ \\
\hline 23320 & Coal-fired electric power plants & Thermal electric power plants that use coal as the energy source. \\
\hline 23330 & Oil-fired electric power plants & $\begin{array}{l}\text { Thermal electric power plants that use fuel oil or diesel fuel as the energy } \\
\text { source. }\end{array}$ \\
\hline 23340 & $\begin{array}{l}\text { Natural gas-fired electric power } \\
\text { plants }\end{array}$ & Electric power plants that are fuelled by natural gas. \\
\hline 23350 & $\begin{array}{l}\text { Fossil fuel electric power plants } \\
\text { with carbon capture and storage } \\
\text { (CCS) }\end{array}$ & $\begin{array}{l}\text { Fossil fuel electric power plants employing technologies to capture } \\
\text { carbon dioxide emissions. CCS not related to power plants should be } \\
\text { included under } 41020 \text {. CCS activities are not reportable as ODA. }\end{array}$ \\
\hline 23360 & $\begin{array}{l}\text { Non-renewable waste-fired } \\
\text { electric power plants }\end{array}$ & $\begin{array}{l}\text { Electric power plants that use non-biodegradable industrial and } \\
\text { municipal waste as the energy source. }\end{array}$ \\
\hline 23410 & $\begin{array}{l}\text { Hybrid energy electric power } \\
\text { plants }\end{array}$ & $\begin{array}{l}\text { Electric power plants that make use of both non-renewable and } \\
\text { renewable energy sources. }\end{array}$ \\
\hline 23510 & $\begin{array}{l}\text { Nuclear energy electric power } \\
\text { plants }\end{array}$ & Including nuclear safety. \\
\hline 23610 & Heat plants & Power plants which are designed to produce heat only. \\
\hline 23620 & District heating and cooling & $\begin{array}{l}\text { Distribution of heat generated in a centralised location, or delivery of } \\
\text { chilled water, for residential and commercial heating or cooling purposes. }\end{array}$ \\
\hline 23630 & $\begin{array}{l}\text { Electric power transmission and } \\
\text { distribution }\end{array}$ & $\begin{array}{l}\text { Grid distribution from power source to end user; transmission lines. } \\
\text { Also includes storage of energy to generate power (e.g. pumped hydro, } \\
\text { batteries) and the extension of grid access, often to rural areas. }\end{array}$ \\
\hline 23640 & Gas distribution & Delivery for use by ultimate consumer. \\
\hline \multicolumn{3}{|c|}{ BANKING AND FINANCIAL SERVICES } \\
\hline 24010 & $\begin{array}{l}\text { Financial policy and administrative } \\
\text { management }\end{array}$ & $\begin{array}{l}\text { Finance sector policy, planning and programmes; institution capacity } \\
\text { building and advice; financial markets and systems. }\end{array}$ \\
\hline 24020 & Monetary institutions & Central banks. \\
\hline 24030 & $\begin{array}{l}\text { Formal sector financial } \\
\text { intermediaries }\end{array}$ & $\begin{array}{l}\text { All formal sector financial intermediaries; credit lines; insurance, leasing, } \\
\text { venture capital, etc. (except when focused on only one sector). }\end{array}$ \\
\hline 24040 & $\begin{array}{l}\text { Informal/semi-formal financial } \\
\text { intermediaries }\end{array}$ & Micro credit, savings and credit co-operatives etc. \\
\hline 24081 & $\begin{array}{l}\text { Education/training in banking and } \\
\text { financial services }\end{array}$ & \\
\hline
\end{tabular}




\section{BUSINESS AND OTHER SERVICES}

\begin{tabular}{|c|c|c|}
\hline 25010 & $\begin{array}{l}\text { Business support services and } \\
\text { institutions }\end{array}$ & $\begin{array}{l}\text { Support to trade and business associations, chambers of commerce; } \\
\text { legal and regulatory reform aimed at improving business and investment } \\
\text { climate; private sector institution capacity building and advice; trade } \\
\text { information; public-private sector networking including trade fairs; } \\
\text { e-commerce. Where sector cannot be specified: general support to } \\
\text { private sector enterprises (in particular, use code } 32130 \text { for enterprises in } \\
\text { the industrial sector). }\end{array}$ \\
\hline 25020 & Privatisation & $\begin{array}{l}\text { When sector cannot be specified. Including general state enterprise } \\
\text { restructuring or demonopolisation programmes; planning, programming, } \\
\text { advice. }\end{array}$ \\
\hline \multicolumn{3}{|c|}{ AGRICULTURE } \\
\hline 31110 & $\begin{array}{l}\text { Agricultural policy and } \\
\text { administrative management }\end{array}$ & $\begin{array}{l}\text { Agricultural sector policy, planning and programmes; aid to agricultural } \\
\text { ministries; institution capacity building and advice; unspecified } \\
\text { agriculture. }\end{array}$ \\
\hline 31120 & Agricultural development & Integrated projects; farm development. \\
\hline 31130 & Agricultural land resources & $\begin{array}{l}\text { Including soil degradation control; soil improvement; drainage of water } \\
\text { logged areas; soil desalination; agricultural land surveys; land reclamation; } \\
\text { erosion control, desertification control. }\end{array}$ \\
\hline 31140 & Agricultural water resources & $\begin{array}{l}\text { Irrigation, reservoirs, hydraulic structures, ground water exploitation for } \\
\text { agricultural use. }\end{array}$ \\
\hline 31150 & Agricultural inputs & Supply of seeds, fertilizers, agricultural machinery/equipment. \\
\hline 31161 & Food crop production & $\begin{array}{l}\text { Including grains (wheat, rice, barley, maize, rye, oats, millet, sorghum); } \\
\text { horticulture; vegetables; fruit and berries; other annual and perennial } \\
\text { crops. [Use code } 32161 \text { for agro-industries.] }\end{array}$ \\
\hline 31162 & Industrial crops/export crops & $\begin{array}{l}\text { Including sugar; coffee, cocoa, tea; oil seeds, nuts, kernels; fibre crops; } \\
\text { tobacco; rubber. [Use code } 32161 \text { for agro-industries.] }\end{array}$ \\
\hline 31163 & Livestock & Animal husbandry; animal feed aid. \\
\hline 31164 & Agrarian reform & Including agricultural sector adjustment. \\
\hline 31165 & $\begin{array}{l}\text { Agricultural alternative } \\
\text { development }\end{array}$ & $\begin{array}{l}\text { Projects to reduce illicit drug cultivation through other agricultural } \\
\text { marketing and production opportunities (see code } 43050 \text { for non- } \\
\text { agricultural alternative development). }\end{array}$ \\
\hline 31166 & Agricultural extension & Non-formal training in agriculture. \\
\hline 31181 & Agricultural education/training & \\
\hline 31182 & Agricultural research & $\begin{array}{l}\text { Plant breeding, physiology, genetic resources, ecology, taxonomy, disease } \\
\text { control, agricultural bio-technology; including livestock research (animal } \\
\text { health, breeding and genetics, nutrition, physiology). }\end{array}$ \\
\hline 31191 & Agricultural services & $\begin{array}{l}\text { Marketing policies and organisation; storage and transportation, creation } \\
\text { of strategic reserves. }\end{array}$ \\
\hline 31192 & $\begin{array}{l}\text { Plant and post-harvest protection } \\
\text { and pest control }\end{array}$ & $\begin{array}{l}\text { Including integrated plant protection, biological plant protection } \\
\text { activities, supply and management of agrochemicals, supply of pesticides, } \\
\text { plant protection policy and legislation. }\end{array}$ \\
\hline 31193 & Agricultural financial services & $\begin{array}{l}\text { Financial intermediaries for the agricultural sector including credit } \\
\text { schemes; crop insurance. }\end{array}$ \\
\hline
\end{tabular}




\begin{tabular}{|c|c|c|}
\hline 31194 & Agricultural co-operatives & Including farmers' organisations. \\
\hline 31195 & Livestock/veterinary services & Animal health and management, genetic resources, feed resources. \\
\hline 31195 & Livestock/veterinary services & Animal health and management, genetic resources, feed resources. \\
\hline \multicolumn{3}{|c|}{ FORESTRY } \\
\hline 31210 & $\begin{array}{l}\text { Forestry policy and administrative } \\
\text { management }\end{array}$ & $\begin{array}{l}\text { Forestry sector policy, planning and programmes; institution capacity } \\
\text { building and advice; forest surveys; unspecified forestry and agro-forestry } \\
\text { activities. }\end{array}$ \\
\hline 31220 & Forestry development & $\begin{array}{l}\text { Afforestation for industrial and rural consumption; exploitation and } \\
\text { utilisation; erosion control, desertification control; integrated forestry } \\
\text { projects. }\end{array}$ \\
\hline 31261 & Fuelwood/charcoal & $\begin{array}{l}\text { Forestry development whose primary purpose is production of fuelwood } \\
\text { and charcoal. }\end{array}$ \\
\hline 31281 & Forestry education/training & \\
\hline 31282 & Forestry research & $\begin{array}{l}\text { Including artificial regeneration, genetic improvement, production } \\
\text { methods, fertilizer, harvesting. }\end{array}$ \\
\hline 31291 & Forestry services & \\
\hline \multicolumn{3}{|c|}{ FISHING } \\
\hline 31310 & $\begin{array}{l}\text { Fishing policy and administrative } \\
\text { management }\end{array}$ & $\begin{array}{l}\text { Fishing sector policy, planning and programmes; institution capacity } \\
\text { building and advice; ocean and coastal fishing; marine and freshwater fish } \\
\text { surveys and prospecting; fishing boats/equipment; unspecified fishing } \\
\text { activities. }\end{array}$ \\
\hline 31320 & Fishery development & $\begin{array}{l}\text { Exploitation and utilisation of fisheries; fish stock protection; aquaculture; } \\
\text { integrated fishery projects. }\end{array}$ \\
\hline 31381 & Fishery education/training & \\
\hline 31382 & Fishery research & Pilot fish culture; marine/freshwater biological research. \\
\hline 31391 & Fishery services & Fishing harbours; fish markets; fishery transport and cold storage. \\
\hline \multicolumn{3}{|c|}{ INDUSTRY } \\
\hline 32110 & $\begin{array}{l}\text { Industrial policy and } \\
\text { administrative management }\end{array}$ & $\begin{array}{l}\text { Industrial sector policy, planning and programmes; institution capacity } \\
\text { building and advice; unspecified industrial activities; manufacturing of } \\
\text { goods not specified below. }\end{array}$ \\
\hline 32120 & Industrial development & \\
\hline 32130 & $\begin{array}{l}\text { Small and medium-sized } \\
\text { enterprises (SME) development }\end{array}$ & $\begin{array}{l}\text { Direct support to the development of small and medium-sized } \\
\text { enterprises in the industrial sector, including accounting, auditing and } \\
\text { advisory services. }\end{array}$ \\
\hline 32140 & Cottage industries and handicraft & \\
\hline 32161 & Agro-industries & $\begin{array}{l}\text { Staple food processing, dairy products, slaughter houses and equipment, } \\
\text { meat and fish processing and preserving, oils/fats, sugar refineries, } \\
\text { beverages/tobacco, animal feeds production. }\end{array}$ \\
\hline 32162 & Forest industries & Wood production, pulp/paper production. \\
\hline 32163 & Textiles, leather and substitutes & Including knitting factories. \\
\hline
\end{tabular}




\begin{tabular}{|c|c|c|}
\hline 32164 & Chemicals & $\begin{array}{l}\text { Industrial and non-industrial production facilities; includes pesticides } \\
\text { production. }\end{array}$ \\
\hline 32165 & Fertilizer plants & \\
\hline 32166 & Cement/lime/plaster & \\
\hline 32167 & Energy manufacturing & Including gas liquefaction; petroleum refineries. \\
\hline 32168 & Pharmaceutical production & $\begin{array}{l}\text { Medical equipment/supplies; drugs, medicines, vaccines; hygienic } \\
\text { products. }\end{array}$ \\
\hline 32169 & Basic metal industries & Iron and steel, structural metal production. \\
\hline 32170 & Non-ferrous metal industries & \\
\hline 32171 & Engineering & $\begin{array}{l}\text { Manufacturing of electrical and non-electrical machinery, engines/ } \\
\text { turbines. }\end{array}$ \\
\hline 32172 & Transport equipment industry & $\begin{array}{l}\text { Shipbuilding, fishing boats building; railroad equipment; motor vehicles } \\
\text { and motor passenger cars; aircraft; navigation/guidance systems. }\end{array}$ \\
\hline 32182 & $\begin{array}{l}\text { Technological research and } \\
\text { development }\end{array}$ & $\begin{array}{l}\text { Including industrial standards; quality management; metrology; testing; } \\
\text { accreditation; certification. }\end{array}$ \\
\hline \multicolumn{3}{|c|}{ MINERAL RESOURCES AND MINING } \\
\hline 32210 & $\begin{array}{l}\text { Mineral/mining policy and } \\
\text { administrative management }\end{array}$ & $\begin{array}{l}\text { Mineral and mining sector policy, planning and programmes; mining } \\
\text { legislation, mining cadastre, mineral resources inventory, information } \\
\text { systems, institution capacity building and advice; unspecified mineral } \\
\text { resources exploitation. }\end{array}$ \\
\hline 32220 & $\begin{array}{l}\text { Mineral prospection and } \\
\text { exploration }\end{array}$ & $\begin{array}{l}\text { Geology, geophysics, geochemistry; excluding hydrogeology (14010) } \\
\text { and environmental geology (41010), mineral extraction and processing, } \\
\text { infrastructure, technology, economics, safety and environment } \\
\text { management. }\end{array}$ \\
\hline 32261 & Coal & Including lignite and peat. \\
\hline 32262 & Oil and gas & $\begin{array}{l}\text { Petroleum, natural gas, condensates, liquefied petroleum gas (LPG), } \\
\text { liquefied natural gas (LNG); including drilling and production. }\end{array}$ \\
\hline 32263 & Ferrous metals & Iron and ferro-alloy metals. \\
\hline 32264 & Nonferrous metals & Aluminium, copper, lead, nickel, tin, zinc. \\
\hline 32265 & Precious metals/materials & Gold, silver, platinum, diamonds, gemstones. \\
\hline 32266 & Industrial minerals & $\begin{array}{l}\text { Baryte, limestone, feldspar, kaolin, sand, gypsym, gravel, ornamental } \\
\text { stones. }\end{array}$ \\
\hline 32267 & Fertilizer minerals & Phosphates, potash. \\
\hline \multirow[t]{2}{*}{32268} & Offshore minerals & Polymetallic nodules, phosphorites, marine placer deposits. \\
\hline & TOURISM & \\
\hline 33210 & $\begin{array}{l}\text { Tourism policy and administrative } \\
\text { management }\end{array}$ & \\
\hline
\end{tabular}




\section{ANNEX E}

\section{AID-FOR-TRADE CASE STORIES OVERVIEW}

\begin{tabular}{|c|c|c|c|}
\hline $\begin{array}{l}\text { Reference } \\
\text { number }\end{array}$ & Author & Title & Sector \\
\hline \multirow[t]{2}{*}{1} & $\begin{array}{l}\text { International Trade } \\
\text { Centre }\end{array}$ & $\begin{array}{l}\text { Moroccan businesses boost exports of processed food, } \\
\text { seafood and leather goods }\end{array}$ & Public sector case story \\
\hline & \multicolumn{3}{|c|}{$\begin{array}{l}\text { www.oecd.org/aidfortrade/casestories/casestories-2017/CS\%2001-Moroccan-businesses-boost-exports-of-processed- } \\
\text { foods-seafood-and-leather-goods\%20.pdf }\end{array}$} \\
\hline \multirow[t]{2}{*}{2} & $\begin{array}{l}\text { Alliance for Affordable } \\
\text { Internet (A4AI) }\end{array}$ & Affordability Report 2015/16 & $\begin{array}{l}\text { Academia and NGOs } \\
\text { case story }\end{array}$ \\
\hline & \multicolumn{3}{|c|}{ www.oecd.org/aidfortrade/casestories/casestories-2017/CS-02-A4AI-Affordability-Report-2015-16.pdf } \\
\hline \multirow[t]{2}{*}{3} & $\begin{array}{l}\text { Alliance for Affordable } \\
\text { Internet (A4Al) }\end{array}$ & $\begin{array}{l}\text { Affordable internet in Ghana: the status quo and } \\
\text { the path ahead }\end{array}$ & $\begin{array}{l}\text { Academia and NGOs } \\
\text { case story }\end{array}$ \\
\hline & \multicolumn{3}{|c|}{$\underline{\text { www.oecd.org/aidfortrade/casestories/casestories-2017/CS-03-A4Al-Affordable-Internet-in-Ghana.pdf }}$} \\
\hline \multirow[t]{2}{*}{4} & $\begin{array}{l}\text { Alliance for Affordable } \\
\text { Internet (A4Al) }\end{array}$ & Affordable Internet in the Dominican Republic & $\begin{array}{l}\text { Academia and NGOs } \\
\text { case story }\end{array}$ \\
\hline & \multicolumn{3}{|c|}{ www.oecd.org/aidfortrade/casestories/casestories-2017/CS-04-A4Al-Affordable-Internet-in-the-Dominican-Republic.pdf } \\
\hline \multirow[t]{2}{*}{5} & $\begin{array}{l}\text { Alliance for Affordable } \\
\text { Internet (A4Al) }\end{array}$ & Delivering affordable internet in Myanmar & $\begin{array}{l}\text { Academia and NGOs } \\
\text { case story }\end{array}$ \\
\hline & \multicolumn{3}{|c|}{ http://www.oecd.org/aidfortrade/casestories/casestories-2017/CS\%2005-A4Al-Affordable-Internet-in-Myanmar.pdf } \\
\hline \multirow[t]{2}{*}{6} & $\begin{array}{l}\text { Alliance for Affordable } \\
\text { Internet (A4Al) }\end{array}$ & $\begin{array}{l}\text { Nigeria: how Africa's largest economy is prioritising } \\
\text { affordable internet }\end{array}$ & $\begin{array}{l}\text { Academia and NGOs } \\
\text { case story }\end{array}$ \\
\hline & \multicolumn{3}{|c|}{ www.oecd.org/aidfortrade/casestories/casestories-2017/CS-06-A4AI-Affordable-Internet-in-Nigeria.pdf } \\
\hline \multirow[t]{2}{*}{7} & Mace Promotions, Ltd. & Sustainability and Empowerment Initiative & Private sector case story \\
\hline & \multicolumn{3}{|c|}{ www.oecd.org/aidfortrade/casestories/casestories-2017/CS-07-Mace-Sustainability-and-Empowerment-Initiative.pdf } \\
\hline \multirow[t]{2}{*}{8} & Samoa & Samoa Submarine Cable Project & Public sector case story \\
\hline & \multicolumn{3}{|c|}{$\underline{\text { www.oecd.org/aidfortrade/casestories/casestories-2017/CS-08-Samoa-Submarine-Cable-Project.pdf }}$} \\
\hline \multirow[t]{2}{*}{9} & ITU & Standardization enabling trust in cyberspace & Public sector case story \\
\hline & \multicolumn{3}{|c|}{ www.oecd.org/aidfortrade/casestories/casestories-2017/CS-09-ITU-Standardization-enabling-trust-in-cyber-space\%20.pdf } \\
\hline \multirow[t]{2}{*}{10} & ITU & ICTs for Sustainable Development & Public sector case story \\
\hline & \multicolumn{3}{|c|}{$\underline{\text { www.oecd.org/aidfortrade/casestories/casestories-2017/CS-10-ITU-ICTs-for-sustainable-development.pdf }}$} \\
\hline 11 & $\begin{array}{l}\text { Broadband } \\
\text { Commission } \\
\text { for Sustainable } \\
\text { Development / ITU }\end{array}$ & $\begin{array}{l}\text { Where does the UN Broadband Commission for Sustainable } \\
\text { Development believe broadband can drive significant } \\
\text { progress in sustainable development? }\end{array}$ & Public sector case story \\
\hline
\end{tabular}




\begin{tabular}{|c|c|c|c|}
\hline \multirow[t]{2}{*}{12} & Chinese Taipei & Repair and Upgrade of Bonriki International Airport (Kiribati) & Public sector case story \\
\hline & \multicolumn{3}{|c|}{$\begin{array}{l}\text { www.oecd.org/aidfortrade/casestories/casestories-2017/CS-12-Chinese-Taipei-Repair-and-Upgrade-of-Bonkiri- } \\
\underline{\text { International-Airport.pdf }}\end{array}$} \\
\hline \multirow[t]{2}{*}{13} & Chinese Taipei & $\begin{array}{l}\text { Belize City House of Culture and Downtown Rejuvenation } \\
\text { Project (Belize) }\end{array}$ & Public sector case story \\
\hline & \multicolumn{3}{|c|}{$\begin{array}{l}\text { www.oecd.org/aidfortrade/casestories/casestories-2017/CS-13-Chinese-Taipei-Belize-City-House-of-Culture-and- } \\
\text { Downtown-Rejuvenation-Project.pdf }\end{array}$} \\
\hline \multirow[t]{2}{*}{14} & Chinese Taipei & $\begin{array}{l}\text { Project for strengthening farmers' organizations and improving } \\
\text { fruit and vegetable production technology in Saint Vincent and } \\
\text { the Grenadines }\end{array}$ & Public sector case story \\
\hline & \multicolumn{3}{|c|}{$\begin{array}{l}\text { www.oecd.org/aidfortrade/casestories/casestories-2017/CS-14-Chinese-Taipei-St-Vincent-Project-for-Strengthening- } \\
\text { Farmers-Organizations.pdf }\end{array}$} \\
\hline \multirow[t]{2}{*}{15} & $\begin{array}{l}\text { African Development } \\
\text { Bank }\end{array}$ & $\begin{array}{l}\text { Impact of mobile payments and banking on the unbanked in } \\
\text { African countries }\end{array}$ & Public sector case story \\
\hline & \multicolumn{3}{|c|}{$\begin{array}{l}\text { www.oecd.org/aidfortrade/casestories/casestories-2017/CS-15-AfDB-Mobile-payments-and-banking-on-the-unbanked-in- } \\
\text { African-countries.pdf }\end{array}$} \\
\hline \multirow[t]{2}{*}{16} & $\begin{array}{l}\text { African Development } \\
\text { Bank }\end{array}$ & Connect Africa Initiative & Public sector case story \\
\hline & \multicolumn{3}{|c|}{ www.oecd.org/aidfortrade/casestories/casestories-2017/CS-16-AfDB-Connect-Africa-Initiative.pdf } \\
\hline \multirow[t]{2}{*}{17} & 1Point Commerce & $\begin{array}{l}\text { Global commerce made easy, simple, and almost local } \\
\text { for buyers to buy better and sellers to sell more; enable } \\
\text { businesses to expand into new markets at minimal costs } \\
\text { and risk }\end{array}$ & Private sector case story \\
\hline & \multicolumn{3}{|c|}{ www.oecd.org/aidfortrade/casestories/casestories-2017/CS-17-1Point-Commerce-Global-Ecommerce-Network.pdf } \\
\hline \multirow[t]{2}{*}{18} & Intel Corporation & Intel ${ }^{\circledR}$ She Will Connect & Private sector case story \\
\hline & \multicolumn{3}{|c|}{ www.oecd.org/aidfortrade/casestories/casestories-2017/CS-18-Intel-She-Will-Connect.pdf } \\
\hline \multirow[t]{2}{*}{19} & Intel Corporation & Connection equals opportunity & Private sector case story \\
\hline & \multicolumn{3}{|c|}{ www.oecd.org/aidfortrade/casestories/casestories-2017/CS-19-Intel-Connection-Equals-Opportunity.pdf } \\
\hline \multirow[t]{2}{*}{20} & The Internet Society & Promoting Content in Africa & $\begin{array}{l}\text { Academia and NGOs } \\
\text { case story }\end{array}$ \\
\hline & \multicolumn{3}{|c|}{ www.oecd.org/aidfortrade/casestories/casestories-2017/CS-20-Internet-Society-Promoting-Content-In-Africa.pdf } \\
\hline \multirow[t]{2}{*}{21} & Alibaba Group & About the "Rural Taobao" Initiative & Private sector case story \\
\hline & \multicolumn{3}{|c|}{ www.oecd.org/aidfortrade/casestories/casestories-2017/CS-21-Alibaba-Group-About-the-Rural-Taobao-Initiative.pdf } \\
\hline \multirow[t]{2}{*}{22} & Alibaba Group & The life of Taobao couriers & Private sector case story \\
\hline & \multicolumn{3}{|c|}{ www.oecd.org/aidfortrade/casestories/casestories-2017/CS-22-Alibaba-Group-The-Life-of-Taobao-Couriers.pdf } \\
\hline \multirow[t]{2}{*}{23} & Alibaba Group & E-commerce in rural China & Private sector case story \\
\hline & \multicolumn{3}{|c|}{ www.oecd.org/aidfortrade/casestories/casestories-2017/CS-23-Alibaba-Group-E-commerce-in-Rural-China.pdf } \\
\hline \multirow[t]{2}{*}{24} & Indonesia & $\begin{array}{l}\text { Capacity Building Program on Quarantine Inspection and } \\
\text { Agricultural Trade-Related Supply Side Capacity }\end{array}$ & Public sector case story \\
\hline & \multicolumn{3}{|c|}{$\begin{array}{l}\text { www.oecd.org/aidfortrade/casestories/casestories-2017/CS-24-Quarantine-Inspection-and-Agricultural-Trade-Supply- } \\
\text { Side-Capacity.pdf }\end{array}$} \\
\hline
\end{tabular}




\begin{tabular}{|c|c|c|c|}
\hline \multirow[t]{2}{*}{25} & GSMA & Multiple & Private sector case story \\
\hline & \multicolumn{3}{|c|}{ www.oecd.org/aidfortrade/casestories/casestories-2017/CS-25-Telenor-Mobile-Internet-Training-GSMA.pdf } \\
\hline \multirow[t]{2}{*}{26} & CUTS International & $\begin{array}{l}\text { Promoting Regional Connectivity through BBIN MVA: } \\
\text { Role of TIR Convention }\end{array}$ & Public sector case story \\
\hline & \multicolumn{3}{|c|}{$\begin{array}{l}\text { www.oecd.org/aidfortrade/casestories/casestories-2017/CS-26-Promoting-Regional-Connectivity-through-BBIN-MVA- } \\
\text { Role-of-TIR-Convention.pdf }\end{array}$} \\
\hline \multirow[t]{2}{*}{27} & eBay with ITC & $\begin{array}{l}\text { E-commerce development and efforts to bridge } \\
\text { the "digital divide". }\end{array}$ & Private sector case story \\
\hline & \multicolumn{3}{|c|}{ www.oecd.org/aidfortrade/casestories/casestories-2017/CS-27-eBay-ITC-Partnership.pdf } \\
\hline \multirow[t]{2}{*}{28} & eBay & Crece Con eBay & Private sector case story \\
\hline & \multicolumn{3}{|c|}{ www.oecd.org/aidfortrade/casestories/casestories-2017/CS-28-Crece-Con-eBay.pdf } \\
\hline \multirow[t]{2}{*}{29} & $\begin{array}{l}\text { International Trade } \\
\text { Centre }\end{array}$ & $\begin{array}{l}\text { T4SD: Sustainability Map: Helping businesses chart a path } \\
\text { to more sustainable trade }\end{array}$ & Public sector case story \\
\hline & \multicolumn{3}{|c|}{$\begin{array}{l}\text { www.oecd.org/aidfortrade/casestories/casestories-2017/CS-29-Map-A-Helping-businesses-chart-a-path-to-more- } \\
\text { sustainable-trade.pdf }\end{array}$} \\
\hline \multirow[t]{2}{*}{30} & $\begin{array}{l}\text { International Trade } \\
\text { Centre }\end{array}$ & $\begin{array}{l}\text { NTM: Increase Transparency, Identify Challenges and } \\
\text { Reduce Trade Costs }\end{array}$ & Public sector case story \\
\hline & \multicolumn{3}{|c|}{$\begin{array}{l}\text { www.oecd.org/aidfortrade/casestories/casestories-2017/CS-30-NTM-Increase-Transparency-Identify-Challenges-and- } \\
\text { Reduce-Trade-Costs.pdf }\end{array}$} \\
\hline \multirow[t]{2}{*}{31} & $\begin{array}{l}\text { International Trade } \\
\text { Centre }\end{array}$ & $\begin{array}{l}\text { EuroMed TIFM: Facilitating trade and investment across } \\
\text { the Mediterranean region }\end{array}$ & Public sector case story \\
\hline & \multicolumn{3}{|c|}{$\begin{array}{l}\text { www.oecd.org/aidfortrade/casestories/casestories-2017/CS-31-Facilitating-trade-and-investment-across-the- } \\
\text { Mediterranean-region.pdf }\end{array}$} \\
\hline \multirow[t]{2}{*}{32} & $\begin{array}{l}\text { International Trade } \\
\text { Centre }\end{array}$ & $\begin{array}{l}\text { Made in Morocco: case study on linking SMEs to the world } \\
\text { of e-commerce }\end{array}$ & Public sector case story \\
\hline & \multicolumn{3}{|c|}{$\begin{array}{l}\text { www.oecd.org/aidfortrade/casestories/casestories-2017/CS-32-Made-in-Morocco-case-study-on-linking-SMEs-to-the- } \\
\text { world-of-e-commerce.pdf }\end{array}$} \\
\hline \multirow[t]{2}{*}{33} & Telenor Group & Disbursing girl stipends via Mobile Money in Pakistan & Private sector case story \\
\hline & \multicolumn{3}{|c|}{$\begin{array}{l}\text { www.oecd.org/aidfortrade/casestories/casestories-2017/CS-33-Telenor-Group-Disbursing-girl-stipends-via-Mobile-Money- } \\
\text { in-Pakistan.pdf }\end{array}$} \\
\hline \multirow[t]{2}{*}{34} & $\begin{array}{l}360 \text { Degrees } \\
\text { International }\end{array}$ & $\begin{array}{l}\text { Accelerating Women \& Youth Economic Empowerment } \\
\text { through Digital Marketing Skills for Entrepreneurs }\end{array}$ & Private sector case story \\
\hline & \multicolumn{3}{|c|}{$\begin{array}{l}\text { www.oecd.org/aidfortrade/casestories/casestories-2017/CS-34-Women-Youth-Economic-Empowerment-through-Digital- } \\
\text { Marketing-Skills.pdf }\end{array}$} \\
\hline \multirow[t]{2}{*}{35} & Global Affairs Canada & $\begin{array}{l}\text { Integrated Border Management to Reduce Trade Costs } \\
\text { in East Africa }\end{array}$ & Public sector case story \\
\hline & \multicolumn{3}{|c|}{$\begin{array}{l}\text { www.oecd.org/aidfortrade/casestories/casestories-2017/CS-35-Integrated-Border-Management-to-Reduce-Trade-Costs- } \\
\text { in-EA.pdf }\end{array}$} \\
\hline \multirow[t]{2}{*}{36} & Yemen & Yemen fish exports access European market & Public sector case story \\
\hline & \multicolumn{3}{|c|}{ www.oecd.org/aidfortrade/casestories/casestories-2017/CS-36-Yemen-Fish-exports-acces-\%20European-market.pdf } \\
\hline
\end{tabular}




\begin{tabular}{|c|c|c|c|}
\hline \multirow[t]{2}{*}{37} & TFO Canada & $\begin{array}{l}\text { Design Africa Program : Market Access, Export } \\
\text { Competitiveness and Digital Bridge for Made in Africa Artisans } \\
\text { Products to Canadian and International Buyers }\end{array}$ & $\begin{array}{l}\text { Academia and NGOs } \\
\text { case story }\end{array}$ \\
\hline & \multicolumn{3}{|c|}{ www.oecd.org/aidfortrade/casestories/casestories-2017/CS-37-Design\%20Africa\%20Program.pdf } \\
\hline \multirow[t]{2}{*}{38} & Myanmar & $\begin{array}{l}\text { Ministry of Commerce, the Republic of the Union of Myanmar, } \\
\text { handed over the Ratification for the Trade Facilitation } \\
\text { Agreement (TFA) }\end{array}$ & Public sector case story \\
\hline & \multicolumn{3}{|c|}{ www.oecd.org/aidfortrade/casestories/casestories-2017/CS-38-Myanmar-handed-over-the-Ratification-of-the-TFA.pdf } \\
\hline \multirow[t]{2}{*}{39} & $\begin{array}{l}\text { Broadband } \\
\text { Commission } \\
\text { for Sustainable } \\
\text { Development / ITU }\end{array}$ & $\begin{array}{l}\text { More than half the world is still offline, what is } \\
\text { the main reason...? }\end{array}$ & Public sector case story \\
\hline & \multicolumn{3}{|c|}{$\begin{array}{l}\text { http://www.oecd.org/aidfortrade/casestories/casestories-2017/CS-39-UN-Broadband-Commision-for-SD-more-than-half- } \\
\text { the-world-is-still-offline.pdf }\end{array}$} \\
\hline \multirow[t]{2}{*}{40} & $\begin{array}{l}\text { Broadband } \\
\text { Commission } \\
\text { for Sustainable } \\
\text { Development / ITU }\end{array}$ & $\begin{array}{l}\text { If we want to connect the next } 1.5 \text { billion people, where } \\
\text { should we be focusing? }\end{array}$ & Public sector case story \\
\hline & \multicolumn{3}{|c|}{$\begin{array}{l}\text { http://www.oecd.org/aidfortrade/casestories/casestories-2017/CS-40-UN-Broadband-Commision-for-SD-Connect-the- } \\
\underline{\text { next-1.5-billion-people.pdf }}\end{array}$} \\
\hline \multirow[t]{2}{*}{41} & $\begin{array}{l}\text { Broadband } \\
\text { Commission } \\
\text { for Sustainable } \\
\text { Development / ITU }\end{array}$ & $\begin{array}{l}\text { The State of Broadband Report } 2016 \text { - recommendations for } \\
\text { policy makers \& world leaders. Which are the most urgent? }\end{array}$ & Public sector case story \\
\hline & \multicolumn{3}{|c|}{$\begin{array}{l}\text { http://www.oecd.org/aidfortrade/casestories/casestories-2017/CS-41-UN-Broadband-Commission-for-SD-The-State-of- } \\
\text { Broadband-Report-2016.pdf }\end{array}$} \\
\hline \multirow[t]{2}{*}{42} & CCTV-News China & E-commerce boosts China's rural economy & Public sector case story \\
\hline & http://www.oecd.or & fortrade/casestories/casestories-2017/CS-42-E-commerce-boosts-Chin & -rural-economy.pdf \\
\hline \multirow[t]{2}{*}{43} & Alibaba Group & Alizila News: E-commerce in Rural China & Private sector case story \\
\hline & \multicolumn{3}{|c|}{ http://www.oecd.org/aidfortrade/casestories/casestories-2017/CS-43-Alizila-News-E-commerce-in-Rural-China.pdf } \\
\hline \multirow[t]{2}{*}{44} & Telenor Group & $\begin{array}{l}\text { Telenor's mobile internet training project in India: raising } \\
\text { awareness of the benefits from getting online }\end{array}$ & Private sector case story \\
\hline & \multicolumn{3}{|c|}{$\begin{array}{l}\text { http://www.oecd.org/aidfortrade/casestories/casestories-2017/CS-44-Telenors-mobile-internet-training-project-in-India. } \\
\underline{\text { pdf }}\end{array}$} \\
\hline \multirow[t]{2}{*}{45} & Telenor Group & Project Prayaas & Private sector case story \\
\hline & \multicolumn{3}{|c|}{ http://www.oecd.org/aidfortrade/casestories/casestories-2017/CS-45-Telenor-Project-Prayaas.pdf } \\
\hline \multirow[t]{2}{*}{46} & Telenor Group & Project Sampark & Private sector case story \\
\hline & \multicolumn{3}{|c|}{ www.oecd.org/aidfortrade/casestories/casestories-2017/CS-46-Telenor-Project-Sampark.pdf } \\
\hline \multirow[t]{2}{*}{47} & GSMA & $\begin{array}{l}\text { Unlocking Rural Coverage: Enablers for Commercially } \\
\text { Sustainable Mobile Network Expansion }\end{array}$ & Private sector case story \\
\hline & \multicolumn{3}{|c|}{ www.oecd.org/aidfortrade/casestories/casestories-2017/CS-47-GSMA-Unlocking-Rural-Coverage.pdf } \\
\hline 48 & GSMA & $\begin{array}{l}\text { GSMA Case Study: Bindez - Connecting the people of } \\
\text { Myanmar with information and content in their own language }\end{array}$ & Private sector case story \\
\hline
\end{tabular}




\begin{tabular}{|c|c|c|c|}
\hline \multirow[t]{2}{*}{49} & Sally Walkerman & CDS: Water and electricity in Mauritania & $\begin{array}{l}\text { Academia and NGOs } \\
\text { case story }\end{array}$ \\
\hline & \multicolumn{3}{|c|}{$\begin{array}{l}\text { www.oecd.org/aidfortrade/casestories/casestories-2017/CS-49-Small-Foundation-CDS-Water-and-electricity-in-Mauritania. } \\
\text { pdf }\end{array}$} \\
\hline \multirow[t]{2}{*}{50} & Sally Walkerman & ACEP Cameroun - Microfinance & $\begin{array}{l}\text { Academia and NGOs } \\
\text { case story }\end{array}$ \\
\hline & \multicolumn{3}{|c|}{ www.oecd.org/aidfortrade/casestories/casestories-2017/CS-50-Small-Foundation-ACEP-Cameroun-Microfinance.pdf } \\
\hline \multirow[t]{2}{*}{51} & Qualcomm & $\begin{array}{l}\text { "Taroworks Provides Social Enterprises with New Services } \\
\text { for Success" }\end{array}$ & Private sector case story \\
\hline & \multicolumn{3}{|c|}{$\begin{array}{l}\text { www.oecd.org/aidfortrade/casestories/casestories-2017/CS-51-Taroworks-Provides-Social-Enterprises-with-New-Services- } \\
\text { for-Success.pdf }\end{array}$} \\
\hline \multirow[t]{2}{*}{52} & Malawi & Malawi Trade Portal & Public sector case story \\
\hline & \multicolumn{3}{|c|}{ www.oecd.org/aidfortrade/casestories/casestories-2017/CS-52-Malawi-Trade-Portal.pdf } \\
\hline \multirow[t]{2}{*}{53} & $\begin{array}{l}\text { Centre for } \\
\text { Empowerment and } \\
\text { Development, Nepal }\end{array}$ & $\begin{array}{l}\text { Coffee Cooperatives Value Chain Model for Production, } \\
\text { Income and Employment (PIE): A reflection from Nepal }\end{array}$ & $\begin{array}{l}\text { Academia and NGOs } \\
\text { case story }\end{array}$ \\
\hline & \multicolumn{3}{|c|}{$\begin{array}{l}\text { www.oecd.org/aidfortrade/casestories/casestories-2017/CS-53-Coffee-Cooperatives-Value-Chain-Model-for-Production- } \\
\text { Income-and-Employment.pdf }\end{array}$} \\
\hline \multirow[t]{2}{*}{54} & TradeMark East Africa & $\begin{array}{l}\text { Trade Certificates at a Press of a Button: Automation of the } \\
\text { Application and Issuance of Certificates of Origin in Kenya } \\
\text { by the Kenya National Chamber of Commerce and Industry } \\
\text { (KNCCI) }\end{array}$ & Public sector case story \\
\hline & \multicolumn{3}{|c|}{ www.oecd.org/aidfortrade/casestories/casestories-2017/CS-54-TMEA-Trade-Certificates-at-a-Press-of-a-Button.pdf } \\
\hline \multirow[t]{2}{*}{55} & Egypt & $\begin{array}{l}\text { Trade Facilitation between the Arab Republic of Egypt } \\
\text { and Sudan }\end{array}$ & Public sector case story \\
\hline & \multicolumn{3}{|c|}{$\begin{array}{l}\text { www.oecd.org/aidfortrade/casestories/casestories-2017/CS-55-Trade-Facilitation-between-the-Arab-Republic-of-Egypt- } \\
\text { and-Sudan.pdf }\end{array}$} \\
\hline \multirow[t]{2}{*}{56} & $\begin{array}{l}\text { International Trade } \\
\text { Centre }\end{array}$ & $\begin{array}{l}\text { Leveraging the WTO Trade Facilitation Agreement to boos } \\
\text { intra-regional trade in West Africa }\end{array}$ & Public sector case story \\
\hline & \multicolumn{3}{|c|}{$\begin{array}{l}\text { www.oecd.org/aidfortrade/casestories/casestories-2017/CS-56-Leveraging-the-WTO-TFA-to-boost-intra-regional-trade-in- } \\
\text { West-Africa.pdf }\end{array}$} \\
\hline \multirow[t]{2}{*}{57} & Philippines & $\begin{array}{l}\text { Philippines Customs Modernization: The Way for Trade } \\
\text { Facilitation }\end{array}$ & Public sector case story \\
\hline & \multicolumn{3}{|c|}{$\begin{array}{l}\text { www.oecd.org/aidfortrade/casestories/casestories-2017/CS-57-Philippine-Customs-Modernization-The-Way-for-Trade- } \\
\text { Facilitation.pdf }\end{array}$} \\
\hline \multirow[t]{2}{*}{58} & Czech Republic & $\begin{array}{l}\text { Improvement of the Situation and Regulatory Framework in } \\
\text { Road Transport in Mongolia }\end{array}$ & Public sector case story \\
\hline & \multicolumn{3}{|c|}{$\begin{array}{l}\text { www.oecd.org/aidfortrade/casestories/casestories-2017/CS-58-Improvement-of-regulatory-framework-in-road-transport- } \\
\text { in-Mongolia.pdf }\end{array}$} \\
\hline \multirow[t]{2}{*}{59} & ECOWAS & $\begin{array}{l}\text { Review of E-commerce Legislation Harmonization } \\
\text { in the Economic Community of West African States }\end{array}$ & Public sector case story \\
\hline & \multicolumn{3}{|c|}{$\begin{array}{l}\text { http://www.oecd.org/aidfortrade/casestories/casestories-2017/CS-59-Review-of-e-commerce-legislation-harmonization-in- } \\
\text { ECOWAS.pdf }\end{array}$} \\
\hline
\end{tabular}




\begin{tabular}{|c|c|c|c|}
\hline \multirow[t]{2}{*}{60} & $\begin{array}{l}\text { NTP/MIP Internship, } \\
\text { WTO }\end{array}$ & $\begin{array}{l}\text { Instituting a National Committee on Trade Facilitation } \\
\text { in Bhutan }\end{array}$ & $\begin{array}{l}\text { Academia and NGOs } \\
\text { case story }\end{array}$ \\
\hline & \multicolumn{3}{|c|}{$\begin{array}{l}\text { www.oecd.org/aidfortrade/casestories/casestories-2017/CS-60-NTP-MIP-Instituting-a-national-committee-on-trade- } \\
\text { facilitation-in-Bhutan.pdf }\end{array}$} \\
\hline \multirow[t]{2}{*}{61} & $\begin{array}{l}\text { NTP/MIP Internship, } \\
\text { WTO }\end{array}$ & Charbar Port - A new trade gateway for Afghanistan & $\begin{array}{l}\text { Academia and NGOs } \\
\text { case story }\end{array}$ \\
\hline & \multicolumn{3}{|c|}{$\begin{array}{l}\text { www.oecd.org/aidfortrade/casestories/casestories-2017/CS-61-NTP-MIP-Chabahar-port-New-transit-gateway-for- } \\
\text { Afghanistan.pdf }\end{array}$} \\
\hline \multirow[t]{2}{*}{62} & $\begin{array}{l}\text { NTP/MIP Internship, } \\
\text { WTO }\end{array}$ & $\begin{array}{l}\text { Overcoming the challenges of implementing } \\
\text { the Trade Facilitation Agreement in Nigeria }\end{array}$ & $\begin{array}{l}\text { Academia and NGOs } \\
\text { case story }\end{array}$ \\
\hline & \multicolumn{3}{|c|}{$\begin{array}{l}\text { www.oecd.org/aidfortrade/casestories/casestories-2017/CS-62-NTP-MIP-Challenges-of-Implementing-Trade-Facilitation- } \\
\text { Agreement-in-Nigeria.pdf }\end{array}$} \\
\hline \multirow[t]{2}{*}{63} & Germany & $\begin{array}{l}\text { IT strategy in Kosovo Supporting the export of IT services } \\
\text { and software }\end{array}$ & Public sector case story \\
\hline & \multicolumn{3}{|c|}{$\begin{array}{l}\text { www.oecd.org/aidfortrade/casestories/casestories-2017/CS-63-Germany-Supporting-the-export-of-IT-services-and- } \\
\text { software-Kosovo.pdf }\end{array}$} \\
\hline \multirow[t]{2}{*}{64} & Germany & Advising Ukraine on Agricultural Trade Issues & Public sector case story \\
\hline & \multicolumn{3}{|c|}{$\begin{array}{l}\text { www.oecd.org/aidfortrade/casestories/casestories-2017/CS-64-Germany-Advising-Ukraine-on-Agricultural-Trade-Issues. } \\
\text { pdf }\end{array}$} \\
\hline \multirow[t]{2}{*}{65} & Germany & $\begin{array}{l}\text { Trade Facilitation Development Cooperation - } \\
\text { Trade Facilitation along the Dakar-Bamako Corridor }\end{array}$ & Public sector case story \\
\hline & \multicolumn{3}{|c|}{$\begin{array}{l}\text { www.oecd.org/aidfortrade/casestories/casestories-2017/CS-65-Germany-Trade-Facilitation-along-the-Dakar-Bamako- } \\
\text { Corridor.pdf }\end{array}$} \\
\hline \multirow[t]{2}{*}{66} & Germany & Trade Facilitation in German Development Cooperation & Public sector case story \\
\hline & \multicolumn{3}{|c|}{$\begin{array}{l}\text { www.oecd.org/aidfortrade/casestories/casestories-2017/CS-66-Germany-Trade-Facilitation-in-German-Development- } \\
\text { Cooperation.pdf }\end{array}$} \\
\hline \multirow[t]{2}{*}{67} & Earth Divas & Empowering Women Through E-commerce & $\begin{array}{l}\text { Academia and NGOs } \\
\text { case story }\end{array}$ \\
\hline & \multicolumn{3}{|c|}{ www.oecd.org/aidfortrade/casestories/casestories-2017/CS-67-Earth-Divas-Empowering-Women-Through-Trade.pdf } \\
\hline \multirow[t]{2}{*}{68} & STDF & $\begin{array}{l}\text { Safe Trade Solutions (2015) A film produced by the Standards } \\
\text { and Trade Development Facility (STDF) }\end{array}$ & Public sector case story \\
\hline & \multicolumn{3}{|c|}{ www.oecd.org/aidfortrade/casestories/casestories-2017/CS-68-STDF-Safe-Trade-Solutions-Film.pdf } \\
\hline \multirow[t]{2}{*}{69} & Bangladesh & $\begin{array}{l}\text { South Asia Subregional Economic Cooperation (SASEC) } \\
\text { initiative to establish a sustainable trade and transport } \\
\text { facilitation monitoring mechanisms (TTFMM) in Bangladesh, } \\
\text { Bhutan and Nepal }\end{array}$ & Public sector case story \\
\hline & \multicolumn{3}{|c|}{$\begin{array}{l}\text { www.oecd.org/aidfortrade/casestories/casestories-2017/CS-69-Bangladesh-SASEC-initiative-to-establish-a-sustainable- } \\
\text { trade-and-transport-facilitation.pdf }\end{array}$} \\
\hline \multirow[t]{2}{*}{70} & United Kingdom & $\begin{array}{l}\text { G-Soko market system - Linking small holder farmers to grain } \\
\text { buyers across East Africa. }\end{array}$ & Public sector case story \\
\hline & \multicolumn{3}{|c|}{ www.oecd.org/aidfortrade/casestories/casestories-2017/CS-70-DFID-G-Soko-market-system\%20.pdf } \\
\hline 71 & TradeMark East Africa & Busia One Stop Border Post (OSBP) & Public sector case story \\
\hline
\end{tabular}




\begin{tabular}{|c|c|c|c|}
\hline \multirow[t]{2}{*}{72} & TradeMark East Africa & Elimination of non-tariff barriers to trade in East Africa & Public sector case story \\
\hline & \multicolumn{3}{|c|}{$\begin{array}{l}\text { www.oecd.org/aidfortrade/casestories/casestories-2017/CS-72-TMEA-Elimination-of-non-tariff-barriers-to-trade-in-East- } \\
\underline{\text { Africa.pdf }}\end{array}$} \\
\hline \multirow[t]{2}{*}{73} & TradeMark East Africa & Trade Certificates at the Press of a Button & Public sector case story \\
\hline & www.oecd.org/aidfort & e/casestories/casestories-2017/CS-73-TMEA-Trade-Certificates-at-a-Pre & s-of-a-Button.pdf \\
\hline \multirow[t]{2}{*}{74} & Jumia & $\begin{array}{l}\text { Changing traders' lives via eCommerce in Africa: } \\
\text { Case of Cameroon }\end{array}$ & Private sector case story \\
\hline & \multicolumn{3}{|c|}{$\begin{array}{l}\text { www.oecd.org/aidfortrade/casestories/casestories-2017/CS-74-Changing-traders-lives-via-eCommerce-in-Africa-Case-of- } \\
\underline{\text { Cameroon.pdf }}\end{array}$} \\
\hline \multirow[t]{2}{*}{75} & Japan & Achieving Quality Infrastructure through the ICT of Japan & Public sector case story \\
\hline & \multicolumn{3}{|c|}{$\begin{array}{l}\text { www.oecd.org/aidfortrade/casestories/casestories-2017/CS-75-Achieving-Quality-Infrastructure-through-the-ICT-of-Japan. } \\
\text { pdf }\end{array}$} \\
\hline \multirow[t]{2}{*}{76} & EBRD & $\begin{array}{l}\text { Rehabilitating railway infrastructure in Bosnia and } \\
\text { Herzegovina with EBRD's support }\end{array}$ & Public sector case story \\
\hline & \multicolumn{3}{|c|}{$\begin{array}{l}\text { www.oecd.org/aidfortrade/casestories/casestories-2017/CS-76-Rehabilitating-railway-infrastructure-in-Bosnia-and- } \\
\underline{\text { Herzegovina-with-EBRD-support.pdf }}\end{array}$} \\
\hline \multirow[t]{2}{*}{77} & EBRD & $\begin{array}{l}\text { EBRD and EU prepare businesses for free trade area in Georgia, } \\
\text { Moldova and Ukraine }\end{array}$ & Public sector case story \\
\hline & \multicolumn{3}{|c|}{$\begin{array}{l}\text { www.oecd.org/aidfortrade/casestories/casestories-2017/CS-77-EBRD-and-EU-free-trade-area-in-Georgia-Moldova-and- } \\
\underline{\text { Ukraine.pdf }}\end{array}$} \\
\hline \multirow[t]{2}{*}{78} & TradeMark East Africa & $\begin{array}{l}\text { Contribution of standards harmonisation and certification } \\
\text { towards reduction in the conformity assessment clearance } \\
\text { time and cost of testing-the case of the EAC }\end{array}$ & Public sector case story \\
\hline & \multicolumn{3}{|c|}{$\begin{array}{l}\text { www.oecd.org/aidfortrade/casestories/casestories-2017/CS-78-TMEA-Contribution-of-standards-harmonisation-and- } \\
\text { certification.pdf }\end{array}$} \\
\hline \multirow[t]{2}{*}{79} & TradeMark East Africa & $\begin{array}{l}\text { Uganda Revenue Authority customs business systems } \\
\text { enhancement programme }\end{array}$ & Public sector case story \\
\hline & \multicolumn{3}{|c|}{$\begin{array}{l}\text { www.oecd.org/aidfortrade/casestories/casestories-2017/CS-79-TMEA-Uganda-Revenue-Authority-customs-systems- } \\
\text { enhancement-programme.pdf }\end{array}$} \\
\hline \multirow[t]{2}{*}{80} & TradeMark East Africa & $\begin{array}{l}\text { Mombasa Port Infrastructure and Facilities Improvement } \\
\text { Project: Gate18/20 and Yard } 5 \text { projects. }\end{array}$ & Public sector case story \\
\hline & \multicolumn{3}{|c|}{$\begin{array}{l}\text { www.oecd.org/aidfortrade/casestories/casestories-2017/CS-80-TMEA-Mombasa-Port-Infrastructure-and-Facilities- } \\
\underline{\text { Improvement-Project.pdf }}\end{array}$} \\
\hline \multirow[t]{2}{*}{81} & Sweden & $\begin{array}{l}\text { Services Trade, Industrial Development and the African } \\
\text { Continental Free Trade Area }\end{array}$ & Public sector case story \\
\hline & \multicolumn{3}{|c|}{$\begin{array}{l}\text { www.oecd.org/aidfortrade/casestories/casestories-2017/CS-81-Services-Trade-Industrial-Development-and-the-African- } \\
\text { CFTA.pdf }\end{array}$} \\
\hline \multirow[t]{2}{*}{82} & Spinna Circle Ltd & $\begin{array}{l}\text { Changing lives through the adoption of e-commerce and } \\
\text { mobile technology as a platform for global connectivity and } \\
\text { market access for women entrepreneurs and small businesses } \\
\text { in fashion and textiles. }\end{array}$ & $\begin{array}{l}\text { Academia and NGOs } \\
\text { case story }\end{array}$ \\
\hline & \multicolumn{3}{|c|}{$\begin{array}{l}\text { www.oecd.org/aidfortrade/casestories/casestories-2017/CS-82-SPINNA-Circle-Changing-lives-through-the-adoption-of-e- } \\
\text { commerce.pdf }\end{array}$} \\
\hline
\end{tabular}




\begin{tabular}{|c|c|c|c|}
\hline \multirow[t]{2}{*}{83} & Brazil & $\begin{array}{l}\text { Technical assistance provided to African countries } \\
\text { on trade facilitation }\end{array}$ & Public sector case story \\
\hline & \multicolumn{3}{|c|}{$\begin{array}{l}\text { www.oecd.org/aidfortrade/casestories/casestories-2017/CS-83-Brazil-Technical-assistance-provided-to-African-countries- } \\
\text { on-trade-facilitation.pdf }\end{array}$} \\
\hline \multirow[t]{2}{*}{84} & STDF & $\begin{array}{l}\text { Electronic Sanitary and Phytosanitary certification for faster } \\
\text { and safer trade }\end{array}$ & Public sector case story \\
\hline & \multicolumn{3}{|c|}{$\begin{array}{l}\text { www.oecd.org/aidfortrade/casestories/casestories-2017/CS-84-STDF-Electronic-Sanitary-and-Phytosanitary-certification- } \\
\text { for-faster-and-safer-trade.pdf }\end{array}$} \\
\hline \multirow[t]{2}{*}{85} & Trini Trolley & e-commerce in the Caribbean & Private sector case story \\
\hline & \multicolumn{3}{|c|}{$\begin{array}{l}\text { www.oecd.org/aidfortrade/casestories/casestories-2017/CS-85-Trini-Trolley-the-Caribbeans-largest-e-Commerce-business. } \\
\text { pdf }\end{array}$} \\
\hline \multirow[t]{2}{*}{86} & UNESCAP & $\begin{array}{l}\text { Framework Agreement on Facilitation of Cross-border } \\
\text { Paperless Trade in Asia and the Pacific: A New Tool for } \\
\text { Enhancing Digital Connectivity }\end{array}$ & Public sector case story \\
\hline & \multicolumn{3}{|c|}{$\begin{array}{l}\text { www.oecd.org/aidfortrade/casestories/casestories-2017/CS-86-Framework-Agreement-on-Facilitation-of-Cross-border- } \\
\text { Paperless.pdf }\end{array}$} \\
\hline \multirow[t]{2}{*}{87} & Pakistan & $\begin{array}{l}\text { Pakistan's digital economy: national perspectives on bridging } \\
\text { the digital divide }\end{array}$ & Private sector case story \\
\hline & \multicolumn{3}{|c|}{ www.oecd.org/aidfortrade/casestories/casestories-2017/CS-87-Pakistan-Digital-Economy.pdf } \\
\hline \multirow[t]{2}{*}{88} & Amazon & $\begin{array}{l}\text { How a small rural business in a developing country was } \\
\text { empowered to effectively expand internationally through } \\
\text { e-commerce with Amazon }\end{array}$ & Private sector case story \\
\hline & \multicolumn{3}{|c|}{$\begin{array}{l}\text { www.oecd.org/aidfortrade/casestories/casestories-2017/CS-88-Amazon-How-a-small-rural-business-in-a-developing- } \\
\text { country-was-empowered.pdf }\end{array}$} \\
\hline \multirow[t]{2}{*}{89} & $\begin{array}{l}\text { Copenhagen } \\
\text { Consensus }\end{array}$ & $\begin{array}{l}\text { Bangladesh Priorities Prioritizing Smart Solutions through } \\
\text { Benefit-Cost Research }\end{array}$ & $\begin{array}{l}\text { Academia and NGOs } \\
\text { case story }\end{array}$ \\
\hline & \multicolumn{3}{|c|}{$\begin{array}{l}\text { www.oecd.org/aidfortrade/casestories/casestories-2017/CS-89-Bangladesh-Prioritizing-Smart-Solutions-through-Benefit- } \\
\text { Cost-Research.pdf }\end{array}$} \\
\hline \multirow[t]{2}{*}{90} & World Bank Group & ShopSoko connects local Artisans to Global Markets & Public sector case story \\
\hline & \multicolumn{3}{|c|}{ www.oecd.org/aidfortrade/casestories/casestories-2017/CS-90-ShopSoko-connects-local-Artisans-to-Global-Markets.pdf } \\
\hline \multirow[t]{2}{*}{91} & World Bank Group & $\begin{array}{l}\text { Kopo Kopo empowers small businesses to shift from cash to } \\
\text { digital payments }\end{array}$ & Public sector case story \\
\hline & \multicolumn{3}{|c|}{$\begin{array}{l}\text { www.oecd.org/aidfortrade/casestories/casestories-2017/CS-91-Kopo-Kopo-empowers-small-businesses-to-shift-from- } \\
\text { cash-to-digital-payments.pdf }\end{array}$} \\
\hline \multirow[t]{2}{*}{92} & World Bank Group & Maxcom Africa makes paying utility bills fast and convenient & Public sector case story \\
\hline & \multicolumn{3}{|c|}{$\begin{array}{l}\text { www.oecd.org/aidfortrade/casestories/casestories-2017/CS-92-Maxcom-Africa-makes-paying-utility-bills-fast-and- } \\
\text { convenient.pdf }\end{array}$} \\
\hline \multirow[t]{2}{*}{93} & World Bank Group & Farmia connects local Farmers to Regional Markets & Public sector case story \\
\hline & \multicolumn{3}{|c|}{ www.oecd.org/aidfortrade/casestories/casestories-2017/CS-93-Farmia-connects-local-farmers-to-regional-Markets.pdf } \\
\hline \multirow[t]{2}{*}{94} & $\begin{array}{l}\text { Asian Development } \\
\text { Bank }\end{array}$ & Microfinance in Indonesia: Bringing Banks into the Community & Public sector case story \\
\hline & \multicolumn{3}{|c|}{$\begin{array}{l}\text { www.oecd.org/aidfortrade/casestories/casestories-2017/CS-94-Microfinance-in-Indonesia-Bringing-Banks-into-the- } \\
\text { Community.pdf }\end{array}$} \\
\hline
\end{tabular}




\begin{tabular}{|c|c|c|c|}
\hline \multirow[t]{2}{*}{95} & Sidley Austin & Pro Bono Legal Advice for Trade Facilitation & Public sector case story \\
\hline & \multicolumn{3}{|c|}{$\begin{array}{l}\text { www.oecd.org/aidfortrade/casestories/casestories-2017/CS-95-Sidley-Austin-Pro-Bono-Legal-Advice-for-Trade-Facilitation. } \\
\underline{\text { pdf }}\end{array}$} \\
\hline \multirow[t]{2}{*}{96} & $\begin{array}{l}\text { Asian Development } \\
\text { Bank }\end{array}$ & Instituting e-Government Procurement in Nepal & Public sector case story \\
\hline & www.oecd.org/aidfo & e/casestories/casestories-2017/CS-96-AsDB-Instituting-e-Governme & rocurement-in-Nepal.pdf \\
\hline \multirow[t]{2}{*}{97} & $\begin{array}{l}\text { Asian Development } \\
\text { Bank }\end{array}$ & Tonga's high speed revolution & Public sector case story \\
\hline & www.oecd.org/aidfo & e/casestories/casestories-2017/CS-97-AsDB-Tongas-High-Speed-Rev & tion.pdf \\
\hline \multirow[t]{2}{*}{98} & UPS & The U.S.-ASEAN Business Alliance for Competitive SMEs & Private sector case story \\
\hline & $\underline{\text { www.oecd.org/aidfo }}$ & e/casestories/casestories-2017/CS-98-The-US-ASEAN-Business-Allian & for-Competitive-SMEs. \\
\hline \multirow[t]{2}{*}{99} & World Bank Group & $\begin{array}{l}\text { Economic Opportunities for Jordanians and Syrian Refugees } \\
\text { Program for Results }\end{array}$ & Public sector case story \\
\hline & $\begin{array}{l}\text { www.oecd.org/aidfo } \\
\text { Program-for-Results. }\end{array}$ & e/casestories/casestories-2017/CS-99-Opportunities-for-Jordanians- & -Syrian-Refugees- \\
\hline \multirow[t]{2}{*}{100} & World Bank Group & Myanmar Investment Policy Project & Public sector case story \\
\hline & $\frac{\text { www.oecd.org/aidfo }}{\text { Project\%20.pdf }}$ & e/casestories/casestories-2017/CS-100-World-Bank-Group-Myanma & estment-Policy- \\
\hline \multirow[t]{2}{*}{101} & World Bank Group & $\begin{array}{l}\text { Using automated data exchange to improve sanitary } \\
\text { registration and boost regional trade in Central America }\end{array}$ & Public sector case story \\
\hline & $\begin{array}{l}\text { www.oecd.org/aidfo } \\
\text { regional-trade-in-Cel }\end{array}$ & $\begin{array}{l}\text { e/casestories/casestories-2017/CS-101-Data-exchange-to-improve- } \\
\text { America.pdf }\end{array}$ & Eary-registration-and- \\
\hline \multirow[t]{2}{*}{102} & World Bank Group & $\begin{array}{l}\text { Kurdistan Region of Iraq: Regional Connectivity for shared } \\
\text { prosperity }\end{array}$ & Public sector case story \\
\hline & $\begin{array}{l}\text { www.oecd.org/aidfo } \\
\text { for-shared-prosperity }\end{array}$ & e/casestories/casestories-2017/CS-102-World-Bank-Group-Kurdistan & q-Regional-connectivity- \\
\hline \multirow[t]{2}{*}{103} & World Bank Group & Gender in Agri - Value Chains, Kosovo, Moldova, Armenia & Public sector case story \\
\hline & $\begin{array}{l}\text { www.oecd.org/aidfo } \\
\text { Moldova-Armenia.pc }\end{array}$ & e/casestories/casestories-2017/CS-103-World-Bank-Group-Gender-i & gri-Value-Chains-Kosovo- \\
\hline \multirow[t]{2}{*}{104} & World Bank Group & Senegal - Warehouse Receipts Financing Reform Initiative & Public sector case story \\
\hline & $\begin{array}{l}\text { www.oecd.org/aidfo } \\
\text { Financing-Reform-In }\end{array}$ & $\begin{array}{l}\text { e/casestories/casestories-2017/CS-104-World-Bank-Group-Senegal-- } \\
\text { ve.pdf }\end{array}$ & ehouse-Receipts- \\
\hline \multirow[t]{2}{*}{105} & $\begin{array}{l}\text { Asian Development } \\
\text { Bank }\end{array}$ & $\begin{array}{l}\text { CAREC Transport and Trade Facilitation: } \\
\text { Partnerships for Prosperity }\end{array}$ & Public sector case story \\
\hline & $\begin{array}{l}\text { www.oecd.org/aidfo } \\
\text { Facilitation-Partnersh }\end{array}$ & $\begin{array}{l}\text { e/casestories/casestories-2017/CS-105-Asian-Development-Bank-C/ } \\
\text { r-Prosperity\%20.pdf }\end{array}$ & -Transport-and-Trade- \\
\hline \multirow[t]{2}{*}{106} & $\begin{array}{l}\text { Asian Development } \\
\text { Bank }\end{array}$ & SASEC Trade Facilitation Programme & Public sector case story \\
\hline & $\frac{\text { www.oecd.org/aidfo }}{\text { Economic-Cooperati }}$ & $\begin{array}{l}\text { e/casestories/casestories-2017/CS-106-Asian-Development-Bank-So } \\
\text { ASEC)-Trade-Facilitation-Program.pdf }\end{array}$ & -Asia-Subregional- \\
\hline
\end{tabular}




\begin{tabular}{|c|c|c|c|}
\hline \multirow[t]{2}{*}{107} & $\begin{array}{l}\text { Asian Development } \\
\text { Bank }\end{array}$ & CAREC Transport and Trade Facilitation Strategy 2020 & Public sector case story \\
\hline & \multicolumn{3}{|c|}{$\begin{array}{l}\text { www.oecd.org/aidfortrade/casestories/casestories-2017/CS-107-Asian-Development-Bank-CAREC-Transport-and-Trade- } \\
\text { Facilitation-Strategy\%202020.pdf }\end{array}$} \\
\hline \multirow[t]{2}{*}{108} & $\begin{array}{l}\text { Asian Development } \\
\text { Bank }\end{array}$ & Digital Economy Study in Central and West Asia & Public sector case story \\
\hline & \multicolumn{3}{|c|}{$\begin{array}{l}\text { www.oecd.org/aidfortrade/casestories/casestories-2017/CS-108-Asian-Development-Bank-Digital-Economy-Study-in- } \\
\text { Central-and-West-Asia.pdf }\end{array}$} \\
\hline \multirow[t]{2}{*}{109} & UNIDO & Breathing New Life into Armenia's Garment Industry & Public sector case story \\
\hline & \multicolumn{3}{|c|}{$\begin{array}{l}\text { www.oecd.org/aidfortrade/casestories/casestories-2017/CS-109-UNIDO-Breathing-new-life-into-Armenia-garment- } \\
\text { industry.pdf }\end{array}$} \\
\hline \multirow[t]{2}{*}{110} & $\begin{array}{l}\text { Asian Development } \\
\text { Bank }\end{array}$ & Instituting e-Government Procurement in Nepal & Public sector case story \\
\hline & \multicolumn{3}{|c|}{$\begin{array}{l}\text { www.oecd.org/aidfortrade/casestories/casestories-2017/CS-110-Asian-Development-Bank-Instituting-e-Government- } \\
\text { Procurement-in-Nepal.pdf }\end{array}$} \\
\hline \multirow[t]{2}{*}{111} & $\begin{array}{l}\text { Asian Development } \\
\text { Bank }\end{array}$ & $\begin{array}{l}\text { Integrated Information Communication Technology Strategies } \\
\text { for Competitive Higher Education in Asia and the Pacific }\end{array}$ & Public sector case story \\
\hline & \multicolumn{3}{|c|}{$\begin{array}{l}\text { www.oecd.org/aidfortrade/casestories/casestories-2017/CS-111-Asian-Development-Bank-Integrated-ICT-Strategies-for- } \\
\text { Competitive-Higher-Education\%20in.pdf }\end{array}$} \\
\hline \multirow[t]{2}{*}{112} & UNIDO & $\begin{array}{l}\text { Building confidence, compliance, and international } \\
\text { recognition for a world-class cosmetic sector } \\
\text { in Colombia - Safe+ }\end{array}$ & Public sector case story \\
\hline & \multicolumn{3}{|c|}{$\begin{array}{l}\text { www.oecd.org/aidfortrade/casestories/casestories-2017/CS-112-UNIDO-Building-compliance-and-international- } \\
\text { recognition-for-a-world-class-cosmetic.pdf }\end{array}$} \\
\hline \multirow[t]{2}{*}{113} & $\begin{array}{l}\text { Asian Development } \\
\text { Bank }\end{array}$ & $\begin{array}{l}\text { Developing Myanmar's Information and Communication } \\
\text { Technology Sector Towards Inclusive Growth }\end{array}$ & Public sector case story \\
\hline & \multicolumn{3}{|c|}{$\begin{array}{l}\text { www.oecd.org/aidfortrade/casestories/casestories-2017/CS-113-Asian-Development-Bank-Developing-Myanmars-ICT- } \\
\text { Sector-toward-Inclusive-Growth.pdf }\end{array}$} \\
\hline \multirow[t]{2}{*}{114} & The Internet Society & Zero-Rating & $\begin{array}{l}\text { Academia and NGOs } \\
\text { case story }\end{array}$ \\
\hline & \multicolumn{3}{|c|}{ www.oecd.org/aidfortrade/casestories/casestories-2017/CS-114-Internet-Society-Zero-rating.pdf } \\
\hline \multirow[t]{2}{*}{115} & $\begin{array}{l}\text { Asian Development } \\
\text { Bank }\end{array}$ & $\begin{array}{l}\text { The Development Dimension of e-Commerce in Asia: } \\
\text { Opportunities and Challenges }\end{array}$ & Public sector case story \\
\hline & \multicolumn{3}{|c|}{$\begin{array}{l}\text { www.oecd.org/aidfortrade/casestories/casestories-2017/CS-115-Asian-Development-bank-The-Development-Dimension- } \\
\text { of-E-Commerce-in-Asia.pdf }\end{array}$} \\
\hline \multirow[t]{2}{*}{116} & $\begin{array}{l}\text { Asian Development } \\
\text { Bank }\end{array}$ & Towards e-Development in Asia and the Pacific & Public sector case story \\
\hline & \multicolumn{3}{|c|}{$\begin{array}{l}\text { http://www.oecd.org/aidfortrade/casestories/casestories-2017/CS-116-Asian-Development-Bank-Towards-E-Development } \\
\text { in-Asia-and-the-Pacific\%20.pdf }\end{array}$} \\
\hline \multirow[t]{2}{*}{117} & $\begin{array}{l}\text { Asian Development } \\
\text { Bank }\end{array}$ & Papua New Guinea Expansion of Microfinance Project & Public sector case story \\
\hline & \multicolumn{3}{|c|}{$\begin{array}{l}\text { http://www.oecd.org/aidfortrade/casestories/casestories-2017/CS-117-Asian-Development-Bank-Papua-New-Guinea- } \\
\text { Expansion-of-Microfinance-Project\%20.pdf }\end{array}$} \\
\hline
\end{tabular}




\begin{tabular}{|c|c|c|c|}
\hline \multirow[t]{2}{*}{118} & $\begin{array}{l}\text { Asian Development } \\
\text { Bank }\end{array}$ & Banking on Business in Afghanistan & Public sector case story \\
\hline & \multicolumn{3}{|c|}{$\begin{array}{l}\text { www.oecd.org/aidfortrade/casestories/casestories-2017/CS-118-Asian-Development-Bank-Banking-on-Business-in- } \\
\text { Afghanistan\%20.pdf }\end{array}$} \\
\hline \multirow[t]{2}{*}{119} & $\begin{array}{l}\text { Asian Development } \\
\text { Bank }\end{array}$ & $\begin{array}{l}\text { Indonesia: Improving Access to Finance in Aceh and } \\
\text { North Sumatra }\end{array}$ & Public sector case story \\
\hline & \multicolumn{3}{|c|}{$\begin{array}{l}\text { www.oecd.org/aidfortrade/casestories/casestories-2017/CS-119-Asian-Development-Bank-Improving-Access-to-Finance- } \\
\text { in-Aceh-and-North-Sumatra\%20.pdf }\end{array}$} \\
\hline \multirow[t]{2}{*}{120} & $\begin{array}{l}\text { Asian Development } \\
\text { Bank }\end{array}$ & Trade Facilitation in South Asia & Public sector case story \\
\hline & \multicolumn{3}{|c|}{$\begin{array}{l}\text { www.oecd.org/aidfortrade/casestories/casestories-2017/CS-120-Asian-Development-Bank-Trade-Facilitation-in-South- } \\
\text { Asia\%20.pdf }\end{array}$} \\
\hline \multirow[t]{2}{*}{121} & $\begin{array}{l}\text { Asian Development } \\
\text { Bank }\end{array}$ & $\begin{array}{l}\text { The Greater Mekong Sub Region Transport and Trade } \\
\text { Facilitation Action Programme }\end{array}$ & Public sector case story \\
\hline & \multicolumn{3}{|c|}{$\begin{array}{l}\text { www.oecd.org/aidfortrade/casestories/casestories-2017/CS-121-Asian-Development-Bank-The-Greater-Mekong- } \\
\text { Subregion-Transport-and-Trade-Facilitation.pdf }\end{array}$} \\
\hline \multirow[t]{2}{*}{122} & UNESCAP & $\begin{array}{l}\text { Enhancing Connectivity Through Implementation of National } \\
\text { Trade and Transport Facilitation Monitoring Mechanisms } \\
\text { (TTFMMs) in South Asian Least Developed Countries }\end{array}$ & Public sector case story \\
\hline & \multicolumn{3}{|c|}{$\begin{array}{l}\text { www.oecd.org/aidfortrade/casestories/casestories-2017/CS-122-UNESCAP-Implementation-of-national-trade-and- } \\
\text { transport-facilitation-monitoring-mechanisms\%20.pdf }\end{array}$} \\
\hline \multirow[t]{2}{*}{123} & $\begin{array}{l}\text { Asian Development } \\
\text { Bank }\end{array}$ & $\begin{array}{l}\text { Going Digital with the Pacific: Lessons from Samoa's } \\
\text { Online Firms }\end{array}$ & Public sector case story \\
\hline & \multicolumn{3}{|c|}{ www.oecd.org/aidfortrade/casestories/casestories-2017/CS-123-Asian-Development-Bank-Going-digital-in-the-Pacific.pdf } \\
\hline \multirow[t]{2}{*}{124} & $\begin{array}{l}\text { Asian Development } \\
\text { Bank }\end{array}$ & A snapshot of e-commerce in Central Asia & Public sector case story \\
\hline & \multicolumn{3}{|c|}{$\begin{array}{l}\text { www.oecd.org/aidfortrade/casestories/casestories-2017/CS-124-Asian-Development-Bank-A-snapshot-of-e-commerce-in- } \\
\text { Central-Asia.pdf }\end{array}$} \\
\hline \multirow[t]{2}{*}{125} & $\begin{array}{l}\text { Asian Development } \\
\text { Bank }\end{array}$ & $\begin{array}{l}\text { Strengthening Trade Facilitation in the Greater Mekong Sub } \\
\text { Region through Partnerships with the Private Sector }\end{array}$ & Public sector case story \\
\hline & \multicolumn{3}{|c|}{$\begin{array}{l}\text { www.oecd.org/aidfortrade/casestories/casestories-2017/CS-125-Asian-Development-Bank-Strengthening-Trade- } \\
\text { Facilitation-through-PPP.pdf }\end{array}$} \\
\hline \multirow[t]{2}{*}{126} & $\mathrm{CBI}$ & $\begin{array}{l}\text { Exporting to Europe through ecommerce the case of CBI's } \\
\text { support to tropical flower SMEs in Colombia }\end{array}$ & Public sector case story \\
\hline & \multicolumn{3}{|c|}{$\begin{array}{l}\text { www.oecd.org/aidfortrade/casestories/casestories-2017/CS-126-Exporting-to-Europe-through-e-commerce-the-case-of- } \\
\text { CBI-in-Colombia.pdf }\end{array}$} \\
\hline \multirow[t]{2}{*}{127} & $\begin{array}{l}\text { International Trade } \\
\text { Centre }\end{array}$ & SheTrades Initiative & Public sector case story \\
\hline & \multicolumn{3}{|c|}{$\begin{array}{l}\text { http://www.oecd.org/aidfortrade/casestories/casestories-2017/CS-127-ITC-SheTrades-Connecting-one-million-women-to- } \\
\text { market-by-2020\%20.pdf }\end{array}$} \\
\hline \multirow[t]{2}{*}{128} & $\begin{array}{l}\text { Ghana (West Blue } \\
\text { consulting) }\end{array}$ & Ghana National Single Window Programme & Public sector case story \\
\hline & \multicolumn{3}{|c|}{$\begin{array}{l}\text { http://www.oecd.org/aidfortrade/casestories/casestories-2017/CS-128-West-Blue-Consulting-Ghana-National-Single- } \\
\text { Window-Programme\%20.pdf }\end{array}$} \\
\hline
\end{tabular}




\begin{tabular}{|c|c|c|c|}
\hline \multirow[t]{2}{*}{129} & $\begin{array}{l}\text { HUB \& SPOKES II OIF/ } \\
\text { MCEC }\end{array}$ & $\begin{array}{l}\text { Case study on the facilitation of trade between Congo } \\
\text { and its neighbours }\end{array}$ & Public sector case story \\
\hline & \multicolumn{3}{|c|}{$\begin{array}{l}\text { www.oecd.org/aidfortrade/casestories/casestories-2017/CS-129-HUB-and-Spokes-Etude-sur-la-facilitation-des-changes- } \\
\text { entre-le-Congo-et-ses-voisins.pdf }\end{array}$} \\
\hline \multirow[t]{2}{*}{130} & $\begin{array}{l}\text { NTP/MIP Internship, } \\
\text { WTO }\end{array}$ & $\begin{array}{l}\text { Rapport non-officiel sur la facilitation des échanges du Burundi } \\
\text { (F02) }\end{array}$ & $\begin{array}{l}\text { Academia and } \mathrm{NGOs} \\
\text { case story }\end{array}$ \\
\hline & \multicolumn{3}{|c|}{ www.oecd.org/aidfortrade/casestories/casestories-2017/CS-130-NTP-MIP-Facilitation-des-changes-Burundi.pdf } \\
\hline \multirow[t]{2}{*}{131} & $\begin{array}{l}\text { NTP/MIP Internship, } \\
\text { WTO }\end{array}$ & $\begin{array}{l}\text { Rapport non-officiel sur la facilitation des échanges aux Comores } \\
\text { (F09) }\end{array}$ & $\begin{array}{l}\text { Academia and NGOs } \\
\text { case story }\end{array}$ \\
\hline & \multicolumn{3}{|c|}{$\begin{array}{l}\text { www.oecd.org/aidfortrade/casestories/casestories-2017/CS-131-Comores-Mise-en-oeuvre-de-la-faciliation-des-changes. } \\
\underline{\text { pdf }}\end{array}$} \\
\hline \multirow[t]{2}{*}{132} & $\begin{array}{l}\text { NTP/MIP Internship, } \\
\text { WTO }\end{array}$ & Facilitation des échanges en Guinée (F04) & $\begin{array}{l}\text { Academia and NGOs } \\
\text { case story }\end{array}$ \\
\hline & \multicolumn{3}{|c|}{ www.oecd.org/aidfortrade/casestories/casestories-2017/CS-132-NTP-MIP-Facilitation-des-Echanges-Guinee.pdf } \\
\hline \multirow[t]{2}{*}{133} & $\begin{array}{l}\text { NTP/MIP Internship, } \\
\text { WTO }\end{array}$ & $\begin{array}{l}\text { Togo - Facilitation des échanges: premier poste de guichet } \\
\text { unique (F05) }\end{array}$ & $\begin{array}{l}\text { Academia and NGOs } \\
\text { case story }\end{array}$ \\
\hline & \multicolumn{3}{|c|}{$\begin{array}{l}\text { www.oecd.org/aidfortrade/casestories/casestories-2017/CS-133-NTP-MIP-Togo-Facilitation-des-changes-1er-poste- } \\
\text { guichet-unique.pdf }\end{array}$} \\
\hline \multirow[t]{2}{*}{134} & $\begin{array}{l}\text { Enhanced Integrated } \\
\text { Framework, RDC }\end{array}$ & $\begin{array}{l}\text { Projet de renforcement des capacités productives et } \\
\text { commerciales de la filière palmier à huile dans le bassin elaecole } \\
\text { du Mayombe dans la province du Kongo centrale (F06) }\end{array}$ & Public sector case story \\
\hline & \multicolumn{3}{|c|}{$\begin{array}{l}\text { www.oecd.org/aidfortrade/casestories/casestories-2017/CS-134-EIF-Renforcement-des-capacite-Palmier-\%C3\%A1-huile. } \\
\text { pdf }\end{array}$} \\
\hline \multirow[t]{2}{*}{135} & Senegal & Le Guichet unique "ORBUS" & Public sector case story \\
\hline & \multicolumn{3}{|c|}{ www.oecd.org/aidfortrade/casestories/casestories-2017/CS-135-Senegal-Guichet-Unique-Electronique-Orbus.pdf } \\
\hline \multirow[t]{2}{*}{136} & $\begin{array}{l}\text { NTP/MIP Internship, } \\
\text { WTO }\end{array}$ & $\begin{array}{l}\text { Rapport non-officiel sur la facilitation des échanges de la } \\
\text { République Démocratique du Togo (F08) }\end{array}$ & $\begin{array}{l}\text { Academia and NGOs } \\
\text { case story }\end{array}$ \\
\hline & \multicolumn{3}{|c|}{$\begin{array}{l}\text { www.oecd.org/aidfortrade/casestories/casestories-2017/CS-136-NTP-MIP-Rapport-non-officiel-sur-la-facilitaiton-des- } \\
\text { changes-au-Togo.pdf }\end{array}$} \\
\hline \multirow[t]{2}{*}{137} & $\begin{array}{l}\text { NTP/MIP Internship, } \\
\text { WTO }\end{array}$ & $\begin{array}{l}\text { Rapport non-officiel sur la facilitation des échanges } \\
\text { de la République Démocratique du Congo }\end{array}$ & $\begin{array}{l}\text { Academia and NGOs } \\
\text { case story }\end{array}$ \\
\hline & \multicolumn{3}{|c|}{$\begin{array}{l}\text { www.oecd.org/aidfortrade/casestories/casestories-2017/CS-137-NTP-MIP-Rapport-non-officiel-sur-la-facilitation-des- } \\
\text { changes-au-Congo-DRC.pdf }\end{array}$} \\
\hline \multirow[t]{2}{*}{138} & $\begin{array}{l}\text { NTP/MIP Internship, } \\
\text { WTO }\end{array}$ & $\begin{array}{l}\text { L'état de préparation de la Côte d'Ivoire au commerce } \\
\text { électronique (F10) }\end{array}$ & $\begin{array}{l}\text { Academia and NGOs } \\
\text { case story }\end{array}$ \\
\hline & \multicolumn{3}{|c|}{$\begin{array}{l}\text { http://www.oecd.org/aidfortrade/casestories/casestories-2017/CS-138-NTP-MIP-Coite-d-Ivoire-Etat-de-preparation-au- } \\
\text { commerce-electronique.pdf }\end{array}$} \\
\hline \multirow[t]{2}{*}{139} & SIECA & $\begin{array}{l}\text { Integración Energética: La experiencia de Centroamérica en el } \\
\text { diseño e implementación del Mercado Eléctrico Regional }\end{array}$ & Public sector case story \\
\hline & \multicolumn{3}{|c|}{$\begin{array}{l}\text { www.oecd.org/aidfortrade/casestories/casestories-2017/CS-139-SIECA-Integracion-Energetica-La-experiencia-de- } \\
\text { Centroamerica-en-el-diseno-e-implementacion-del-Mercado-Electrico-Regional.pdf }\end{array}$} \\
\hline
\end{tabular}




\begin{tabular}{|c|c|c|c|}
\hline \multirow[t]{2}{*}{140} & SIECA & $\begin{array}{l}\text { El Tránsito Internacional de Mercancías (TIM): logros y resultados } \\
\text { en El Salvador }\end{array}$ & Public sector case story \\
\hline & \multicolumn{3}{|c|}{$\begin{array}{l}\text { www.oecd.org/aidfortrade/casestories/casestories-2017/CS-140-SIECA-El-Transito-Internacional-de-Mercancias-(TIM)- } \\
\text { logros-y-resultados-en-El-Salvador.pdf }\end{array}$} \\
\hline \multirow[t]{2}{*}{141} & Bangladesh & A2i and e-commerce & Private sector case story \\
\hline & \multicolumn{3}{|c|}{$\begin{array}{l}\text { http://www.oecd.org/aidfortrade/casestories/casestories-2017/141\%20CS\%20-\%20Bangladesh\%20-\%20A2i\%20and\%20 } \\
\text { E-commerce.pdf }\end{array}$} \\
\hline \multirow[t]{2}{*}{142} & Bangladesh & Access to information programme & Private sector case story \\
\hline & \multicolumn{3}{|c|}{ www.oecd.org/aidfortrade/casestories/casestories-2017/142-Access-to-information-programme.pdf } \\
\hline \multirow[t]{2}{*}{143} & UNIDO & $\begin{array}{l}\text { Strengthening the National Quality Infrastructure (NQI) in } \\
\text { Nigeria to increase the competitiveness of Nigeria's goods and } \\
\text { services on the domestic, regional and global markets }\end{array}$ & Public sector case story \\
\hline & \multicolumn{3}{|c|}{$\begin{array}{l}\text { www.oecd.org/aidfortrade/casestories/casestories-2017/CS-143-UNIDO-Strengthening-the-National-Quality- } \\
\underline{\text { Infrastructure-(NQI)-in-Nigeria.pdf }}\end{array}$} \\
\hline \multirow[t]{2}{*}{144} & UNIDO & The promotion of agrofood quality labels in Tunisia & Public sector case story \\
\hline & \multicolumn{3}{|c|}{$\begin{array}{l}\text { www.oecd.org/aidfortrade/casestories/casestories-2017/CS-144-UNIDO-The-promotion-of-agrofood-quality-labels-in- } \\
\underline{\text { Tunisia.pdf }}\end{array}$} \\
\hline \multirow[t]{2}{*}{145} & UNIDO & Promoting Connectivity: Easing the woes of clearance & Public sector case story \\
\hline & \multicolumn{3}{|c|}{$\begin{array}{l}\text { www.oecd.org/aidfortrade/casestories/casestories-2017/CS-145-UNIDO-Promoting-Connectivity-Easing-the-woes-of- } \\
\text { clearance.pdf }\end{array}$} \\
\hline
\end{tabular}

Note: After the 1 February deadline for the monitoring exercise 15 case stories. These case stories have been uploaded to the joint OECD-WTO website, but are not part of the analysis in this report.

\begin{tabular}{|c|c|c|c|}
\hline \multirow[t]{2}{*}{146} & USAID & $\begin{array}{l}\text { The US-ASEAN Connectivity through Trade and Investment } \\
\text { (US-ACTI) project launches live implementation of the ASEAN } \\
\text { Single Window (ASW) }\end{array}$ & Public sector case story \\
\hline & \multicolumn{3}{|c|}{$\begin{array}{l}\text { www.oecd.org/aidfortrade/casestories/casestories-2017/CS-146-USAID-The\%20US-ASEAN-Connectivity-through-Trade- } \\
\text { and-Investment.pdf }\end{array}$} \\
\hline \multirow[t]{2}{*}{147} & USAID & Food Security- Mobile Money Accelerator Program (MMAP) & Public sector case story \\
\hline & \multicolumn{3}{|c|}{$\begin{array}{l}\text { www.oecd.org/aidfortrade/casestories/casestories-2017/CS-147-USAID-Food-Security-Mobile-Money-Accelerator- } \\
\text { Program-(MMAP).pdf }\end{array}$} \\
\hline \multirow[t]{2}{*}{148} & USAID & Women in Informal Cross Border Trade in Southern Africa & Public sector case story \\
\hline & \multicolumn{3}{|c|}{$\begin{array}{l}\text { www.oecd.org/aidfortrade/casestories/casestories-2017/CS-148-USAID-Women-in-Informal-Cross-Border-Trade-in- } \\
\text { Southern-Africa.pdf }\end{array}$} \\
\hline \multirow[t]{2}{*}{149} & USAID & $\begin{array}{l}\text { A Trade Portal Improves Transparency for Imports and Exports } \\
\text { in Myanmar }\end{array}$ & Public sector case story \\
\hline & \multicolumn{3}{|c|}{$\begin{array}{l}\text { http://www.oecd.org/aidfortrade/casestories/casestories-2017/CS-149-USAID-A-Trade-Portal-Improves-Transparency-for- } \\
\text { Imports-and-Exports-in-Myanmar.pdf }\end{array}$} \\
\hline \multirow[t]{2}{*}{150} & USAID & $\begin{array}{l}\text { Peru's progression to higher value technologies with } \\
\text { Standards Alliance support }\end{array}$ & Public sector case story \\
\hline & \multicolumn{3}{|c|}{$\begin{array}{l}\text { http://www.oecd.org/aidfortrade/casestories/casestories-2017/CS-150-USAID-Perus-progression-to-higher-value- } \\
\text { technologies-with-Standards-Alliance.pdf }\end{array}$} \\
\hline
\end{tabular}




\begin{tabular}{|c|c|c|c|}
\hline \multirow[t]{2}{*}{151} & USAID & $\begin{array}{l}\text { Removing Certificate of Origin Requirements to Facilitate } \\
\text { Trade in Agricultural Products in West Africa }\end{array}$ & Public sector case story \\
\hline & \multicolumn{3}{|c|}{$\begin{array}{l}\text { www.oecd.org/aidfortrade/casestories/casestories-2017/CS-151-USAID-Removing-Certificate-of-Origin-Requirements-in- } \\
\text { West-Africa.pdf }\end{array}$} \\
\hline \multirow[t]{2}{*}{152} & Digital Divide & Digital Divide Data and Impact Sourcing & Private sector case story \\
\hline & \multicolumn{3}{|c|}{ www.oecd.org/aidfortrade/casestories/casestories-2017/CS-152-Digital-Divide-Data-and-Impact-Sourcing.pdf } \\
\hline \multirow[t]{2}{*}{153} & Facebook & She means business: when women succeed, we all win! & Private sector case story \\
\hline & \multicolumn{3}{|c|}{$\begin{array}{l}\text { http://www.oecd.org/aidfortrade/casestories/casestories-2017/CS-153-Facebook-She-means-business-when-women- } \\
\underline{\text { succeed-we-all-win.pdf }}\end{array}$} \\
\hline \multirow[t]{2}{*}{154} & Facebook & Telecom Infra Project (TIP) & Private sector case story \\
\hline & \multicolumn{3}{|c|}{ www.oecd.org/aidfortrade/casestories/casestories-2017/CS-154-Facebook-Telecom-Infra-Project.pdf } \\
\hline \multirow[t]{2}{*}{155} & Australia & Road Infrastructure Rehabilitation in Cambodia & Public sector case story \\
\hline & \multicolumn{3}{|c|}{$\begin{array}{l}\text { www.oecd.org/aidfortrade/casestories/casestories-2017/CS-155-Australia-Road-Infrastructure-Rehabilitation-in-Cambodia. } \\
\underline{\text { pdf }}\end{array}$} \\
\hline \multirow[t]{2}{*}{156} & Australia & $\begin{array}{l}\text { International Labour Organization Better Work Programme - } \\
\text { Stage } 3\end{array}$ & Public sector case story \\
\hline & \multicolumn{3}{|c|}{$\begin{array}{l}\text { www.oecd.org/aidfortrade/casestories/casestories-2017/CS-156-Australia-International-Labour-Organization-Better-Work- } \\
\text { Programme\%E2\%80\%93Stage-3.pdf }\end{array}$} \\
\hline \multirow[t]{2}{*}{157} & Australia & $\begin{array}{l}\text { Australia -World Intellectual Property Organisation Funds in } \\
\text { Trust (FiT) Program }\end{array}$ & Public sector case story \\
\hline & \multicolumn{3}{|c|}{$\begin{array}{l}\text { www.oecd.org/aidfortrade/casestories/casestories-2017/CS-157-Australia-World-Intellectual-Property-Organisation-Funds- } \\
\underline{\text { in-Trust-(FiT)-Program.pdf }}\end{array}$} \\
\hline \multirow[t]{2}{*}{158} & Facebook & Facebook Express Wifi Empowering Entrepreneurs in Nigeria & Private sector case story \\
\hline & \multicolumn{3}{|c|}{$\begin{array}{l}\text { www.oecd.org/aidfortrade/casestories/casestories-2017/CS-158-Facebook-Express-Wifi-Empowering-Entrepreneurs-in- } \\
\underline{\text { Nigeria.pdf }}\end{array}$} \\
\hline \multirow[t]{2}{*}{159} & UNIDO & $\begin{array}{l}\text { Inclusive and Sustainable Industrial Development for Shared } \\
\text { Prosperity: Programmes for Country Partnership }\end{array}$ & Public sector case story \\
\hline & \multicolumn{3}{|c|}{$\begin{array}{l}\text { www.oecd.org/aidfortrade/casestories/casestories-2017/CS-159-UNIDO-Inclusive-and-Sustainable-Industrial- } \\
\underline{\text { Development-for-Shared-Prosperity-Programmes-for-Country-Partnership\%20.pdf }}\end{array}$} \\
\hline \multirow[t]{2}{*}{160} & $\begin{array}{l}\text { Inter-American } \\
\text { Development Bank }\end{array}$ & $\begin{array}{l}\text { How to Reduce Trade Costs with Modest Investments - } \\
\text { The Foreign Trade Single Window in Latin America } \\
\text { and the Caribbean }\end{array}$ & Public sector case story \\
\hline & \multicolumn{3}{|c|}{$\begin{array}{l}\text { www.oecd.org/aidfortrade/casestories/casestories-2017/CS-160-laDB-How-to-Reduce-Trade-Costs-with-Modest- } \\
\text { Investments-The-Foreign-Trade-Single-Window-in-Latin-America.pdf }\end{array}$} \\
\hline
\end{tabular}




\section{ENHANCED INTEGRATED FRAMEWORK}

The EIF is a global partnership that is dedicated to supporting the Least Developed Countries (LDCs) to use trade as a tool for economic growth and poverty reduction through job and income opportunities. The EIF empowers LDCs to identify where and how trade can form an integral part of their national development strategies and assist them in harnessing Aid for Trade towards this objective.

The EIF provides country specific and customized support that addresses the full suite of trade capacity building needs. Through building trade capacity, the partnership works together to support the LDCs' own drive to:

- identify and address the priority constraints to trade;

- ensure trade directly supports the national development agenda;

- set up institutional and coordination mechanisms for trade related technical assistance;

- initiate policy reform and mobilize additional financial and technical resources to address priority trade needs.

\section{INTERNATIONAL TRADE CENTRE}

ITC is a multilateral agency fully dedicated to developing the international competitiveness of SMEs. As a joint agency of WTO and UN, ITC focuses on small business export success. ITC works especially in least developed countries, landlocked developing countries, fragile and post-conflict countries, Small Island Developing States and sub-Saharan Africa. We help to build vibrant, sustainable export sectors that provide entrepreneurial opportunities, particularly for women, young people and poor communities.

Focus areas for SME competitiveness include:

- Developing trade and market intelligence

- Building a conducive business environment

- Strengthening trade and investment support institutions

- Connecting to value chains

- Supporting regional integration and South-South linkages

- Mainstreaming inclusive and green trade

\section{UNITED NATIONS CONFERENCE ON TRADE AND DEVELOPMENT}

UNCTAD, which is governed by its 194 member States, is the United Nations body responsible for dealing with development issues, particularly international trade - the main driver of development. Its work can be summed up in three words: think, debate, and deliver. Reflection on development is at the heart of UNCTAD's work. It produces analyses that form the basis for recommendations to policymakers. UNCTAD is also a forum where representatives of all countries can freely engage in dialogue and discuss ways to establish a better balance in the global economy. In addition, UNCTAD offers direct technical assistance to developing countries and countries with economies in transition, helping them to build the capacities they need to become equitably integrated into the global economy and improve the well-being of their populations.

UNCTAD holds a ministerial-level meeting every four years to discuss major global economic issues and to decide on its programme of work. Every two years, UNCTAD organizes the World Investment Forum, which brings together major players from the international investment community to discuss challenges and opportunities and to promote investment policies and partnerships for sustainable development and equitable growth. 


\section{INTERNATIONAL TELECOMMUNICATIONS UNION}

ITU is the leading United Nations agency for information and communication technologies (ICTs), driving innovation in ICTs together with 193 Member States and a membership of nearly 800 private sector entities and academic institutions. Established over 150 years ago in 1865, ITU is the intergovernmental body responsible for coordinating the shared global use of the radio spectrum, promoting international cooperation in assigning satellite orbits, improving communication infrastructure in the developing world, and establishing the worldwide standards that foster seamless interconnection of a vast range of communications systems. From broadband networks to cutting-edge wireless technologies, aeronautical and maritime navigation, radio astronomy, oceanographic and satellite-based earth monitoring as well as converging fixed-mobile phone, Internet and broadcasting technologies, ITU is committed to connecting the world.

\section{BUSINESS FOR ETRADE DEVELOPMENT}

The research presented in the paper by Kati Suominen is ideated and produced by her firm Nextrade Group. She is also Founder and Interim Executive Director of Business for eTrade Development and authored this chapter in that capacity. Business for eTrade Development has been launched alongside the UNCTAD-led eTrade for All initiative as a private sector voice to help developing country governments, international agencies, and leading donors optimize public policies and aid allocations for ecommerce development and cross-border ecommerce worldwide.

\section{WORLD BANK GROUP}

The World Bank Group has set two goals for the world to achieve by 2030: end extreme poverty by decreasing the percentage of people living on less than $\$ 1.25$ a day to no more than $3 \%$; and promote shared prosperity by fostering the income growth of the bottom $40 \%$ for every country. In the area of trade and competitiveness, the World Bank Group helps countries achieve these two goals through rapid and broad-based economic growth, centred on strong contributions from the private sector. The World Bank Group is working in this area to help countries expand the volume and value of trade, enhance the investment climate, improve competitiveness in sectors, and foster innovation and entrepreneurship.

\section{WORLD TRADE ORGANIZATION}

The World Trade Organization (WTO) is the only global organisation dealing with the rules of trade between nations. At its heart are the WTO agreements, negotiated and signed by the bulk of the world's trading nations and ratified in their parliaments. The goal is to help producers of goods and services, exporters, and importers conduct their business.

The WTO's main activities are to:

negotiate the reduction or elimination of obstacles to trade (import tariffs, other barriers to trade) and agreeing on rules governing the conduct of international trade (e.g. antidumping, subsidies, product standards, etc.)

administer and monitor the application of the WTO's agreed rules for trade in goods, trade in services, and trade-related intellectual property rights

- monitor and review the trade policies of its members, as well as to ensure transparency of regional and bilateral trade agreements

- settle disputes among its members regarding the interpretation and application of the agreements

- build capacity of developing country government officials in international trade matters

- assist the process of accession of some 30 countries who are not yet members of the organization

- conduct economic research and collecting and disseminating trade data in support of the WTO's other main activities

- explain to and educate the public about the WTO, its mission and its activities.

The WTO currently has 164 members, with more than two-thirds developing economies or separate customs territories. 


\section{ORGANISATION FOR ECONOMIC CO-OPERATION AND DEVELOPMENT}

The OECD is a unique forum where governments work together to address the economic, social and environmental challenges of globalisation. The OECD is also at the forefront of efforts to understand and to help governments respond to new developments and concerns, such as corporate governance, the information economy and the challenges of an ageing population. The Organisation provides a setting where governments can compare policy experiences, seek answers to common problems, identify good practice and work to co-ordinate domestic and international policies.

The OECD member countries are: Australia, Austria, Belgium, Canada, Chile, the Czech Republic, Denmark, Estonia, Finland, France, Germany, Greece, Hungary, Iceland, Ireland, Israel, Italy, Japan, Korea, Latvia, Luxembourg, Mexico, the Netherlands, New Zealand, Norway, Poland, Portugal, the Slovak Republic, Slovenia, Spain, Sweden, Switzerland, Turkey, the United Kingdom and the United States. The European Union takes part in the work of the OECD.

WTO, Geneva

ISBN WTO: 978-92-870-4539-3 (print); 978-92-870-4554-6 (e-book/PDF format)

OECD Publishing, 2, rue André-Pascal, 75775 PARIS CEDEX 16

ISBN OECD: 978-92-64-27846-2 (print); 978-92-64-27847-9 (e-book/PDF format) 


\section{AT

\section{AID FOR TRADE}

\section{AIDFORTRADE AT A GLANCE 2017 PROMOTING TRADE, INCLUSIVENESS AND CONNECTIVITY FOR SUSTAINABLE DEVELOPMENT}

This edition of Aid for Trade at a Glance focuses on trade connectivity, which is critical for economic growth, inclusiveness and sustainable development. Physical connectivity enables the movement of goods and services to local, regional and global markets. It is closely intertwined with digital connectivity which is vital in today's trade environment. Yet, the Internet remains inaccessible for 3.9 billion people globally, many of whom live in the least developed countries.

This report builds on the analysis of trade costs and extends it into the digital domain, reflecting the changing nature of trade. It seeks to identify ways to support developing countries - and notably the least developed - in realising the gains from trade. It reviews action being taken by a broad range of stakeholders to promote connectivity for sustainable development, including by governments, their development partners and by the private sector. One message that emerges strongly is that participation in e-commerce requires much more than a simple internet connection.

Chapter 1. Overview

Chapter 2. Setting the scene

Chapter 3. Digital connectivity and trade logistics

Chapter 4. The contribution of services trade policies

Chapter 5. Spanning the Internet divide to drive development

Chapter 6. Improving the e-trade environment

Chapter 7. Harnessing e-commerce for sustainable development

Chapter 8. Closing the small business and gender gap

Chapter 9. Promoting trade inclusion in the least developed countries

Chapter 10. Public-private priorities for aid for trade in the digital era

Chapter 11 . Financing connectivity

Chapter 12. Aid for inclusive trade and poverty reduction
Contributed by the WTO

Contributed by the OECD and UNCTAD

Contributed by the WTO

Contributed by the ITU

Contributed by the World Bank

Contributed by UNCTAD

Contributed by the ITC

Contributed by the EIF

Contributed by Business for eTrade Development

Contributed by the OECD

Contributed by the WTO

Consult this publication on line at http://dx.doi.org/10.1787/aid_glance-2017-en.

This work is published on the OECD iLibrary, which gathers all OECD books, periodicals and statistical databases. Visit www.oecd-ilibrary.org for more information.

978-92-64-27846-2

$432017061 \mathrm{P}$

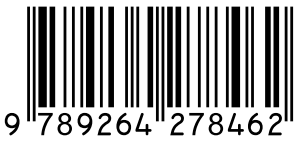

